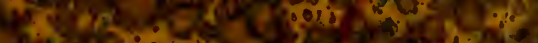

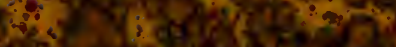

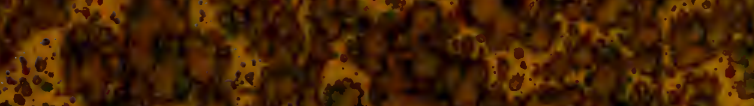

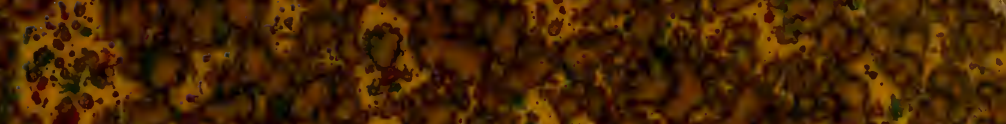

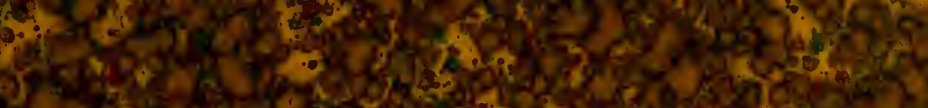

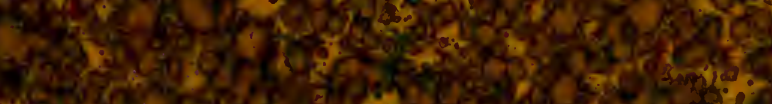
tor

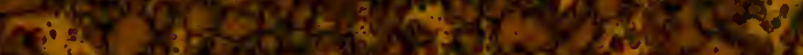
adsesecos 1. 2. 35 .

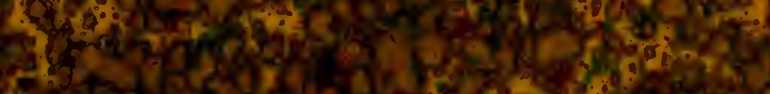

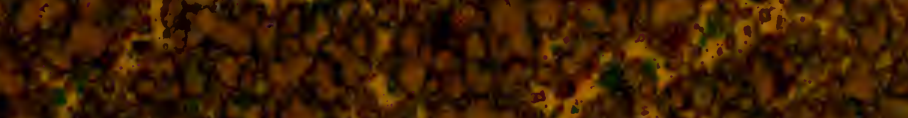
Tho

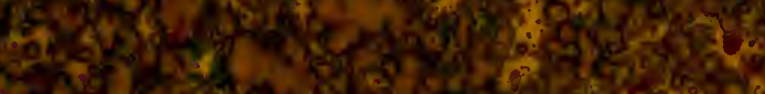
(2000 20035

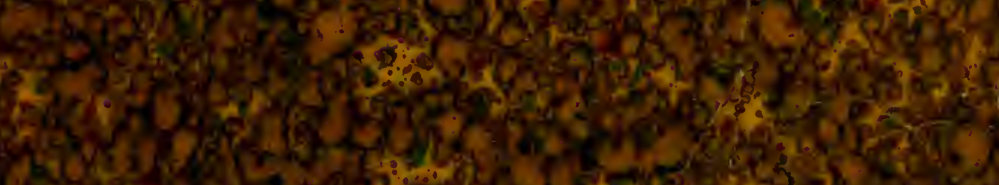

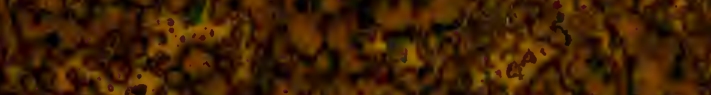

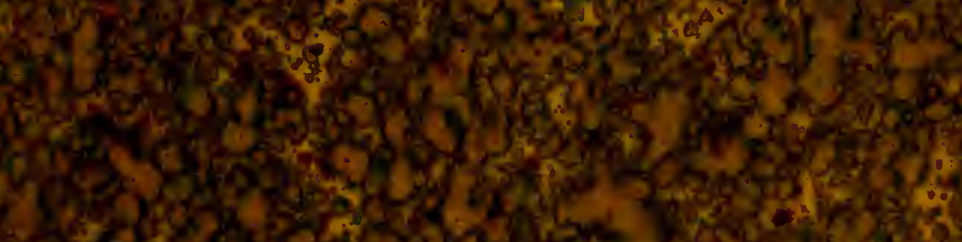

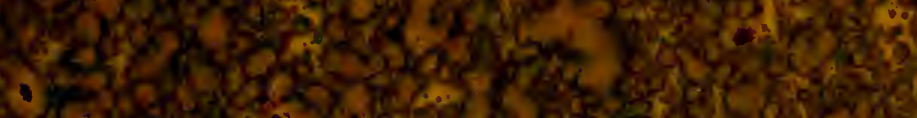

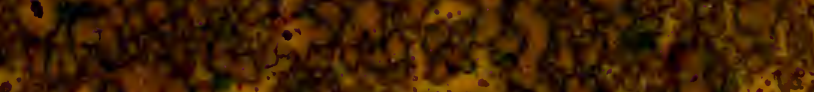




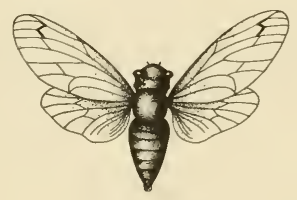

\section{LIBRARY OF}

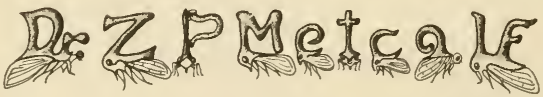
1885_1956 
1)

$=$

a

s

1

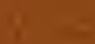

*.

3

1

$y$

$y$

11.

$=$

$=$

-12

1.

1

I

a

I.
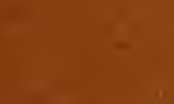

1

$=$

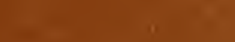

1

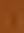

$2 x$

군

1

1 

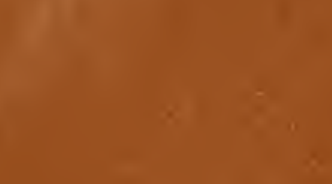

$\frac{1}{2+1}+2$

1

1)

1

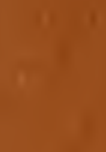

$=$
1.

1) 1

$-1$

$a$

iv

7

$y=$

y.

$=$

1)

7

4

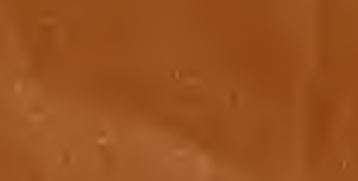

14.

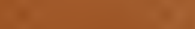

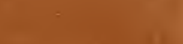

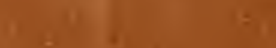





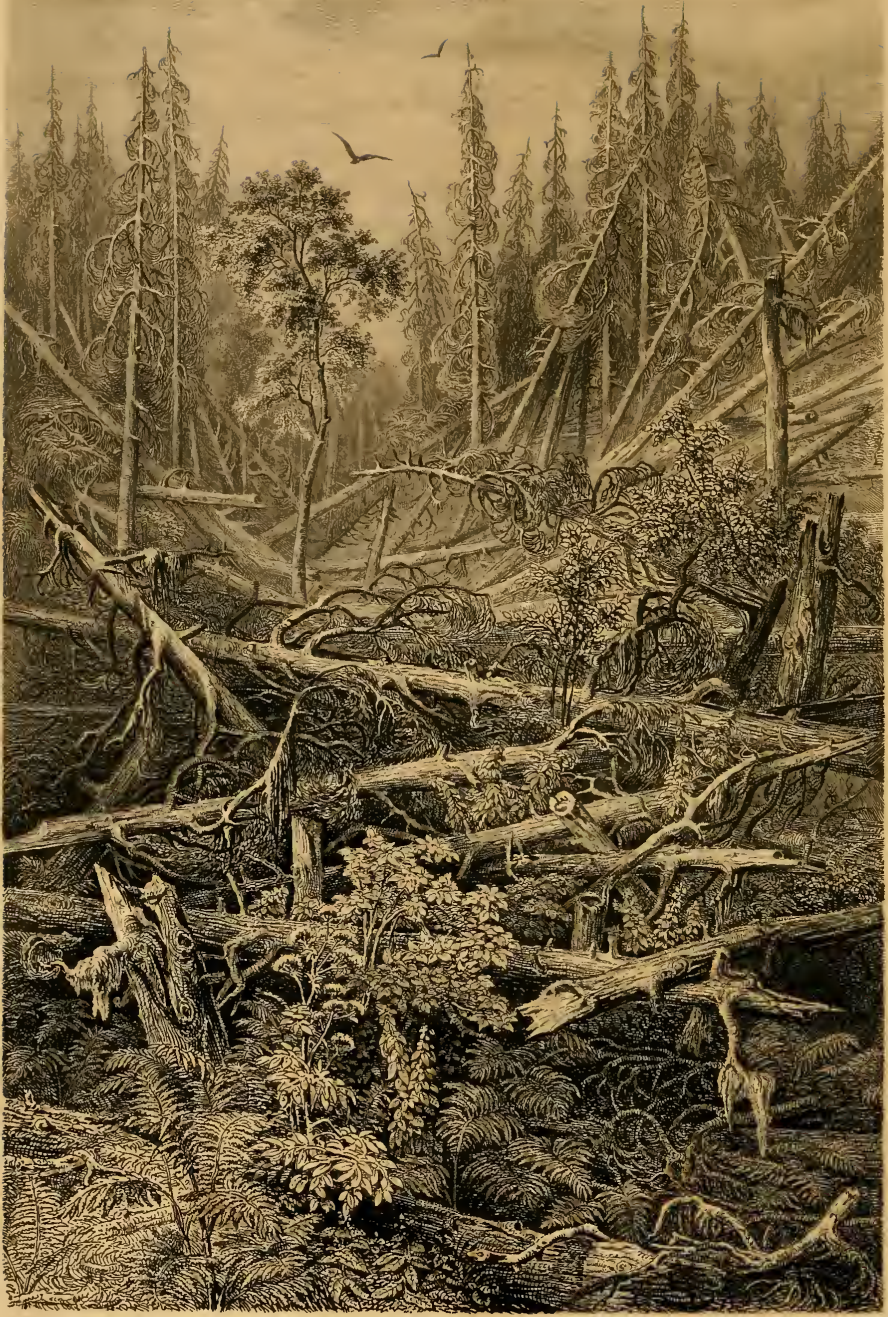
E $A_{1+2}+? \mathrm{gow}$ 
Dic

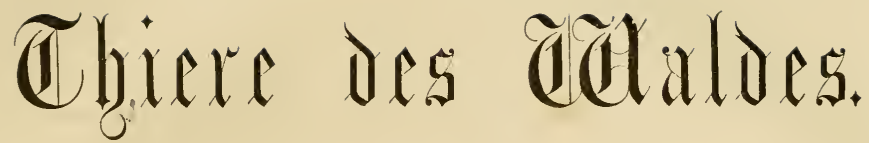

(5) ejolitiont

butt

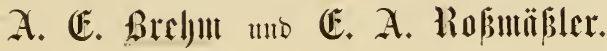

ittit 3 管upfersticlyer,

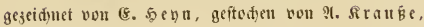

und 97 g)olzschnitter,

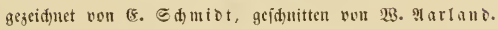
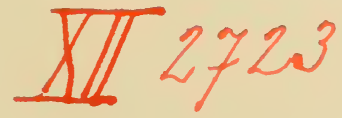

3 weiter Bando.

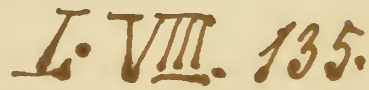

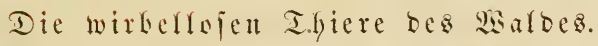

\section{LL. Stgatsuntery y Prig - Noustadt}

Peivin uns focidelluera.

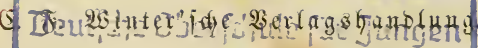

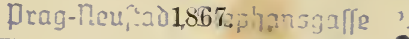
Eehrarbütrani $\mid$ Inv. M3 Fat. $\Gamma_{:=:}$ 


\section{$\mathfrak{y o r w o r t}$}

Mie fich alferbings erjt währent ber Bearbeitung bieję

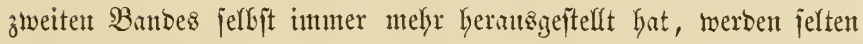
bie swei Theile eines wemn audy won werfdjiebenten Berfaffern aber

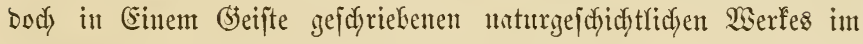

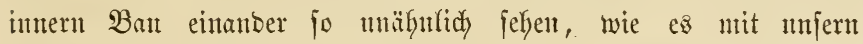
"Thieren bes WGalbes" Der Fall ift. Whir Galten es buher

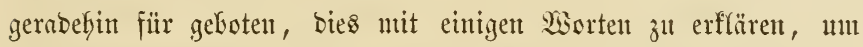
es baburdy unfern Rejern begreiflidy unto bamit andy verzeifflich,

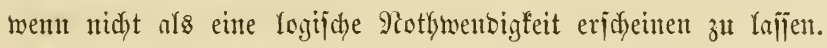

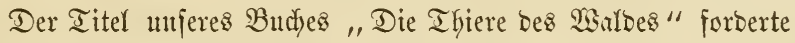
ebenfo bie Berfaffer hermts, Demperfen eine pitteresfe, weun nidyt

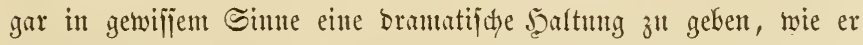
ofne 3weifel bie Rejer verfiifgrt unto and Gered)tigt, Derartiges

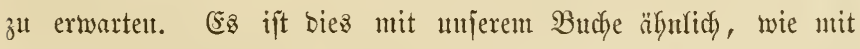

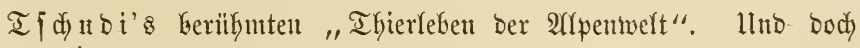

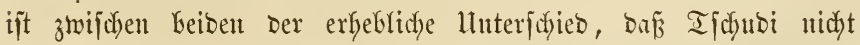
Glos bie Minten bes gemaltigen arrpenthenters vorfingren, fondern Daßj er biejes jelbjt jofjirbern Durfte, weldyez Rez̧tere uns verjagt war, ba unjer Budc) (i. bie Borrebe zum erften Bambe) eine

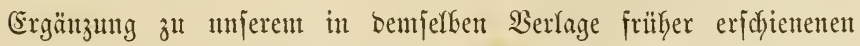
Werfe "Der Warb" fein folfte, wir alfo ben Schauplats bes 
Rebens mo Treibens mierer Thiere burdy genauntes Bud) als

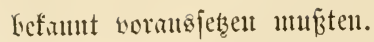

So wou ber einen Seite anjgeforbert, won ber anbern ge=

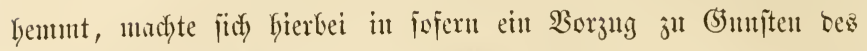
eriten Bantes geltent, als bei ben wirkelthieren, andh shne cigent=

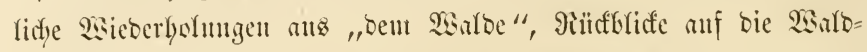

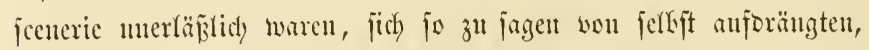
ba jie in biejent cine fo jtarf herwortretente 9iolle ipielen, baj

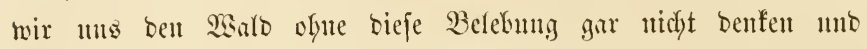

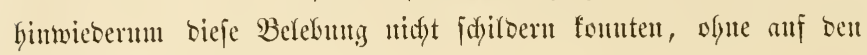
פaralo Bezug zu nelynten.

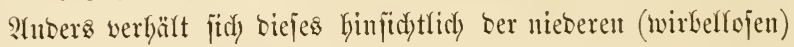

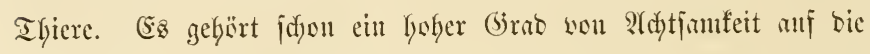

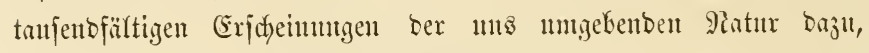

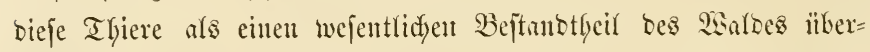
haupt zul benterfen, fie als foldhe jull wïrbigen, wenn fie fich zeigen, uns zu vernitjen, went fie fid) zurïffgezogen babent. giur went

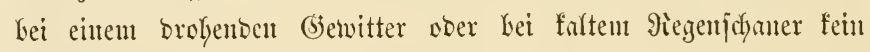
Falter zwijhen bem niebern Siejweig unberflattert mo fein siäfer Grumunt, feblt nus etwas; mo and) bas würben mir wieffeidyt nidyt vermifien, wenn Daun nidyt jugleidy and bie Bogeljtinment verjtıumut wären.

Bei biejer für bie Srbeit fajt ftörenben inneren und änjeren

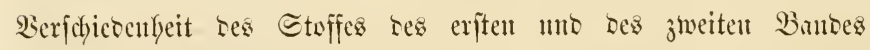
bemiilyten wir uns in bem worliegenten zweiten Banbe nabezn

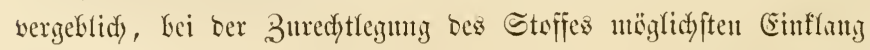
mit sen eriten zul erreidyen.

Shu ftörenojten war natïrlidy zuntedyit fodon bie ungehenere Ulugleid)heit bes Untfangs tes Stoffes. Sn erjten Banbe founten

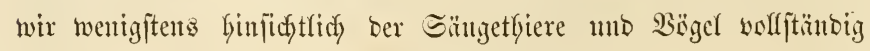

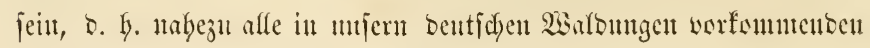




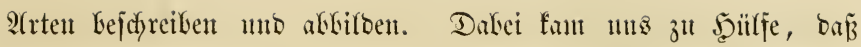
wir bei unfern Rejern finfichtlich bicjer beiben Iflerflaffen bie (5)rmbjüge als allyemein Kefannt weramsjetzen burfen. Beibes ijt

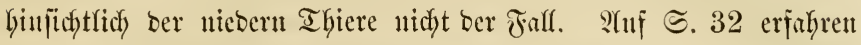

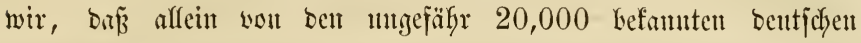

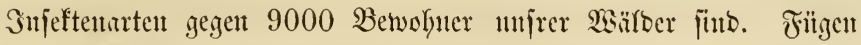
mun andy bicjer Smunte bie ïbrigen Sifaffen ber nicbern $\mathfrak{B a r b}=$

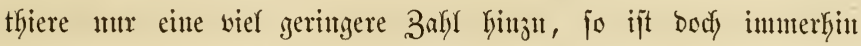

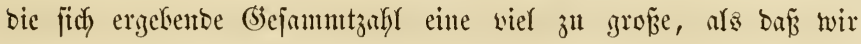
Gä̈tten Daran benfen fëututen, and) nur won jeber Bonttung eine

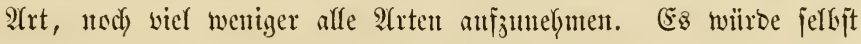

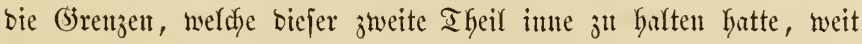
überjofritten haben, wem wir jebe in ben bentichen sisalbe ver=

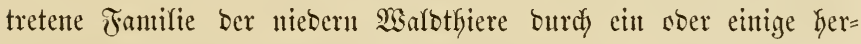
worragento Beifpiefe Gätten repräjentiren wolfen.

SGie wir unz ben fireiz mujerer Rejer gebadyt baben, fo

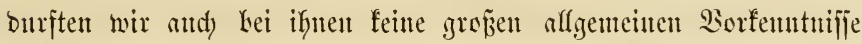
über bie it jeber Bejiefnuting fo weit anseinandergekenbe niebere Thierwelt woranşę̧en. Die Begriffe Snjeften unb Mitmmer, wo=

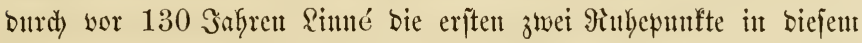

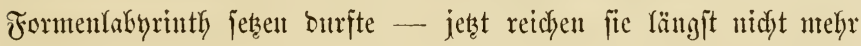
ans; unb wem wir bei ber injtematijeden 2(norbmung ber niebern Warbthiere and nidyt ben neneftent Etambpunfte ber Wififenfichaft

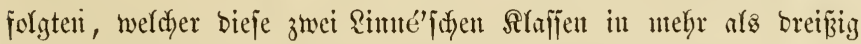
zerfällt, fo fonten mir bod anf. bent Rinuépdyen Stanopunfte nidyt jtebent breiben.

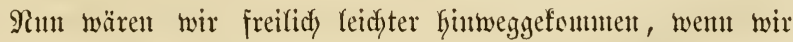
anz ben im $\mathfrak{S a r b e}$ vertretenen Silaffen nieberer Warbtfiere einte

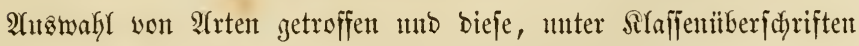

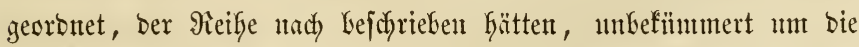

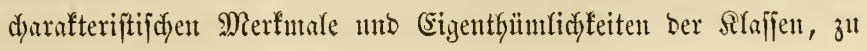




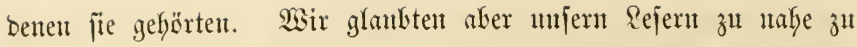

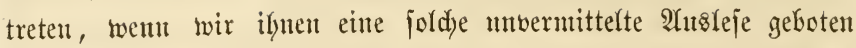
Gätten. WSir würsen es audh fïr eine beleibigung bes $\mathfrak{B a r b e s}$ angejeben Guben, für meldyen wir bei unjern Rejern uno Rejerimen bie gleidje Riebe wie bie mujrige voransfęzen, Gätten wir fein, in jeiner bunten 3ufamurenfebung bod) fo abgerunbetes, einfheitfiches

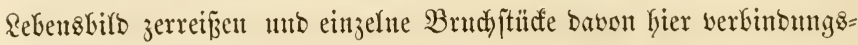
ros aneinanber reihen wollen. Snbem wir ben $\mathfrak{U}$ mutäntoen nach

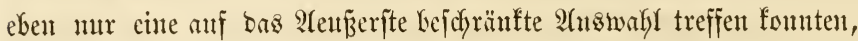
wollten wir menigitens bie Cteflen des Cnjtems Kezeidhnen, wo wir jie heransgenommen baben; nub babei juthten wir ben 3wedf zut erreidyen, burdy bieje injtematifdyen Bejeidynumgen bem Rejer

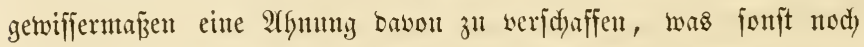
an biejen Steflen neken bem Jecransgegriffentu ftehen mag.

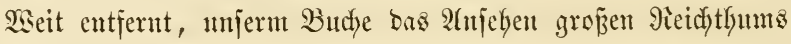
geben z" wollen, haben wir ifgu vielmetgr ben Stempel ber $\mathfrak{A}$ (rmuth

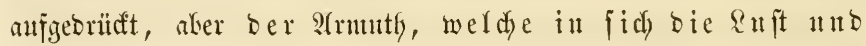
bie Rrajt zu Miefrermerb fühlt. Dieje Rujt unb Sraft wollten wir anregen, no wenn uns bies gelungen ijt, fo haben wir mijer Biel nicht werfehlt. Ilto bier fommen wir anf einent ferneren Itnterfdjed zmifden unjern heiben Bänben, bei weldyem biesunal ber $\mathfrak{B}$ ortheil anj Seiten bes worliegenden ift.

Es werben unr menige unjerer Refer in ber Rage jein, bie in erjten Banbe bejdriebenen Thiere rekentig ober wentigitens in

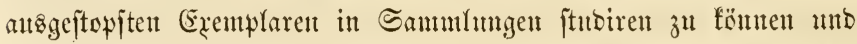
faum Ciner soer ber Artibere wirb fo bevorzugt jein, wentgitenz bie B̈̈gel und bie ffeineren Sängethiere in einer eigenen Samm=

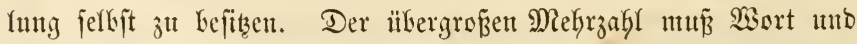

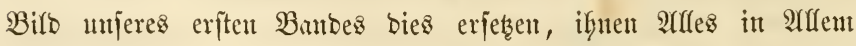
fein. $\mathfrak{B a s}_{\mathrm{B}}$ unfer zweiter Banb bringt läßjt fid nidjt mur meijt mit Reidftigfeit im Sarbe ferbjt bedbadgten, fonbern wir fömen 


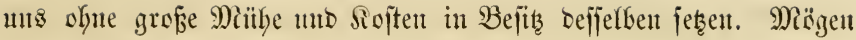
unjere Rejer mu babei bas (sejanmtuterial, weldyes mper Bud

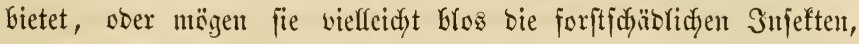
ober bie gefellig lebenten, ober bie (5)alfinfeften ins 2uge faffen unt iu Walbe auffucten wollen, in affen Fïllen finbet es fidd in Der beworzugten Rage, ein Füfrer zu alle bem zn feill, wowon es erzählt hat unb was man faft immer leidyt zugänglid) unt erreids= bar finbent wirb. Wir madyelt aud gar fein Jebl Daraus, Daiz wir bei biefen jweiten Banbe gar jefrr bie 9lbjicht gefabt baben, mijere

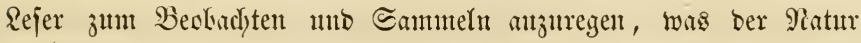

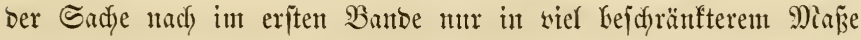

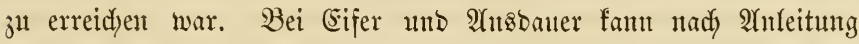
unjeres Buthes jidy jeber Rejer eine Sammtumg ber nieberen Thiere Der Waldungen feinter Untgelung anlegen. 3n biejen 3wedfe haben

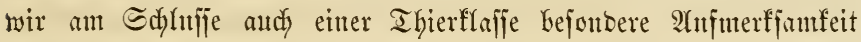
gemürbigt, weldse bisber vou bem Eammeleifer febr vernadyläjïgt worben ijt, sbgleidy jie bie anf fie gewenbete Beadytung un fo melyr lohnt, je weniger fie fid) bem unadjtfanten ?atge auforängt

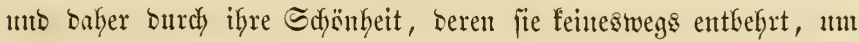

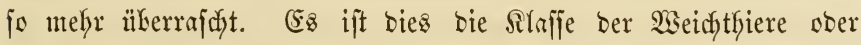

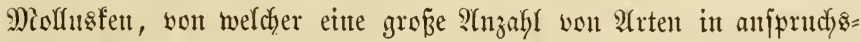
rofer Burïffgezogenteit unjere Walbungen bemobnt.

Daß̉ bie Injeften in mijerem Banbe einen übermiegenden Theil bes Ranmes eimtebmen, wirb weder anffallen nody Tabel

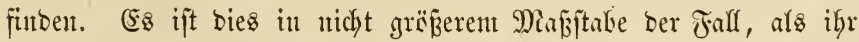

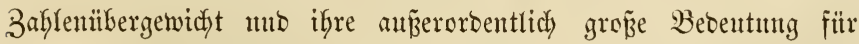
sen $\mathfrak{B a l d}$ redytfertigt ja forbert, Deghalb haben wir and mit be=

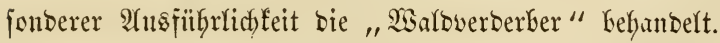

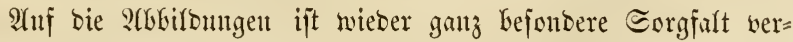

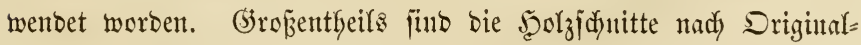
zeichumugen nadh ber 2atur, zum Theil aker and nady guten 
Sorkilbern gefertigt, in Yeçterem Falle jebod) faft immer mit Ber= greidjumg mutïrlictyer Exremplare.

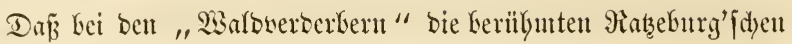
Sinniften vielfach) benntz̧t worben fint, bebarf feinte Eingeftämb=

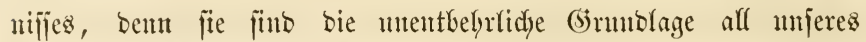

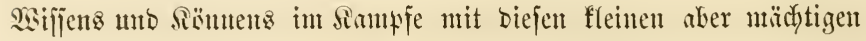

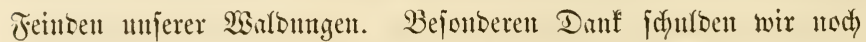

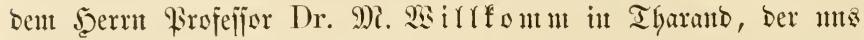

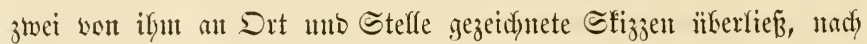

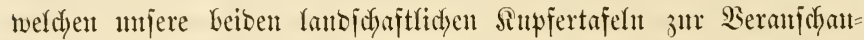

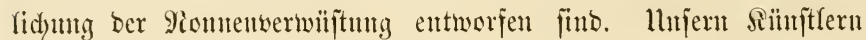
wie ber Berfagsthmolung Gaben wir Gier ebenjo wie bei ber Ber=

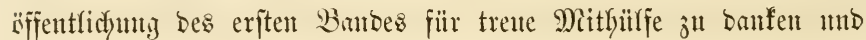

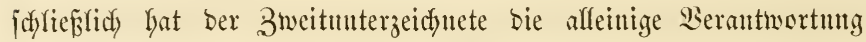
dicjes Bandes ju ribernefunen, ba biejer, wie fdyon in ber Sorrebe 3ntm erften Banbe angefiutbigt murbe, jeine afleinige 2 frbeit ift, bei

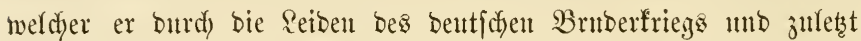

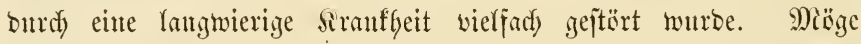
man bies bent Yetzen Theile ber Shrbeit nidht ju jehr anjehen. Into fo leyent wir ben biejen ziveiten Banto netent ben erften in bie bände unferer Sejer, benten mm beibe jufmment eben fo eine

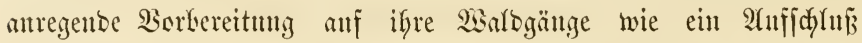

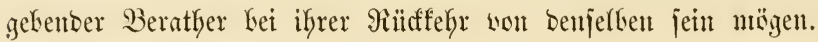

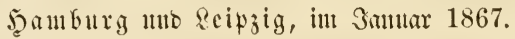

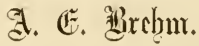
i. A. Mossmïssler. 


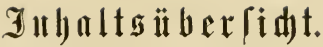

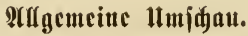

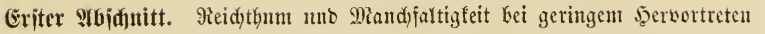

20 finten nir bie niebern 2 balsthiere?

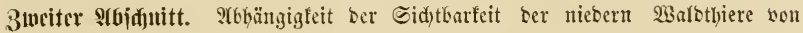
ben Sahreszeiten, won ifrer Sebensweife und ifyren Entwidfungsznfänben. Enige פeriüngung. . . . . . . . . . . . . . . . . . 11

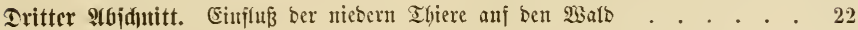

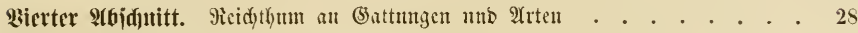

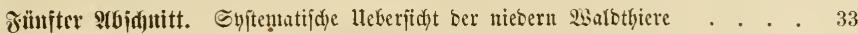

\section{Dic Injeftenuclt.}

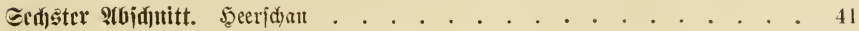

Gicbenter $\mathfrak{A b j d u t t . ~ D i e ~ S e r w a n d u n g ~ . ~ . ~ . ~ . ~ . ~ . ~ . ~ . ~ . ~ . ~ . ~ . ~} 58$

P(d)ter 9fbidjnitt. Die $\mathfrak{G a l b v e t b e r b e r ~ . ~ . ~ . ~ . ~ . ~ . ~ . ~ . ~ . ~ . ~ . ~ 7 s ~}$

A. 巨d)metterlinge . . . . . . . . . . . . . 82

1. Die Rome . . . . . . . . . . . . . . . 86

2. Der @djwammipinter ober Dispar . . . . . . . . 107

3. 4. Der 1 Geibenjpinter utb Solbajter . . . . . . . . . 109

5. Der Ricfernfpimter . . . . . . . . . . . . . . . . 111

6. Der Eiffen = Frocefítonsipinter . . . . . . . . . . 113

7. Der Mingelfinter . . . . . . . . . . 118

8. Der Pothidfwanj ober Budjenjpinter . . . . . . . . . 120

9. Die Forl $=$ ober Riefern $=$ Eule . . . . . . . . . . 123

10. Der Riefern $=$ ober Eidjenfpanner . . . . . . . . . 126

11. Der $\mathfrak{B a l b l i n t}$ en $=$ Spanter . . . . . . . . . . . . 127

12. Der Froftipanter. . . . . . . . . . . . . . 129

13. Der Birfen $=$ ober 2 fitipanter . . . . . . . . . . 129

14. Der $\Re$ ieferntrieb $=\mathfrak{G i d f l e r}$. . . . . . . . . . . . . 132

15. Der Fidytenrinben = EBiffer . . . . . . . . . . . 134 
16. Der Eidfen = Widfer . . . . . . . . . . . . . 136

17. Die \&ärdłen = פinirmotte . . . . . . . . . . . . 137

15. Die Sefpinnfmotten . . . . . . . . . . . . . . 139

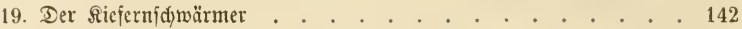

20. Der Bienenjđ)wärmer . . . . . . . . . . . . . . 144

21. Der Baum $=$ ober Sectenneiphling . . . . . . . . . 148

B. $\mathfrak{\pi} \ddot{\mathrm{a}}$ er.

22. Ber Fid)tenborfentäfer, Budboruffer . . . . . . . . . 153

23. Der frummzäbnige Borfenfäjer . . . . . . . . . . 157

24. Der 9lubbolzborfenfäfer . . . . . . . . . . . . . 159

25. Der Rärcbenbortentäjer . . . . . . . . . . . . . . . 159

26. 27. Der grobe unb Der fleine Marffäfer . . . . . . . . 160

28. Der bunte Ejdenbafttäfer . . . . . . . . . . . . . 163

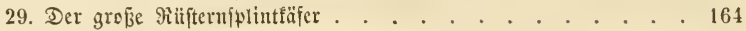

30. Der grob̉e Fidententifelfäfer . . . . . . . . . . . . . 167

31. Der meifídjilbige Rieferntïfieltäfer . . . . . . . . . . 169

32. Der grobe jomarze Яitfifelfäjer . . . . . . . . . . . 170

33. Der Erlenrüfielfäfer . . . . . . . . . . . . . 171

34. Ser Sgafelnuß̈täfer . . . . . . . . . . . . . . . 172

35. Der 2rpfelblüthenftedfer . . . . . . . . . . . . . 173

36. Der groß̉e Eidyenbodfäfer . . . . . . . . . . . . . . . 176

37. Der groß̉e Papheltodfäfer . . . . . . . . . . . . 177

35. Der gelbitreifige Egsentiodfäfer . . . . . . . . . . . 179

39. Der 3imntemanmb = Bo dffäfer . . . . . . . . . . . . 179

40. 41. Det groß̉e unb fleine Espenblatttäfer . . . . . . . . 181

42. Der Erlenblattfäjer . . . . . . . . . . . . . . . 183

43. Der Siefernblatttäfer . . . . . . . . . . . . . . 183

44. 45. Der gemeine uno Der Gunte Slopffäfer . . . . . . . . 184

46. Der Eidjeumerfteäfer . . . . . . . . . . . . . 188

47. Der Maifäfer . . . . . . . . . . . . . . . . . 189

45. Der großje marmorirte Maaitäfer . . . . . . . . . . 192

49. Der Gonnentwenbtäfer, Brad)täfer . . . . . . . . . . . 193

50. Der Pflajterfäfer, ipantide Fliege . . . . . . . . . . 194

C. Uberfrügler.

51. Die Ricfernblattmcöpe . . . . . . . . . . . . . . 200

52. Die Rothfaf $=$ Riefernblattmespe . . . . . . . . . . . . . 202

53. Die grof́e Birten $=$ Blattregłe . . . . . . . . . . . . 204

54. Ḋie groß̈e \$̧olzmeste . . . . . . . . . . . . . . 205

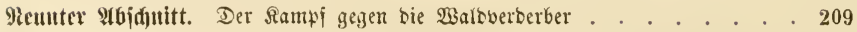

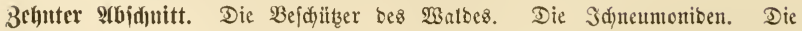
Morbfliegen . . . . . . . . . . . . . . . . . . . 225

1. Die grof̌e Rieferupinner $=\Xi$ d)lupfwespe . . . . . . . 235

2. Die tleime Riefernjpiner $=$ Sd)Lpfwespe . . . . . . . . 237

3. Die Riefermipinner $=$ Eiermępe . . . . . . . . . . 239

4. Die Morbfliege . . . . . . . . . . . 243 
๖. Die monbfledige Sdurebfliege . . . . . . . . . . . 245

6. 7. Der : Barb = Sanbtäfer un ber grüne Sandtäfer . . . . . 246

8. 9. Der Sartenlauffäfer un Der getörnelte \&auftäfer . . . . . 250

10. Der ßuppentäuber . . . . . . . . . . . . . . . 252

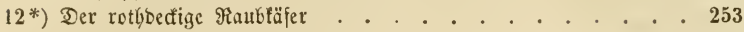

13. Der ameifenäbnlidje $\mathfrak{B u n t t a ̈ f e r ~ . ~ . ~ . ~ . ~ . ~ . ~ . ~ . ~ . ~ . ~} 254$

14. Die gemeine Florfliege, bas \$erlhaft . . . . . . . . . 255

15. Die gemeine Plattbaud libelle . . . . . . . . . . 258

Erfter 9Gjquitt. Die Ballinfelten . . . . . . . . . . . . . 265

Die Eidentnospen = अallmespe . . . . . . . . . . . . 267

Die Eidjenblatt= 5alfmegpe . . . . . . . . . . . . . 267

(3alfen anterer Eidjengallwespen . . . . . . . . . . 271

Die Rojengallenmespe . . . . . . . . . . . . . 273

Der Fidjtenrinbenflattiauger . . . . . . . . . . . 280

Die Rïfterngalfen $=$ Blattluus . . . . . . . . . . . 280

Die Blattgallen $=$ Blattweape . . . . . . . . . . . . . . 280

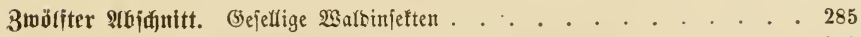

Die 2 meifen . . . . . . . . . . . . . . . . . . 289

Die gejelligen 2 sespenarten . . . . . . . . . . 304

Die Jeorniffe . . . . . . . . . . . . . . . 308

Die gemeine 2 sespe . . . . . . . . . . . . . 316

Die 5̧origbiene. . . . . . . . . . . . . . 317

Die Erbbunmel . . . . . . . . . . . . . . 327

Die $\mathfrak{T h o m a} 8=\mathfrak{T r a u e r m i l d e}$, ber Seertwurm . . . . . . . . . 331

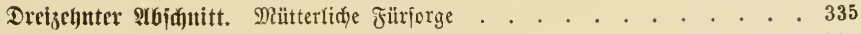

Der Walomifttäfer . . . . . . . . . . . . . . 337

Der Pillermälzer . . . . . . . . . . . . . . 338

Der gemeine Iobtengräber . . . . . . . . . . . . 339

Der Birfenblattrolfer . . . . . . . . . . . . . . 343

Der ped)braune Wafferforbentäfer . . . . . . . . . . . 347

Die Tapejierbiene, ber Blattidneiber . . . . . . . . . . 350

Die Daffelfliegen : . . . . . . . . . . . . . . . . . 355

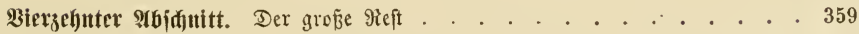

Die Şalbflïgler. (Die đdwwarzgeftreifte Dectwanze. Die rotbleinige

Banmmanje. Der 2 afferjtorpion. Die gebörnte Dornzirpe. Die geöhrte Rleinjirpe. Die Singcicabe.) . . . . . . . . . 363

Die Berabflïgler. (Der behaarte Springidmanz. Der Blafenfǘ.) . 366

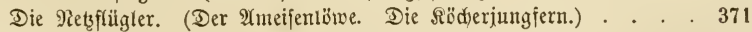

Die Fädjerflïgler. (Xenos Peckii uno Rossii.) . . . . . . . . 378

Die 3reiflügler. (Die gemteine Wafferfliege.) . . . . . . . . 379

Die $\mathscr{A}$ berflitgler . . . . . . . . . . . . . . . . 384

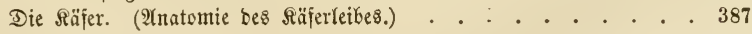

Die Sdymettertinge. . . . . . . . . . . . . . 399

") Durd) ein Beriehen ijt im Teçt Die 3iffer 11 überfprungen worden. 


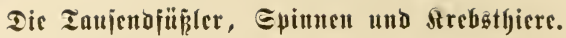

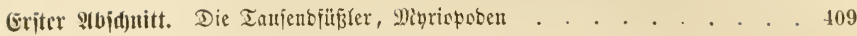
3writer 9(bidnitt. Die Epimen, Iradjniben . . . . . . . . . . . 413

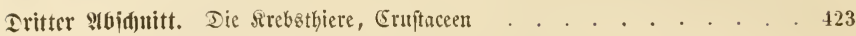

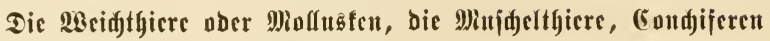
und dic 2 B̈̈rmer.

Eriter 9tbidınitt. Die $23 c i d$ thiere ober Moluałen . . . . . . . . . . 429

3writur Mgjduntt. Die Maridelthiere, Eondjiferen . . . . . . . . . . 462

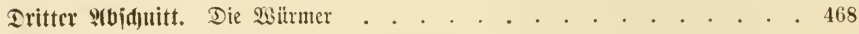

Gdiluij 


\section{Allgemeitue t(muld)mut.}





\section{Errter Ab/dnitt.}

\section{Reidstbum unto Mandffaltigfeit bei geringen Servortretent.}

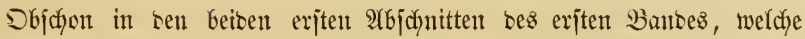
bie gemeinjame Heberichrift "Der $2 a$ alb uto bie Thiere" tragen, andy bie nieberen, bie jogenannten wirbeflojen Ifiere mittegriffen mto mitberücfict)

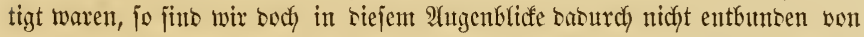
ber Serpflidytung, unferen Rejern, bie wir ja weniger unter ben Thierfutbigen juchen, einen Stanspunft ju bereiten, bon wo ans wir alsoann mit ifnen

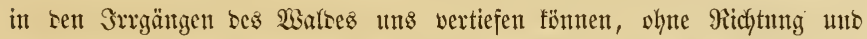

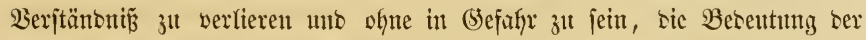
nieberen Waldthiere jँ ınterichäżen.

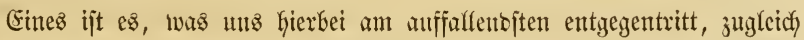

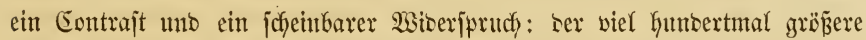
Reidfthum unjeres 2 albes an mirbeflofen Thieren uno bennody beren fajt

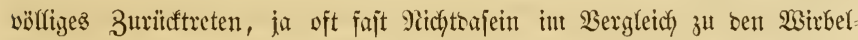
thieren. WBir fönnen nicfyt leidfyt hymbert Schritte weit in einem im Jrüblings glanze prangenben $\mathfrak{W a}$ lbe geben, whne wenizjtens einige jeiner befieberten

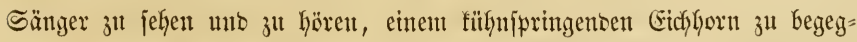
nen, wähyento uns weser ein Säfer ober eit Sdjutetterting, noch eine Spinnwebe, eine Sdynedfe auffärt; unb boch biurfen wir mit Sidyerheit an=

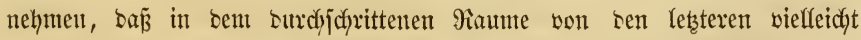
Şutberte un uns, unter, über แms waren, von benen wir nidgts getwahr werben.

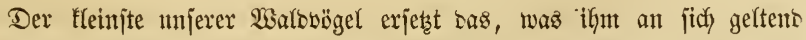

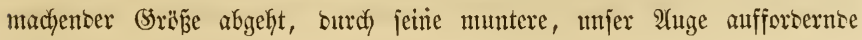




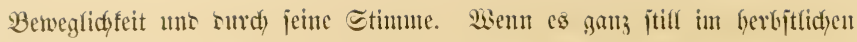

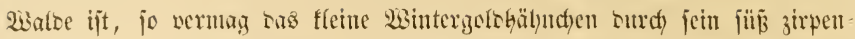

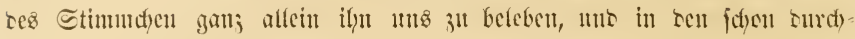
jidstiger wersenten Sironen jeben wir mit Frente bie fleinen muteren

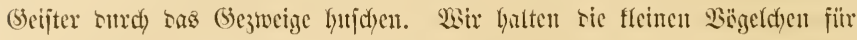

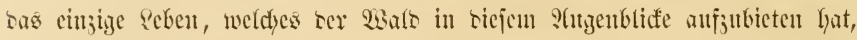

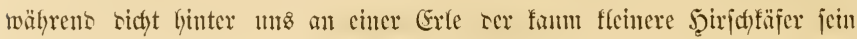

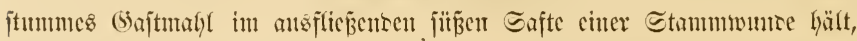

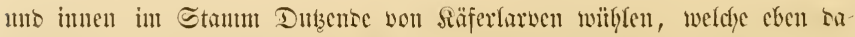

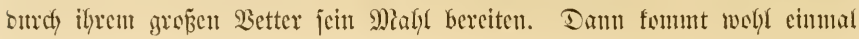

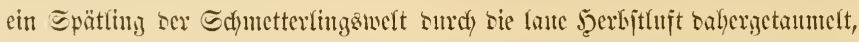
aber "untyorbar wie cin Stern", "luntlos wie cin (bebanfe"; oter eine

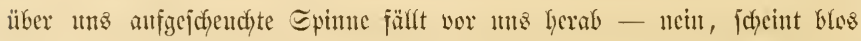
herabzufaflen, fie bleibt in ter suft hängen, senu wir jelyen ja sen Jaten

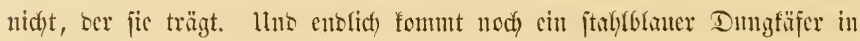

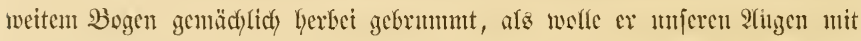

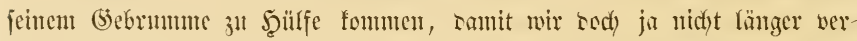

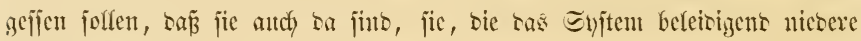
Thiere nennt.

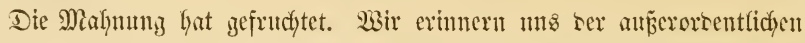

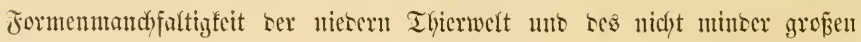

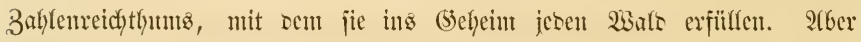

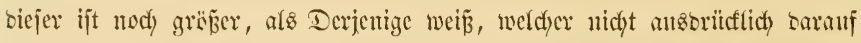

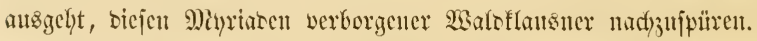

3nsem wix uns jetzt bes 3nhaltes miceres eriten bantes erinnern, fo haben wir nun an rer Sdywelfe bes zweiten ten einleitenten Şatptgeranfen

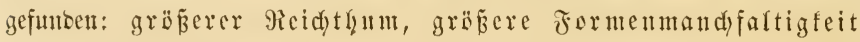
ber nieberen Ifiere neben viel geringerer Sidjtbarfeit.

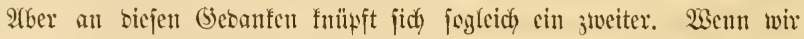

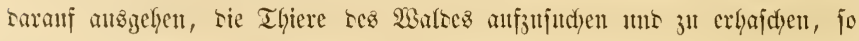

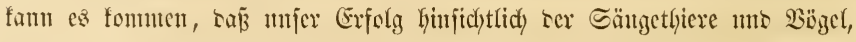
ber surche uno mun voffends gar ser Jijche ein jefre geringer ijt, wäfrento wir jïf)er fein fömnen, an micseren (Setfier eine ïberreiche Ernte jul Galten,

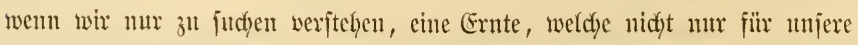
Sammlungen fids eignet, jontorn wahrbaftig nidyt minber cine joldye, 
wethe unjerer Sienutniź vom Reben, unjerer Bewunterung feiner taujenter= lei (Sejez̧e uno Mittel, mjerem warmen (Befühl fïr bie uns umgebende Thierwelt Bercicherung uno Befriebigung fuafft.

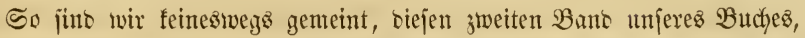
ber sie nieberen Thiere ses $\mathfrak{W a l t e s}$ fdjitoern joll, als sen nieberen Bant

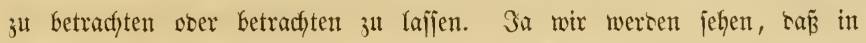
siejer nieceren Thierwelt cine Miacht werborgen ijt, won weldfer bas Reben ses Walces fortwähreno berrolyt ijt, cine Macht, wor weldjer bie häheren Thiere, utto wären es bie furchtburen Thiere bes llrwaltes ber Wente= freije, eine verjchwintente Shnmadyt jint. (Serabe bie jüngjte 2 ergangen= heit hat sen grauthlyafen $\mathfrak{B}$ eweis geliejert. Wir werten ifn fennen lernen in oen ungliafflichen Fid)tenwalsungen Sitf̧atens uno Ditpreupens, wo vor

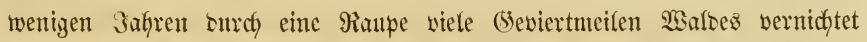
worten jinto. (Segenïber siefer Miacstentfaltung einizer nieberen $\mathfrak{S a l b t h i e r e , ~}$

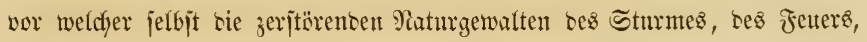

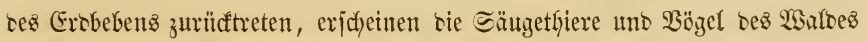
als harmloje wejen uno unjere jtolze Macfit als bic Dhmmacht eines Rinbes.

Jragt ify uns, wo finten wir bie nieberen Tfiere bes 2 Galtes? fo antworten wir: frayt lieber, wo finten wir jie nidft? Rein Schlupfwinfel

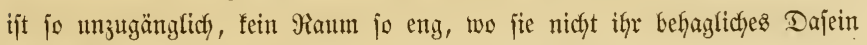

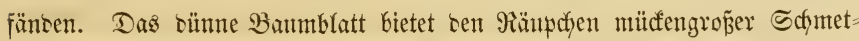

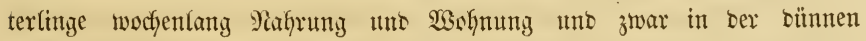

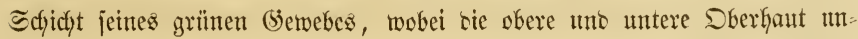
berithert bleiben uno bie beiben weip̄en 2 sänbe ber engen Bef̧anjung Gillben. Sa ber Hebermuth einer rätgfelvolfen (5rmppe ber nieseren 2 aldtfiere geht

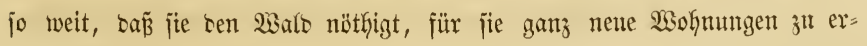
fimben uno jubereiten. Doer ijt es etwas 2 (noeres als bies, wenn ber Stich) einter (5aflfwespe bie eidfe nötfigt, bie (5alfe wadfjen zu lafjen, was an jich nicht in ber Tatur ser Fidye liegt? Into zwar lafjen jich bie Salf-

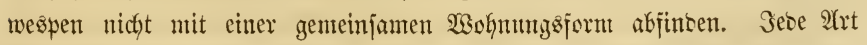
will jür ifyre Snngen eine anbers gejtultete Wiege haben, bie eine anf ber oberen, bie antere auf ber unteren $B$ lattfläclye, bie eine in ber Rinte, eine vierte in oer Snospe; bie eine hiber ftrictgró, bie anbere flein uno genau gejtaltet wie ein mit Seite überiponnenes Snöpfdyent. 
3nrem bie Baflwespen unt sie ifnen ähntichen Ballunüfen ihr 2 ejen

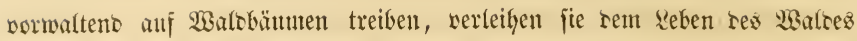
vor Sem Reben unferer ïbrigen Bffanzentwelt gerabefin einen gan bejonbern

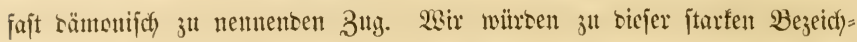
mung bes Eingriffis ser Gallwespen in Las Biloungaleben ser Bäume feinen bejontern Bruno haben, wenn bic Ballen formloje 2tustwitd)je wären, wie fie aud fomit an Fiflanzen uno Thieren in Folge cinter frantfaften Bellen=

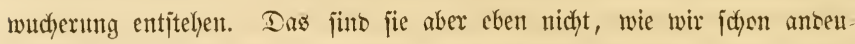

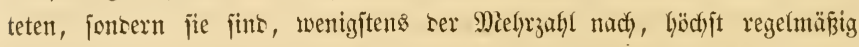
uno jefy mandfaltig zejtaltete (sebilse, beren Mandsfaltigfeit rod) auf feine antere $\mathfrak{B e i f e}$ besingt fein famu, a Saftes, weldyes Ias (Salfwespenweibcten mit sem winzig fleinen (Ei zugleid)

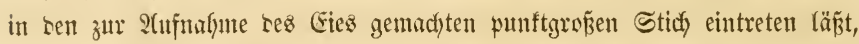
bei jeber. Sallwespenart fälyig ift, eine anbere Wirfung auf bie Bilsungs= fähigfeit ઈes Bflanzentheiles ausjü̈ben. Doch wix sürfen einer genaueren Bejpredyung tes Jiatumumbers nicht vorgreifen. Diefe 2tnbentungen ge nügen, bie fleinen (Sallwespen, bie nur sent jorgfältigen Siadforjdyer be

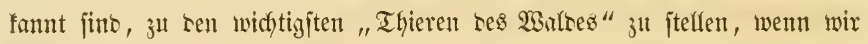
widytig nicht blos sas nennen wollen, was surch feine Größze orer fonjitigen

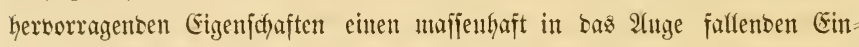
orutef herworbringt.

Wenn bie Miıirer, wie jene twinzigen Schnetter(inggräupchen heiǩen,

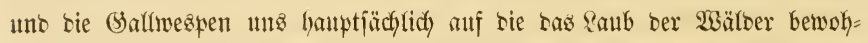
nenten nieberen Thiere hinweijen, fo ergiebt cinte weitere Siadjorjdyung,

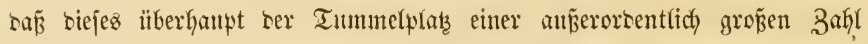

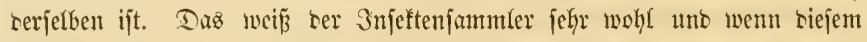

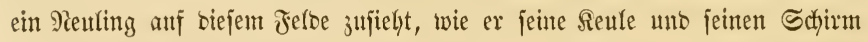
antwenbet, fo wiro er mit Staunen inne, weldhes Sceer, mnerreidfbar für sas Aluge, sort oben in ben grïnen \&aubmajien haujt.

Ein halber Snbianer judft ber 3njeftenjäger beim Beginn ser 3ago in feinen Walbgrünten zunädjit jeine wolylwerjtedte Sienle aus irgent einem

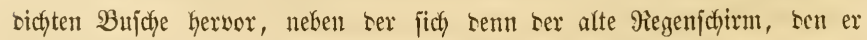

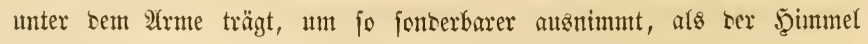
feine cinzige regenbrohente $\mathfrak{W o l f e}$ zeigt unt er ifn auth nicht alz Sommen-

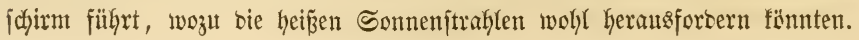




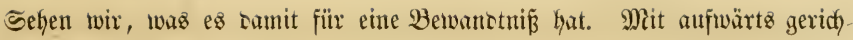
tetem $\mathfrak{B l i d f e}$ ftreift ber Maun ourch sen Walb. Su ben Sronen, nament=

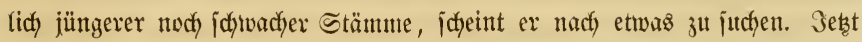

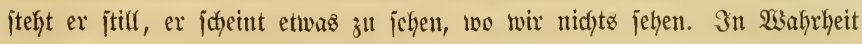

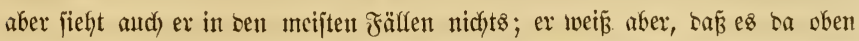
nidjt nux etwas zut jefen, fonbern autd) zu erreidfen giebt. Setzt fpannt er jeinen Schirm auf. 58 regnet aber sod nicht uto aud fein Sonnenjtrafyl fälft surd) sie bid)ten \&aubfronen. Er legt sber jtecft feinen ausgejpannten Sounenffirm berfehrt, bie ફ̧B̈hlung uns ben Stab nach aben, an ben

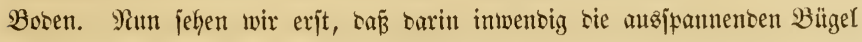

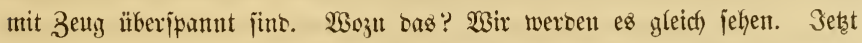

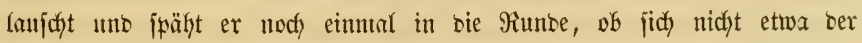

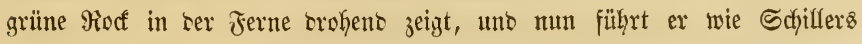
Märoz auf sie Wegelagerer mit jeiner wudjtigen Reule "getwaltige

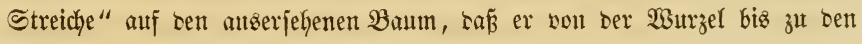

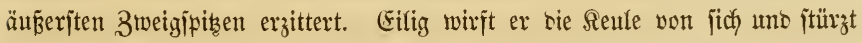
anf ben Sdfirm loz, in weldyen es won allerhano fleinem Setfier friebelt uno frabbelt, welches alfes ber Seulenjchlag aus ber Baumfrone herab= gejditttelt hat. Behento Räfer, die sor Sdyred nidyt an bas Fliegen benfen, fint emjig beuritht, jid) auts bem Staube zu madjen, Spannraupen madben ilyren hohen Sabzenbudfel zun fpannmefifenten Fortjdyritt, fleine Güpjenbe Cifinben verfdywinben mit fräftigem Sprunge, zufammengeringelt liegen grïne uno gelbe âferraupen neben trägen $\mathfrak{B a u m t w a n z e n ~ u n o ~ v e r : ~}$ sutzten Sdylupfwexpen, sie jidy freilidy isfnell auf uno Dawon madjen -furz ber Injeftenjäger hat mur ju hajdyen ıno zu greifen, ım bes Bejten won bem bunten 2 Bitbe habgaft zu wersen.

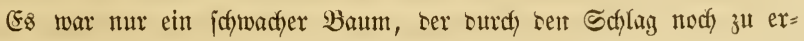
jơüttern war, ober ein nieberer 2 (jit eines ftärferen, befijen augenblicfliche 3njajien wir vor uns Gatten, tmo jidfer nod) nicht alfe, senn vielfeicht ooppelt fo viele fieten über sen Umjang tes Scjirmes Ginats orer befannen

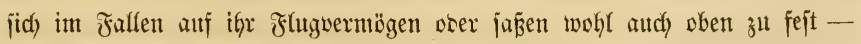

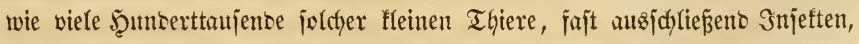
miijīen aljo an einem warmen Sommertage in ben Ranbfronen eines $\mathfrak{W a l t o s}$ verbreitet jein!

Uno เas, was an nieberen Thieren sie Sironen ser Wafobäıme belebt, 
ijt rieflectht faum fo siel, meijt ficfer weniger, als bas, waz an unc muter

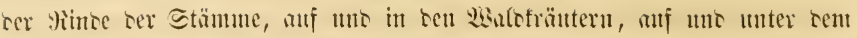

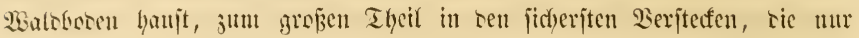

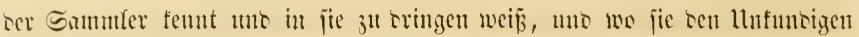
im böcbiten (Sirase ïberrajchen, menn er sort jufällig anf fie jtöp̆t.

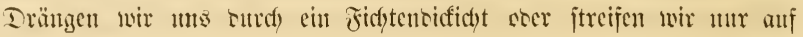

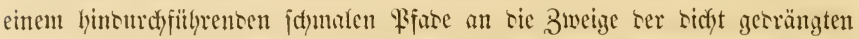

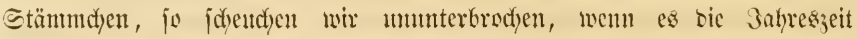
gerabe mit fids bringt, sie Schamen ber fleinen meijt Kelffarbigen Mistten auf, welde aber fofort cin neues gleidjes Beritect auffudyen, une eben jo

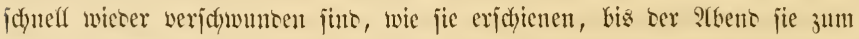
lujtigen Schwärmen herworuft, soñ jie oft weit finweg bent trentojen sichte juffiegen uns ben ungeafnten Tor finten.

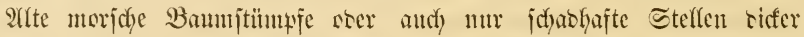
Stäume verratlyen andy sem aufmerffamen ?hge sas Dajein ocr Thier-

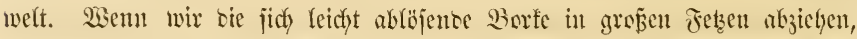

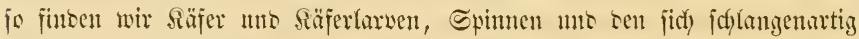

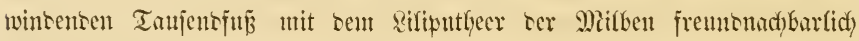
oter wofly and cinater als Tobfeinte anffuthent beijammen. In sen

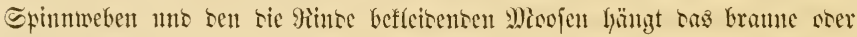

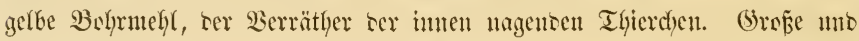

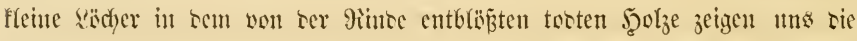

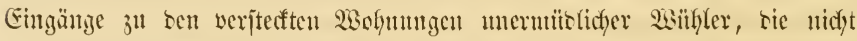

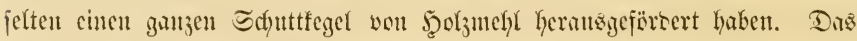
ந̧eer ter Almeijen, sie wumberbaren Banneifterimnen, treffen wir balt in

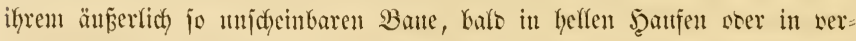
jettelten fich weit hin erftrecfenten Bïgen, immer aber ijt finm ein anteres

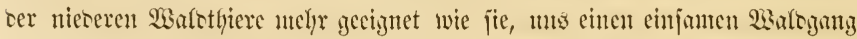

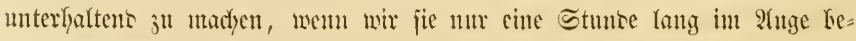
Galten wallen.

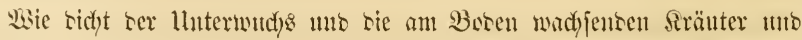

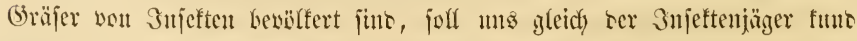

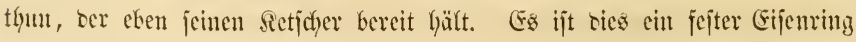

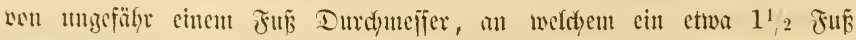

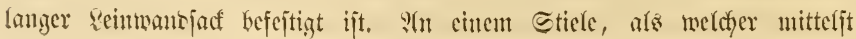


einer Schranbe ber 3minge ber Spajieritod sienen fanu, hanshabt er biejes

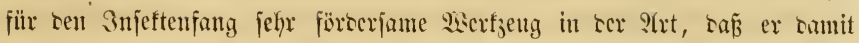

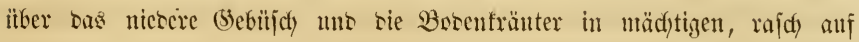
cinanter folgenoen Bütyen hinfent mo sabei sen Stiel imumer fo in ser

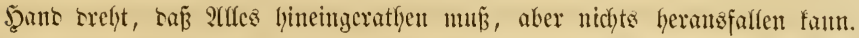

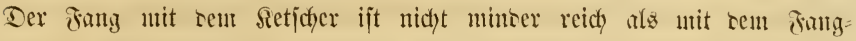

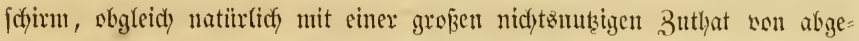

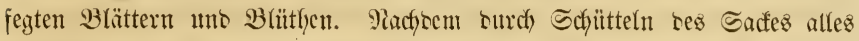
Rebentige anf seffen Boben finunter gebentelt ift, werten bie sbenauf liegenon \$iflanzentheile jdynell abgenommen un sas Spridywort: im 3ipfel

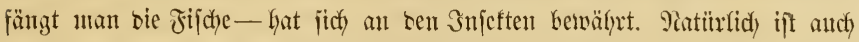

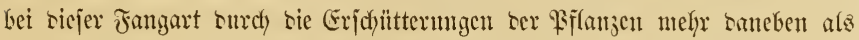
in ten Sacf gefallen mo sody ift bie Ernte jelyr reidy. Es mürbe das

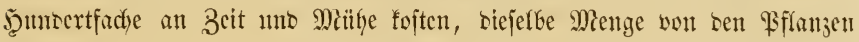

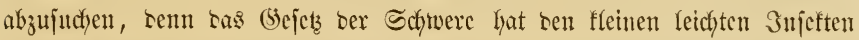

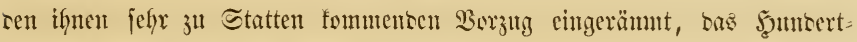

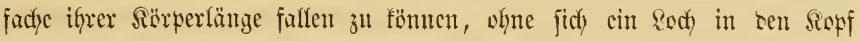
3tt fdylagen, was uns unfelifbar wiberfülyt, wenn wir mu brcimal mamns

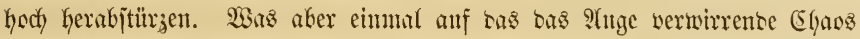

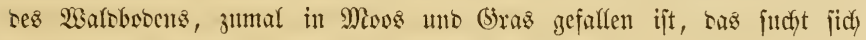
[d)wer mieter herans.

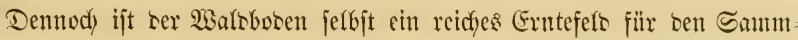
ler nieserer Warbthiere. Davon rwiffen anbere Sente freilich nichtz, benen

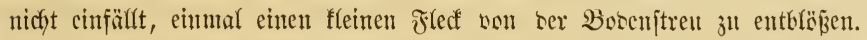

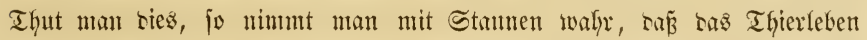

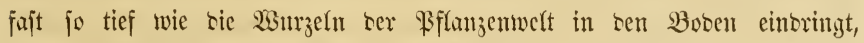

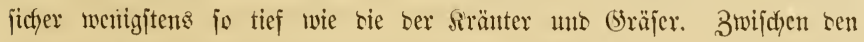
binrren, tiefer unten fendyten uno fanlenten $\mathcal{B}$ lättern, 9 (j) = uno Rinoen=

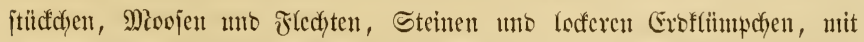
Einem Saort in bem Mixtum Eompojitum, was ben Waatoboben bitset, nber viefmefy in ben engen (Scmädyern siejer Proletariermofnnm regt fid)

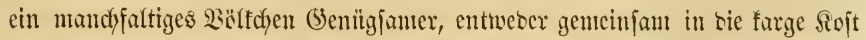
jich theilent, melyr aber einanber jelbjt anffrefiento mo befehoent. J̧ier fonmen ju ben 3njeften aud) nod) eine Menge 2(rten aus ben verwanbten

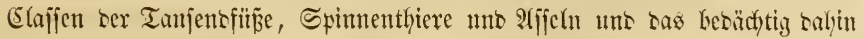




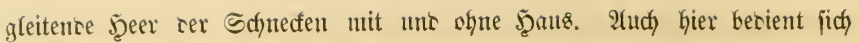

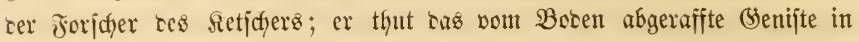

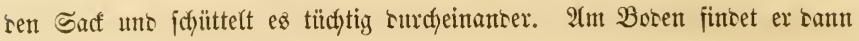
mieber alles sebente beijammen.

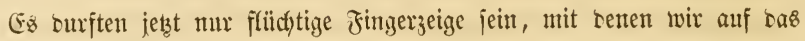
Dajein ber nieseren Thiere in 2 albe Ginmiejen. Sie reidjten aber aus,

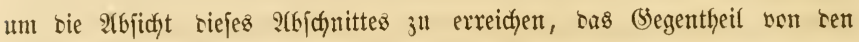

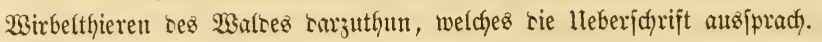

$3 a$, es ijt jdwerer, einen Sort im $\mathfrak{B a l b e}$ ju finten, wo bie nieberen Thiere nidgt hamjen, als jie sarin zu fimben. Heberall fint jie ba. 


\section{Bweiter Abrdnitt.}

\section{2rbbüngigfeit ber Sidftharfeit ber nieberen Walsthiere von ben Gafrezzeiten, won ifyer Rcbensmeife mo ifyren Entwirfelungąuttünon. Entge Berjïngutg.}

Objdyon wir auth unter ben höheren Thieren ses Walbes Winter=

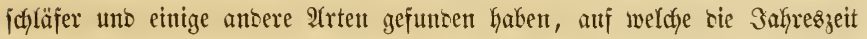
uno bie Witterung hinjichtlich) ihres Şerbortretens einen irgenbnie bepitim= menten Einflus ausübt, jo finset jith sies bod in einem nod) viel Gäheren (Srabe bei ten nieberen Thieren unt es wirb baburd) beren Servortreten als waldbelebento (Sejtalten ungleid) melyn beeinflufist. Sa man mur jagen,

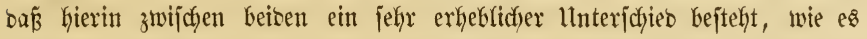

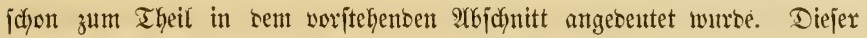

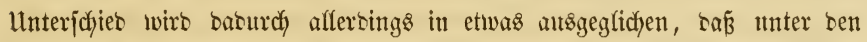
nieberen $\mathfrak{B a l b t h i e r e n ~ f e i n ~ w a n b e r n b e s ~ i j t , ~ o . ~ h . ~ f e i n ~ j o l d h e s , ~ w e l d j e s ~ z e i t = ~}$

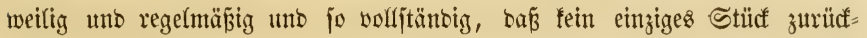
bleibt, feine beutiche Şeimitätte verläßjt, um nady mefyr ober weniger, oft

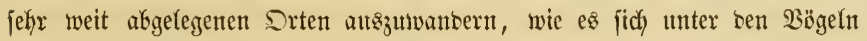

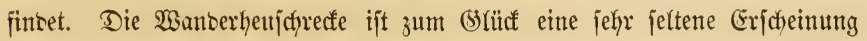
in Deutjolano uno bann gehört jie, swenn fie fitth einmal als sanoplage zeigt, Lem Walbe nidyt mefyr als ser übrigen \$flanzenwert an. Dody werben wir einige intergeorbnete Fälle bes $\mathfrak{B a n b e r n s}$ bei einigen anteren Snjeften finten, weldfes aber bielleidjt mehy ein unfreinifliges ift. Mit bem Wanbern bes Seerwumes uno ber Proceffitonstautpen hat es eine antere $\mathfrak{B}$ etwandiniñ. 
3u teiner Zeit tritt, wie wir uns jofton saran eximerten, sic nictere

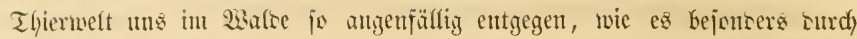
rie Sö̈gel rie hähere thut; aber and in sicjem Burüctreten giebt jid nach

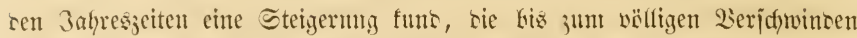

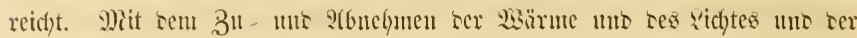

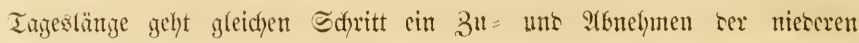
Ifiere ses Waltes, wenigitens was beren Sidftbarjein betrifft.

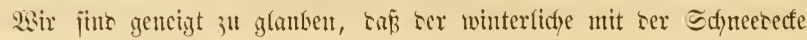

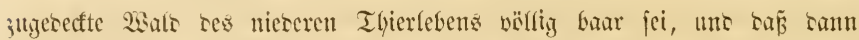

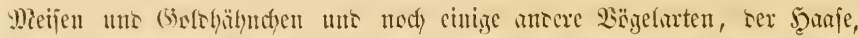

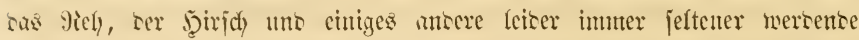

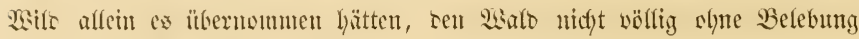

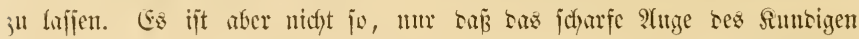

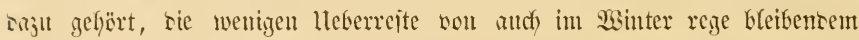

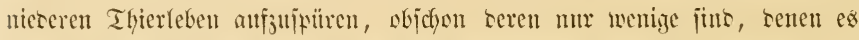
won ser Patur bejdicben ijt, regefmäp̃ig aud) im winter munter uno lebenting 3u jein, wie 3. B. Ser jemen Yiamen mit Red)t tragente Frojt= jofuetterfing (Acidalia brumata), ter erft im Yiovember uns December

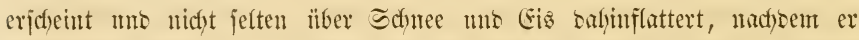
vom Suni an ben ganjen fob̈nen Sommer mo jeerbjt tief in ser Eroe alö Finte werjchlajen gat.

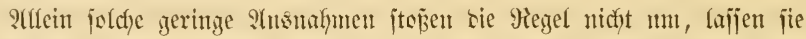
vielmefyr erjt red)t sentlid) hervortreten, sa joldye eimjelne winterkelsen sus

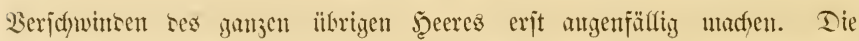

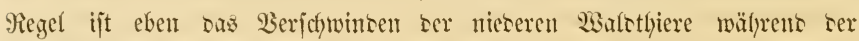
rginterş3eit.

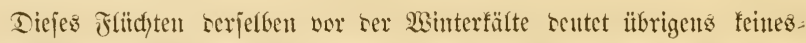
wegs allgemein anf eine größ̆ere Empfindfichfeit fïr siejelbe, senn man

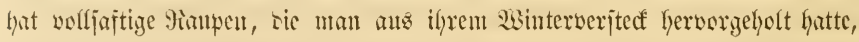

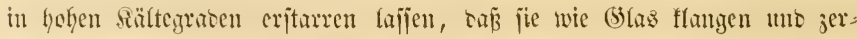
bracten, aber mach lamglamem Wiercraufthanen wieser aufleben jefen, ja saffelbe gejaly mit it Eis eingefrorencu. Achnliches hat man an Bantแno 2arajferfdyeden beobarchtet.

Echon währento scr 2 Binterutunte berung cine vorïfergefense Stei=

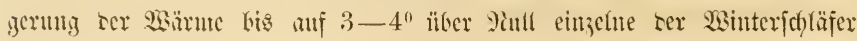




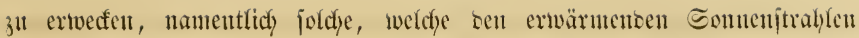

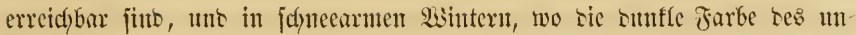
becectten Bobens ber Wärme eine größ̈ere Machtentfätung crlaubt. Steigt

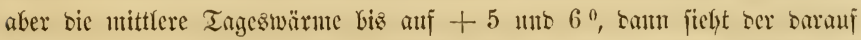

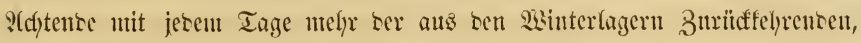
namentlich aus ber (Elaffe ber Snjeften uno ber Epimten, sic natïrfich

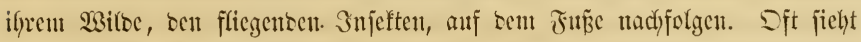

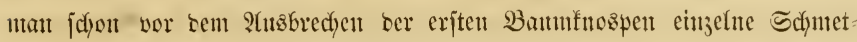
terfinge, bejonters sen Eitronenfalter, Colias Rhamni, uno sen fletnent

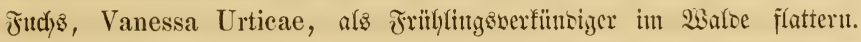

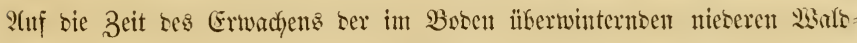

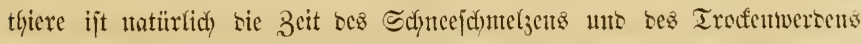

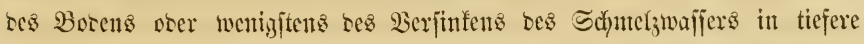

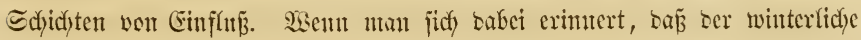

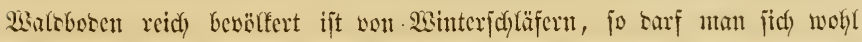

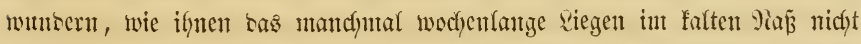

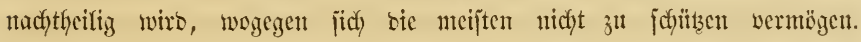

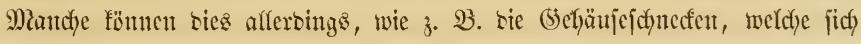

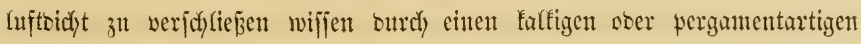
Winterbecel, ben jic bein Ginnintern in bie Mä̈toung igres (bebäufes

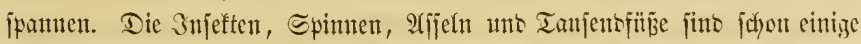
3eit lang wieber auf bent Platze, elje bie Edynecfen nadyfommen, bie in ber Riegel erịt bie Siegetation, für viele sie unentbelyrlicle Rebensbebingung, eitten Borjprung geminten lajfen. Daun ift gewölynlich ser exite warme

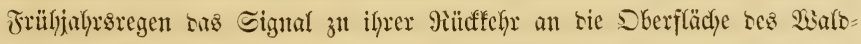
bobens, in befjen Tiefen fic jidy eingegraben hatten. Ween man jie rort vor ifyrent Wicberertwadyen fincet, fann man bie Berwunberming sarïber nidyt

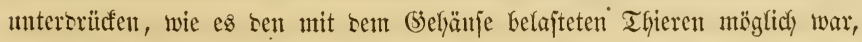
nicht jeften funstief jich Ginabjubohren.

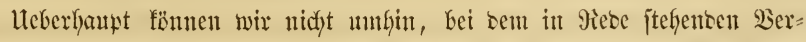
laffen ber Winterquartiere ber nieberen Walsthicre barauf aufnterffant $3^{\text {u }}$ machen, wie biejelben oft mit wahrem Spïnjunte sie pafjenten Dertlidy=

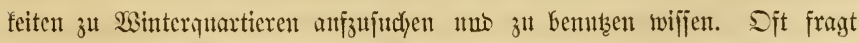
man fich erjtaunt, wie es ben Thieren möglidy gewejen jein ms̈ge, in เas

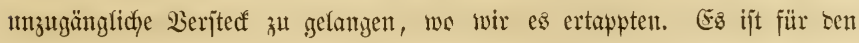




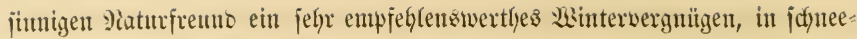
freten Froftwetter un ben Stamm eines Banmes bie Bobentecfe befutjam wegzuräumen, unb bie in sen mandffaltigiten Stellungen in ben nad) unjeren

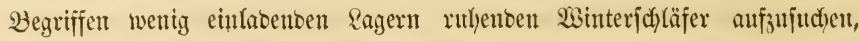
bie sant meijt in ser 2 ärme แnferer 5̧and bald anfwad)en, wobei man

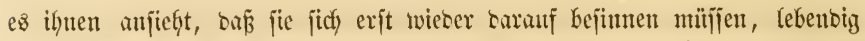

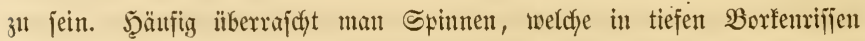

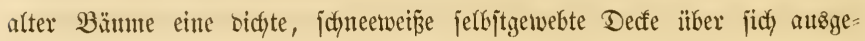
jpant haben mo sarunter mit an ben seib eng angegegenen beinen ifre Winterrube halten, aber angenblifflich erwadyen uno savon eilen, wenn man jie in ifyer Rulbe ftört.

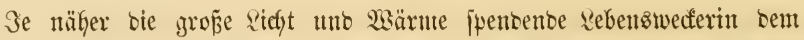

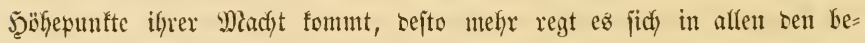
idjriebonen Berjtecfen ber nieseren $23 a$ arthiere, uno namentlich won Ente

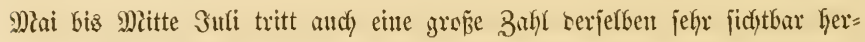

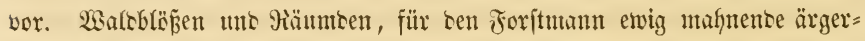

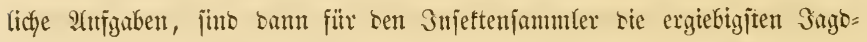

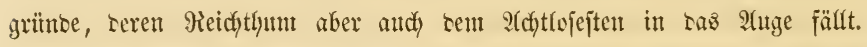

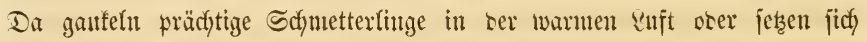
necfeno sor unfere finfe, forbern uns herats, fie von ber Bhume abzu=

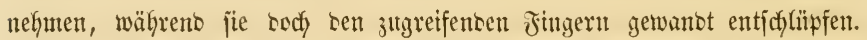
(3erabe unjere fdjünften Tagfalter jub meift Walsbewolyner. Dod) wer:

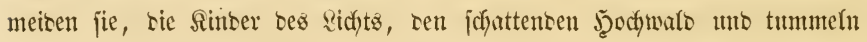

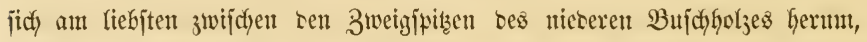

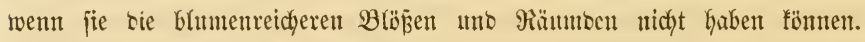

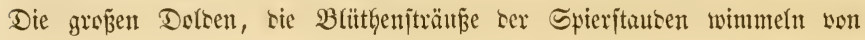

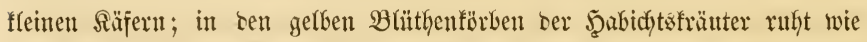

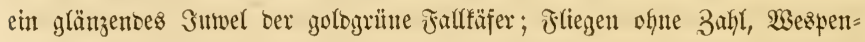
arten unb gejuäftig ihren Raub juchente Sdylupfwespen fliegen ab unb zu, wälyeno träge (5oldfäfer uno $\mathfrak{B}$ lattwanzen in sen humbertblütfigen Scfirmen

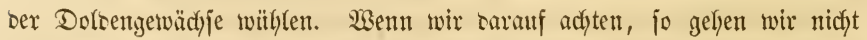
leidft zehn Sdyritte weit anf bem fonturdyglühten Walbwege, olne cañ

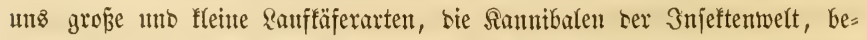
gegneten, weldje nimmer ruthen, auf ifre Claffenverwanbten, bie oft größ̈er

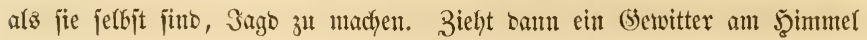




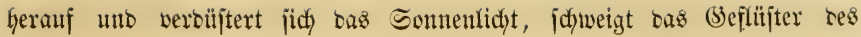
Eaubes in ber exitorbenen \&uft, baß̧ bas erjte ferme (5roffen von affer Ereatur vernonmten werbe - Sann ergreift wie sie Sänger in ten Wipfeln io autf) bas jtumute 5̧eer ber Injeften wie unz jelbjt ser Schaner vor bem

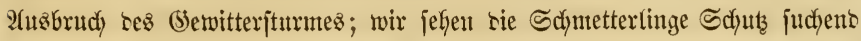
walbeinwärts flattern, Fliegen uno Wespen jint bereits finwes, ehe wir jie

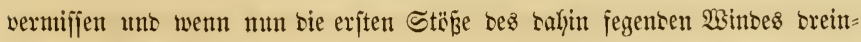
fafyen, ijt bercits alles in Sidjerheit. Das fino weifyebolle 2lugenticfe ber Dffenbarung ser Matur. Das reben, was uns eben nod) huntertfültig

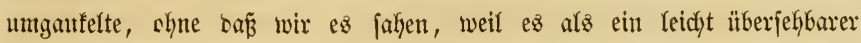
Theil hes (Sefanmtbilbes uns entging - nun offenbart es fich uns burch

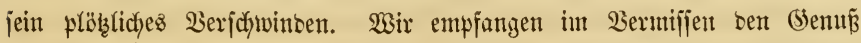

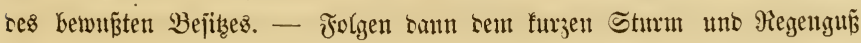
nod) warme jontige Stunsen, fo sautert $e s$ nidjt lange, bis bie Flitdyttinge

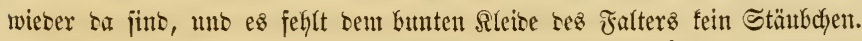

Die Zeit ber hödjiten Zebensentfaltung ijt es andy für jene won affen

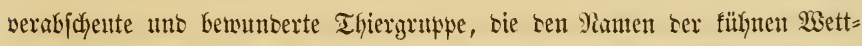
jtreiterin, ser funffertigen Spinnerin 2lradjne, trägt. Der Walo ijt von einem Şeere von Spinnen bevälfert, ẗber seffen Bröfe ben Unerfabrenen

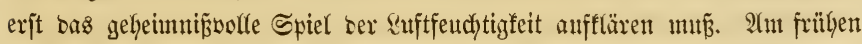
Morgen jiefht man żwar bie Spinnen ferbjt nidyt, aber taufenträ̈ltig bie Spuren ifyer Anwejengeit, wo man eine Stunbe fpüter nichtz mefyr bavon jeken twärbe. Denn wer hätte nidyt idjon auf Jidytentulturen unt an ben

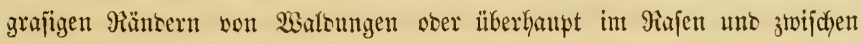
anberen Bobenpflanjen, bie mit Millionen punftgrof̈er Thaupertchen be= secften uno erft baburdy fidftbar getwortenen Spinngewebe betwuthert, meldje bidjt gewoben, flach uno meift nit einem Tridjter in ser Mitte verjeben, itber bie \$flamzen Gingejpannt jins. Unten am Enbe biejes Trichters lauert bie nimmerjatte Spinne uno bebent in furzer Beit ifye hinterlijtige Schladyt= banf mit ben lleberrejten ifyer Dpfer.

Die Spinnen find in ber Mefrzahl jehr von ber (5unjt ber Witterung abfängig, weil ez bie Injeften jint, von benen jie leben. Dod) werben jie von ungünjtiger trüber uns fïflex Bitterung nidjt immer in befaglidje Berjtecfe getrieben, jonbern viele verharren in langer Sebulo im Mittel=

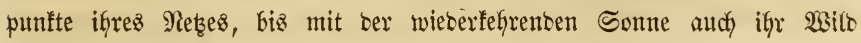




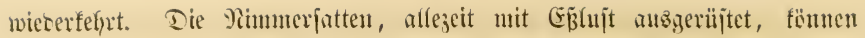

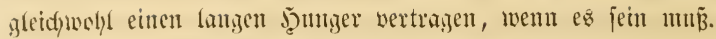

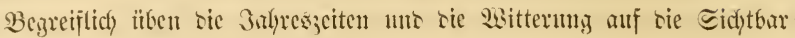

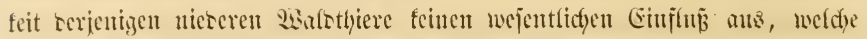

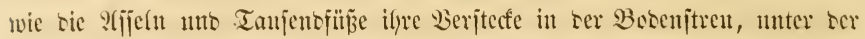

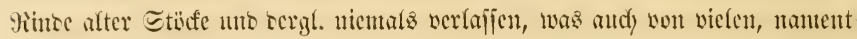

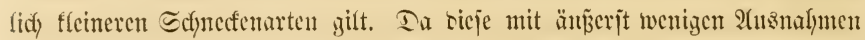
füble Fendytigfeit uno Echatten lieben, fo finten jidf) tie nidst wenigen

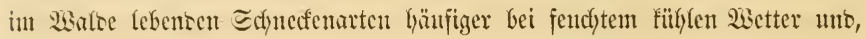

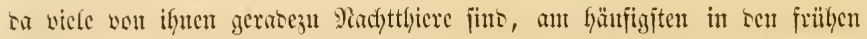

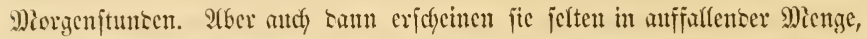
obgleid) ser Erjafjrene jie unter sicjen Bebingungen lyäufiger futet als jonjt.

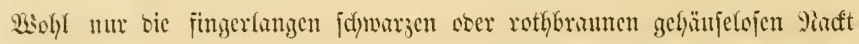

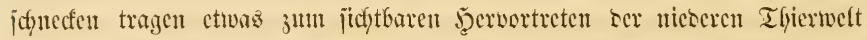
im 2surtse bei, sa jie bei fendytem 2 setter, mamentfich nach Fegen, oft in Dienge mit uns sicjefben 23 ge wantefn nno uns mitten in Somner cinen Jall wie auf bem Eije bermlajien fünnen, wemn wir auf cine foldje von idflipprizen Sdylem Strotzente tretento angiglitten.

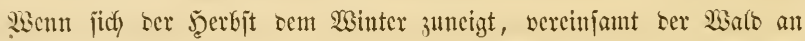

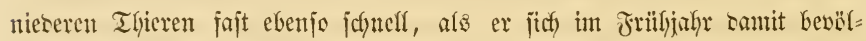
ferte. Dabei tann aber nach) cinem fumzen Sctober=, ober im Gebirge jefbjt Septemberwinter cine nochmalize 9ïiffebr marmen Wetterz tie bereitz berichendfent wenigjtens theitneije wieber hervorlocfen, uno es jino nament=

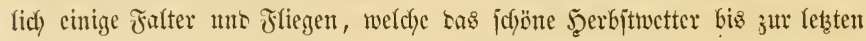

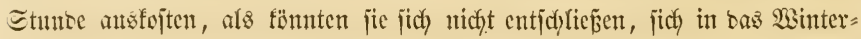
grab ju legen. WGer fönnte bann, währento ify jerbjt frëjtelt, cinen joldyen

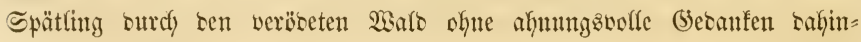
flatteru jehen?

Inter Len vielen zum Theil an sas $\mathfrak{B}$ unberbare grenzenten Eigen= thïmfichfeiten, wosurdy sic Snjeften fajt einjig sie ïbrige Ifierwelt n̈ber= ragen, ijt sie alfbefannte Berwanthng sie bemerfensiverthejte uno jngleich)

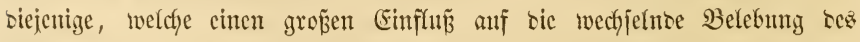
Wartos ansitbt. Se nach sent Rebensabjefuitt, in welchem ein 3njeft jtcht, fann ez für ben, weldyer mur tas jicht, was jich feinem 2ługe auferïngt, entweter nicht vorhanten jein orer burd) jeine Menge andy ten 2(d)trojeiten 


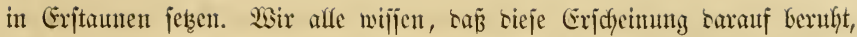

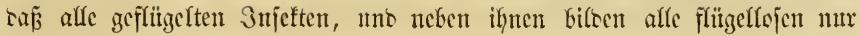

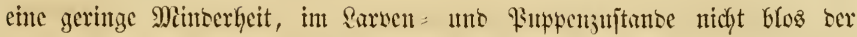
Flïgel ermangeln, jonbern antd) anžer biejem Mangel meip̈t cinte träge uno werjtecfte Rebenzmeije füfren. Der Jorjtntam, bejīen ?lujgabe cв ijt, jeine

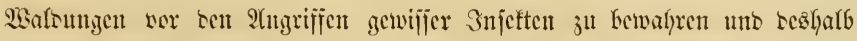

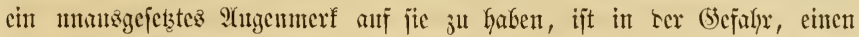
argen Feino jull

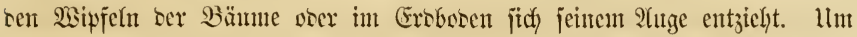
fo mchr wiro er sann ïberrajdyt, wenn bas gefälyrlidye Injeft jeine retzte

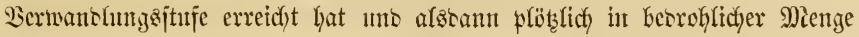
ifym um ten Sopf fliegt.

Es giebt feine antere Thierclafie, in weldyer eme po grindidje Bejtalt=

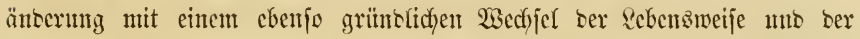

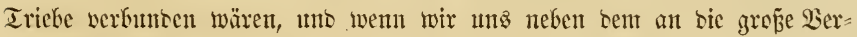
mefyrungsfähigleit ber 3njetten eximern, jo liegt bic Folgeridjtigfeit bes Einfluffes anf ter J̧ant, weldyen jic anf bie Belebung bes $\mathfrak{W a l b e z , ~ j a ~ m i x ~}$ werten jehen anf sefjen Seben unt Tos ansüben fönnen.

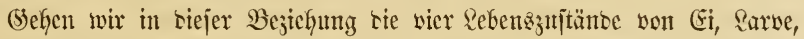

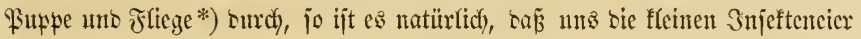
nur bann nidyt entgehen, wenn wir jie aufujudyen wifjen. Selbjt biejenigen, weldye an freien Stellen in groper Menge znjammen abgelegt werben,

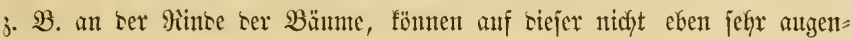
fällfig Gerwortreten.

Bon ben Qarwen fömen nur biejenigen jich als Waftbebölferer geltento madyen, welche gejelfig beifammen leben ober went cinzeln lebente in un= getwölntidyer Mienge jich vermelynt haben. Eigentlidy gejelfig lebenber giebt

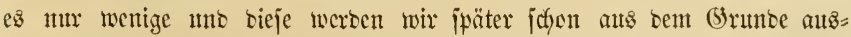

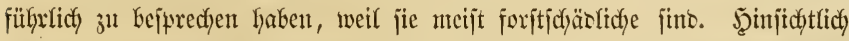
ungemöhnficyer Steigerungen ber Menge irgento eires Walsinjeftes ober auth

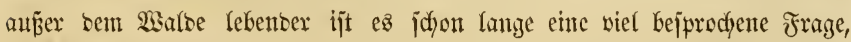

*) Wsetl alle mit Frlïgeln begabten Smifeften biefe erft im volffommenen Buftanbe erhalten, wentigftens erit gebraudjen tönnett, nent man fie in biejem Fliege. Das

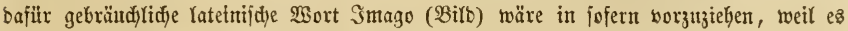
audi) bie ungefiligetten $\mathfrak{s}$ jeften mitbegreift. 
was ber Gruns ju ciner fo ungewölynfidjen Bermebrung fei, ofhe bisher gehungen ijt, siejen (Srumb mit Eidjerfycit nad/zumeijen.

Bei ben vielen Feintoen, weldje bie Injeften namentlid) unter ben Bögefn mo in ifyrer eigenen Elafic haben, lag ser Geranfe jefy nahe, saj bic Sermekrung ber 3njeften surch eine voryängige Derminterung ifyrer

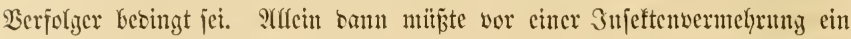
zablreichercs Dorthantenjein ifyer Feinte zu Kemerfen gewejen jein. Dics ijt

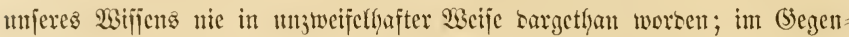
theil hat man inmer Sclegenfeit gethabt, zu jehen, wie mit sen an Mienge zunthmenocn Snjeften immer aud bie Menge igrer jeinte zutrimut, uno

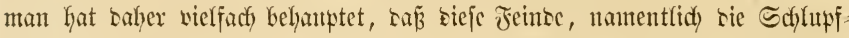
wespen, cs feien, was ber mandymal afler Bejdrribung fpottenten Ber=

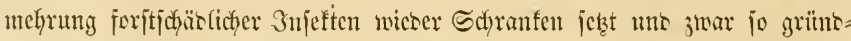

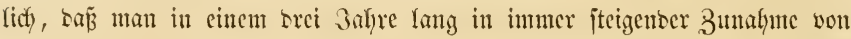
einem 3njeft verwijteten Wafte in vierten $3 a h r e$ fein einjiges mefr tavon au Reben fimbet. Wienn sieje Behautptung begrüntet wäre, fo übten als:

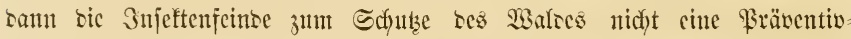

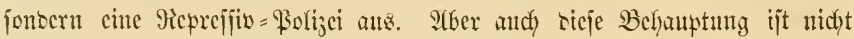

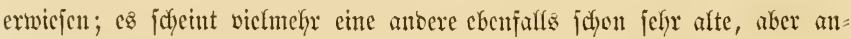

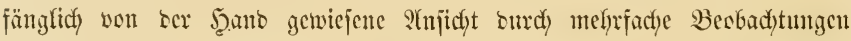

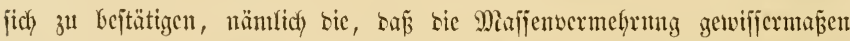

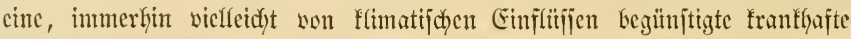

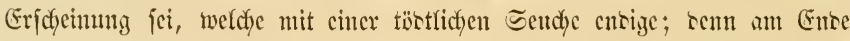
ciner Snjeftenvermefyrung fah man uzählige 3njeften jterben, ohne saj jie 3n ifyer wolfenteten Entrwifefung mo jum Eicrlegen gelangten ober won ifyen Feinsen irgeno wie jul leiren gehabt bätten.

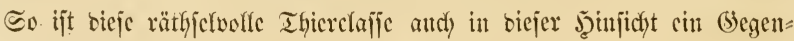

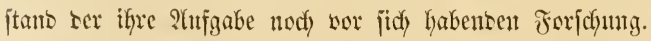

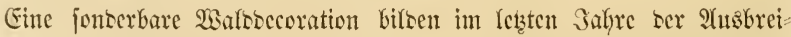

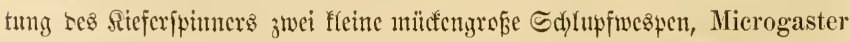
nemorum, unto ordinarius. 3Gre mabcnförnigen Eärwdyen feben 3n mehr

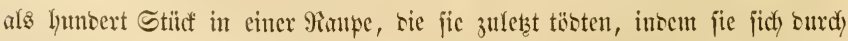
beren Şaut heratsosfiren uno fid) frfort anf ihr secr in ihrer nächjten

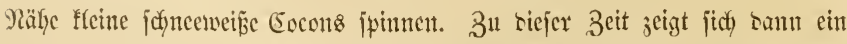
bon bem Sieferfyinner hoimgefudter Wald mit zahflojen weißßen Flecfen 
Gebecft, sie ïberall, namentlidy an aflen Theilen ber Siefern felbit, zu bemerfen fint.

Nicht minser abentenertidy uno wie in einent Banberbaffet aus ben

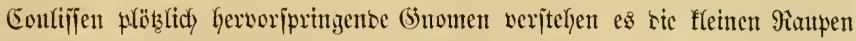

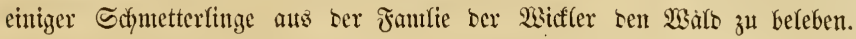
Dies gilt numentlidy won benen bes grünen Eidjentwiffers, Tortrix viridana,

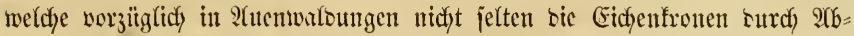

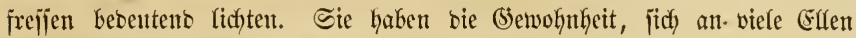

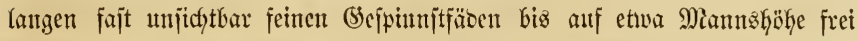
in ber suft aufjuthängen, was fie namentlich) bann plöbzlich uno in Menge

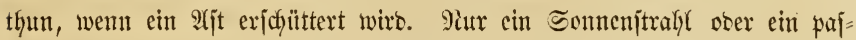
jenber Şintergrumo madjt bann bie Fäben ber iiberall herabfängenben flemen lebendigen Pentel fichtbar.

Dã num sie bewegungalojen unt jubem meijt verborgen untergebract)= ten Huppen nod) weniger jutr lebenden Staffage bes Walbes beitragen

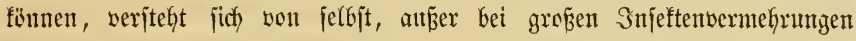

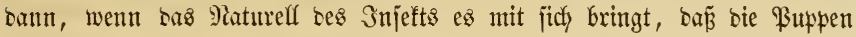

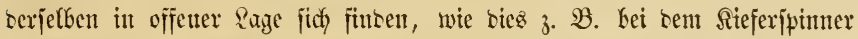

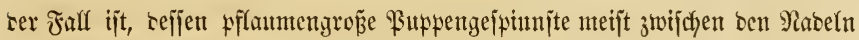
unt an ben fahlen Tricben angelängt werben.

Bei bem ben meiîten Эnjeften als Fliegen eigenen Flugvermögen ijt

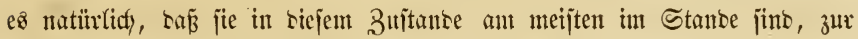
Belebung bez 2 baloes etwaz betzutragen uno wir werben sarüber bei ben fpäteren Eimzelbetrachtungen 23 untersinge lyären.

Bou ben thbrizen niereren 2 alothieren fann im Sinte wie jetst von ben 3njeften nidyt gerebet werten, La feines berjelben eine jo burdjgreifente Berwandlung jeigt.

Entridy ijt hier nody einer Seite tor nieberen Wartstyiere jut gebenten,

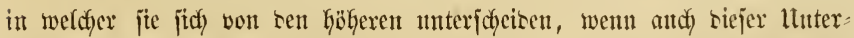

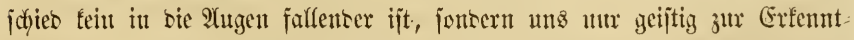

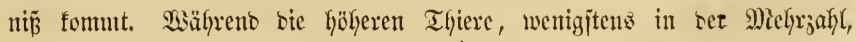
viele Salye hittereinanter - jo weit jie nidyt bon ber Sago ober ifyren Jetnben getöbtet werben - sen 2 alo beleben uno wix biefleidyt ohne es

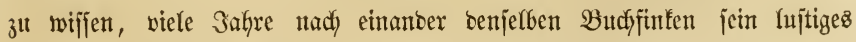

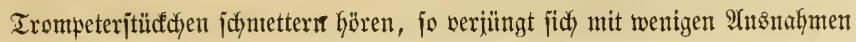




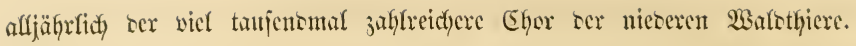

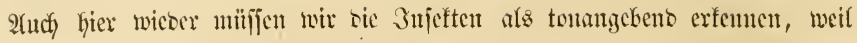

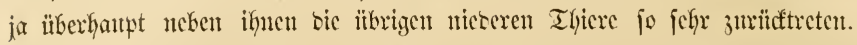
(Siebt es and) nidjt wenige Injeftent, weldye länger als cin 3ahy leben

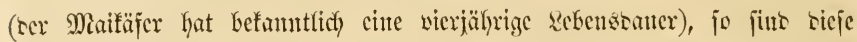

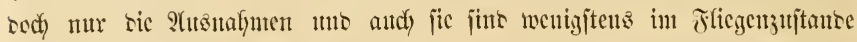

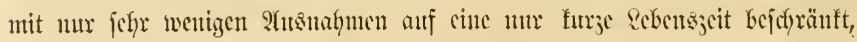
inbem won bex (scjummtoanter ifyes scbens tas llebrize anf bic früfyeren

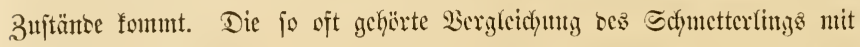

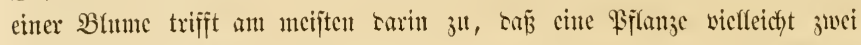

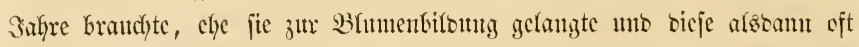

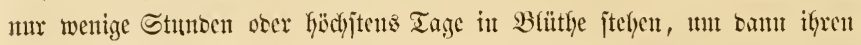

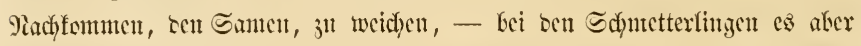

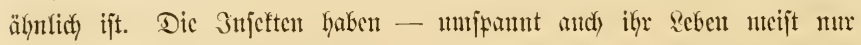

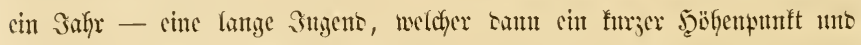
bicjent ofye âtersuerfalf ber Too folgt, nacheem, für viele Imjeften beinahe

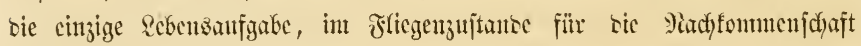
gejorgt worten ift.

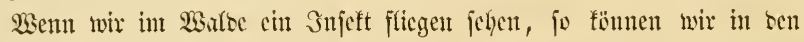
meijten Fäflen jidfer jein, baj es im vorizen Sommer nod) nidyt ba flog

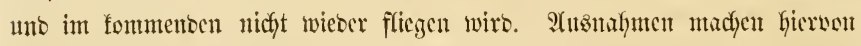

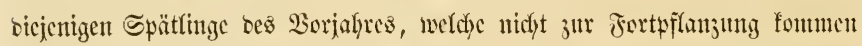
fonnten uno nach ber lleberwinterung in eincur Beritecf nody sie Somme eines zweiten Sahres jehen.

Unter ben noch tiejer als sie Injeften in ber Stufenjolge ses Sujtems

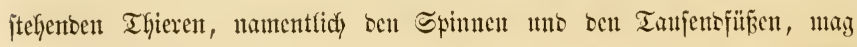

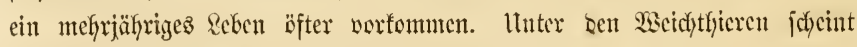

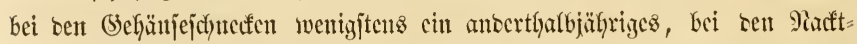

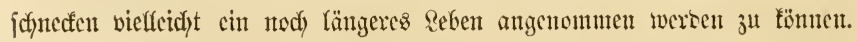

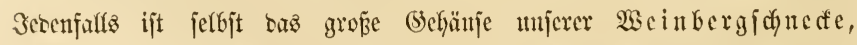

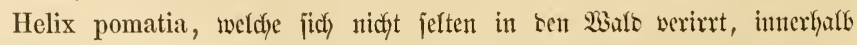
eines Safures fertig. Dayegen ijt hier cines Miluchettfieres im entzegen= gejeşten Sinne 3n zebenfen, benn ein Wurstfier fann man bie in einigen

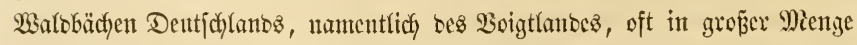
rebente Perlenuufdel, Margaritana margaritifera, nennen. Dont 


\section{1}

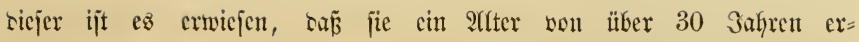
reichen fann.

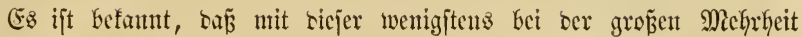

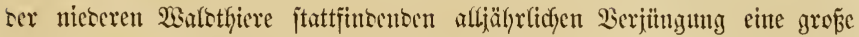

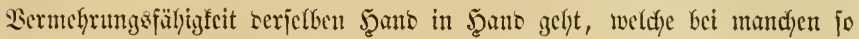

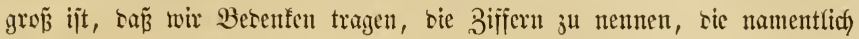

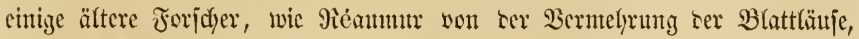
bic jo redft eigentlich $23 a$ rothiere jino, angeben.

Wo jüfyrlich Miflionen jterben, ba joflte man wenigjtens bas Unther=

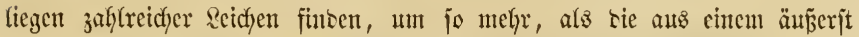

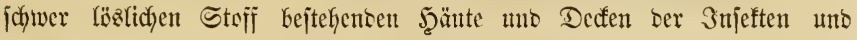
injeftenverwansten Thiere jelyr lange ser Berwejung wiberjtehen. Dennods ijt uns biejer wiberwärtige STblicf erfpart. Gefjr jelten jiegt man Injeften=

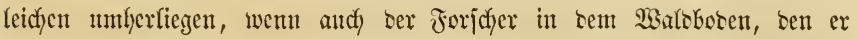
nad) Rebenren surdjittcht, nidyt jelten sie jojier unverweslidyen \$anzerjtütfen

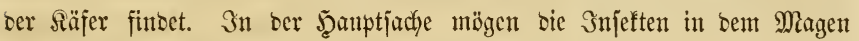
ifrer juflreichen Serfolger bejtattet werben. 


\section{Dritter Xb/d)nitt.}

\section{Gunfluf́s ber nieberen Thiere auf bent Wals.}

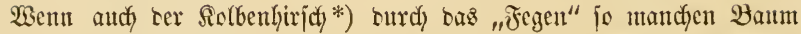

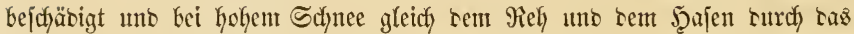

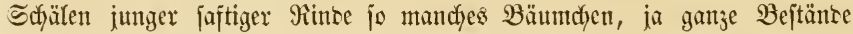

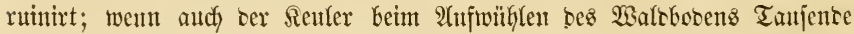
von aufipriešenben Bäumdyen töstet - io ijt, von ben jamenfrefijenten

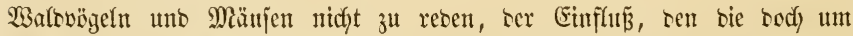
vieles jtärferen Göheren Thiere alf ben 2 alo auz̆̈̈ben, body nidyt entfernt mit sem zu vergleidfen, sen bie nieseren Thiere in 2 altoe oft in po ver=

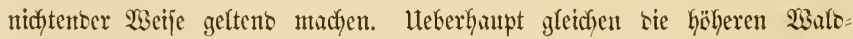

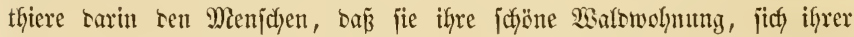
freuteno, fdyonen, weun aud nidyt pflegen ober gar aufbauen; es jei benn,

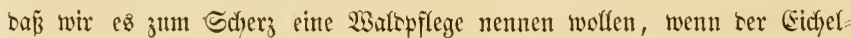

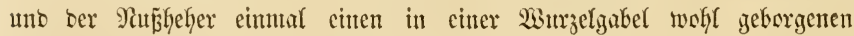

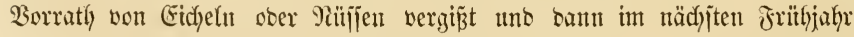

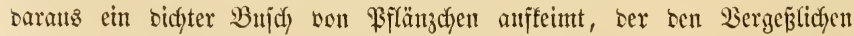

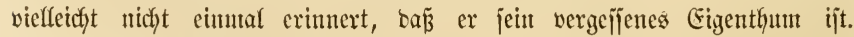
Freilich mag ber befieberte \$̧amjter in sen meijten Fällen inzrwijchen von bem Tobe ereilt worben jein.

*) So heifst befauntlich ber Şirfd, fo lange bas aufgejetzte neue (Setweih nody mit

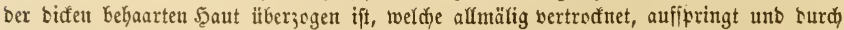
"Das Fegen" an bett Baumftänmen abgerieben wirb. Siebe in BDo. I. S. 242 auf ber Tafel ben fegentben Dambirid). 


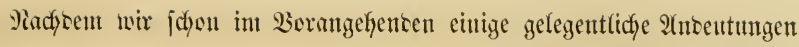

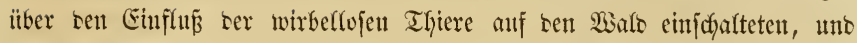
wir bei Betradftung ter einzelnen hervorragenten Arten berferben has auts= fülfrlich) jut jofiltern Gaben werten, waz sieje Gjeriu leijten, mus uno fann

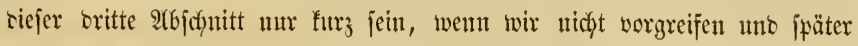
wieserfyolen wollen, was bodh am meijten bas Snterefife unjever sejer an=

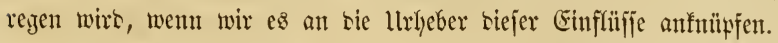

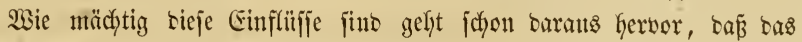

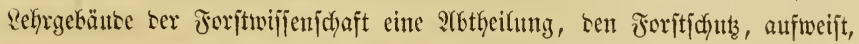
melche es in iffrem wejentlicfen Theile mit bem Edjut bes Forjtes bor sem

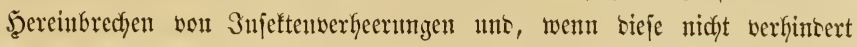
werben föunen, mit ber bertifgutg ber hereingebrodjenen Snjeftenmaffen zu thut hat.

Itnter ben nieseren 233 arstfieren finto unr sie Snjeften, weldye einen

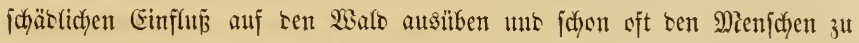
einem Sampfe Gerautszefortert faben, in weldem biejer Geinafye inmer ber Bejegte war. SUlfe übrigen Elajien ter wirbellojen Thiere, beren simé blos 2, Sie neuere unto neuejte Syftematif aber 8, ia bis 20 unt meffe unter= jofeiret, fint nidgt nermb̈gent, einen irgentwie erheblichen Einflun auf ben

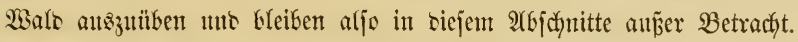

3untädjit haben wir bie Bebentung ber 3njeften für bas Beftefen uno

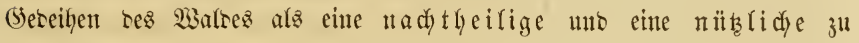
unteridgeiben.

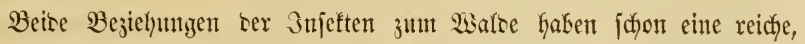

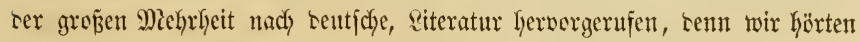

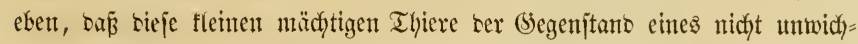
tigen Bebietes ber forjtwiffenfdaft fint. Ěs jei bei biejer belegentheit

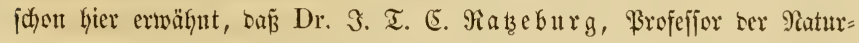

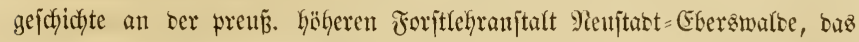
Meijte uno bas bejte geleijtet hat uno an bie Spitze aller auf biejem (5e= Giete thätigen Forfder zul itellen ift.

Die \$iäne ber Forifterwaltung, beren hohe Bebentung nutr von $23 e=$

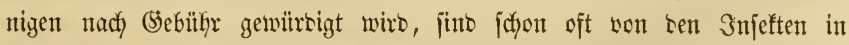

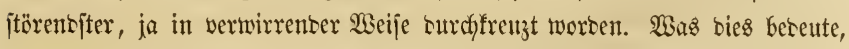

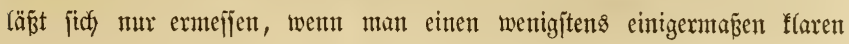


Uteberblicf über cas ganje Bebäube ber Sertwaltung eines Jorjtes uno in crweiterter (5eltuty ber Forjte eines Eantes hat; mo uod) mebr wiro Der=

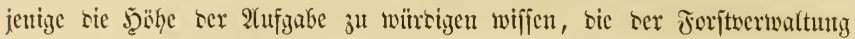

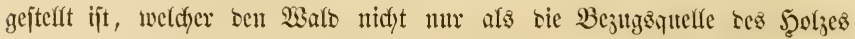

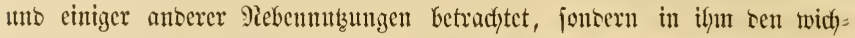

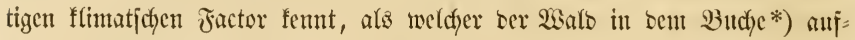

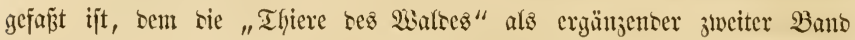

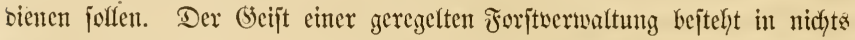
(Soringerem, als in cinem Sermögen, weldes bie Erfabrunty surdy bie $2 \mathfrak{e}=$

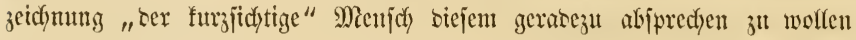

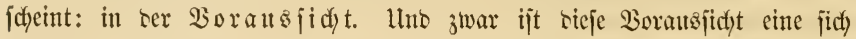

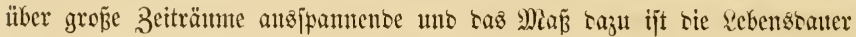

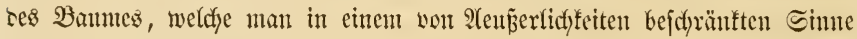
fajt eine etwige nennen fann**).

Wenn wir bie Berentung bes $\mathfrak{B a l t c s}$, namentfich ser Duelfwatoungen unjerer Ströme, für bie Betwäfferung cines Santes, uno bie ausgebehnten

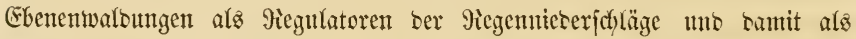
Erthalter ber Bobenfrudftbarfect ridytig witrbigen; wenn wir ferner bie fidt)

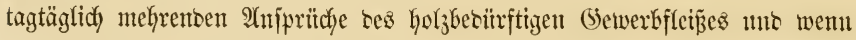
wir endlidy bie Rangjamfeit crivägen, womit ein Wals, ben wir neu oher an ber Stefle eines verwitffeten erjiehen wollen, herandädyjt — jo fann es uns nidft entgelyen, weldy hoher (Brab won beredyuther mo jorglidfer aior:

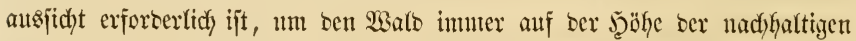

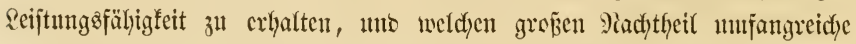
Störungen ber Bered)nngen uno \$iäne siejer Boransjicht herbeifityen

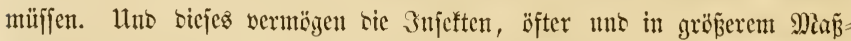

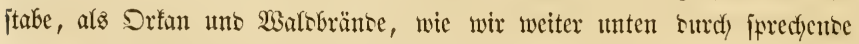
3ahlen, benen wir Gier nidfyt vorgreifen wolfen, fennen lewten wersen.

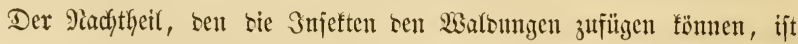

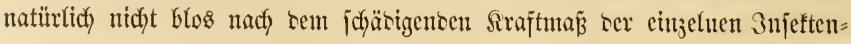

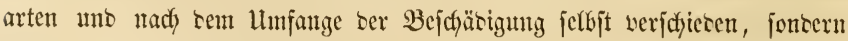

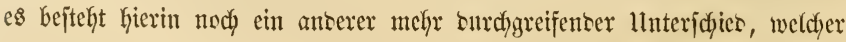

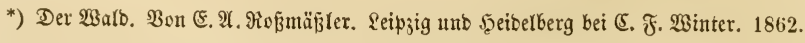

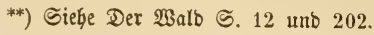




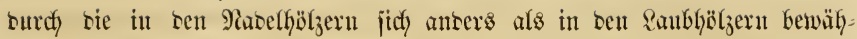
renoe Witerftantafraft bes Baumlebens Gebingt wirb. Da bas Blatt das ben Baun eruälyrende uno aljo befjen \&eben erbaltenoe Drgan ift, fo hat

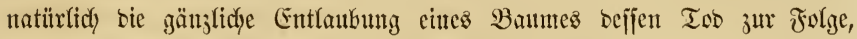
bafern er nidft in Stante ijt, bie verforencn $\mathfrak{B}$ (ätter burd) neue 孔u $\mathfrak{e r}=$

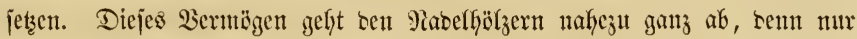
bie Siefer (Pinus silvestris) bejitzt es in einizem (5rabe; wäfrent anf ber anbern Seite affe unjere Eaubbäınte biejes Lermögen bejtzen. . Darants folgt, baß bie Nabelwaltungen weit mehr von ben 3njeften ju leiben haben,

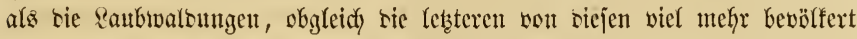

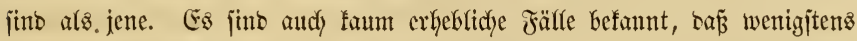
in sen Qaubholabejtänden - wohl in Eulturen - burd) Snjef̌ten erheb= liche Berwifitungen angeridytet worben wären.

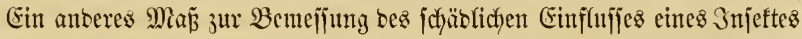

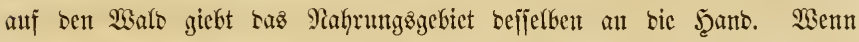
wir nux bie Shamen ber nach ifren Futterpflanzen benannten Edymetter= linge surdygetyen, ja wenn wir แns mux baran erinnern, wic lange man

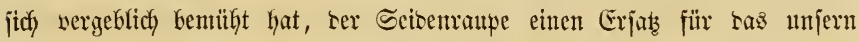
Madfwinter nicht vertragenbe Manlbeerlaub ju Gieten, fo uitifen wir uns

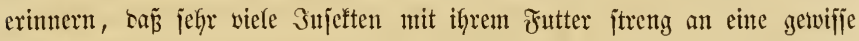
Pflanjenart gebunten jint, was bei viefen jo weit geft, baj jie jebe ansere Nahrung verjammähen uno jterben, wenn jie ifye Futterpflanje nicht haben.

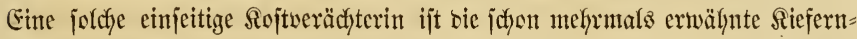
ratpe, Bombyx Pini (Gastropacha) L., weldye temmady mux ben Siefern=

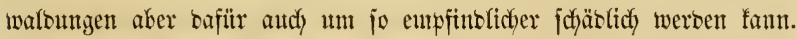

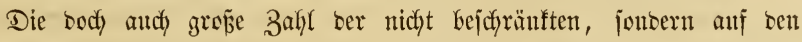
verjefiebenjten Baumarten frefjenten 3njetten fint eben barum in ber

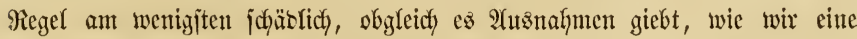
ber furchtbariten in ser Nonne, Liparis Monacha L., fennen lernen wersen, weldye -- ein jonjt jeltener fall - ebenjo gierig bie harzreidjen Siefern uno Fidften entnabeft, wie bie bod, ganz anbers bejdyaffene Säfte füfyrenben Raubhölzer fahl frip̧t.

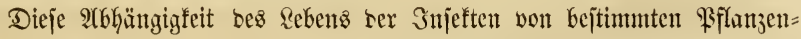
arten, weldye jidfy, wie wir jdyon hörten, bei ben Gallwespen bis ju pein= lidfer Эnnefaltung ber einen ober ber anoern $\mathfrak{B}$ lattjeite jteigert - befutbet 


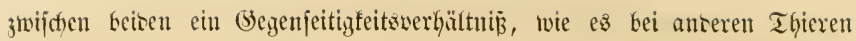
felten vorfoum unt wie ez baher in ben Didftungen alfer. Bölfer Beacftunt

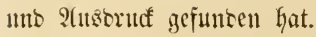

Bei ber außzerortentliç) grof̌en Menge tex anf nno in ten Bäumen bes $23 a t r e z$ ify 2 ejen treibenten Injeftenaten fann bei einigem Yadyenfen

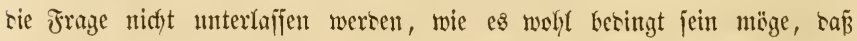

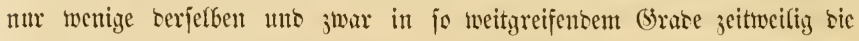
Sdyranfen ihrer gewöhnficten Bermefyrung ïberjdyreiten bïrfen, währeno

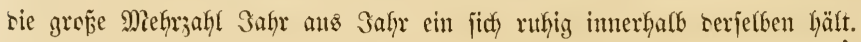

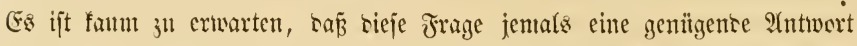
finten werte. Dieje wiltre sine io ticf eintringente Sientniñ be ganzen Sebensöfonounte ber Injeften beiberlei Strt erforbern, wie wir jie twohl fofwerfich jemals ju erringen hoffen bünfen. Diejer für unz fo traurige Borzıly ber Injeften finbet, fo weit wir unz erinnern fönnen, bei

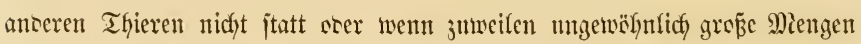
berfelben, namentlich bon. Bägeln unto flemen Säugethieren anftreten, fo

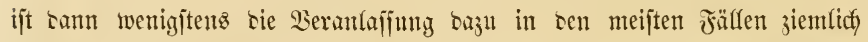
bejtimmt nadyumeijen, 3. B. in ciner bie Sermebrumg ungewöhnlich begünt=

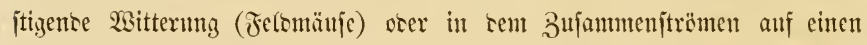

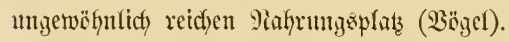

So jüno and in biejer Bejief̧ung bie 3nfeften ganj geeignet, cine Welt won 23 untern genannt 3 wereen, wenn wir nux unter $23 u n b e r$ nidjt

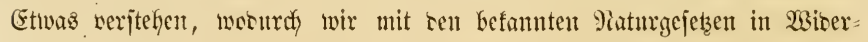
ipruct) gerathen.

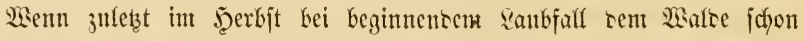

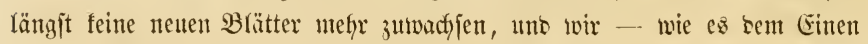
bon uns einmal erging - von allen mujeren saubgolzarten 3 einem wifjen=

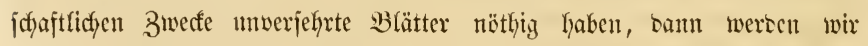
wicter in einer anteren Weije sen ganz alfgemein berbreiteten, wenn

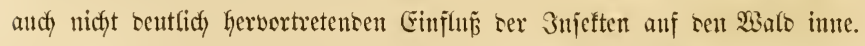
Dann miijīen wir unter ben jafflojen mod) worhantenen Blättern förm(id)

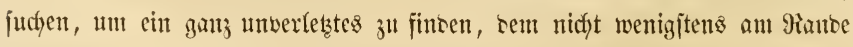
ein Spitzdyen won cinem nagenoen Snjeft abgenajoft oter ein Rody ge= frejןen wäre. 


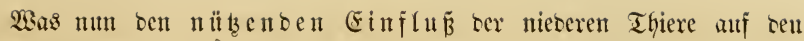
Walo betrifit, fo funn siejer natitrlich mur cin mittelbarer fein ourcty

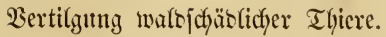

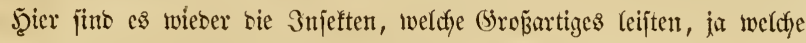
auf biejem (5ebiete ïberfhanpt etwas leijten, was nennenzwerth wäre.

Die Elajfe oer Snjeften jteht nidyt mur in ber vorbin angebenteten

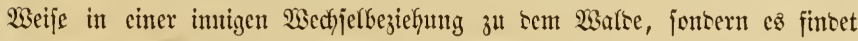

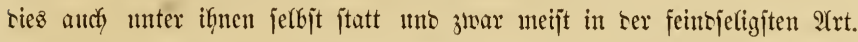

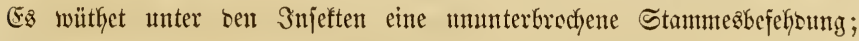

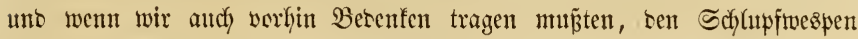

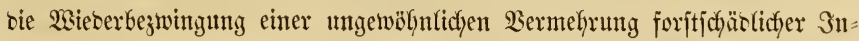

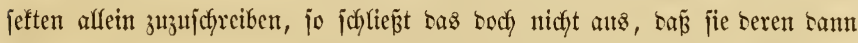
Millionen töbten, bie vielfeicht bie Bermefyrung noch weiter fortgejetzt Gaben würben. Biefleifft - benn nachgewiejen ijt bies nicft uno wiro wohl audf niemals nachjuweijen jein. Dicjent Preiz uno 806 jteht sie Behauptung

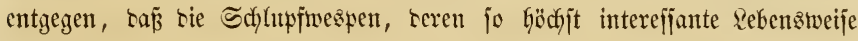
wir fpäter fennen lernen werben, mur franfe Injeften verfolgen, sie auch ofye bieje Berfolgumg vor cer Erreichung bes Jliegenzujtantes ju (Brunte gegangen fein wïrben.

Sei bem wie es wolle - wir haben in einem wie im anbern Jalle ein Miecht uno eine Berpflichtung, won nüthlichen Walrimfeften ju iprechen.

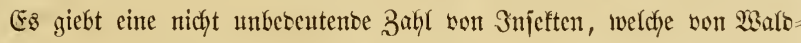
infeften reben, namentfich in sen Drommgen ser Säfer, Bsespenartigen uno 3meiflügler, von seren 5̧elbenthaten wir exit fpäter reben werben, wenn wir jie jelbjt ju juilbern haben.

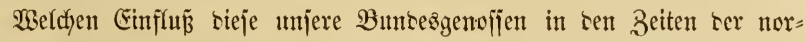

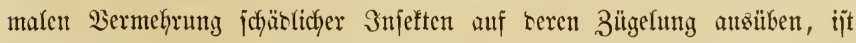
nicfyt befannt unt wirb auch fdwer ju ergrïnsen jein, weil bieje bant ge=

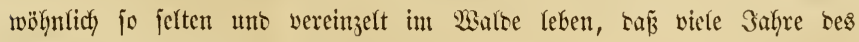
emijgften Sudfens baju gehören wïrben.

Bon anteren nitzenten wirbellojen Ificren, ๖. h. joldjen, bie feine

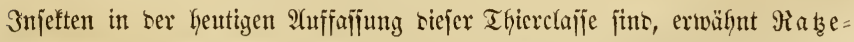

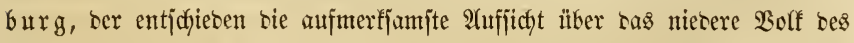

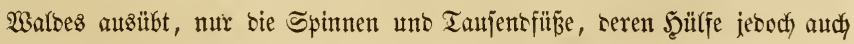
nur eine jebr bejchränfte ijt. 


\section{Wierter Abrdnuitt.}

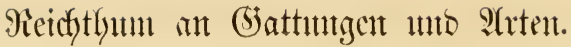

Bişer jwadyen wir bloz von ter auperortentlid) vielfeitigen Berbrei=

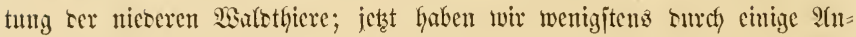

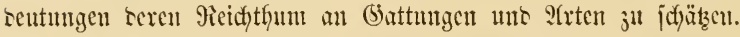

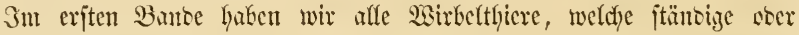
auch แm worïberizebente Betwohner bes Waltes jüt, jujammengeзӓ̆lt แ⿰㇒

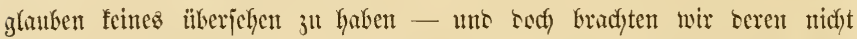

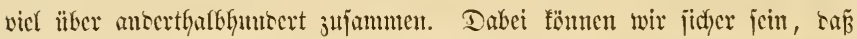
wir, wenn wir bie 2särser von ganz Dentidylano surefjitreifen wollten, bod) feitts finten wintoen, was wir nicht zejchilsert hätten. (5anj antors wïrte $c$ s mit ben nicreren Thieren jein; woflten wir afle in sentidyen

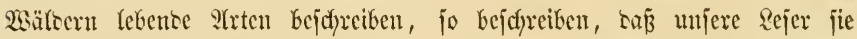

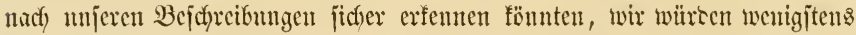
jünf cbenjo sicfe Bänoe wie ter vortiegente jdyreiben milifen; uno wenn

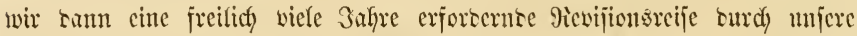

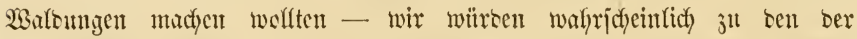

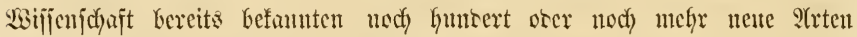

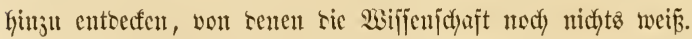

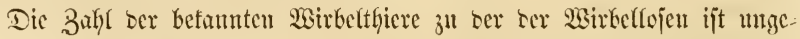

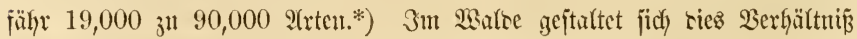

*) Der jorgjame \&eunis giebt in feiner treffidien ङynopfis ber Maturgejodidjte bes

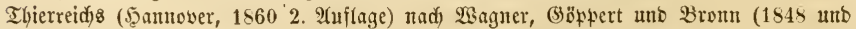
1850 ) bie 3 ab) ber befamnten $23 i r b e r t b i e r e$ auf 18,567 , bie ber 2 birbellojen auf 88,330 an. Da jebody feitben wieber 14 Sahre vergangen fint, nitifen bieje 3ahlen jetzt bebeuten böber jein, wäbren bas serbältniß̄ ungefägr bafielbe geblieben fein wirb. 
für sic $\mathfrak{B i r b e l l o j e n ~ n o d ) ~ v i e l ~ g i ̈ n j t i g e r , ~ s e n n ~ a f f e i n ~ v o n ~ b e n ~ ı n g e j a ̈ l b r ~}$ 20,000 bentfidyen Snjeften fonmt fictyer ein Siertel, aljo 5000 2frten, auj

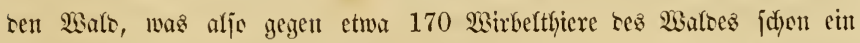
grop̧es llebergenicht fïr bie nieberen ergiebt.

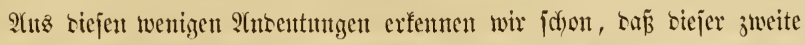

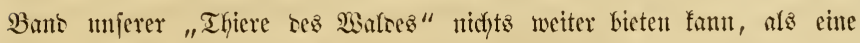

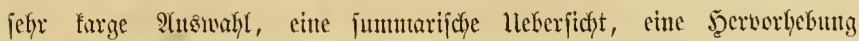

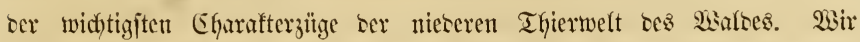

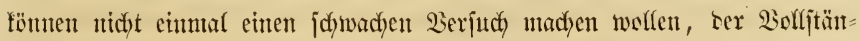

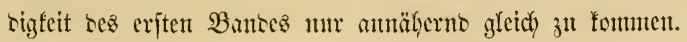

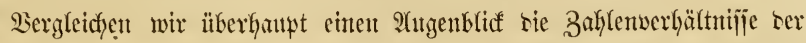

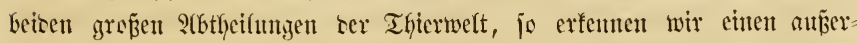

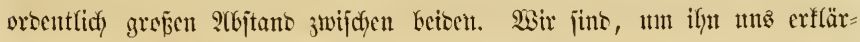

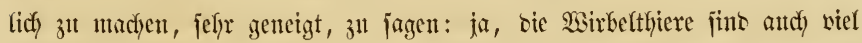

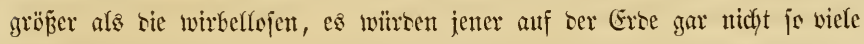

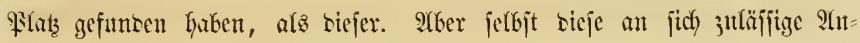

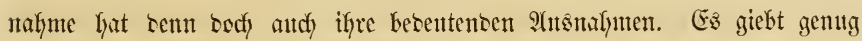

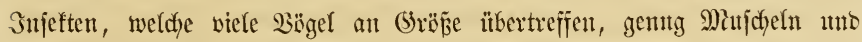

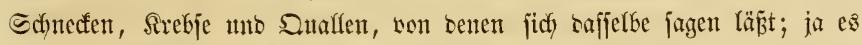
gielst Folypen, beren Serallen = Stöcfe ein mäp̈tzes Zimmer ganz ausfitllen

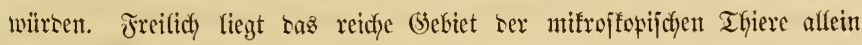
auf Seite ser 9 (btheilung ser WBirbellojen, uno es ijt nicfyt ju viel gejagt,

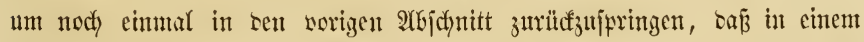
gropien Sumpfe ntelyx Snfuforien entfalten fein fönten, als bie ganje Erbe an Wirbelthieren ernährt. Sa, wenn ein Egrenberg soer Stein es Daranf antegen mollen, fo fönnen fie won biejen sutrdy Sleinheit grof́en Thierchen in wenigen warmen Sommertagen in cinem Staje 2aajer eine

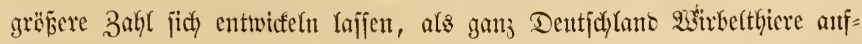
zuneifen hat.

Wir ipracten won ten Fifjyen bes Mieeres als cinem (Słleidynifje für

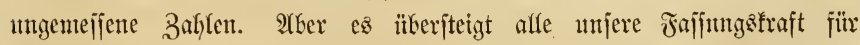
Bahlen, wenn wir an bie nieserjten Mieertlicere, bie Snfujorten unt Warzel=

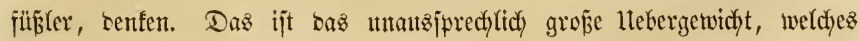
in ser Zुahl bie nieberen

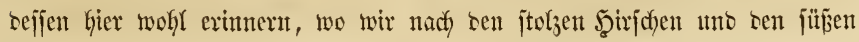




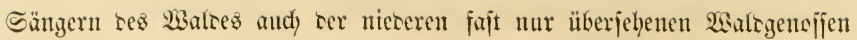
berfelben gebenten wollen.

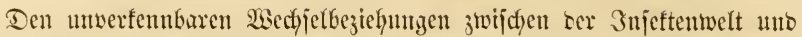

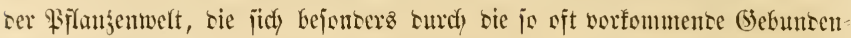
heit ber Snjetten an bejtimute Futterpfilanjen auşpridyt, hat man aud)

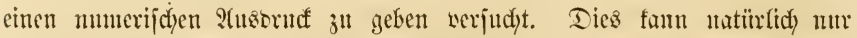
auf sie Zalylen ber beiserjeits befannten 2(rten bejrünset werten, weldye nothwentig nod) weit unter Ienen ber mirflich auf ber Eros worfhantenen

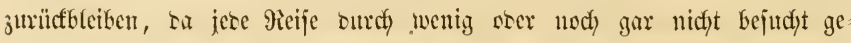
mejene Säntor eine Mienge neuer $\mathfrak{Y}$ rten an bas sidft bringt.

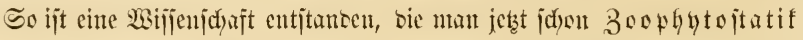

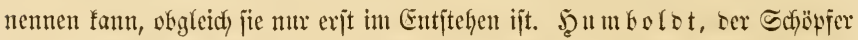

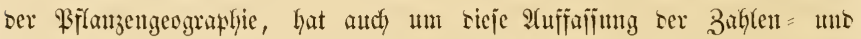

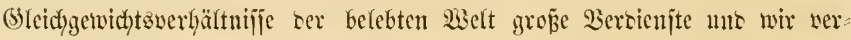
verweifen unjere Rejer anf Dejïen "P(njictyten ser Matur."*)

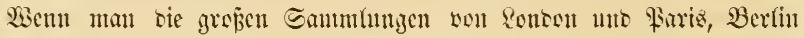
uno Wien bejuctyt mo bie unabjefbaren 9ieifen ber Pflanjenpacfete unt bie nach) vielen \$̧แncerten ju jüb)(enten 3njeftenfäjten jieht, fo faum ser lln-

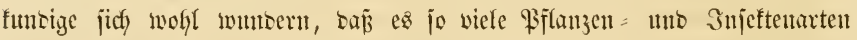
anf ser Eroc giebt. Das Berliner Muljem jteht ben beion zuerjt ge= namten weit nach uno semuded Gatte man Dajelbjt bereitz 1859

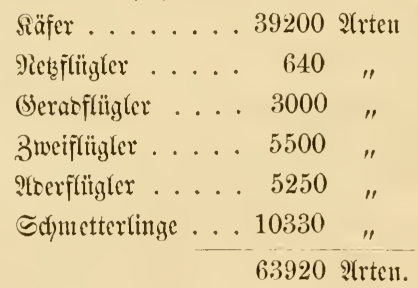

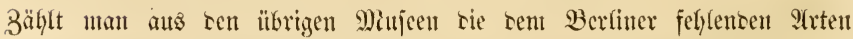

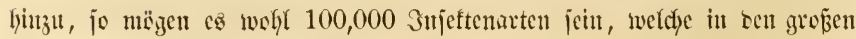
Eamulungen aufberwafyet weroen.

Miste aber verlyält jich bieje Simnte zu ber (5ejanntfumme ber muth) maß̉lich auf ter Erte lebenten Injeften uno wie ijt ez möglich, mit einiger 


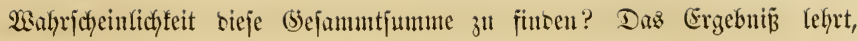

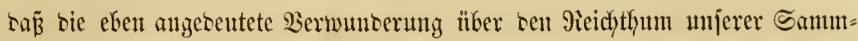
fungen, ben ber llufunbige für gleich) Gieft mit bem Reidfthum ser Erse

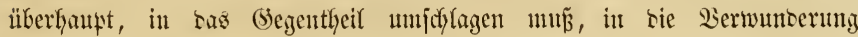

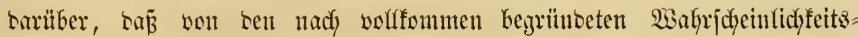

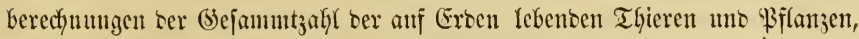
mur erjet ein jefye fleiner Theil uns befannt geworben ijt.

Die Syjtematif, in Berbinsung mit ser Statif, Statiftif uno (5eco graphie ber Bflanzen, mur hier bie Mittel an bie ந̨ano geben, bieje

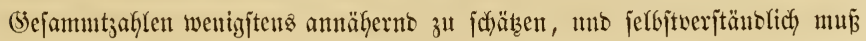
Dabei bie Stnwentung biejer Setzteren muf bie Thiere, beziehentlich Snjeften

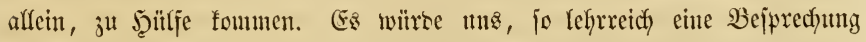

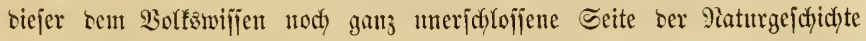
jein wïrbe, jezst bod jul weit won unjerem 3iele ablenfen, wenn wir tiefer barauf eingeken wolften. Wir bejchränfen uns daher auf einige furze $\mathfrak{A} \mathfrak{n}=$

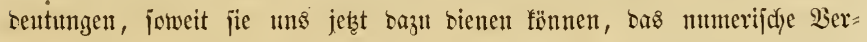

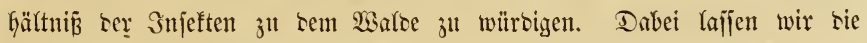
anteren Elafjen angehörigen nicberen. Thiere anzer ?Yyjał, weil jie ja nur mentizes beitragen zu ter nicberen $\mathfrak{B a l d b e b o ̈ l f e r u n g . ~}$

Die (5ebunbenbeit vieler Injeften an ihre Futterpflanzen mo bas

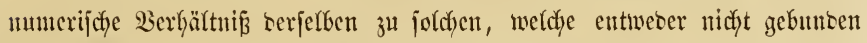

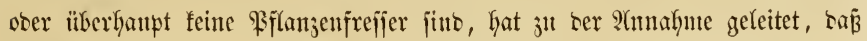
ungefälyr auf je 1 Pflanzenart 7 Snfeftenarten fommen. Da

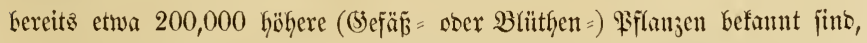

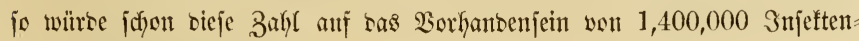
arten jobließ̈en lajien.

Würbe tas ïberwärtigente Material, weldjes fich tem reijenben

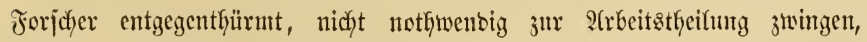

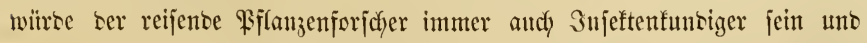

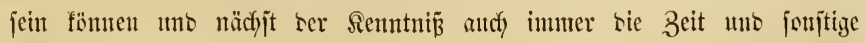
Dittel haben, 3u ben gejammelten Bflanjenarten aud immer sie baråuf lebenoen Snjeftenarten $3^{11}$ jammeln - was in ber ïppigen Tropennatur

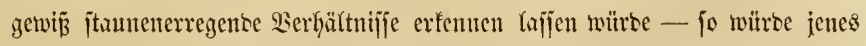

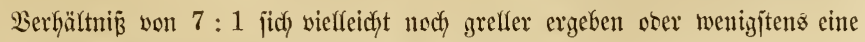
thatjächlichere Begrünoung erhalten. 


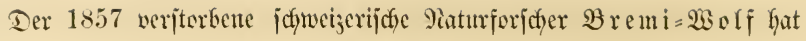

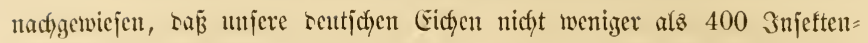
arten beherbergen.

9iageburg jagt in jeinen "Waltwerterbern": "Jut (5anzen hat

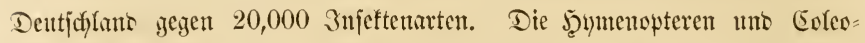
pteren fint am reidjiten vertreten, erjtere (wespenartige) wenigjtens mit 6000 S(rten, Letztere (Säfer) ctwas ïber 5000. Sion ten ïbrizen fommen circa 3000 auf bie Repioopteren (Jalter), 4000 auf Dipteren (3weiflitgler),

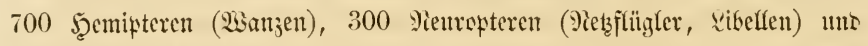

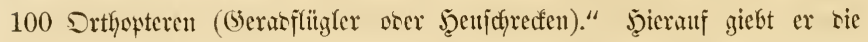

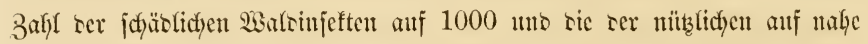

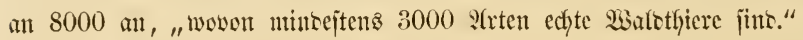

So erfyalten wir senn bie ungefente Summe won 9000 affein ser Snjeftenclafic angebörensen nicseren Thieren bez Wartses, neben melther,

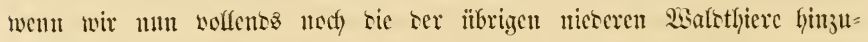

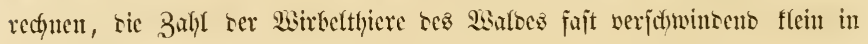
รen ફ̧intergruno tritt. 


\section{fiiufter Ab/duitt.}

\section{Syjtentifidye lleberfidyt ser niesern $\mathfrak{B a r b t h i e r e . ~}$}

Was wir unter wirbellojen Ihticren зu verjtelyen haben, erflärt jidy

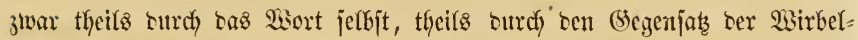
thiere leidyt wou-jelbjt; aber bennod) bürite es für viele unjer sejer nidyt ganz ïberfliifitig jein, bie Frage ctwas näber zu beleutsten.

Rinne theilte befanntlich เaล Thierreidy in sic 6 Elaffen ber Säuge

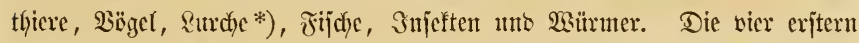

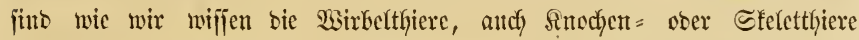
(Animalia vertebrata, s. osteozoa s. spondylozoa) gcuannt, weil fie ein inneres aus Snodjen gelenfig jujammengejełses (5erüjt haben, weldyes in

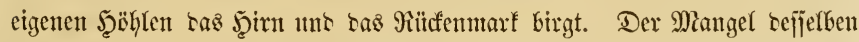

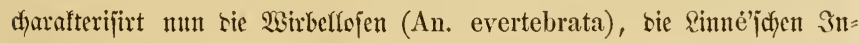
jeften unto 23 ürmer.

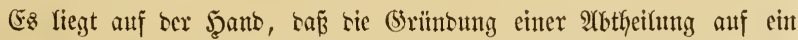
negatives Sientycidjen, auf einen Mangel (bes inneren Efeletz) ein Fehler ijt, benn aus einem Mangel fann idy etwas nidfyt erfennen, wenn idy nicht vorber an ciner anberen Atbetheilung bas Mangetnoe femnen gelernt habe.

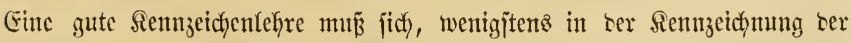
grop̌en (Sruppen, nidyt negativer, fonbern pojitiver Mierfmale bebienen. Wenn mir 3emanto jagt: bas ijt ein Thier, weldes fein Sfelet hat, fo erjahre

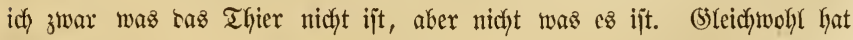

*) Die nur bei jehr menigen biejer Thiere zutreffente Bententung 2 mphibien

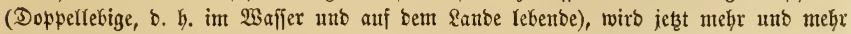
von bem alten edjt beutjalyen 20 orte \&urd) verbrängt.

Die Thicre Deฮ 2 aldees. II. 
jitc) ricje von bem grofen (5eorg Euvier herritfrente Benennung cine

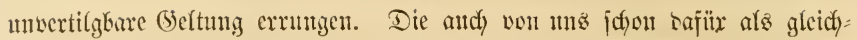
berenteno gebrandfte B̧enemung niebrer Thiere, gegeniber ben högern (23itrel $\Rightarrow$ ) Thicren, ift affertings faum weniger แแzulänglid).

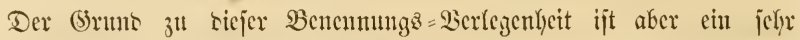

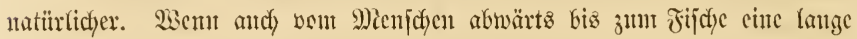
Stufenleiter ber mandfafltigiten Ilyiergeptaltungen liegt, jo haben fie alle

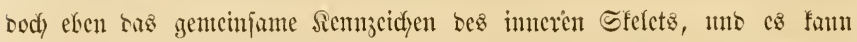

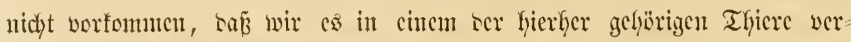

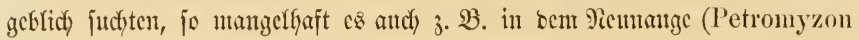
fluviatilis) attegebifret ijt.

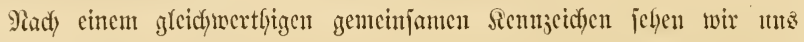
bei ben 23irbelfojen wergeblich um. Sie ftimmen eben leriglidy in tem

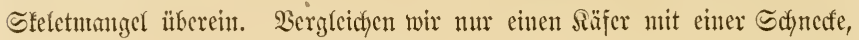

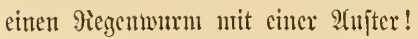

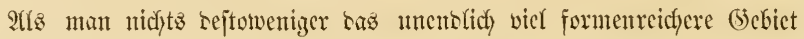
ber wirbeffrien Thiere anfer ber (Stlieberung in Elaffen in grö̈pere (Sruppen abtheilen wollte, fonnte cin maäggebentes Sienuzeidjen nidyt unbenerft

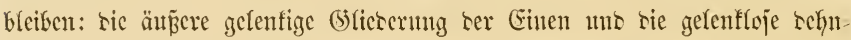

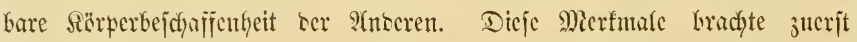

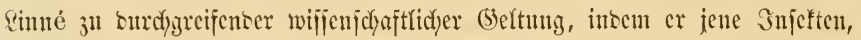
bicje 2 situmer namnte.

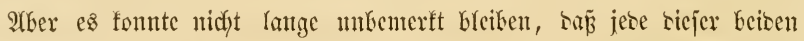

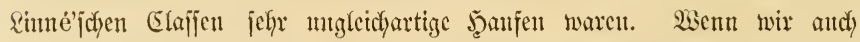

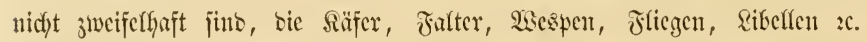

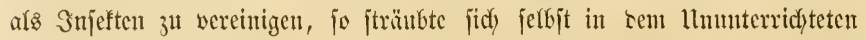
ein inneres, wem auch metares befühl sagegen, andy sic sirebje mo

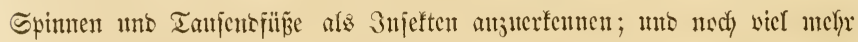

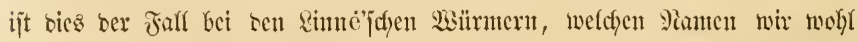

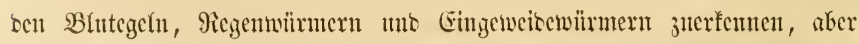

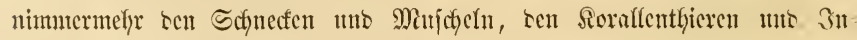
fujorien. Şier milipte cinc weitere (S)liescung norgenommen wersen.

So wurbe aus ben Suntéfhen Injeften bic obere Unternbtlycilung ber Birbeflojen - bic (5)lictertbiere (Arthrozoa s. Polymeria) uno ats

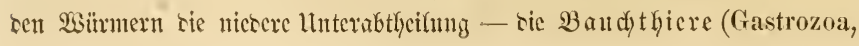


soer ifres tefynbaren Sïrpers wegen aud animalia contractilia), tuto sieje beisen ltnterabtheitungen wurten sant in engerer 2 cgrenjung in

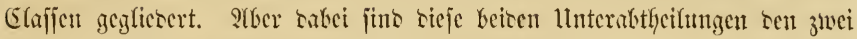

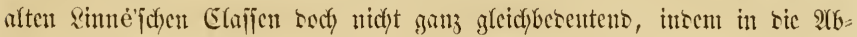

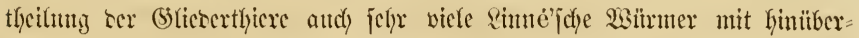

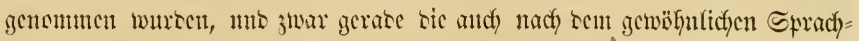

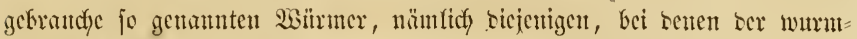

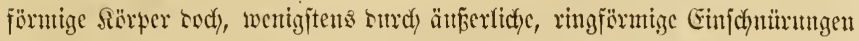
it (B) Yescr abgetheilt ijt (3. B. Regentwum, Egel, Eingeweiremïrmer, Ece=

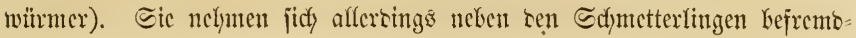

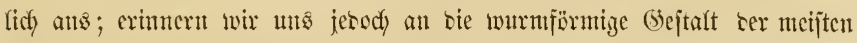
Injeftenlarben- (Matpen, Engerfinge), fo jojwintet oas Bejremblidye unb

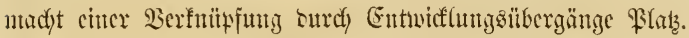

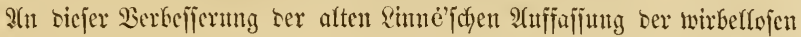

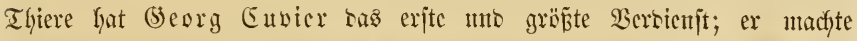

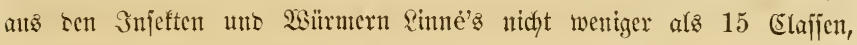
weldye in ter netejten 3eit bis ïber 24 jerifalten worben fint.

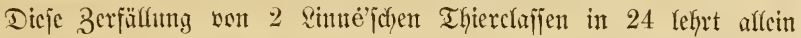
¡c) Thiere feit miffen, unb wir erimerten uns fdyon verher baran surch bie

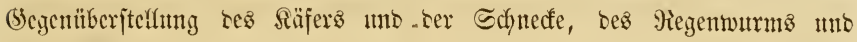
Der 2Itifter.

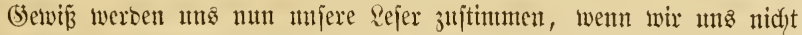
shue einige vorbcreitente Bliffe in bicjes Chans Gineinjtïzen modjten,

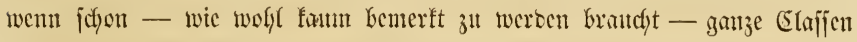

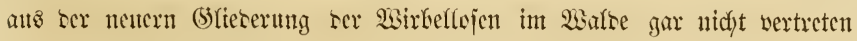

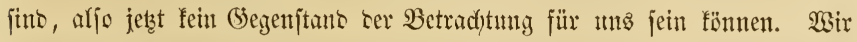

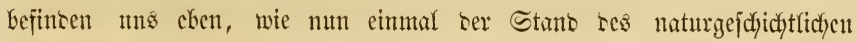

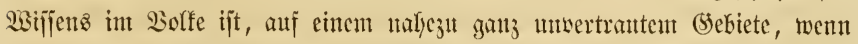
wir won ben, ifren alfyemeinen Eharafteren Gebermann bctannten, Winbel=

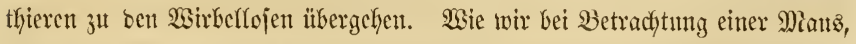

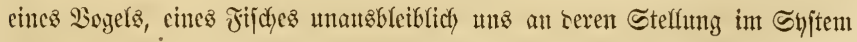

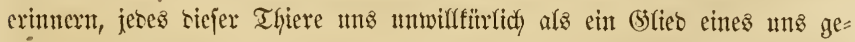
räuffigen (5anzen erjdycint, fo folf es, nach unjerer Meeinung, aud mit einer Friege, cinter Edynecfe, einer Spinne ber Faff fein, sie unts int 


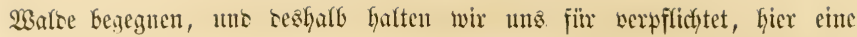

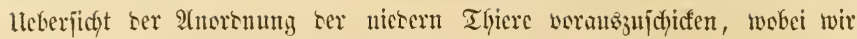

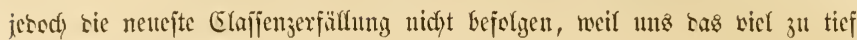

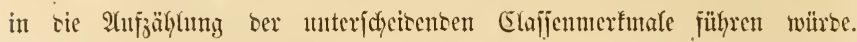

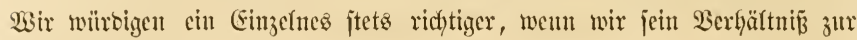
Sejammtheit fennen.

Sntem wir ten negativen (begenlats Ies Efeletmangels nidjt weiter

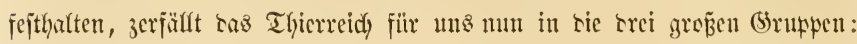
I. Bairbelthiere, II. (5liebertyiere uto III. Baudythiere. Die eriteren, in unjerem exjten Banbe erlerigt, nun auj jidf beruhen fajfent, bleiben sie beizen letzteren übrig.

\section{II. (5licicthicre, Arthrozoa.}

Thiere, weldye aus mefhreren, sft vielen, hinter cinanberliegenten, ge= lentig bemeglidyen seibesringefn gebiloet jutb, mit einer meijt fejten, oft jogar

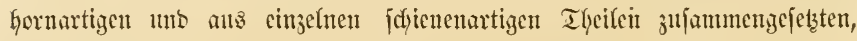
bei viefen aber aud weidyen Beredung, sie, wenn fic loart mo jufammen-

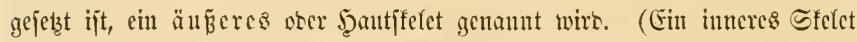

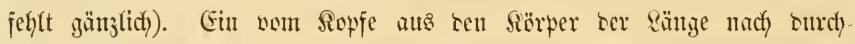

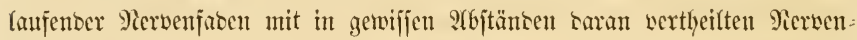

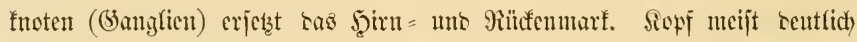

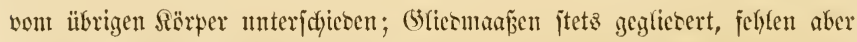

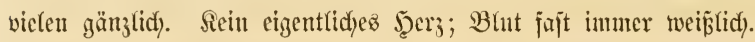

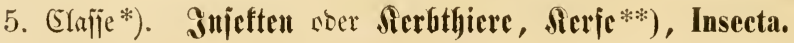

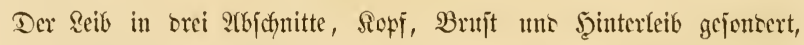
6 gegliererte Beine, 2 Fïhler, meijt Flügel (4 orer 2); bie Midhrzahl mit einer Berwantung. \&ano = แno Sinfwaffertfiere.

*) $\mathfrak{Z}$ ir benten bie vier $\mathfrak{W}$ irbeltbierclaffen als voratı̊gegangent.

**) Sbgleidy im 1. Theile biejes 2 utdes burdgängig ber Rame Rerbithicre gebrauddt

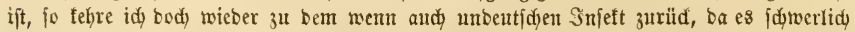
iemals geringen wirb, $є \&$ surd) cimes ber genaunten beiben neu gemadten $\mathfrak{B}$ örter ju berbrängen.

$\Re$. 


\section{Elaffe. Epinututfjicre, Arachnidea.}

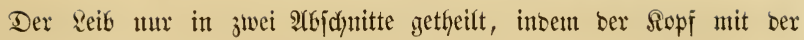

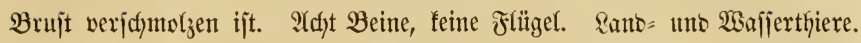

\section{Elafje. Sirebö= ober Sirultenthicre, Crustacea.}

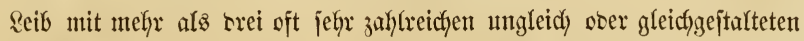
IGbidfnitten ober Mingeln, weldye meijt eine harte Sdjale (Sirufte) tragen;

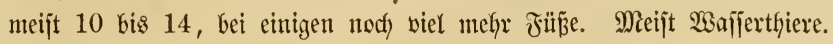

\section{8. (Slaffe. MBïrmer, Mintyeltwürmer, Vermes.}

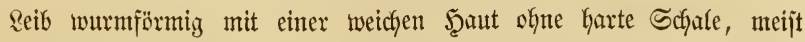

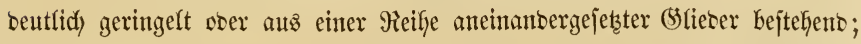

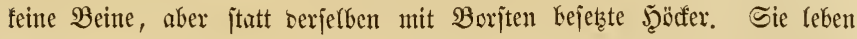

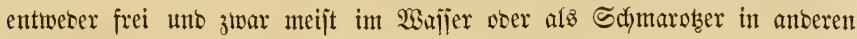
Thieren (Eingeweibemürmer).

\section{Bandthicre, Gastrozoa.}

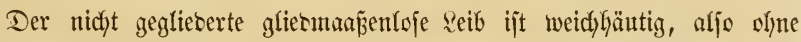

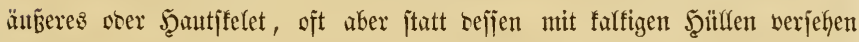
(ङdjnecfen, Muldjeln, Seejterne), weldje ein äıţeres Sfelet vertreten.

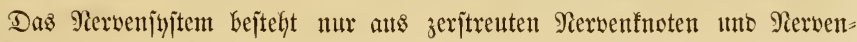

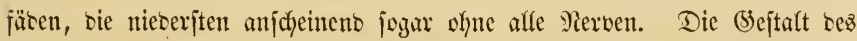

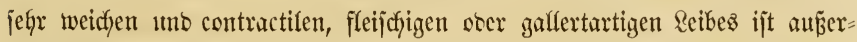

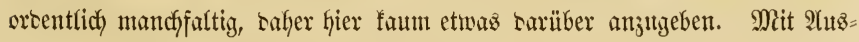

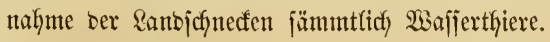

\section{Clafje. Beidjtyiere, Mollusca.}

Reib gejtrectt, mit einem beutficfen aber butrdf feinen ફ̧ats abgegrengten,

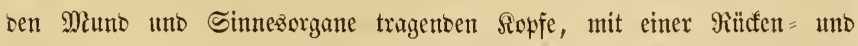

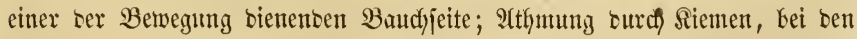

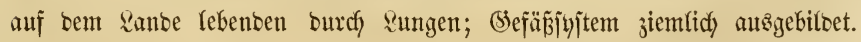

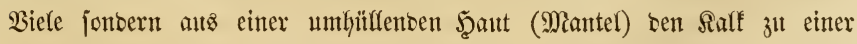

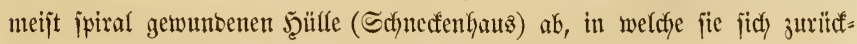
zief̧en fönnen. Meift WajajerbewsGner. 


\section{Clajic. Minidjelthiere, Conchifera.}

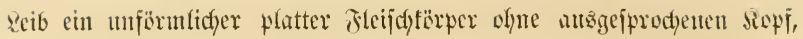

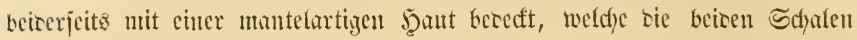

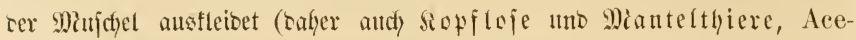
phala uno Palliata), atร Bewegungourgan sient sic jungen = ober beil förmize quștrectung bes sïrpers (salyer and) beilfübler, Pelecypoda). wajjerthicre, meijt frei beweg(id).

\section{Elaffe. Strnflthiere, Radiata.}

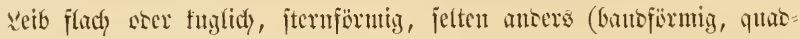

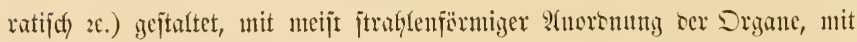
im Mittelpunfte liegenten Minne, entweser mit citer zarten secr sifferen

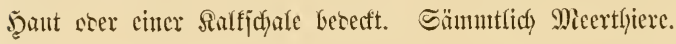

\section{Claffe. Polypen, Polypi.}

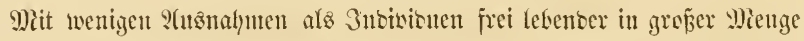

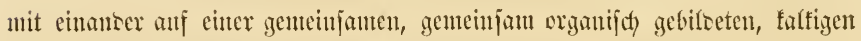
orer fnowplichen llnterfage (Foltypentëcfe, Soralfen) werwadjener Glumen= äfntidyer Thierdyen, mit cinem von eiteu Fülyferfranz umbebenen Munte.

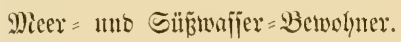

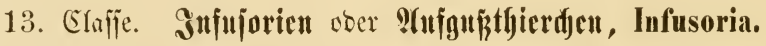

Meijt mifreffopijdye gaffertartige, nacte scer mit eimem Salf - orer

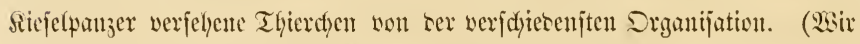
vereinigen soer itbergetyen fier viele Formen ber nieserjen Thierwelt, itber seren Etellung in Thierjujtem, ja jum Theil ïber beren 3utheifung ju

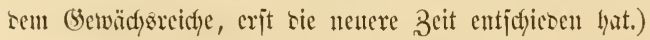

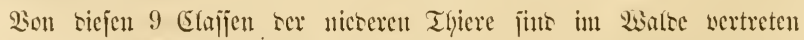

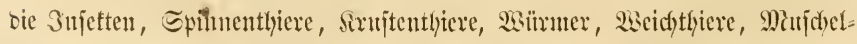
tyjere, Bodypen uno 3njujorien; es beibt aljo nut cine, sic sex Strahls= thiere, unwertreten. 
Die Inlektemuelt. 



\title{
Sedjster Xb/dnitt.
}

\author{
Seerjactaut.
}

Wenn wix bie Snjeften zuweilen bie Bägel ber nieberen Thierwelt nennen Gören, wobei man bann von jenen junädhjt bie buntbefieberten Sdymetterlinge im $\mathfrak{A}$ uge haben mag, jo madyt jidf auf ber anbern Seite

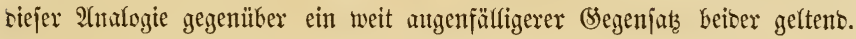
Bon affen Göheren Thieren fint Sie Sögel biejenigen, weldye ifren idjarf

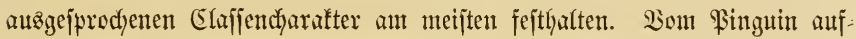

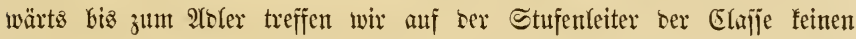
Boger, ben wir nidyt mit unzweifellyafter Sidferkeit jofort für einen $\mathfrak{B o g e l}$ anjehen müp̈ten, ja wir fönnen jeren befiebigen Sogel hernefmen, ım an

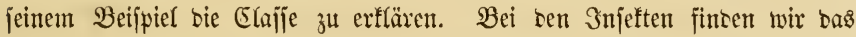

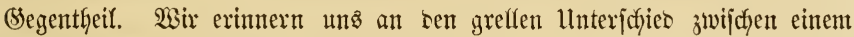
buntfarbigen breitbejdyingten Tagfalter unt einem gepanzerten geweif= tragenten Şirichfäfer, wir benten an eine Şcujdyrecfe unt einen Floh. Wähten wir eines biejer Thiere als Beijpiel, um baran bie Injeftenclafje

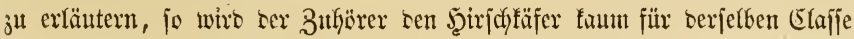
angeförig halten, wenn wir jie nach bem Sdymetter(inge erläuterten ober umgefehrt.

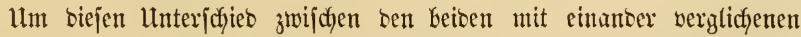
Tfierelajfen in anberer 2 seije ju bejeidynen, jo erlauben wir uns, bie

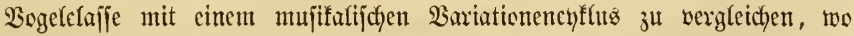

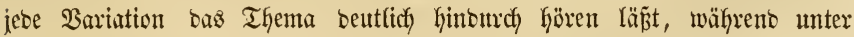
ben Snjeftenvariationen viele vorfommen, weldje faum bas Thema er: fennen laffen. 


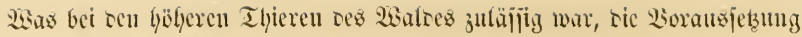

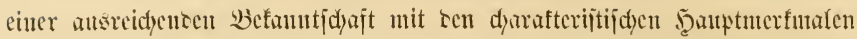
ifyer Syjtentatif, sürfte bei ten nicoern Thieren viclfeicht meniger zufäjïg jein. Son ren ïbrigen nod) weniger beadteten nicoen Ilyeren ju jofmeizen,

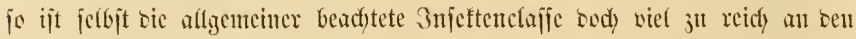

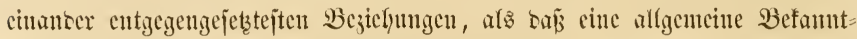

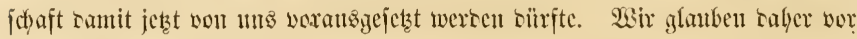

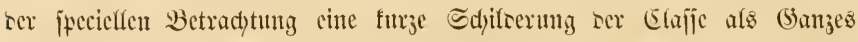

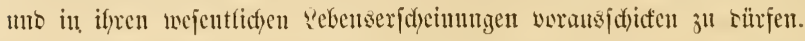

Die uns foch befannte an Tllgegenmart grenzente berbreitung tor 3njeften - nแx ธas Mieer ijt ber 3njeften günjlich beranbt - miro wejentlidy suret) ifrr Flugvermögen beringt, scijen nur cine fleine Minberheit entbehrt. Das jlugvermögen ijt aljo, namentlid) im vergleidyenten

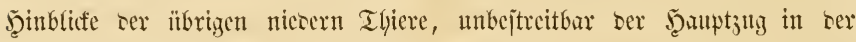

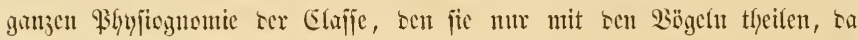

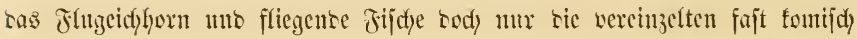

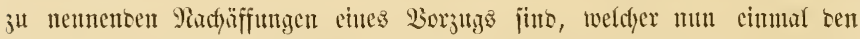

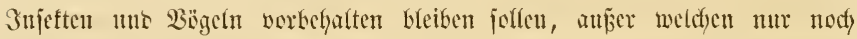
sie Flecermäufe ed)te Jtieger fino, wie senn ïberhanpt ric ganze Sïnge= thierclaffe cine gicfapitulation beinalye alfer voransgefenter bauptformen tes Thicrreicfs genamut weroen famm.

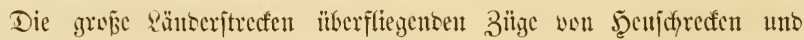

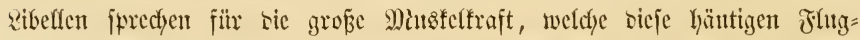

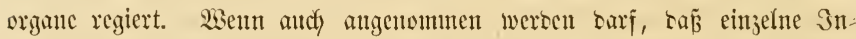
jeften, namentfic) Faltex, won icm suftjuge zuweilen jefbjt gegen ilfren Willen getragen oocr wenigitens gelenft werten mögen, fo juro sody autd) Fülfe befannt, wo fie expicttlich surct) eigene Siraft weite Flugwanberungen gemadyt habeir.

Meben bicjer yoben Qebensbebentung ber Fltïgel haben sicje einen

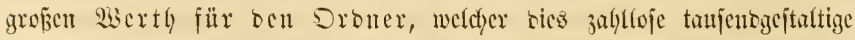

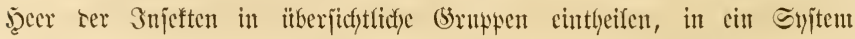

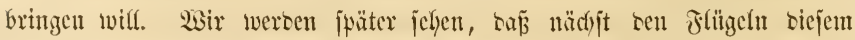
3wecte andfy bic Manttheile wejentfich sienen.

Wie in affen Theilen uto Berfültniffen tes Reibes uno \&ebens ber

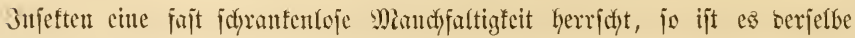




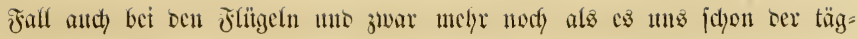

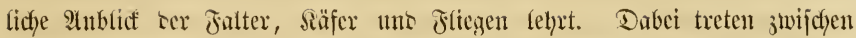

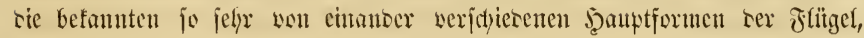

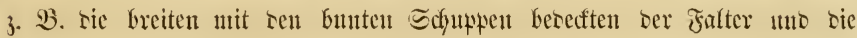

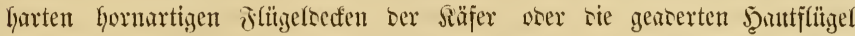
ser Ftiegen, fo viele werbintense lleberganggfurmen eit, saj man jelbjt in Zweifel jein tann, weldye sicjer Fornten man vor jidd habe. Es giebt wanzenartige 3 mfeften, seren Dberflügel an Edymetterlinge crimmern uno

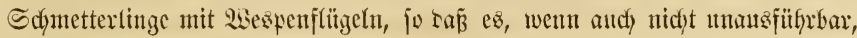

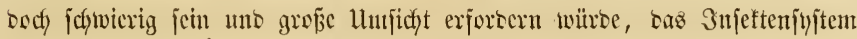
aflein anf bie stitgel z̆l grïnoen.

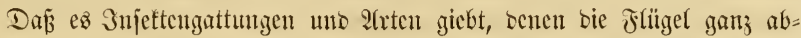

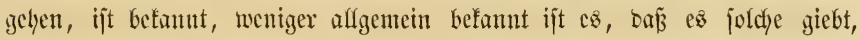
bei senen mus sas citte (Scjolecht berjefben entweser ganj crntangelt, ober

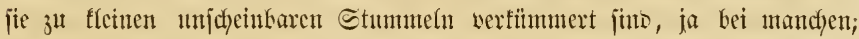

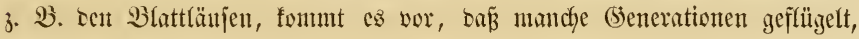
anbere ganz flïgellog jür.

Wenn es nicht ju weit von mierem Ziele abfïlyrte, fo würbe cine

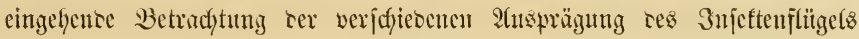
wohl geeignet jein, uns viele intercijante uno unterfaltenoe Serhältnifje ju

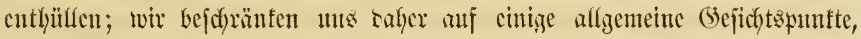

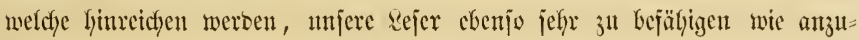
regen, in ser geeigneten Sahreszeit eigene Flïgelfttbien zt Machen, was nicht shue fohnenten (Senur bleiben wirt.

Die 3njeftenflügel jimo nidyt wie rie Sogerfïlizel verwanberte Beine,

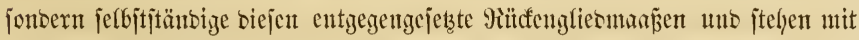

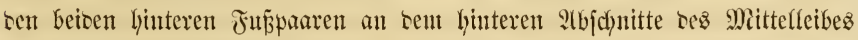
(and) Brujt genant), weldyer born sen Siopi unb linten ben quergejdyienten ந̧iuterleib ober Bautd) trägt.

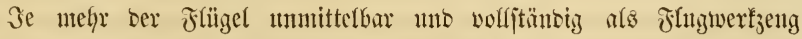

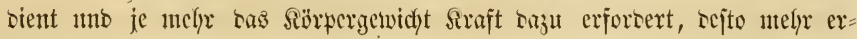

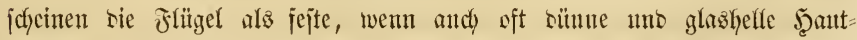

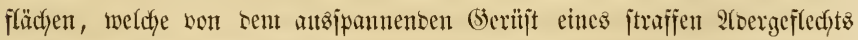
burdjzogen fint. So follte man wenigitens meinen; wir werben jeood)

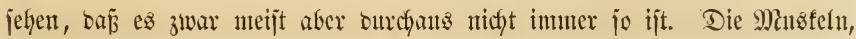


meldye sic Flügel in Bewegung jetzen, müijen jefhr fräftig fein, benn es ift

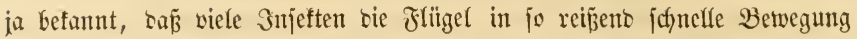

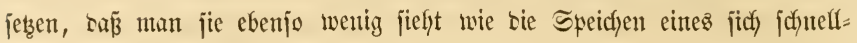

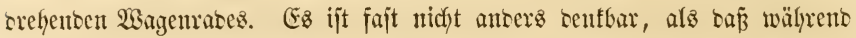

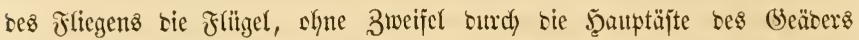
biel jtraffer ansgefpant werben fönnen, als wir jie finben, wenn wir bie=

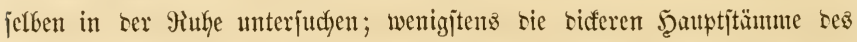

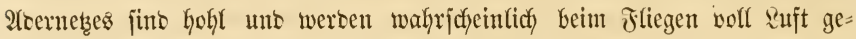

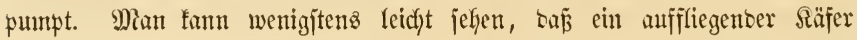
baju einige 3eit nöthig hat; benn er jtrecft junädjit unter ben etrwas aus= einanter gefpreizten Flïgetocfen jeine jujammengebrechnen flügel aus uno fliegt bann erit nady cinizen 9 Itgenbliden auf. Dody jdyeint hierin eine

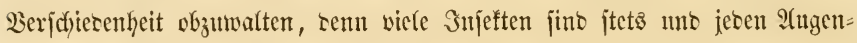
blicf jun jofortigen $\mathfrak{A}$ fffliegen bereit.

Die Bewegung ser 3 meftenflïgel ijt twejentlid) anbers sermittelt als bie ber Bogelflügel, weil faum betwegente Mitželn, wie es bei ten B̈̈gchn ber Jafl ijt, in bie Flïgel jelbjt eintreten; jentern bicje Mitsteln bleiben imertyafb bes Mittelleibes, tno intem in siejem sie erforberlidyen

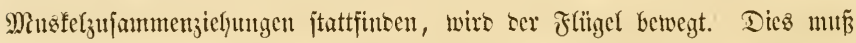

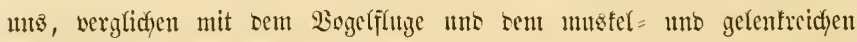

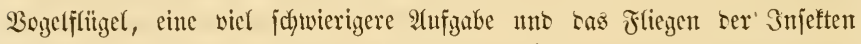
eine weit betwunberungaswertyere Erjefyeinung bïnfen als scr Bogelflutg.

Wir bürfen unjeren \&ejern, joweit jie uidyt bereits mit sen Injeften=

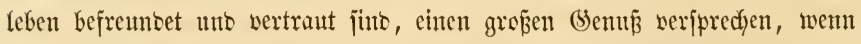
jie namentlicy in injeftenreichen Micoer = ooer Mittelwaloe in warmen

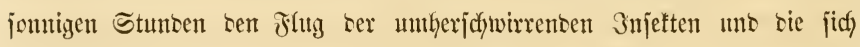
barin ausprägenben Bejonberkeiten beobadyten uno sann aber audd an ges fangenen Snjeft an ben Flïgetn jefbjt uady ben Besingungen jener forjdyen.

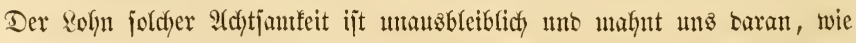
man jwar auf jecem Spajiergang taujenberlei jieht, unb rody oft twentig

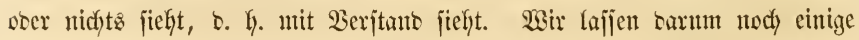
weitere $\mathfrak{A}$ noentungen iiber ben Flug ber Injetten folgen.

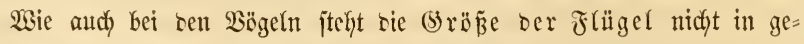

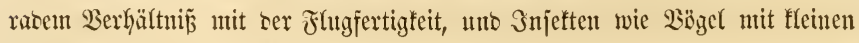

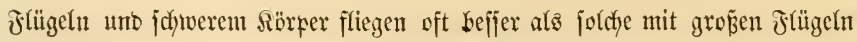


uno fleinem leidjten Sïrper. Der jafwere Aftbatros hat zwar lange aber

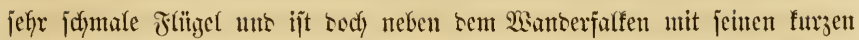
ipitzen Flitgefn ser gewaltigjte Flieger. Der breitbejdywingte Tagjalter be=

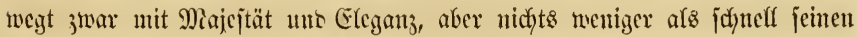

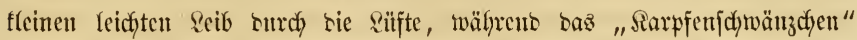

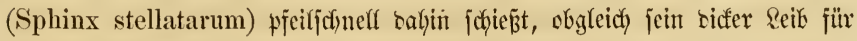

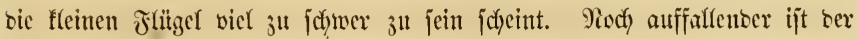

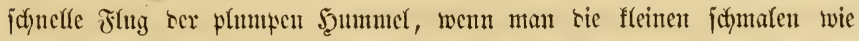
ein (baflerthäutthen sünnen Flïger anjiefyt.

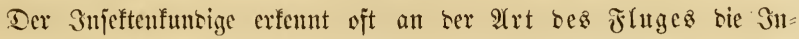

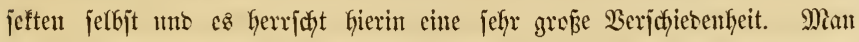

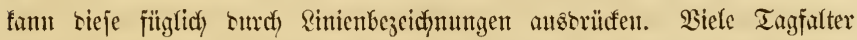

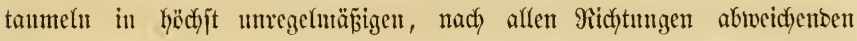

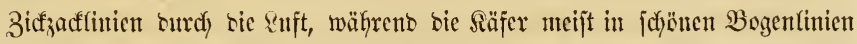

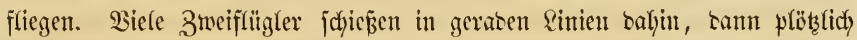

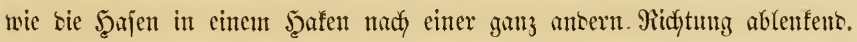

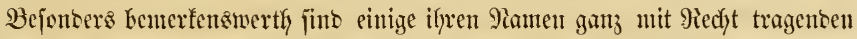
Schrebfiegen (Syrphus) Iaburd), baj ihnen sie suft fajt wie ein fejter

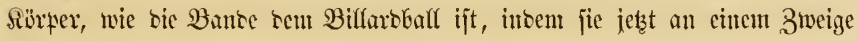

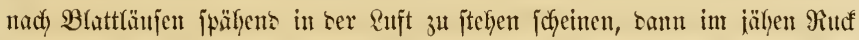
jidy in ber suft forticfnelfen, um bann vieffeidfyt faum cine Spame weiter wie fejtgenageft jd)weben zu Kreiben. Die Worljafweber, Bombylits,

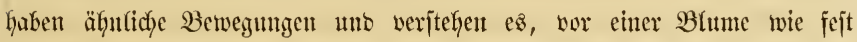

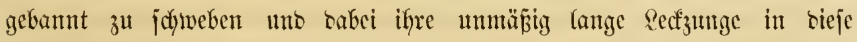
hineinzujojieben, jo รaß̧ Der gejellige auf = unt abjdywebente Miüfentanz fintet jeinen (Segenjus in bem langjam bafiu brummenten Flug ber J̧ummetn.

Dic Sdnelligfeit oer Flügelbewegung ijt, wie bei vielen Iag-

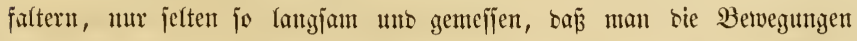

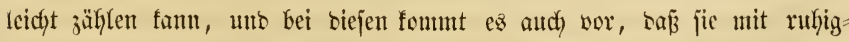
ausgejpanten unberwegten Flïgeln bahiu gleiten, wenn aud nicht jo jtaunen-

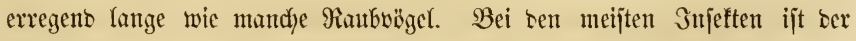

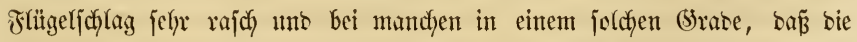

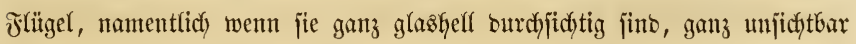
merten, währent bann gefärbte nur als ein bunfelnber Schein jidjtbar merben. 


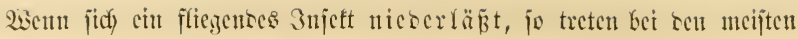

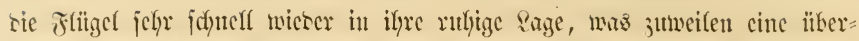

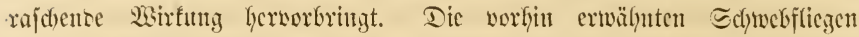

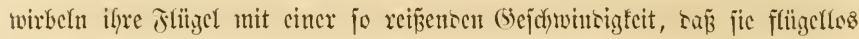

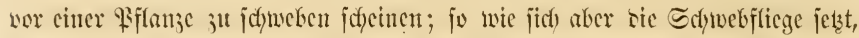

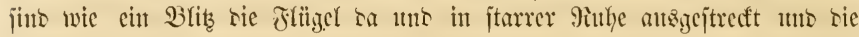

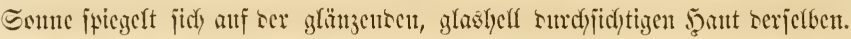

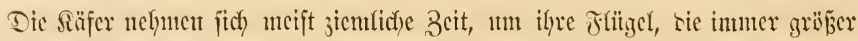

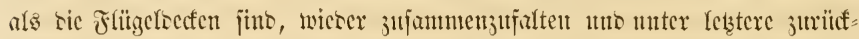

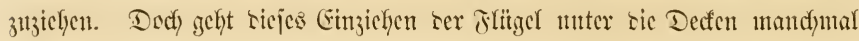

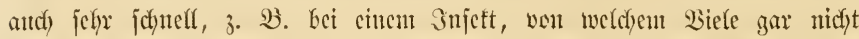

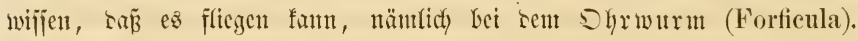
Eharpantier befantet, saj ser fleine Shrwum, (F. minor) bei ber

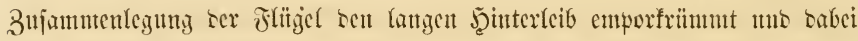
jeite 3ange antwentet.

Es ijt jefwer ju jagen, wie weit bei sen vierflïgeligen Snjeften, wenigjtens wenn sie vier Flïger won gleidfer Bejefaffenheit jins, sic jwei Jitigel ciner Eeite als ein (baujes oser jeses für jid thätig ift. Erjteres ijt wohl her Jalf bei senen, weldhe, wie vicle Alserflïgler, im

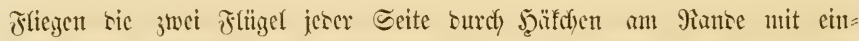

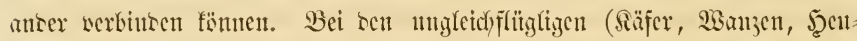
fdyreffen) jino inmer sie unteren sic eigentfidyen Flugrgane, wälyreno sic

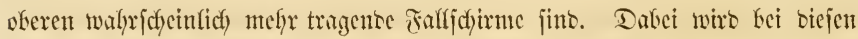

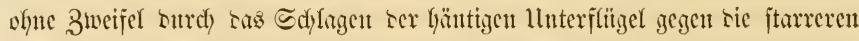

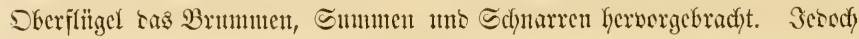

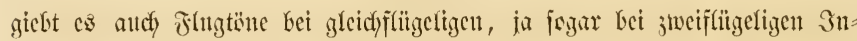
jeften, bet benen alje bex (5rutto saju cin anserer fein unt

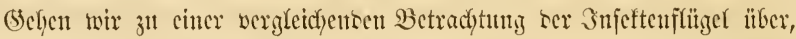

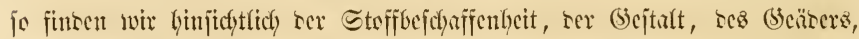

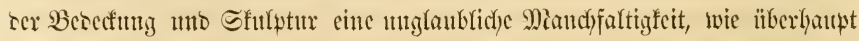
bielfeidyt bon fcinex Thierclajfe mit mefyr giecht wie won ben 3njeften ge

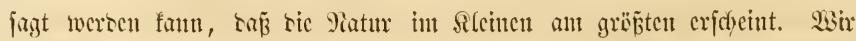
feuten alle sas butnte Siteto ber Eefyuttextinge, weldye cine juperfeine

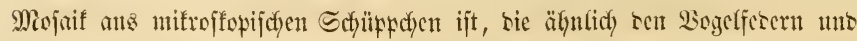

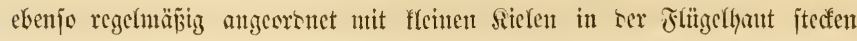


uno zwar fo loje, saß̧ wir jie nit sem Jinger bei ser leijejten Berillyrung

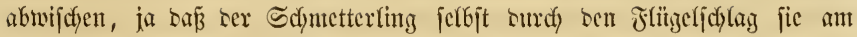

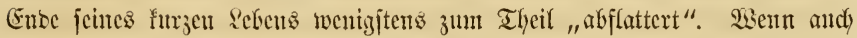

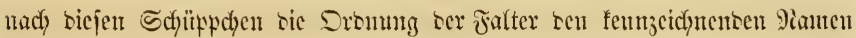
Sodjuppenflügler, Lepidoptera, crfyalten lyat, jo finto jene sody and antern Эujeften eigen, namentfidy sen Säfern, unter senen ber pradbtodfe Briffant:

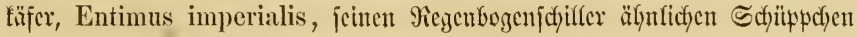

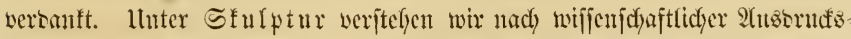
weife sic oft Ḧberans jierfidyen uno regehnäp̈tzen Sertiefungen uno Erthaben lyciten an Injeftenlcibe, wo fic bejonbers anf ben Jlïgclbecfen ter Säfer

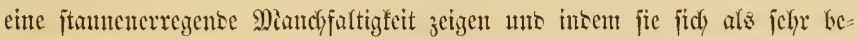

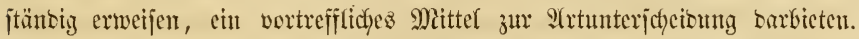

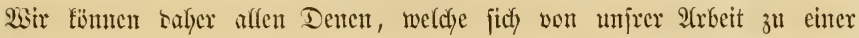

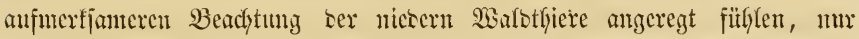

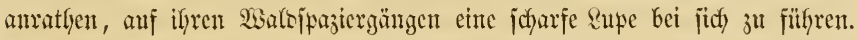
In lyunsert Fällen wirb jie ifnen bie unjdyeinbaren, glanjlojen uno bijpter gefürbten Sberflächen ber Injeften, mamentlich ser Säfer, in cine Pradyt ser nieslichjiten Sfutpturen auflöjen*).

Eime herborragente Molle fpicht bas (5eäber ber Flügel unt giebt auch Sen beisen Dromungen ber wespenartigen uno ber feejumgernartigen

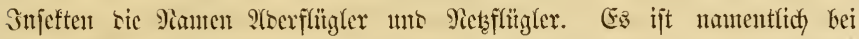
Den crifteren wenigitens bas ser Dber = ober Dorberflïgel ein widytiges

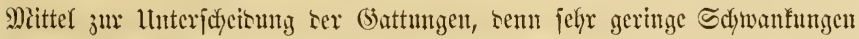

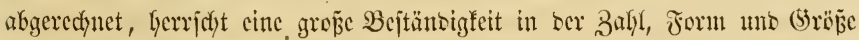

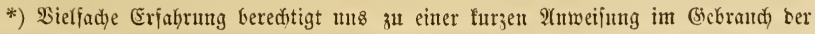
Eupe. Erftens ift eine gute Doppelfupe einter cinfudjen vorjujiclyen. Bcint (Bebrandy

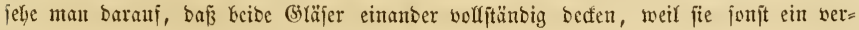
jertes Bild geben. Man bält bie \&upe fo bidjt vor bas $\mathfrak{A}$ uge, nälyrenb bas anbere

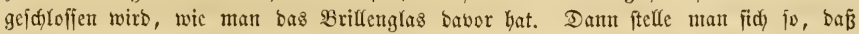
ber zu Kejebende Gegenjtant vorle Befeuditung hat. Mit ber andern banb bringt

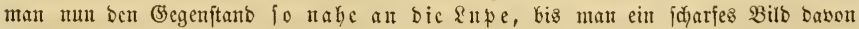

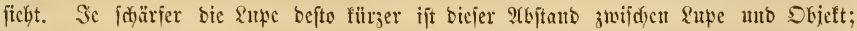
Se nad) ber Sdyürfe von wenigen \&inien bis 1 3off. Sn jeber gröferen Stabt crbält man bou ben Sptifern bic gecigneten Rupen, weun man angicbt, baj̃ man fie in ber Jnjeftentunbe aumenben wiff. Man befommt fodon bou 1 Thlr. bis $1 \frac{1 / 2}{2}$ Ihlr. red)t gute Doptellupen. Man mäble mur fold)e mitt Meifingfaffung, woil bic Soormajiłung in ber פärme fid mirft uno bann bie (5)äjer ciner Dopperfupe nidgt melyr paraflel ftebent. 


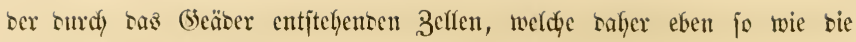
Slocrn jelbjt fejte Benenmungen erfialten haben. Man mag taher nod) fo

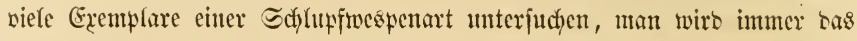
Jlügelgeäber ïbereinjtiument finton. Ein 3njeftenfuntriger wiro aljo leidyt jehen fönnen, weldyer Arerflïglergattung ein abgeriffener Flïgel angethöre.

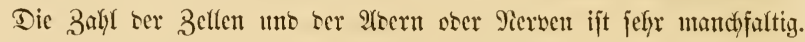

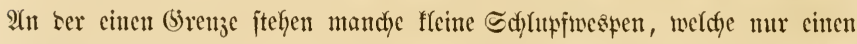
cinzigen furzen jogenamuten Fabiatnerb uno in Folge ocfjen gar feine Zer=

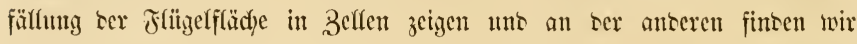
bie Seejungern, bei benen befanntlich) โณв (beäber cin feines viclmajchigez Retž bilben.

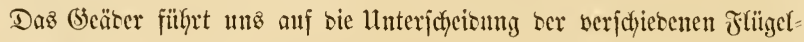
arten, benn fajt mux bei ben jogenamnten echten Flügeln fintet es bei

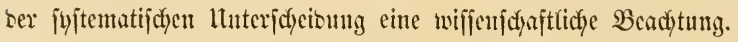

llnter edsten Flägelu haben wir sic vier Flïgel ter Falter, ber

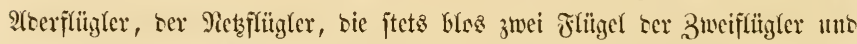

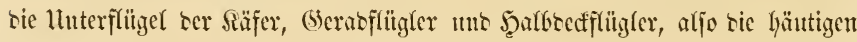

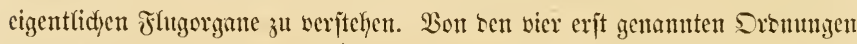
fint ïe aflgemein befannt; weniger bon ben itbrigen unt es ijt bafyer ciniges von ifnen zu fagen. Das Bemerfensmerthejte an oen Mtuterflitgeln biejer

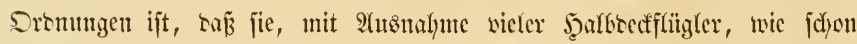

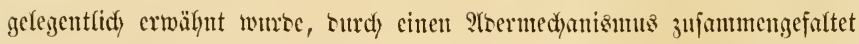
werben, weil jie immer entweber länger ober breiter, ober beibez zugleich),

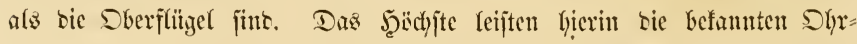
wïrmer, Forfieula, bie twaffridyeinfich bei vielen unjer sejer gar nidyt alz fliegente Thiere gegolten haben werben. Ilnter ben 2 fleiturn fajt vierecfigen

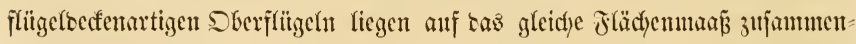

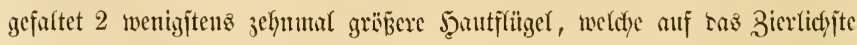
geabert fint. Hnjere Jij. 1. jeigt einen fliegenten Shrmum; linfs ijt

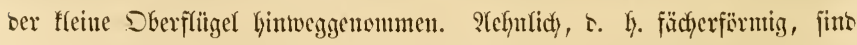
bie Iluterflügel bei allen geflïgelten (serasflüglern, ju weldyen and bie Shrtwithmer gebören, gefaltet, wozu nun bei ben letztern nody eine Duerfaltumg himzufommt. Wenu man bic surd) nichts geredytfertigte Silfeu vor biejen belyenben Thieren überwintet uno an einem getïtteten Shrmurm nach) Tuffebung ber Deffen bie Flïgel auseinanberfaltet, jo miro man 


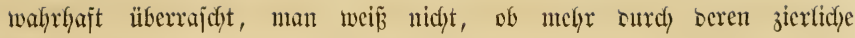
Acterung;, ober surefy ify Borfanoenfin Ḧberlyaupt.

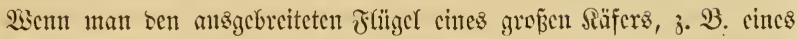

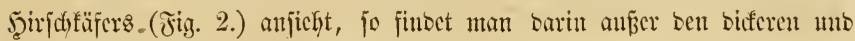

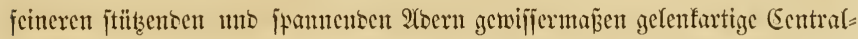
puntte, won weldyen aแะs bas Zujammenfalten sclfelben jtattfintet mo man

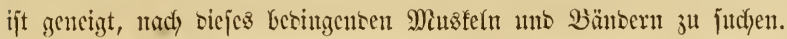

Fig. 1.

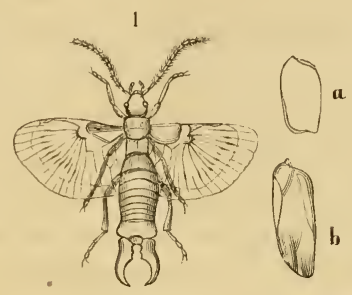

2
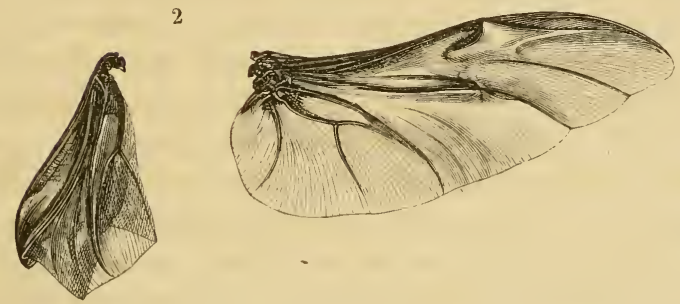

1. Ein fliegenter Shtwum, Forficula auricularia; a ein Sherflïger, b ein juljammengelegter llitterflïgel.

2. Ein linfer ltnterflïgel, fo wie er zulammengejaltet unter ber Flïgelbedfe riegt;

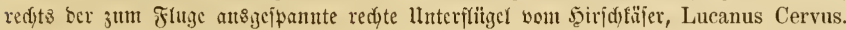

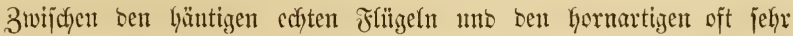

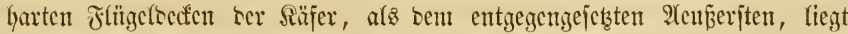

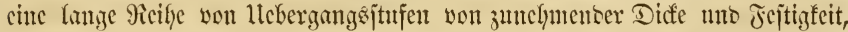

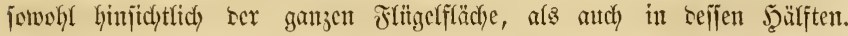

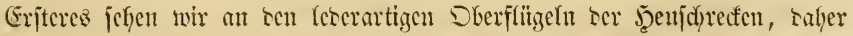

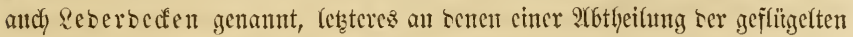
Wanzen, bei senen fic an scr Bafizhälfte hart unb hornartig, an ber 
Spitze weid) uno häutig, alipo gewijifermañen halbe Flügeldecten fins, beshalb aud) Sealboedfen gcuamut.

Selten jüno bie beiren Flügclpare jiemlid), nie wolljtänsig von gleidyer (sejtalt; an meijten ijt es bei ben sibellen ser Jall.

Seter jüt nody, che wir weiter gehen, rer jozentunte affterflügel, ztwei flügelartige Şautläpłd)en, uno rie jtednabeffërmigen beibe nur bei ten 3weiffïglem, furz ju ertwähnen.

Wars un sie bei ben edyten Snjeften ftets in 3 Faaren vorfanbenen

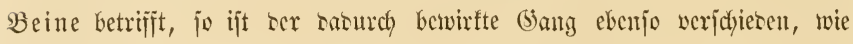
wir

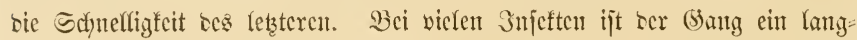

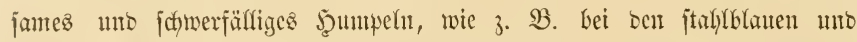
jdywarjen Dungfäfern (Geotrupes), und jerbjt sic Sanffäfer (Carabus)

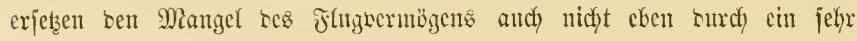

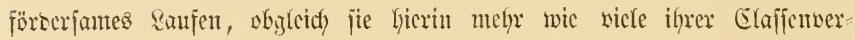

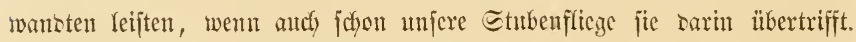
Freilid) fömen bie flugfertigen Snjctten einen behenten \&auf entbehren, woneben jelbjt einige ungeflügefte jelyr fanle Fuñzünger funt. T(m wentigiten gehen bie Jalter, objdyon gerabe unter ifyen cin jtutzerhaftes

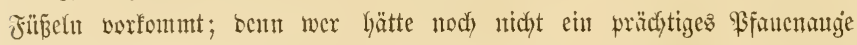

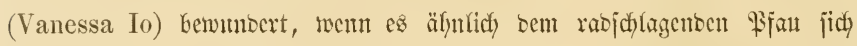

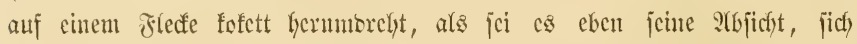

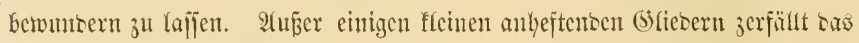
Snjeftenbein in 3 J̧anpttheile: Schenfel, Sdyienbein uno Fñ ooer

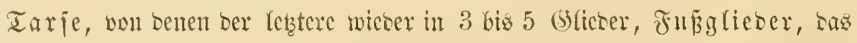
leţte meijt mit $\Omega(a n c n$ verjelen, fid glicbert.

Das norbcre Bcinfaar ift jtets nady born, bic hinteren nach hinten gerichtet unb wiro nidyt blos beshalb, jombern anch meil es oft jun (Streifen,

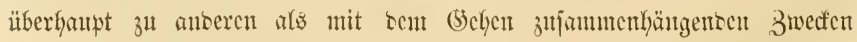

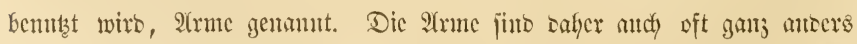
geftaftet uno aużgebiloct als bie 2 cigentfidyen Beinpaare, wou weldyen

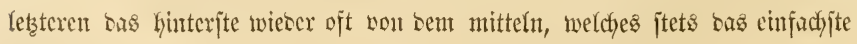
ijt, jelyr abweidyt.

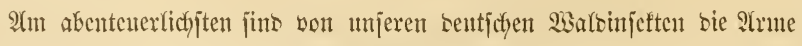

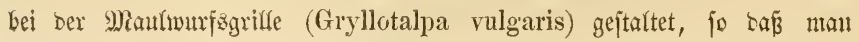


Daran bie genannten 3 \$̧aupttyeite faum wieder erfenut. Sie füb fräftige breite Srabjcheite geworben und eximnern an bie Borberbeine bes Mautmuris.

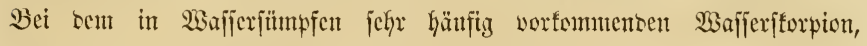

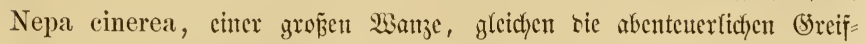

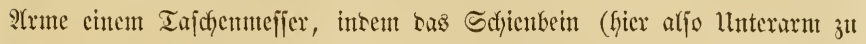
nennen) wie sic Slinge in bie Sdyeibe sent biffen Sdyenfel (Dberarm), eingeflappt werben fann.

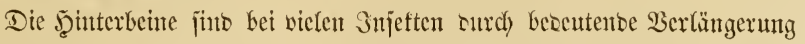

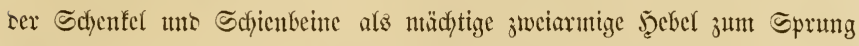

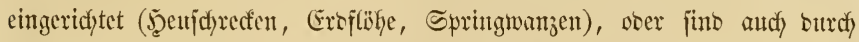

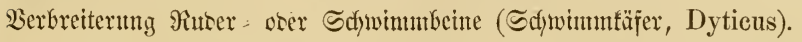

In einigen Injeftenorontugen, an neijten bei ben Säfern, bietet bie 3ahl ber Fuffoficoer, meijt 3,4 orer 5 , thie mefr, cit wertfoolfes Dittel

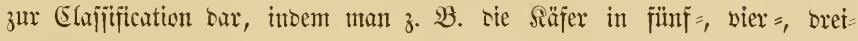

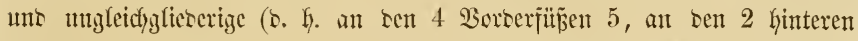

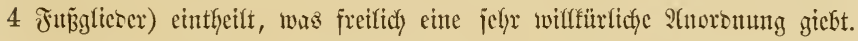

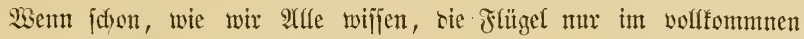
3ujtante sen 3njeften zutonmen, fo ijt es mit ocu beinen bei viclen

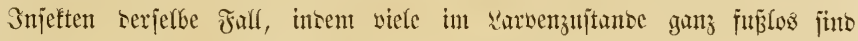
(Bicnen=, Flicgen, wiele Räferlarwen), wälyreno cs anf ber anben Seite andf Injeften giebt, weldye als sarben methr als 6 Beine haben. Dieje

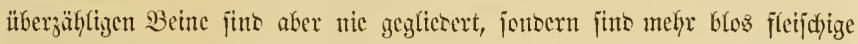
hautige Stummel, itto fommen in ber Buble von 2 bis 8 Faaren vor.

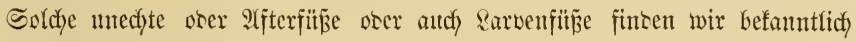
bei ben Sarwen (Yiatpen) ber Sdymetterfinge.

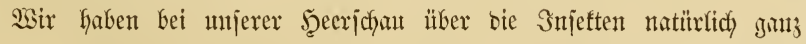

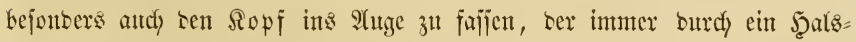
gelenf won bem Mittelletbe gejontert ijt. Miur jelten ijt ber Sopf utwer:

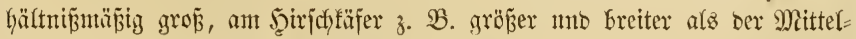

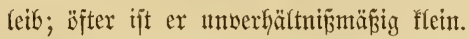

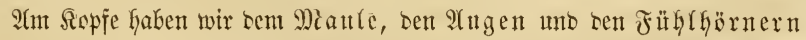

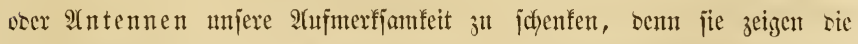

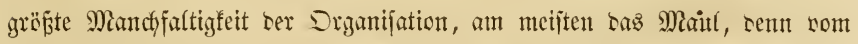

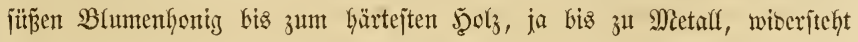
nidfts ben fräftigen Sitefern ber Injeften. 


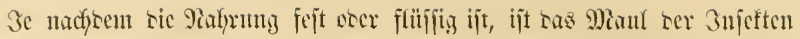

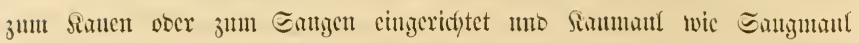
wicocrum höchjt manteffaltig mosificirt.

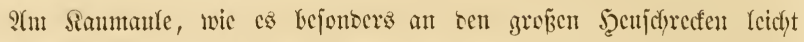

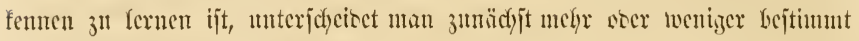
auzgeprägt $\mathrm{Ober}=$ uno luterficfer, jeser chte horizontal wirfente atts

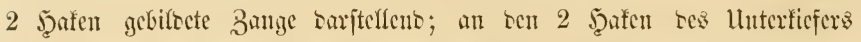

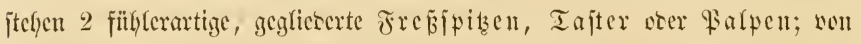
oben uto bon unten wiro tas Mianl won ciner Sher = mo ciner llnter

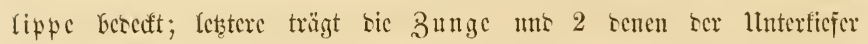

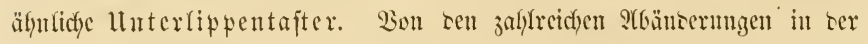

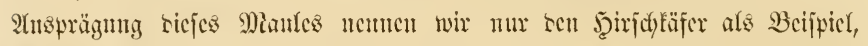

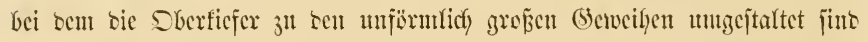

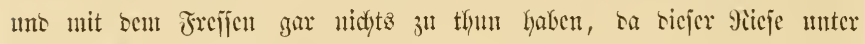

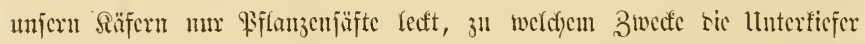

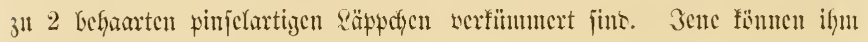

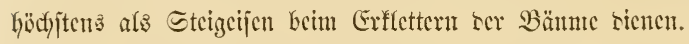

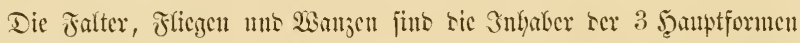

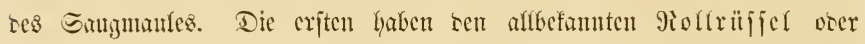
Sauger, cin lamiges Doptelrofyr (wic an cincr Dopteffinte), weldyez jum

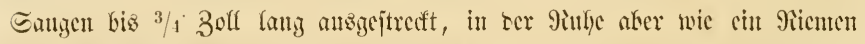

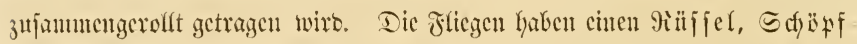

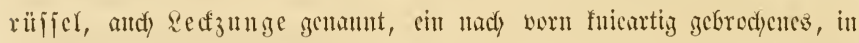

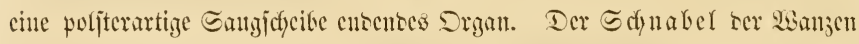

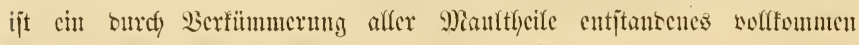

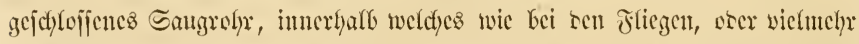
3weiflïglern, bie z" 4 feinen 2 orjten umbewantelten Sber = me llnterficfer

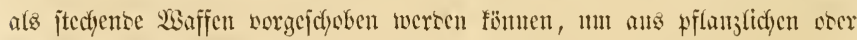

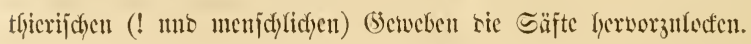

Dies in wenigen flütrtigen 3̈̈̈gen bie Bifsung bes Bujeftemunules; wofften uto fümten wir aber ticfer cingehen, fo würton wir in fecucm

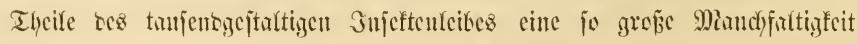

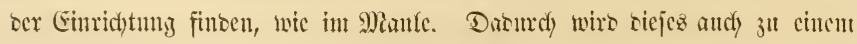

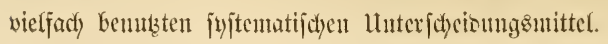




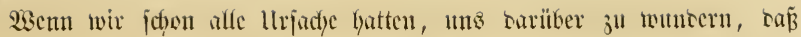

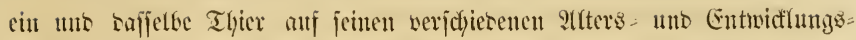

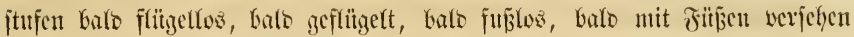

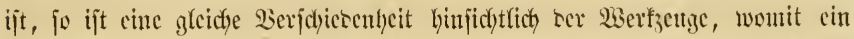

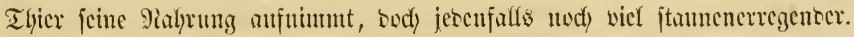

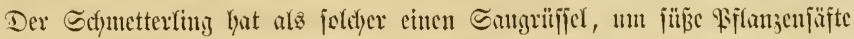

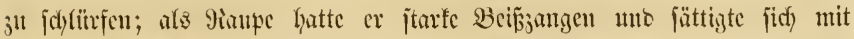

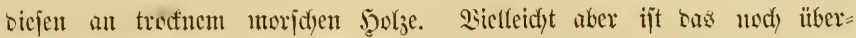

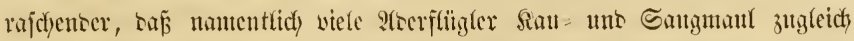

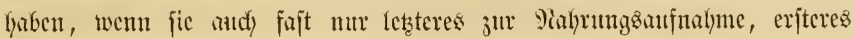

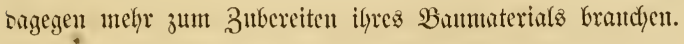

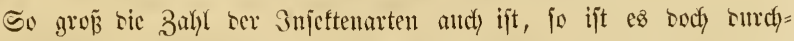

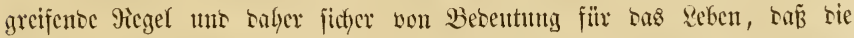

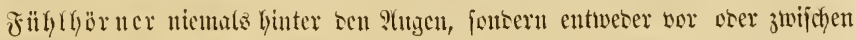

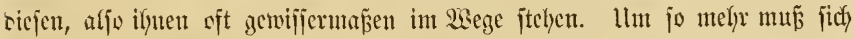

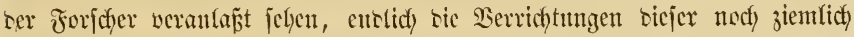
rätf̧jetfaften Drgane ju crgrünocn. Man braudft un einige wenize 3njeften

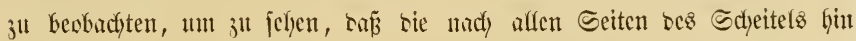
beweglidyen Fühlyg̈rner gemiffermasen bie Dolmeticher beffen fitto, was im Injefteninnern vorgebt; ja bei mandjen, 3. B. ben 2tmeijen, idyeinen fie Drgane ser Mittfeilung ju fein.

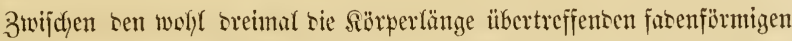

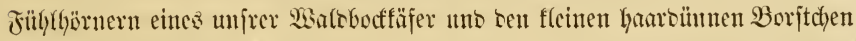

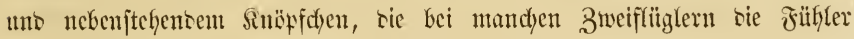

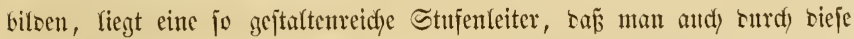

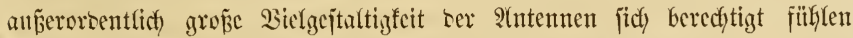

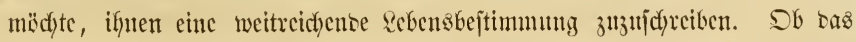

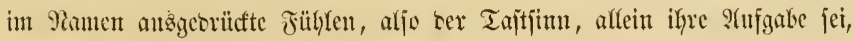
ijt jehr ju bejweifeln, wenigjtens ijt es sann cin Fithlen nidyt blos ber

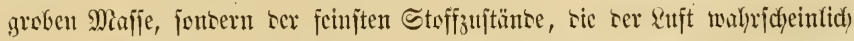

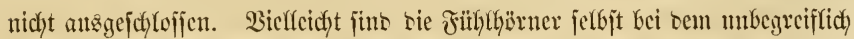
feinen witterungsverntögen betheifigt, weldyes j. $\mathfrak{B}$. Ien Tostengräber (Necrophorus) aus weiter Ferme herbeiruft, um einen für mfere Saje nody gar nidjt riechenben fleinen bogel ju bejtatten. 


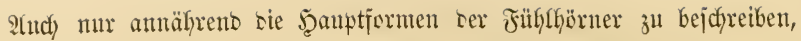

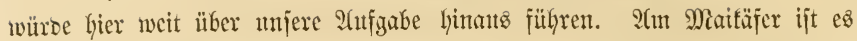
ein jicbenjtraffiger Fächer, bei anteren 3 njeften cin Samm ober eme Säge,

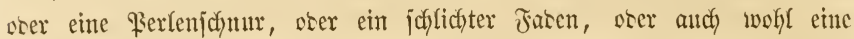
jefönjalynige Feber - immer jino sic Fühthörner aber alts einzelnen, be=

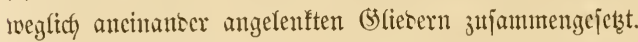

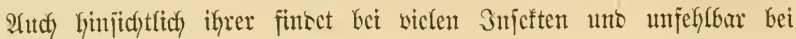
affen mit einer bolffontnmen Berwanthung in sen verjefiebenen Bujtänoen

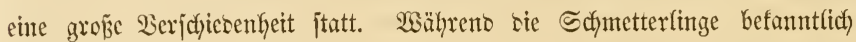

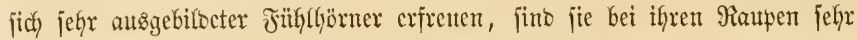
flein uno unjycinbar. 2tudy nady ben Bejoledftern fint jie mandymal

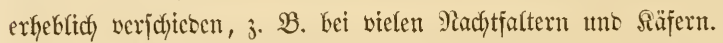

Das $\mathfrak{A}$ thge ser 3njeften ijt jeit alten Bciten eine Eelebrität, uno

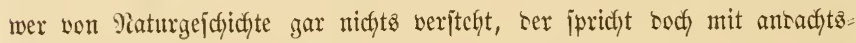
boller Salbung bon bent Fliegenauge, bas aus io unt fo viel taujcho

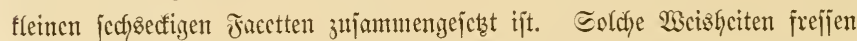

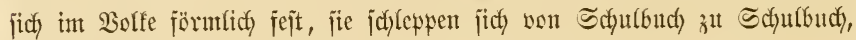
uno bcfommen banu sic guten Sente einmal ein jofches 9 turge unter bem Mifrojfsp zut jelyen, jo glanbent jie's nicht, weil ez nidjet ganl mit bem eingebilbeten Bilbe jtimmt. Serenjalfs verbient ber Bau bes Snjeftenauges nidjt bloz unjere $\mathfrak{B c t w u n b e n n g , ~ j o n t e r n ~ a n d ~ b a s ~ c i f r i g e ~ S t u t i u m , ~ w e l d j e s ~}$

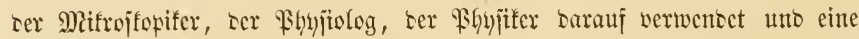
ganze Siteratur sarüber gejchaffen, shne boch alfe cinjchlagenten Fragen

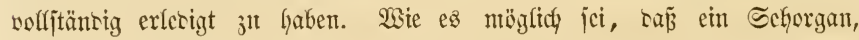

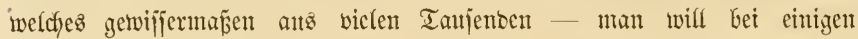
Sdyntterfingen 60,000 annefymen - von cinanter abgejonterter, gleid $=$

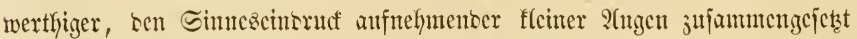

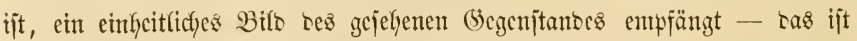

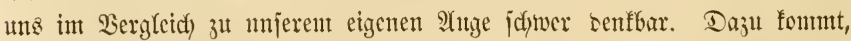

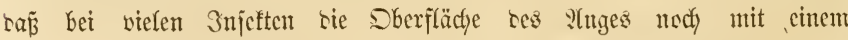

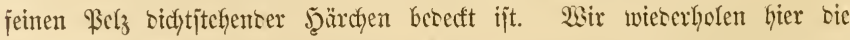

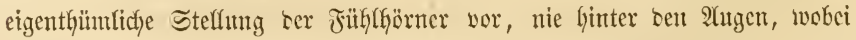
audd) nod) saomrdy - man mödjte jagen bas Sorredyt ber criteren jich

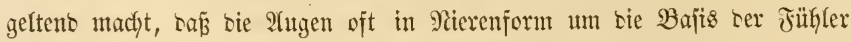

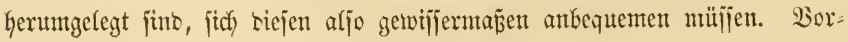


behaltlich bes gegenfeitigen Stellungşerbältniffes machen jïch bei ntanchen

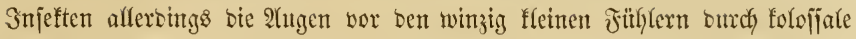

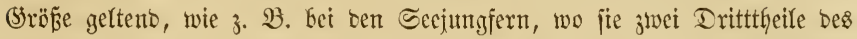
Sopfes einnefyment, auf tem Scheitel in ciner geraben Sinte aneinanter jtopenen.

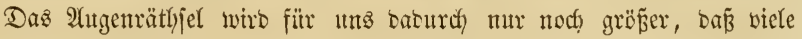
Snjeften im volffommen Zujtande neben biejen großjen zujanmenge= fetzten ober Mezzangen aud nody fleme einfache ober Mebenaugen unb zwar in ber 3ahy von 2 ober 3 haben, weldye inmer in ber Mlitte

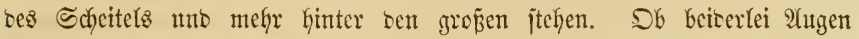
gleich wirfen ober berfefteben, bie einen fern=, bie anderen nahejehent, jenfredht

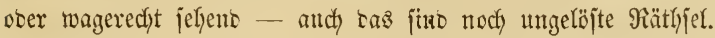

Şenn wir ben Flïgelmangel in ben frifłeren 3ujtänben bez Snjefts um to menizer auffalleno finben bïrfen, giebt, bie ïberfaunt feine Flïgel haben, fo muf es uns viel mehs auffallen,

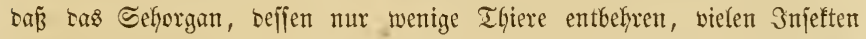
im Sarvenzulftante fef̧lt, wie namentlich ben fuß̄lofen Räfer = und Fliegen=

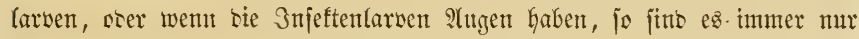
Mebenaugen, benn affe Infeften mit volffonmer, ober ïberbaupt mit

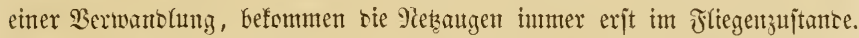

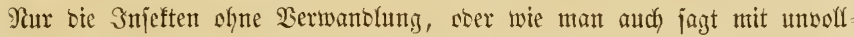

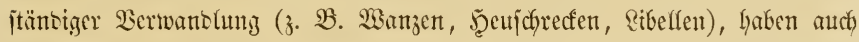

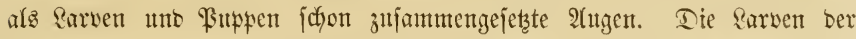

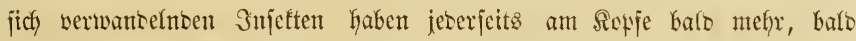

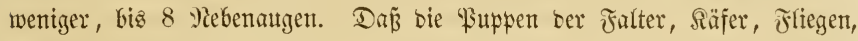

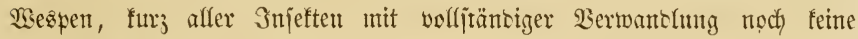
Yłtgen bätten, tann man eigentlich nicht jagen, benn in bem SYugenblidf

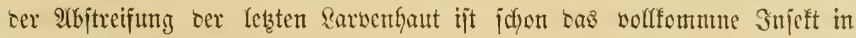

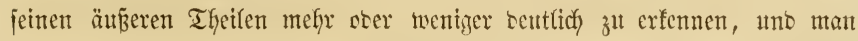
jiefyt 3. 2B. an ber Schmetterlingaputppe aud bereits bie 24ugen bentlich

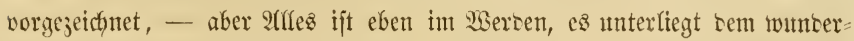
baren Dorgange, ber ants ber Piampe cinen Schmetterling, auts bem 234 m

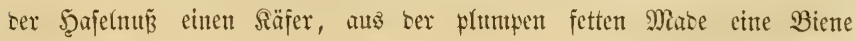
werben ln̈ß̈t.

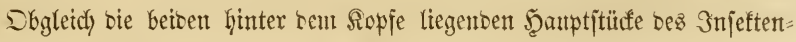
reibes, bie wir ats Mittelleib ober Brujt uno ats Şinterleib ober 


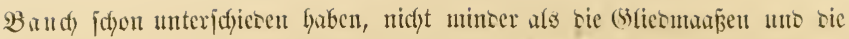

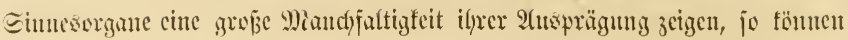

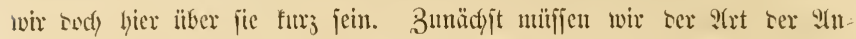

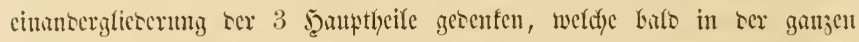
Breite ser unit cinanoer verbutsenen Iheile ftattfintet, wenigjtens jwijd)en

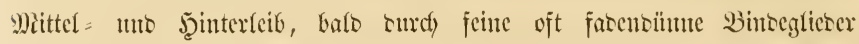

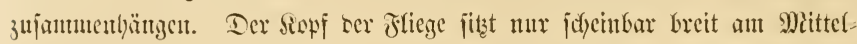

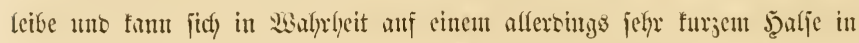

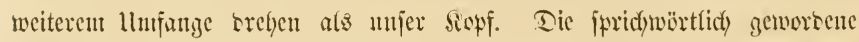
"Wespentaille" wiro bei mandyen Snjetten ans ocr Dronung ber ?Ter= fliigler ju cittem langen farensïnnen "Bauchjiticl", won sem man faum

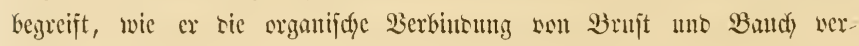
mittelı fann.

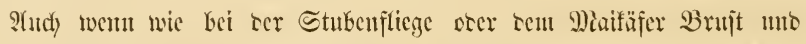
Bandy sidyt uns in ilfrer ganzen Breite nit citanter nerbunten fins, fann

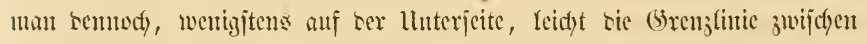

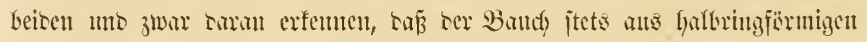

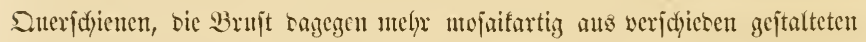

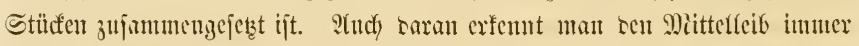

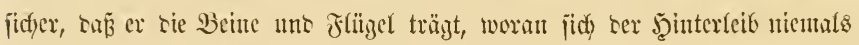

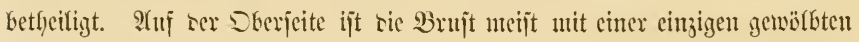
Platte, sem Brujticjilts, berecft.

Bei sen \&arven ser 3njeften mit vollfommute Berwantumb, 3. 23. sen

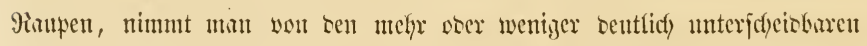

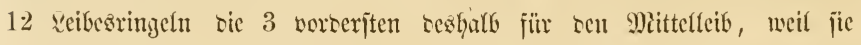

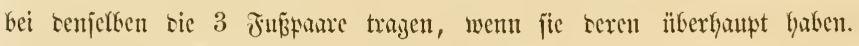

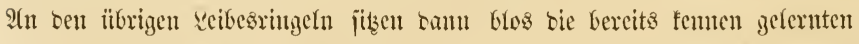

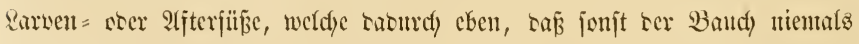

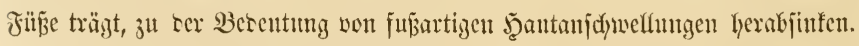

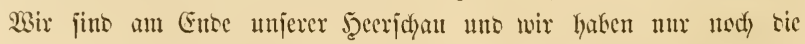

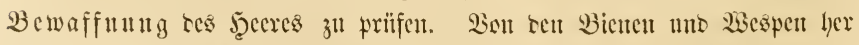

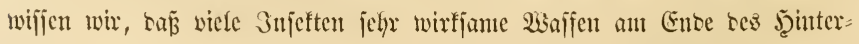

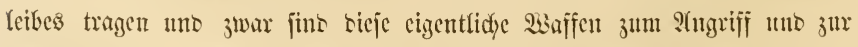
Bertheibigung; antere, bie แns jelbjt nidft weniger fïblbar gentadyt werben, uno oben an Maule jidy befinoen, fino feine cigentfidyen 2 afjen, jontern 


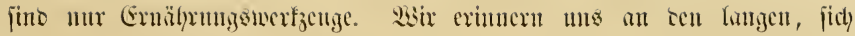

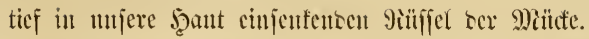

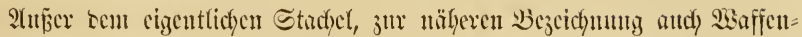

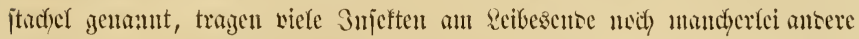

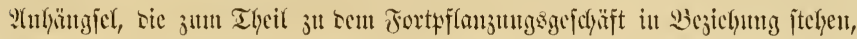

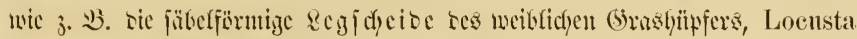
viridissima, tie Säge, sutd) weldhe tic Säje = voer Blattwegpen in oen

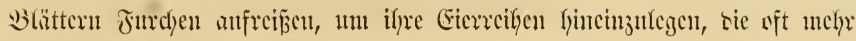

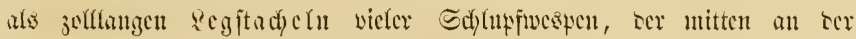

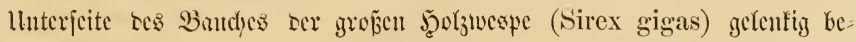
fejtigte lange harte \&egbohrer, um bant zur luterbringmig ocr Eicr tiefe

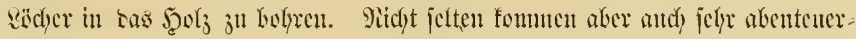

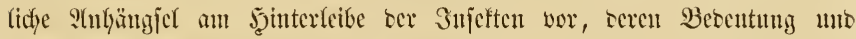

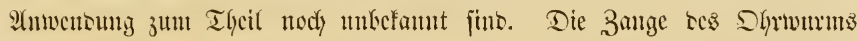
femen wir affe; tie tide Sirbsiffecte ter Sfurpionflieze (Panorpa communis), sic fonterfare Gabel am Edywaze ter Gabclidwanzante (Har-

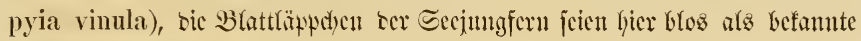
Beippicle genannt.

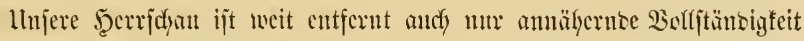

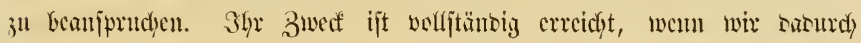
ricjenigen unfrer sefer, sic jich bisher nod) nicmals mit ser 3njeftenwelt

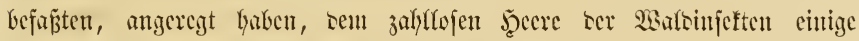

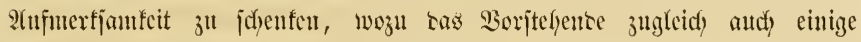
anleitung uno Fingerzeige geben wollte. 


\section{Siebenter Ab/dnnitt.}

\section{Die Bermanolung.}

W3er jidf gern munbert - unb bas ijt ja eine Riebhaberei vieler, wenn nicht ber meijten Menjojen - ser hat bazn tie ergiebigite Bclegenfeit bei oer Betrachtung ber 3njeftenverwantung. Ilno trotzbem pap̃t gerate auf jie

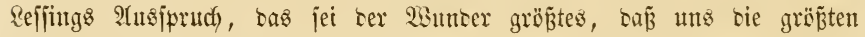
Wuncer jo alläglidy werten, werben follen. $23 i r$ Iffe haben menigitens in unjrer Sintheit einmal cinen Schmetterling jeine Derwanthungşujtänse burdflaufen jehen uno meinten ofme uns barüber ju verwuntern, Las ję nun einmal jo. Wie wiüron wir aber unglüubig ben Sispf jofjütteln, wenn uns ein Bielgereijter erzählte, er habe in jernen santen ein Thier gejehen,

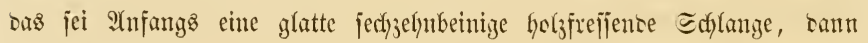
gerathe es lange Beit, von einem jetsenen Sary umidjlojien, in einen

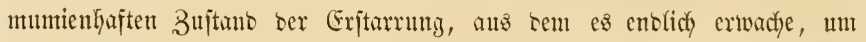

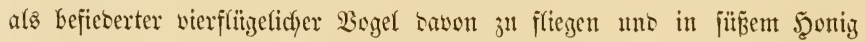

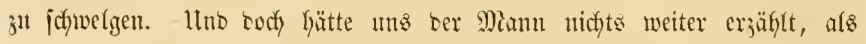
was wir bei ben 3njeften alz $\mathfrak{B}$ irffich)feit Yäugjt fennen!

Es unterliegen feineşwegs alfe 3njeften einer berwanthng, wie vicl:

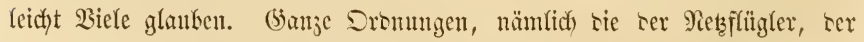

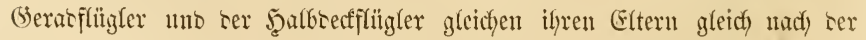

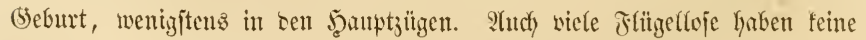
Berwantung. Dagegen erletisen rie Dromtugen ber Säfer, Itber = voer

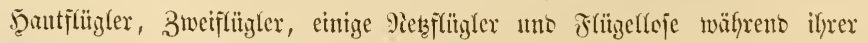

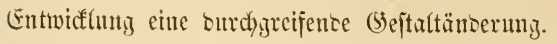




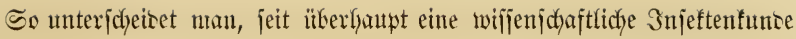
bejteht, eine unborrjtänoige und eine borritänoige Injeftenber= wanolung, fa immerhin audd bei sen Injeften, weldye gleidy nady ifyer

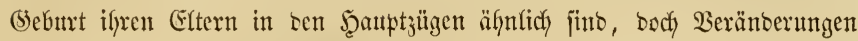

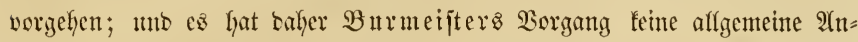
nafme gejunben, bie unvolftäntige Sermanolung überlfaupt gar nicht als eine Bermanthng gelten zu lajfen uno bemzufolge bie Injelten in fich vermanselnoe (insecta metabola) tno in jidy nidyt verwanbelnoe (i. ametabola) einjutheilen.

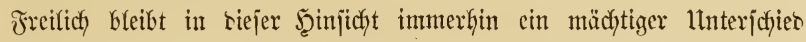
3rifichen cinem Sdymetterfing, an weldyem nichts an jeinen \&arwen = ober

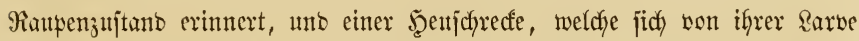
nur burdy bie bebeutendere (Sröß̈e uno tie bolffommmen Flügel, bie ber Rarve vollïtänoig mangelten, unterjacheibet.

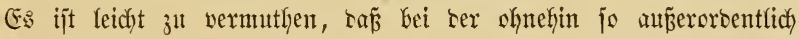

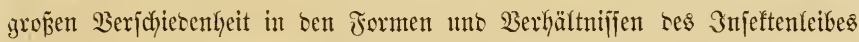

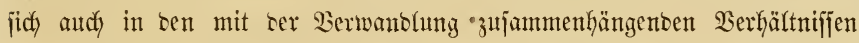

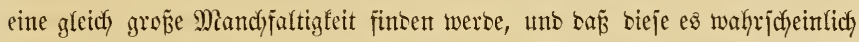

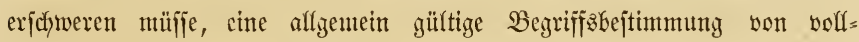

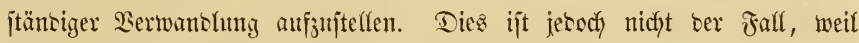
bas Şauptmerfmal fein gejtaltlides (morphologijches), jonbern ein in ber

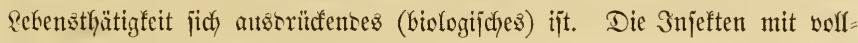
jänoiger Mietamorphoje gerathen in einen mefy soer wentzer lange an

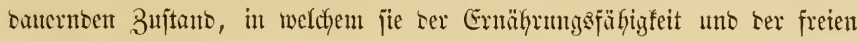
Drtşbemegung (Rocomotivität) berautft jino: sen Fippenzujtano, wäfreno

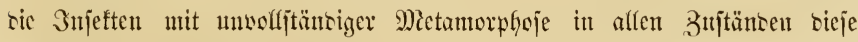

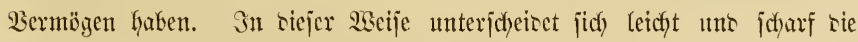
volfjtänsige von ser unvolfiänsigen Berwandlunis.

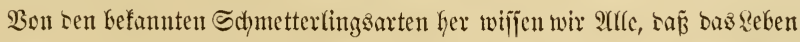
oer 3njeften in 4 3ujtänbe zerfällt, weldye bei benjenigen mit volljtäntbiger

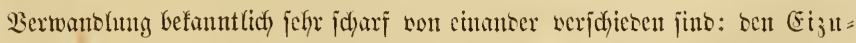
itand, ren sarvenzujtans, sen suppenzujtano uts sen Fliegen= zujtans.*) Seber ijt reidy an Erjobeinungen, weldye cben jujamnten sie

*) S. bie 2 mmerfung auf S. 17 . 


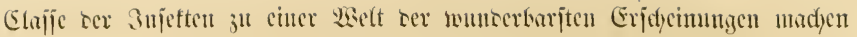

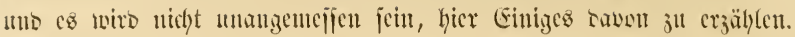

\section{Der Eijultanto.}

Siur wenige 3njeften zeigen Rebenriggeburt, wobei fid) wieserum auffalfente bejonserfyeiten finten, insen sabei sie jungen Bnjeften entwerer

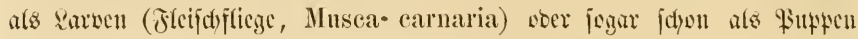

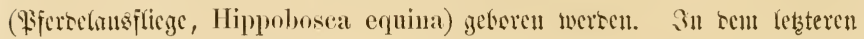

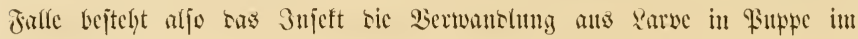
Minttcrlcibe.

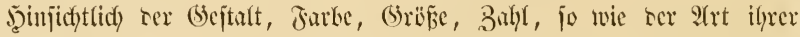

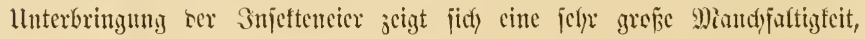
worïber bei ben cinjelnen ansï̈lyrticher ju behantefnoen 2balbinjeften ju iprechen jein wirb. Son ter gewölnulichjiten Form, sen fuget ofer cif̈̈rmigen,

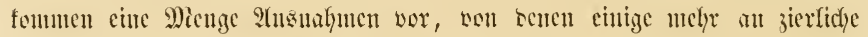

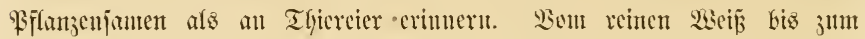
Mietallglanj foumuen affe jomben wor, jogar jumeilen jierticfe punftirte ooer

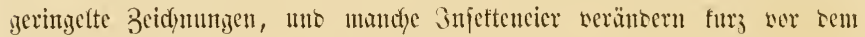
9tůfricd)en ilye Färbung.

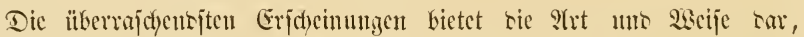
wie viele 3nfeften ifpe Eier unterbringen, Im baburdy nidyt aflein ifyr

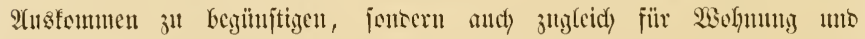

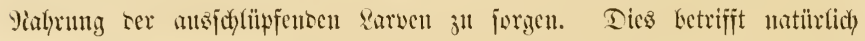
befonbers sicjenigen zalyfreidyen Imjeften, weldye in \&arwenjujtunse jidy ijolirt in bejontocren B̉ebältuiffen fittren.

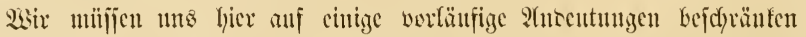
แno erinnern zunüchjt an bie 9lrbeitsbienen, weddye fïr jeces von ocr

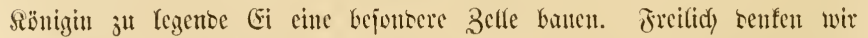

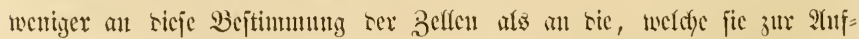

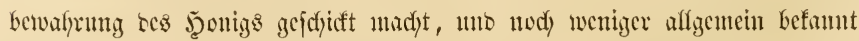

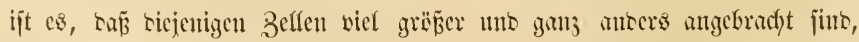
in weldye Eicr, ans senen Säniginnen werten, gelegt werten joffen. Eine ser Biene jelyr ïlutidye Wespe, sie Tapejierbicue, Megachile centuneularis, jucty jidy junäd)jt in irgeno cinem faulen Bamuftumue sie berlaffencn 


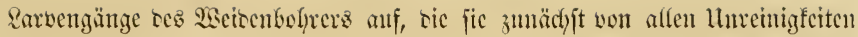

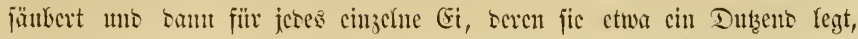

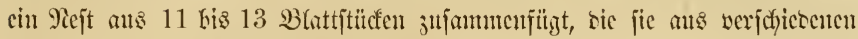
Baum =, meijt aber 9iojenblättern jefucioct. Dicje Pecjter, aljo jtets fïr

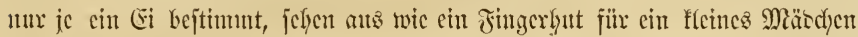

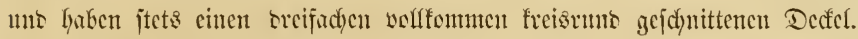
Elye sicje aber aufigelent wersen, füllt sic Dinterbiente ocu Fingerhut etma

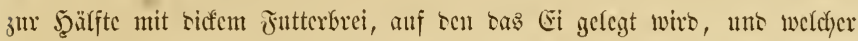

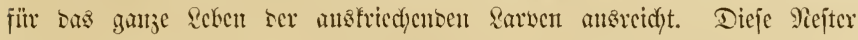

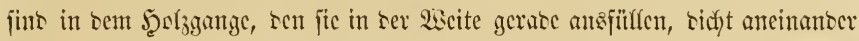

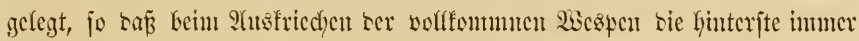

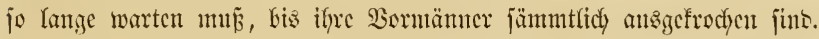

Der Erbjectno scr Fidytentuältcr, ser Budderucfer = Borfenfäfer, Bostry-

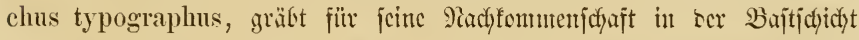

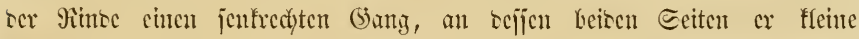
(5ritbedyen ansonagt, in weldye bie cinzefnen mildyweißen Eierdyen abgelegt unb sann mit feinem Mitubemefyl veriftridgen werben.

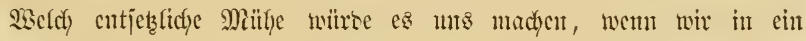

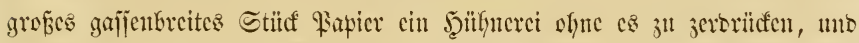
an cher ser vier Eefen anfangento, cimrolfen mïß̈ten! Ein fleiner fliegen-

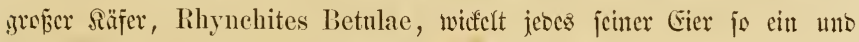
besicnt jidf) ธaju cincs gropicu Erlenblattes.

Dodf fFäter wersen wir bicje uno viele ansere fälle won mütterlidjer

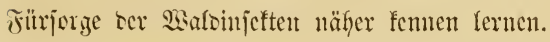

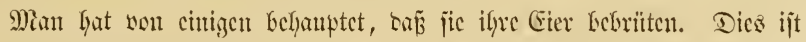
abcr ein gutgemeinter sratfum. Sint bie Eicr cimmal gelegt, mo zmar

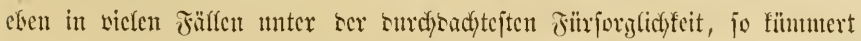

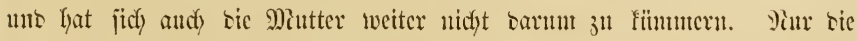
Shrwitumer Gefüten ifge Eier mo tragen fie an antere Drte, went ber alte 3u trodfer geworten war.

Die Dance tes Eijujtanses ijt bei sen werjofictencn 3njeftennten

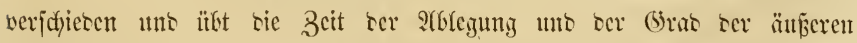

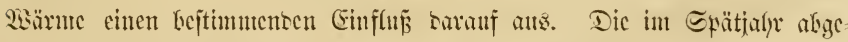

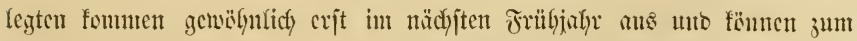

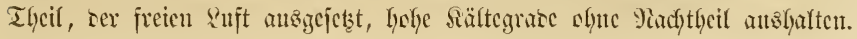


Jür viefe zärwdyen ijt bie eben verlajīene Eijdyale sie crifte Epeije,

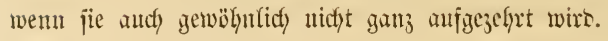

\section{Der Raruelizlitalio.}

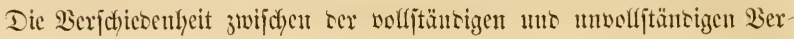
mandung verbictet uns, bas sicjen bes sarvenjultantes geftattlidy zu

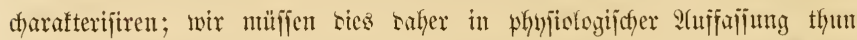

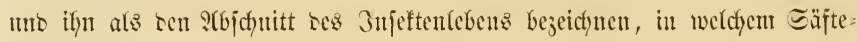

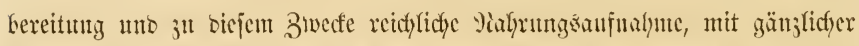

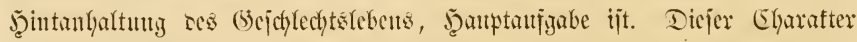

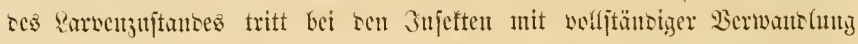

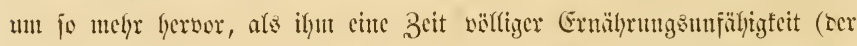

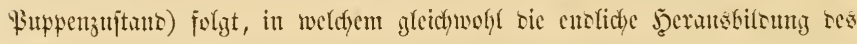

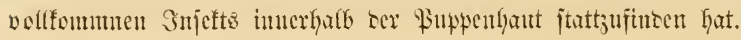

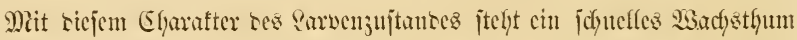

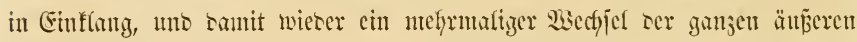

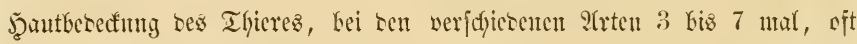

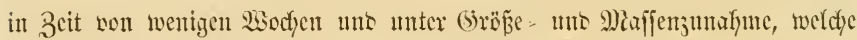

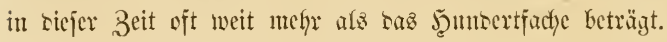

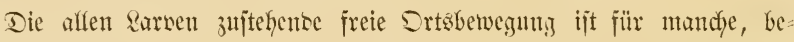

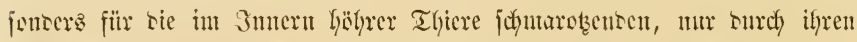

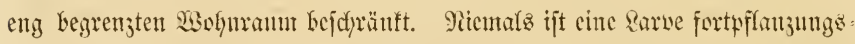

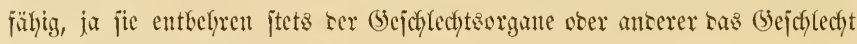
verratyenter Sentuzeidfen.

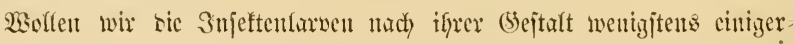

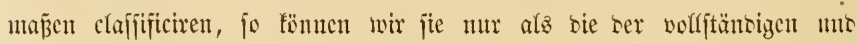

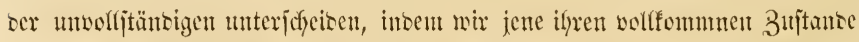

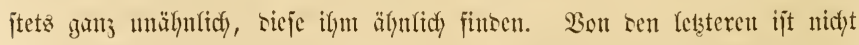

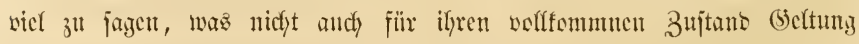

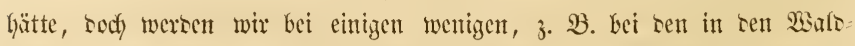

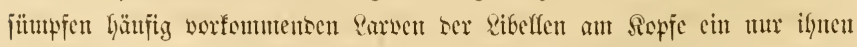
unb iffren Buppen zuffonmentes Organ finten. Sonjt fint fie neben

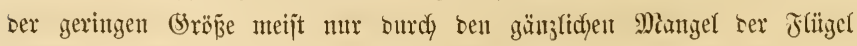
verjojiebert. 


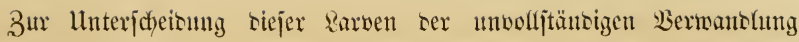

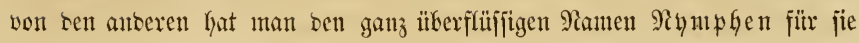
eingefitfyrt. Ebenjo hat man ie nady ifyer Beftalt uno Srganijation viele Rarben ber bolftäntigen Berwanthlung afs Raupen, Mfterraupen, Würmer, Miaben näher bezeidfnet, was uns bercit geläufitg ift.

23ie bie 3njeftentarven jidf bejonters burd einen mujterthaften 2 (2ppetit

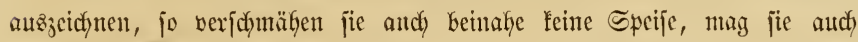

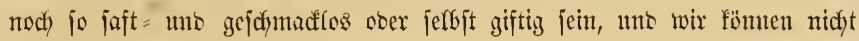

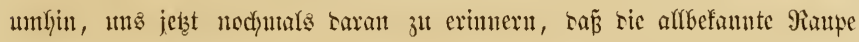

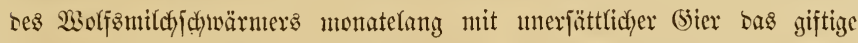

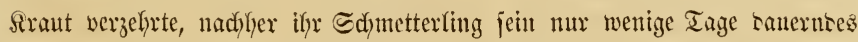

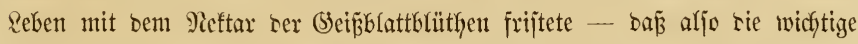
Rebensberingung, sie Ernälnumg, ben volljen 2 hntheil an ser Metamor= phoje uninut.

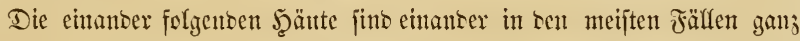

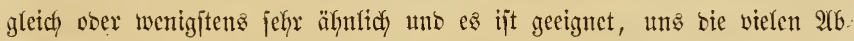

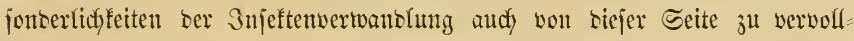

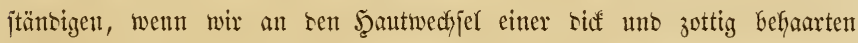
Bärenraupe, Aretia Caja, benfen, weldye in eriten Stugenblife nady ber

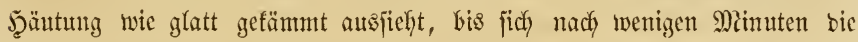

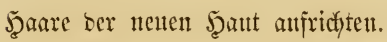

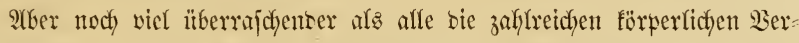
fojierenheiten ber Earven von iflrem volffommen 3ujtante ijt ber Unterjajieo

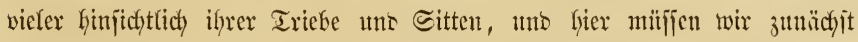

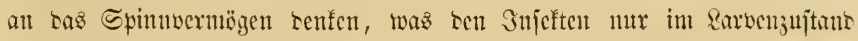
juffommt uto butrd Drgane vermittelt ift, weeldye fajt inmer im Maute, nur bei wentigen am 2(ffter liegen.

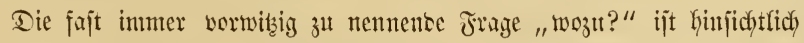
des Spinnvermögens ser Snjeftenlarven nur sabmrdy einigermaß̃en ent=

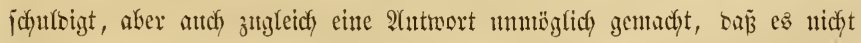

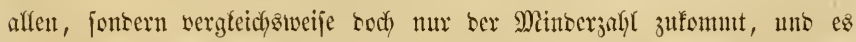

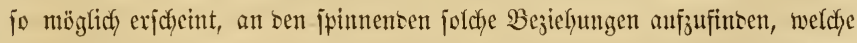

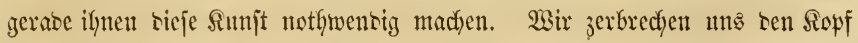
nidjt barüber, ob Diejenigen redyt faben, weldje im Spinnvermögen ein Mitter

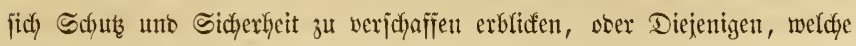


Sarin cincn pafipen Drany fefyen, cinen Stoij los zu werten, weldyen bie

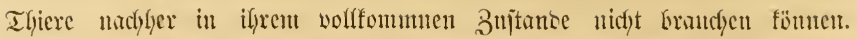

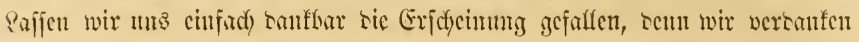

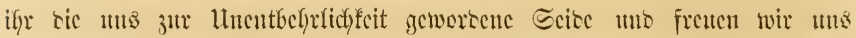

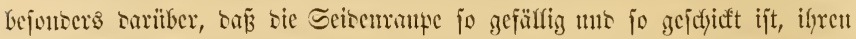

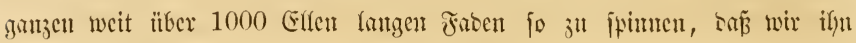

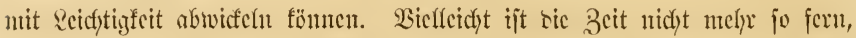
wo tic Eidyen mịcrer $23 a ̈ l o c r$ แns cine nene Seiscuraupe füttern werten.

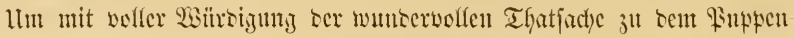

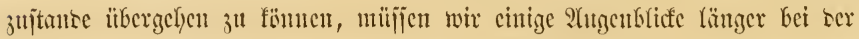

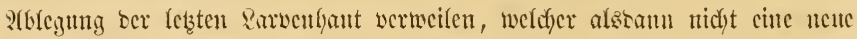
glcidye, jonten bic \$supenlyant folgt, möge mun sicje numicnartig bas

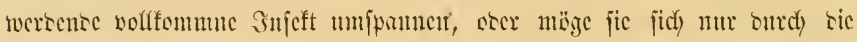

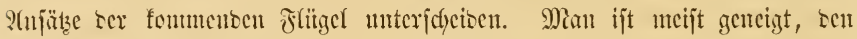

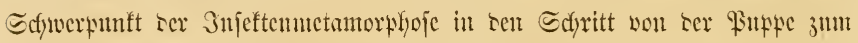

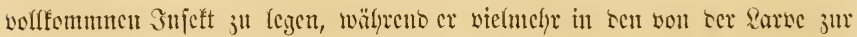

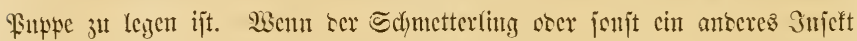

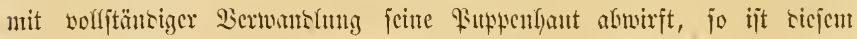
Ereigntifi ein oft vicle Dionate langer Zcitramn vorangegangen, in weldyem

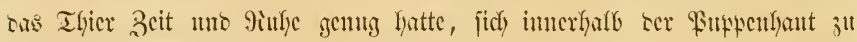

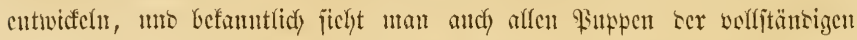

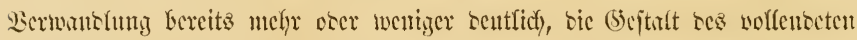

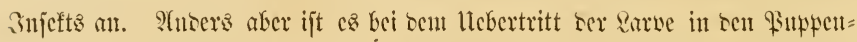

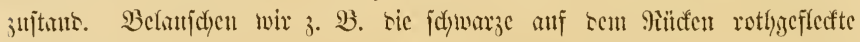

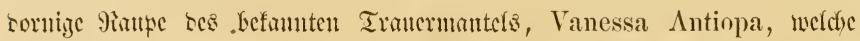

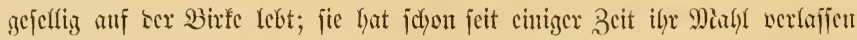

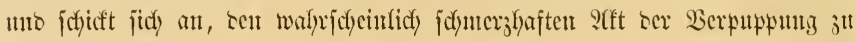

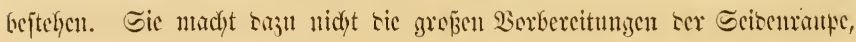

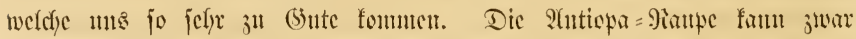

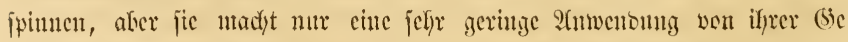

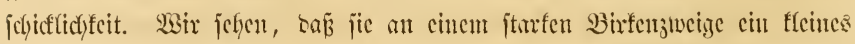

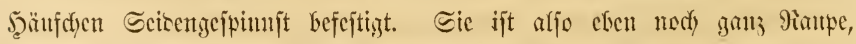

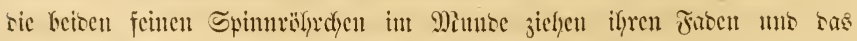

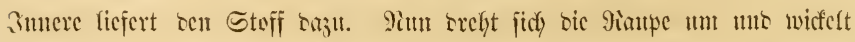

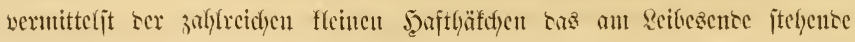




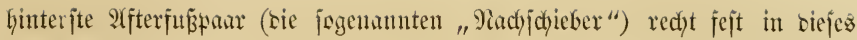
Seibenflümpd)cn, bann hängt jie fỉch wie cin Seiftänzer häuptlings fret in

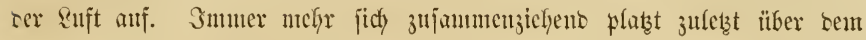

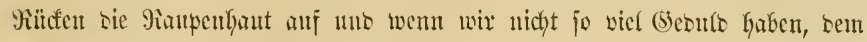

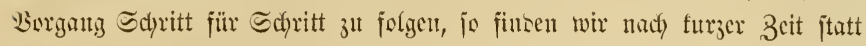

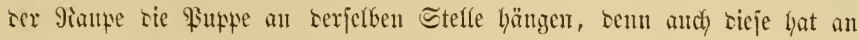
ifyrer હdywanjpitze ähnlidye ફ̧afthäfchen. Sagar sie abgemorfente 9aupenlyaut

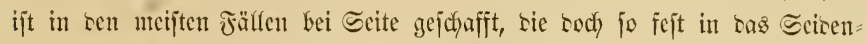
flümpdyen eingehaft mar.

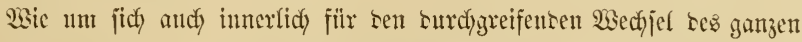

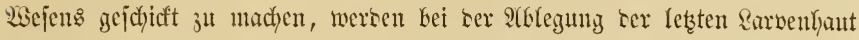

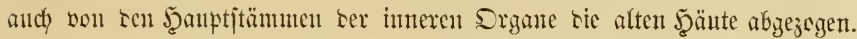

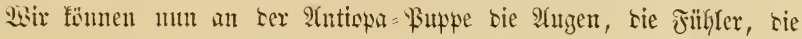

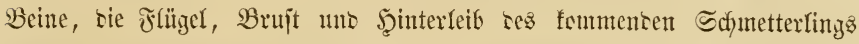
seutlich unterfocisen - affes Theile, won senen sie Maupe in siejen

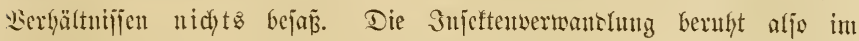
llebergang atts sent \&arwen = in sen Fuppenjujtant, nicht in beu Uebertritt

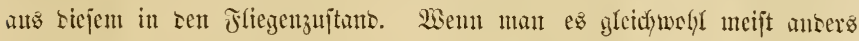

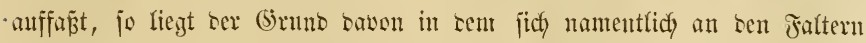
jo glänzeno geltent mad)entent llnterichiese zwijchen ser jujeintost eingejargten

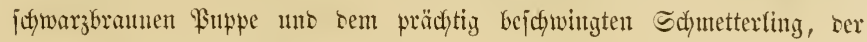
fajt im sit ants jener fervorgefft.

\section{Der- Buppenzuttano.}

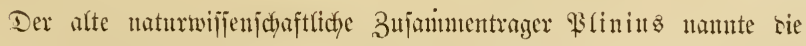
oft mit golbigen ober filferuten Fledfu gejicrten Puppen ber Tagfalter Egryfaltis wer Ehryfaris, mo tie Puppen ter Bienen siymphen. beibe Benenumgen juto in ser Snjeftenfutre anfgenommen, insen man

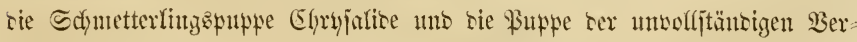

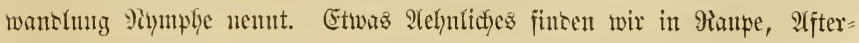
ranpe, Mabe, Wurm für Sen Rarvenzujtant. Dicjes wie jenes ijt unnöthig unt fann leidft 3n 3rrthümern verfüfyren, intem man bei ben verjdyiebenen

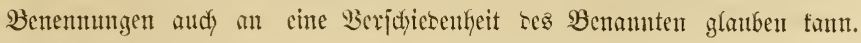


Darum woflen wir im Serlanf mnirer Mittheilungen unz bloz ber $B_{e}=$ nemung sarwe uto Buppe besienten, uno wenn uns, was bei ber lants-

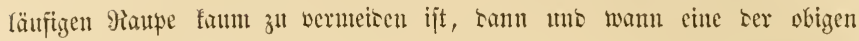

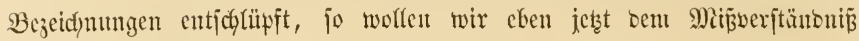
vorgebengt haben.

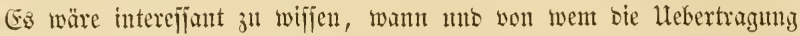

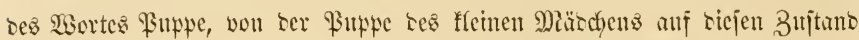
oce Snjefts zuerit jtattgefunten labe; scun bieje Mebertragnng ijt boch wohl anzunchumen. Bei ben Mömern berentete pupa ein Mäbdyen, mo anch sie Puppe rejiclben, nicht Injełtenpuppe.

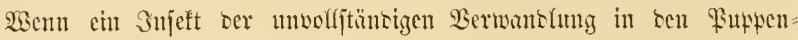
zujtant tritt, jo hat bas im Sergleid) jum eben verlajienen sarbenzujtance

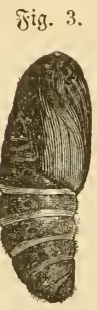

รig. 4.

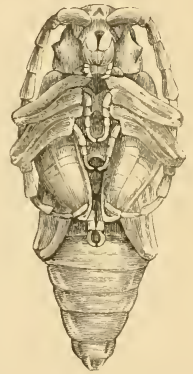

Fig. 5.

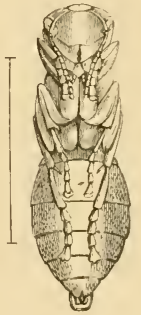

รig. 6.

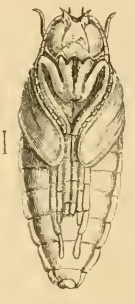

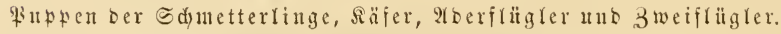

Jig. 3. Sicfernfpinter, Bomlyx Pini.

4. Der groß̉e Bodfäfer, Cerambyx heros.

5. Dic 5ornific, Vespa crabro.

6. Dic sicicrngallmide, Cecidomyia Pini.

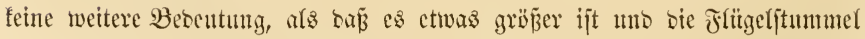

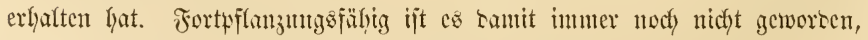
obgleich) bei vielen rie (5ejededeftsiverfjentge fereits vorkanten fint.

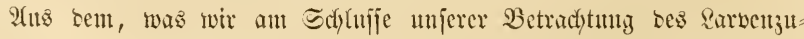

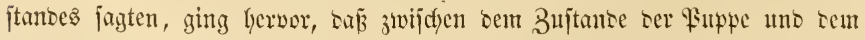

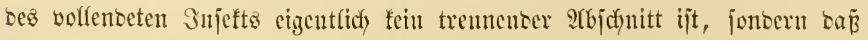

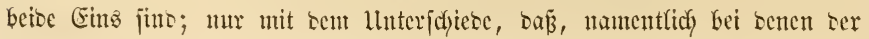




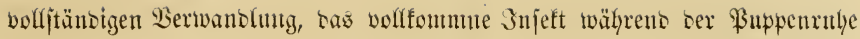
in jeinen Drganen zil beren Betfätigung wollents fertig gemadft wiro.

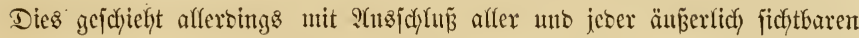

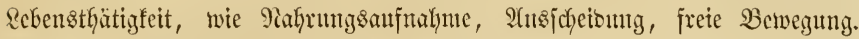

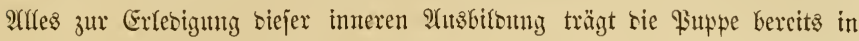

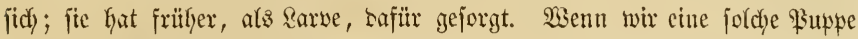
auts ifprem Geipinnte nefmen, falls jie ein jolches hat, fo fönnen wir immer bas vollensete 3njeft Laran exfennen, wenn aud') natürtich nur in jeinen ફ̧auptzügen.

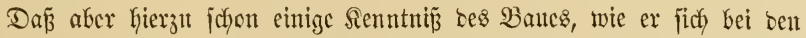

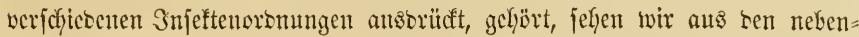
jtekensen Figuren, won benen wir Fig. 3 afferbings fofort afs eine Falter= puppe (Bombyx Pini von ber Scite gejełen) crfennen, währent 4, 5, uno 6 mux Der (ben̈bte als bic \$uppen eines Räfers (Cerambyx heros), cincr

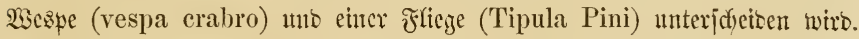

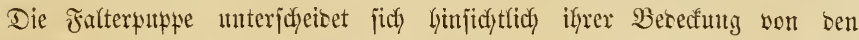

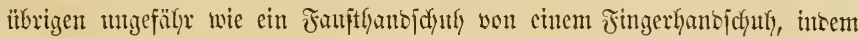
bei ify affe Theile von einer gentinjamen Şauttocfe umidyloffen fint, währent bei ben itbrigen jebes einzelne (s)tico jein bejonberes fejt auffiegenbes Jutteral hat. Bei sen Schmetterfingspuppen ijt nur zumeilen uno zwar

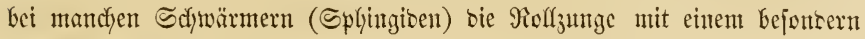
Jutteral verjegen, jo baj fie am Stejichte Genfelartig frei lostritt.

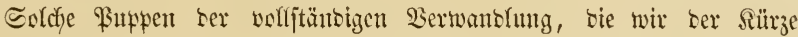
wegen vorfftänbige Puppen nennen wollen, finben wir befanntlich oft in ber

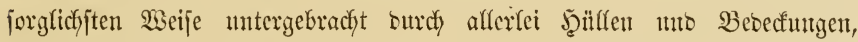

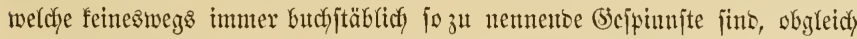
ber zufammenfittente Rcint, woourdy bie verjofierenjten Stoffe (Stcindfen,

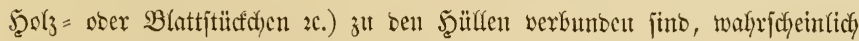
immer Seibenjtoff ijt. WSir werben fpäter bei Betradjtung ber einzelnen

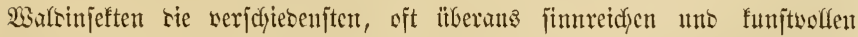

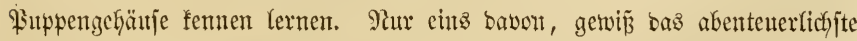

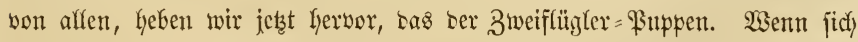
sie Fflegenlarbe in bie \$ruppe vertwanteln wifl, fo wirft jie bie leţte Rarwenthaut nicht ab, jonbern bieje hebt jich mur von bem nen entjtunbenen Puppenleibe ab, bläjt jich etwas auf, erbärtet, färbt jich meijt sunferfajtanienbraun 


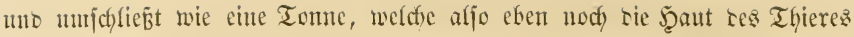
war, locfer ric \$itupe.

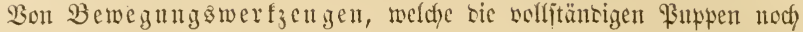
als jolche in Afnwentung bringen, finben jich nur geringe Spuren; ¿afyu

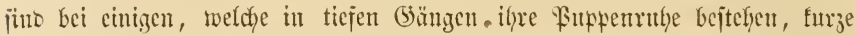
Witcergäfthen an sen Reibesringeln jut redyen, mit tenen jie jich bis an

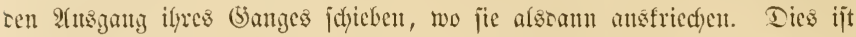
3. 2. bei rer Buppe ses \$acirenbolyrers, Cossus ligniperda, ser jalf.

Wälyreno sen Rarven, senen ier mbolftänrigen wie senen ser woll

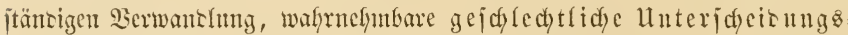

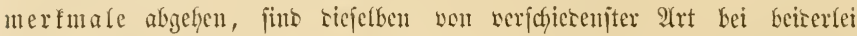

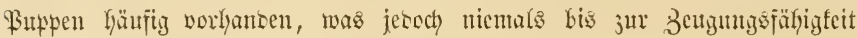

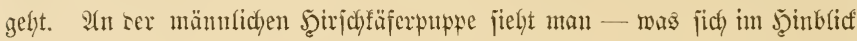

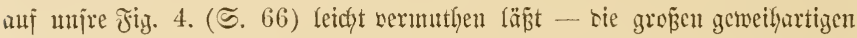

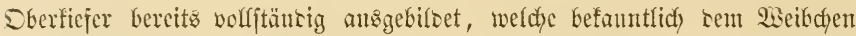
uno afjo and refjen Buppe fehlen. Dic mit sen slügefïtummeln verjegenen

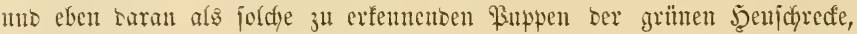
Locusta viridissima, jüto als weibliche leidjt ju erfenten an ter jäbel=

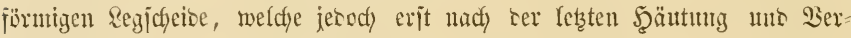
wanding zum volfemmen 3mjeft in 2Birfamteit tritt.

Dic Daner bes Puppenjuftandes ift ebenjo wie scs Rarvenzl

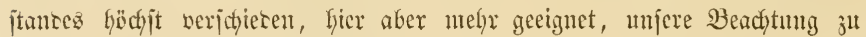
erregen, als es jebenfalls bemerfenşwerth ijt, Thiere viele Mionate lang in

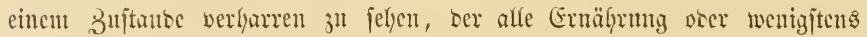

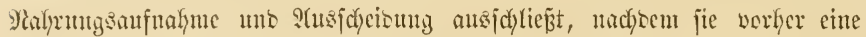

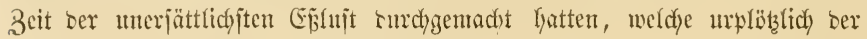
ftrengiten Entfaltjamfeit Plałz madjte.

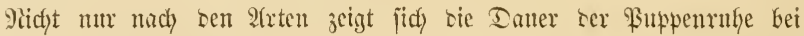
ben Injeften mit wolftänbiger Berwandlmg - benn bei ren antern ijt

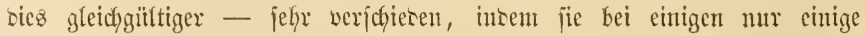
Tage, bei anteren cin Safyr tme länger samern fanm, jontern aud bei einer uno berjelben 21rt zeigen jich Darin Sdywanfungen, weld)e lyauptjächlich Durdh Göbere orer niebrigere sä̈rme ter Umgebung beringt fint.

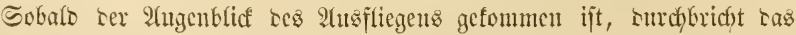
bolffomme 3njeft ric \$supenthant, mobsi sicje kei sen Jalterpuppen in 
Drei Theife, bas Sopf, Brujt- mo Baudjfutteral zerfülft, währeno es bei

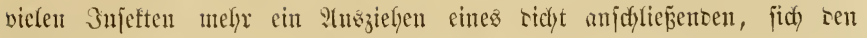
cinzelnen Sörpertfyeilen anpafjenten Sicibes ijt (j. Jig. 4.5 6).

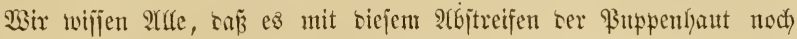

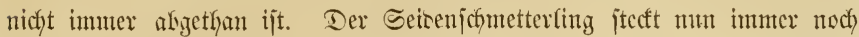
in feinem sidjt uno jodjex unzerreip̧bar fejt gemobenen feiscnen Säfig, bie Fliege immer nod) in iffrer vorfin bejatrebenen jum Eown geworbenen

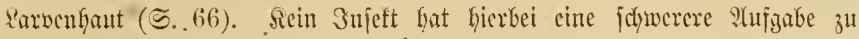

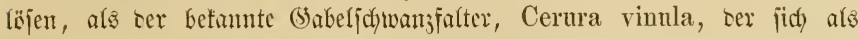

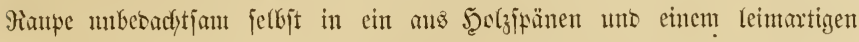

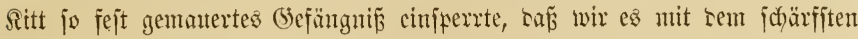
Mefĩer faum öffuch fönnen, wie viel wentgex ter zarte uno weiche sarin nody eingefdloffene Solymetterling, sem sajn alfe Werfjenge fehlen, ta ifym

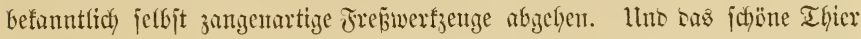
will jich boch nidyt getwaltjam surd) einen Mauerrí̧ linturd) trängen, was

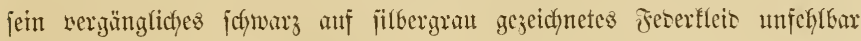
jerftëren wïre! Hno wie jollte cs einen joldyen Mauerrif fertig bringen?

Diejer wic ser Seicenfdmetterting unt vicle antere berienen fidt), sa ibnen medyanifdye Mittel ganz abgehen, eines cfenifdyen Mittels, einer jahrfen Säme, weldye jie ans sem Mante abjontern mo woourdy an ber Stelle wo ber fioff bes Ificres jidy befinoet, fdynelf cin Body in bas Eocon gefrefien miro.

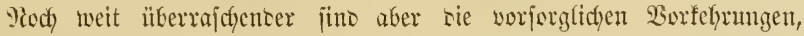
welche einize 3njeftenlarven treffen, un jich bereinjt als vollenbeten Snjeften bie Befreiung ants ifjrem felbjtgebauten fierfer ju crmb̈glidyen. S3ir greifen

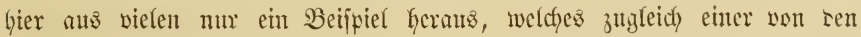
Fällen ift, in weldyen tie Yatur fïn uns cine Borerfinterin ift. In siejem

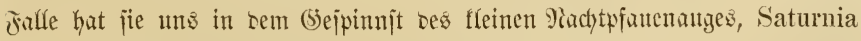
Carpini, ras Miotell jener Piattenfalfe gefiefert, weldfe ans einem fleinen, einem Bogelbauer gleidgenton Drahtfäfig bejtelt, in bejijen oberem Theile

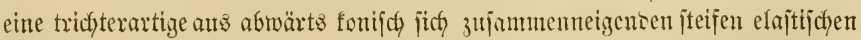
Drähten bejtegt, zwijeyen benen fich tie 9iatte, un zit ocm Söber ju gelangen, zwwar leicht abwärts brängen, aber nicht wieber heranstommen fann, weif

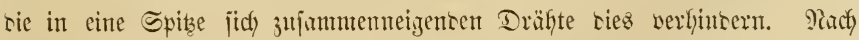

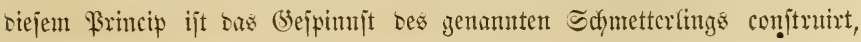




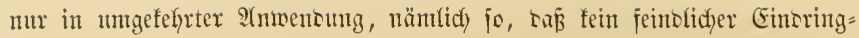
ling Kincin, aber ser antsgefrodhene Schmetterling leid)t heraus fumn. Die Fig. 7 zeigt siejes (5ejpimujt uno Fig. 8 sen jenfred)ten Durcficdnitt

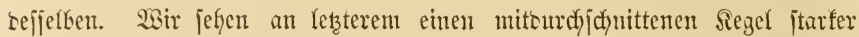

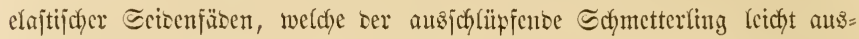

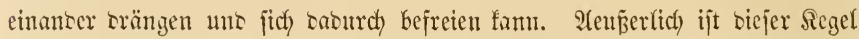

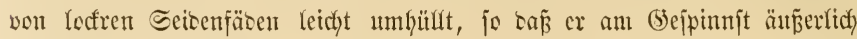
meijt nidht jidftbar ijt.

Diejelbe Eimridytung hat ber in neuerer Zeit zur Seisengeminnung empfohlene japanejifde Schnetterfing berjelben (5attung, Saturnia Arrindia,

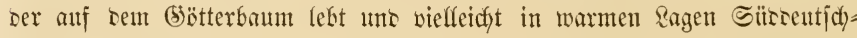

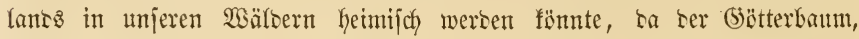
Ailanthus glandulosa, unjer ßlima eben fo vollfommen verträgt, als er

Fig. 7.

Fig. S.
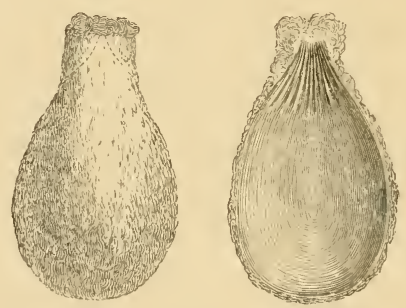

7. Beipinnft Des fleinen Raditpfanenauges.

8. Senfredjter Durdjidyntt sejierben.

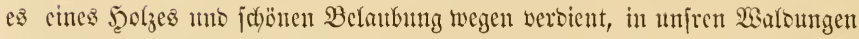

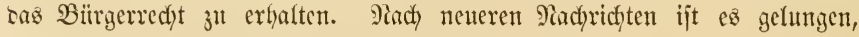

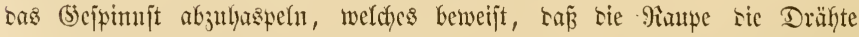

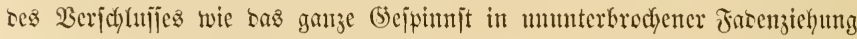
fertigt.

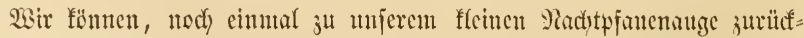
fehrent, nicht unterlaijen, eine hödjit merfwïrsige Mattheifung cinzujhalten, meldye vielleidyt Manchem fajt unglanblich foheinen fämnte, wenn nicht eben

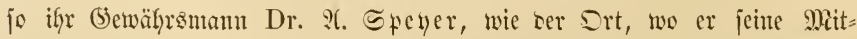

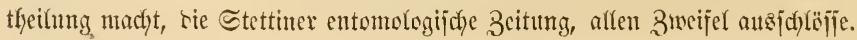




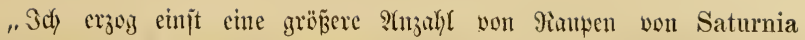

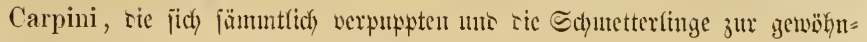

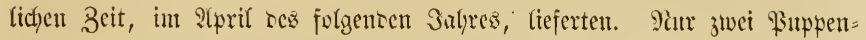
gefpinnite blieben liegen. Das eine serfelben war nidst, wie gewöfnlich)

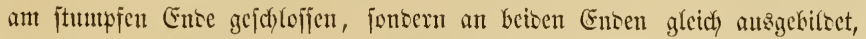

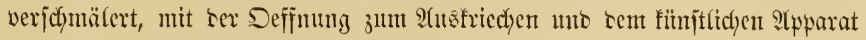

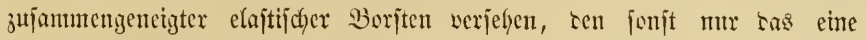
Enbe bejizzt. Das ijt fojon melynuals beobachtet worben*). Der Julter,

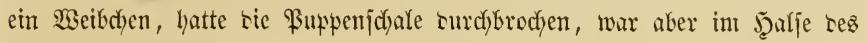
Eocons ftecten geblieben, wo ich in zappelno fant. Er blieb ein Sirïpwel."

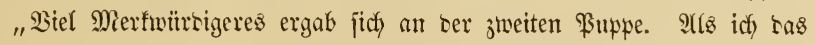
übrigens normal gebilote Eocon zffnete, lag sie \$uppe verfehrt in bem-

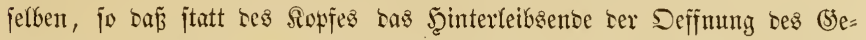
jpinnjtes zugefehrt wax. Die \$uppe jerbjt wax gut gcbiloct uno völlig

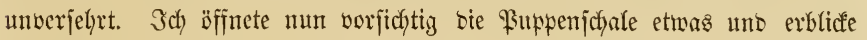

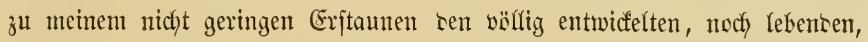
männlichen Falter wieserum in verfef)rter \&age, ben fopf in 2rfterenbe, ben ફ̧interleib in Sorbertheile ser $\mathfrak{B u p p e}$ - Iffes natürlidy fo eng von

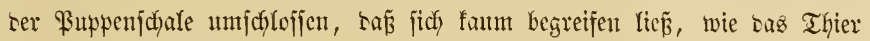

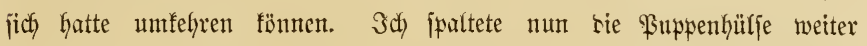
uno ser Sdymetterling frod, in ber Weije hervor, baß er ben Borterleib

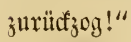

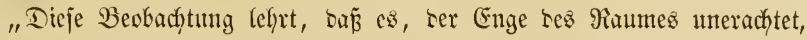
einem Echmetterling nach volfenteter Entwicflung möglich ijt, fich innerbalb

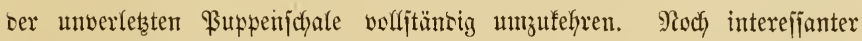
jint bie pindyologijacten Folgerungen, bie jich Laran anfntipfen. $23 a s$ fonnte Den Falter zu einer jo gewaltjamen 2(njtrengung, zu einem bem gewöbulichen Moous res 24tร́fdlïpjens fo ganz zuviserlaufenten Begimnen treiben?

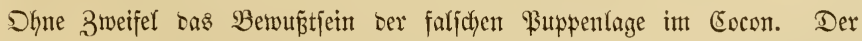

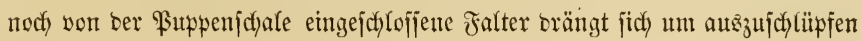

*) Diejer Srrthum, biefe fehlerbafte Fertigung Des Befpinnftes ift einer von ben

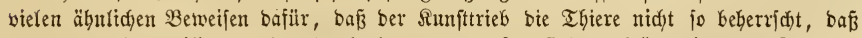
bieje bemjelben willen = uno gebantenlos untermorfen finb. Wäre bies ber Falf, fo fönttent foldhe Srrthïmer nidyt vortommen, benn eit jouveräner als Raturgejets fid) geltentb madjenber Snjtinft fönnte nidyt irren. (Es mup alfo, wenn aud nod) fo eng begrenzt, eine freie Selbftbejtimmung bas Thier bei jeinen Ergengniffen reiten. 


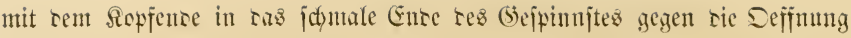
berjelben linein uno iprengt lier erjt ric Sdyale.

Innjer Julter trinf bei biejem Derjuche auf bas gefchlojicte hintere

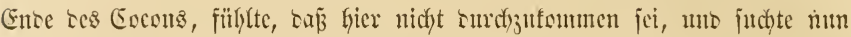

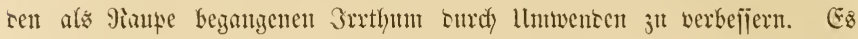

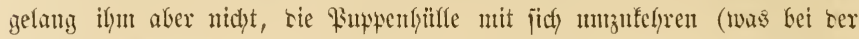

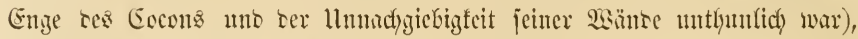

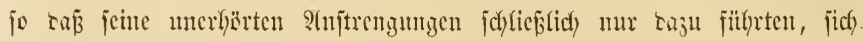
jefbit inmerbalb ser Sdjale hermuzubringen uns taburdy in eime nedh viel hoffuntugstojere Sitnation ju gerathen als vorker. Dent an ein Durd)=

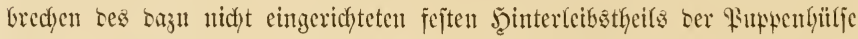
war nicht zu tenfen. So fant idy ifn benn burdy bie viclen ?njtrengungen

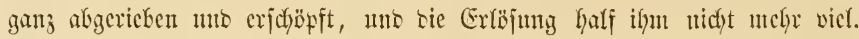

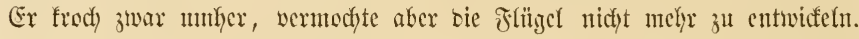
Wir haben lier alpo ein Thier, weldyes surd) eine fejte, mempfintidfe

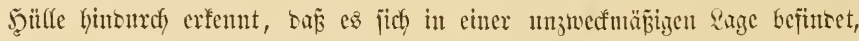

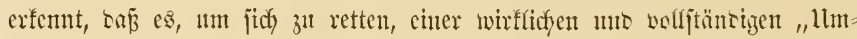
fefyr" bebarf, aber nicht einficytig genug ijt ztt wiffen, saj nicht jere

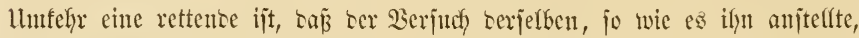

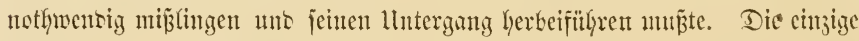

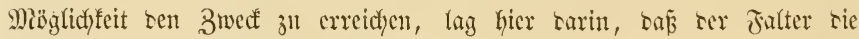

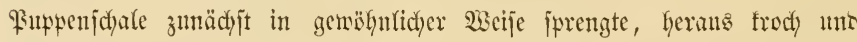

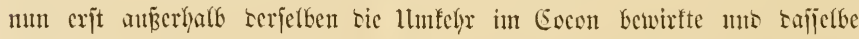

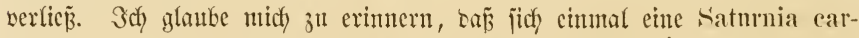

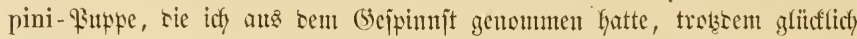

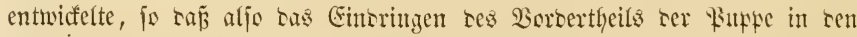

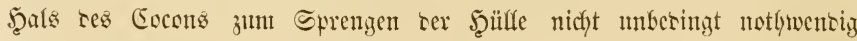

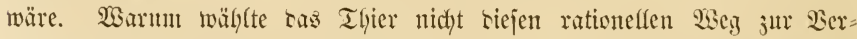

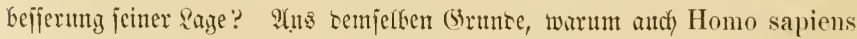
in analogen Fäflen nicht immer feinem Triviafnamen Egre madyt." -

\section{Der volfomume ober Frlicgenzultanto.}

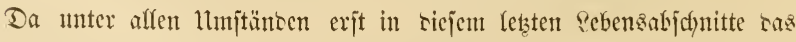
3njeft fortpflanzungeföfig miro, fo fino bie frïheren jufanmengenommen 
als sie Šmgeno 311 betradyten, wetdye fïr bie meijten 3njetten eine viel

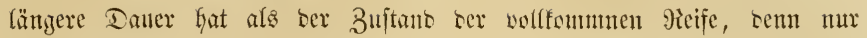

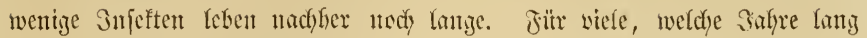

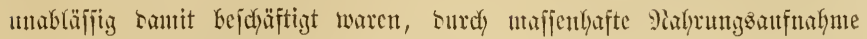

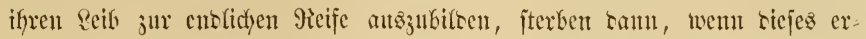
reidyt ijt, fdyen nach wenigen Iagen ober Stmlocn, nadysem fie fïr ben Fortbejtan ifyer $\mathfrak{2}$ rt gewiffenthaft gejorgt, für ifyen eigenen aber nidytz gethan, vielfecicht fiam Piafyrung ju fich genoumen hatten. So tritt ber

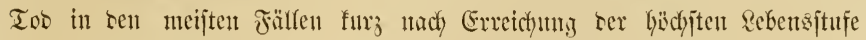

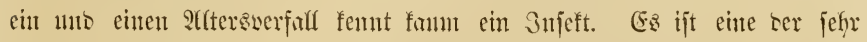

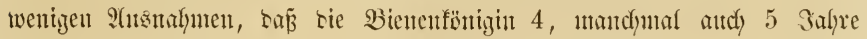
lebt uns, eine edfte santesontutter, ifyen Staat bevölfert.

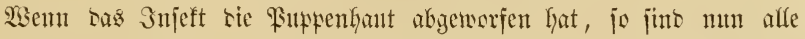

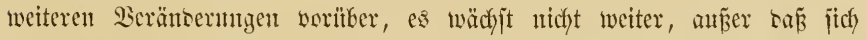
bei ben geflitgelten, was aber mu wenize Mimuten in 9njprutch niumt,

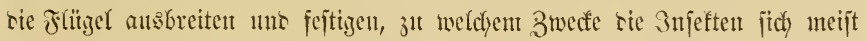
an einex jenfredyten Jlädye nieberlaffen, bamit bie herabhängenton Flitgel

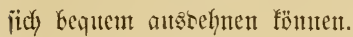

Die Eintagsfficgen, Ephemera, weldye ifyen Namen mit wörtfid) ju nefymentent gied)t tragen, madyen in ber ganzen Elafje bie affeinige 24ts.

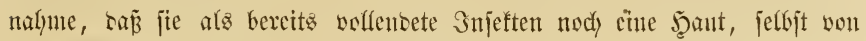

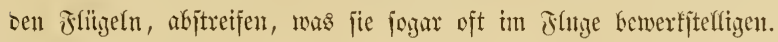

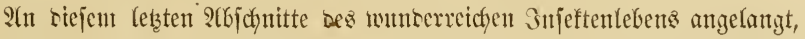

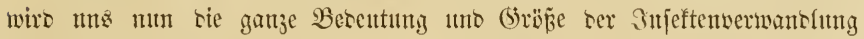
am tiefiten jum Bemuštjein fonmen, wenn wix uns jetzt cine alle Dromungen ser Walcinjeften unifajente Samulung borifteflen nts neben siejer von oenjerben 3njeften eine Sammlung ifrer suppen uns cine sritte von ifren

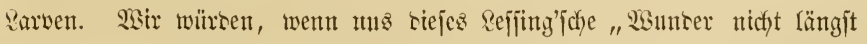
alltäglich) geworten wäre" glauben, Drei Sanmulungen von brei fimmelmeit

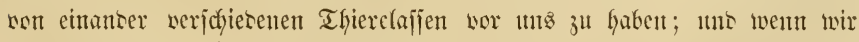
einem Sinte bie trei Sanmultngen neben einanter zeigten, es wïrte jict)

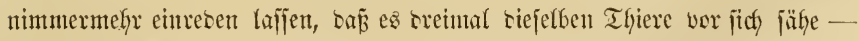

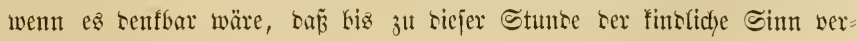
fd)loffen geblieben wäre wor tem, was vor ifm friecht mo fliegt. 


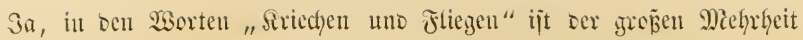

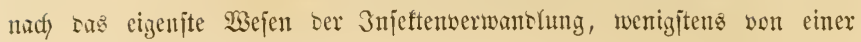

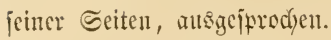

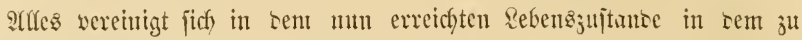
Guncerterlei Mitteln uno Borjergfichfeiten greifenten Bejtreben, sas von affen Seiten berrohte Fortbejtefen jeiner 21rt ju jicfern, uno bie jpäteren

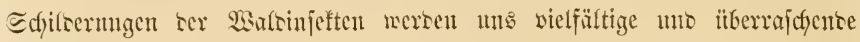

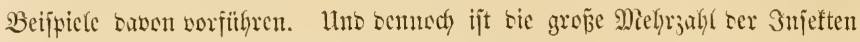

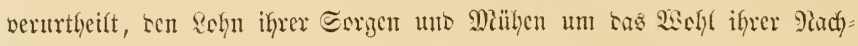

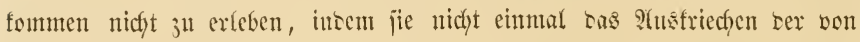

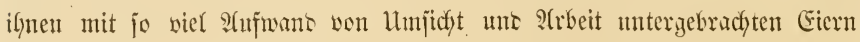

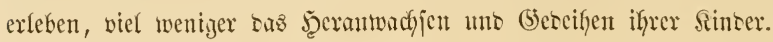

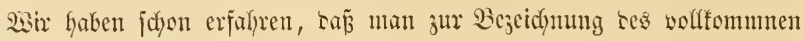
Stantes tas gemeinfune $130 r t$ Fliege fïn afle 3njeften vorgejdylagen hat,

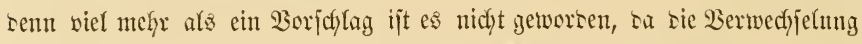
nit ser Stubenflicze won ber allgemenen 2 mnahme abgefalten hat. Fajt

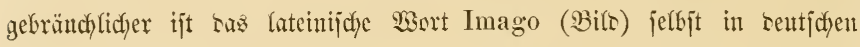

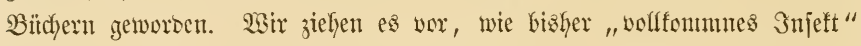

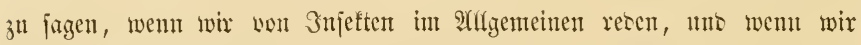
ben vollfommmen 3ujtano ingeno eines bejtimuten Snjefts meinen, ben Drmungšnumen falter, Räfer, Jicige $z$. anzuwenten, Laker 3. B.: ber Sdymetterfing ter soer jener Maupe exjecint im Mcunat Miai zc.

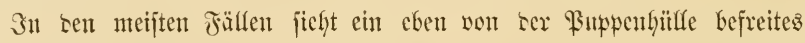

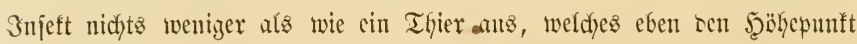
jeines Rebens erreicht hat, wie wir fohon vorhin anreuteten. Wir fommen aber fier nod) cinmal mit einizen Waorten baranf zutrüf, tum nm noch einen Borgang Gerworzhneben, ser einigermapen an sie Farbenerjdyeinumg bei ber Entfultung ciner Brïtle erimnert. Wenn befauntlidy bas Wejen ber Farben nidfyt in Den farbigen Stoffen jelbjt, jontbern in sen von bicjen

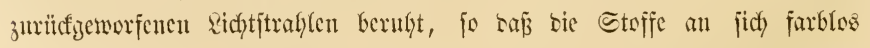

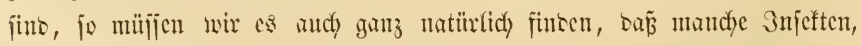

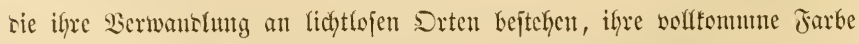
erjt erfauten, nacheen fie an bus sidyt heransgetreten fint. Dies gejehieht jeoody nidft fo pläblidy wie cine Stange Siegeflact roth cridseint, wenn wir jie aนฉ einer finfteren Simmer an bas sidjt heranstragen, fonbern es 
crforbert bies bei viclen Injeften oit nod) eine mehr voer wentiger lange

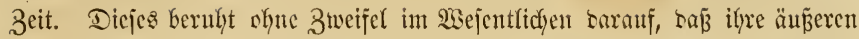

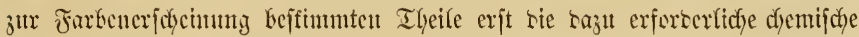

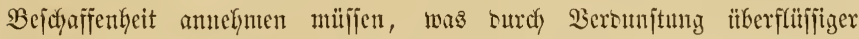

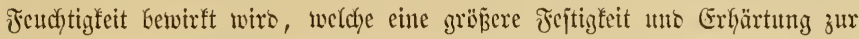
Folge hat. Fajt alle Snjeften oer worfommnen Serwandlung fino nach

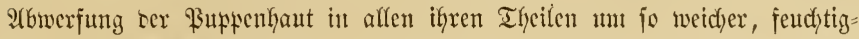

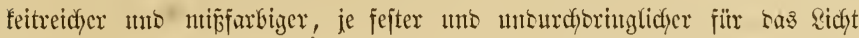

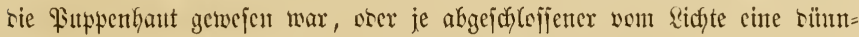
Gäutige \$suppe gelegen hatte. Die aus joldyen Buppen atsfommenten Snjeften bebitrfen mefyr ober meniger langer Zeit, un mit ber Berounjtung

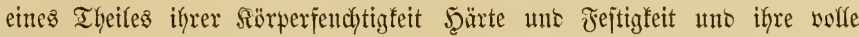
Färbııtı zll exthalten.

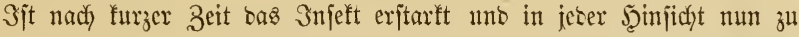

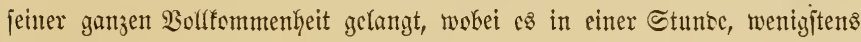
was tie Flügel betrifft, un bas Mefrrfache gräß̄er getworten ju jein jcheint,

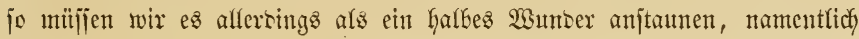

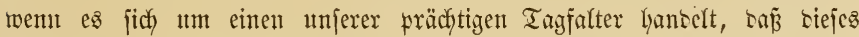

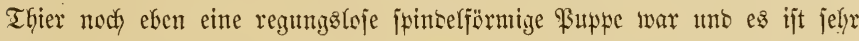

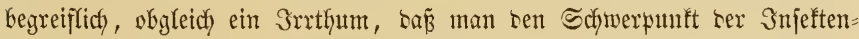

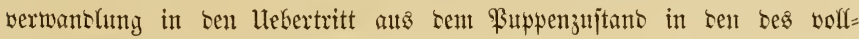
fomminen Injefta gelegt hat.

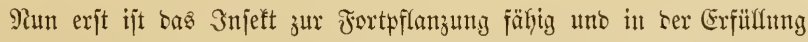
biejer Rebenzaufgabe bejtegt audy bei viclen Injeften beinabe allein sie $\mathfrak{B e}=$ thätigung iGres ignen nur noch übrig bleibenten futżen Rebens, aus bem

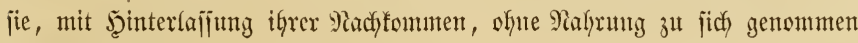
haben, icheiben.

Heber bie (sejtalten ber volffommnen Injeften ctwas zu jagen, ijt hiex

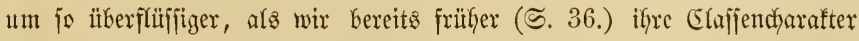
angegeben haben uno im Nadjpolgenoen ourdy Billo uno Wort Bcipiele alfer Dromungen fennen termen werben. Die Stubenffiege uns ser Seget= jalter, ber Şirjafläfer uno die Blattlaus mögen uns als zwei łaare von Form = Extremen sienen, wie jie tanjenbfältig im Peidy ber Snjeften jidy auforängen. 


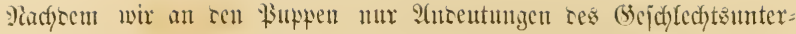
jajietre fanten, begeznen uns nun an ten volfenteten Injeften zuweilen

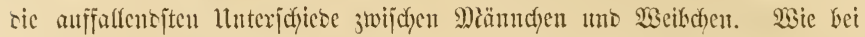

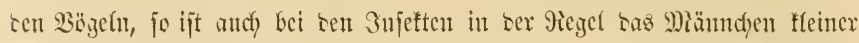
a vorfommen (J̨irfdyfäfer).

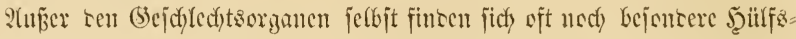

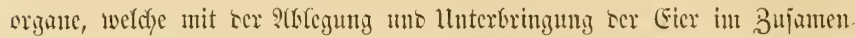

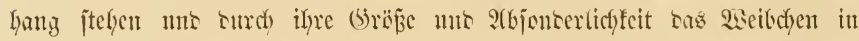

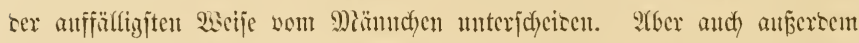
ijt faum cin änzeres Srizan, an weldyen fid) nicht bei cinem obex ben

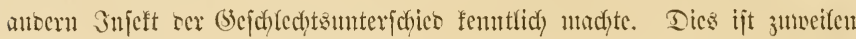

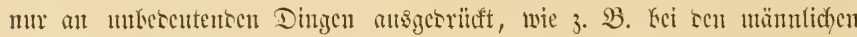

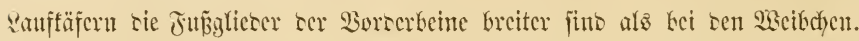

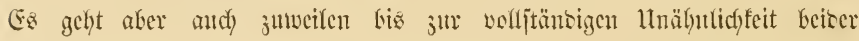

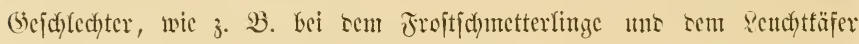
(rem jogenannten Sohantiswïmedyen). Sitcle von uns twerten als Sinaben

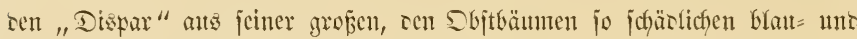

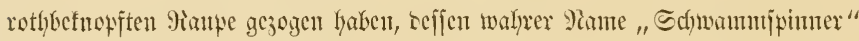
andy in ser Sinaben=9omenflatur sem lateinijđen weidyen mupte, sa Dizpar

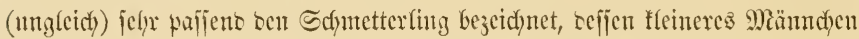

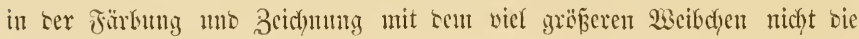

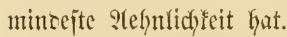

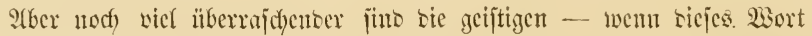

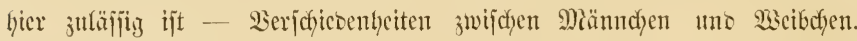
Wer senft bier nidyt junächjt an bie fanlen, ju nidyts weiter als zu bem

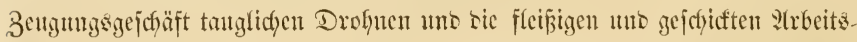

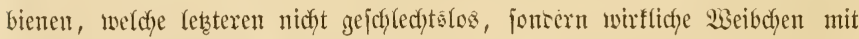
unentrvicfeft Eleibenden Zengımgsorganen finb! Ifn riejem Drte jei mu

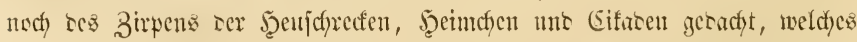

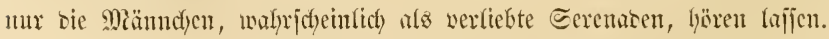

23ir foumen nod cinmal auf bie Sïrze ses Rebens in volffommnen

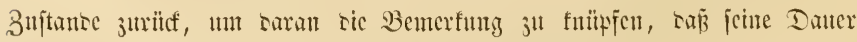
in engiter Bejichunz zun Fortpflanjungsgefchäft jteljt. Sit mit riejem eine

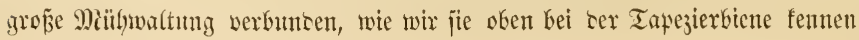


lernten (ฐ. 60), fo fann bie Dauter eine jiemlich lange jein; mto wie

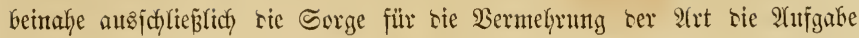

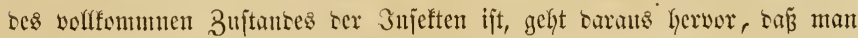
felbjt Eintagsfliegen saburdy zul ciner adjttägigen Rebensoaucr gebrad, hat,

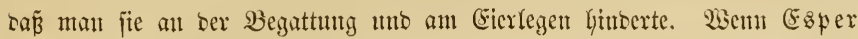

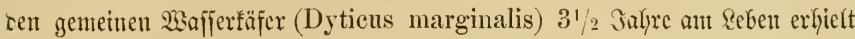

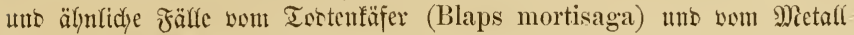
fäfer (Cetonia aurata) befaunt jino, jo warent bies wafyrjucheinlich wor ber Begattung eingefangene Thierc. Dieje Erjoheinnng erinnert an eine äbultiche in Pflanzenretche, ittoem man cinjäfrige \$F̆fanzen, 3. B. bie 9iejebe, taburdy

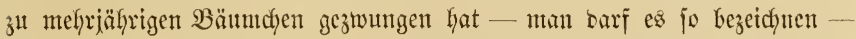

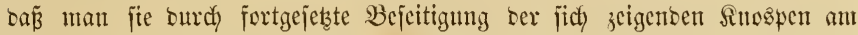
B̧lïhen und Frutchttragen finderte.

So geht ber mädjtige Drang, ber Groe Den belebentent Schnulf zu erhalten, jiegreidy surdy bie ganje Scyöpfung, uno viefleidyt zeigt ex fith

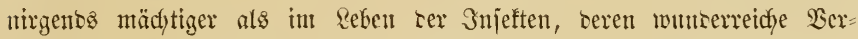

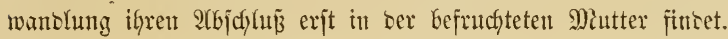




\section{Adjter Xłb/d)nitt.}

\section{Die Malduerderber.}

Wir wollen uns zuerjt mit benjenigen Wartrinjeften unt jwat genau

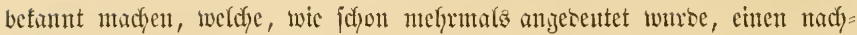

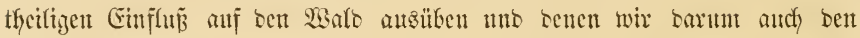

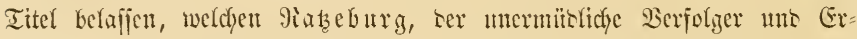

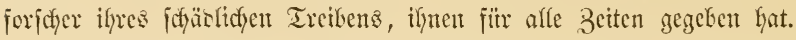

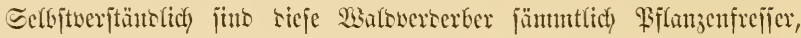
obgleidf ser Echaten, sen fie amridfen weniger sarin beftegt, baj jic uns

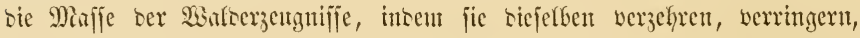

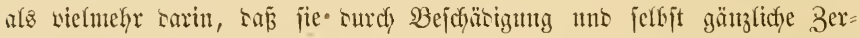
ftörung widjtiger Sebensorgane ber Bäıme seren Reben berrofjen, uno jelbjt

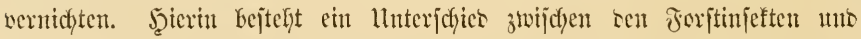

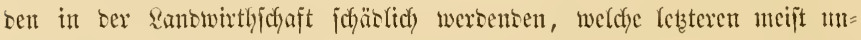
mittelbar ben Felbertrag je(bit fdymälern unb biejen jogar bis anf bie Spectyer verjolgen ( (ormwum).

Bei ser 23idftigfeit ser Walsungen, nicht nur ifyer Proonfte, fontorn

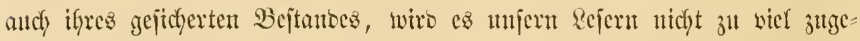
muthet fein, wenn wits fie anfforbern, fidf mit uns cimmal anf ben Stans=

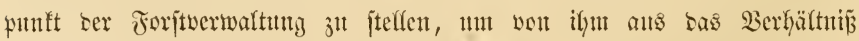

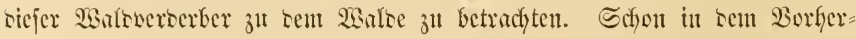

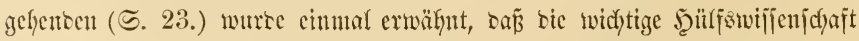

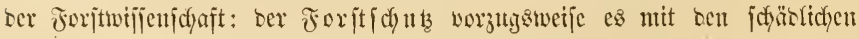

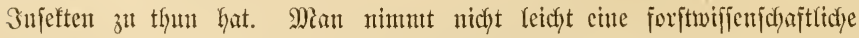

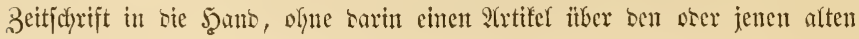


Erbfeino bes Baumlebens orer jerbjt über einen net Ginzugefomntenent Warbwerberber ju finten. Dicje Seite ber praftijdyen Boologie ijt jogar nidyt ofne rebraft bejprodjene Streitfragen, mter benen biejenige lange 3eit cinen Kciñen Sampf herborrief, ob ber Borfenfäfer nur franfe, affo olgnefin bem Tobe verfaflene, ober auch gejunte Fidjten befalfe.

Wer von unjern ecjern "ben Waalo" gelejen hat, weldyem tas vor=

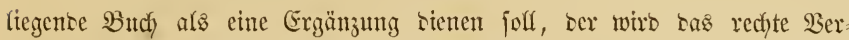
ftänbniç für bas Madjfolgenbe mitgebradjt haben, benn ex hat baraus sen Beruf ses Foritmannes höber auffaffen ute beutgeilen gelernt, als es ge= mölnutich geidyieht.

Die an ben angefïhrten Srte (ธ. 24) alz Seele eiter guten Forit =

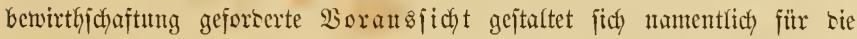

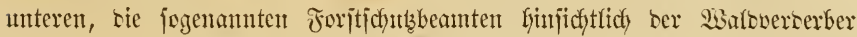

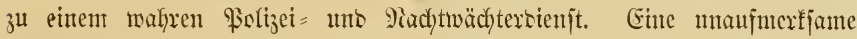

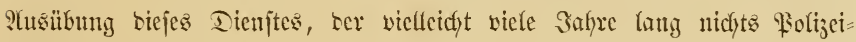

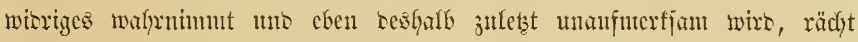

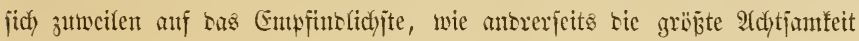

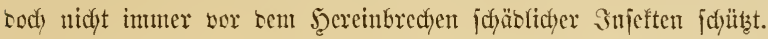

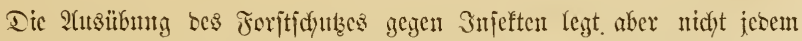

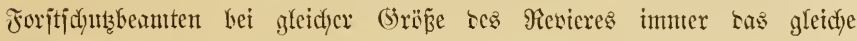

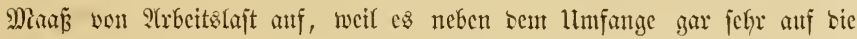
Beidyaffentheit tes Revicrs anfount. Sdyon fritfer (ङ. 24) erfutflen wir,

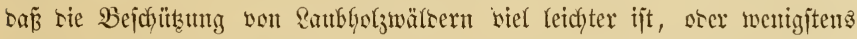

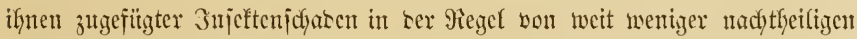
Folgen begleitet ijt als es in ben Tabetwaltungen ber Fafl ijt, weil tas

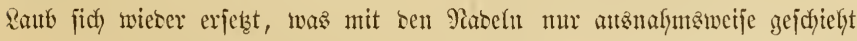
unb saher eine bölfige Entrabchung in ber Reget ben Too bes Baumes zutr Folge hat.

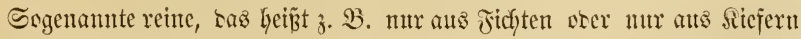

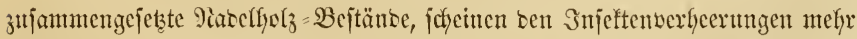

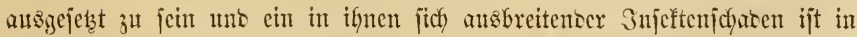

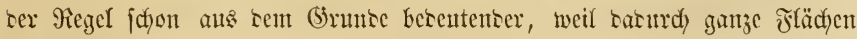

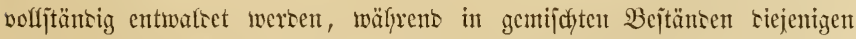

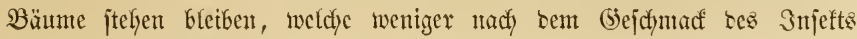




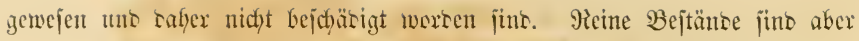

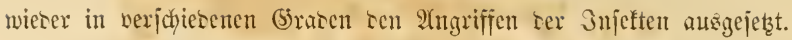

Dabei fpieft wenigitens in 3eiten bes Waffenjtillitantes - tenn is

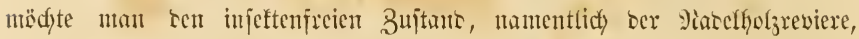

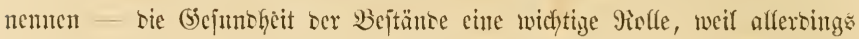
in gejunser sage, auf gntem gut berecften Bosen jtefsense gejutre Bejtänse menizer in Sejably fino, won 3njeften angegrifïen zu werten als antere.

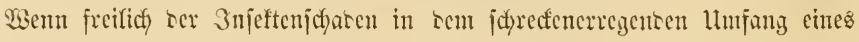

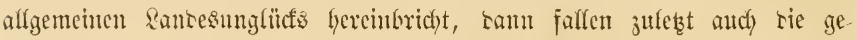
jüntẹten Bejtänce.

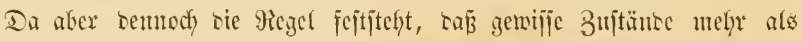

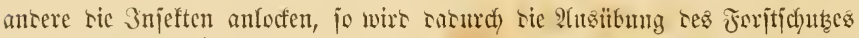

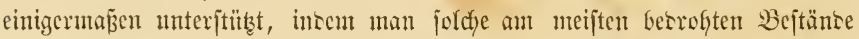

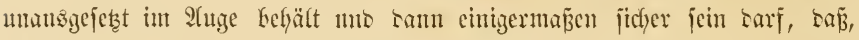

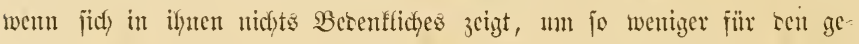

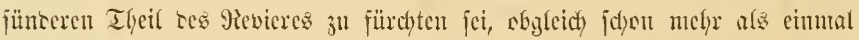

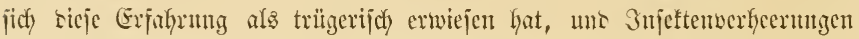

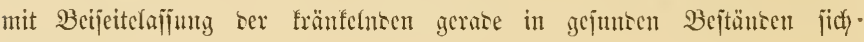
entipannen.

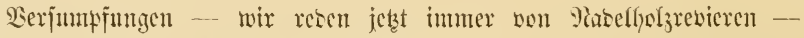

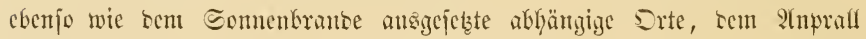

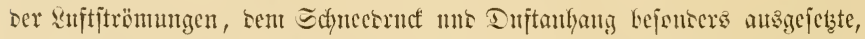

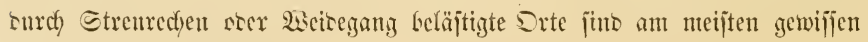
Walowerterbern anzigejetzt.

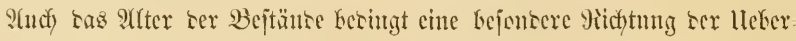
wachung, sem mandye Injeften jiehen gewijie 2(tterselafien ror unt sie Sulturen mo jutigen Diffichte haben bejentere Feinte.

Der Winterndy Gat in Parelfolzrevieren immer cin lleberbantonefyuen

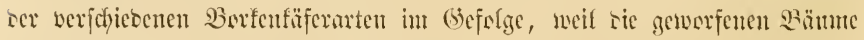

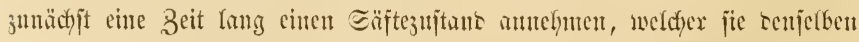

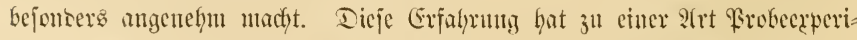
ment gefülfrt. Sn 3eiten ober an Srten, weldye ju ter Bejorgniž cimer

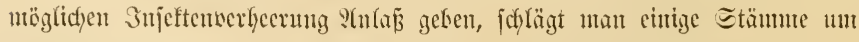

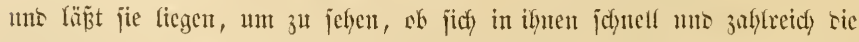

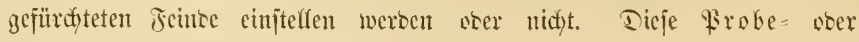




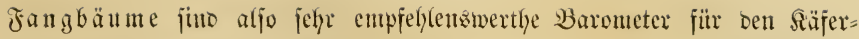

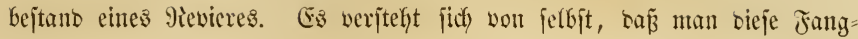

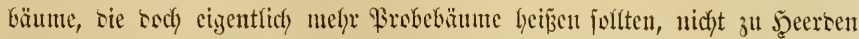
werben lǟ̧t, won senen aแร fich bie säfer

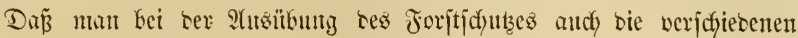

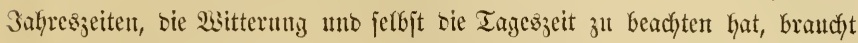
faum hervorgefobeu ju werten. Dies jetzt voraus, baj ber Schubzbeante

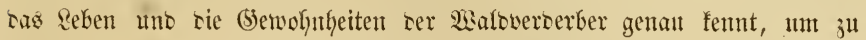
wijfen, wann uno wo ex cinte joldyen im $\quad F i=$, Rarven $=$, Fuppen $=$ ober

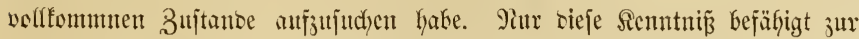

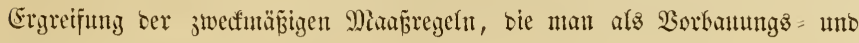

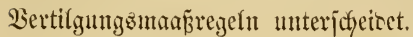

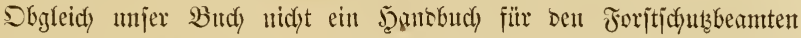
fein wifl, jo will es body ein juldjes wenigitens injoweit mit jein, alo sarin affe entjujecen jorjtjdyäblidyen 3njeften gejdjifert werben joffen, uno

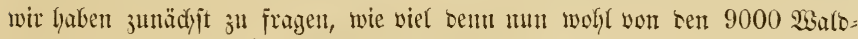
injeften (5. 32) wir als Walowerberber in Sinne bes Foritichntues ju betrachten haben.

Die Jrage ijt nidyt jo leidyt ju beantworten, แno ев geht

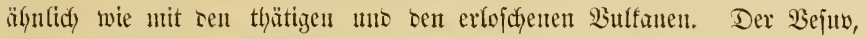
ber in $3 a$ lyre 79 Fompeji veridjüttete, galt Damals fïr einen erlojchenen Sulfan. Sn ber Ifyat hat jid) jeit ben letzten 30 Jafyren, feitben wir

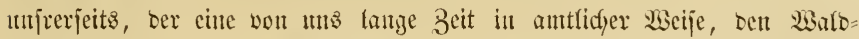

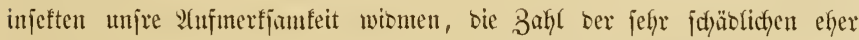

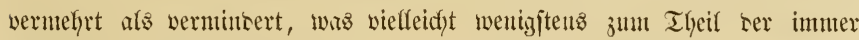
allgenteiner gewortenen Erjiehnung reiner Bejtänte juzuja)reiben ijt.

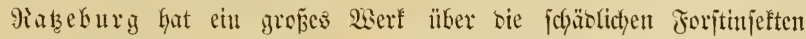
in brei Duartbänben gefdrieben, bei sejjen Durd)blättern Einem für ben

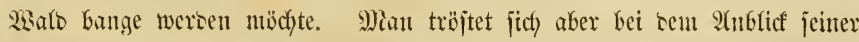

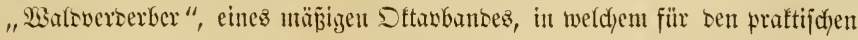
Bebarf bes Sifutzbeanten nur bicjentigen 2 trten angenonmen finto, weldye

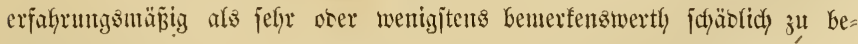
trachten jits. 


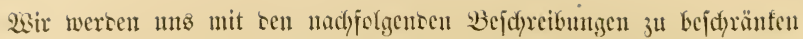

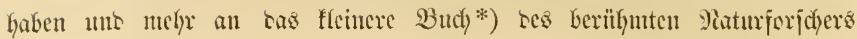
anjchlię̧ent.

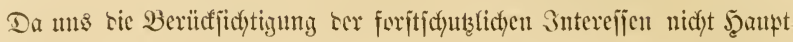

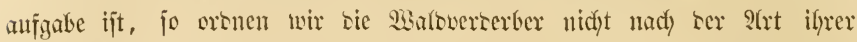
Schäelicyfeit, jonbern nach sen 3njeftenorbunngen uns innerlyalb sicjer

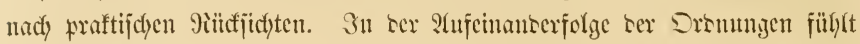
man fid) faum becngt, insem sicjelfen nicht in sem (brabe, wie ca bei

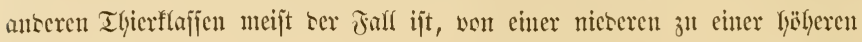
Stufe anfiteigen, fonbern int (5sumse gensmmen alfe von cinem ziemlids)

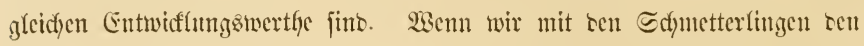

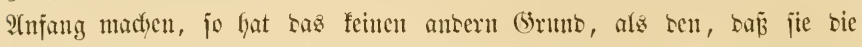
vieblinge von aller Sieft jinb, cin Sorzug, sen freilicty bie num folgenten an wenigiten verbienen.

\section{A. Sthmetterlinge.}

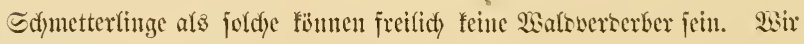

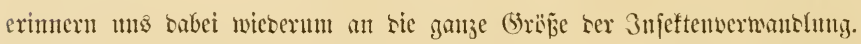

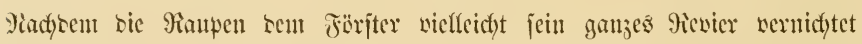

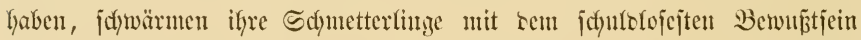

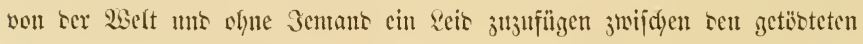

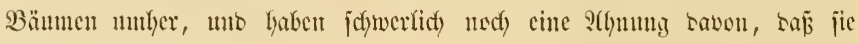
bie llebeltgäter finto uno jidf jelbjt ilyr grïncs enjtrevier wernidgtet haben.

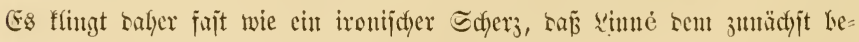

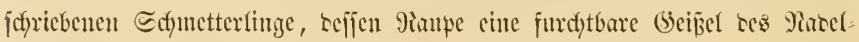
watres ijt, sen Mamen ber Gnj̈fertigen "Yionne" gegeben hat.

Dic uns f(c)on befannte natïr(id)e Bejectränfung vieler 3njeften anf

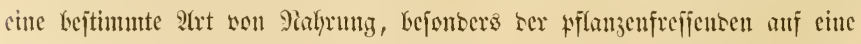

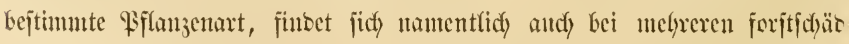

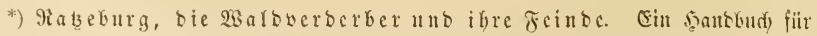

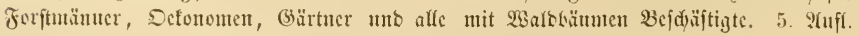

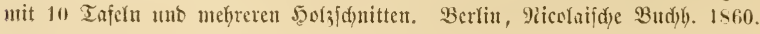




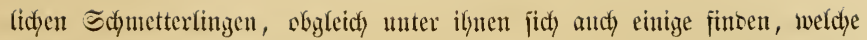
fierin jiemfich unbejuränft jinb uno baher nach ben verichiebenjten Seiten hin verberblich werben.

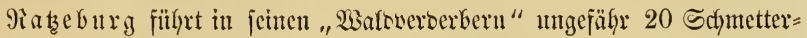
lingsarten auf, cine 3ahl, weldye aud wahricheiulidy, wenigitens hoffentfich

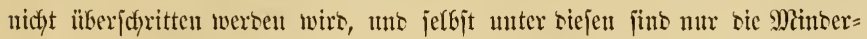

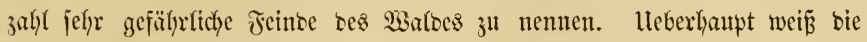

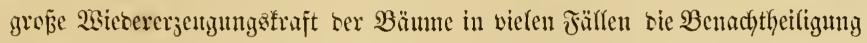

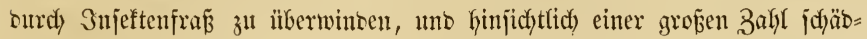

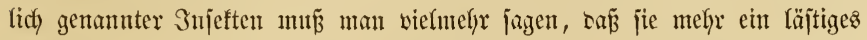

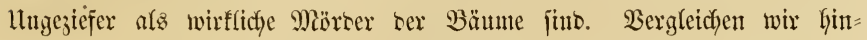

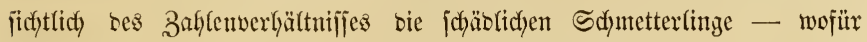
wir cigentfich immer bejtimuter Saupen jagen jollten - mit anberen jodäb=

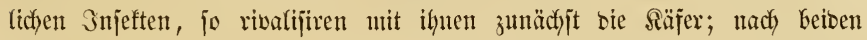

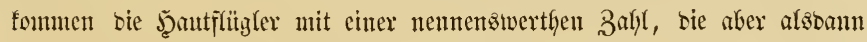

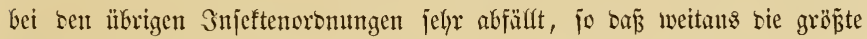
Zahl ber Waltweroerber ben orei genannten 3njeftenorbmungen zufällt.

Ege wir bie Schmetterlinge unter ben $\mathfrak{B a l b w e r b e r b e r n ~ e i n z e l n ~ b e t r a c h t e n , ~}$

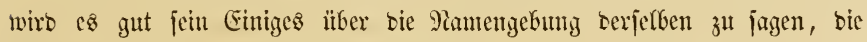

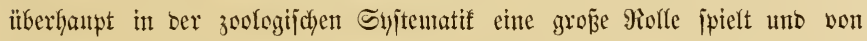
Soldfen, weldye nidyt ticjer in bie Wijienjuguft einbringen wollen, jebre oft

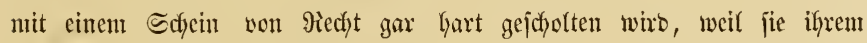

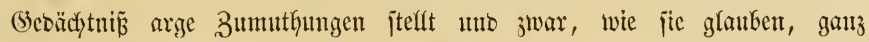
olyue Misth.

Das Miadjplgenbe gilt zum Theil ganz allgemein won ben Thieren ïberhaupt uno zwar von ben nieseren fajt nod' mehr als won ren wirbel= thierent.

23er von unjeren Ecjern nur nach einem beralteten 3 tudje ober in jeiner jefy weit zuridffiegenten Simbheit Schmettertinge gefangen unt ge=

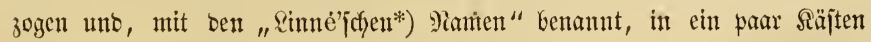

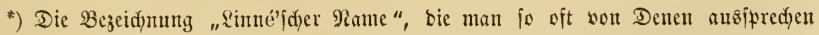
bört, weldye ber Satumiffenid)aft fern ftehen, veranlaß̧t uns zu einer fleinen Erläuterung.

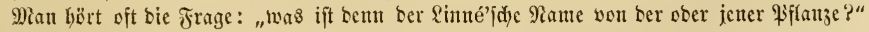
obgleich bieje vielfeidst erjt ganz nenerlidy entbedt worben ift, aljo Qiuné nod) ganz un=

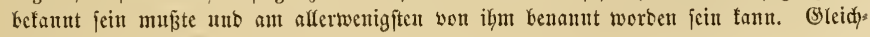


jujammengejtedt hat, ser hat es mur nit wenizen (5attumgsnamen zu thum gehabt. Simté, ber groje Erfinder ocr naturgejuidftictsen Viamengebung,

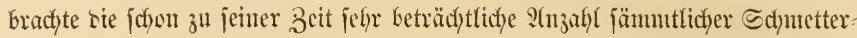
linge in nur 3 grop̌e (5attungen: Papilio, Sphinx uno Phalaena, uno theilte die letztere in sie llntergattungen Bombyx, Noctua, Geometra, Tortrix, Tinea, Pyralis ıno Alucita. Segemuärtig jün tarans, zแnächjt

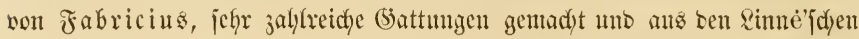

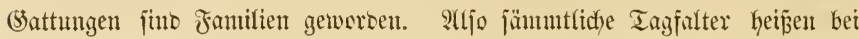
Rimé Papilio, z. B. P. Athalia, P. Latonia, P. Cardui, P. Populi, P. Machaon, währent bieje fünf 2hrten jeşt ju sen 5 (5attungen Melitaea, Argymnis, Vanessa, Limenitis gchüren mo mur sie leţte Papilio ge=

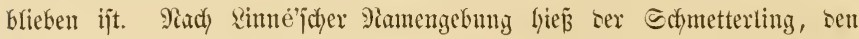
mir sen Meigen ber Waltwerterber exöfinen lajien wollen, Phalaeua Bom-

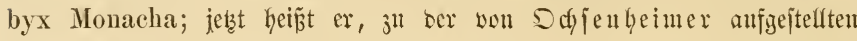
(5attuny Liparis gegogen, Liparis Monacha, inom bie alte Simuéłche (5attung Phalaena ju einer Familienbenenmung fïr bie Spinner, Phalae-

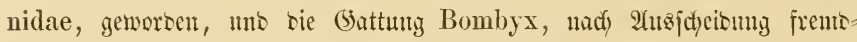
artiger Elemente, anf ten Seitenfinmer, B. Mori, bejdyränft morben ijt.

Diefe Revolution in Ser Mamengebung hat alfersings ben ltebelitano

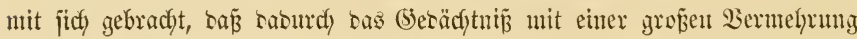

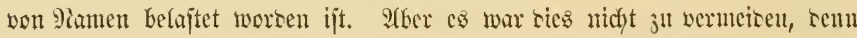

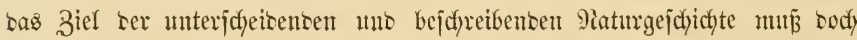
immer bahin gehen, nux Das wirflid) als werwant 3ujammengehörige

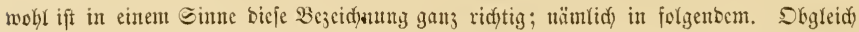

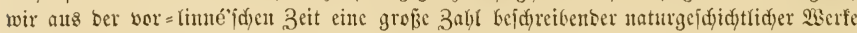

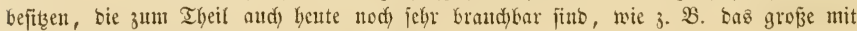

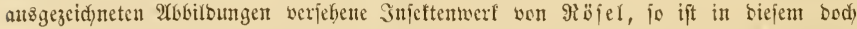
tein Thier, feine Piflanze mit einem Keftimmten unter fdeibenben Ramen berfeken, fonbern

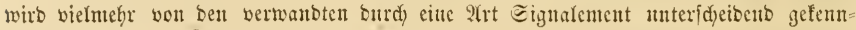
jeidyet. Misjel bat jür bie Sdymetterfinge nod) feine ansern bejeidjungen, als inbem er beren Faupen furj d)arafterifitt; io nent er 3 . B. Den Ed)walbenjowanj, Papilio Nachaon: "bie eimfante, jd)öne, grïne Fendjelraupe mit jdmarzen Duerftreifen, and) rotben Flectein." Das ift natïllidy meniger ein Rame als cine llmid)reifung. (Da

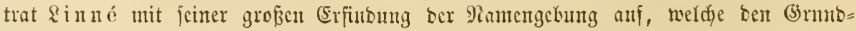

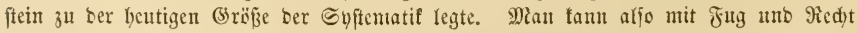
bie hentigen, weil nad ber \&innéfdjen Erfintung feftgeftellten, Mamen ber Ihtere unt

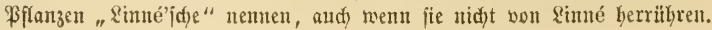


unter einen gemeinjamen Mamen jujammenzujafien uno bas llnverwante burd) befontere Benenmmgen von einanter jut untericheiben.

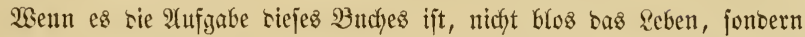

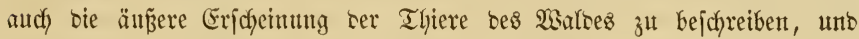

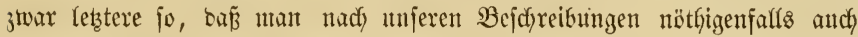

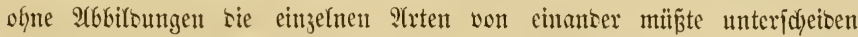

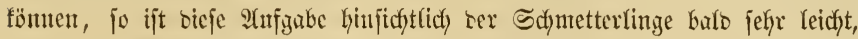

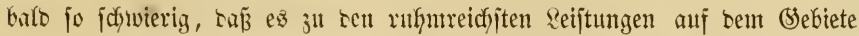

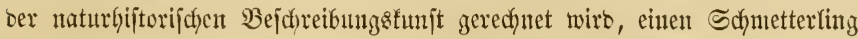

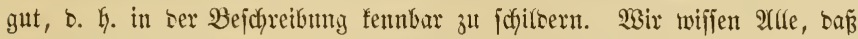
bie meijten Tagfurter wegen ifrer bejtimmten mo ficharjen Farbenwertheilung

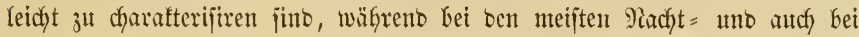
vielen Dänmerungsfaltern zas (Segentypel ber Fall ijt. Bei vielen 2lrten, namentlich atts ber Fumilic ser Euten, Poctuen, bie bei einer felyr wenig marfirten 3eichnung einanber jefyr äfultich jutro, ift es beinabe eben po

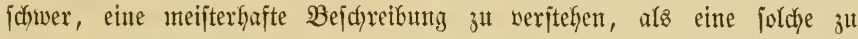

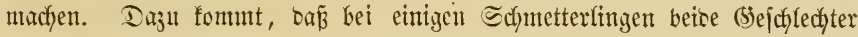

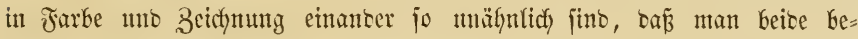

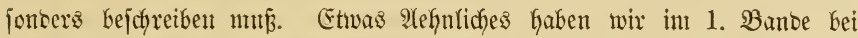
Den $23 a$ ats gitgnern uno sen Falfen exfalyten.

Bergleidjt man bie Schutterlinge bes heiß̈en Erogïrtels mit unjern

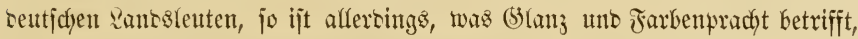
ser Borrang fehr auj Seiten ber exiferen, wie biez ja itberfantpt bie Regel bei ben tropifdyen Tfieren แnto Pfilanzen ijt. AfGer - man gejtatte unz

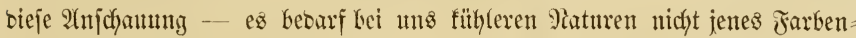
fpeftafels, un unjer 23 ohlgefallen zu erregen. Unjere ganze Thier = 4tto

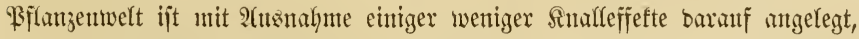
bie Ilrtheile mnjeres (5ejchmacfes zu vertiefen, mo babei verfieren twir nidftz, wir gewinnen biefmebr, wir getwinnen uns jelbjt, unjer 2 ejen, weldjes

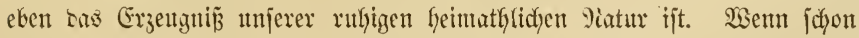

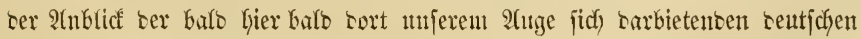
Falter uns erfiett, fo werlangen wir Den jul jehen, ber shne Bewuncerung irgent einen, ben eriten bejten finten einer geortneten Sammlung betradfen

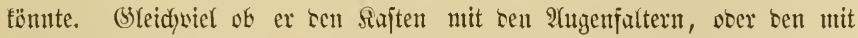

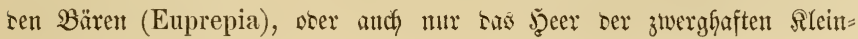


fdymetterlinge ergriffen habe, ober tie Srtensbänter (Catocala) ober jumal

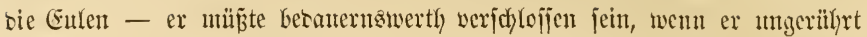

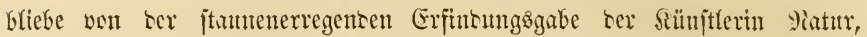
welche einem fodficyten Mistiv treu bleibeno mit geringen Mitteln cine Fülle von Stubien zut bidften weif́. Da crfennen wix in ben 4 grofien flachen

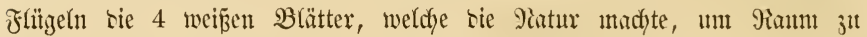

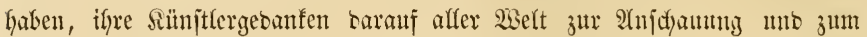

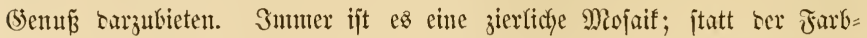
jteindyen jehen wir mifroffopijche Feberjchüppdyen, ser jarblojen Flügelfant

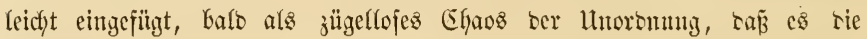

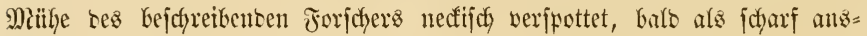
geprägtes Form $=$ mo Farbenbilo.

Wenn ber Bejizzer einer wohlgeorbneten Sdjmetterlingsfammlung von ben Sorgen uno Më̈fen bes Berufes ermübet ben inneren Frieben bcs Bergejfens jutht, fo fincet ex ifn unferblbar, inbem er jich cin Stünodyen

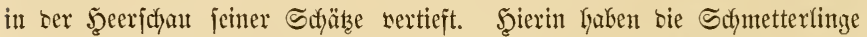
einen entiffiebenen $\mathfrak{B o r z}$ th, ber noch won ber geringen Softjpieligfeit ber Erwerbung unteriftüzt wirb; benn nidyt blos bie Sdyönfeit, ja weniger als sieje ijt es bie exfindungercidfe Miandjartigfeit, was แns alts bem wor

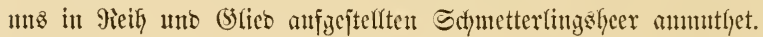

\section{Die Monne, Liparis monacha (Ph. B.) $\left.\mathbf{L}_{\circ}{ }^{*}\right)$}

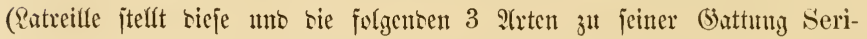
caria, Jranz von Paula Schenf zu jemer (5attung Laria).

Bon ben 8 emropäiffen 2 rten ber (5attung Liparis fint 5 ben

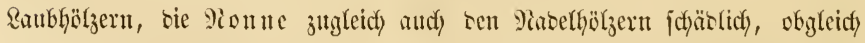

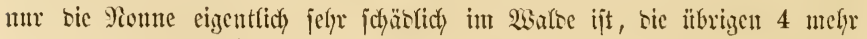

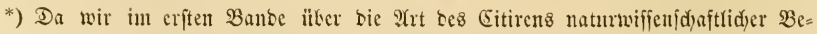
neunungen nidjts gejagt baken, wir aber annebuen bürfen, Бaß̧ unter urjern \&ejern aud) foldbe fein werben, bie mit ben Gebräudjen ber natumiffenidyaftlidsen Syftematif

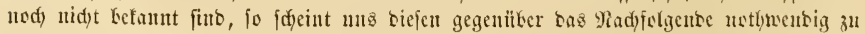

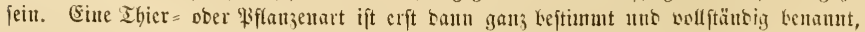

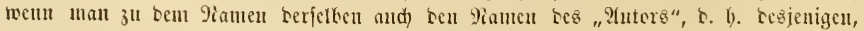
melder ienen Ramen gegeben bat, in einer 2lbfïrumy binjufïgt. Daber werben ujere 


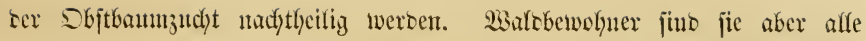

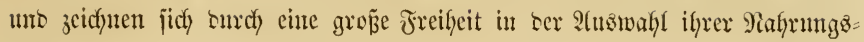

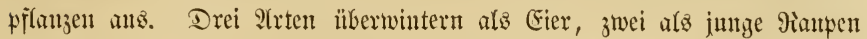
unt baben jäfrefict) mur eine (Stentration. Shre, wem and) nidyt eigentlidy

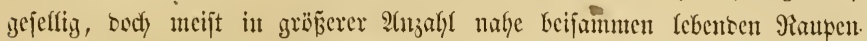

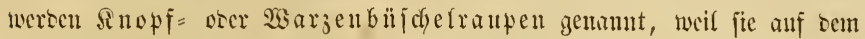

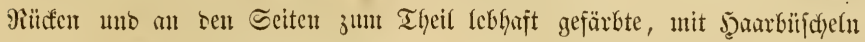
vcriehene, fnopfartige $23 a r z e n$ trajen. Shre bunfelgefärbten, oft metallijd)

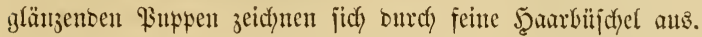

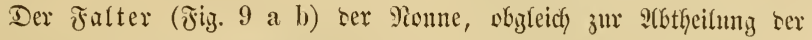

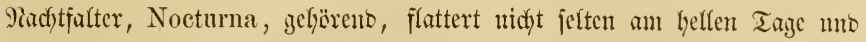
ähnelt auch in jeiner zanzen Erjofycinung cinigermajen mantyen Tagfaltern, obgleich ifym sas charafteriftijeye Merfmal ber letzteren abgeht, in ber 9itulye

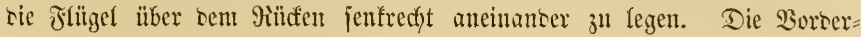

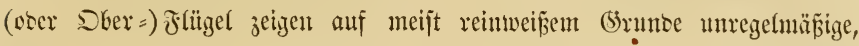

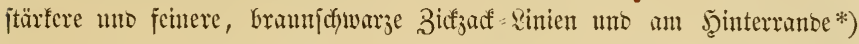

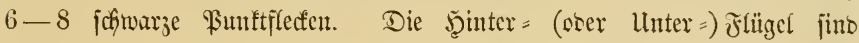

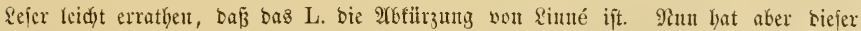
wic wir jdon miffen, ben Sdymetterling nid)t Liparis, jonbern Phalaena Bombyx

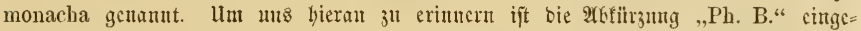

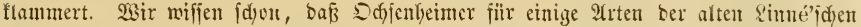
Gattung Ph. Bombyx bie (5attung Liparis gegritmbet lyat, zu benen aud) monacha gehört. Sagt mant mut aber Liparis monacha $D$ dfi., fo fagt man cine llumalurbeit,

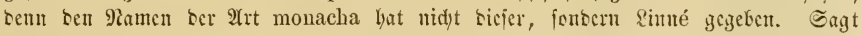
man Liparis monacha L., jo ijt bus wicber unrid)tig, weif sic (5) attung Liparis von Sdjenbeimer benamt ijt. Da es aber mu Bejetz ber Frivrität in ber Ramengefung

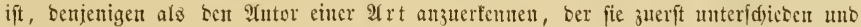

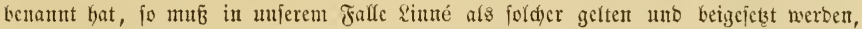

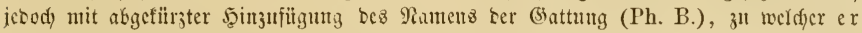

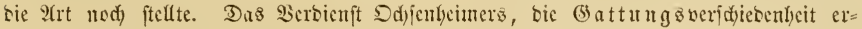
fannt jul baben, barf nidyt bei ben 2 rteu zul Geltung foumen, fonbern bei ben (5)attugeu. Mau jagt baber 3. 2 . bic Gattug, ju weldyer sie $\mathfrak{A} r$ monacha gchört, ift Liparis Ochsenh. Diez fdyeint unz, wenigftens bem llnterzeidjucten, bie allein

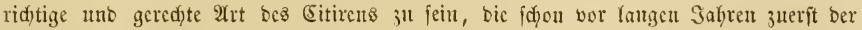
Botanifer 2 . Reidycubad) bejolgte.

$\Re$.

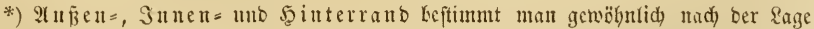

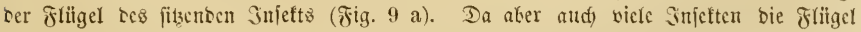
wie Fig. 9 b tragen ober bicic für bic Sammlung io ausgefpant werben, fo ment man

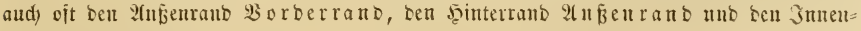
ramb feinterrand. 


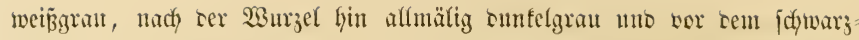
geflecten J̧interrante mit ciner granen unt bentficlyen Flecten = Binte.

Fig. 9.

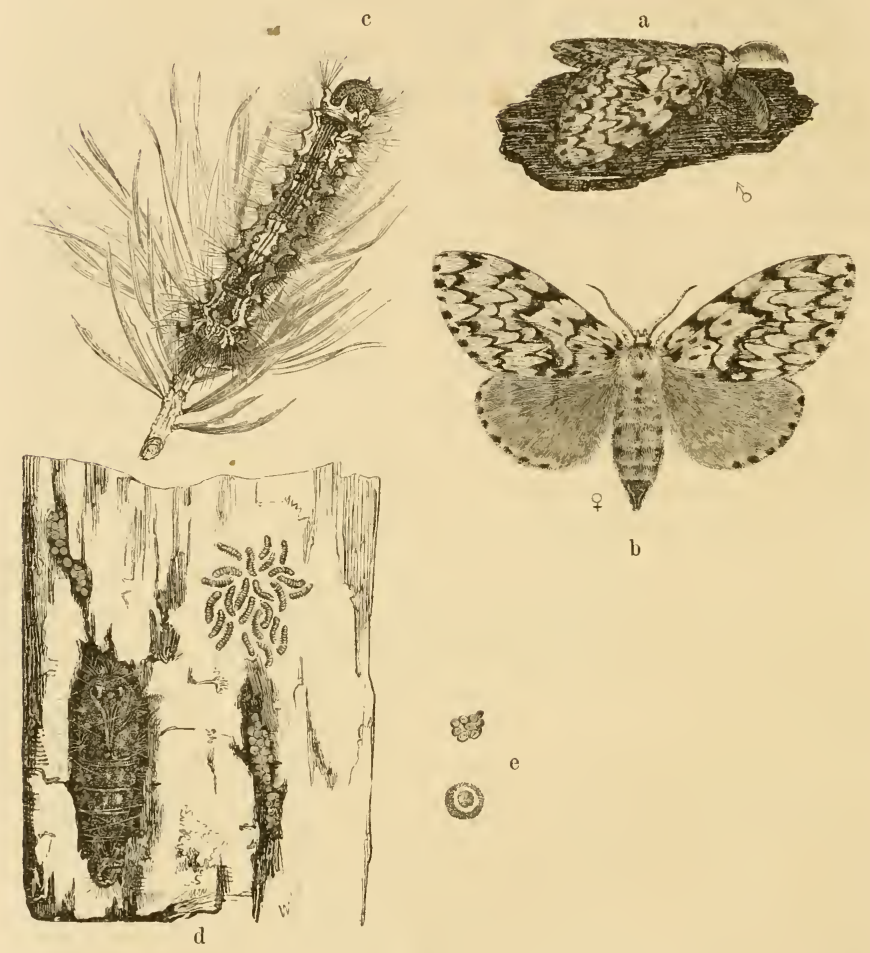

Die Nonue, Liparis monacha (Ph. B.) L.
a. männlidjer, b. meiflidyer હ̃d)metterling.
c. Mautip.

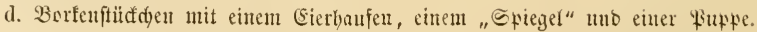

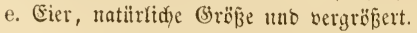

Dieje 3eidfuntng fiubet jid) je(ten bei 2 Exemplaren ganı übereinjtimmeno

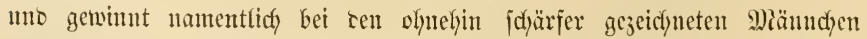

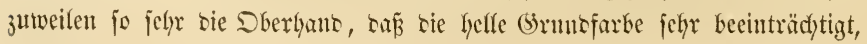


ja fajt ganz verträngt wiro. Die llnterjeite zeigt bie fdywarze Zeichnung Ler Sberflïgel meijt verwajdener, bie ber Interflügel sagegen oft bejtimmter.

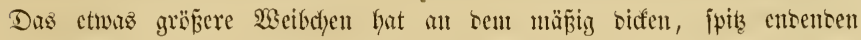

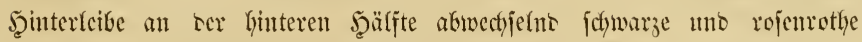

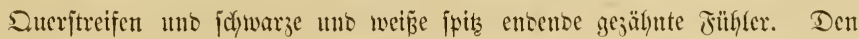

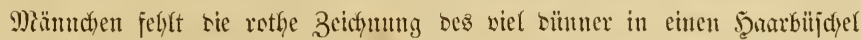

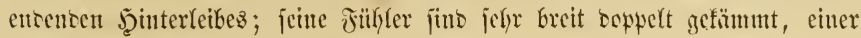
Jeocrfafne äbntich.

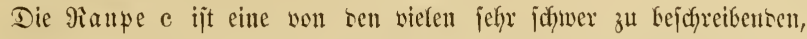

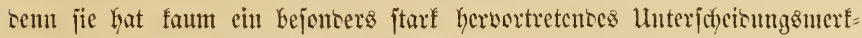
mal; fie wiro gegen 23 . Lang, hat 16 Fitipe (6 redite uno 10 Ifter:

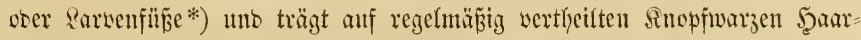

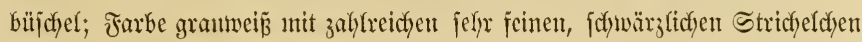

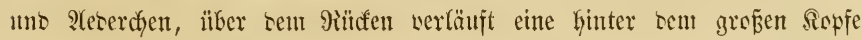
mit cinem fajt jammtichwarjen Fleaf beginnente Binbe, sic finter ber

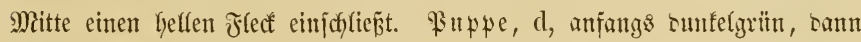

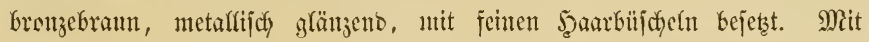
einigen wenigen Coconfübent in sen Borfenrijjen befepitigt. (Eier, d, etwaz

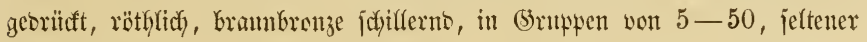
biz 150 in sen Rinbenriffen verborgen.

Der Sdymetterling fliegt je nath ber Wärme Enbe ober stufang

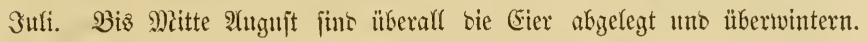

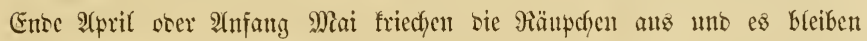
einige 3eit $(1-6$ Iage, je nady ser Witterung) bie aus cinter Eiergruppe fitammenten in fleiten Beferfichaften, bie man Spiegel genannt hat, in

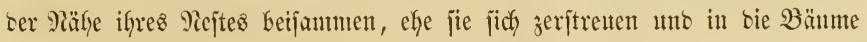
emporifeigen (baumen). Sn Suni ober Sult fint sic 9iaupen auszewadjen

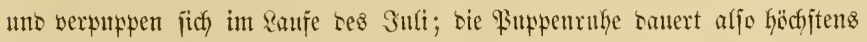

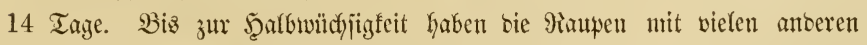
rie (Serwohnheit jith an Fäben herabzulaijen, wenn fie belïftigt werben.

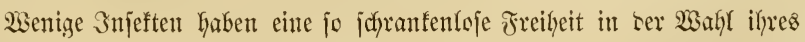

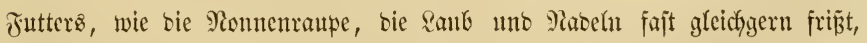

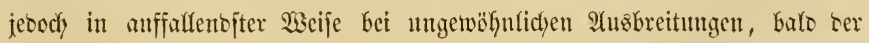

*) ธ. ธ. 51 . 


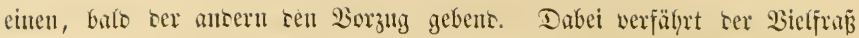
ned) obentrein mit unnïzer Serjdyentung. Mamentlidy bou ten Mareln

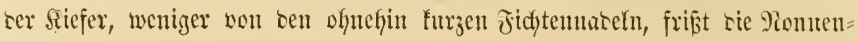

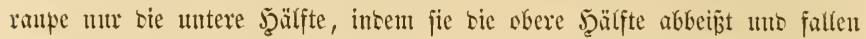

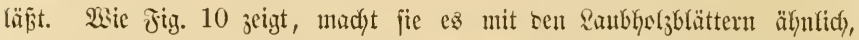
intem jie รas Blatt ganz ober wenigitens grop̃entheils abjanteibet mo meijt foit nutr ben Blattitiel friēt*). Dafer verrathen aun Boben liegente frijctye

รig. 10.
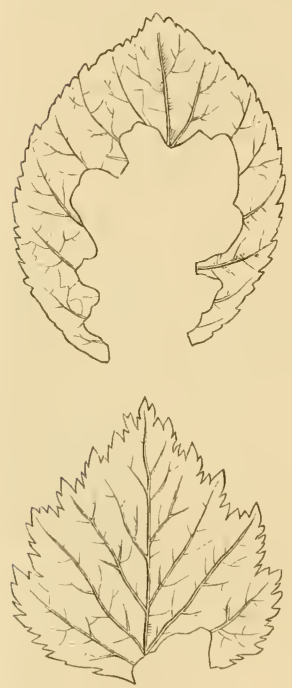

Durd) bic Ronnemraute ab= geid)uittene mo berabgefallene Blätter. jtiefloje Blätter ober frijd) Nareljpizen bie $\mathfrak{A} 11=$ wejenkeit von Mionnemranen in ren Wipfeln. Dies ift eines ton ben Merfjeidjen, auf weldye ser sen Forjtiduts ausubente Forftnann immer jein SGugemmerf riçten mun.

Sm letzten Gafjzebent hat jidy bie Siome weit über sen Borfenfäjer no bie grof̌e Siten raupe finans zn rem Mange tes mädytigiten Waltwerwijters cmporgejdumngen. Sone beiren

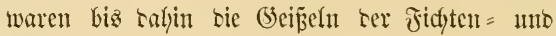
ber Siefermmebiere, uno in letzeren ftanto erjt an sritter Stelle bie 9onnte. Dies ijt mun anters geworben uns man tarf jagen, baj mit rem Salyre 1852, orer vielfeidyt tod einige Gafjre früber, für ten $\mathfrak{W a l}$ cine "thelte $\mathfrak{Y}$ (era" be= gonnen Gat. $\mathfrak{B i s}$ Ealyin muţte man faum bon

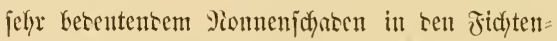
revieren, wälyrento numentlidy einige pommerictye Siefermetere cin Sies bawon jull jingen hatten, woriiber 1828 bïlow-giteth beridytete.

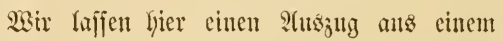
officiclen Beridyte tea Frofefior Wirffomm in Tharanto folgen, ber in Saljrgange 1864 bes

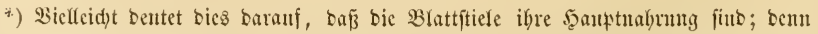
ba eine ficfermaber in iffer ganjen \&änge von gleidjem (Sejd)utad ift, fo ift nidjt redjt

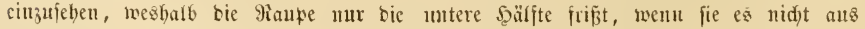
med)anifder (5emolntheit won ben Blattitielen her thut, bie woht anbers fdjmeden mögen als sie Blätter jelbft. 


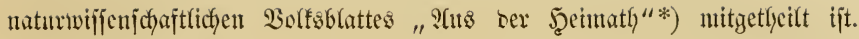

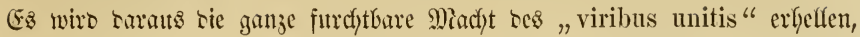

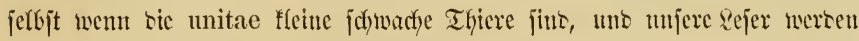

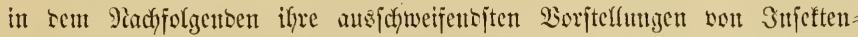

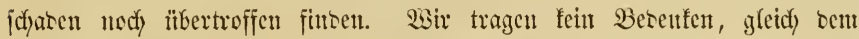

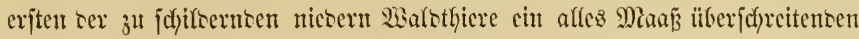

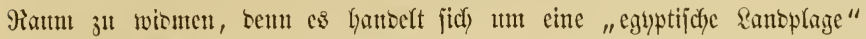
Der Menjeit.

"Da rie Ranbfg̈lzer bie vertorenen Blätter wieber erjetzen fönnen, jo

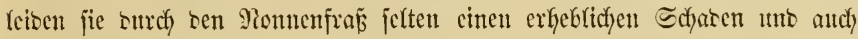

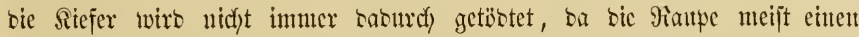

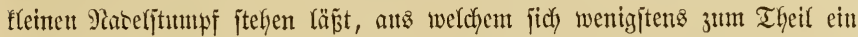

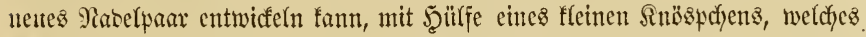

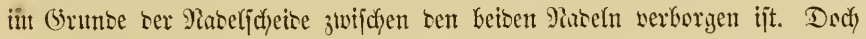
fennt man aud in Sicfermrevieren, namentlicy Fommerns (1828), bebentente

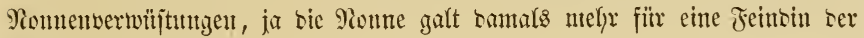
Sitefer als ser Jichte.

Da brad), ungefähr 1852 beginnend, eine Faupenwerhecrung ïber bie

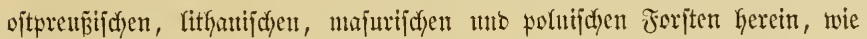

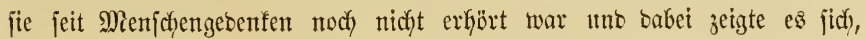

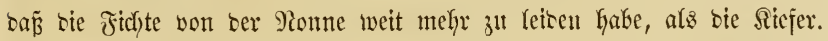

Profefior 2 illfomm wurbe 1863, wo tas furchtbare Ereignif be=

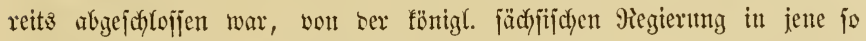

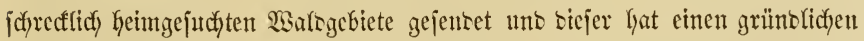

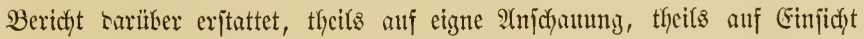
5or sortigen Mevier $=$ Yeten uno Mittheilungen ser Foritbeanten gegrïntoct.

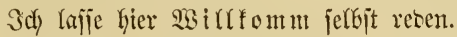

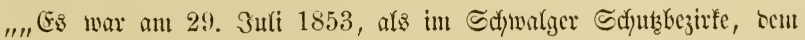
jüblidjiten bes Rothebuter Forits, Der Monnenjounetterling alf cimmal in unzäfliger Mienge erfecjien, intem serjerbe in wolfenartigen Mafjen, vom Sitsmino getricben, herbeizog. Binnen wenigen Stunben verbreitete fidt

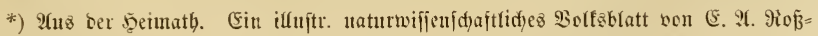

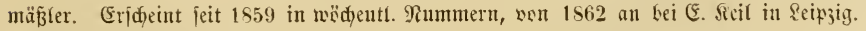
Sabrespreis 2 Thaler. 
ser Sdymetterling and

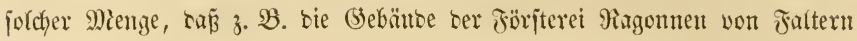
förmlich incrujtirt uno bie Sberfläche bes \$illwumgiees von barin ertrunfe=

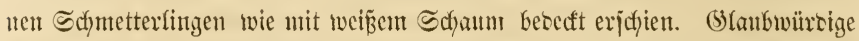

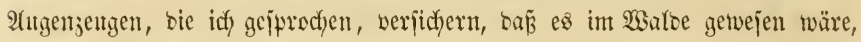

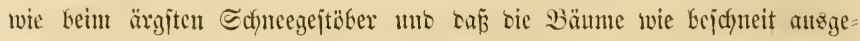

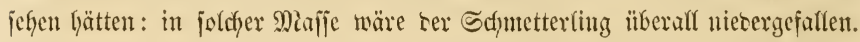

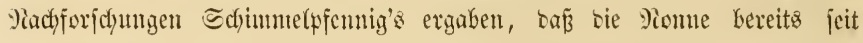

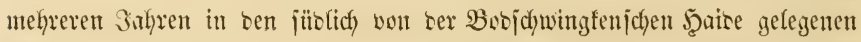

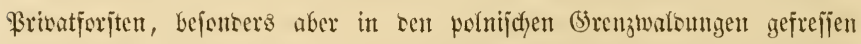
unt jich bort, wo nichts fïr iqye Sertilgung gejchehen war, jo ungehener

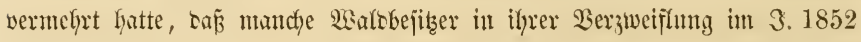

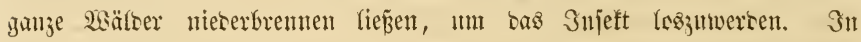
wercher Maffenfajtigfeit 1853 ser Monnenfalter anfgetreten jein mab, erkellt aus ter Thatjache, baß̧ bie Mienge ber wom 8. Nugujt bis zum 8. Maa

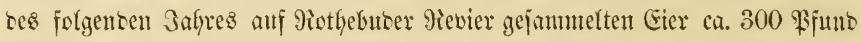
betrulg, orex, ba auf 1 goth minoejtens 15,000 Stïtf gehen, ca. 150,000,000

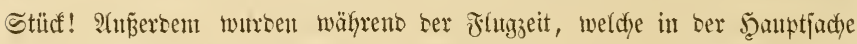

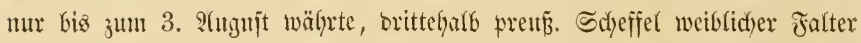

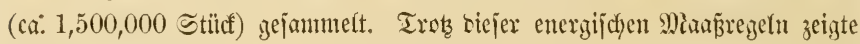
fich im folgenten Frithjabr eine joldse Micnge won Raupenjpicgeln, jelbjt in

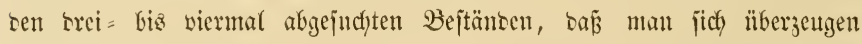
mungte, man habe faum bie ફ̧älfte ber abgelegten Eier gejammelt. Utı bas war aflertings nidft muberbar, ta bie Tonne ifre Eier, allen bisheri=

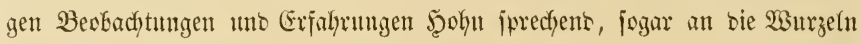
uno zwijdyen bas Mros ser Bobenjtren, besgleidyen bei ben Fidyten in ter Srone bis zum hödfiten Wipfel hinauf abgelegt hatte, was bas Sammeln matürlich jefy: eridfweren muriste. Niddstsejtowentiger waren in fajt affen Sagen, wo ber Sdymetterting jidy in Menge gejeigt hatte, im (5)anzen auf einer Fläd) von 14,500 Miorgen, sie Bäıme Staum für Stamm abge=

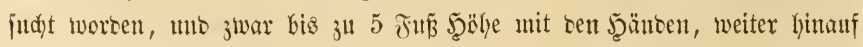

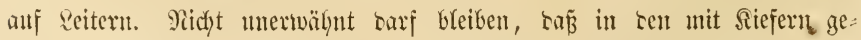

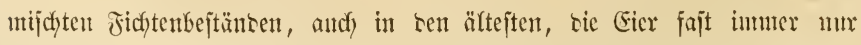
an ben Fidjten abgelegt exfdyienen, un jelten an Siefern, bcun bisher ijt

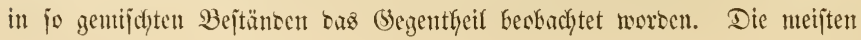




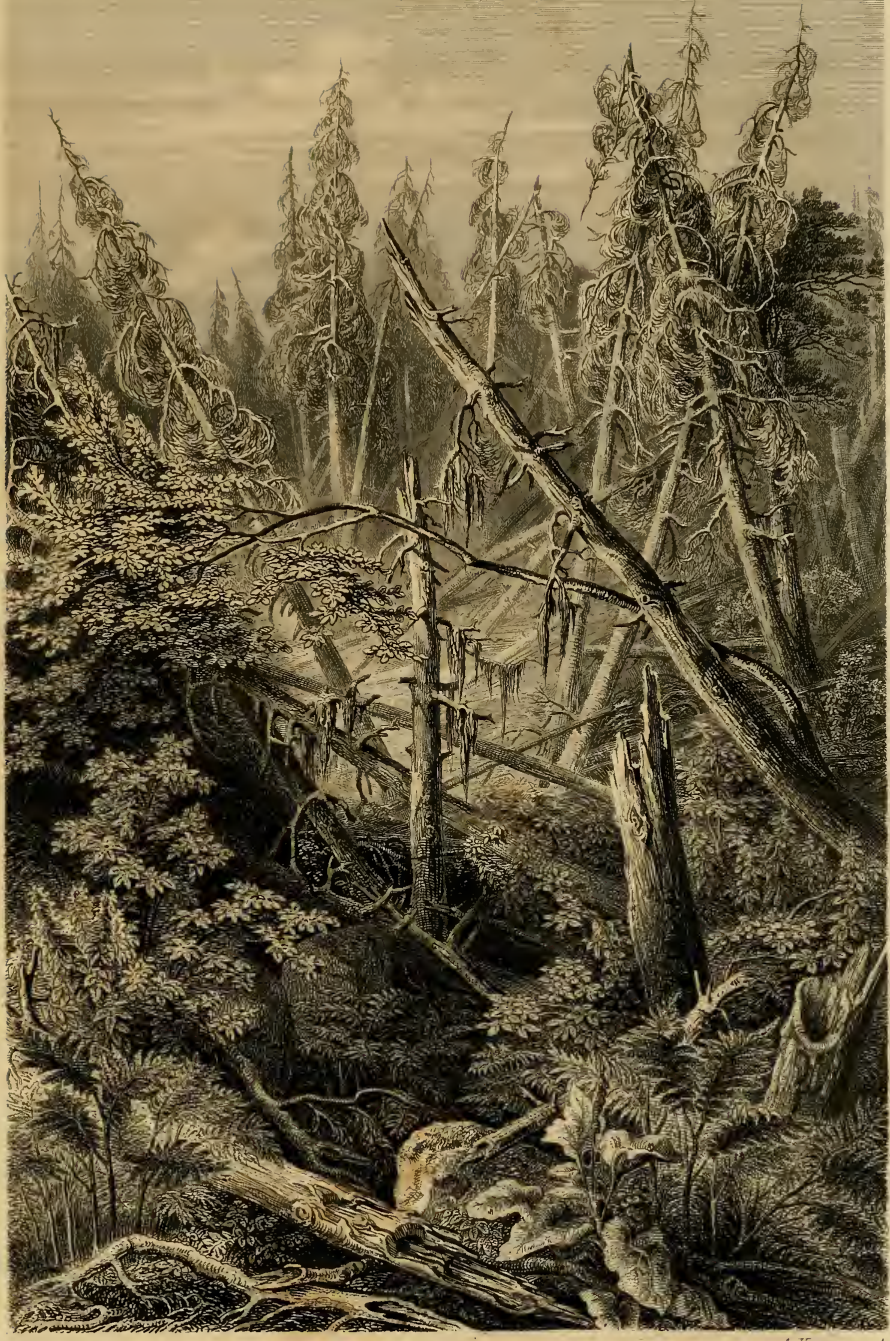

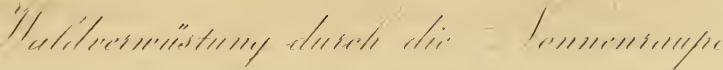



Eier fanb man imuter an alten ftarfen Fidjten (bi: 2 soth an einem

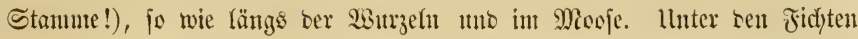
waren mur bie bereits mit raufyer Borfe werjefenen mit Eien befegt, niemals sie nody glattrinsigen, überfqupt feine Stämune unter 12 Zoll Dutd) mefjer au untern Ense. S(ud) an Birfen mo j̧ornbäumen fant man

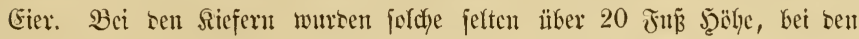

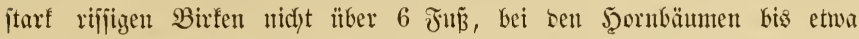
10 Juß wout Boben geredyet gefunben; Dagegen bei ben Jidyten, wie

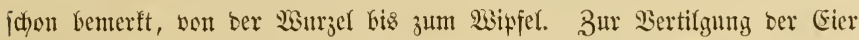
trugen wejentlidy ber-Buntfpedyt (Picus major), ferner sie Jinfen bei; audf) murbe eine grop̉e Menge von (Elemalarven*) um tic Eierhanfen bemert. Irotz alferem waren eine ungeflenre Menge Eierhanfen ̈̈brig geblieben, sem

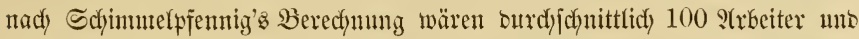

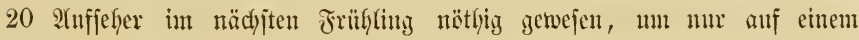

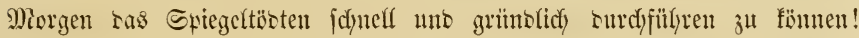

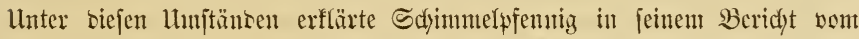
15. Jebruar 1854, in wéldyem er bercits borl "tiefen Sdymerges ren lluter

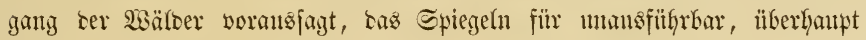

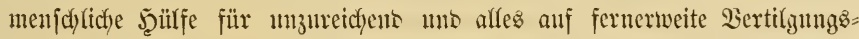

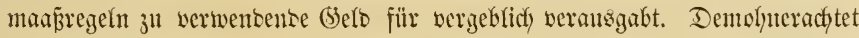

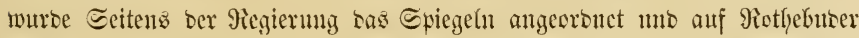
Pevier aud wirffich biz zum 18. Miai vorgenommen, natürlidy mit völlig unz̧reidyenten Sräften. Dabei hatte man sie Beobadytung gemadyt, oañ

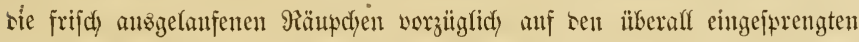
J̧ornbäumen frap̃en uno erjt nach ber Entwiffelung ser Jidytemmaitriebe nach ben Fidjten manterten, wo jie zuerjt bie Maitriebe fo ftarf benagten,

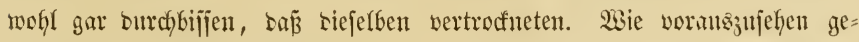
wejen war, hatte sas Spiegelı gar nidfts gelyolfen, benn bie Raupe ver-

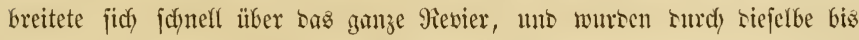
3um 12. Juli, wo ber Jrấ ju Ence ging, bereits ca. 800 Mrorgen Fidften

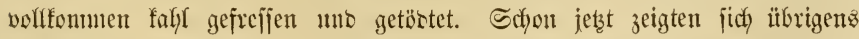

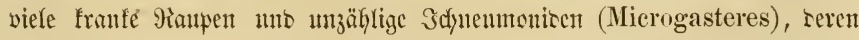

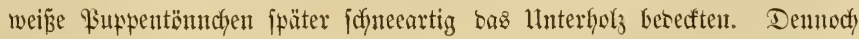

*) $\mathfrak{S}$ ir merben ben 2 meijentäfer, Clerus formicarius, ppätex feunen Yernen. D. $\mathfrak{S}$. 


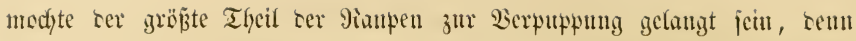
bie anģgefrodfenen Schmetterfinge beceften bie Bejtänte nod) majfenhafter,

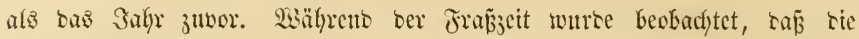
Fianpe sic Fidytenuabeln ganz verzehrte, sie Sicjernaceln tagegen, wie längit

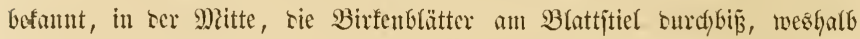
ber Boben unter sen Sicfern แmo Birfen mit herabgefalfenen Yarelititufen ıno $\mathfrak{B}$ lättern

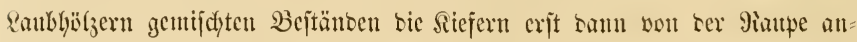
genommen wurben, nacfirem bie Jidgten fahl gefrefien waren, bie 5̧orn=

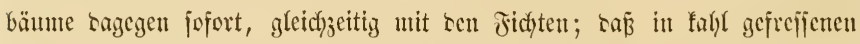

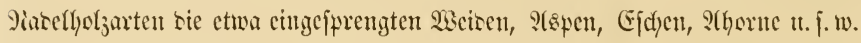

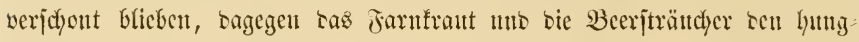

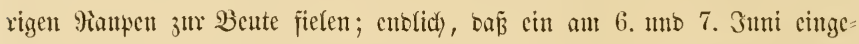

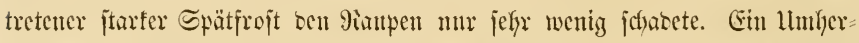
wancern ber 9iaupen aแz fah) gefrejfenen Bejtänben nach nod) แnverjelynten

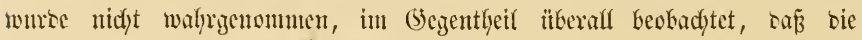

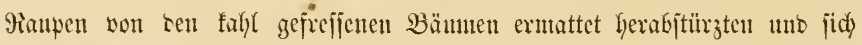
unter seren Edjirmfläche amjammetten. Siele serjelben mögen nicht zแ⿰ Serputpung gelangt jein, viele wurten audf won ren Fröjcten (!) gefrefïen. bäume, unter benen jidy Ameijenhaufen (bon Formica rufa)

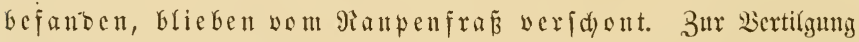

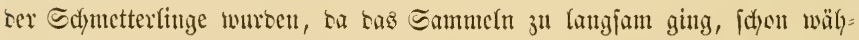

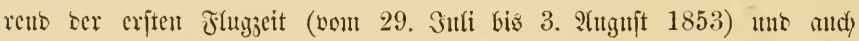

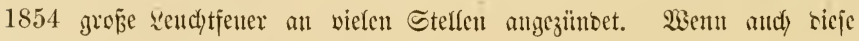

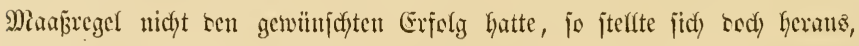
tan bie Sdymetterfinge in ben fahl gefrefijenen Srten, wo alfein Renthtfenter

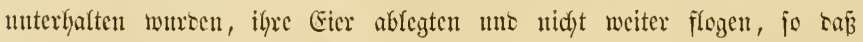

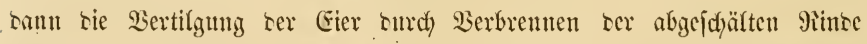

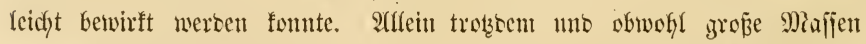

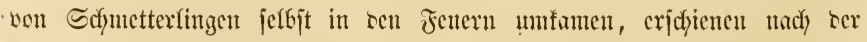
Jltggeit won 1854 tic Eier fo mafjenhaft abgelegt, taß man won weiterem

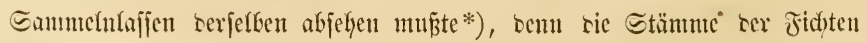

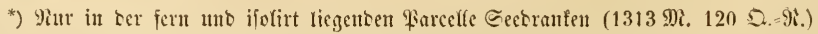
nutren Eier gejammelt (im (banzen 26 fifund) und Daburd) allerbing jener gorft 


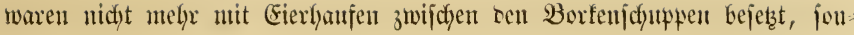
bern anf ber ganzen Dberflädbe von bidjt an = unb itbereinanoer liegenton

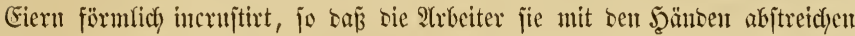
founten, wentgitens an ben Stämmen, an weld)en mu in Winter zuvor

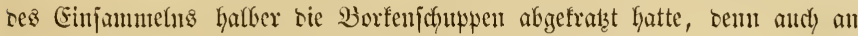
foldye hatte bie Mionne ifyre Eier gelegt. Die Wipfel waren jeboch biesmal

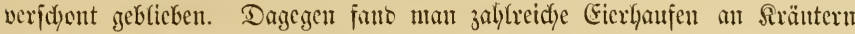
affer 2(rt, fogar auf Tabafisflanzen (es wirt in Miajuren Nicotiana rustica häıfig angebaut, namentfidy aud in ben bärtchen ser niebern

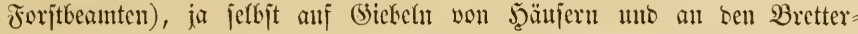

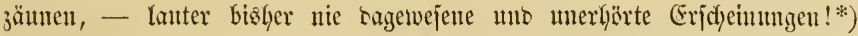

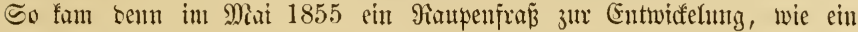
joldyer wohl jeit Menjdyengetenfen nody nidyt bagencjen ift unto hoffentlicty nicht wieber vorfommen wirb. Biz zum 27. Smi waren anf 9iothebuber

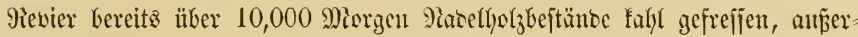

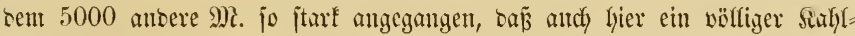

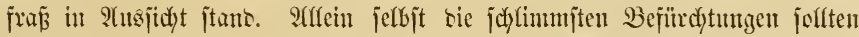
nod) weit ïbertroffen werben! Denn bis Enbe Sulf eridfienen bie meifiten Jidyten bes ganzen Reviers kahl gefreijen, biejelben anj einer Jläche von 16,354 $\mathfrak{M i}$. Gereits getiotet, anf einer anbern won $5841 \mathrm{Mi}$. jo jtarf be

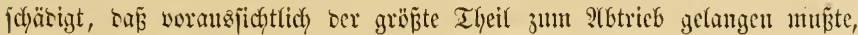

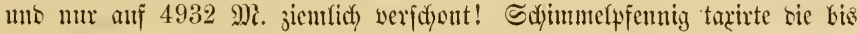

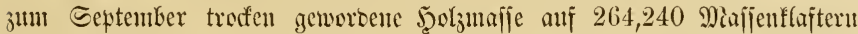
ober auf 16 Silaptern pro Miorgen ser oben angegebenen Fraźf̆läche. Die

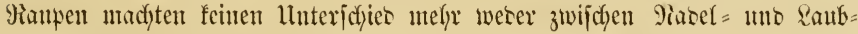

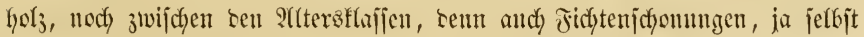

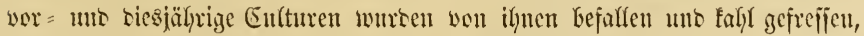

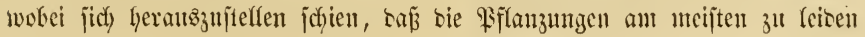

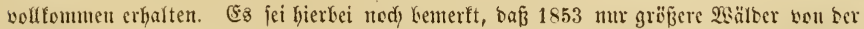

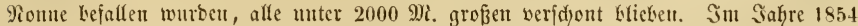

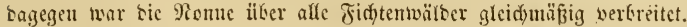

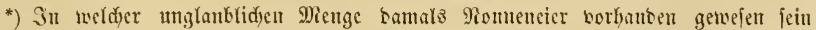

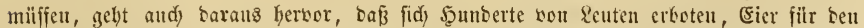

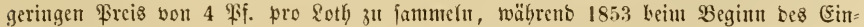
\{ammelus bas \&oth mit 5 Sgr. bezahlt werben muß̃te. 


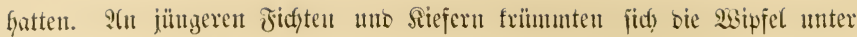

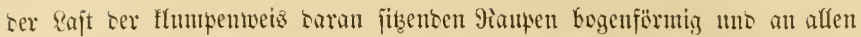

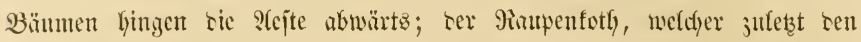
ganjen Booen tes Lialtes 2 bis 3 Zoll hod, ia an mandyen Steflen bis 6 3olf hody betecfte, riejelte munterbrodyen gleidy einem jt a t fen*) গiegen aแ๖ ธen Sronen ter Bämme hernieber, แnto balo war. fajt feein grünes

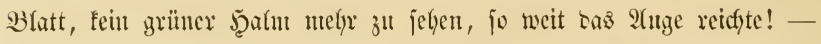

Die Monnenverfeerung war vorïber, affein, nod) elfe siejelbe zu Ense ging (jeit Jrübling 1855), begam eine neue Snjeftencalantität jich) 3n ent-

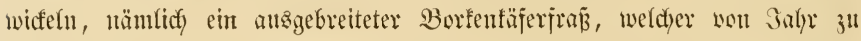

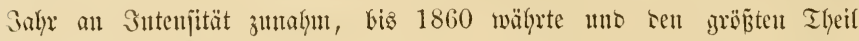

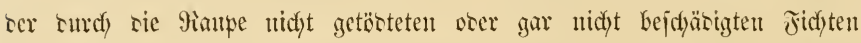
volfenrs wernidytete, aunerten audy cine Mienge Sicfern toot ober frant

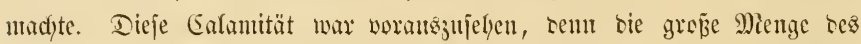

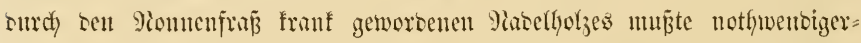
weije zur Bermethrum ber Borfenfäjer, mit weld)en man bereits jeit Gafjren 3ll fämpfen gefjabt hatte, wejentlid) beitragen. Sdyon im 2rpril 1853, aljo

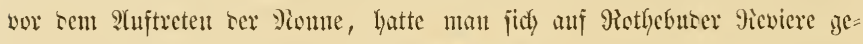

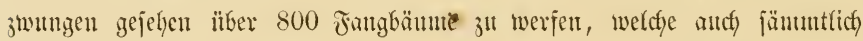
itarf befalfen worten waren. Trotzoem hatte man in jenem Jahne in tom

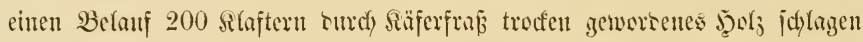

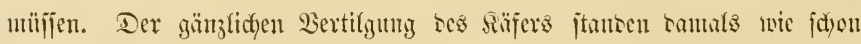
feit einer 9ieifye won Gafhren sie alten 120-150jälyrizen, in aflen älteren Bcjtänten cinzch uno horjtweije vorhansenen Jichten entzegen, weil ricje

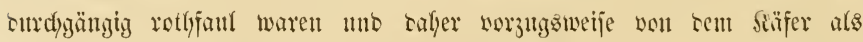

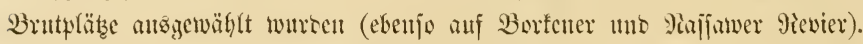

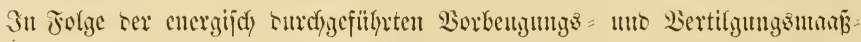

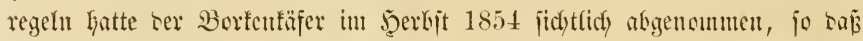

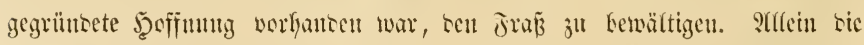
jd)nefle 9 (t)

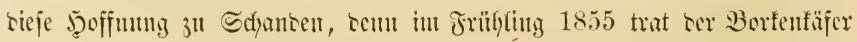

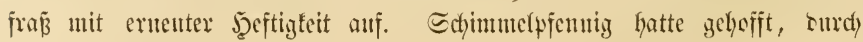

*) Es wutbe bigher won Mandjem fïr llebertreibung gebalten, wenn utan fid bes

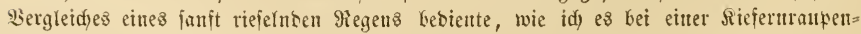
ausbreitung gebört babe.

$\Re$. 


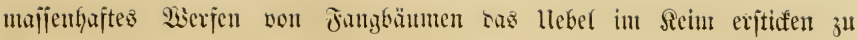

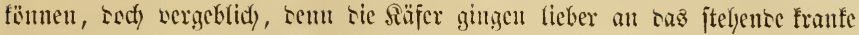

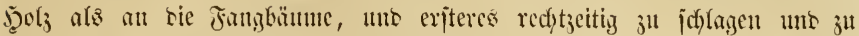

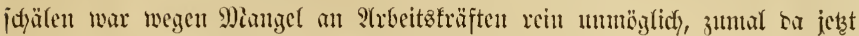

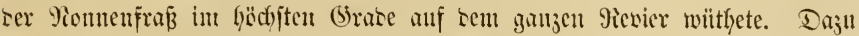

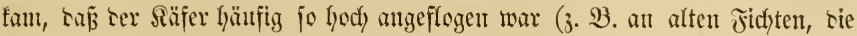

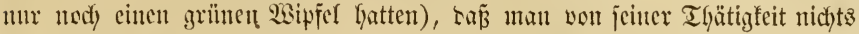
mafyrmelgmen fonnte. Balo griff ber Säfer aud) ganz gejunte Bejtänte an, unt in joldfen wurbe er büdyjt gefälyrlidy. Ente s(prif 1857 jdymärmten ric Borfenfäfer in unglaublidyer Mienge mo bald madyten biejerben ben

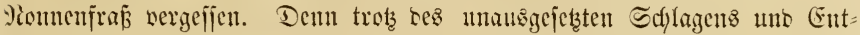
rinbens ber befallenen Stänme, bie balto nach Ianfenten zähiten, erjajienen

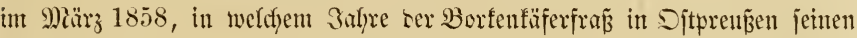

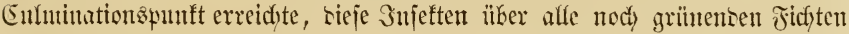

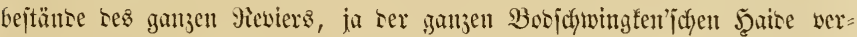

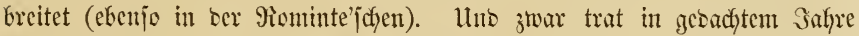
bejonters Hylesinus palliatus in ungebeurer Mienge auf, wälyrens biz ca= fin vorzïglicy Bostrichus typographus gefrejen Gatte. Die Jraffitiguren tes genannten Bajtfäfers, weld)er in sem vielen vou 2 sint gebrodjenen franfen utlo abjterbenten J̧olze Brutpläłze in Menge fano, bebecften

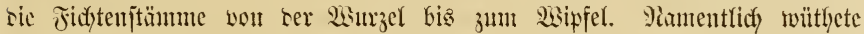

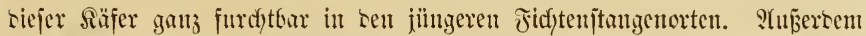
famen Hylesinus polygraphus, Bostrichus chalcographus, Laricis, Abietis unt pusillus fäufig vor, won seren Fra

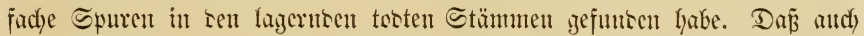
Bostrichus lineatus in unglanblicfer Menge erjedien, Sarf bei sen bamals

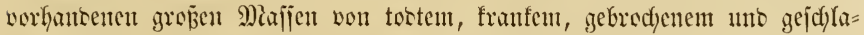
genem $\mathfrak{S c o l}_{3}$ nicht 26 unter nehmen. Derjelbe ging jogar gejunbe jtehente Jidften an uno in Bejeflad)aft von B. bidens, stenographus un Hyl. piniperda aud sic Siefern. Da alle zur Berminterung ber Bortenfäfer

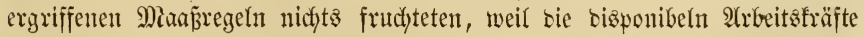

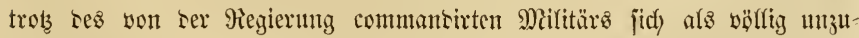

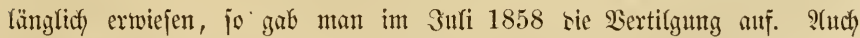

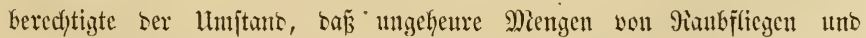
Sdymaroberinjeften erjujienen, weldye gegen sie Borfenfäfer z" Jelie zogen, 


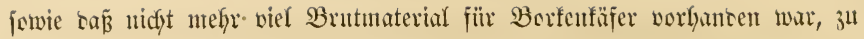

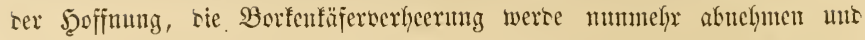

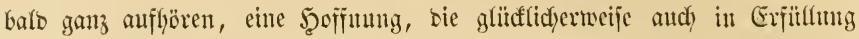
ging. Sm 3afy 1858 jdywärmten ẗbrigens bie Borfentäfer vicle 9)icilen

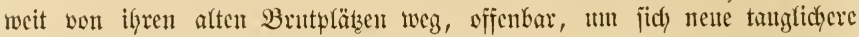

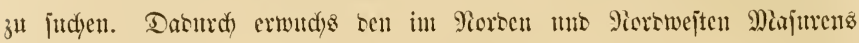

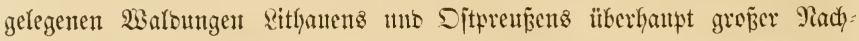
theil. Dort nafyn ber Borfenfäferfrá nod siel berententere Dimenjionen an, ałz in Majuren, weil sort niddyt fo viel Jiddten wou ber Plonme ge töotet worben waren. Sn Majuren uns Ditlithanen iagegen fanten bie

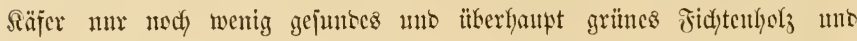
fonnten beshalb nidyt fo verterblidy werten; bem tas suth ten Nomen-

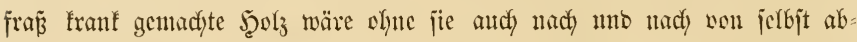
gejtorben oser burch ben Jraí anterer Injeften getörtet worten. Nadh bem

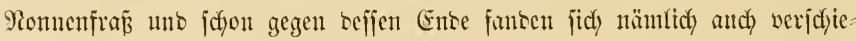
sene $\mathfrak{B}$ veffäfer ein, insbejontere Cerambyx luridus uno indagator, weldye nicht alfein bas auf bem Stamme troffen geworbene, fontern auth baz nody

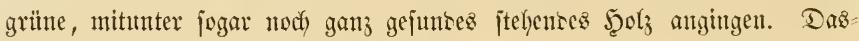

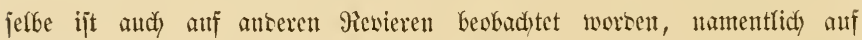
Tajfawer, wo bejonters viele rothfante Jidften sem Fraje tos C. Iuridus

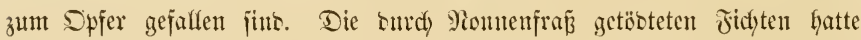

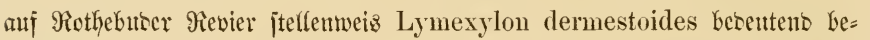

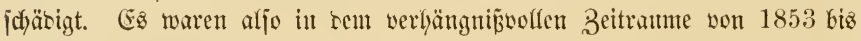

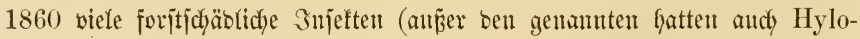
bius Abietis uno Pissodes notatus in ten ganzen Fichten = unb Siejern= jchonungen, fowie Lytta resicątoria an ben Ejdyen bebentent gejreffen uno

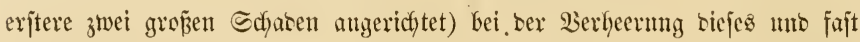

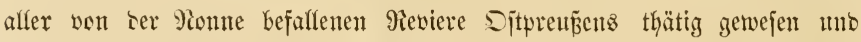
surdy ifgr vereintes Wirfen eine ungehenre Majfe Miabelfolz getöstet worben.

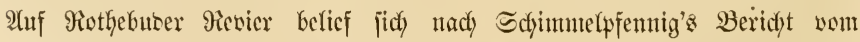
1. Detober 1862 bie Giz Safin abgejtorbene 5̧olzmajie in runter Sunme

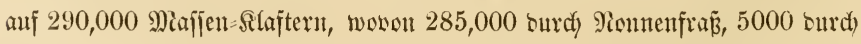

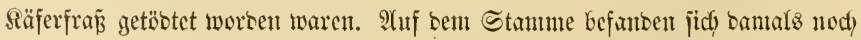
mintejtenz 153,000 囚laftern. Die vermüjtete Fläthe betritg 32,931 Morgen,

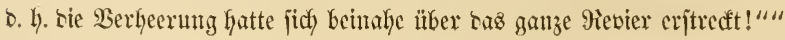




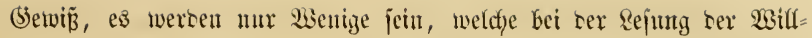
fomm'idyen Darjteflung nidyt von Stauten crgriffen worten jüb. Fin 2 alo =

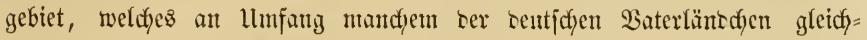
foumt, in wenigen Sahren surd) fleine Strjeften in eine mit Baumleichen bekectte Biijte werwantelt - eine Erjoheinung, eine Wirfung, wowon man (ich) fawwer cine Sorjtellung madyen fann.

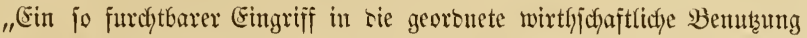

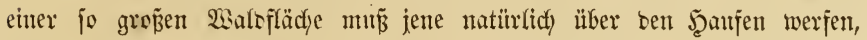

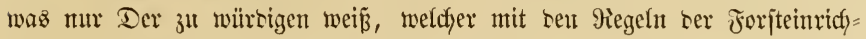

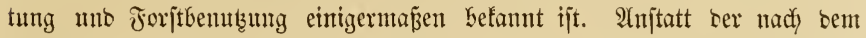

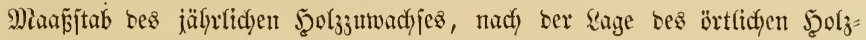

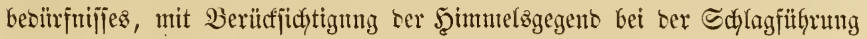

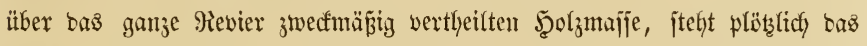
ganze Revier, hier Wartoflädyen von Duabratmeilen, zur Derfïgung bes J̧ol 3 bebarjes, ber gar nidjt ba ijt.

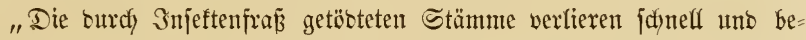

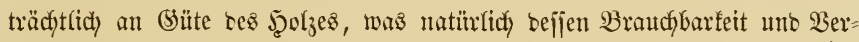

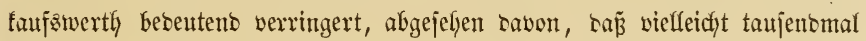

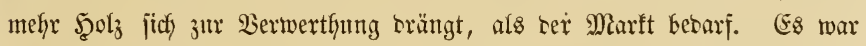

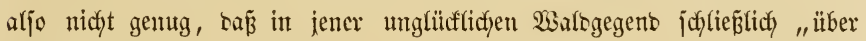

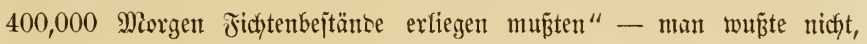
wie man bie Unmajien von getöbteten Stämmen verwerthen joffe, wobei

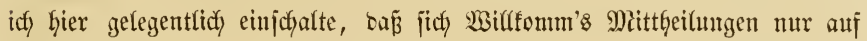
Staatß̊foriten bezichen, währento "bie \$rivatwäloer eben jo gefitten Gatten",

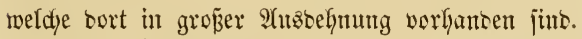

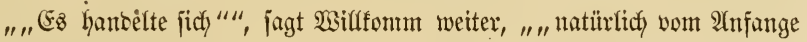

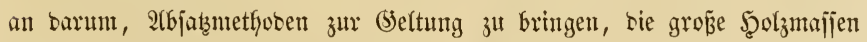
binnen furzer Zeit z" conjumiren im Stanbe jein würben. Man glaubte

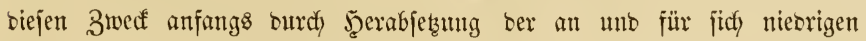

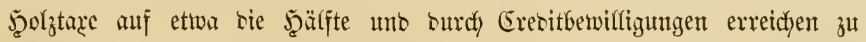
fönnen; aber obwohl bieje bem holzconjumirenton \$ublifun gemacten (Ex=

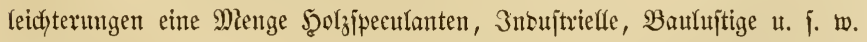
anlofte, unb obwohl man zur Bermeitung ber Eoncurreng Seitens bes

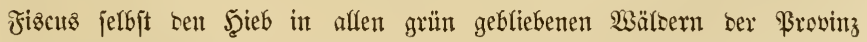

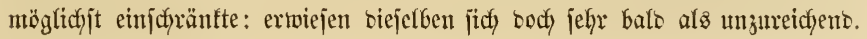




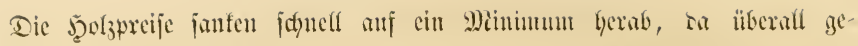

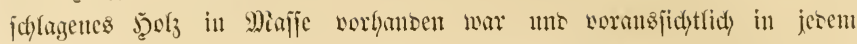

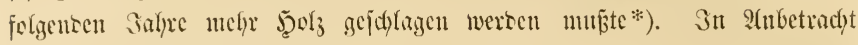

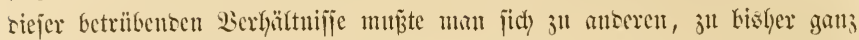

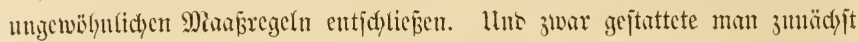

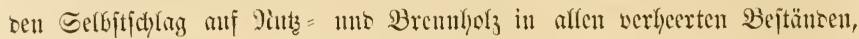

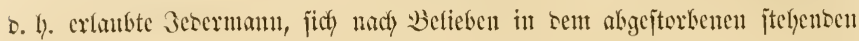

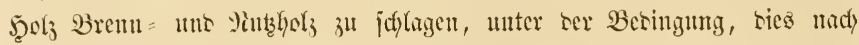

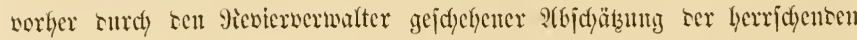

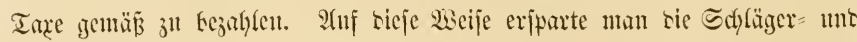

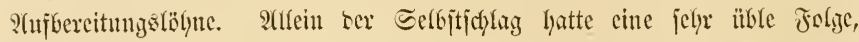
weil ein 3erer unr wegnafhm, was cr gerabe braudyen founte. Gs ktieben

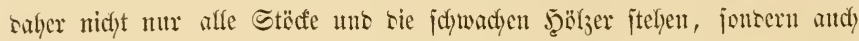

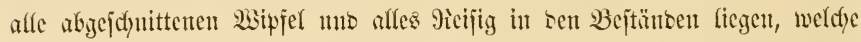

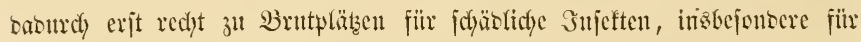

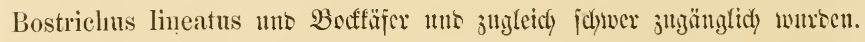

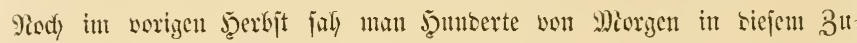

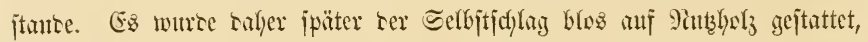

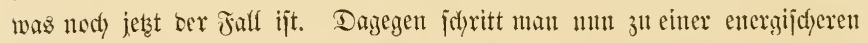

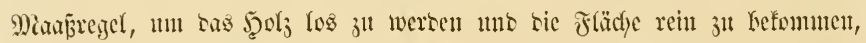

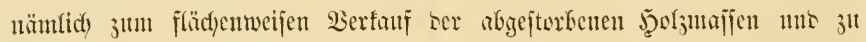

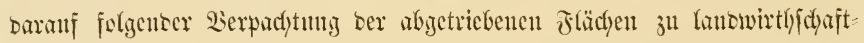

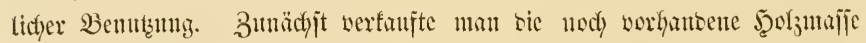

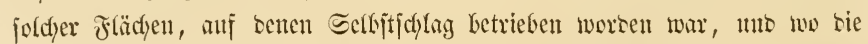

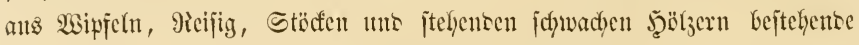
Mafje innter nod) bis ju 10 Miajpenflaftern pro Miorgen betruy, morgen=

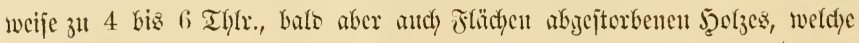

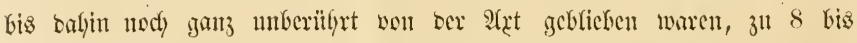
10 Thlr. Hwo Mcorigen. Diejer Flächenverfanf ift nod) jedzt (1863) im

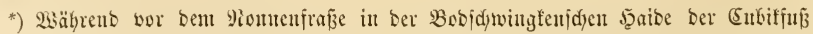

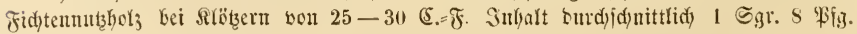
mad) ber Taxe gefoftet hatte, wmbe beriefte 1855 mur nody mit 8 Fig. Gejahlt. Der

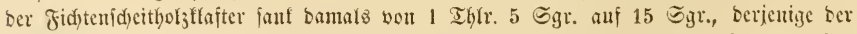

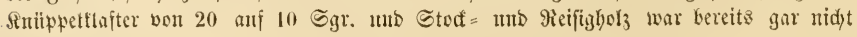
mebri abjujetzen. 


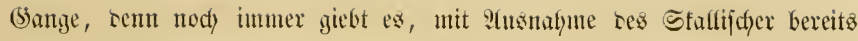
volffommen geräumten 9ieviers, anf alfen 9ievieren, insbejonbere anf giothe=

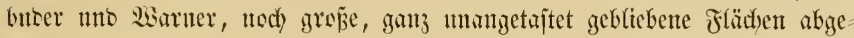

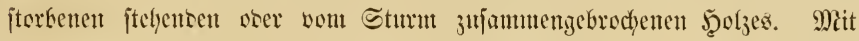

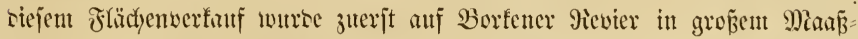
ftabe vorgegantigen, nachoem 1857 ber jetzige $\mathfrak{B}$ erwalter seffelben, Jeer

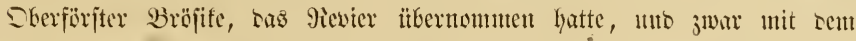

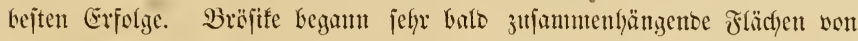
5 Miorgen ju verfaufen, was groß̄en Stnflang unter ser läntlichen $\mathfrak{B} e$ -

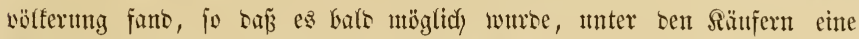
Stustwahl zut treffen. In ser That loar sas Borfener 9ievier im vorigen

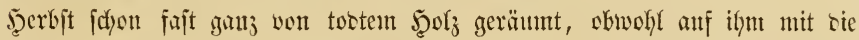
größ̈ten Berlyecrungen vorgefommen jint. Durdy joldyen Flädyenverfantf

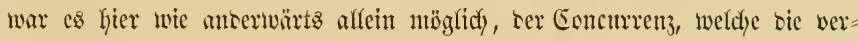

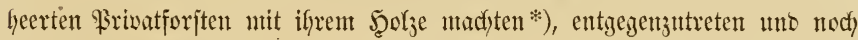

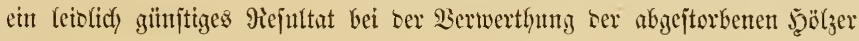

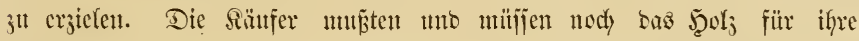
Mechnung idslagen, aufarbeiten tmo fortichaffen. Lajien mo sies binnen eines

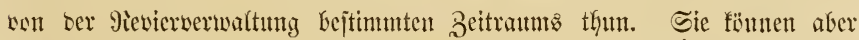

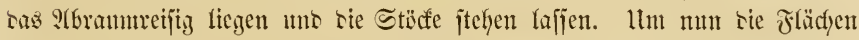

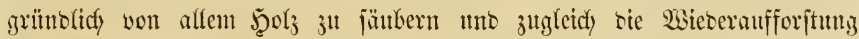
vorjuberciten, fam man auf sen jerenfalls glifuftichen (Seranfen, joldye abgelyoljte Flächen, jpäter audf) biejentigen, anf benen frither mur Selkjtichlag

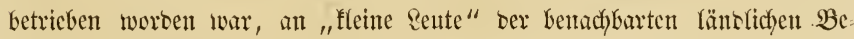
völferung, weldye jelbit feinen orer mut geringen (5runsbejits haben, 3t

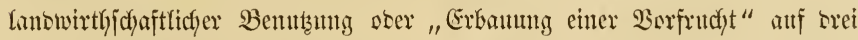

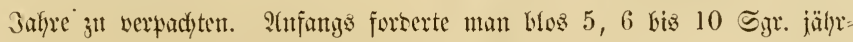
lichen Wascht pro Diorizen, aber balo fonnte man ben Padyt jteigern, sa jith imnter mehs sente einfantsen, weld)e sergleidyen Flächen pachten molften,

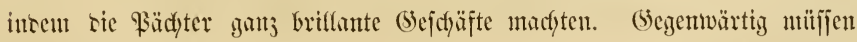

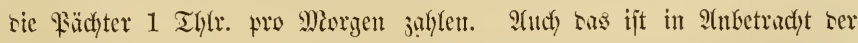

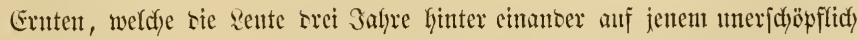

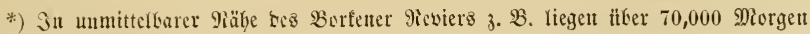
Bribatforftett. 


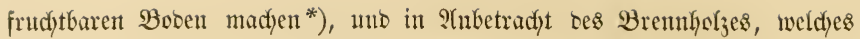

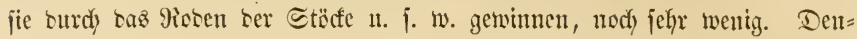
ttod) erzielt man burch bicje Methobe jetzt cinen Piettoertring pro Miorgen won ben verfeerten Fläd)en, an weldyen vor ber Galantiät bei volfbeitanbenen Flädyen nidft zu benfen war. Mian verpactet ïbrigens autch nod) ganj

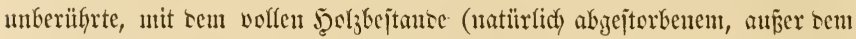

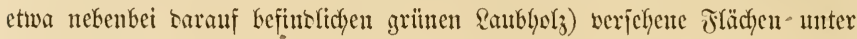

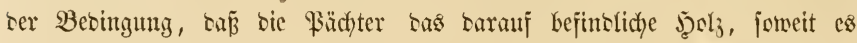

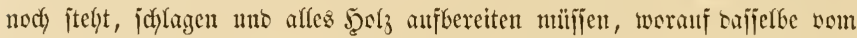

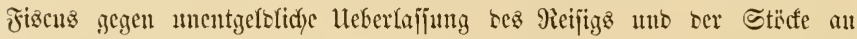
ben \$ädyter ïbernoumen wirb. 2(uf biefe Weije erifart man itberall bie

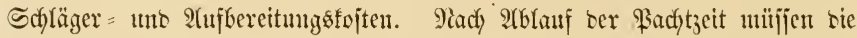

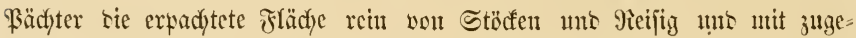
ebneten Stodfödyern ber Mevierwerwaltung ïbergeben, weldye num auf bem

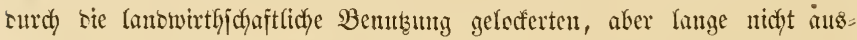
gejangten Boben bei ber Enltivirung ein jienlich reidftez Spiel hat."

"3um Schlus theile idy nody folgente 2 (ngubent ïber sen Betrag bes Injeftenjuabens แad) Willfomm mit.

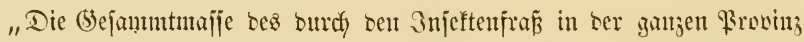

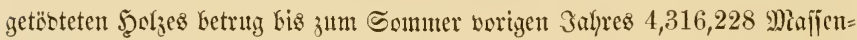

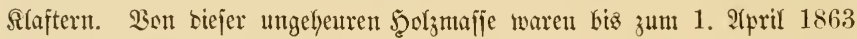
verwerthet

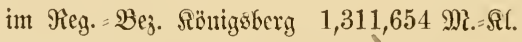

(5)unbinmen 2,126,045

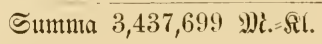

unt bafïr aufgefommen

im Reg. = Bez. Rönigsberg 1,767,978 Thtr. 19 Sgr. 2 ßf. Bruttoertrag. (5umbinnen $2,690,450=14=5=$

Summa 4,458,429 Thlx. 3 Sgr. 7 $\mathfrak{F i}$.

*) Die Ertragsfäbigfeit bes Bobenz auf Borlener unb Mothebuter Mevier if́t gerabezu fakelhaft! Die Bädter erbanten shne jebmebe Düngung, bie fie and) gar nidjt befdaffen tönnten, im erften Sabre entweber Fladis, weld)er vorzüglid, gebeiht, soer Rartoffeln,

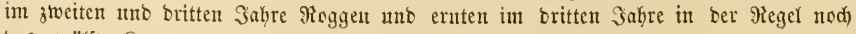
bas zmälfte Siorn. 


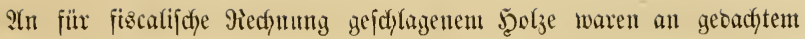
Termine nod) borbanten

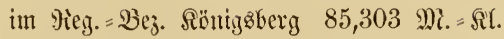

$$
\begin{aligned}
& \text { (Sumbinnen } 78,553
\end{aligned}
$$

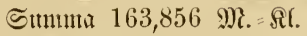

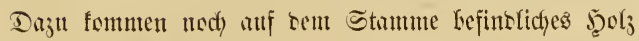
im Pieg. = Bę. Rïnigsberg 187,000 Mi. = Rl.

(5)mbinnen 527,673

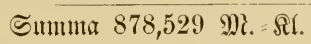

nod) vorräthige muermertlyete Sujeftenfyör

Die Sröß̄e ser verbeerten Maloflädye betrug

$$
\begin{array}{r}
\text { im Rej. = Bez. Sïnigsberg c. } 150,000 \text { Morgen } \\
=\quad \text { Sumbinmen " } 268,244 \\
\text { Summ } 418,244 \text { Miorgen, }
\end{array}
$$

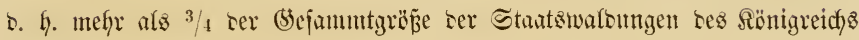
Sactjen.

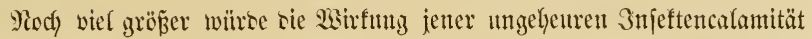

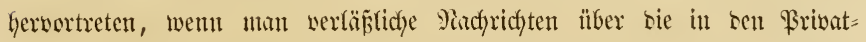

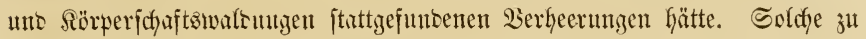
befdyaffen ijt bis jezzt nicht möglich gewejen. Mian funn fitd jeboch ein

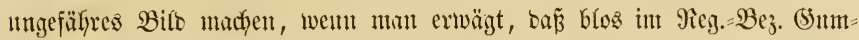

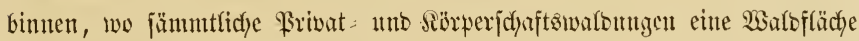
von 255,497 Miorgen repräfentiren, simch ben Pionnenfraj 282,750 Maff.=

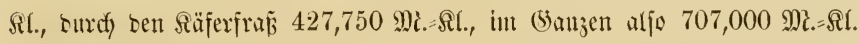

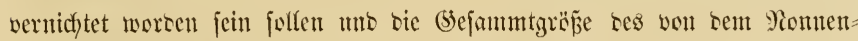
frás betreffenen W3arcs c. 55,060 Miorgen betrug. Dieje Majfe abge=

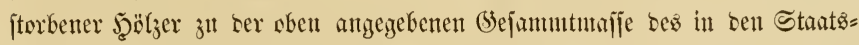
walsungen ber ganjen \$rovinz trodfen geworrenen Şolzes Ginzundubirt, ergiebt bereits sie ungeheure Majfe vou 5,023,228 Mafjen-Slaftern ober $351,625,960$ rhein. Euriffuñ! -"

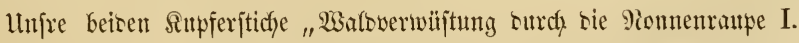

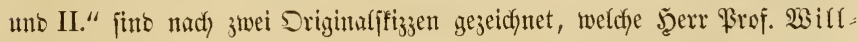
fomm an Drt uno Stelfe entworfen uno uns tiberlafjen hatte. Şören wir num aber nod, was serjetbe in feinem Beridjte itber sen ?tnbfidf eines 


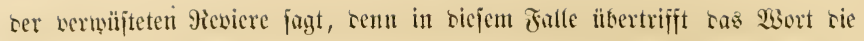
bilolidye Darjethuty.

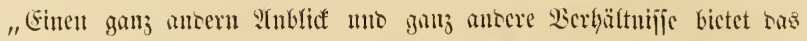

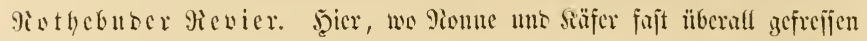

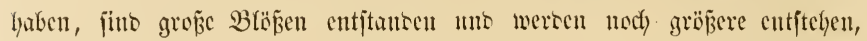

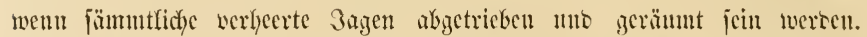

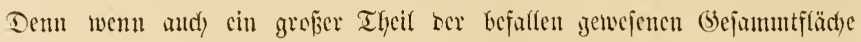

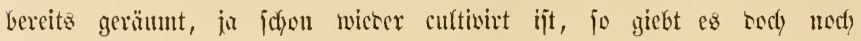
Tanjente won Miorgen, weldje cntweocr nod) gar nidyt in 9tngriff genom-

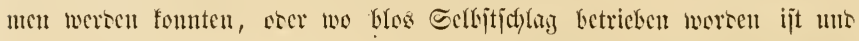

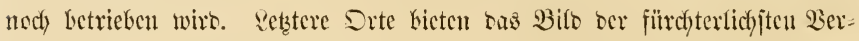
wiijtung sar, oenn juifd)en itehenten, aber surd) rie fallenten Fidsten siel

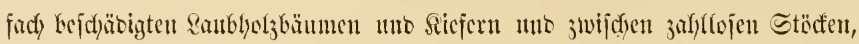

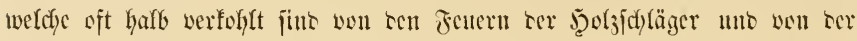

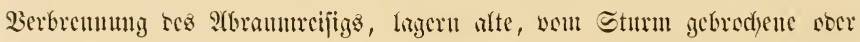

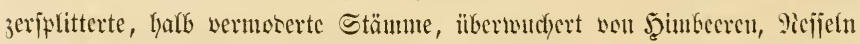

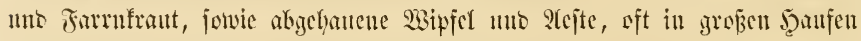

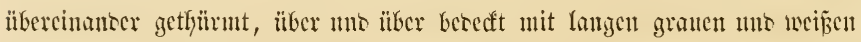

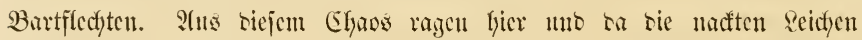

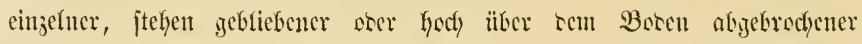

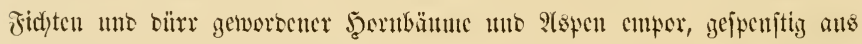

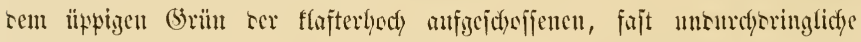

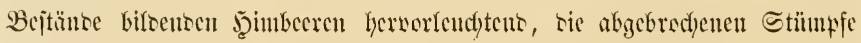
nidyt felten cinjeitig oocr imerlich) (Incun jie rothfunt gewejen waren) wer: foblt uno in ben feltjamiten formen zerjplittert. (Einen myleidy idfuner-

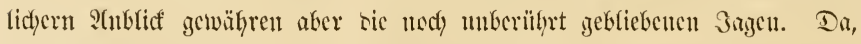

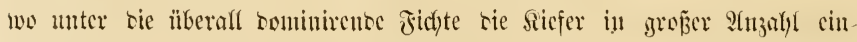
zeffrengt ift, soer ber 23 ino weniz lingelangen fonnte, jtehen bie trodfen

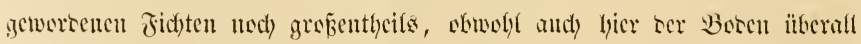

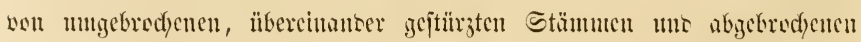
23ipfeln berectt ijt; wo sagegen wenig Sicfern waren ober oer wisino nad)

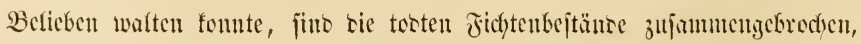

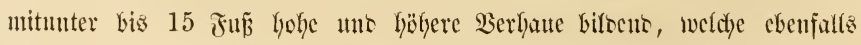

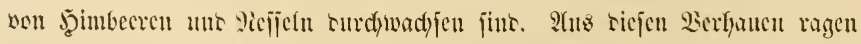

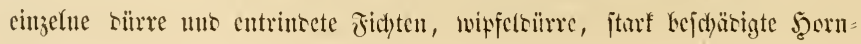




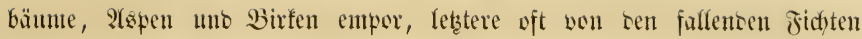

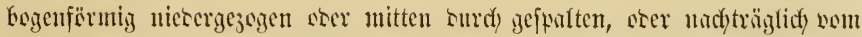

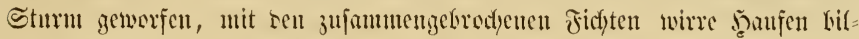

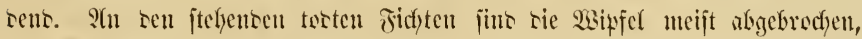

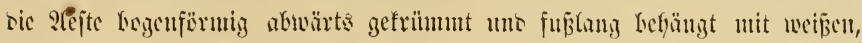

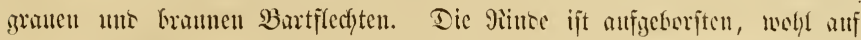

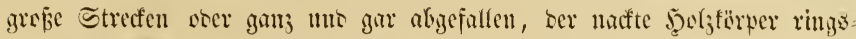

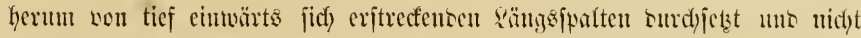

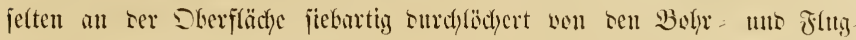

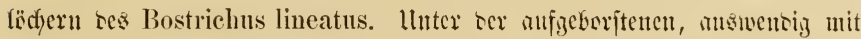
Fledyten thberzogenen Barfe, sie jid) leidyt in grepen Fistatten abtrennen

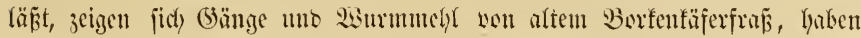

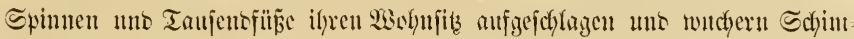

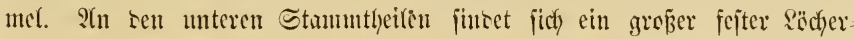
fill3 (Polyporus pinicola Fr.) in reidylidfer Mienge, weldyer aud bereit

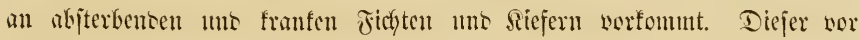

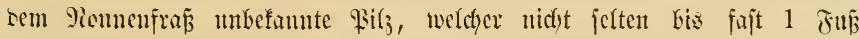

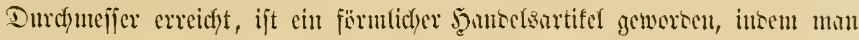

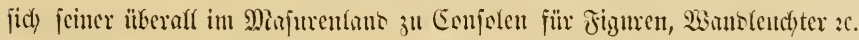

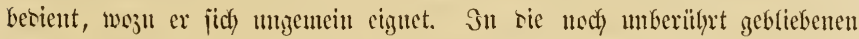

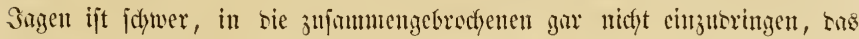

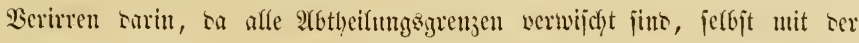

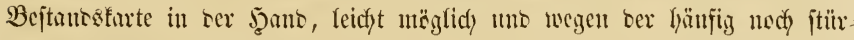

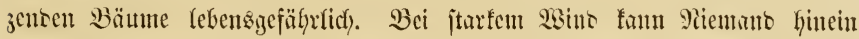

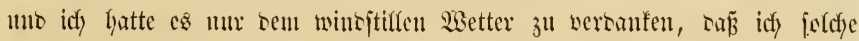
Bejtänse beficftigen fonnte. Barto nach scu Minupenfrape, wo alfes trocfen

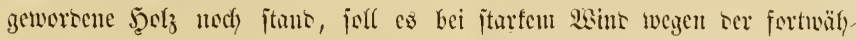

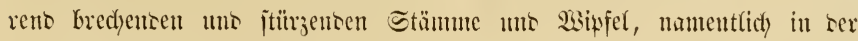
Stille ser Yadft, aแs ser Jerne wie cin gut unterbultenes Miottenfener ge=

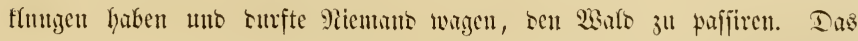
Sunere ser mit fajt reiten, nody jtehenten Jidften berecften Gagen madyt

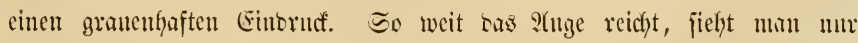

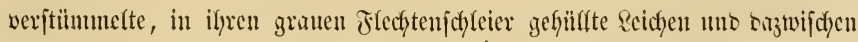
lyafb ımo ganz umgebrochene Stämme shne cine Spm von Brïn, aufer

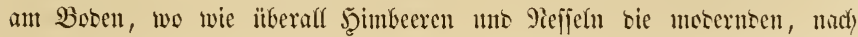


alfen 9ïd)tungen unberliegenden Stämme überwad)jen haben; eine Torten-

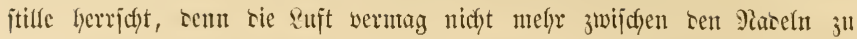

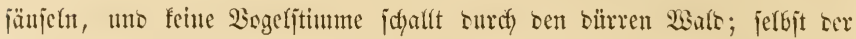

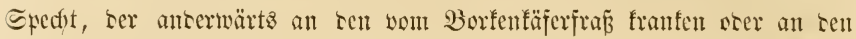

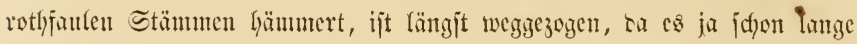

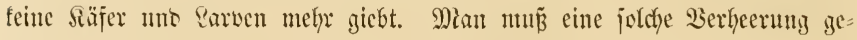

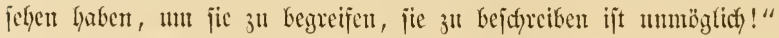

3um ङ

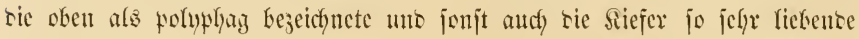

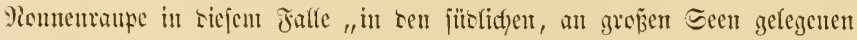

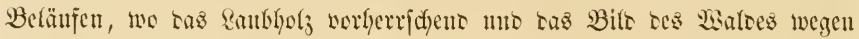

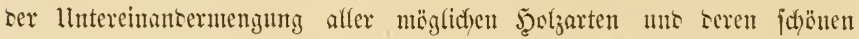

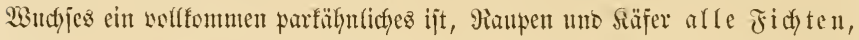
auch) tie ganj sereinzelt jtehenten, alte uno junge, getöotet, wešhalb man

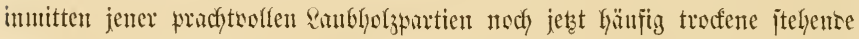
Jidften jieht, seren graue fled)tenbehängte Reidjen jettjun gezen ras ïppize (5riun Les Saublyolzcs abjtedjen". -

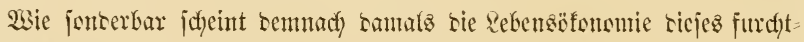

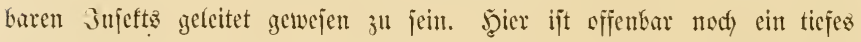
rebensgegeimniž verborgen, scijen zojung in siejem falle, weun jie mög=

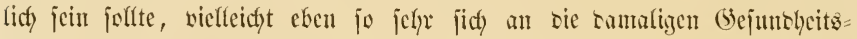
zujtänte oer Ficf)te wie an bie Pianpe jelbjt zu wenten hätte.

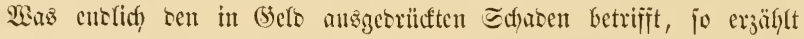

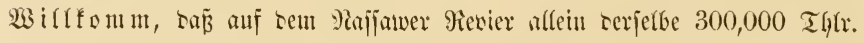
betragen habe, wejentlich sarauj beruhent, saj mu rieje Summe ter $25 e r t h$

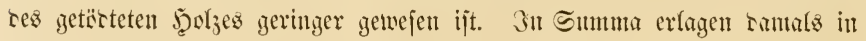

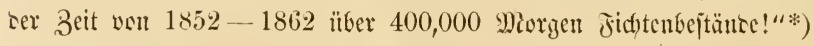

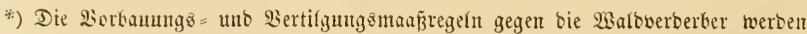
wir an Sđflujie biejes 2fbidnittes bejpred)en, weil mandje bavon für mebrere ober alle gialbwerberber gleidy antwenbar uno geboten finto. 


\section{Der Sdumamujpimer oder Dišpar, Liparis dispar (Ph. B.) L.}

Der weifriche Sdymetterling, ciner mujerer größ̈ten Viachtfalter,

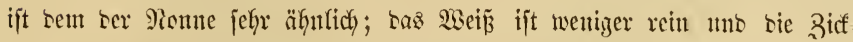

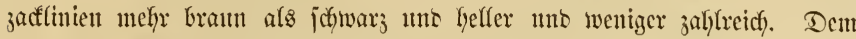
viel bifferen folbigen Şinterleibe feflt bas 9oth. Das viel flecincre Miä nn c) en ifit ganz verfffieben gefärbt (dispar, ungleid)), bic (brumbfarbe aller

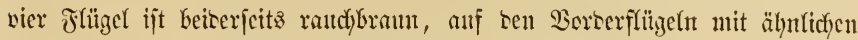

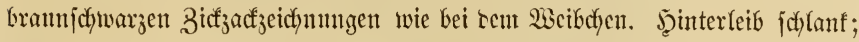

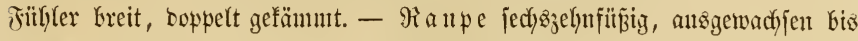
$61 / 2$ Eentimeter lang, biffëpfig, langfhararig unt leicht ju untericheiren an

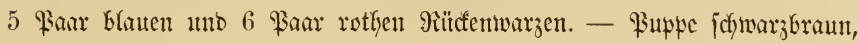

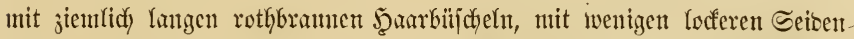

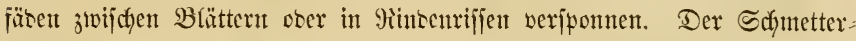

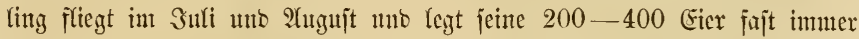
in einen flactyen rumofichen Silumpen zufammen, sen er burds beftiges

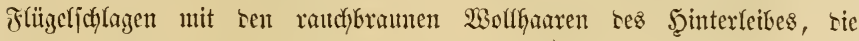

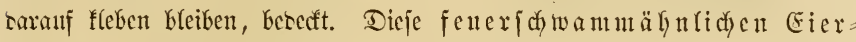
flumpen finton fich meift an sen Banmitämmen. Erjt im näcbjten Jrithjaht friedyen bie Räupchen ans, weldhe wie bie ber Nonne noch einige Tage neben bem "Sdywamm" in "Spiegeln" Geifunmen bleiben uno jidy bann erjt in sie Baumfrome vertheifen; nut bei fohlecftent Wetter ober zut

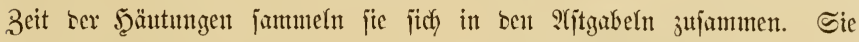

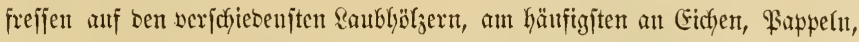

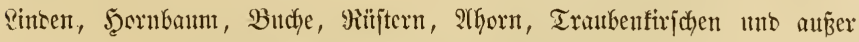
bem $\mathfrak{B a}$ alde an verfchiebencn Dbjtbäunten, am liebjenten an Pflaumen. Durch

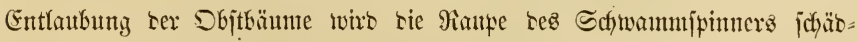

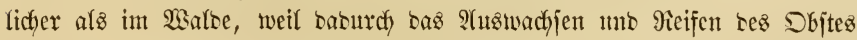
verfintert wirb. Die Serpuppung geiffiegt von 9tnjang Suli an, jelten

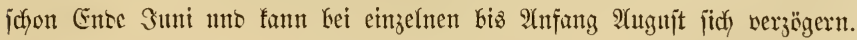
Pach etwa 14 Tagen friedft ber Schmetterfing aus. Die Weibchen lafjen

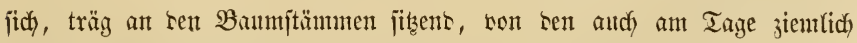
lebhaft fliegenben Männdyen auffutchen. 


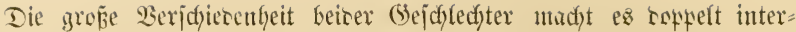

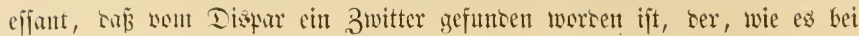

fig. 11.

1,

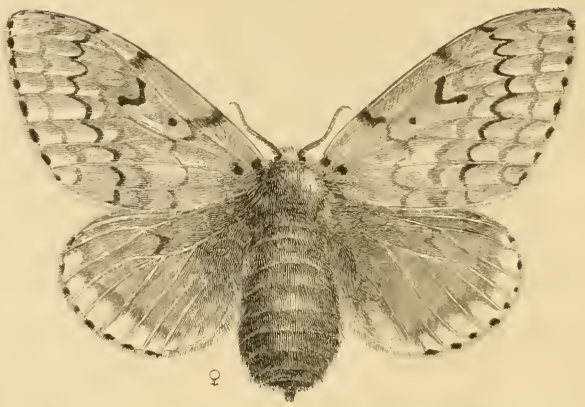

a
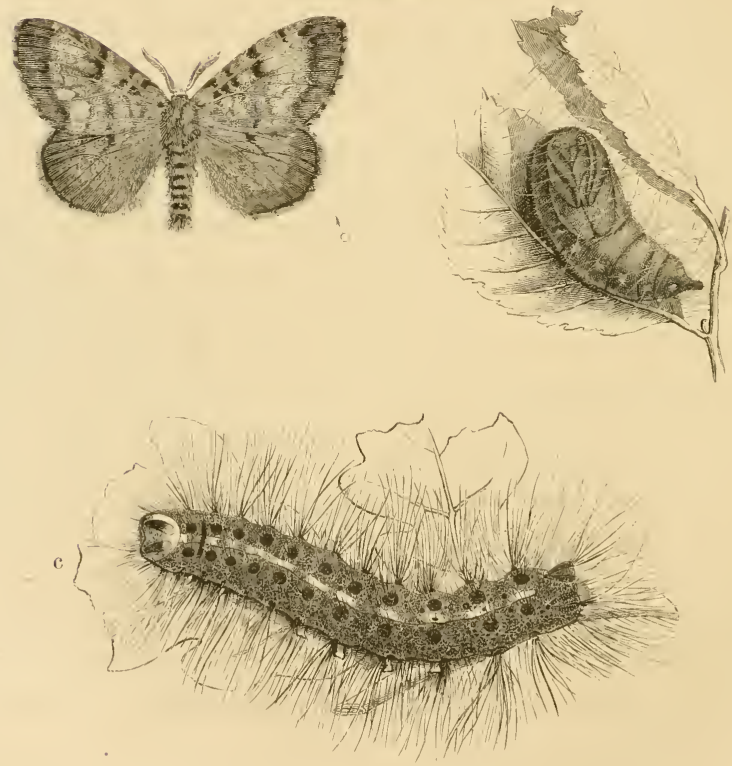

Der Sdfwammipinucr, Liparis dispar (Ph. B.) L.
a. männtidyer, b. weiflidyer ミ(d)metterfing.
c. Siatpe. d. Sitte. 
Snjeftenzwittern gewibnlich ber Fall ijt, äußerlidy an ber eimen Seite weib lidye, an ber anbern bie mänulichen Sienuzeidyen au jitch trug, aljo an ber

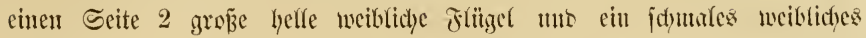
Jüflgorn, an ber antern 2 flechere ounfle mämnliche Jlitgel tur ein breites soppelt gefïunntes mänulid)es J̈̈lyl(for'u.

\section{Der Mecioenjpinuer, Liparis salicis (Ph. B.) $\mathbf{L}$. \\ IIIID}

\section{Der Sioldafter, Liparis chrysorrhora (Ph. B.) I.}

fint zwei in jober 2 Beziefunty cin ariser jelyr verwanbte un๖ äly liche Sclynetterfinge, wälyrento in ifyren gaumen Ginlängliçye lluter.

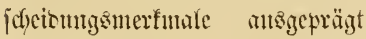
finto, wie ties bei ben Jaltern ziemlidy oft ser Jalf ift. Glyre Jarbe ijt ein blenoeno reines 23ei größ̈eren 2 eibenjpiuner milds= bläulidy fojimmert mo ricjen Gier uno ba ben Bolfsnamen Miolfendieb cingetragen hat, wäfrent berjelbe jonjt and) Singelfur genannt wirt, weil jeine Beine jofwarz geringelt jint. 2tm (5olbafter. jeidynt jidi) neben tem blenbenoen 2 seif bes ganzen übrigen förters an

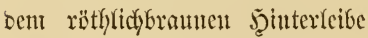
cin roftigelber affertyarbüfdyel (ठ), ober am jdywarijbrantuen ein roty = ซig. 12. a.

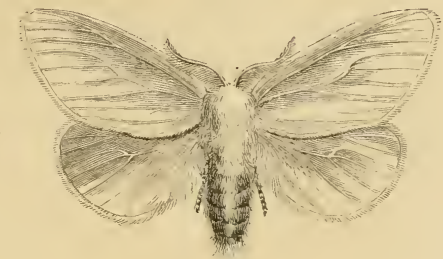

b.
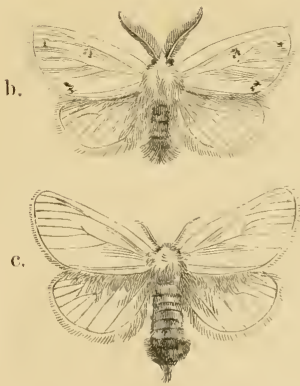

a. Der $\mathfrak{B e i b e n f p u n e r , ~ L i p a r i s ~ s a l i c i s ~ ( P h . ~ B . ) ~ L . ~}$ b. Miännd)cu bes (5oldafterв, Liparis chrysorrhoea (Ph. B.) L. c. Wietboen bes Gartenbirnipinners, L. auriflua (Ph. B.) L.

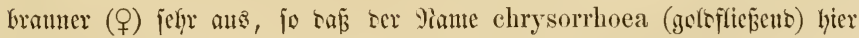
alferbings weniger paffent ijt, als bei sem jefyr verwanten (batenbirn

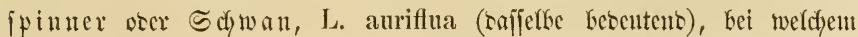




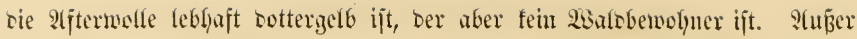
siejer Jarbe ter afterwolle miterjuciset jidy L. auriflua nod jidyerer burdy sen ungewögntiç langen Jranjenjam tes Smmenrantes oc Borterflüget vor L. chrysorrhoea. (Jig. 12 e.)

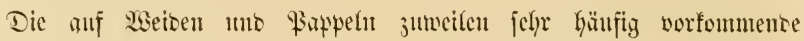

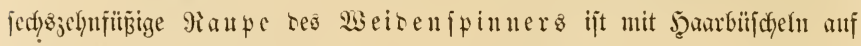
rothen sinopfwarzen verfeben uno saturch jofort ju erfennen, baj über ben

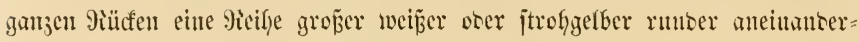

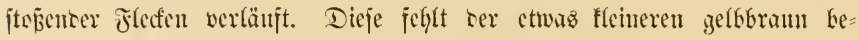
haurten Raupe bes (soloafters weldye jid) Dumed zwei beiberjeits neben

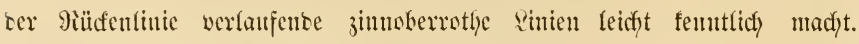
Die Fuppe ijt cbenfalls mit Şambäjcheln bejeţt.

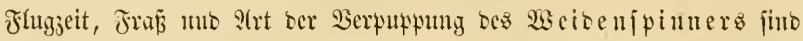

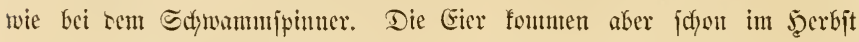

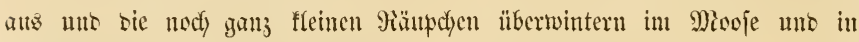

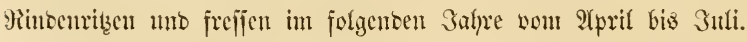

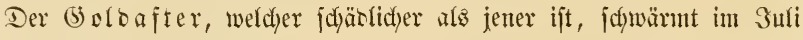
Abenta uno legt jeine 200-300 Gier an bie Unterjeite ber Blätter. Schon im Suli ober in SHgujt eridyeinen bie Mäupdyen unb nagen an ben

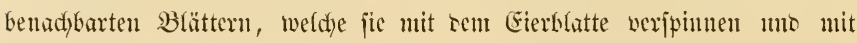
einem rïnnen Scibengejpinujt überziefgen. In biejent (scipimnt ïberwintern

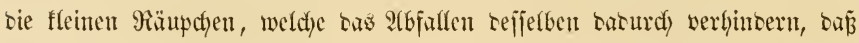
fie tie Blattjtiele mit tem Bueige fejt verjpinnen. Diez jum sie kefamnten

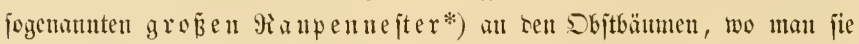

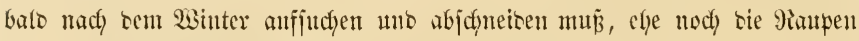
ifj Winterlager verlajfen uns jidfy über sen Baum verbreiten.

Tlle sicje brei meizen Scfunctterlinge, weun wir ben bloz genumnten

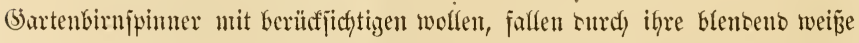
Jarbe, wenn jie träge an ton bunfeln Stänmen jitzen, reidjt in's Ŷtuge.

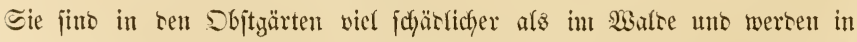
unverantwortficher Weije in sen \$appelafleen, ten Simnbiloern ber sang tweitigfeit, förmlidy gehegt uno wanbern bann in benad)barte Gärten über.

*) Die fleinen 9 anpennefter fino bie ans nur einem Błatte beftebenden Sinterquartiere ber Raupe Des Baummeiß̧lingż, Pontia Crataegi (Pap.) L. 


\section{Der Riefermipinuer, Gastropacha Pini (Ph. B.) L.}

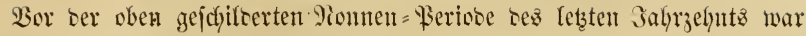

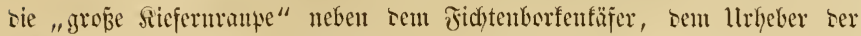

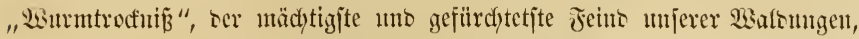
uns fie ijt, wem and bon scr Monne meit übertroffen, nody inumer cine (5)eiz̄el ser Aiejernwaltomiget.

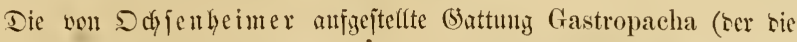
(5)attung Lasiocampa Schrank finoityu ijt) entlält 32 europäijcte S(rten,

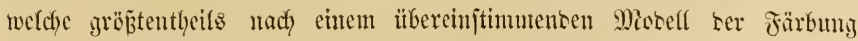

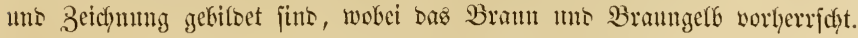
Man bringt bie 2trten in 2 (5ruppen, je nacfocm fie auf oen Borterfïligefn

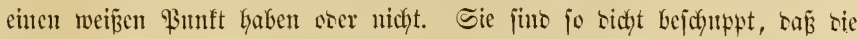
Flïgef zutweilen, 3. B. bei ben Sicfernfpimner, bem glatt anliegenton Miäuje=

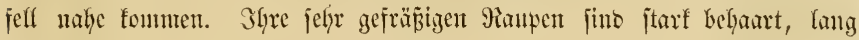
gejtrecft uno tragen meijt hinter ocm 2. uno 3. Seibezringel bejonters ge=

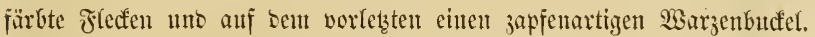

Der Siefernfpinner ijt einer ber grö̈ten mo idfwerfülligifen unfer

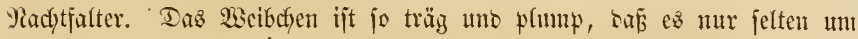

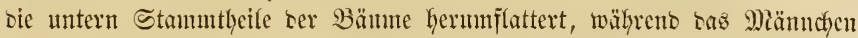
wie gewöhnlich lebbafter ijt, uno jefbjt am Tage herumflattert, แแ taz

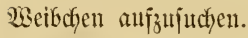

Ŝn ser Färbung iît faum ciut Schmetterfing (a b) veränterlicher, intem neben ber argebilocten Pormalfürbung (b) nicht felten folche mit faft einfarbig grauell ober graubrauten. Borterffitgeht vorfonmen. Die Borter=

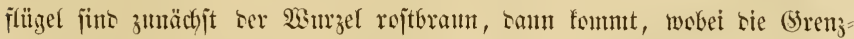

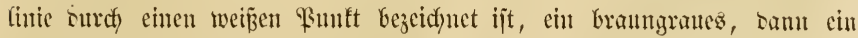

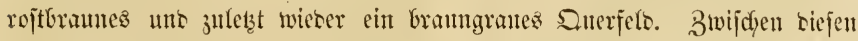
jints sie (5trenglitien buthtig ausgezadt uns melyr ober mentiger sunfler ge=

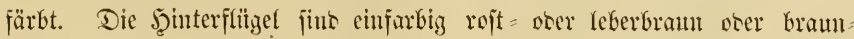
gran. Die Itnterfeite aller 4 slitgel ijt einfarbig graubraun ober braun=

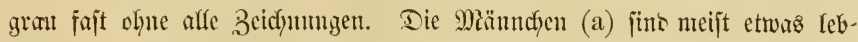
hafter in ser särbung unb fchärfer in ser Zeidynng ber Sorserflügel, uno ba fie meift aud) beträdytlidy fleiner find als bie Wieibdyen (b), fo fönnte

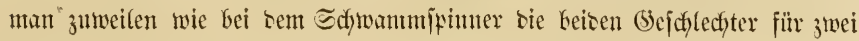


Fig. 13.

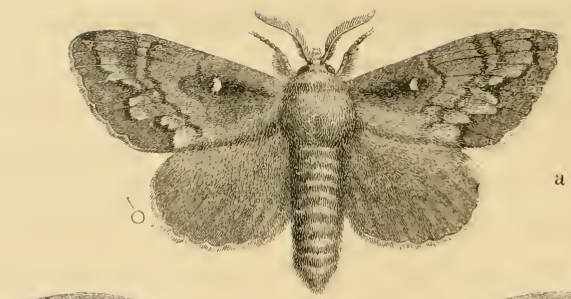

a
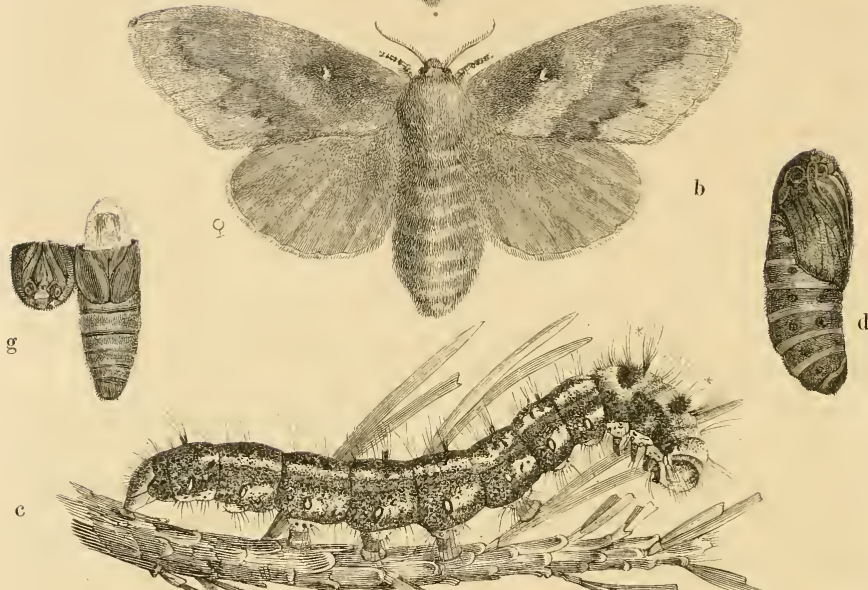

e

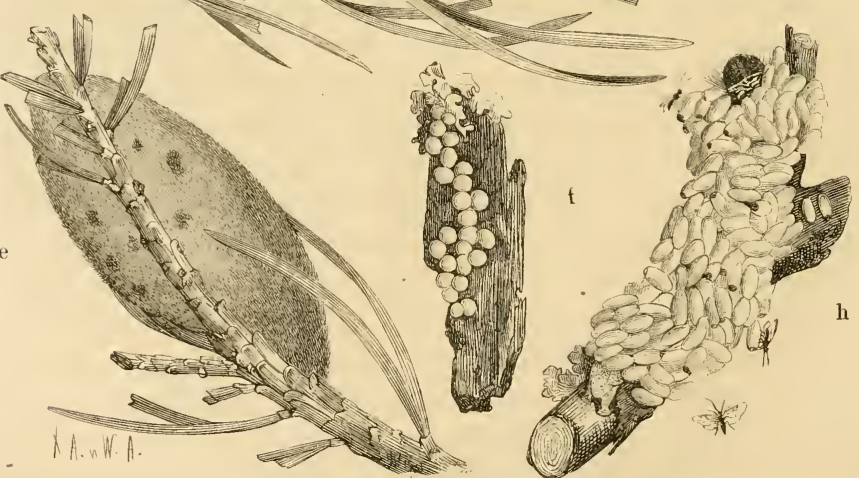

Fig. 13. Der Rieferufinner, Gastropacha Pini (Ph. B.) L.

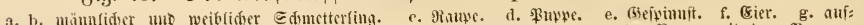

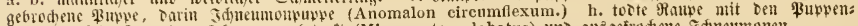

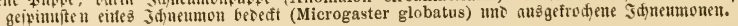




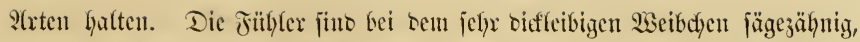
bei sem joblanferen Miänndf)en breit beftelt fammzäf)nig.

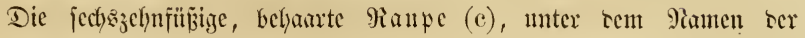

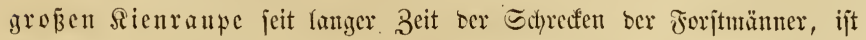

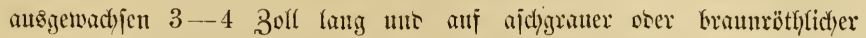

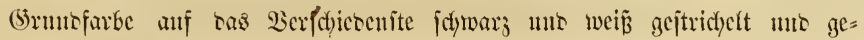

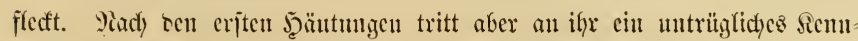

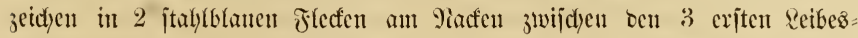

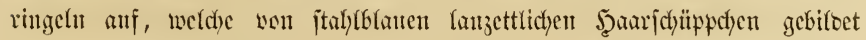
werten mo namentfich Leim Jeerabbiezen Des Ropfes beutlich hervor treten $\left(c^{* *}\right)$.

Die Puppe ijt bramnjywarz unt, wic and) fei affen workerbejdyriebenen

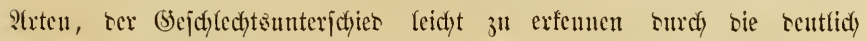
crfemibaren Steffen, wo tie Fühler fiegen. Sie ijt von cinem braungrauen,

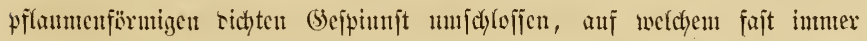

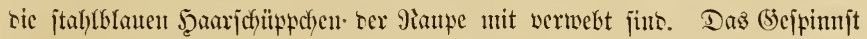
ijt an oer Siopfifeite mit cinen rocferen Sciscngemirx verichloffen.

Die Eier (f") bou ber (bejtalt uno Brö̈e cines Senfforues, anfangs landfyrïn, nor teu ?Hefrictyen gran.

Der Edymetterling. fliegt un bie 9)itte tes Suli, balo früfer, balto ipäter uno legt bie $100-250$ Gier in fleineren \$sartien an bie Borfe meijt

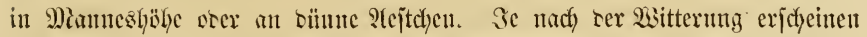

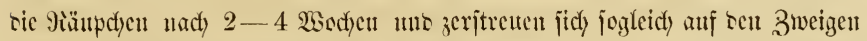

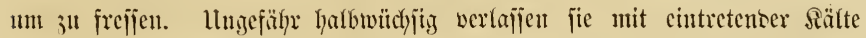
in Setober, felten erit im Sovenber, bic Bämne, un unter ser Bobenften

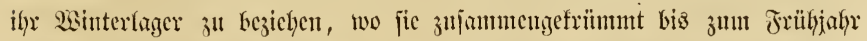

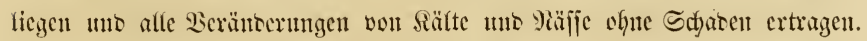

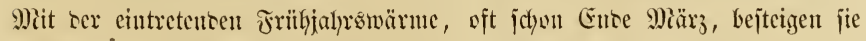

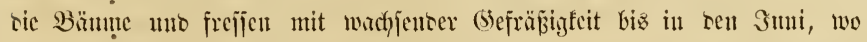

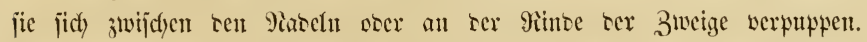

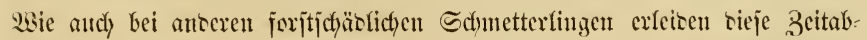

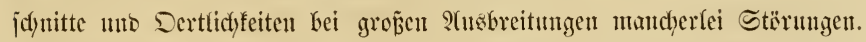

Die Sianpe tez Siefermpintures ijt bisher nur anf Ricfern, Pinns

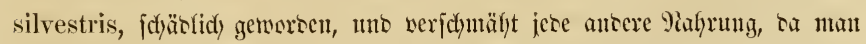

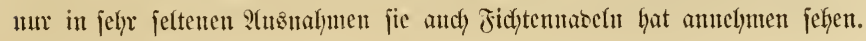




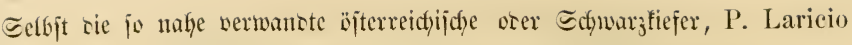

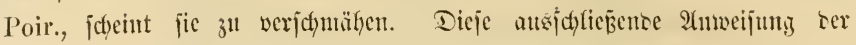
Raupe anf bie Siefer madyt sicje natürtich) für sie Riçermbalsungen um

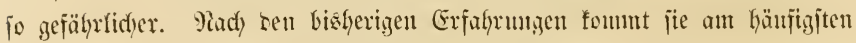

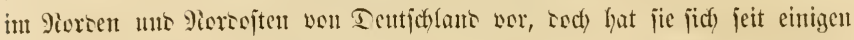

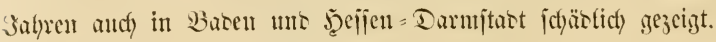

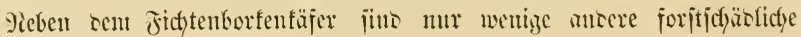

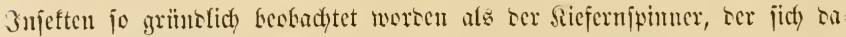

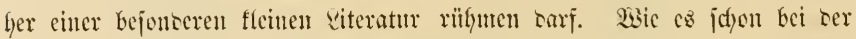
Poune gelegentlid) erwäfnt wutre, unto wie es and bei anteren Forjtitipften

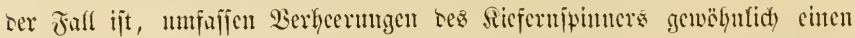

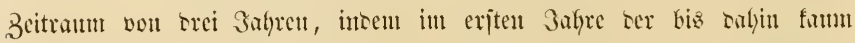
in einzelnen Exemplaren anfïutobar gewejenc Ect)metterling in fictbarer

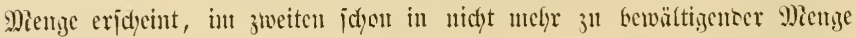

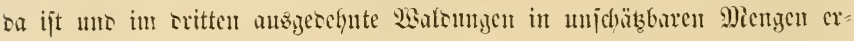

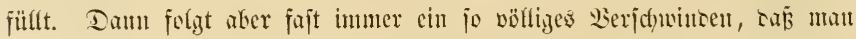
int vierten 3afyre fein cinziges febentes Exemplar metyr fintect, wo man in

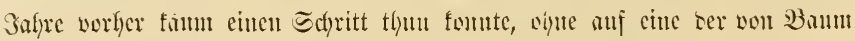
3" Baum wanbernten Manten j"l treten.

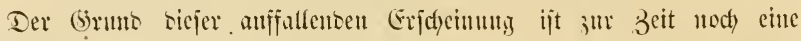
Streitfrage. Wir werten fpäter sie ïberans intereffanten Grmpten tor

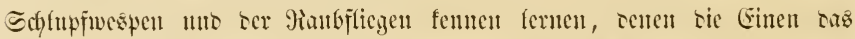

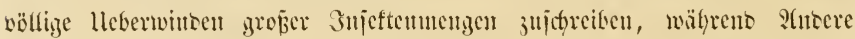

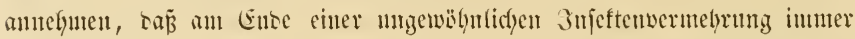
eine Seuche cintritt, weldye sie nody weiter getyente Bsermetyrung werffintert.

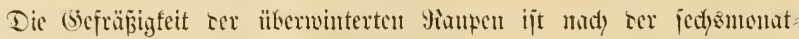

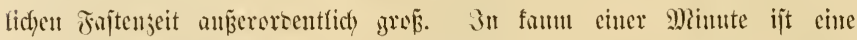

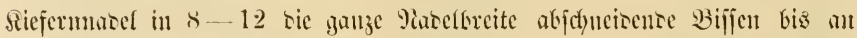

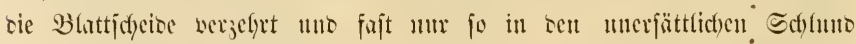

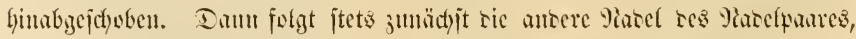

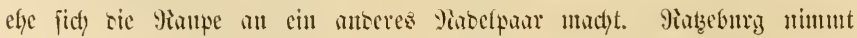

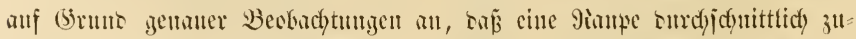

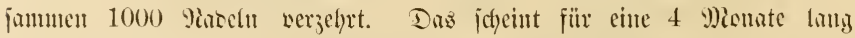

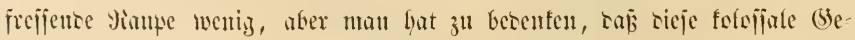

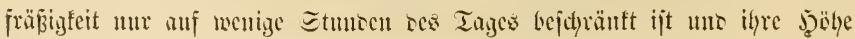




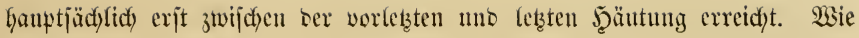

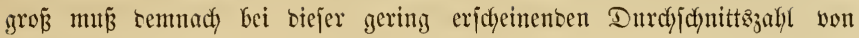
1000 Pabeln für jese Raupe sie Zahl ser Yetzteren jein, wenn 3. 23. anf sem prentip. Mieviere Thiergarten in ben 3afyen 1838 แno 1839 jujammen

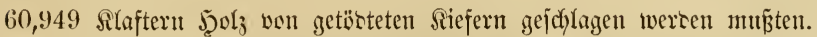

Die 23ertilgung bes Siefernjpinners lyat jeit langer 3eit ben Scharf

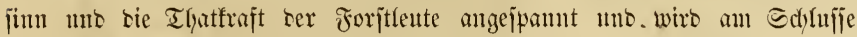

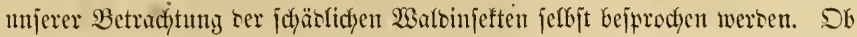
babei bie 40 Sdylupfwespenarten, weldye töstente Schutarotzer ses Sicfern=

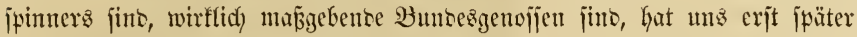

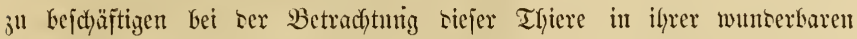
Rebensweije. Dabci weroen wir auf unjere Figur $13 \mathrm{~g}$, h zuritffonmen.

\section{Der Cidfen= Proccijitongipinuter, Gastropacha processionea (Ph. B.) L.}

Yädyt broz bie Bienen, 2respen, Atmeijen uno bie anbern in riejer

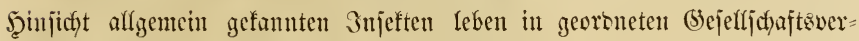

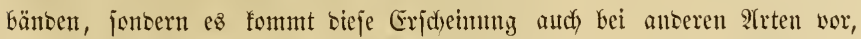
weldfe weniger befannt fint. Unter biejen fint namentfidy ber Procejfionz:

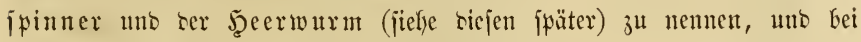
biejen beioen ipridyt jich bie (sejelligfeit woräigfich in ten gemeinjamen ge=

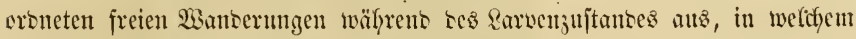

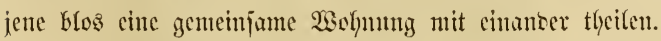

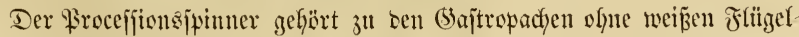
punft (j. vor.) mo ijt eine ber fleinjten 2lrten. Der $\Xi$ d) metterling (a)

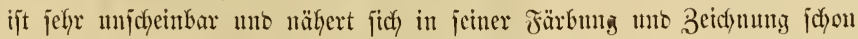

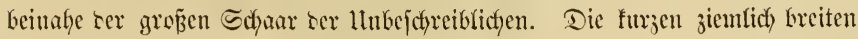

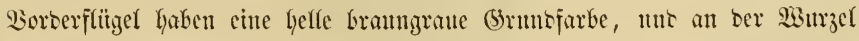
cinen weig̈lidyen Flect, an weldyen jwei jientidy nahe beifammen jetyente

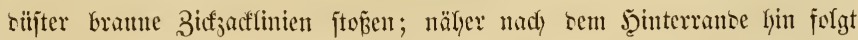
anf ein breites reines Mittelfers eine sritte gleicyartige unb juifjuen biejer in bem unsentlich funtfflectigen Şinterranse jteht eine jebr unteutlidse vierte.

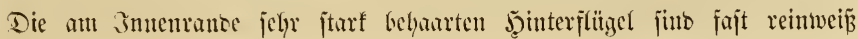


mit einer fodrägen braungrauen Edyattenbinte. 24uf ter Itnterjeite fint bicje Zeichungen nux menig benerfbar.

Fig. 14.

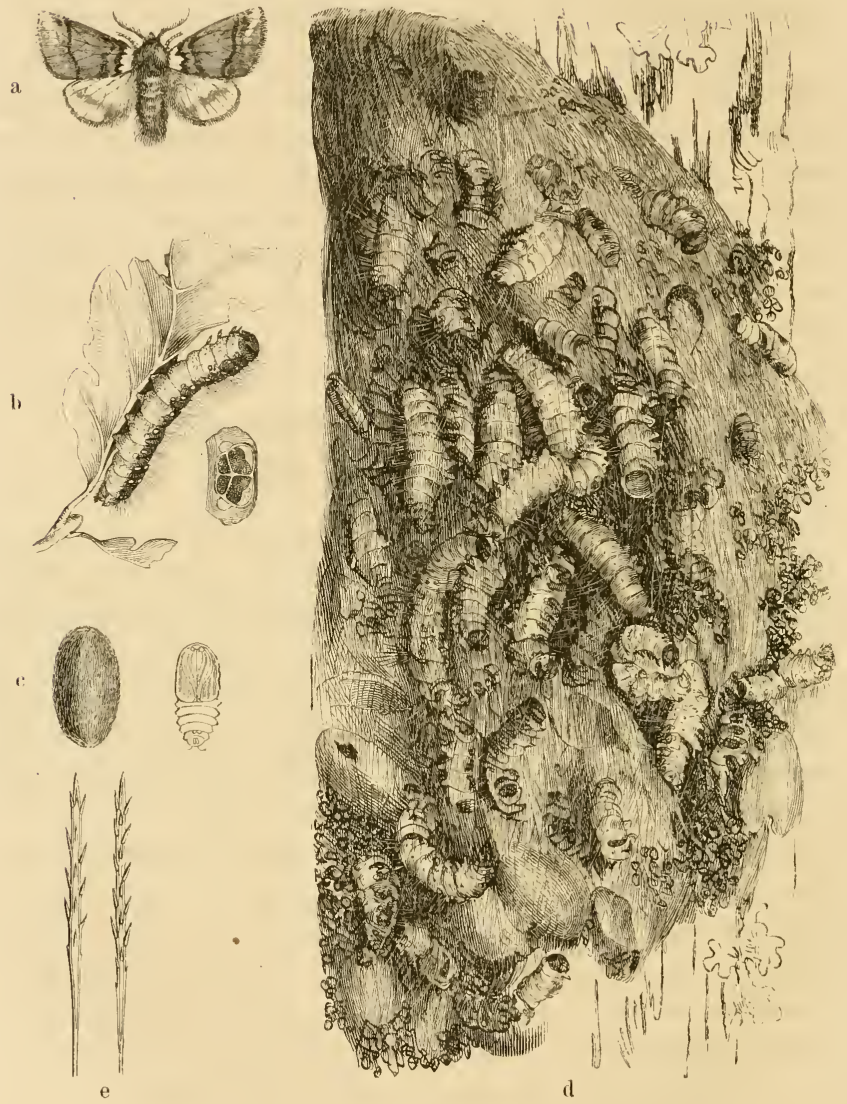

Der Eiden= firocefifongifuner, Gastropacha processionea (Ph. B.) L.

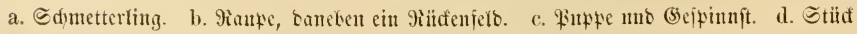
eines Gejpinmf́tballens. e. Bifthaare, jehr ftarf vergrößert. 


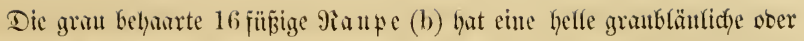

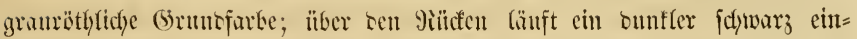

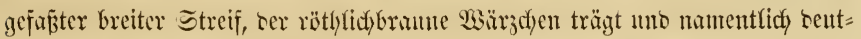

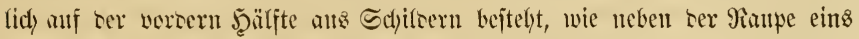

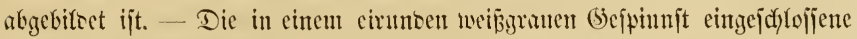

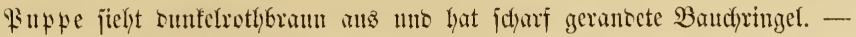

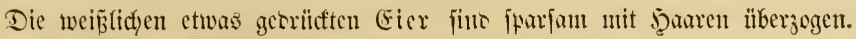

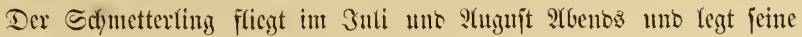
$150-300$ ïberwinternoen Eier, bie ex in j̧anfen ablegt uno leidft mit

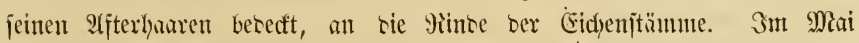

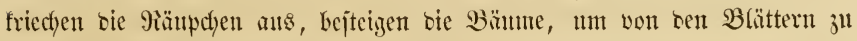
leben uno itgr gejelliges seben ju begimen. Sie jieben jidy ben Tag fantilienweife an cine gejdühte Stefle ocs Stammes, ant liebjten in 9ljt=

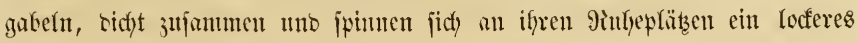

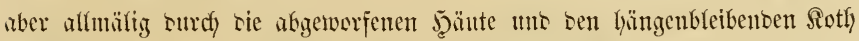
inumer ridjter werbentes baflenförmiges (Sejpinnjt (d). Mit einbred)enber

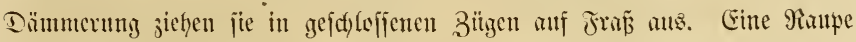

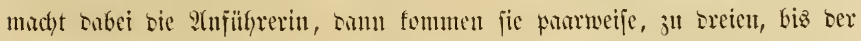

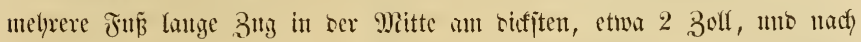

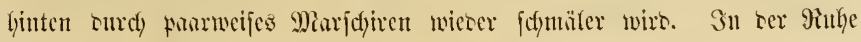

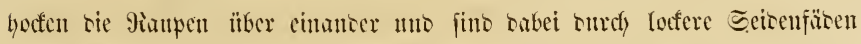

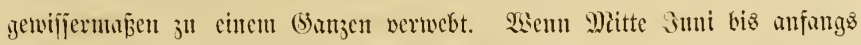

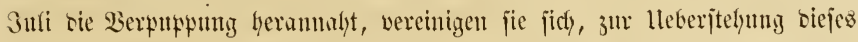

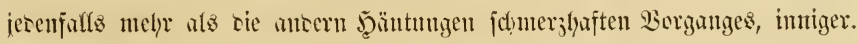

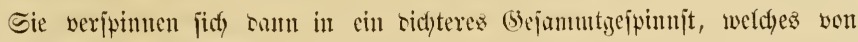

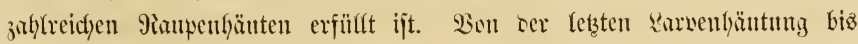

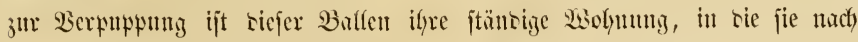

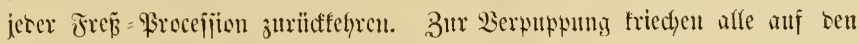

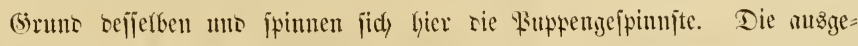
frodjenen Sidymettertinge mitijen fich affo mithjam fintomrdyarbeiten, um bas Freie zlt zुetwinnen.

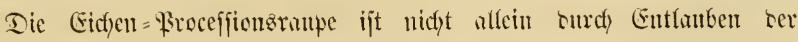

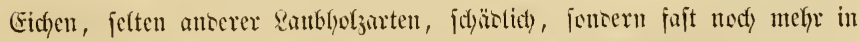

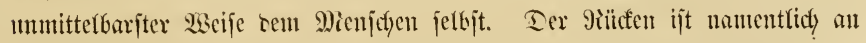

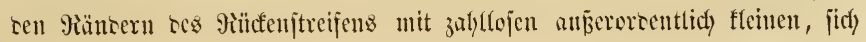




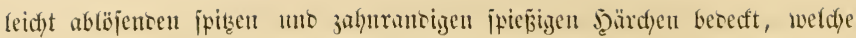

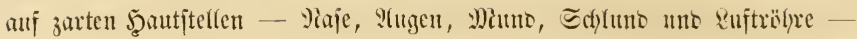

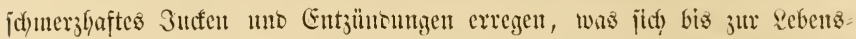

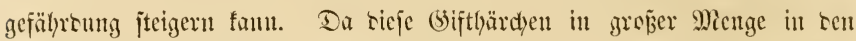

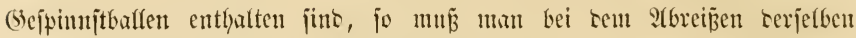

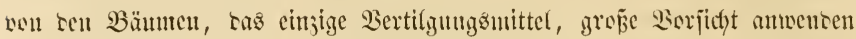

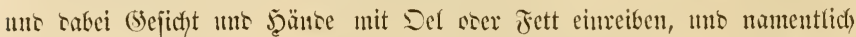

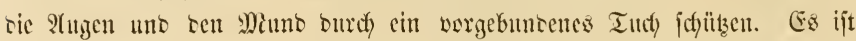

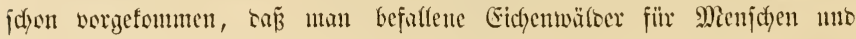
Biely lat abjerren milijen.

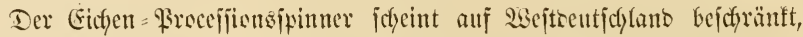

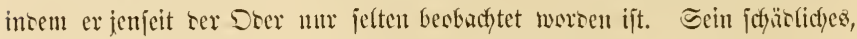

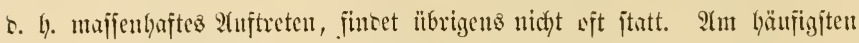

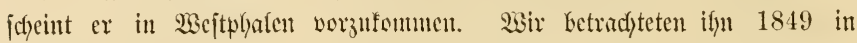

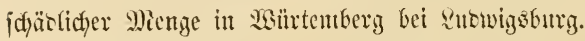

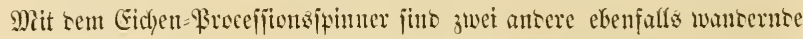

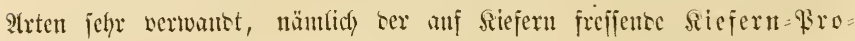
cefjionsfpinner, Gastropacha pinivora Treitschke, uno ser in Sitocuropa anf ser \$inie (P'inns Pinea L.) rebente Pinien=\$rocefionsfpinuer, Gastropaclia pityocampa Fabr.

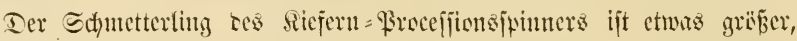
heller un untentfidfer in sen 3eidyuntzen. Er fliegt im Sorfoumer.

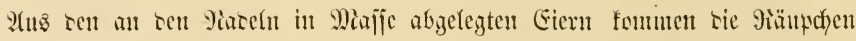

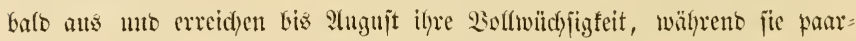
weife in bantfürnigen 3iïgen wantern. Sic ïberwintern als \$itppe in ter Erte. Die $1 \frac{1}{4}$ 3oll langen Sianten haben siejelbe giftige Eigenfld aft wie ric ber anf oer Eidhe lebenten ?Irt.

\section{Riıgelipinter, Gastropacha neustria (Ph. B.) L.}

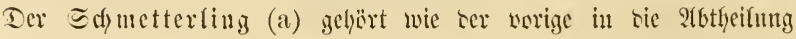

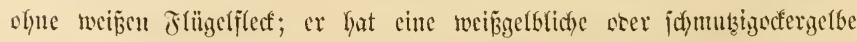
Farbe nit cinem ctwas bunfleren Suerbante ïber sie Mitte ser Lorber.

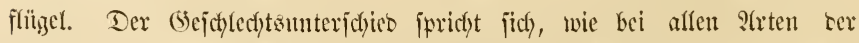

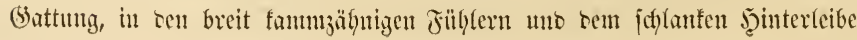


bes fléteren Miänuthens ans. - Die Miaupe (b) ijt unter bem Viamen Ringel= noer Banoranpe affgemein befant mo als Echäbigerin ter Sbjtbämute gefürchtet. Sic wiro recidylidy 2 3oll lang, ijt weitlämfing be= haurt uno bat eine blangrane brumbarbe mit mefyeren orange= ober jiegel=

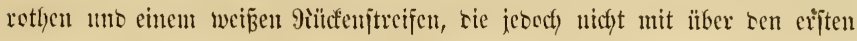

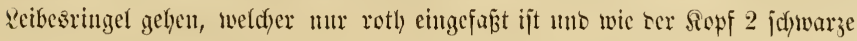
Funfte trägt. Wie bei ser uadfolgenton 2(rt rufgt bie blangrane ober Dunfelbrame \$suppe in einem opppelten Sejpinnit, eincm inneren bidfteren

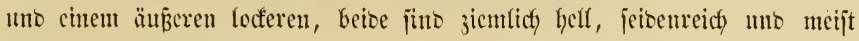

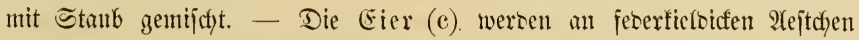

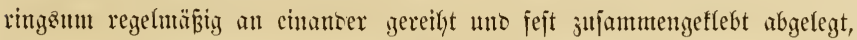
fo saj sasurch ein breiter jefwarzbrantuer Fing gebilbet wirb, ben utan

Fig. 15.
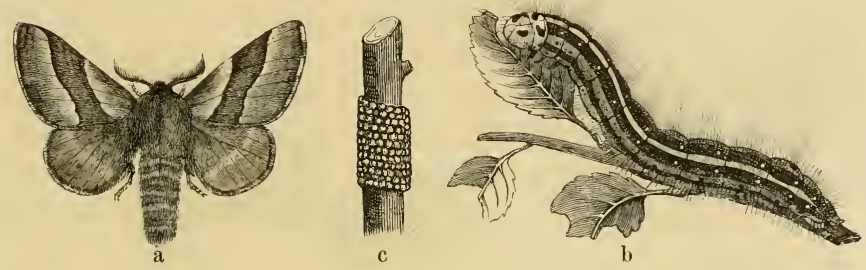

Der Mitlgelfuinner, Gastropacha neustria (Ph. B.) L.

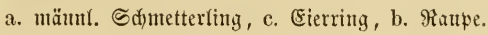

abziegen faum uno ser eintem Mä̈lyinge ber Schneiser äbnelt. Man hat

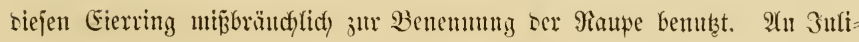
abenten fliegt ser Edymetterfing unt jetzt jofon fo zeitiz jeine Eierringe

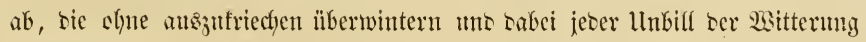

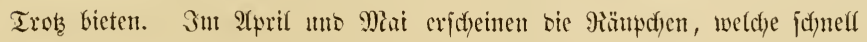

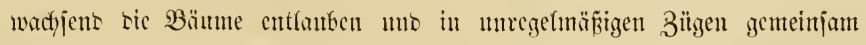

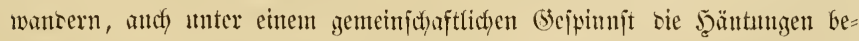
ftef̧en. Bor ser Berpuppung jerjtreucn jie fidf uno im stmi uno. Sult fint sie (Sejpimnjte meijt jwijdyen $\mathfrak{B}$ lättem ju fincen.

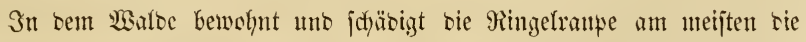
Eidyen uno fam tasurdy, bejonters wenn es jmize Eidhen.trifit, nadtheilig 


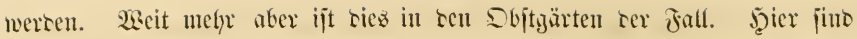

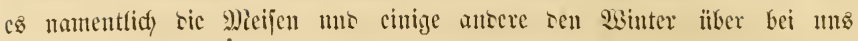

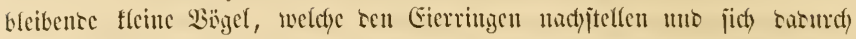

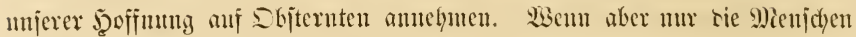

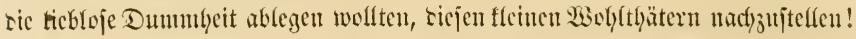

\section{Der Rotbidwatz ober Bude ujpinner, Dasychira pudibunda (Ph. B.) L.}

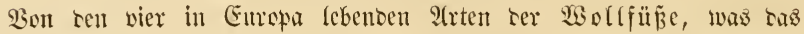
23ort Dasyehira ansorïct, gef̧ören 2 zщ ten allbefanten sentichen Raupen,

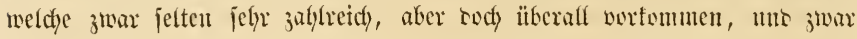

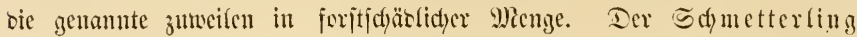

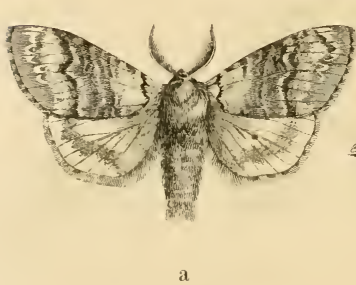

Fig. 16.

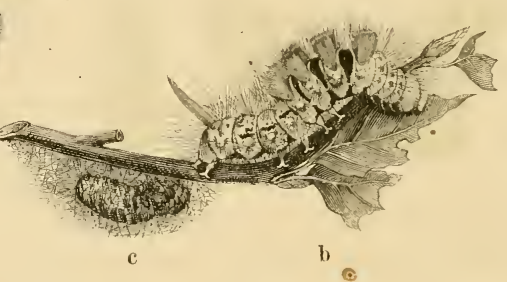

Der $\Re$ othjd wanz, Gastr. pudibunda.

a. mäunlidjer Edjutterling, b. Maupe, c. Fupte.

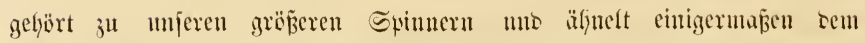

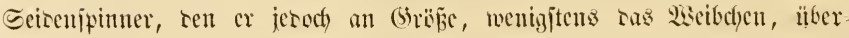
trifft. Dic (Stunsfarbe aller 4 jlitgel ijt trïbucié, anf sen surch 2 etwas

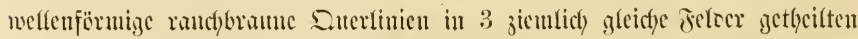

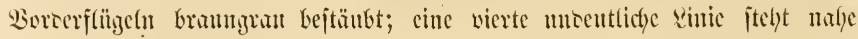

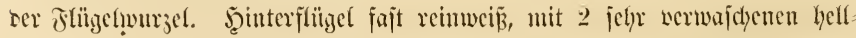

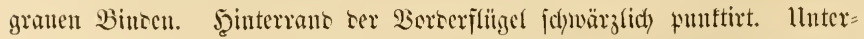

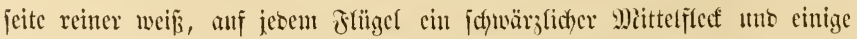

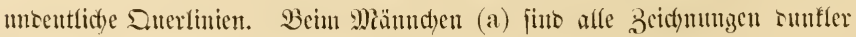

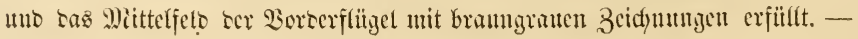


Die Maupe ijt wegen ilyrer auffalfentem Senuzeidyen allbctinnt; in ter mehr ober weniger rein citronengelben, röthlidyen ooer grïnlichen sidften

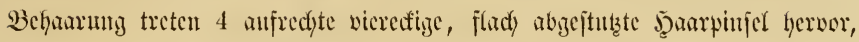

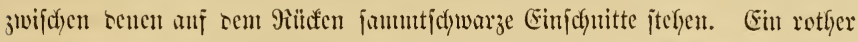

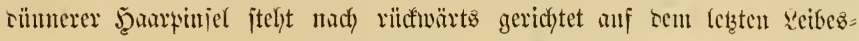

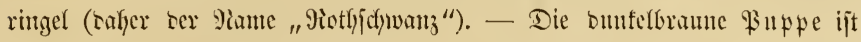

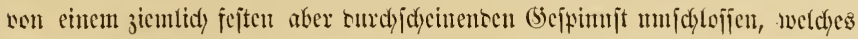

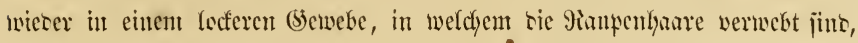

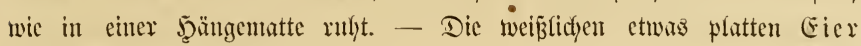
riegen frei anf Banmminte.

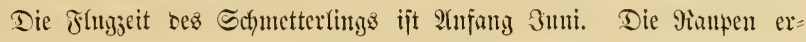
fdyeinen im Suli, ffelettiren anfangs sie Blätter nur, bie fie fpäter ganz

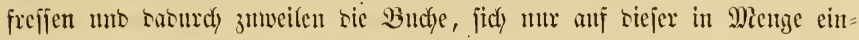

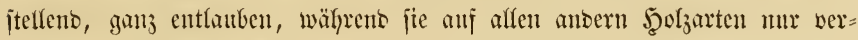

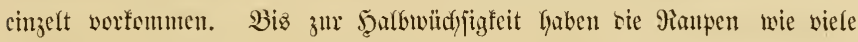

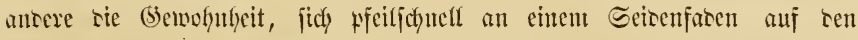

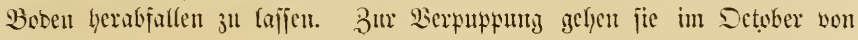

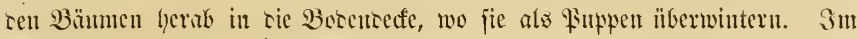

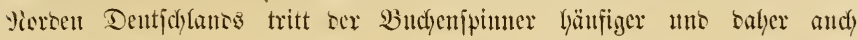
jöhätictyer auf alz int Silten.

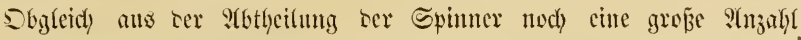

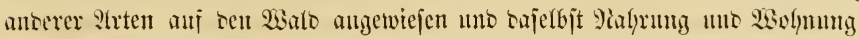

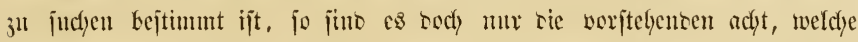

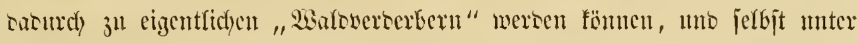

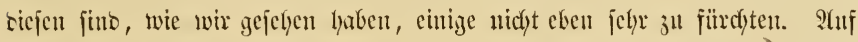

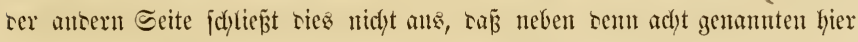

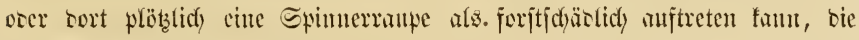
in siejer Eigenjuaft risher nod) nidjt betannt gewejen ijt. Es fint eben

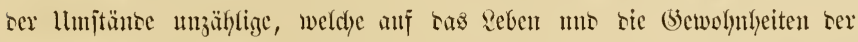

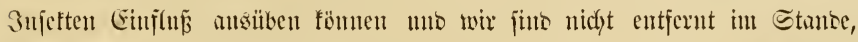

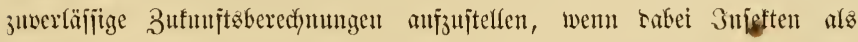
Jafteren anjtreten f̈̈mcn.

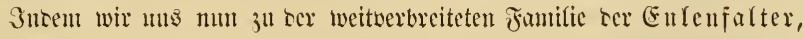
Jioctunen, wenten, mus ats bentertenswerth herborgehoben werten,

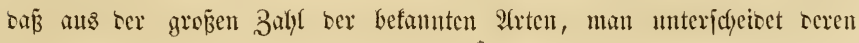




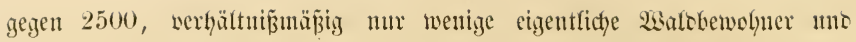

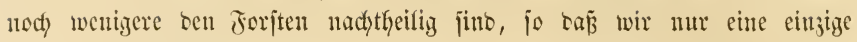

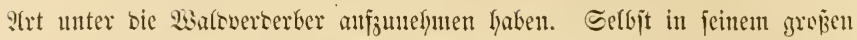

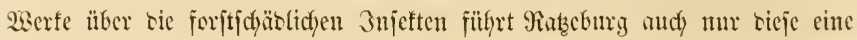
:rtt, N. piniperda, als jđ fäblid) auj.

Die Yioctuen füto ber Mieflyzahl nady son geringer sber faum mittler

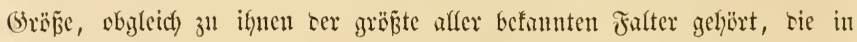
Brajilteu lebente Sgrippina, Erebus Agrippina Cram., weldyer bis 10 3oll

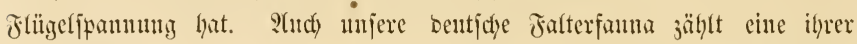

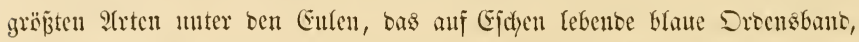

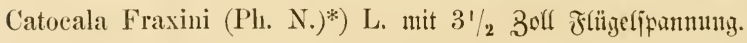

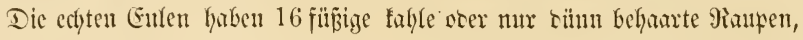
währeno sie Sruppe ber fpinnerartigen tharige mo sie ter fpannerartigen 10 orex 12 fü̈̈ige 9iaupen haben. Sie leben meijt non nieceren Sirüutern uno verpuppen jift in ter Erte.

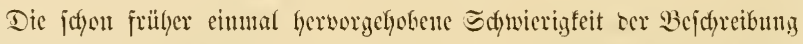
ser Jarbenzeidfunth ocr Sdyntetterlinge gilt ganz bejonters von ben Ëtlen. Bei viclen finten jids nuf ten Sorterfitigetn nebententanter ein fleiner

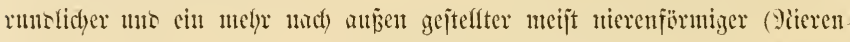

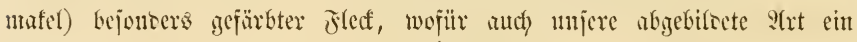
Beijpiel giebt. Die J̧interfïlïgel fund meijt jetyr einfact) gefärbt, wowon

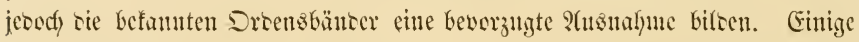

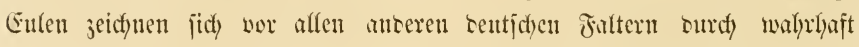

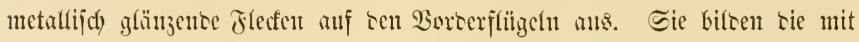

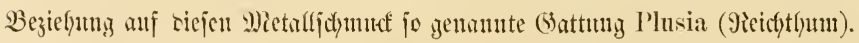

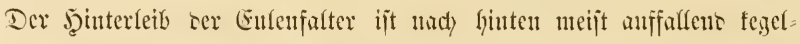

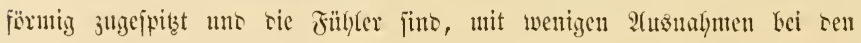
Miämndyen ciniger (Sattungen, cinfact) boritenfürmig.

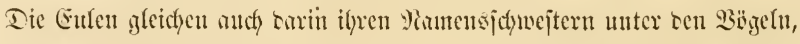
sañ fie an Tage fich) in oer Berborgenbeit verjtefter Drte faften mo

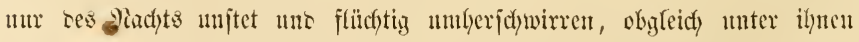

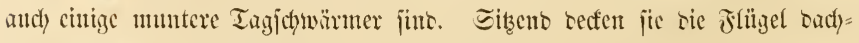
f̈̈rutig über sen Şinterleib.

*) Simné vereinigte alle Falter ber Familie in ber cinen Gattung Phal. Noctua. 


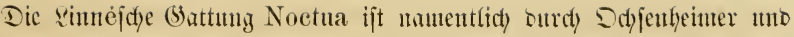

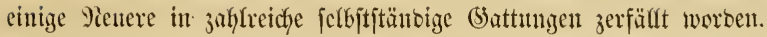

\section{Die forl = Eule, Sicfert = Eunle, Trachea piniperda (Noct.) Esper.}

Der Fafter (17 a) ijt ciuer ber fleinflen unter ben Eulcn uno won

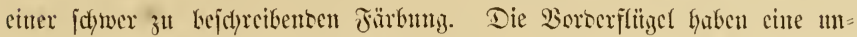

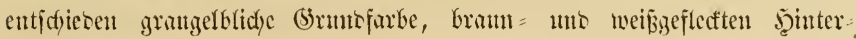
(ooer Itusenrant), etwa 1 sinie von ifm entfernt jicht fidy anter itber ben

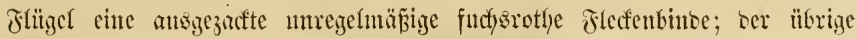

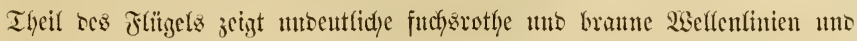

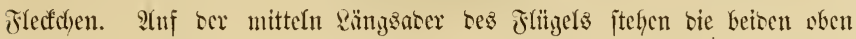

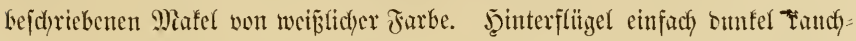

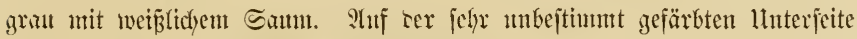

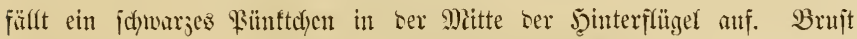

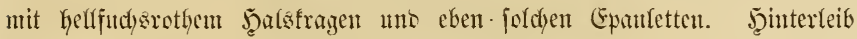
j(d)warzgraut. Füfler lang, fein mo bicht gezälnnt.

গia uno jeberfeits einem nrangegelfen Strcifen. Sopf bram.

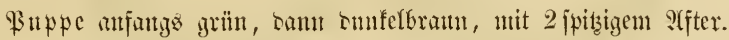

Die harbfingeligen genabelten Eicr find grïn, furz vor bent Stusfriechen

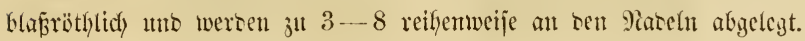

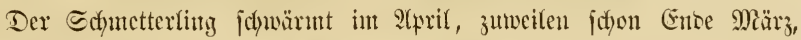

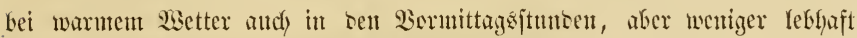

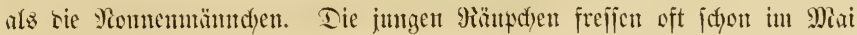
an ben eben entwiffelten Diaitricben ser Siefer mo bofyren fid) Sabei in bieje ein. Später frejīen jic andy bie älteren Mabeln bis tief in bie Mabcl= f(d)eide und macten, vou 2 sipfel anfangent, ganze Bätmte fahl, bie aber

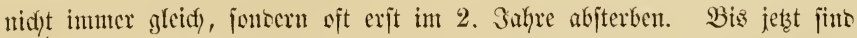

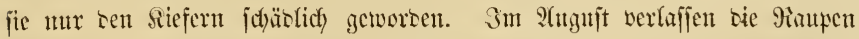

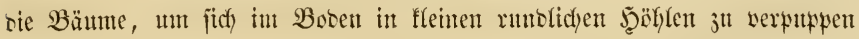
uno zil itberwintern.

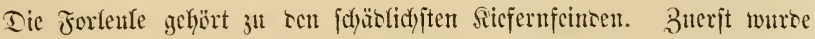
man 1783 auf igye Lertwititungen, nanentlich itt Franfen, aufuerfiam. 
3n sen funjiger Saftren war jie in Scjlejien tulo \$sjen uno in Branten

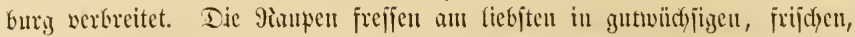

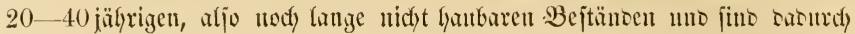

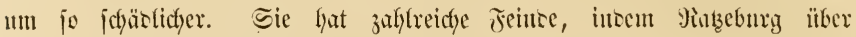

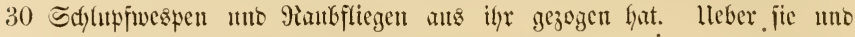

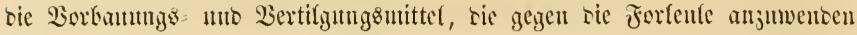

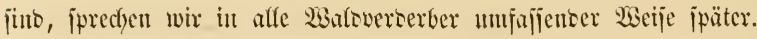

sig. 17.

a
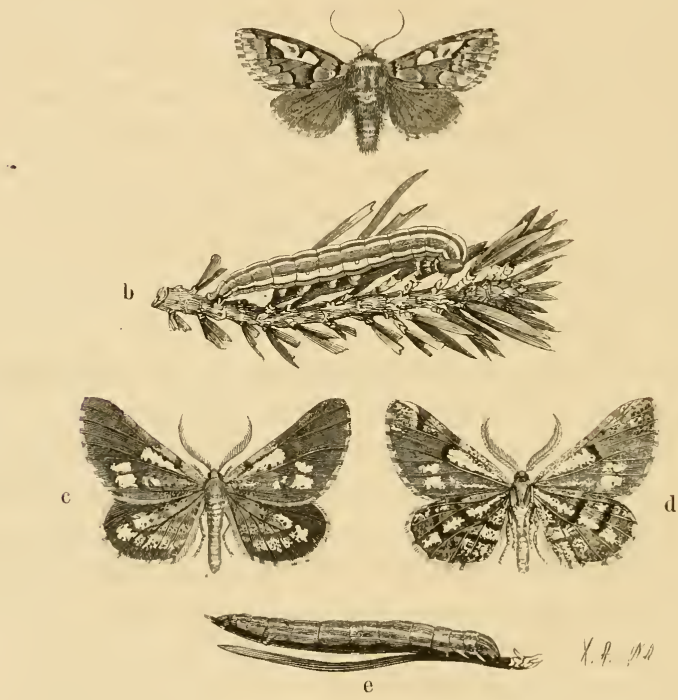

Die Ricfern= wer Forleule, Trachea piniperda (Noct.) Esper. a. Edututertinz. b. Miante.

Der föbren= ober Rieferufpanuer, Fidonia piniaria (Geom.) L.

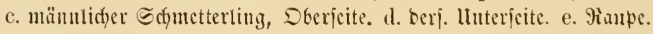

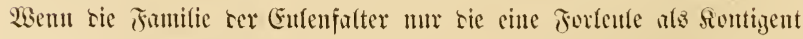

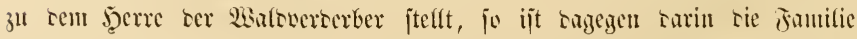

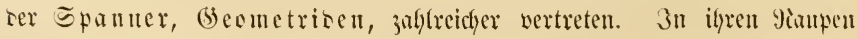
finto rie Epanner affyentin ats befonbere jict) atszeidynenbe (5ruppe betannt, 


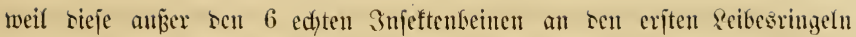

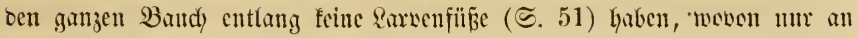

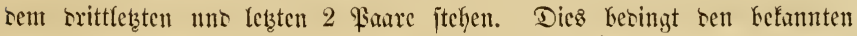

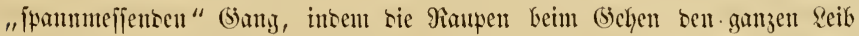

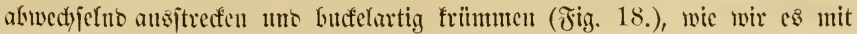
ber J̨ant machen, wenn wir sie :änge cines (5egenjtantes nach) "Spannen"

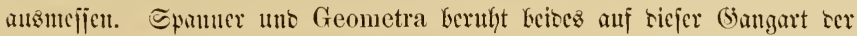

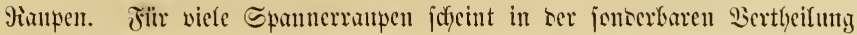

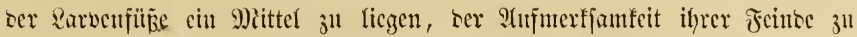
entgekgen, wie wir riez bei rem Birfenfpanter jehen werten.

Die etwa 1800 befannten Epannerarten fint ïber ben ganjen Ero

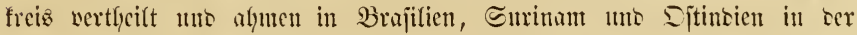
Irbtheilumb ber llraniben an (5röṕe, Sejtalt mo Farbenpradst sie Tag

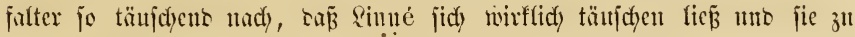

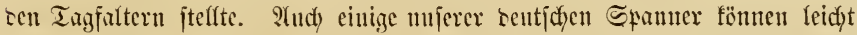

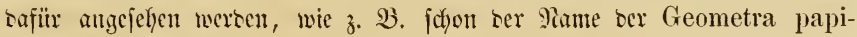
lionaria antentet.

Der Meidfthum an Trtell ser Sdynetterlingsorbunng bringt juldye

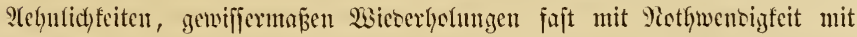

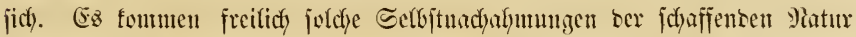

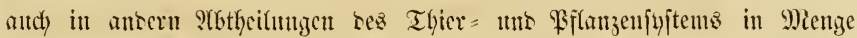

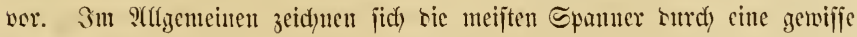

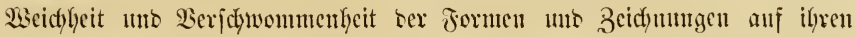
fajt immer anffalleno sünnhäntigen Flügefn aแs, was freilich cine Mienge

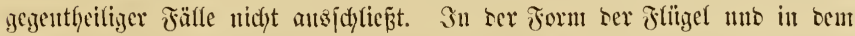

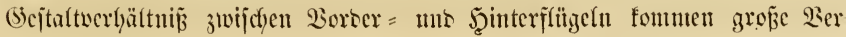

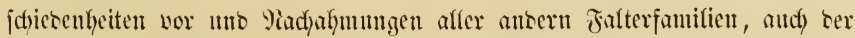

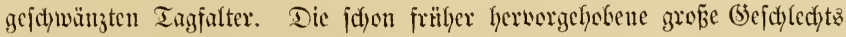

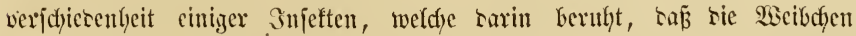
flügellos jüt, fimbet jich and bei cinizen Spantern, obyleidh auffallenber

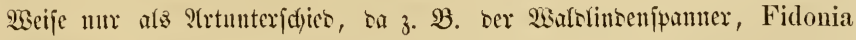

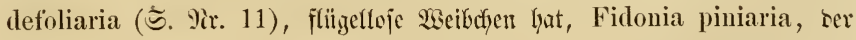

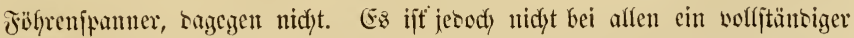

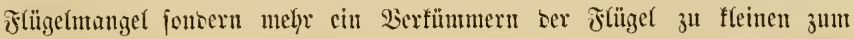
Fliegen volftommen unbrandibaren Etummeln. 


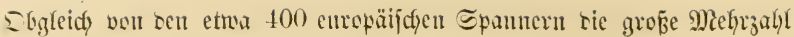

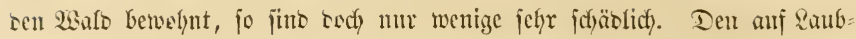

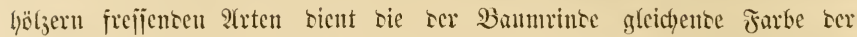

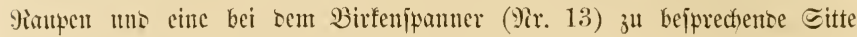
getwifferma pen als Sidncrung bor itpren żenten.

\section{Der Sicfert = ober F̈̈̈renjpauter, Fidonia piniaria (Phal. Geom.) L.}

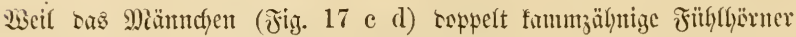
hat, encigt ter afrtnume auf aria*). Aud jonjt fino wenigitens anf ber

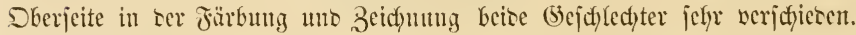

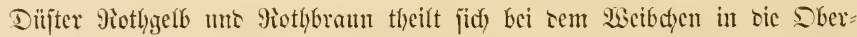
jeite aller 4 Frä̈zel, wälyreno mit Beibelialtung berjelben Bertheifung uno Begrenzung bei sem Miämadyen safür bïjter Dunfelbraun un Strohgelb

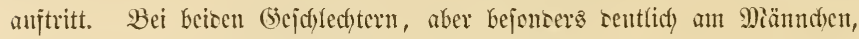

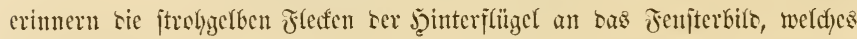
ocr Sonnenjacin anf tie Dicle cines 3immers wirft. Anf ber Interjeite

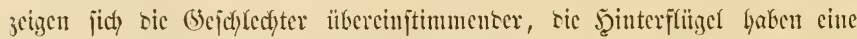

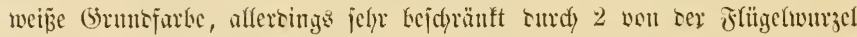

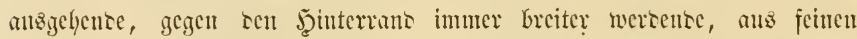
Flectef)en bejtelyente helf(rraune Streifen nno 2 quer über sie Flügel gehente

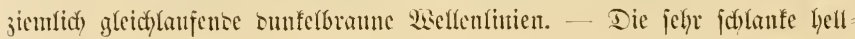

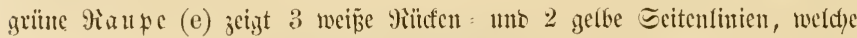
anch) nit ïher sen cbenfalls grün gefürbten siopf jid) erjtrecfen. Dic anfangs

*) Sinné madyte bie juftematijdye 3ujammengełïrigfeit ber Steinjd)mettertinge (i. bịeje

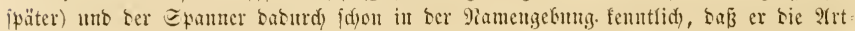
namen alfer serjenigen Epanter, Deren Mlämndyen tammfärmige Fïbler baten, aแf aria enbete (3. 23. defoliaria, aescularia, fasciaria), sic ber anberen Epanner anf ata (j. 2. brumata, grossulariata, psittacata); bie ber Zïn§ler anf alis (3. B. pinguinalis, farinalis); bic ser $26 i d f e r$ anf ana (3. B. viridana, strobilana); sie eer Miotten anf ella (3. 2. granella, roborella); bie Der Fesermotten auf dactyla, nad) ben "Jingern" in weldye ibre Flitgel geipalten fino (3. B. pentarlactyla, hexadactyla).

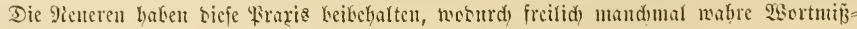
geburten eutiteben, ;. 23. nanana anfitat nana, juerghaft. 


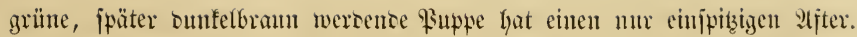
So ijt a jo bie Raupe uns bie aud etwas fleinere Fupe, trokz ber groß̄en

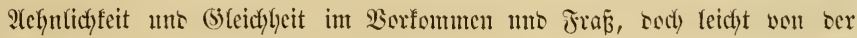
Eule ju unterjacheibent.

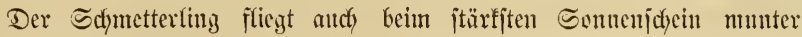
untyer uno zwar meift von Mitte Suni an, sie im vorizen 3alfue friti) ver= puppten aud mohl ctwas früher. Daz 2 betbejen legt bic (Fier an tic

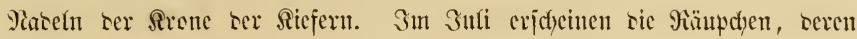

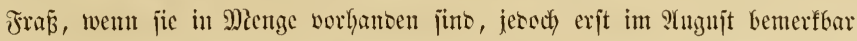
wirs. Sm September hängen jie jïh sen Epinten gleidf anjejeineno jum

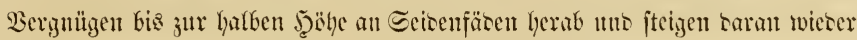

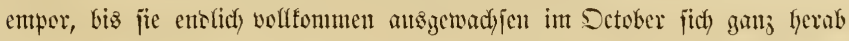
ipinnen uno unter sem Schirme ser Bänme, afjo ofye weiter zll friechen, wie sie Enlemranpe, im Erobosen unter ber Booenjtreu verpuppen.

Das in beummfigenter Mienge anftretente $\mathfrak{B o r b}$ antonjein tes Föbren

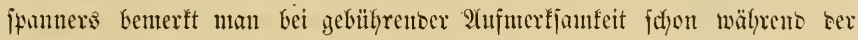

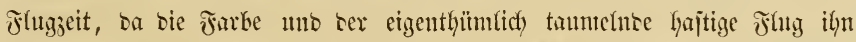
leicht erfennen läp̈t. Ex ift jwar nidyt in teme (5rate wie sic Forlente ju

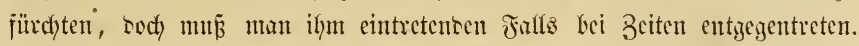

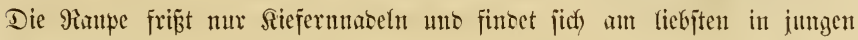
Bệtänıen cin.

\section{Der Malolitıben= Spautuer vober Blattrüılber, Fidonia defoliaria (Phal. G.) L.}

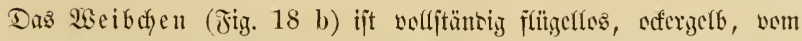
Sopf an sen ganzen seib cutlang unit ciner Doppelteilge größ̄erer uno an

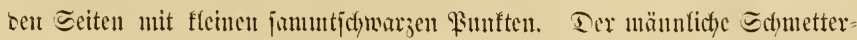

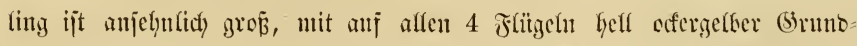

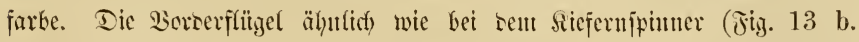
5. 112) in 3 jelser getheilt, seren nittefites ctmaz beller als bie ketoen

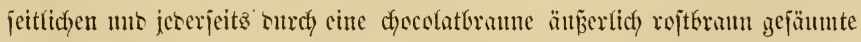

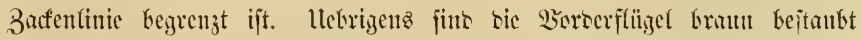

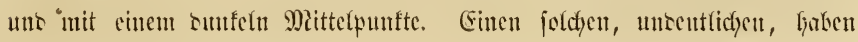




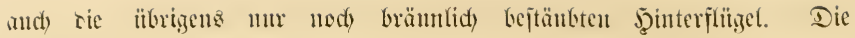
Llnterjeite gleidyt ber oberen, mur jint an ren Borberflitigen bie Beidymungen ctwas heffer. - Die gianpe (e) ijt brammoth, an ben Eeiten jdywefelgelb mit rothbramem Etridye anif jerem (5elente. - Die

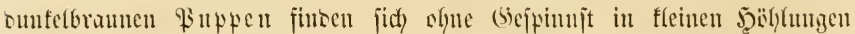
unter ser Bocenjtren.

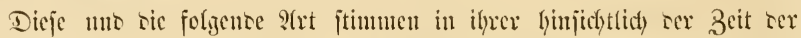

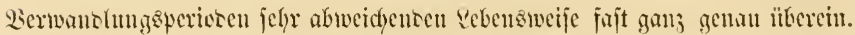

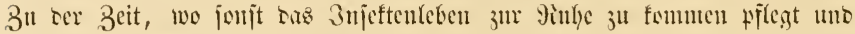

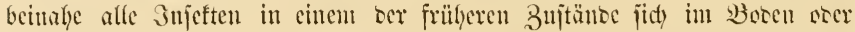

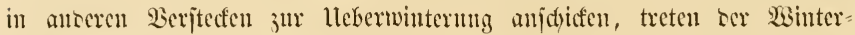

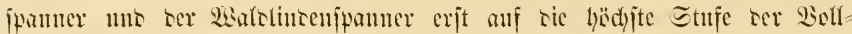
fommenheit. Bon Mitte Setober an bis in sen Miowember, ja bis in sen December jd)wärmen tic Sdymetter(inge in ser Dämmerjtute, nadysem

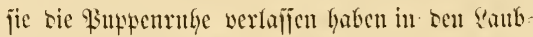

Fig. 15.

b
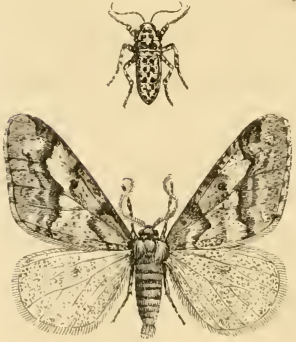

a

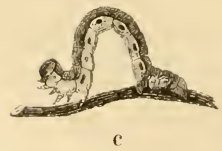

Der garbrinbenfpaner, F. defoliaria.

a. Miämndyen. b. Mseifdyen. c. Maltie. gülzern, Bauntgärten un Dbjtanlagen umlyer, aljo sit wenu bereits ticfer Sd)ucewinter - berrjdyt. Matïrlidy jinto bie jefwerfülllig unther flatternoen Ect)metterfinge błos Miännd)en, แmm

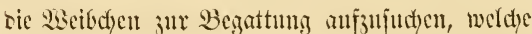
miibjefig an sen Etïmmen cumporfriect)en, fpäter ilyre winjig fleinen Eier in sen somb

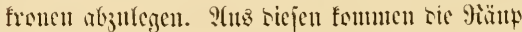
chen erit in Miat folgenten Babres soer form iu Stpril berwor. Sic bolyren fid) Sann in sic auforechenten Sintępen cill mis jerjtïren jie

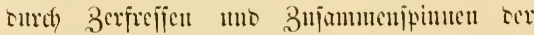

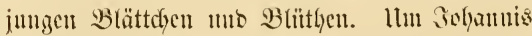

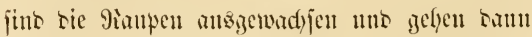
$2-3$ Boll tief in sic Erte, Im jitt) 311 ber puppen uns atts ber fistpenrulye erjt ju ber angezebenen fpäten Balyrezzeit lyervorzutreten.

Der Edyasen beirer 3mpeften tritt in

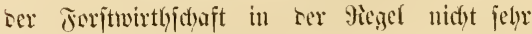
bedenteno hervor, obgleid) es bei cinizer ?tuf 


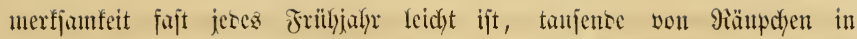

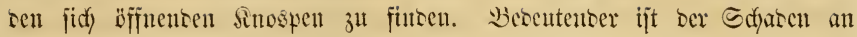
sen Dbjtbäumen, weldfe, wenn man sen Pantpen nidjt entigegentritt, wenigjtens cinen geringeren Dojtertray geben. Cis jei im voraus an sie befannten Theerringe crimnert, wostrdy man siefen beisen jchäblidyen 3njetten ju bejegnen jucht.

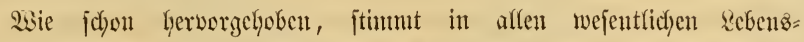
erjedetnumgen ber

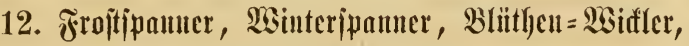 Acidalia brumata (Pl. G. G.) L.}

iibercin, befĩen 2 scibdyen wenigitens 4 fleine,

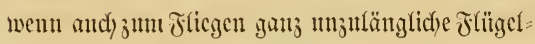
jtımmtel hat. Das Meänndyen, beträdytlich fleiner als von vor. STrt, ift von bilīter bräunlich grauer Järbutng, ser Sortserflitgel mit zahlreichen neijt untentridy werwajdyenen, quer über sie Flïgel lanfenten süftern Weffentinien. J̧interfitïget grantich wei⿸厃㔾, feirenglänzent, in langen Jranjen:

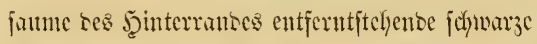
Pïnftctyen. Dic Füfler זcs Miäuntyens fino farenfermig unb bafer bie Enbigung bes itrt= namens auf - ata. - Die giöndyen jino grïn.
Fig. 19.

b
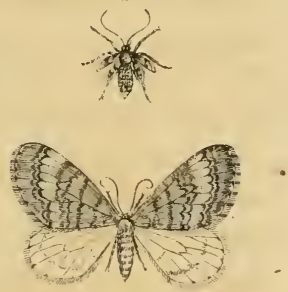

a

Der Froftipaner, Acidalia brumata (Ph. G.) L.

a. mämulidber, b. meiblidyer ङdymetterling.

\section{Birfeuppnuner, atitjnumer, Amphidasis betularia (Ph. N.) L.}

Die Flïgelform und ter bide seib machen sieje (5attung in affen

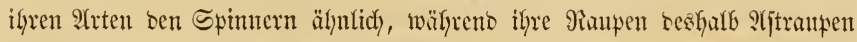
genanut wersen, weil jie in ter Firrbung uno ourdy cine oft angenonmene

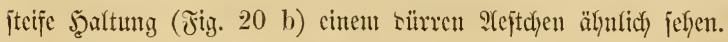

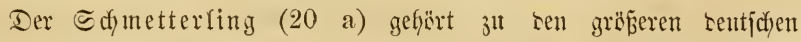
Spanmern mit ungewöhnlich lang geftreften Sorberfïlïglu uno viel fürzeren

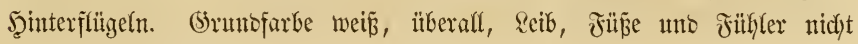




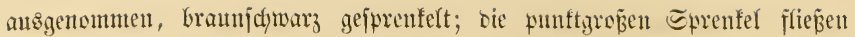

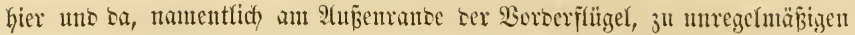
Flecfen uno sinien zujammen. Das viel fleinere Miänndyen hat ropfelt

Fig. 20.

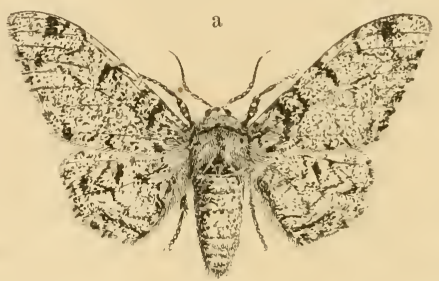

c

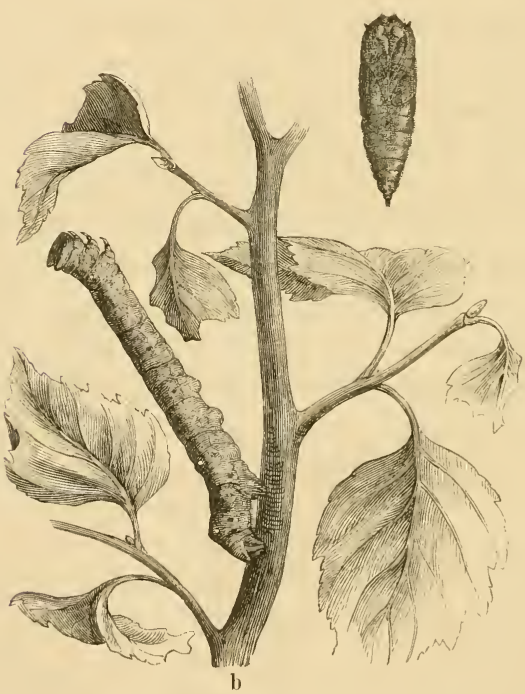

Der Birfenipanuer, Amphidasis betnlaria (Ph. G.) L.

a. meiblider Edjunctering. b. Panpe. c. Finpe.

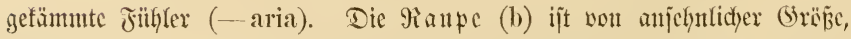
¿iferall gleidy bidf, mit zientidy fleinem, am Sdyeitel cingeferbten Sopfe; 
ric Farbe ijt, wie cs fdyeint, ie nad) sem Jutterbanm, sreifact) veriffyieben: günfidgran (Eidyen, Eberejdyen mo Birfen), jeltuer bräunlid) ober gelblidy.

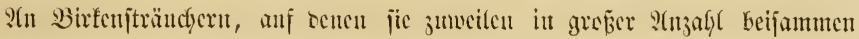

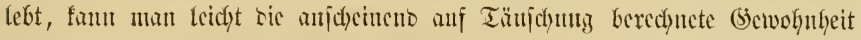

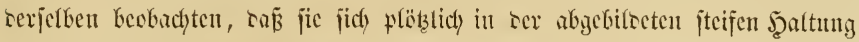
vout 3meige, anf sem jie fitzen, abbiegen, fo oaß̧ man jie leidyt für sünne

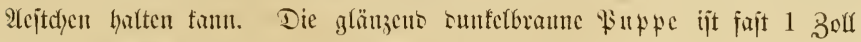
lang unt hat an Ente cincu geferkten 2lftergriffel.

3 Eeptember und Detober jint bic Manten, sic anf sen ver=

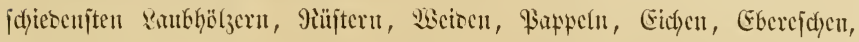

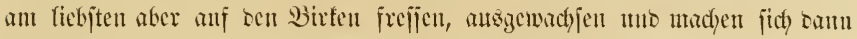

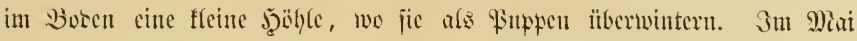

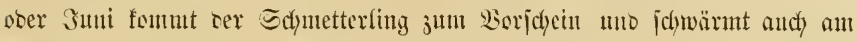

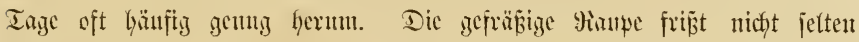
junge Birfen uno fräftige Stodfobsen gauz tafyl, fo ouß sieje längere 3eit banads fïnmern.

Snocm twir uns sarant bejdyränten, bicje menigen Spanner, แno

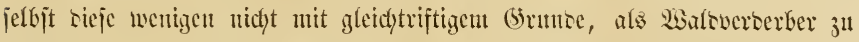

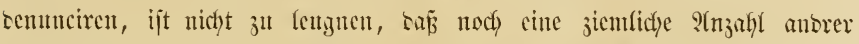

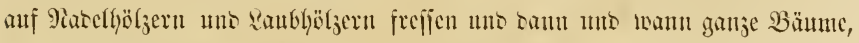

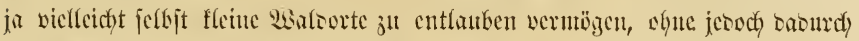
einen erlycblictyen Schaden anzuridyten.

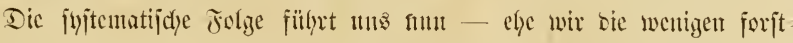

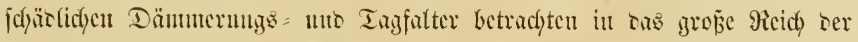
Rleinjduetterlinge, Mierolepidoptera. Miach bem Sorgange bez

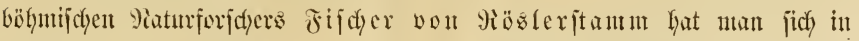

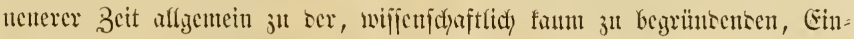
theilung ocr Sdymetterlinge in (5) rofichmetterlinge, Macrolepidoptera

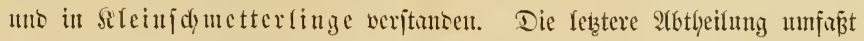
die 4 fanticn oer 3ünsler, Pyralidae, ser ssicfler, Tortricina, ser Schaben, Tineina, und ser Fesermotten scer (5eifteden, Pterophoridae.

Dieje fleinjten uno jahlreidjīten Schmetterfingsurten, beren 3udft uns

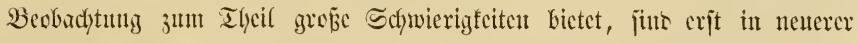

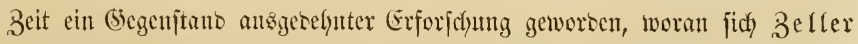
in (5togan, Jrey in Bitrich unb Stainton in sonton aut meiften 


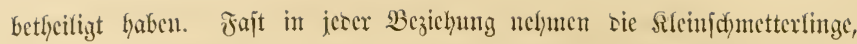

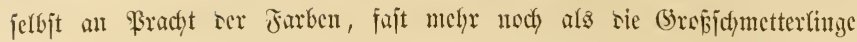

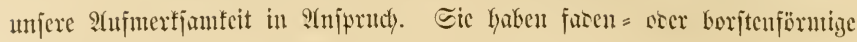

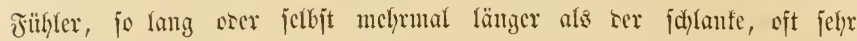

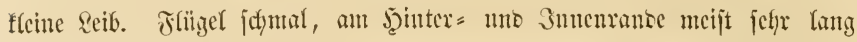

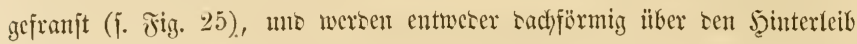

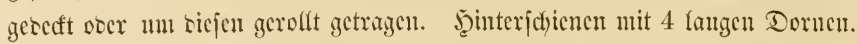

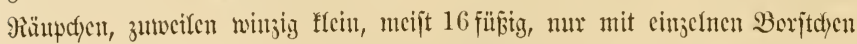

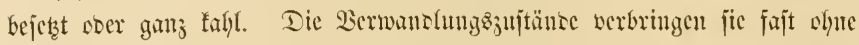

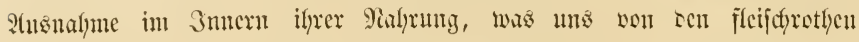

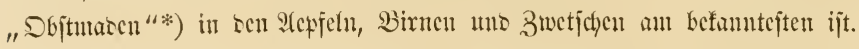

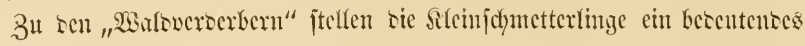
Eontingent, uno obgleich mu wenige einen jehr bercutenten Ecf)aren anju= richten vermb̈gen, fo werben wir bod) cinige fennen lernen, weldje sicjen Namen, ober ridytiger nod) sie Bencun!ng "Banmocrberber" redft cigentfict) verbienen, intom fie bic Bäume nidjt tïoten, aber bucfjitäblich verterben.

\section{Der Sicferutrich=2Siffler, Coceyr Buoliana (Phal. Tortr.) Fabr.}

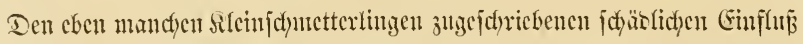

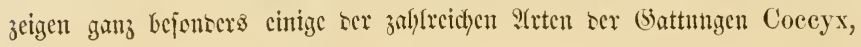
Fig. 21.

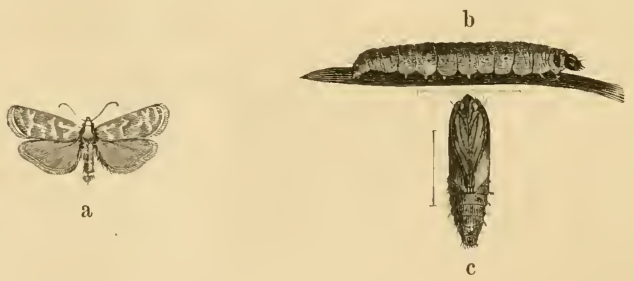

Dex $\mathfrak{B}$ u ol $\mathfrak{B}=2 \mathfrak{B}$ idfler, Coccyx Buoliana (T.) Fabr.

a. Jalter. b. 9iaupe. c. \$itppe. (Die beiftehenden Sinien bejeidnen wie immer sic

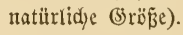

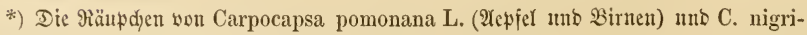
cana Fabr. (3wetjdyen uแb Pflaumen). 


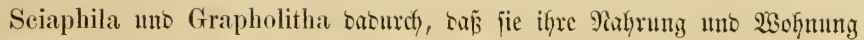

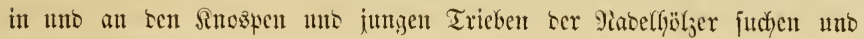
Daburch bic Entwicflung ber jungen $\mathfrak{B a ̈ u n t e ~ w e j e n t l i c ̧ ) ~ b e e i n t r a ̈ d y t i g e n . ~}$

Der Schucterling (Fig. 21 a) Des Sicferntricb = ober Buol=

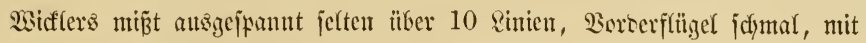

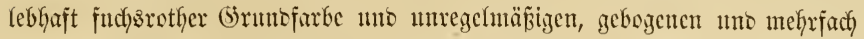

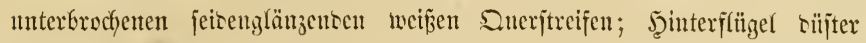

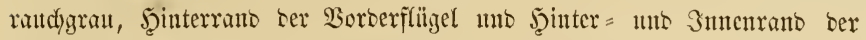
Jeinterfliigel mit jiemtidy breitem bellem Jranjenjaum. Interjeite einfach röthlichyrau. Tiaupe bis 7 \%*) lang, in ber Sugeno ounfelbrautn, erwadjen

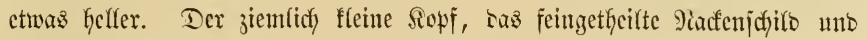

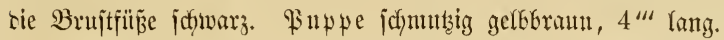

Snt Inli, wenn bie Minitriebe ber Siefer volffommen berholzt jino,

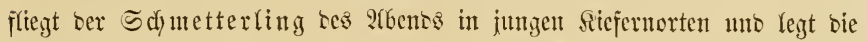
Eier żwijtyen bic finospen an ben Epitzen ber Tricbe. Die giäupdyen foumen nod in Şerbjt aus mo benagen bic Sntospen, was fict) aber nur

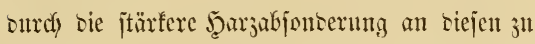
crfennen giebt. Erjt im jolgenten Miai, tocm sic Triebe jidy entwicfeln, bemerft man ilyre jă̈̈o= lidfe $\mathfrak{A}$ mwejenlyeit, inten jidh bie Iricbe an ber Seite frïnumen, wo unter einer Şarz= unt (Se)

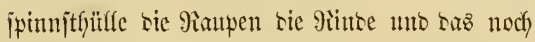
ganz junge J̧oly surdyjrefien, andy wohl wou einem Triebe 3 ll einem benadybarten thbergehen. Da biez immer nux in ber unteren joülfte sex Triebe geicficht, fo twächjt ter unverfebzte Theil berferben jicf aufridftent in geraber Yitdtumg weiter, wälyrento bic Sirümunng bes verleţten

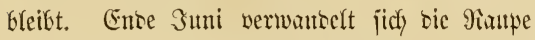

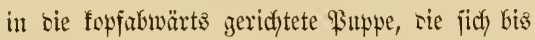
an bas Eingangzlod herabidjiebt uno ausfiliegt.

Sbgreich nur bie wenigiten Triebe jterben uno abbrechen, fo sermujtaltet body bie bleibente

รig. 22.

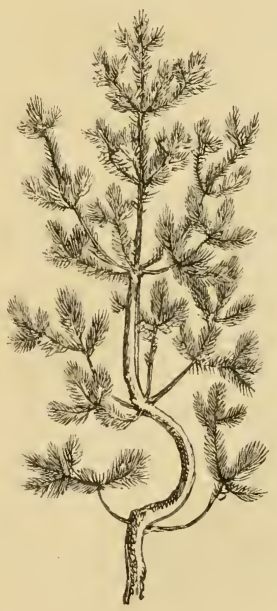

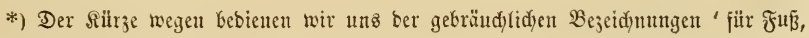
" für 3olf, " für Rinie. 


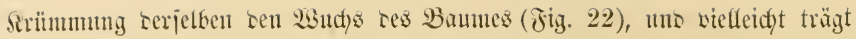

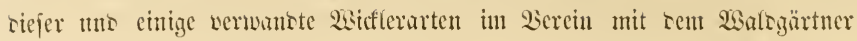

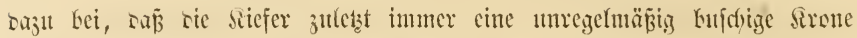
befommt, wälyento jie mely als Fichte uns Tanne megen tes Diangels an

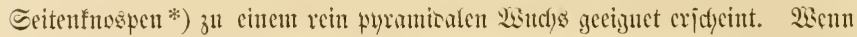

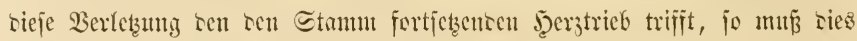

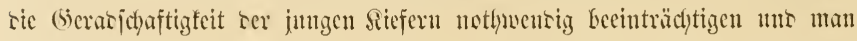

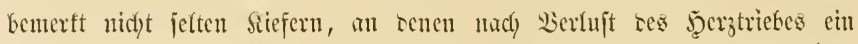
Duirttrieb jid) aufgeridytet hat, um ben Etanm fortjulfezen. Dieje $\mathrm{Er}_{\mathrm{x}}$

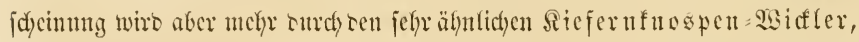
C. turioanana L., bewirft, ocfifu Maupe fajt mu sic Serjifnospe angeht.

Unterfalb ser Dnirle fincet man an jungen Siefern jiemlid) bäıfitg

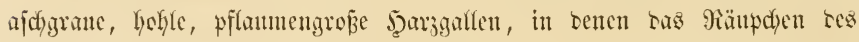

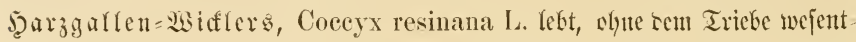
(id) nadytheifig zit werten.

3enn sieje unt cinize ansere 2 stefler mut anf ser siejer leben, fo fudyt ser Mabel=93iffer, Lozotaenia piceana (Tortr.) L. uno ber fdyarze Maserbol s wiffer, Grapholitha coniferana saxesen, neben

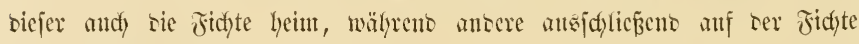
ooer Mothtame (Pinns abies L.) hanfen. Dics gitt in bejonters fääo= lichem (Strate won rer folgenten alt.

\section{Der Fidjtentintoen = Widfler, Grapholitha dorsana ('Tortr.) L.}

Der fleine, in ter Färbung ntı Beidynung etwas beränterlidfe Sd) metterling (Jig. 23) gefjört jut ren 23 iffler = ?(rten mit einem jogenannten Spiegefflect anf sen Lorrerflïzeln, oer an แnjerer Fig. 23 smrds bie 4 fleinen barin unter cinattor itehenten jofwarzen Strichel ju erfennen

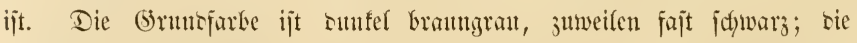

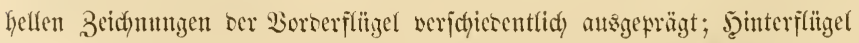

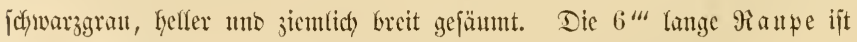

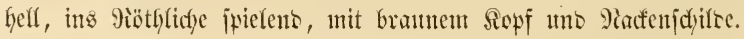

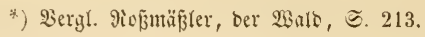


Der Edymetterfing flient gezen Mitte Snni, mo legt bie Eier waht=

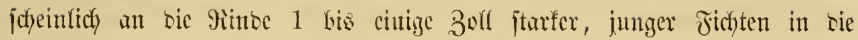

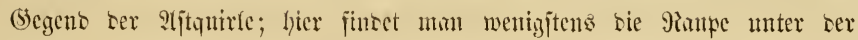

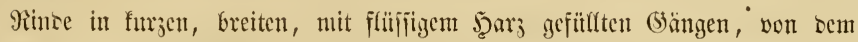

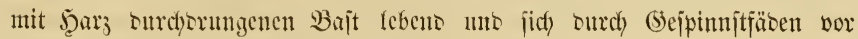

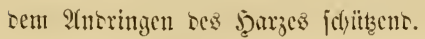

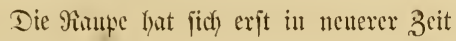
bemerfbar genudyt uno in Fidstensidficyten,

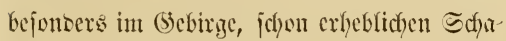
ben angeridytet. W3enn an jungen Jidsten

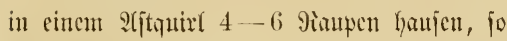
fönnen fie ourdy ringsum reichente Berịtöruny tes Briftes bic Saftbewegung unterbrechen uno

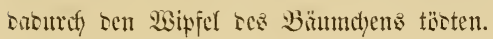

Der ähnlidye, aber bes Spiçelf̈lecto cut befyrente Fidftenjapfen=sidfer, Coceyx strobilana (Tortr.) L., lebt tno enturifeet jich iu sen Bapfen ser Jidyte. - Stls jelyr j(d)äblich gilt, numentlich in (Scbirgarevieren, Ler Fidfennejt=23iffer, Coceyx herey.

'Fig. 23.

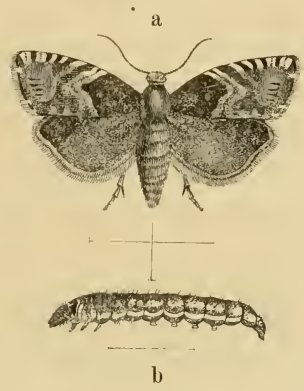

Der Fidetentuben=2Bidfer, Grapholitha dorsana (Tortr.) L.

a. Edymetterling. b. Maupe.

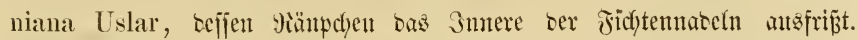

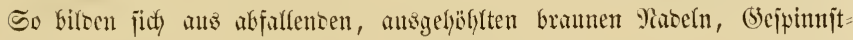

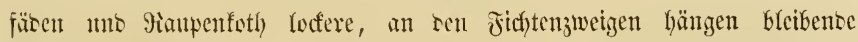

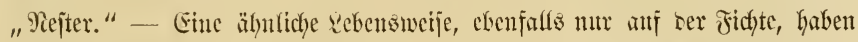

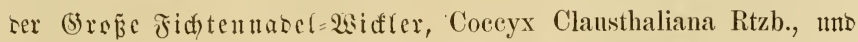

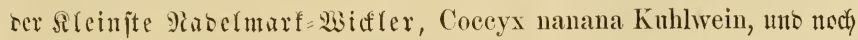

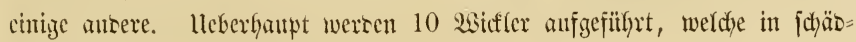
licfer sieije anf ser fichte jumarotzen.

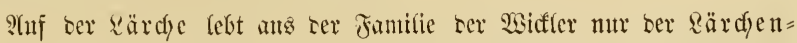
rinben=23idfler, Coecyx Zebeana Rtzb., wno ter anty an Siefern unt Fidyten lebenbe Mabel $=23 i$ ifler, Lozotaenia piceana (Tortr.) L., jebody obne merflich joürlicty zal jein.

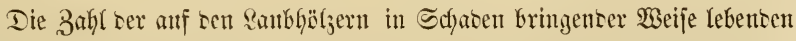

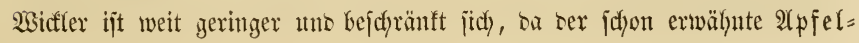


Gidffer, Carpocapsa pomonana L., ıux auf DGjtbüumen hault, aflein anf bie nadffolgente 9 (rt.

\section{Der (Eidjen=2Siffer, 'Tortrix viridana $I_{0} *$ )}

(Salneiden=2Biffer, (5) rïn=2Biffler, (5rïne Eidyenmotte.)

Der Sdymetterling (Jity..24 a) ijt mit feinem anteren sentfochen

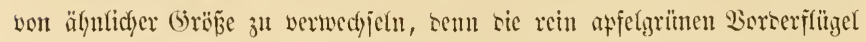

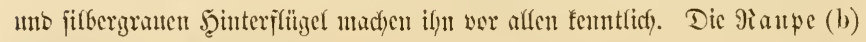

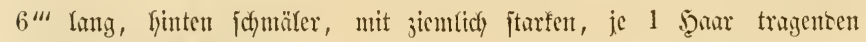

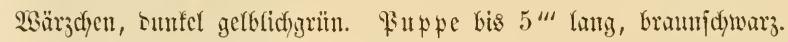

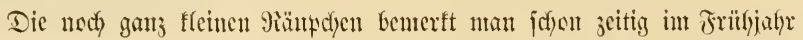

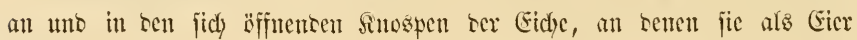

\section{Fig. 24.}

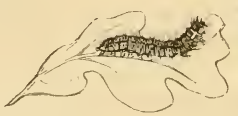

b

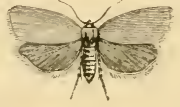

a

Der Ėiden=23iđfer, Tortrix viridana $L$.

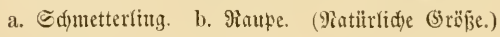

übermintert haben. Sic frejien bann bis jum Suni แแ๖ hängen in tiejer

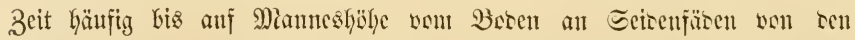
Bäumen berab. Ente Suni berpuppen jie fich in einem soer mefyeren

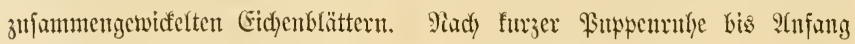
Sulf fliegt ter Sdfmetterting.

Wenn ter Fichten-Widfer aud nicht leidyt einen 2 anm töstet, fo fann

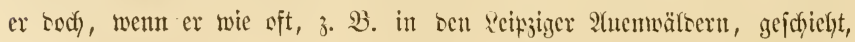
mefyrere Safyre finter cinanter in Menge worlyanten ijt, sen Zuwadys mo die Eidyelernte erhyeblidy beeinträdytigen.

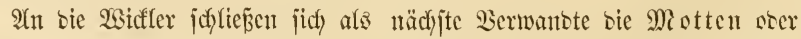
Sd)aben, Tineinen, an, weldye meijt beträdytlidy fleiner als tic wicfler

*) Einer wou ben etma 8 europäijden 2 Siffern, weldye ben alten (5attungsıanen Tortrix L. Gelyalten haben. 


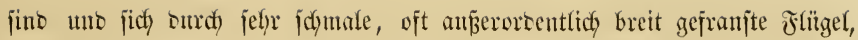
unterjacisen. Die sebensmeije ter jefyr fleinen giündyen ijt jefy ver=

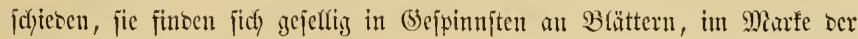
Stengel, int 3nuern won B(üttyen ober aud in ser bünuen Sdfidft Des Bhattjleijaces zwijach sen beiberjeitigen unverferyet bleibenten Sberbäuten eingejd)lofifen (Mininer). Mandye Keben in einem Sacfe, ten jie mit jidt

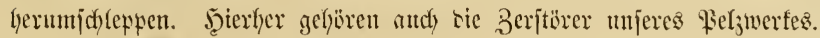

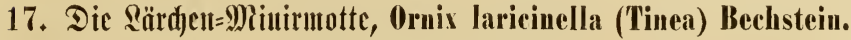

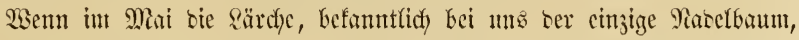
ber nicht wintergrïn ijt, ifje jutngen Pabelfiijd)el cben ju entfalten beginnt, ba jicht mant oft jüngere, $8-20$ jülrige

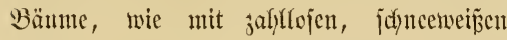
Bhätydyen berceft, rie nad) eintigen Tagen

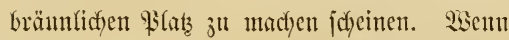
man sie Erjofeinumg nälyer unterjucht, io

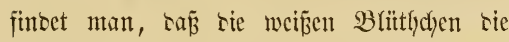
ansigebublten uno baher brentento wein aus: jefhenten 9abelfpitzen fint, bie aber jojnell vertroffiren uno brann werten. Dies ijt tas

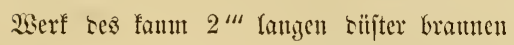

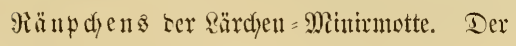
Sd)metterling (Jig. 25 a) ift cuner ber flcinjten uno unjucinbarjten bie ca giebt, jeibenglümjent, ajd)gran, mit fef)r jomalen, breit gefranjten Flügeln. Er fliegt Ente Mai, im (5ebirge 2 ufang 3mi, mo legt jeme Eier an tie särchennabchn. Das brann=

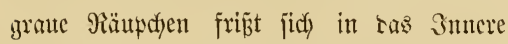
einer Narel ein unt zelyrt bon tem grünen

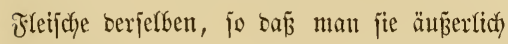
surdyjchimmern fieft. Wenn fie int Sep=

Fig. 25.

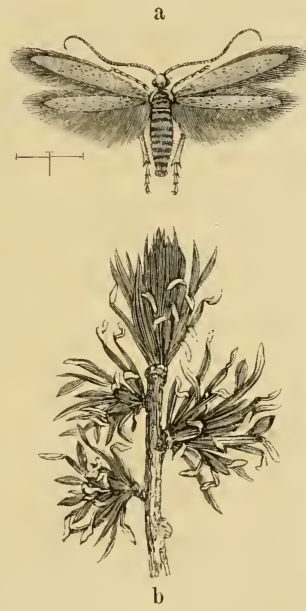

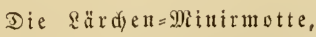
Ornix laricinella (Tin.) Bechst. a. Sdimetterfing. b. \&ärchen $=\mathfrak{T r i c b}=$ ¡fitze mit anthängenten Säcten uno atıgefrefienen Mabclipitzen. tember jiemlidy ausgetwadjen junb, bereiten jie jich ans sem Spitztheile einer ausgefrefjenen 9abel einen Sacf, ähnlidy wie ilyre Serwanten bie 


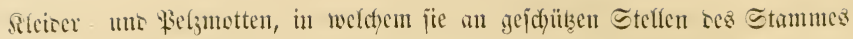

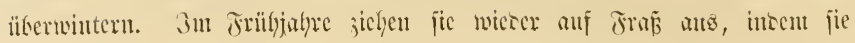
mu mit ben Borberteibe ans sem Sad hervortreteno siejen nadjidyletpen.

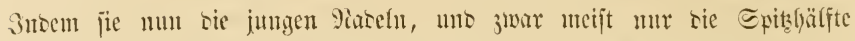

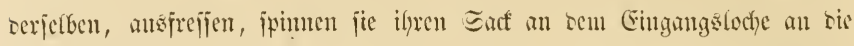

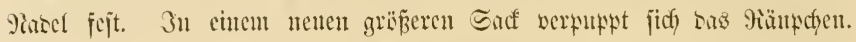

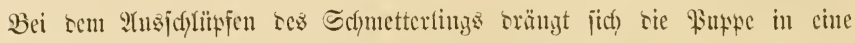

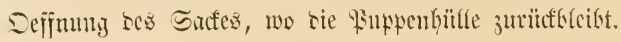

Su ser 3eit, wo sie 9ianten ansgewadjicn unt verpuppt fint, bemerft

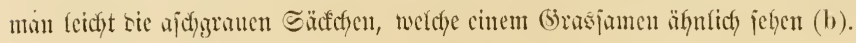

Bei ber sähigfeit ber Bürd)e, sic vertorenen Blätter burd) neue 3 แl

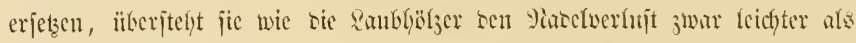
bie antern Pabelfälzer; man lyat aber sennod) cin Sïmmen mo längeres

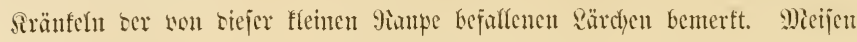

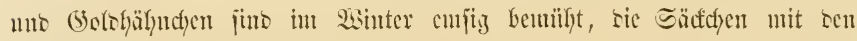

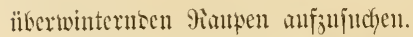

Yeben einizen antern, aber noch wenizer ichäolichen Minoelfoljntetten,

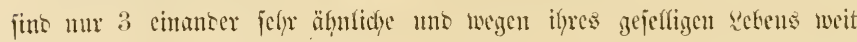

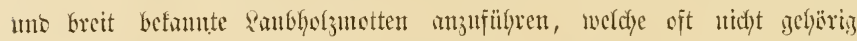

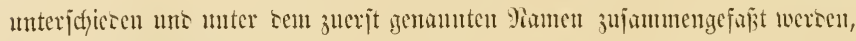

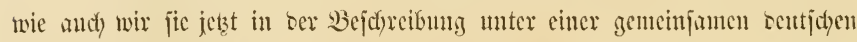

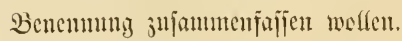

\section{Die Bejpimufmtotten,}

Ilyponomenta padella (Tin.) L. (Tit.j. 26 a).

II. coguatella ('Tin.) Ilïbu. (b).

II. evonymella (Tim.) L. (c).

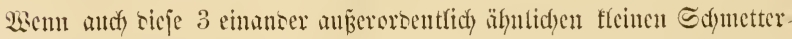

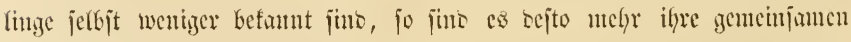
Scipinnite, von weldyen wir nicht jelten ganje Büijdye ïberjponnen finten.

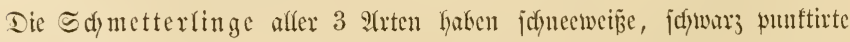
Borser = แno sunfelgrane, breit gefranjte J̧interflitgel. Jn ser 3aht mo Bertheilung ber joywazen fiunte uno in oer Farbe ses Franjenjaumes liegen bic geringen Hnterjdeizungzmerfmale. H. evonymella (c) hat bie 
jalylreidjiten, etwa 50 Punfte auf sem Fügel; padella (a) un๖ cognatella (b) beibe weniger, etwa 30, uns jinto won einanser verichieben burch

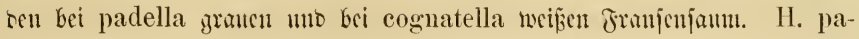
della, sie fleinfte, flaftert ctwa $10^{\prime \prime}$, sie beisen anoern gezen $12^{\prime \prime}$. Die

\section{รig. 26.}

a
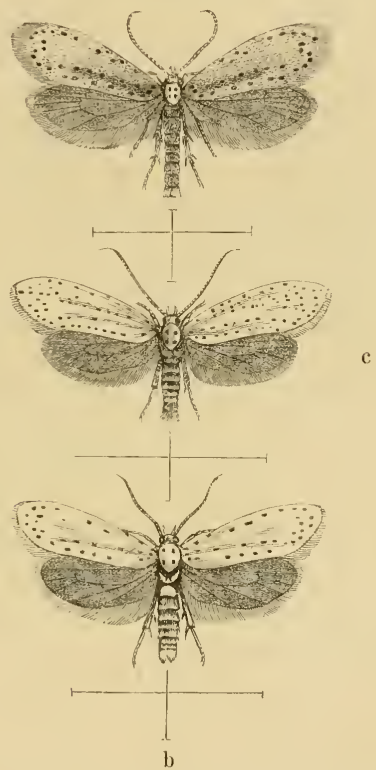

Die (5) f pinnftmotten, Hyponomeuta padella (a), cognatella (b) unb evonymella (c).

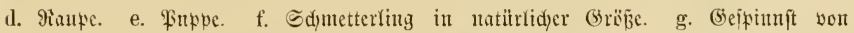
H. evonymella (i. folgente ङ.) Bei ben Sdmetterlingen bejeidunt bas fitell bie natituridue (5) röß̧e.

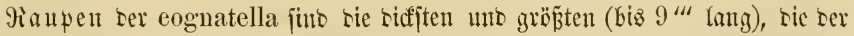
padella sie jchlanfiften. Die von eognatella uno evonymella jüb getb, bie erjeteren helfer uno reiner, bie ber padella fino grïntich ober getblictgrau;

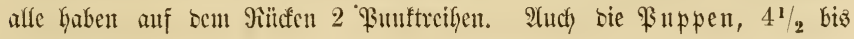


$5^{\prime \prime}$ lang, haben geringe, aber boch Ginlänglid, çarafterijtijche Unter= idyeisungsmerfmate.

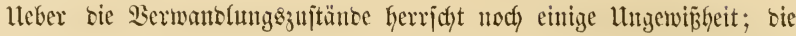

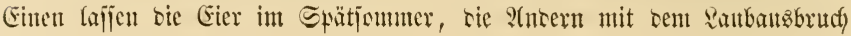

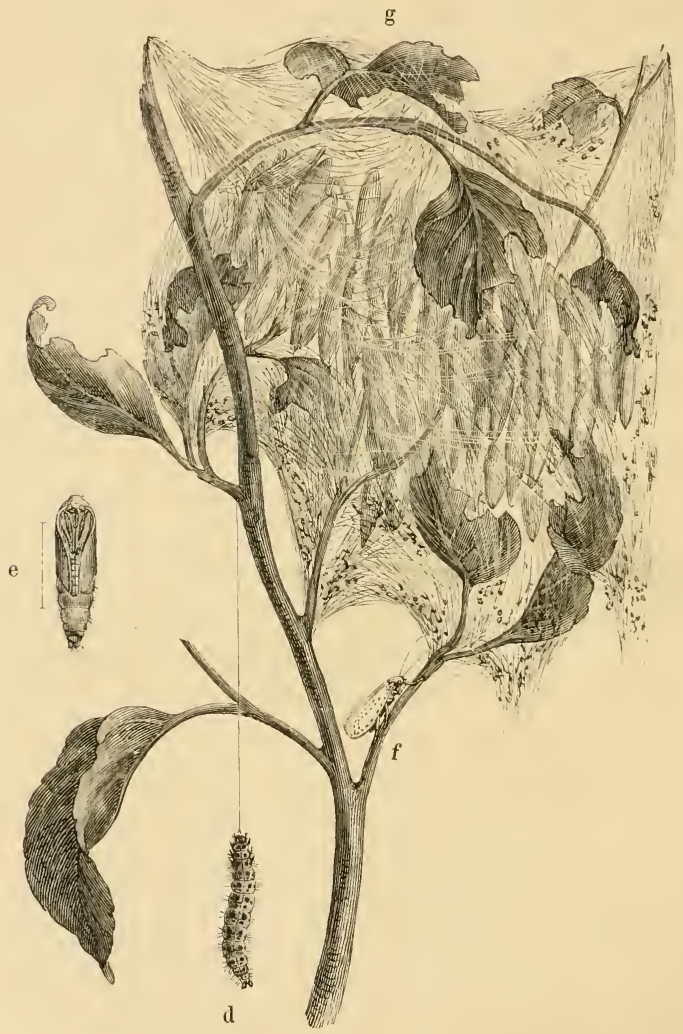

Sieke vorbergehente Eeite Fig. 26.

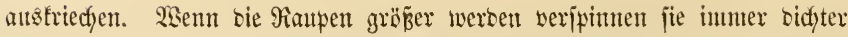

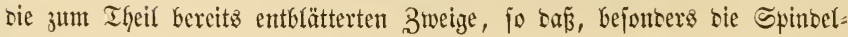




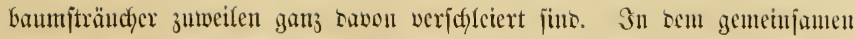
(5ewebe hängen von evonymella แto cognatella bic wou cinem unomed)=

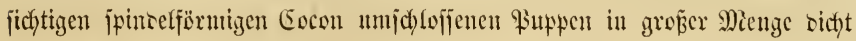

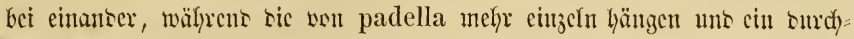
jidytiges Eocon hutben. Dic Flugzeit ift fo jicmlidy fiit alfe gleidy Ente Эuni bis atnfang Эulti.

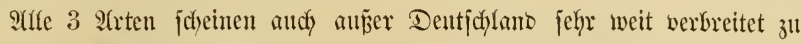
jein, roch ift viclfeidyt erît nod ju entidyeiren, won werdjer ser 3 jo äfn= fidyen $\mathfrak{A}$ rten sies gilt, wie andy sarïber nod) Ilnflarfyeit herridyt, wie jie jich) zu ifyen Futterpflanjen verhalten. Man hat jie auf ser Iraubenfiriche (Prunus padus), Edjlefrorn (Pr. spinosa), Ebcrejcye (Sorbus aucuparia), Mespilus- un Pirus-\{rten, am bäufigiten aber anf ben Spincelbanm ober Praffenfütthen (Evonymus europaeus) gefuncen. H. padella folf 1837 auf ciner grop̃en Stretfe alle T(epfelbäume entblättert Kaben, won benen sie Befpinnfte wie Fejtons herabfingen, wäfrent unter sen Bäunen ber Boben wie mit Seibe tapejirt war. Einen erfyeblichen $23 a l d i d f a b e n$ bringt feine hervor uno wir nafymen jic hier mefy seshalb anf, banit unjere

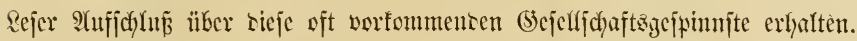

23olften wir jetzt nod) weiter fortfalyren, sie anf ben Walbbäumen

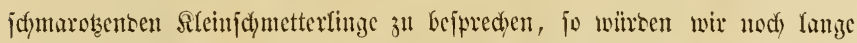

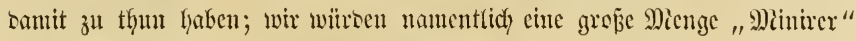

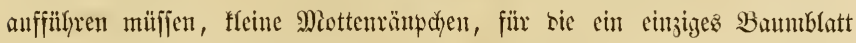

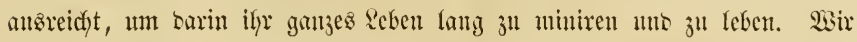

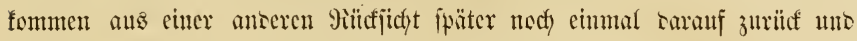

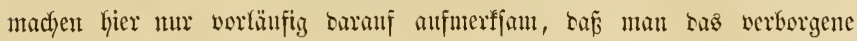

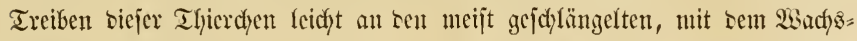
thum bes Miäurdyens alfmäfig breiter wertenten Minen extennt, weldye surch ifre meift jtrohgelbe Jarbe ecicht auffallen.

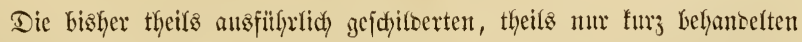

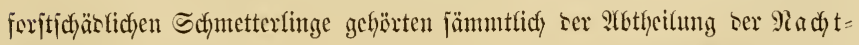

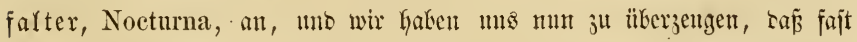

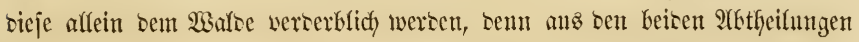
ber Dämmerunģfalter, Crepusenlaria, uno ber Tagfalter, Diurna, 


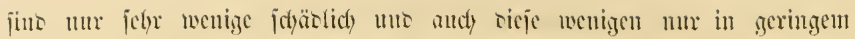

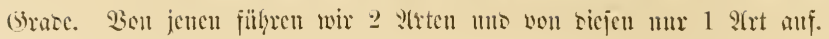

\section{Der Siceferıjd)wärmer, Sphinx Pinastri L.}

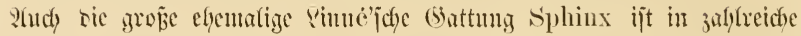
(Sattumgen jerfällt แmo bicje in 3 Jamilien geornet worten, in rie

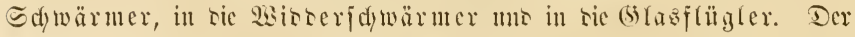

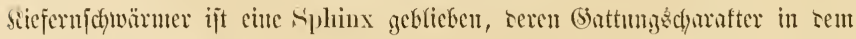

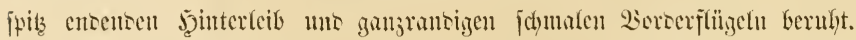

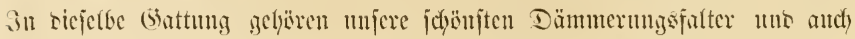

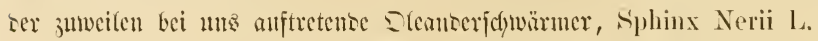

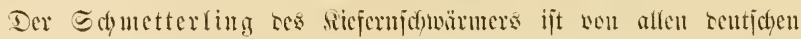

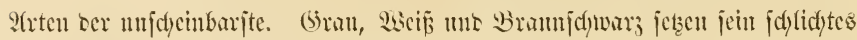

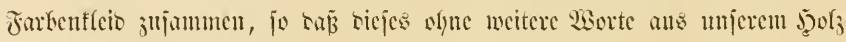
jefnitt (Fig. 27 a) vollfommen 3 erjehen ijt. Die șïller fint, wie es

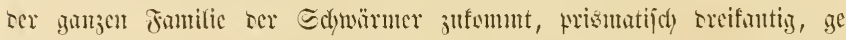

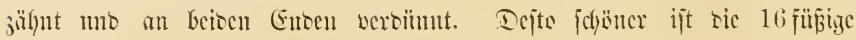

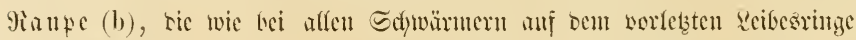

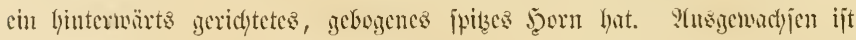

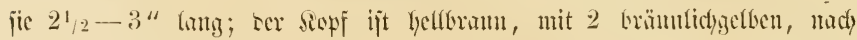

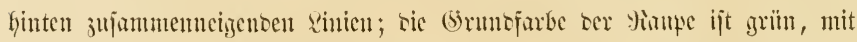

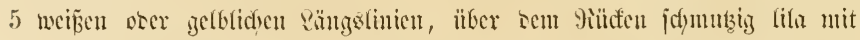

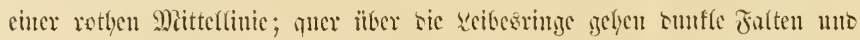

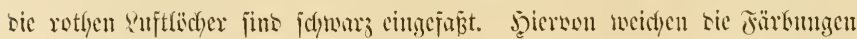
ser jüngeren gimuen beocuteno ab. Die fistpe (e) ijt bis $18^{\prime \prime \prime}$ lanb,

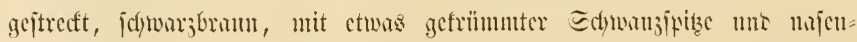

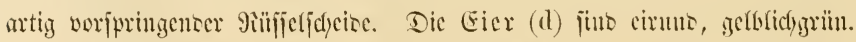

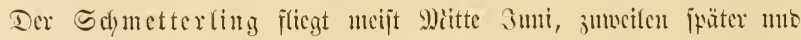

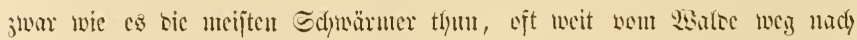

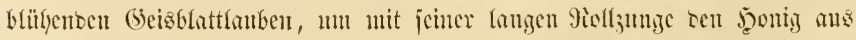

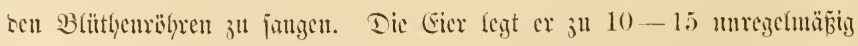

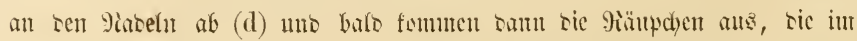

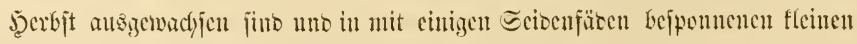
Erobablen ala fittpen überwintern. 


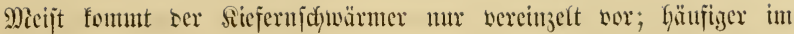
(befolge ses Siefermptuners (5. 111); bod) fennt man cinize Fälle, wo

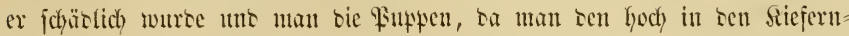
mipfeln frejfenten Faupen nidft beifommen fann, in Erobooen fanmeln

fig. 27.
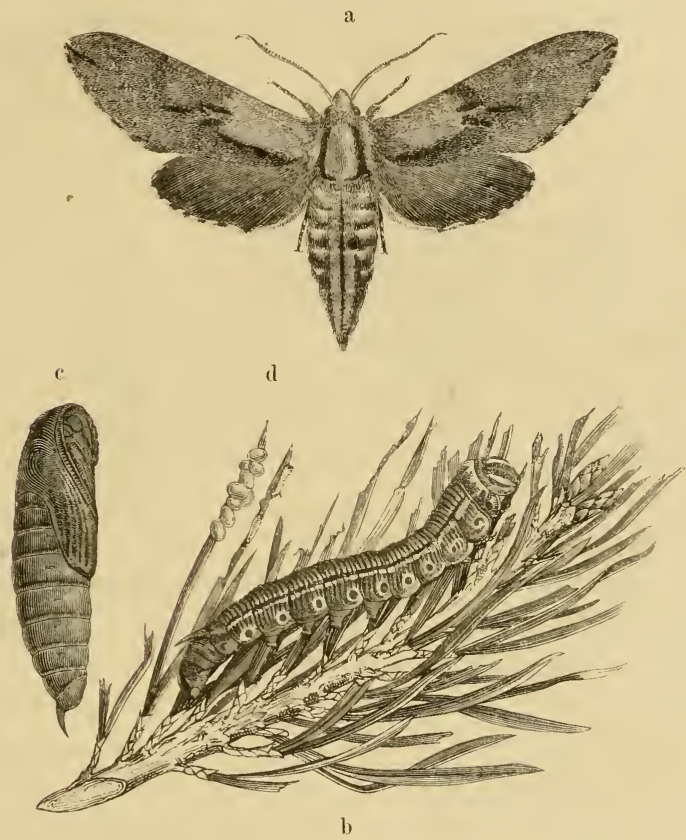

Der Rieferufd wärmer, Sphinx pinastri L.

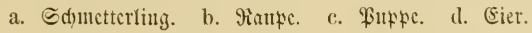

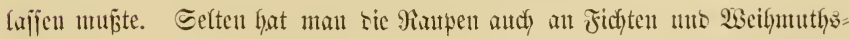
fiefern frejīeno gefunten.

Wic anbere jelyr befamnte Schntterfinge hat ser Sicfernjpinter cine

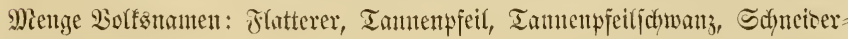
peele เ. \%. w. 


\section{Der Bienenjđwär'mer, Sesia apiformis (Sphinr) L.}

2aer biejes in jefwarjbram mo gelb gefleisete Snjeft mit ben glas:

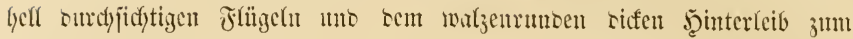

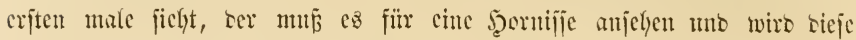

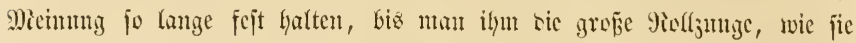
mur bie Echmetterfinge laben, gejcigt hat. Dic Yintm licbt es, fich jut weilen jelbjt nadyzmatymen.

Fig. 25.

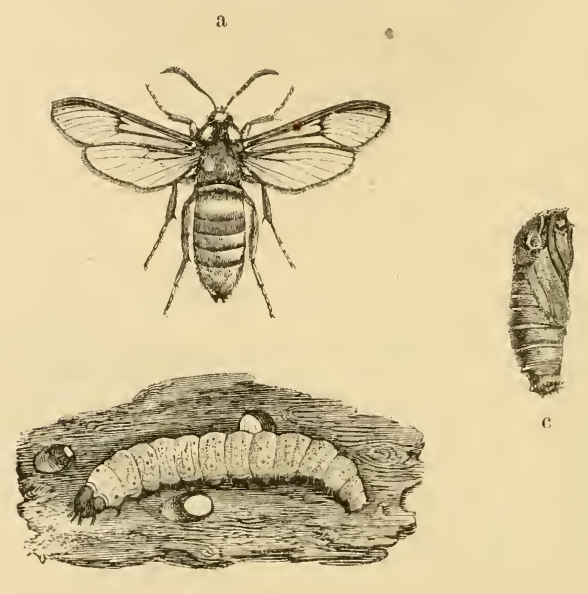

b

Der Bicucujdröruer, Sesia apiformis (Sph.) L.

a. Edmetterfing. b. Fante. c. Fuppe.

Die (5) las; d) wämer, wie man bie (5attumy Sesia ihrer grobentycilz

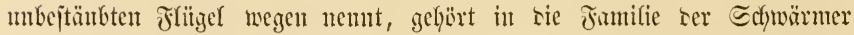

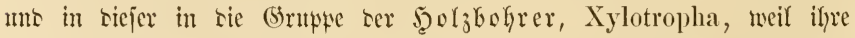

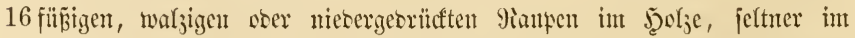
Marfe, ser Bäume leben. Die Feoljbolyrer werbinten sie familie ser

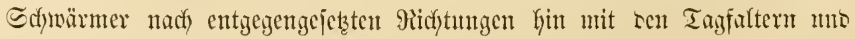

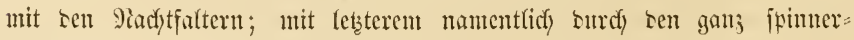
ähnficyen aflgemein befamten 2 eisenbofyer, Cossus ligniperda L. 


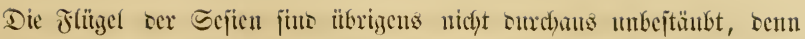
nic)t nur bus Flïgelgeäber, jontren bei cinizen ?laten ganje Stellen ber

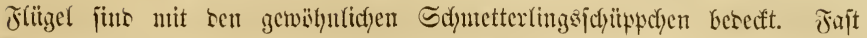

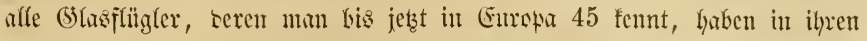

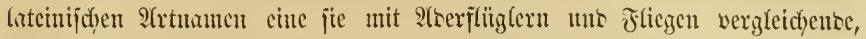
anf formis (fürntig) entente $2 \mathfrak{B}$ cnemutng, $\mathfrak{3}$. B. spheciformis, culiciformis, asyliformis', mutillacformis, wenu bamit and nicht gejagt fein joll, son jie mit Sphex, Culex, Asylus uno Mutilla grop̃e 2(ebnliçfeit hätten, jonjt miïß̧te unjere abgebilocte ?lat crabroniformis heiß̌en, nad) Crabro bic

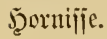

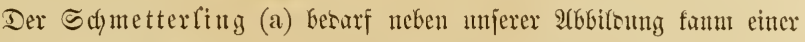

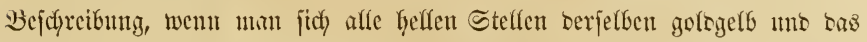

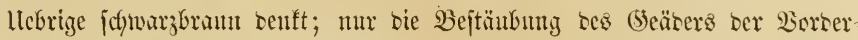

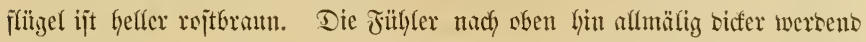

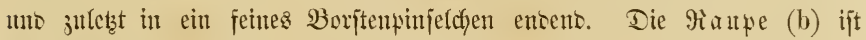

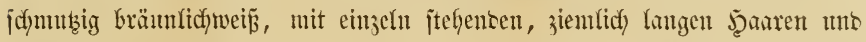
braunem loonigen Soffe. Dic \$suppe (c) ijt an ben Santen ber abge

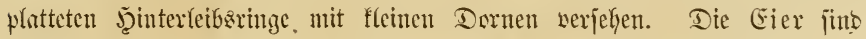

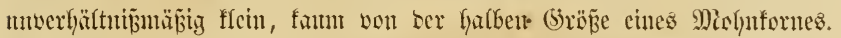

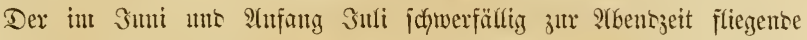

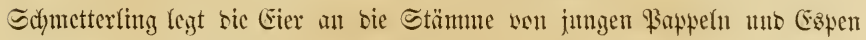

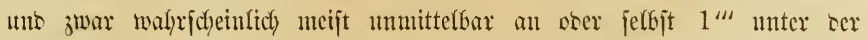

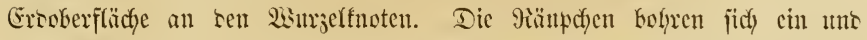

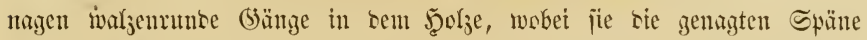

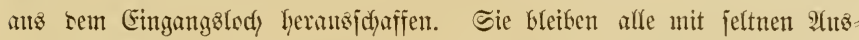

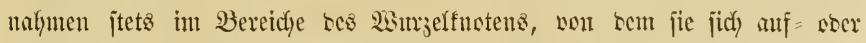
abwärts unt wenige 3 off weiter bohnen. Die sabudd angeridftete Beritörung glecdfyt bolffommen ber cines Borffäfers, Saperda Carcharias (Cer.) L.,

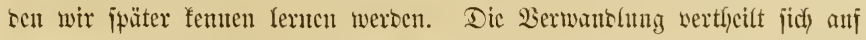

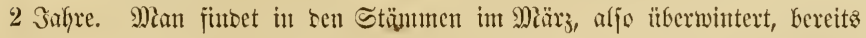

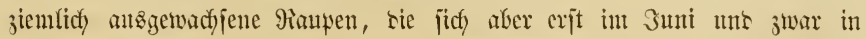

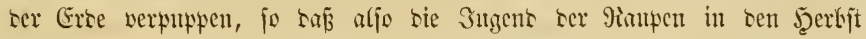

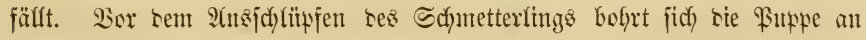

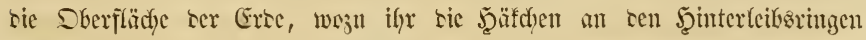
rienen. 


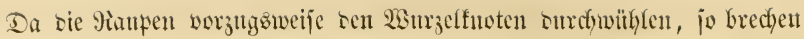
joldye junge Bappeln wor sem Sturme leid)t ab. Micijt jeood) werlyeilen bic

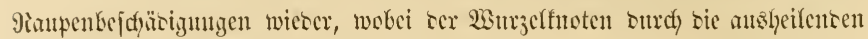

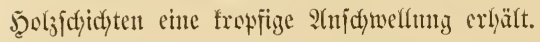

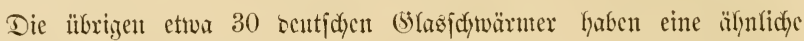

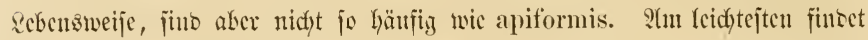
man biejen intereffanten Sdjuntterling, wenn mạn Enbe Suni junge Espen ichüttelt, wocurdy siejelben herabjalfen tuto reidyt gejungen wersen. Sint

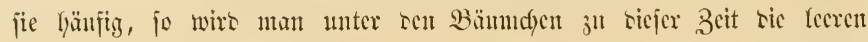

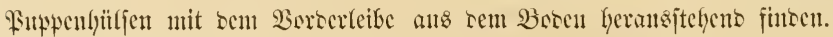

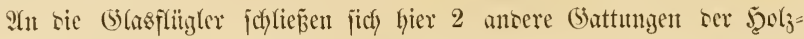
bohrer = Edynetterfinge an, weldye sicjelbe rebensweije haben, aber fajt noch weniger jefürfich) werten, oa jie mefjr vercingelt in alteu seer jelbjt in twoten Stämmen ifyre Wiblylereien treiken. Dicje fins crjtens dic Gattung Cossus

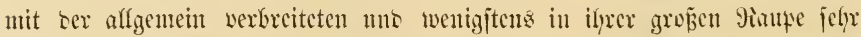

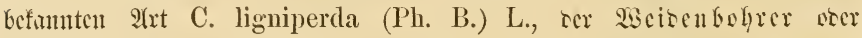
Jुorgourex.

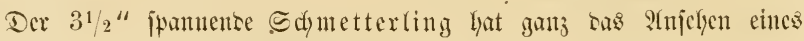

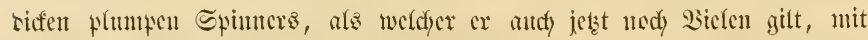

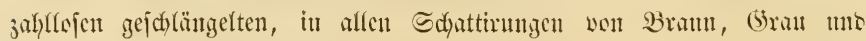
Schwarz gefürbten Snerfinien nno Jlecfen. Dic biffe, fette, bis $3{ }^{1}{ }_{2}$ "

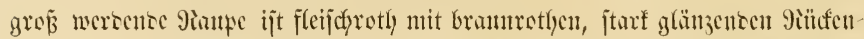

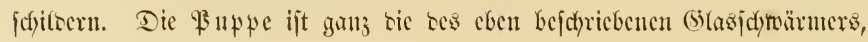
nun nody cimmal jo lang mo viel biffer. Die Entmicflung tanert 2 bis

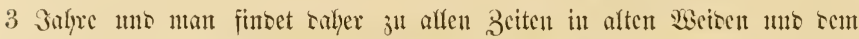

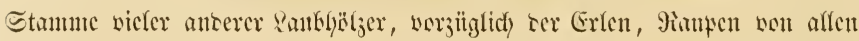

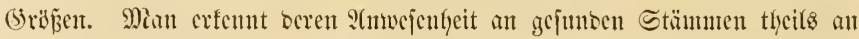

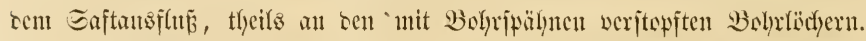
Wenu ber Echmetterfing ansfrictsen foll, is arbeitet jich bic timple mit

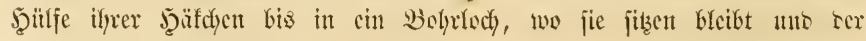
Jalter ifyre Decten fiprengt.

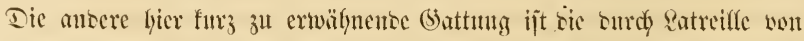
Cossus abgetrenute Gattung Zenzera mit ocr $3^{\text {war }}$ feltenen, aber eben fo verbreitet worfummenten 9(rt Zeuzera Aeseuli (Ph. Noet.) L., ber blau= 


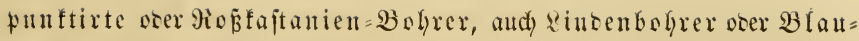
jicb genannt.

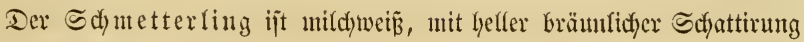

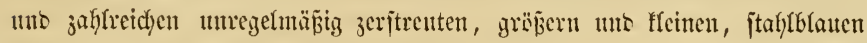
Fisuften, seren sie Şiuterflitgel $m$ wenizere zeigen. Die $1 \frac{2}{3}$ "lange

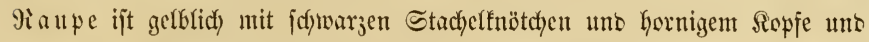

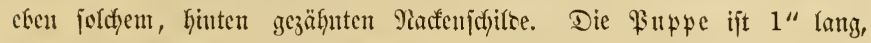

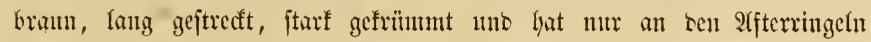
flcine நॄäfdyen.

Die Rebensmcije gleicht ber bes 2 seirenbolyrers. Die Raupe lebt am bäufitgiten in ber Birfe uno Erle.

3nthen wir vinter sen Schmetterfingen mun ju sen Simbern bes Sidytes ïbergehen, bie wir eben beshalb fïx sie hädjiten, wollentetiten ju halten

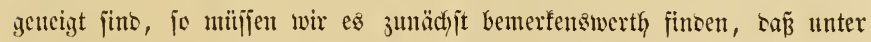

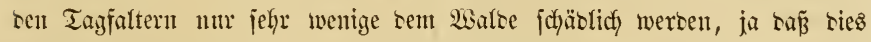

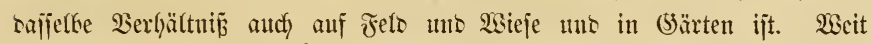
zahlreicher werten wir unter ifnen bie Sdymutfö̈gel ses 2 alses vertreten finbent.

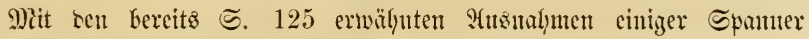

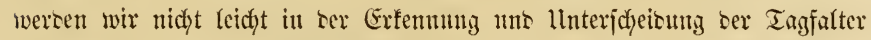

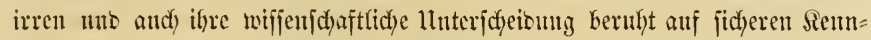
jeidfen, unter senen namentlich sic jelyr langen fabenfïrmigen, in eitre

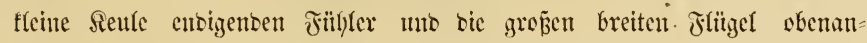
itelsen, weldye ser ruthente Schmetterling jenfred)t zufanmmengeflappt trägt.

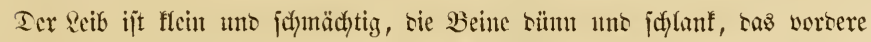
Baar bei viclen 21rten nu verfümmerte Stumutel. Die 16 beinigen Paupen

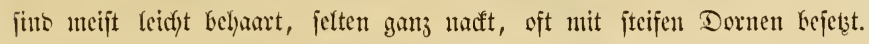
Die \$rtwpen jüb nie in einem (Scjpinnjt eingejd)lofien, fontern hängen frei abwärtz mit ser Sdywanjipitze in einem fie an ifre luterlage be=

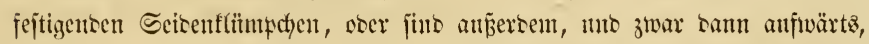
sit noch nit einem Fabengurt an senferben angeleftet. Sic fint an ifyrem Sorsertheil meijt mit Ecfen uno Sauten uns oft mit Mietallflecfen verjicrt,

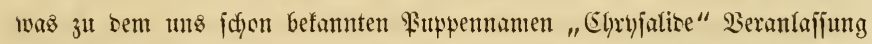
gezeben hat (S. 65). Dic \$uppenruthe ift bei allen son furzer Dauter. 


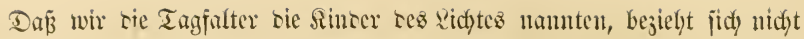
mux anj iłx heiteres Tagfeben, weldyes an Munterfeit gleidyen Sedritt hält

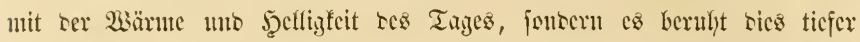

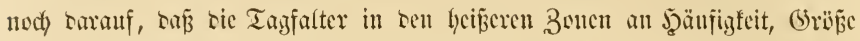

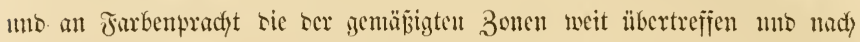

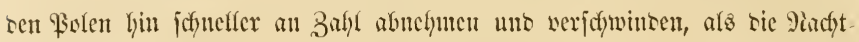

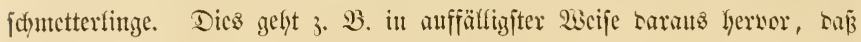
bei Fiará in Brafitien affecin 600 strten vorfommen, währen ganj Dentịd)=

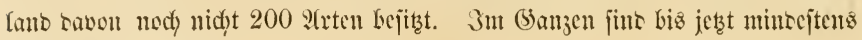
5000 strten befaunt.

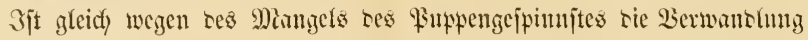
ser Iagfatter vicl cinfacter; fo bfcibt iffer Derwantumig immerhin sic

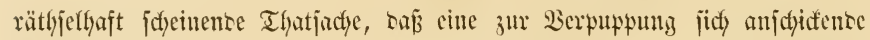

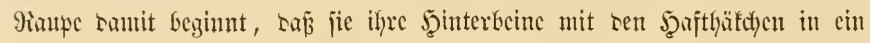

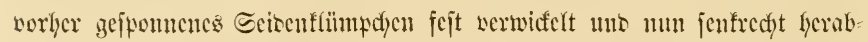

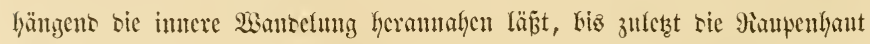

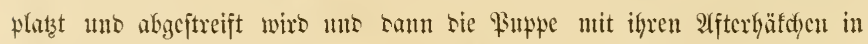

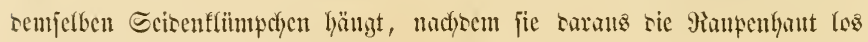
geutadyt uno jortgejdyleurert lyat.

Da wir mur cincn salswerterber an scr Jamilie ser Ianfalter anf-

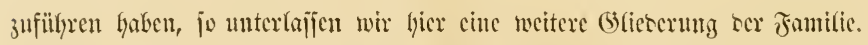

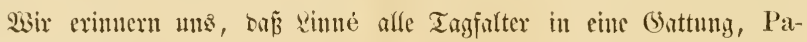
pilio, sereinigte.

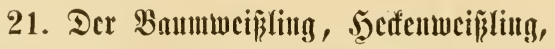 Pontia crataegi (Pap.) L. (Pieris cr. Schrank).}

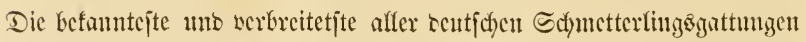

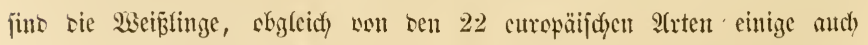
mit bunten Farben geziert jus, wie 3. 23. and unjer sentjder 9urora= falter, P. cardamines (Pap.) L.

Dex Schmetterling (Jig. 29 a) bebarf neben miferer atbritsung feiner weiteren SBcidfreifung uno er unterfacioct fidy leidyt bou ben ber

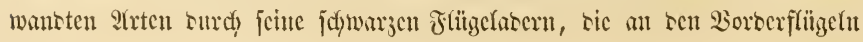




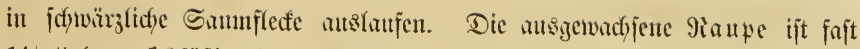
$1 \frac{1}{2}$ " lany, 16 fïp̈ig, furz weid)harig, mnten mo an ben Seiten blangran,

ริtg. 29.

a
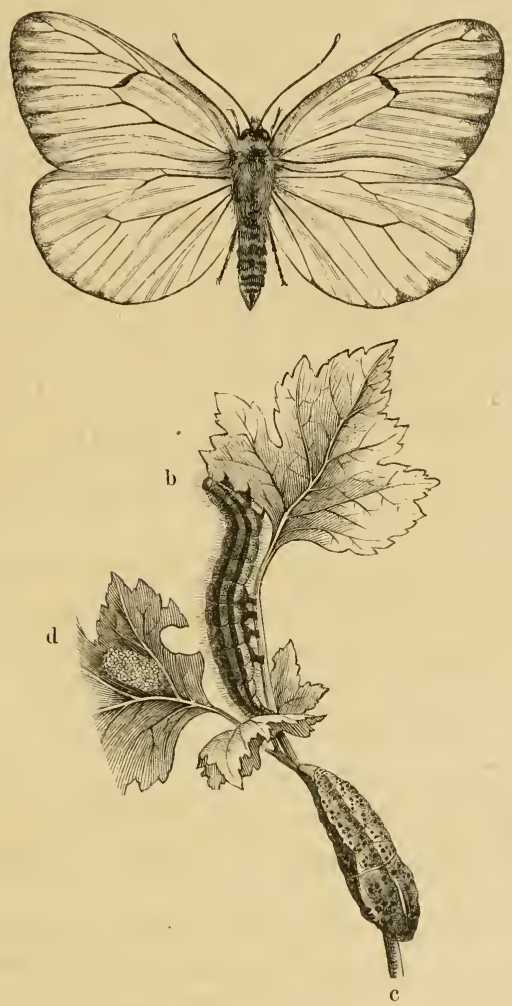

Der $\mathfrak{B} a$ unweiñliug, Pontia crataegi (Pap.) L.

a. Edymetterfitg. b. Ranpe. c. Pupte. d. Fier.

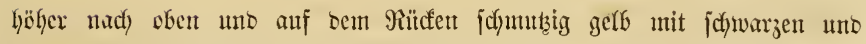
braumrothen Sängsiftreifen unb jdywarzem Ropfe. Die an Zweigen unb 
viefen antern Steflen mit tem Schwanjente mo cinem Seibgunt $\left(c^{*}\right)$ be

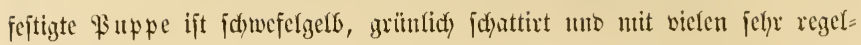

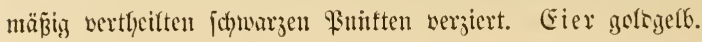

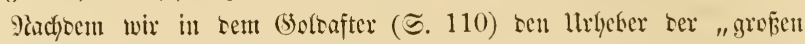

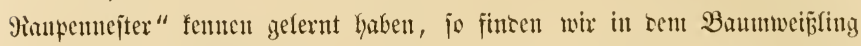

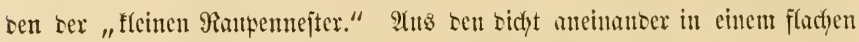

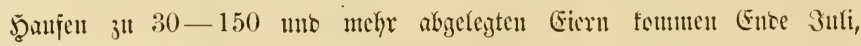
ipätejtens im September die 9ïupdyen ants, die bis zum Eintritt tes

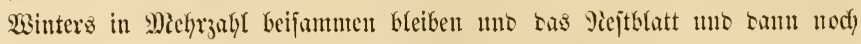
antere benageno felettiren uno veripinnen. Wit Cintritt bes 2 sinters fino

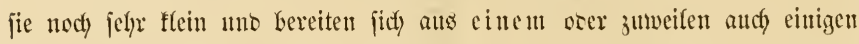
nebeneinanberjtebenten Blättern, seren Stied jie mit Seisenfären an Trtebe

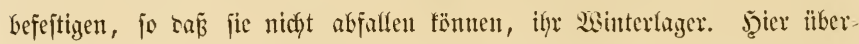
wintern jie uno zeritrenten fidf) in näcbjten Frïbjabs itber tie 3iveige, wo

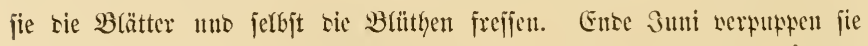

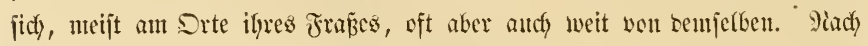

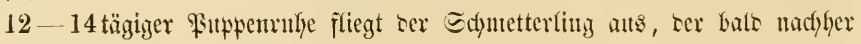
einige Iropjen eines bhtrtrotgen Saftes won jid) giebt. Dics hat wejentfidy uit zll ber Fabel vout "Blutregen" beigetragen.

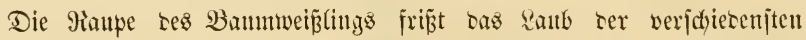

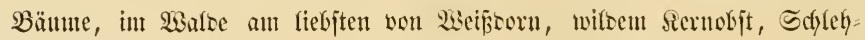

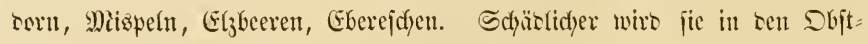
gärten. Wenn ber Schnetterfing fehr hämifiz ijt, jieht man ihn oft in

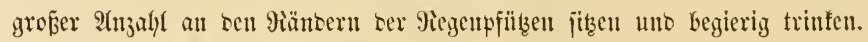

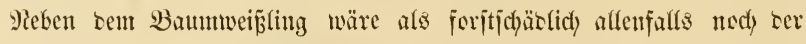

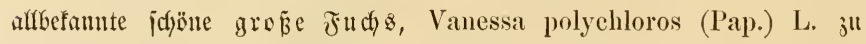
nenten, ber, aber body un jelten, bejonters cinjelne Zweize bes wifoen Siridjbaums entfanbeno jidf) bemerflict) madyt.

\section{B. תäfer.}

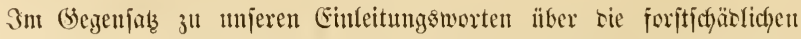

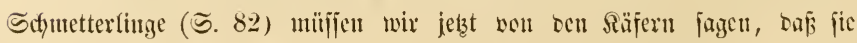

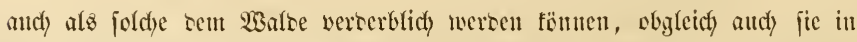

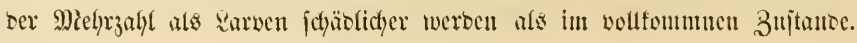


23 as wir a. a. D. Hiber tie Yamengebung gejagt haben, gilt and won

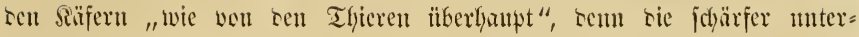

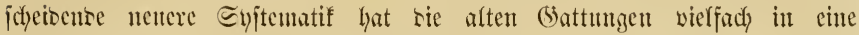
Dienge feeinerer Battungen zeripalten mitīen. Dasurd) ijt sie obutehin

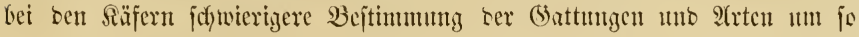

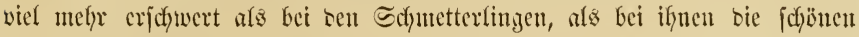

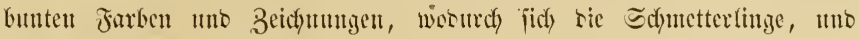

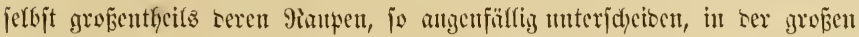

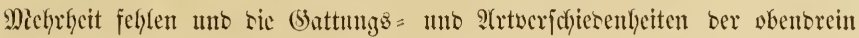

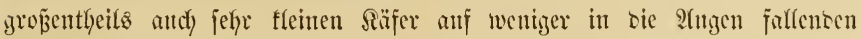

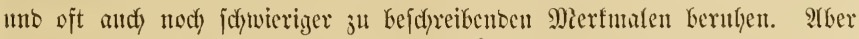

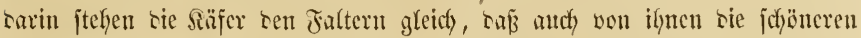

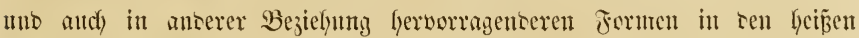
Errgïrteln vorfoumen.

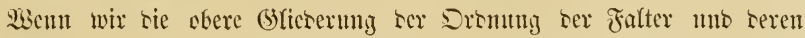

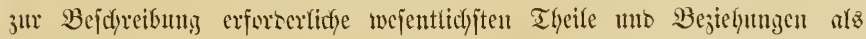

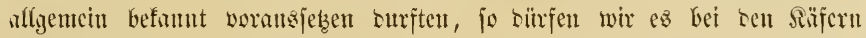

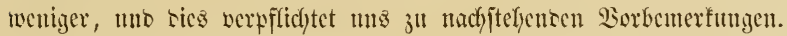

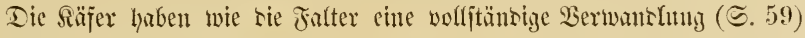
unb werten als Gier geboren. Shre Sarven find thetls fubloje Miaren,

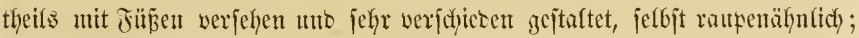

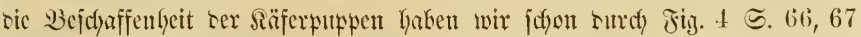

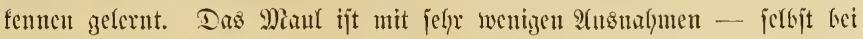
sen Sarben - cin Samorgan. Der Qeif zerfällft immer jefyr bentfich in Sopf, Brujt (Mittelfeib) uno j̧interfeib, welder leţterer unter ben be= fannten hornartigen Flïgeltecfen 2 zufammenzeraltete Flïgel träjt, weld)e

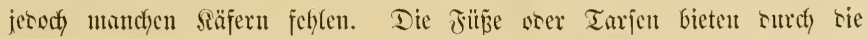

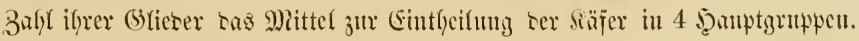

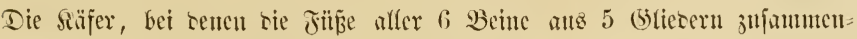

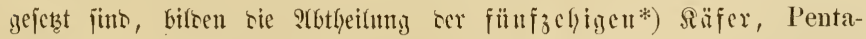
mera; sie nit 4 blictern an alfen 6 Futhen sie Dierjefigen, Tetramera; bie mit 3 bstiesern an affen 6 Finsen sie Dreizehizen, Trimera; mo

*) Die 3eben liegen natïrlidy nidjt neten cintanter wie unfere, fonsern fino wic bie Brieber cines Fingers an cinnollor gefïgt. 


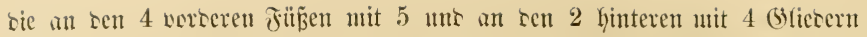
sie ungleidszefigen, Heteromera. Dies gicbt jreilidy un cinc fünjtlidye

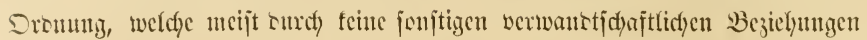

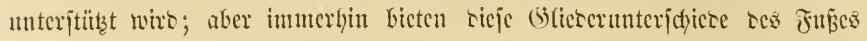

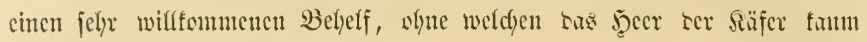
3tt bewältigen jein witube.

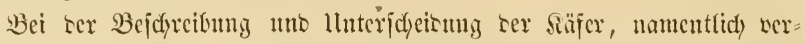

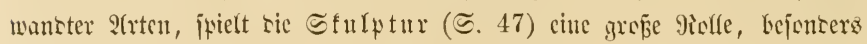

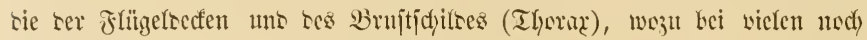

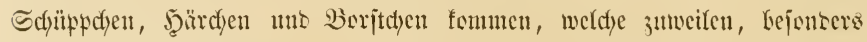
bei einizen Miïifeffäferarten, in Ien prädytigjten Yegenbogenfarben glänzen, woomdy ter befannte Brifrantfäfer, Entimus imperialis, aแs Brajilien,

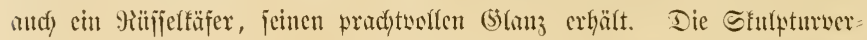

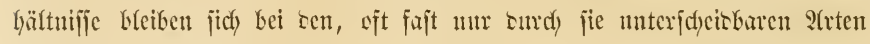
wumberbar gleidf), uns es ijt talyer Kejontere Sorgfalt auf sie, nidyt jelten

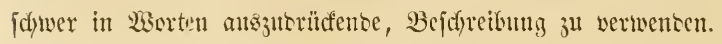

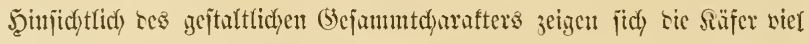
mandjaltizer ars bie Sdfmetterfinge, unter weldyen lödyjtens sie flïgelfejen

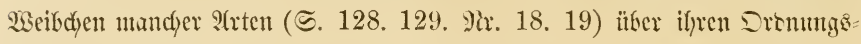

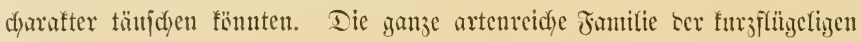
Säfer, Brachelytra, wirt ser Infuntige faum fï̀ Siäfer halten, un w wie

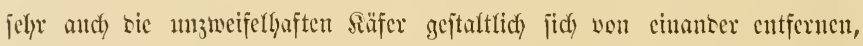

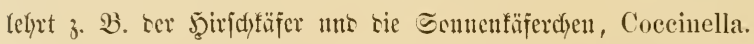

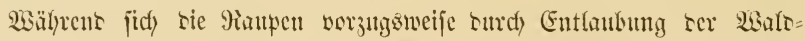

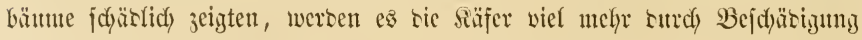

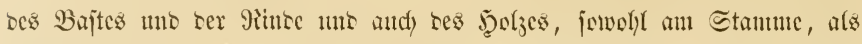

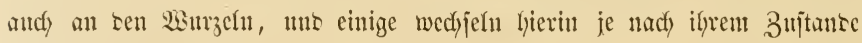
alı :arwen orer Säfer.

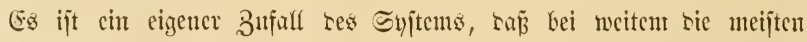

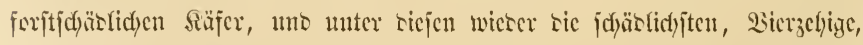

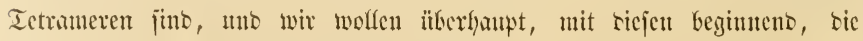
2(rten nad) bicjen J̧auptgruppen anorinen. 


\section{a. Sierjebige, Ietrameren.}

\section{Der Fidtenborfefäfer, Budbrufter, Bostrychus typographus (Dermestes) I.}

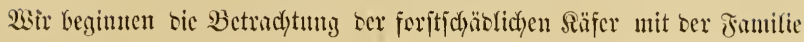
ber borfenfäfer, Boftrydinen, sic man bentidy-- obgreidy bies fein ifuen

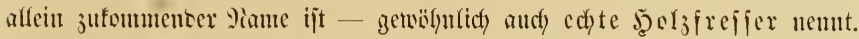

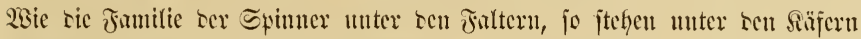

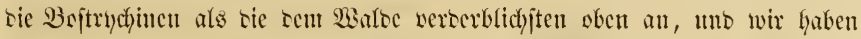

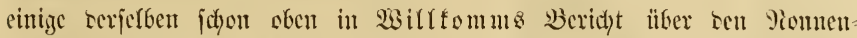

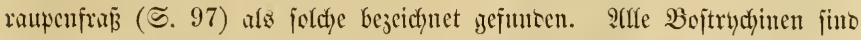

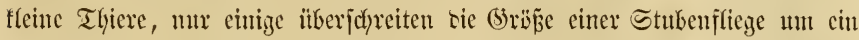

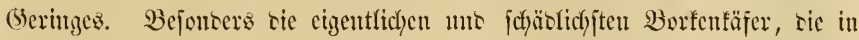

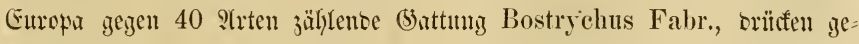

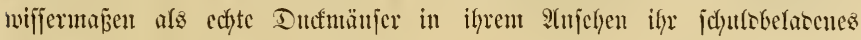

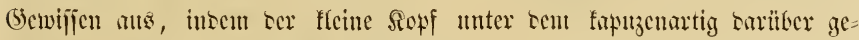

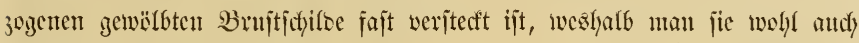
Sapuztäfex genannt hat.

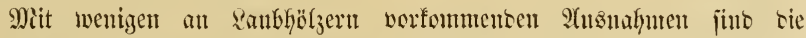

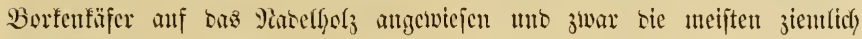

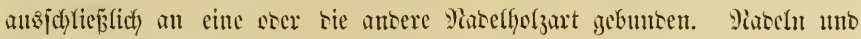

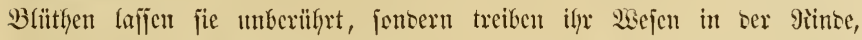

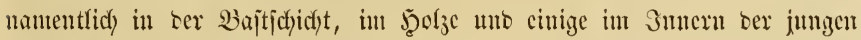

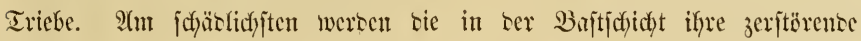

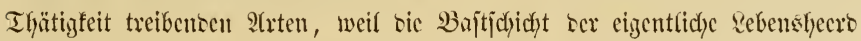

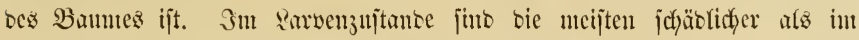

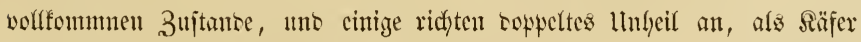
ธen Baum an einer altern Steffe angreifent als fie co im :arvenzulftante

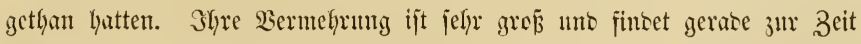

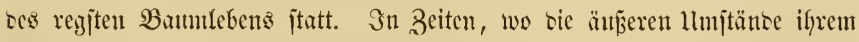
Bcteeifen gerabe bejonters günftig fint, fintet bei mandjen eine soppelte

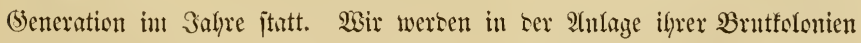

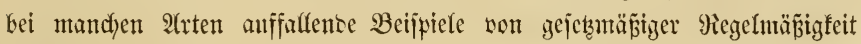
finten. 


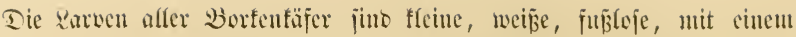
hornizen gelbbramen Sïffden verjelgene, weidje Miacen, weldye immer

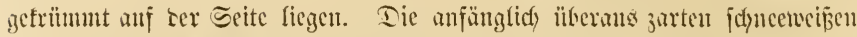

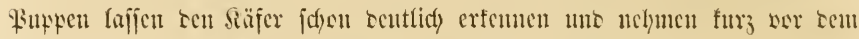

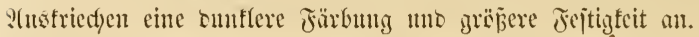

Der foürtidjite, aller Wortentäfer ift bie folgente ?trt.

Æig. 30.

c
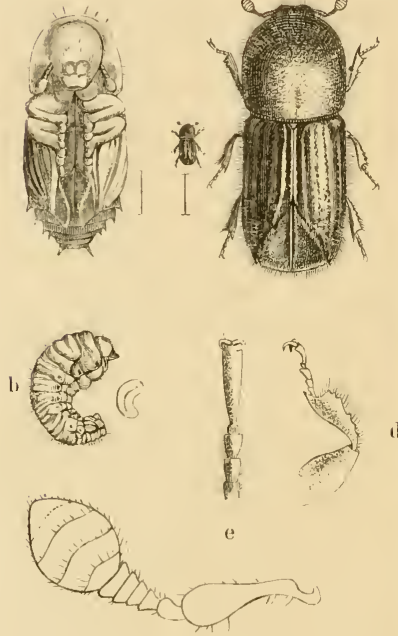

$\mathrm{t}$
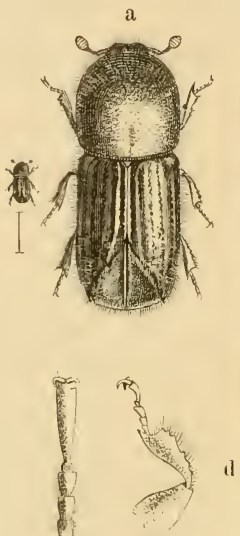

Der Fidy teutorfeufäfer, Bostrychus typographus (Derm.) L.

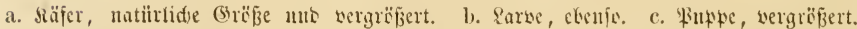

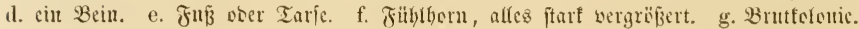
h. Theil ciner foldyen wou B. chalcographus, natïrtidye (5rö̋je.

Der $\Re$ äfer (Jig. 30 a) ift walzenfërmig mit fïr feine cnge 230 lynung

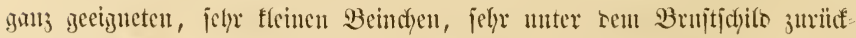
tretentem Sisfie mit feulenförmizgen Füblern (f) uno äntort feite Farbe

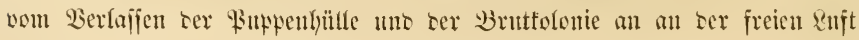




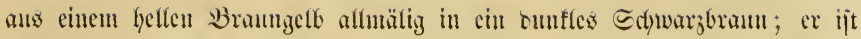

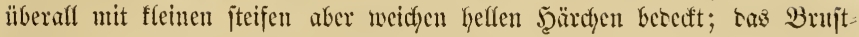

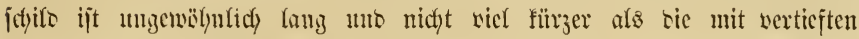

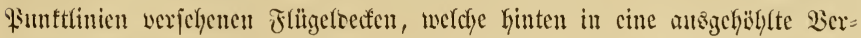
tiefung abgejtulzt fino, seren oberer giano jererjeits mit $3-4$ fleinen 3ähndyen bejez̧t ift. Dic \&arve trägt zur llnterjacibung uno Erfenmung

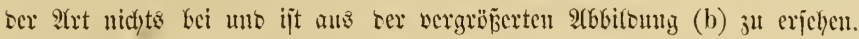

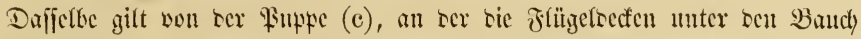
herumgchdagen jint. Won bejonterem Snterejie ijt tie Dcfonomic tes Burfenfäfers. Der in ber 9iegel foyon im Stpril ober Maa fliegense Räfer bolyrt fid) in ser häheren Stammregion ber Fidjten, ta wo bie ftarfen Sejte beginnen, felten tiefer muten nad) bem Boben $3^{u,}$ ein jenfredytes

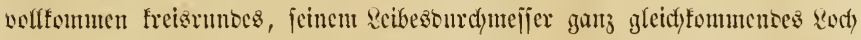

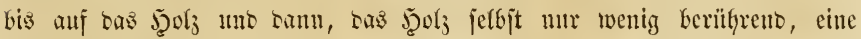

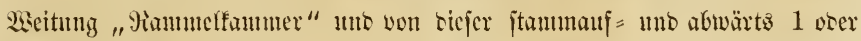
2 lothredste Mittergänge "Zothgänge", uno in biejem cinize bem Bohrlodge

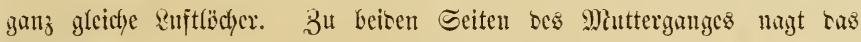

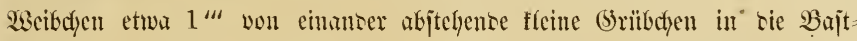

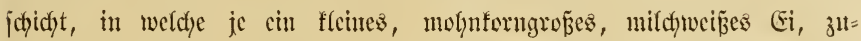
fammen $30-100$, gelegt uno nit feinem Bohrmeht berectt wirs. Die

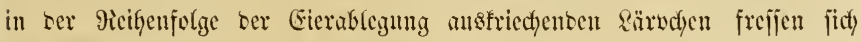
mefhr ober wentiger redjtwinflig, an ben Enoen tes Meutterganges fritz=

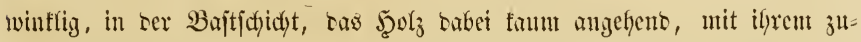
melymenten 2 axdystlyum immer breiter uno länger werbente, etwas ge= jđ)längelte \&anvengänge, bie bie Sarben finter fid) jtets mit bohrmelyl antz. ftopfen. $3 \mathfrak{m}$ Serpuppumb nagt bie \&arbe am Ente ros Rarvenganges eine

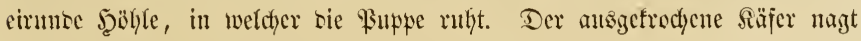

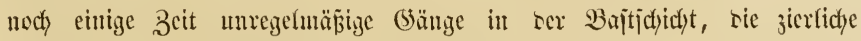

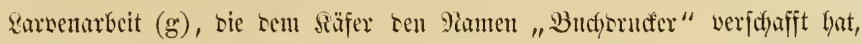
zeritörent, unt bohrt jich an ciner befiebigen Etclfe zulfezt cin "Fluglod,", um in tas Freie ju gefangen. Diefe Entwicfefung erfortert je nady ter

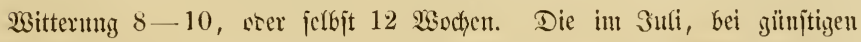

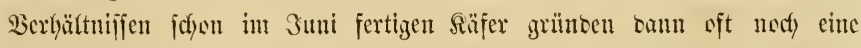
zweite Generation, sie aber in ber giegel erft im folgenton Galje zur Sollenoung fommt. 
Sit an ciner Fidjte burch viele folderer Brutfolonien sie Baftichicht

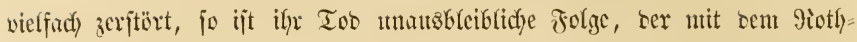

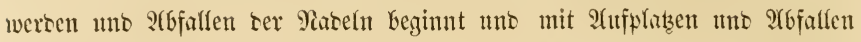

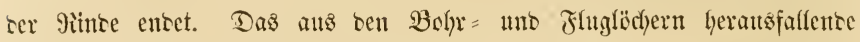

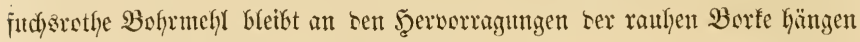
uno verräth sie $\mathfrak{2}$ (nwwejenfeet ocs Räfers.

Es ift lange bartiber geftritten worten, ob ser $\mathfrak{B}$ orfenfäfer in ganz

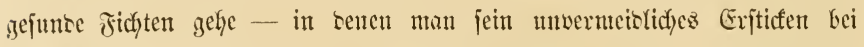

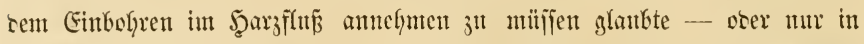

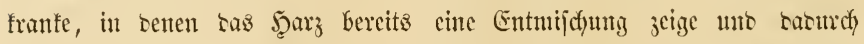

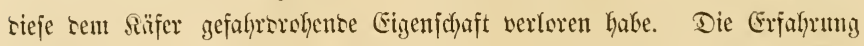

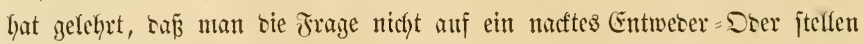

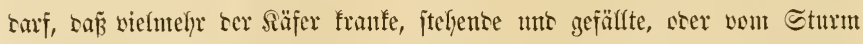

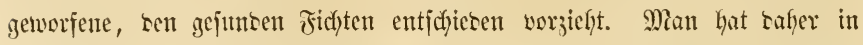

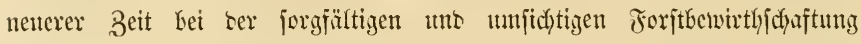
weniz melyr won bem Borfentäfer zll reisen gefabt, wälyeno frither,

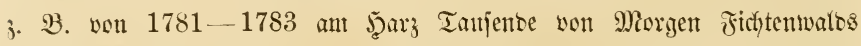

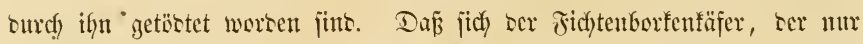

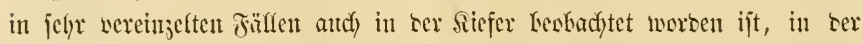

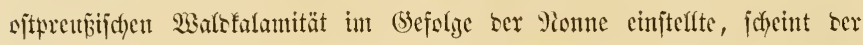

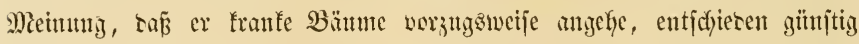
3n icin.

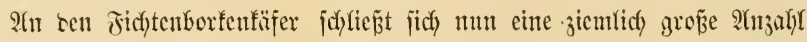
anterer, meift fleinerer Bostrychus-?Yten an, bie für fid aflein, getwiffer=

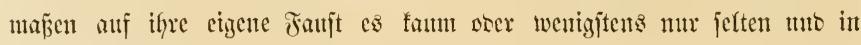

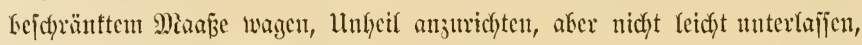

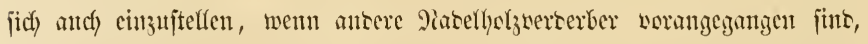
unt saut entweser audd bie Fidyte oter antere Baumarten anjulfallen, auf bie fie angewicjen fint. 2ion sicjen ijt namentlidy ned) ser fleine Fid ten= borfenfäfer, B. chalcographus (D.) L. Ju nennen, ser cingige in ter Sidgte haulente Borfenfüfer, ter feine Sothgänge, jonternt "Steringünge"

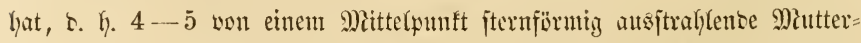

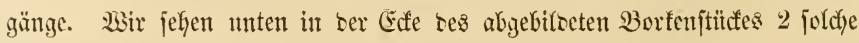
Mittergänze, bie zu $2-3$ anberen gefjören, bie nicft mit auf bus borfen= jtituf fielen. Dieje Sternffolonien jefen ganz bejonters zierfidy aus, was 


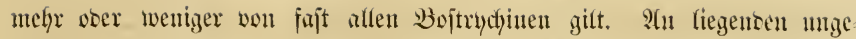

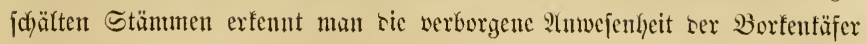

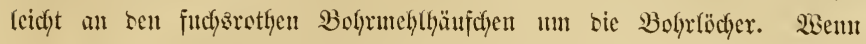
man baun in angemeffener Entfermung mit cinem jpizen Diefīer cin Dierecf

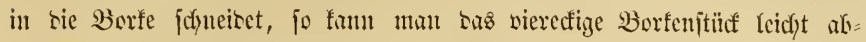
tremen und finbet Dann, went man gerabe ben geeigneten 3eitpmuft ge

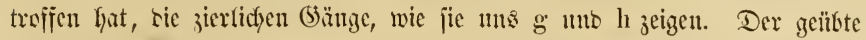
Jorjtidyuzbeamte erfennt bam leidjt an ber Jigur siejer (5änge nuter $\mathfrak{B} e$

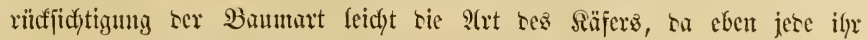
bejtummtes Militer befolgt.

Dem Sidjtenborfentäfer ijt ber grof́e Riefernborfenfäfer, B. steno-

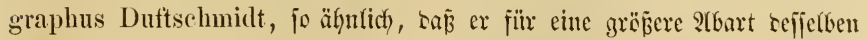
gelyalten wurte. Er lebt jajt nut in gefälften Siejern uno ijt saher fium

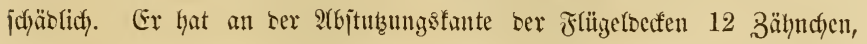
ber ansere blos 8 .

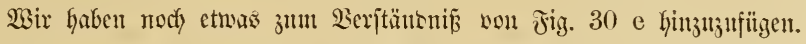
Wir zählen baran nidyt 4, jontorn 5 Tarfenglieber, won benen sas lange

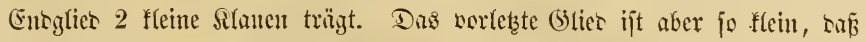
es reidyt ïberjefen wersen faun uns bei ser ?tuffifellung ber Tetranteren won Batreille and wirflidy Ḧberjefen wirt. Da biefes winjige worletste Iarjenglies bei ten Ictrameren in ser 9iegel worbanten ijt, fo nemen jekt

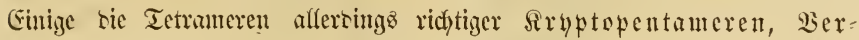
borgenfüufzehige.

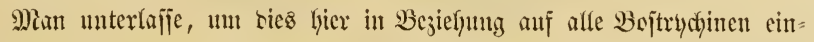

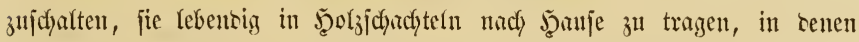
jie jidy mit seidytigfeit ein Ffudytloch bohren uno entfoumen.

\section{Der frumuızälyıige Borfenffäfer, B. curvidens Germar,}

hat feiten Yamen won ben fleinen bei hem Miänndyen (Fig. 31 b) frumuten

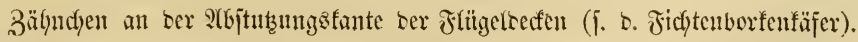
Ex ift bief feimer als ser vorfyerigehente uno hat auth eine antere Sfulptur ter Jlïgeltecten. Das Weibchen (a) hat anf sem Sopfe einen fleinen gold =

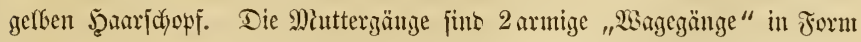
einer Slaumer

Bon biejen Mittergängen gef̧en sann 


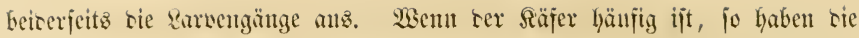

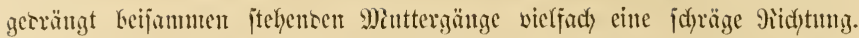

Diejer Sä̈er ijt ser J̧anptfeino ser Tanne, Pinns picea L. (Abies pectinata Dec.), mo quat in ten jebünen Tamemrevieren tes Edywarz

Fig. 31.

b
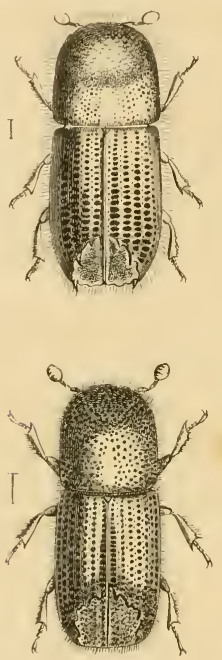

d a
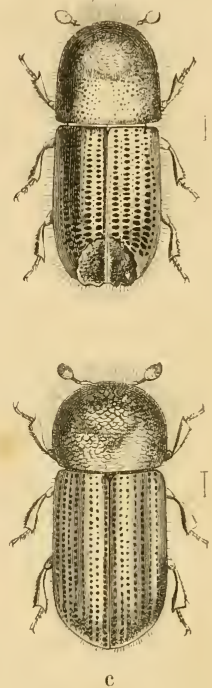

a. b. Der $\mathfrak{f}$ rum MCännd)en mid $\mathfrak{B}$ cibdyen.

c. Der 9 ub thof; borfenfäfer, B. lineatus Gyllenhal.

d. Der eärd)enborfentäfer, B. laricis Fabr. Alfe ftarf vergröbert.

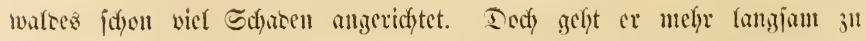

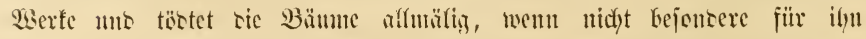

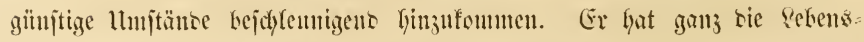
weije tes Fidstentorfentinfers, mit bem er zuncilen gezen bie Fidhten ge: meinfame Eadje madyt tuts and) in Särdyen borfoumt. 


\section{Der Mublyolzborfeufüfer, B. lineatus Gyllenhal,}

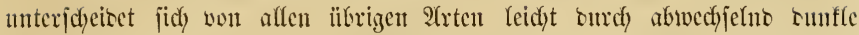

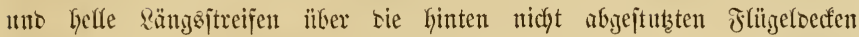
(Fig. 31 e).

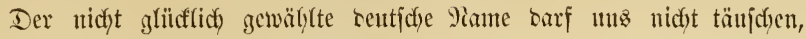

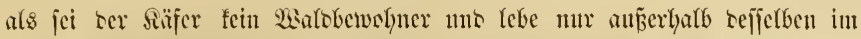

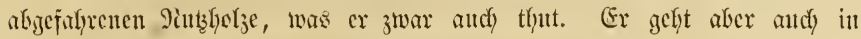
ftelyenbe Stämme, Tammen unt Fidften; an Gänfigiten in franfe Bäınte, uno in gefällte Stämme. Er Golurt fich Gice im Squril uno Mai tief in

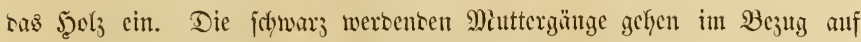

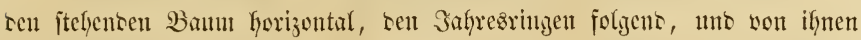
gehen rie jef̧r fuzzen, ganj geraben \&arbengänge rechtwinflig aus. Dasurch

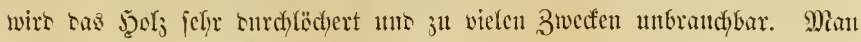

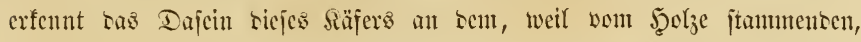

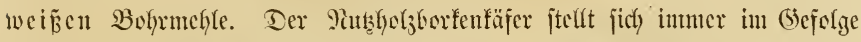
anterer, ben Fidyten unt Tannen jedäblichen Injeften ein, wie wir sics

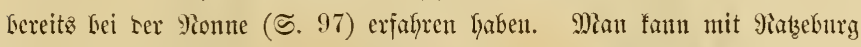

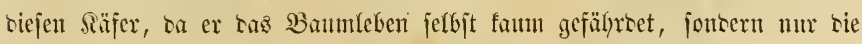

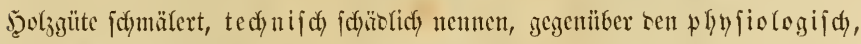

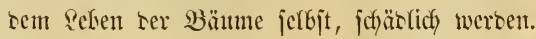

\section{Der Qärdjeuborfeufäfer, B. laricis Vabr.}

Der Siäfer (Jig. 31 d) ift fleiner als B. typographus nno hat an

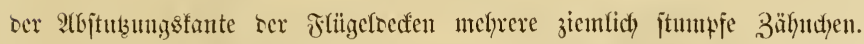
Die Defontomic uno Berwandungazeit ijt sicjelbe wic bei jentent, er fommt audf) nit ifym in ber Fichte, bejonters aber in ser särdye wor, wo bas

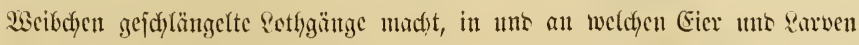
żtweilen trantbig beijammen jüzen, woburd) anjtatt ser Sarbengänge bann

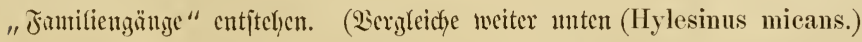

Eine jweite, nidyt biel weniger artenreiche (Sattung ber Borfenfäfer

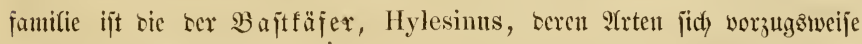
auf ber Siefer anfgalten.

Die Battung ijt, wenn and mur burth ein minjiges Mierfmal, aber

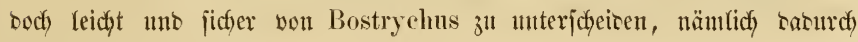




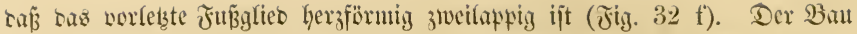

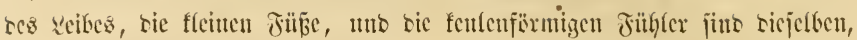
num ijt sie füzzere Brujt nady born nerffidy werfdymälert uns ser sioff

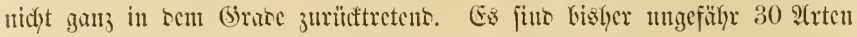
in Europa gefunten worben, sie aber nicht alle in Bänmen lebent.

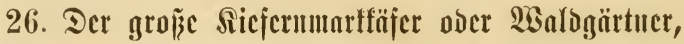 Hylesinus piniperda (Derm.) L.,}

t!lø

\section{Der flcine Sicfetmunrffïfer, II. minor Hartig,}

fömnen füglidy wercint befprodyen werten, weil jie nidyt mur cinntrer zum

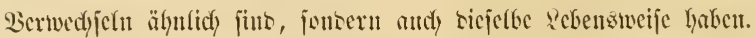

Fig. 32.

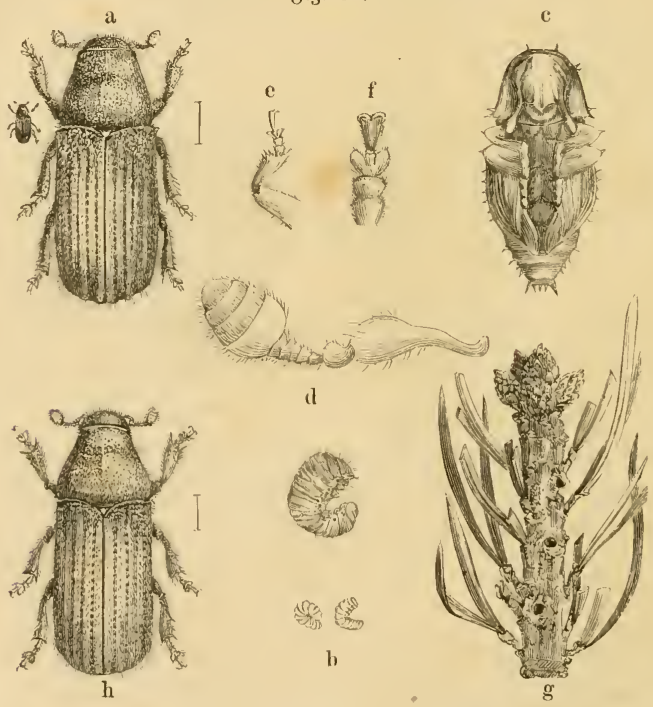

Der groß̧e uto fleine sicfernuaffäfcr, Itylesinus piniperda (Derm.) L. umo II. minor Hartig.

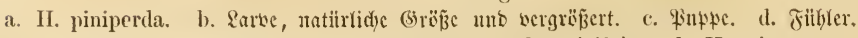
e. Bcin. f. Iarjengliçer. g. Yurgefrefiene Sicferntrickffitze. h. H. minor. 
Fig. 33.

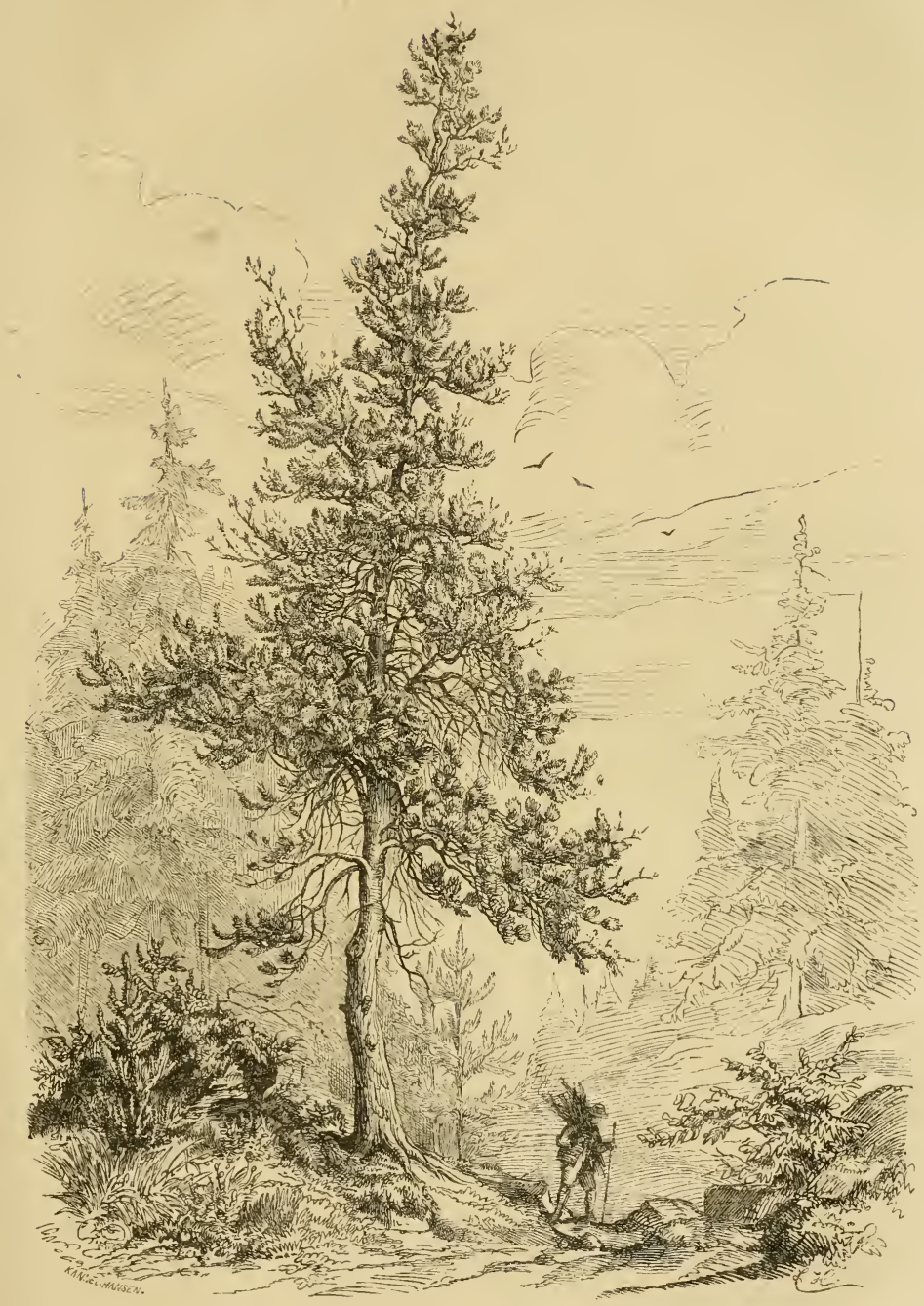

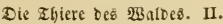




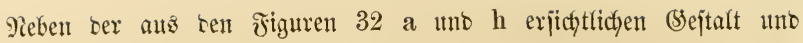
Sfulptur erfennt man fie reidyt an tem Gereits angejïfyrten (Sattungstenn=

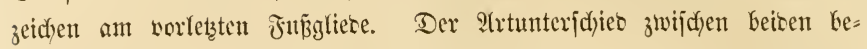

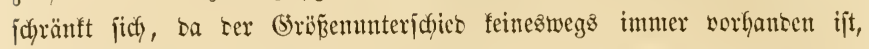

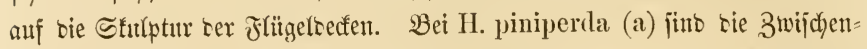

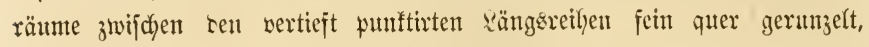

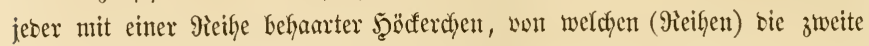
vor ber hintern Jgerabbiegung ber Jlïgeltedfen aufgert, bei H. minor (h)

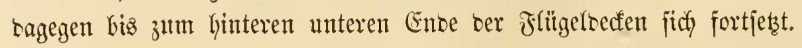

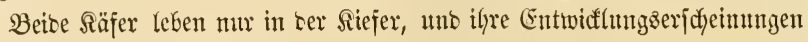

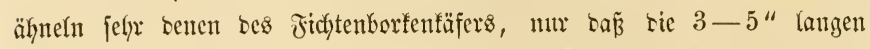
Rothgänge von piniperda immer mit einer harfenartigen frünumung an= jangen, währent ber minter Gänftige minor zweiarmige $\mathfrak{B a g e g a ̈ n g e ~ h a t , ~ w i e ~}$ B. curvidens unto Hylesinus fraxini (j. Jig. 34 b). Der groß̃e legt jeine Butffolonien in ben bifferinbeten Stamntheilen unb bejonsers gern in ßlafteridyeiten, ber fleine bagegen in ben bünminbigen oberen Theilen bes

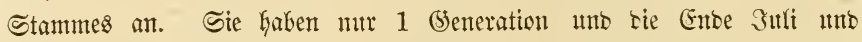
2lnjang $\mathfrak{A}$ thuft, ober bei warmem $\mathfrak{B}$ etter nod) früher autsfliegenten Säfer ridften bann an ber Siefer eine andere $\mathfrak{H}$ rt von Scharen. an, intem fie (id) $1^{1 / 2}-2^{1 / 2}$ " unter ser Spitze ber Siejerntriebe einbolyren, unb bie Mart= röhre ausfrejfen uno bies wolyl in ber Regel mit melyr als einer Triebjpize thun, ba man jehr häufig nod) ganz frifdye, vom winbe abgebrodjene ofhe

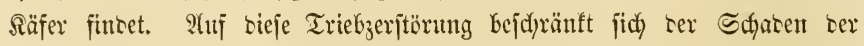

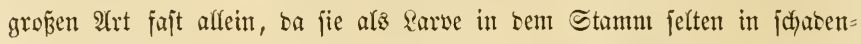

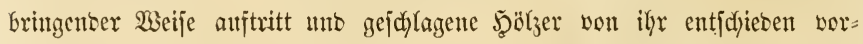
gezogen werben.

Wie (eid)t zuerrathen, hat biejes Berjtören ber Triebjpizzen bent häuftizeren piniperda ben Namen "Walbgärtner" veridfafft, weil bie fo vieler Triebe beraubten Bäume wie von (5ärtnerghano augigeäjtet ausjeken (i. Fig. 33).

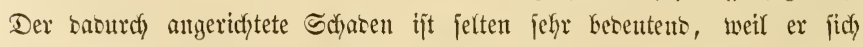
meijt alf bie Mantbäume jüngerer Bejtänte in Ragen, weldhe sem Sonnen= branto jef̧r autşgejęzt jino, bejdränft.

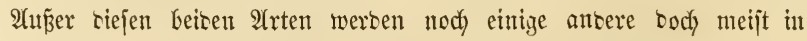

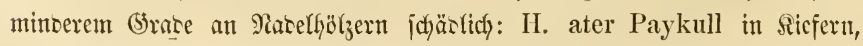
H. cunicularius Kn. ałs \&arven in Fidjtenjtöcfen und als Säfer am 
Wumzelfnoten junger Fidjten nageno, H. palliatus Gyll. an affen Rabel= hälzern, unb H. micans Kugelann, bie größ̄te von alfen $\mathfrak{A}$ rten, attigge= zeidfnet burch bie "Familiengänge" ber Rarven, weldye fid in ber Siefern=

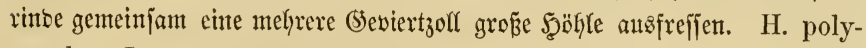

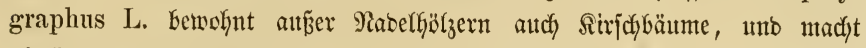
ähnliche bofpelarmige Wagegänge wie ber folgente, weldyer ber gefdicftejte von alfen biejen ફ̧olzichnetbern ijt.

\section{Der bunte Eidjentbaftfäfer, llylesinus fraxini Fabr.}

Peben bem uns befannten Battungşcharafter ijt biejer gebrungene

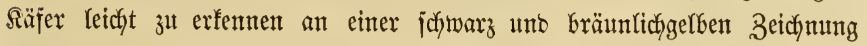

Fig. 34.
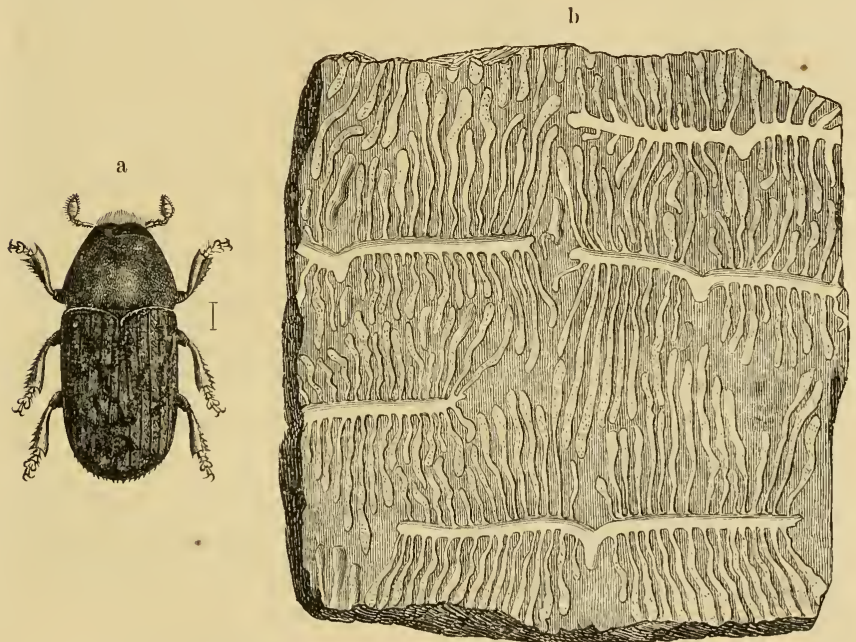

Der bunte Éd)enbaftfäfer, Hylesinus fraxini Fabr.

a. Der Räfer. b. Die boppelarmigen "Wagegänge“ mit ben babon ausgehenben \&arvengängen.

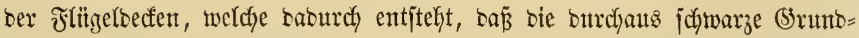

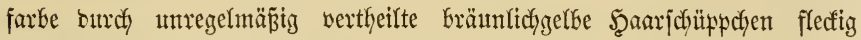
unterbrocken wiro (Fig. 34 a). 


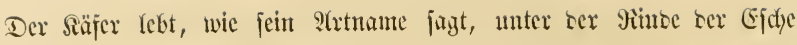

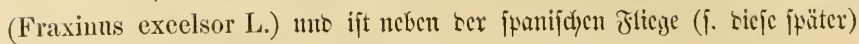

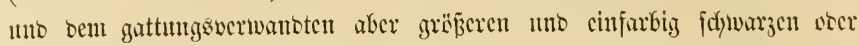
brannem Hyl. erenatus, ser sritte im Bunte ser Efdyenterterber. Die

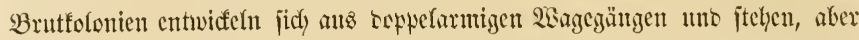

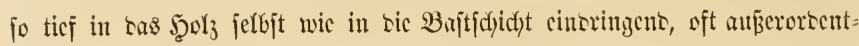

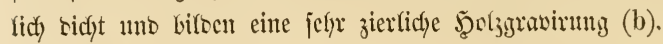

\section{Der großß̨e Miiijterjplintfäfer, liccoptogaster scolytus Ilerbst.}

Die Eplintfäfer, seren man ctwa 12 2lrten in Emropa jälylt, fino

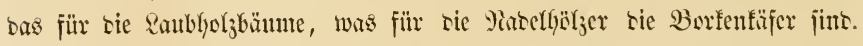

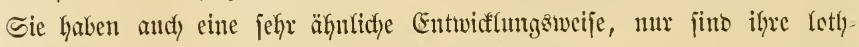
redyten, bei vielen and) wageredyten Miuttergänge oft fïrzer, bie Rarbengünge

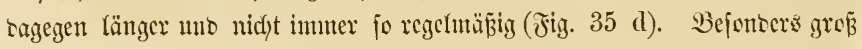
uno ausgerchnt fint bie Brutfolonien tes E. destruetor unter ber Birfenrinte, flein un zierfidy bic ocs E. multistriatus Marsh. unter 9iiliternrinte. Das Bruftictito mit bem Sopfe zujammen ift meift faum fïrzer

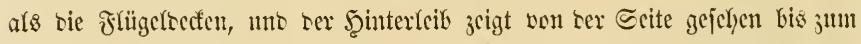

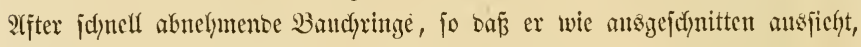

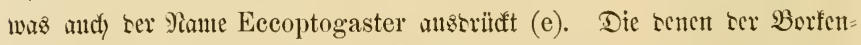

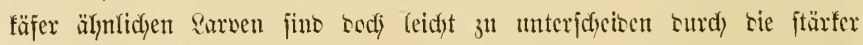
gemölbten exiten 4 Reibestinge, won benen ser erjte 4 flcine lyornige Schilschen trägt.

Die abgebilbete 9 art unterfecheiret jidy won rem ned) größeren, in ser Birfe lebenten E. destruetor Oliv. Durdh nux cinfadye- jeine Fimttlinien

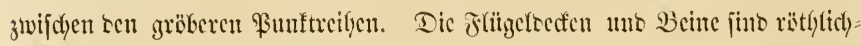
braun, übrigens ift ser ganze sä̈fer meijt ganz fdywarz vocr brau gefleftt.

Sn Mïijtern, anf weldye fid) ter Räfer ju befdyränfen fdycint, hat $\mathrm{cr}$

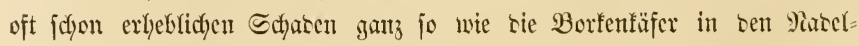
bäımen angeridytet.

Der nicfyt viel fleinere E. intricatus Koch lebt in ser Eidfe uno hat

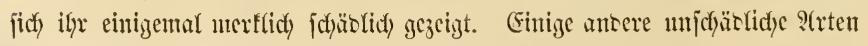

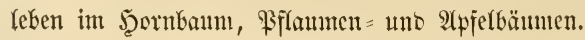


Eine jweite Familic sor vierzclfigen Säfer, weldye mefrere jefr widjtige

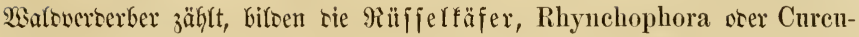

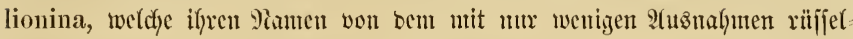

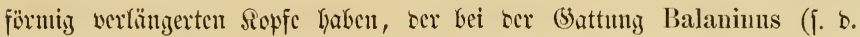
Fig. 37) 3n einen malyen (Elephantentïjiel wirt.

Fig. 35.
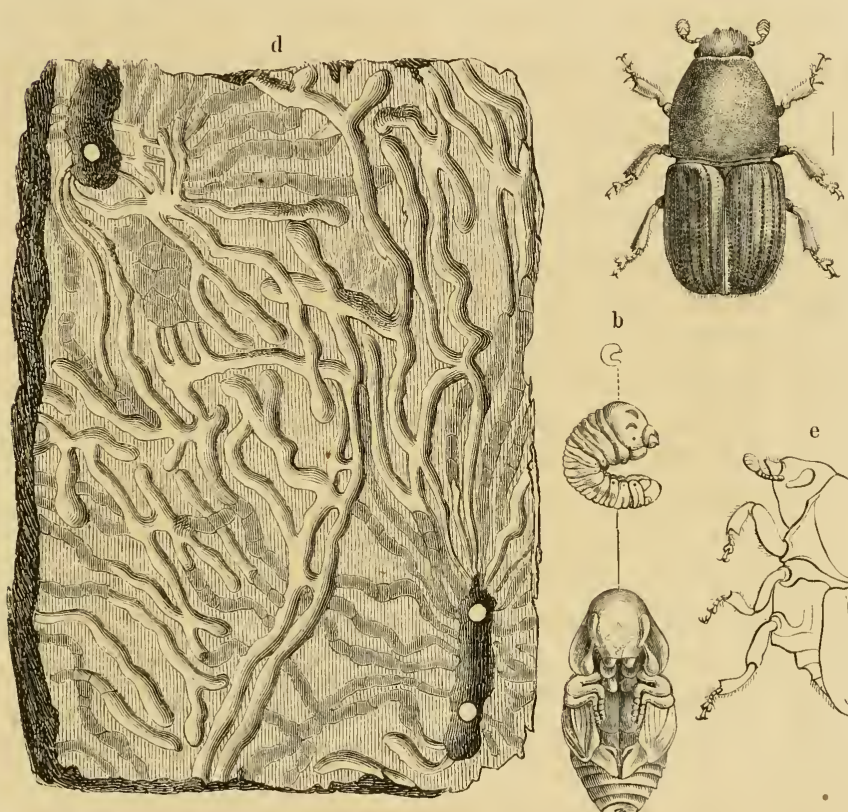

b
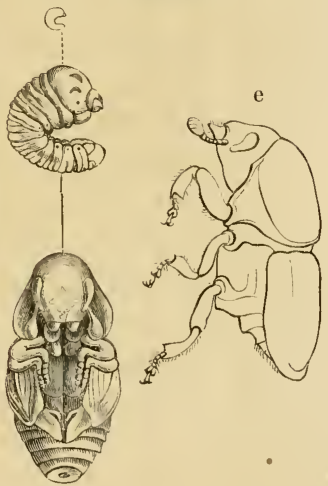

Der grofe Aïfterniplintfäfer, Eccopt. scolytus H.

a. Räfer. b. Sarve. c. Fuppe. d. Bruttolonic, e. Eccopt. destructor von ber Seite.

Die Ritiferfäfer Gaben in jeber Şinficht fo vich llebereinjtinmentes,

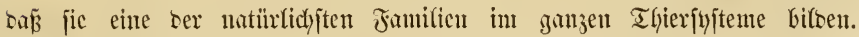

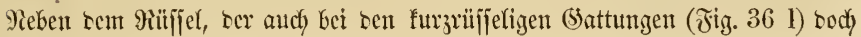


immex bem Ropfe eine jefr vorigejtrefte Şaltung uns Forut gicbt, fint ç namentlidy bie gefnieten ober gefnidfen peitjdyenäfnlfichen Fïhler (j. bejonter

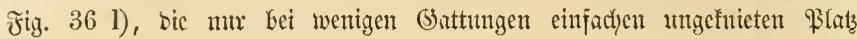

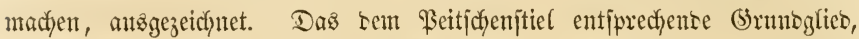
weldjes meijt eben fo lang ijt wie bie ïbrigen, bie Breißrelglieber, zmanment= genommen, fann in eine oft bis zum Âtge reidjento 9iume (c) juntidfigelegt merben. Dam fieft es aus, als ob bie Fïlyler bicht bei bent 2uge ein=

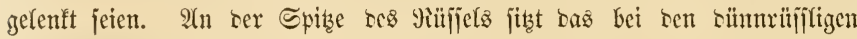
außerorbentfich fleine Maut. Der Ban scr meijten ijt gefälfig mit vor= waltenter (5rößje bes oft cirmm gemölbtent J̧interleibes. Die Beine haben fajt immer bejonters fräftige Schenfel, mo bieje fimb bei vichen mit einem

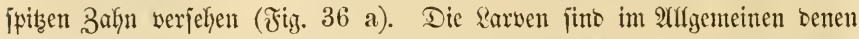

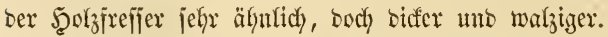

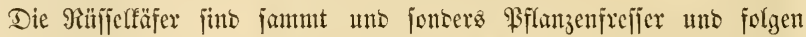
raher in gleidyem Miaaße ber Şäufigfeit ber Segetation itberall nach, zmijhen ben 23 endefreijen an reidyften vertreten mo nach sen Polen Gin abnefment.

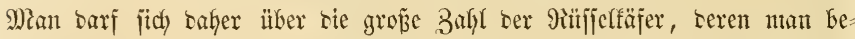
reits gegen 10,000 2trten femut, nidyt mutnern. Der berillymte SBrilfant= fäfer, Entimus imperialis (Cnre.) L. anto Brajtien gefyört auth in bie Fantlie ser 9iüfielfäfer.

Die Battungen mit einfadyen geraten Fïhlern, weldye sie albtheilung ser (B) erasfüblerigen, Orthocera, Gifon, enthalten feine ertheblichen Waltwerberber, mähreno unter scn Siniefühlerigen, Gonatocera, mehrere

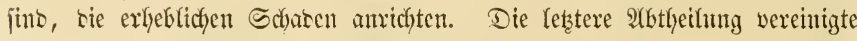
simné in bie Ritejengattung Curenlio, weldhe jekzt in viele Battungen zerfäft, von benen feine ben Pamen Curenlio behalten, jonbern biejen Yamen ber ganzen Familie abgetreten hat.

- Die Bafl ber in unjeren Saloungen wohnenben Ritijelfäfer ijt jefyr

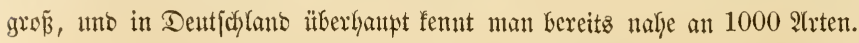




\section{Der großße Fididentiificlfäfer, llylobius abietis auct. *) (Curc. pini Rtzlog.)}

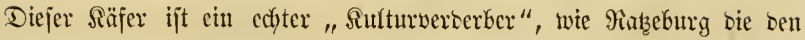
jungen Bammplanzen johabenten 3njeften in Begenjatz ju ben bie gröp̈eren Bäıme bejchäbigenten "Bejtanb\&ీverberbern" nennt. Bon ben bisher be=

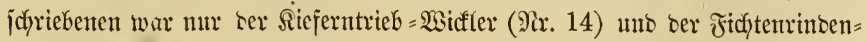
Witfler (9ix. 15) Sutturverberber.

Der アäfer (Fig. 36 a, b) gefört zu Den wenigen plump gebauten

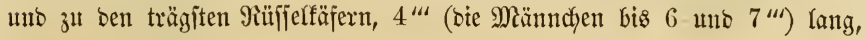
sunfel, oft fodwaz fajtanientraun, überall mit einzefnen jtrohgelben, furzen uno sidfen bichtanlicgenten Borjtchen bejetzt, bie namentlichy auj ben Flügel= becfen ju unterbrodjenen Fleffenbinben jidf bicfter zujammenjtelfen; an alten Räjern fint bieje Borjtchen oft ganz abgejtreift; alle Theile jüb jeen uno

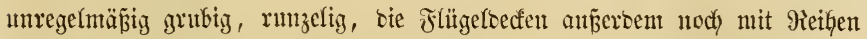

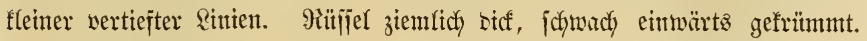
Die Schenfel haben an bem Ente cine tiefe Einbutchtung uno Daritber einen

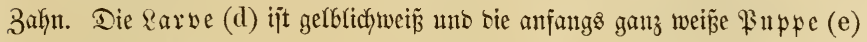
zeigt wie alle Säferpuppen alfe Theile bez Säjer's.

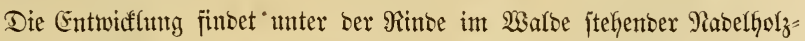

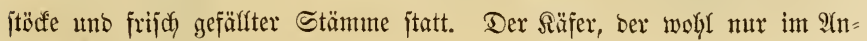

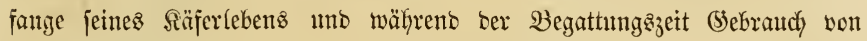
jeinem Flugvermögen macht, erjacint am Gäufigjten in Borjommer mo legt jeine Eier an ten bejetchneten Drten in bie Mitnremriffe ab: Die aus = friechenten Rarven vermëgen jeboch nicht surch Pagen in ter Splintjchicht ber Stöcfe unb jelkjt nichyt in sen gefällten Stäntmen einen Schaben anju richten. Diez thun, aber un fo empfutudidyer, mtr bic Säjer surch Benagen

*) Şier föntu twir eine trodne, gelebste Benterfung uidyt umgelyen. Simné be= fdyreibt eine Curculio abietis uno einen C. pini, wobei ibju ingetto einte Srruttg paifitt

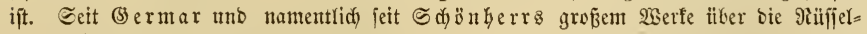

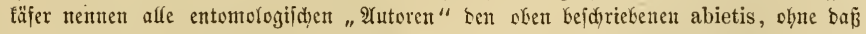
man beftinmt fagen fann, ob es abietis bes \&inné fei. Daber ift oben abietis , auc-

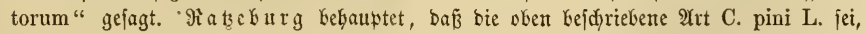
worin ifm bie alten Foritidjriftifeller maajgebent waren, unb bie ncueren ibm grofien= theils folgen. Uns fdjien es angenefien, bie won ber cutomologifden Wiffenidjaft allge= mein angentommente Ramengebung zu befolgen. 
Fig. 36.

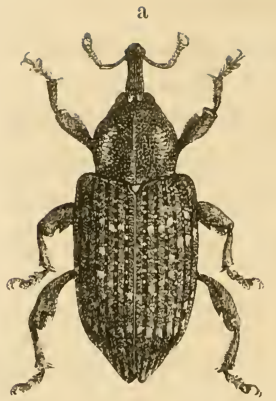

c
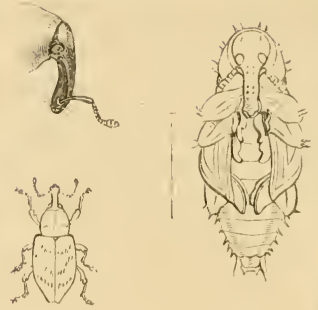

(1)

b
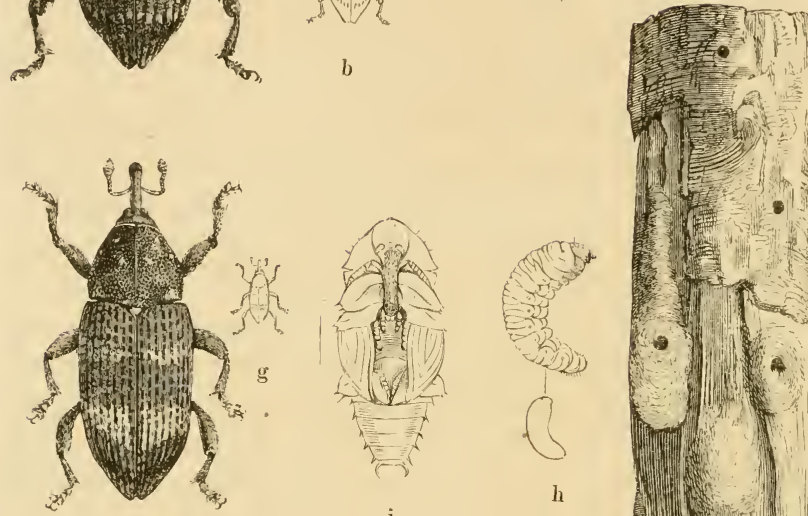

$b$

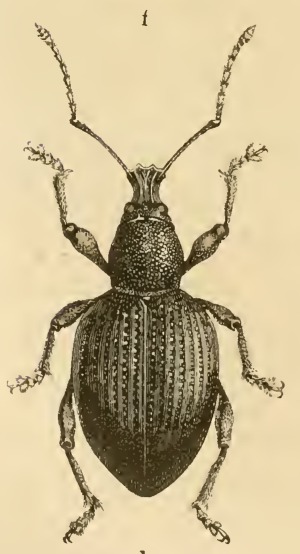

i

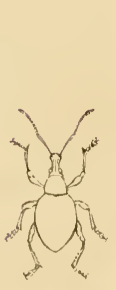

h
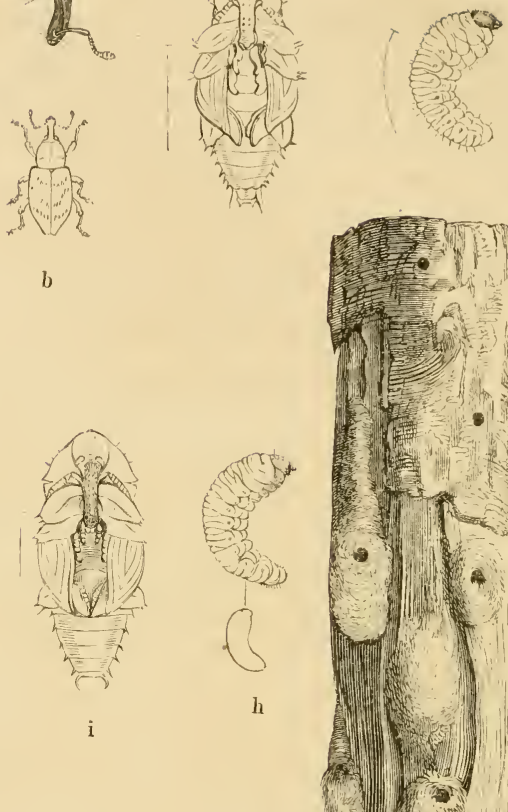

in

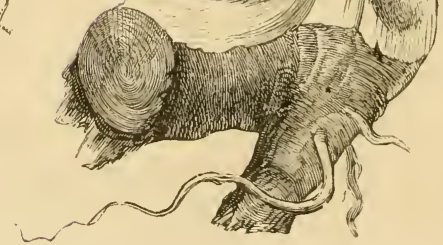

$\mathrm{k}$

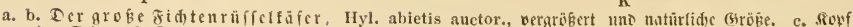
von Der Geite. d. Rarve. e. Butwe. f. g. Fer fleime Ricferntiffelfäfer Piss, notalus Gyl cben

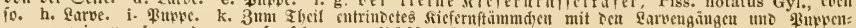
wiegent. I. m. Der große fdwarze Riffelfäfer, Otiorhynehus ater Ilerbst., efenfo. 
ber Minbe ber jungen Pflanzen, bejonters in ben Pflanjftulturen, weil wer: pflanzte $\mathfrak{B f l a n z e n ~ i m m e r ~ c i n e ~ Z e i t ~ l a n g ~ k r a ̈ n f e l n , ~ w a s ~ b i e ~ S i a ̈ f e r ~ m e l y r ~ a n = ~}$

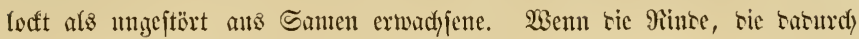

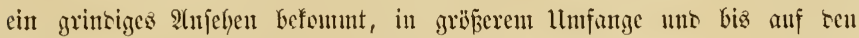
Splint abgentagt mirt, fo find bie $\mathfrak{B f l u ̈ n}$ linge unrettbar vertoren. Se fleiner uno jünger bicje, uno je melyr bie Sultumen ber Sonne unb Trodfenteit

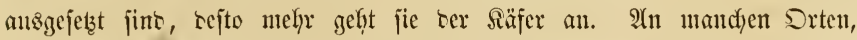

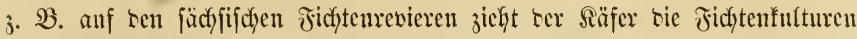
ganz entffjicten vor, wäfyrento man ilyn anberwärts ebenjo juäblich in

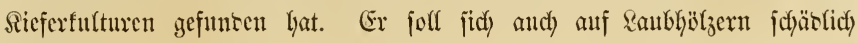
zeigen.

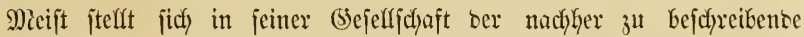

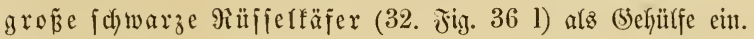

\section{Der weißjןjilldige Riçeruriilifelfäfer, Pissodes notatus Gyll.}

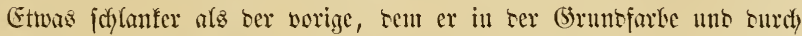

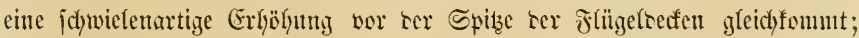

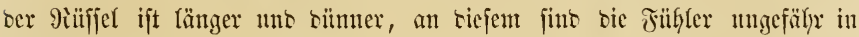
oev Mitte, bei borigem nabe am Mante, angefügt; sic Schenfel fino olye Einbudftung uno Zahn uno auserbem ift ex nodf surd sic färbung ser Flïgeloefen bejonters dyarafterifint, intem jebe cine (vorbere) halbe uno cine melyx nach ljinten ftelgente ganze umregelmäp̈ige Suerbinte trägt, weldye

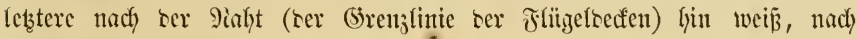
aแß̧en rothgelb ijt. (ร̈ig. 36 f.)

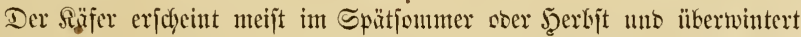
an Stammente ber Siefer in ben Minbenrifjen. Im Jrülyjafyr lengt ex feine

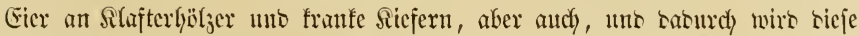
2rit oft jefy werberblich, an bie 9imbe junger $4-8$ jäfrriger Siefern, mnter beren 9linbe sie \&arben in Splinte ein wenig gejd)längelte meijt abwärts gehente (5änze แnto an beren Ente eine Puppenwiege frejīen, bie fie mit

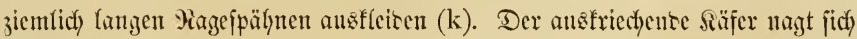

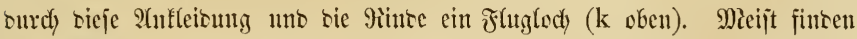

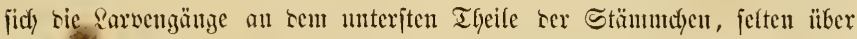
sem eriten ifitguirt. 
2tüer stefer leben nod) 6 aurere Pissodes-2lrten in ter Siefer, eine in ter Tame, unb eime in ber Fidjte. Inter jenen befintet jids aud) ber anzeblidfe Cureulio abietis L. (nad) Matazeburg), sen wir mit allen übrigen neueren $\Omega$ äferfintigen Pissodes pini auetor. nennen müfjen.

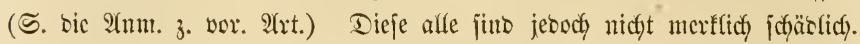

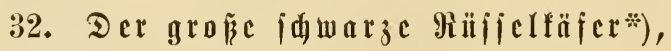 Otiorhynchus ater (Cure.) Ilerbst.}

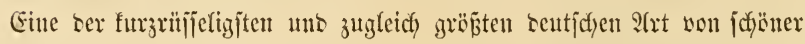
ebenmäp̈iger (5ejtalt. Der Sopf in einen fmzen, fdynanzenartig verbreiterten

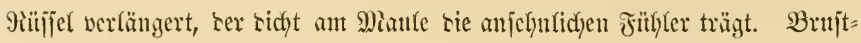

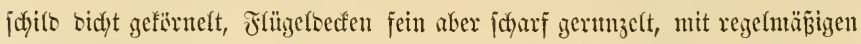

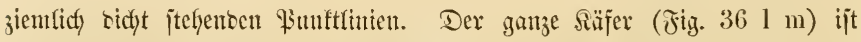

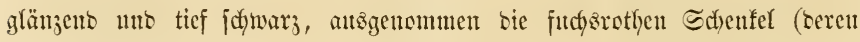
Spizen ober Siniee abgerect)uet) tno Sdjicnbeine; jcroct) fino bei einer ganz jdymarjen 2 (Gart (Otiorh. unicolor Hbst.) autd) rieje jdywarz.

Die Serwanding fintet im Eroboren ftatt, wo bie Sarve an ben

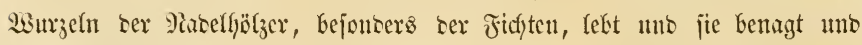

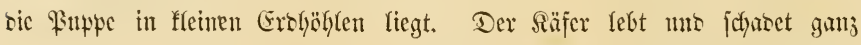
wie Hylobius abietis (\$. 167), in befien (Sejelfjdaft, obgleidy in ber Yiegel

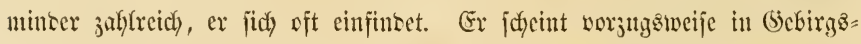
twalbungen zit lebent.

*) 28 ie juon bei ben beiben vorkergebenben $\mathfrak{A}$ ten, fo fümen wir and hier für bie (5)attung feinen bentidyen $\Re a n c u$ geben, fonbern behelfen $n$ z mit ben bentiden Famifien= namen and) fitr bie (5)attungen. (E) bent fo wie uns ergebt $e s$ aud alfen anberent bie

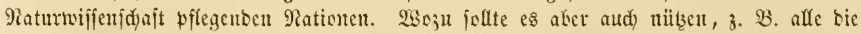

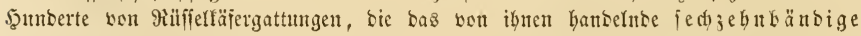

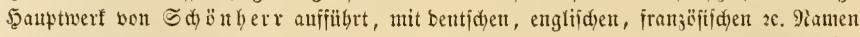
3u berjeken, ba fid bas Bolf jeine Ramen jür bie Raturtiorper nidjt nady foldyen ipitz=

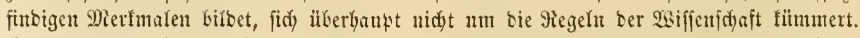

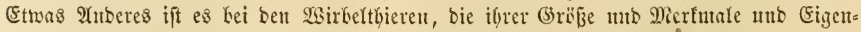

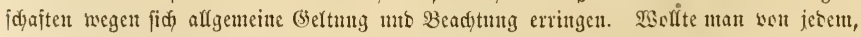

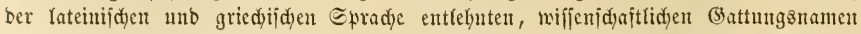

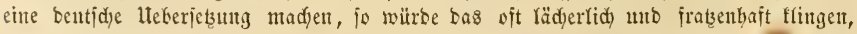

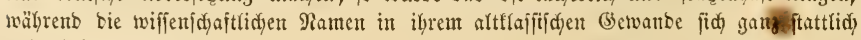
unb egrbar ausitehmen. 
Es leben nody biefe arten ber Gattung Otiorhynchus in bent bentifden wä̈lbern, seren überhaupt gegen 230 in Europa gejunben worben finto; aber feine weiter ridjtet in sen Walbungen Schaben an.

\section{Der Erleuriijiflfäfer, Cryptorhynchus lapathi (C.) L.}

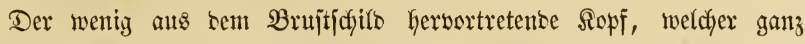

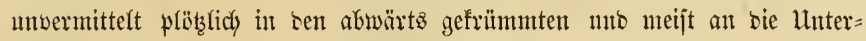

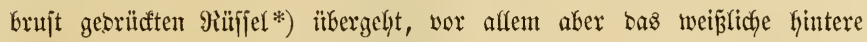

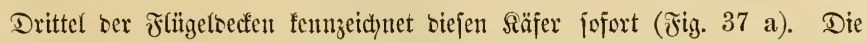

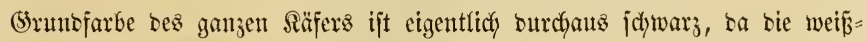

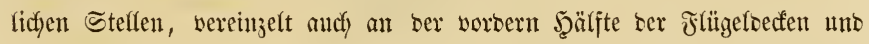

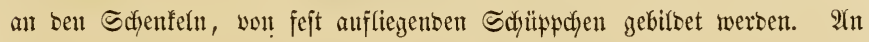

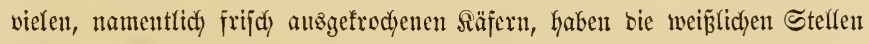

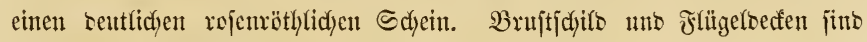

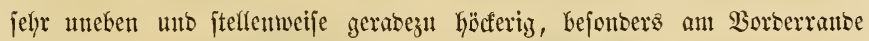

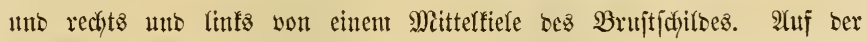

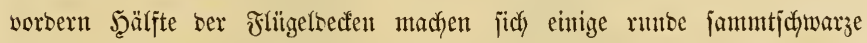

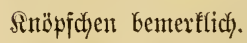

Der überwinternte Säjer fommt im Mia zum Sorjchein uno legt feine

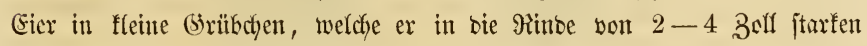

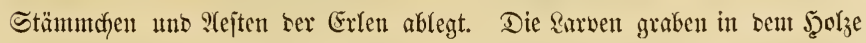
unnütfig weite (sänge, bie oft bidft unter bie 9imbenoberffaut foummen mo

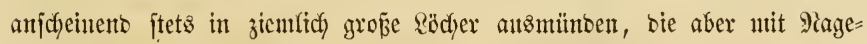
ipähuten verftopft finto.

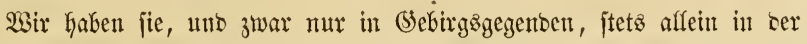

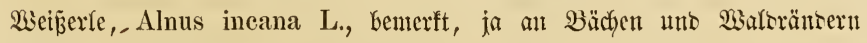

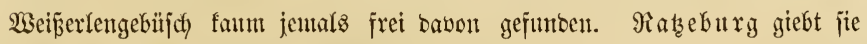
audy in ber Sedfwarzerte, A. glutinosa L., an. Sener wiro fie wirflict

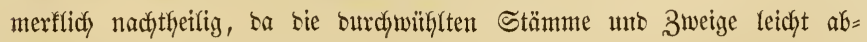
brecjen unb jelbjt abjterben.

*) Daв bejagt ber (Sattungsname, zut beutid etwa Berftecttrilifiler. 


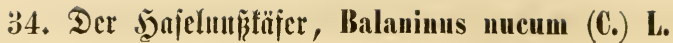

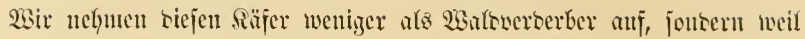

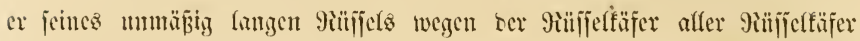
ijt; un sazu ijt er unjern simsern ser Spapserterber, weldyer nit ifpnen

§ig. 37.

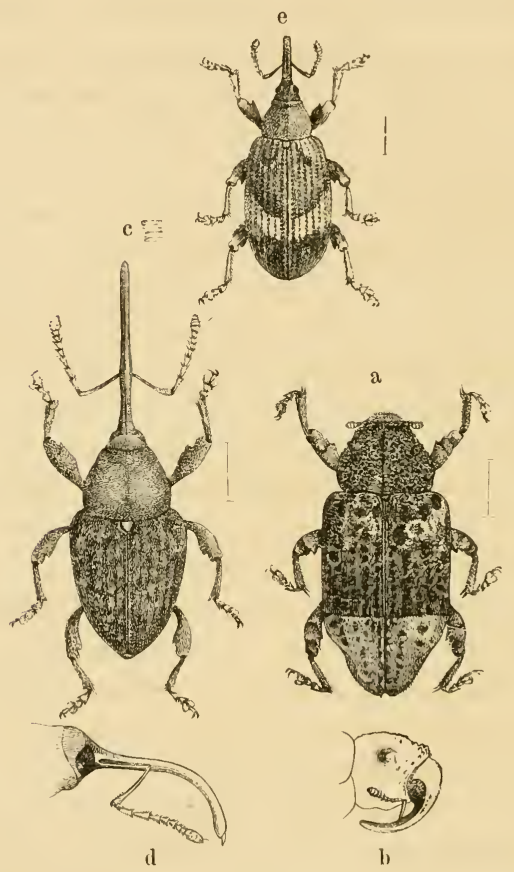

Der Erleurifieftäfer, Cryptorhynchus lapathi (Curc.) L.

a. Siäfer. b. Siopf won ber Scite.

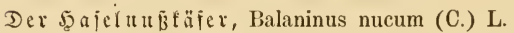

c. Räfer. d. SRopf won ber Scite.

e. Der atfelbrïtlentiffelfäfer, Anthonomus pomorum (C.) L.

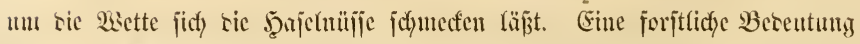

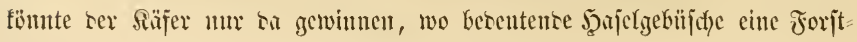




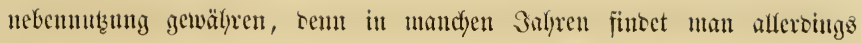
sen fünften Theil ter Mïiffe won ser Miare bes Sä̈fers betwolynt.

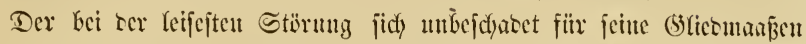

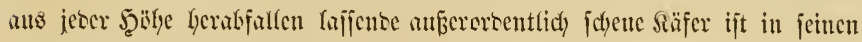
(5ewohnheiten eben besfalb jojwer zn beobadjten. Dod jteht jo biel fejt,

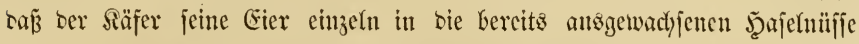

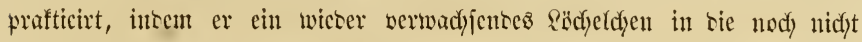

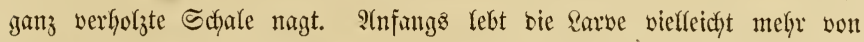

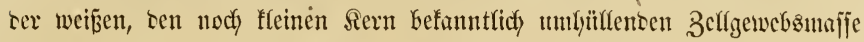

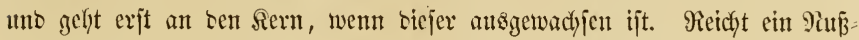

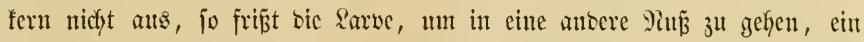

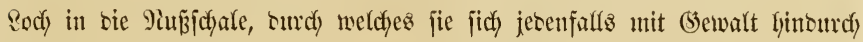

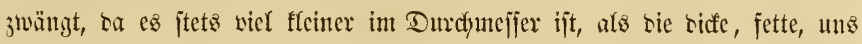

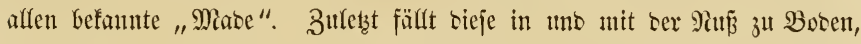
wo fie jich bis 1 Fun ticf in tenjelben cingräbt unt verpuppt. Sn oen wenigen beobadyteten Fällen faly man bie Säfer erft in folgenten ober zweit= folgenten Salye ericheinen.

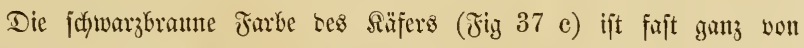

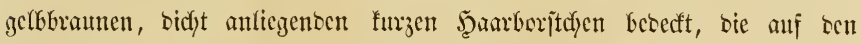
Flïgelbedfen meijt fleine unbentlidye Jlecfen bilben. Die Flïgelocefen, reren jebe für fich an ber hintern Spize abgejtmmpft ijt, bifren zujammen mnge=

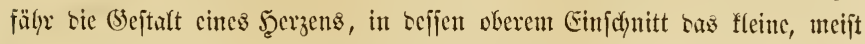
etmas sidfter behante un taher heffere Schilsdyen jefy benterfbar herwor: tritt. Unjere arbbiloung zeigt uns an ten Sdyenfein neben einem fleinen

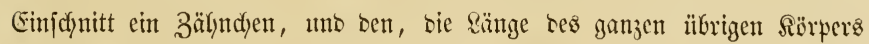
crreichenten bïmmen gefrïmmten Siüjjel.

2łn and) in ten fo herben bitteren Etdgefn. Bal. glandium Marsham, in

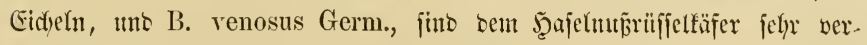
want uno kaben einen etwas fiimzeren gitifiel.

\section{Der Irpfelblitffenfted)er, Anthononus pomorum (C.) L.}

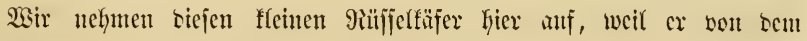
Waalrobjt in unjere Dbjtgärten ̈̈bergegangen ift, uno uns lier surch 


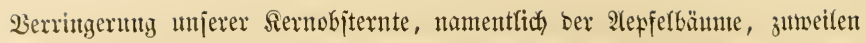
fehr jeçäclicty miro.

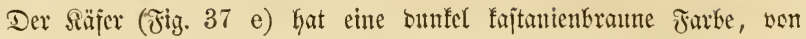

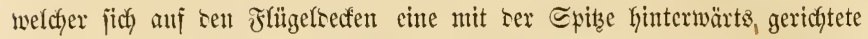
braungelbe 2 sinfelbinte unt eben fo gejärbte Flïgeltedfenpitzen auszeid)nen. Er ijt ïberall mit anliegenten grauen, jefr feinen ફ̧ärchen locfer bejekzt, was jeboch ben (3lanz ber Jlügelbecfen nicht ganz, uno nod, weniger sie

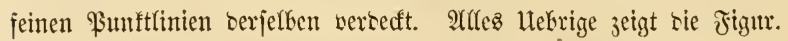

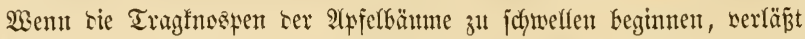
ber Säfer jein Winterlager in ber Bosentecfe unb bejteigt bie Bäume. Er legt ein orer mthrere Gier in fleite genagte Brïbdyen ber Inospen. Die Rärbdyen fonmen wahnjdyeinlidy erit aus, wenn bie Stiele ber $\mathfrak{B}$ (üthen= fnospen jidf) z" verlängern beginnen, orer fangen wenigjtens bann erift redjt

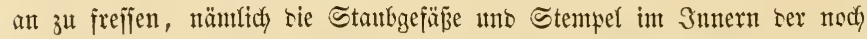

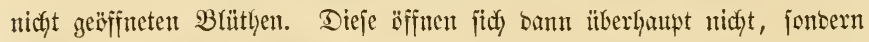
werben braun uno welf, bielfeidyt jelbjt etwas benagt, uto bilsen ein ichützentes Dach über ber zarten Rarve. Se fülter bas Bhlüthentwetter ijt,

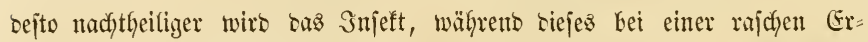

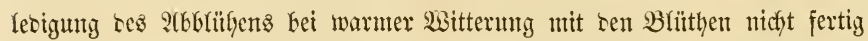

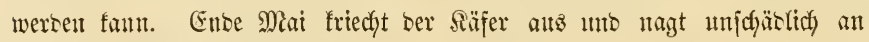
jungen 2 pfeflbaumblättern.

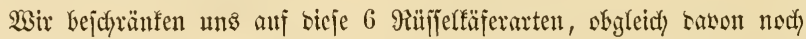

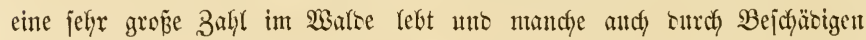

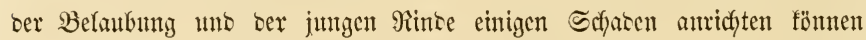

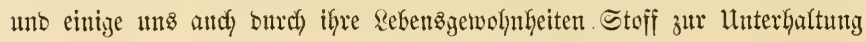
gegeben haben witrben. Wix milijen uns aber bejd)rüufen. WGie jęr ez

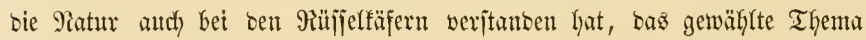
ber Form in vielen hunbert bon Bartationen z" mobutiren, fam แns im

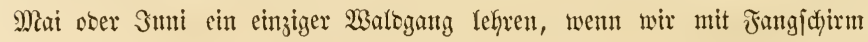

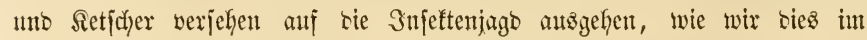

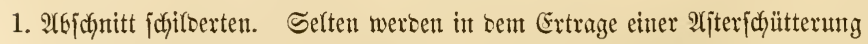

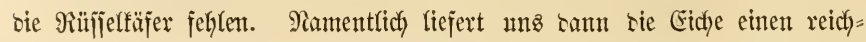
licfen Beitrag, ¿arunter aud einige $\mathfrak{A}$ ten von präd)tiger golbiggrüner Färbung. 


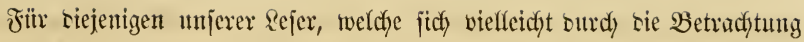

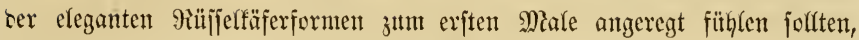

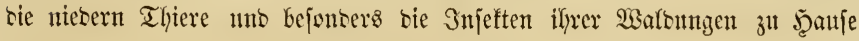
mit ber supe näber z" betracten, worats bann vielleidyt bei Mandjem eine Snjeftenjanmulung wirt, wollen wir lifer z'war feine volfytänbige $\mathfrak{X}_{\mathfrak{n}}=$ leitung 3tt einer ?(ntegnumg unb Einridytung einer foldhen geben, wir wollen jie aber bavon benadyridytigen, bá̉ ganj bejonters bie Miilifferfäfer zu ben=

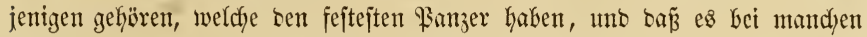

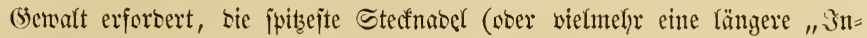

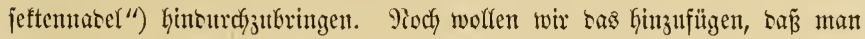
bie Naber, natïrlidy nadjecm bie Säfer in jtarfent 2 Seingeift

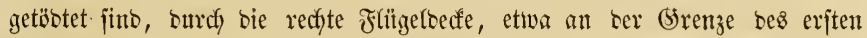

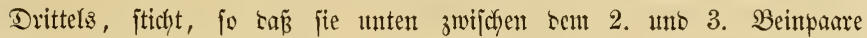
Gerausfommt. Man ftect bas 3njeft möglidjit Yjoch auf bie Maber, bamit

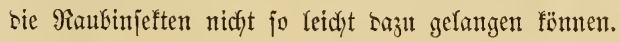

Eine britte waltoerterblidye Fanifie ser Tetrameren, ober ridjtiger Siryptopentameren, biltset bie ser $\mathfrak{B}$ offfäfer, songicornen sber Eeram=

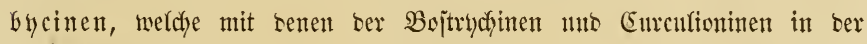

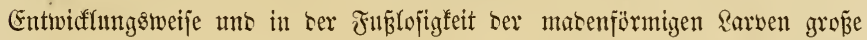

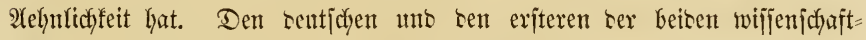

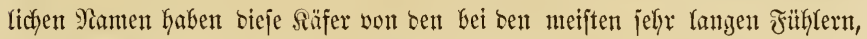
bie bei mandyen an bie ந̧ärner bes Ziegen = uns nody methr bes Steinbodes erimern. Bei bem namentfich -auf Bimmerpläţen fid hermmtreibenten Astynomus aedilis (Cer.) L. jino die Finflfer viermar fo lang afz ber Reib*).

Der Sïrper ber Bodfäfer ijt nterflich in bie Ränge gezogen, nady Ginten meift jtarf verfdymädytigt. Die 2 Atgen finto bei viefen fefyr tief

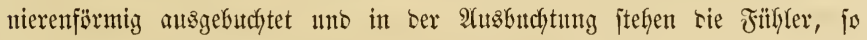

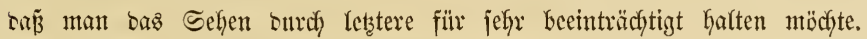
Bei mefreeren 2 rten ijt bas Bruftifjitto an ben Seiten mit einem voer

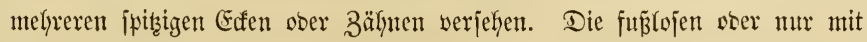

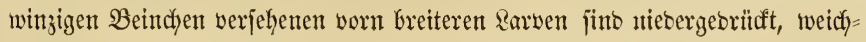

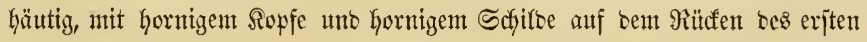

*) Rod länger, tämlidy 6 mal fo lang finb bie Gaarbünmen Filbler einer zierlidyen Motte, Adela de Geerella L., weldje auf ben Wiejen jef̧r häufig ift. 
veibestinges, mo and) bie folgenten haben oben in ser Mitte meift cin jayar begrengtes runlyeres Sdjilto (j. Jig. 38 b).

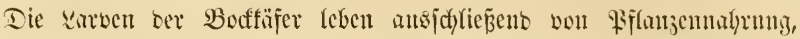

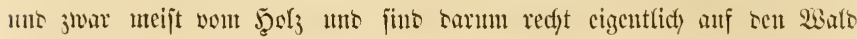
angetwiejen.

Man fennt bereits gegen 4000 Arten, bie, je näher sen Wentefreijen,

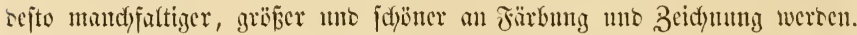

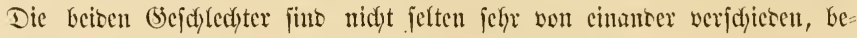
jonters surdy tic groß̈en geweiffartigen Dberfiefer ser Meänndyen mand)er

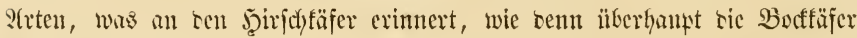

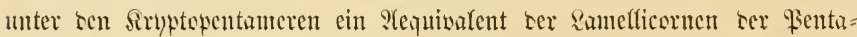
meren jint, sie wir surdy sen Miaifäfer Melolontha vulgaris Fabr. femen. Lleberhaupt fommen bei ben Bodfäfern sie verjejictenartigiten Bijarterien

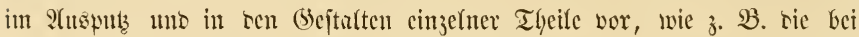

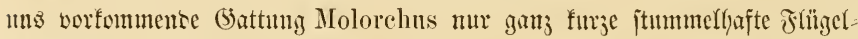
tecfen hat. Bicle Bocffäfer fümen cincu \&ant won jid geben, einen jeinen

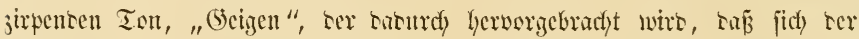

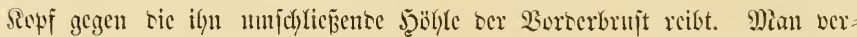

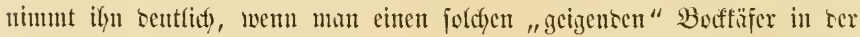

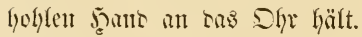

Der Schaten, sen die Boffäfertarwen in unjeren Bsälsern amrictenten,

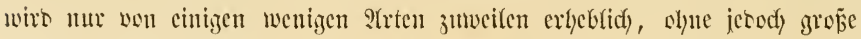
bैerhujte herbeizufülyren.

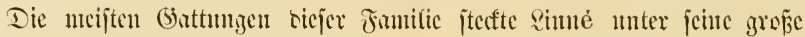

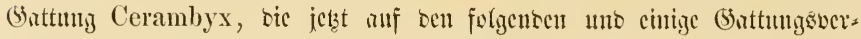
wante bejd)ränft wirt.

\section{Der großß̨e Eidjenboditiffer, \\ Cerambyx heros L. (Ilammaticherus heros Megerle).}

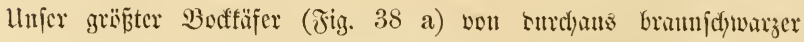

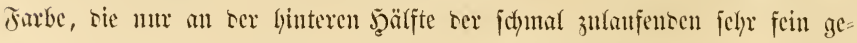
förnelten แno mit einigen fajt nur angebeuteten \&ängs(inicn verfelyenen Flïgersecten aflmälig in 9iojtbram ïbergeht. Das Bruftictyilo ijt grob 


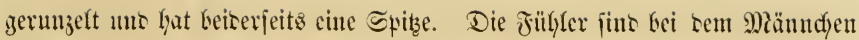

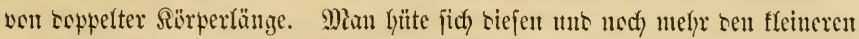
ganz fatwarzen Booffäfer C. cerdo L. mit cinem ansern älnnlidjen be=

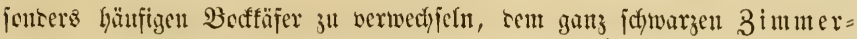
jeröter ster Weber, Lamia textor, an weldyem aber sas Mianl jenf=

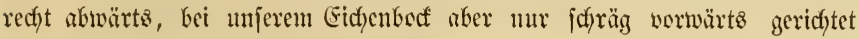

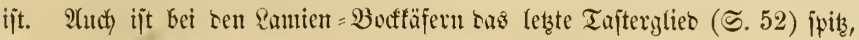
bei Cerambyx un jeinen Berwansten breit abgejtutzt.

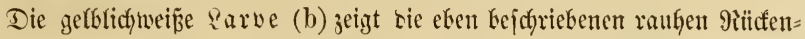

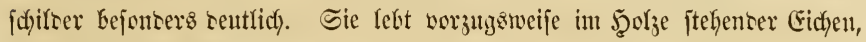

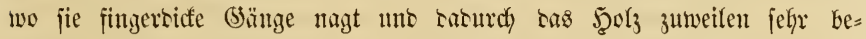

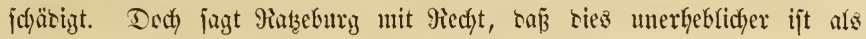

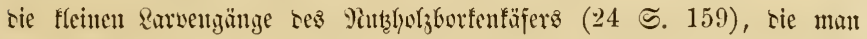

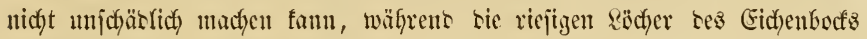

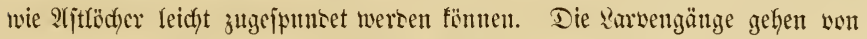

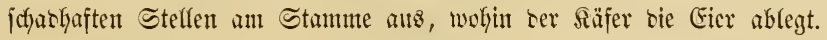

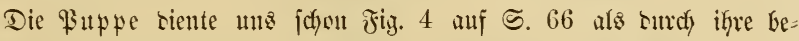
Icutente (Srïbe jidy bejonters empfefllentes Beijpiel ser Säferpuppen.

23ir nafmen sen Eidfenbof hier mehr afs einen ber hervorragentiten

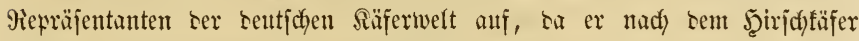

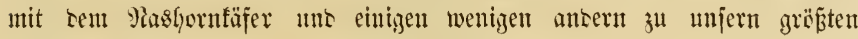
Räferm gehört.

\section{Der großze Pappelbofffäfer, Saperda Carcharias (Cer.) L.}

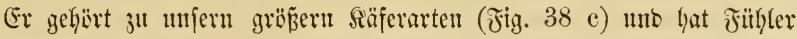

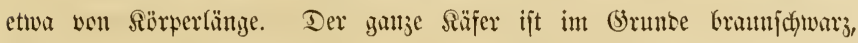

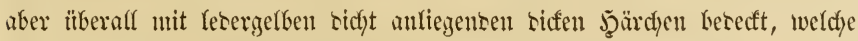

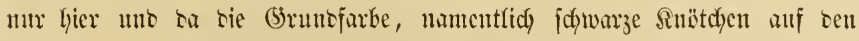

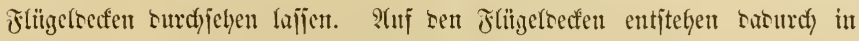
ber Mitte 2 unbentfiche, nicht immer vorfanbene Duerbinoen. T(ts ein Mitglict ser Samicngruppe (jiche vorker bei C. heros) trägt er jein Maul jenfredyt abivärts geridytet mo bie retzten Tajterglieber fint ifitz. Die gelblichweiṕc Rarte (d) ijt mu ganz an Ente verichmälert, an ser Seite

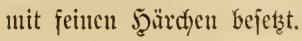


Fig. 38.

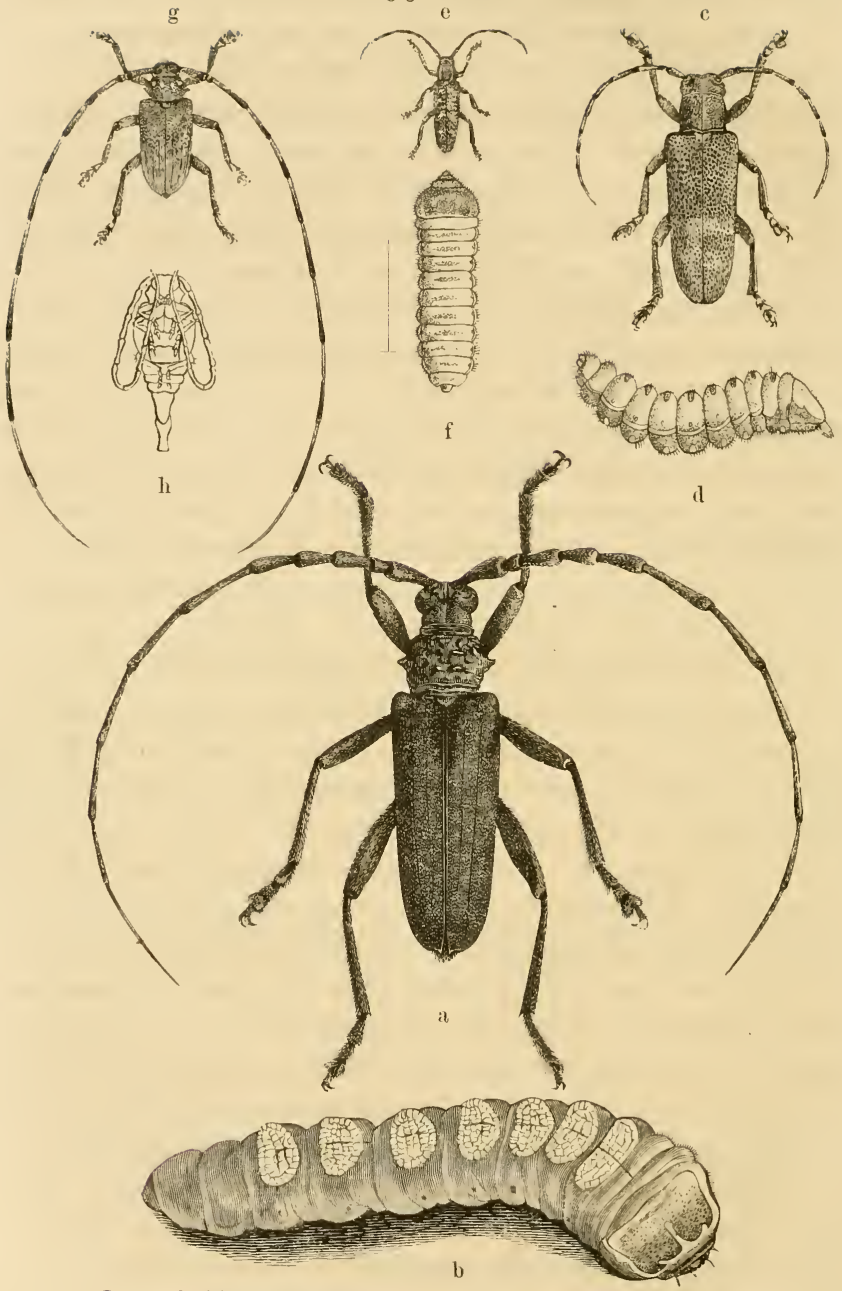

Fer grufe (sidgelloudfäfer, Cerambyx heros L. - a. Stifer. b, surve.

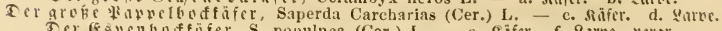

Ter Eavento of töfer, S. populnea (Cer.) L. - e. sinfer. f. Earve, vergr.

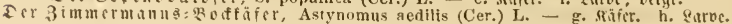




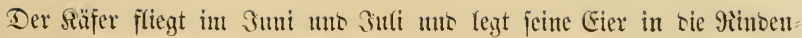
rijie verffiebenter Raptelarten, bejonters ser Eapen (Populus tremula L.),

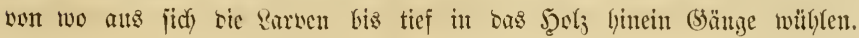
Pady ben 2. Winter werpuppen fie jich hier un bie Säfer fonment baher

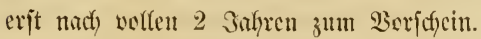

Da biejer Sï̈fer jeine Eicr nidyt leidjt an ättere als ctwa 20 jälyrige

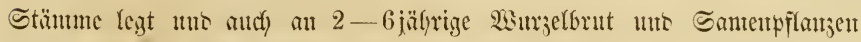

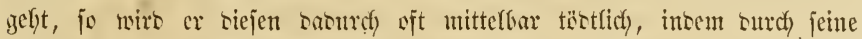

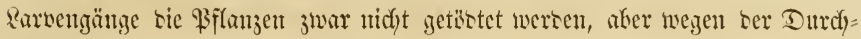

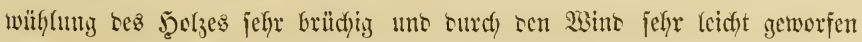

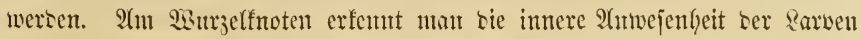

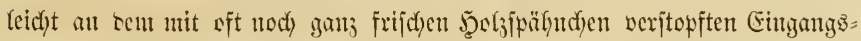

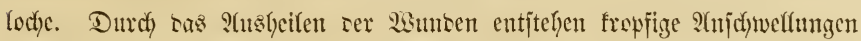

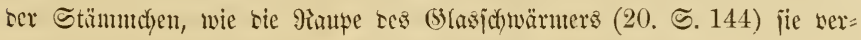
anlap̃t, bie oft in Sejefljdaft riejes Bodfiffers in sen Eapen haujt.

\section{Der gelloftreifige (Ëpenbodfliffer, Saperda populnea (Cer.) L.}

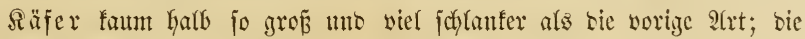
Srutbfarbe ijt ebenfalls jchtwarz, aber ebenfalfs non gelbgrintich granen

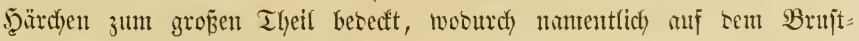

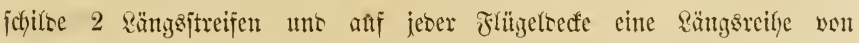

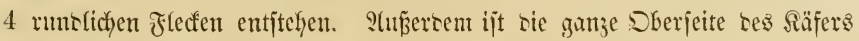
tief runzelig punftirt (Fig. 38 e).

Dic Rarve (f) lebt jwar aud im Stamme, abcr ebcn jo hältfig in

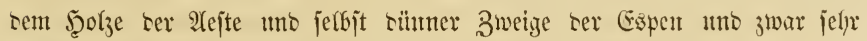
häufity. Sie wiro saburdy natürlidy sem (Screchen, aber nicht leidyt tem

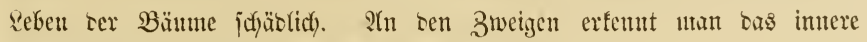

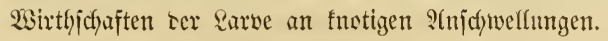

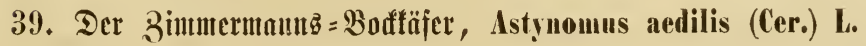

Wir geben riejem langhärnigiten affer teutidyen Bocffäfer siejen beutfacu Tamen, weil cr bem Yrtmamen aedilis (im Tieulatein: Ban= meifter) entjpricht uno weil ser Säfer bcjouter hänfig auf Bimmerplätzen 


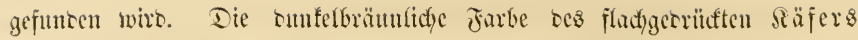

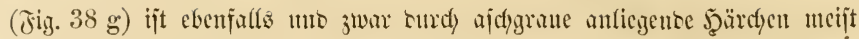

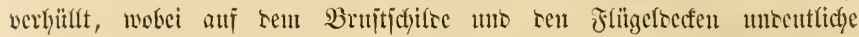

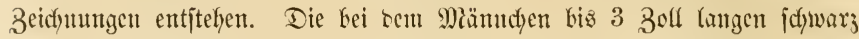
geglieberten jefyr langglicorigen Fïtlfer jint immer mefyrmal fänger als ser bischjtens $7^{\prime \prime \prime}$ lang weroente scib.

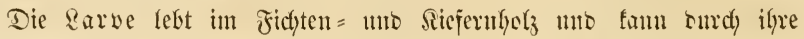
(5änge rajielbe mandymal erfeblich veridylectstern. Es ijt aber nidfyt

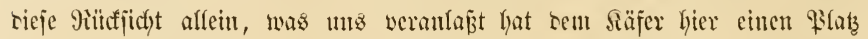

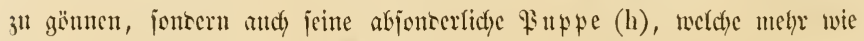

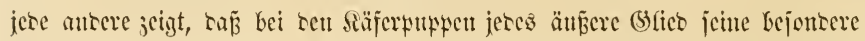
Berectung hat, tenn wis jeben sie beiten Jithler wie sie erjten rïnten

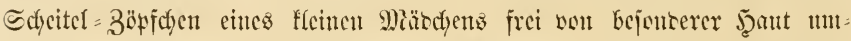

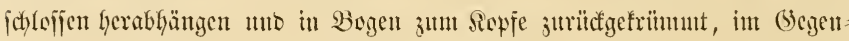

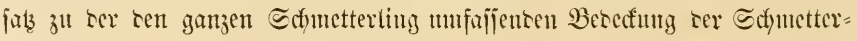
filtgiputpe.

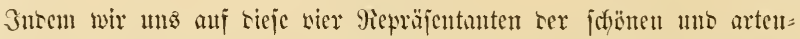

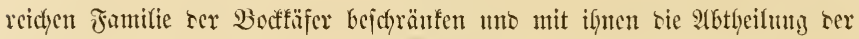
vierzeligen noer verburgen jünjzehigen Säfer bejaltę̧en, wicserlyolen wir,

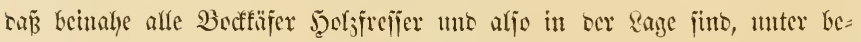

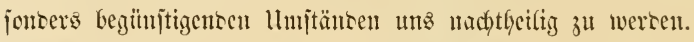

Es folgt nun nod) bie fajt nur atz fleinen uno jebr fleinen Säfern

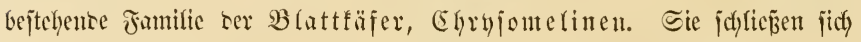

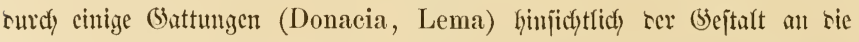
Bocffäfer an, fino aber fonjt meijt vou auffaflento gebrumgener fumzer sörper=

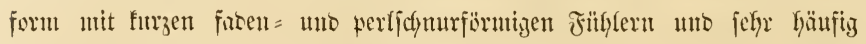
lebgaften mo metaffij(f)en Farben. Sam entichiebenjten d)arnfterifiren jids

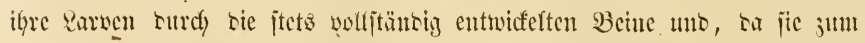

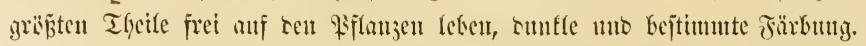

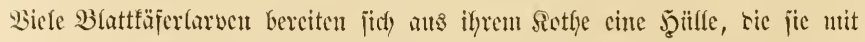
jith) hermutriagen. Die uncijten verpuppen fith wie rie Tagfalter frei auf

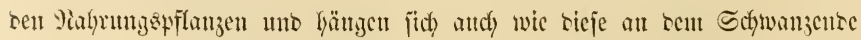

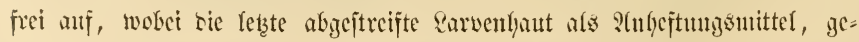

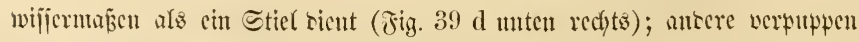

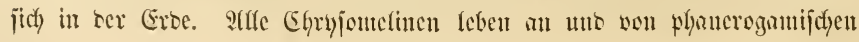




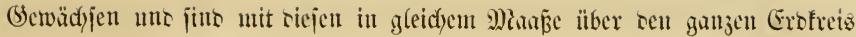

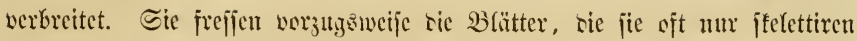

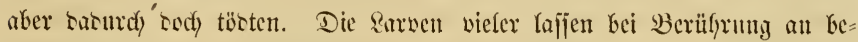
fitumten Punften zalfreidye jtart uno wioerlidy nady bittern Mianochn riechenice Saftröpfiden austreten.

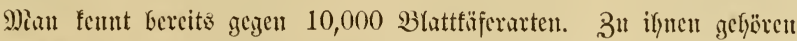

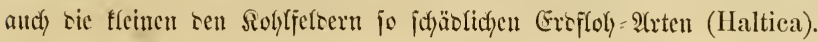

\section{Der groß̌c (Eapenblattfäfer, Lina populi (Chrysom.) L. \\ t11t}

\section{Der fleine CEppenblattfïfer Lo tremulae Fabr.}

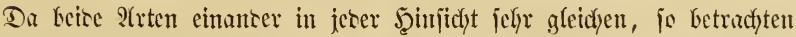

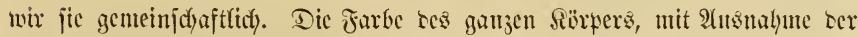

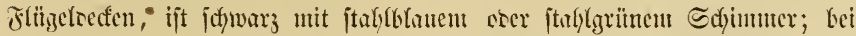

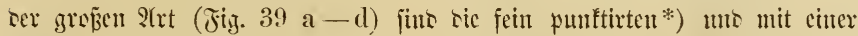

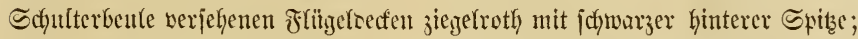
bei ser fleinen (e) ijt sie Farbe ser Ftïgeliseden rebhafter uno reiner, sem Bimnober nabe foument uno ohne sie juwarzen Spizen. Das Brujtidjilo

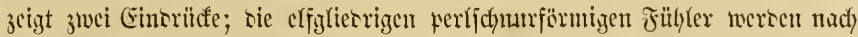

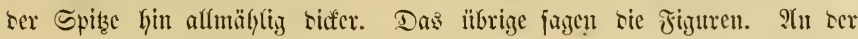

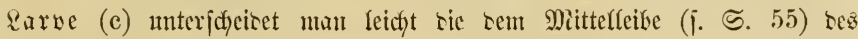
volfommenen Bujtantes entipredfenten anters gebanten, auch tie 3 langen

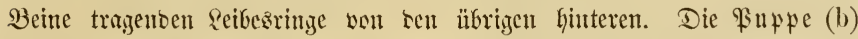
zeigt nidyts llngewöfnlidyes; an ber wie oben bejefrieben aufigeryängten, wou ter antoren (Pï̈ffen:) Scite gejefenen \$supe (d unten rechts) ift ser obere

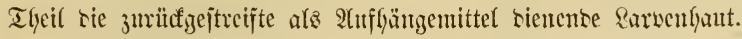

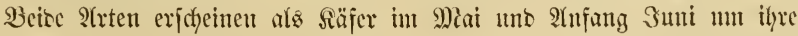

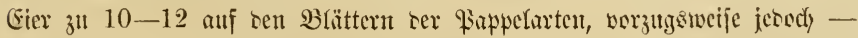
nix haben jie nic anf anteren Bappelarten gefursen - anf sen Bitter= fappeln oser Espen (Populus tremula L.) abjulezen, nicmats aber auf

*) Dies 2 Sort bezeidfnet bei ber Sfulptur ber Snjeften nidft farbige Funfte, fonbern punftförnige Siertiefungen uno jollte saber, was aud) Miandje thun, burd) nabelftidjig werbrängt wercen, wå punctatus mörtlid) audd) becentet. 
Æig. 39.

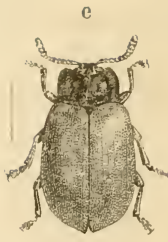

a

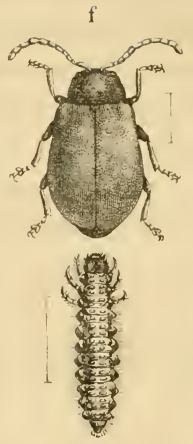

g

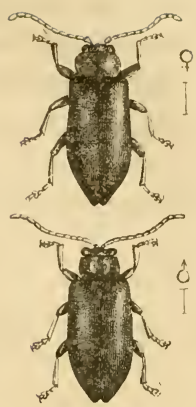

$\mathrm{k}$
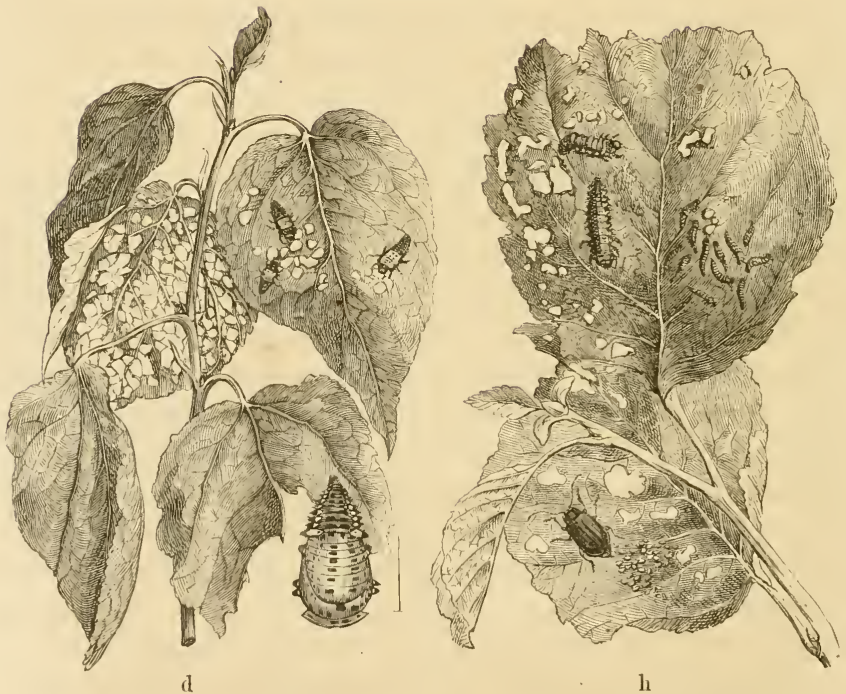

h

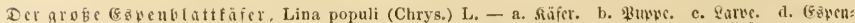

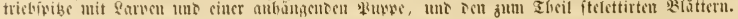

Der fleine (5. ancublattfifer, L. tremulae F. - e. finfer.

Del (Erlenblattfäfer, Agelastica Alni (Galeruca) Fabr. - f. slafer. g. Earve. h. Erlentricbipize

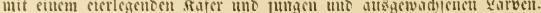

Der fiefernblattfäfer, Luperus pinicola Andersch, - i. weiblid)er, k. mäuntidłer fäfor.

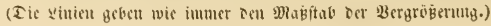




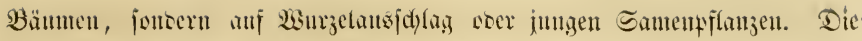

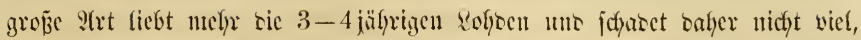

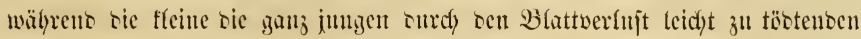

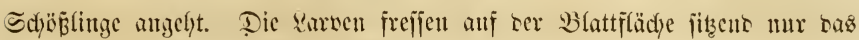

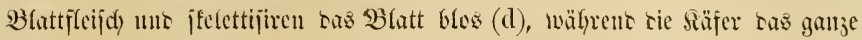
Bhatt werzelyren un nur bie grobjten Mippen jtehen Kajjen. Man fintet

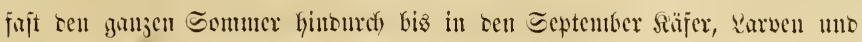

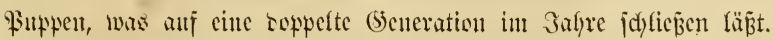

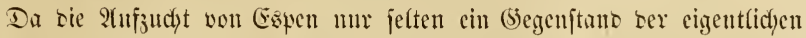

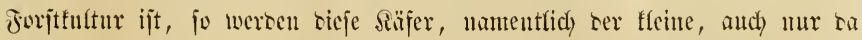

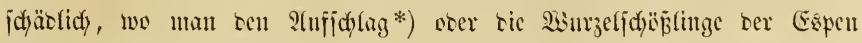

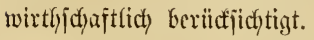

\section{Der Crrlenblattfäfer, Agelastica alni (Galeruca) Fabr.}

Siteiner als bie worigen uno surdyans von sunfel ftaflbfuner färbung

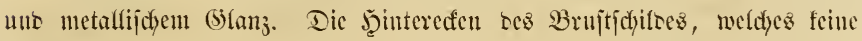
Eimbrïcte hat, finto abgejtumpft (Jig. 39 f). Das trächtige 23 cibchen hat cinen tie Flïgefreden emportreibenten jtarf angejd)wolfenen J̧interfeib แnt

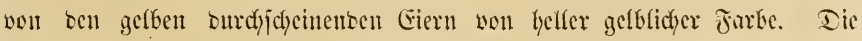

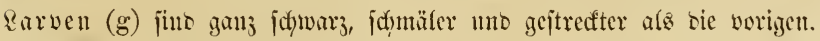

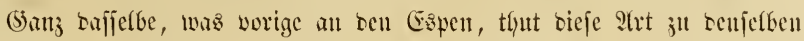
3afureszeiten au ren Edywarj= Exlen, Aluns glutinosa L. (Jig. 39 h) un jutweifen audt) an ten Birfen uno jwar mefyr als jene and) an ätteren

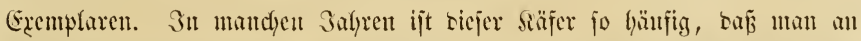

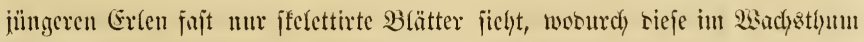

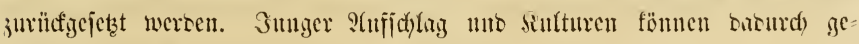
tïstet werten.

\section{Der Ricjerublattfïfer, Luperus pinicola Andersch.}

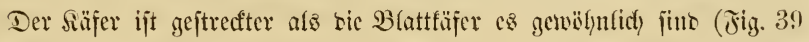

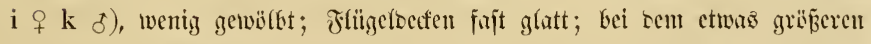

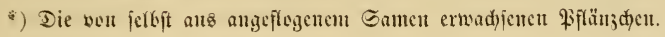




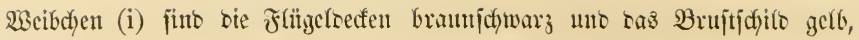
bei sem Männdyen (k) beire bram

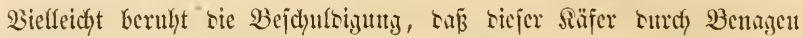
ber jungen Sicferntricbe fdäblidy merre, auf einer ungenanen Beobactstuntig.

\section{b. Jiinfzehige, જ̉entrmeren.}

Dbgleich sie Säfer mit 5 Juß̧glictern an alfen 6 Beinen sie ïber wiegente Melyzahl ser ganzen Säferoromung attomadyen, sa man 30 fïnf

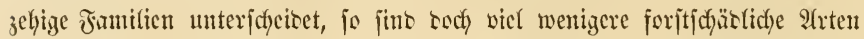
unter ilyen, als in sen blos 6 Janticn Dierzebiger. 2Bejentlicy ift ties

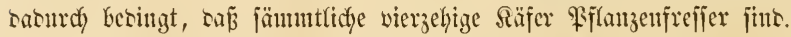

Die wentgen hierher gehörenten idgäblichen Räjer gehörẹn ben beiten alten Famitien oer Sägehörnigen, Serricornen uno ber Blatt hörnigen, Samelficornen, an, von benen aber bie exptere in neuerer Beit in vicle flcine Familien zerfällt worben iit.

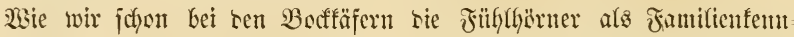

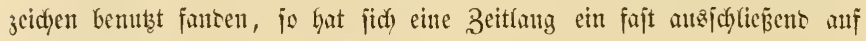
siejes 9)ierfmal gegrüntetes Säferityjem erhalten, bej̄en 8 Fantiliemamen wir hier furz anfïhren woflen. Die crifte Familie ift sie cinzige nidft nadh

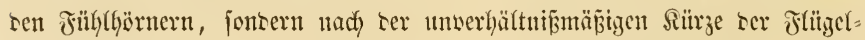
becfen benannte: Brachelytern, Lic anteren heiß̄en Elavicornen, Samefli cornen, Sisjtricornen, Monilicornen, Filiconen, Serriconen unt Songicomen.

\section{Der gemcine Silopffäfer, Tobtemulyr, Anobium pertinax L. IIII}

\section{Der bunte Silopfläjer, A. tessellatum Fabr.}

Die Atmobien gerg̈ren mit rer folgenten Gattung in tie fleine Jannilie ber 50 olzbogrer, țylophagen, bie als Sarven wie and in ton anbern

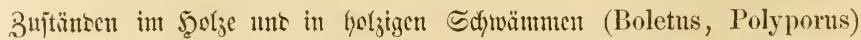
leben uns fid näbren. Die Anobien jinto flcine, zientid malzenfürmige Räfer mit abwärtz gebogenem verjteften Sopfe (Jig. 40 b) d). Sie

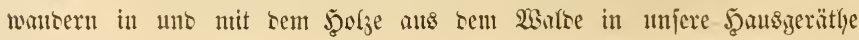




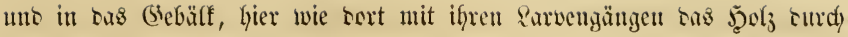
rüblento uno brïfyig madyent.

Der gemeine slopfläfer (Jig. 40 a b) ift ganz jodwambraum mit

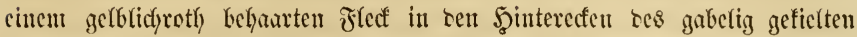

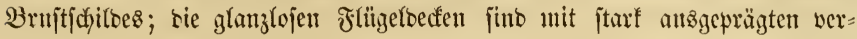

Fig. 40.

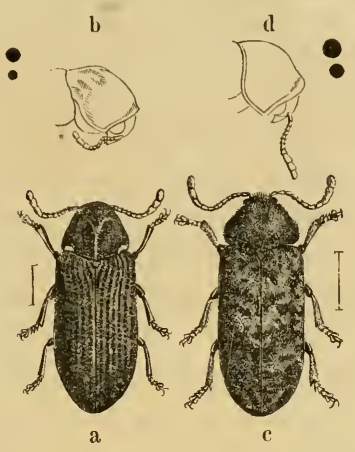

Der gemeine Rlopfäfer, Anobium pertinax L.

a. Säfer. b. Sopf won her Geite. Sben bie (Brößje Der Fluglöd)er.

Der bute slopffäfer, A. tessellatum Fabr.

c. d. e eberijo.

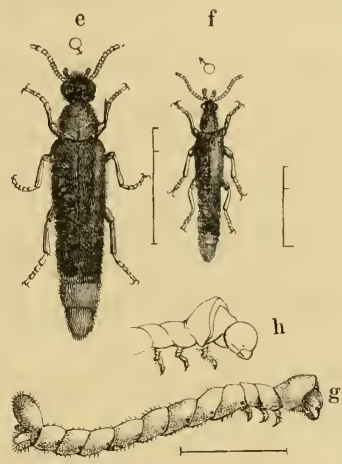

Der Eidentuerftäfer, Lymexylon navale $\mathrm{L}$.

e. meiblid)er, f. mäunlidyer Rïfer. g. Sarbe.

h. ber vorbere Theil berjelben mit meit vorgejtreftem $\Re$ orfic.

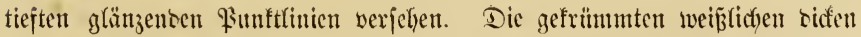

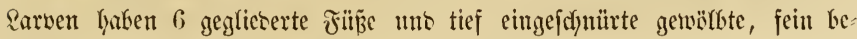
haarte Scibesringet.

Dicjer uno ber foligenbe Räjex unt nod) zwei antere S(rten, Anobstriatum uno carpini, Gaben zu ben ?tberglanben von ber Iobtenubr Beranlajfung gegeben, worüber wir hicr folgenbe Beobadjtung, an tessel-

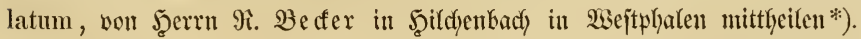

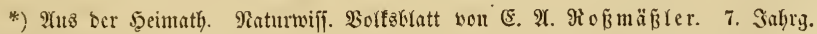
$1565,9 i, 45$. 


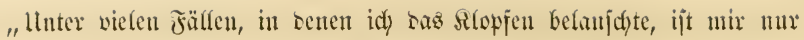
cin einziger befannt, wo siejes ter Räjer anżerhalb verriçtete: es lwar am

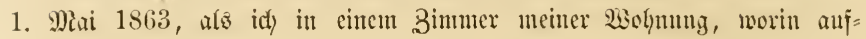
gehobenc alte Dielen aujzeftelft waren, sicjes gegen atbent hörte. Daz

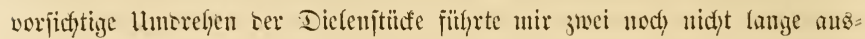

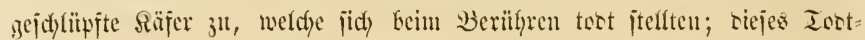

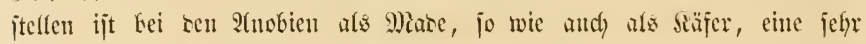
d)arafterijtijdye Gigenjofaft. Iex Säjer croulret alfe Sutalen shne jeine Berjtelfung fahren ju lajien. Mian nennt ifu besfalb and "Trobzfopf". Er bleibt mit anyejogenen Beinen uno Fülyfern lange Beit wie toot in ser

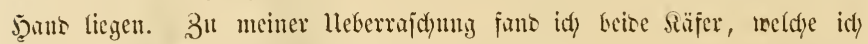

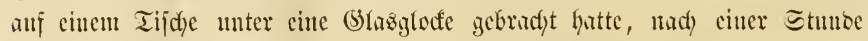

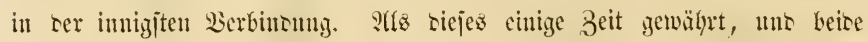

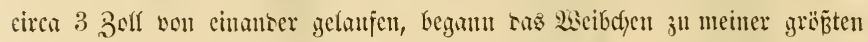

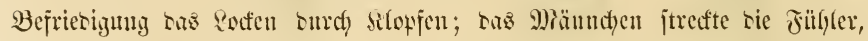
als um ju lanjach, gerase ans, uns antwortete nad) sem juciten 9ufe

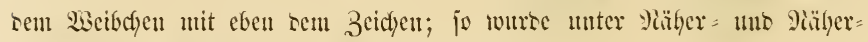
rïcen ricjes Qiebcosnett mit Exioly fortzejeßzt.

"Dicjes abwedjelnte Slloffen uns begatten sanerte in gräperen un

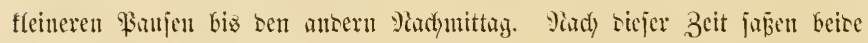
Säfer rulfig entfernt von einanber. Des anbern Miorgens ftrandyelte sas

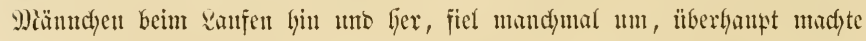

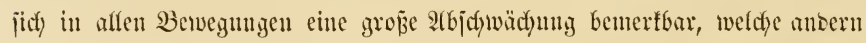

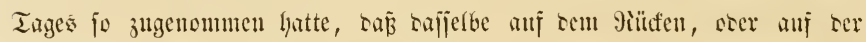

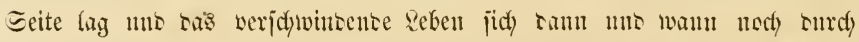
frampflyafte Betwegunizen ser Beine, ser Mantheile seer jübler jeigte.

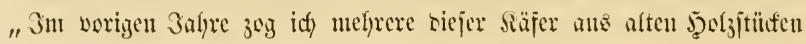
แno fano bie oben angegebenen näheren llmitänse bejtätigt.

"Dicjes Saljr entwifelten jict) am 1. S(pril won ticjen Säjern jwei,

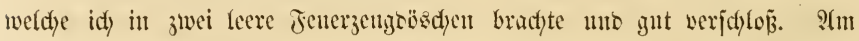

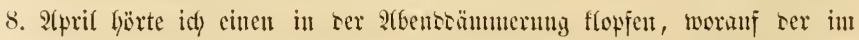
antern Iöschen bafo antwortete. Zu meinem seis mar leb̧terer ans mir unbefanten llijacten an andern Miorgen abgejterben. Der antere lebente

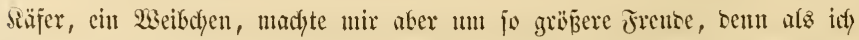
mit einer Stricfnated surdy Stopen mi ben Iija, wormi sas Döstyen 


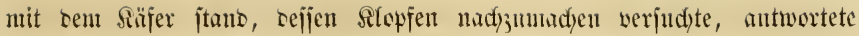
mir baffelbe mit bemielben Zeid)en, uno zwar an fpäteren warmen Iagen,

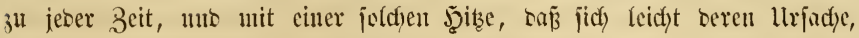

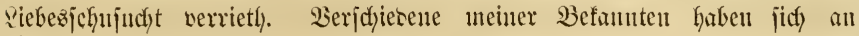
biejen Dutt erigëzzt.

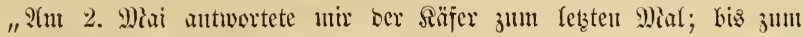

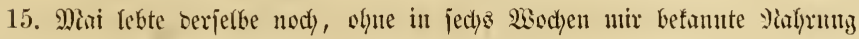
3il jict) genoument jull haben.

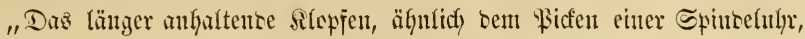
weldyes man an warmen Tagen ober in wamen Pä̈dten im Suni, 3nfi uno Ângajt hört, verrichtet Anobium pertinax L., bie eigentfiche "Iooten

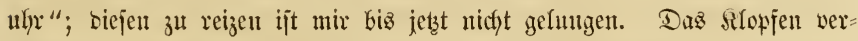

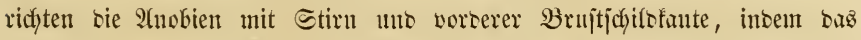

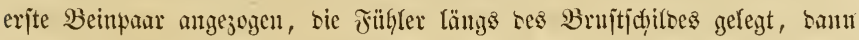

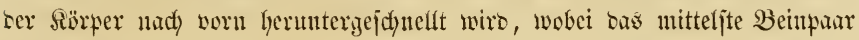
al\& $2(d) j e$ bient."

Miady biejer Beobudytung mï̈̈te ber von Miandyen ausgejprodyene

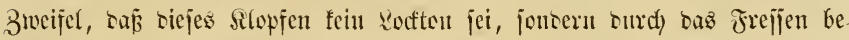

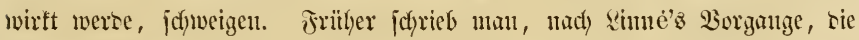

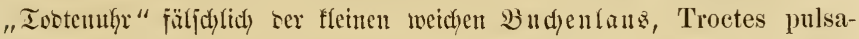
torius (Termes) L, zll.

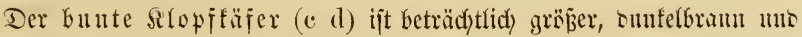
locfer mit fleinen antiegenten gelblichen ફ̧ärdjen befleioct, woourdy auf ben

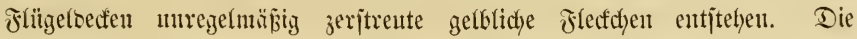
übrigens ber vorigen jehr gleidfe sarve ijt entfpredjeno gröper.

Dieje un nod) einige antere Arten, seren sie Sattung Anobium in Furopà 36 zählt, fino im Secrein mit einigen ansern Säfern (bejonters Ptinus sur L. uno Ptilinus pectinicornis Fabr.), weldfe jümmtlid)

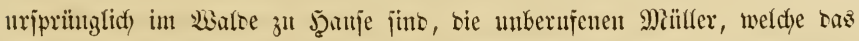

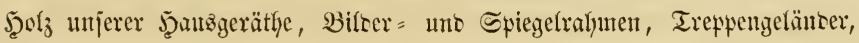

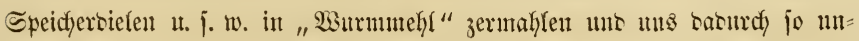
beilwall werben.

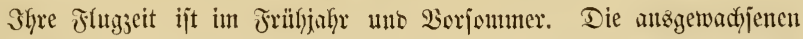
Rarben finset man währento seß wie abgejtorbenen, im Walte mefyr in $2 a n b=$ als in Macelyolzbäumen. 


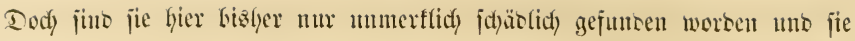

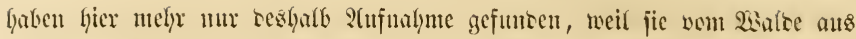

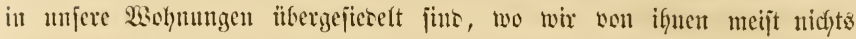

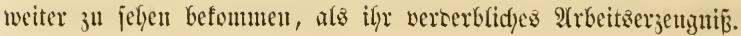

\section{Der (Eidentwerfftäjer, Lymexylon navale (Cantharis) I.}

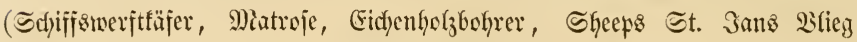
ber ફ̧at(länter).

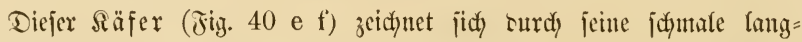
geitrecte beftult unt funzen, einen Theil bes Şinterleibes fervertreten

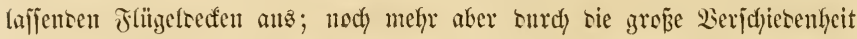

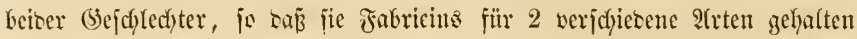
unt Das Miänndfen (f) L. flavipes genamnt hat. Das reidylid) un tie

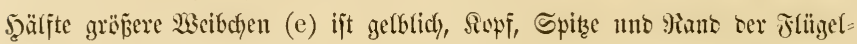

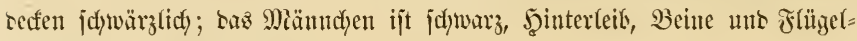
seden am (brumbe getblid).

Die sünne zarte $1 / 2$ " lange 6 beinige $\mathscr{E a r v e}(\mathrm{g})$ fann iflren sopf unter sem Gutfigen erjten seibestringer weit voritrecten uno fajt redftwinftiz ferabbiegen (h). Das binterite (s)lies ift aufwärts Glajenartig aufyetrieben.

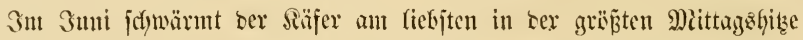
unto legt feine Eier an frante entblöß̈te Stellen alter (Eidjen ober Eidfen=

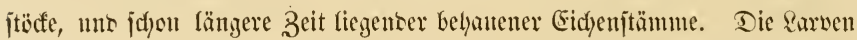

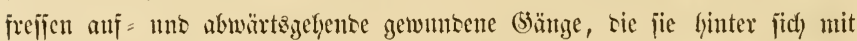

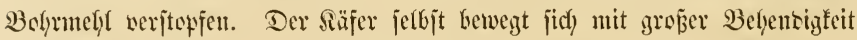

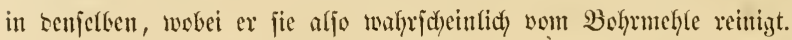

Sinné beobadytete zum erften Miale 1746 auf tem alten Edjiffziwerft aun Mieerbujen won Gsthenturrg in vierectig behanenen Eidyenitämuren sie

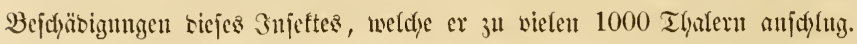

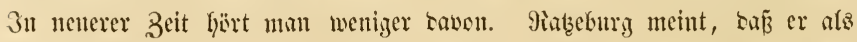

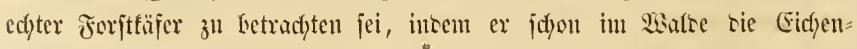
itäunute angelyt.

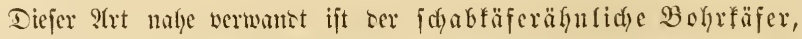

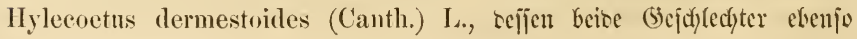




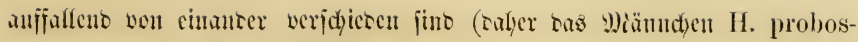
cideus Fabr.) Er treibt jeit Wejen mef̧r in Duıchenjtäımten.

\section{Der Manifäfer, \\ Melolontha vulgaris Fabr. (Scarabacus Melolontha L.)}

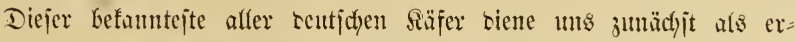
läuterntes Beijpiel ter Jantilie ser Blatthörnigen, ¿amellicornen.

Dieje, über ten ganjen Ertheis werbreitete, aber wiererum jwijden

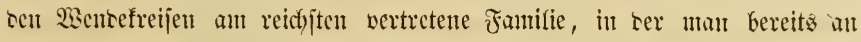
6000 Plrten zähgt, Gietet bie 9iejen unter ton Säjern, inten 3. B. Ser in Mittel = uno Siltamerifia lebente jęfulesfäjer, Dynastes Hereules

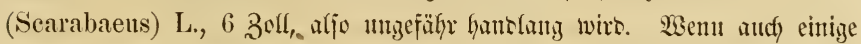

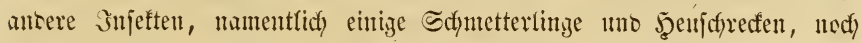

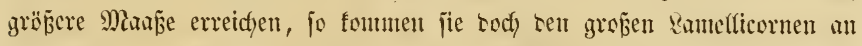

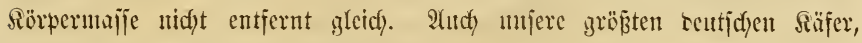

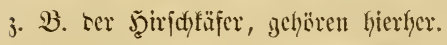

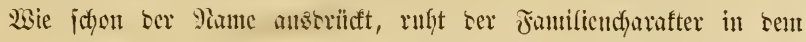

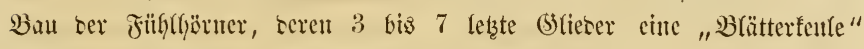

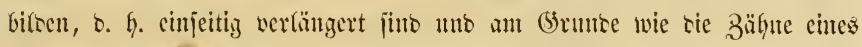

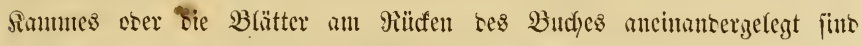

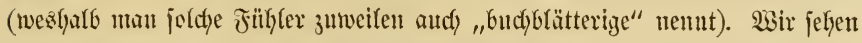
Dies bejonters tentfich an ten Füflern tes gemeincu (Jig. $41 \mathrm{~g}$ uno h) uno tes groß̧en marmorirten Miaifäjers (i). Wem and in ciner fo artemreicfen

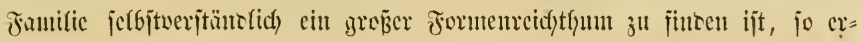

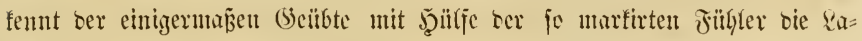
meflicornen leidft an tem mafïizen, meijt plumpen Ban bez meift jtarf

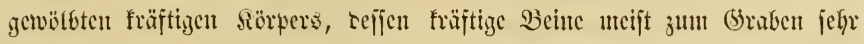

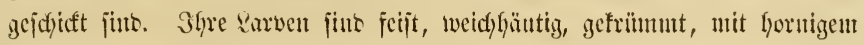

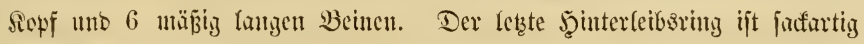
gefdywotlen (e).

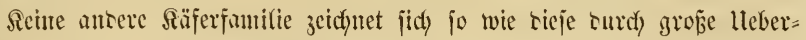

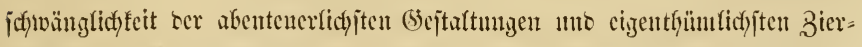

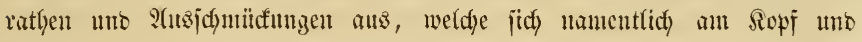


Brujtictito angebrad)t finten. Dieje jonterbaren Decorationen jüt meijt

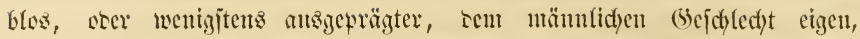

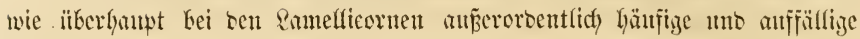

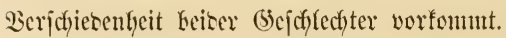

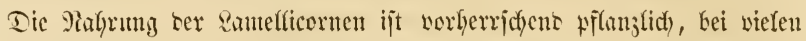

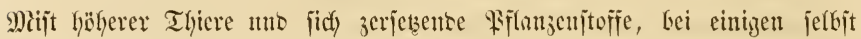

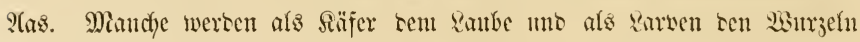

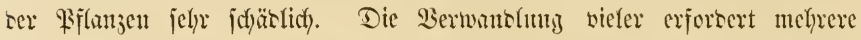

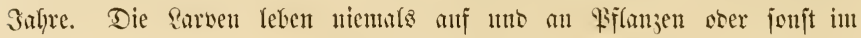
Freien. - Eelyr viele fierher gehärize säfer, bie jebzt in jablreichen (5attungen untergefradyt jint, wereinigte ?imné in ber Battung Scarabaeus, bie jetzt gar nidyt mefye bejteft, jonbern jich eben in jene mit Berfult ses Pamens anfigelojt hat. Fabricus behielt sen Raunen für bic befannten

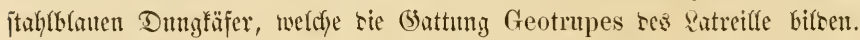

Dic Maiffäfer, Melolontha, won benen wir 3 Prten betradyten wolfen, gelyëren einer won ben 6 (5ruppen oser Ilnterfamilien ser Blattyörnizen an, ben saubjeffern, shyllowhagen, seren sarwen fämutlich bon ben Bamrzeln lebenter Semädjje leben.

Der gemeine Miaifäfer, Melolontha vulgaris Fabr. (Jij. 41 a),

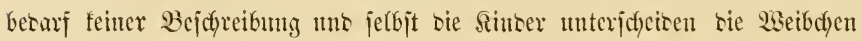
leidft au ser anjefulidyeren Brätterfeute (h) von ter ser Männdfen (g).

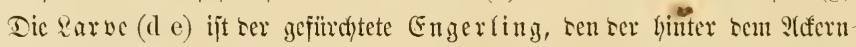

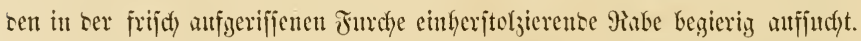

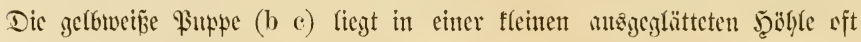
bis 3 Fuß ticf iun Groboocu.

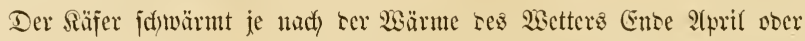

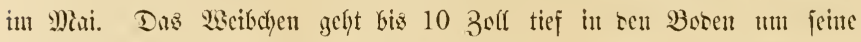

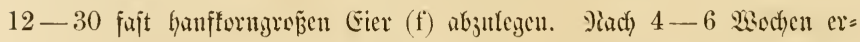
id)einen bie sarwen uno bleiben smun frefiens bis zum jweiten Sommer beifanten. Dann jeriftrcuen jie jidf) uno gehen je nuch ser 2 ärme ber

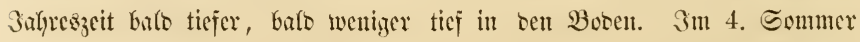

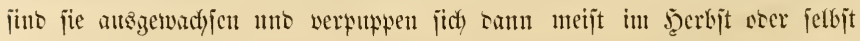

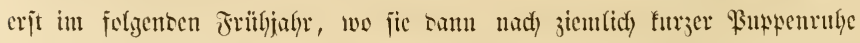

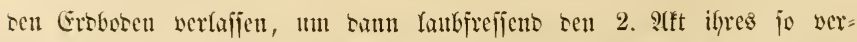

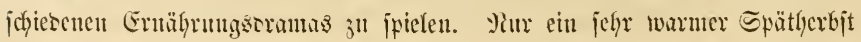




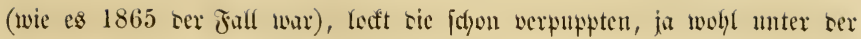
Erte ichon entpuppten räfer nod herwor.

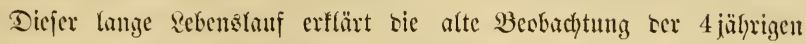

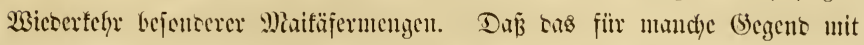

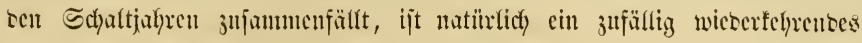

Fig. 41.
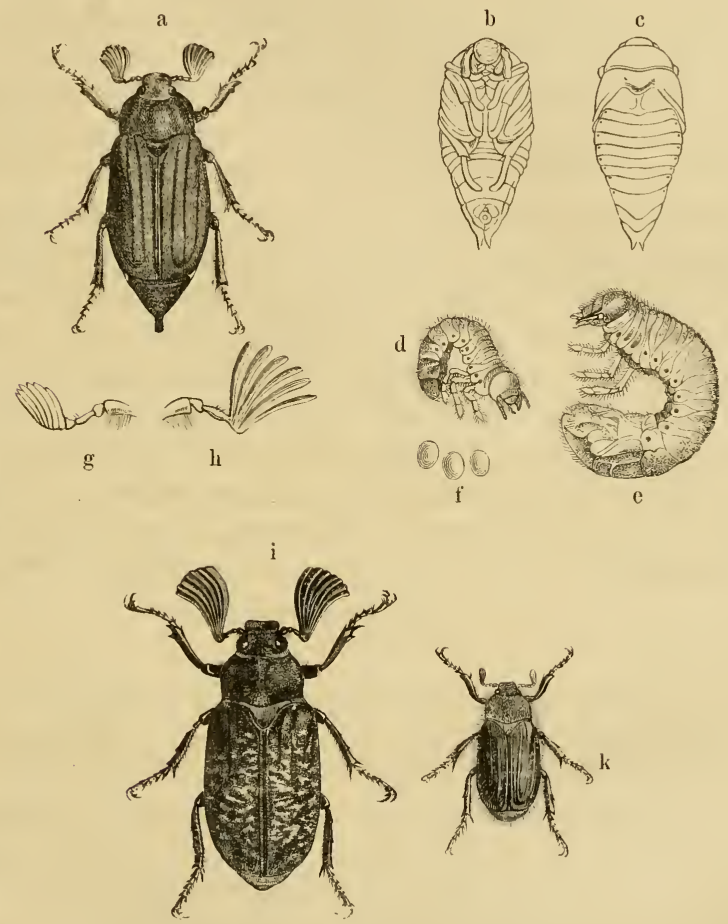

Der Miaifäfer, Melolontha rulgaris Fabr.

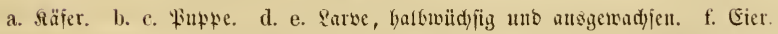

g. weiblicfer, h. mäunlidłer Fitbler.

i. Der groß̧e marmorirte Miaifäfer, M. fullo (Se.) L.

k. Der Souneumenffäfer, M. solstitialis L. 
3uinmmentreffen. Eben fo bejtumt, wie man in jecem 5. Soumer einen

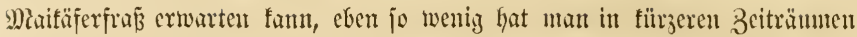

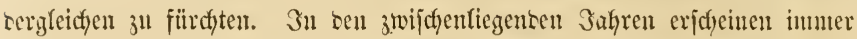

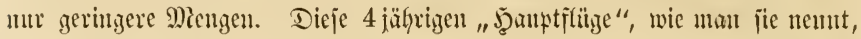

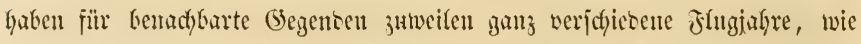

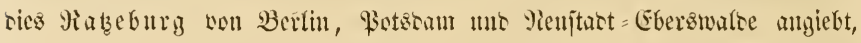

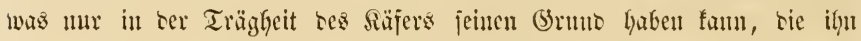

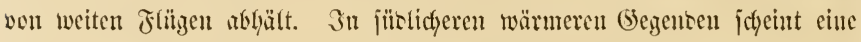

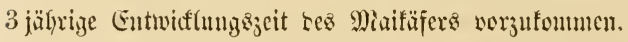

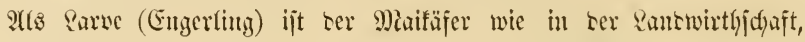

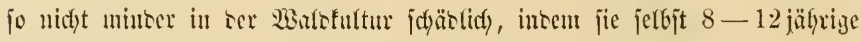

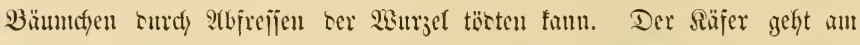

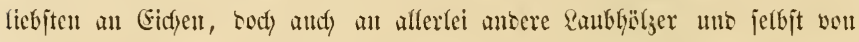

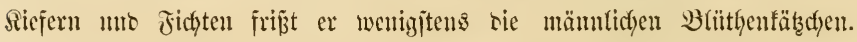
Darurdy fanm aber ser Maifäfer แm fo menizer einen Baum tösten, als er bie Entanbung nidyt mefyrere 3afyee nad) cinanter micherfyet. 9idytz

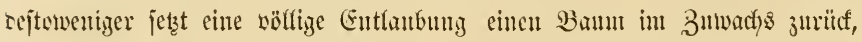

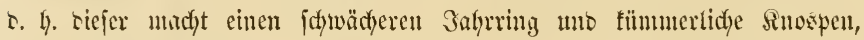

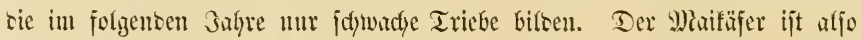

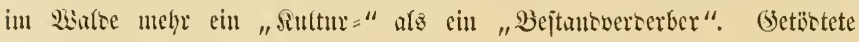

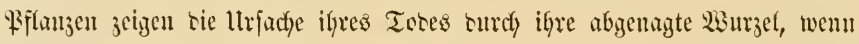
man jie aแถู่วteht.

\section{Der groß̋e mtarmtoritte Miniföfer, $\mathfrak{B a l f e r , ~}$ Illelolontha fullo (Scar.) L. (Polyphylla f. llarris.)}

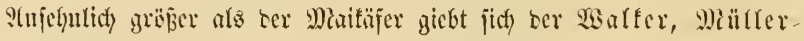
fäfer, Sieinfäfer, Tiger, Tamen=, Domner, Dünentäfer

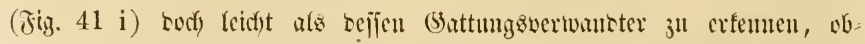

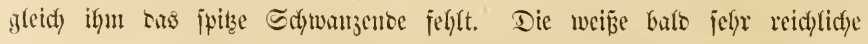

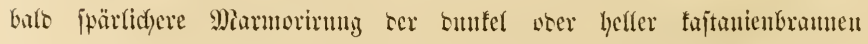

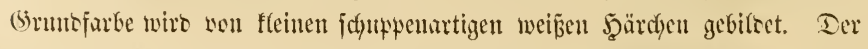

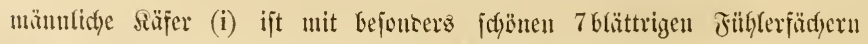
verjegen, währeno ber Marifäfer bfos 6 Fädyerblätter hat. 


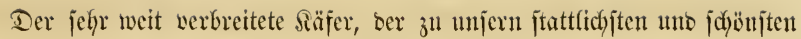
gegört, fdyeint ïberall sen jantigen (5egenben ben Sorzitg ju geben, wo er

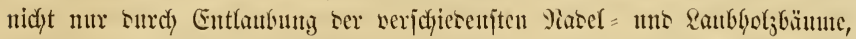

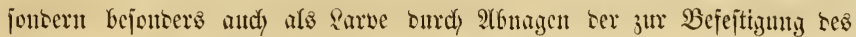
Ffngjantes bientenoen Sirüter uto (Sräjer (vorjüglich auf Dünen, bafjer

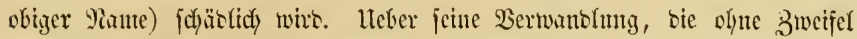

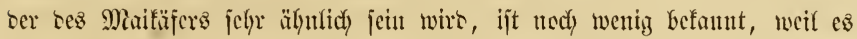
viel fdywieriger ijt, sen :arwen in bem locferen Sanbboen madfyujpüren.

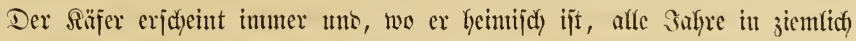

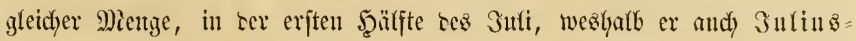
fäfer genaunt twirb.

\section{Der Sonucnwendfüfer, Bradfüfer, M. solstitialis (Scar.) L. (Rhizotrogus s. Latreille).}

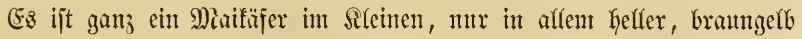
gefürbt, utto ftarf belpart (Jig. 41. k). Dic Flïgeloedfen jüb Durch)=

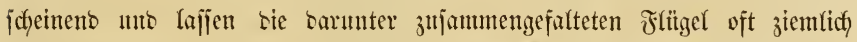
Deutfidy erfennen. Der Füblerfäd)er ijt flein uno hat mu 3 Blätter.

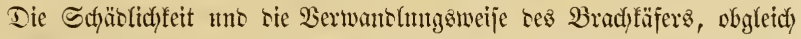
von letzterer nody nicht biel befannt ijt, gleidfen benen bes Maifäfers, jeboch ijt exjtere niemalz von gleidfer Erheblichfeit. Seine fleinen Engertinge,

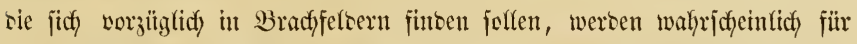
unatsgewachjene Maifäfer = Engerfinge gebalten, won senen fie faum 孔u unterjacheiben jint.

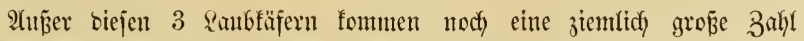
anberer $\mathfrak{A}$ rten in Dentidylano vor, weldye zujummen bie (5ruppe ser Mai

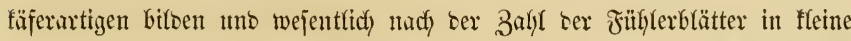
(5attungen gejondert jinb, wäfreno jie früber in ber (5attung Melolontha vercinigt wurben. Eintge bavon, 3. B. Phyllopertha horticola (Scar.) L. fönnen ben $\mathfrak{B a ̈ u m e n ~ u n o ~ S t r a ̈ u d y e r n ~ f đ a ̆ ̈ b f i d y ~ w e r t e n , ~ a n b e r e , ~ w i e ~ A n i s o p l i a ~}$ fruticola Fabr. sent (betreibe. Rabzeburg füfyrt 14 \&aubfäferarten als foritichärlich auf. 


\section{c. Itngleidyzebige Jeteromerent.}

(ธ. ธ. 152.)

\section{Der Siflajterfïjer, „ipaniijhe Flicge", Lytta vesicatoria Valor. (Cantharis v. Gieofiroy).}

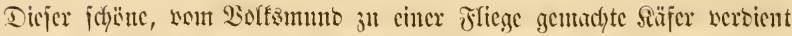

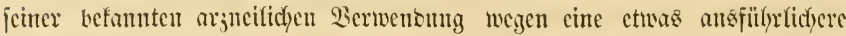

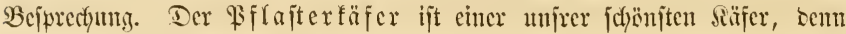

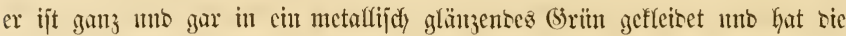

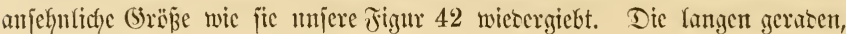

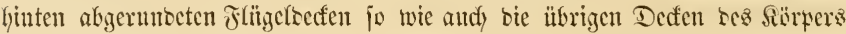

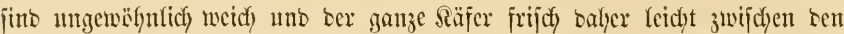

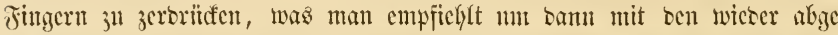

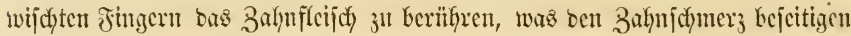

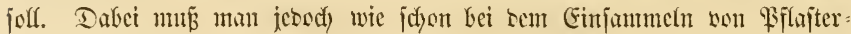

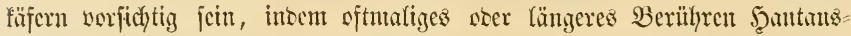
jod)läge hervorruft.

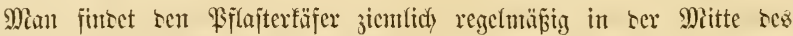

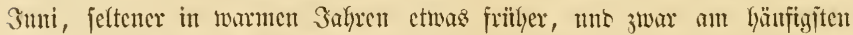

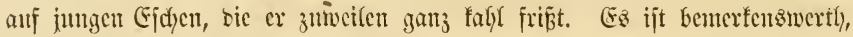

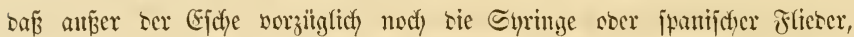
Syringa vulgaris, uno ser Siguffer ober giffeinveite, ligustrum vulgare,

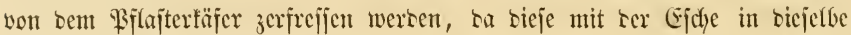
natürlidfe gamilic (bie ber Delbanngetwädjje, Sleaceen) gechören. Ilm is

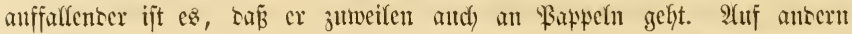

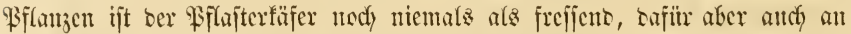

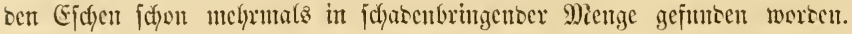

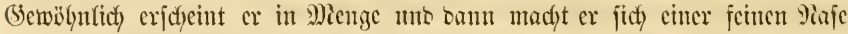

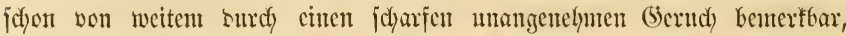
welderer sent ber Miäufe älgtelt.

Das gcjeflige Beifanmenteben tes volfenteten süfors jolfte cigentfich

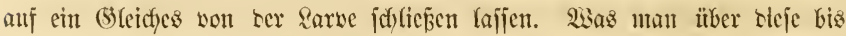

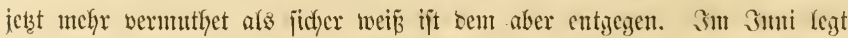

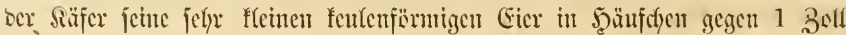

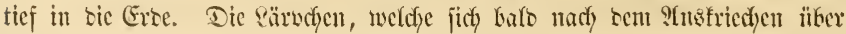


ben Booen verbreiten, jut fo flein, oaj man jic lange Beit verfannt nno

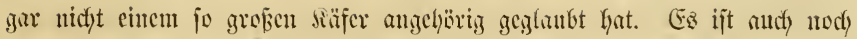

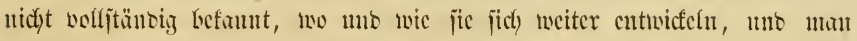

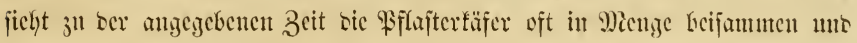

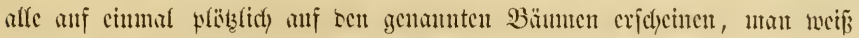

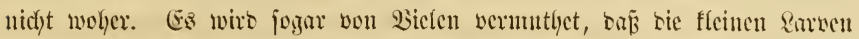

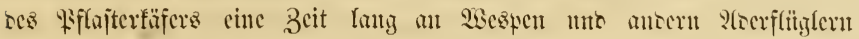

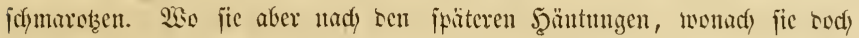

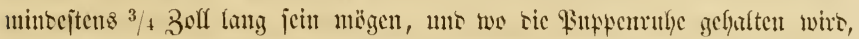

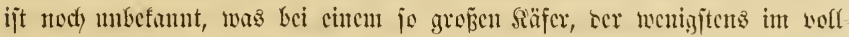

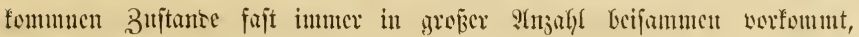
afferbings jefyr anffalleno fein muí.
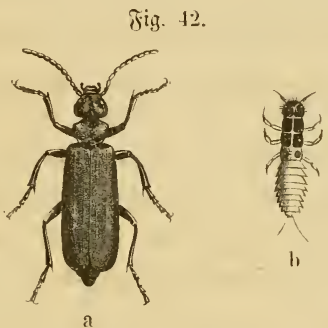

Der Hiflajterfäfer, Lytta vesicatoria Fabr.

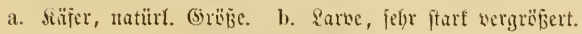

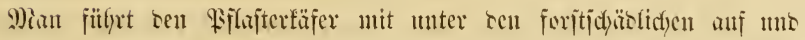

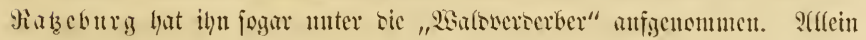

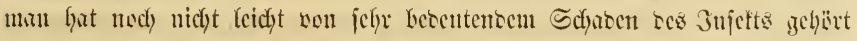

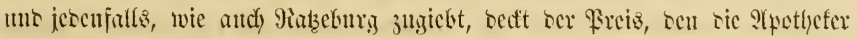

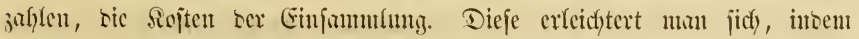

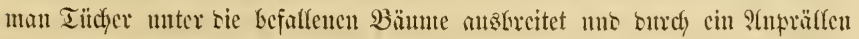
an riefo sie Sïjer herabjctüittelt.

Dic blajenzichence Siraft ber Eantharicen - wie man sie Siflajterfäfer

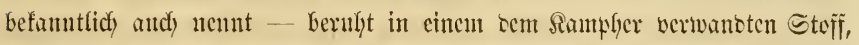
oem Cantgaribin, weldyer jidf) in ben imern Igeifen bes säfers uno be

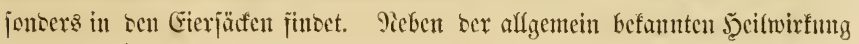


hes Blajen = ober Spanijdfflegempflajters ijt ber wixtjame Stofi tes 3nfeftes interlid) genonmen ein töstlidjes (5ift uno wirft in fleinen (baben in anj

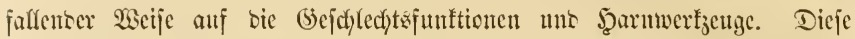

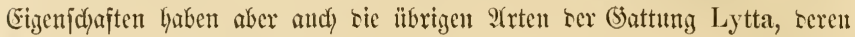
Europa, namentfidy im Süben, noch jedjz beherbergt.

Das rein bargejtellte Eantlyarisin bejteht ans fleinen gliumerartig glän

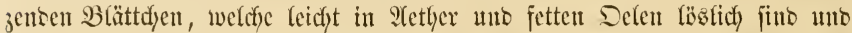

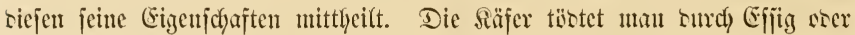
Schwefelfüure uns trodnct jie sann in crwärnter :uft. Das ans ben ge

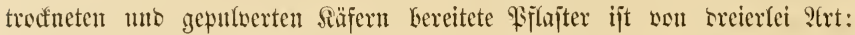
gemeines, immernälyrenocs un fogennutes Droutt'jues. Dejonbers an crifteren crfennt man nod) seutfid) bie grünen metarlifich glänzenten Stïuf

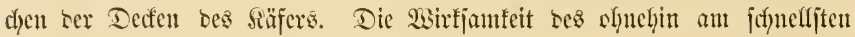

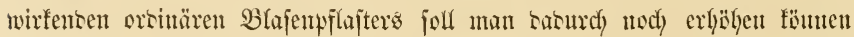

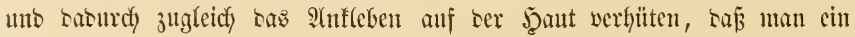
frijich mit Del geträuftes Stücf Seiscupapier anj bas Piflajter legt.

Intent wir hier bie gicilye ber walfuerberbenten säfer fchliejen, harben

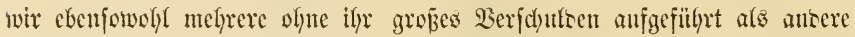
meggelaffen, weldye viefleidyt eben jo jebr genamt ju werhen vertient hätten.

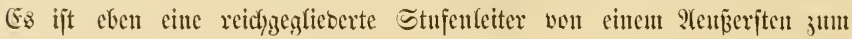

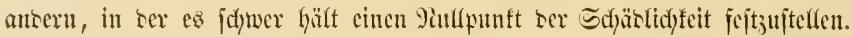

\section{Itoerfliigler.}

Dic beiben vorigen Injeftenormungen haben in ber Spradbe ser $\mathfrak{B i f j e n}$.

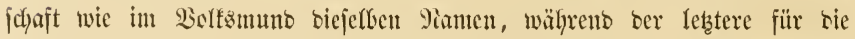

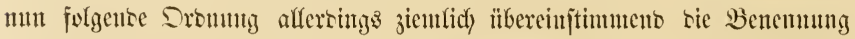

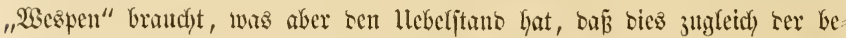
fontrere Nante für eine ober einige (5attungen biejer Srountg ijt. 2/udy bie

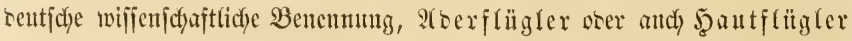

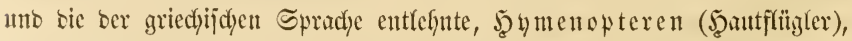
haben ilyre Miängel, intem ja aud) anbere 3njeftenorbunngen gearerte,

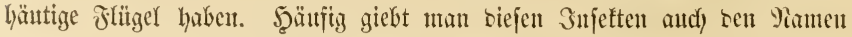

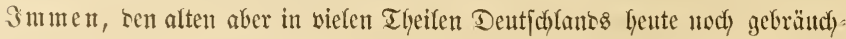
lichen Daunen ser SBienen. 
Da bicle QTerflïgler cinigermafen an 3njeften anterer Dremungen

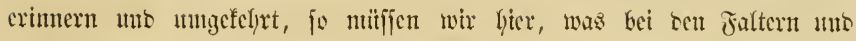

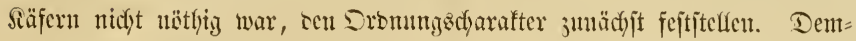

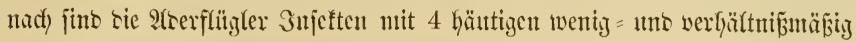
grufmafdyigen flïgch, Gintere meift fleiner afs wortere, mit wben wou eincr

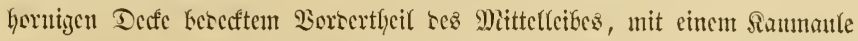

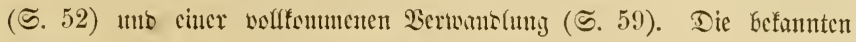

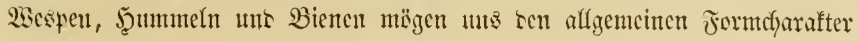

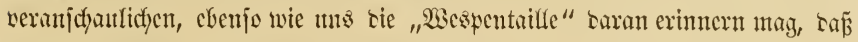

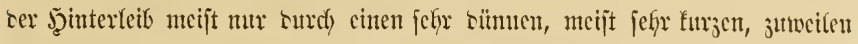
aber andy muncertidy langen Sticl mit bem Mittelleibe zufammenfängt.

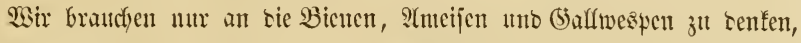

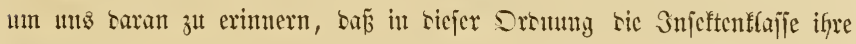

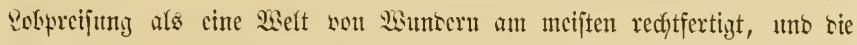

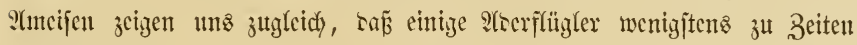
flitigellos juito.

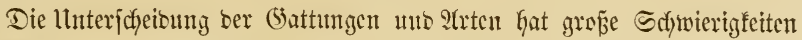

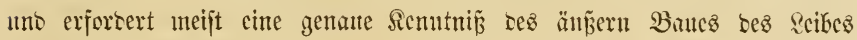

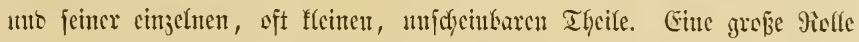

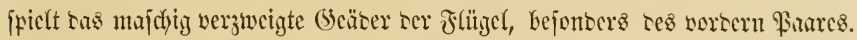
Die Sarurdy gebilieten Beflen voer Mlajdyen unto bie siefe ungrenjenten

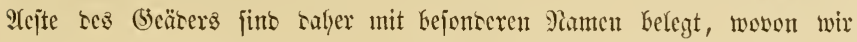
weiter unten wenigjtens cine fuzge Mittheilung madjen mïfifen.

Was sie Betentung ser 2 (terflügler für sen 23 ald betrifft, fo fino von

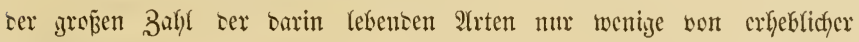

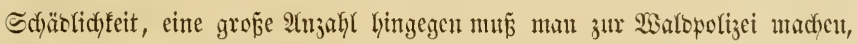

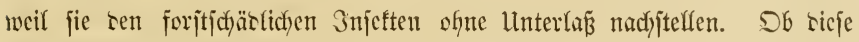

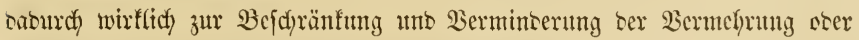

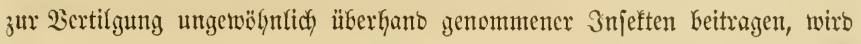
affersings von Mandyen, 3. 2. Felbjt bon Tatseburg bejtritten. Dieje

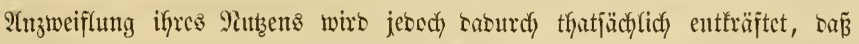
Diejclben bie Begünjtigung uno Unterjtützung ber Bermefyung foldjer 2rexflügler amrathen.

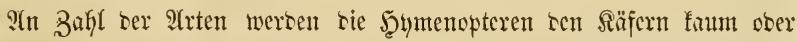

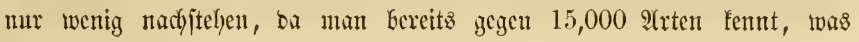




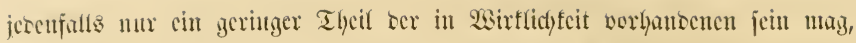

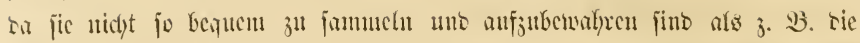

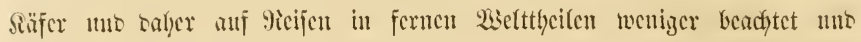
3ciaumelt woresen fins.

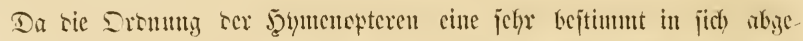

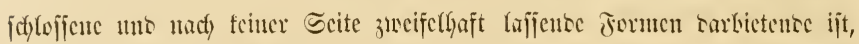
jo crfannte jie jofon vimné als jold)e mo jie ijt and bis anf bie nencite

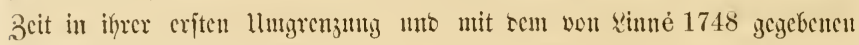
Sianen beibehalten worben.

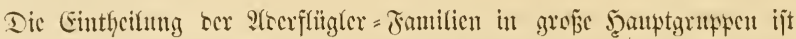

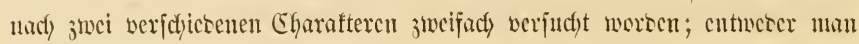

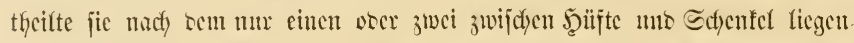

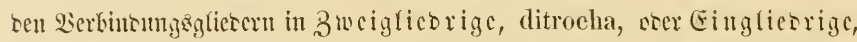

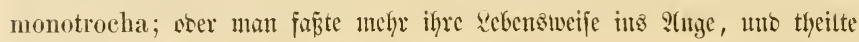
jie in Stadyeltragense, aculeata, Jnfeftenfiefienoe, entomophaga, uno Prfanzenficfienoc, phytophaga. Wir folgen ocr letzteren Ein

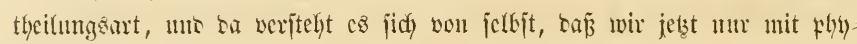

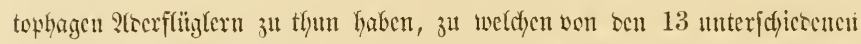

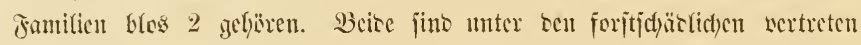
uno jwar bejonbers ric exite, sie Blatt- ored Sägewespen, Tenthresinisen, Savon man bercits ïber 1000 s(rten unterifheioct, weldye, joweit fic vime befunnt waren, won igm in ocr Einen Battung Tenthredo vercinigt murben.

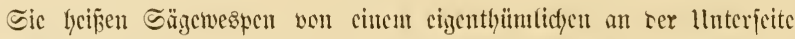

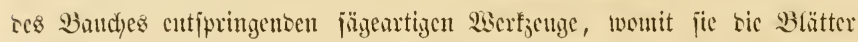
anfrizen, un in bie Futhen ilyee Eicr abjulegen. Sic haben won allen

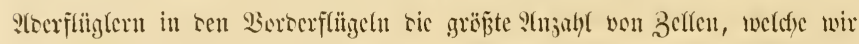

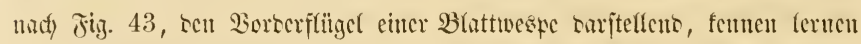

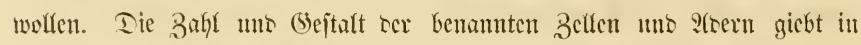

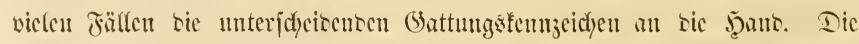

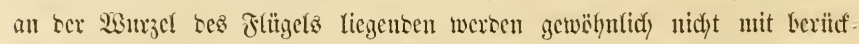

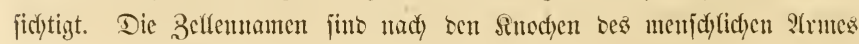
gewälylt, mit sem man sic Siorterflïzel vergleidyt.

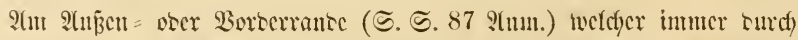

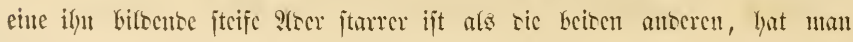




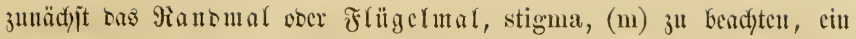

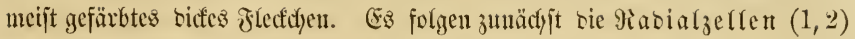
ธamn 4 Subitalzellen $\left(\mathrm{e}^{\prime}-\mathrm{e}^{\prime \prime \prime}\right)$, sann 3 Disfoiralzellen, $\left(\mathrm{d}^{\prime}-\mathrm{d}^{\prime \prime}\right)$ unt sann 2 Submebialzellen $\left(\mathrm{s}^{\prime}-\mathrm{s}^{\prime \prime}\right)$, dben liegt an ber Spize bie

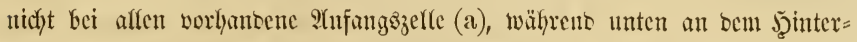

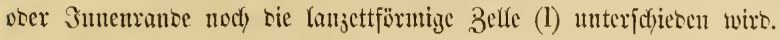

Fig. 44 ift ber Sorberflitgel einer Sdyfupfwespe, an weldyem bie Bezeichnungen bie gleidye besentumg lyaben. Die fleine zweite Subital= jelle (e") hat hier ben bejonteren Mamen Spiegeljelle, Areola.

ซig. 43.

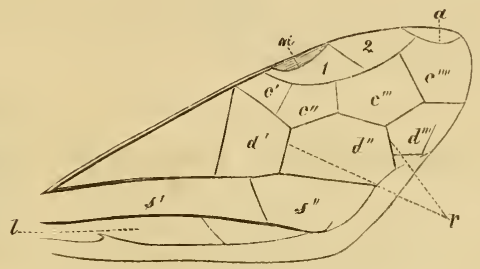

Fig. 44.

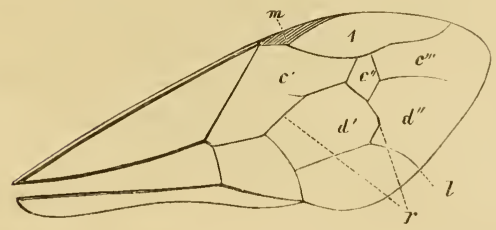

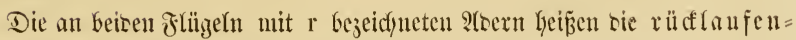
bell Soern woer Rerven. Dabei bebarf es nidyt erjt nody ber Bemerfung,

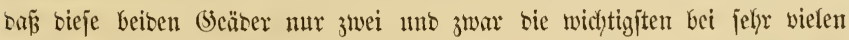

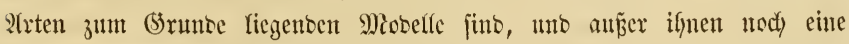
Mienge anbere 2(servertheilungen sorfonumen, wobei jecoch inmer je nad)

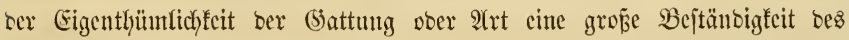
(5eäbers jtattfintet.

Dic $B \mathfrak{l a t t}=$ ober Sägewespen find ftete Begleiterinnen ber

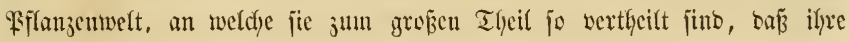




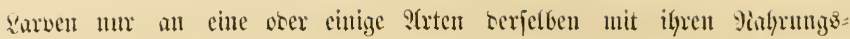

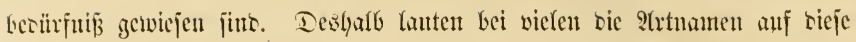
Jutterpflanzen 3. 2B. Hylotoma rosarum, Allantus Scrophulariae, Lophyrus Pini.

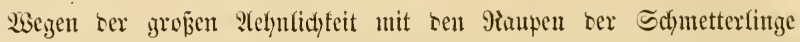

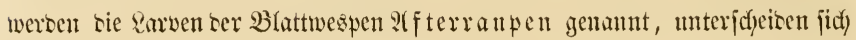

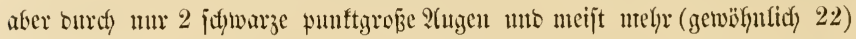

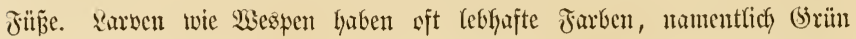
uno (5clb. Die afferrantpen lyaben bie (Sctwohntheit beim Sizzen bas hintere Ente scs \&eibes eimbäts ju frïmmen ober empor ju frïmmen tulo bei

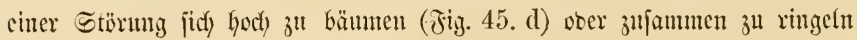
(Jig. 46. g). Einige 2trten leben als sarven gejeffig uno mand)e verurjachen anf ben Blättern gallenartige $\mathfrak{B}$ lajen.

\section{Die Sicferublattwe spe, Lophyrus pini (Tenthr.) L.}

Die 23 espe (Jig. 45 a b) ijt non ber (5röpe ser Stubenfliege uno

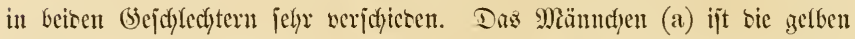
Beine anzgenommen ganj jawar; unt hat breite bopkelt fammzälnnige Jüfyler (c); Las 2 seibchen (b) ijt größ̄er, sidfer, gerrungener, Sioff jajt

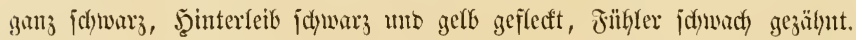

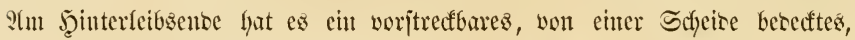
aน⿰氵 2 Blättern bejtehentes jägeartiges Drgan (h), um samit in sen

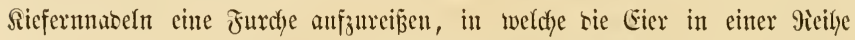
abgelegt werben. Dic beiren (jejd)lechtern gleidyen bünnen Flïgel kaben zahfreiche, jiemtich gleiche Deflen. - Die Earve (d) (Iffterraupe) hat

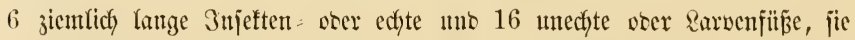

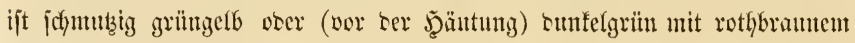

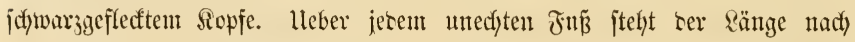
baz Zeidjen eines Semifolon $(\cdots)$. Die Puppe $(g)$ liegt in einem ei=

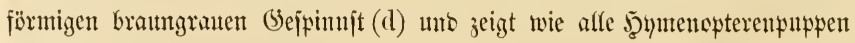
jugn afle Theile ser $23 e$ pe.

Dieje unt antere berwante 9rten haben im Salyre 2 (Senerationen.

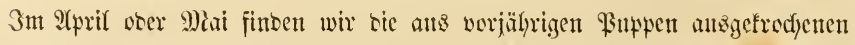
3espen, weldye an bie Siefermnadn igre Eier ablegen. Die ans tiejen 


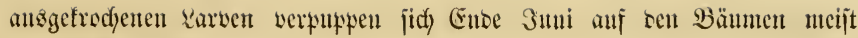
an ten Pabchn iłre Bcjpinnjte ampinneno (d). (Segen Ente Suli fommen Daraแ bie Wespen ans, weldye in gleidter Weife ifre (Eier ablegen. Die

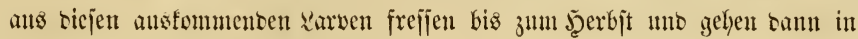

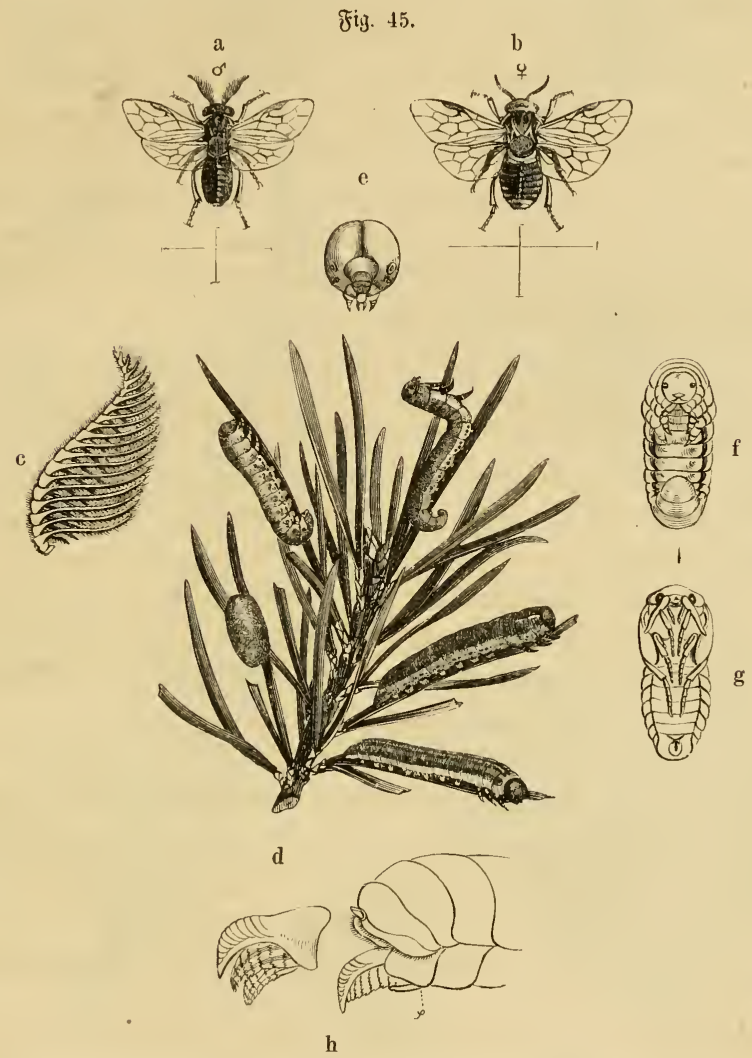

Die Riefernblattwespe, Lophyrus Pini (Tenthr.) L.

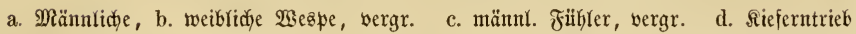

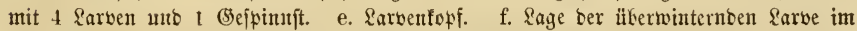
Eocon. g. Futppe. h. Şintereib ber meibl. Wsespe mit ber herborgeftreften Säge, baneben leb̧tere befontor 


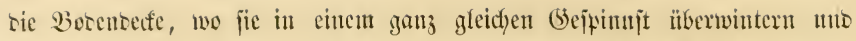

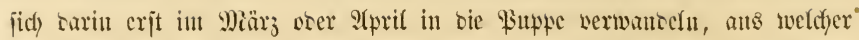

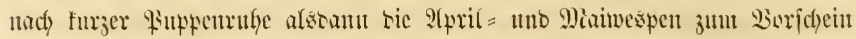
fonmen. Bumeifen fommt eine in ifyen ltrjad)en nod) nidfot crflërte

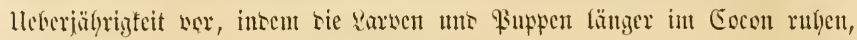

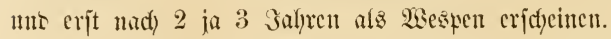

Dieje ecbensucife becingt in einem Sommer einen Soppelten affer =

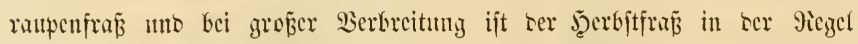
jtärfer, weil and, von ber Überwinterten (Scneration viele Wespen crit im

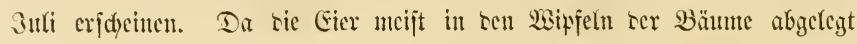
werben, fo tritt and zuerjt hicr surd) Ien Fra ein. Dicjelben feben meijt in Jamilicn gejellig beijammen wn zieben jid) fpäter in bic unteren Theile ser Banmfrone herab.

Dieje un auf ber gemeinen Riefer frefïento afferanpe hat jofen

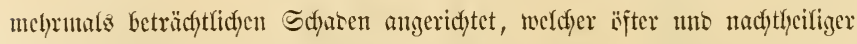
anftreten müroc, wenn fic nicht fo lanje als mïglich fräftig twadjentoc

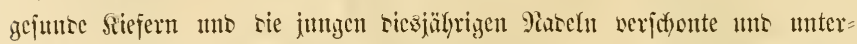

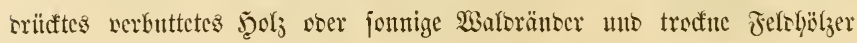
entfoctercen vorzöge.

Tus serjelben (5attung leben nod) antere Trten anf rer Sicfer, jum

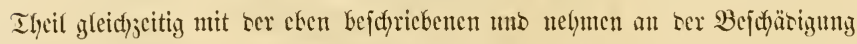
Theil; 3. 2. L. variegatus Hartig, L. Laricis S'chïff., L. similis Hrt. tuno anterc.

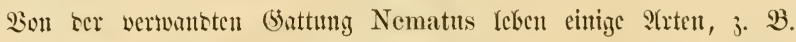
N. Laricis Hrt. uno N. Erichsoni Hrt. fathörlidy anf ë̈rdfen, anocre

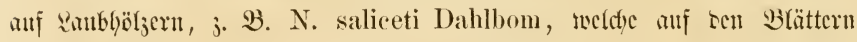
melyerer 2keisentarten sic befanten beiscrjeits eifürmig lyerwortretenten Gallen bilset, in uneldyen bic sarven leben.

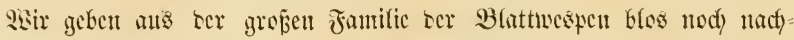
follgente żwei $\mathfrak{T}$ irten.

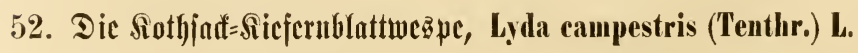

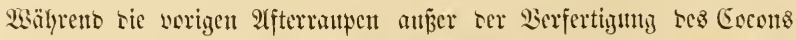
nid)t ipimen, leben sie :arven oer (5attunty Lyda (mit 24 sentidyen $\mathfrak{2}$ rten), 
Fig. 46.

a

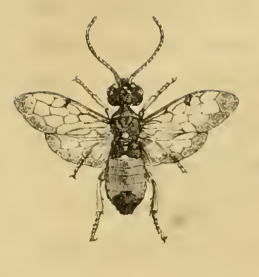

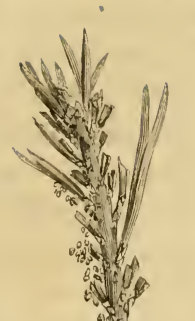
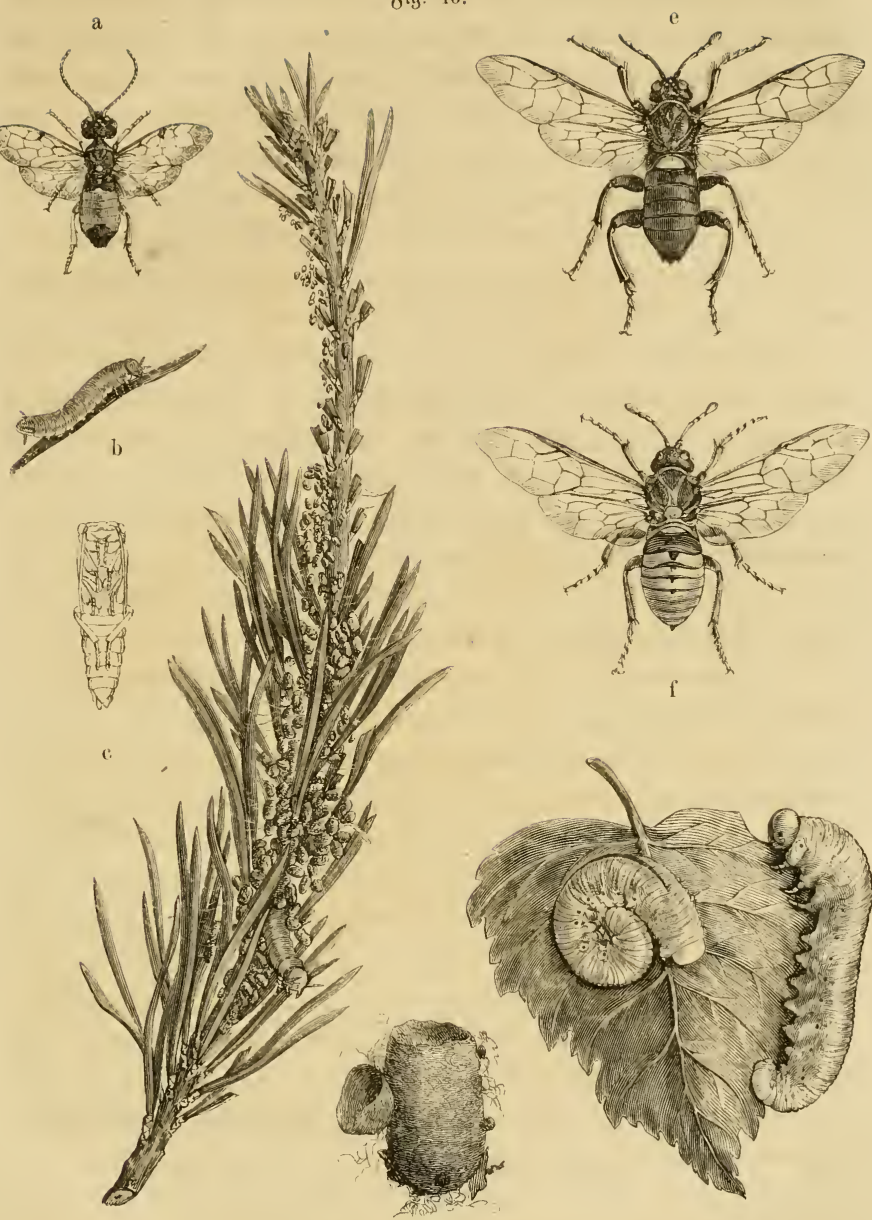

d
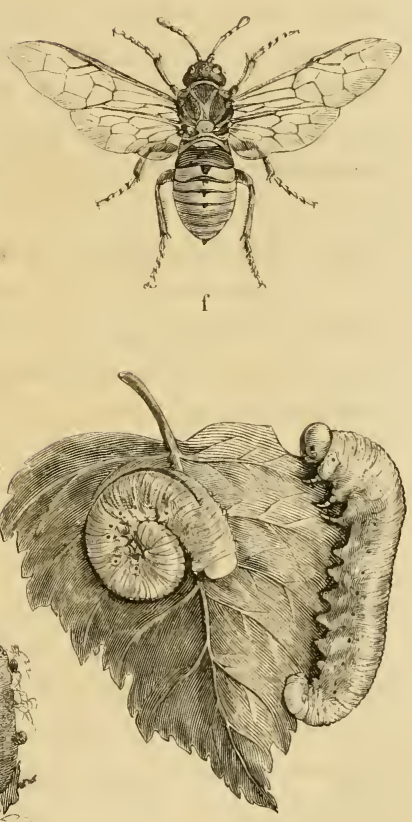

g

Die rotbiadiefermblattwespe, Lyla campestris L.

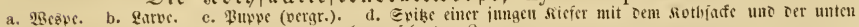
berruticfertocll \&arve.

Die grofe Birfentuattwespe, Cimbex variabilis Krl.

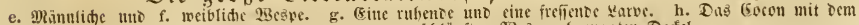

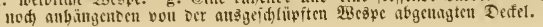




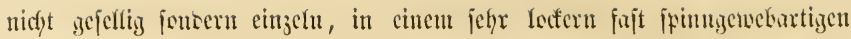

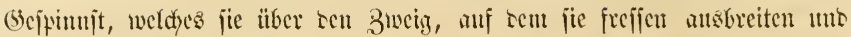
in weldyem (Eaber ser beutfdye (Sattunganame) ber Sioth bängen bleibt (Jijum 46. d).

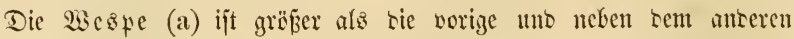

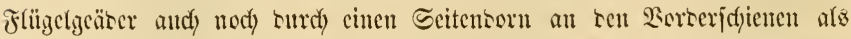
Lyda erfenubar uno surd) sen rothbramen nux an ter Spitze fdywarjen

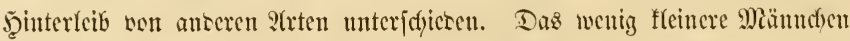
hat tic glcidje Färbutig. Die \&arve (b) hat anjer sen 6 edjen Beinen

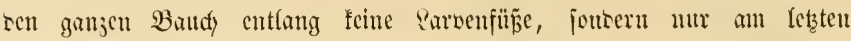
Qcibestingel nod) 3wei fel)r jeitlid) geitelfte, aนsึwärto gerid)tete, steiglictrize,

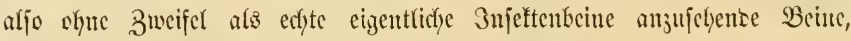

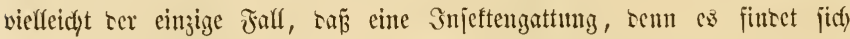
ries bei allen sysen, in cinem 3ujtante 4 Faur jeglicserte, aljo edfe

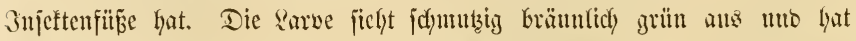
cinen gelbbraunen Sapf uts bunfleren Mï̈fenjtreif. Sie Puppe licgt in ifrem Scipinnit in ter Erte.

Dlye 2Hwentung ber bei vor. Itrt bejdriebenen Säge werten bic Eier cinjeln uno oberfläcylidy an bie Sicfermabefn gettebt uno sic im Suni

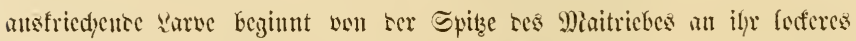

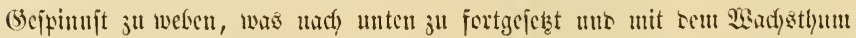
serfelben inmer weiter wiro, wälfreno gleid)jeitig bic sarin hänjenten

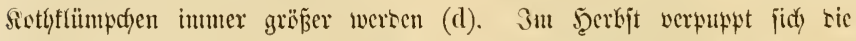
Sarve in ter Borentedfe uno im ?tpril uto Mai crifycint tie Wespe.

Da rieje $\mathfrak{A}$ rt fajt nux bie gejüntejten 2-3jährigen Sicfermpflänjofen angreift, fo famn jie auf oen Euttmen, wemn jie jehr bäufig ift, erbeblicfen Schaten anrichten. Darin jtelgen ifyr einige antere syoen = 2 rten bei, rie

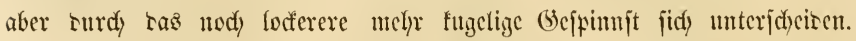
Dicje jü L. erythrocephala, weldje ju 2-3 \&arven beifanmen lebt, L. pratensis uno L. hypotrophica.

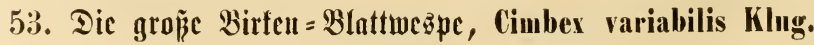

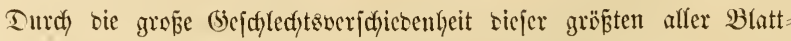

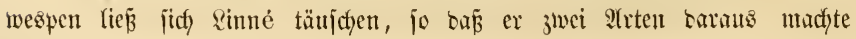




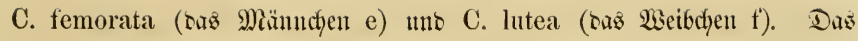

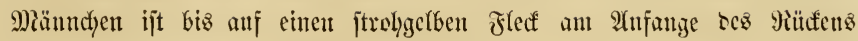

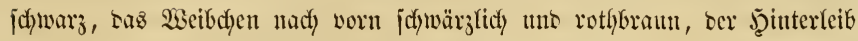

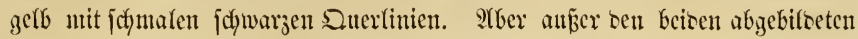
Şauptfärbungen fonmen viele weitere Farbenabätbermigen vor. Farben=

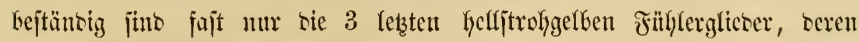
lekztes cine eiförmige Reule bilret. - Die \&arve (g) wiro von llnfunrigen

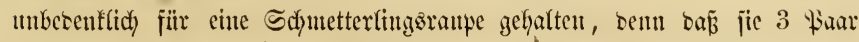

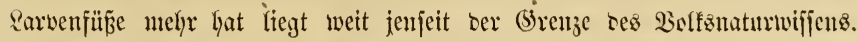

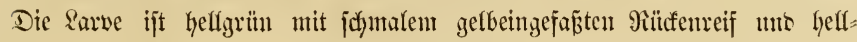
grünltudyen Sopfe. Bein Sizen rollt jie bas Sdywanzente fajt inumer

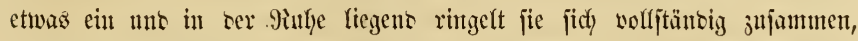
währeno fie fidy mit ben 6 Sorberbeinen anf ifyer sajerjtelfe fejtyäfelt. Sn September finbet man bie anzgewadjenen 2 fterranpen am häıfigiten unt jie verpuppen jich bann am 3weige voer an ber Frte in einem bis zoffangen bidften sunfelbraumen eirumben Eocon (h).

Dieje afferraupe jojeint nur Bitfenlaub ju frefien uno folf einmal

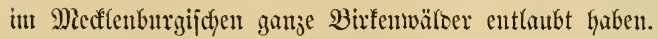

Fine verwante nur wentig fleinere 2 frt, C. amerinae Fabr., madyt ein aus einem jefy jierticyen Majdyengemebe bejtehentes Cocon.

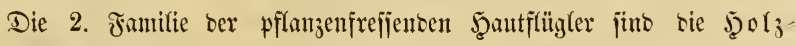
wespen, Hrocerisen ober Siricioen, mit nux wenigen (5)attungen uno Arten, rwelche aber zum Iheil in veriffiebener Şinjidyt viel Eigen thümlidçes bieten.

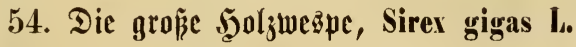

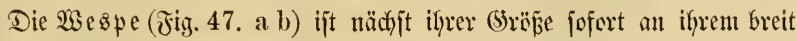

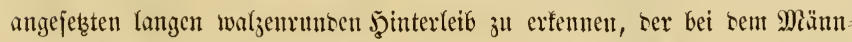
dyen brammoth, worn uno an ber Spitze jofwarz, uno bei tom Weibdyen citronengelb ijt mit breitem ben 3 . Gis 6 . Bautdyring einnefynenben jdywarzen

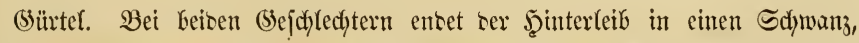

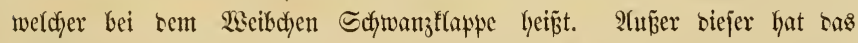
Weibdyen an ber llnterjeite bes Banthes, nod) vor ber Mitte beffelben ein= gelenft, einen recfytwinftig aufrichtbaren cünnen aber fejten uno rafpefartig mit 


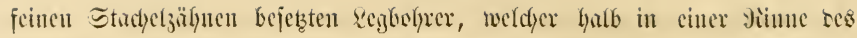

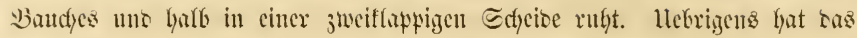

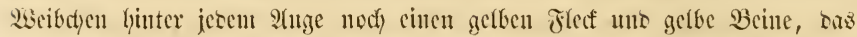
Miäundyen hat bieje Flecfe mebr rothgelb nns jefwarz uno gelb geringerte

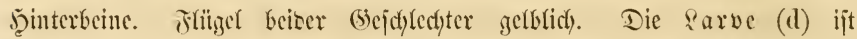

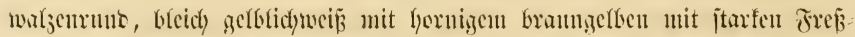

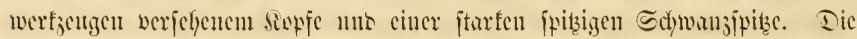

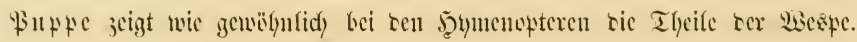

Fig. 47.
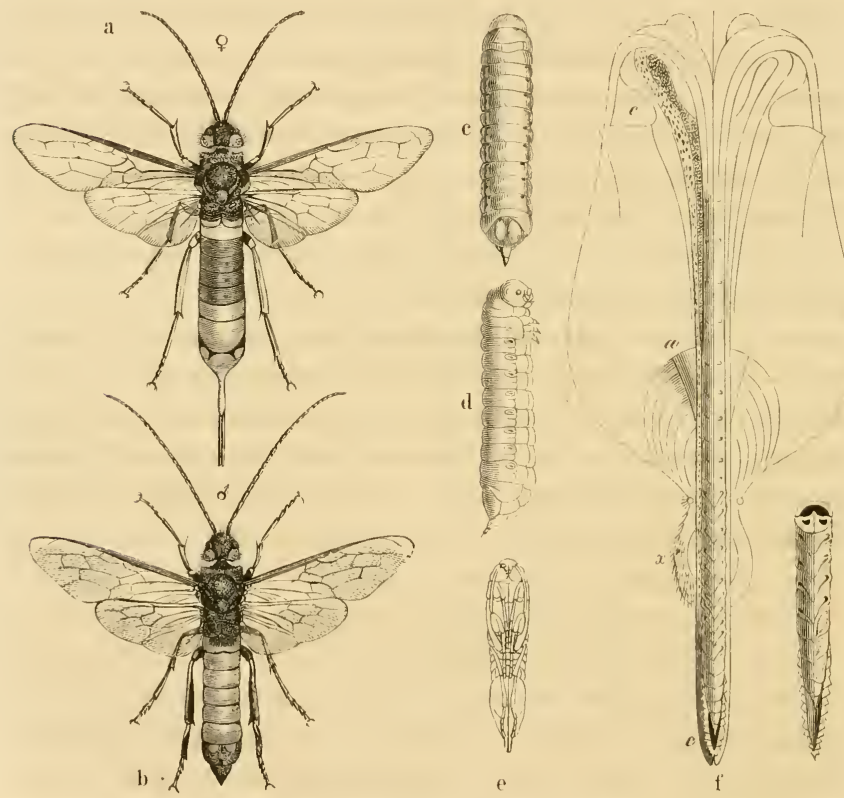

Die grofe borzwezpe, Sirex gigas L.

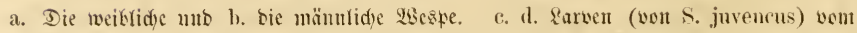

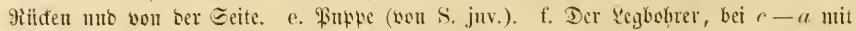

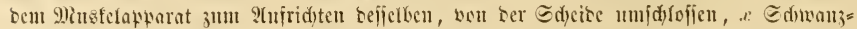

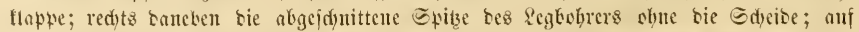

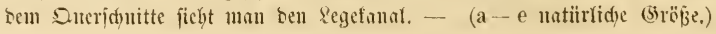




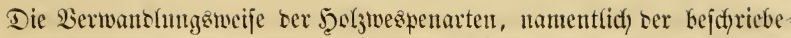
nen, hat juyon oft bas Staunen ber sente erregt, inbent bas gropie jtattlicfle

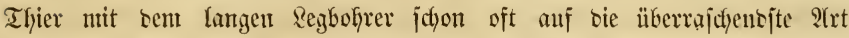

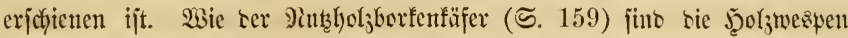

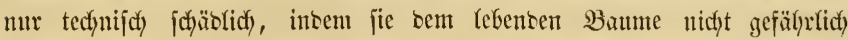

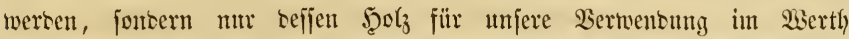
jdyäbigen. Sic fliegen in Sntui ober Suli mto bohren fïr jebes einjelne

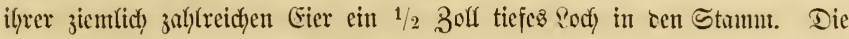
aubfommenoen \&arven frefien jich tiejer in sen Stamm ein uno nagen mit

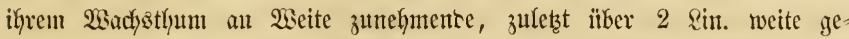

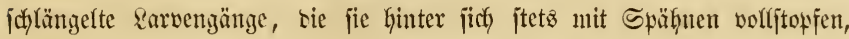

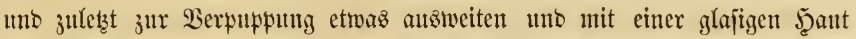
ïberjiegen. Der sarwenzuftano sauert wahrjdyeinlidy mintejtens ein Safyr,

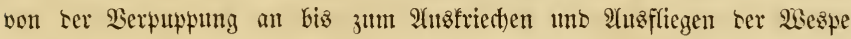
vergeht alsoanm nody einize 3eit, beren regelmäß̈ige Dauer nod nidyt hinlängliç) befannt ijt, bie aber unter llunjtünoen jef̧r verlängert werben

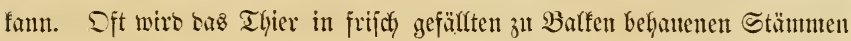

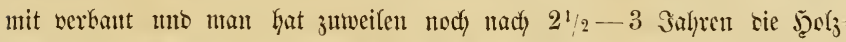

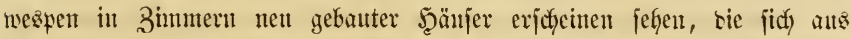
ben Sdyweflenbalfen surdy bie Dielen Ginturdy gefreljen hatten. Sogav sie innere $1 \frac{2}{3}$ Sin. sicfe Bletankfleibung einer Sifte hat man jie mit curchnagen jefhen. Da bie jid) verpuppente Rarve feine Ritufjicht anf bie

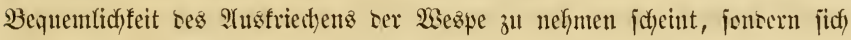
oft tief im Staume verpuppt, fo hat bie ansigfrodhent $23 e s p e$ jidf oft

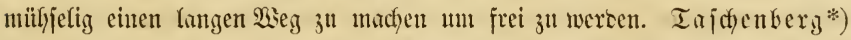

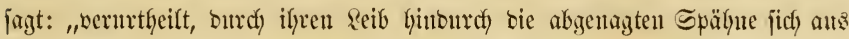

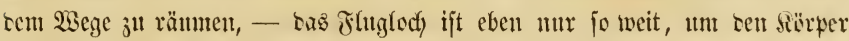

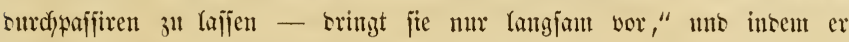

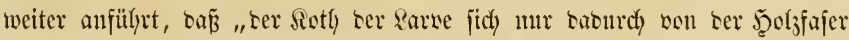

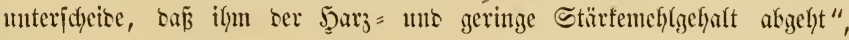

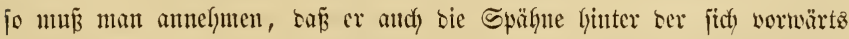

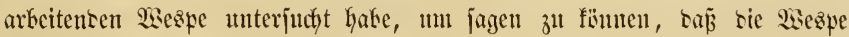

*) 2Gas ba fliegt uno friedt. Bitber aus bem Suleftenlebent won Dr. E. R. Tajdenberg. Berfin b. Boffermann 1861. Sebr empfehlenswerthe antegente Sdjibermigen. 


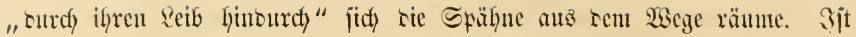

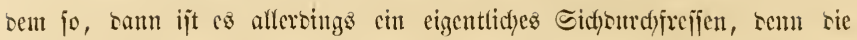

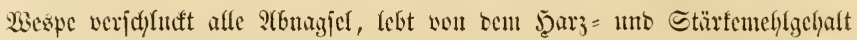

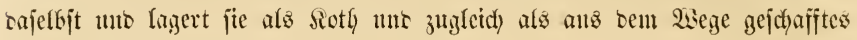

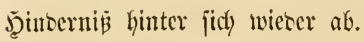

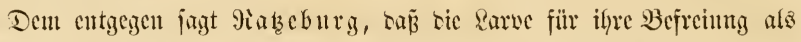

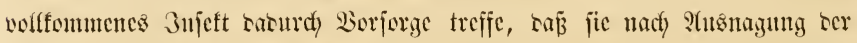

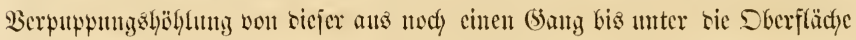

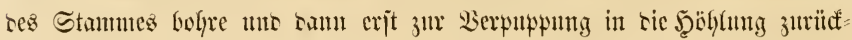

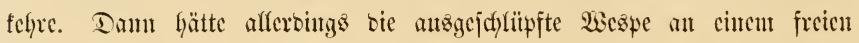

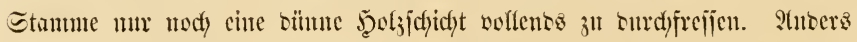
unt fadyieriger wirt sie 9 ?tufgabe freifich mer in werbauten Balfent.

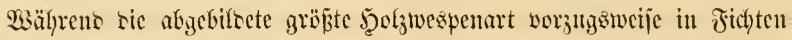

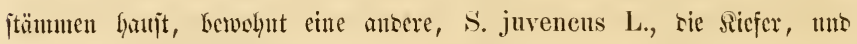
eine sritte, S. spectrum L., auser tor Fidfte audf nody särdfen uno Tamuter.

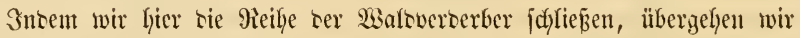

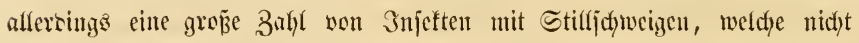

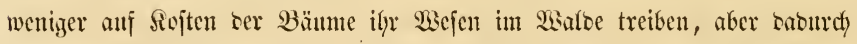

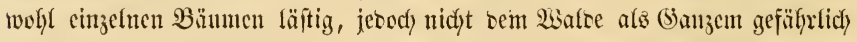

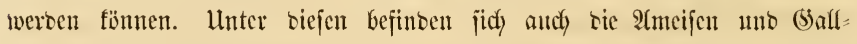

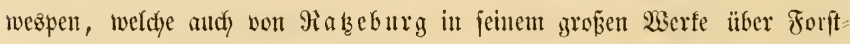
infeften anfgenommen worren jint. Dieje beiren 3mpettenfamitien bieten

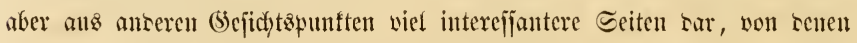

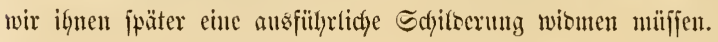




\section{Hleunter Xb/dnitt.}

\section{Der Aampf gegen bie Malbuerberber.}

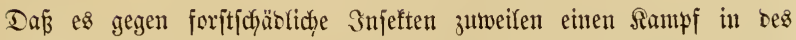
23ortes ernjtlidfiter Bebentung gilt, haben wir aus ber Sifjitrerung bes

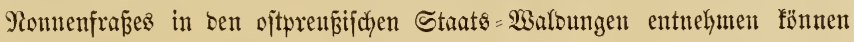

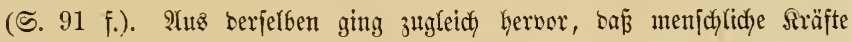
in biejem Saupfe unterliegen, wenn es entweber überjelyen over unterlajjen worten ift, zแm rechten Beit vorbauteno uno abtwehrento einzutreten. In rem angefïlyrten Falle whitre aber wahricheinlidy jelbjt biejes vergeblid gewejen jein; benn bei fo ungeheuren zu[ammenhängenten Walsflächen witroe es

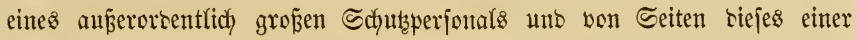

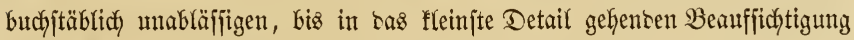
beriirfen, um zuletzt body nidyts weiter zu erreidjen, afz ben Trojt, bas unabwentbare abzumenten ivenigitens feine Mïhe - uno sojten gejdyeut

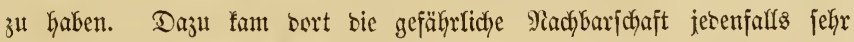

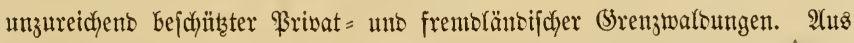
biefen übertrug fidy bas Hebel unaffhaltfam wie bas Miasma einer Senche.

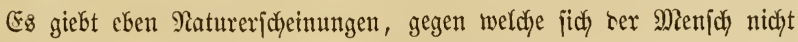
Gimreidjento jchü̈zen fann uno z" biejen "Sialamitäten" icheinen neben ben

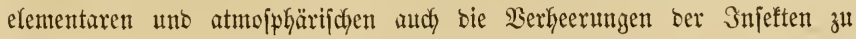
gehören, unter weldyen bie ફ̧enfdyedfen ja länğt eine trabitionelfe $2 \mathfrak{b}=$ rühntheit getworben fint.

Begentiber jo gropen Serluften und Berwaltungaftörungen, wie fie idjon oft genug burdh bie Forjtinjeften Kerbeigeführt worten fint, uno angefidyts ber zur âbwebr joldher angejtellten uno - freifich meift jdyledjt

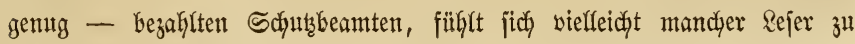




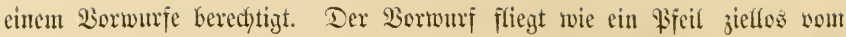

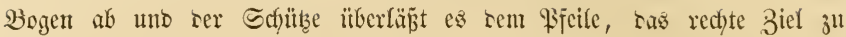
juchen unt zu treffen. Der Pjeil triffit audf, sas ijt jidyer, ster er fintet wenigitens ein 3iel, uno ment ex jelbjt es nidyt finset, jo lenft man ifn banach. CEs jüb sic unteren Beamten, an benen, wenigitens sit gentig,

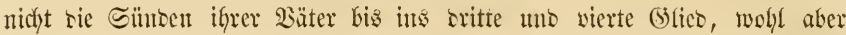
iffer Sorgejetzten bis in bie sritte แno vierte flafje ber 5eofrangorsmug heimgejucht werben, weldye am grünen Tijdye birigiren uno rejeribiren, wie nadjlyer in grünen waloe abminiftrirt werten foll.

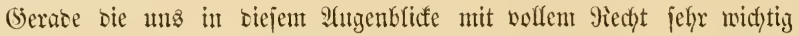

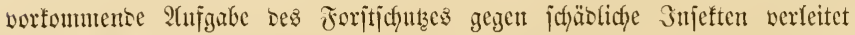

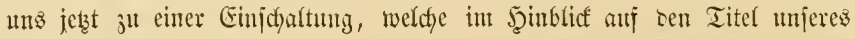

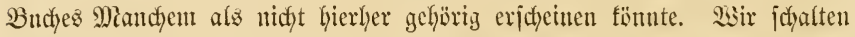
nämlidy ben Saz ein: wenn wir mit వuverpictyt auf sie Bufunt unjeres rentidyen Walbes bliffen wollen, jo rilite man sen ansilbenten Forjtwertwalter mit tüdytigem Wijīn aus, แno hat er jich bies erworben, bann gejtatte

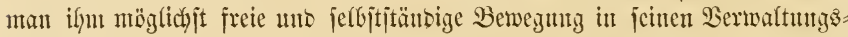

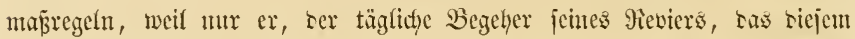
am meijten eben 9otgtbuenoc au bejten beutrtgeilen แto aušführen fann, menn auch auf bie hohe Sieriügung cine unterthänige Berichterftattung oft niç, warten faun*).

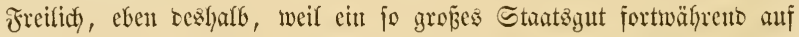
ben Spiele jteft, welches, werloren, nie jo wie ez war wieser erjetzt werben faum, fcheint auf Seiten ber oberîten Träger ber Berantwortung

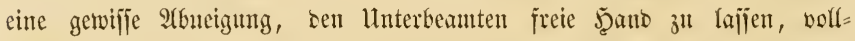

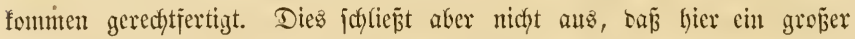
Srrtfyum jtatfïmben, ein groper fofgenjchwerer Jehler begangen werben fann. Se gebuntener bie sie jefützenoen Mariegch - in ber weitejten

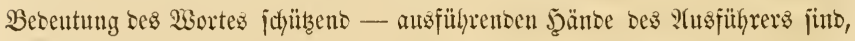
bejto leidjter wiro es ifym, sie Derantwortung für begangene Derwaltungs:

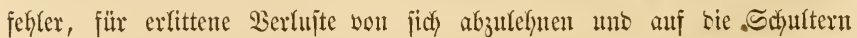

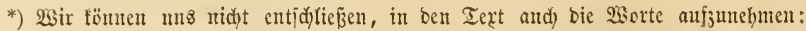

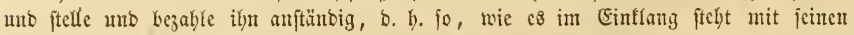

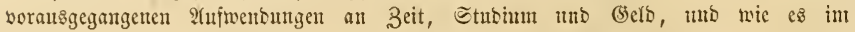
Einflang fteht mit bem unjdätżbaren Staatigut, bas er werwaltet. 


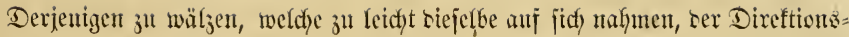

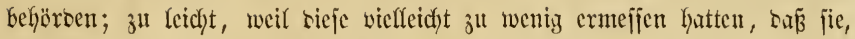
fern bom 9icvier, gar nicht in ber Raze waren, inmer bas 9itchtige an= orbuen ju fönuen. -

Wer $\mathfrak{A}$ trez bloz thut wie uno weil es ifym jo befohlen ijt, ber wirb

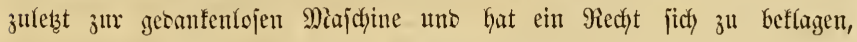

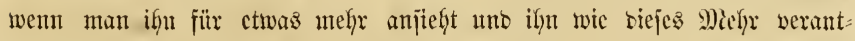
wortlich machen milf. Er verfiert aber auch bie \&ujt an jelbjtitüntbigen Denfen, weil ifgn bas jelbititänoize J̧anteln verjagt ijt.

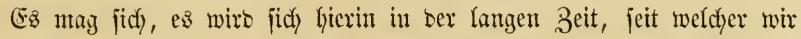
ser Frage ferner jtelyen, vieles jum bejiern geänbert haben. Der Bormurf

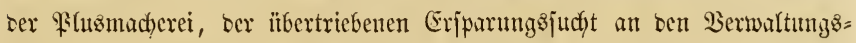
fojten, bes cinjeitigen Fejtfultens an Maximen - ex war uno ijt hicr uno ba vieffeidyt nod) gerectytfertigt.

Ulnter allen Umitänoen exheijdyt baher fein 3weig ber Stautzocrwaltung melyr alz ber ber Forjten ein gejuäftsfreumblicyes - man geftatte แns

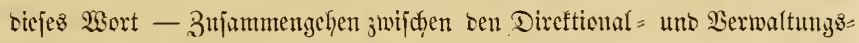

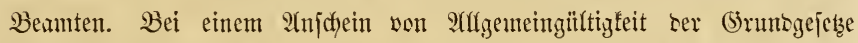

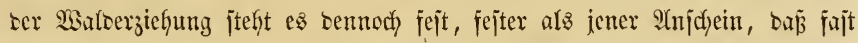

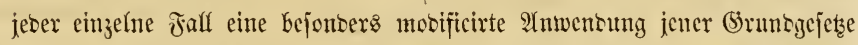
forbert. Dieje Miobificationen fönnen nur Las Werf ber grïndicjjen

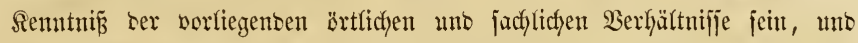

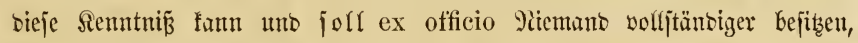
als ber Sertwalter bes Renters.

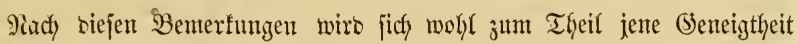
zu einem Sortwurf megen unabgewenteter Snjeftenverkeerungen verfieren, uno wenigftens von Denen abgewentet haben, weldje bemielben zunüchit aus=

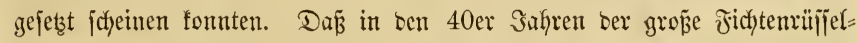

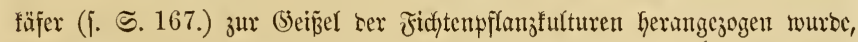
ijt, joweit Gier menjoflicherjeits von einer Berjdyulbung bie Rebe jein

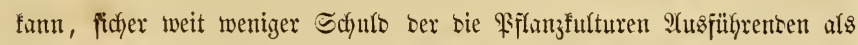
Derex, weldye bei ber (benehmigung bez Siulturfojtenanidjlagz um ben Pfennig feilichten.

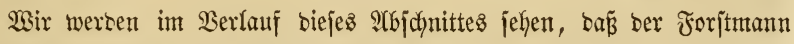
nidyt bloz ber Bäume bes 2 ăldes twegen, bie ex zu exziehen uno zu pflegen 
hat, jonbern audf wegen ber Thiere Les Waltes, wor senen er jene zh

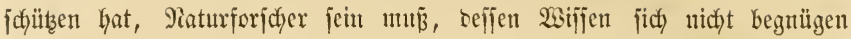

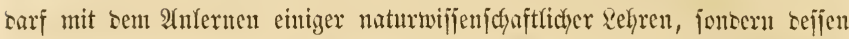

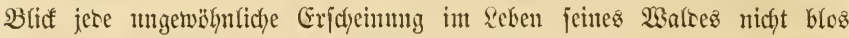
als joldye erfennt, jonbern jie in ifyrem Besingtjein ntu in ifren Conjeguenjen begreift uno zu nützen verịtelyt.

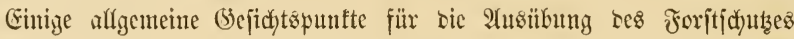

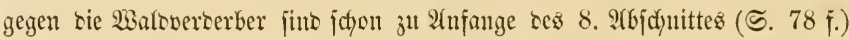
berifhrt worten, worauf wix lyier verweijen.

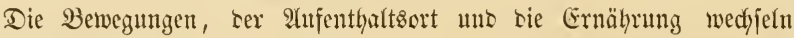

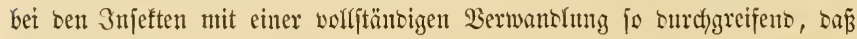

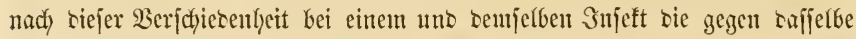

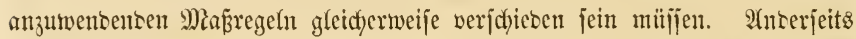

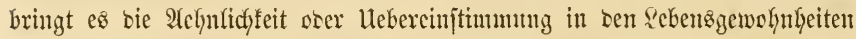

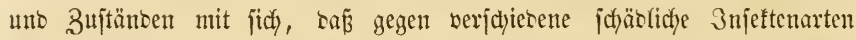

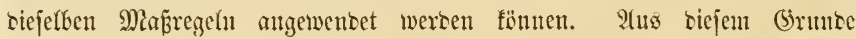

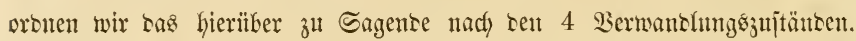
Wir werben sie gegen sie Waltoverberber zu ergreifenten Map̃regehn, bie vorbanenten jowohl wie bie wertilgenten, als sie jidy son felbjt ergebentoen

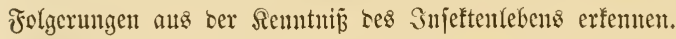

Die gegen bie Eier ber Injeften anzmmententon Zeritörnngginittel

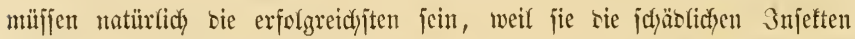

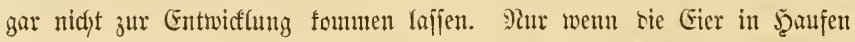
zufammengelegt werben, fann แtan an ify 2uffuchen uno Berftören tenfen, wie bei ter Ronne uno tem Sicfernfpinuer, weldye zugleidy ilyre Eier mentigitens grop̈entheils in erreid)barer ફ̧ähe an sen Stämmen ablegen.

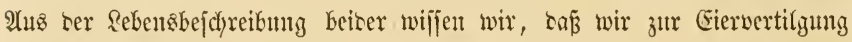

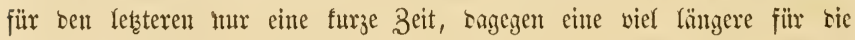
Nonne Yaben, weil bie Eier siejer itberwintern. Die F̧anogriffe mo Werfzeuge zum Einjammeln unt Tösten gehören nidyt hierher. Wohl aber ijt Gier an Anfang unjerer Betradjtung Les Sampfes gegen bie Warlo:

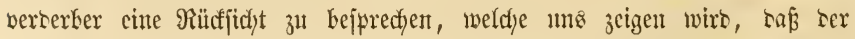
Einjammlung serjelben in irgeno weldyen 3ujtanbe nidft aud gleidy sic Bernichtung auf bem Fuß̌ zu folgen habe. Şierbei greifen wir einigermaßen

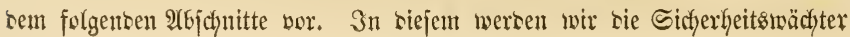


bes 23albes fennen zu lernen Gaben, untex weldyen sie. Sdylupfwespen eine widftige Rolle fpielen. Zweien bon biejen begegneten wir jajon vor: läıfig in Fiğtr $13 \mathrm{~g}$ unb h auf $\subseteq .112$ bei bem Siefermpinner. Die Sdyfupfwespen, von weldyen melyere taufeno 2 rten in Deutichlanto vorfommen, leben unb entwicfeln fich als Scfmaroberer in Snnern anberer lebenbiger Sufeften, weldye baburdy zuletzt inumer getöbtet werten, bebor fie fid fortgepflangt Gaben. Währeno bie fo verfolgten Infeften wenigitens im Fliegen= zuftanbe vor biejen ßseinigern neift ficker fint, finben jids sieje bagegen fogar in sen Eiern ein. Einige fajt mifroftopiid) fleine Sdylupfwespden regen ifye faum fidftbaren Eierdyen in Michrzahl an poer in Sdynteterfingseier,

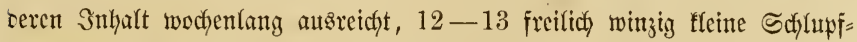

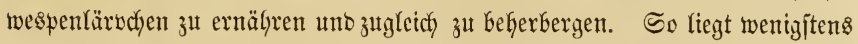

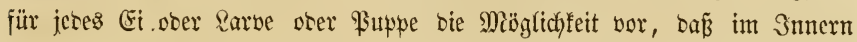

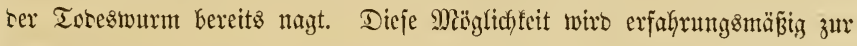

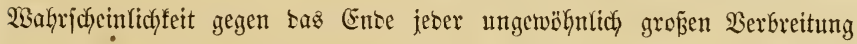

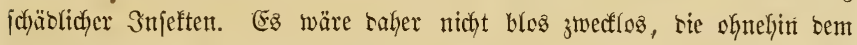
Tobe Serfallenen noch bejonbers aufjufuchen unb zit töbten, jonbern es wütben babei unjere Sefülffen im Berjtörungğwert mit getöbtet werben. Es gilt jogar, aus ben fo bejalfenen Wartoberberbern ifre Snjajfen zu erzieken, ja zım Theil zu biejem Zmedfe jene noch eine Zeit lang zu füttern.

Dies gejuieft in iogenamten 3roingern. Dies jumb in ber. Art

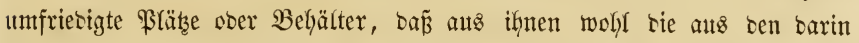

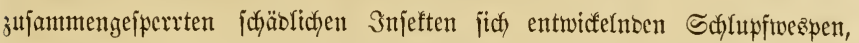
nicht aber bieje felbit bie Freifeit gerwinmen fömen, jofern unter jenen nod) einige entwicflungsfähig gewejen jein jollten. In jold)e 3rwinger, auch oft bejonbers Raupenzwinger genannt, werben bie aufgelejenen ichäblidjen

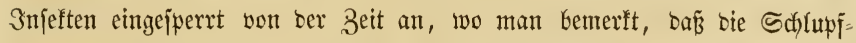
wespen uno Mortfliegen in ifnen fich) Gäufiger zn zeigen beginnen. Daburd) wito bie Entwifflung riejer letzteren begünjtigt uno bod) biejenigen

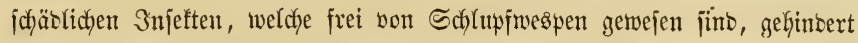
weitern Sdjaben anzurichten. Das biejen alferbings ofne Bortheil gegebene

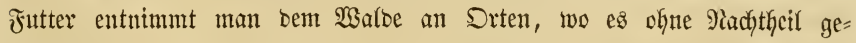
qujehen fann.

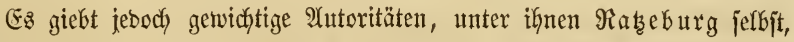
welche auf bie 3rwinger feinen anbern Werth legen als hödjfens ben, in 


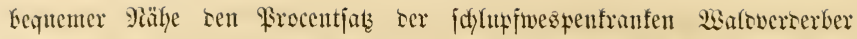

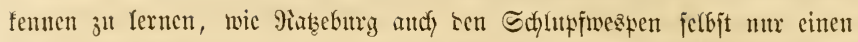

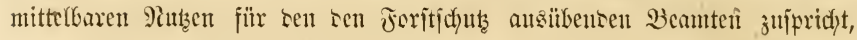
worilber wir fpäter bas sisidytigjte mitjutheifen faben wersen. Immerhin

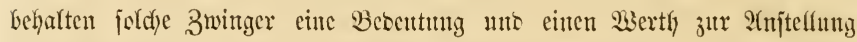

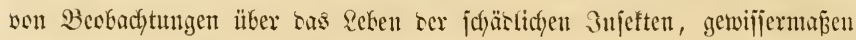

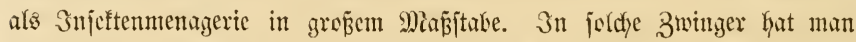
nun bei sem Sanmeln ocr Eier jefädfidyer Infeften, namentfich bes Sicjernjpinners uno ber Monne, sic Eier gebradyt, un aus ifyen bie fleinen Sd)lupfwespdyen ausfliegen зи lajjen.

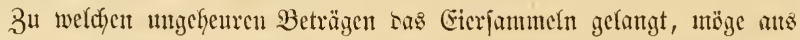

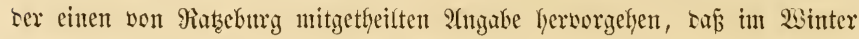
von 1839 auf 1840 alfein in Biejenthaler Mevicr in ber Frovinz Branten= burg 10 Centmer Nonneneier gcjammelt twutben, beren 20,000 auf ein Both gingen. Diejes Beijpiel giebt juttgleidy einen Begrifi, wie wirffam Das

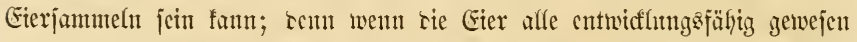
finto, fo ift burdy seren Eimfanmlung cine ganz enorne Mienge von Manten aun Jrefien verfintert worten.

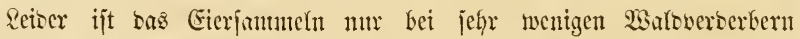

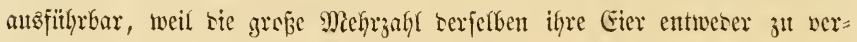
einzelt socr an unzugängliçen Drten ablegt.

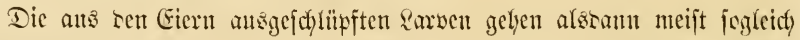
ober wenigftens jefr balto ifyent Jutter nad), wenn nidjt sie Eier jelbjt ju) an auf oocr sidyt bei semjerben untergebradyt maren (Borfenfäfer,

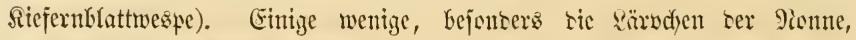

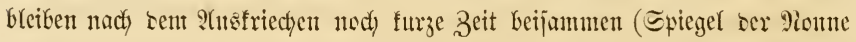

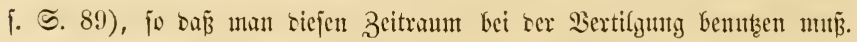

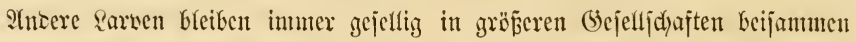
(Proceffitonarmatpe f. Scite 116), wå ifye bertifgung nod) melyr erfeidytert.

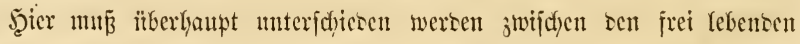
Rarven uno senen, weldye cinen werborgenen 9lufentlyattzort haben, z. $\mathfrak{B}$.

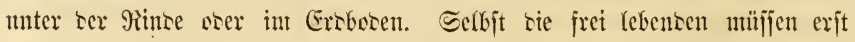

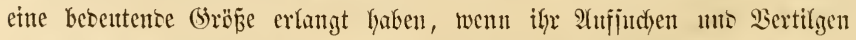

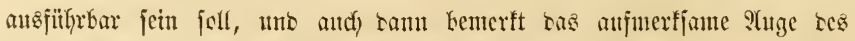

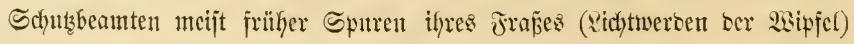


als jie jelbjt, namentidy wenn jid) bie Jeinte hod) oben in ren Wipfeln befinten. Ein bejonters aufmerfjames 2(nge mur man namentfich it Narelfolzrevieren alf ben an Boben liegenben Faupenfoth haben, ber

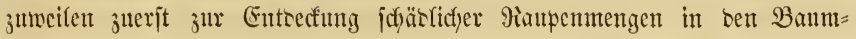
fronen gejülyrt hat.

Die Danter sez :arvenjuftantes uno bie Salyrezzeit in weldye er fülft

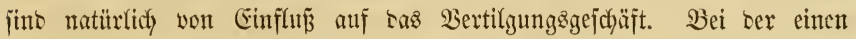
2rrt Sautert ber Earvenzujtano nur wenize Mionate, bei einer anbern ein Gafyr uno sariliber; wir Gaben aljo bort nut eine furze hier eine lange

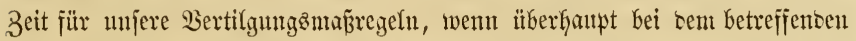
Injeft jicty cer sarvenzujtanto bejonbers bajïr eignet. Heberminternoe

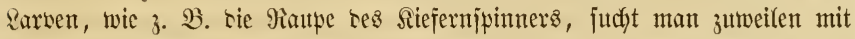
sem bejten Expoly entweber in Winterlager jelbjt, unter ser Bobenjtren, ober man fängt jie in ben Tagen tç Miecterbejteigenz ber Bäume ("Dez Bäumens") an ten Stämmen, währent ifjrer nur fdfwer ober gar nidyt

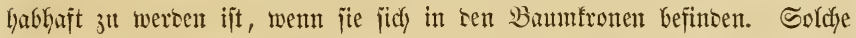
fönnen aber jutweilen surch Erjojütternng tes Baumes burdy wicberfolte jtarfe Schläge gegen ben Stamm, weldyer bajn natürlich noch nicht jul jtarf jeit barf, herabgeworfen uno bann am $\mathfrak{B}$ oben auf untergebreiteten Deffen abgelejen werten. Bei füblem Wetter, bufer im Sommer in ben frïhejten Morgen $=$ uno in ben 2(bencitunben faffen bie Mianpen am reidftejten. Die

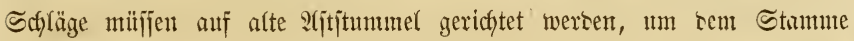

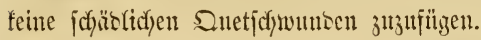

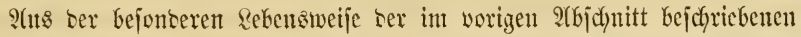

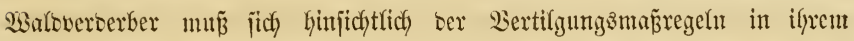
Sarvenjujtante sas Zwectmäpige ergeben, was freilich eben fo autdy von

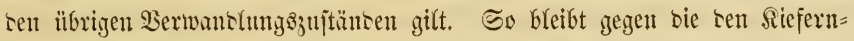

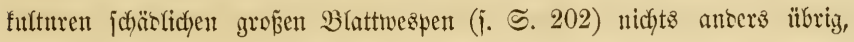
als bie einzeln in ten Rothjäffen an ten jungen Siejern lebenten \&avben

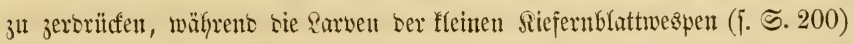

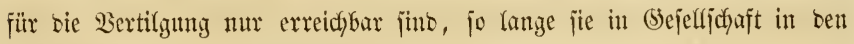

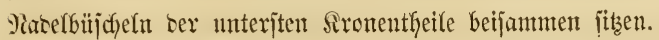

So reicft ez auch ijt, eine einzelne Mitifetyäterraupe vom \&eben zum Tobe ju bringen, jo exfortert bies bei gropen Berkeerungen, wo ticjelben faceffelweife eingeliefert werten, viele Sorgfult. Srünoliches Beritumpfen 


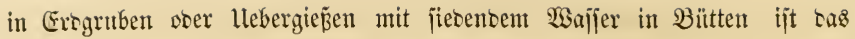
jicherjte Mittel.

Was bie in Frobocen, sft ziemlich tief verborgenen \&arven betrifft, io läß̈t jich gegen biejelben jelten mit Exfolg etwaz thun uno ijt wohl zut unterjcheiben von bem Winterruke = ober Berpuppungzanufenthalt unter ser Bobendecfe (Moozlaub orer Mabelitreu), wolju sie Borfolgung mit gutem Erfolge erjtrefft wercen fann. Ein eigentlicfes Berfolgen ser Engerfinge (Maifäferlarwen) ift baher faum ausfiührbar. (5egen jie forwie antere Ero=

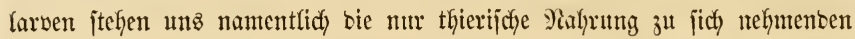

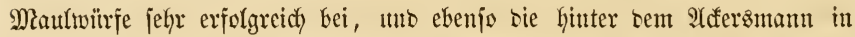
ber frijchaufgerijīenen Furche bie Engerlinge auflejenten Srähen, bejonters ber Saatrabe, Corvus frugilegus L. Mautwurf uno Saatrabe werten aber leiter von $\mathfrak{B} i e l e n$ werfannt tmo alz jđjäblich verfolgt.

Die Bertilgung ber in Snnern tes Baumes, ter 2Tejte ofer tes

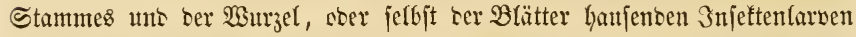
funn fajt nur bewerffifelfigt werten unter gleichzeitiger 3eritörung biejer ifrer Schlurpfwinfel jelbjt, was in ber Şauptjad)e ber burdh bie Rarven angericfteten Bejchäbigung gleich foumt. Wie foll man rie Rarven ter Borfenfäfer, ๖er Splintfäfer (ङ. 165), ๖ев Ertemrïfïelfäferв (ธ. 171),

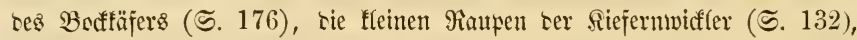

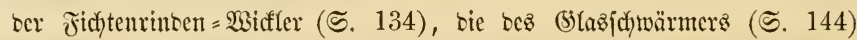
ancers in feine betwalt befommen, als intem man jie unter ber Yinbe ober im Şolze bes Stanmez anffuttht?

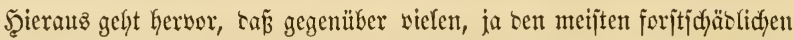
Snjeften bie Bertilgung uidjt anbers ausfïfyrbar ijt, als inbem man jie

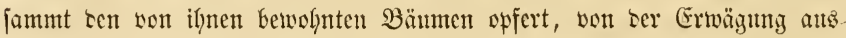

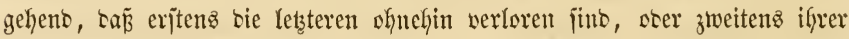
burdy bie barin enthaltenen Rarsen, ober viefmetyr teren Tiadjtommen,

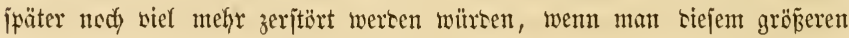
Hebel burdy ธå fleinere nidyt vorbengte.

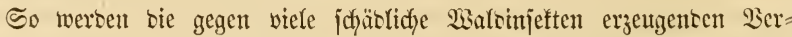

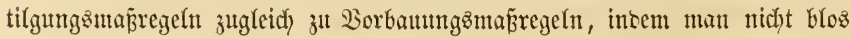
einzelne Bämme, fontern viefleidft hunberte, won senen nod) gar nidft ermiejen ijt, ob jie bon ten barin nagenten Barven getöbtet worben jein 
witroen, opfert, bamit jie nidyt zu Entroifflungsherben werben, bon wo

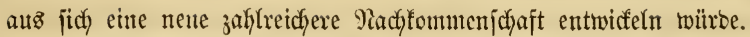

Dev Fuppenzujanb madyt bei einigen Wabberberbern bejonbere

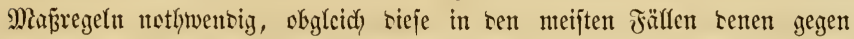
bie Rarben gleich jein werten, nämlich Dann, wenn jicty bie Puppen an benjelben Stelfen unb unter gleidyen Bebingungen finten wie bie Rarven. Sa wir haben unter ten Walsocrterbern cinige fennen gelernt, welche jidh

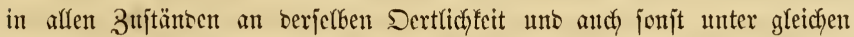

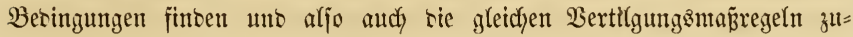

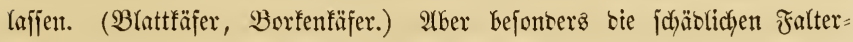
arten erfortern im Puppenzuftanbe meift andere Maß̃regelu als in bem vorausigegangenen Rarvenzultante, weil jic jidy unter anberen örtfichen $\mathfrak{B} e=$

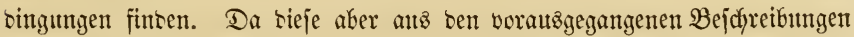

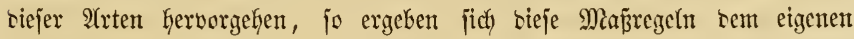
Rachenffen leidyt von je(bjt tms brauthen faum bcjonbers Gier angegeben

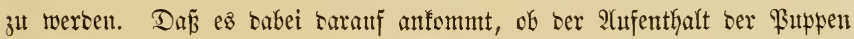
für uns ein crreichbarer jei - was sft nidyt ber Faff ijt - verjtefjt jich won jelbjt. Es läuft babei, wie aud') nadbher bei ben vollenbeten Injeften, natürlich auf bas Töbten ber aufgelejenen, "gefammelten" 3njeften Ginaus. Da aber ben zum Siatpen $=2$. fammeln geoungenen 2 rabeitern nidft ofne Beleg vertraut werten barf, baj̃ jie bie zum Säubern ifnen zugetwiejenen

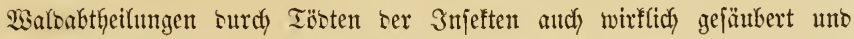
nicht blos in Reviere fidh Kerumgebref̧t Gaben, fo barf ifnen bas Töbten entwerer gar nidyt überlajjen ober wenigjtens รus 2 (fbliefern ber getöbteten Snjeften nicht erfajien werben. Dies bringt aflerbings in mandyen Fäflen eine mefr alz soppelte Zeitaufwentung mit jidf, als eigentlich zur $\mathfrak{B e r}=$

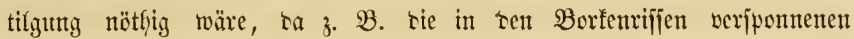

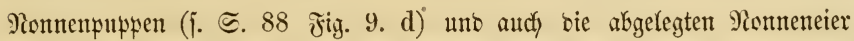

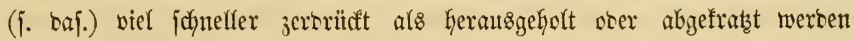
fönnen. 3it bas Einjammefn unb afbliejern nidht zuläjfig, wie z. $\mathfrak{B}$. bet

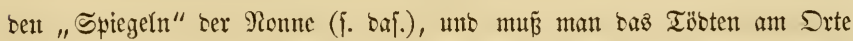
vornefymen, fo ijt eine nadjgehonte Sontrole zuwerläffiger Reute erforberlidy.

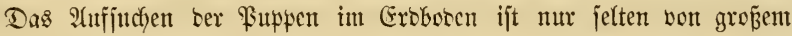

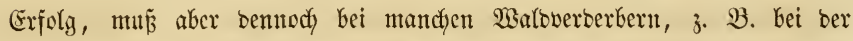

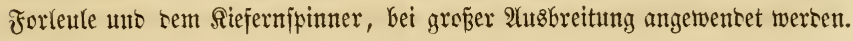


Die Flugjertigfeit uno rie furze \&ebensonter ser meijten 3 meften im Fliegenjutanoe exfdywert bic Bertilgung berjelben ungemein, ja macht

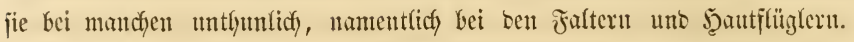
Die säfer machen mit wenigen 2 tużafymen von ifyen Flïgeln feinen fo

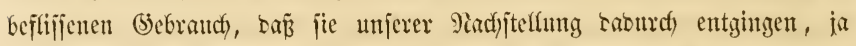

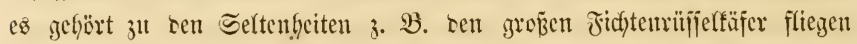

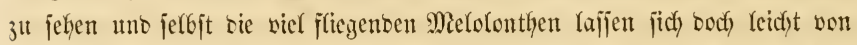
ben Bäumen herabjchïttelu uno am $\mathfrak{B}$ coen anflejen. Dit ift bas Ein= janmeln ber vollfommenten Snjeften beshalb wirfungslos, weil fie ifre Eicr bereits abgelegt haben. Bei mandjen Snjeften, Gejonters bei ben

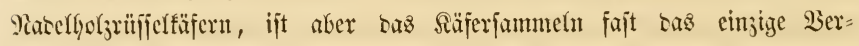
tilgungsumittel uno bei ben genannten Räfern Kebient man fich baju mit

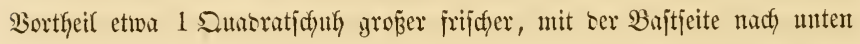

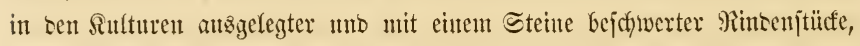
unter welchen jidf bie Säjer jut gitthe jammelı uno wo man jie bes Tages einmal ablicit. $\mathscr{H}$ efgnlidy bienen jrifche Reijigbüntel, aus benen man sic

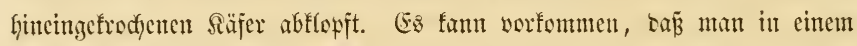
won bent Siejernntarffäjer (j. S. 160) jefhr befaffenten Beitante bie von cinem jturfen simbe herabgetworfenen Triebjpizen (†. ऽ. 162) auflejen

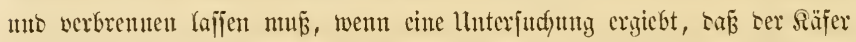

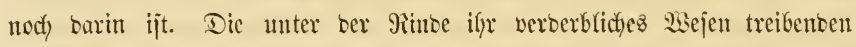

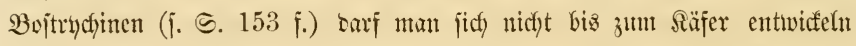

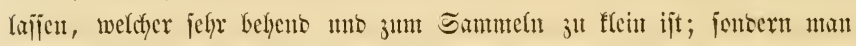

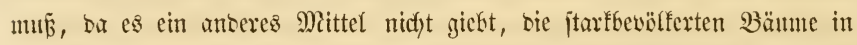

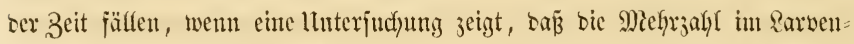

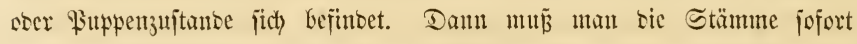

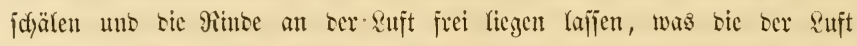
ungerwëGnten sarven uno Puppen jicfere töstet, was mit benen ber meijten Sïfer ser Fall ijt, jofern fie nicht frei un ber sujt leben wie bie ber

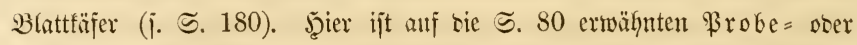
viefmely bej̄er Fangbäume zu verweijen, benn jic jint eben wie ifjo

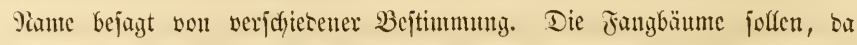
bie $\mathfrak{B}$ orfenfäfer frunfe Bänme in ber Siegel Kieber angehen afs gejunte, bie

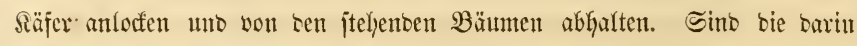

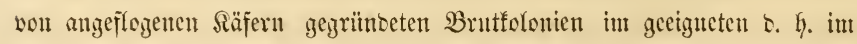




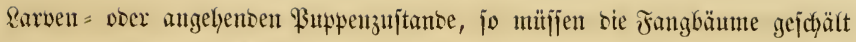

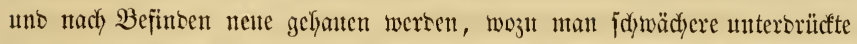

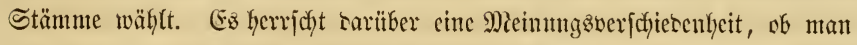
bie Fang = unto Frobebä̈me entwipfech unto cntäjten ober ob man fie mit

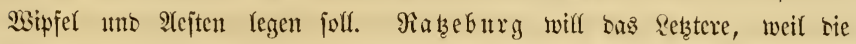
Yabeln bie Saftcirfulation nody eine Beit lang unterfyacten unto aljo autch

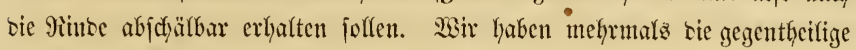
Beobadytung gemadtit.

asie bei sen Boptrydjunen fo fömen and anbere im Snnern ber

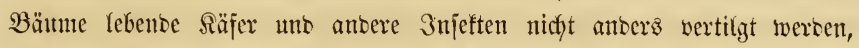
afs unter methr ober weniger umfängficten SpFern an Bänmen vber beren

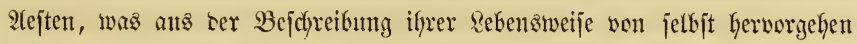

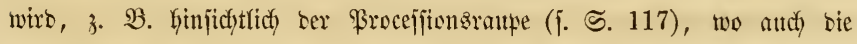

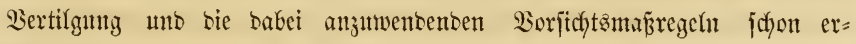
wähnt wutrben.

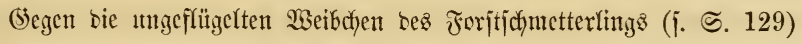
unb bes $\mathfrak{i s a f t ( i n t e n f p a n n e r s ~ ( ธ . ~ 1 2 8 ) ~ b i e ~ b e f a n n t e n ~ T h e c r r i n g e ~ i n ~ b e n ~}$

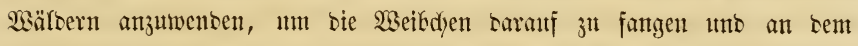

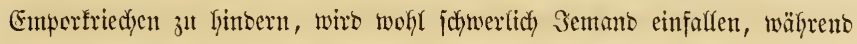
fie in ben Sbjtgärten befanntlich sft angeweenbet werben.

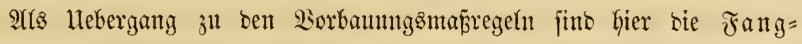

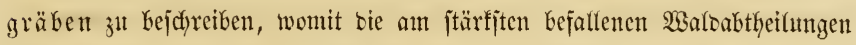

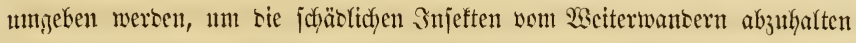

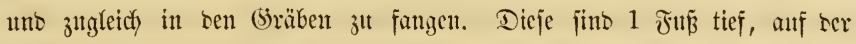

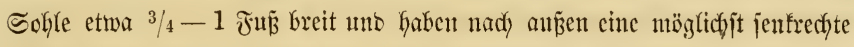

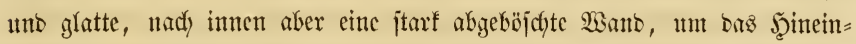

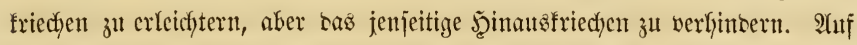
her Sohle bringt man in ber ganzen Breite berfeffecn alfe $5-6$ Sdyritt gerabmantige 4-6 3oll tiefe Fanglïf)er an. (Bicgen bie, wie wir bereitz

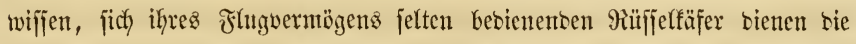
Fanggräken in offenten Ragen unto auf unbenarbtem Bosen um fo beffer,

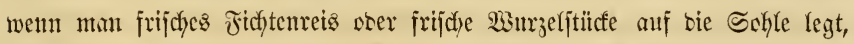

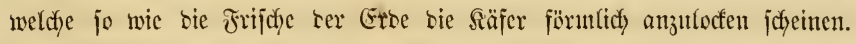

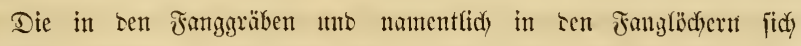
jammeenben Snjeften werben alzoam weggeidaffit ober gleidy an Ort uno 
Stctle getöbtet. Die ₹anggräben jint bejontoer gegen bie Siefermantpen tuto bie 9ïilifeefäfer angewentet wortent.

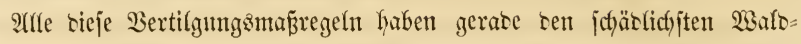
injeften gegeniliber ben zwiefact)en Manngel, sáp fie eimmal zat ber Zeit, wo

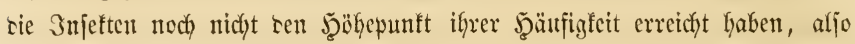
gegen nod) geringe Miengen angetwentet, foitfpicfig unt ungenitgent jint,

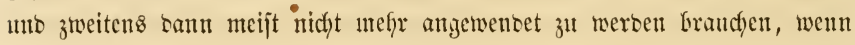

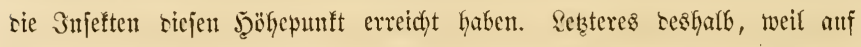

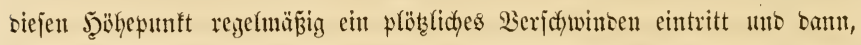
wie wir bies bei ber Moune zejeben haben, alle Bertilgungsunittef nidgt

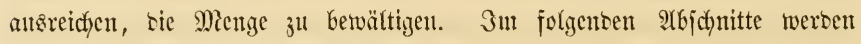

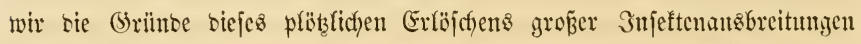
3th bejpredyen labent.

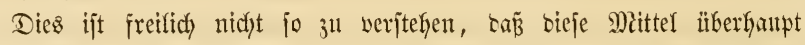

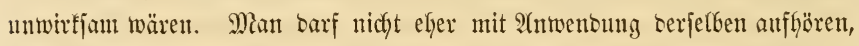
als bis man fidy won sem fidfern Bevoriftelyen bes Ertäjdens ber Snjetten

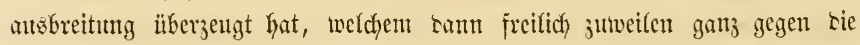

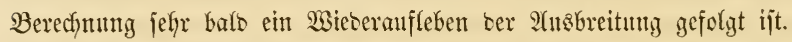

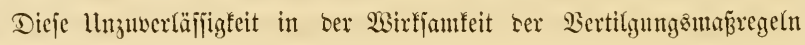

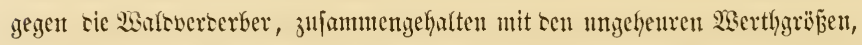

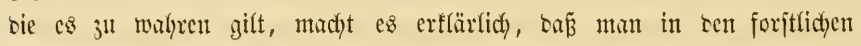

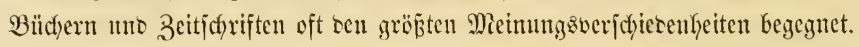

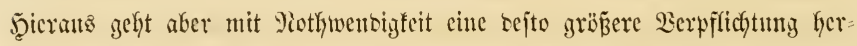

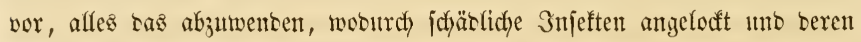
Bermefrumg beförbert werben faurn.

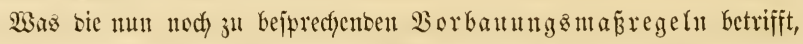

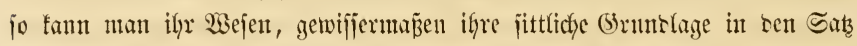

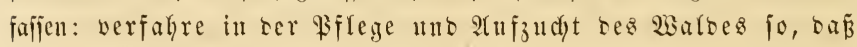
ex in arfen Theifen cin feiner vatur angemeffenes gejunbes

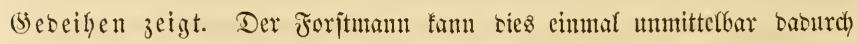

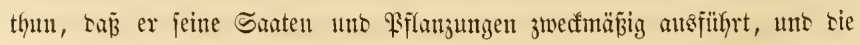

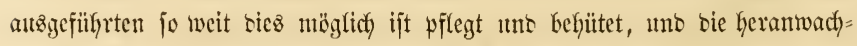
jenten fo wie bie alten Beitänte burdy 2ufäjten - was in neterer Zeit immer mefyr gewürsigt wiro - Durdforitungen, ridftige Edjagfïthrung,

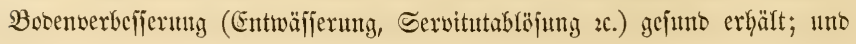


zweitens fann er es mittelbar barurdy, Dás cr bie übeln folgen elementarer Ercignifie (Sdjuee uno withbrudty, Jroft 2 .) befeitigt.

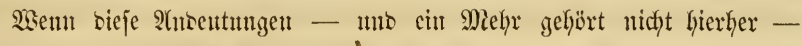

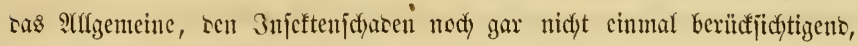
im Aluge hat, jo ergeben fid) werfdyictenartige Bejonkerbeiten ber Borbaunng

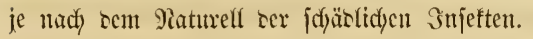

Dabei sarf nidjt แnermälyt bleiben, $2 a \tilde{\beta}$ ç nod) cine Streitfrage

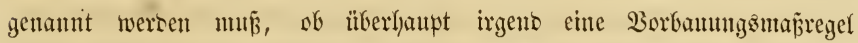
jidyern Sdyus gewäfrt, ober, anoers gefät, ob eine hereingebrodjene

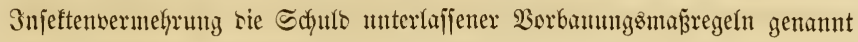
wersen müfje. Es fum fein, saj bieje Jrage noch nidyt genugjam in ser forjtfictyen Riterattur crërtert worben ift.

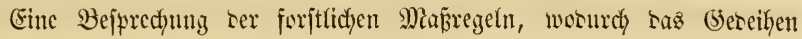
res $23 a r c e s$ in feinem ganzen llmfange geförbert werben jolf, witrse uns jetzt zu tief in sas (bebiet sex Forjtfultur uns Forjtbemirthjefaftung füfren Into wir müfïen uns baher auf biejenigen bejdyränfen, weldye in tumittelbarer Bejiefjung ju forjtidyärdidyen Snjeften jtefen. Sene Dorbannngemafregeln würthen wir alfgememe, sic lemtern aber bcjontcre nenten fömten.

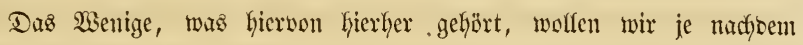

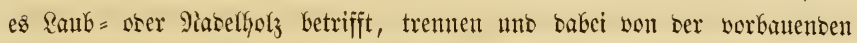

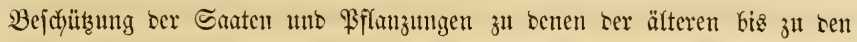
haubaren $\mathfrak{B}$ cjtänten fortj(d)reiten.

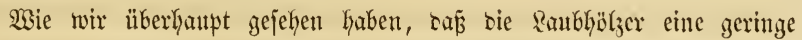

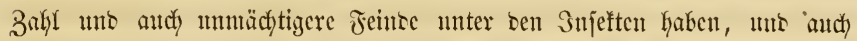

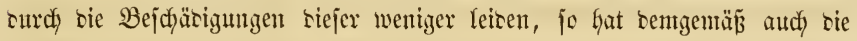
Borbanny im Raubholgmaloe faum melyr als nichts ju thum. Dazu fommt,

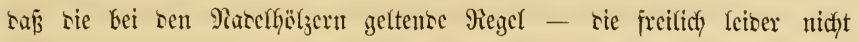

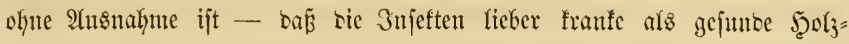
pflanzen angetgen, fïr sic saublyälzer nidjt zu getten fodseint.

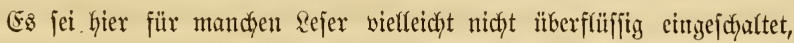

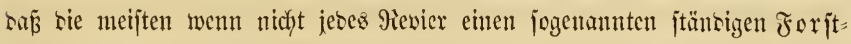
soer Pflanzgarten, ober minbejtens einen nadh Bebultfnís verlegten Saatfamp Gaben, in weldyeu bic Bflümzdyen atz Samen erzogen uno

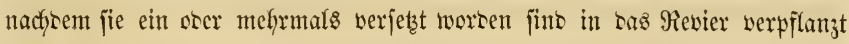
werben, menn nidft bie Saaten umittelbar an Srt unb Stefle im Mievier 


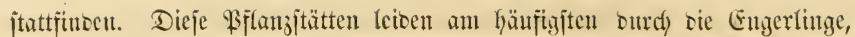

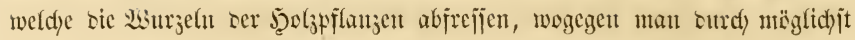

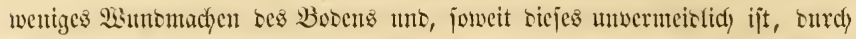

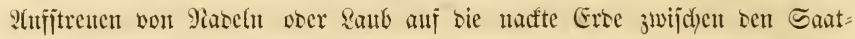

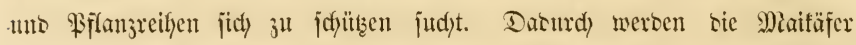

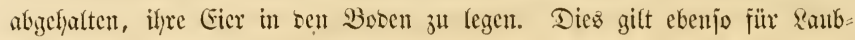

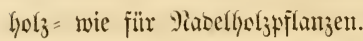

Qţ

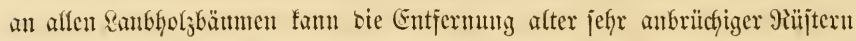
genaunt werben, in weldyen fid) ser groṕe Eptintfäfer (ธ. 164) immer in Mienge cinfinbet, uno von weldfen auts bann jeine Madjfonmen jidy andy

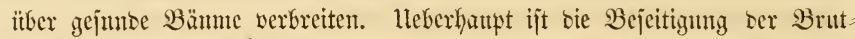

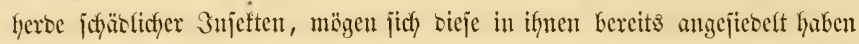

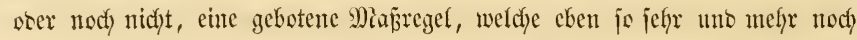

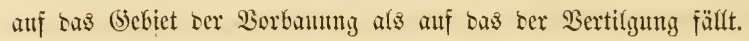

23erfen witr nut nody einige $\mathfrak{B}$ fidfe auf baz was porbauend gegen bie

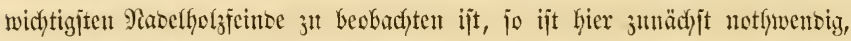

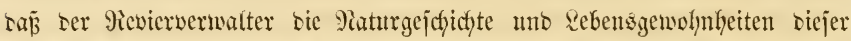

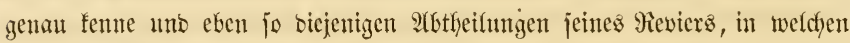

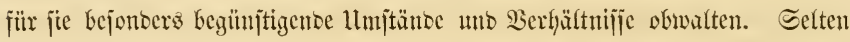
wiro ein größ̈erez Mevier, ganı bejonters int (jebirge, fjulfituttlidy ber boben=

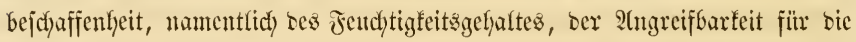

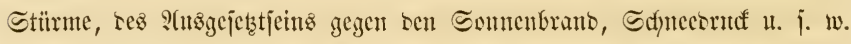
in aflen Theilen gleid) jein, jonbern wiro in biejen Begiefhungen mefyr ge=

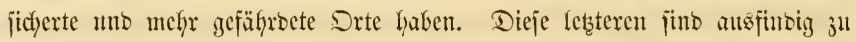

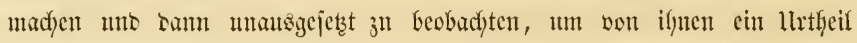

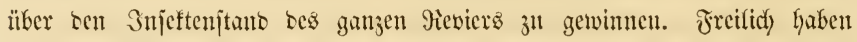

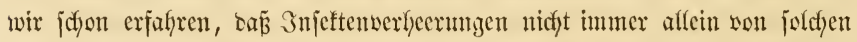

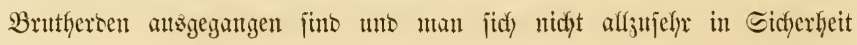
miegen barf, ween man bicjelben frei von Snjetten fimset.

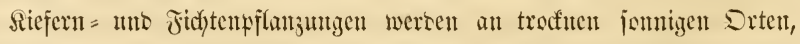

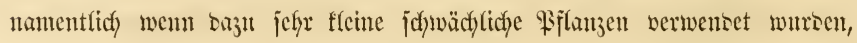

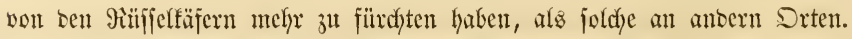

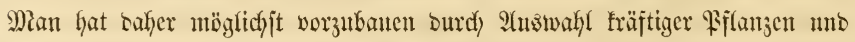
surd) jorgfältige Atusfüffrung ter Serrflanzung. 


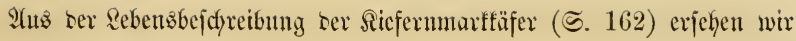

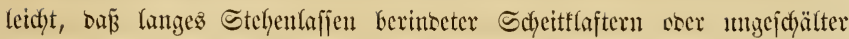
Stänme auf sen 9evieren nad)theifig weroen fann. Lleberhaupt ijt balbige

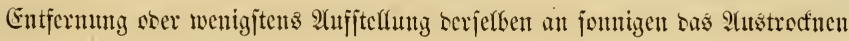
beförornocn Drten anjurathen.

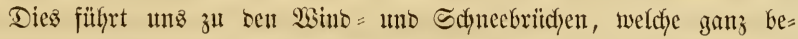

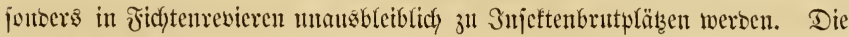

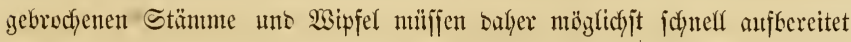
mo entfernt unb bie Stämme wenigjtens fofort gejuält werben, um bie

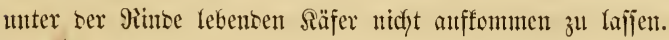

Q4ud) wenn es ber Stum nidyt bis zum Werfen brachte, jontern bie

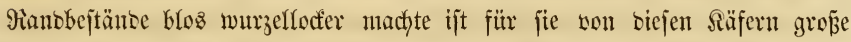

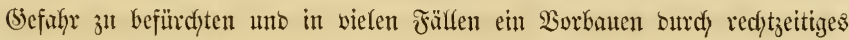
Fällen angezcigt.

Snbent wir nadi bicjen ?(noentungen bie widftige unt verantwortungs:

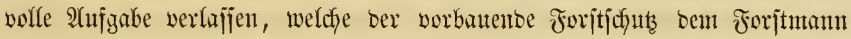
ftelft, wolfen wir แnz nody baran exinnern, ba alf jein Sorgen und Wartjen exfolglos safin jofwinten jieht, wenn jein

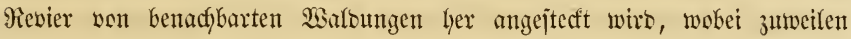

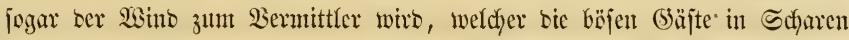

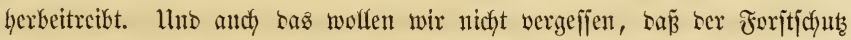

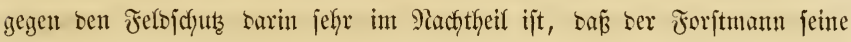

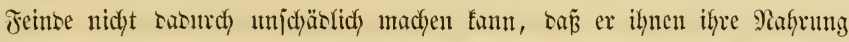
entjieht, was bent Ranbwirthe als leţtes Mittel immer itbrig Gleibt, inoem ex bie zerftörten Felsfritdyte eine Zeit lang nicht mefyr bant mo badurch fajt immer mit Exfolg jeine Feinoe los wirb. 


\section{Bebnter Ab/dhnitt.}

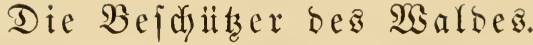

23er unto was es eigentlich) ijt, wodurch nnjere Walsungen bor sem

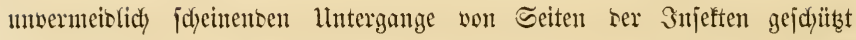

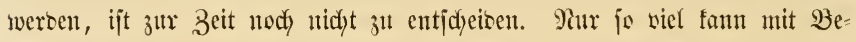

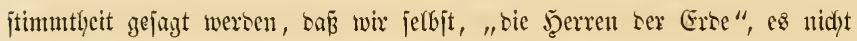
jinto. Lnjere Madft wäre nidyt in Stante, im Sampfe es mit jenen

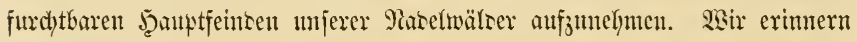
uns an sas, was nad) 33 illfomm Echilterungen iiber sie Nonnenver= heerungen in Ditprenßen berichtet ift (ङ. $91-106)$, unb bengen uns in

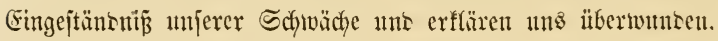

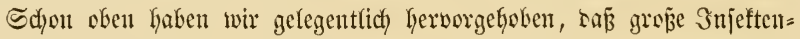
verfeerungen faft immer mebr ober weniger beftinm einen breijäfrigen

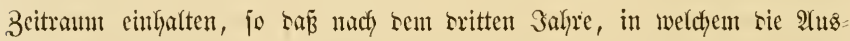
breitung sie liöchite, oft an bas Unglantblidje grenzente Stufe erreicht hatte,

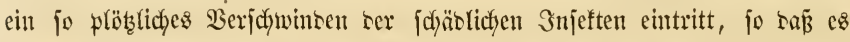
in vierten Galyre funm gelingt, an ben $\mathfrak{W a l r o r t e n}$ autd mur cin einziges 3ll finten, wo man bas Gahr vorker bei jebem Sdyritt auf fie trat uno ber Gerabfallente Soth ser in ben Witpfelt freffenten Maupen sas (Seräujd eines Regens verurjachte.

Dieje jdyarfe Beitbegrenjung ber 2 alowerkeerungen burd Snjeften finbet fid) namentlich bei sen beisen ichäblicbjten Sdjmetterlingen, ben Riefern=

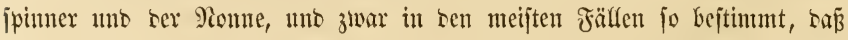
man eben fo jicher, wie man Kente an jebem Erfoly feiner Bertilgungs:

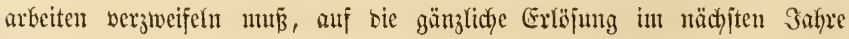
redyen barf. 
Wenn wir über sie (5rïnse siejer Ertöjung nod) in llufluren jüt,

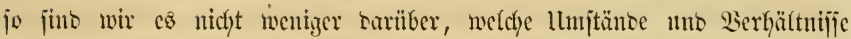

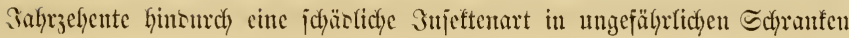

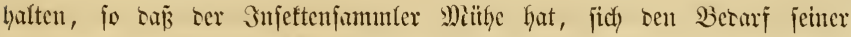

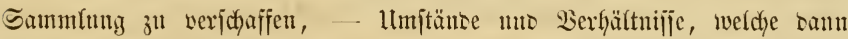

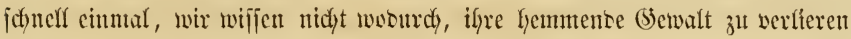
fochenen, fo saż in wenigen Safyren sie jo lange Beit faum bemertbaren

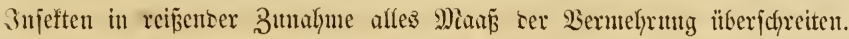

Slyne sem untren werten ju wollen, was wir im erjten Banse sicjes

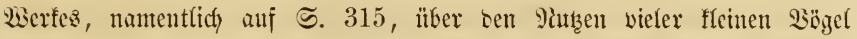
ourd) Sertilgung zafllojer Snjeften zu rïfmen hatten, fo focheinen ood jie es weser z̆ fein, wå für gewöhnlich sie waloverterber, nametitlich

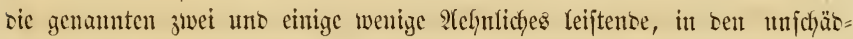

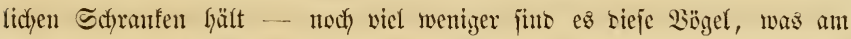

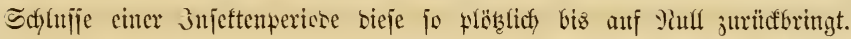

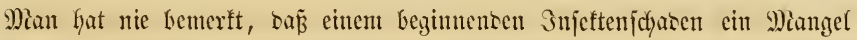

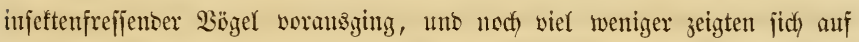

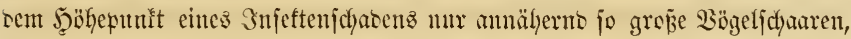
wic fie nötbig jein wïroen, um jene Mitliarten ju vertilgen. Mian hat

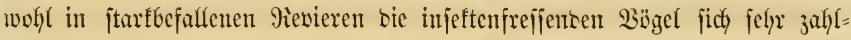
reidy einfinton jehen, aber niemals in joldyen Mengen, saj jie mit bem

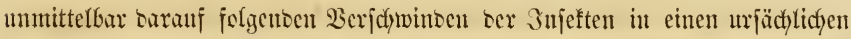
Bujamutenfiang gebracht weroen fonnten.

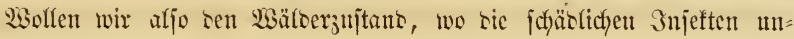
bemerft zurüdtraten, cinen 3ujtand

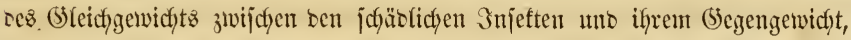
jo mitijen wir vor ber ఏanto eben leiser cingejtehen, noef nicht gemıjam ricjes (Segengewidft za fennen.

Smmerhin mögen es vorjugsిweije bie $\mathfrak{B}$ b̈gl, namentlich bie 3njeften=

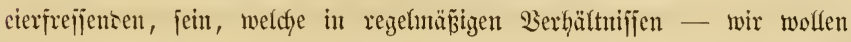
uns fo ansbrïden - bas lleberfianonefnten ber Snjeften berbinbern; aber

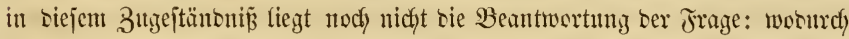

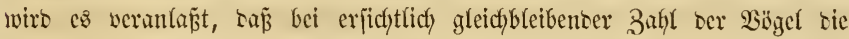

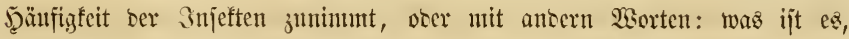
was riejes (Steidfyenidyt anflebt? 
2ufcheinento viel annefmbarer bieten jich sie jayon mehrmals ermähnten

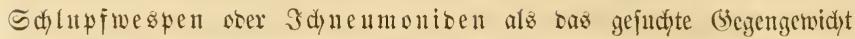

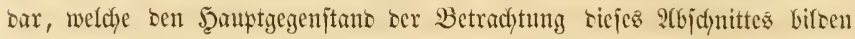
werben. Wenn man in erften Balyre einer Sicfermaupenverhernng in sen

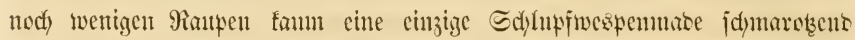
finbet, fo finbet man bann im zweiten jdyon ziemfich viel uns im britten faum eine frei won siejen töstfidyen Edymarobern. J̧ier liegt alfo tex

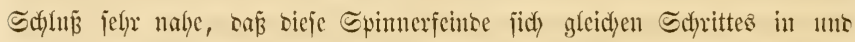
mit ifynen wermefnen uno ifyer zuletzt ફ̧erren werten.

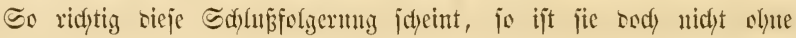

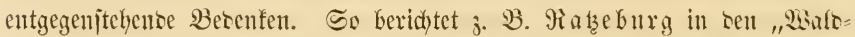
werberbern" (ङ. 93) ans Miedfenburg folgensen Fall: "pbgheidy oer Exinmer

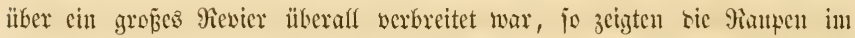

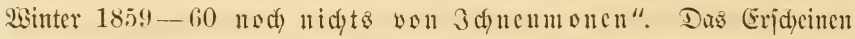

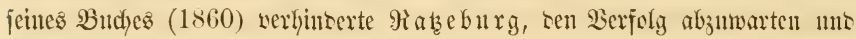
3u beridjten. Ex nennt bas Safj aber ein "Borjafy", was uad) feinen

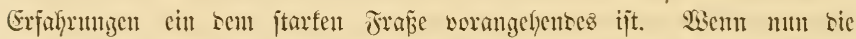
brei J̨auptfeince dez Spinucr (Anomalon cireumflexum, Nicrogaster

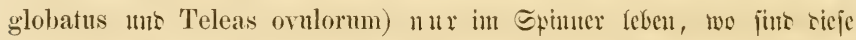
bann in ben folgentoen Gabren 1860 - 61 - wo jic nidyt gefehft haben werten - hergefonmen, ba jie 1859 - 60 in ifjm nid)t vorflamben waren?

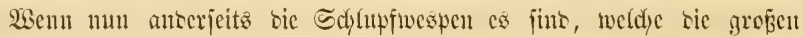
Mengen von Spinncrn, un bei bicjen Beippiel zn bleiben, an Enos ciner Serheermug fajt bis auf Sinlf gebradjt haben, fo jumb mul bagegen bie

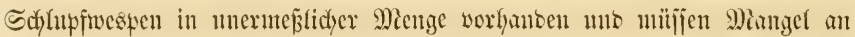
Unterfonmen (bies bietet cben nu ber Sfinner) leisen. Da mun gerate rie

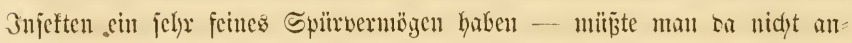

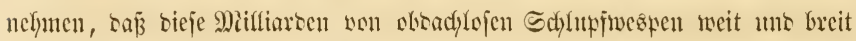

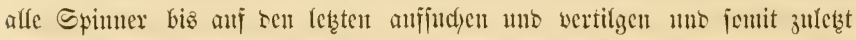

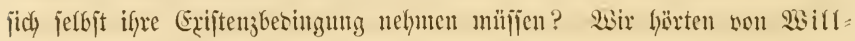

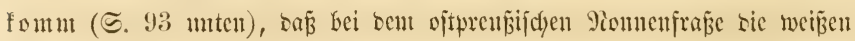
Buppengeipinnjte sex Mifrogufteren (jitcle S. 112 Fig. h) Das llnterholz "fidyeeartig" behedten. Alfo weldye zahlloje Mienge biefer fleinen Schmarotzer munte jid sort entruicfelt hoben, ba beren fefy oft immer ie 100 ans Einer giane herworigelyen. 


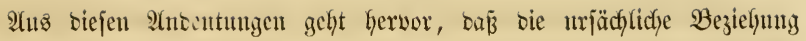

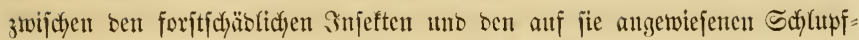

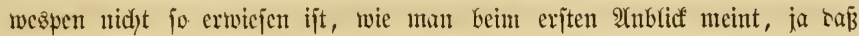

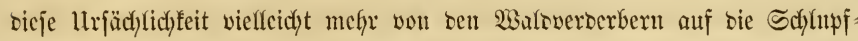
nespen ausgeht als ungefefyrt, worauf wir jogleich weiter cinzugehen haben.

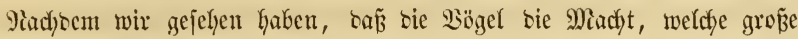
3njeftenmengen wicher bejeitigt, beftimmt nidjt jint, unb von ben Schlupf wespen bies mintejtens jraglidy ijt, jo bleibt, wenn nidut eine andere, won tus nody nidjt cimmal bermutlyete Madjt im berborgenen wirft, nody eille

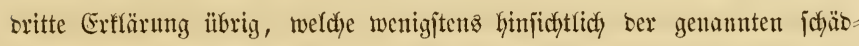

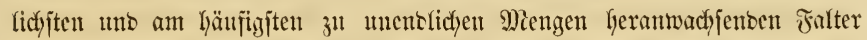

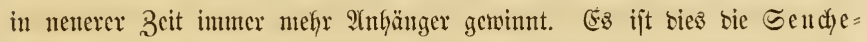

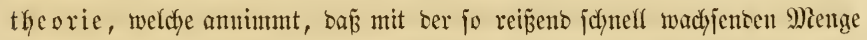
oer Snjeften jidy in ilynen cine Seutde entwidfelt, weldye mit bent ärtlidfen

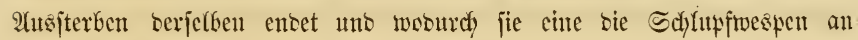

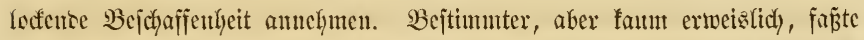

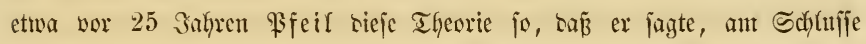
einer joldyen manjlojen Dermchrung verlören bie Injeften saz fort= pfllanzungsvermöget.

Da wir faum mit bcujenigen Störungen befannt fino, weldyen ber gefunce Berlauf unjerer Särperfunftionen unterworfen ijt, jo ift bor ser

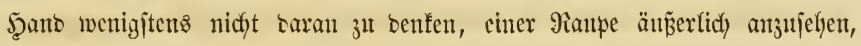

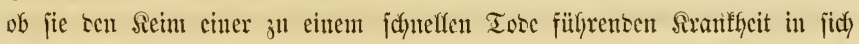
trage. Erjt wenn wir jie vor ber Serpuppung iterben jahen unb bann bei

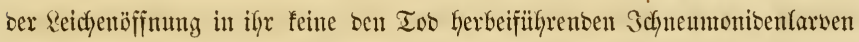

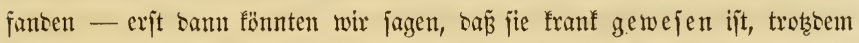

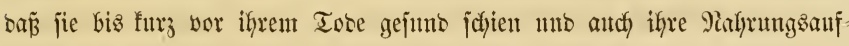
nafure - befauntfich fajt bie einzige jicftbare Rebensthätigfeit ber Sarve fcine 2 tonahute zeigte.

So ijt es, ähnlich wie bei bem $\mathfrak{B}$ orfentäfer mit ben franfen ober gejuben Fidften, bor ber 5̧ano mur nody eine Streitfrage, ob bie Sdylupf= weapen ilyre Eicr nur in frante Maupen legen oter audy it gejumbe.

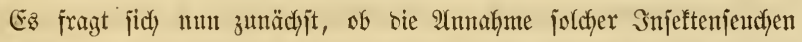
zuläjïig fei. Es ijt fein Brumb borkanten, bieje Frage zu vermeinen, ba wir jonjt idyon an anbern Ifjieren, an Fflanjen unb an uns felbjt 
Eeuchen mandjerlec 2 trt fennen. Wenn wir aber audf allen Gruno haben, Injeftenjeudfen für möglidy, ja für wirflidy zul halten, fo wize es vieffeidft

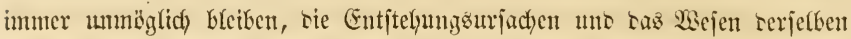
3u ergrünten, oa wir wafyrjheinlich nicht eimmal im Stanbe jein weroen,

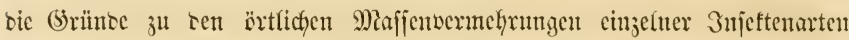

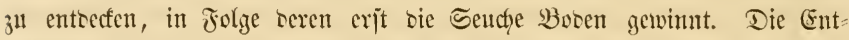
becfung biejer Grünbe ift um fo wenizer zu hoffen, als bie äuñeren Dier

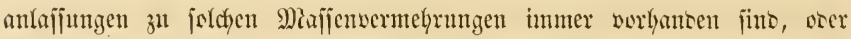

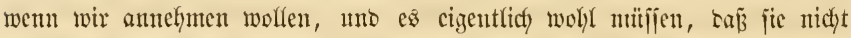

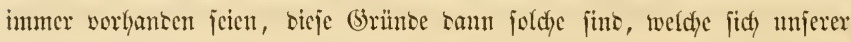

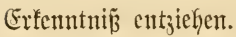

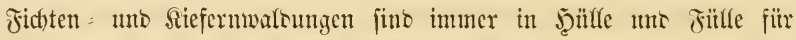
Ponnen unb Spinmer vorfanben unt zwar in allen senfbaren 2(bjtujumgen ses

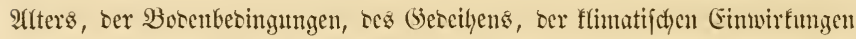

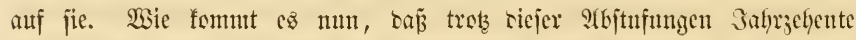

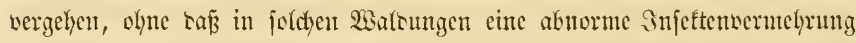

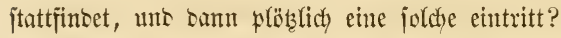

Dieje unt verwante Fragen jins jeşt noch nidjt ju beantworten. 2(ber

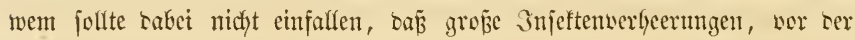

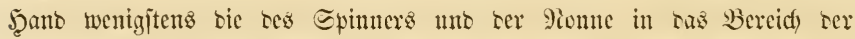
meteorologifchen Stationen aufgenommen werben folften? Erijt wem sic

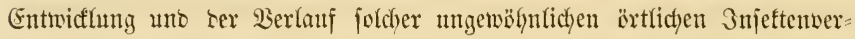

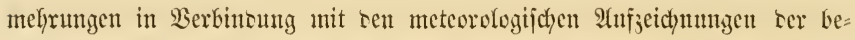
treffenten Sertlidfeit (sieje freilich in weitem Umfange genommen) gebrad)t

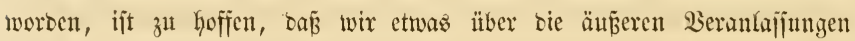

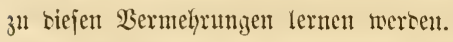

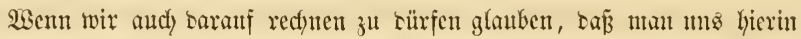
beiftimmen merse, fo molfen wir sod) nicht veridftweigen, suj sic fo in

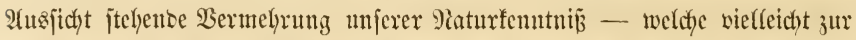

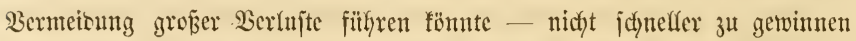

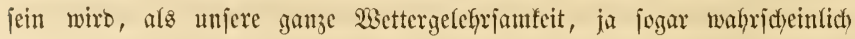

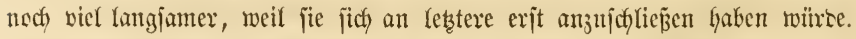

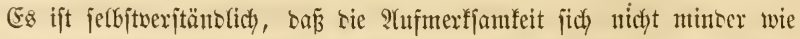
auf bie Walowerberber aud auf seren widytigite Sdymarober zu critreften

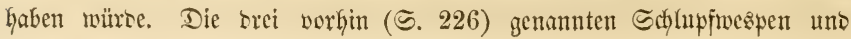


Der Siefermipinner biloen als untrennbar zujammengehörize Theile eine Paturericheinung won interefijantejter Berentung.

Durdy bie Saudfetheorie, um nod) Einizes über bieje hinguzufügen,

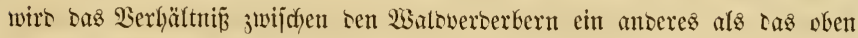
angegebene, ja in gewifjem Sinne ein umyefefrtes, intoem nidjt jene von siejen vernicftet wersen, fontern ungefehrt sie Schlupfwespen surch bie

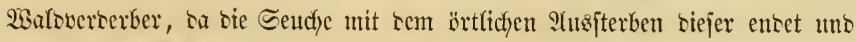
sacurd) jenen bie Exifitenjbebingungen vertoren gehen, was um fo gewaltthätiger, graujamer mödyten wir jagen, auftritt, als ja bie Seuthe eben Mitliarben von Sdyntarotzem das Reben geyeben hatte, sie mun, ba jie eimjeitig mo

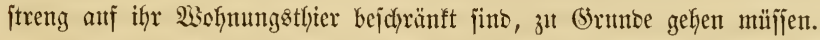

Wenn bie Sendyetheorie ridytig ift, wie jie es ju jein jojeint, fo tarf

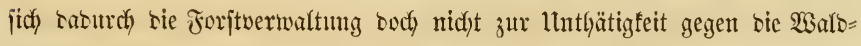
verberber werleiten lajjen; benn wenn aud) eine Sermehrung berfelben in

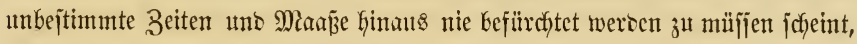
jonbern jie auth) ohne unjer Butflun in wenigen Safyen wieber ertijat, jo

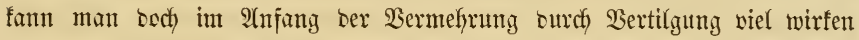
uno auth Ipäter Durch Borbaumg (namentlich Fanggräben) viel erhalten.

Tady biejen Bemerfungen über bie Bebentung oer "Bejđützer res Walteg" fönnte man, wenigitenz wegen ter Schlupfwespen, Btweifel hegen, ob biejer Efrentitel äberfaupt beroient jei. Gs wiberfpricht ber fehr gang=

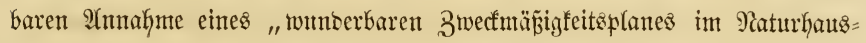

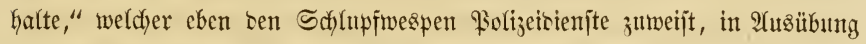
bejien jie bie Injeftenarten, wcldhe einmal bie gewöhntidyen Sdyranfen ber

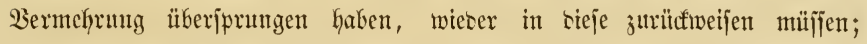

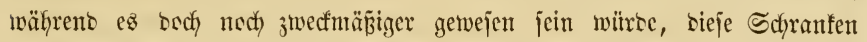
lieber gleich unilberidyreitbar zu jiehen, woourdy fo umfangreidfe \$flanzen=

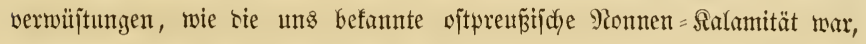
überfhatpt vermiesen worben jein würten.

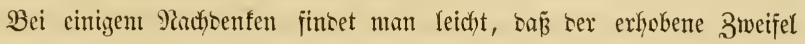

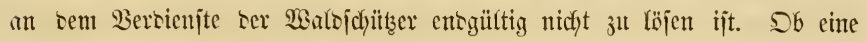

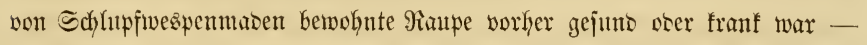

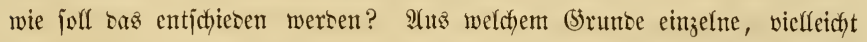

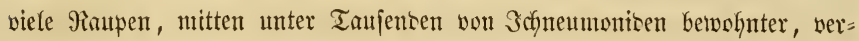
idfont gebrieben jins, ijt eben jo wentig ju jagen. 
Sajjen wir sas aber saljingejtexlt, inmerfin jino rieje interejianten

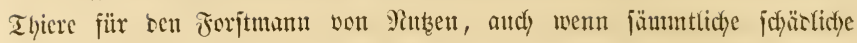
Rianen ohne bie Sdylupiwespen bor ber Erreddyng tes bolffommenen

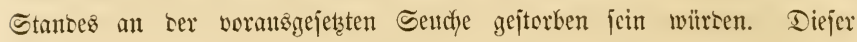

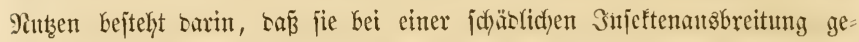

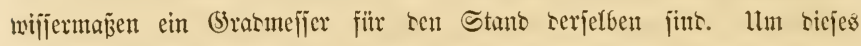

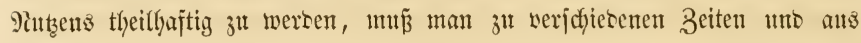

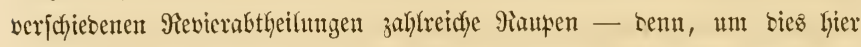
ein für alfemal einzuld arten, mur jolchen gegenitber haten jich bisher sie Sdjlupfwespen merflidy gelteno gemadft - im Snnern unterjudjen. Den rurch Benzint orer Sdjwefeläther orer auth in Wcingeift getöoteten Fianpen

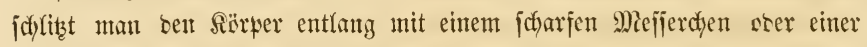

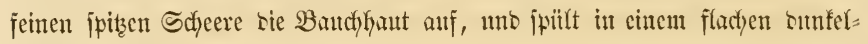

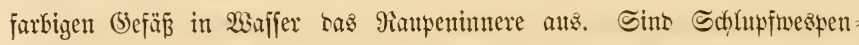
larben, bie ben Räjemtaben ähneln, sarin, fo. werben fie, oa jie ntemals

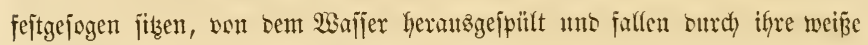

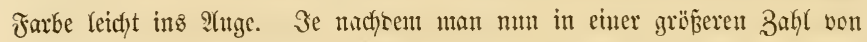

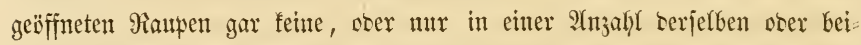
nahe in affen Safluffwespenumaben finbet, banady hat man entweser sie

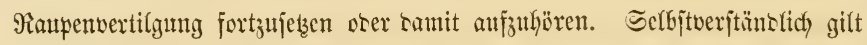
bies blos von beinahe atżgetwactjenen, Ler Serpuppung bereits nahen Mautpen, benn nod) jebr fleine, audf) wonn fie fänuntfich) Gejaflent wären, withten immer nody eituen erheblidyen Sdyaren surch Frefien auridgten fönnen, sa fie erjt furz vor ser Derpuppung wou ifyren Schmarokern getïbtet worben jein würten ober exjt als \$ippen.

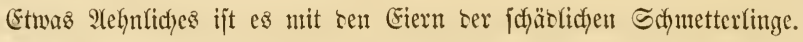
Freilich) ijt beren Unterjudyung ofne eine itarf vergrößerernse \&upe uid)t auts:

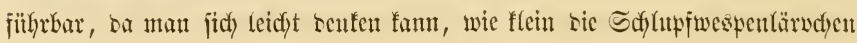

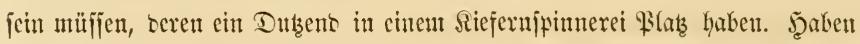
sie Cier in Ier Miehrjahl je cin flemes wie mit einer Stefnatel gejtodyenes

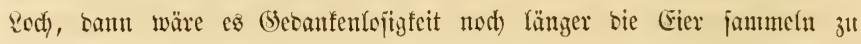

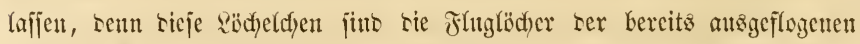
Sd)luffwespdyen. Man witrie aljo blos lcere Eierjobalen vertilgen!

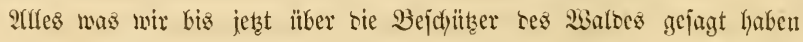
bezog jidy leriglidy auf bie Schlupfwespen, obgleidy and anbere 3njetten= 


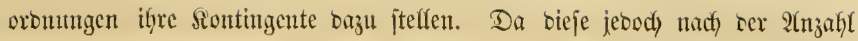

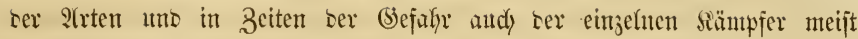
ungleich) geringfitigiger erjdyeinten, fo wolfen wir über jie hier nidyts âtrge= meines voraแล์ chicfen.

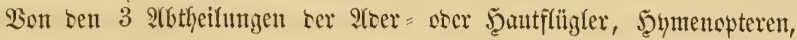

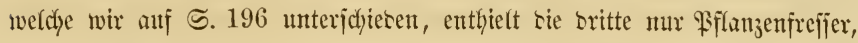
beßhalb \$intophagen genannt, uno carunter bie cinjigen Walcwerberber ber

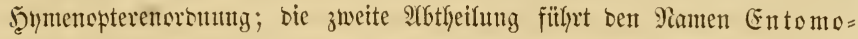
phagen, Injeftenfreffer, ober 3 d) neumonisen, Sdylup fwespen. Atm

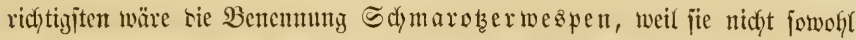
sie Injeften äı

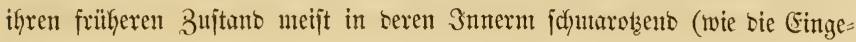
meibemüntur) verbringen, von ben Säften iffer Schlachtopfer leben unt biefe

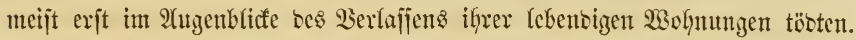

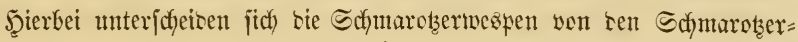
wilumern tarin, Dás fie nidyt in beñ Därmen ober anbern Drganen ber wou ifnen bewohnten Snjeften, jontern jrei in ser Reibeshg̈ble berjetben unt, insem fie bie ebeln Rebensorgane verffyonen, jautgent leben. Man

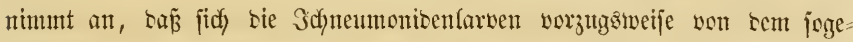
nannten Fetfförper nälyren, einer gelblichen, ats locferen Fettlappen

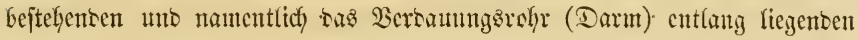
Majfe, weldhe, ba fie jich fait nutr in ten sarven finbet, wahrichecinlidy cin Ricjervejtoff ijt, welder bei ser Berwandlung alfmälig verbrandest wiro

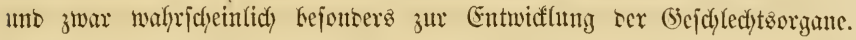

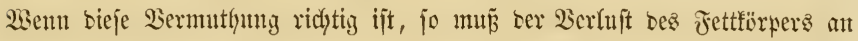

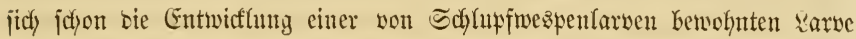
bis zum volffoumenen Stance verfintern.

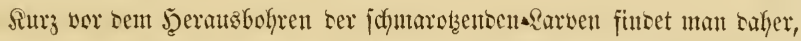

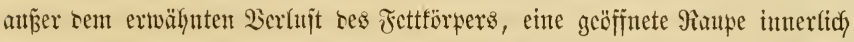

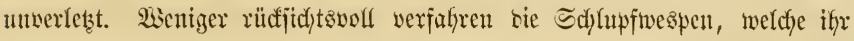
Schlactoptopfer erjt vertajien, wenn fich biejes bercits verpuppt hat, benn man - fintet von ifnen bie \$rtppe meijt ganz ausgefreffen. E: giebt aber and cinize twenize äuß̈erlich) idyutarotzente Sd)lupfwespen. Die Rarben biefer finten fich bann wie

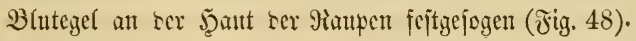

Fig. 45.

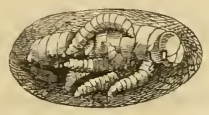




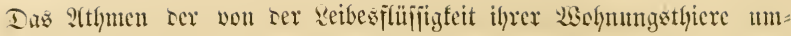

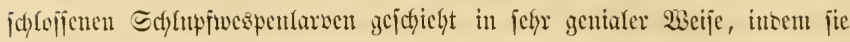
jich Iaju ser Athentorgane ser erjteren bestenen. Sererjetts verlänft bicht

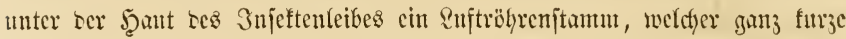

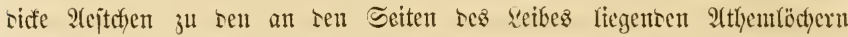

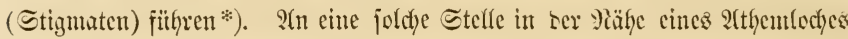
heften jith) sie Sdymarebzer(arven mit ifrem secibesente oft an, wo cine attyemëffrnung liegt, uno athmen fo gelegentlich mit.

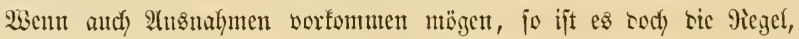

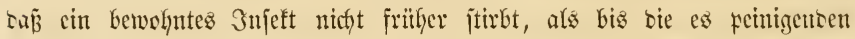
Schmarotzer - - benen jein Reben genifjermapen allein angehört - Dazu reif fith, entweoer alz sarben ober als volfentete 2 sespen es ju serlajien uno ifgm, namentlich im eriftern Falle, sasurch felbjt ren Too geben.

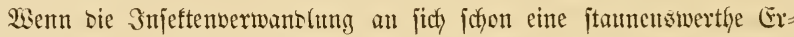
fdjeinung ift, wobei bie Pantpe fich in sie mumienähnliche Fuppe ungeftaltet,

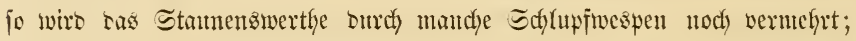
nümlich surdy biejenigen, welche von ifyen Wirthen aus sem sarvenjuitunte mit in sen \$appenzujtano Gimitbergenonmen werben. Die Qarve ser grožen Sch)upwespe bes Siefernjpinners, Anomalon circumflexum L., (jiche Fig. 50. a) lebt cinzeln in ber Sicfermantpe, was sicje aber nicht hintert,

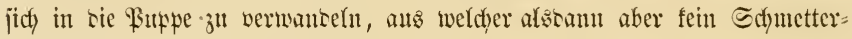
ling, joutern bie groß̈e Schlupfwezke herworgeht (i. Scite 112 Jig. g.),

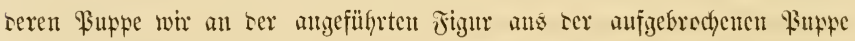
Ies Jalterz heratsiguten fehen. Soldye Doppelputpen, wie man fie nennen

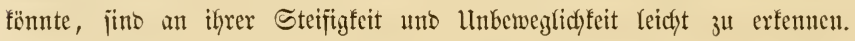
Den bewohnten \&arven, namentfid) ser Schmetterlingšraupen, merft man jelbjt wenn jie mit 3dyneumonitenlarven jull humberten ganz vollgejtopft

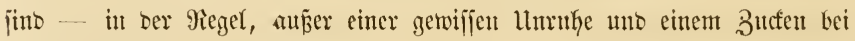
ser Berülyrung, ifyr Reiben nidyt an. Bei ten nacften Maupen jieht mun jeroch bie in ben jarteren Steflen ser Jૃant feit haftenten Edfalen ser

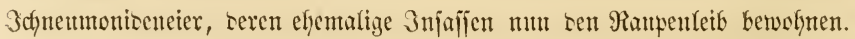

*) $\mathfrak{3 i r}$ feljen bieje jebr beutlich an folgenten Figuren: S. 112 Fig. c. (weiß̄e

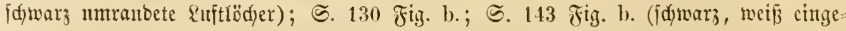

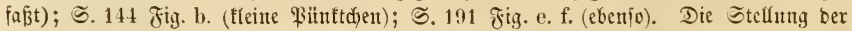

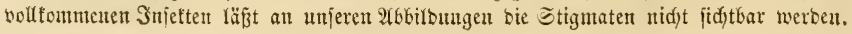




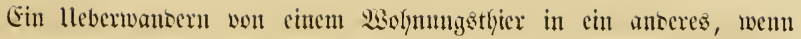

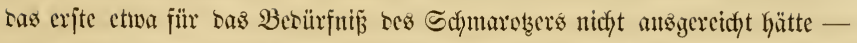

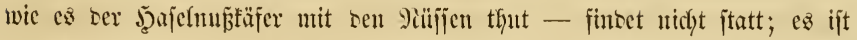

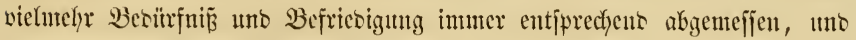
butach legen gröfere Sdylupfwespen inmer nur ein Ei, fleincre nelyrere -

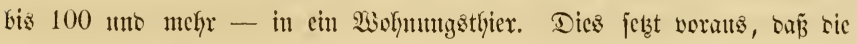
eierlegenton Sathluffwespen bie filyon won anberen belegten Maupen unter=

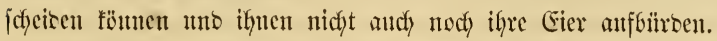

STm getwifylichiten fintoet man sie Sdyneumonisentarven in ben sarven ifyer Wirthe, feltner in sen Eiern mo Buppen, ant jeftenjten ned iu

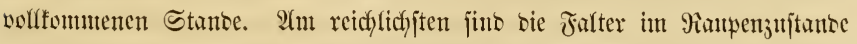
besadyt, sech ijt feine cinjige Snjeftenorommg verjidyont, jelfjit in foldyen İnjeften, sie iumer im $33 a f j e r$ leben, hat man Sdylupfwespenlarben ge-

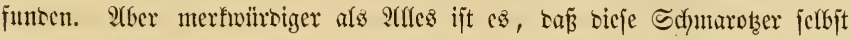

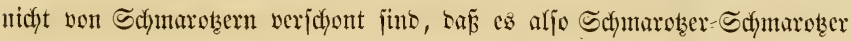
giebt. So reben 3. $\mathfrak{B}$. in ten flemen Miffrogajteren, seren cine afrt Fig. 51. a abgebilset ijt, wieter antere noch viel fleinere Schltwfwespen, weldye lebtere alfertings cine eigene llnternbtheilung fïr fich bilben. Unter riejen Doppeljumarokern finsen jidh bie fleinjten Injeften, viele nicht größ̈er als $1 / s$ sinie แno sabei sody mit 4 Flügetn mo allen übrigen Thcilen verjelyen.

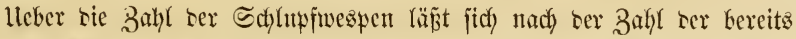

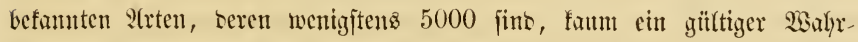

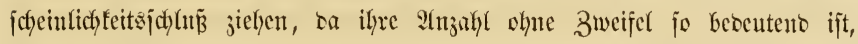

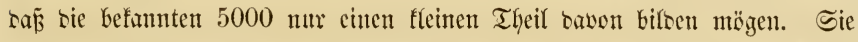

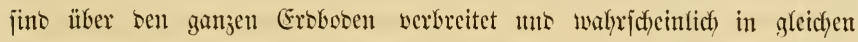
Berhältnififen wie bie übrigen Injeftentoronungen, in benen fic vorzhtgs: weije jamarotzen.

Es gefört utr geringe 2tufmerfjamfeit baju, sie elegant uno joflanf gebauten Schlupfwespen in bem Keichten sft wippenten Flnge auf ifyren exfictytlicfen Spionirzügen zu besbadyten uno von alloeren, meijt plumper uno jdywerer gebauten Wespen ju unterjefeisen. Man barf jich nur am Waltesrante, wo ats bem Mantogebilfich hohe Doloen unto antere blïhente

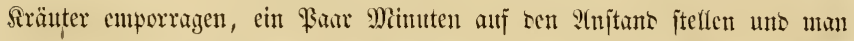
mirb balo bieje Beontuen bes 2 artoes ab = uno zuftiegen jehen, mur fumze 


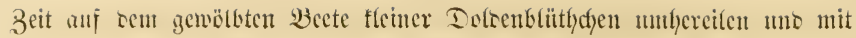
sen langen, oft in foünem Bogen gefrümunten Fïhlern nad) Bente tajtent. Fajt jerer Salag liefert sem Injeftenfloffer audy einige Edylupinespen in

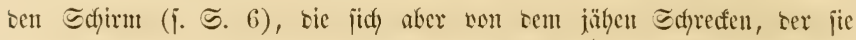

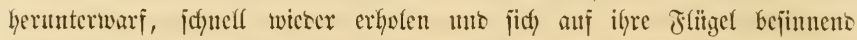
eilig anf mo savon fliegen.

Fig. 49.

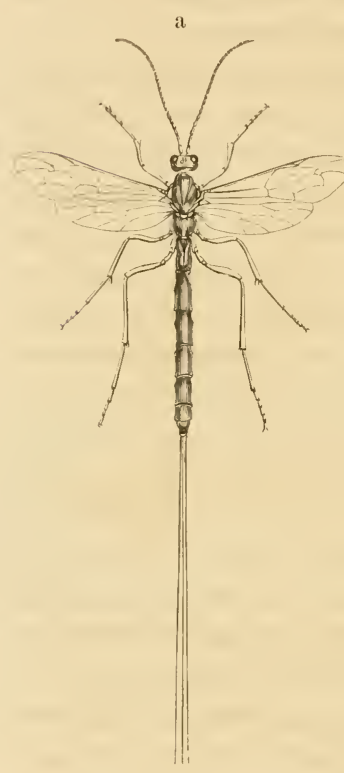

a. Ephialtes manifestator

(Ichnemm.) L.

b. Pimpla instigator L.

M3ir jef̧en in Fig. 49 a. Ien grä̈̈ten Eeutichen 9ie präjentanten sicję গiüı. Gervolfes in natïrt. (5rö̈̄̈e, ber auf einen jeiner süh)l. Görner mit seichtigfeit cin Dutzeno jeiner münigen Fanilicntwerwanten, sie Ius entgegengcjetzte (5rï. Benextrem biloen, omrd) bie ëifte tragen fönnte; ca ijt cin $23 e i b c j e n$ son Ephialtes manifestator (Ichneumon*) L., weldfes jeinc

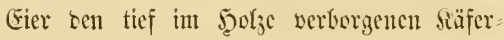
larven anfbürbet, wojll ifym ber lanze sezbolyrer $3^{\text {It }}$ Statten foumt. Bejijer nod jeigt sen (Scjtaltcharafter ber cdyten Эdynemmonisen die andere Jigur (b) mo cbenjo sie grofic Sd) (n) fwezpe ses Aicjernipinners, Anomalon circumflexum (Ichu.) L. (Jig. 50. a).

Die Intericycisung in (5attungen uno

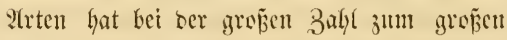
Theil jo fleiner Thiere tie grëß̈ten S(j)wierig. feiten unb jtübst jich fïr sic (s)attungen bauptfüct)lich anf bas Flïgelgeäzer - bejoncers ber:

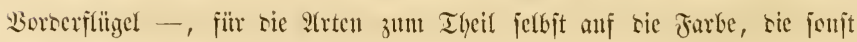

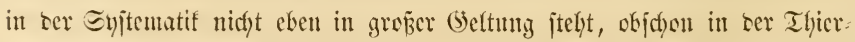

*) Linne vereinigte nod) alle ilym betannten Sdylupfwespen in ber (5attung Ichneumon, bie ifäter namentlid) vou Grobenthorft, Rees v. Ejented, Wesmael, Jeartig unb Anbern in zablreidye Gattungen zerfäfft worben ift. 
funbe mefy als in Ier Piflanzenfunde. Tiazeburg theilt bie Sdylufwespen, inbem er fie in weiten Sinne auffap̃t, nach bent Flïgelgeäber in $\mathfrak{B} \mathfrak{r a}=$

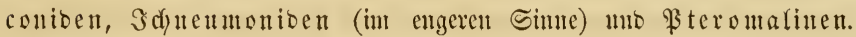
Tiepräjentirt wersen bieje srei Familien, bie erjte burch Jiz. 51. a, bie

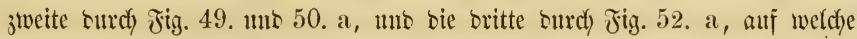

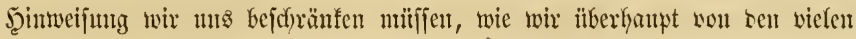
Gumserten bentidyer 2 alsidyutumoniben nur sie folgenten brei herwerheben, weil jie von affen bie wichtigiten jimb, wenn anbers bicien Thieren eine

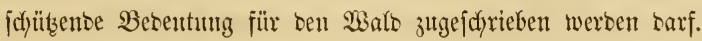

Wir geben worker nody ben Eharafter ber Entontophagen, weldye mefr

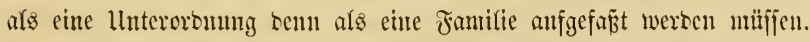

Die weiblichen $23 e s p e n$ haben einen meijt frei an bem Jeintertcibe hervor: ragenden vou zwei Slappen jeitlidy umjdylofienen Regebolyrer (Fig. 49. a).

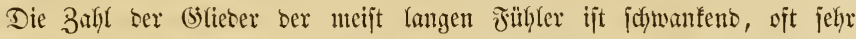

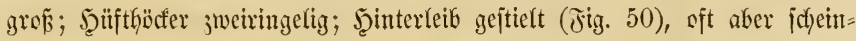

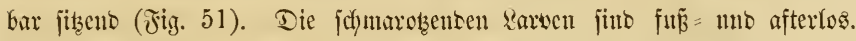

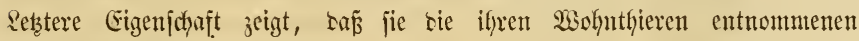
Säfte ofyne Mejt vermenden.

\section{Die groß̌c Sicferuppinter $=$ Sdylupfweăpe, Anomalon circumflexum (lehn.) L.}

Die in natïrl. (5rö̈ß̈e abgebiloete 23 spe (รig. 50. a) zeigt bejonbers

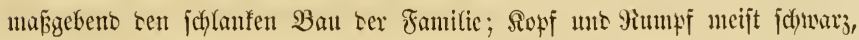
ઝ̧interleib ge(breth), Fübler braumroth), Seine röthlicfgelb mit hellen Sdjentertringen uno an ben bintern beinen mit jefwarzen Spizzen ber Sdyenfel uno Edjicnbcine. Flïgel bräuntidytrïb mit röthlid) braunem

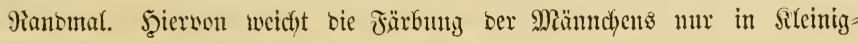
feiten ab. Eegebolyer ftž, nicht bejtüntig herbertretent.

Die Rarve $(c-f)$ ijt anggewadjen eine (f') jajt cinen $3 \mathfrak{o l l}$ lange biffe Miade, weldje bevor fie bieje Gejtalt erfält bie wunterbarjten Mictanor=

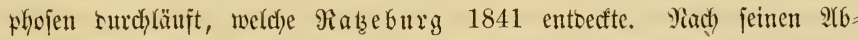
biloungen fino bie unjrigen fopirt. Ex unterffeibet 4 Stabien. Das crite Stabium (c) jeigt fidh in ben crit $6-8$ Sinien langen wody jungen Siefermratpen, in beren Sunern bas nod) feine sinic lange fabenoünne 


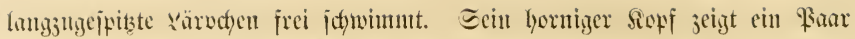

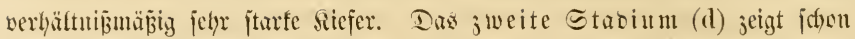

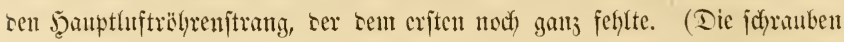

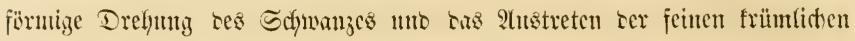

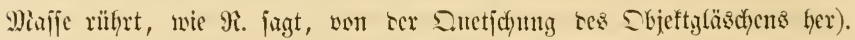

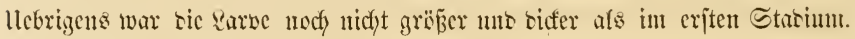

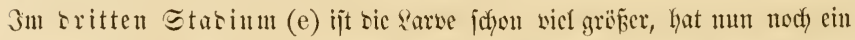
3weites (unteres) Sicferpaar, wollfommen werzwocigte Suftrïhren (Irad)cen),

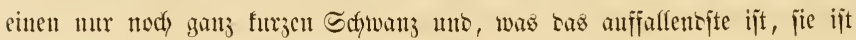
in cincr (nicht mit abgebilbeten) jacfartigen Bajaje einzejd)lofien, weldye

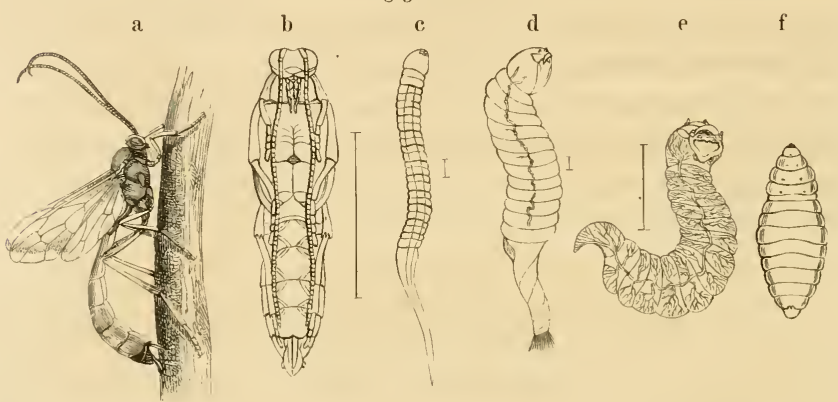

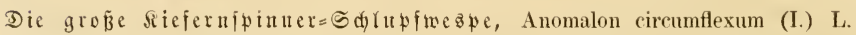

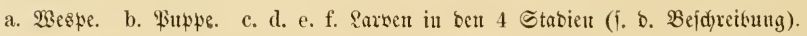

Yiabeburg, wohl mit giectht, für cine fid abhebente sarwenthant anjieft,

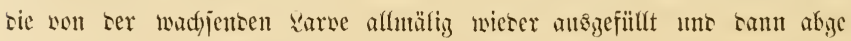

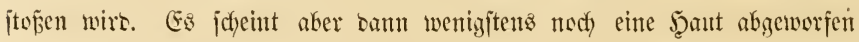

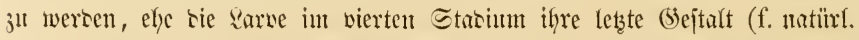
(3r.) amutumt, bis 3 meldem 9 . saher nod) weitere Berwanthngsiftufen wermutget. Sä̈hreno in sen früheren Starien bie sarwe fret im 9ianpen

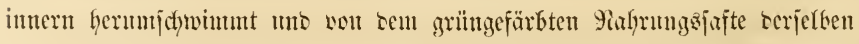

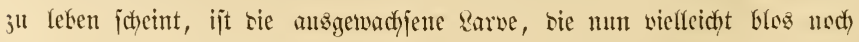

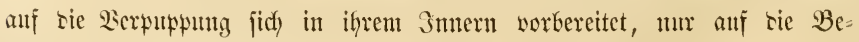
gruptung ifres Blazes beradit. 


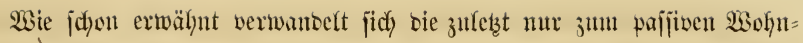
hans ber ?nomalon=8arve getwortene Spinnerratpe nodh in bie Buppe

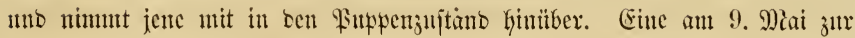
Puppe gemortene wutse an 11. unberweglich und an 30. Wiat entidylïpite Darans bic 23espe, wälfrento weldyer Zeit jidc barin tie sarve in bie Puppe (b uns S. $112 \mathrm{~g}$ ) werwantelt hatte, welche wie inmer bei sen

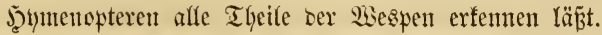

Dieje Sdy hupwespenart ijt wie anbere aud monophagijd mto joar fïr ten Siefermjpinner, o. h. jie jdymarobt auper ticjem in feimer ansern

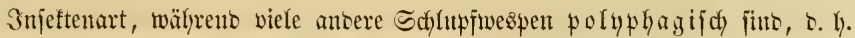
in verichiebenen Snjeftenarten reben. SBagher jüb jtetz nur eimzefne Sarven Savon in ben Spinnerraupen gefmben worben, unb zwar fajeint bie Mespe

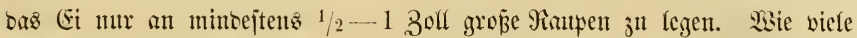

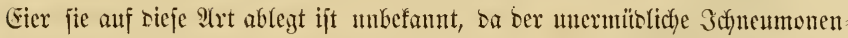

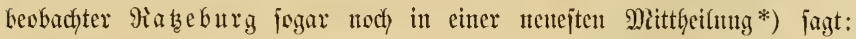
"Direfte beobadytungen über bas Eierlegen biejer Ydjncumonen feflen merf witroiger Weije immer nody."

\section{Die fleine Siejernjpinter $=$ Sthlupfweappe, Hierogaster nemorum Ilart. Itto globatus (Ichuı.) I.}

Wir falfen hier zwei einanter fefp ähnfidye fleinere Sdylupfwespen jujammen, weil jie eben seshalb oft verwedjelt werion mögen un beibe glecit) emjige berfolger bes Siefernipimers jutr.

Die $\mathfrak{W e s p e n ~ ( F i j . ~ 5 1 . ~ a ) ~ j u ̈ r ~ n o d y ~ v i e l ~ f l e i n e r ~ a l s ~ e i n e ~ S t u b e n f l i e g e , ~}$ Siopf, Brutj uno Bauch jofwar, mit gelblichen Beinen, welche bei erifterer

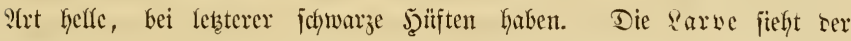

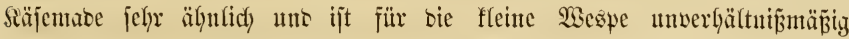

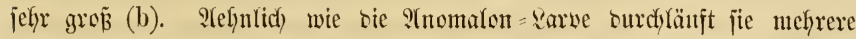
Entwidfungaftaoten. Die \$ eirunsen Seibengejpinnit.

*) (5)runert's forftlidje $\mathfrak{B l a ̈ t t e r . ~ M e u n t e \& ~ S e f t . ~ 1 8 6 5 . ~ W B i r ~ f i n d e n ~ i n ~ b i e j e r ~} \mathscr{N} 6=$

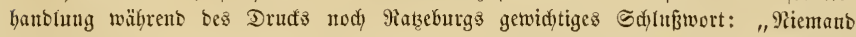

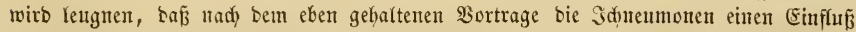

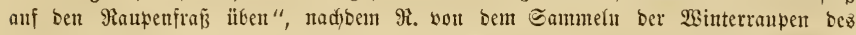
Riefernfpinners gefprod)en hatte unb sabei bie Sdnenmonen geidjont wiffen will. 
Dicje beiren flemen Wespen, neben senen Tiazzeburiz nody M. ordi-

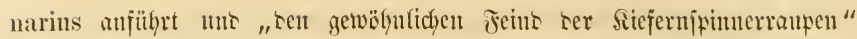

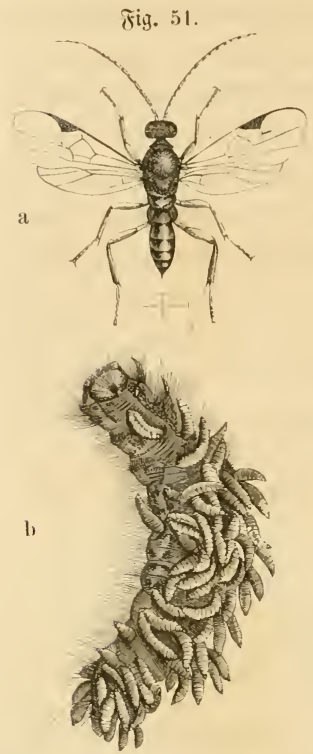

Microgaster nemorum IIart.

a. פisezpe (jtarf wergröbert).

b. Eximerrantpe mit sen cten fic verlaffentoen tarven ses Miffrogajter bebectt.

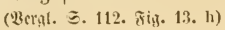

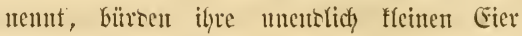
wie es fuchut immer mur Einer gaupe anf eimmal altf, bis 120 ant ser Bahbl, jo sak eine jientidy aแsigemadjene Siefermante won

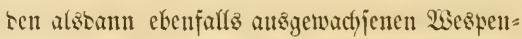
larven förmlich) bollgejtopit ijt uno letztere, menu man sie 9iaupe öfïnet, als ein Yebensiger Brei tarants hervorquelfen. Sino bie sarven 3ur Berfutwputig reif, fo befyen jie jidy, jebe an einer antern Stelle, Durdy sic Piantenlyant herans (b) uno fpimmen jidd) jete in furzer 3eit

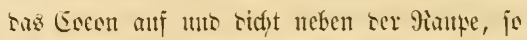
saj sicje ganj sabon besecft ijt, um io mefir als jie jet)ell ju cincm leeren Baly jujammen fällt, in wefdyem jeosed alle immern Theile umberjefrt gefuncen werten. (Seite 112. Fin. 13. h). Diach etwa 10 Tagen surdty. bredyen bie SGespdyen ifye (Scipinnjte; rods fommen ans sicjen anjtatt ilyrer and nidyt jelten Ecfmarotzer = Edymarotser herwor, io

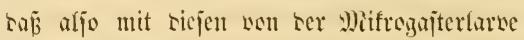
bafjelle zejofielyt wie bon Seiten ter Epinner: rante mit rem stmemalon.

Was tic Bebentung sicjer mnjerer fleiten

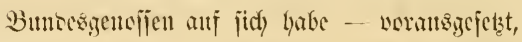
raj jie nidyt an eine Sianpenjentde gebumben

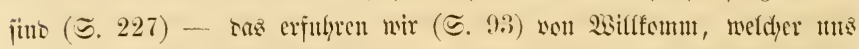

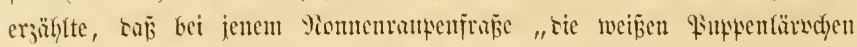

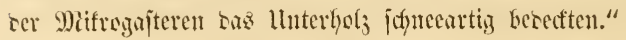




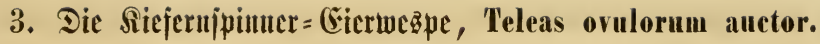 (T. terebrans $\Re i b$.)}

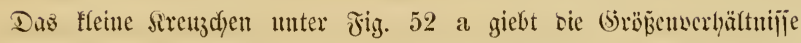
ber ïberams fleinen 26 espen an, weldje gunz fdywarz unt seren fein bebaarte groje Flügel fajt gamj olume (Seäber jür. Die gebrod)enen nad) bent Eribe lin fenlenförnig verbicten Jübler fino jelyr tief aum (Befidyt anjejetzt (b). Der fleine abge= itutżte Şinterleib ift fajt fegelfärmig. Son sen Earven uno \$rupen, weldye jo minjig tlein jinto, baj̃ ocren $12-13$ in einem Schutetterfingsei Maum uno Parlynug finben, ijt cben ocsigalb fanm ctwas jull bejdrciben.

Sion beul etwa $15-20$ bis jebzt unter= idfiebenen beutjden 9 rten erreidyt feine bie Qänge einer \&inic; sic meipten finto $n$th $1 / 2$ \&.

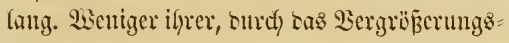
glaz leid)t ju überwinbenoen, fileinlycit als wegen ifper Lebercinftimmmung in ocr fajt ourd)gängig fdłwarzen Färbung, fino sie 2frten jdyer ju unteridycioen uno saljer ift sie Jrage ned) unentfaleben, ob sie Teleab: 2rten anf je nut cine Sd)metterfingsort bejc)ränft jitro, ober scren beliebiy melyrere werfolgen.

Die Entwidfming vour Einbringen ber Ieleaseicr in bie Schmetterlings = (oocr and) Wanzen $\Rightarrow$ ) Eier bis zแแ 2 (nsflliç̧en ber

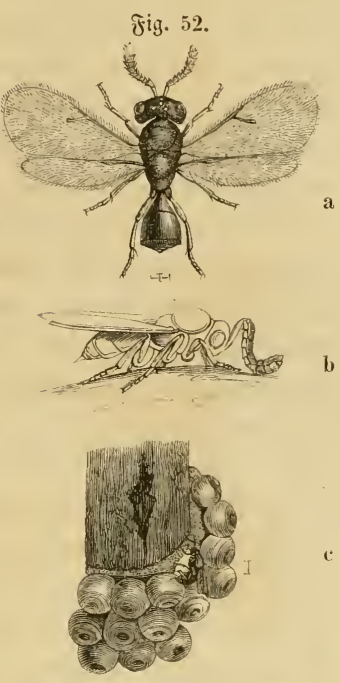

Teleas orulorum anctor.

a. 2Gespe; b. bicje fizento wull ber Seite gejebent.

c. Eicr ses 9ingelipinners, auf weldyen einte Tcleasmespe fitst.

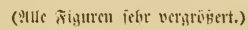
23espcten banert $4-6$ 3odfen, won benen tod) wenigftens cin Drittel ter 3eit auf ben sarwenjutanto fommen uno fo lange aljo ser Sorratly bes

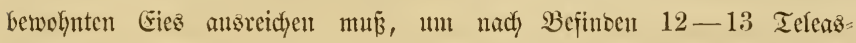

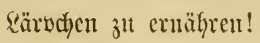

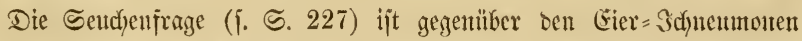
bejonters jobmierig zu beantworten, ba 
ob fidon bie Eier oer Schntterfinge ben firanffeitsfeim in jich tragen mo rnourd bicje Sd)murober anlodfen, sic aljo alscam ifyrerjeits cin \$sitte=

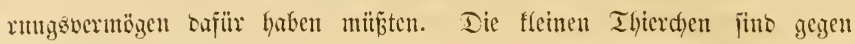
baz Entre won Saupenwerfeerungen jafon in jo ungeheuren Miengen auf

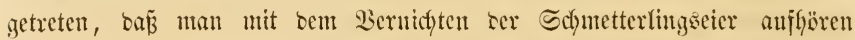

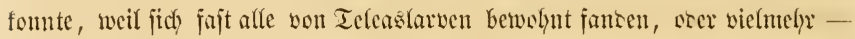
scun sicje llnterjudyng witube z"l mübjefig mo jeitrautento jein - tweil

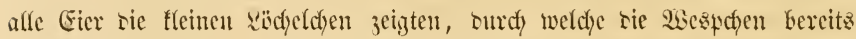
atteggeflogen maren. Jreilich fallen sie winjig flemen Tlierdyen, gegen

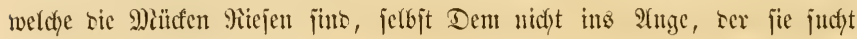
uno ifre 2 (nwwejenlycit fennt.

Sbgleidy bie Scthlupfwespen - went wir sie Entifycisumg ter Eeudfen frage sabju gejteflt jein lajjen - für sen 2 Salt won gropere Bercutumy jïn, fo muifijen nix แns bod) auf bicje wenigen Bcijpiele bejdyränfen.

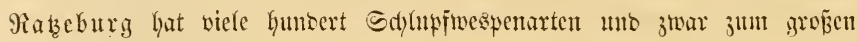
Theil jerbjtgezogene, bejdyrieben, weldye in Forjtinjeften fdymareben. Zeben reren body allein 40 in sem Siefernjpinter!

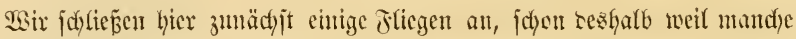

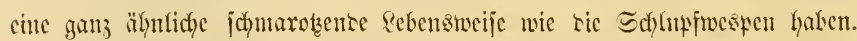

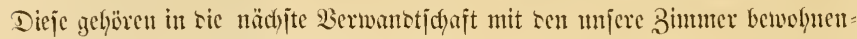
sen uno mijere Fleijchweräthe verfolgenten ïberall befamten Fficgenarten,

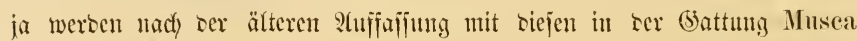

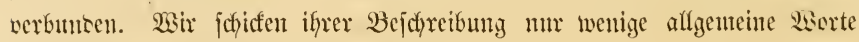
jux Charafterifirmtig ser ganjen Drommg vorans.

Dic Jliegen, Zweiflïgler, Dipteren, ftehen an oer Zahl ter

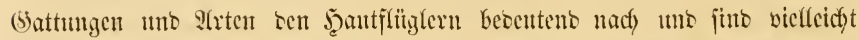
sicjenigen Injeften, weldye am wenigiten nady ben werjediesenen filimaten

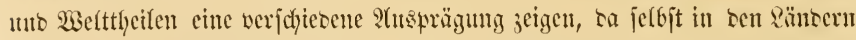

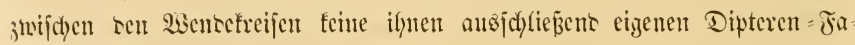
uitien auftreten.

BSent and) unjere Stubenfliegen, Jeifdffiegen, Miüfen uno cinige

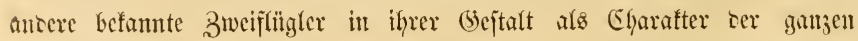
Drsmung getten fünnen, fo fonmen bod) gemtg antere Sweiffïhyler vor,

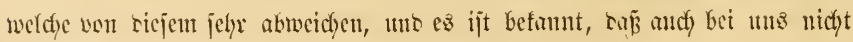




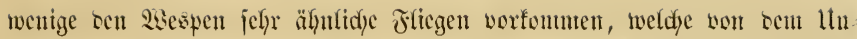
funtigen wie bieje, aber natïrlidy ofne (5runt, gejürchtet werben. Bei riejer

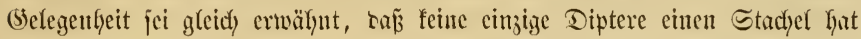
wie bie 2isespen unb Bienen - bie ify jtets an Iffer haben - Fonbern

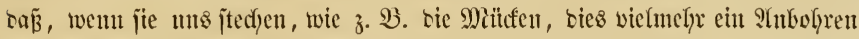
burd) einen Sangritifel tes Manbes ijt. Llebertjant fintot jidy ein edjer

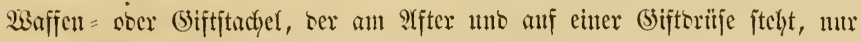
bei ந̊tymencpteren.

Die Fliegen jint Injeften nit volffommener Serwantung, jautgenton Manntheilen uno nux eituem Flïgelpaar (bem vorberen), inbem bie Unter

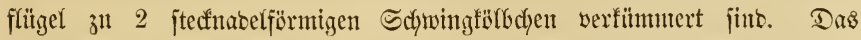
Şautläppdyen, weldyes bentlich) jidjtbar wiro, wenn mant ciner Fliege sie bei=

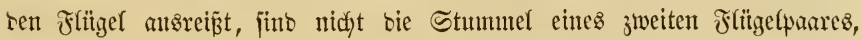

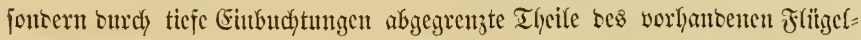

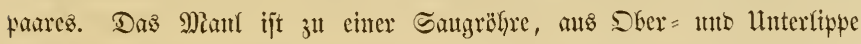
3njanmengejeţt, gebilset, innerbalb weldyer sie beiten Siejerntaare in borjten = ober mejferförmige Sted)organe mmgenantelt jint, mu bantit bie Thier = ober Prflanzentürper anjutbohren, beren Säfte bie Fliege jangen will. Die Angen finto bei ben meiften Fliegen jefyr ausgebifoet uno nefymen bei vielen ben gröp̈ten Theil bca Sopjes cin. Drei Rebenangen fint bei ben meiften vorhantoen.

Die Sarven ber Fliegen fint inmmer fuñloje, meift farbloje uno weid)

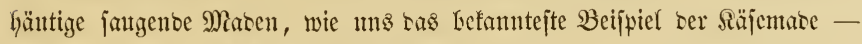
ric Sarve von scr Säjcfliege, Piophila casei L. - zcigt. Wenn wir mit biejer unb Fcinjdyneffer aud) mit ber Sarve ber wi(bpretlicbenten

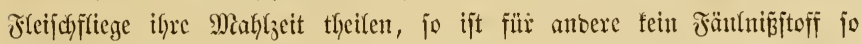

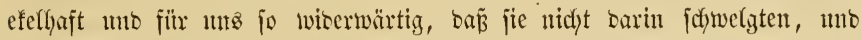
julfebt milfjen wir jelbjt ben "Seidjenwurm", ber Rarve ber Sarcophaga

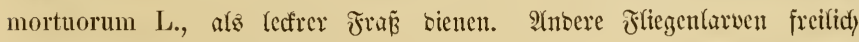

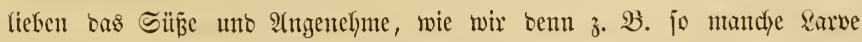

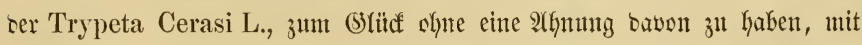

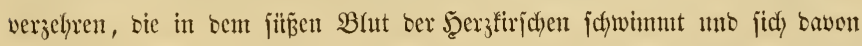

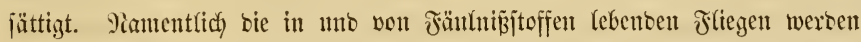

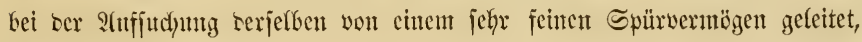

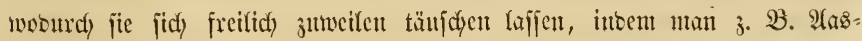




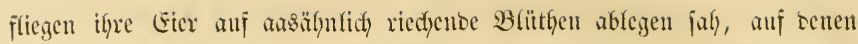

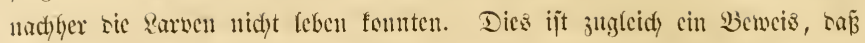
joldye fogenannte 3njtinfte sic Ifiere nidyt ju willenlojen Eflawen utad)en; tenn wenn jie bies wären, fo fünten fic nicht irren.

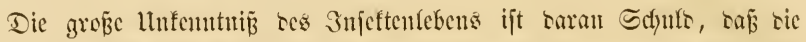

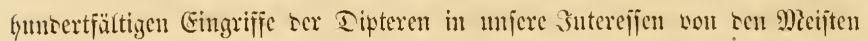

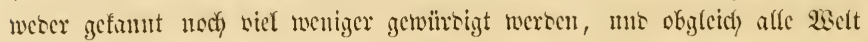

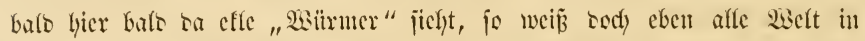

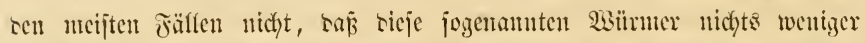

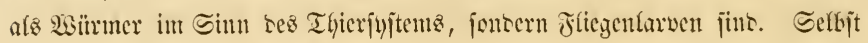

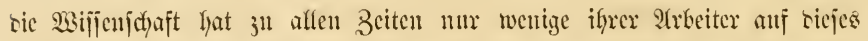

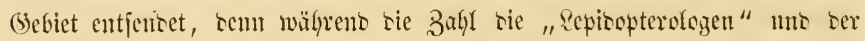

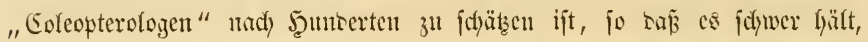

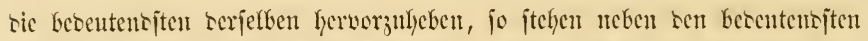

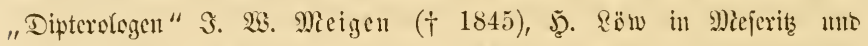

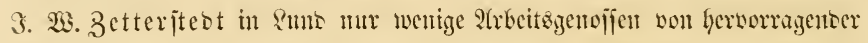

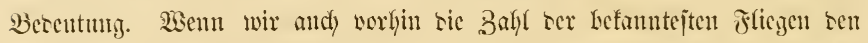

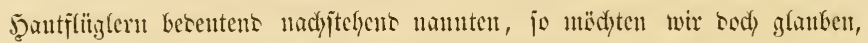

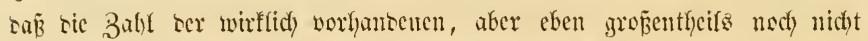

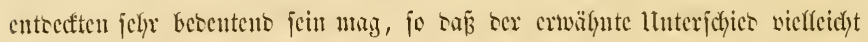

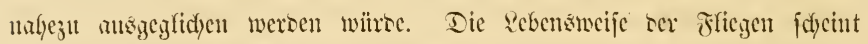

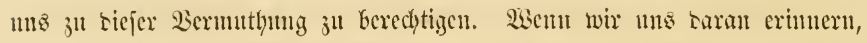
Don fo viele Dipteren äfnnlidy wie and viele ansere 3njeften mit Viafyrung แnto Wobnung ftreng anf geniffe PFlanzenarten angenicjen fint, uno weun

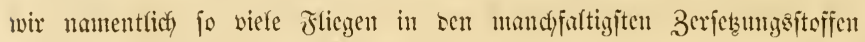
antreffen, jo sürfen wir annefyucn, ba

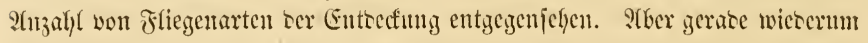

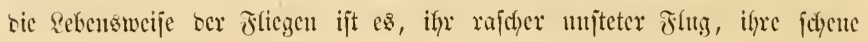

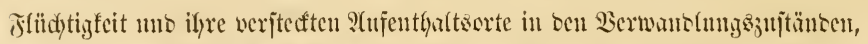
waz bic 2luffinoung uno namentfich ifre Erzichung erjoywert.

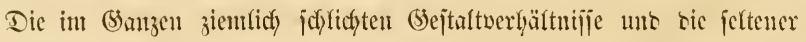

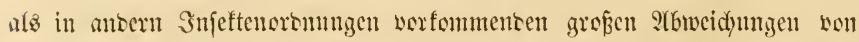

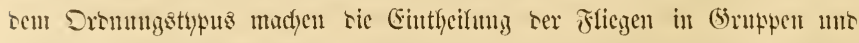

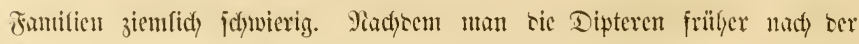

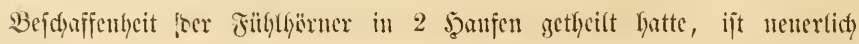




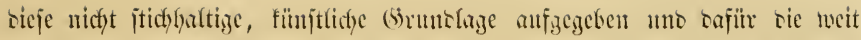

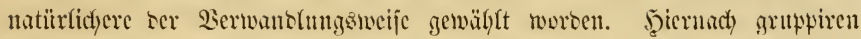
jich) bie Dipteren, abgejehen von ten beiten fleinen Bünften ter Fuppiparen

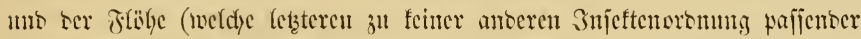

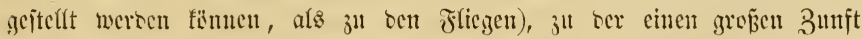

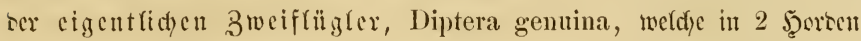

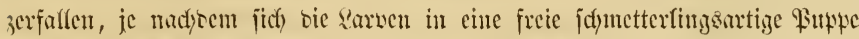

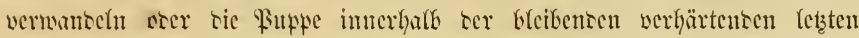

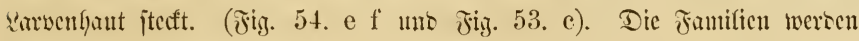

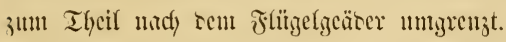

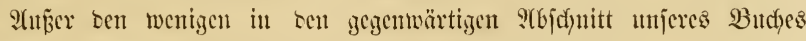

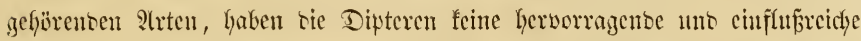

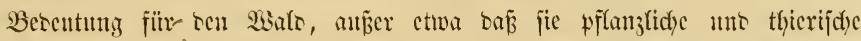

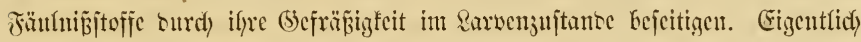

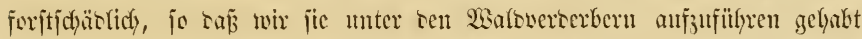

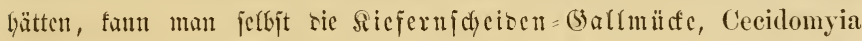
brachyntera Schwaegrichen, faum nemen, seren fleine Barbe in ten

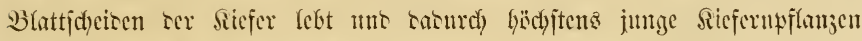
ctmos in 2indys zแrïcforingen fann.

Die eben genamten Buppiparen bitoen eine fleme, fids bumeth oen

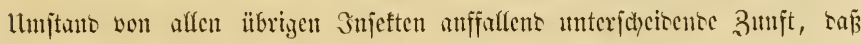
fic nidyt als Eicr geboren werten, fontern Ei= uns sarvenjultano im

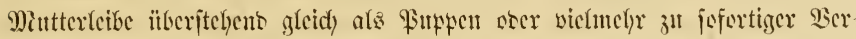
putpung reife sarven geboren werben.

\section{Dic Morbflicgc, Tachina fera (Husca) L. *)}

Die Jantilic ber cigentlichen Fliegen, Mitscarien, ift bic arten

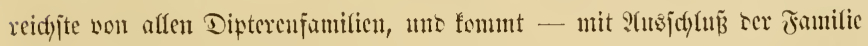

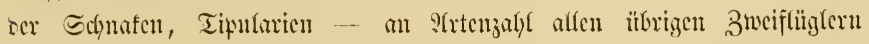

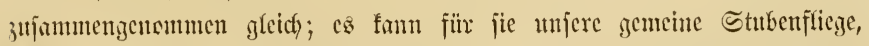
Mnsea domestica, alo (5rumbgejtalt geften. Shre Earven leben zum Theil

*) Lsie mir eв biaber jajon mchrmals gefunben huben, fo vercinigte Qinné eine

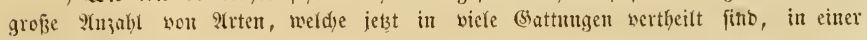
groß̉en (Gattung Nusea. 


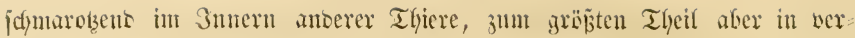

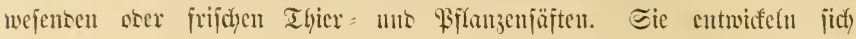

Fig. 53.

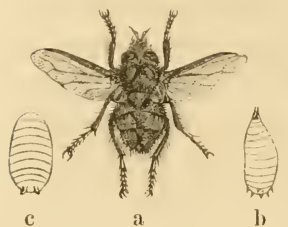

Die Morofliege,

Tachina (MI.) L.

a. Fliege, b. \&arve, c. Fintwe.

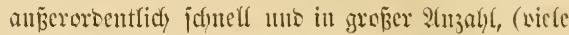
werten gleidy als fleine sarwen, weld)e meijtens id)nell madjen, getoren) uno salyer finten wir ricje cizentlich jo zu nententen ofleyen wom criften Triffjafyr bis żun Epätherbjt serbreitet. Tic \$uppen ser fliegen riejex Jamilic soer seren

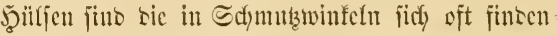
sen sunfel fajtanienbramen bis 5 Pin. langen eirunsen Sïrper, sic ser Unfunsige nicht jut senten weif. Die brame Jëlilje ijt sic pergamentartig

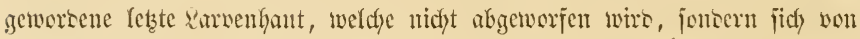

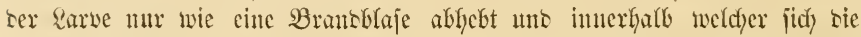

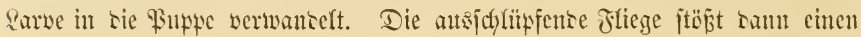

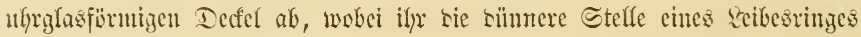
an sex alten, zur Şïlje geworbenen, sarwenfant behülffich ijt.

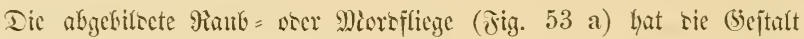

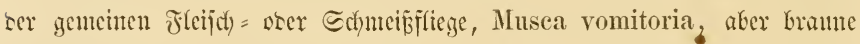
jurben. Dieje als Beipipiel abgebilcete Filiege repräjentirt cine jicmlich amjerntiche 3ahl won Echmarotzen, weldye in sen Jorjtinjeften, au häıfigiten in sen Jaltern แn blattwespen, unt zwar in seren varben

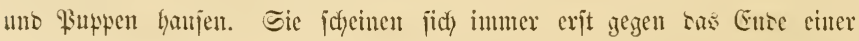
3njeftenverbeerung in Mienge einjufinoen uno fpäter a(z sic Schlupfweşpen mit ifyer Şitffe ju fonmen. Eie boflensen ifyre Eutwifflung entweser in

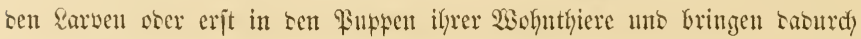
biejen ten Tob.

Die in Beziefunig auf rie Echlupfwespen befprodjene Eentyetheorie

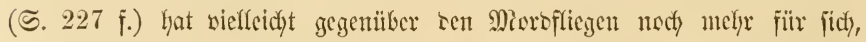

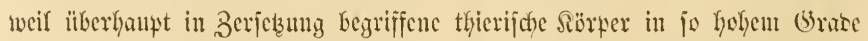

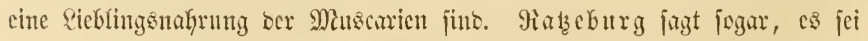

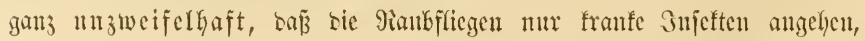

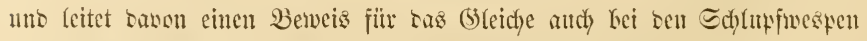

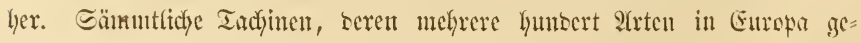
funten werten, idynturotzen in Snjeften. 


\section{Die monofledfige Sdjwebjlicge, Syrphus seleniticus Meigen.}

Dic Jiz. 54. abyebilsete Fliege gibt ¿er Janilie set Sdyebfliegen, Surphiben if)ren viamen, seren Ângeförtige in veridsie:

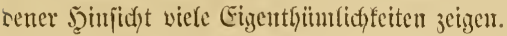
Die oft messenähntichen Jliegen jelbjt, sic man un beiß̄en Somnenjchein häuffig ım Dol:

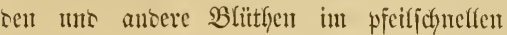
Sdywebfluge antrifft, haben meijt lebfiafte Farben mo jum Theil eme nody viel jollanfere (sicjtalt als sie abgegitsete 9 (rt, wäl)teno an= sere cine plumpere Form haben. Shre Sarven reben theils in jofnutzigent 2 ajjer, jelbjt in joflunmigen atbtrittsgruben orer it แutntigent joolz ober frei anf \$fflanzen. Die reczteren (b) Gaben meijt lebrafte Jar=

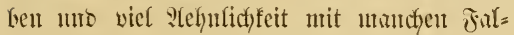
terratpen (ben jogenannten Sdjiforatpen, Lyeaena), ımธ näfyren jich von B̉attlüufen uns sen frei lebenten sarben eintzer säfer (Coccinella) uno Florfliegen (Hemerobius) mo werten susurd nüblich. Die Fuppe (e f) Imjerer 2lrt ijt eine edfte \$istppe ums fitżt mit sem jtielartig verlängerten J̨inter:

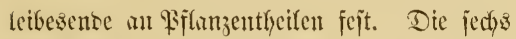

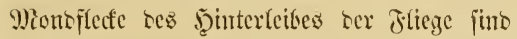

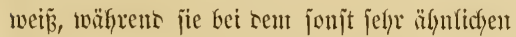
nuch) lä̈tfigern s. pyrastri L. jobuefelgerb ïur. รig. 51.

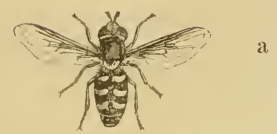

c
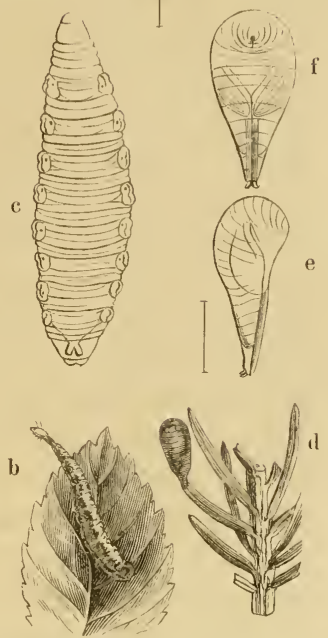

Dic montflentige Edyncofliege, Syrphus seleniticus Meig.

a. Fitiege. b. Die ansgeftrefte Sarbe, matilixl. (5r). c. Diefelbe z̆jammenzezogen, sergrëß̧ert. d. Futpe att eiter Fidytemtabel, natïrl. (s) e. f. Diefe vergr. tou ber Scite uno bon unten. 


\section{Der $2 S_{1} I_{0}=$ Snudoüfer, Cicindela silvatica $\mathbf{L}$.}

\section{Der grülle ober Fello= Sallofïfer, C. campestris $L_{\text {. }}$}

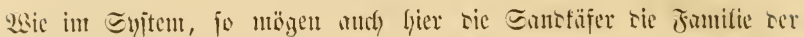

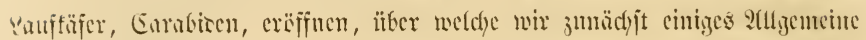

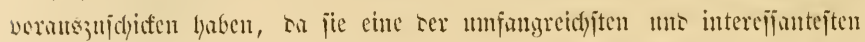
atbtheilungen ser saffer bilicen.

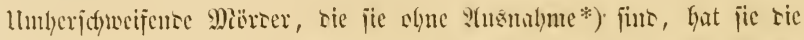

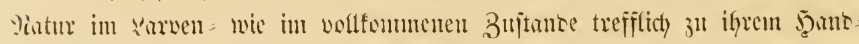

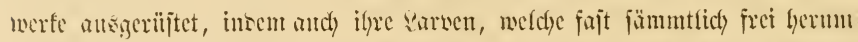

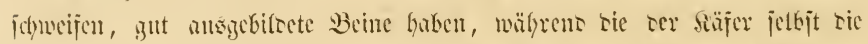

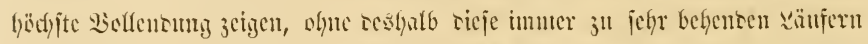

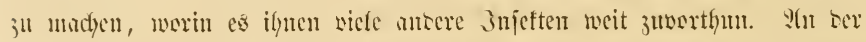

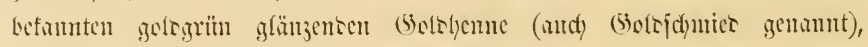
('arabus auratus L., un cinizen bermanten $\mathfrak{A}$ rten, senen wir auf affen

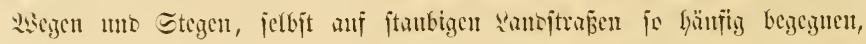

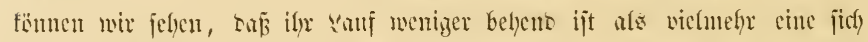

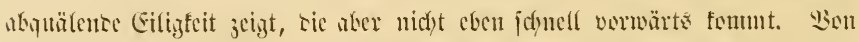

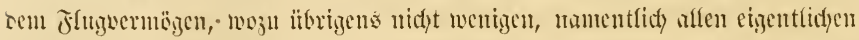

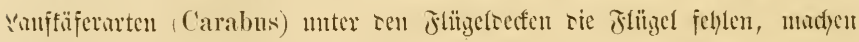

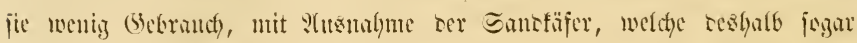
idtuer ju fangen fints.

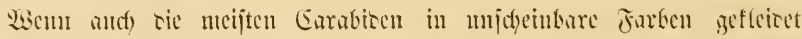

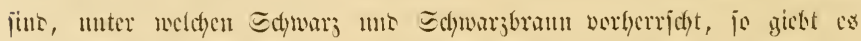

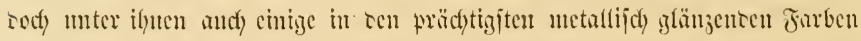

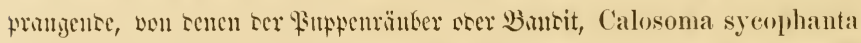

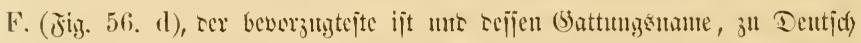
Edyänleib, jugleid) ton in ter ganjen jamilie jo jebr vorlferridyenten ele.

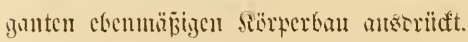

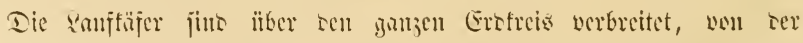

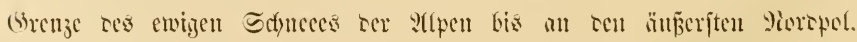

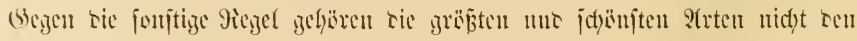

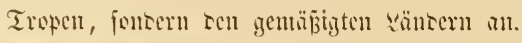

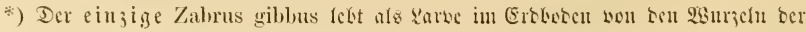
Fiflaujen, mas jeosd wielleid)t aud) anf einem Srrtbum bernht. 
Dic vauftäfer haben an affen Beinen 5 Fubglieser (jülo Psentmeren ธ. 151.), an scn llnterfiefern jescrjeitö 2 Tnjter, afjo mit sen beion

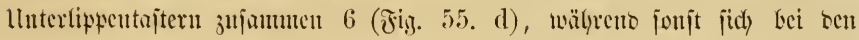

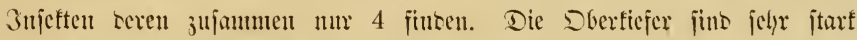

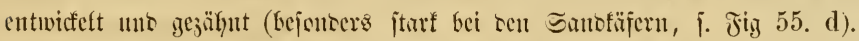

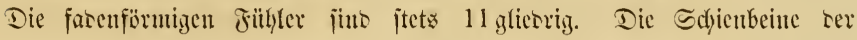

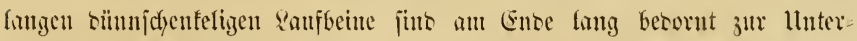

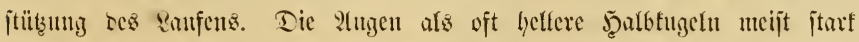

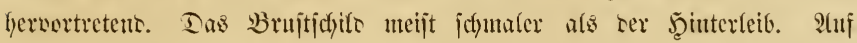

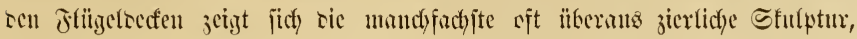

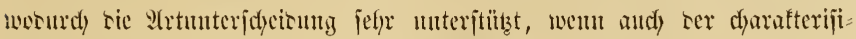

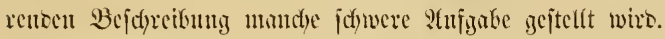

llnjweifelfajt jü sic sauffäfer sie efezantejten säfergeitalten uno plumpe foumen finm unter ifjuen vor.

Den EGarafter ser :arven veranjdantichen sie Jig. 55. e-g, 56 . b u. e

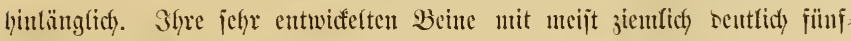

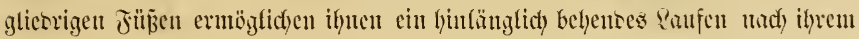

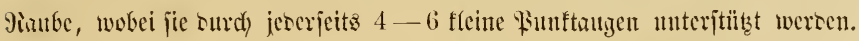

Die Yalyrung ser Rauffäfer uno ifrer sarven bejteht vorjugsiveife in

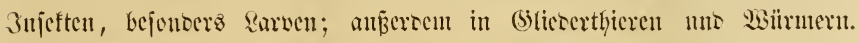

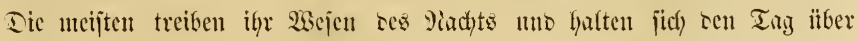

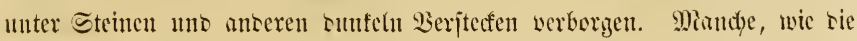
Santfäfer, jinto sayegen in helfen warmen Sonnenjchein ant febentigiten.

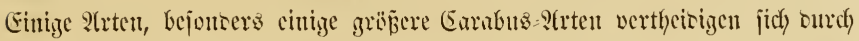

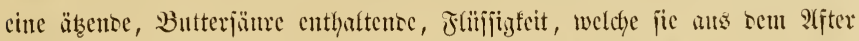
in Form eines Dunjter weit hin ju ipritzen veritehen. Der fdyönc jtuhlblaue Carabus intricatus L. hat wolyt jesen Säferjanmler idyon oftumalo

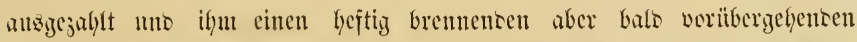
Scfmer; in (bejifft wermrjacht. Der and) Gierfger gefjöente Bumbaroirfäfer, Brachinus erepitans L., verjudyt jids nit jeinen Dunjtbonben feine 2 er folger vom reibe z"l halten.

3"t ben oben bereits angefïndigten Sanbfäfern iberigebeno fo bitren

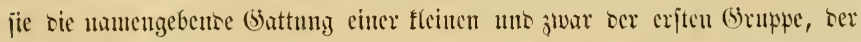
Cicintelioen, ber Juntife, won seren etwa 600 befunnten जiten die meiften in warmen säncern แno nux wenige bei uns in Dentichlanto vorfommen. 
Whas Morduft, sie tas eizene (bejd)led)t nidyt verichout, uno rufye-

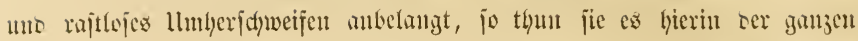

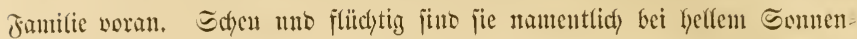

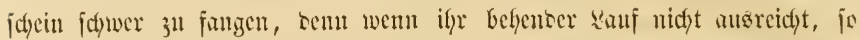

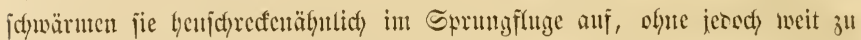
fliegen, uno balten jo ten 3njeftenjäger lange in 2tthem, bis tiejem ein glïtfictyer (5rifi gefingt.

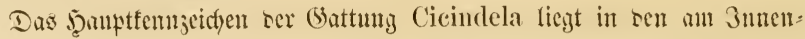

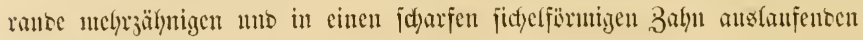

Fig. 55.

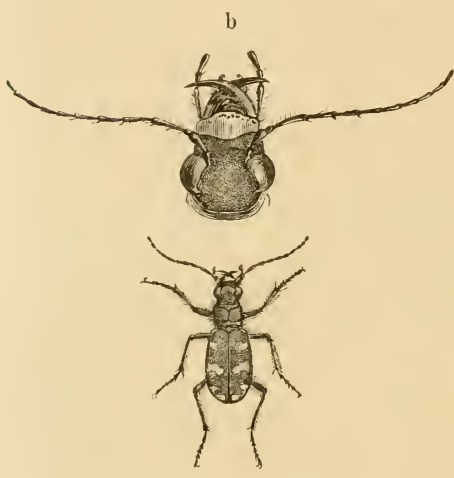

a

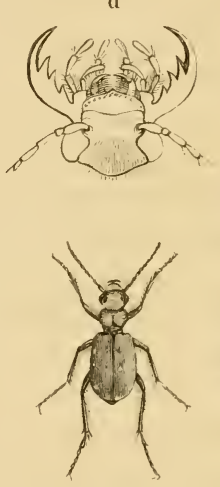

C

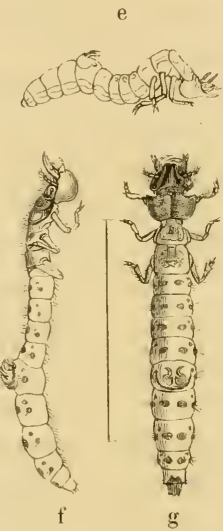

Der 23 a

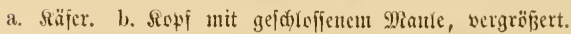

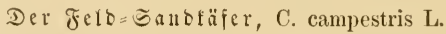

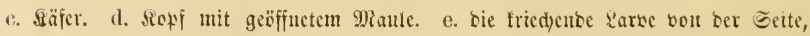
nat. Srr. f. bicjerbe etenifo, wergr. g. biefelbe vou sben, wergr.

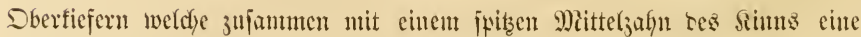

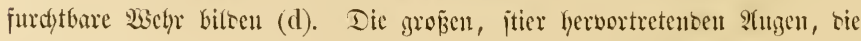
bei C. silvatica bon einem germujeten vioe fajt beidjattet fins, geben mit

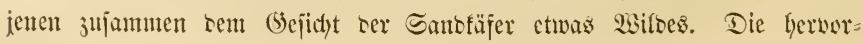




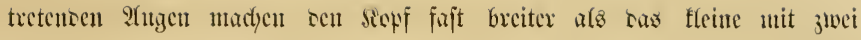

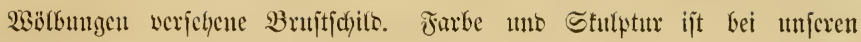

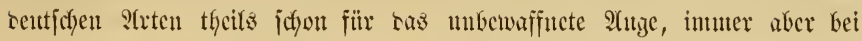

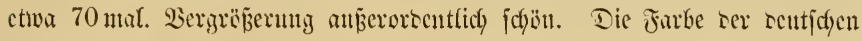

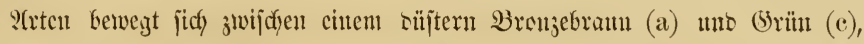

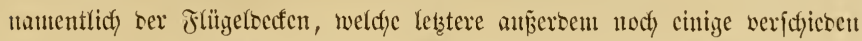

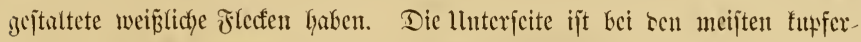

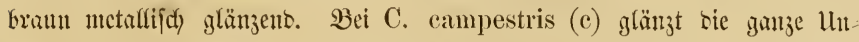
terjeite jmaragsgrïn, wäfrens bie Schenfel แn Sdyjutbeine farminrotl)

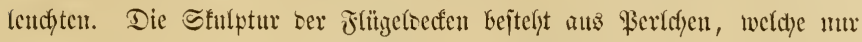

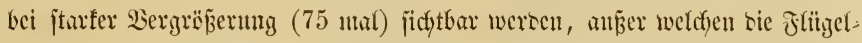

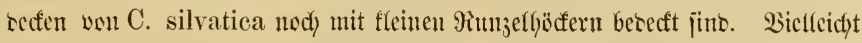

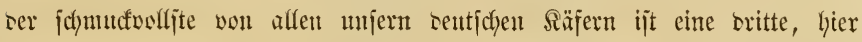
nicft mit abgebilocte $\mathfrak{Q}(2 \mathrm{t}, \mathrm{C}$. hybrida L., anf seren unjefcinbar ofivengrïnen

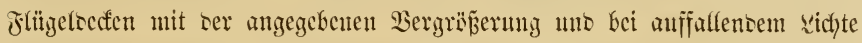

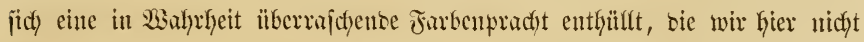
näher bejd)reiben, um unjere sejer nicht un sie Ucbertajdyung z̆ bringen.

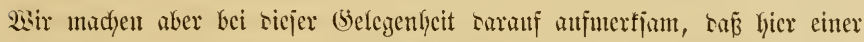

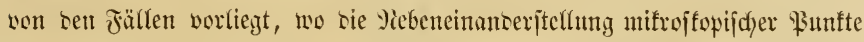
ser reinften uno briflanteften Farben ene micheinbare Mifdjarbe gicbt.

Die Barwen ter Sanbfäfer lemen wir ans Jig. e-g als abentence= lidfe (Befd)ökfe fennen, an weldyen namentlidy bas fropfartig anjejchlwollene

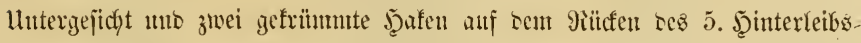
ringes anffallent. Sie graben jich jenfrechte, fcoerfieldicfe, bis 18 3oll ticfe

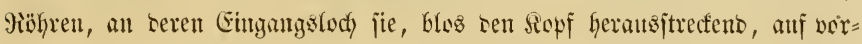
beilanfente Snjeften lauern, bie jie Ginnbjeleppen, ausjangen mo sann bie lleberrejte wieser heraustragen. Dabei wie bei scm Ban ber Mübre sicnt

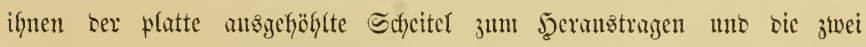

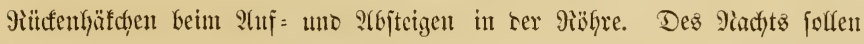

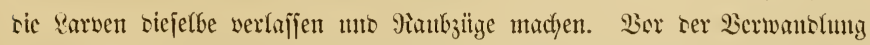

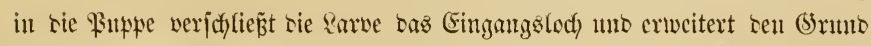
ser ŞB̈hle. Erit 1848 hat man rie \$appe fennen gelernt, weldye anf ocn

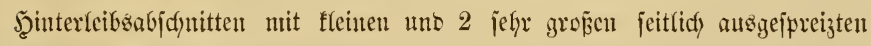
Spizen werjefyen ijt, mit senen jie walyricheinlich zur leidjteren Bejreinny

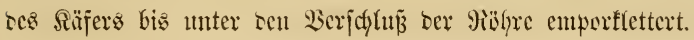


Tie immer mertuptizen Santeafer uno seren surven sertifgen, wo jie

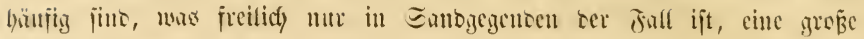
עienge 3njeften.

\section{Der Gortenlauffüfer, Carabus hortensis $\mathbf{L}$. แ110}

\section{Der geförnelte Sauffïfer, C. granulatus L.}

Dicje ser familic ren 9amen gebente (5attmiz, won meldfer mbefïlys

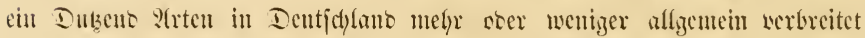

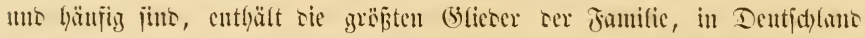

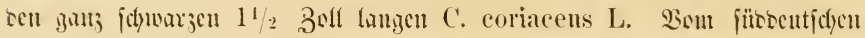

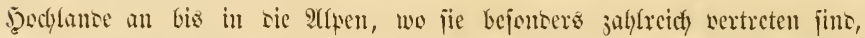

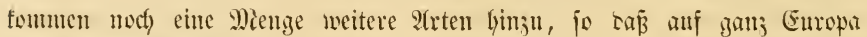
stiva 120 fommen.

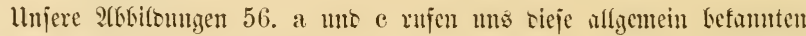

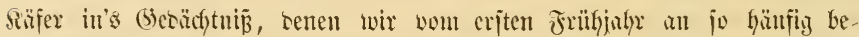

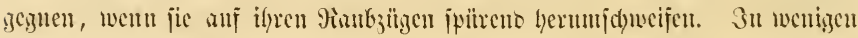

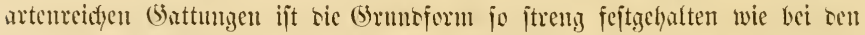

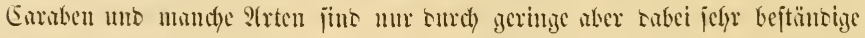

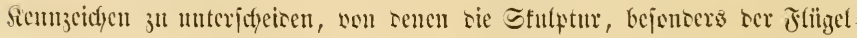

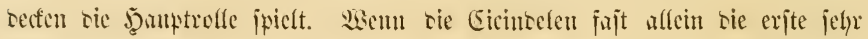
fleme brupte ser Fanilie bifocn, is fint sie Earaben mur cin fleiner Iyeil

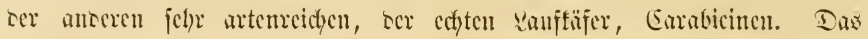

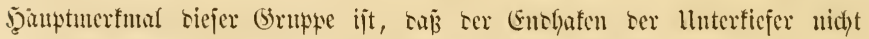
wie bei ten (Eicinselisen beneylich ijt.

Den Earaben feblen meijt bic llnterflïgel mo baun jïto and bic

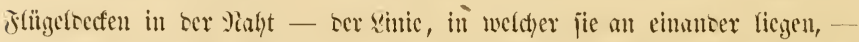

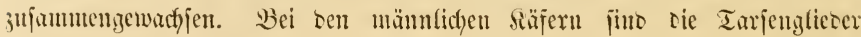
ser Lorberbeine verbreitert.

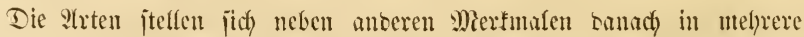

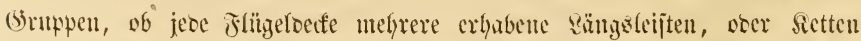

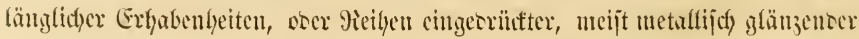
Funte orer nichts won biejen zeigt. Carabus hortensis L. zeigt has oritte, C. granulatus L. sas erjte tiejer siemnjeidyen. 


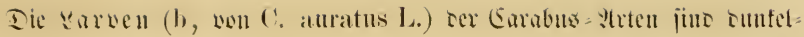

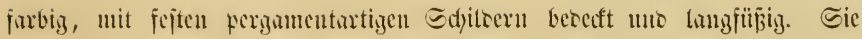

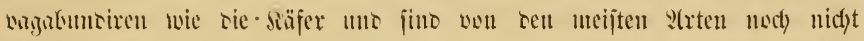

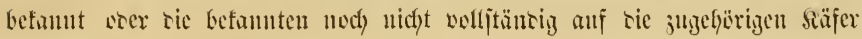
jurïifigefïlyt.

Fig. 56.

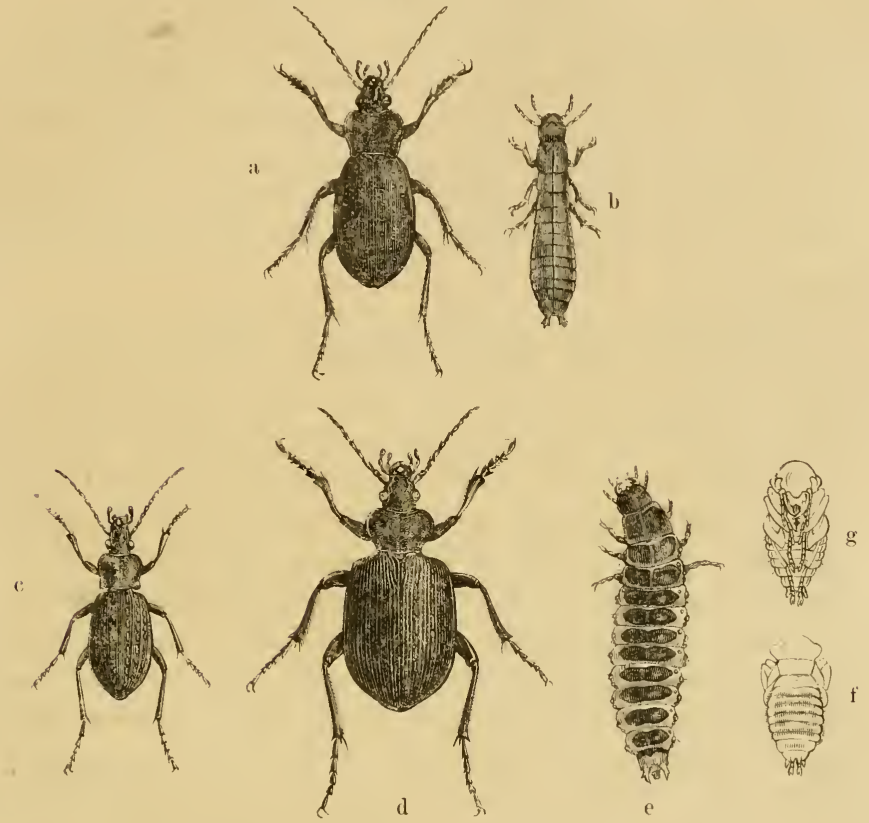

a. Der Garteulauftäfer, Carabus hortensis L.

b. Sarve ber (5olbbenue, C. auratus.

c. Der getörnelte Eauffäfer, C. granulatus L.

d. Der Miorofäfer, (alosoma Sycophanta (Car.) L.

e. Deffen tarve; f. g. Whppe won ber lluter = uno Dherjeite.

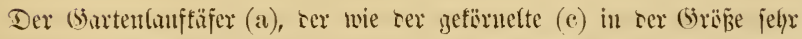
veränserfid) ijt, ijt sben bräunlidy erjfarbig mit metalfifd)en eingerrïdten

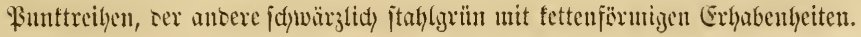




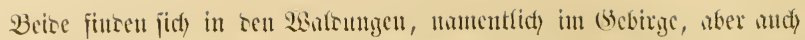

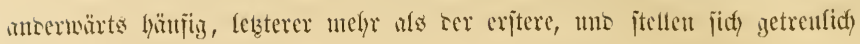
cin, wenn 3njeftenverbeernngen ilynen eine reidye Beute gewähyen.

\section{Der \&uppeurüuber, Miordföfer vocr Bandit, Calosoma sycophanta (Car.) L.}

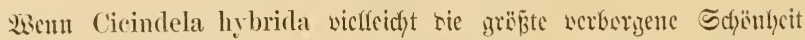

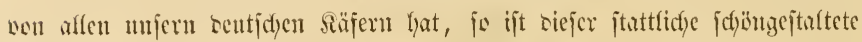

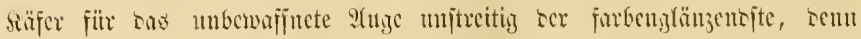

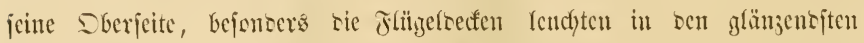

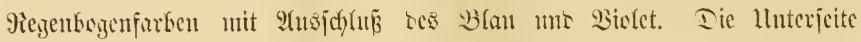
ijt fdywar; nit blan = mo jtaflgrïnen Edyinmer. Dic fräftigen Beine jitio forwary.

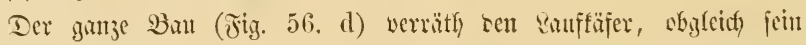

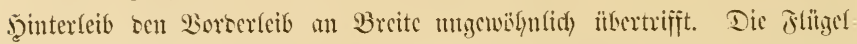

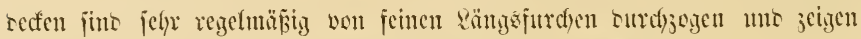

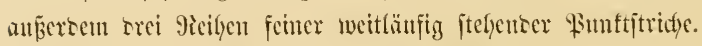

Dic sarve (e) ijt nidjt mincer fräftig gebaut mo ijt muter unjern

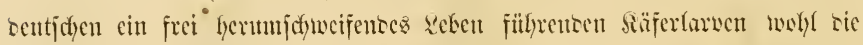

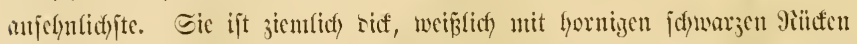

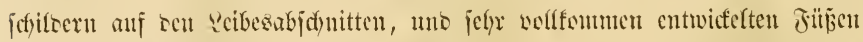

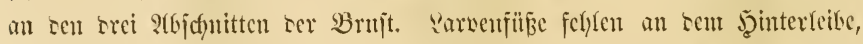

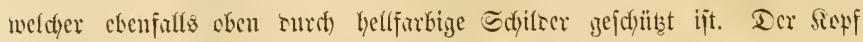
ift anffalfeno flein uno oer in llunrifie lanjettlicle seib mad) worn uno finten

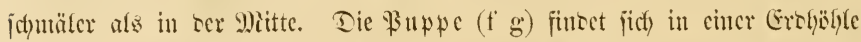

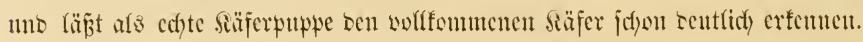

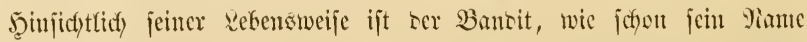

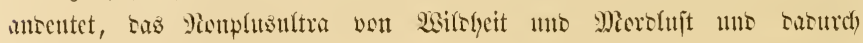

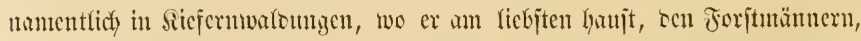

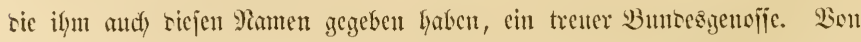

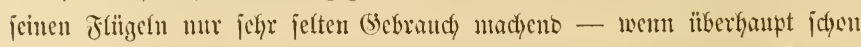
Semano ify friegen jah - Hlettert ex mit großser (5emanotheit bie Sicjern

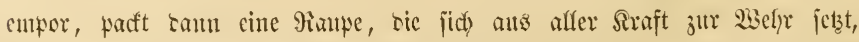

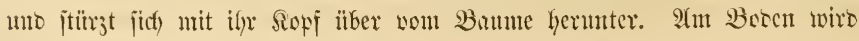


sie Bafgerei fortzejetzt wns enolicty bie überwuntene 9iaupe in Brei zerfant unto wenigitenz theifweife gefrefien. Man hat beobad)tet, baj ein Bansit

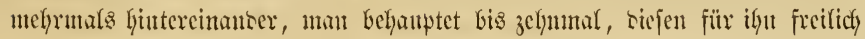
in jeinem fejten \$anjer ungefälyrfiçen Miöroerfuftiprnng wieserfyolte. Gelbjt

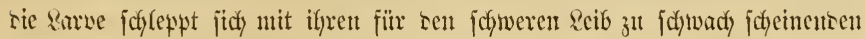
Beinten auf bie Bäune uno madyt renjelben Salto mortale mit ifyer Bente, sic jie jesed nicht jerfanen, jontern un anşăgen famm.

In Siefermrevieren finbet man sen Bansiten wenigjtens einjefn inmer,

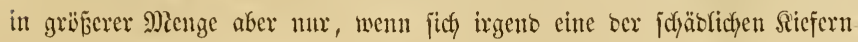
zampen in Mienge cingefunoen hat.

Eine anbere nur $7-8^{\prime \prime}$ lange $\mathfrak{2}$ rt, C. inquisitor, lebt in Eidfenwältorn

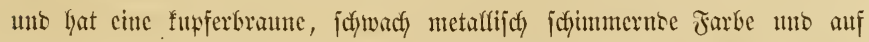

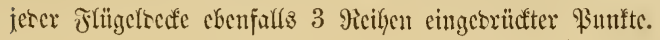

\section{Der rothjoctige Raubfäfer, Staphylinus erythropterus $\mathbf{L}$.}

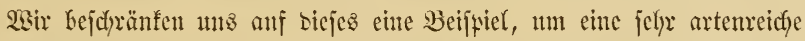
unc interefijante gantilie ber pentamerifdyen Säfer worzufïfyen, weldye wegen

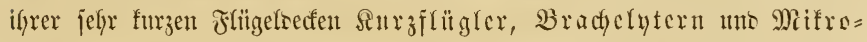
pteren, ooer uach ben widytigften (Senns and Staphylinion genannt werben. Man erfennt jie Ycicht an ber johlanfen fdjunalen (Sejtalt (Jig. 57. a)

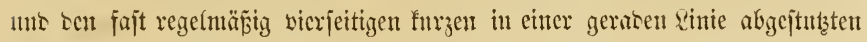
Flïgelsecfen, welche ben gröp̈ten Theil bes mit $6-7$ jreien hornizen Duerjojienen bebecten jeinterteibes unberectt laffen uno unter benen

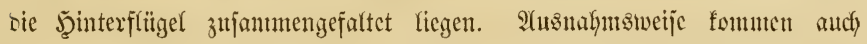
(5attungen mit 4 mo jelbjt mit 3 Fufigfiebern wor. Fïhler $11=$, jelten

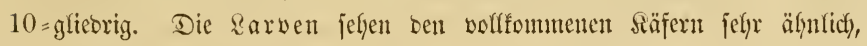
mur feylen iftuen natïrlidy bic Flügcl.

Die fajt in affen ifyen 2 reten, beren man bereitz mely als 2000 fennt, iefyr inbereinftimmeno gebanten Staphylimiden werten oft für Ohrwiinmer gehalten (†. S. 49. Fig. 1) uno jtehen biejen in ber aflyemeinen (5ejtalt

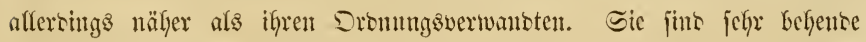
Thiere, in Dentidylans meijt noch viel ffeiner abs bie abgebifoete ?rt, meijt won sïftern unjdycinbaren Farben, mo tragen, namentfich wem man jie beumrulfigt, ben ફ̧interleib oft emporgefrïumt. 


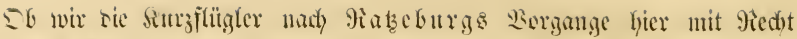
unter ben Bejdyüzeru ses 2 sultes auffïlfyen ijt unjicher, senn in ser

sig. 57.

a
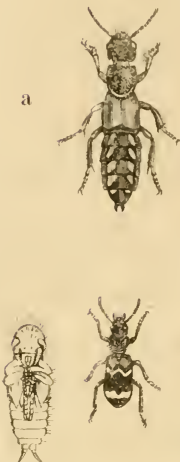

d

b

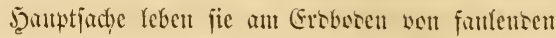
Stofifen tut vicle jogar int frifhen 9)iijt ser Hinser. Einize gefören fognu ju sen 2meijen

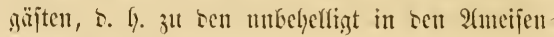
haufen lebenten 3rjeften.

2(tร bejonsers benterfentwert) verbient her. vorgeboben z" werten, baß̈ cinzelue (3attungen zlt ธen jefyr wenigen siafern gelyären, weldye

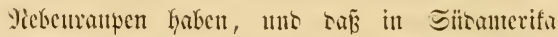
einigye lebensig getörente 2 trten entrefft worten jittr.

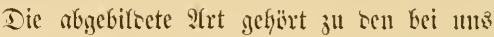
in sen Sarteungen, aber and antermärtio an fäufigyten vorfoumenten Surzflüglern. Dic (5)runsfarbe ijt branurotly, namentlidy anj sen

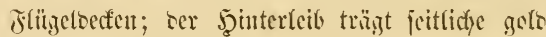
glämjente Fitzflectchen.

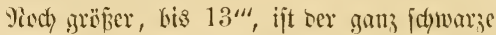
formicarius (Attelabus) L.

b. säfer. c. Garve. d. Punpe. (c. IIIt d, vergr.)

\section{Der nmcijenälyulidłc Buntfäjer, Clerus formicarius $\mathbf{L}$.}

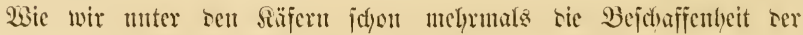
Jühler als jhitematipden befelf femen gelernt haben, fo begegnen wir

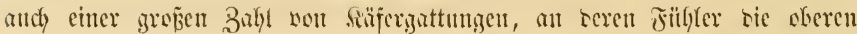

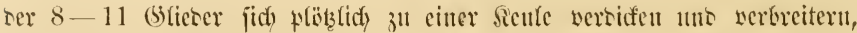

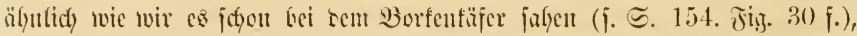

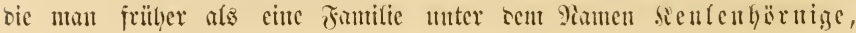

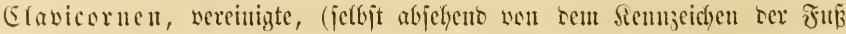
glieberjalyl, weldyes wir als sberjtes albtheilungsnterfunt oer siäfer ange

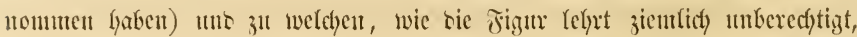
rie Buntfäfer andy jetzt nody von Miandyen geredfuet wertent. Sn ber neten

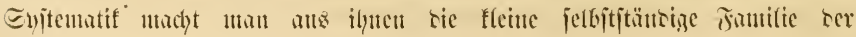




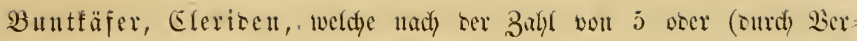
fümmerung ธes fünften) von 4 Juşgfiebern in 2 (Sruppen getheift wirt.

Die Elerisen haben im sfflgemeinen sie Geptalt ser abgebilseten aft

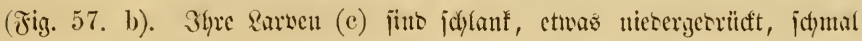
mit gornigem Soff un hornigen Platten auf sen vorteren 9imzen. Man

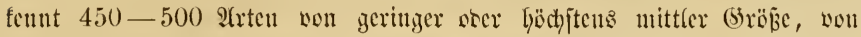
tenen sie Michnagl anf sie Tropenzone foumt. Sie leben meijt auf Bämmen, bie Sarven ser Stufften verfolgeno, worjïglich unter ber limse.

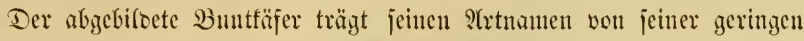

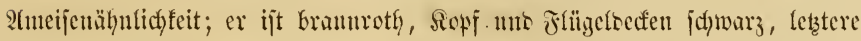

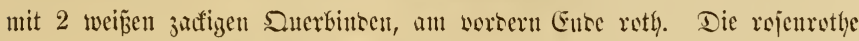

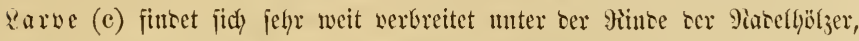

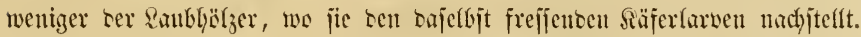

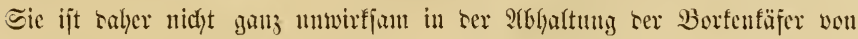
$3^{11}$ grofier Bermelyrung, obgleidy jie nidft im Stanse ift, einer tennody

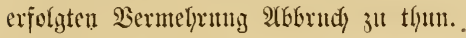

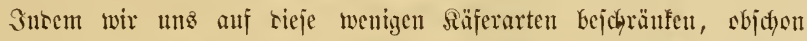

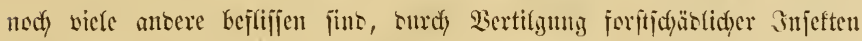

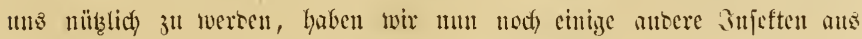

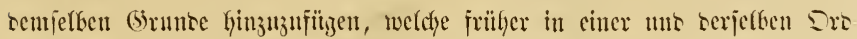

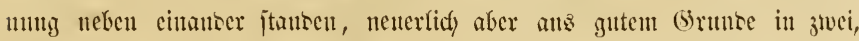

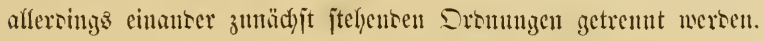

\section{Dic gemeine Frlorfliege ober ons Pierlfaft, Chrysopa perla (Ilemerobius) L.}

Die Dromung ber Metzffügler, Menropteren, in welder biejes uno bas folgente Injeft beijammenjtanten, wutre eben burdy sicje 3 ser

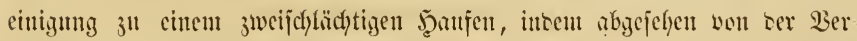

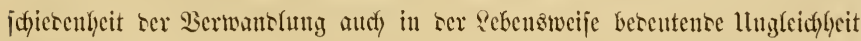
obrwaltete.

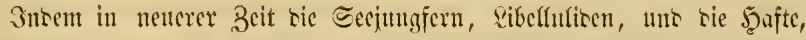

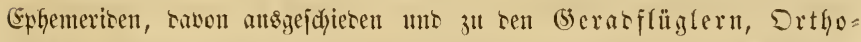

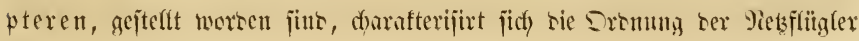




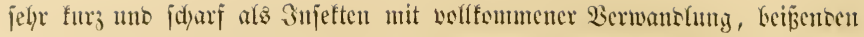

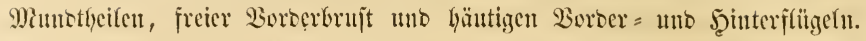

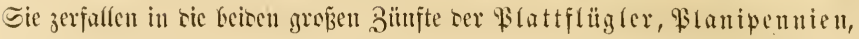
Ino Pelzflïgler, Iridyopteren, mit ser oritten Eleinen Bunft ser Füderffügler, Etrepfipteren.

Fig. 58.

a
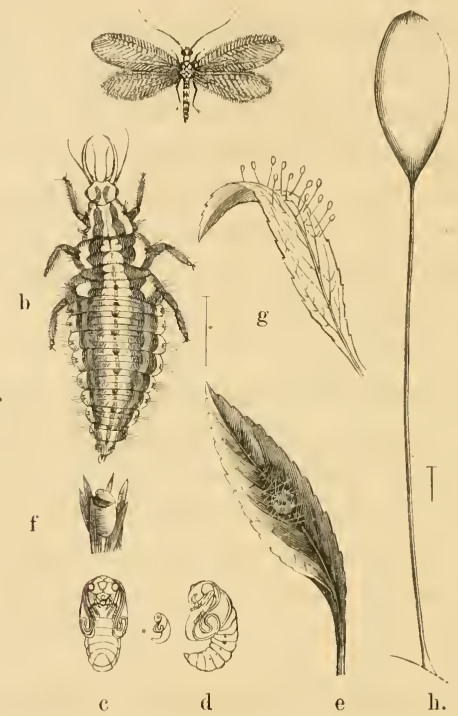

h.

Die gemeine frorfriege, Chrysopa perla (Hemer.) L.

a. Fliege. b. Earve. c. d. Fupte, lluter = n. Seitenanjidyt. e. Das uod gefdrlojiene Scipiunt auf cinem Blatte. f. Das geöfnete Beipiunft zwijden Fidjtennabelu.

g. Die gefticlten Eier anf eittem 23latte. h. Einzeltes Ei.

(Fig. b. c. d. h. melyr sber wentiger ftart wergr.)

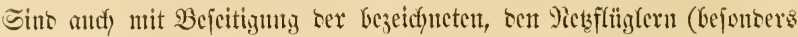
wegen ber mangehtoen Derwandumg) frembartigen Elemente sieje zu eincr

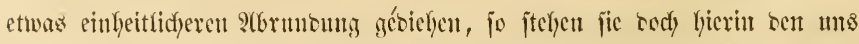

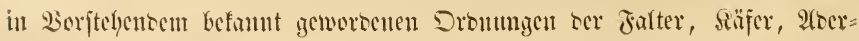




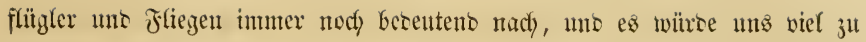

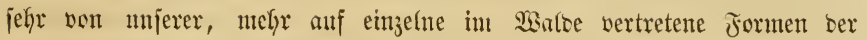
niesern Thierwelt bejchränften Betrachtming ablenfen, wollten wir jebzt

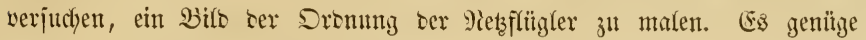

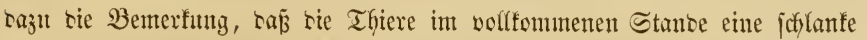

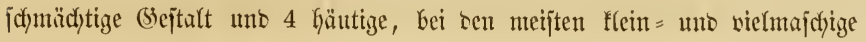
Flïgel haben, won benen bie finteren bei sen \$elzflïglern anters gejtaltet uno ber Sänge nach zแjammengefaltet wersen fönnen. Die Belzflügler

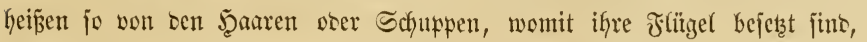
obgleich) bei ben \$lattflïglem bas (Beäber meijt ebenfalfz nit furzen jteifen

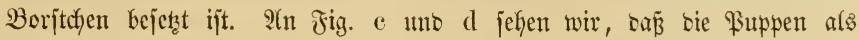

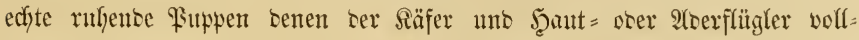
fommen glecthen, aber vor tiejen- bas voraus haben, tap fie vor tem

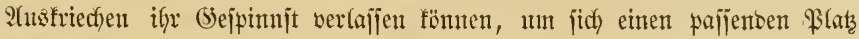
jux Entpuppung zu jucten.

Sn ber angenommenen Umgrenzung bilsen bie Peţfflügler mit faum

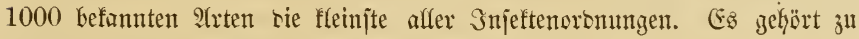

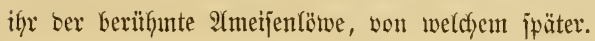

Die abgebitote gemeine Florfliege (Fig. 58. a) erjocint jefr oft

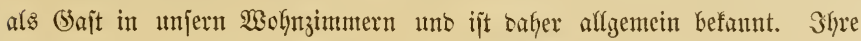
Farbe ift entweber hell apfelgrïn soer grïnlidbgelb, weldfe Farbe an ben

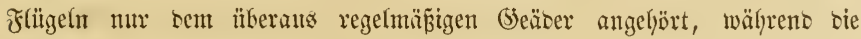
Flïgelfaut jelbit farblos uno glashell surdjifititig ift. Die atugen treten als grüngoldige 5̧albtugedn an Sopfe herwor unb haben ber (Sattung ben Namen (Chrysopa = (5olbange) gegeben, won weldyer gegen 18 strten befaunt fint. Die Rarve (b) ähnelt bem Ameifentöwen uno hat am Siopfe zwei Sangzangen, sic Dberfiefer, mit benen jie ifren Raub burchfneipt uno zugleidy ausfaught, ba fie an ber Spitze ein södfeldfen baben uno hoht jint. Bejonters merfwürbig fint sie Eier ser florfliegen, weldye nit langen Stielen auf $\mathfrak{B}$ lättern gruppenweije auffitzen uno jogar für Blattpilze gef̧alten morten jimo (als Ascophora ovalis).

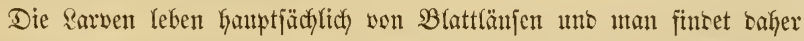
bie jonberbaren Eier meijt anf $B$ lättern mo anbern von Blattlüujen be= völferten Bflanjentfeilen. Der baburch bent 2 aloe gejdaffene Jiutzen ijt aber jebenfalls nur jehr gering anjulfdlagen. 
Binné ftellte bie Chrufopen nody ju feiner Gattung Hemerobins,

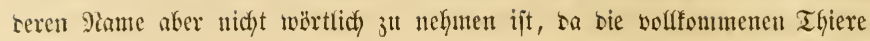
länger als einen Tag leben.

\section{Die gemcime \$ilattbaudflibelle, Libellula depressa $\mathbf{L}$.}

23ir haben eben erfahren, sap̃ bie artemeidye Bruppe ber sibellen

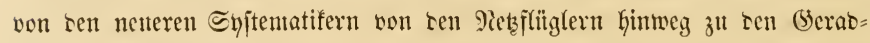

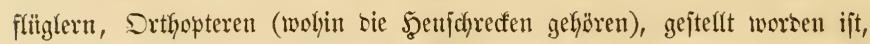
wo fie als bie Familie rer \&ibelfulinen mit einigen anteren bie Zunft ser amphibijdyen (serabflügler bilsen, weil sieje Snjeften jünmtlich als Sarven uno \$uppen im Sajjer leben.

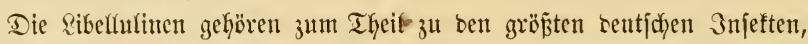
tenn bie in Dentjdyland jefyr verbreitete Aeshna grandis hat einen an 3 Zoll langen Reib uns ebenjo weite Flïgelipannung. Der Fltig ier meipten ift fräftig uno fajt ungeitüm uno bei einigen wegen ser Etartheit ber

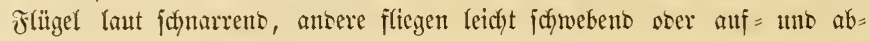
tanmelno. Biele fino bejonters an Barmit uno Şinterfeib mit Kebhaften Farken geziert, unter weldgen fimmelblau, grïn uno gelb workerrichen; bie gemeine Secjungfer Calopteryx virgo (Libell.) L. ijt ganz uno gar jtahlblat gefärbt.

2(n sem futrzen uno fräftigen fajt quarratijchen Mittelleibe fitzt ser

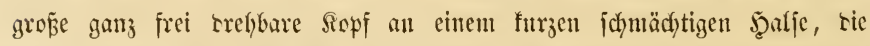

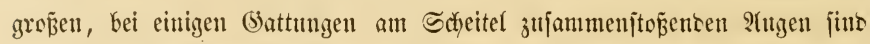

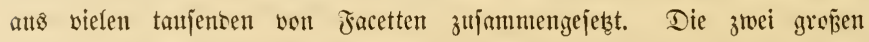

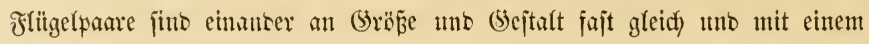

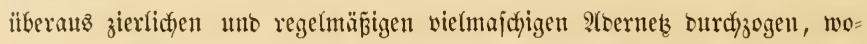

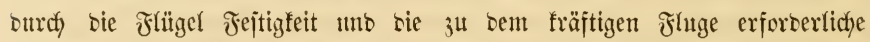
Spannung erhalten. Der Şinterleib ift lang uno bei sen meiften unver=

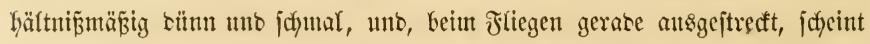

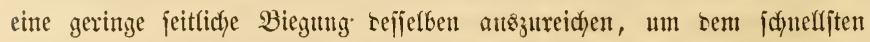
Fluge plöbzfich eine antere Ridytung zu geben.

Die Serwandtung ber Ribelfulinen ijt eine unvolffommene. Die Rarven unb Puppen, jofern man zwijdyen siejen nody einen Unterjfyieb madhen will,

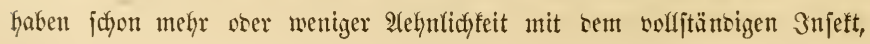


nur baß ben eríteren bie Flügel ganz feblen, bei ben letzteren nux als

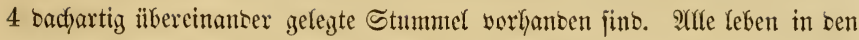

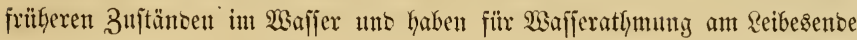

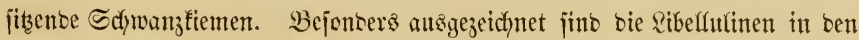
friifheren Stänten burdy eine jonberbare Ungeitaltung ser Unterlippe, weldye sem träg am Boben ter (Bewäffer friectenten Thier beim Fange jeines Raubes jehr bienfich ijt. Der untere jifmale Theil ber Intertippe, weldyer getentig an Maute angejüigt ijt, ijt junächjt abwärts gegen bie 2 rujt ge=

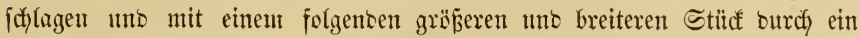
Eharniergelenf berbutten. Diejes zweite grofe Stüf ijt vorn mit 2 als

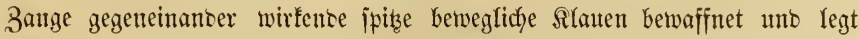

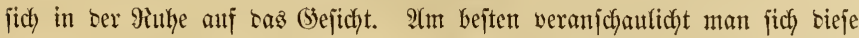
jonterbare "Fangmabfe", intem man folgenten Sergleidy madyt. Denfent wir uns einen unferer 2 trme anjtatt an ber Sdyutter an bem ந̧alje einge= Yenft, wir legen sann ben Dberarm abwärts an bie Bruft, biegen im Elbogengelent ben linterarm aufwärts uno legen bie Şano auf bas Bejiçt. Die Finger entfprechen bann ben beiben Rlauen ber Fangmasfe. Wie wir

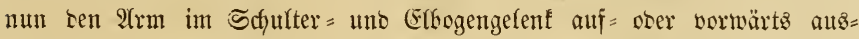
jtrecten uno jo etwas ergreifen fönnten, was 4 m bie Ränge unjeres 2 (rmes von unjerem Matnbe entfernt ift, unb an ben Munt heranbringen burd) ben wieber in bie vorige Stelfung zurïffebrod)enen $2(r m$, fo madft $e$ s auth bie ribeffenlarve, intem jie bie in ber Muthe aufeinanber liegenten Theile

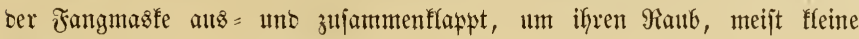
Waflerinjetten, zแ ergreifen.

Unjere Figuren e d e zeigen uns bieje Fangmasfe von verjujebenen

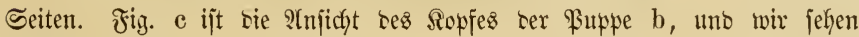
Daran sie Fangmasfe in ber 9luffe won ber Seite; Fig. d zeigt fie von unten uno e jtefft ten Sopf mit ausgeflappter Fangmasfe bar, an welcher wir worn bie beisen jichelförmigen jehr jpitzen Rlauen jefyen. Itnmittefbar ïber biejen liegt bei ber Mithelage ser Fangmabfe bas Mianl.

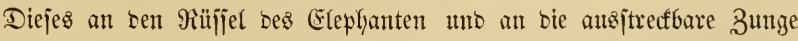

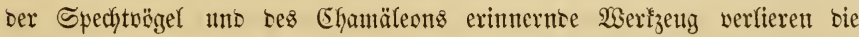
sibeffutinen mit ber abjtreifung ber \$suppenlyant. Die Entpuppung gejdjefyt anßer ben Waffer. Die ßuppe triedyt an einem Mohritengel ofer einer anbern paffenten Uferpflanze über ben Wajjerjpieger hinaus, umflammert 


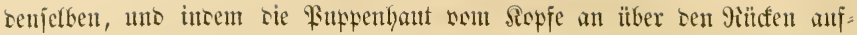

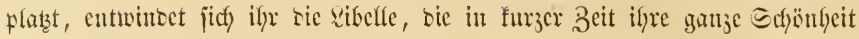

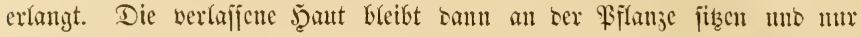
bei genauerer lluterjutdung bemerft man, baj man fein lebentiges 3njeft,

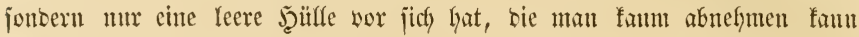
ofne jie zu zerbriaten.

Fig. 59.

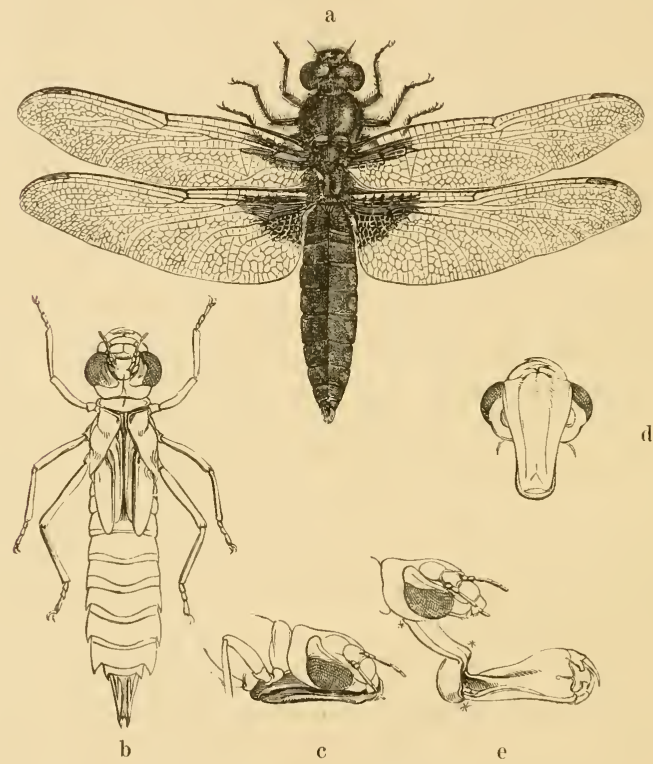

Die Flattbaud)liberle, Libellula depressa L. (a)

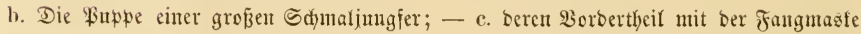
in ber Mithelage; - d. Der Sinff ebenfo von inten; - e. berferbe mit auzgeflappter

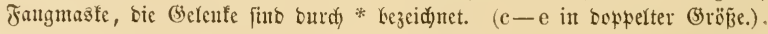

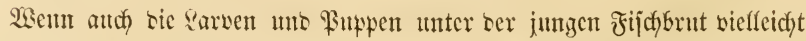

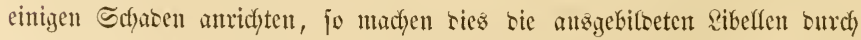
Bertilgum vieler 3njeften bod, wahrjdyeinlidy wieber gut, benn jie gebören 3u Den räuberifdyjten Thieren. 


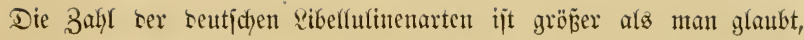
weil man jie jelten rubig jizen jicht uno sie Unterjicheioungsmerfntale nur bei wenigen in fluge ins 2uge falfen. Son ben etwa 100 emropäifdjen

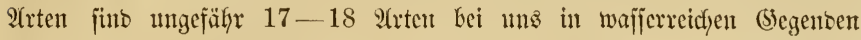
überall gemein. Einige 2 (rten, namentlich) bie abgebitbete $\mathfrak{A} r t$, fint wie bie Wanberheujdyrecfen jayon mefymals in ungehemen Bügen beobachtet worben. Bon etwa 40 joldyen Beobadytungen Geridytet ந̧agen in ber "Stettin. naturto. Zeit." ïber eimen, Len er in Smn 1852 in Stettin fah, ber von รer am Gäıfigiten wanternoen L. quadrimaculata L. auşgefüffyrt wurbe. Win entleynen bavon Folgenbes:

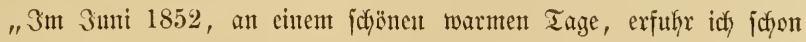

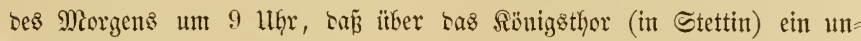

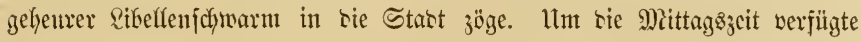
idi) mich bafin mo jah nody inmerfort sifelfen in bichtgebräugten Mafjen in sie Start jiehen. Sic geförten 孔ll ber 2(rt, von ber an häufigiten 3ä̈ge vermerft jint, (uämlich von 40 beobacfteten bie ફ̧älfte) zu Libellula quadrimaculata L. Um bas intereffante Schanjpiel genatter ju betradyten, ging idy zum Thore finatts uno fonnte hier auf eincm freten Blatese ben Bug genau beobactente. Denft mau jich non ber b̧übe bes Thores aus nach Dewan (etwa 1/4 Meile) Gin, senn bort nafym, wie idh ipäter entbectte,

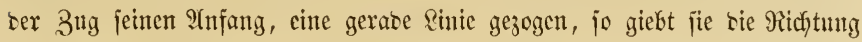

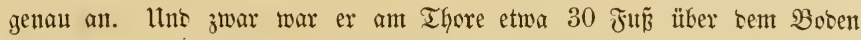
erfyaben, sa sie Srone ses bort befindtityen Warfes ben 3itg zum Theil

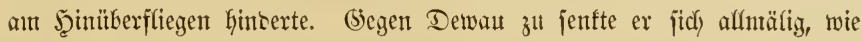
man an nahe ftehenten Bäumen fđjätzen fonnte, Into wo er bei Dewau

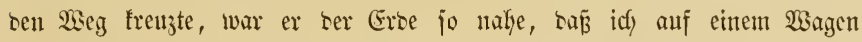

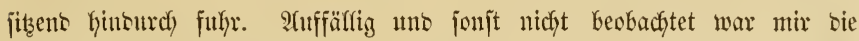

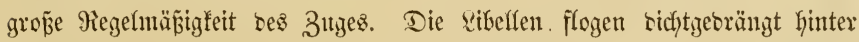

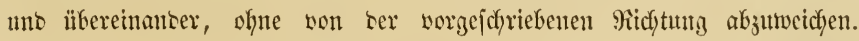

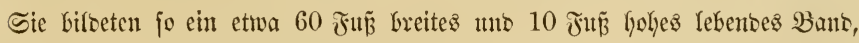
bas jidy un fo sentficfer marfinte, als redjts uno linfs sawon bie suft rein, won Snjeften leer erfdjien. Die Sdynefligfeit ses 3uges war ungefähr bie

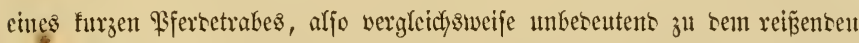
Fluge, ser jonjt biejen Thieren eigenthümlid' ift. Bei näherer Betradjtung

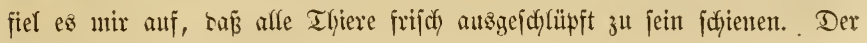


cigenthÿ̈mlidye (5lanz ber Flïgel bei Ribelfen, bie nody nicht lange bie

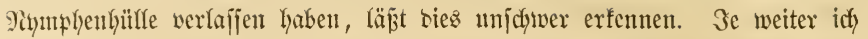
bem Zuge entgegenfuthr, je jünger waren offenbar sie Thiere, bis idy nady Dewan fam uno in bent bortigen Teidje bie Duefle bes 3uges entoefte.

Die Färbung ter Thiere uns bie Confiftenz ifyer Flïgel betwies, ba jie nur an jerben Miorgen ifye Serwandung ïberjtanten haben fonnten.

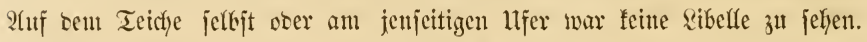

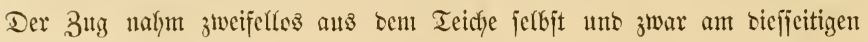
ufer jeinen Lliprung, unb bejtunto aus Thieren, bie nidyt länger ber=

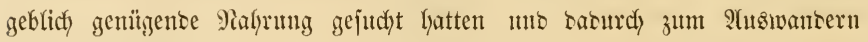
gezivungen waren.

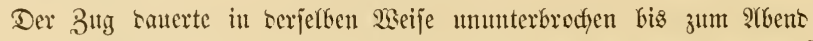
fort; eine Sdjützum ber 3 ahyl ber Thiere mag idy mir nidjt erlauben. Merfwuitrig gentig ̈̈bernadytete ein Theil berjelben, oa bie Thiere mit Sonnenuntergang 3n fliegen auffören, in ren sem Thore zumächjt gelegenen

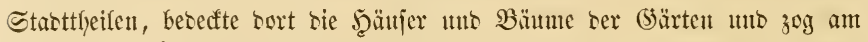
folgenten Miorgen in felber Midftung weiter. Tuf cine Shlufrage, bie idy

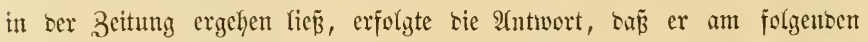

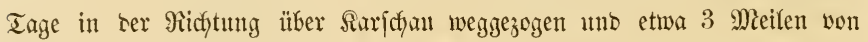
Rönigsberg gejeben worben jei. Sein weiterer Berbleib ijt mir nidft be= fannt getworben.

Şarten wir die beobadytete Thatfache 3njammen, fo liegt hier m. zweifellaft ber inftinftartige Trieb ciner Drtsueränberung bor, ba bie Thiere gegen ifyre (5etwofnfheit, uno bewor an igher Beburtsitätte Mangel an Pialyrung ifnen fütylbar gemejen fein founte, in geregeltent Zuge, gleidffalla jehr gegen

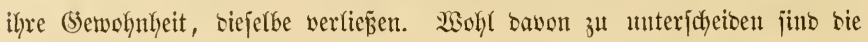
ungehenren Sdywärme bon sibelfen, bie wir in mantyen Sabren an ten

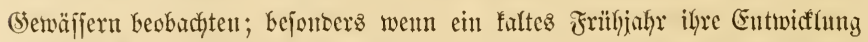
verzögert hat uno einize warme Iage plötzlid) bie verippätete Entwiffung zit Wege bringen.

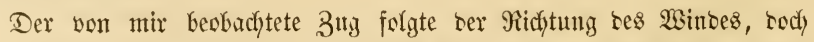

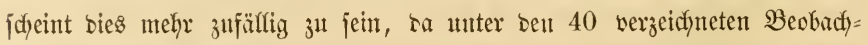
tungen ein groß̧er Theil nidyt bie herrichente Winbrictutung einfieft. Die

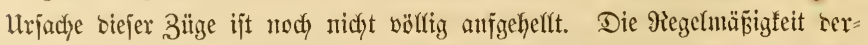
jelben, bie bem Raturell jener raftlos umberjdyweifenten Thiere wiberipridyt, 
beoingt alfersings einen bejtimmten 3 wed. Da bie Sibellen jich als fräftige

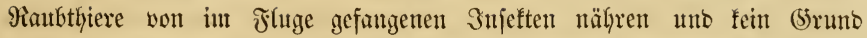

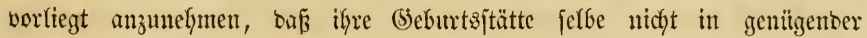
Mentge liefern fönne, zunal ba iljr Reben im längiten Falle mur wenige

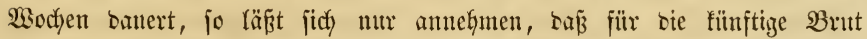

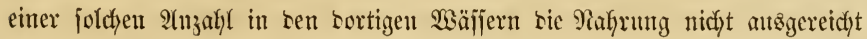

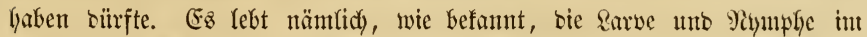

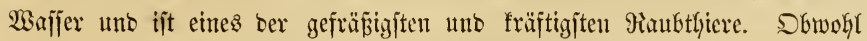
mun sie Teiche un Dewan Len Sommer nicht attstrodfnen, mögen jie boch einer joldyen Ueberfïllung von frefienben (5äjten nicht genügen fönnen. Wie ichon erwähnt ijt etra bie ફ̧älfte ber beobadjteten Züge (gegen 20) von L. quadrimaculata ausigefïfyrt, 3 mal von L. depressa uno eiumal

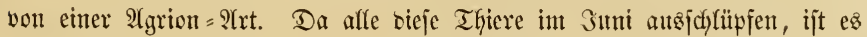
natïnlich, ธå̉ bie Züge jtetż in siejem Monate jtattgefunoen haben. L.

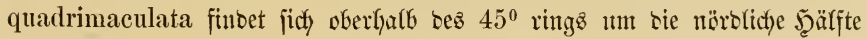

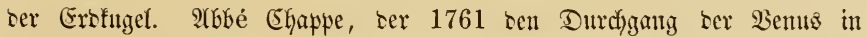

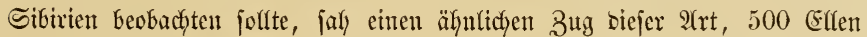

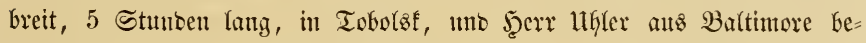

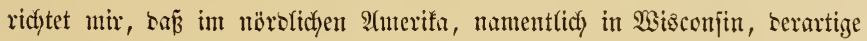

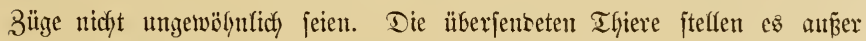

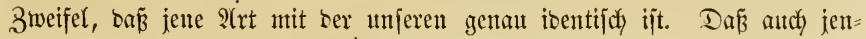
jeits bes Aequator serartige sibellenjüge sorfommen, bin idy jelyr ju meinem Sdyaben belebyt. Sch hatte einem Sammiter in Brajilien ben

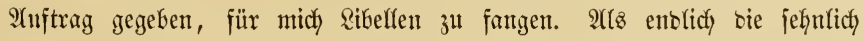
erwarteten Säjten eintrafen, war idy itbel erjtaunt, in allen mur 3 2rten in grofer Mienge zlt finden, bis oer beiliegente Brief mir bas Mätbjel erffärte burdy bie naive Bemerfung: "bieje Thiere feien in Schanten

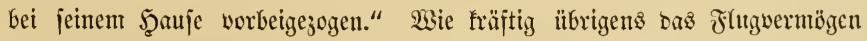
biejer IGiere ijt, geht auz ber werbürgten Ihatjache herwor, baz Sdjiffe sibelfen auf hoher See 600 englifdye Mieilen vom \&ante fliegent ange= troffen haben."

Dieje jtannenerregenten Thatjactjen f̈̈men unjer Snterejpe an biejent

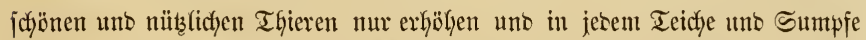
ober in jtefjenten Wajfergräben fönnen wix jef̧r Yeidjt bie frühern Stänte einer Ribelfuline finben uno bie wutberliche Fangurăfe fennen lemen. 


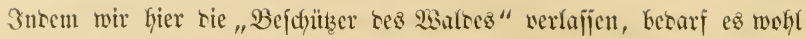

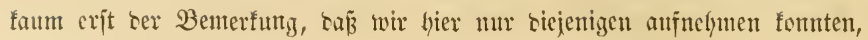

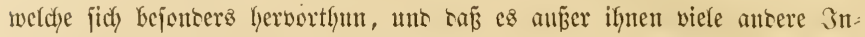

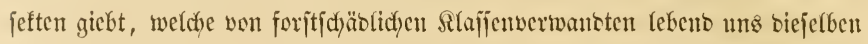
Dienjte erweifen, und jelbjt unter ben 9lten ber folgenben afbjantitte wer sen wir joldyen begegnen. Es herrjodt eben in ber Silajfe ber 3meften ein unaufyörlidyer uno taufenrfärtiger $\mathfrak{B}$ ruberfrieg. 


\section{Elfter Xb[dnitt.}

\section{Die (5) all $=3$ njeften.}

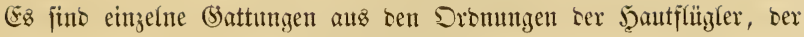

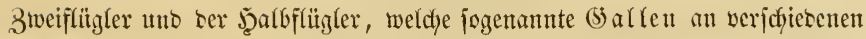

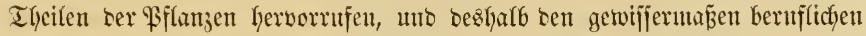
Yamen (5aff = Injeften crbalten haben. Diefe Erjocintung ijt cine won benen, an welche man wie Refings Yathan es thut, bie Malymung fïr bie

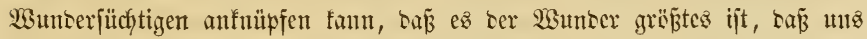

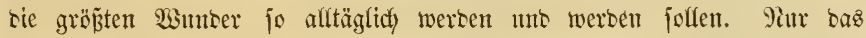

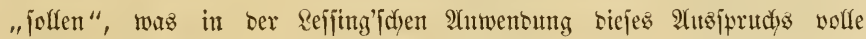
Berechtigung hat, ift ber Baffenbilonng gegenüber weniger berechtigt, benn ez entgeht basurdy nody ben Mieifen ber befriebigente (benuz eines Ein= blides in einen Paturvorgang, weldyer mefyr wie viele anbere 2 stmoer ge= nannt 3u werben verbient. Inbem wir biejes fagen, bebarf es woble nidgt

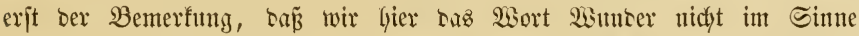

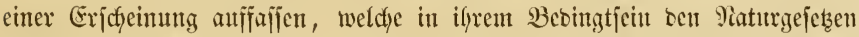

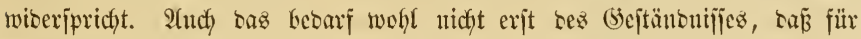
uns poldye Wunter nidfyt vorfyanben fitto.

Wem wir sie Sallenbilsmig eine wumberbare Erjofyenumg nemen, fo gefdjelyt bies beshalb, weil jie auf cinem bejtmmenten lleberyreifen cincs Thieres in bas Bejtaltungsleben ciner Piflanze bernht. Der ftoffitiche Ilyeil ocs Borganges fann ms zwar in Erjtannen jełzen, weyen bes für umjere Mittel vielfeidyt unnteß̧baren Minimunt, weldyes an Stoff babci in Wirf: jamfeit tritt uns, je nachbem biejer Stoff von biejem ober jenem (Balt= 3 njeft auf bieje ober jene Bflanze, siejen ober jenen Theil serjelben übertragen

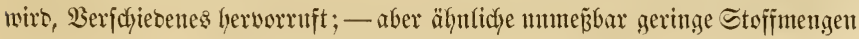




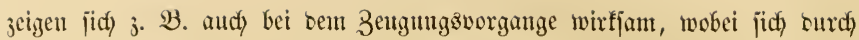
siejelben sie auffalfentiten efterlidyen $\mathfrak{B}$ cjonbertyeiten vererben.

"Wir ftotzen ober eingefilbeten Mienjobenfinter nenuen uns zumeiten bie

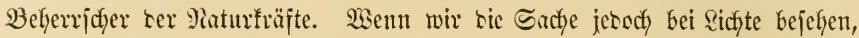

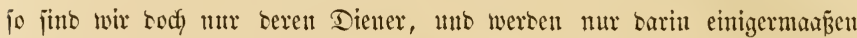

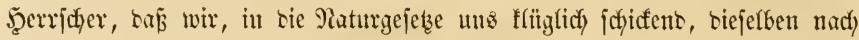
tmjerem $\mathfrak{B}$ iffen Yeiten lernen, wie es mandyer alte trete Diener mit jeinem

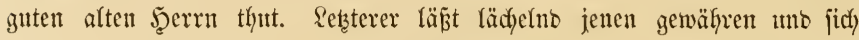

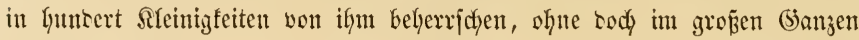

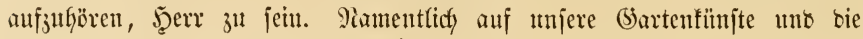

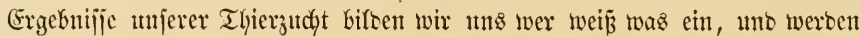
boch) won ben (5)afl = Injeften Gimmefweit ïbertroffen. Stolz zeigen wir auf

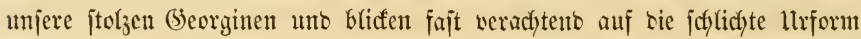

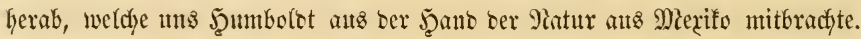
Mit meijterfichem Behagen jef̧en wir anf einen Dbjtbaum in unjerem

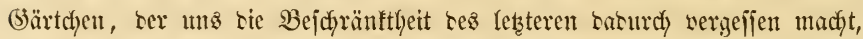

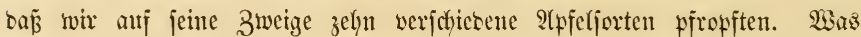
thun wir benn aber in beisen Fäflen mebr, als wir benntzen bie ser Natur

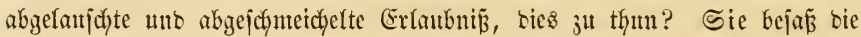
Sraft, nicdt wir.

"Metgr thun num freilidy bie (5afl= Snjeften and) nidyt. Afber bie Matur

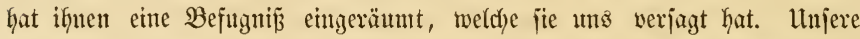
taujento Gartenfunititücfe sermögen bod) nidyt cine einzige Fflanze ju zwingen, etwas ifrem jelbjteigenen 2 sejen Frembes zu bilten. Die (5)all=

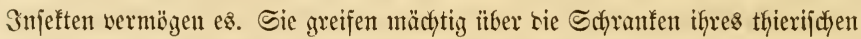

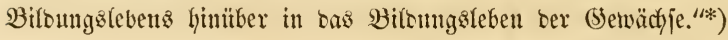

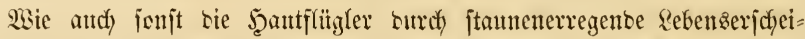
nungen jidf wor anbern Injeftenorbnungen ansigeidynen, fo fino auth bie (5allen ber ફ̧autflitgler niddyt mur sie bäuffigiten unb mandyfaltigiten, foncern

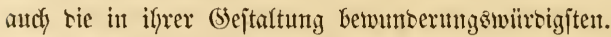

Wenn wir uns an bie นms allen befannten Gaflenbilonngen erinmern, welche uns bie Jig. $60 . \mathrm{k}$ uno 62 . e veranfdyantictyen, uno babei ertwägen, bå̃ allein auf sen Eichen gegen 50 berichicbene Ballen gefunben werben,

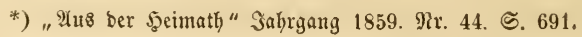



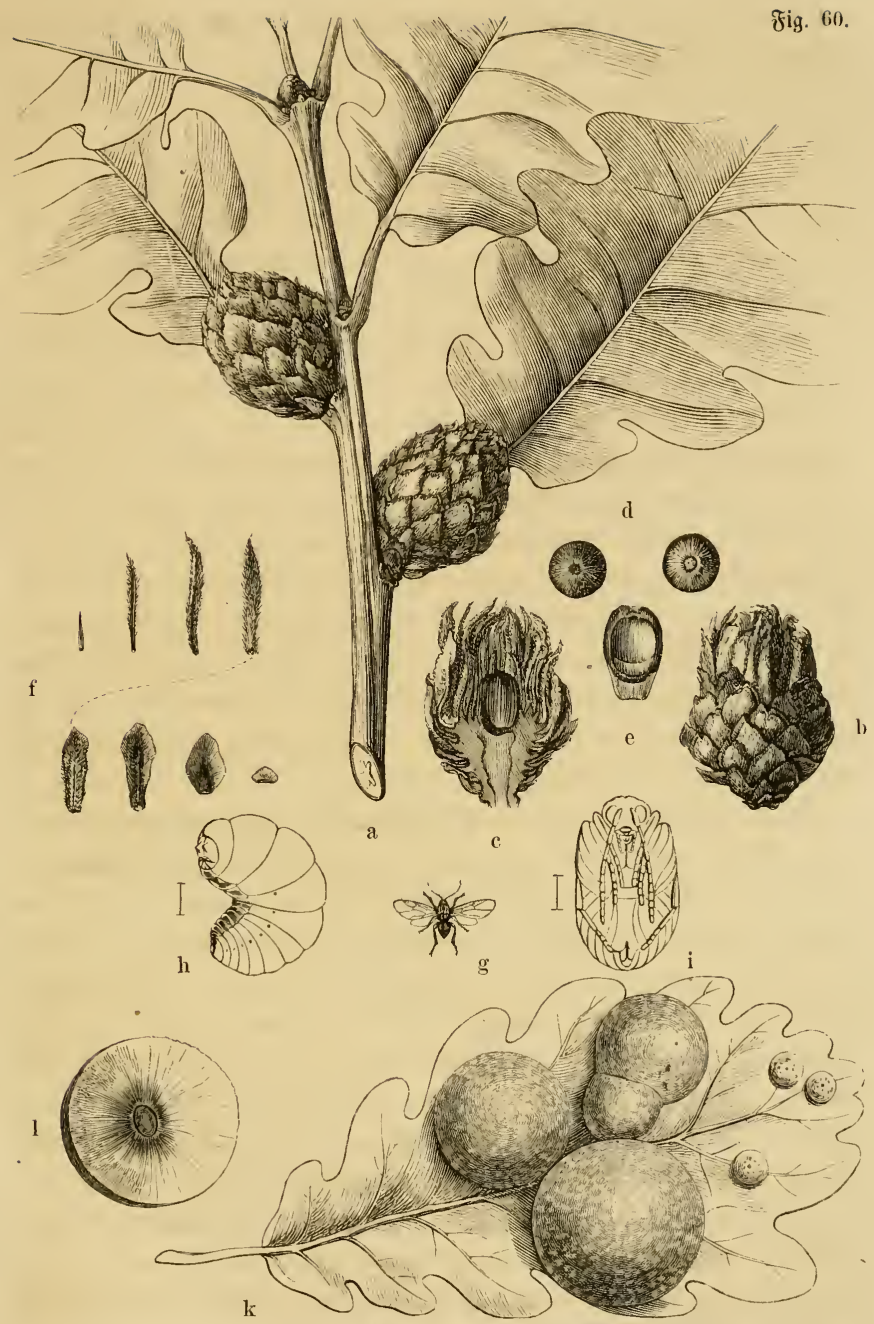

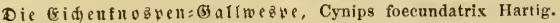

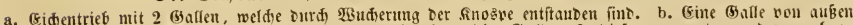

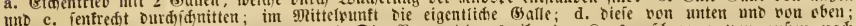

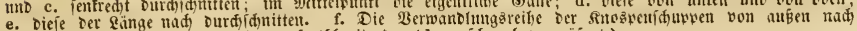

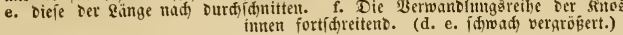

Die (Eid)enflatt= (5) allwespe, Cynips folii L.

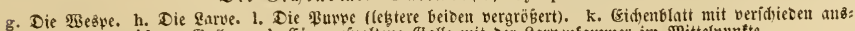

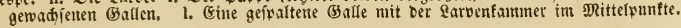


bon renen jeoe iffre beftimmte won ben übrigen abmeidfente uns oft fehr abjonocrliche Bejchaffentyeit hat - jo milffen wir bei bem 2erjuche, แms

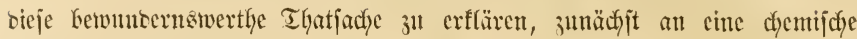
Erftärung benfen.

Dic (5aflen fino inmer bic 2 siegen für bie felyr fleinen sarben ber

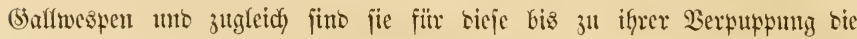

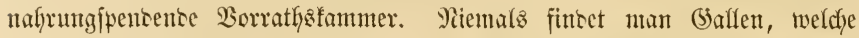
für bas jelbjteigene, won einer örtlidyen inneren franffhaften Dispojitton veraulap̈te Werf ber betreffenben Fiflanze gefalten werben fönnten, fontern immer fintoen twir fie in unmittelbarer bejiefung zu einer ober einigen (baflwespenlarven. Unterjudyungen haben ergeben, baj mau cben fo wenig annefmen barf, bie Balfwespen legten ilje Eier erjt in bie bereitz fertigen

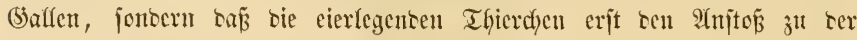
(5aflenbiloung geten. Unjere abbiltungen zeizen uns 5 unter jich jefyr

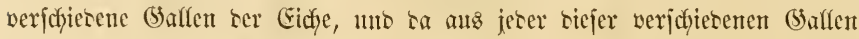

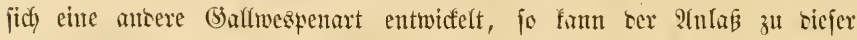

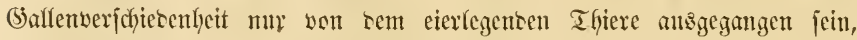

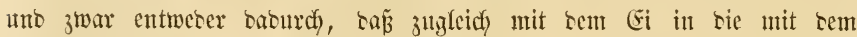

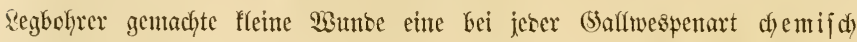

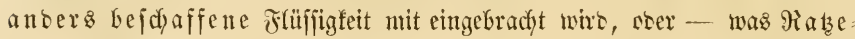

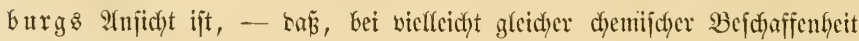

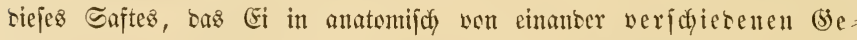

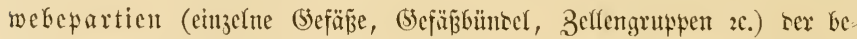

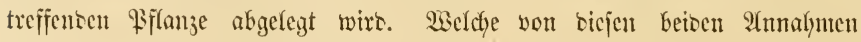
mun, ober ob feine won beiten bie richtige fein möge, unter alfen berbält=

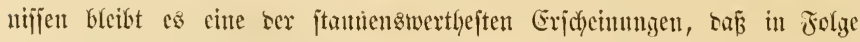

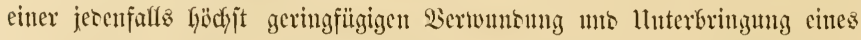

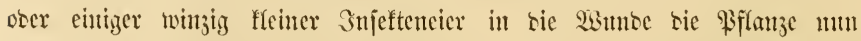

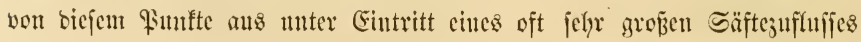

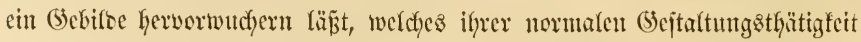

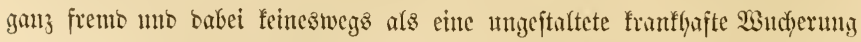

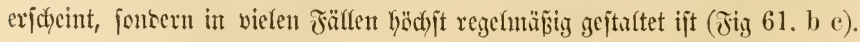
Dies gilt ganz befonters wou ben cinen fleinen mit braungelber Seite

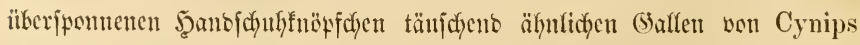
Réaumurii Hartig (Jig. 61. b), weldye bei ftarfer Lergrö̈̈erung and 


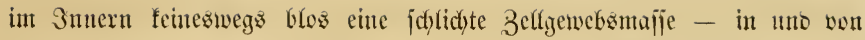
weldyer fich bas särbchen näffrte, — jondern eine jefarje Scheioung von

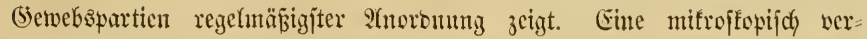

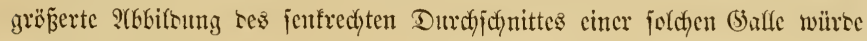
einent tes wahren Sacfwerhaltes unfunbigen botanifyen Mifroffopifer als ein anatomijçes säthjel ericheinen.

Sere Salfwespenart, Deren. Jaartig in einer fleinen Edyrift ("ïber

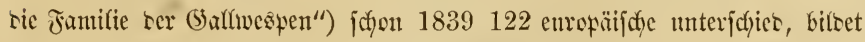
eine anbers gejtaltete uno bejchaffene (Safle, ober vielmehr veranlap̧t sie

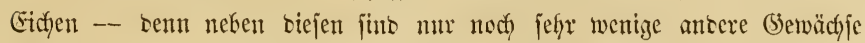
mit biejer fonberbaren Serbitut belajtet - zut seren Bifoung. Man faun

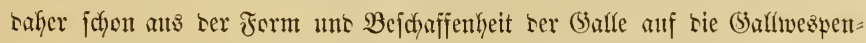

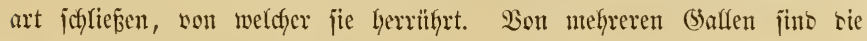
Ilrkeberinnen nody nidyt befannt.

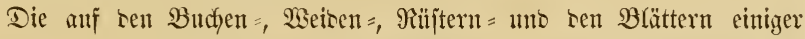

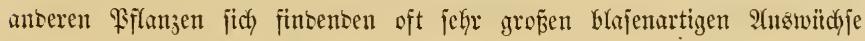

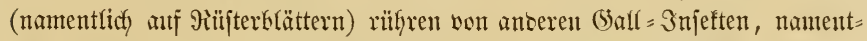

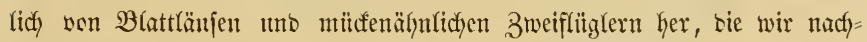
her befprectien.

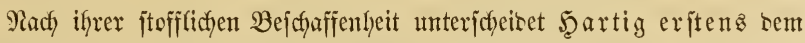

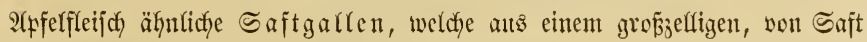
itrobzenten Zeflgetwebe beftehen, in melchem fid) Spiralgerän̈e; ähnlich wie ium Ilpjel, vertheilt finten. Sn ifnen fincet fich feine Spm von Stärfe=

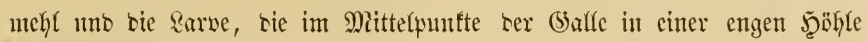

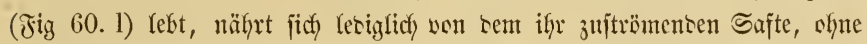

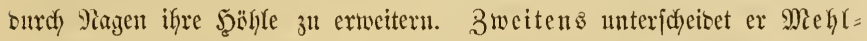
gallen, weldye unter einer holzigen Minbenidfidft in sen Zelfen bes. weidfen

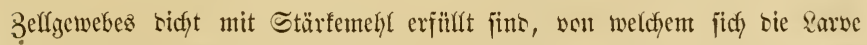

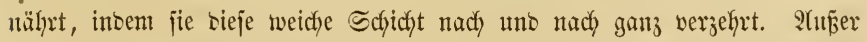

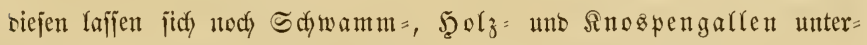
idyeiben, zut weldyen letzteren bie Jig. 60. a abgebilbete gehört.

Ferner fanm man mit Şartig bie (5alfen in ein = แno mehrlanmerige theifen, wo bann in jeber Sammer eine Rarve lebt. Mach bem Pffanjent= theile, auf weldyem man bie \$alfen finbet, nennt sieje J̨artig Blattgallen,

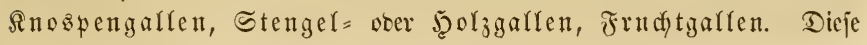


Ërtlichen Bebingungen ser Ballenbiloung werben won ben Balfwespenarten immer jtreng $b_{\text {cobad)tet. }}$

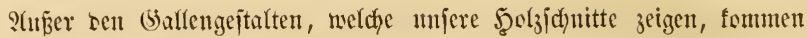
ned) viele antere nidyt minter anffiflfente nor. Befonoers bemerfenswerty ijt bie (Bafle von C. ramuli L. (Jij. 61. a), weldye an sen jungen Trieben ter

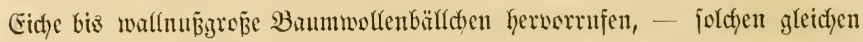
jie menigitens bollfommen - sie inwentiz fid z" eirunten neben sinanser= fiegensen Zellen fïr sie einzelnen Sarven versidften. Die beisen sarnnter abgebilseten (Baflen betecfen zutweilen fajt bie ganze Unter p̧eite ber Eidfenblätter (nve ïberfonupt sie meijten (Sallen anf oer llnterjeite fitzen), uno entipricht sem Mittelpunfte jeser Galle, in weldyem jie aftein angeheftet jint, anf ser oberen B̧attjeite eine fleine Diarbe, weldye bei ser Galle son

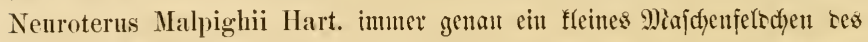
Blattgeäbers ansfïllt, wälyreno fie bei Réaumurii immer aud cine an=

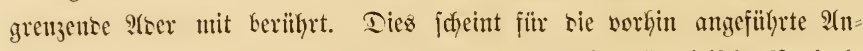

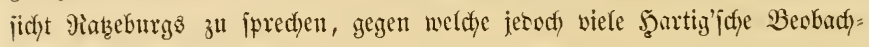
tungen anjufülyren wären.

23ir führen hier nody sie beisen getwerblich midftigen. (Galfen ber

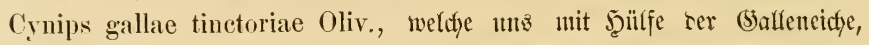
Quereus infectoria L. bie runcen levantijchen "Balläpfel" liejert, nno bie. von C. calicis Burgsd. an, weldjer wir sie "Snoppern" verbanten.

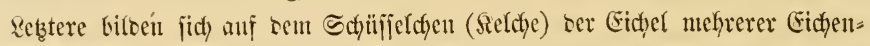

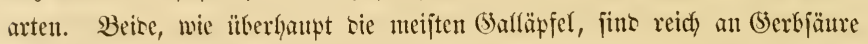
unt crhalten saburd) für uns sie widftige Bebentung in oer (5erberee uno Färberei. Es ijt als ob sie Eidfe siejen für uns jo wertfyodfen Stoff

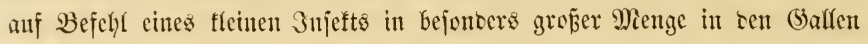

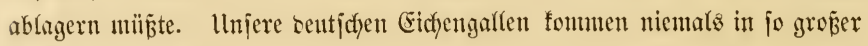

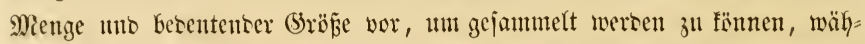
reno wir แnะ erinnern, im Detober 1837 in Ungarn unter einer zientidi freiftehenten (sidye sen Booen bicht mit ßneppern itberfäet gefunden ju haben.

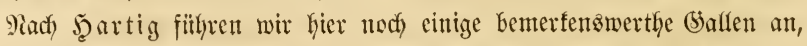
von senen sie Urbeberinnen zum Theil nody nidht befannt fint, twio benen ફ̧artig, was wohl zuläfiig ijt, nady ifyren (5allen (1839) pränumeranto einen 2trtnamen gab. Cyn. disticha H. madyt eine erbjengroṕe (5alle,

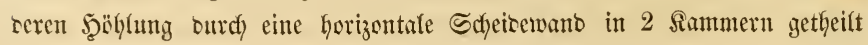


Fig. 61.

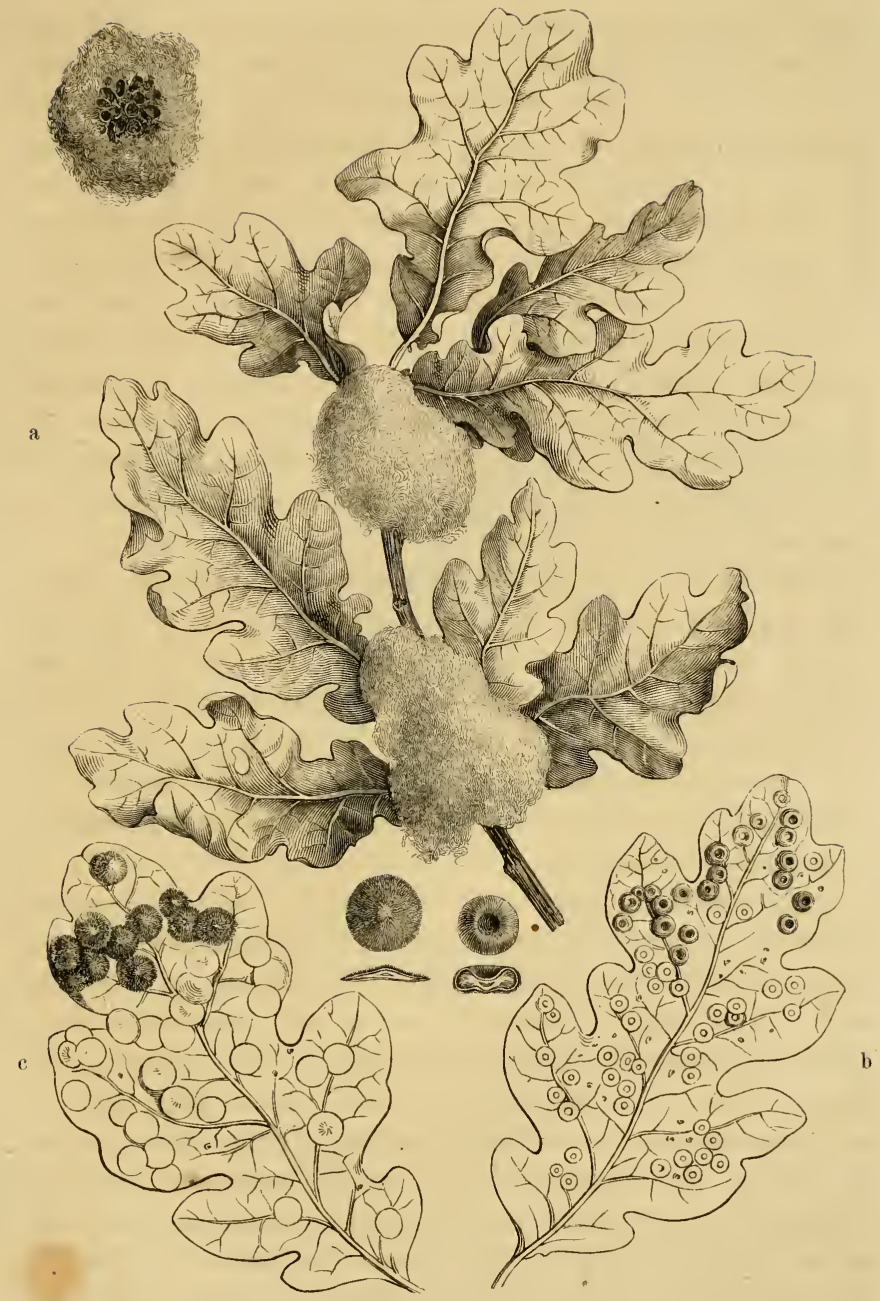

a. (5allen von Cyuips ramuli L. - b. Galfelt bon Neuroterus Réaumurii Hartig. c. Balfen von Neur. Malpighii Hart., von allen baneben einjelne Ballen. 
ift, won benen aber immer mu sie che bewolnt ijt. Teras terminalis (Cyn.) Fabr. wermijadyt meijt an ten Epitzen ser Eidhentriebe bis 2 3oll

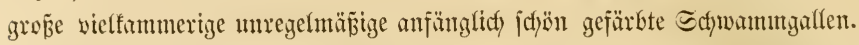

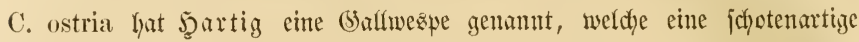

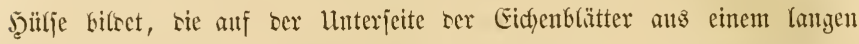
Eimjdyitte ber jtärferen 23 lattrippen hervorwächit umb in welcher bie eigentliche nierenfürntige (balle, genau wie sie Erbje in ber Sityote, angewadjien

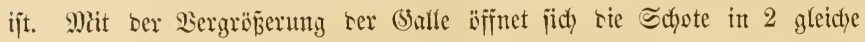
Jä̈lften wie bie Sdyalen einer Injter. Die Salfen won C. globuli Hart.

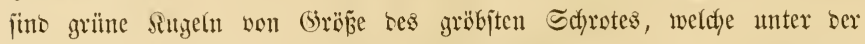

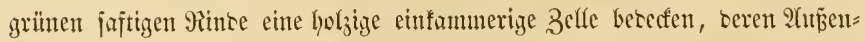

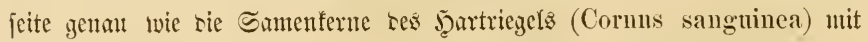
netzartigen seijten berecft ijt. Die im Spätherbit aus ser Scitentnospe ber Eidje Gervortretenten Gallen ber C. glandulae H. Gaben bie Fermen ber Eidjel mit Einjd)tú

2up̃er riejen und ähnlictyen (bejtaltungen fommen aber in einter langen

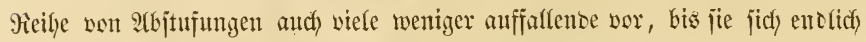
auf bloje stufidweflungen ber Triebe, Suozpen, Blattitiele ber Eidhe be

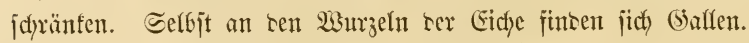

\$im an wenizen anberen Piflanzen finten jich (5aflen, 3 . 2 . an ben witsen Fojen, an Bibmbeerjengeln unb jelbjt an einigen fräutern, wie

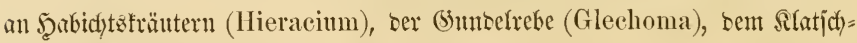
molyn (Papaver Rhoeas).

Die allbefaunten grün= uno rothgejärbten "Sd)lafäpfel", wie im Bolfzunt sie (5aflen ter Rojengaffwespe, Rhodites Rosae (C.) L. beipen (Jig. 62.), finb Daburch bejonbers beachtenswerth, als tie Roje,

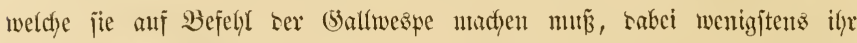

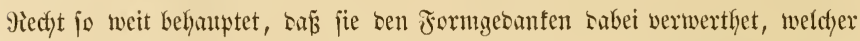
mefjere Pojenarten - au meijten befinntlich bei ber Moosiroje - ju moosartigen (Sebilben an sen jünf Sielchzipfeln veranlä̈t. Wir jehen dicz

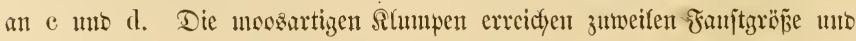
finten jict) an alfen Theilen ber wifben Miojen, woomedy bieje mefr ober weniger verunjtaltet werben. Die zaflfojen fein gefieserten moosartigen

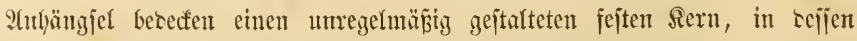
vielen Sammern bie Rarben cinjefn leben. 
Die Schlafüpfel waren in ocm siujt tes früheren, nun Sott fei Danf

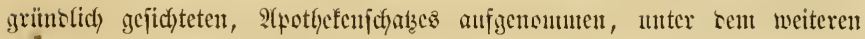
Tiumen Sdylaffauz, Sdylaftumjen, Miojenfdywanu, Bebegutur, Fungus Rosarum, F. Bedeguar, Spongia Cynosbati.

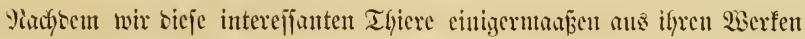

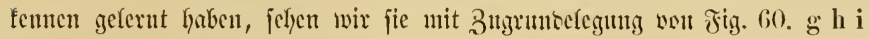
unธ 62. a nuแ felbjt etwas näfer an.

\section{รig. 62.}

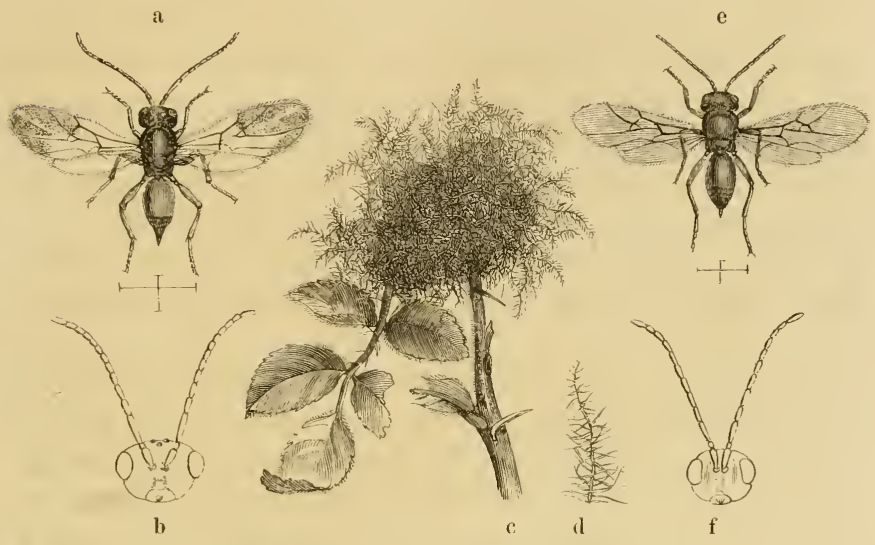

Die Siojeugallwespe, Rhodites Rosae (Cyu.) L.

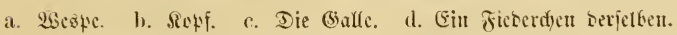
e. Aylax Brandtii (Cyu.) Ratzls. f. Siotrf.

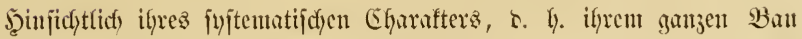

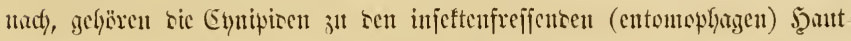

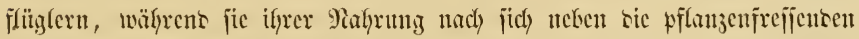
(phytophagen) jtellen, aljo beise innig mit einanser verbinten (j. $\Im .198$ ).

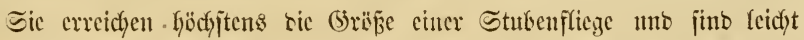

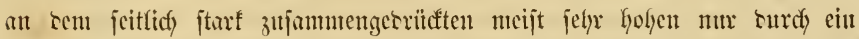
furzes sünnes Stieldyen mit sem Mittelfeibe verfunsenen J̧interleibe ju erfenten, an bejijen Ente ser gefrünmte Pegitachel licgt. Dic lyinteriften 


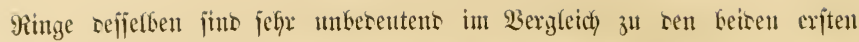
(62. a uno c). Die Flügel ähneln in (beäber benen mand)er 3dynemmonion. Die Fühler fint fabenförmig, nicht gefrünmut, $13-16$ gliebrig.

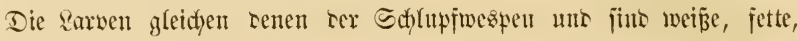
fup̃loje in ihren Bellen gefrümnt fiegente Maben. Die \$uppen funt sie getwëlntictyen ber ந̧ymenopteren.

Die Eierablegung hat bas Bejontere, sañ, un surch ben viel ju engen

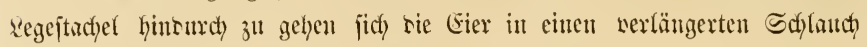

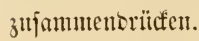

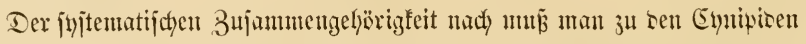

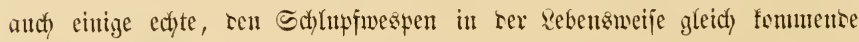
Schmarober jtelfen mo eine fernere fleine (5rmppe, rie man mad) j̧artig Snquifinen, Einlieger (Einquartiermn), nent, incen jie in ben, von

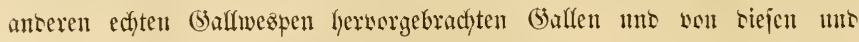
teren llrhebern reben. Ein jolther Eutieger iit Aylax Brandtii (Cyn.) Rtzb. (62. e), weldyer in sen Scflafrofen lebt. Sntem man jie anz ihren

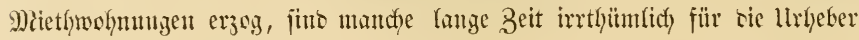
serjelben gethalten worton.

Gá ijt eine nod) bejonters herworjubebente Thatjudye, welche ben Forjdyern

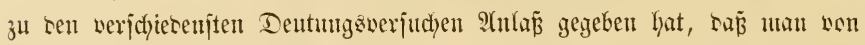

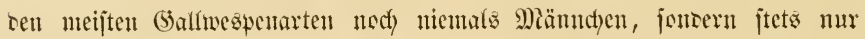

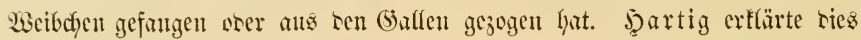

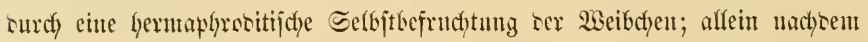
Sieboro bies surdy anatomijaje Unterjuthung wioerlegt hat, nabm man $3^{4}$ ber jogenanuten Farthengzenefis - sie wir weiter unten bei ben Blatt=

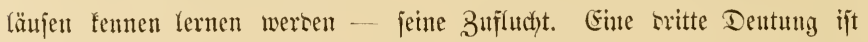

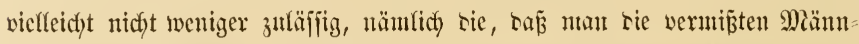
dyen nod) entrecfen wiro soer fogar vieffecd)t länglt fennt, shne in ifgnen rie (Sejudyten ju erfenmen.

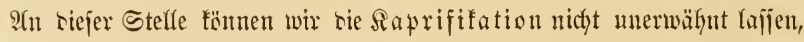

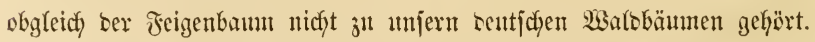

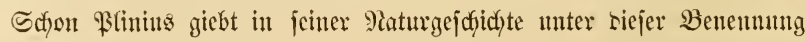

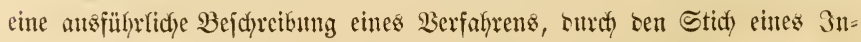
feftes bie Jeigen zll zeitigen, weldyes aber fdyon lange vor igm befannt uno

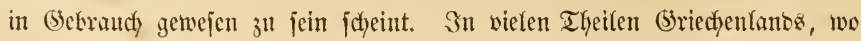




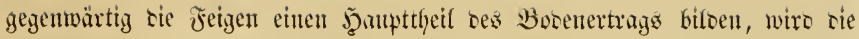

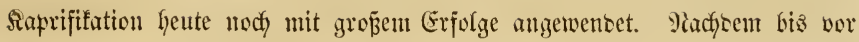

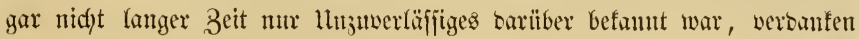

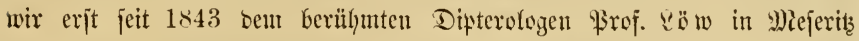
eine genaue Sdyilberung ber Saprifitation ber Feizen, wie er jie anf ber griedjijaen 3njel Reros fenten lernte.

Die Benennng biefes Zeitigungšverfafyens. fommt von eaprificus her, was ben wilten Feigenbanm, bic Boctajeige (von eaper uno fiens) berentet, in beren Frifdyten eine Gallwespe lebt, weldye Fabricins Cynips psenes*) namte, bie jetzt aber nach (5ravenforit Blastophaga grossorum

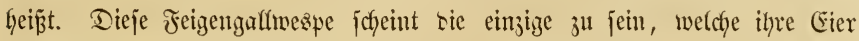

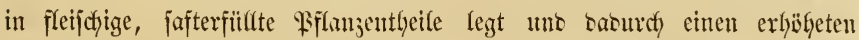
Saftzujtrom nach biejen hervormft. 2atn ift alferbings bie Jeige feine eigentliche Jrudyt in sem Sinne wie bie Sirjofye oser bie Weinbeere eine ift, fontern wie ber Fitftenzapfen nur ein fogenannter Fruchtitano, uno

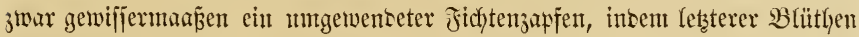

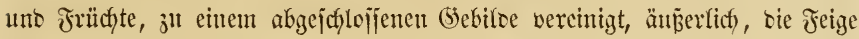
bieje aber innerlich trägt. Mian fam bie Jeige auth mit einer groß̄en Blitthenjcheibe ber Sonnenroje, Helianthus annums L., vergleidfen, wenn man jich siejc aufmärts in eine hohle Sugel zufanmengejogen senft, bic alsoann inwentig mit ben zahlreidfen Einzelblüthchen ansigefleibet fein würbe.

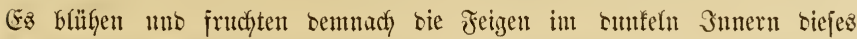

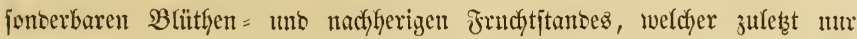
oben che fleine Deffinung befommt; uno intem wir eine Feige effen, ijt

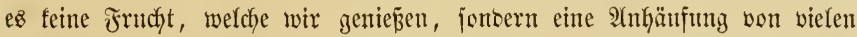

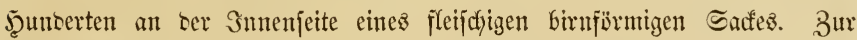

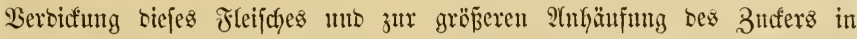
bemjelben trägt eben bie Jeigengaffwespe bei. Dies wïrte jic wahricheinlich

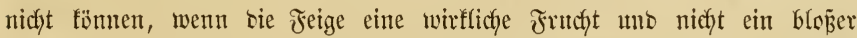
Jutudjtitanto wäre, befien Zellgetwebe eben ser Wanchermy, weldfe von ser (5alfwespe Gerborgernfen wirt, fähiger ift, als bas zarte Zellyemebe bes

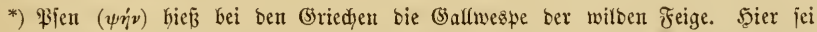
nod) nadigetragen, baß̉ Sinné nody alle (5alfwespen in ber einen (Sattung Cynips ver= einigte, unb baßj erft $\mathfrak{5 a r t i g ~ b i e ~ n o ̈ t h i g e ~ B e r f a ̈ l u n g ~ b e r j e l b e n ~ i n ~ f l e i n e r e ~ w o h l u n t e r = ~}$

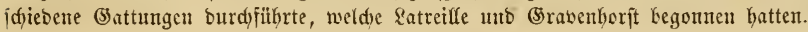




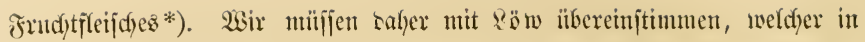

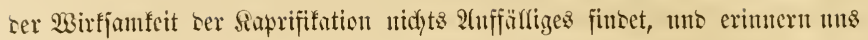

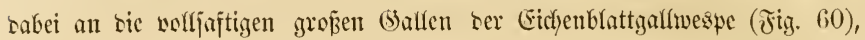

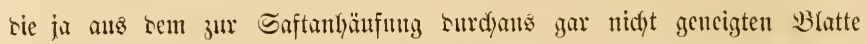

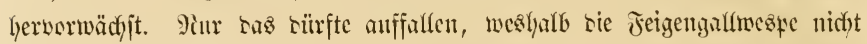
and) bie wiften Feizen, in senen fie mpipringlidy lebt, vorfyajtig madyt, fonbern mur bie bercoelten Feigenjorten, anf weldye jie fïmittidy übertragen werten แuा

Heber sas (sejdyäft rer Saprififatisn macht 8 ö iv in ber "Stettiner entomolog. Beit." (1843 S. 66 uno f.) intereffante Mittheilutgen, wown wir hicr unk Einiges herborkeben. Die won sen nicorigen witoen Feigen= ¡tränd)ern gefuntmelten Jeigen entlyalten oft an cinem gewififen Drte fajt

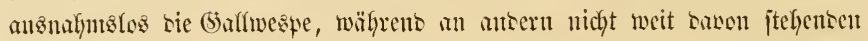
Strüuchern alfe Feigen frei sawon finb. Die gejummelten Feizen werten

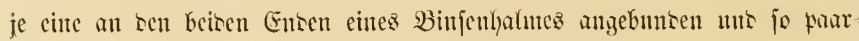

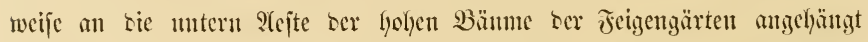

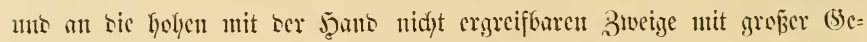

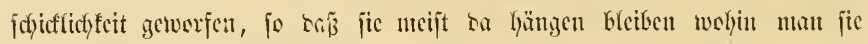

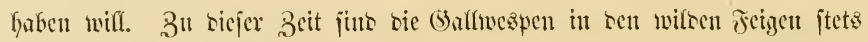

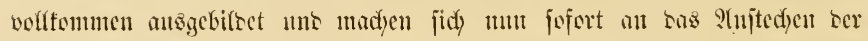
Feizen, in seren Piadybarichaft man jie gebracht hat.

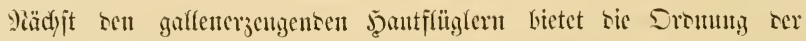

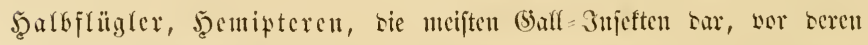

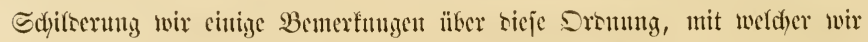

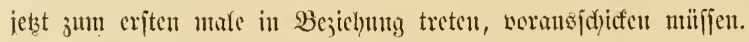

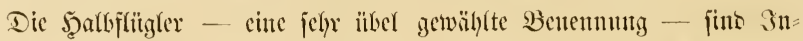

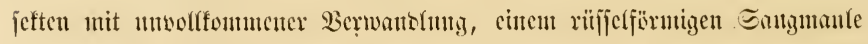

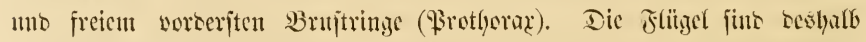
alz Ormungsfennjeidfen meniz brandybar, weil jie bei biejen 3njeften mad)

*) Es ift jebod eine foldse nidyt ohne Beifpier, wic bie allgemein befanten

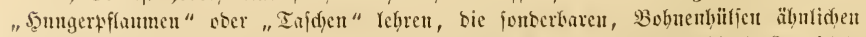

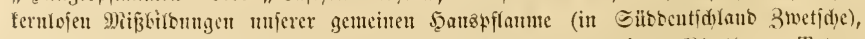

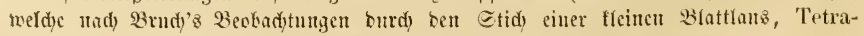
neura pruni, herworgetrad)t werben. 


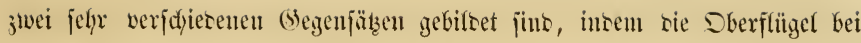
ben einen von gleidyartiger bejdy affenlyeit, bei sen anocrn sagegen an ifyer (5rumblälfte hart mo leserartig, oft wie bic Flïgetbeffen ber säfer jogar lyornartig uno unx in ber Eno= ober Spizhälfte fäutig uno gearert fint.

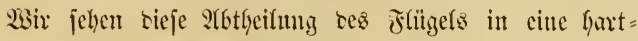

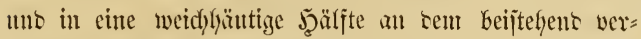
größ̈ert abgebifreten Sberflïgel einer .unjerer gemeinjten 26als = Baumwanzen, Pentatoma rufipes L. (Jig. 63). รig. 63. Wegen riejer Flïgelbejduffenteit vieler siejer Injeften, sie aljo gleidfjan halbe Flügelbeffen (ser Säfer) haben, nante man sie ganje Dronung

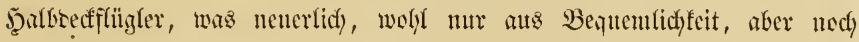

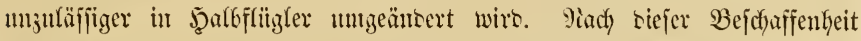

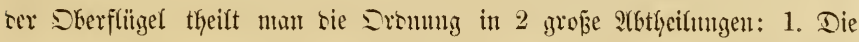

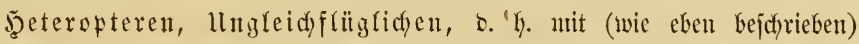

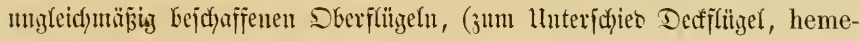
lytra genamt) mo 2. Die 5omopteren, (5)cidfflügrigen, mit gleids)= mäp̄iz bejd)affenen Dberftïgefn. Die lluterflïget fino immer edfte häntige

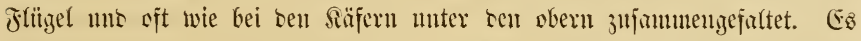

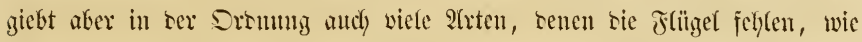

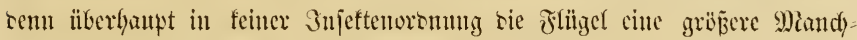

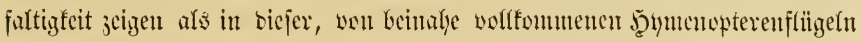
(Cicaren) biz ju Flïzelseffen äfnlticfen (viele Banmuanzen).

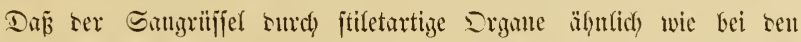

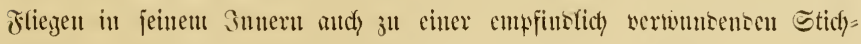

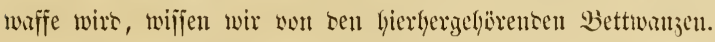

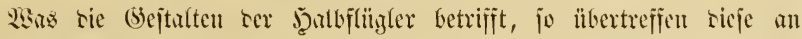

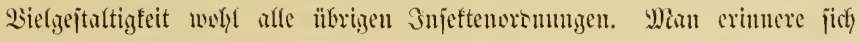
an sie befannten ueijt anffalfento flattger ritcten uno in Sïrperumfreis

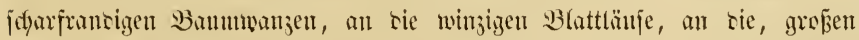

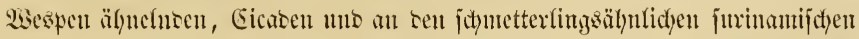
Saterucnträger neben unjerer Bettwanze no sie sürren langbeinigen in

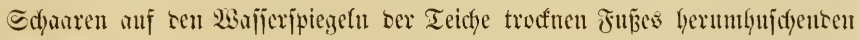

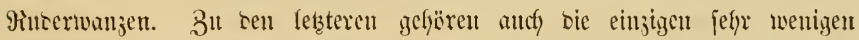
Snjeften des Mieeres, rie Mieerwanjen, Halobates, weldhe freilidy and) nur anf, niemals aber in beu Mieere leben. Şierbei barf wohl gelegenttids 


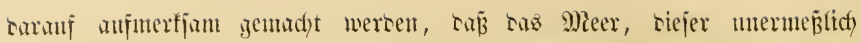
reiche Mintterjidyock jür zahfloje Thierformen, nady bem bisherigen Stante unjeres 2Bijfens f́cine Injeften birgt. Sopf nto Borterbrujt zeigen jith

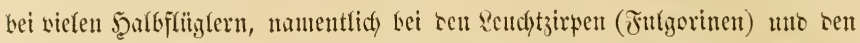

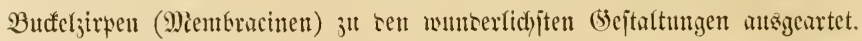

Man fennt gegenwätig etwa 12,000 atren bicjer ïber alfe Theile ber Erte verbreiteten, ant reichjten uno vielyejtaltigjten aber in ten heiß̄en Ersitridyen, bejonbers Brafilien, wertretenen Snjeftenorommy.

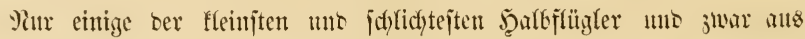

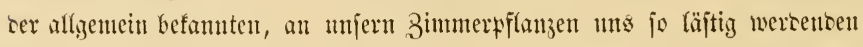

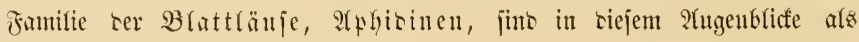
Ball 3njeften fïr uns won 3nterejije.

Shre (Salfen jimb aber ill citcm wejentfichen Putmfte won benen ter

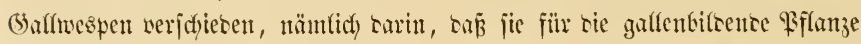

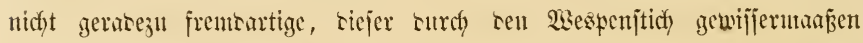

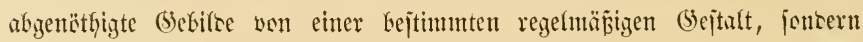

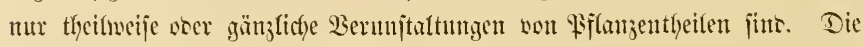

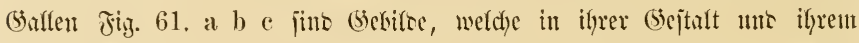
ärtfichen 2luftreten an nidhts eriunern, was sem Sejtaltungstricbe ser Eidfe

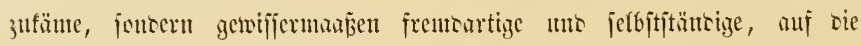
Eidjentricbe uns Blätter verpflanjte, wenn and) aus ricjen jelbjt ent= iprungene Rörper. Daher foumt co andy, saj sie meijten (Saffen ter

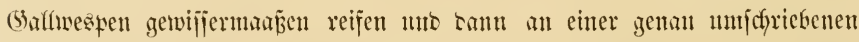
Stelle jidf ablijen. Soldye Ballen werten wir nadyer audh bei cinter

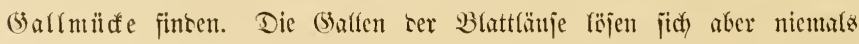

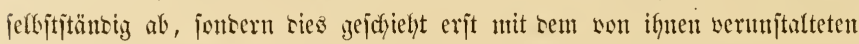

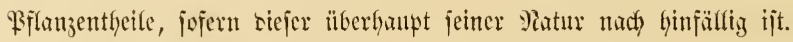

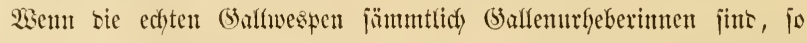

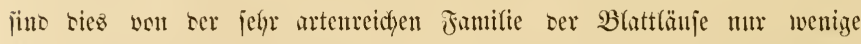

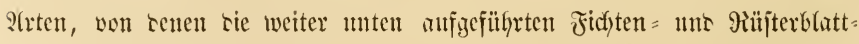
läuje tie befauntejten jüt.

Durch bie anf sen in Bimmern gefhultenen Mionatsorojen jeften feflente grïne fette 9iojenblattlams, Aphys rosae L., ijt uns sie Bejtaltung ter

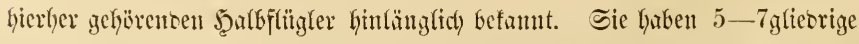

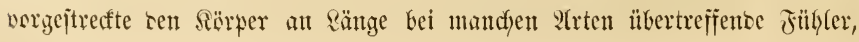




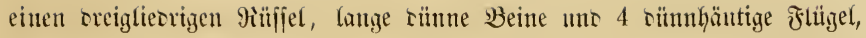
welche jebod) häniftg fellen.

Die jelten mehr als $1^{\prime \prime}$ lamgen Blattläuje jutgen sen Saft ter (b)e

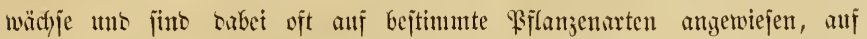
weldhen jie jidf vft ten ganjen Sommer finturdy in ridyten Sdyaren fin=

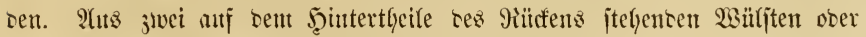

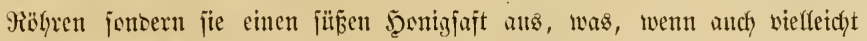

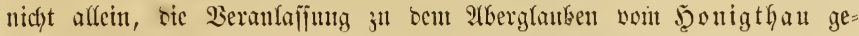

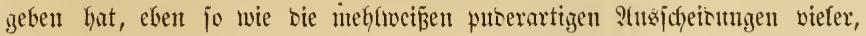

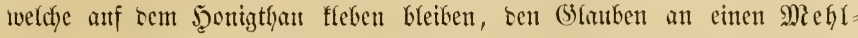

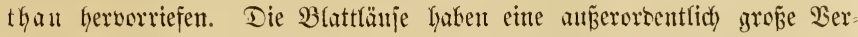
mehrungsfäbigfeit, womit mandye anffallente Eigenthümlichfeiten verbunten

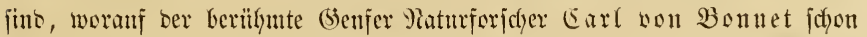

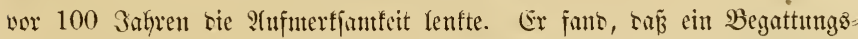

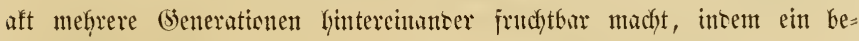

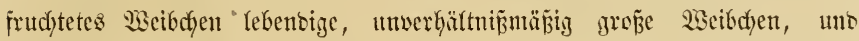

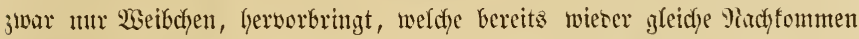

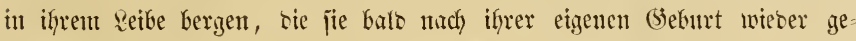
bären, uno fo mehrere benerationen - Bonnet will 9 beobuchtet haben -

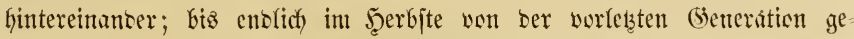

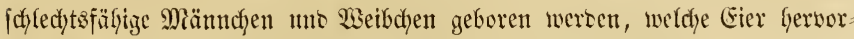
bringen, atts senen in nïdjiten Frïfjafy uno Sommer twieser mu weibliche (Senterationen hervorgehen. Dicje zengungaloje Bermelyrung ter Blattlänje hat man fïr eine Parthenogenejis (jungräuftche (jeburt) gefalten. Da aber bet Thieren mit parthenogenetijcher Fortpflanjuttg ïberhanpt gar feine

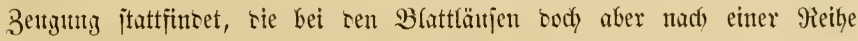

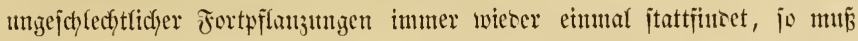
man sie eben gejuffterte Fortpflanjungart ser Battlänje vicfmebr (5) e nerationsmedfel mennen. So nemt man bie won bem Dänen Steen=

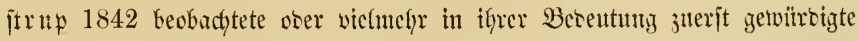

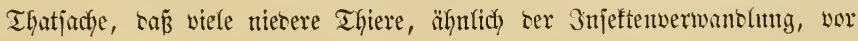

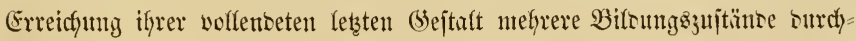
laufen, aber in bicjen fortpflanzungzfälig juno, was befauntlich) mit ben Barben uno Buppen ter Injeften nicht ter Fall ijt. Soldye jorts

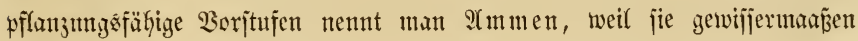


Fig. 64.

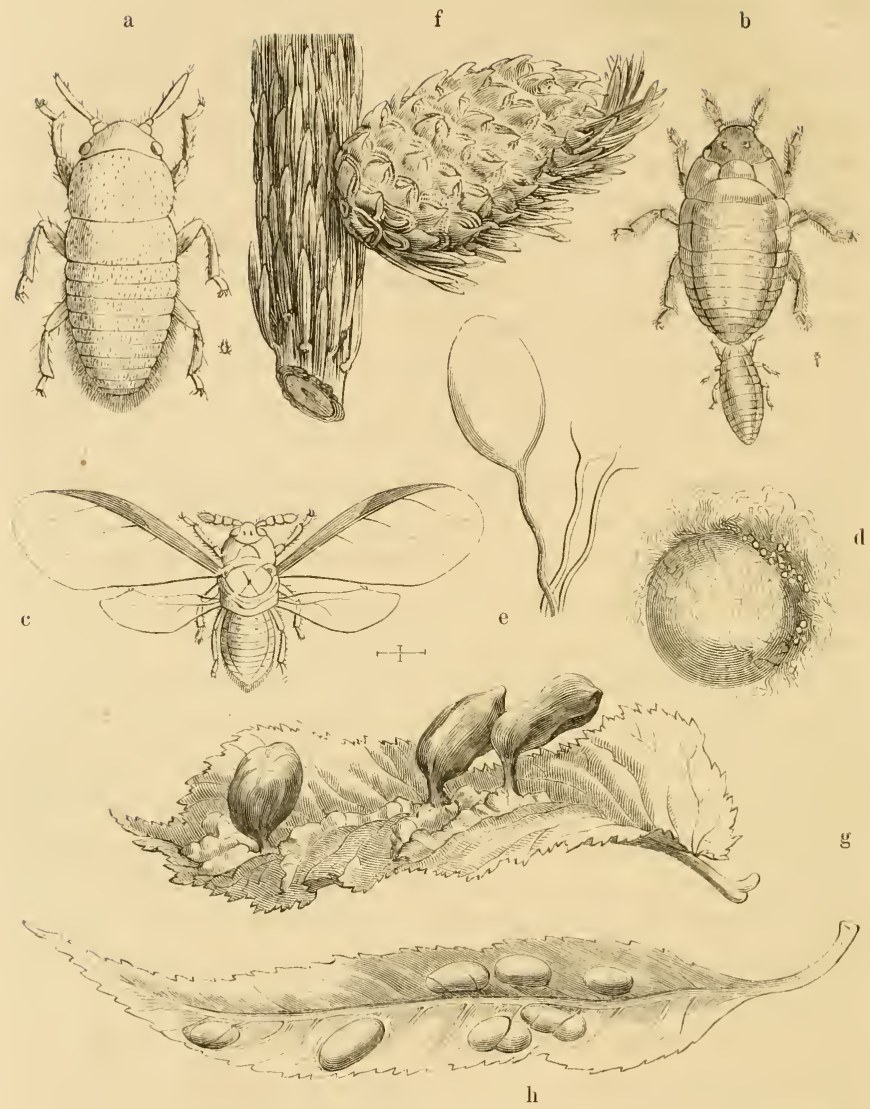

Der Fidytenrindenjanger, Chermes Abietis L. (Ch. viridis unt coccineus litzb.)

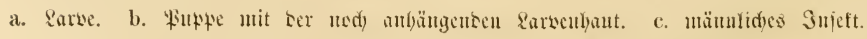

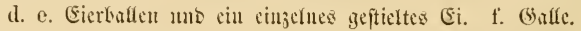

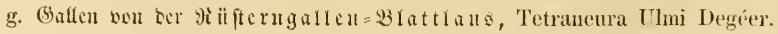

h. (ballen wor ser ascisenblattgalleu=-Blattweske, Nematus saliceti Dahlbom. 


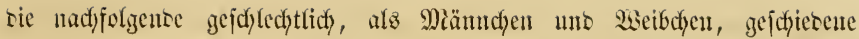

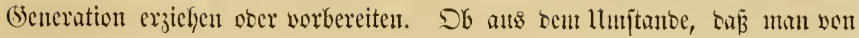

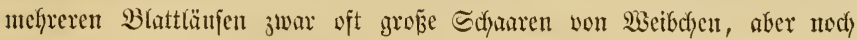

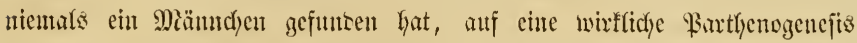

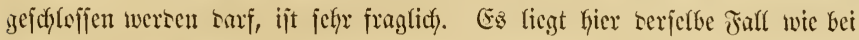
ten Galltwespen wor.

Son sen gaflenbilsentoen afphiben füfnen wir mu bie an hänfigften mo jwar anf ser Fidyte mo Giliter fidi) bemerflidy madyenton anf.

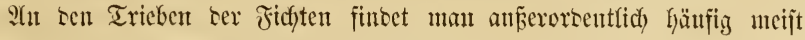

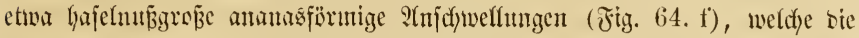
Fid)tenrinsenlats, Chermes abietis (Aphis) L., vermfacyt, tuto morats

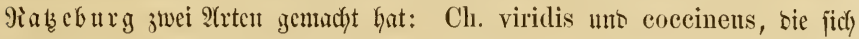
andy in ifyen (Sallen etwas unterjaciren.

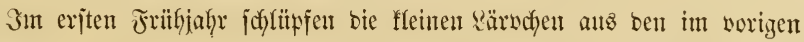

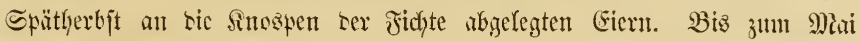

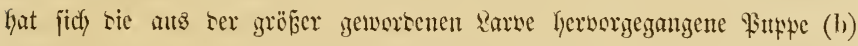

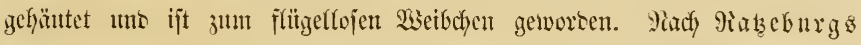

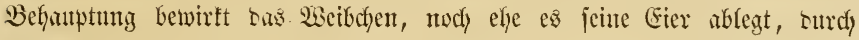

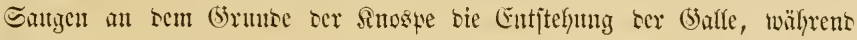

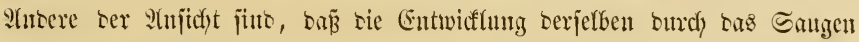
ser jungen särvdfen hervorgernfen twiro. Die gejticten Eter werben in

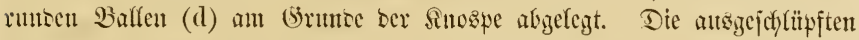

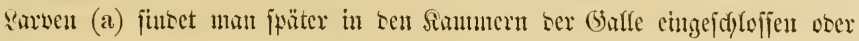
andh anken an benfelben. Enbe Suni bis 21tguft werfen sie \$sttpen (b)

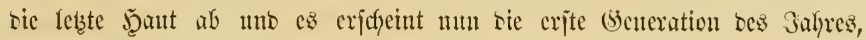

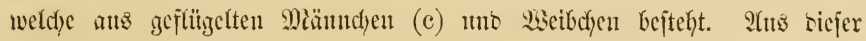

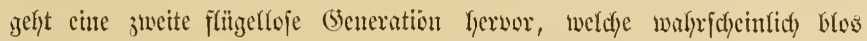

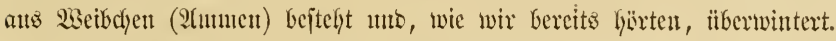

So jelyr mas atdy bie jierliche (Scjtalt ber (5alle (Jig. 64. f) ttber=

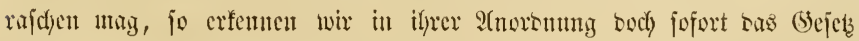

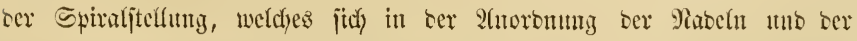

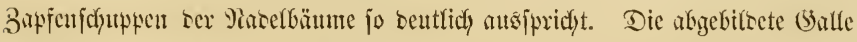
ift burd) Serfitumerung eintes Seitentriebes entitansen, uno hat bic eitte (bie an unferer Figur nad) unten gefefyrte) Seite beffelben uidjt jur Mit=

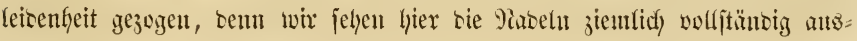


gebilcet; uno baj and) an biejer Seite bie Streftung bes gefenumten Triebes jich) gelteno ju luachen gefudyt hat, jieft man an ber oberen Sirimmung

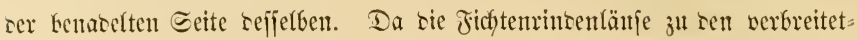
jten snjeften gefjören, fo wiro nicht leidyt einer unjerer Sejer bergeblich

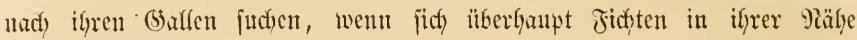

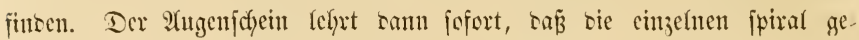

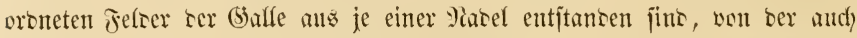
sie Spitze immer nod) 3 ll fefen ijt. Eime fanm minter als bei sen Gaffen

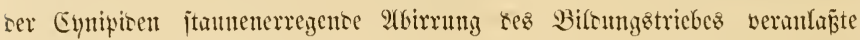
ten Baum, an sem non sen Thierdyen bewolnten Triebe ans jeser Shatel eine breite, gewölbte, won ber Marelipize gefrënte હdyuppe jub bilren, wefdye

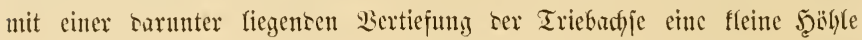

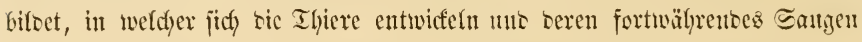

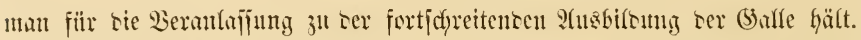
Durd) Eintrodnen nno alfmäliges I(bjterben ber (salfenj(d)uppen frïmmen

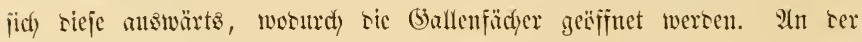

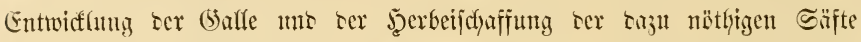
fofeint tie Bajtichidyt Ies Triebes jich entwerer nidyt $3^{4}$ betheiligen, wer

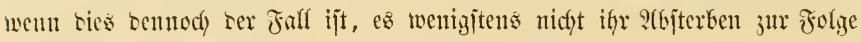

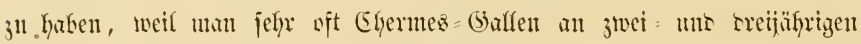
mó jelbjt nod) ätteren Tricben jieft, sieje aljo noch Jathre lang barïber finnusgemad) jen fint. Diez fs̈nnte nicjt gejdhefen, wenn unter ber (Bafle

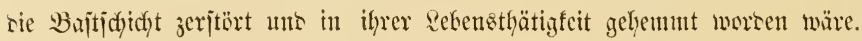

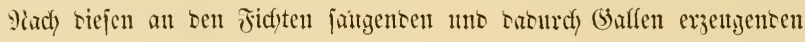
Ifphisen wollen wir nod) 4 arten crtwäfnen, weldye anf sen Blättern ber

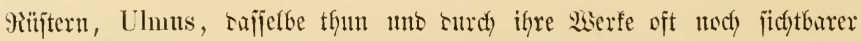

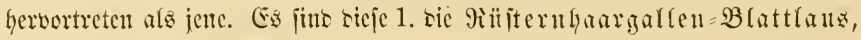
Schizonenra lanuginosa Hartig, 2. Sie Giüternblajen=Blatt= faus, Schizoneura Ulmi (Aphis) L., 3. bie Rititerngallen Bhattras, Tetraneura Ulmi (Aph.) Degéer, uno 4, sie weiñe Tiijterublattlans, Tetraneura alba Rtzb.

Die erje mo sritte funt bie benerfbarften, weil fie sie gröften, 3n-

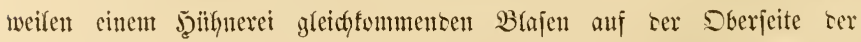

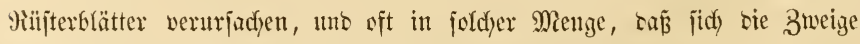

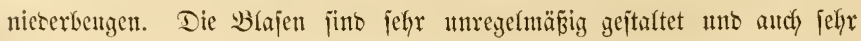




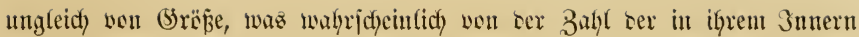

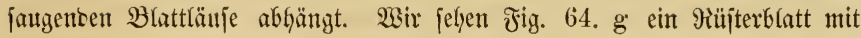
verfdyicten grofien Baflen von Tetraneura Ulmi.

Diefe unb noch siele antere, jum Theil ebenfalls Bumlenbiloung wer:

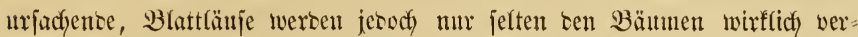

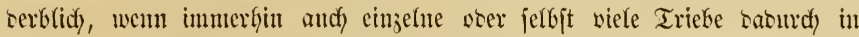

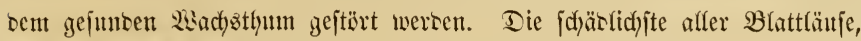

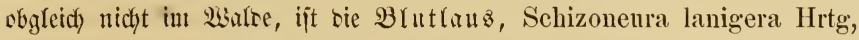

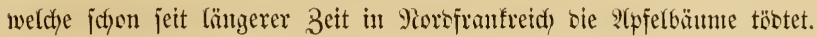

Bon anteren Blattläujen, weldye wentgitens bemerfbare berunjaltumgen an Wabteäımen Gervorufen, nennen wir ftuz nadffolgente.

ந̋̈̈ıfig fielyt ıtan anf ben verjofieceniten Baunarten bie Blätter, befonters tie jungen rumzelig = weflig getwölbt wit röffelartig aubgeböglter Ilnterfeite. Ifn sen sinten bewinft sies Aphis Tiliae L., am Schneeball A. Viburni scop., an 2tpfel = แmo Binubäumen uno au Schwarzoorn A.

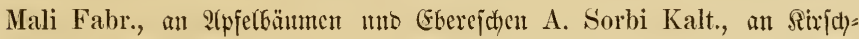
bäumen A. Cerasi Fabr. แnto an anbern Baumarten thun anbere Blatt

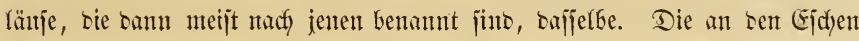
oft jicftbaren bichten Baffen jujanmengedrängter kraujer lno audf jonjt

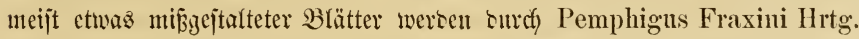
veranlaf̧t. Llnter Scdywarzappeln finset man am $\mathfrak{B}$ oben häıfig abgefallene Blätter, seren Blattjtiele in ser Mitte breit angejc) wollen unc locfenartig gebreht jint, was von Pemphigus bursarius (Aphis) L. werurjacht wirt.

Affe bieje und nody viele anoere $\mathfrak{A}$ rten, tweldye feinerlei gaffenbilbenben

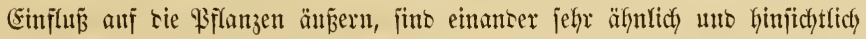
ifrer Rebens = uno Berwandangsweife fefyr verwant. Der lange feine

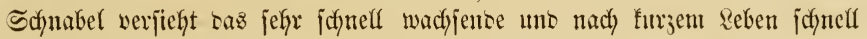

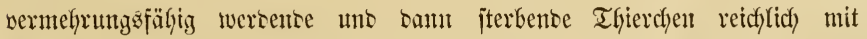
Pahrung, uno sa jie gropentheils in bidyten Schamen beifanmen leben, fallen jie leicfyt in bas 2 tuge.

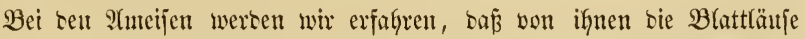
gerabe wie Mitchfitge befantelt werten, obgleid) fie ifynen bas antere Pro=

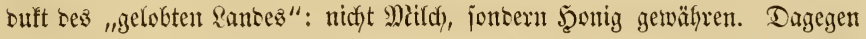
haben jie in ben sarven ber 5.245 bejdyriebenen Sdywebfliegen, grimmige Berfolger. Daffelbe gilt won ten Barven ber Florfliegen (ङ. 250), welche 


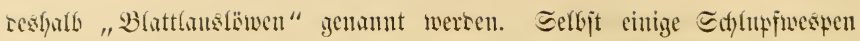

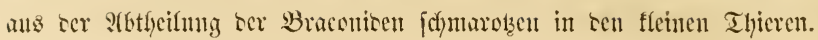

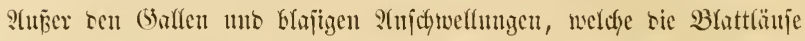

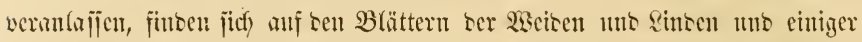

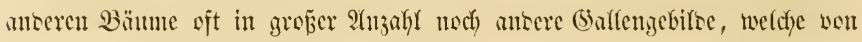

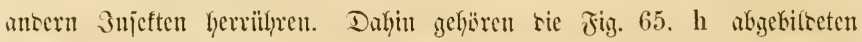
unf beiren Eeiten meijt glesch jturt herwortretenten cif̈̈rmigen zuweifen

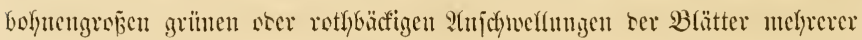

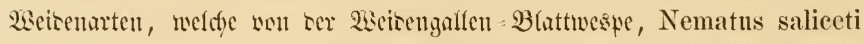
Dahlbom, seren Earve sarin lebt, werurjatyt werten. Dieje frip̈t jidf int

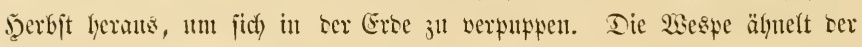

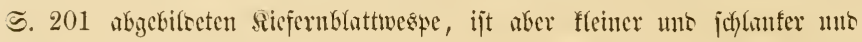
flat cinen ganj fotwarzen scib.

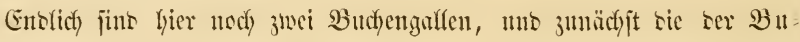
d)engallmütfe, Cecidomyia Fagi Hrtg., ju ermälynen. Sic finoet jidt)

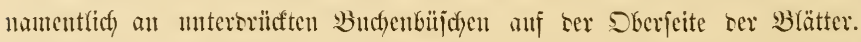

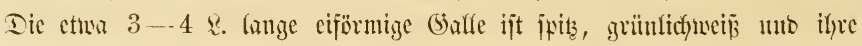

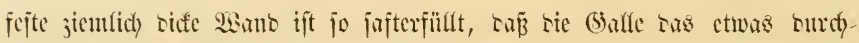
fdyeinente ?njelyen einer reifen 3 einbeere zeigt. Mecijt finten jie jidf) cinje(n,

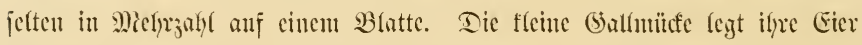

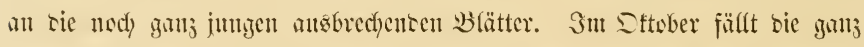

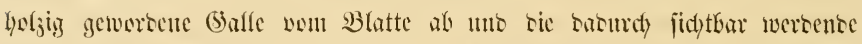

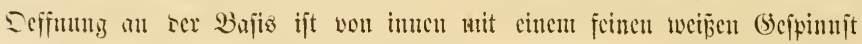
werict)(ojīen. Die Serpuppung erfolgt in ser Galfe.

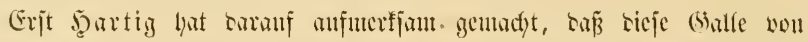

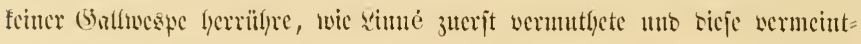
fidye llikeberin Cynips Fagi nannte.

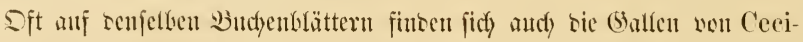
domyia annulipes Hrtg.; sicje fut aber vicl fleiner uno bifoen ein bräunfidjes bichtes mo feites Pinfecthen.

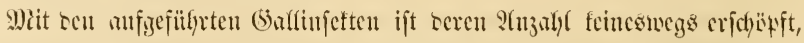

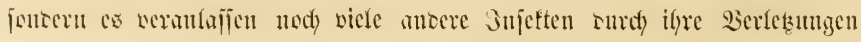
mandyerlei Sermuptaltungen ser Piflanzentyeile, bie man in weiteren Simu (Hallengebilo neunen fönute. 


\section{Bülfter Ab/dunitt.}

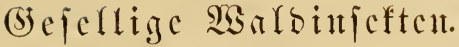

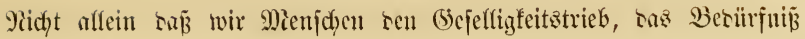

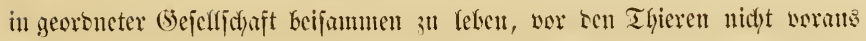
baben, er fintet fidy bei sicjen ober wenigitens bei einizen Thjeren nody

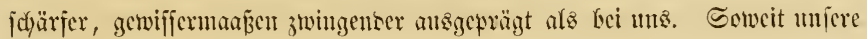
lleberficferungen reidjen, wir f̈nten ?ancifen uno Bicnen afs gefelfige Thiere,

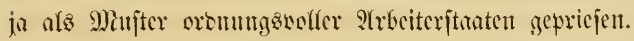

23ir finten aber sicje Miujter, sic wir in Denfiprtidyen mujern Siuteru 3ux Padyafuntug sorbalten, nidjt unter sen böheren, foutern unter sen

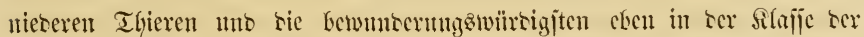
Snjeften. Dic oft unjere bädjpte Bebunterung erregenten Erjobeinungen tes

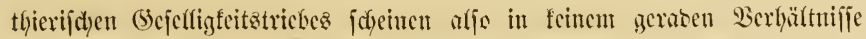

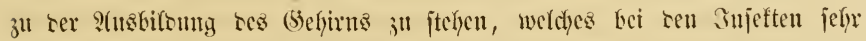
flein uno mur wenig von oen ïbrigen (5anglienfusten in ber (5)anglienfette

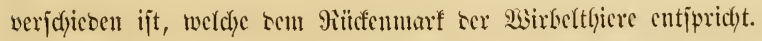

Elge wir sie Stanten ser Infeften betrad)ten, weldye neben ter Micti=

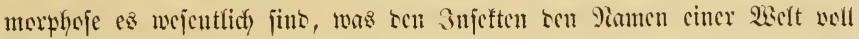

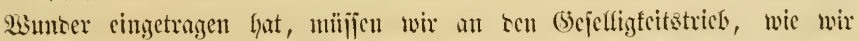
ifn eben am bäd)jten bei einigen 3njeften ansgeprängt finben, snsicnize ab-

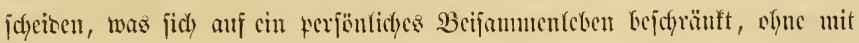

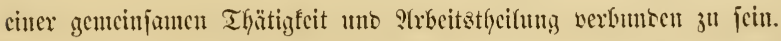

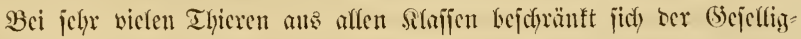
fcitstrieb anf cin heertentweijes Bcifanmenteben, weldyes oft bros mefor won

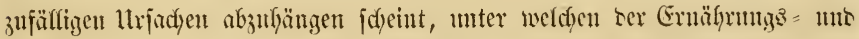
ser Fortpflanjungstriet cinc grofe givfle fpict. 
bei ben Injütonstbieren, sie wir fagn gejellig lebent finten uno

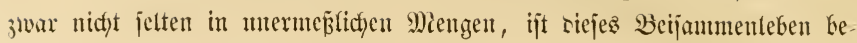

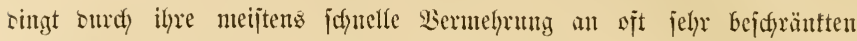
Dertíchteiten von einer bejtimuten, ifpr Reben bejonters begünjtigenten be

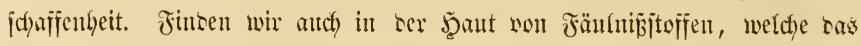

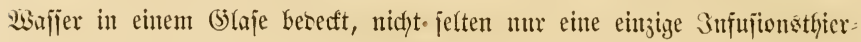

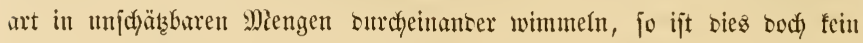
eigentfich jo zu nentuentes gejelfiges beijammenteben, weil jid) bie Mitlionen Shierdyen nidjt um einanter befïmmern, fierin aber, in bem 3ujammen wirfen $3^{\text {th }}$ einem gemeinjamen 3 wecfe liegt tody allein sas $\mathfrak{B c j e n}$ ser mafyen Bejelligfeit.

Solche blos perfönliche Thiergejelfjchaften - jelbjtweritänslidy won

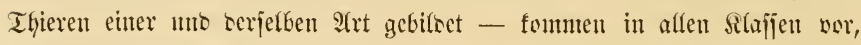
bis zu sen Elephantenfyeerten uno sen in J̧orten won vielen Taufenten bie

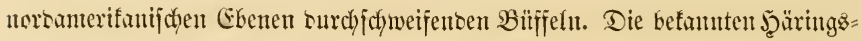

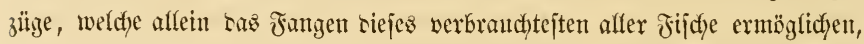

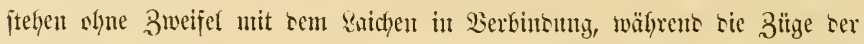

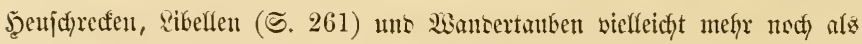

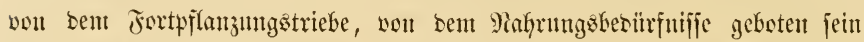

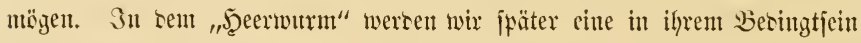

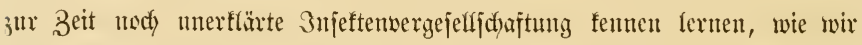

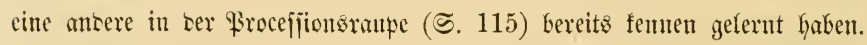

Man fömute geneigt fein, bie jum Bau ser Soralfen (Botypenitöté)

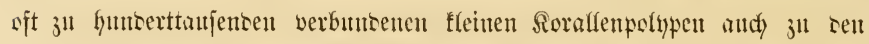
gejelfigen Iflicren ju redynen. Wienn jie biez mären, fo würten jie

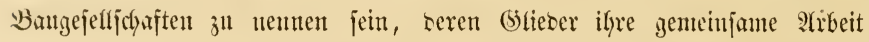

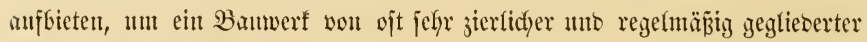

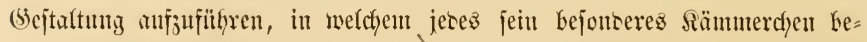

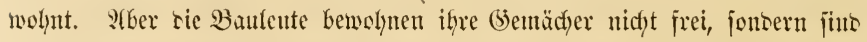
uit ihnen, sie cinen Theil igres zcibes bifon, uno affe inszejannt unter jid) verwadjen. (Sejelfigfeit jetzt aber indiviouefle Freilyeit ber einjeluen unter jid) gejellig Bereinighten rotats.

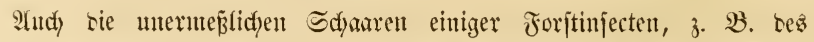

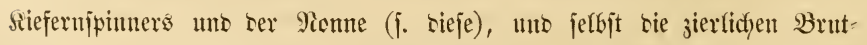

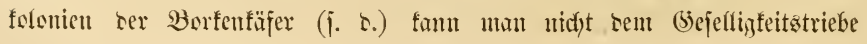




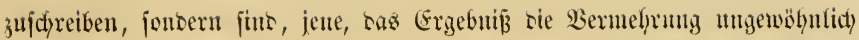

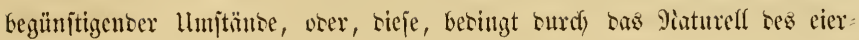
regenoen Weibdjent.

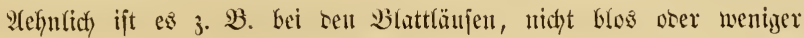
jogar bei ben gulfentbilbenten, fontern melyr nody bei sen freifebcusen, weldye

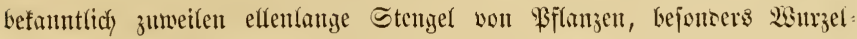

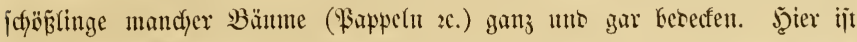

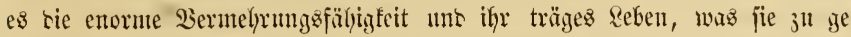

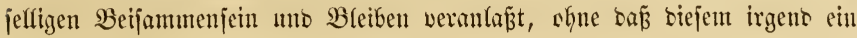
gemeinjanter 3weaf ju Srunte lïge.

So k̈mnten wir benn unter ben Snjeften edyte (5ejerljobaften zu Erreidyung eines gemeinfamen Bwefes, ber fich in jeiner lyädjten berentung

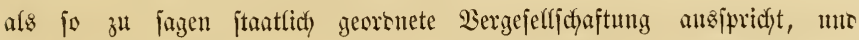
mafjenlyaftes Beijammenleben ofme ein foldjes Ziel, unterjueiten.

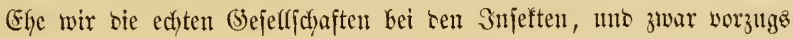
meife sieje, näfer betradften, mïjfen wir hier in vorans nody einer ber mert

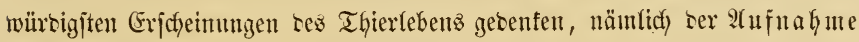
frember Thicrarten in ben 5̧anghalt geferrig lebender Snjeften.

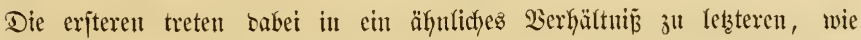

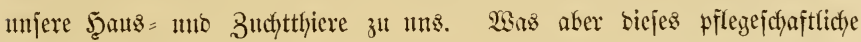

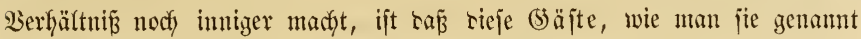
hat, frei fïr jidy uno olyne bieje \$rflege gar nidjt leben fünnen.

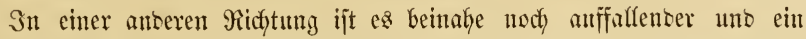

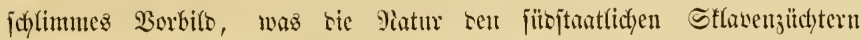
gegeben hat, baf jogar bie Sllavenhalterei bei cinizen gejefligen Thieren vorfommt. Sn beiren Beziefyungen zeidhnen fidd bie âmeijen ans.

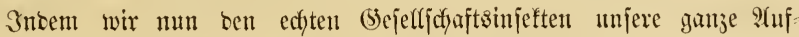
merffamfeit zuwenben, fo begegnen wir ben meiften uno betwuterungsivitr=

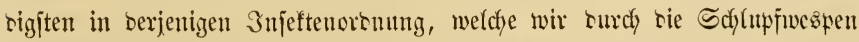

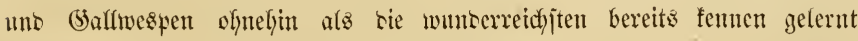
haben, in ber ber Şatflügler, Şymenopteren.

Sdyon früfer (ธ. 198) joflofien wir แms sen Styitematifern an, weldye bie J̧antflüglex in bie 3 Atbtheilungen ber Stadfeltringenten, ber 3njeftenfreffensen uno ber Bflanzenfrefienten eintheilten, uns lernten unter ben beiten lebteren Jeinte wic Bejchützer ses 2 alses fennen. 


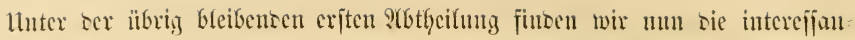

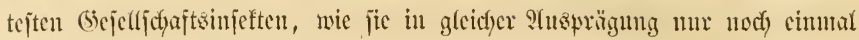

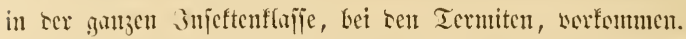

Dic Stact)eltragenten âtorflïgler, Hymenoptera aculeata, fino nแ

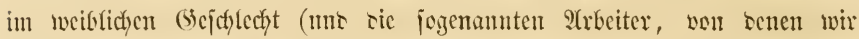

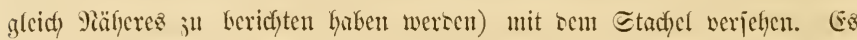

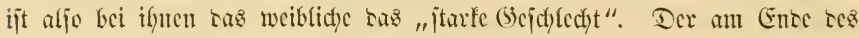

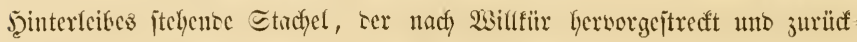
gezegen werten faun, ijt hoht unt mit einex (Biftbraje in Serbinsmlg, anf

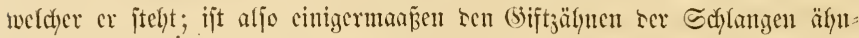

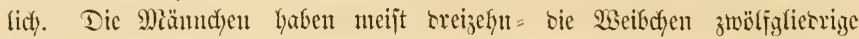

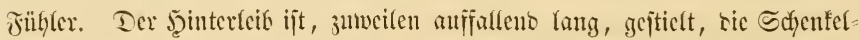

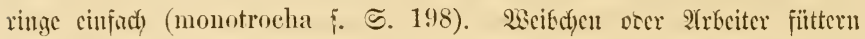

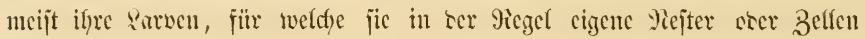

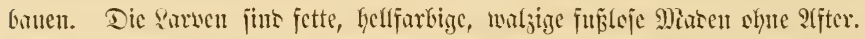

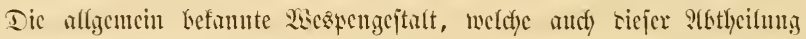

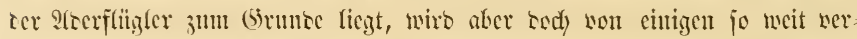

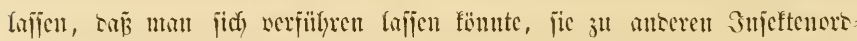

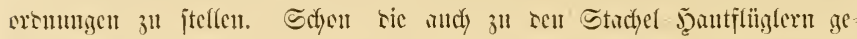

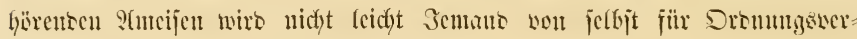
wante rer SBespen mo Bienen balten.

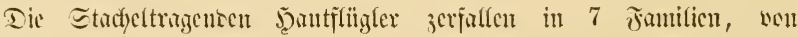

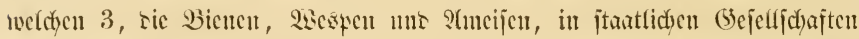

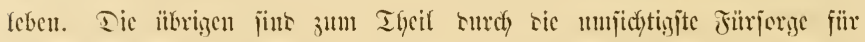

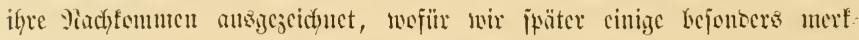

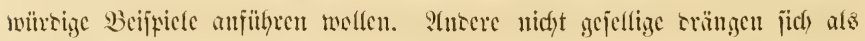

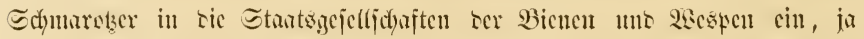

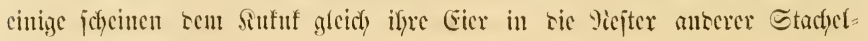
knuttitügler jul regen.

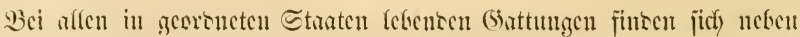

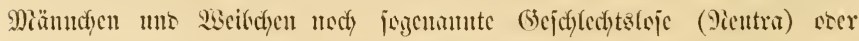

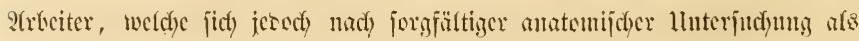

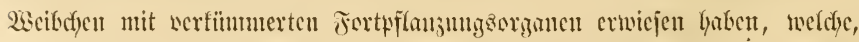
wic wir fpäter jeflen werten, unter llmjtünten fäbig werten fünuen, Giev

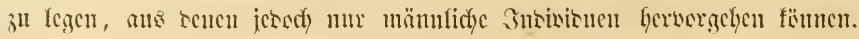




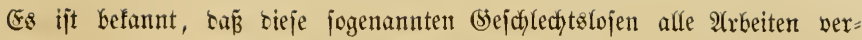
ridjten, welche sas Bejtehen bes Bejelfjhaftsuerbanoes erheifdyt, währeno

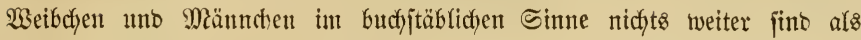
Bäter uto Mitter ifrer Ranbestinter. Die grof̉e Bebeutung biejer ver= fïmmerten, jtt etwiger 2Trbeit vermtheilten 2 seibcyen fïr bas Bejtełen oes.

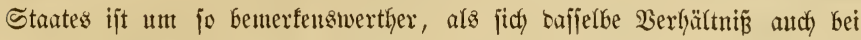
ben Termiten finbet, bie wir eben neben ben gefelljchaftlichen ફ̧autflüglern alz bie einjigen weiteren in georoneten Staaten lebenben Injeften bezeid)= neten. Der Werluft ber Mitterjrettoe ijt biejen jonterbaren, gejeflechtlict) besentungslojen Brefdäpfen burch Freute an ber Arbeit für bas gemeine soht ttib an ber Pflege frentber Sinter exjetzt.

Wir beginnen bie Betradfttutg ber gejelligen \$̧autflüglex mit ber Familie ber Ameijen, Formicarien, von benen bis jetzt ungefäly $800-900$ 2(rten befannt junt*), meijt fleme Thiere, theits von ber all= befannten Âmeijengeitalt, theifs, namentlich in heiz̈en Räntern, von an=

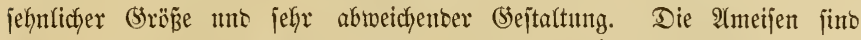
Hiber ben ganzen Ertboben verbreitet uno juthen wegen ifyer Baute am liebjten trodene walbige hodggelegene biegenten auf.

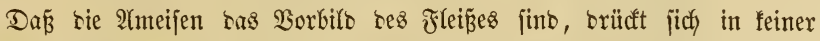
Sprache beutlicher atts, als in ber bentichen, welche einen inverbroijenen

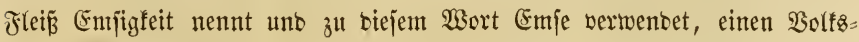
namen fïr $\mathfrak{A}$ meije.

Die mämnlichen unb weibfichen 2 meijen haben 4 bäutige wentgmajcyige Flïgel, welche aber Ginfällig fint unto nach ber Begattungzzeit abgemorfen wercen; bie 2 trbeiter jint jtetz flitgellos uno an ser idymächtigen zujammen = georiidften Brujt, gegen weldye ter fuglige Şinterleib jehr abjticyt, zu erfennen.

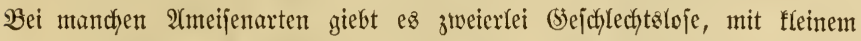
uno mit groß̈en Ropfe, won Denten bie lekzteren Solbatentienjte werrichten. Die Fithler fint gefnieet, 2(1tgen bei ben Männdyen groß́, bei ben 2trbeitern fleit, jumeilen ganz berfïmmert, bie 3 Nebenaugen (Fig. 65 . 4) bei beisen (Sejejlectyern jtets vorfanten, bei ben 2 trbeitern oft fehlent. Bei biejen ijt sie Borterbrujt, bei ben Männdyen แno Meibdjen sie Mitterbrujt jehr

*) (5. Mayr hat affein in Defterreidy 300 Arten unteridjieben. 

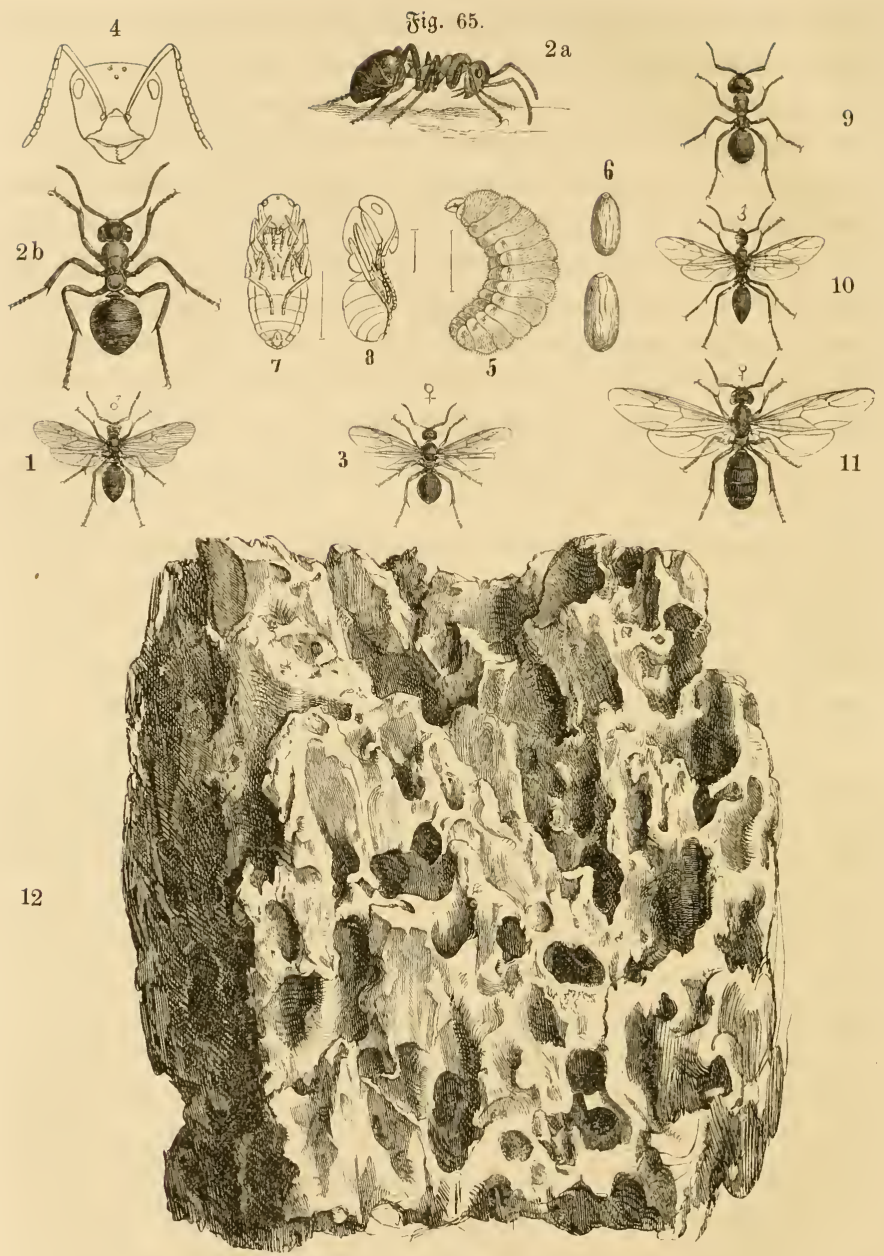

Die rothe 28 aloameife, Formica rufa L.

1. Mäm 7. 8. Hinpue.

Die $R \circ B=$ In

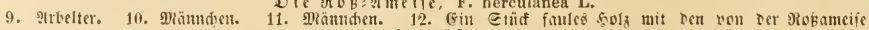
gemad) teu (5ingen.

(2. 4.5. 7.8. vergröbert. Durd) Berichen iñ anf Diejer Tafel ftatt Der Buditaben 3iffern gejanitten worben.) 
ausgebildet. Der 1. ooer 1. unb 2, Šinterleibsring fehr flein uno als furzes Stielchen Den biffen Şinterleib tragent $(2 \mathrm{~b})$.

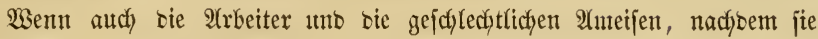

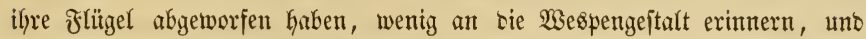
bei vielen atth ber Stadyel berfümutert ift, fo fitto jie body edgte Stachel= Gautflitgler.

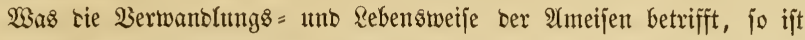

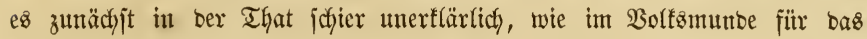

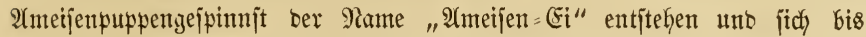

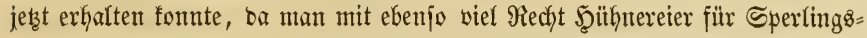
eier Galten fönnte. Die \&arben un \$uppen haben bie getwöhnlichen uns befannten Sennzeidyen ber Dronung, nur baß̃ bie Rarven bei ben ફ̧äutungen eine geringe (Beftaltberänberung erleiben.

Das jefyr leidjt zu beobachtente Treiben ber 2Imeijen inmerhalb ifyres unter einem grop̈en Steine leidft zu finbenben $\mathfrak{B a u e z}$ ijt leiber ben Meijten unbefannt, weil man fidh vor iffen brennenten Bijien, nidjt Stichen, fürdytet. Afferbing - was man freilich bei biejer Furdyt nidjt in $\mathfrak{A} \mathfrak{n}=$ ichlag bringt - ijt bie 2rat siejer $\mathfrak{B}$ erwumbung fajt überlegt boshaft zu nennen, benn nacfoem bie Âmeife mit ifyen Freß̧zangen uns einen fleinen

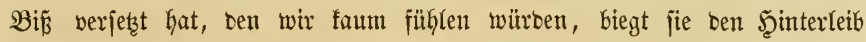
unter jich bortwärts uno jpriz̧t ein Tröpfdyen ifyes brennenben Biftes

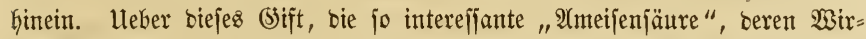
fung wir jhon alle exfahren haben, fhalten wir Gier einige Mittheilungen ein. Neben ifyer auf ober vielmehr in ber \$̧aut einen brenmenten Sdymerz herborrufenten Eigenjaflaft wirb wohl bielen unjerer sejer ber erquidfente

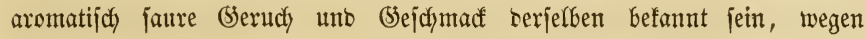
weldyes jie audy in unjeren 2 rzmeijdyas eine Stelfe gefunben, in neuerer

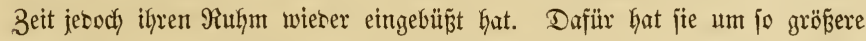

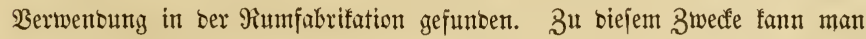

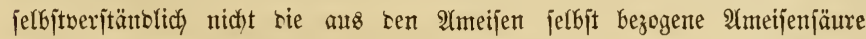
verwenben, weil sieje bazu in viel zu geringer Mienge zu erlangen fein mürbe, fonbern fünitlidy bereitete. Diejen Triumph ber neueren Ehemie werbanfen wir Döbereiner, weldjer vor etwa 40 Jafjen bie Ameifenjäure burch Behandung von WSeinjteinjäure mit Braumptein unb Sdywefeljäure

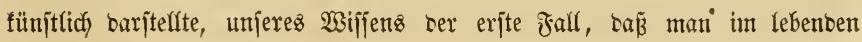




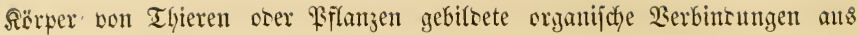
ifrem Elemente nadbilben fonnte. Sn neuterer Beit hat man noch viele ancere Darfeflungamethoben gefunon. Die natïrlide 2tmeijenjäure max jonjt nur jdyer uno in jefyr geringer Menze zu gewinnen, intem man bie zerquetjdyten in ein Reinwantjäfdyen gebunbenen $2(m e i j e n$, sie man mur jawwer von ber Spren ser 2Ameijenhanfen tremen founte, mit 2 ajjer bejtillirte.

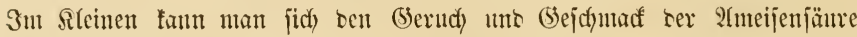

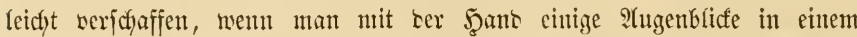

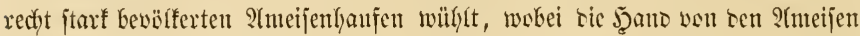

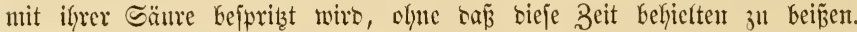

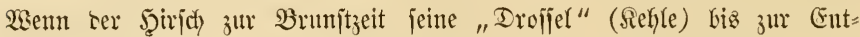

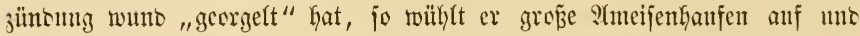

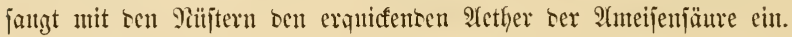

Wix alle fennen ben ganz gleidyen frennenten Sdymerz, weldyen twie rie Aneifen and bie Brenneffleln herwornfen; er fommt won semjelben Stoffe, senn in sicjer mo anteren nit isgenannten Brennfyaren verjefenen

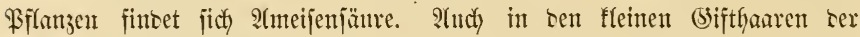

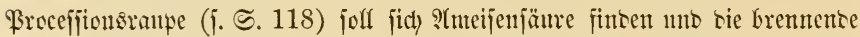
Eigenjuaft berferben bebingen.

Die concentrirte 2 meijenjäıre ift cine jeffr äßzenbe, anf ber J̧ant, and) wenn sicje nidyt verletzt ijt, Эuffen uno Brennen hervorrufente, farbloje,

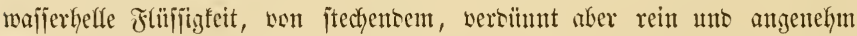

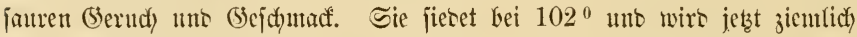

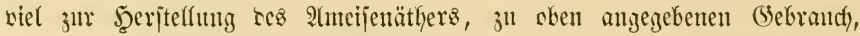

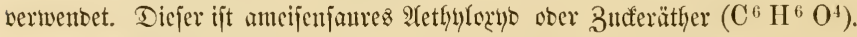

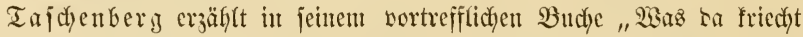
mo flient"*) folgenten Dorfalf, worans ser Gicicfthum ser Ameifen an

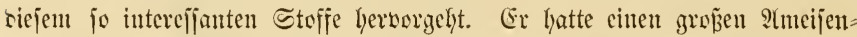

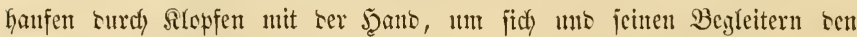

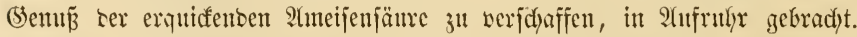

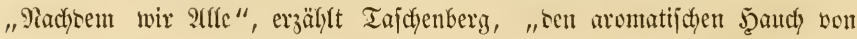

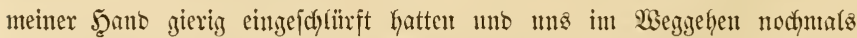
nad) ben förbar fefr แmangenelju berïfyrten erzürnten Thieren umwansten,

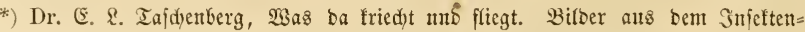
Yeten. Bertin, א. Boffelmann, 1861. Mit 2rbbiloungen in 5ooljidjnitt. 


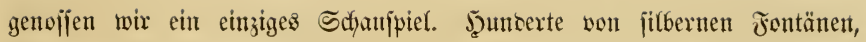
befenthtet burdh bie Strahlen ber finfenten Sonne, fprntoelten von affen Seiten biz gegen 2 Juß hod in bie gewürz̧te $2 u f t$ unb läjten fich auf

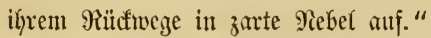

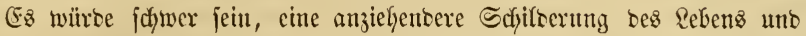
Ireibens ter Atmeifen jt geben als bie, weldye Iajdyenberg liefert, uno bie wir baher hier unverfitrzt einffyalten.

"Ein wahres Sergnügen gewährt $e$ s, bieje emfigen Thiere - von ber Arbeit ift ja ifgr Rame hergeleitet*) - afferwärtz sic Bammaterialien unb

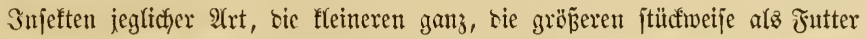
fïr ifye Simber herbeijdyaffen zu jehen. WSie ser geübtejte Âtbeiter fennen fie alfe Sunjtgriffe, unb unbewuñt, wie bicjer, bringen fie bie Bejetze ber

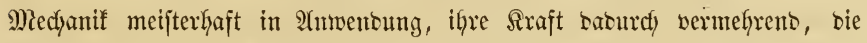

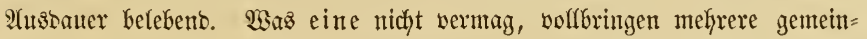
fam ober einanber ablïjent, bismeilen andy ungejdidter uno mit mełar

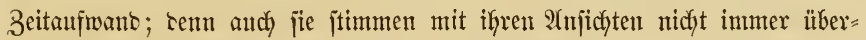

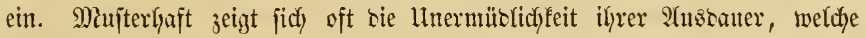

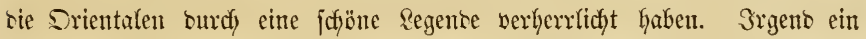

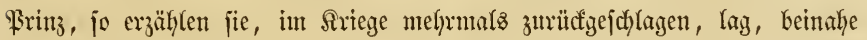

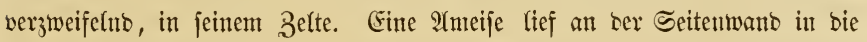

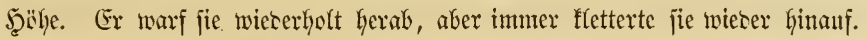

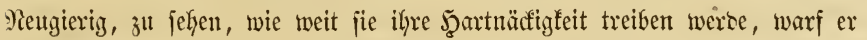
jie adytzig Mal herunter, ofye jie baburch zu entmuthigen. Er jelbjt

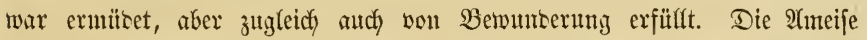

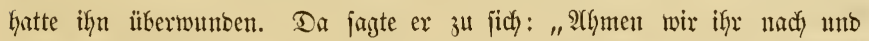

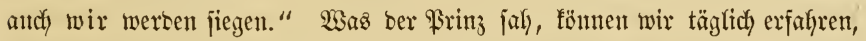

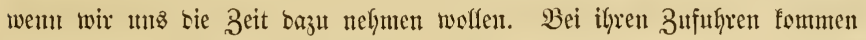
sen 2 (meijen bie breiten Straß̃en zu Statten, weldye fie anlegen uno mit ber Zeit ganz glatt treten; jie "ziehen weniger Schlange", mie z. B. bie glänjenbidywarzen unjerer (Särten, marichieren aber atth in ziemlidy georb=

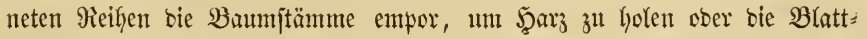

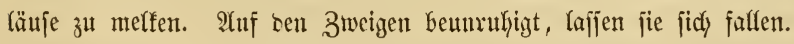

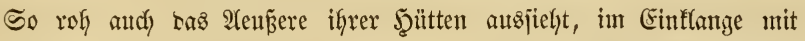

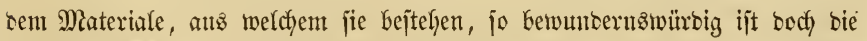

*) 23 ir nehmen vielmehr die umgefehrte 2rbleitung an.

D. $\mathfrak{B}$. 


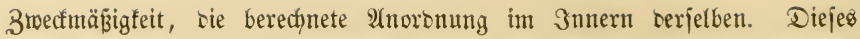

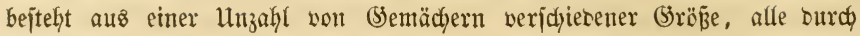
(Sänge mit einanber berbunben uno in veridfiebene Stofmerfe vertheilt, einige tief unten in ser Eroe, anbere in rer Suppel Һев (5ebäuber. Sente jino beftimmt zur 2(ujnahme ber Эugeno bei faltem Wetter, oder über

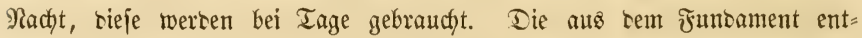
nommene Eroe wiro mit ben jajon genannten ober ungenannten Materialien gemijht uno giebt זem luftigen Shlofie feinen Şalt. Strahlenartig jüfyren (Sänge von bem Innern nady aupen, sie Thore ber volfreichen Stabt, ourch aus = uno einpafïrente Bewohner fortwähreno belebt, für Frembe aber veridhlofien burdy bie $23 a d$ e haltenten "Stabtjoltaten"; bie

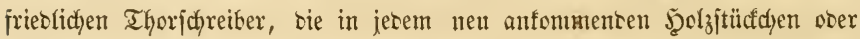
Räupchen etwa S) Zahl = ober Schlachtiteuer = Defraubation wittern mëchten, fennt man in jenen Republifen fo mentg, wie in unfern tyortojen, in

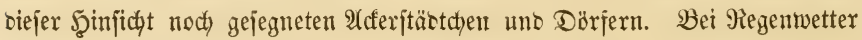

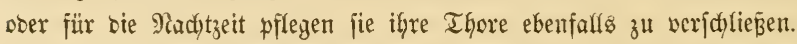

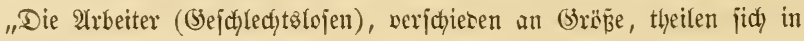

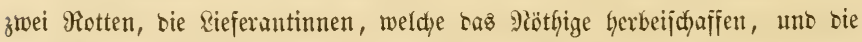
Gän\&lid)en Wärterimnen, weldye bie innern Familienangelegenheiten, bejon=

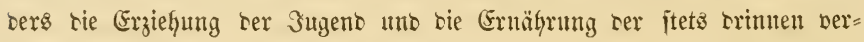
borgenen Männdjen uno weibdjen bejorgen. Shuen füllt eine ungeheure,

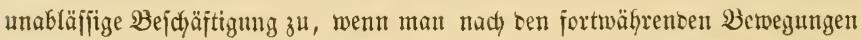

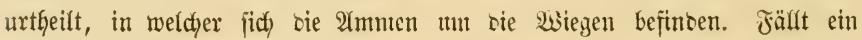
Regentropfen, fdheint ein Somnenitrafl, io giebt eo cinen affgemeinen $\mathfrak{A} u f=$ ftano, eine Umbettung afler Sinber, uno bas mit unermïblictem Eifer. Man jieht, wie bie Bflegerinnen sie groß̧en sitnser behutjam aufheben, meldje jo viel wiegen, wie jie jelbjt, uns biejelben won Stoctwert ju Stodf= merk bis zu ber exforterlidjen Stelle tragen. Das ijt jebody nidyt 2(llez. Die Sorge ber Ernährung ijt hier viel zujammengejetzter, als bei ben Bienen. Die fleimen hirjefornartigen Gier müjjen belectt uno mit einer ernäbrenben Feudytigfeit verjekgen werben. Die Rarven দjaben inmer \$̧unger uno wollen in furzer Zeit erwadjen fein. Dic Ruppe, weldje fich ein

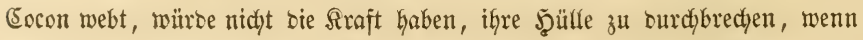
nicht bie aufmerfjamen $\mathfrak{B a ̈ r t e r i n n e n ~ b a ~ m a ̈ r e n , ~ s i e ~ a u f ~ s i e ~ 3 u f u n g e n ~ i m ~}$

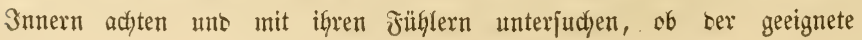




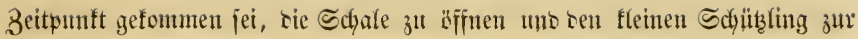

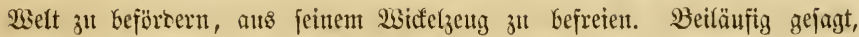
reitfen 23 Tage hin, alle sieje Stufen zu burdflaufen. Sest, follte man

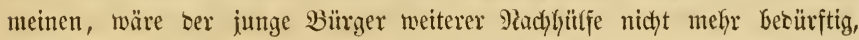
befähigt, jidy) felbjt fortzutlecfen uno bie angebornen Tafente zu üben. Dem ijt aber nidjt fo, er ijt nody ein sino utto wiro als joldes betradjtet.

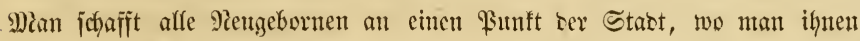

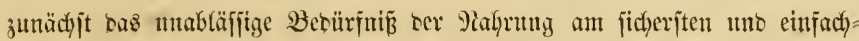

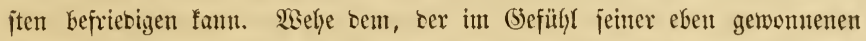
Siraft vorwiţ̧ig jeinen eignen (bang gehen unto jidh entancipiren wollte;

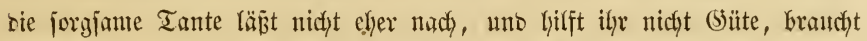

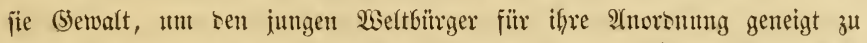

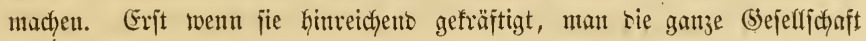
mit ben 3tnern ber Stabt vertraut madjte, füffrt man jie nad) auß̌en, zeigt iffnen, wie man jagen müffe, uno gemäfnt fie saran, fïr fidt jelbjt

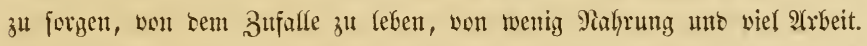

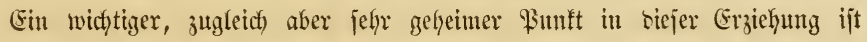

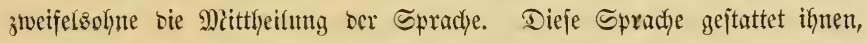

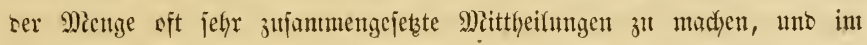

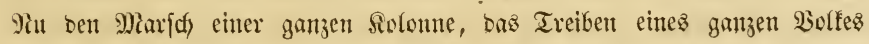

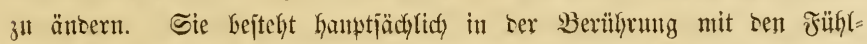

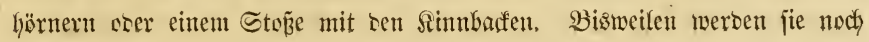

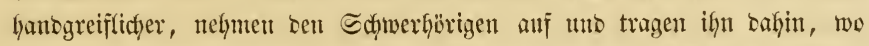

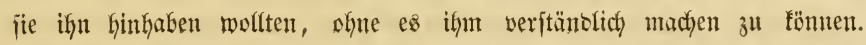
Mit biejer lebryajten Bejitiftration verbinben jie noch viele anbere, uner=

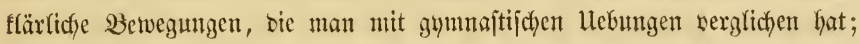
jie jpielen mit iffen jtets tajtenten, bann wie franfGgaft bibrirenten FüGlern,

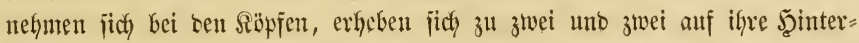

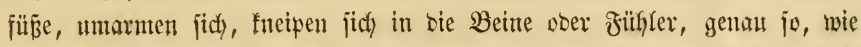

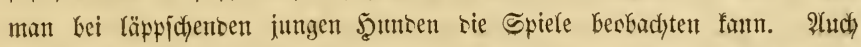
an ernjten sämpfen Lajīen jie es nicht feglen, zwar nidft entbrannt im

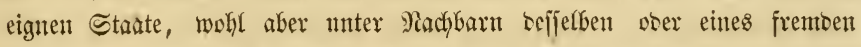

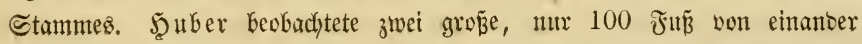

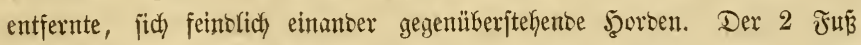
breite $\mathfrak{2}$ egeg war mit 2 meijen ganz bebectt, weldye etwa in ber Mitte 
Defiefben jich begegueten. Şier entbrannte die Schladt, ein mörterifdyer Rampi. Iaujenbe von ihnen hatten einzelne ફ̧öhen erflommen und pacten fich mit ifren gewaltigen 3angen im müthenben 3weifampfe. 34 ben Seiten fino nody mefyrere bejdyätigt, (Sejangene zu madyen uno nad ifyer

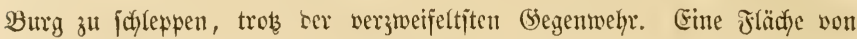

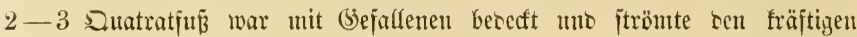
Duj̣t ber Säure meithin in die Rüfte. BBci cinbrecfyenter Dunfelheit fehrte

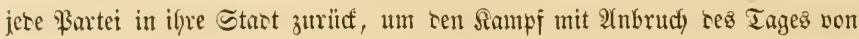
Penem mo weit mörterijd)er zu beginnen, als am vergangenen. Dabei waren bie gemöhnliffen 2 rbeiten in beioen Solonien in feiner Weife unter= brodyen, fie gingen fort, wie in tiefiten Frieten, nur zogen immer wieser meue Srieger aus uns Iransporte von Bejangenten famen an. (5)ré̉e

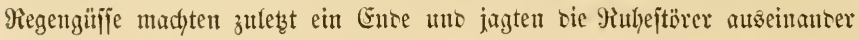
wie einige wohfgeridgtete Fenerfprizen oie aufgeregten (Sentüther bei einem Bolfäanflaufe jo grïndlidy abzufïlylen vermögen.

"Der überrajdyenrfte 2(uftritt, ben man mit anjehen faun, ijt eine

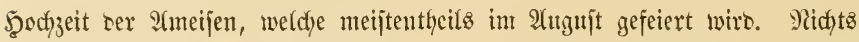

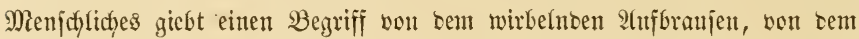

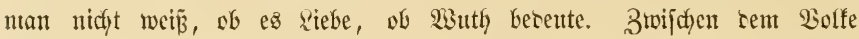
wilter Brautpaare, weldye von nichts zu wifijen id)einen, irren llngeflügelte umber unb greifen bejonsers bie an, weldye fid) am meijten verwicfelt haben, beiß̄en fie, zerren jie jo jtarf, taß̉ man meinen jolfte, fie wollten fie zer= malmen. Daz ijt aber nidyt ilyre 2tbjicht, jie wollen jie zแm Siehorjant,

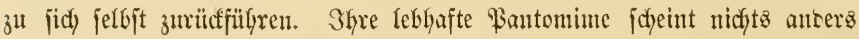
jagen zu wollen, als: "jeit verjtämbig, haltet Maá̃ uno Ziel!" Dieje Sungfraten ïberwadyen aljo and tie Siebenten uno jüfyren eine ftrenge

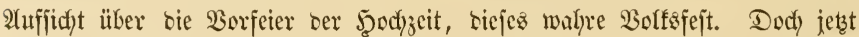

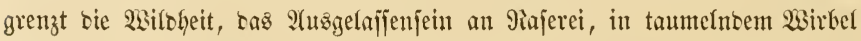
erhebt jich bie geflïgelte Schaar, zunädjit im wedfelnten Steigen umb Sinfen, zuletzt hoch in bie süfte mo verfdywintet in weiter Ferne. Pim

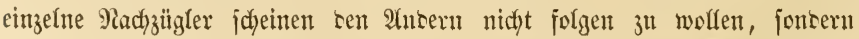
bem Saterlante Trene angelobt zu haben, vieffeidft waren fie borker ermit=

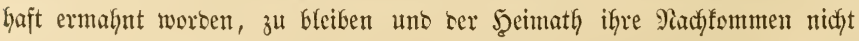

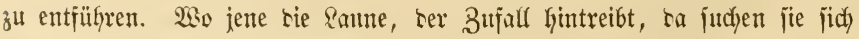
eine neue Wohnjtätte, grünsen ifgre folonien. Tanjente yon ignen werben 
Gierbei eine Beute ber Böget orer fallen in bas $\mathfrak{B a j f e r , ~ w o ~ f i e ~ v o n ~ b e n ~}$ Fijcyen weggejdynappt werben. Die Miänndyen verjobwinten alobald, jie haben ifyen 3roef erfülft uno - jterben. Die 2 seibchen verrichten zu-

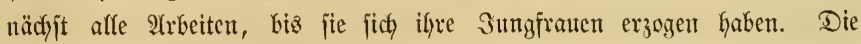

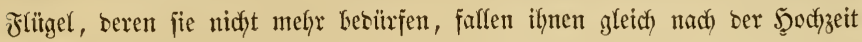
aแs, wenn ancers jie biefelben im wilben Taumed nidft f(t)on verleren."

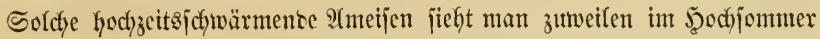

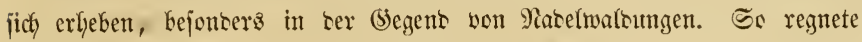
ez am 4. 2lugujt 1856, erzähyt Tajchenberg, obei St. Saphorin in ber

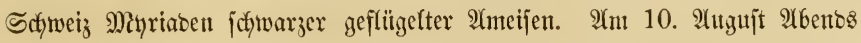

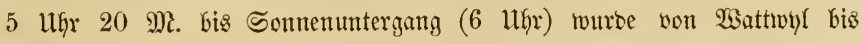
Ridytenjtein, ber Thur entlang eine won Sïbmejt nad) Norbojt ziehenbe Schaar geflügelter jubwarzbrauner Âmeijen beobadytet, bie jich in einer

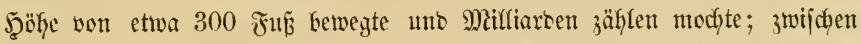

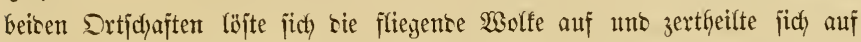

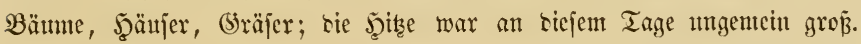
Die 2tmeijen bieten uns aber trody mefrere anbere interefjante Seiten bar.

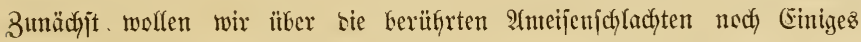
nadjtragen, weldfe jeit $\mathfrak{S} \mathfrak{u b e r *}$ ) (1810) won Megreren Geobacftet unt bejtätigt worben fins.

Dabei ijt bejonbers bie, anthy jomjt vielfältig beobacftete, auperorbentlich

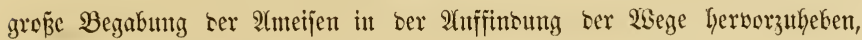
rie man jait eine Drientirungågabe nennen mödjte. Rałzeburg erzählt,

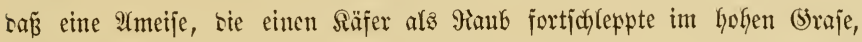
ber für jie boch wie fïr uns ein Hrmalb fein muste, nach mefrmaliger

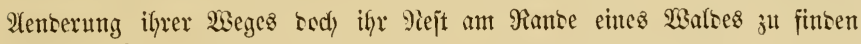

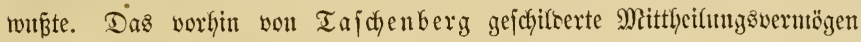

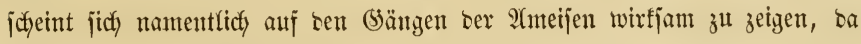

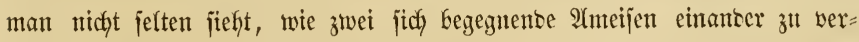
jtänbigen icheinen unb bann bie eine mif ber anteren wieber unfefrt. Ein

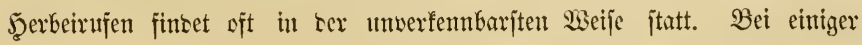
Alumerffamteit findet man ben ganzen Sommer finturch, namentlidy in

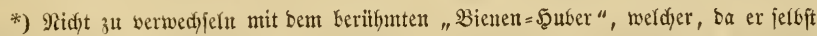
blinb war, burd) Bermittlung eintes Dieners, jeine widytigen Beobadytungen an ben Bienen madjte. Son biefen fpäter bei sen Bienen. 


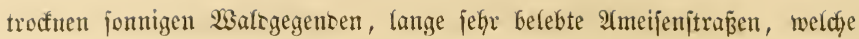
non ifuen gejäubert uno geebnet- jür. Bur Zeit ber 2beizenernte bemerften

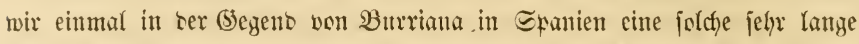
Ameijen = Ehanjiee, auj weld)er viele Taujente bon Z(meijen Weizenfürner

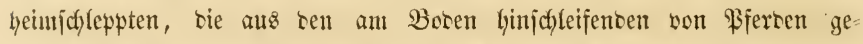
tragenen Garben ausgefallen waren. Es war zwijhen Mienjach uno Ifieren ein "empïger" 2 Betteifer sez Erntens non einem uno Lemjelben

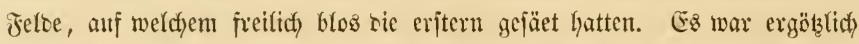
anzujefen, wie sie fleinen idjwarzen Sajtträger non sen über jie finmeg= fegenten Aeflen über sen .̧aufen gerifien mo surd) einanter gequirft

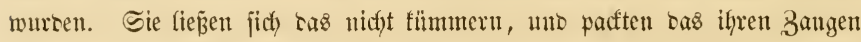
babei vieffeidyt entfallene wieizenforu, weldyez jeywerer war als jie jelbjt, wieser fejt uno madjten jich bantit ans bem Staube, was jefy butchitäbfict) zu nelymen ijt.

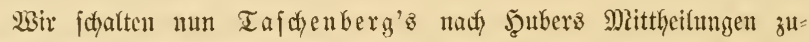

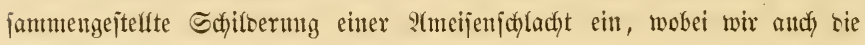
Sflavenhalterei ber atmeijen fennen lernen werben. Alfo aud hierin

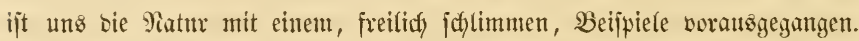

"Die röthlidyen 2 meijen (F. rufescens), mit einem Stactel verjehen, wertajfen, um Sflaven zurauben, ilyre 230 hnumgen, jeboch nicht eher,

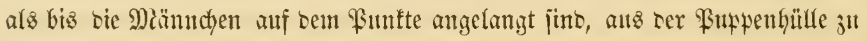

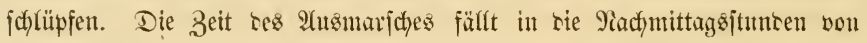
2 biz 5 uhf cincs jelyr warmen Sommertages, nadjsem auzgejante Späher zurtïfgefelyrt jüt uno nun ju Sisgmeifern bienen. Shre oben ermähnte

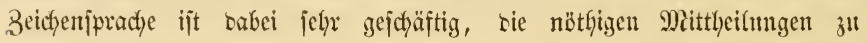
madjen. Einize pflegen ben Bortrab ju bitren, fie fino aber nidyt weit voraus, fo fefjen fie um, fdyfießsen fid) rem (Sros bes Şeeres an uno anre treten an ifye Stelle. Inf bejdywerlidfem Mlaxidye, surdy (5ras uno anf unebenem Terrain zeritreuten fich einzelme unabjichtfich, weldye bamn nit

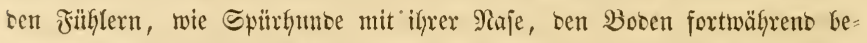
riilyren uno bie 2 rme wieber auffuthen. J̧aben fie nach bisweilen an=

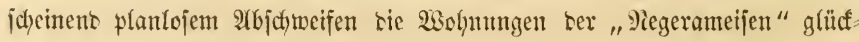

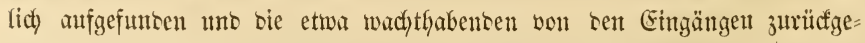
brängt, weldye unter 1 mitänben znerjt angreifen uno fich auf ben Sortrab mit rajenter 23 th werfen, fo bemächtigen fie fich ber tapjer wertheibigten 
Stast nicht ofne harten Sampf vor unb imnerhalb ber Mauern berferbet, erftürmen bic Sinderjtuben uno fefren belaben mit ben fisppen uno Sarven bon $\mathfrak{A}$ beitern anf remjelben wege zurü, wo fie Gerfamen. Die armen Yeger entflieken nad allen Seiten un fudhen zu retten won ifren Sleinen, jo viel fie fümen. Das Siegesglüd bei fold) entjetzlidten

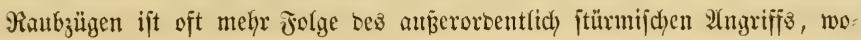
mit fie ben Mhuth ber anteren nieseridhlagen, als ber eigentfichen Heberlegenheit, obgleid) sie angreifente \$artei in iłren Insivibuen sic ftärfere ift. Bisweilen müfifen jie aber aud) ber Hebermadyt ter Sdywarzen ertiegen

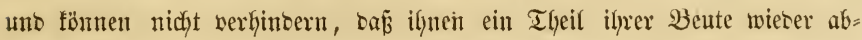
genoumen wirb. Dies gejdjeht bejonbers non einem antern, wie es jdyeint, mutbigeren Bolfşitamme, ber Mituirameife (F. cunicularia), weldyer ebenfalls vor Sinberraube won Seiten jener Rothlyäute nicht gejichert ijt. In anberer Weije geftaltete jidy wieser ser Raubzing ber blutrothen 2(meife

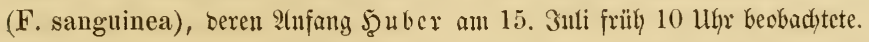

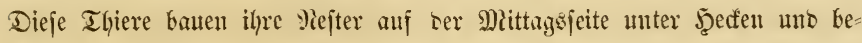
rauben beire $\mathfrak{A}$ rten ber cben genannten Stammwerwanbten. Ein fleiner

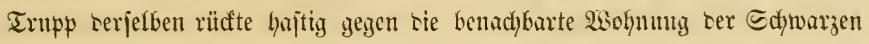
an uno zerjtrente fid) bort. Dieje famen in Mienge anz ifjem J̧interhalte hervor uno madjten mefrere (jofingene. Die Entfonmenen fdjienen auf

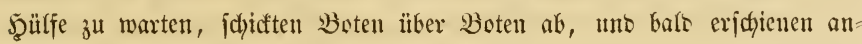

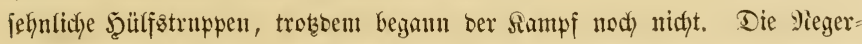

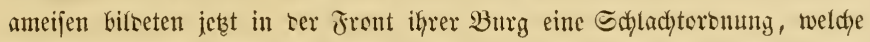

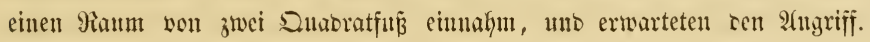
Sleme Scharmützel fielen nor, che ser eigentlidje Sampf bon ten Sdywarzen begonnen wurbe. Modf lange vorker, ehe ber 2tusgang serjelten jich ent=

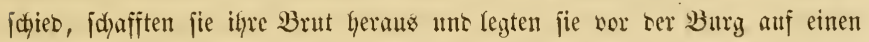

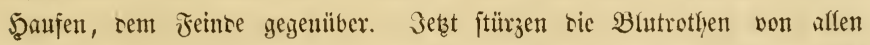
Seiten auf bie Edhwarzen los, sie Edyladyt ift mürterijd. Dieje, fid) jerbjt vergeffent uno ifyre cigne Sidferkeit, verjudfen ihre Sinter ju retten

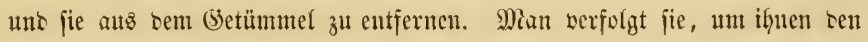
(Segenftand ifyer Riebe zu entreisen, anbere oringen in sie verlajfene Burg ein uno jdyleppen fort, was fie nody an Braudybarem, fimben, fo tas balo

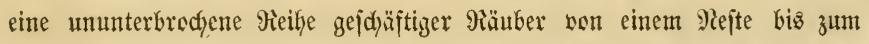
anbern fich aubbehnt. Dabei verging Ler ganze Tag, ein Theil ber Madft. 
On ser eingenonmenen Burg wax cine Bejałzung zurüafgetafjen worben, uno an folgenben Morgen fing ser Transport ber geraubten Sinter vou

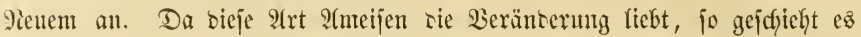

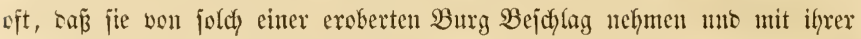
ganzen Jamilie in biejelbe ïberjiteteln. Die Beranbten, bie nie 2tfez wer=

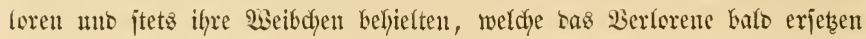

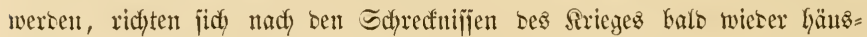

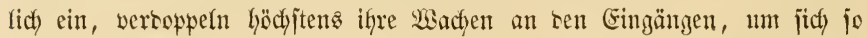
bejier worzujeken, ober finten einen neuen Srt, wo jie vieffeidnt meniger

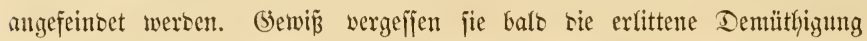
uno gehen ifyren gewolynten Bejdäftigutgen nach. Was wirs aber aus ben (S)eraubten, ten armen \&arven uns Fuppen unter ben granjauten Frento= lingen? Der Mame "Sflawe" bezeidfnet ifyr 2008 nux injofern, als jie von ben 3hrigen gemaltjan getrennt wursen, im Uebrigen geht es ifhen fo wohl, afz es ifnen mur bei 3enen ergehen würte. Sie gehïren zur grof́en Jantilie, haben nidyts wou Drut ju empfinten mo exhalten ifye volfe

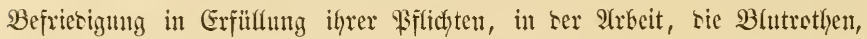

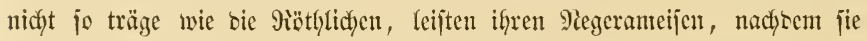
jid) siejelben ans ben sarven uns łuppen erjogen, wacfern Beiptant bei affen Bejejäftigungen, tragen jie jogar, wem (5efalyr broht, in 2tmerfen=

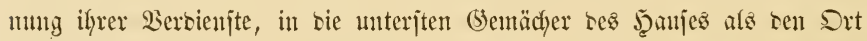

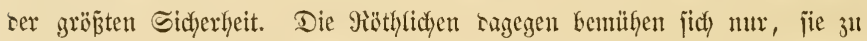

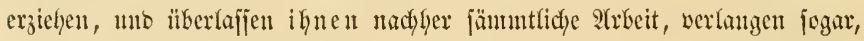
won ifnen gefüttert z"l wersen. Das ijt viel werlangt who jengt von einer

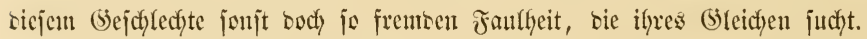
Man hat jie entichulsigen wolfen unb behauptet, ifye Munstgeile jeien jo

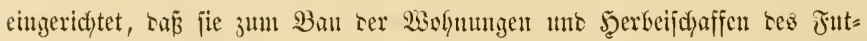
ters jich nicht eigneten. Dem jei, wie ifm wolfe, genuy, jie thun es nicht.

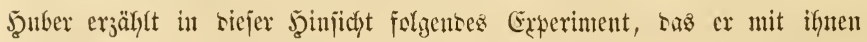

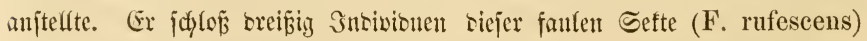

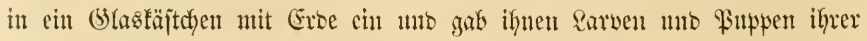
eignen Gattung, fowie einige Pegermeijen = \$mppen mit, aber feinen ein= jigen Sflaven. Sn cincn Winfel sicjes (Sefängnifjes legte er ifnen etwå

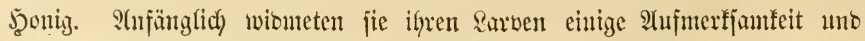
trugen fie hin uno her, balo aber vernadyläjigten jie siejerben uno ließ̃en 
bie meiften in weniger als zwei Tagen werhungern. Sie jerbjt nafmen feine

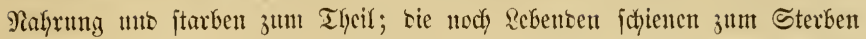

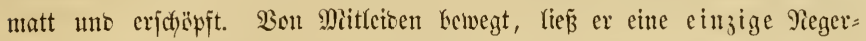
anteife lyinein, weldye für fidy allein fogleich sie Drbunng wicher heriftelfte.

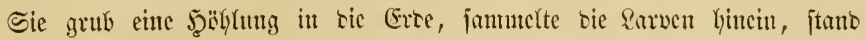
ben Puppen bei, weldfe bereitz ber Entwidfturg nahe waren, turo erbielt

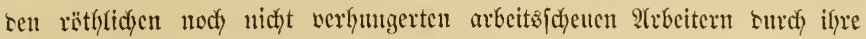

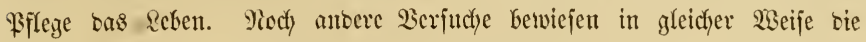

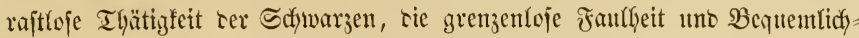

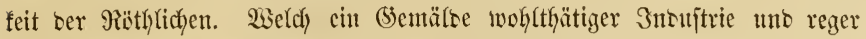
Strebjamfeit in Begenfatze z"l ben jdyedffichen Folgen ber Bequemlidjeit uno ber Inbolenz!"

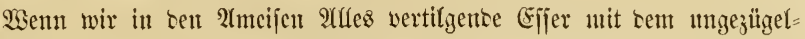
fitn (Sejdymad fenten - ocr 2tuntom besiente. jich jonjt ifyer, um in ifyren 3sohnungshaufen gelegte fleine Thiere von ifmen ffeletiren zu lajfen, ja jie jollen eimmal jogar bie Sfelctirnng eines Sirofobils bejorgt haben - jo bürfen wir uns billig wutbern, baj wir in ren Staaten bicjer Saunibalen eine Menge frember 3njeften aufgenommen finten, weldje von ifnen nidjtz $z^{u}$

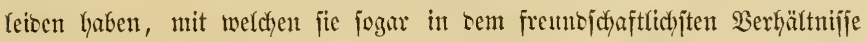
leben, ja von benen einize mit affen ifyen Rebenzbedingungen an bie (5ejell= jefaft ber 2(meijen gewiejen fint. Man nennt riefe Mitbenolyner ber

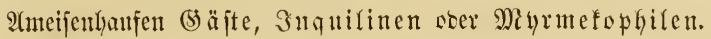

Die Zaht ter SAmeifengäjte beträgt bereits über 300 uno zwar jino sieje in ber Mefhrjahl Räfer, von beuen wir einige ter widftigiten uno am lätrgiten befannten aufithyen.

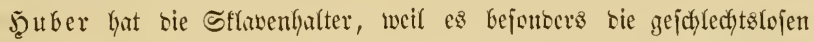

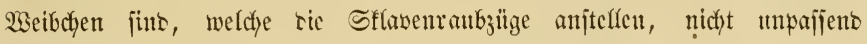

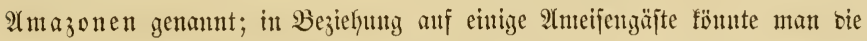
Imeifen, in beren Staaten fie wohnen, J̧ollänber, in ber Bebentung bes Betriebes ber Mildynirtyjdyaft, ucunen.

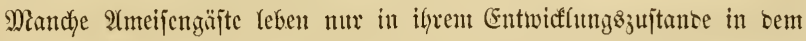
Imeijenfyanfen, wie bies fidyon lange won sen Earven uno in einem aus Eroflümpchen zuammengefiigten Eocon geborgenen \$uppen bes (B) olbfäfers,

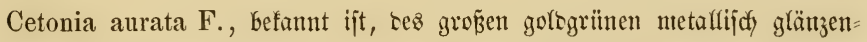
sen etwå plattgebrüctten Säfers, sen wir namentlidy im Sommer auf ben 


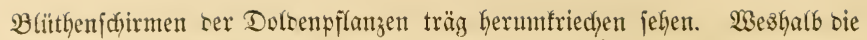

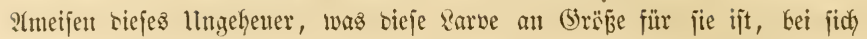

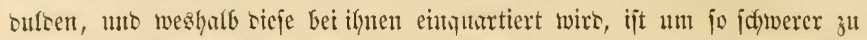
begreifen, sa jie jidy jonjt aud in 5̧anfen won Sterbertohe uno im 3nnem

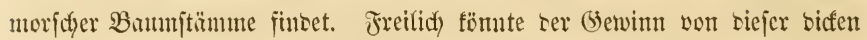

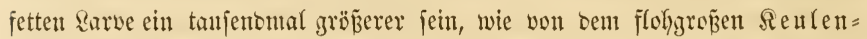
fäfer, Claviger foveolatus Preyssl., wenn jie trzu belegenfeit giebt, was unjeres æ3ifjens wenigjtens nody nidyt ermittelt ift. Diejer fleine Glinte uno aud jonjt ganz unbegülfliche Säfer fintet bei ben 2 (nneifen gajt= lidye llnterfunft, wiro von ifnen gejüttert tmo abgemartet, giebt aber bafïr, wenn bie Beobadytungen ridytig jint, sen 2tmeifen ein freilicy minzig fleines

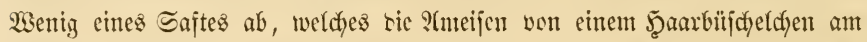
Ente jeiner Flügetrecten abjangen. Freilidy ijt ber Ertraj siejer Mitch)

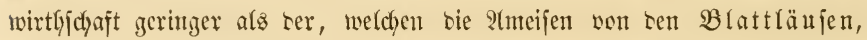

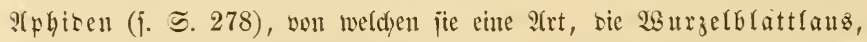
Aphis radicum, in ten unteriten (Semäcyern ifres Bantes aus sen Eiern erzieben uno alshann sen von ilymen abgejonoerten ફ̧oniglaft lecfen.

(5z ijt bejonbers bie แแz anf $\Im .254$ burct) ben rothoedigen $\Re a n b=$ fäfer bcfant getwortene famifie ber furzflïgligen Räfer, won weldjer

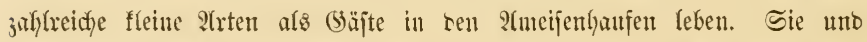

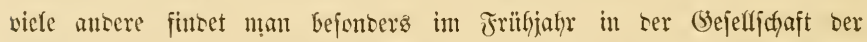

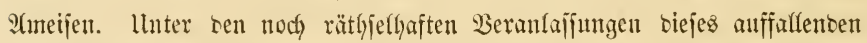
Beifanmentebens barf man wohl an wenigiten an eine feinojelige Arbjicht biejer (5äjte senfen, weil sie an Bahhl übermiegenden tapjeren 9 (meijen mit ifnen ofhe 3weifel bafo fertig werben wïrben. Die bei uns fefr häufth vorfomuteten Formica rufa L. uno F. fuliginosa Latreille beherbergen

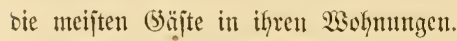

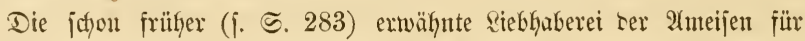

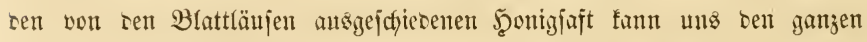

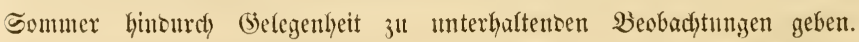
Man ıiro Ia ut \&eidtigfeit Bäume finsen, an seren Stämmen $\mathscr{A}$ meijen

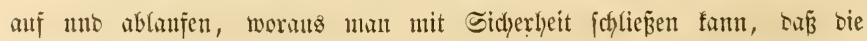
Sirone เer Bäume won Blattläujen bevälfert ijt, nanentlich) bie üppigen Triebe serjerben, weldye befanntlich) won biejen oft ganz beceft jint. B̉e= quenter Gat man sie Beobadjtung au üppigen 2 surzelidjößfingen แno 


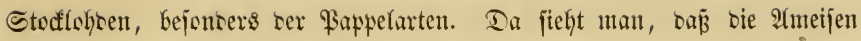

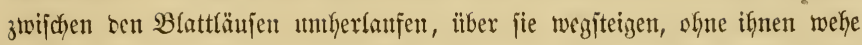
3u tḩun, jie mit if̧ren langen Füffern betajten. Diejeß Betajten, worin

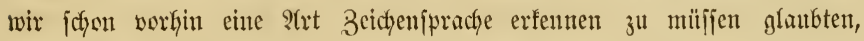

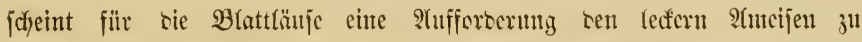

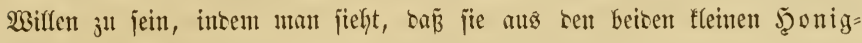
rähren, welde viele atrten am Ente tes j̧interteibes haben, fleine

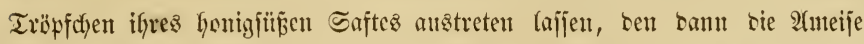

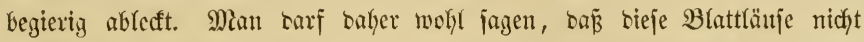

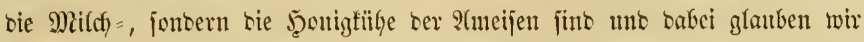

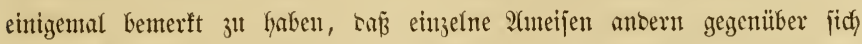
ein Bejitzectyt über bie Blattlansbevölferung eines fleinen Triebes ober

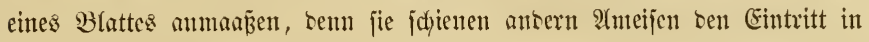
ifren Blattlanşâtall jut werwelyren.

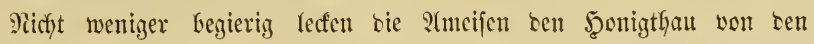
Banunblättern ab (weldyer betunntlich) wenigitenz zun Theil nidgts anberes

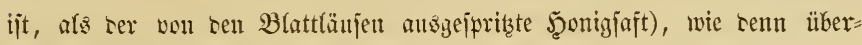

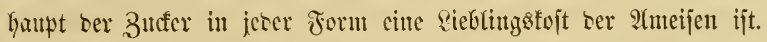

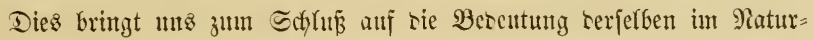

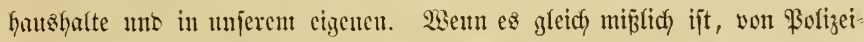

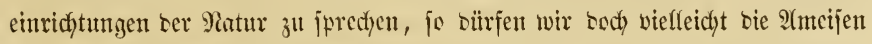

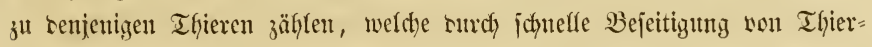

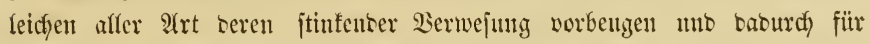

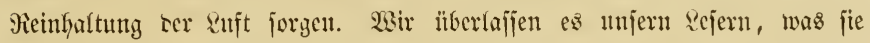
ïber bieje Jrage urtheilen worlen. Sn tropifgen :äntern freilids, wo bie

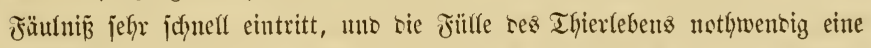

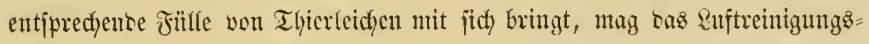

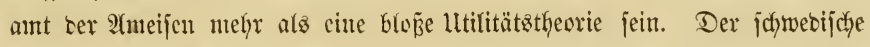
Reijente \&uno erzählt, Dar er faum Zeit gefhabt habe, einen eben ge=

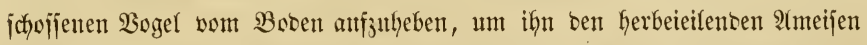

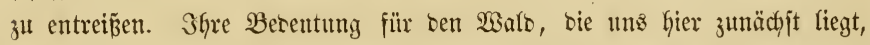

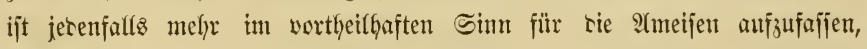

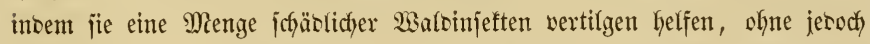

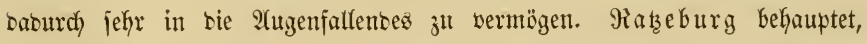

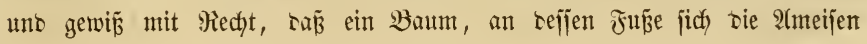




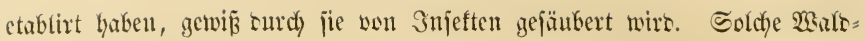
ameijenthaufen nefmen bejonters an troctuen fonnigen Stellen in Bebirgs:

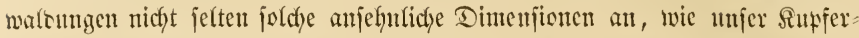
fitch jeigt uno jinto ein Borfdymad won sen Fiejenbauten, melche mandje

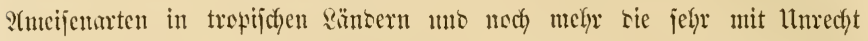
"weipe 2(meijen" genamten Termiten auffïfren. Der Schaben ber 2(meifen im 3nneren jtehenter Banmjtänme ift höcbjt mahrifheinfich) für

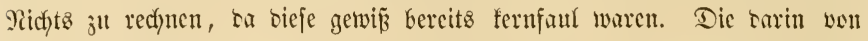

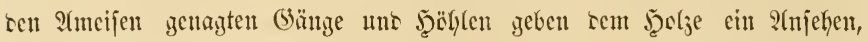
meldyes einizermanãen an sie Miorcheln uno cinige antere ähnlliche $\mathfrak{B i z z e}$ crimmert, insem zwif̧chen sen zelfenartigen Piäumen meijt mur ganz bïnme Wänte itehen bleiben, nod) viel tümmet ats es unjere nad) ter Siatur ge= zeidynete Jig. 65.12 saritellt.

23enn man in ber freien Pantur sen 9(meijen für ifys Treiben jesen= falls freie J̨ano lafjen famn, fo jino jie uns um jo unlebjamere Säjte in umjerer Behaujung uno an ren Epalieren unjerer Dbjtgärten. Es gilt

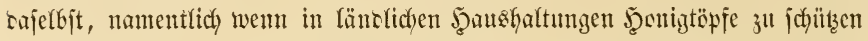

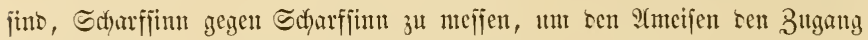
abzujdyncisen, uno nidyt jelten finsen wir zuletżt bod) unjern 23 itz won ibnen befiegt.

Hnjere Signmen, anf seren Interjarift wir berweijen, ftelfen zwei in unjeren 2 alsungen jelyr verbreitete 2 aldameijen tar, won weldyen Formica

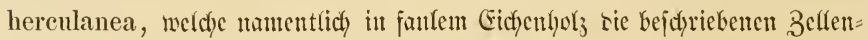
bauten macht, sic größ̄te curopäijche Trt ijt.

Die von sinné in bie eine Battung Formica vercinigten Arten finto fpäter in zaflreiche Sattungen zerfällft uno bieje fogar in 2 (5)ruppen ge=

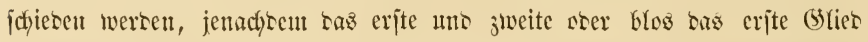

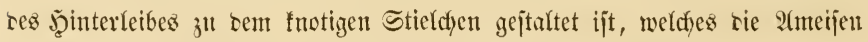
anszeichnet nno weldyes wir an Fig. 2 b bejonters seutlidy jehen.

Eine 3tweite gejellig lebente Jamilie oer Stacthel $=3$ mmmen*) ijt bie oer Wespen, 3espoden, weldye son allen itechenten Sujeften sie gefürchtejten

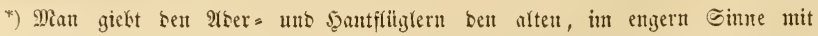

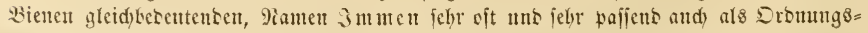
benemung. 

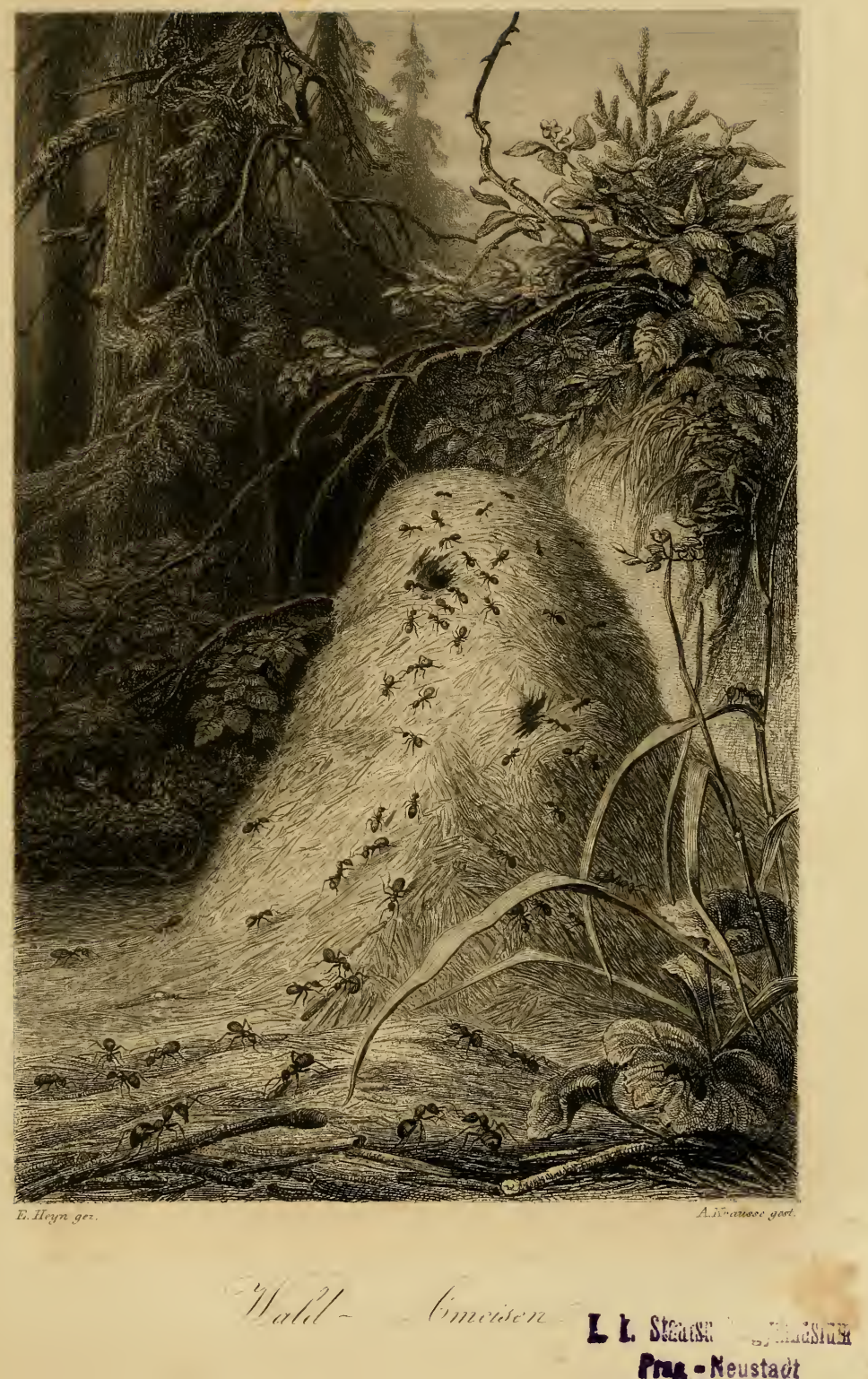


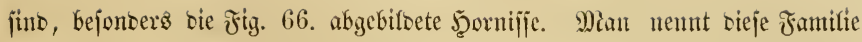
audf Faltentwespen, weil igre Sorberfitigel in ber 9uthefage ber Ränge

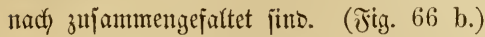

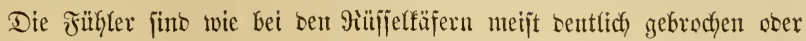

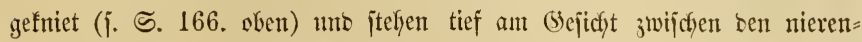

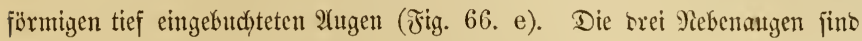
immer fefyr benttlidy vorkanben. Maul mit fräftigen unter sent breiten

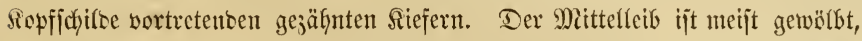

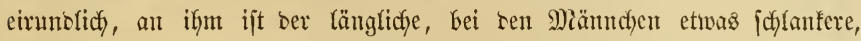

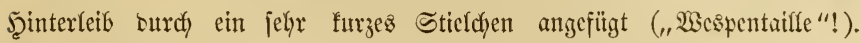

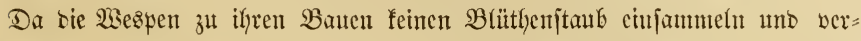
wenten, jo feylt iffuen andy an ben Şinterbeinen bie sen Bienen zut biejem

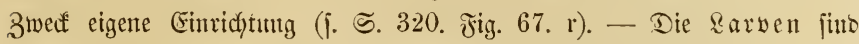

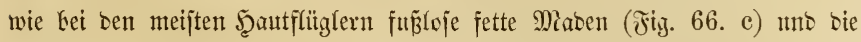
\$uppen, ebenfalls ser allgemeinen Sromungaregel zu zolge, zeigen bereits beutfich) alle Theite bes volfitänbigen Snjeftę (d).

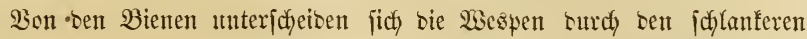

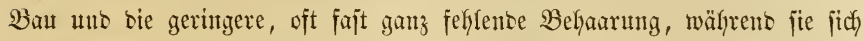

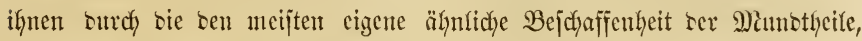

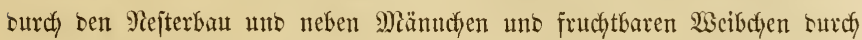

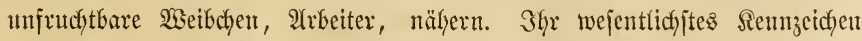

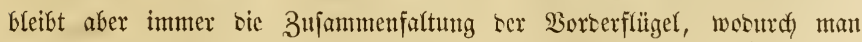

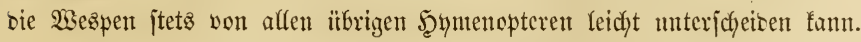

Shrer Rebensweije nach theilt nant bie 23 espent in bie, allein in biejen

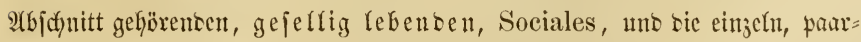

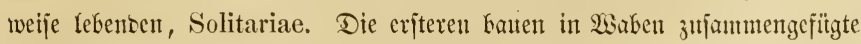

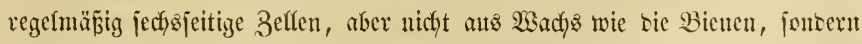
auz einem papierartigen Stofï, woju jie zerfaute \$rlanzengewebe verwenbent.

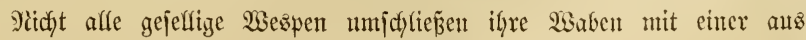

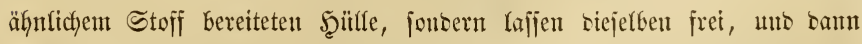
bejtehen sie von 2 ober 3 fleinen jodeibenförmigen 2 saben gebiltceten Mejter aus einem mit einem Stiefe ober ber ganzen 1 luterfiädje angeffefteten mefyr

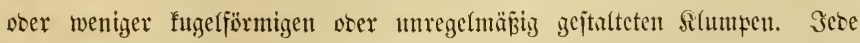

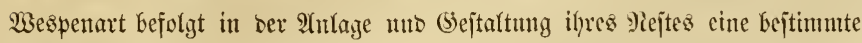
Regel. 
Dic jeit sen ältejten Zciten beobadfeten $\mathfrak{B e z p e n n e j t e r ~ - ~ j e f o n ~}$

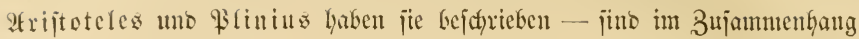

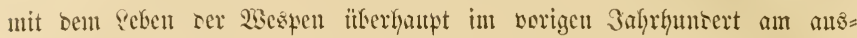

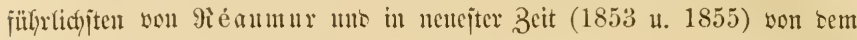

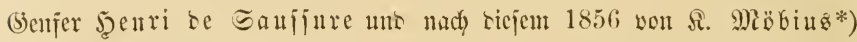
in J̧anburg abgeflantelt worten, wobei letzterer eine reidhe Summlnng bon

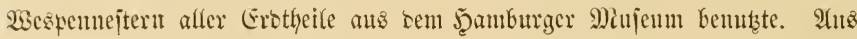

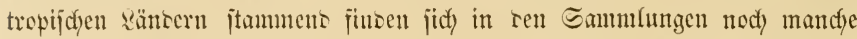

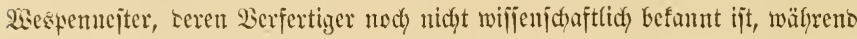

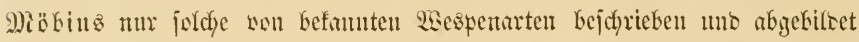
hat. Sei sem grop̃en Intereīe, weldyes sie nejtbanenten Wespen erregen, wiro es unjeren sejern willfommen jein, wenn wir ans Miöbius "sie

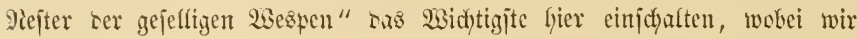

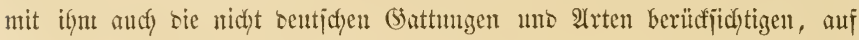
weldje jich überfautpt Miöbius alfein bejayränft.

Simr wenize reseppemejter, bet uns gar feine, finten jich in Gro=

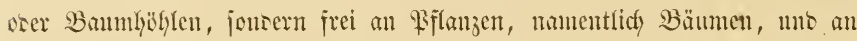

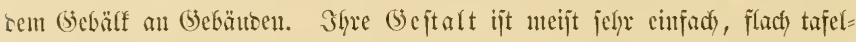
förmig, furz ster lang malzenfürmig, fegel=, ei= ober fugeffürmig (sie meijten längenten reutichen). Das Piejt zer Krajitianifden Polybia eatillifex Mäb. gleidyt einem Tiegel mit 4 furzen Jïnên. Sie jüb entweber mit einem Eticle angehejtet orer von mefreren \$f́cilern zejtütżt orer mit ifrer

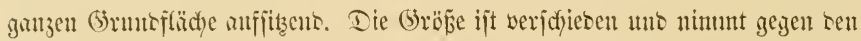

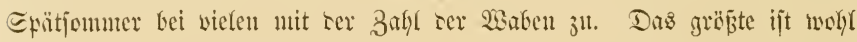

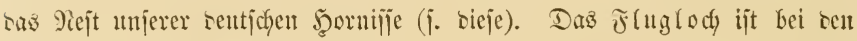
Gängenen 26espennejtern unten angebrad). Die 2 aben fint in ten mit einer Jätlfe werjefenen Jejtern entweber jeitfich an beren imeren $23 a n t$ angeheftet ober sie erifjgebilbete anf berent (5runbe, mno sann rie nachge= Ganten smé) Duerpfeiler mit sen frither gebilseten verbunten.

Bei Charterg'ts sericeus (Vespa) Fabr. werben tic 2iaben als

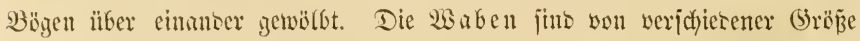
uno Bscitnlt, wälyrento cie Zellen ftets wie tie Bienenjellen regehmäp̈ig

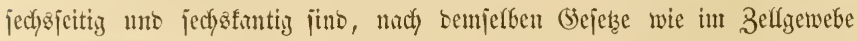

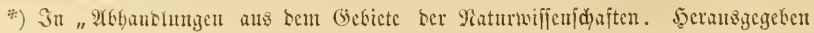
v. D. naturw. Serein in 5amburg". III. 35. S. $117-171$. Mit 19 col. Tafent. 


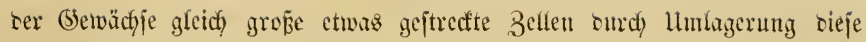

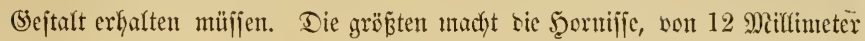

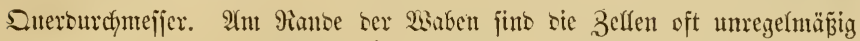
gebogen und bienen nicht zแx Brutpflege, fonsern zux Befejtigung ber Waben an ser llmbüflfung. Micijt liegt sie Deffunng ber Beflen nad) unten, bei jentrecten Waben liegen sie Beffen horizontal; jelten jüt sie Zeffen ¡đđjü̈g aufwärtż geridjtet.

Bon bejonserem Interefife finb sic won sen wespen $j^{\text {ut }}$ ifyen Tejtern verwenteten $\mathfrak{b} a u j$ toffe, welche Miöbins bei alfen mifrozfopifich unterjuctenten aus sem Pflanzenretche entrefynt fanto, bis anif Polybia cayennensis (V.) Fabr., welche aus Selym baut. affe Theile uno Bervebe ser Bflanjen

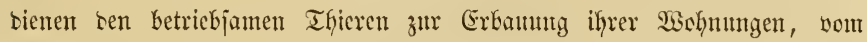

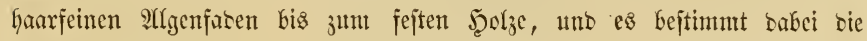

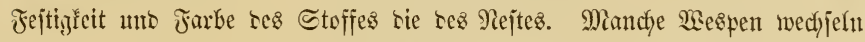
bei igrer Maurerarbeit mit berjdyicbenen berfdyieben gefürbten Etoffen ab,

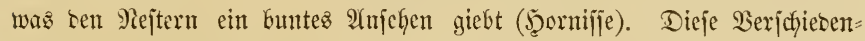
artigfeit ses Banftoffez jugeint aber nidyt bon ber werjejiebenen Wably bex

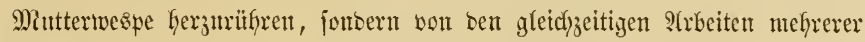
Befülfen, weldye veridyiesene Bauftoffe herbeibringen uno samit an ifrem Benjum abgejomsert won ben üfrigen arbeiten. Durd) bicje Bumtfarbigfeit

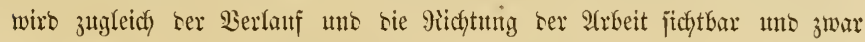

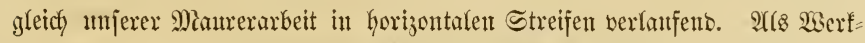
zenge bienen ben $23 e s p e n$ tie fräftigen Dberfiefer uno rie Borberbeine แtro als Mërtel ein fefyr Danerhafter ipeidhelartiger Stofi, weldher jeinem

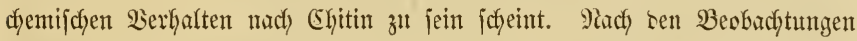

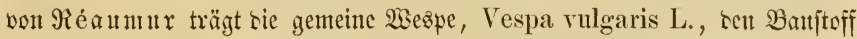

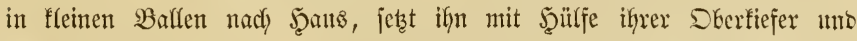

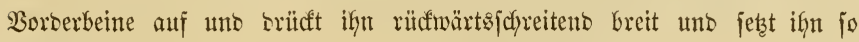
banbartig an.

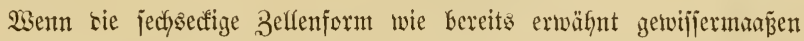

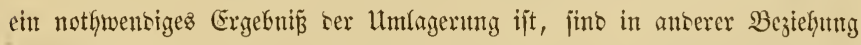
bie Wespen nicht ganz bie Eflaven bes jogenannten Injtuftes, insen fie 3. B. nach ber Schwere ifres 3u erbautenden Miejtes eine Itnterlage von einer angemejiften Iraglraft auzinählen uno sen Micjtern bie exforberlichen Stüzzen uno Befejtigungsmittel geten. Die wešpen werwenten je nach 


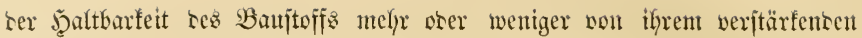

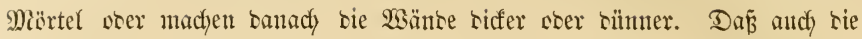
Wesspen bei beut Baut ifrer Miejter nidft blinblings ben Injtinfte folgen, geht auz ber Beobachtung von be Sanffure herbor, welcher cin Wespen neĭt in einem fyolylen Bante ofne bie, an riejem Drte unmöthige, Şitlle fant.

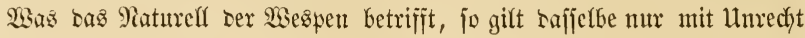
ats wilo mo feiusjelig, benu mu wenn wir jie, freilich vft jefhr ofgne

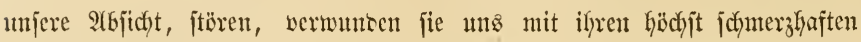
Stidjen. Shre Tabjung ijt jefyr mandyfaltig; als sarben werben fie won

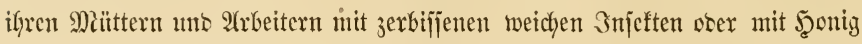
gejüttert, weldyen sieje ben fertig sen Bienen geraubten ober auj $\mathfrak{B}$ (umen

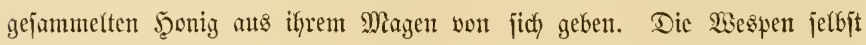
leben von Früdsten, Butfer, jelbjit Fleijh) utto vielen antern Dingen.

Die Wespenjtaaten werben won cinem überminterten im Şerbjt be $=$

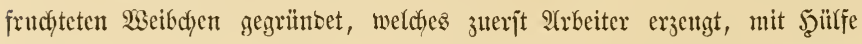
biejer bann ben $\mathfrak{B}$ au fortjetzt, ın im Spätjommer aud frudt)tbare $\mathfrak{W e i b d j e n ~}$

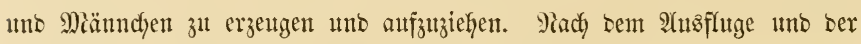
Begattung ser letzteren lọ̈t fich bann ber Staat auf.

Die 26 czpen fint itber bie ganje Erbe verbreitet, am reidylidyjten je ïppiger sie $\mathfrak{B} e$ getation ijt. Mit Einjohlun ber einjeln lebenben untericheibet man bereits gegen 900 Arten.

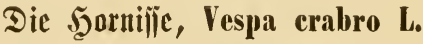

Dieje gröpte unjerer beutjhen $23 e s p e n$ gehärt mit nody 9 weiteren

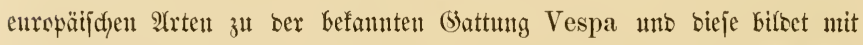
Der (battung Polistes für Dentjhlant sie ganze atbtheilumg ber gejelfigen Jaltenwespen. Sie ift ebenjo affgemein befannt wie gefürdytet, uno weil fie fetzteres ijt, werben jie nur wenige unjerer sejer genau angejefen haben. Kią bei ber nody vicl verbreiteteren gemeinen 2 espe, Vespa vulgaris L. jefwarz ift, ift bei ber jeorniffe theils rothbraun, theils johwarzbraun, uno bie (an ben Figuren a mo b) heflen Stelfen fino bei ifr braungelb, bei

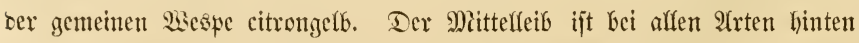
unto ser J̧interleib vorn fajt jenfrectit abgejtukt uno beibe ganz unten nur

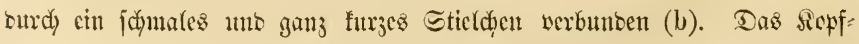

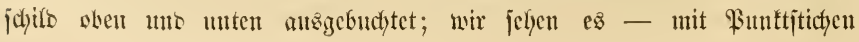


Fig. 66 .
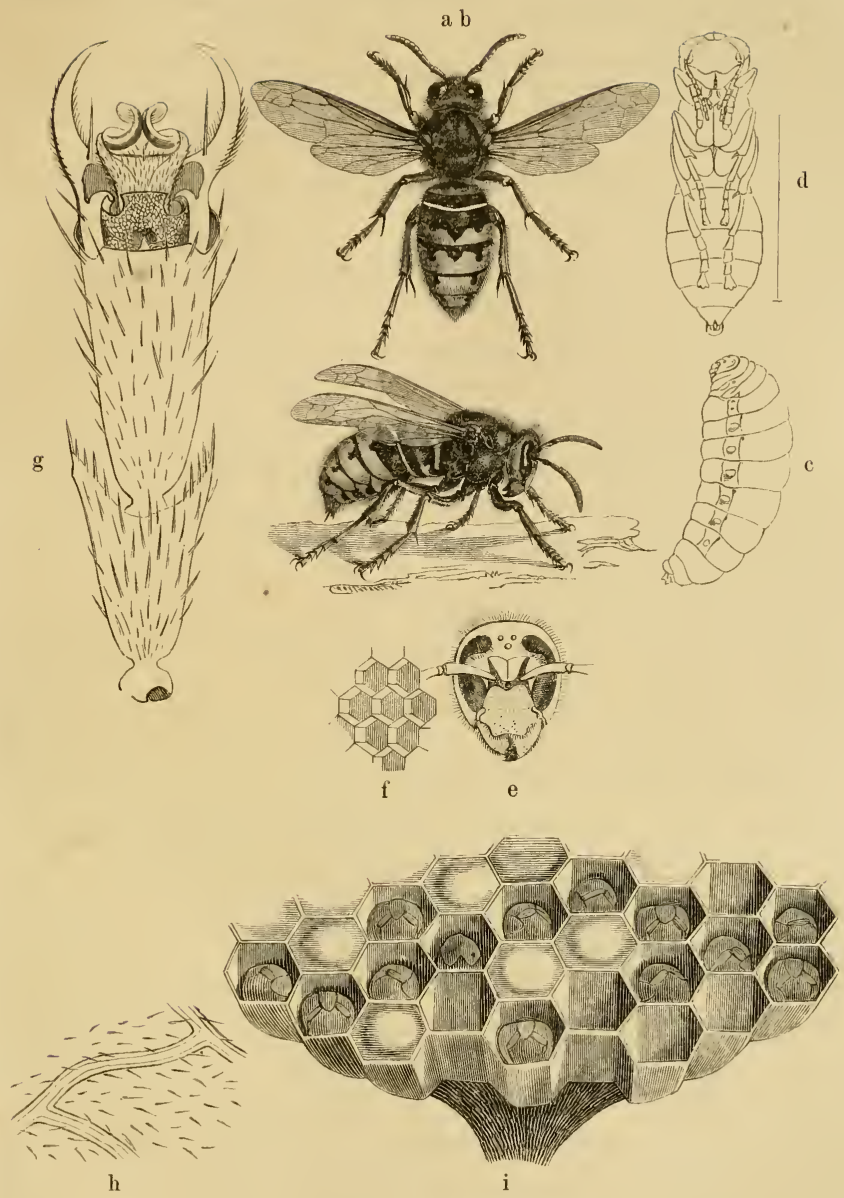

Die Scornifie, Vespa crabro L.

a. Dieferbe vou sten, b. von ber Seite, fitzens. c. Larbe, you ser Scite. d. Buppe. e. Ropf von vort. f. einige Facetten ber शietzangen. g. bie Entbglieber cines norbern

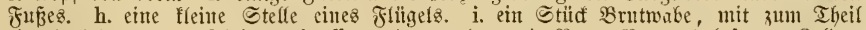
eingebedelten, zum Theil nod offnen leeren ober mit Brut (Fintwen) bejetzten Bellen. (c. d. e. i. wenig, f. g. h. ftarf vergrö̈ß̈ert.) 


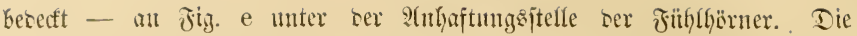

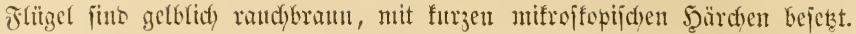

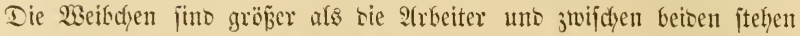

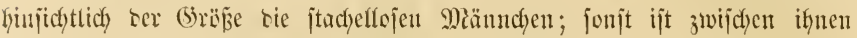
fecin lluterjofiet.

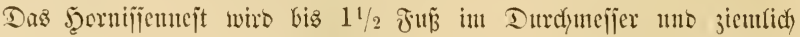

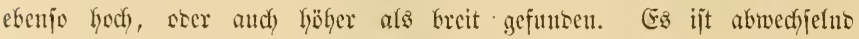
odfergelb uno braun gejtreift uno felyr bröffelig mo jerbrectlich, weil bie

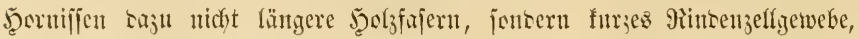
bejonsers von jungen Ejahen, verwenten, mo enthält gewöbnlich 5 horizontale Miaben.

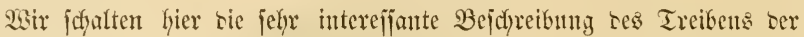
Sernifife ein, weldye fohon vor langer Beit auf (5runo einer jety jorgfältizen Beofad)tung ㄱ. 23. F. Mïulfer in Zinffens Magazin ber Entomologie mitgetheift hat. Wir werten tarans erjeken, baj bieje gefïredeten Thiere

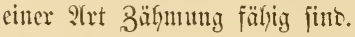

"Es twa im 2tnfang tes Mionats Miai 1811, als idy cines Tayes

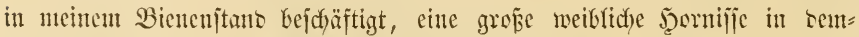

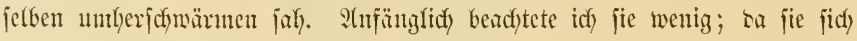
aber mehrere Tage finter cinanter erbliffen lieś, wernuthcte ich, fie habe in Sinte, irgenswo ein Picjt anjulegen. Sch gab nut genauer anf jie

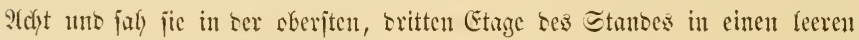
Bienenforb ans Stroh einfliegen, ber anf einem Brete ftant. Einige

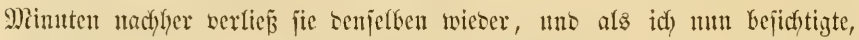
fant ich bas bereits angefangene Peft. Es bing oben in ber Mitte ocs

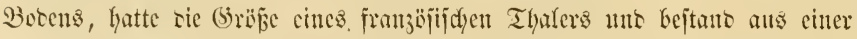

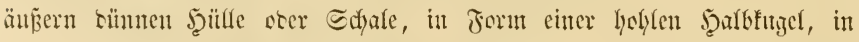

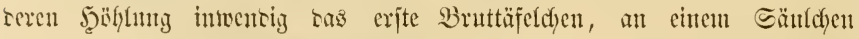

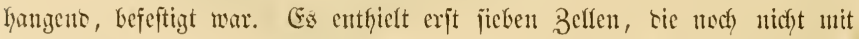

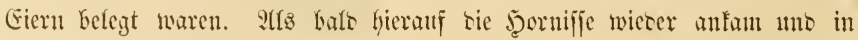

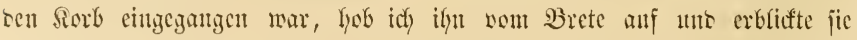

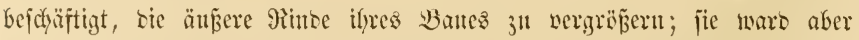
surd) sicje Störntg jogleidy umuhig, fulfr einige Miale jummeno uno erbojt

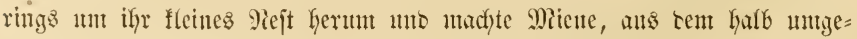

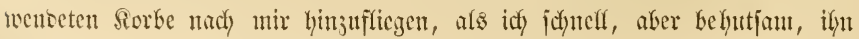


wiebcr umwenbete the alf fein Brett ftefle. Da idf mix borgenommen hatte, bie jidh hicr fo ungejudd barbietente Selegenfeit zur Erforjdyung ber Şornifjen = Sefonomie fo gut wie möglich zu bentuen: fo munte idf vor

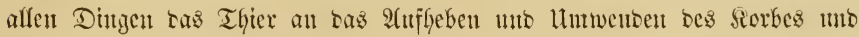

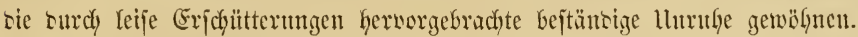
In biejer 2(bjidyt kob idy an biejen no eintigen folgentoen Tagen, fo sft

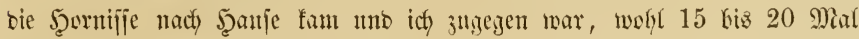
jeben Tay ben Sorb alf unto wentete ighn um. Bals war jic an bicje

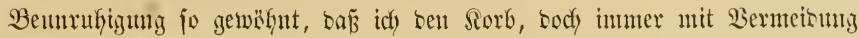

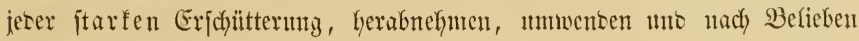

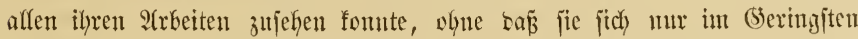

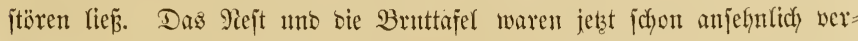
gröpert, แno mefyrere Bellen fanben jich mit Eiern belegt. Die Şornific baute fleip̈ij; fie blicb, wenn jie ausgeflogen war, 6,8 bis 10 Minnten aus unb bractyte ifjre Banmaterialien, nämlich einen rumben $\mathfrak{B a f f e n}$ abge-

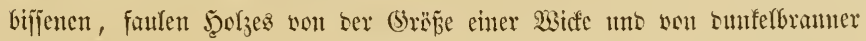
Farbe, ben fie im Fliegen jwifdyen bem Simn uno ber Siruft eingeffemunt trug. Slyne fich im (beringiten, wenn fie eben eingeflogen war, burd)

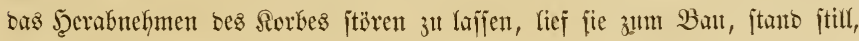
nafyn sen mitgebrachten Baffen zwijdyen bie Sinte ber Borberbeine uno biß̈ num, insem jie benfelfen gleichzetitig fortwälyreno zwijchen ren Sinen uno bent Simne gegen fich herun rollte unb an ben Ban anbritufte, Stitufdyen

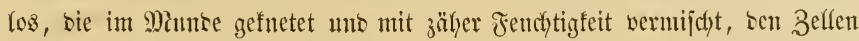
ober ber äıß̌ern Schale angejeţt uno mit ธen Freß̈zangen won beiben Seiten angeorïaft uno geebnet wumen. Dies alles gejdyah mit ansmefmentor

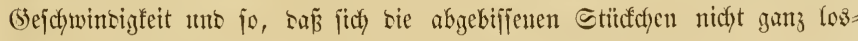
trennten, jonbern wie ein Faben won einem Snanle gleichjam Lnastuifelten.

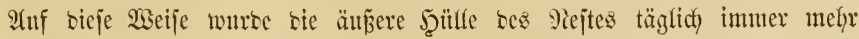

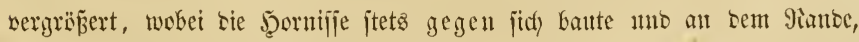
wo jie vorlfin anfigeföt hatte, wieber anjangent, nno unter ber 2trbeit 3urïtfweidyent, ben über eine sinte breiten, nen angejetzten Streifen in einer

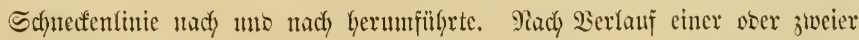
Mimuten war ber mitgebrachte Sorrath jebesmal verbrundfyt, woranf fie jogleich wieber autsflog uno nenen Stofi, inmer von ber nämlichen Jarbe,

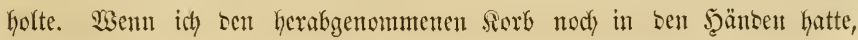




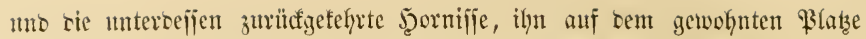

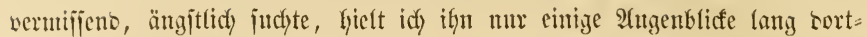

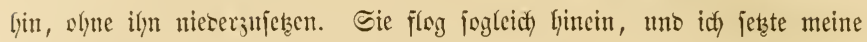

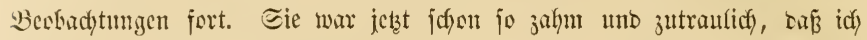
jogar sen umyemenbeten Sorb aus sem etwas sunfeln Bienenjtante hinaus in Ien Garten tragen founte, ohne saj jie, jelbjt währeno ses Gehens,

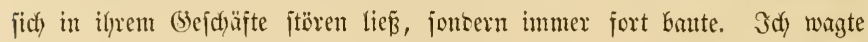
ez enclidy, fie anjurühren, uns jtreichelte fie mit sem Beigefinger leife uno

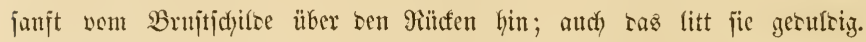

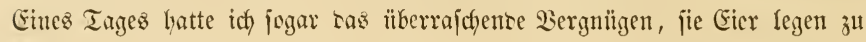
jehen. Sch fratte ten umgetwenteten Siorb vor mir, außerhalb res Bienen=

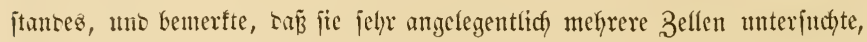

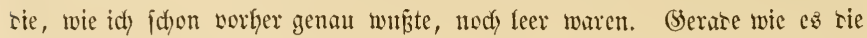

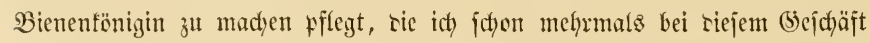

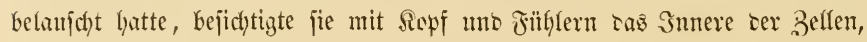
wenrete jid) jorann un uno jenfte sie Spitze res J̦interleibes meit in bie= jelben hinab. In riejer Stellung verfarrte jie 8 bis 10 Sefunien, uno

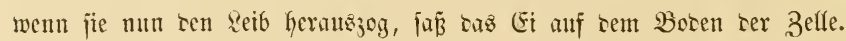

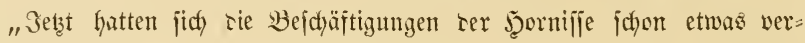

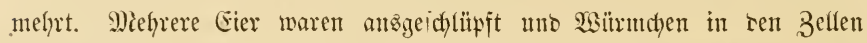
befinclidy; audh fïr bieje mußste fie nun Sorge tragen. Sch bemerfte nut,

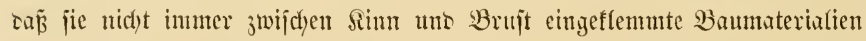
herbeijctleppte, fonsern von Zeit jul Zeit bei ifrer Rïtffely einen Ballen

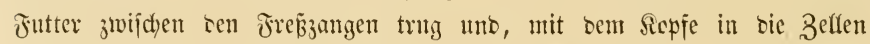
jd)lïpfeno, fütterte. So lange bie Surven nod) flem waren, fonnte id) rieje Operation nid)t genau beobachten, aber mm fo Tentfider als fie größ̈et

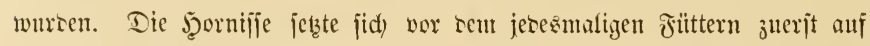
rie Bruttufel hin, flnetete oen jdyon jerbifijenen Slumpen Speife unter bes

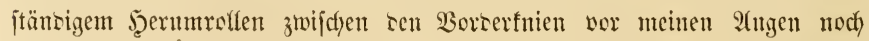

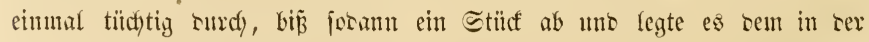

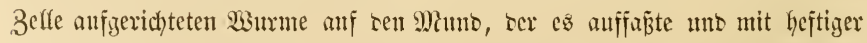
Begierte in furzer Zeit verzefrte; uns jo fulfr jie von Zeffe zu Zelle fort,

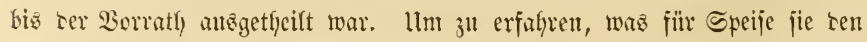

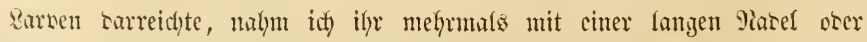

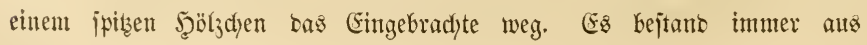


zerbiijenen weidyen Theilen werjdyiebener weidyflïgliger Snfeften, ats zer= biffenen Bienen, ober won ben Bienen heratzgeworfenen Drohnen, oder

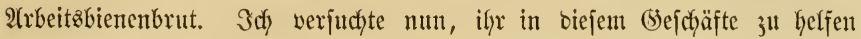
uno bas Futterlyolen zu exleidytern, unt reidyte ilyr zuerjt mit ber Spize

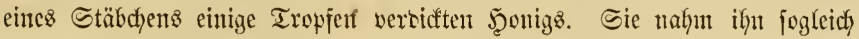
mit sem Munoe ab mo fütterte in nämlidfen 2 tngenflicfe cinige Maben tamit. Nun gab id iffr von ton Bienen herausgeriffene unzeitize Brut,

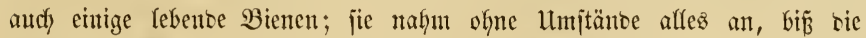
Beine unb bie ïbrigen trodfnen Theile ab, fnetete âtes zu einem weichen Brei uno theilte ify aus. So gewölynte idh jie num, täglich Speije von mir

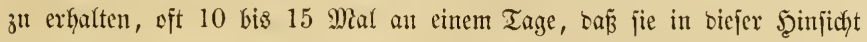
nicht zahmer uno zutraulicher werben fonute, als jie idf) ben Sorb umwendete uno ifyr eine lebentige ober toste Biene barreichen wollte, richtete jie jich jebesunal bei ber 2 mnäherung meiner ફ̧ano jojon von weitem auf, fich auf rie fintern Beine fez̧ent, uno nafm mit Begierte tå Dargebotene won meituen Fingern, zerfuetete es autgenblicflich)

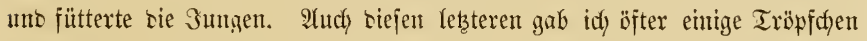
ફ̧onig ober zeroritute Bientenbrut auf ben Muno, uno siejes Futter

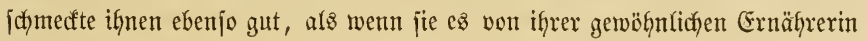
empfangen hätten.

"Die ältejten ber vorfantenen Rarven waren nun ausgemadbjen; fie überfpannen bie Deffnung igrer Belle uno gingen ifrer Berwantelung

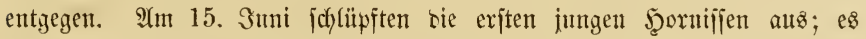
twaren $3^{\text {wei, }}$ senen aul folgenten Iage noch melyrere folgten. Einige Tage verweilten jie im Wejte, sann flogen jie aus, bradjten Banmateriafien uno

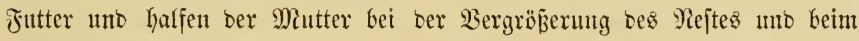
Jüttern. Sie ließ̃en jïh übrigens in allem ebenjo behanteln wie bie alte

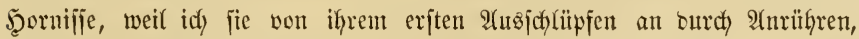

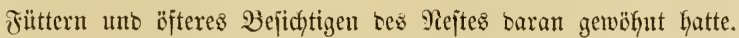

"Befdüfte hatten mich Gisher verhinbert, bie Dauer ber werffyiconen

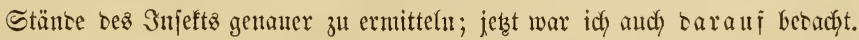
Эd) bezeidnete mir auf ber Bruttafel, bie idf genau unterfudste, unb bie bereits bie (5röß̈e bes untern Theils einer Theetajfe erreidjt hatte, mehrere noch leere Beffen mit einem Tröpfdyen Farbe nitteljt eines ßinjels. A̛m folgenben Morgen (15. Suni) waren jie mit je einem Fi bejebt, unb 


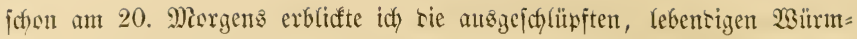
chen. Dieje twaren am 29. Miorgens ausigewadyjen uno fingen an fith

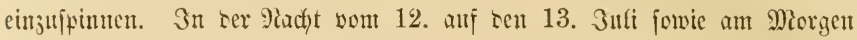

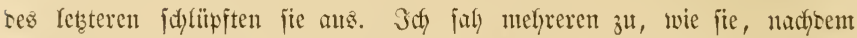

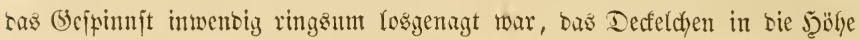

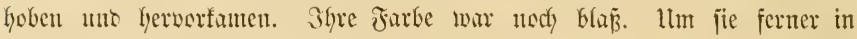
ihrem Treiben fpeciefler in's Stuge faffen zu fömnen uno nicf)t ntit ben \#̈brigen 18 bis 20 bejefwijtern ju werwedfjeln, bejeicfnete idy mir cinize

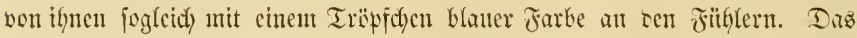

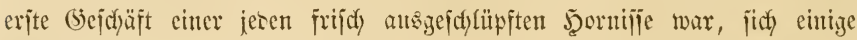
2tugenbficfe lang Fithler und beine ju reinizen, sann aber in sie jo eben

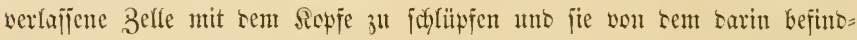

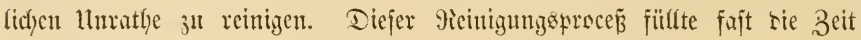
einer Sierterjtunte. Şierauf mijoten jie jith unter bie übrigen unb halfen jdyon in ber exjen halben Stunte ifyes Dajeins sie innere. Sefonmie bejorgen. Den ifnen begegnenten älteren ந̧ornijןen, weldye bie eingetragene Epeije fneteten, nahmen jie jogleidh cinten Theil ihres Broctens, ter ihnen

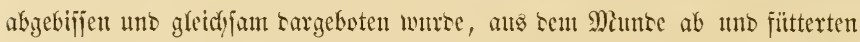

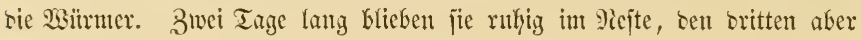
jahen jie fich in ber weett um unb brad)ten, gleidy ben anteru, balo Jutter, balo Stefï zum Bumen heint. Die leeren Zelfen wurten nad) einizen Tagen wieber mit Eiern belegt. Som 10. Suni an hatte unterseffen sie Miutter=

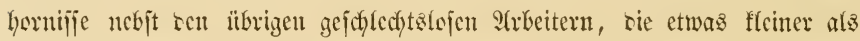
jie waren, bie zweite Bruttafel angejangen, sie einen hafben 3oll nuter

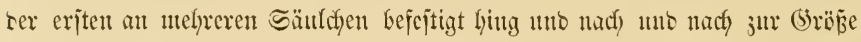

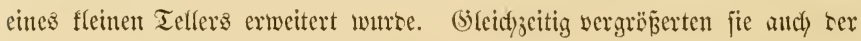

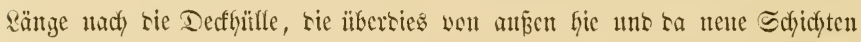

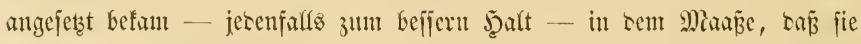

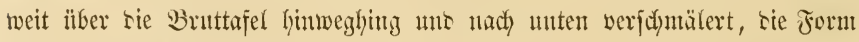

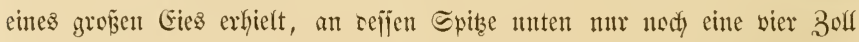

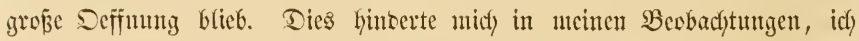

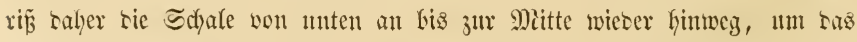
Snnere genauer betradyten ju fönnen, und tremnte audf jeren folgenten Tag von bent, was jie twieber angebant hatten, einige Stïcfe los, unt mir bie

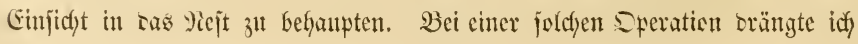


immer zuerit bie auf ber Schale jitzenten Jुornififen mit cinem Stäbchen

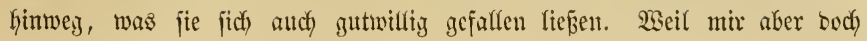

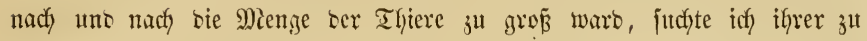
itarfen 2icrutefrumg entgegenturbciten unb werwumbete jeben Tag mit ciner Pabel cintige Witrmer, sic alsonn von ben f̧ornifjen aus ben Beflen gezogen

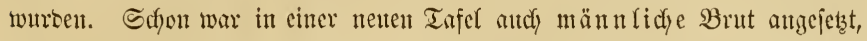
und idy fah ber Erbaumng cinter vierten für bie fïnftige Miutter entyegen, als meinem Pejte cin invorhergejehenes lnglïd wiberfufyr. Die alte Mutterhornifie, bie nod immer jeten Tag anteflog, blicb auf cutmal aus;

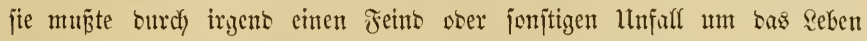
gefonmen jein. Das 9ejt war nun weif́eflos. Die $\mathfrak{A}$ rbeiter, $40-50$ an ber Zahl, waren zwar nod eine Zeit in getwohnter Weife thätig uno be= jorgten sie vorlyantene Brut, bie nody jum Theil ansidylitpfte. Tardy mb Inach war aber ify Eifer gelähmt, fie werloren fidc) mehr uno mehr uno in Sitrjem jtano bas Piejt - leer."

Der aufmerffante Beobachter fitgt noch einize Bemerfungen zur (5cichidyte

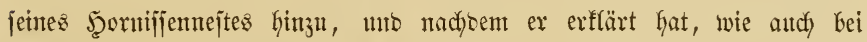

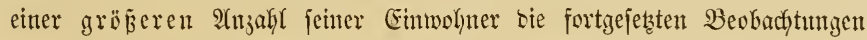

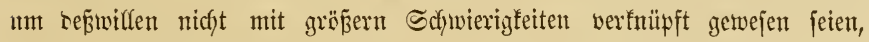
weil er bie hingufommente Brut immer in berjelben $\mathfrak{B c i j e , ~ w i e ~ b i e ~ a l t e ~}$ Feornifije, an bie Störungen gewöhnt gehabt hätte, fäfyrt er fort: "Dft nahm ich bas mit 30 bis 40 joorniffen bejetzte liejt von feinem Stanborte Ginweg uno trug es in ben Sarten, um bort meinen Simbern ober ben mich bejuthenben Jremben sic 9trbeiten biejer Thiere uno bas Smere iffrer Wohnung zu zeigen. Sch trug ben Forb ftets umgewentet, unb nie futhr eine Şorniffe zornig herans, fontern alfe arbeiteten ruthig fort, ofhe fich im (Seringiten jtören zu lajīen, ein Theil baute an ben Beffen, ein anberer an ber äuñern Schale, anbere fïtterten ober liefen umber. Sm Beifein ber Zuichanter reidjte idy ifnen jooann Futter, bas fie aud joyleidy austheilten.

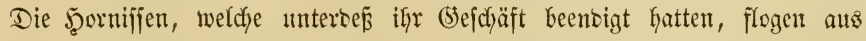

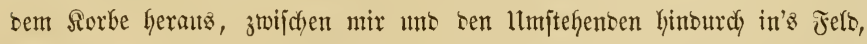
um nette Borräthe cinzulammeln. Mittlerweile aber hatten jich bie won

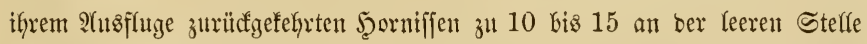
bes Bienenjtantes verfanmelt, wo ifre 230 finung fonjt ftant, uno jafwärmten

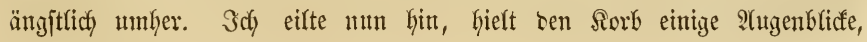


ohue ifn nieberzujetzen, an jeinen gewohnten Stancort, uno jogleidy flogen

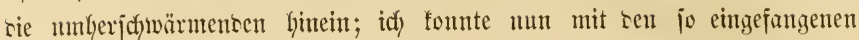

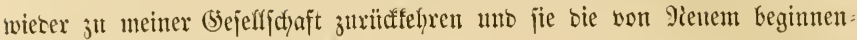
ben Irbeiten betwubern laijen."

\section{Die gemcinte $\mathfrak{B}$ ç̊pe, V. vulgaris L.}

Dieje alrbefannte Wespe gehört unt ber 5̧ornifie in biejelbe (5attung

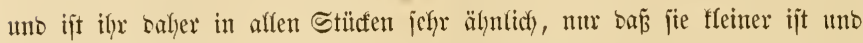

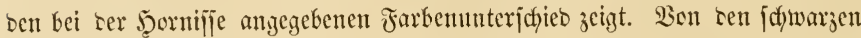
Querbinben bes gelben Şinterleibes geft tiber sie Mitte reffelben ic eine idywarze Spize hinterwärtz, zu beren Seiten je ein jajwarzer \$unft jteht. Der gröp̈te Theif bes bejichts, zwwei vorbere jeitliche uno vier hinten ïber Srenz jtehente länglidye flecfe bes Mittelleibes gelb. Flïgel brännlid) rauctygraut.

Sn riejen Farben uno aud in ber affgemeinen Beptalt ftimunen mit ber gemeinen Wespe eine Menge anterer Wsezpenarten tiberein, sie man aber bei einiger 9tufmerffamfeit leicht surdy sie 2(meinanterfügung von Mittel= uno Şinterleib unterjajeiren wiro, wie wir bieje sben bei ber Şorniffe be= idjrieben haten.

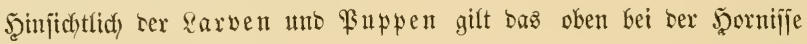
(5) jagte.

Das jiemlidy befannte $3 e s p e n n e j t$ finbet jich an benjelben Srten wie

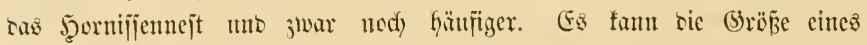

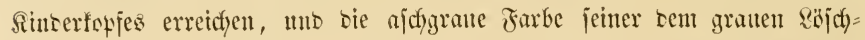

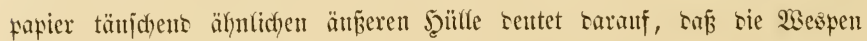
ben Baujtofi norzugsıeife von ben ï6erall vorlantenen Züunen uno Breter=

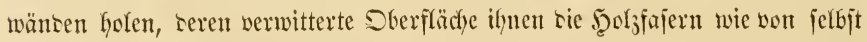
rmbieten. Ȩ enthält in feimem Inuern 8-10 aนв bemjelben Stoff wer: fertigte 2 aben, beren Belfenöfinumgen abwärts getehrt fino uno weldhe surct)

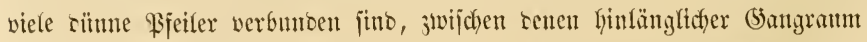

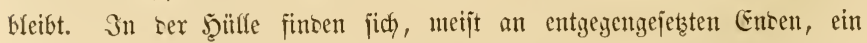

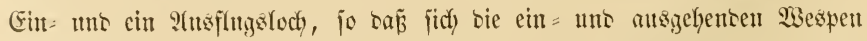

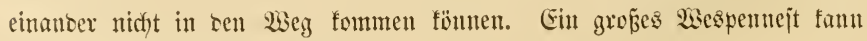
über 5000 Brutijellen enthalten. 


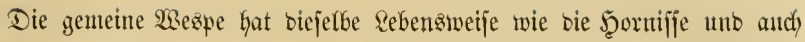

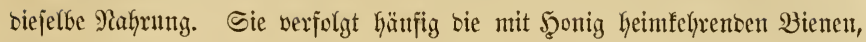

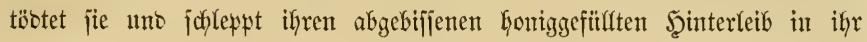

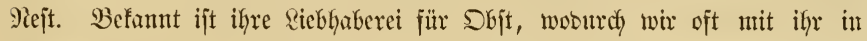
unliebfame Berüfrung fommen. Seffr verwant unb oft mit ber gemeinen

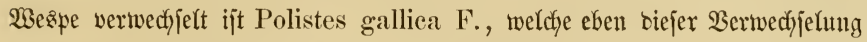

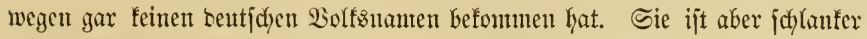
uno namentlidy ifye beinterleib vorn nidyt fo breit abgejtutşt enbent, fonbern mefyr verfdymälert uno butrd ein bentlicteres Stieldyen mit bem Mitteffeibe verbunben.

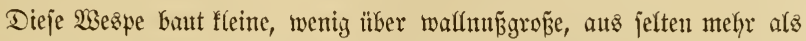

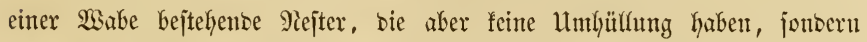

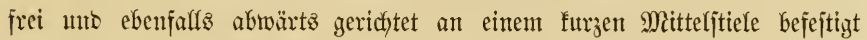

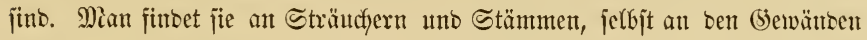
jonnig liegenter zenfter. Sie gefg̈rt eigentlich nicht hjerher, benn fie lebt nidyt gejellig, jonbern ifre siejter bejtehen inumer nur aus ben wenigen Machfoumen einer Menttertweape.

\section{Die Şonigbiene, Biene jळledthin, Apis mellifica $\mathbf{L}$.}

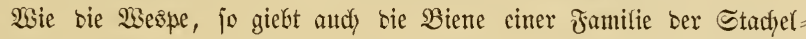

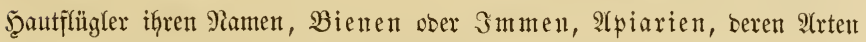
wie bie ber $23 e s p e n$ nut zum Theil gejellig leben unb banm ebenfalls 2trbeiter

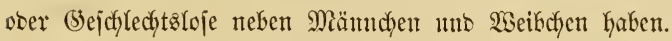

Die 2̂rten biejer Familie, weldye etwa 2000 aus alfen \&änbern be= tragent mögen, Gaben meij̈t eitren etwas plumperen mo gebrungeneren Sörperbau, als er jonjt ben b̧ymenopteren eigen ift, uno fino audd meijt

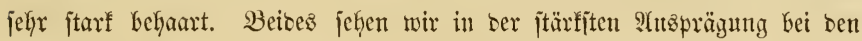

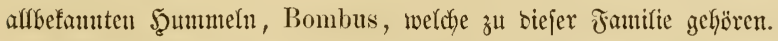

Die 2 Angen finto nidjt, wie wir cz bei bent $23 e z p e n$ fanten, ausgebudftet

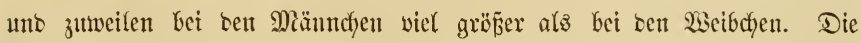

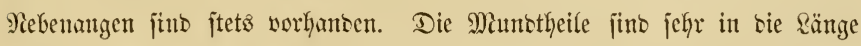
gezogen, bicht an einatber gelegt unb fo eine 2hat Miüffer bitsent, ber etwa

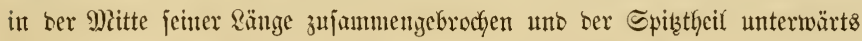

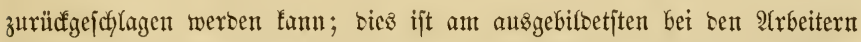

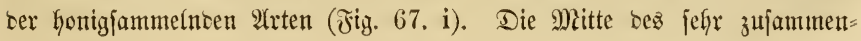


gejetzten Mumbes nimmt bie jefyr verlängerte Bunge ein, weldye ten Şonig= jaft jerod nidyt anfjaugt, jontern anflecft, nacfoem bie juarjen mejjerförmizen Unterfiejer sen ifgn enthattenten Theil ser Biflamze angejtodyen ober zer= junitten haben.

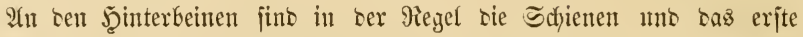

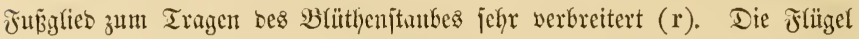
jinto nicht zufammenfaltbar. Der (sijtitachel ber 2 seibchen uno 2 frbeiter ijt mit 23iberhafen verjeken mo bricht beim Stich ab.

sinne vercinigte alfe (5fieser siejer Jamilie in bie eine grop̃e (5)attung Apis, sie aber jetzt in zaffreiche (5attungen zerfällt, uno bicje micter feit Ratreilfe in 2 Gruppen getheilt fiul. Won biejen haben wir es nur mit einizen 2 (rten bex expten, ser eigentlid)en Bienen, 3n thun, weldye

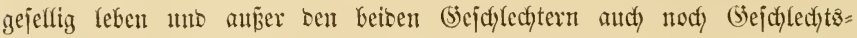
roje haben. Dody aud bei biejen zeigt ber Bellenban nidjt immer bie

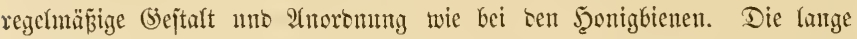

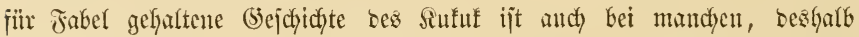

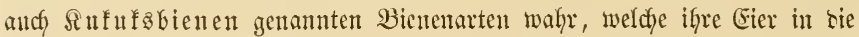
gejülften Beffen anterer 2lrten regen un siejen bie Pfleze iffer Sumgen aufbüren. Den Sufufsbienen felyt aber auch bie zun Einjamnetu bez Banjtoffs beftimute Dorridytung an ben J̧interbeinen; man fann ifnen

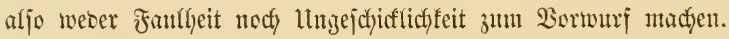

Das Erjdyeinen ber Bienen ift an bie Błhïthenmonate uno ifyre Thätig= feit an Somnenjejein gebunben.

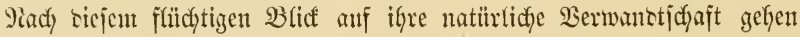

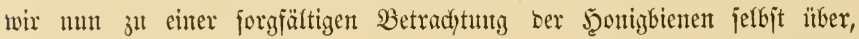

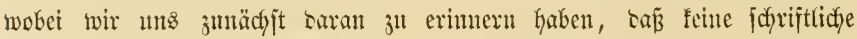

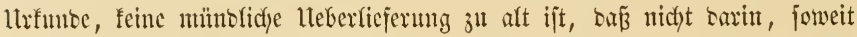

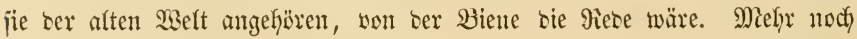

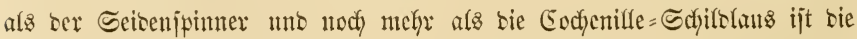

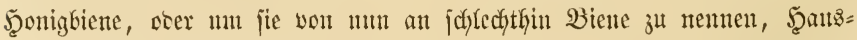

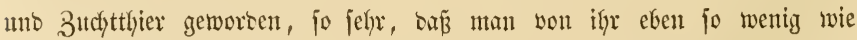

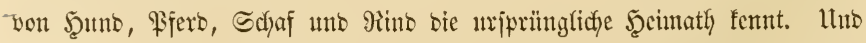

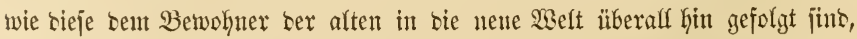
fo gilt sies auth won ber Biene. Sm Sabre 1675 won ben Engläntern

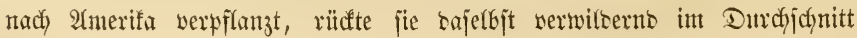




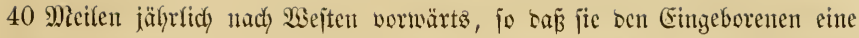

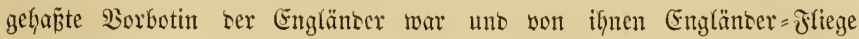

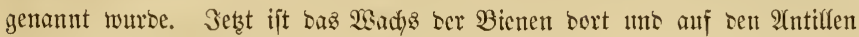

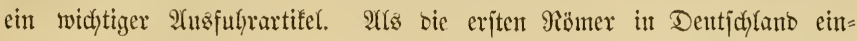

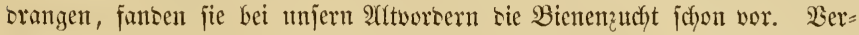

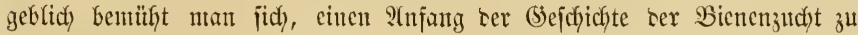

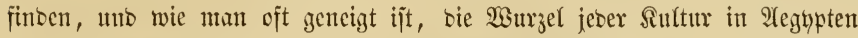
zu juchen, io hat man es audf mit ber Bienenzudft getfan. Dic (5riecfen

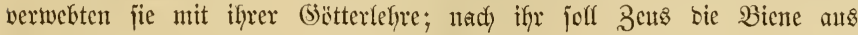
ter Şornifie gemacdt und jie mit ber Sumpt ber Şonigbereitung begabt haben. Wer fennt nidjt bas liebliche (sebidyt won Aluafreon, in weldyent

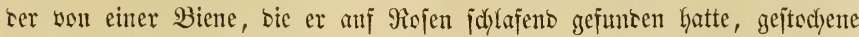
Eroz wefflagento zll jeiner Mitter eilt, bieje ify aber lächefno bebentet,

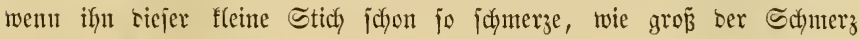
terer jein mitffe, weldye er mit jeinem (sejchoj treffe.

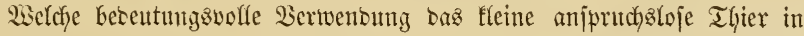
ber Sittenlefyre uno in ber Didytfunjt zu allen Beiten gefuncen hat, bebarf feines Şinneif̧ - mo fo fönnen wir bie Biene eine ber erjten, wenn nicht sie erjte Beriffyntheit ber Thierwelt nennen. Sa jerbjt anf bem Felbe

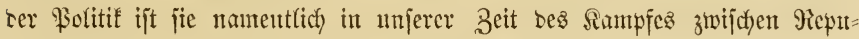

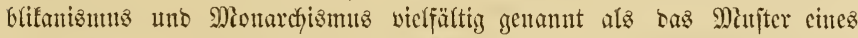
Monarchen, ber jeinem Staute nux (Sutes that uno aun Bb̈jestfyun burcty

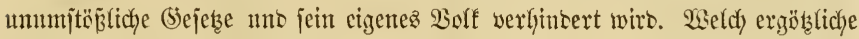

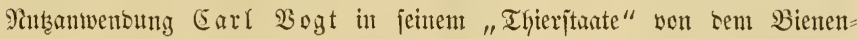
jtuate gemadyt hat, ijt nidyt minber befaunt. 2Bitroigte body ber jomjt Piichtz mïrbigenbe Eroberer bie Bienen, jeinen Saijerntantel mit ifren gortenen abbiliern zน jieren.*)

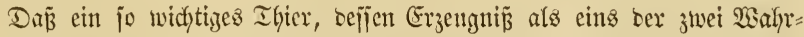

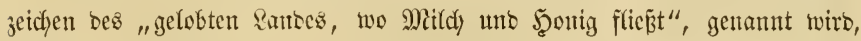

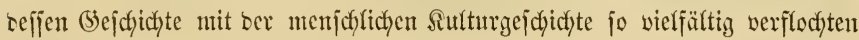
ijt, jeine cigene uno zwar jefhr umfangreiche Riteratur hat, ber Segenjtano

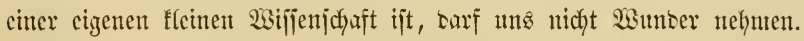

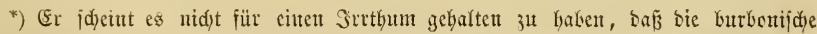

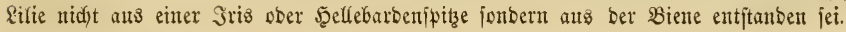


Fig. 67.

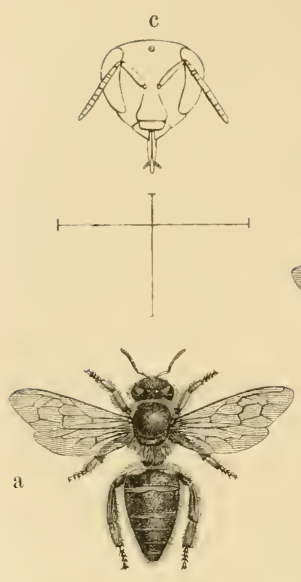

Q

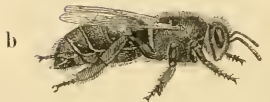

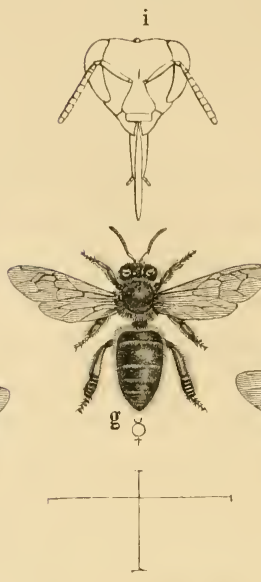

ఛ
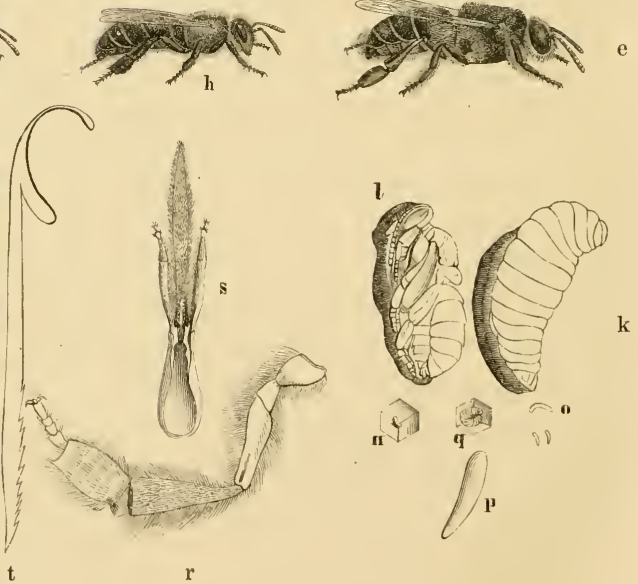

Dif $50 n i g$ biene, Apis mellifica L.

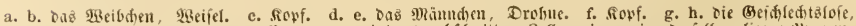

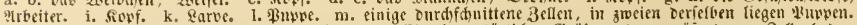
n. o. p. Der Boben einer 3efle mit Dem $(5 i$, mto (5ier in natürlider (5röbe uno vergröвert. q. 3ellenboden

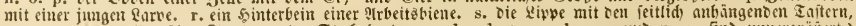

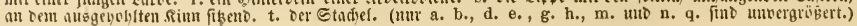




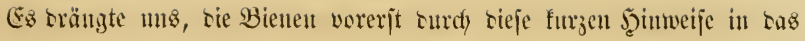

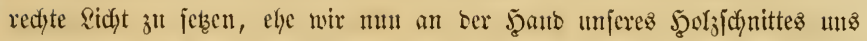

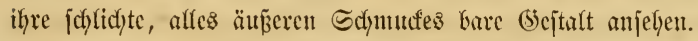

Die Figuren b h e jeigen fie 1 เి in fizenter Stelfung, wie fie erfentuar uns int seben nic anters entgegen tritt, benn wenn bie Biene fliegt, fönnen wir ilyre fdywirtenben Flïgel faum jefyen, uno es finto saher

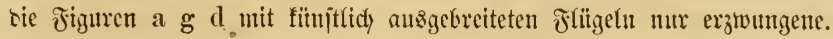

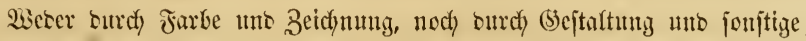
Reunzedthen auffallent, wïrse sie Biente nody reidyter mit anberen ifyrer

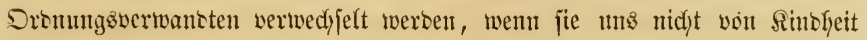
an gezeigt worben wäre. Wir exfennen jie melye an iffrer Sdynudfojigfeit uno

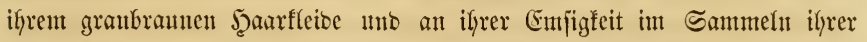
Borräthe, als surdy irgent weldes in sie 2tugen fallentes Merfmal. Die (5attungsfennjeidyen - weldye, sa wir in Emopa nur sieje cine Bienenart

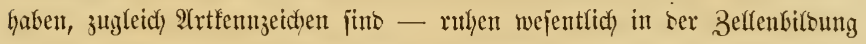
ber Dorberflügel unb in ben Miangel eines Entborns an ten J̧interjofienen.

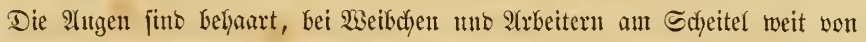

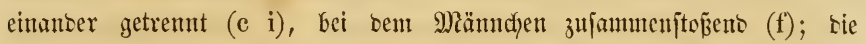
Piebenaugen jtelyen im Dreieff (f); bie Miuntheile, ganj bejontors bei ben

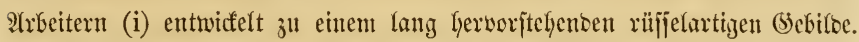

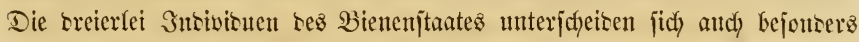
burdh bie Serjdjierenteit in ber Form tes J̧interfeibes, weldyer bei bem 2seibchen (a) nady linten entidfiesen fegelförmig jich zujpizzt, bei bem Meänndłen (d) breit eiförmig ijt.

Son bejonterem Suterefje ijt ber Ban ber J̧interbeine ber 9rbeits=

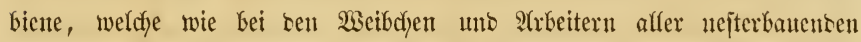
Bienenarten 3um Eintragen bes Blittycujtanbes eingeridytet fino, wowon

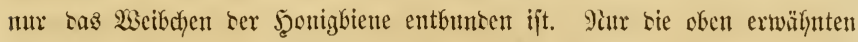

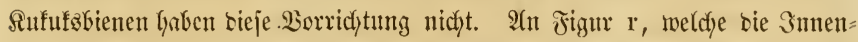
jeite bes redyten ફ̧interbeincs einer arbeitabiene sarjeflt, jino bic erften beiben

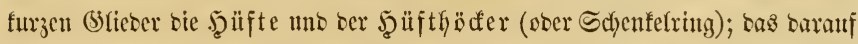

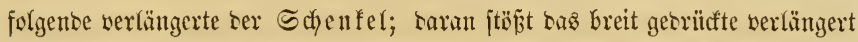

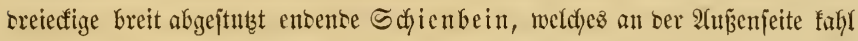
uno glänzens, an jeinem breiten Enbe hohl cingcoritct, an Pianbe mit Sam=

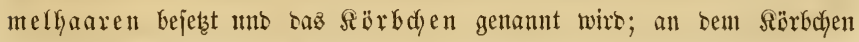

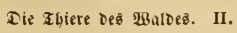




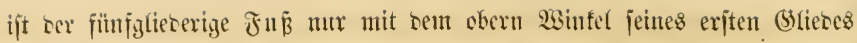

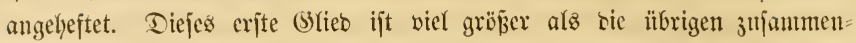
genommen, plattgeorïnt, länglid' vierecfig mit 4 ipitzen Erfen, uno hat ben bejonteren Namen Ferje; fie ijt an her inneren Seiten reifhenweife mit Jaaren bejetzt mo wiro beshalb auth bic 23 itrite genannt; an mutern

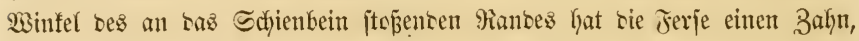
ren Ferjenhenfel.

Die Blüthenitanb fanmelnoe 2 rbcit\&biente idneiset sie Staubbentel, wenn jie fidy nody nicht won jerbjt geïfinnet haben, mit sen Siefern auf, fajfen ben B̉lütfyenjtantb in fleinten Sitümpdyen mit sen Borberfüß̈en, sicje idjicbent fie sen Mlittelfü̈ßеn an, weldye fie alsbann alz bie jogenamuten

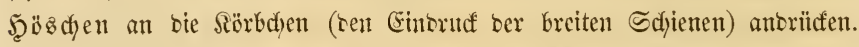
Bei riejen 9 trbeiten uno zur Befejtigung ser Staubförpertfen bienen bie

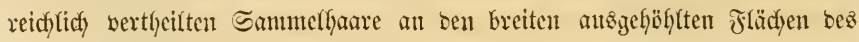
รörbdjenz แno ser Jerje.

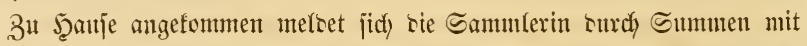
ben Flügelı, morauf bic Gaucnben Arbeiterinnen herbeifonmen, ify bie

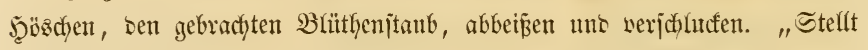
(iid) feine ein, weldye ter eben 5̧eimgefelyrten ifyre Bürte abnimmt, -- cin

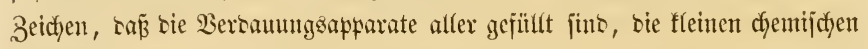
Raboratorien mit Bereitung tes $\mathfrak{B a d j j e s ~ v o l l a n f}$ ju thun baben - fo friectft

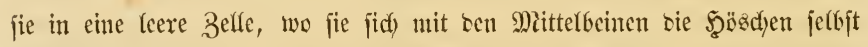
ausziegt nuo sann ju ciner antern 2trbeit ïbergeht, soer fich ter 9iube

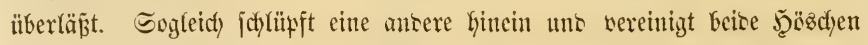
3ł einem Baflen, sen man am (brunce ser Befle fintet. Dieje jogenannten

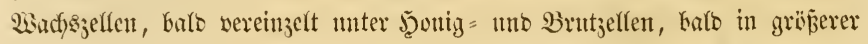

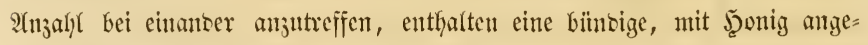

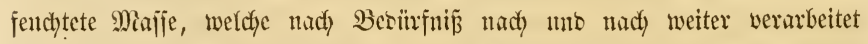
ober verfüttert wirt. Sie bitben alfo tie Dorratbafammern, Magajine für Baumaterial uno Futter." (Tajdenberg.)

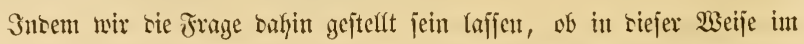
Bienenftaat bejonbere Bünfte ter Buträger uno ber Maurer bejtefyen, ober

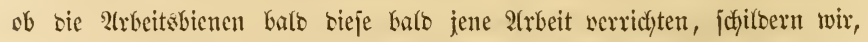
in bem 2 ejentlidyen nach Tajd)enberg, ben weiteren Sorgang ber Bienenarbeit. 


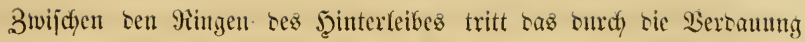

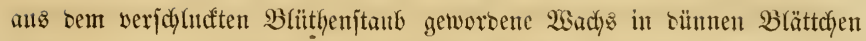
Fervor, weldye sie biene mit tem Jerfenlenfel abuimmt. Sie fülfrt es

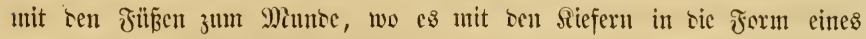
Bantes gebradjt wirt. Tieben biejen Drganen fint bei ter 2 (rbeit nod) bie

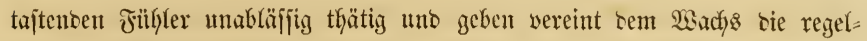
mäßige Zettenform.

Befanntlidh Gängen sie Bienenwaben in Stodfe, weldye Bejtatt biejer

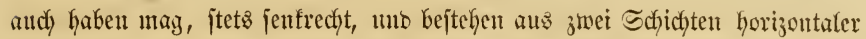

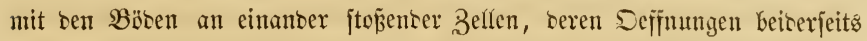
an ber Wabenfläct)e liegen. So liegen alfo bie Bellen̈̈fffnungen żweier nebenteinanter fängenber $23 a b e n$ einanter immer gegentïber, mit einem

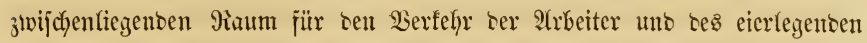
Wseibchens. Sn einem ftarf bebölferten Stoúf fint oft vicle Şunterte won

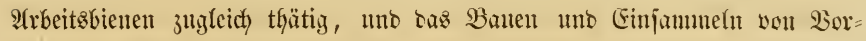
räthen fajreitet rajdy vorwärts. Dabei werridgten dic Einen sic 9trbeit bes

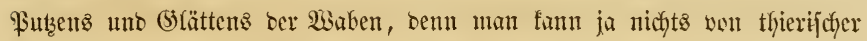

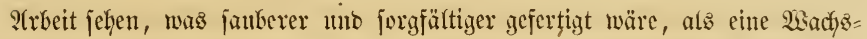

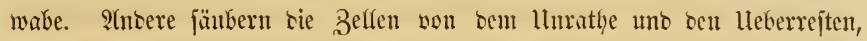

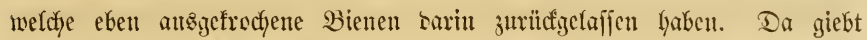

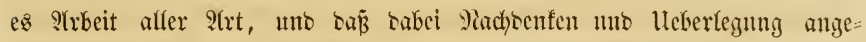

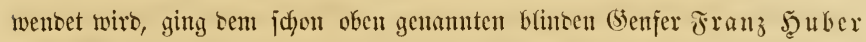

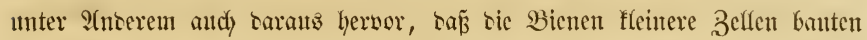
alz er ifnen ben werfü̈gbaren 9iunm werffeinert fyatte. ST(z) in einem feiner

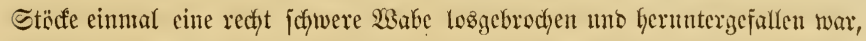
erfanben bie Bienen, unter ?tnwentung eines bejonters haltfaren harzigen

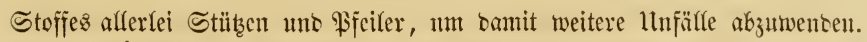
Ein anbermal war ein nact j̧onig liijterner Tootenfopf (Acherontia Atropos) in einen Stod eingebrungen mo hatte barin viel llutfeil angeridgtet. In= bem Şuber vergeblidy nad) Mitteen jann, feine Bienen vor joldjen 9iufge=

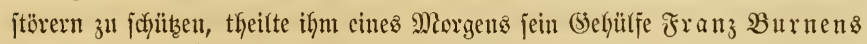

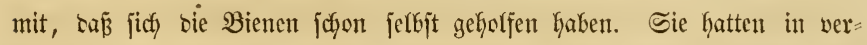

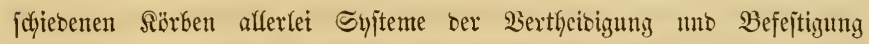
erfonnen uno verjudyt. Bato fïfyrten jie won 2sadys cine Manter mit

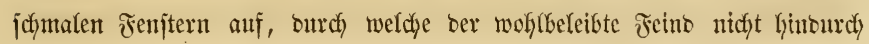




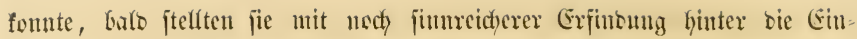
gangstrjïren abwedjeflno lyintereinanber Sdyanzen, zmijdyen tenen ser bicfe

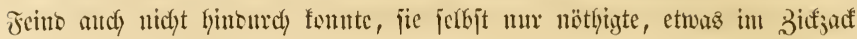
eill uno alls ju getent.

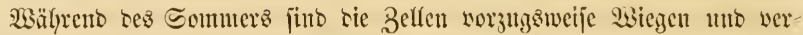

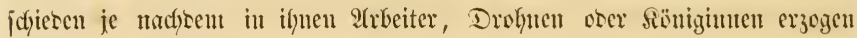
werten jolfen. Die Drofmenzellen juto grö̈̈er als bie 2trbciterzelfen. Die

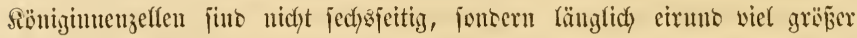
uno mefyr jenfredyt angebradyt. Wä̈fyrento ses 23 inters jus sie Zeffen

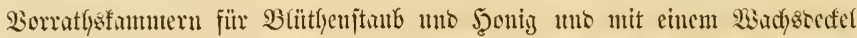
verja)lofien. Dieje Dorratlizmagajine tes Stautes werben von sem Dolfe

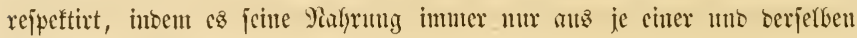

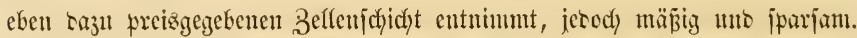

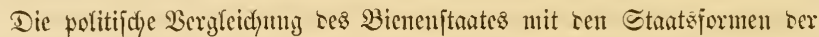

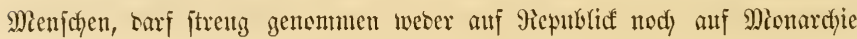
jüflyen, benn bie Sïnigin regiert weber mady gouvernirt jie; jie ijt surchatis gar nidytz weiter afs im Gudjitäblid)en Sinne eine \&antesmutter mo mu

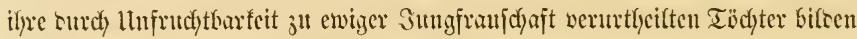

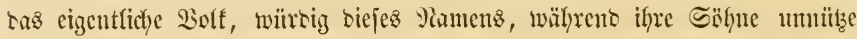

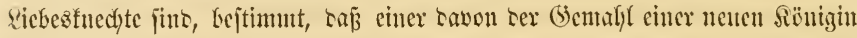
werbe, sie bann ohne ifn cine nette Eolonie grünoct. Mit cincm Pomten=

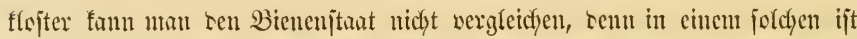

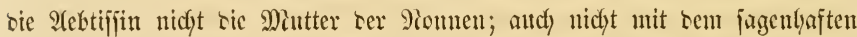

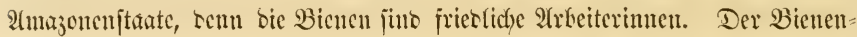
fitan faun eben mur mit jidy verglidyen werben; er ijt ein unvergleidylidyes

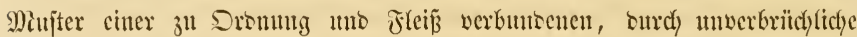

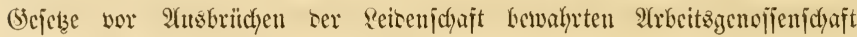
(5) (eicher, - wie cs unter uns Mienjchen nod feine giebt. Die Sïnigin - wie unberedytigt ijt sieje bencmunn! - ijt ben Bienen als eine (5ie wäbrleijtung

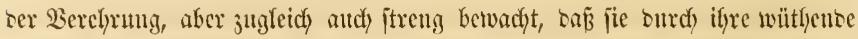
Eiferfutdyt auf ilyre cizenen Tëdyter bie 3utunft bes Fortbejtantes nicht in (Sejałp bringe. Sie ift Miutter, mehr als sionizin soer Pröjicentin, bie

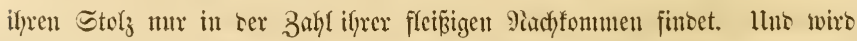

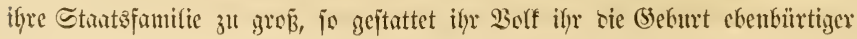


Töd)ter, bie ธann bie lleberbölferung hinausfütyren, un fidh, mit allen

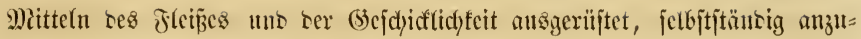

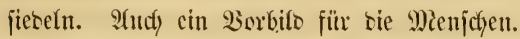

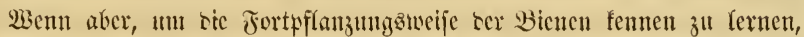

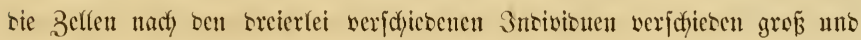

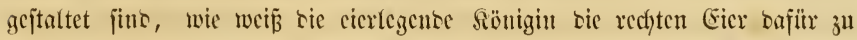
legen? Die fownierig fdychnente Beantwortung sicjer Frage ijt ziemlidy

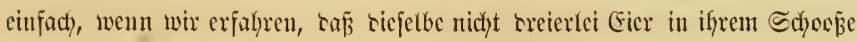
birgt, jonbern bie surdyan gleidjen Gier nur verfobieben behancelt, wäfrento jie jie legt.

Es ift hier junädyjt eine erit in neterer Beit feitgejteflte Thatjadye

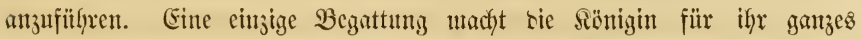
Seben, etwa fünf Salyre, jrudbtbar. Dabei fülft jich eine Blaje neben bem

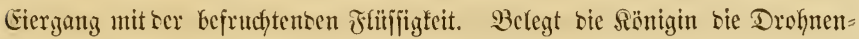

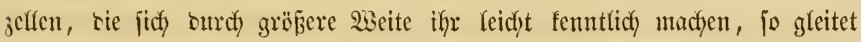
tas ei wor ber Samenblaje vorïber, obne befrudtet ju werten, benn es ijt

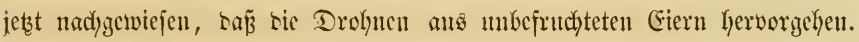

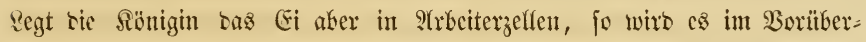

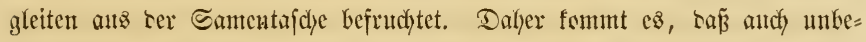

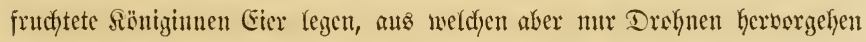

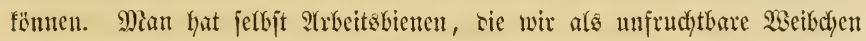
fennen gelernt haben, Drolynencier legen jehen. Das Ci wiro ftets surch ein borker auf ben Grumb ber Zclfe gebradjtez Tröpdyen cincz flebrigen

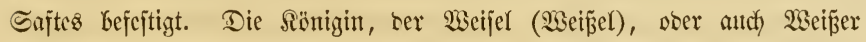

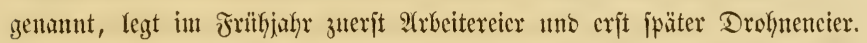
Bei Beginn ber wärmern Gahreszeit werten bie Sïniginnenzellen (23eijel= wicgen) am Sante ser Waben gebaut uno an ben in jie gelegten Ciern thut bie Sönigin jelbjt nichts, um eben teine 2(rbeiter jonbern Söniginnen

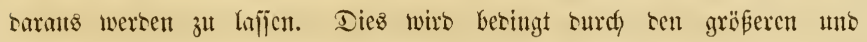

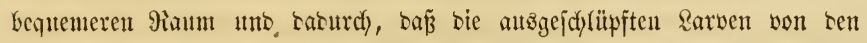

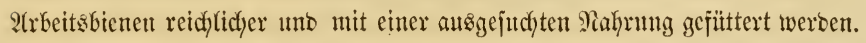

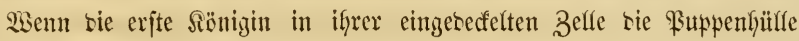
abgejtreift hat uno jich befreien will, waz jie burdh einen eigenthümlichen pfeijenten Ton (Tüten) anfümbigt, fo verläpt bie alte Sïutgin mit einem Theile ber Arbeiter ben Stoff, was man "Sorfdyarm" nennt. Die Nen= 
geberne tritt baun als J̧erricherin an sie Stelle uno in sie Piechte mo Fiflidyten ber ansigewanterten Mintter. Bevor bies gejdyieht, madyt jie in

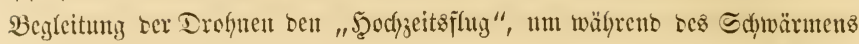

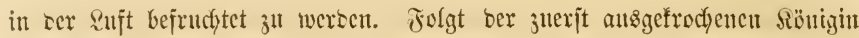

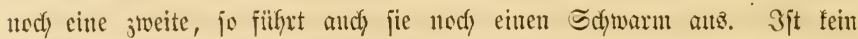
weiterer Sdywarm jul erwarten, fo werben sie mux ber (jattenfflidyt bicnenten Drolynen, bie jonjt nid)ts als fanle Frejןer jüt, iu ber "Drobuenjaladjt" getïrtet und ans rem Stodfe geworjen.

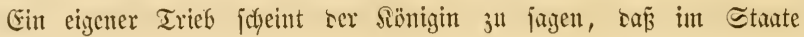
Menardyie herrfych folfe, was fie ju ciner töbtlidyen Eiferjudyt gegen antere

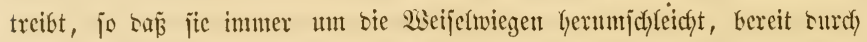

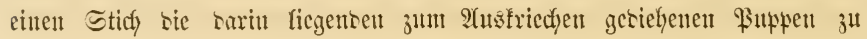
ermorsen. Dic $\mathfrak{A}$ rbeiter jucfen jie mit rejpeftwoller (5emalt savon abzu= halten, uno nux wen neue Sdymäme nicht mefyr bevorjtehen, aljo die

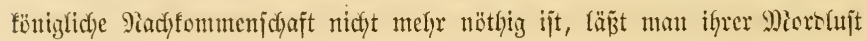
an ben eigenen Tödhtern freien Sauf. In einem Bienenitode fommen aud

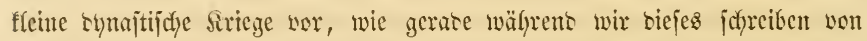

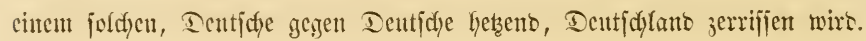

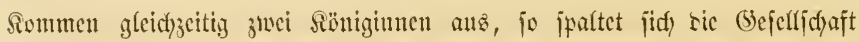

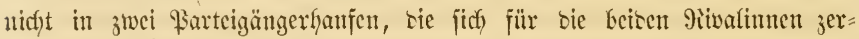

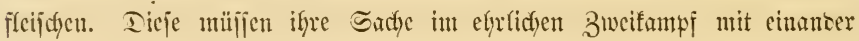
jelbit ausmadjen uno sic Siegerin wirb von ren rufiz jujchenten boffe cann willig anerfinnt.

2Birs surch einen 3ufulf ein Stod weijellos, jo geräth rie Stants: orsmung in Berjall, uns mu wenn cine sönigin herbeizejdyafft werben faul, wiro jie wiecer herigejtellt, zu ricjem Ense, jo wiro berichtet, erbanen

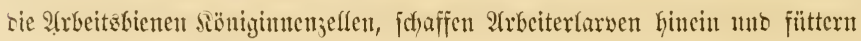
sicje mit sen vorlyin angegethenen Mitteln 3 ll Sïniginnen auf.

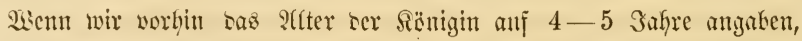
jo werben bie Trbeiterinnen in Eomuer meijt mux 6 wastyen alt, meldye

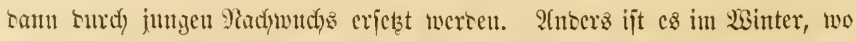

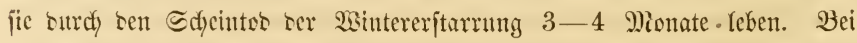

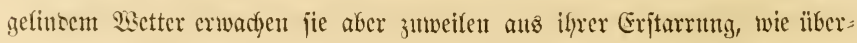

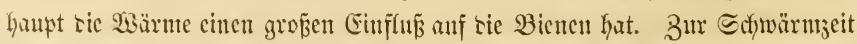

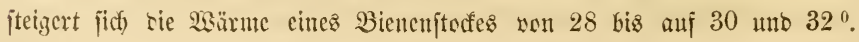


Doch wir miijien abbrechen, obgreich bas Mitgetheitte, fo unwerbält

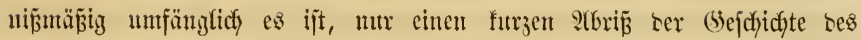
Bienentebens fietet, un wix als Gierlyer midyt gehöreno sie Bienenjuddyt ganz

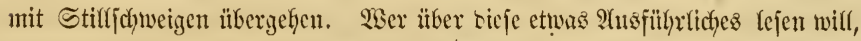

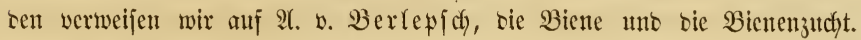
Miüflyantjen 1860.

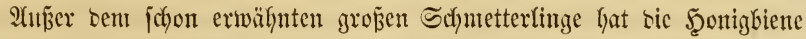
aucf) noch antere Feinte, nicht blos 9iäuber ifyer Sorrätbe, joubern autdy

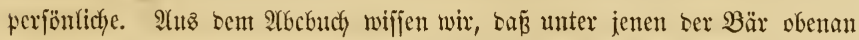

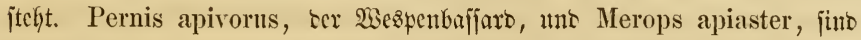

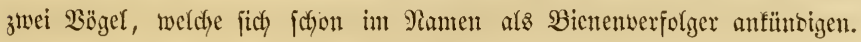

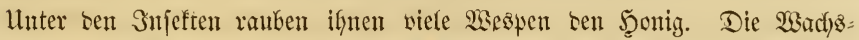
jufabe, Galeria cerella, zerfturt bie Waachbuaben; ser Bienenfäfer, Trichodes apiarius F. fripht tic \&arben ter Bienen; tie merfmintbig fleinen Rarven

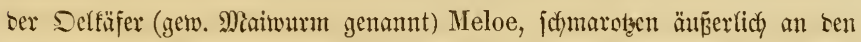
Bienen; rafjelbe tfyut bie Bienenlaus, Braula coeca Nitzsch.

Wir tragen noch nact, sas nach neuern Mactyrictsten bie nach 2U1jtralien

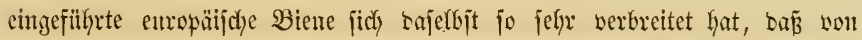

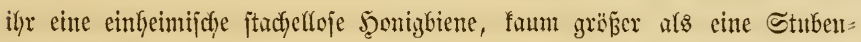
fliege, fajt verbrängt worten ijt, äf(nfic) wie oer (Europäer bie llrbetwohner

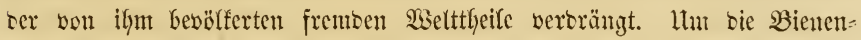
neiter zu entrecfen bebienen jich bie Cingeborenen eines finureidyen Mittels.

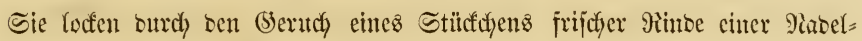

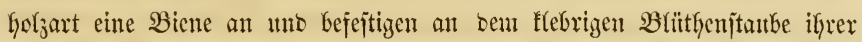

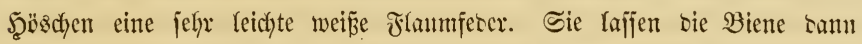

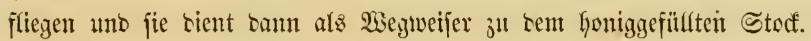

\section{Dic Erohumumel, Bombus terrestris Fabr., แIID ifle Berwandten.}

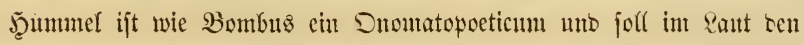

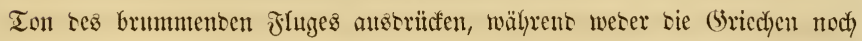

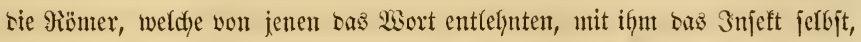
fonbern mur ten saut tes Bienenfluges bejeidyneten. 


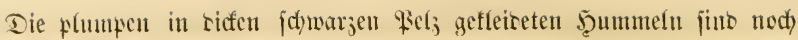

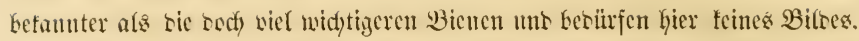

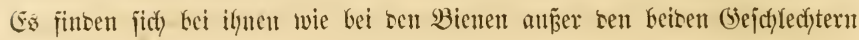
autc) Strbeiter.

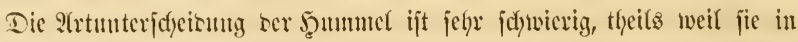

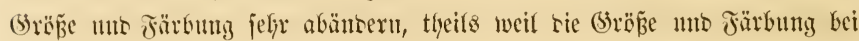

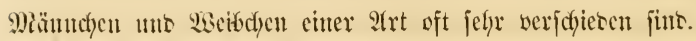

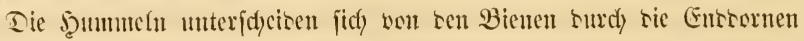

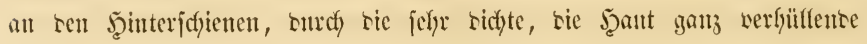
theifweije bunte Befharung, Surdy bie in gerarer sinte ftehenten brei Dieben=

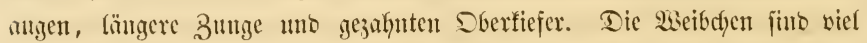

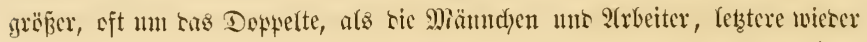

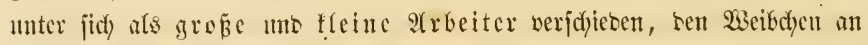
Gejtalt uno Jarbe glcich, wäl)reno hierin won beiren bie viel joblanferen

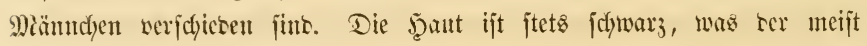
fofwarzen Bebaarung ilye Tiefe gicbt.

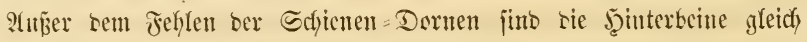

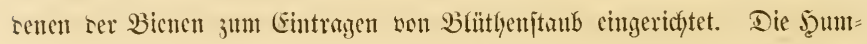

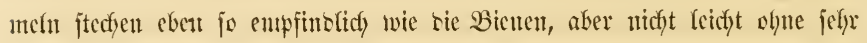
gereizt zu jein, wie fie remn n̈berfaupt gutnüthige gerntrige Thiere genanut twerten föm

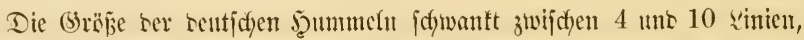

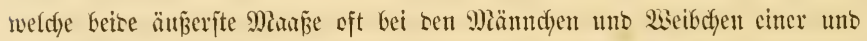

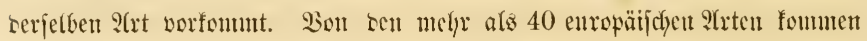

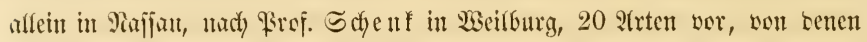

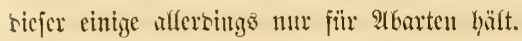

Das seben ber J̧ummetn, weldye Iafdyenberg fely treffens bie Büren unter sen 3njeften nenut, ijt anf unterirsijche ober joujt wie sem

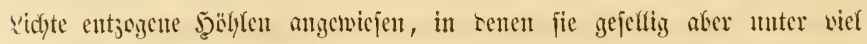

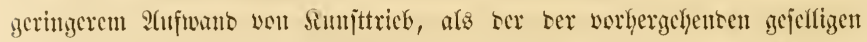

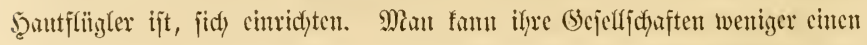

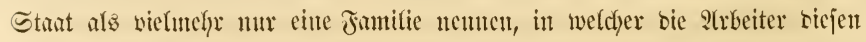
Yamen nicht alfein berbienen, ba audy bie $23 e i b d y e n$ uno Miännctyen arbeiten, affe son einer uno terjelben grofen Manter abjtanmuent, welche ben

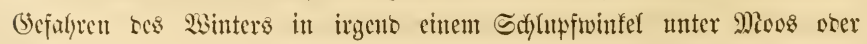




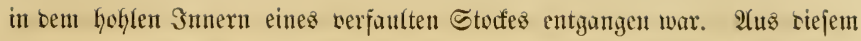

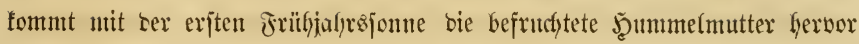

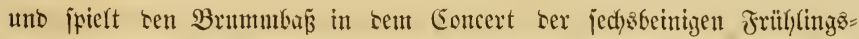

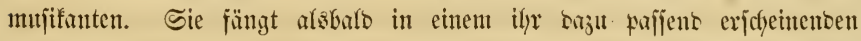

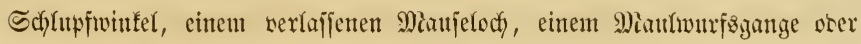

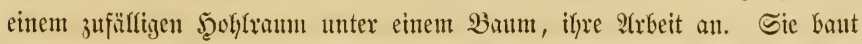

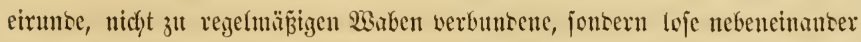

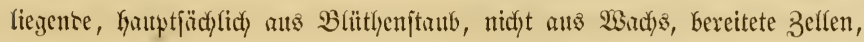

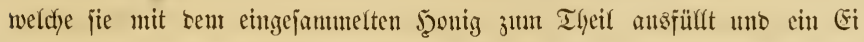

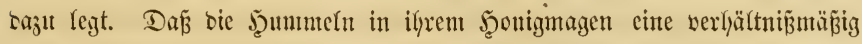
grof́e Mlenge von bentig Kergen, "wifien bie Buben wolyl" - um mit Iajoenberg jul reben - "renn jie fangen uno töbten jie, um mit ren

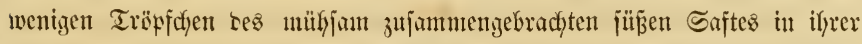

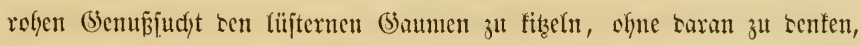

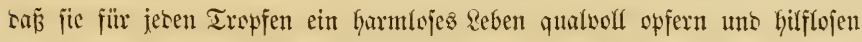

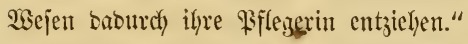

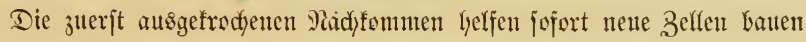

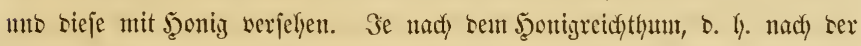

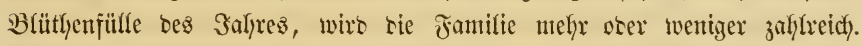

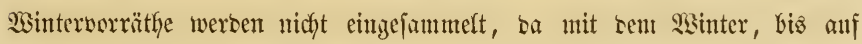
cinzelne überlebente Mätter, sie J̨unmeln meift jterben. "Die jungen

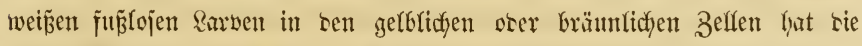
Mutter anfangs gegen bie erfte $\mathfrak{B r u t}$ zu vertljeisigen, weldye in mörberifdjer sujt jie heransziehen mo vernichten mödjte; balo aber ift jie eines befifern

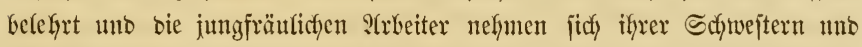
Brïber an unb bejorgen bie 2ictpflegung berjelben. Den Ertwadjenen

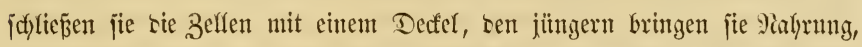

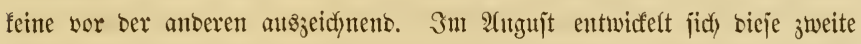

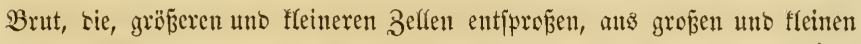
Weibchen uno Meändyen befteft; bie 2lrbciterimen murben fort uno fort won alfem 2 nnjang an geboren. Die Janilie ijt nun verbollfiänsigt mo

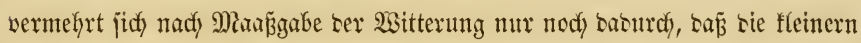
Weifdyen Eier legen, ans benen nu Mä̈ndyen Gerworgeken. Wie sie Stammfyalterin zuerft ifye Pioth hat, sie ztweite Brut in ifyrem Entiteyen vor ser exifen zu joützen, fo foll jie audd gegen bie grofenen Weiber jenter 


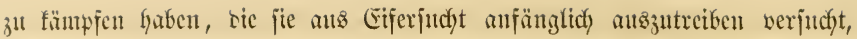

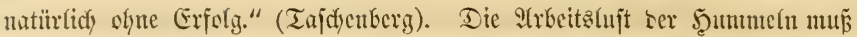

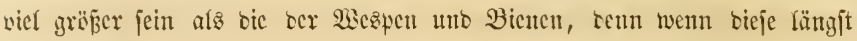
foflafen, jielyt man oft lange nad) Sonnemuntergang nody honigjanmelnoe

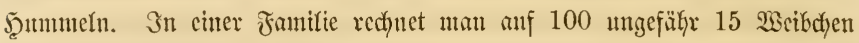

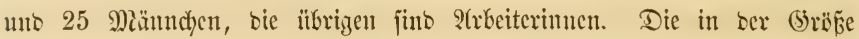

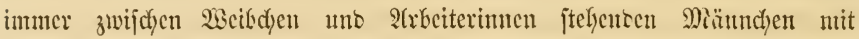
flcinerem Siopje, jđ)mäferen bärtigen แmb zweizähnigen Dberfiefern, jinto in

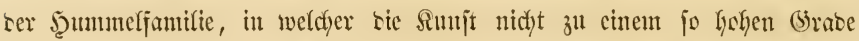

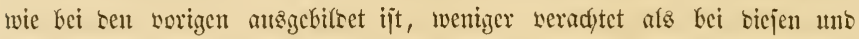

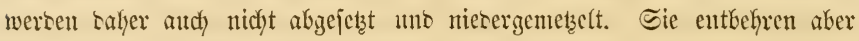
cbenfallz wie bei alfen Etacterfyantflüglern oer 23 affe.

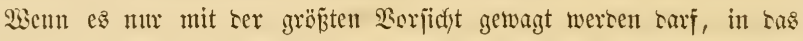
3ntere eincs Baucs won Wespen, Jeornifjen ober wilsen Bienten einzu-

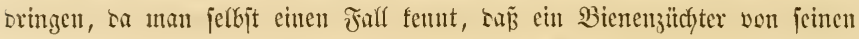
Bienen tort gejtodyen worten ijt, fo hat es bei cintiger Borjicht weniger

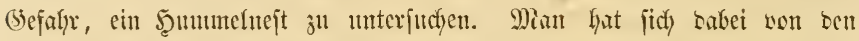

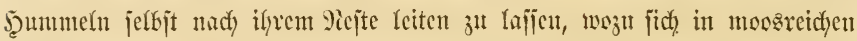

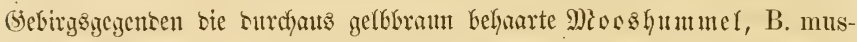
corum L., am bejten cignet. Sie berefft ifpr Nejt jiemlid) Loffer mit Mions

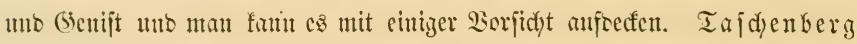

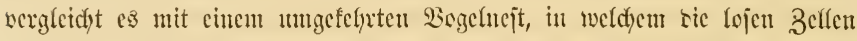

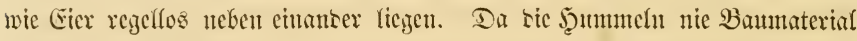

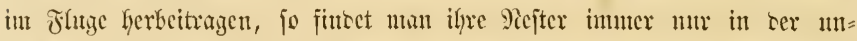

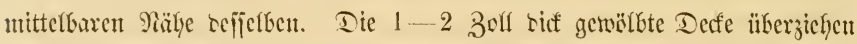

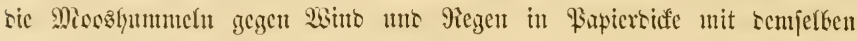
Stoff, aus weldhent sie Belfen gebilsct futr. Der oft in cinem gemumbenen

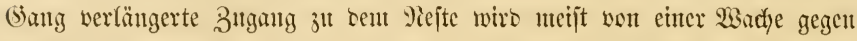
Ameijen mo anterer Jeinbe bejez̧t. "Trobzem mülïen jic einc Mienge

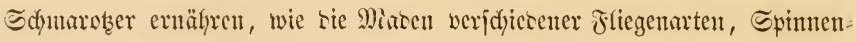
ameifen (Mutilla), die Sdymaroberfyummeln, sie Maupen mehrerer

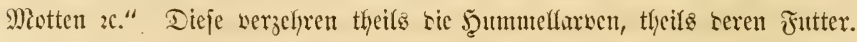

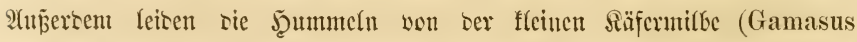

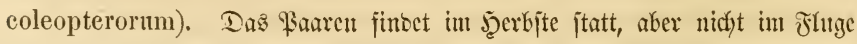

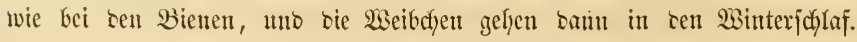


Der Stich ber J̧unmeln, ben jie nut jur Dertheibigung antwenten, ijt zient=

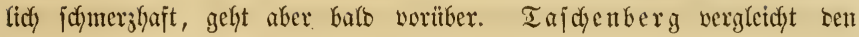
Sdjmer's jehr ridjtig mit cinem eleftrijuen Sdylag.

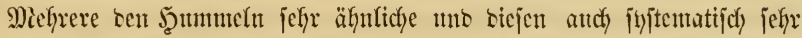

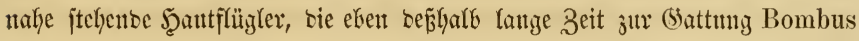

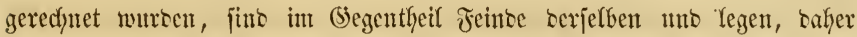
Sd)marob̧erfummel, Apathus, genaunt, ifre Eier in J̧mmmelnejter,

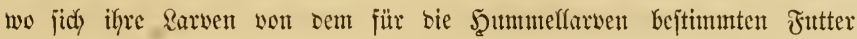
exnälyren.

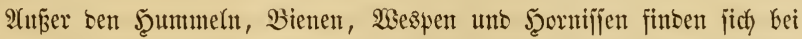

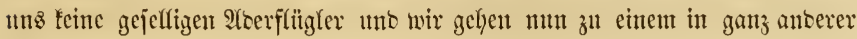
Weije gejelligen Walbinjeft ïber, weldyes lange Zeit ber (5egenítanto bes Iberglattbens war uno vielleidyt nody ijt.

\section{Dic Thoutaß = Trautermüffe Sciara Thomae L.}

Die Sromung ber Zweiflitgler, itber weldfe wir jadon frither, (S. 240 ii.) eine allgemeine Heberiidft gewaunen, bietet in ber flecinen Thomas=

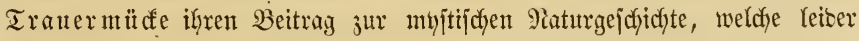

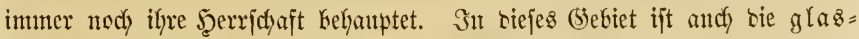
flüglidye Trauermülde, Se. vitripennis Klg. Zu vertweifer, meldye bie Sartoffeffranffgcit verffyutret haben jollte, wäfrent eine antere, Sc. piri Schmiedberger, an ben \$iflaumen erherefidyen Sdyaben anridytet unt Sc.

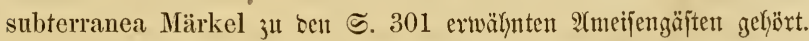

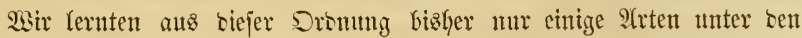

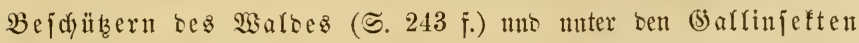

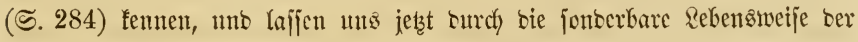

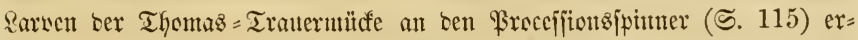
innern, weldyer, who zwar nidyt blos in Rarvenzuftante, ju ben gejefligen

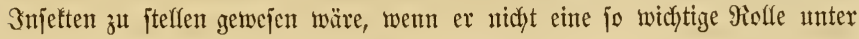
ben $23 a r b v e r b e r b e r n$ ficicte.

Die Trautermilưfe jelbjt, in iffrem boflenbeten Stanbe, war längit bes = fannt, ars man erft im Saffre 1845 burdin unmittelfare Beobadjtung in

*) Tad bem St. Thomas= Tage benaunt. 


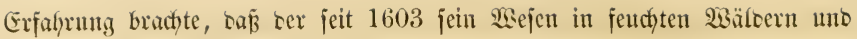

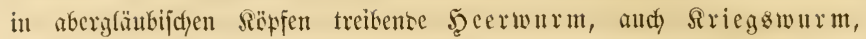

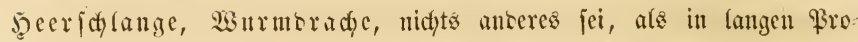

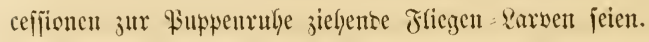

Die Jifiege (a) ijt fleiner unb johlanfer als sic Stutenfliege, Sopf

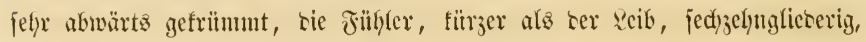
fabenföruig, feit behaart; finter sen oben nidyt ganz zujammenjtö̌enten

Fig. 65.

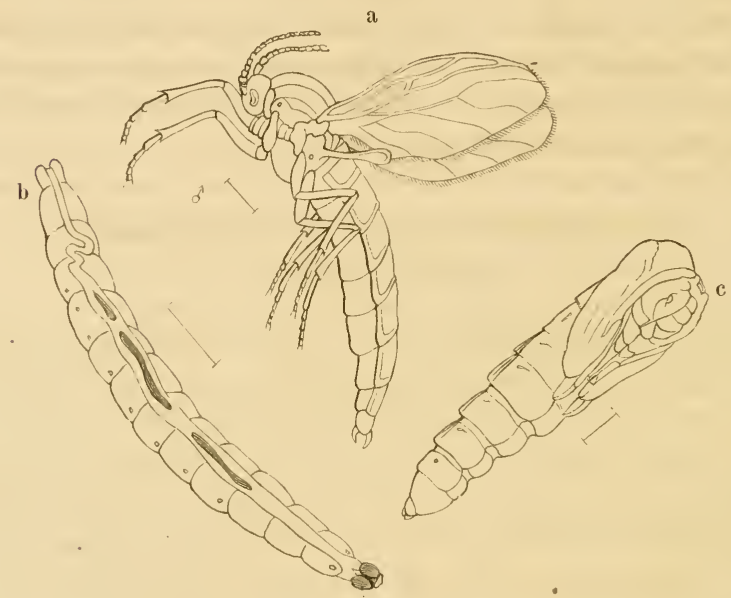

Die Ihourastanerficge, Sciara Thomae Fabr. (ber beerwurm).

a Die fliege. b bie \&arbe. c Die Fuppe (alfe trei fehr vergröpert).

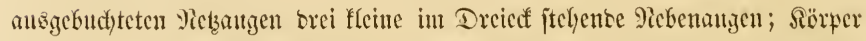

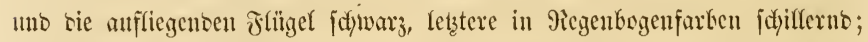

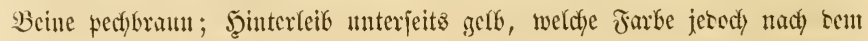
Tobe verjofwintet.

Die Sarve (b) $3 \frac{1}{2}-4$ Sinicn lang, fefy zartfäıtig mo in Scben

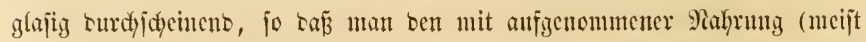
Erte) gefüllten Darm tentlich) fieft; Sopf fofwarz; an Ence Ler vorteren

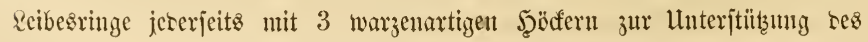




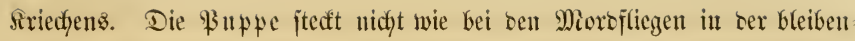
sen letzteren sarventyant, fontern ift frei unb läß̈t bie Theile oer Fliege beutfid) erfenuen (c).

Man fimbet sie zuerjt bei llpjafa wou Fabricils entbecte mb he

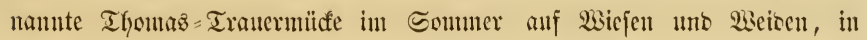

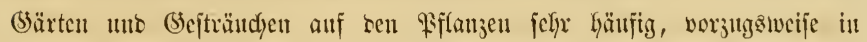

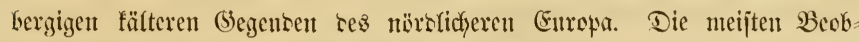

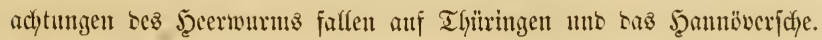

Es war ser befaunte Edyuämer Caspar Sdyenffelot, welder

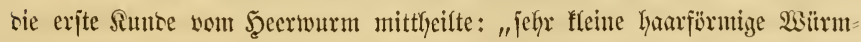
d)en, weldye in Somuter mie cine Sette zufammenfä̈ngento umberjichen,

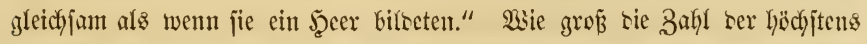

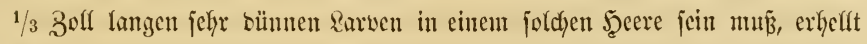

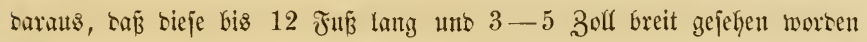
fillo. Die Büge, in benen sic Rarven biuf über wlo an einanber gebrängt fint, friedyen mely. wie eine Sdynecfe als wie eine Sdylange langjam über

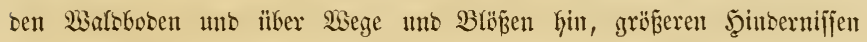
ausiweidjent, geringere ïberjteigeno ober burdy jie worübergehent jidy fpaltent.

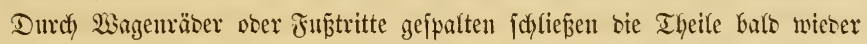
an cinanber. Man kat melfrere Z̈̈̈ge fich vereinigen, anbere cine Zeit lang

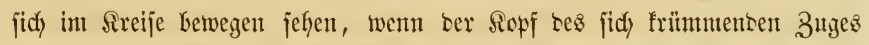
zufürfig an ben Sdywanj gerieth, bis ber Irrtfyum burdh Trenumg wieber

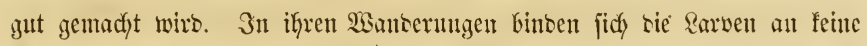
Tageszeit, mu meiben jie sen kell auffaffenten Sonnenjacen. Dies ijt wezen ber zurten Keidyt bem 2fustrocfnen unterfiegensen Rïrperbejdyaffenlyeit fehr er= flärficf), wie man benn and in ber gegenjeitigen Bebjïtung vor Sertrodfnen sen (5runb bes geneinjanen 2 anberns in jo bichter Aneinanberträngung hat

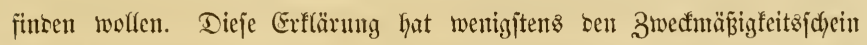
für jid), wäfyrento ein anterer (5runt zu biejer Sereinigung nody nicht nad)= gemiefen werben fonnte. Mierfwürrig ift, ba mitten in bem fich betwegen= sen 3uge jidy viele Rarwen berpuppen, bie bann von ben anbern mit fort=

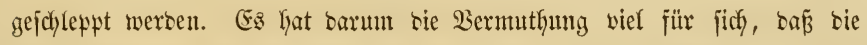
Wanberung mit cer Serpuppung ooer viefmefyr mit bem Hebergang ans bem

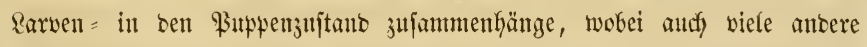

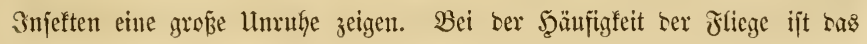




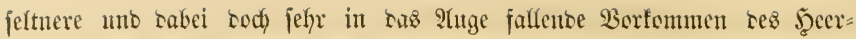
wurmes bemerfenswerth. Daher ijt in ber Riegel jere vorgefommene $\mathrm{Fr}$ =

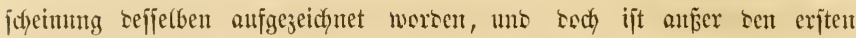

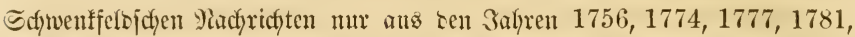
$1826,1844,1845,1849,1850,1853$ mth 1856 Las Erjoheinen bes รูeerwurms aufyezeidyut worben.

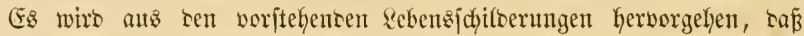
sieje Beippiele gejelligen Beijammenlebens inmer sen 3 wedf ber (Erreid)ung cines gemeinjamen Dortheils haben unter Befolgung einer feitftehenten

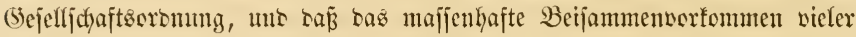

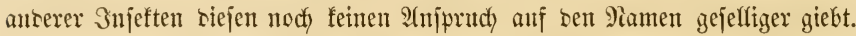

Meben ber Raupe bez Froceffinsfpimers, weldjer wir eine mahre Bejelligfeit - obgleid) nod lange nidft in tem anzgebilseten (Brace wie bei sen aufgejülyten j̧autflïglern - bereits juerfamten, finten fid) unter

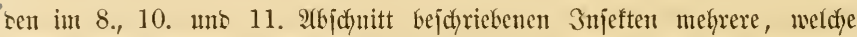
zeitweilig ober in gewijien Sebenzabjethitten majentyajt beijammenleben, waz meijt sarin jeinen (Srunt hatte, Daś sie Eier, ans senen jie herwargingen, in Miebrzahl sidjt beijammen abgelegt worten waren. Wir fanten es jo

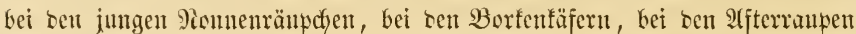
ser Siefernblattwespe, sen Rarben ser Mitfogajteren, sen Fidjtenblattjangern mib anberen. Sn ähntichen, feinen gemeinfamen Bwed wor 2ltgen habenten

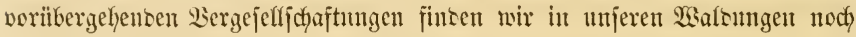
eine Menge anterer Snjeften, Lie wir aber hier unerwähnt lajjen. 


\section{Drcizebuter Xb/d)nitt.}

\section{Miitterlidye Fiirforge.}

Bei ber in gewiffem Simne geiftigen Afufajiung, weldye wir bei bex 3ujammenfteffung ber Walbinfeften bisher befolgt haben, Gheiben utnz nod) mehrere ïbrig, bie wir als Majter mïtterlidjer fïrjorge nod) bejonters

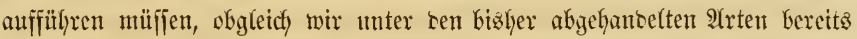

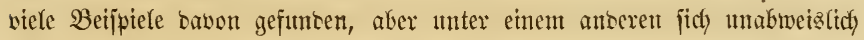

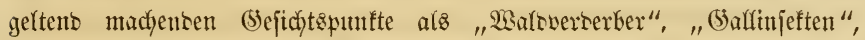

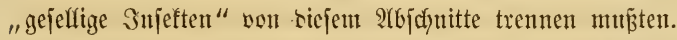

Es ijt befannt, bá

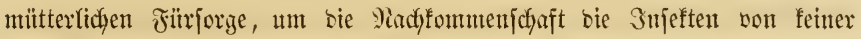
anberen Thierflafje itbertroffen werben, wenn idyon biejelbe jich nutr anf

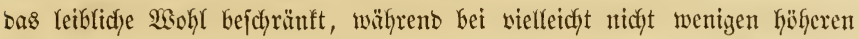
Thieren joga eine geijtige \$fflege, eine förmlidfe llnterridytung uno Erziefyung ber Şungen vorfonmt. Dieje reßztere ijt bei sen Injeften jejon beshafb

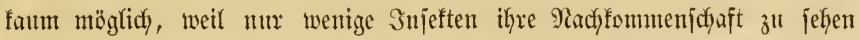
befommen, wenigitens nidyt in beren ausgebilbetem Bujtanoc. Waie jolfte ber Seibenfpinner fein Pantpenfint, wenn ex anbers burdy einen 3ufalf jo lange am Reben geblieben wäre, im Spinnen unterridyten fönnen, sa ev

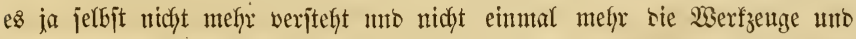
ben Stoff bajn bejtizt!

Die Sorge un bas (5ebeifen igrer Radffommen vermrjadyt vielen Mutterinjeften eine namenloje Mä̈lye uno $\mathfrak{A}$ rbeit, uno man beobachtet bakei

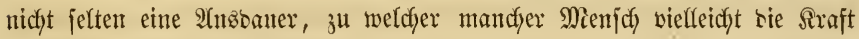
nicht in itch finben roüre. 


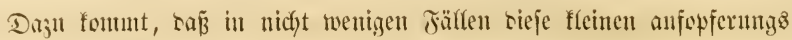

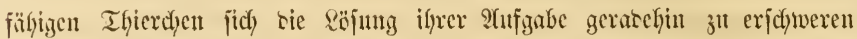
fcheinen, inten bie $\mathfrak{A}$ rbeit jut Unterbringung ifjer Eier, weldye, wenn jie

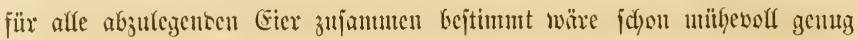
fein wïrte, für jetes einzelue Ei bejonocrz geleijtet wirt.

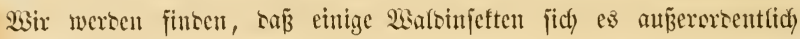

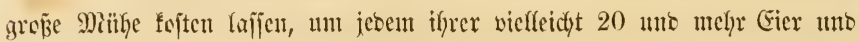
Den ausjchlïffenben sarwen ein behagliches uno gejichertes lluterfommen $j^{\text {ul }}$

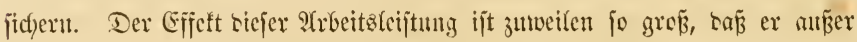

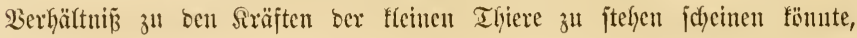

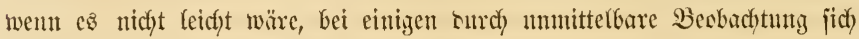
wom (segentlyeile jul ïberzenzen.

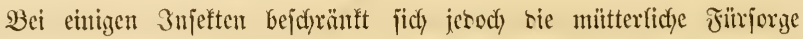

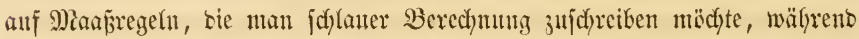

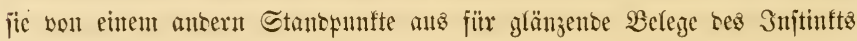
gelteno gentad)t werben fönnen uno werben.

Sn ben nadyfolgenten Sdjitoerungen werten wir uns natintidy mur auf bie bejontsers hervorragenten Fälle von mïtterfidyer Fürjorge ju be= jchränfen lyaben, weil wir jonjt beinahe sie ganje 9ieige alfer befmuten

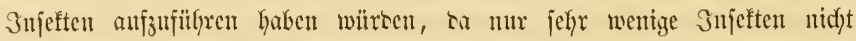

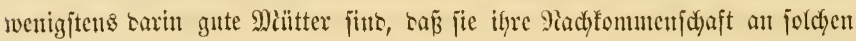

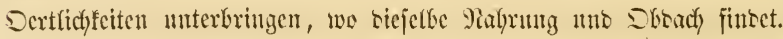

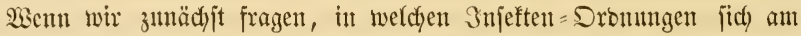

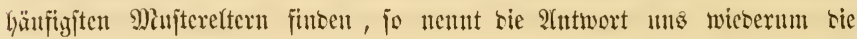

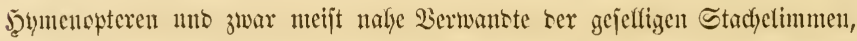
nächjt bicjen bie Säfer unb Bweiflitgler, wäfyrento in ben ïbrigen Dronungen nur sercinzelte Beifpiele vorfommen. Sntem wir sic auffalfenbiten Bei= ipiele ausfülyrticher bejpred)en, befolgen wir bie bei sen 2 alboerberbern bejolgte Pangfolge ser 3ujeftenortmungen.

Was zunädjit sie Sdymetterlinge betriffit, fo fömmen wir bei ifnen

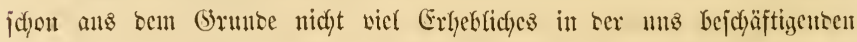
Jrage crwarten, weil ilyr ganzer Ban, an weldyem bie breiten, weitans:

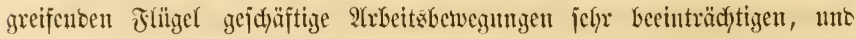

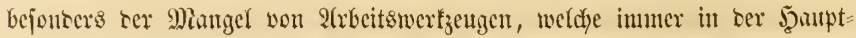
jache sie Samwerfzenge des Mantes jun, es werbieten. Die Sdymetterlinge, 
am entichiebeniten bie Tagfalter, fino fo recht eigentlidy bie Repräjentanten

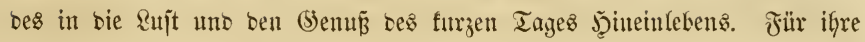

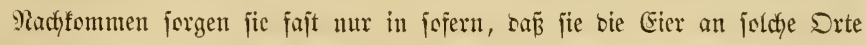

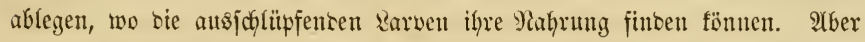
aud babei mact)en fie es siefen nidyt inmer alfzu bequem, ba wie wir

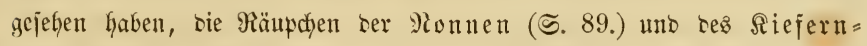
ipinners wom unteren Stamme, wo bie Eier abgelegt merben, erjt weit

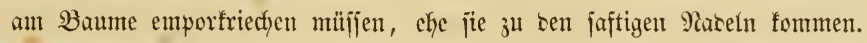

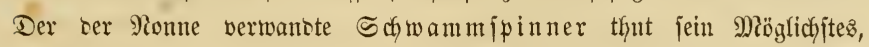
inbem er jeinen Eierhaufen mit ben 230 llhaaren jeinez Seinterteibes bebecft,

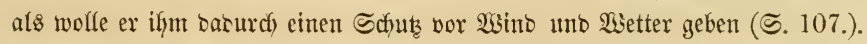

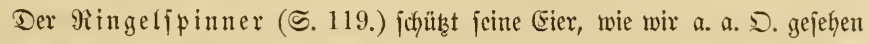
haben auf eine antere $\mathfrak{A}$ rt.

(5) (änzentere Bemeife von Mutterforge finben wir bei eintigen ßäfern

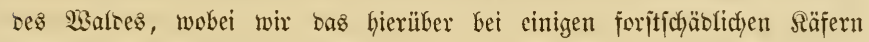
(Sefayte nicht wiecerholen wollen.

Es jino hier zunächjt einige 2 rrten aus ber 2 Gbtheilung ber Säfer mit

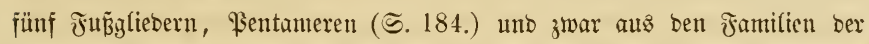
Blattfornfäfer, wohin Łer Maifäfer gehört (ऽ. 189.), uno ber ber Ansfäfer, Silphiten, zu befprechen. Die crīteren fino die Miftfäfer, Geotrupes, Billenfäfer, Copris, uno der Billenmärzer, Sisyphus; bie lezteren vorzuggneife bie (Sattung ber Tobtengräber, Necrophorus.

\section{Der Baldmiftfïfer, Geotrupes silvaticus Fabr.}

Sdyon auf unjerer S. 4. gebadften wir bez "itahlblauten Dungfäfers", welcher "in weitem Bogen herbeigebrummt fommt"; er mo nod) zwei anbere:

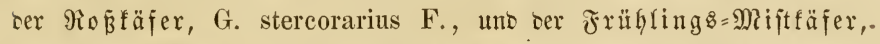
vernalis $L$., fino in unferen $\mathfrak{B a}$ oungen jefr verbreitet, namentlich wo fich viel Wito ooer Weibevieh funcet. (5i fino plumpe breite hod)gewölbte uno saher fajt halbftgelige Räfer mit breiten ungelenfen Beineu uno furzen Fühlern mit einer fleinen $B$ lätterfeule an ber Spize. Sie fino ourchauz

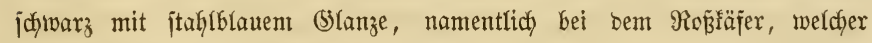
1 3oll lang unto von aflen ber grö̈pte ift. 


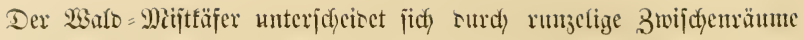

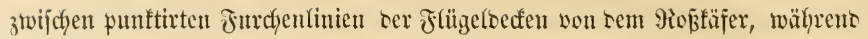
sie Flügelecten bes sritten faum beutertbar punftirte siucu hat.

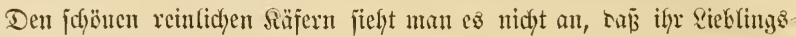

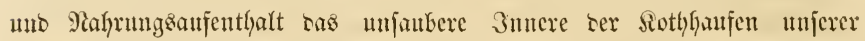

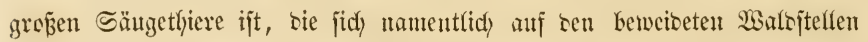
Finben. Inter biefem übel suftemben Sothe entwicfelt fich ser Säfer, intem

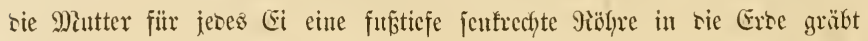

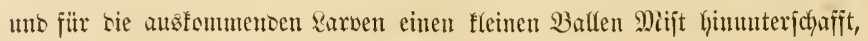
ju welchent sas Ei gelegt wirt.

Der Maturforjcher, ber sen cmpfintofanten Efel nidyt kennt, finset sieje Brutjtätten leidjt, wenn er cine oberflächlidy harte mo trocfene suffans= leerung untwentet, unter meldyer sft jiemlidy bidyt beijammen bie Eingangz:

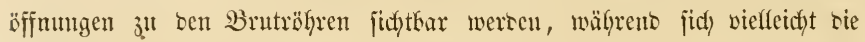

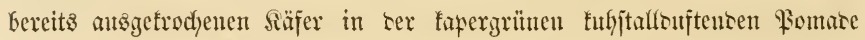

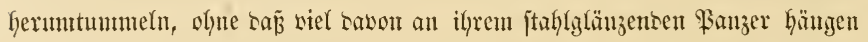
bleibt. Selten finıet man, wie jefyon bei ser Biene crwäfhnt murte, eituen

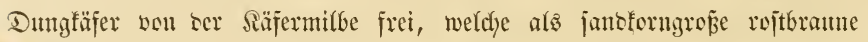

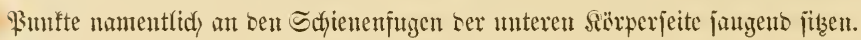

\section{Der Pillenwü̈ljer, Sisyphus Schaefleri L.}

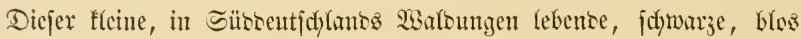

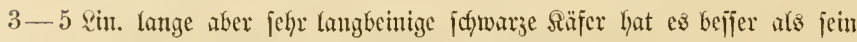

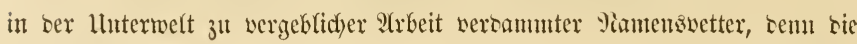

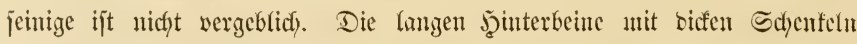

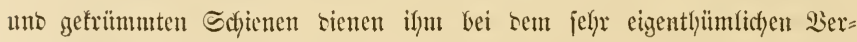

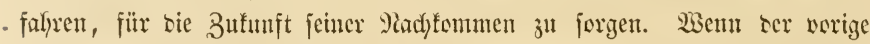

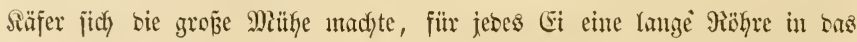
(Eroreid) zu graben uno etwas won ser lecferen Butunftsfojt baju zul legen,

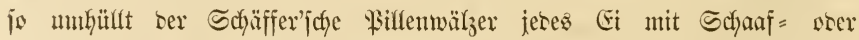

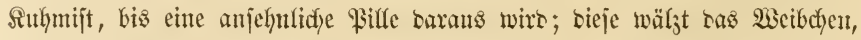

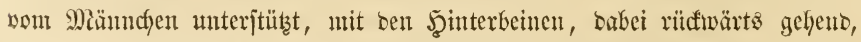
auf oft jiemlich weite Streden bis an cinen fidhern Dot, wo jie nieber= 
gelegt wirb. Die mitten in ifrer Futterpille ansfomumeno Rarbe hat savon zu leben biz zur פerpuppung, welthe in ter Erte nox jich geft.

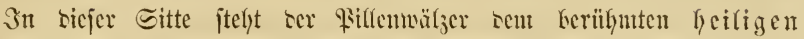

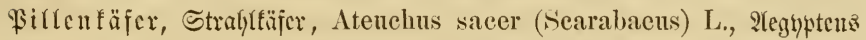
jebr nahe, weldyem ser in Sïttirol bänfig vorfonmentre Ateuchus sacer

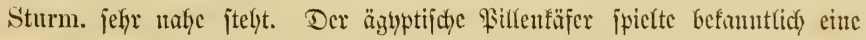

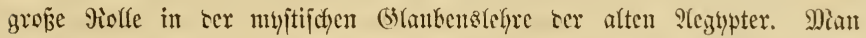

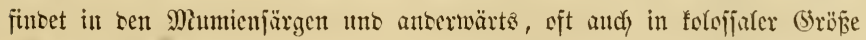

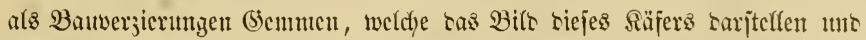
Sfarabäen genannt werten. Der Säfer găt atz mebr als cinemt (5runbe

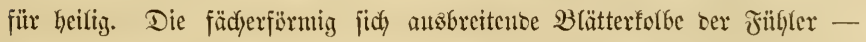

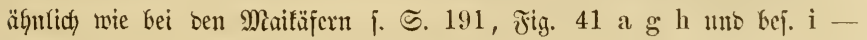

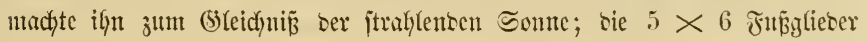

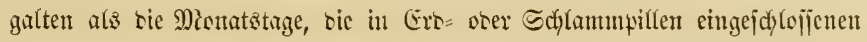
uno bei cintretenter wärute barans jith entwiffelncen Eier liepen sen Aegyptern bas Thier aus Erre won jelbjt entitefen, baher Alonogenes ge= namnt. Dic Sfarabäen mmben bejonbers als Amulet getragen, in Jinger ringe gejä̌t bejonbers von sen Solraten, weldye saburdy Eourage befamen,

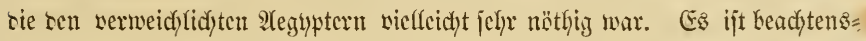

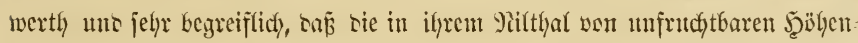

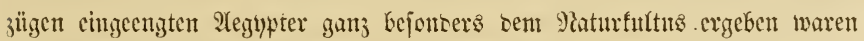
uno eine Mienge heilige $\$$ fiflanzen uno Ifiere Gatten, sen Sbis voran. Die

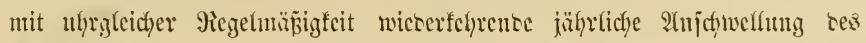

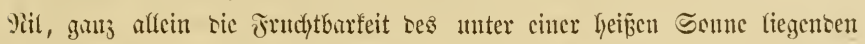

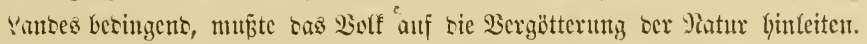

\section{Der genteine Todtengrüber, Necrophorus vespillo L.}

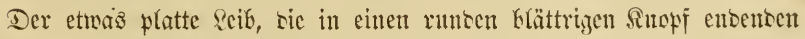

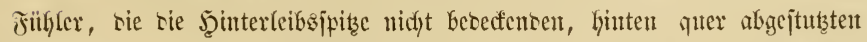
J゙lïgelsecfen itelfen bie Iobtengräber ju ser ctwa 300 9trten begreifenten

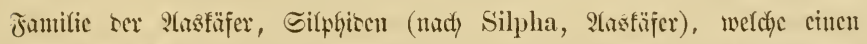
Theil ser efemaligen gropen Fumilie ser Sieulenförmigen, Elavicemen, ausımacht. 
Bon sen 9 reutictien 2 rten ser (Sattung Necrophorus ijt bie genannte Urt bie an häupitgiten vorfonmence (Jig. 69.)

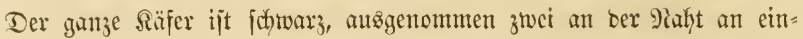

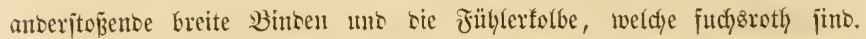

§ig. 69.

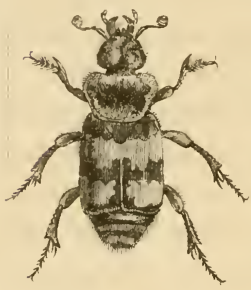

Der gemeite

Tobtengräber,

Necrophorus vespillo $\mathrm{L}$.

Der Borcerrano sez-Bruftichiltes iit gelbhaarig uno an ben fräftigen Beinen jinto bie Sdjienen bes finteriten Baares gefrümunt (noc) jtärfer afs an ser 2 (bbilo.). Jünf ancere Arten haben einte ganz ägnliche Färbung, finto aber ourdy fleine Miertmale gut von rem gemeinen Tostengräber unterffyiecen.

Wir finten bie Tootengräber überall sa, mo fich) Zeictyen von Miautmürfen, Miäufen, fleimen

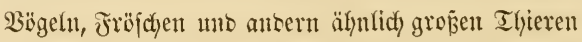
am Boren finten. Währento bie Silphen jich es bequemer machen mo ilyre Eier an bieje reichen ablegen, bieje mögen jid) wo uno wie imucr füben, io ïbernetymen sie Iobtengräber, ifyen Tamen butefjtäblich exfïllent, bie Bejtattung serjelben, un jüb saourdy, was bie saju aufgebotenen firäfte

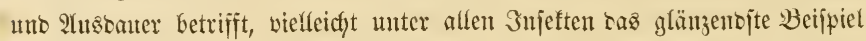

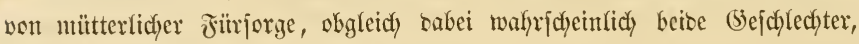
ja jogar zumeilen unverwante (Sefjülfen thätig jinto.

Wir entefynen hierïber einige Stellen aนß ciner anjithenton Schilcerung

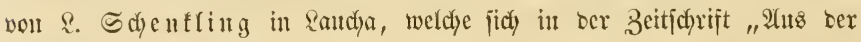

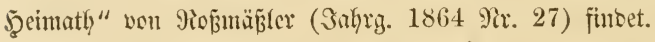

"Allfe Tootengräber jino ritlyrige Scjellen, benen in Bejug auf regen

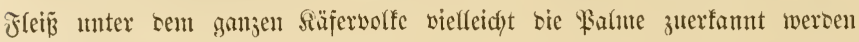

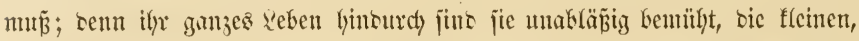

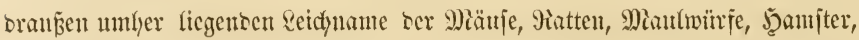

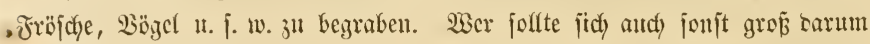
fümmern, ob sicjen Torten ein efyrlidy Begräbniź zu Theil werbe ober nicht, wenn fie nicht won ber अatur angetwiejen wären, foldyes zu thun? Sobalo fie einen in Lerwejung itbergegangenen Cabaver wittern, fommen fie

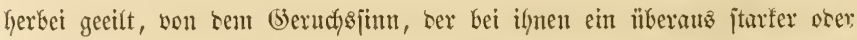

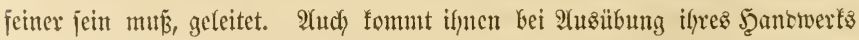

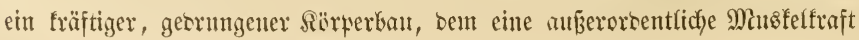


inne wohnt, jehr 3 "l fatten; tem cin cinzelner vermag eine toote Maus,

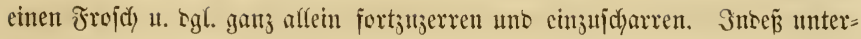
jiegt fid) felten ciner alfein biejem midstigen (sefdyät. Sobalo ber eine ober ber antere einen pajfenten Fumb gemtadyt hat, jieht er jidy affes erjt

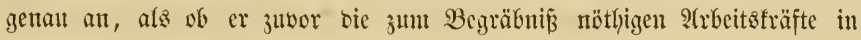
Beredynung itefle. Madjoem riejes gejdehen, fliegt ex jdynell won bannen,

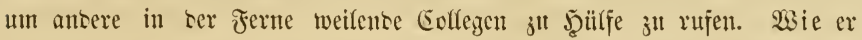
biejelben von jeiner Entbecfung benadyrichtigt, wie jidy bieje Iflierdyen ver = ftänoigen, ijt cine nod) nicht anzgemadyte Sadje. 2(ber genng, fie eilen mit ifym herzı uno madjen jich alsbalo an bie 2trbeit. Es ift interefijant, einem jolchen Begräbniß̄ beizuwolyten; benn burdy Wehflagen uno Gaumern

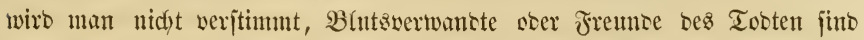
nicht zugezen. THber bie serdye in ten seiften fingt bas (5rablied uno ber Sufuf hält bie seidyenprebigt vom hohen Banm herab. - Treten wir näher. "Siege, wie fie ben Seidfnam won aflen Seiten betradyten uno um= ¡chreiten, gleidjam als ob Maañ jum (5rabe genommen werben folle. Nan wiro ber Ertbosen gemujtert, ob er and zur 2Alfnahme ses Torten recht geeignet jei. Es jefeint ifynen 2 fles in Sronung, benn einige bon ignen

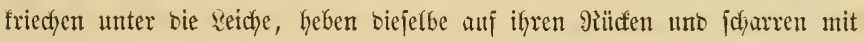

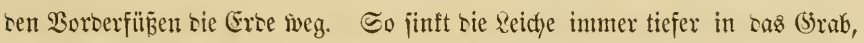
ofgne saj man von oben jieht, wie es jugeht. Dod) halt, jezzt jinft jie nicht mehr, wantt nur hin uno her; bie (bräber finto auf einen harten (5egenitano gefonmen, fie fönnen nidht tiefer. Sie halten inne uno pflezen

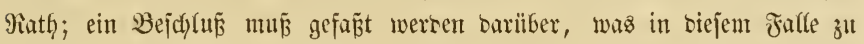

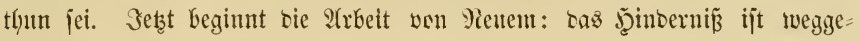
räumt, tiejer uno tiefer jinft ser seidynam, bis enofid) nidjts melys von ifgm zh jeken ijt.

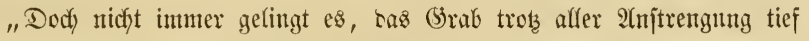
genth zu graben, weil ser 30 ben viefleicht zu hart ober ju fteinig ijt. In. foldyen Jäflen wälyen orer idjleppen sie Tootengräber bie Reiche an einen paffentern Drt, un fie hier zu berjenfen.

"So gejtaltet jid) ¿as Tootengräber = (Sejchäft bei günjtigen Bertyältnifjen. Aber entjalten nicht hierbei sie Ihierdyen eine riejenumäpige Igätigfeit? 4 bis 6 von ifnnen witrten im Stanse jein, binnen 3 Stunten eine Manz vollitänoig ju begraben. Einer ifyrer erjten Beobachter fperte 4 Säjer in 
ein mit Erbe gefüllftes uno wohl verwahytes (Staz. Die angejteflten Berjudde

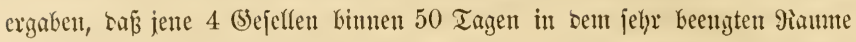
12 ecidyname vergraben hatten: 4 Fröfthe, 3 fleine $\mathfrak{B o ̈ g e l , ~} 2$ Fiface,

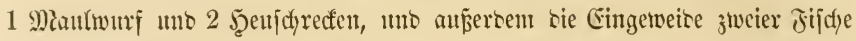
unt zwei Stïte von einer Dajenlunge. Bei einem antern Berjuche ver=

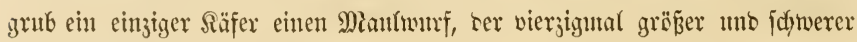
als er jelbjt war, in 2 Tagen.

"Yieben biejer Regjamfeit offenbaren bie Räfer aber and eine $\mathfrak{2}$ th

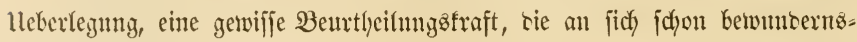
werth) ijt, sie aber in Erijtannen jebzt, wenn man bört, wie jofwer Semant

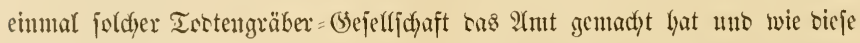

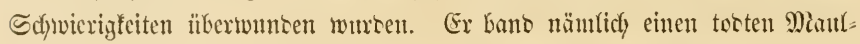
mur an tas ente Enbe eines Fatens, währent er bas antere Ente an

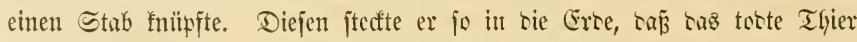
jiemlicy anf ber Erte auflag. Balo fimen aud einize Tostengräber un begannen ify 2 serf. Da jie aber jahen, saj̃ alles Untergraben vergeblidje Miüfe wax uno sie Seidye immer nidyt nadyinfen worlte, jo lielten jie inne

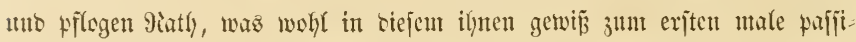
renten merfwitroigen Fafle zin thun jei. Llub jiche, fie hatten bas Fechte

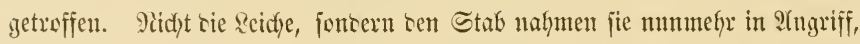
an oem jene befeptigt war, wühlten fo lange an iflu herum, bis er jum

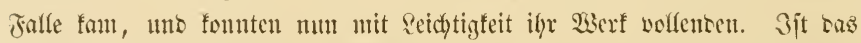

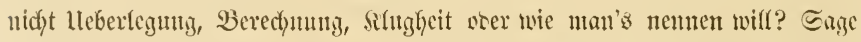

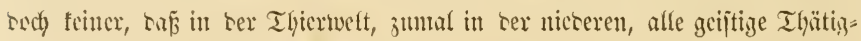
fcit aufgöre!

"2Sas haben num aber tie Tortengräber bavon, baj̃ fie ungerufen herzmeifen, um bie Tooten ju begraben, sie fie nichts angeben, ja sie nidyt eimmal ifres bteichen fint? Tragen fie mely savon tem bes sutfufs Danf

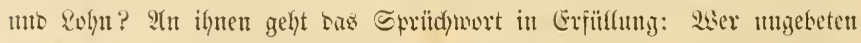

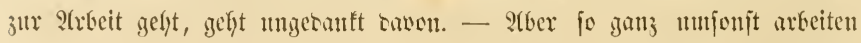

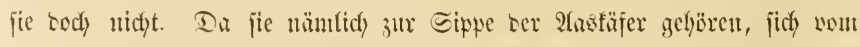

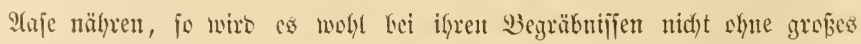

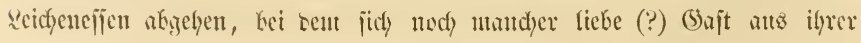

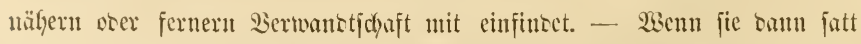
jint, fo juns jie sie beften Frentre, mas aber nidyt inumer ter Jalf ijt, ba 


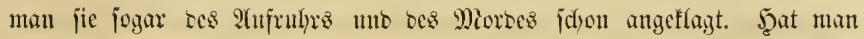
fie nämlid) irgenswo shne Jutter cingejd)loffen, fo frif̧t einer sen anbern. Wenten wir uns inbej weg von biejer traurigen Secne uno betradjten wir

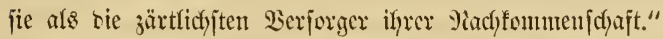

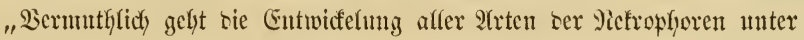
gleidyen Serbä̈ltniffen von jtatten. Die Wieibdyen berjelben legen ifye läng=

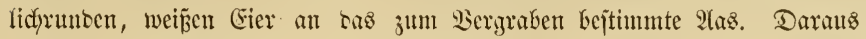
fommen bie Rarven. Der glänzente Siopf ocrjelben mit Zangengebiä mo

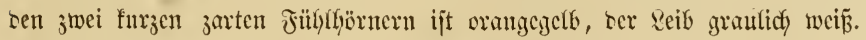
3edes Seibezgelenf hat oben einen rothgelben Flecten, bie nad) binten zu immer sunfler wersen; anjertem haben affe 4 jadarfe herborjtehente Spizen, bie nad) hinten jul länger werben; ber letzle 9iing hat nur 2 Spitzen, bie aber unter alfen sie lämglten jurb. Bermutblid hilft fitc) bie sarbe mit senjelben in ser Erbe fort, sa sie 6 rotfgelfen Jü̈̈e unter sen 3 erjten

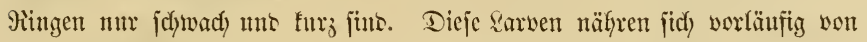
Dem vergrabenen 2 aje uns verichonen jelbjt sie Sinedjen nidjt, ipäterfin

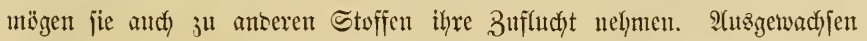
crreicfen fie eine sänge von antertfyalb Zoll. Sommt baun bie Zeit ber Serwandung, fo gräbt fidh sic sarve nod) tiejer, formt jich alts (Frbe eine

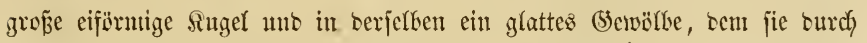

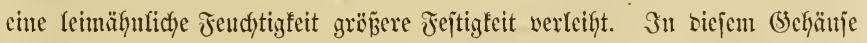

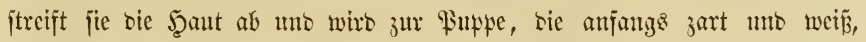

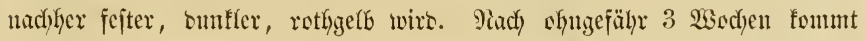

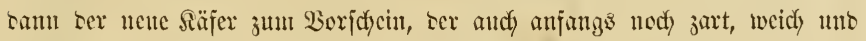

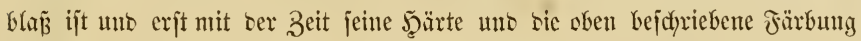
crlangt. Erjt nadjoen biejes gejcheben, bricht er aus ber Erte herbor, um

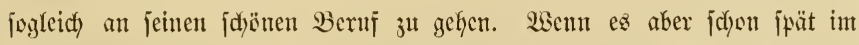
J̧erbjt fein jollte, verbleibt er bis zum mächjten Jrübjafyr in ber Erre."

\section{Der Birfen= Blattroller, Bhynchites Betulac (Attelabus) L.}

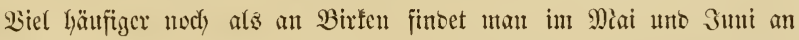

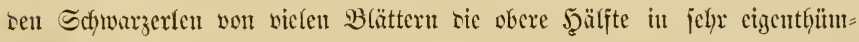

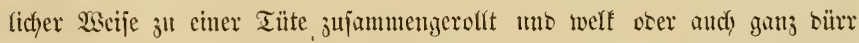

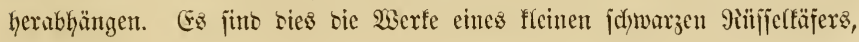


weldyer nady ilynen ben obigen beutichen Pamen erfalten hat. Die fdjöne Familie ber 9ü̈jfelfäfer lernten wir bereits $\subseteq$. 165 fennen, zu beren $\mathfrak{2}(b=$ theilung ber (Serabfithlerigen bie Blattroller gebören, won weldyen 33 Irten in Europa borfoumen.

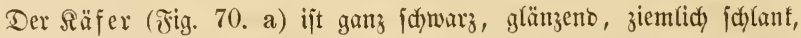

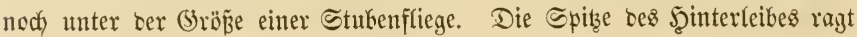
Fig. $\mathbf{i} 0$.
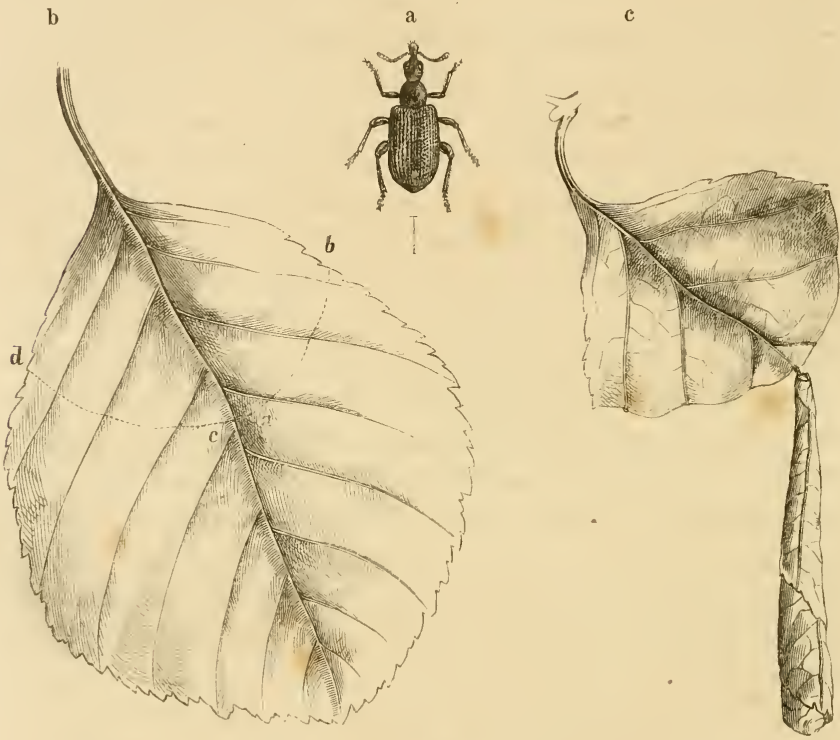

Der Birfent $=2 B$ attroller.

a. Der Räfer. b. Errentratt mit ber Sdjuttlinie a-b. c. Die fertige Fiolle, in weldyer Das Ei ftedt.

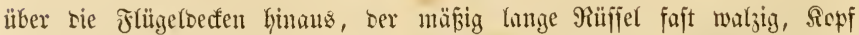
finter ben 2 (ngen nidjt verengt, bie Schienenipitzen haben feine ફ̧afen uno ser Snnemrano berjelben nidjt gezäfnt. - Die Rarven mo fino wie bei allen Mitifielfäfern.

Die Trtbeit, weldye sie bejorgte Mintter jur Bergung if̧rer Eier auf

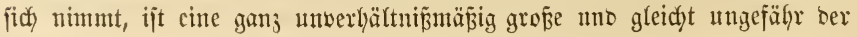


werche es uns machen mürbe, ganz allein uno shne weitere J̧ülfsmittel als

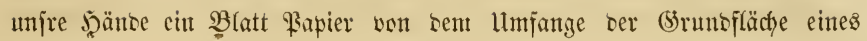

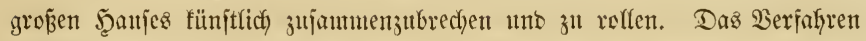
Des fleinen Sïfers ijt folgendes.

Şat ser Siäfer ein paifentocs Blatt autgengählt, jo ijt jeine nächjte 2trbeit, bafjelbe in ber oft fefyr unregelmäß̈igen Bogenlinie d e a b

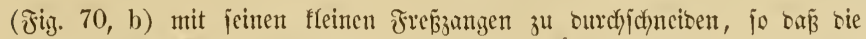

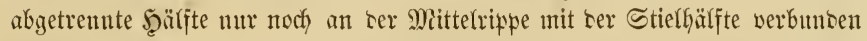
bleibt. Er fängt nidyt an Miande, jonbern bidft bei ber Mittelrippe (bei a) an, uno füfyrt ben $\mathfrak{B o g e n j} d$ nitt bis an sen Mano (bei b) fort, jeboch fo,

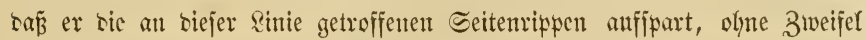

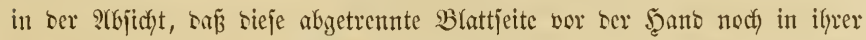
Rage bleibe unb ify nidyt alz lofer Fetzen bei jeiner weiteren 21rbeit hintere.

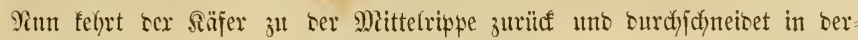
jelben Weife von e nach d hin bie anbere BBlattjcite. Sit er bamit fertig,

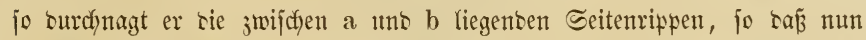
bieje rechte Şlattjeite ganz abgetrennt ijt. Setzt wiro in ber Effe bei $b$ bie Dherhaut מes 2 hattes als cine fleine Tajoye von bem Blattzelfgetwebe losgenagt uno in bieje Tajole ein winjigfleines Gi gelegt. Nun Keginnt mit Şülfe ser Beine beirer Sörperjeiten, won ser B̧attfeite b beginnento, bas

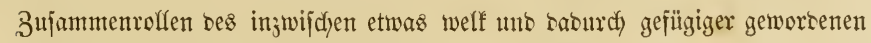

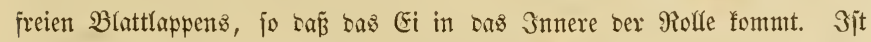

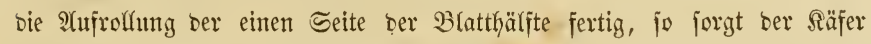
ourch) mehrmalizes Einfneifen, bas sie Rolfe fich nidyt wieber alfrollt, was jajon die etwaz flebrige Sberfläd)e ses Grlenblatteśs verbintern hilft. Nam werben sie Seitenrippen ser linfen Bhattfeite surdhidnitten uno bieje $u m$

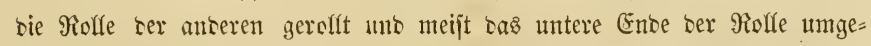
fnicft uno surdy einige Siniffe befeftigt (Jig. 70, c). Nad) Kurzer Zeit Friecht

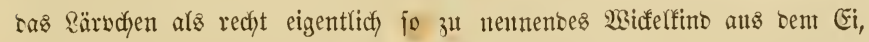

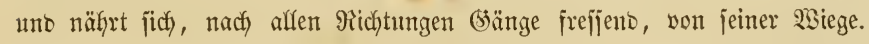
Eine Beit lang idfeint sie Blattrofle ourdy ben Saftzutrom surth bie Mittelrippe nod) ertährt ju werten, aber zuletzt fitubt fie ab uno bricht ganz vertrocfnet ab. Die barin mit herunterfalfente sarve gcht alsiann wafrifcheinlich in ben Booen, um jich zu verpuppen. 


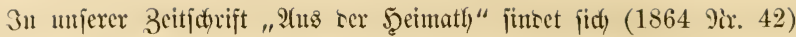

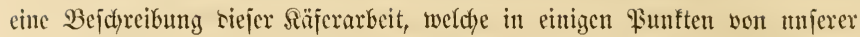

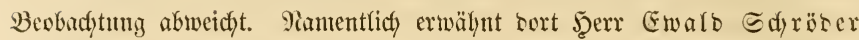

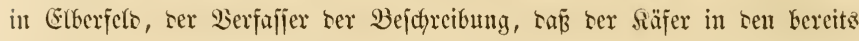

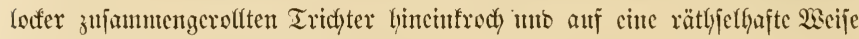
ign inmer sidfter jujammenzog.

Wie viel Eier ser Räfer legt ift nody nidyt befannt, jebenfalls aber

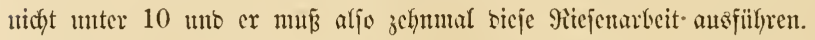

Wir jaben bie bei ciniger 2tumerffanfeit namentlidy an bohen Birfen-

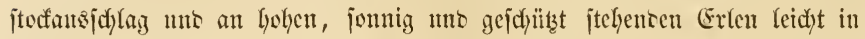

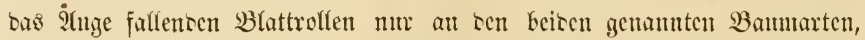

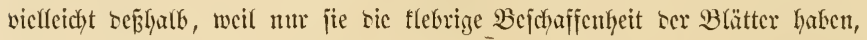

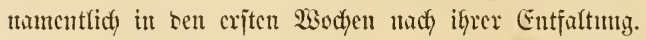

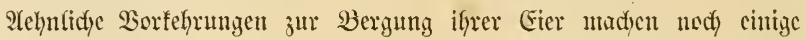

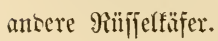

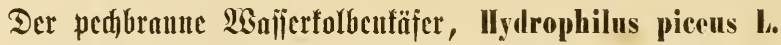

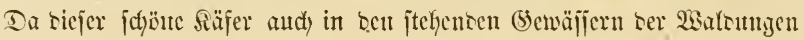
lebt, fo bïrfen wir ilyn Gier um fo mentiger übergehen, als er für feine Eier

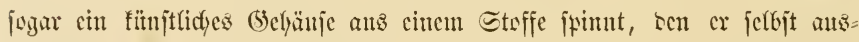

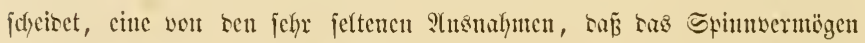

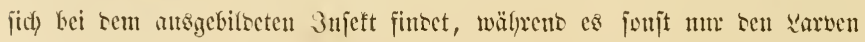
jufomut. Die (5attung Hydrophilus bilset mit nod) eitrigen (5attungen

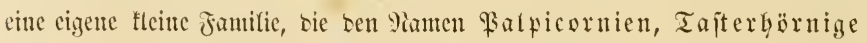

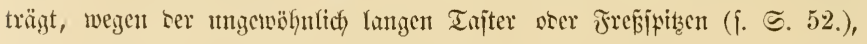
weldye fogar länger als bie Fühlgörner fins.

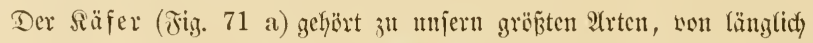
cirmoer Form, weniy gemörbt, mit jicmlidy fdarfem Yantmmfange, omtel

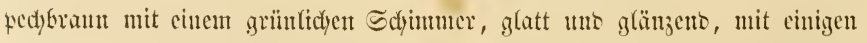
nur wenig berticften, gefdywungenen zarten Psunftiticylinien über sie Flïgel= recten. S(n sen ziemlid) furzen Futhlern bitsen bic 4 oberjten felyr abweidyento

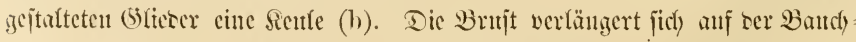

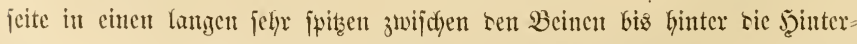
fiibe himans reidyenten gerasen Dorn. Das Echilsd)en (an ter Bajts 


\section{7}

3mijachen ben beiben Flïgetbecfen) ijt jefhr grof mo bifbet ein fajt gleidf)= jeitigez Dreiecf. Die Mittel = unt J̨interbeine, bejontocrs bie in jtarfe

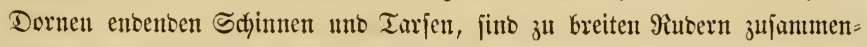

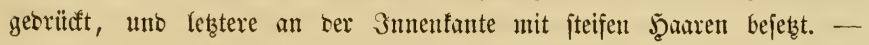
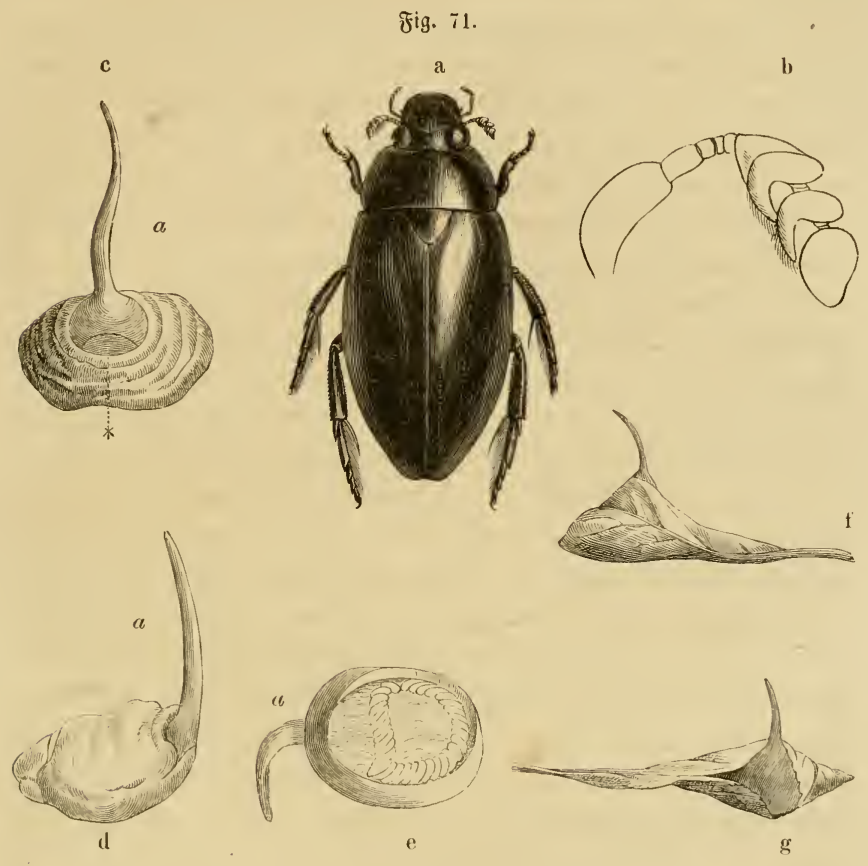

Der ped) Erate 2 bajertorbentäjer, Hydrophilus piceus L.

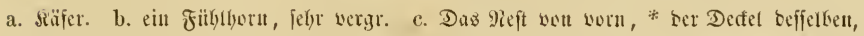
d. Dafferke wont ber Seite, e. Saffelbe won unten mit weggeidntittentem bioben; an c. d. e. bejeidyet $a$ ben hornähntidsen Maft. f. unt g. Das gieft bes lautfifferartigen Sutfen= wafferfäfers, H. caraboides L.

Die Zarve, bie แms içzt zumächjt nidyts angeht, ift ein fleines mit jtarfen

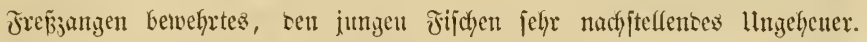
Die Fuppe hat nichts Eigentfyümlidges. 
2Bas uns an tiejem Bewohner unjerer Fijoteidye mo $\mathfrak{B}$ eifer, nument=

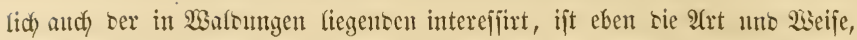

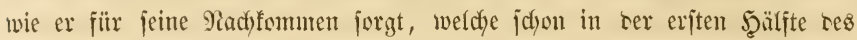

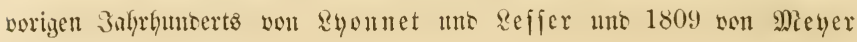
befdyrieben worben ijt.

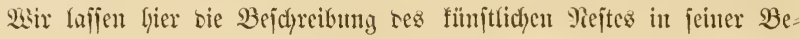

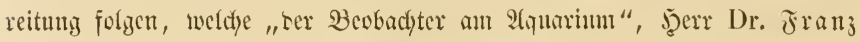
Schlegel, jetzt Direftor bes joologifden (Sartens in bireslau, in mierer

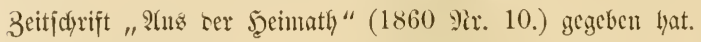

"Das̃ 2aeibdyen - mu riejes fpinnt - legt jidy an bie Dberflädye

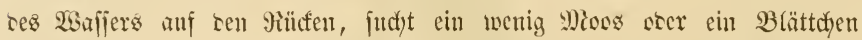

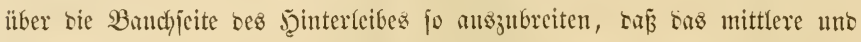
Gintere Jußpaar bavon bebeft wird, währeno die freien Borterfüpe โas Blättchen oder Las Mions von oben her gegen Den Bauth srüten. Sofort

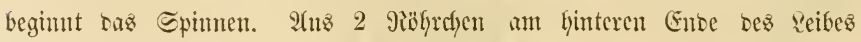

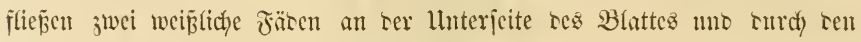

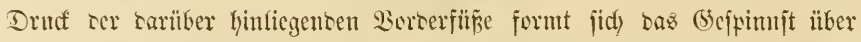

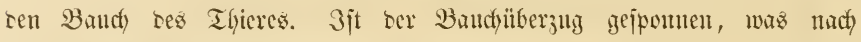

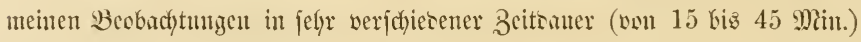

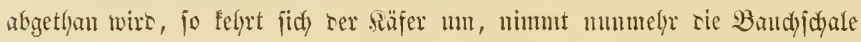

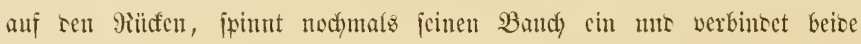

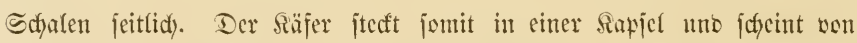

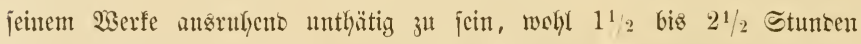
lang. Schneiret man aber, nad) Miger's Worgang, einen Theil ses

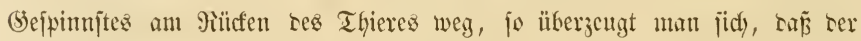

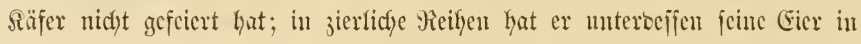

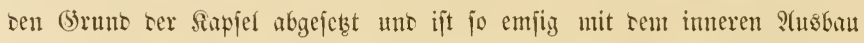

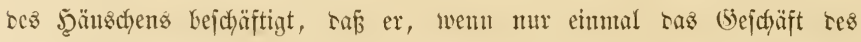
Eierlezens begomen hat, fid Indy hic meugierige Scheere tes Beobadters

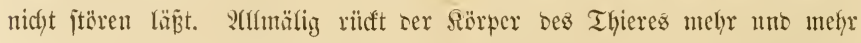

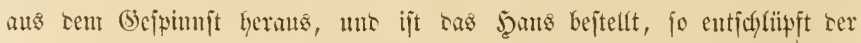

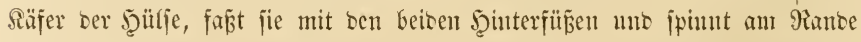
ber Deffum Faten alf Jabell runoum. Die Definung wirb enger uno befoumt eimen etwas gewuljteten Saum. Darmif zicht er Jä̌en querïber,

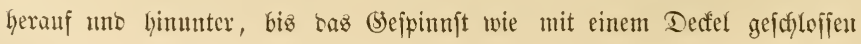




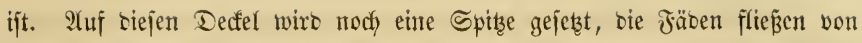
unten nad) oben uno bon ba zurüd; bie folgenben Fäben werben immer etwas länger unb fo thärmt fich) bie Spize auf uno wirb zu einem etwas gefrimmten J̧orne (e d e, a). Das Werf ift volfenbet, es war eine 2lrbeit von 4 bis 5 Stundent. Der flcine Siüntter mujtert jein $23 e r f$

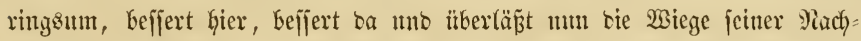
fommenjdyaft bent idhaufelnben Elcmente. Dod wic cin Schifflein mit jeinem Majte treibt bas Mejtchen leidjt uno jidfer auf ocm Wajper bin,

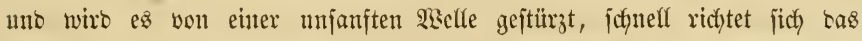
Şorn wicber auf. Die (Sejtalt ses 9icjtchens ijt ziemlich) eiförmig (Fig. e d). In ben 2(b6ilsungent füto bie $\mathfrak{B l a ̈ t t e r}$ ober Mroostheile weggelajןen, melche vom Thiere als crite (Sruntage beim Baut beffelben benutzt werten, bamit

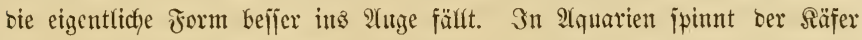
auch obne bieje Beifülfe; jie jobeint alfo bent Ifiere nicht unbebingt noth=

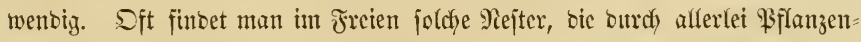
ankängiel gerabezu unfenntlidy geworben jint.

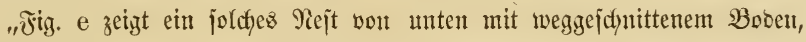
fo baß̃ man bie zicrlich) georbneten Eier, ungefülyr 50 an 3ahl, bidjt am Boben liegen jiefyt. Der ganje übrige Raum über ben (Eiern nach ber

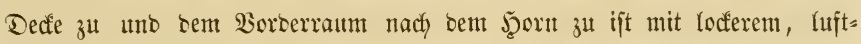

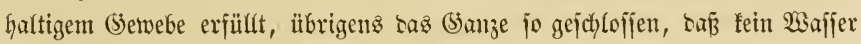
einbringen faun. Waie widftig ift gerube bieje Einridfung! Die Eier nehnen sen unteren uno hiuteren Theil ein, über ihnen uno im Borber=

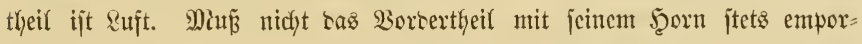
ragen, uno wirb es ja gejtürst, inmer wicber fitch aufrictyten?

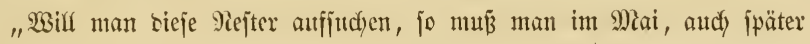
noch, mit bem jogenannten Schäpfer in jtehenben meer(injemreidfen $\mathfrak{B a ̈ f f e r n}$ fijdyen. Mach Werfauf bon 16 bis 18 Iagen fommen bie Rarven aus bem Refte queraus, inben jie ben Decfel, auf welchem bas J̧orn auffitzt, an ber=

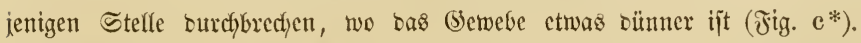

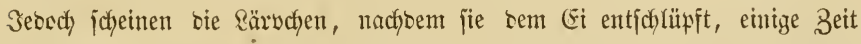
in bem Mejte zu berweilen, ntan fagt bis nach ber exfen 5ä̈ntung. Nie= mals aber fonnte id̆ in bem verlaffenen (S) Łäuje abgeworfene Şäute finten,

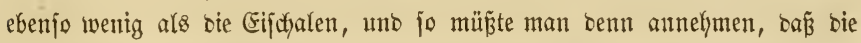

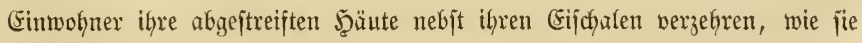




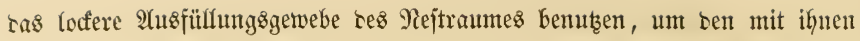

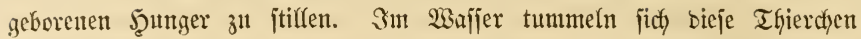

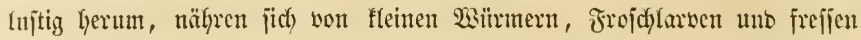

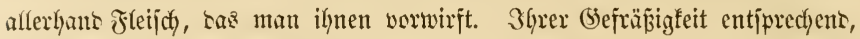
wadjen jie jonell. Berïhyt man jie, fo geben jie eine sunfle jtinfente Fliiffigfeit von jich. Enolich reift sie Sarve zut Derpuppung, jie verlä̈pt

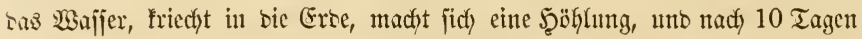
etwa tritt bie \$uppe aus ber aufgeplatsten Rithfenlyant ber Rarve hervor.

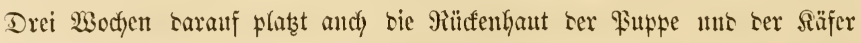
arkeitet jich aนz ber Ş̈̈llfe Geraus, bleibt aber nody bis er jo weit erjtarft ijt, um bic Erbe burdjbredjen z̆ fönnen, in ber Şöhle liegen. Maan be= hauptet, Dá̉ biez 10 biz 12 Tage Dautere. Doch wowon jollte ser Säfer

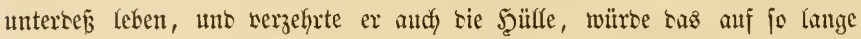
Zeit genügen? $\Im d$ jelbjt habe feine Beobachtnngen barüber gemadyt."

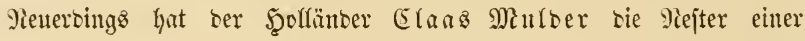
keineren 2 rt, bes lauffäferartigen Solbentwafierfäfers, Hydr. caraboides L., bejurieben unt abgebilsct. Diejelben werben ftets in cin nicht ju breites, biegjames 3 lättchen eingefjülft unb bei ber Bereitung ijt Das 9) ebenfalls mit cinem Majte verjebene Miejtchen sar.

Die 2 rbeit, welche bic gejelligen गॄy gemeinjam voflbringen, nach sem förberjamen Frincip ser 9trbeitztheilung, nimunt won uid)t wenigen antern S(rten sic Miutter allein auf fich, höct)itens

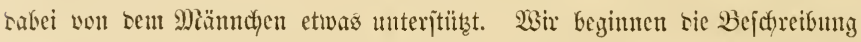

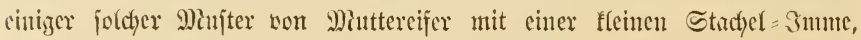
weldye sie Erfinberin Des Tapejiergewerbes genannt zu werben vercient.

\section{Die Tapejierbicue oder ber Blattjuncider, Megachile centuncularis Fabr.*)}

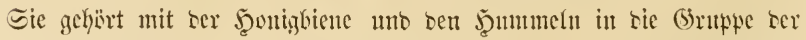
ect)ten Dienen, aber in sie lluterabtlyeilutng serjenizgen, weldye sen 2 blïthen= jtanb nidyt wie jene an ben J̧interbeinen, jontern an ber llnterfläctye tes

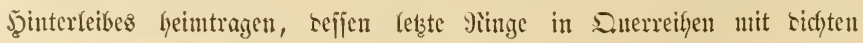

*) Son Sirby zur (Sattung Apis, von Srriger zu Anthophora geftellt. 
Borjten bejeb̧t jür, uno bie man besharb Banddjammler nennt. Die ähnlid wie bei oen Bienen gejtalteten Miunotheife treten hody mefyr fervor

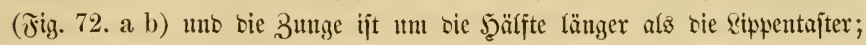
bie Dberfiefer jino jefyr lang uno jäbelförming, ter j̧interteib ser 5 bis 6 Sin. langen $\mathfrak{B e i b d y e n ~ a b e r ~ f a j t ~ f l a c h , ~ s f t ~ n a c h ~ o b e n ~ g e r i d y t e t ~ u n o ~ n a c h ~}$

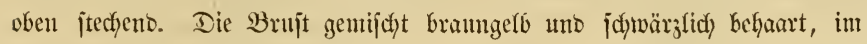
Ilter graulidy. J̧interteib oben fajt fafhl, ber 1. 9iing zottig graulid) be haart, oer 2. bis 5. 9ïng mit je einer weiñen J̧aurbinte. Interleib bidyt

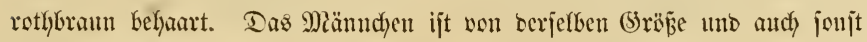
wenig verjechieben.

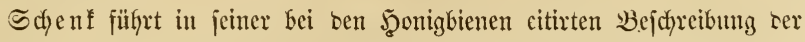
Najjauijden Bienenarten 11 von ifm bajerbjt gefunbene Tapejierbienen= Arten auf, welche igre Pejter in Baumlëcher, Manerjpalten, Erolëcher an-

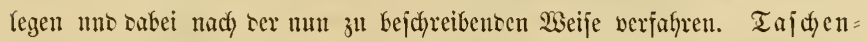

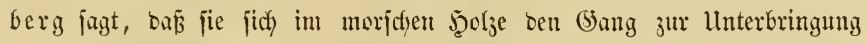
ilyer Jiejter and ferbjt nagen. Sie bejuchen wie and viele antere Aber: flïgler an warmen jontigen Tagen im Mai uno Suni unjere Blumen gärten uno lieben nach $S$ d)enf bejonber bie befannte grop̉e Sornblume (Centaurea montana L.).

Dic nächjte Sorge einer Mutterbiene ijt, j"ll Ilnterbringung ifyrer

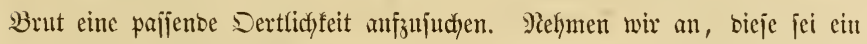
verlafjener \&arbengang im Snnern eines fauten Baumftammes, won ange

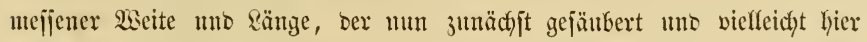
mo da ctwas ausgeweitet wirs. Diejer Sang foll eine Sinberjtube werten, abgetfeilt in einzelne (Semüdjer für je cin Sint uno jedes (Scmad) fanber

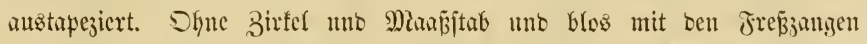
werjehen - benn wahricheinlidy mit biejen arbeitet sie Biene - geht es

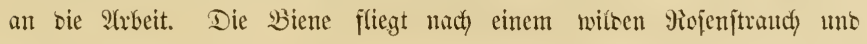

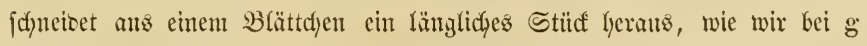

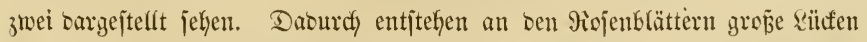
(c), bie wir bei einiger ?(ujmerfjamfeit an ben Rojenjtöcfen leidft anfïinsen. Das ift ras erjte Tapetenjtïct, welches nad, J̧anje getragen uno vielfeid)t

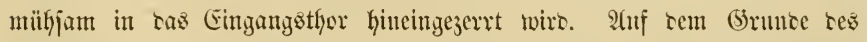

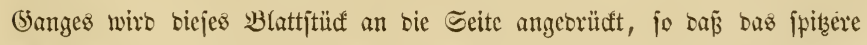
Ence teijerben gefrimmt fidy an ben Boben anlegt ( $g$ rechtó). So werten 
Fig. 72.
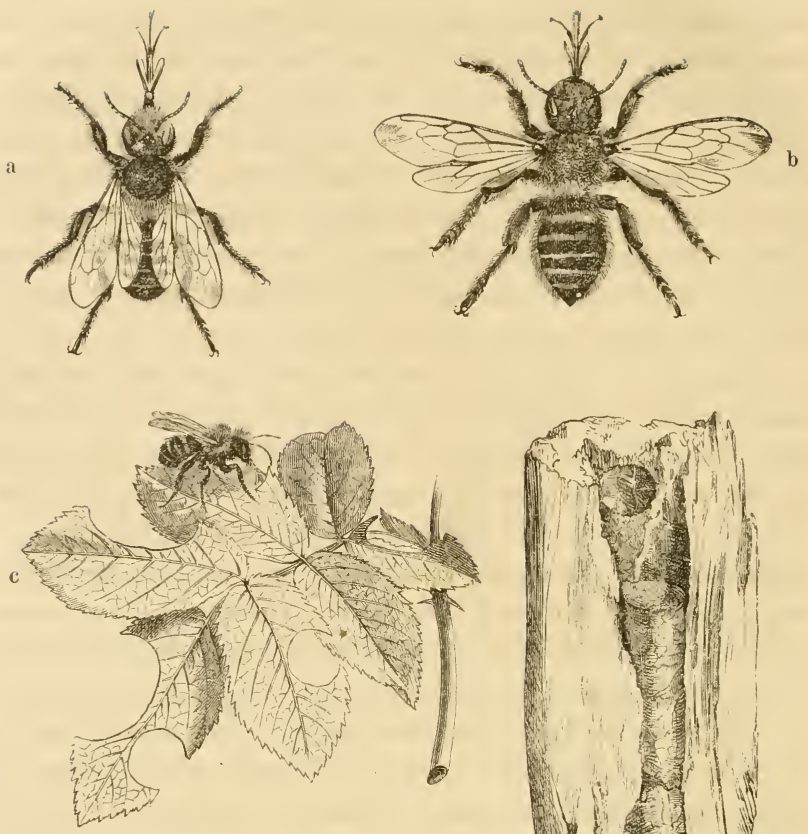

h

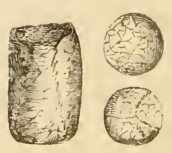

e

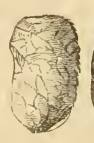

f

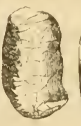

g
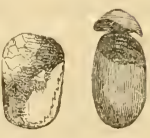

$\mathrm{k}$

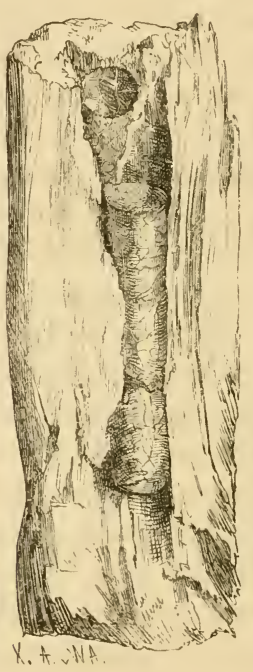

d

Der Blattiduciber obęr bic Iapezicrbiene, Megachile centuncularis Fabr.

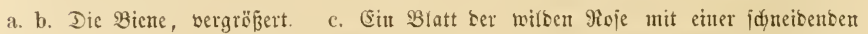

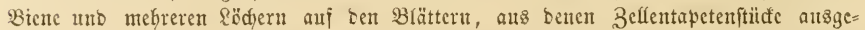

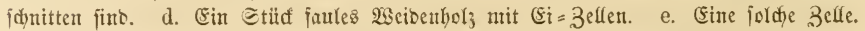

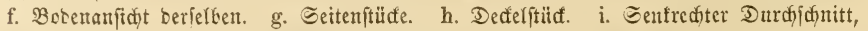
am Boben ber erkärtete Futterbrei. k. Das (5ocon mit bem von ber ausgejdlïpften Biene aufgeiduittenen Dedel. 


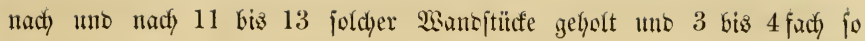
ïber einanber gebrücft, Då̃ immer bie Fläche eines imtern über bie Fugen

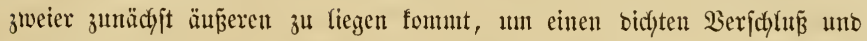

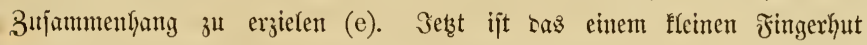

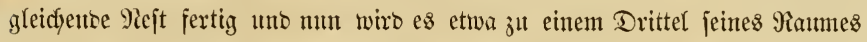

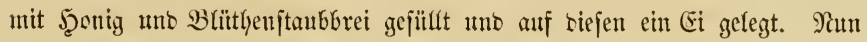
aber holt bie empige Mutter noch einen Berichlun herbei. Diejer bejteht

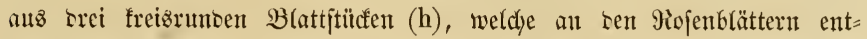
iprechente Ë̈djer Ginterlajijen (c). Dieje Decfel müjjen, über einanber gelegt, genau in bie Deffung ocs Jingerfutes pafjen ntmo werben an

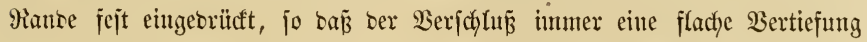
bilbet. Auf bas mun fertige Mejt (e) ober noch beffer Wiege werben nun altore, wie bas erfte aus sen 14 bis 16 zmeierlei Stïlfen bejtehente, bidyt

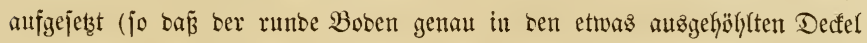
tos unteren paj̃t) (d) uno zwar 10 bis 12. Daz Thier hat aljo gegen

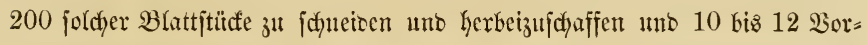
ratfisfaummern für eben fo viele Simber z̆l füllen, was bei günjtigem $\mathfrak{W e t t e r}$

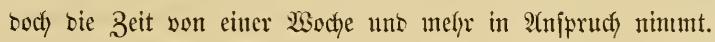

Die balo ät ben Giern ausfriedjenden \&arben zefyren num von bem Futter, weldyes ifnen bie jorgliche Mutter mit auf iłre sebenzreife gegeben

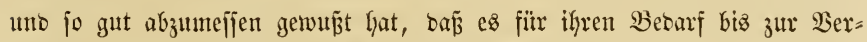
puppung gerabe auzreicht. Shren Sioth fleben bie Sarwen rings an ben

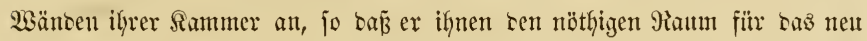

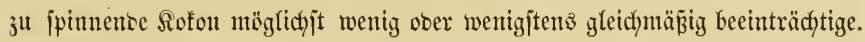
Das Rofon ift eirutto, füllt bie nun leere Speijefammer volftündig aus uno ift aus zarten rothbraumen Seisenfäben nidjt eben jefr bidjt gemebt.

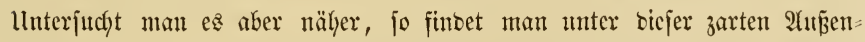

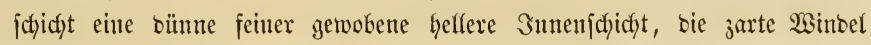
für bas $\mathfrak{B}$ uppenfindchen. Se nach ser Mitternng übermintert rie Tapezier= biene als ausigemadjene Rarwe ober als Buppe uno fommt als Biene exjt im jolgenben Frühjahx aนt.

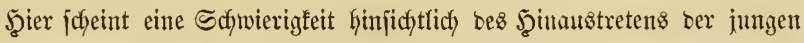
Bienen an bie Freibeit obzumalten. Da bie in ber unteriten $\mathfrak{W}$ sege als Ei zuerjt geborene Wespe 8 bis 10 Tage älter ijt als sie in ben oberen uno oberjten, alle zufammen aber body Sinber Einer Miutter jino uno mit 


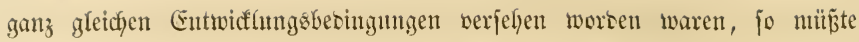
ntan glauben, Daßj bie unterjte Biente juerit aus ber Puptentyant friechen, aber nun an Ifnsfliegen verlyinoert fein mülje burth bie vorliegenton ge= idjwifterfichen (5emädyer. Ginte hähere Madyt, sie Madyt ber Jrïhjahrs=

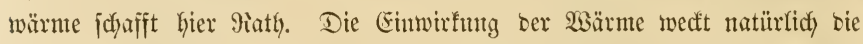

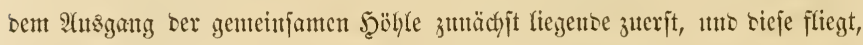
obgleich sie zulebst geborene, zuerjt uno an bequemjten ans, benn bie fol= genten Gaben babei sie Mï̈lye, bie 9ejt = uno Sofonböben ter vorberen

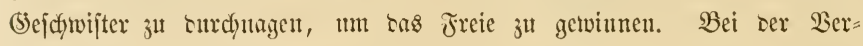

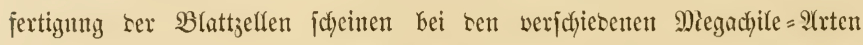
nicht nur beridgiebche Blätterarten angewentet jut werben, fonbern twir Gaben auth bergleichen gejehen, an weldyen ber Boben nicht won ben ein= gebogenen Spizen ber Wanotapeten gebilbet war, jonbern ebenfallz aus

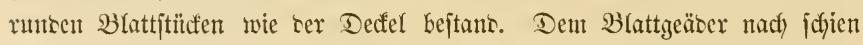
Der Spizahorn bie Tapeten getiefert ju haben.

Mebent ben Tapezierbienen zeidjnen jidh in ser (Strtppe Der "Ginjumen Sunjtfienen", wie man bieje von Mutterliebe getricbenten atrbeiterinnen audy nennt, nody vicle anbere burdy älynlidye arbeiten aus, namentlidy bie (5attungen ber Edyauzen= ober Belzbienen, Anthophora; $\mathfrak{g}_{0} \mathfrak{l}_{3}=$ bienen, Xylocopa; (5rab= oder Rappenbienen, Panurgus; Ero= ober Sanbbienen, Andrena; Seibenbienen, Colletes; Manerbienen, Osmia; Wolrbienen, Anthidium; Sdblupi ober Sd)erenbienen, Chelostoma; Röderbienen, Heriades; Miörtelbienen, Chalicodoma. Sie legen ifre Meepter an ben werfdyiebenjten Drten an, in alten Bann= itämmen, Jels = uno Erojpalten, in Sansboden uno wensen sazn bie wer:

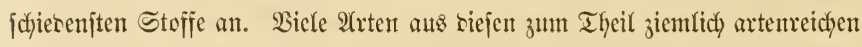
Sattungen leben it unjeren 2 alsungen, befonters in ten gebirgizen unto

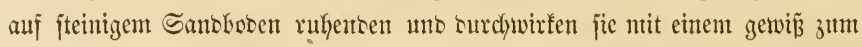

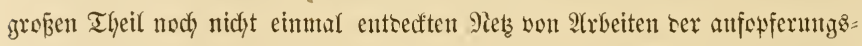

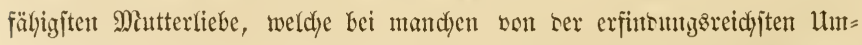
fid)t geleitet werben. Ât Beifpiel biejer lez̧terẹn fei fier ıur erwähnt,

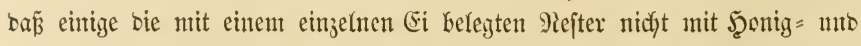
Brïthenjtanbbrei für bie ansfonmente \&arve füflen, jonbern, ba bieje auf

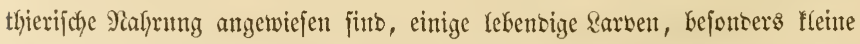
Sdjmetterlingstantpen herbeijdyleppen. Damit num aber sieje bis zum $\mathfrak{A}_{1}$ 
friechen bes (Fies nicht jterben uno verfanten und basurdy tas (begentlyeil bejien bewirfen, weshalb jie herbeigejedufft worben fino, fo werten fic ourdy einen reichten Stid) geläfutt uto bleiken in biefem Bujtante unveränocrt, bis bie Bienenlarbe ifrer als Speife bebarf.

Biefen wenn nidyt affen biejen einjunten Sunjtbienen wiro ifyre Mïhe uno 2 trbeit an einem Theile ifyrer Sinter bereitelt, intem trots alfer Dor: fidyt währent bes Erbautens ber Mefter eine Mienge Sdymarotzer, unter biejen bie fidon oben genannten Silfufsbienen un viele Sdylupmeapen

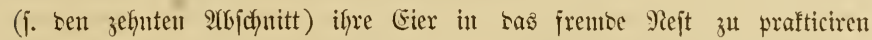

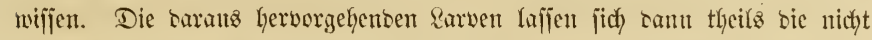

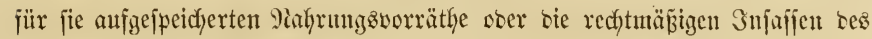
Tiejtes jelbjt jumeden.

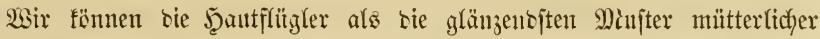
Mrïlywaltung nidot werlaffen, ohne unjere Sejer sarauf aufmerfjam zu machen, Dấ

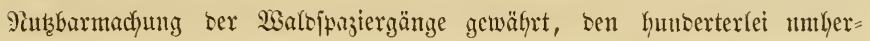

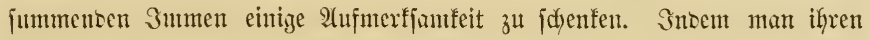
Bewegungen nadjgeht, wiro man sft zum Eingange ifyer \$iefter geleitet unb finbet bort (Selegentyeit, ifyre 9 rbeiten zu bewunteru.

Die gropere, nach Iaujenten von Arten zählente Snjeften = Dronung

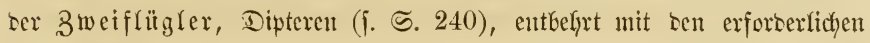
Sörperwerfzeugen audy ber (Sefdficflichfeit, burch bejonbere Beranjtaltungen

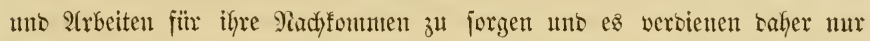

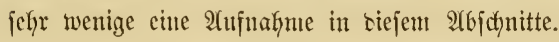

Die Biesflegen soer Daffelfriegen, and Bremen soer Bremjen genaunt, zeidfuen fidh Gierin nody am meijten ans, obgheidy ber neurejte Bearbeiter ifyer Maturgejdyidjte, Brauer in Witen, gejeigt hat, bañ jie

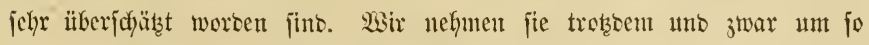
fieber Gier auf, als wir baburd) (belegentheit erfalten, mundje anbere fefyr anffallente Eigenbeiten serjelben mitzutheilen.

Die Biesfliegen gefgoren in bie uns bereits befannte atbtheitung oer 3weiflügler, beren Puppen in ber lez̧ten, nidjt abgeworfenen, Earwenthaut jtecfen bleiben, unt haben bie affgemein befannte (sejtalt mo sörperver= hä̈tnifife ber Stubenfliegen, Fleijos = uno Miorbffiegen, mit benen fie auds in 
bie Familie ser eigenttidfen Fliegen, Miusarien, gehüren (i. 5. 243). Sie

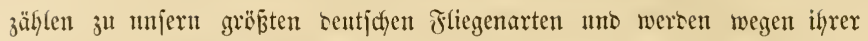
meijt braunen Farbe uno Zeidhnutgen uno wegen ifyres brummenten Fhtugez oft fiir Wespen orer ந̧ormifien gehalten.

Shre jefyr furzen in Stimböhfungen entipringenten Fithler bejtelyen aus einer auf einer Wazze jtehenten fleinen borjte. S(m auffallentiten

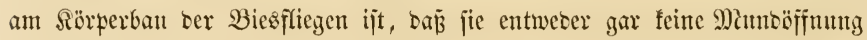
uno teinen giilifel ooer beires bod, wenigitens nur verfümmert haben.

Wie bie ilynen verwanbten Mrorofliegen jo haben auth bie Bieşfliegen

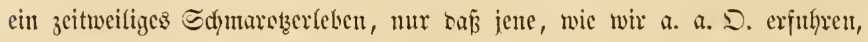
in antern Snjetten, sieje bagegen in SäHgethieren fđumarotzen แnd jwax

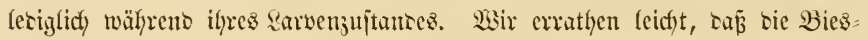

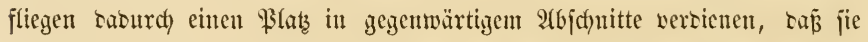
shne 3weifel bejontere Beranjtaltungen treffen miljen, um ifre Eier in

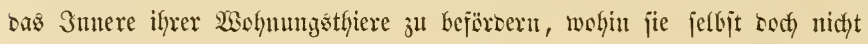
bringen fönnen, es audy gar nidft verjuchen, ia $\mathrm{es}$ wohl in ben meijten Jülfen nur anf Sojten ifyres eigenen sebens gejchehen tömte. Allerbingz erfortert es hierzı bei einigen irten feiner bejonteren Beranjaftungen,

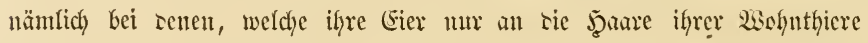
ablegen, von two auz bie auzgefrodyenen sarven fid in sic j̧ant rerjelben einbohren mo in seren innerer Schidyt leben uno fich nülyren. Son anteren, beren Rarven in bem Miagen, in sen Därmen, im Schlunbe, in ben Tajen uno Stimubhlen ter SBohntyiere hanjen, wurbe alfgemein an= genonmen, bã bie Mintterfliegen in fluger Berechnung bie Gier mut an sen Söppertheilen ablegen, wo bas Thier fid) lecten taun ntmo babei bie abgelegten

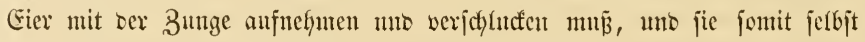
an iffen Bejtimmungsort beförtert. Dagegen wirt von Mandyen in netterer

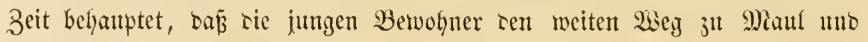
Maje jelbjt ju finben wijjen.

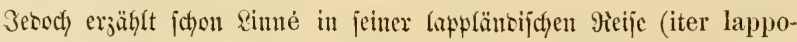
nieum) von berjenigen Biesfliege, weldye ifjre Eier in bie wajenlöd)er ber

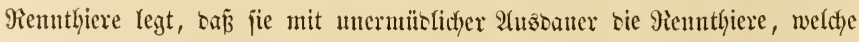
baburdy in bic fyöchjte $\mathfrak{A}$ ufregung fommen, tagelang verfolgt, bis eins ber= jelben cimmal einen 2 (ugenbliaf jtill jteht uno ber Fliege es möglich madyt, ein Ei los zu werten. 


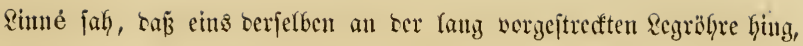
jeoen 2Yugenblicf bereit wollenbs afgelegt zu werten.

Die Bießfliegen fint rectjt eigentlich Wiegelayerer unjerer $\mathfrak{B a l b u n g e n ,}$

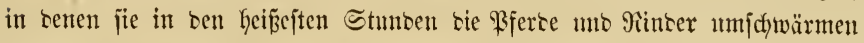
unb ganz bejonbers autch bem Mothwilo mo sen Rehen nadjgelyen. Bejonters bie in ben Waloungen weitenten Dichberben finb ifjren Berjolgungen jehr ansigejęzt. Sogar ber Mienja jelbjt ijt, wenigitens in heiß̄en Ränbern,

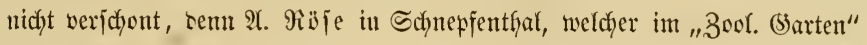

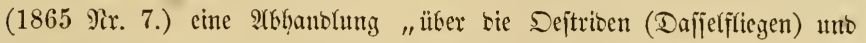
bie Beobachtung berjefken in bell zool. (Särten" weröffentficht hat, erjäflt,

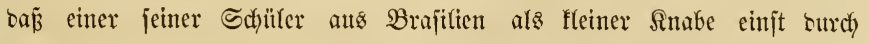
Dermatobia noxialis mit zwei siden Beulen an Sopfe behaftet getwefen

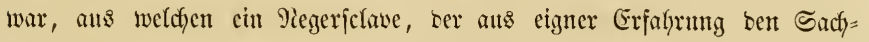
werlaalt fannte, bie biffen Miaben ausbrïfte, nadjoem er vorlyer bie Benten nit Tabafsjaft bejtrichen hatte.

Die Dajjeflarven fint autgetwadjen bidfe fette länglid, eirunbe Maben, bie an ten Reibešringen unb namentlich am Ropfringe mit Rränzen von rücfwärt geridyteten Şafthafen beję̧t jint, surch weldye jie jich) an ifyren

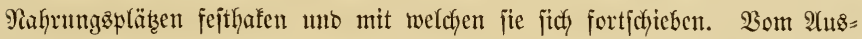
friect)en aus tem (Ei an biz zur Berpuppung änbern burch ફ̧äutungen bie

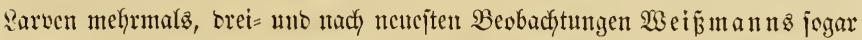
viermal, ifre (Seftalt. Bon Enbe Februar bis Enbe Mai gelangen bic

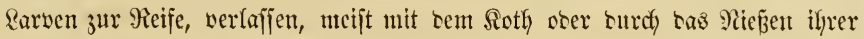

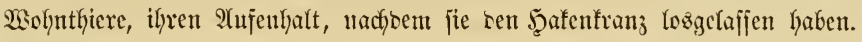
Dies gejofieft in ten frithen Miorgenftunben uno jie fuchen sann an irgent einem Berjted einen pajfenden Sort zu Berpuppung. Man finzet bie Bies=

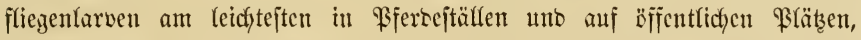

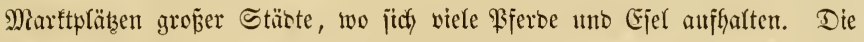

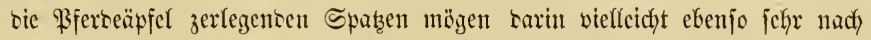
sen fetten Rarven wie anad) unverbauten Şaferförnern futcfen.

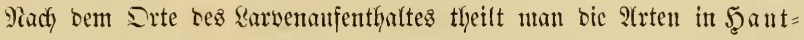
baffeln, Magentaffeln uno Mafenoafeln. Die letzteren werben nach

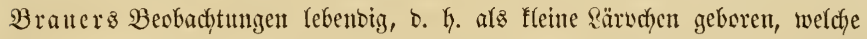

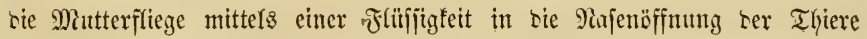
ipritzt. 


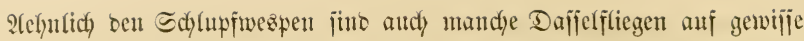
Thtere atz Edynarotzer bejchränft, währeno antere, twie ebenfalfs viele Schlupfwespen, hierin eine freiere $\mathfrak{B a b l y}_{\text {haben. }}$

Die frither in ber (5attumg Oestrus L. vereinigten 2 rten werben jetzt

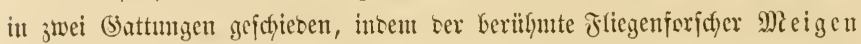
bie 2rten mit fleinen, rie Sdywingfürdyen nid) berectenten Doppel=

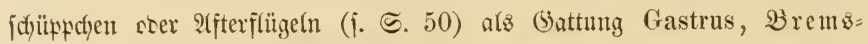
friege, abgetrennt hat. Ganz neuerlidy jino beise Gattungen nody weiter in fleinere jerfüflt worben.

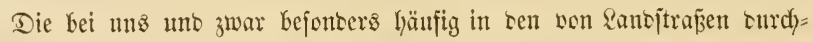

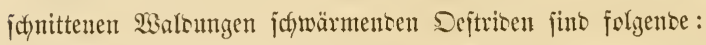

1) Die Rafenbiegliege bes Rothwilbes, Oestrus amibarbis

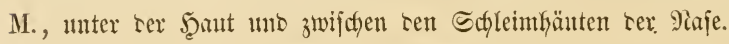

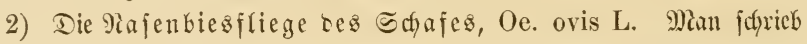
foupt ten aus ber Taje in bie Etimbölle mo Stimgrube (baher "Stirn= grüblex") friedyenten \&arwen tie Derurjachung ter Drehfranflyeit ter Edyafe 3u, weldye vielmefyx won tem Blajenfdyanz, Dueje oder Drehwurm, Coenurus cerebralis, zu ten Eingeweitewümern gebörig, werurfactyt wirt.

3) Die ginderbiezfliege, Oe. bovis L., lebt unter ber j̧ant bes

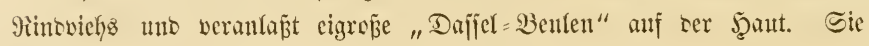
folfen audy an Bferbe, Ejel und fogar Schaje getyen.

4) Die roitgelbe \$feromagen= Bremgfliege, Gastrus equi Fabr., weldye iffe Gier Gejonters an bie j̧are ter Dorberbeine bes Pijerbes ablegt.

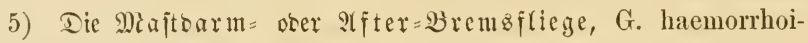
dalis F., wetche ifyre Gier an Taje mo vippen tes Wifertes ablegt.

6) Die Jajen=bremsflege, G. nasalis L., Deren Earven fidf

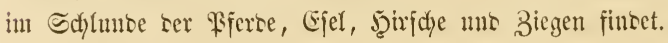




\section{bierseljuter 'Ab/d)nitt.}

\section{De $\mathfrak{i}$ grof́e $\mathfrak{R}$ e ft.}

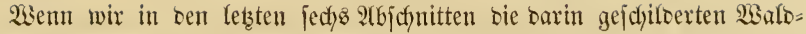

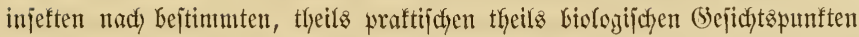

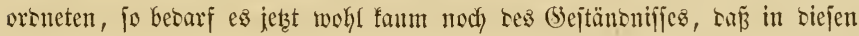

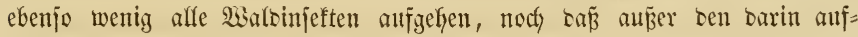

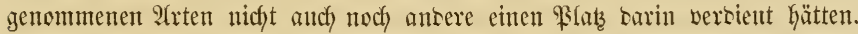
Es bietet ja cben feine antere Ifierflafje eine jo grofe Miandffaltigfeit ber Rebensigewohnheiten wie sie ber Snjeften. Darurch fömnten wir uns ję̧t audf) leidgt verführt jeken, neben ben worjtehenoen 6 Sategerien nod weitere nufzujtellen. Wir unterlaffen es, wie wir ïberfyaupt sicje 5 Rategorien in ber J̧auptjache nux Deshalb auffeflten, um biejen 2. Band unjeres

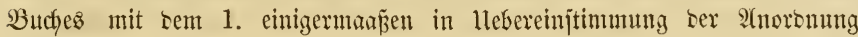
3น bringen.

In Den im 1. Bant angenommenen Eintheilungen gingen bie Wirbet=

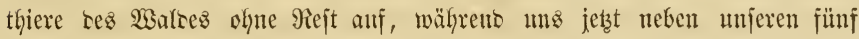

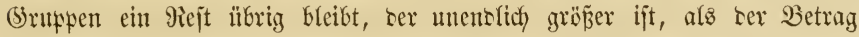

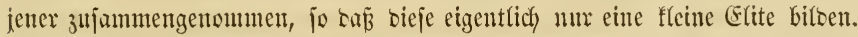

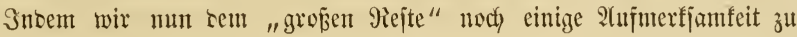

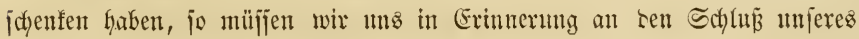
4. 2(bjc)nittes (ङ. 32) befdyciben, baj von einer Einzelbejdyreibung nidjt

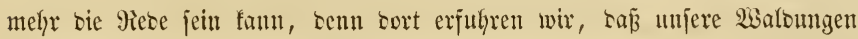
mintejtens 9000 Snjetten beferbergen.

Wir reigen in Folgensem unjere Mijterung an sen Jaren bes Sujtems ber Snjeftenwelt uno bejchränfen แns auj J̧ervorhebung tes an meijten in 


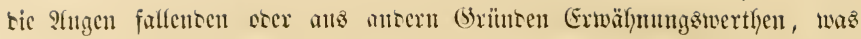

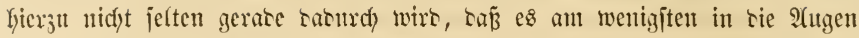

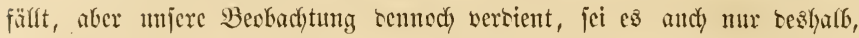
ıum bic ganz in ter Stille unt im 2̧erborgencn, zum Theil unter tem

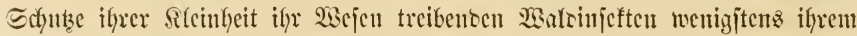
Dajein nach fennen ju lernen.

Bei ter Bugruntelegung tes Gnjeftenjyjtems füx tie nadyfolgente Schilterung folgen wir bemferben in aufiteigenter Reifenfolge, weil uns

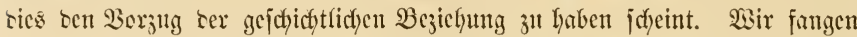
mit sen anf ser Stufenfeiter ber Snjeftenwelt am ticfiten jtelyenten Formen

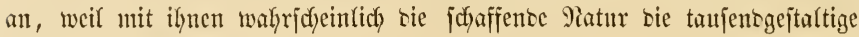
Pieilge ticjer Thiere begaun.

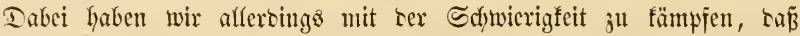
man sarïber ftreiten fam unt.jtreitet, weidje von sen 7 Injeftentormumgen sie unterife unt weldye tie hödjite jei. Der Bruno biejer Schwierigfeit

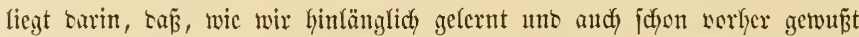

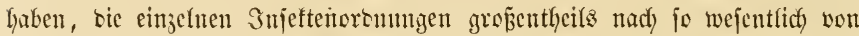

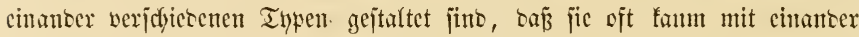
werglidyen uno nady ben injtematifdyen Şähenwertbe gegen einanoer abge wogen werben fümen. Unfer Edjünheitżgejühl fann sabei cben jo wenig

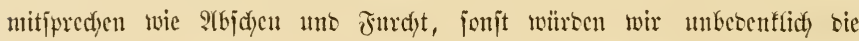

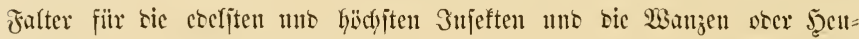
icfrecten für sie nicterjten crklären.

Bergleidfen wir aber einen bunten Sdymetterling mit ciner vibelfe,

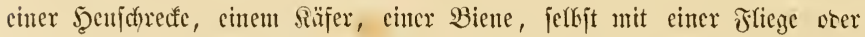

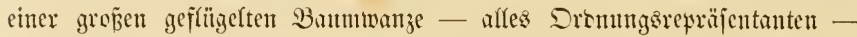
jo ift es beinafye unmöglidy, hattbare Grïnoe für eine Steflung tes Einen

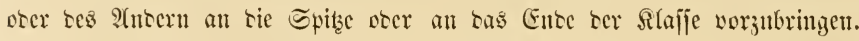
Es ijt eben bie Infeftenffajje cine Tljergruppe, in weldyer bic Natur nady

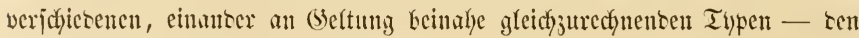
7 genamnten - gearbeitet hat.

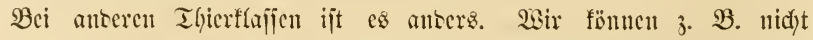

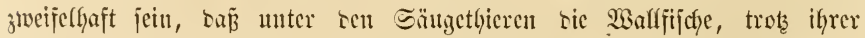

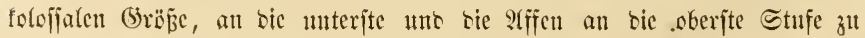
jtellen jint. 
Will man biejenigen Injeften für bie ınvollfommenen erflären, weldye erit eine mehrmalize Gejtaft = unb Rebensänberumg (Bermanthung) zut burd)= laufen haben, elge jie ifje hödjite Bolffommenheit erreidyen, fo ift bas

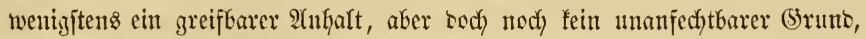
uno jwar um jo weniger, als bie mit ber Berwandlung verbunbenen $5 \mathrm{r}=$

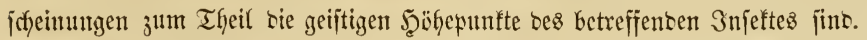

Dies kringt uns folgeridytig zu ber Frage, ob nidyt bie Injeften, ba

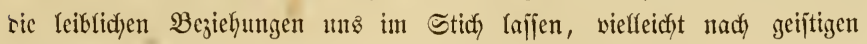
Beherfen z" ortnen feien. Daun milifen wir nady unjeren bizherigen

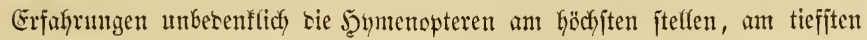

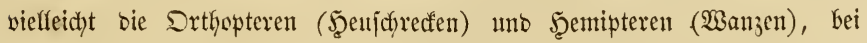
benen man weber von Sunjttrieben noch von fonjtigen geiftigen Bermögen viel ju rithmen lyat. 2(ber gerabe bieje beiben Dronungen gleidyen ben gëchjten Thieren barin, baja jie feine Serwandlung lyaben.

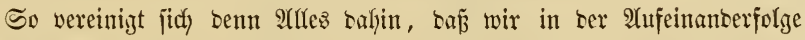
ber Injeftenortmungen jajt freie Şano haben, unt inbem wir jeţt mit ben

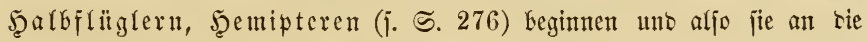
unterjte Stufe ber Injeftenwelt verweijen, fo gejefieht bies wegen ber un=

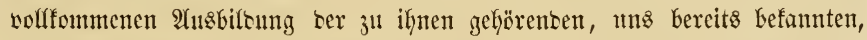
Blattläuje, we'dye jich uno mithin sie ganje Slafife an bie Milfen (jux Slafie ber Epinnenthiere geljörig) nadjbarlich anreigen.

Dem twas über bie Dronungâknnzeiden ber Şemipteren a. a. D. mitgetheilt ift, haben wir lyier nidyts weiter Gimzuzufü̈gen. Die bort ihnen

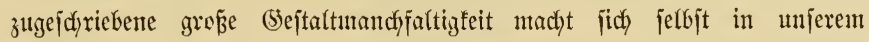
gemäß̄igten Şinmelştrich an ben zahlreichen :Trten geltent, welche unjere

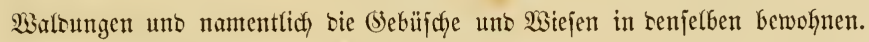
Selbit in ben Rachen, Sïmpfen uno (Bräben fommen mehrere Battungen sor, wie benn aud nach bem Sortommen bie junädyjt ju Kefprechenten

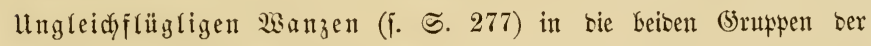
Sanowanzen, Seocoriben, uno $\mathfrak{W a j f e r w a n z e n , ~ S ̧ y o r o c o r i b e n , ~ e i n g e t h e i l t ~}$ werten, welche beibe wieber in 4 Familien jerfallen.

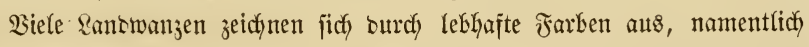

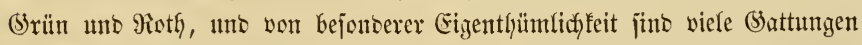

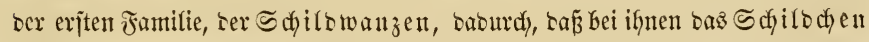

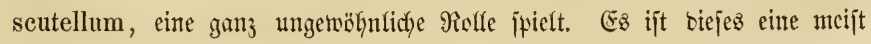




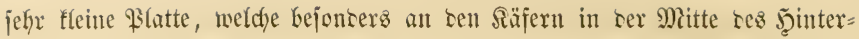
rantes ses brujtictilites bemertbar ijt, wo won ifm sie sie beiben Flïgel=

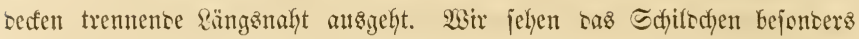

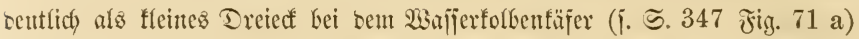

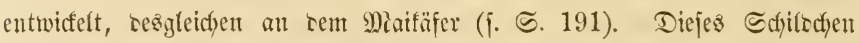

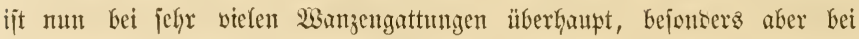

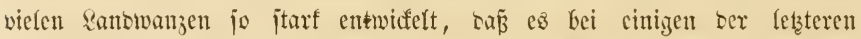

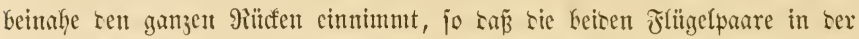
gintlye jeitfidy sarunter gejdyeben wersen. Dies ijt am jtärffiten bei sen Danady jo benannten Deffwanzen, Tetyra, ser Fall, von benen einize $\mathfrak{A}$ rten, 3. $\mathfrak{B}$. Lie zinnoberrothe jofwä3gejtreifte T. nigrolineata, (Jig. 73 a) namentfich in unferen (bebirgşwaloungen hänjig vorfommen. Die \&anto wanjen wie bie meijten ungleicyflitgligen Şenipteren, fint platt gebrüatt

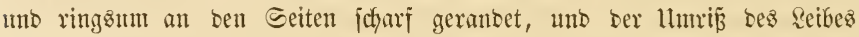
nidft jeften mit jeitfid) voripringensen Effen mo Sianten.

Wir finten eine grop̧e Mienge von Rantwanjen an sen Baumjtämment, an sem Raube ber 3weige uno bejonters anf ben Blitthenfdjirnten ber

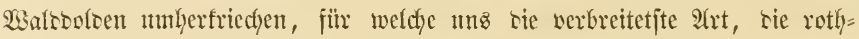
beinize Baumwanze, Pentatoma rufipes L. als maj̃gebentrs Beifpiel siene (รig. 73 b). Siele savon Gaben, namentlich zertrïcft, sen befannten ctel= hajten 2 anzengerutd, während einige einen angenefmen Sbitgeruth haben. Shre Nahrung beiteht vorzugsweije in Ien Säften anterer Injeften, weldye

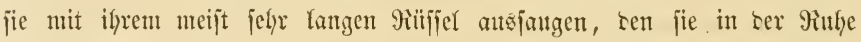

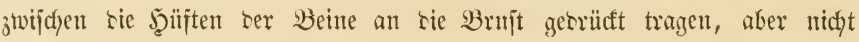
bamit jtedyen wie einige $2 a j$ jerwanzen.

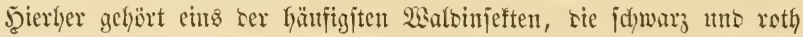
gezeidynete flügelloje Jeuerwanze, Pyrrhocoris apterus L., weldye

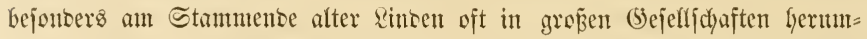
friedyt. Die größte sentidye Ranomanje ift sie getblidgrüne, an ser Epize bes Şinterleibes und 2 Spizen Les Dorberridfents rothe Stachelwanze, Acanthosoma haemorrhoidale L. mit 7 imien, mälyrent es aitch fef) fleme won faum einer sinie Ränge giebt, 3. 23. Die Springibanze Halticus pallicornis F.

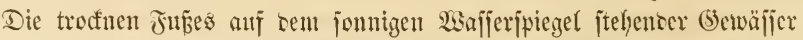
j()aaremweife herumlanfenten Wafjerläıffer Hydrometra, Limnobates uno 


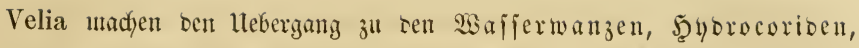

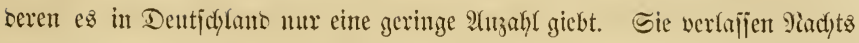

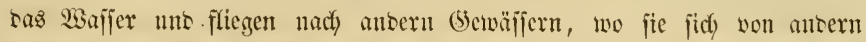

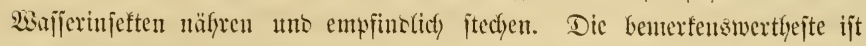
die Wafjerfforpionwanje, Nepa cinerea L. (Jig. 73 c), fo genannt wegen ter eigentfÿ̈ntidyen ju Fangarmen mugejtalteten Sorberbeine, seren Sdfienbeine in cine ginne ser verbiften Sdyenfel wie cine Miefferflinge

Fig. 73.
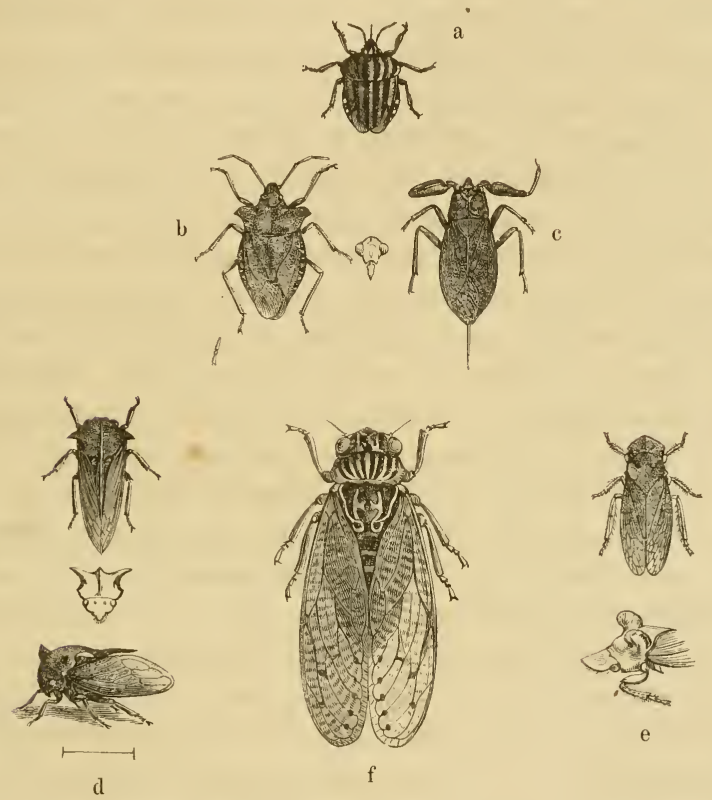

e

a. Die $f$ dy wrzgeftreifte Dedtwanze, Tetyra nigrolineata L.

b. Die rothbeinige $\mathfrak{B} a u m$ wanze, Pentatoma rufipes L.

c. Der Wafferfforpion, Nepa cinerea L., linfs ber Sopf, vergrëßjert.

Od. Die gehörnte Dornjirfe, Centrotus cornutus L., itt Der Mitte Siopf uno

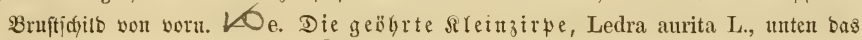
Bruftidjilo vou ber Seite. $-\mathrm{O}_{\mathrm{f}}$. Die gemeine Singcifabe, Cicada orni L. 
eingeflappt wersen fümen. Sie ijt in 23 alsladyen jehr häufig; eben io bie

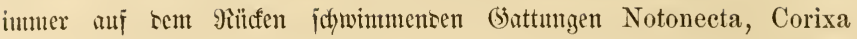
(Sigara) uno Ploa, won benen fich babei ber Rïlfenildwimmer, N. glauea L., ganz abentenerfich ansinimut, wenn ex mit feinen langen $u=$

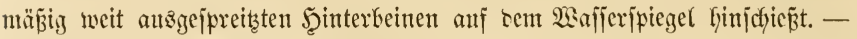

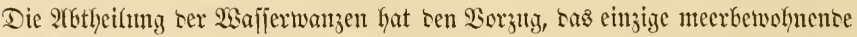

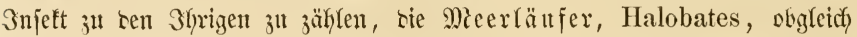
and) bieje nur Spajiergänge anf bent glatten Spiegel ter tropijdyen Micere madjen, niemals aber untertautchen.

Wir gehen zu ben (b) leidfflügeligen ફ̧albflüglern Hemiptera homoptera ïber, beren wejentfichen Afbtheilungsod)arafter win anf 5.277 fennen rernten. 2łuch jie zerfalfen in 4 Jamilien, in weldfen ser gejtalt= liche $23 a n j e n t y)$ pus, mit fajt alleiniger Beibefaltung bes langen itechenben

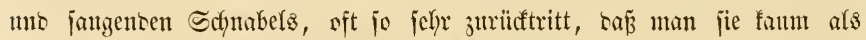

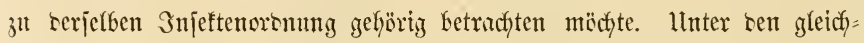
Flïgligen ફ̧emipteren, weldye if)re Fftïgel immer badfförmig über ben \&eib gerefft tragen, fommen nodh vief mehp als bei ben llngleidfflïgligen aben=

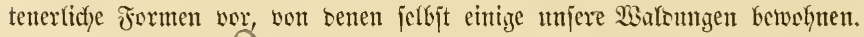

Wer möchte tie Fig. $73 \mathrm{f}$ abgebifrete Sing= Cifare für eine Drommigs:

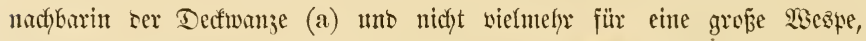

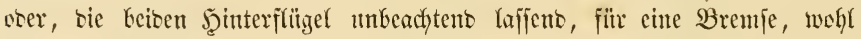
jelbjt für cinen (5lagfalter (j. S. 144) halten? Die Sing= Eifaben

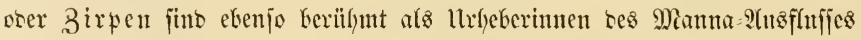
an ber Manna=Ejche, Fraxinus Ornus L. wie surdy ten bejang ter

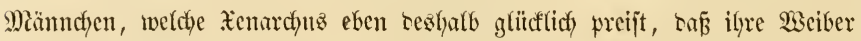
jtumm junt. Die edfte Sing = Eifare fommt in Dentjdylano nidyt vor, wohl aber eine verwanste 2 rrt, Cieada concinna Germ., weldye in warmen

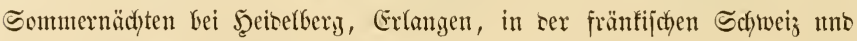

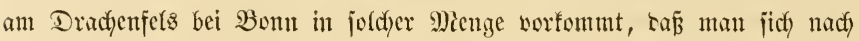
v. Siebold einen Begriff von tem Gifurenlärm in Sütemropa madyen fam. Der Singapparat bejtelyt jecerjeits an ter $\mathfrak{B a j i s}$ tes Jeinterteibez

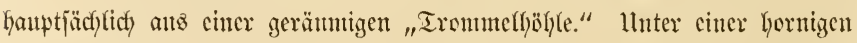
Platte an ter Baudchjeite, seren Şinterrano frei ijt, zeigt jidf) cine elajtijche

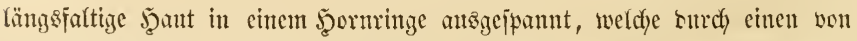
ber mittleren formigen Scheisemano tes 2. Bandyringes entfpringenton 
ftarfen Mitsfel abwedjefuo gejpant uno exidylafft werben fann. Der hier= burd) erzengte pfeifente Ton miro surdy eine groß̃e bidftangrenzente \&uft=

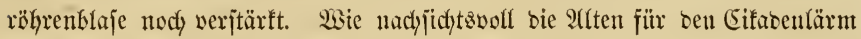
gewejen jino, geḩt aus ber alferliebjten Maythe hervor, weldye erzählt, baj

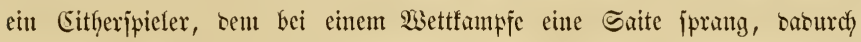
ber Sieger über jeinen Nebenbuthler wutbe, baj eine herbeifliegende Eifabe jich) auf jeine (sither jeţte uno bie felylenbe Saite exjetżtc.

Wie bie Singcifaben, fo gefört aud eine wie lucus a non lucendo

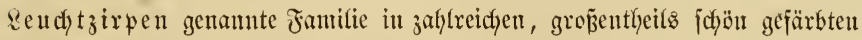

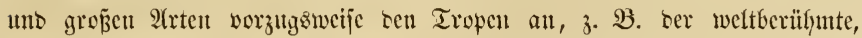

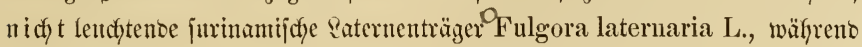
wir utre einige fleitue unbercutente 2(rten haben.

Dagegen juto bie Familien ber Buffelzirpen mo der Sleiuzirpen in unjerem 2 Galogebiete jiemlich reid) vertreten und barunter ourdy cinige abenteuerfiche Gejtalten. \$u siejen gefört vor allen bie geförnte Dorn= зirpe, Centrotus cornutus Fabr., beren hochgemölbtes Brujtiffilto born 2 jeitlidy abjtehente funze fpitze j̧örner hat tuto nach hinten in einen fajt ïber ben ganzen Şinterleib linwegrayenten harten ipizzen Dorn vertängert

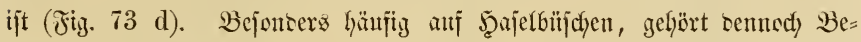

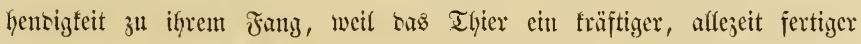
Springer ijt, was in jofern etwas 9äthjelfajtes hat, alz sie j̧interbcine in feiner Weije als Sprungbeine bejonbers eingerichtet fint. ந̋̈̈ufig begeguet man ben ebenfalls ipringento jaywarjen, blutrotbgeflectten Stiru= zirpen, OCercopis sanguinolenta L. utro ber Sdyaumcifabe, OAphro-

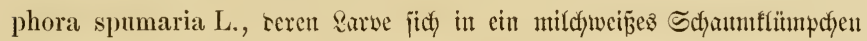

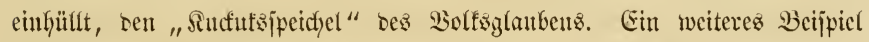

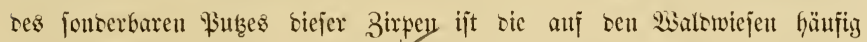
vortoumende geögrte sileitzirpe, Ledra aurita L. (e).

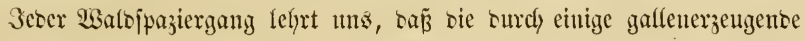
Arten un jajon befannt geworbene zafilreidfe bruppe ber Bflanzenläuje

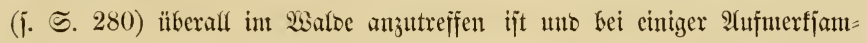

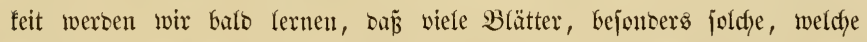

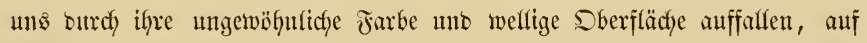

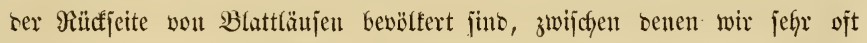
aud) $\mathfrak{A}$ meijen umheripazierento antreffen werben (†. $\Im$. 283, 302). Mit 
Ler :upe funben wix an ben fleinen Thierdjen leidyt ten feinen Sangriififel, an weldyeut wir itberfyant nody eine Mienge anbere jecnipteren als joldhe erfeunen werten, bie wir fonft viefleicf) fïr fleine abenteuerfich geftaltete

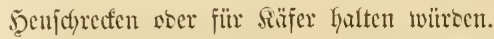

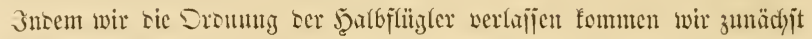

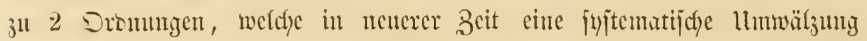

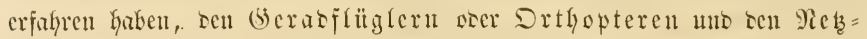

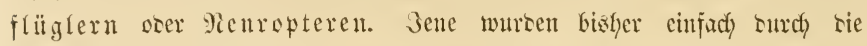

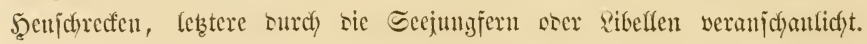
Setż aber werten, wie wir jolyon anf 5 . 258 exfultyen, sieje beioen allge= mein befamnten 3njettenfamilien ju sell Beraoflïglern gejteflt uno der

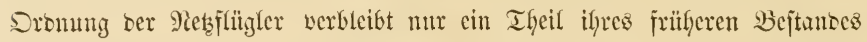

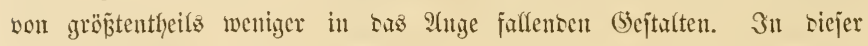

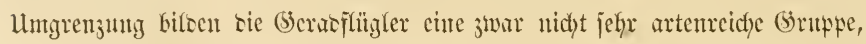

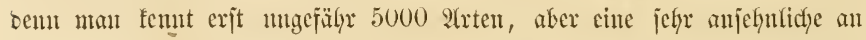

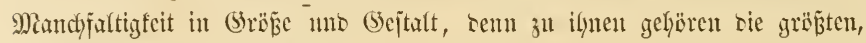
wenigitens lümgiten Snjetten.

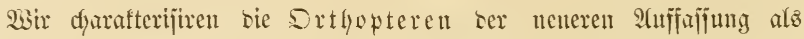
Snjeften olyne ober mit mux nuvollftänsiger Berwanolung uno

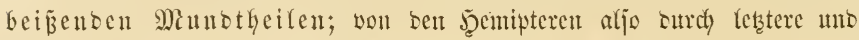
won sen Mieuropteren surdy eritere unterjajeren.

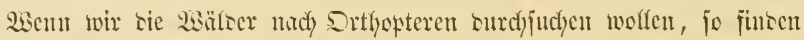

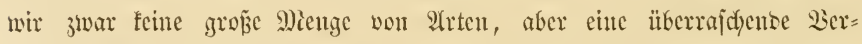

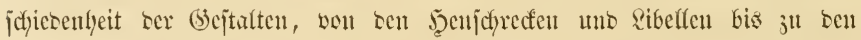

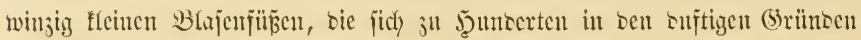

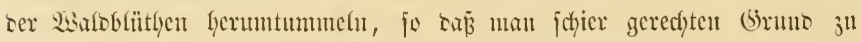
3weifeln hat, ob bie 3ujanmenjteflung jo mwertwander Formen berechtigt jei.

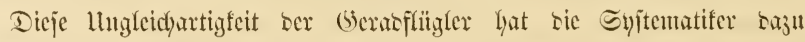
gezwungen, aus ifnen nicht weniger als 16 Familien ju madyen uno sicje in 7 3̈ünje зu vertbeilen.

Mit sen fleinjten uns unjefeinbarjten beginnens lyaben tvir junächjt

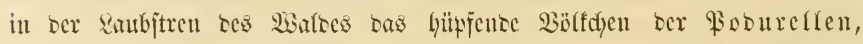

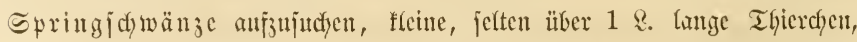
werdye an Reibescnse eine unter sen Baud zurthfigelegte Springgabel haben,

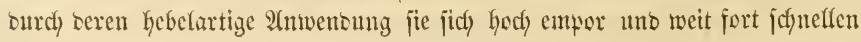




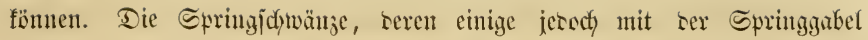

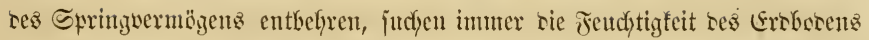

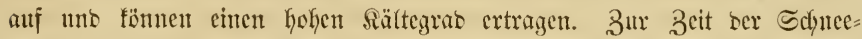

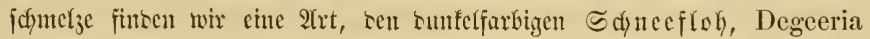
nivalis L. oft in zaffrojer Mienge anf ber fdymetzenten Schnefläctye herum= hüpfen, wälyreno ber (5letfdyerfloh, Desoria glacialis Nicolet mur in ber (Stetffyerregion auf Stetfderwafjer gefunten wirt. Die Fig. 74 a abgebilsete 2hrt, ocr behaarte Epringfdymanz, Podura villosa F. ijt bejonters in Bebiiffyen an Booen werbreitet mo cine ber grä̈ten uno buntejten. $\mathfrak{A}$ uf Regenlachen in 2 aloungen finben mir im heižen
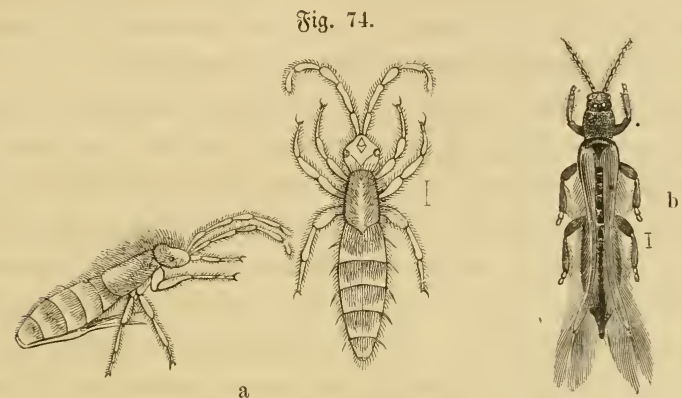

a. Der behaarte Springiduanz, Podura villosa F.

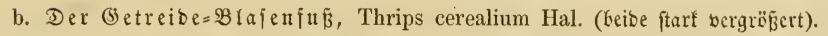

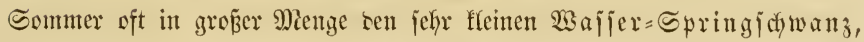

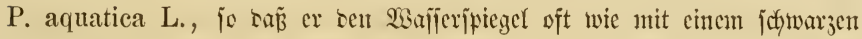
Fulver bebedt.

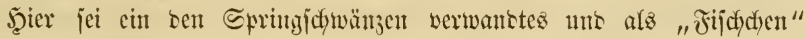
allgemein Gefanntes Tlyierdyen ermähnt, ber \ndfergajt, Lepisma saecharina L., jenes in Eorrathgfammen uno Sirantä̌n behente umber: ja)lïpfente mit jülbergrauen jeisenglä̈zenten Schütppdyen bebectte Ifjier, weldyes bejonbers tem 3utfer nadyjteflt uns mit bemjelben bei uns ein= gefïlfyt jein jofl, was jesody unerwiejen ijt.

Sm Srunbe von alferfano Walbblüthen, bejonbers aber zwijdyen ben Blüthen ber Doltenprilanzen bemerft man fehr oft fleine ganz joymale meijt 


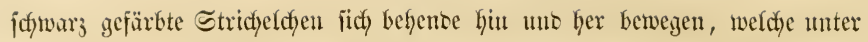
oer supe als fleine Thierdyen erfennbar werben, Blajenfüß̈e, Thrips,

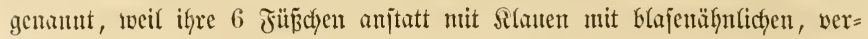

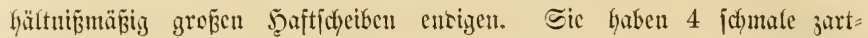

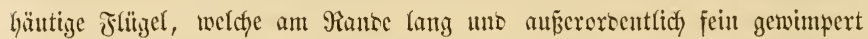
jitno. Es giebt jiemlich vicle 2 rrten, welche in Jij. $74 \mathrm{~b}$ burdy ben an sen (setreiseäfyren nagenten Thrips cerealium Haliday vertreten fint. Micijt fino bie Mämnç) flïgeffos.

Bon riejen 3̧wergen un Anfängen ser Seracflügler, neben weld)en

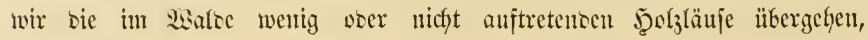
founnen wir nu ju anfehnficfen audf allgemeiner befannten jormen, weldye zum Theil zum Belebung bes 2 salocs mejentlict) beitragen. Gs jint

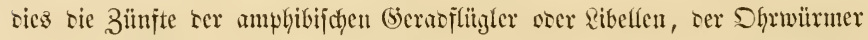

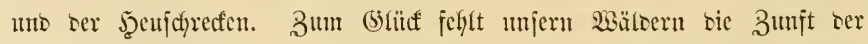

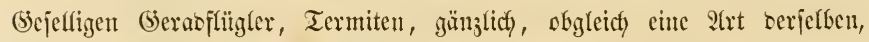

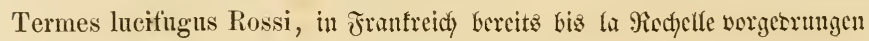

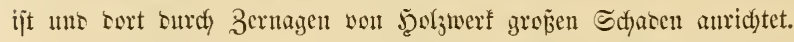

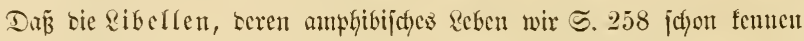
lernten, in unjeren jonnigen Yicoer = uno Mittefwäloern unb bejontoers an

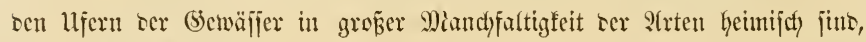
bebarf fciner Erwälymug. Dic morogierigen Thiere umflattern bentejudyo sic Bäjdye uns machen fich audf) beu nidyt auf bie "nicteren Thiere bes Bafocs" actenten : :uge genugiam benterflid).

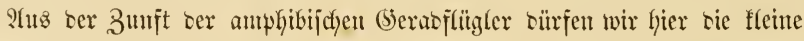
Familie ser Eintaggfliegen oce מ̧afte, Eqhemerioen, nidyt unertuäbut

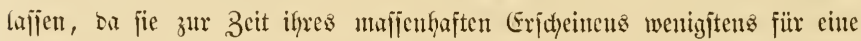

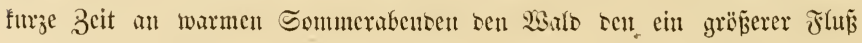

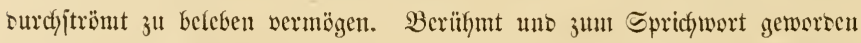

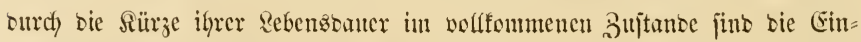

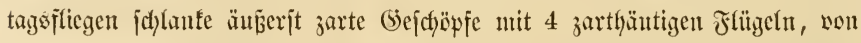

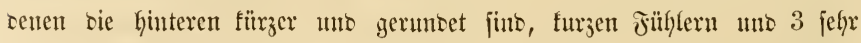

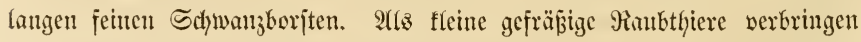

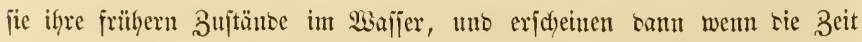
iffres Jfiegentebenz gefounuen ijt oft plözhlid) in ungeheurer Mienge an beu

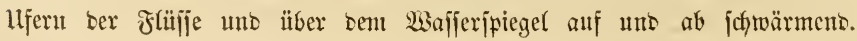


Bejonders merfwürbig uno barin in ber 3njeftenflajie eimzig bajtehent fint

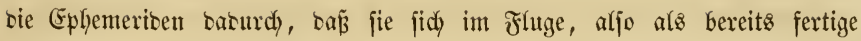
3njeften, noch einmal häuten, bie Jlïgel nidft auzgenommen. Balb nach ter auf bem Wafferfpieget wollzogenen Begattung fliegt bas weibchen in

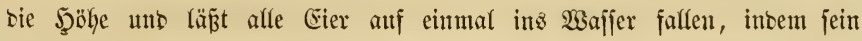
Şiuterleib aufplatzt. So erfolgt nad) menigen Stunten ebenio plötzlich) ser

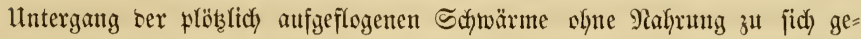
nommen zu haben, wojt ben jonberbaren Thieren auds bie Muntbthetle,

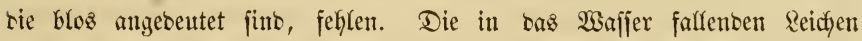

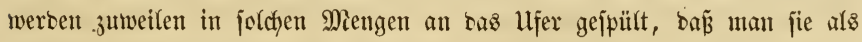
"Lfferas" zum Dïngen verwentet hat.

Weniger affgemein unt ungejucht jidy geltent machent fint bie zahl= reidy in Walte lebenten 5ुeujdyredfen uno ifyre unmittelbaren nächjten Bermanten, bie Sdyaben unb (Brabhenjdyeden, weldye ztiammen jonjt fajt affein bie Dronumg ber Drthopteren bilbeten. Sn biejem weiteren Sinne werben bie Sd)riden, um bieje bon Dfen empfohlene umfajfenbere

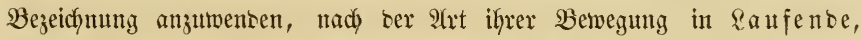
Schreitente uno Springenbe eingetheilt. Die fdyreitenben Srtfopteren

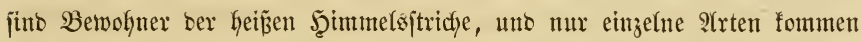
im jüblichen Eıropa bis in bie öfterreichijchen Sïjtenlänber uno vereinzelt nod) nörblicher vor, intem bie lierher gehörige Fangheufdrecfe, Mantis religiosa L., bei $\mathfrak{B i e n , ~ a m ~ S a i j e r j t u h l ~ u n o ~ b e i ~ F r e i b u r g ~ i m ~} 2$ br. gefunben wirb, jeboch mefy auf $23 i e j e n$ aโz in 3 älbern lebt. Dagegen bieten bie laufenten (Seratflitgler atts ber Familie ber $S_{d}$ aben einige allgemein ver:

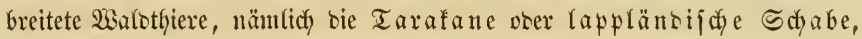
Blatta lapponica L. uno rie beutide Sdabe, Bl. germanica L.,

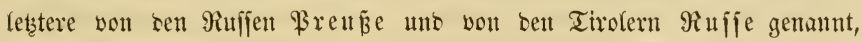
was auf ifye Einjolleppung rentet. Beibe Arten wie audf eine britte, bie

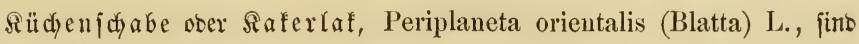
ourdy Waarenverfenoungen tmb burd) bie Schifffahrt wafyre Sozmopoliten gemorben uno jeţt fajt überall zu ફ̧auje uno überall als immer fungrige Jrefier läptig.

Um fo reidfer fint bie gerabflïgligen Springer in unjerem Walt= gebiet wertreten, obgleich man jich babei hüten mur sie flïgelfofen \&arwen

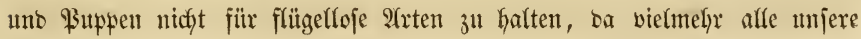

Die Styere Des 2 Batocs. II. 
bentichen ভdyriden geflitgeft fint. Bei affen fint sie Şinterbeine surdy jtarf verbicfte Echenfer, uno gropenththeils aud) zugleid) surch Serlängerung ber Shyenfel uno Schienbeine Sprungbeine mit 2tußnafime ber Maul= wurfagrille orer 3 erre, Gryllotalpa vulgaris Latr., bei wefdyer bafür bie Borberbeine breite Srabbeine wie bie bes Maulmurfes fint.

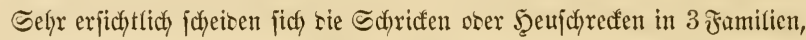
meldje jämuntlich zahlreidy in unferen \$äloern vertreten fint: (Srabheu= idreden, Feloheufdreden unb saublujdreden.

Zut Den erfteren gebört neben ber idyon genannten Werre nody bie Felogriffe, Gryllus campestris, in unfer bereicly, wo beibe zutweilen in Foritfulturen surch Benagen ber $\mathfrak{B u r z e l n ~ b e r ~ B a u m p f l a ̈ n z c h e n ~ i d j a ̈ b l i c h ~}$ werben. Die Felblyeujdyeden, Acribioiben, Gaben wie bie Raubfeujdyreden bie allbefaunte Şeujd)redengeitalt, unterjacion jich aber von letzteren, weldye

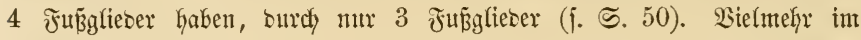
Walde, namentlidy Süb = und Mitteldentidylanos, als im Felse fommen ztwei unjerer fobänjten Felohenjdyreden vor, Acridium stridulum, bie Sdyartheufdrefe, mit rothen, uno Acr. coeruloscens L. mit himmel= blauen Şinterflitgeln, welche beibe aufgeidyeucht nach einem furzen Bogen=

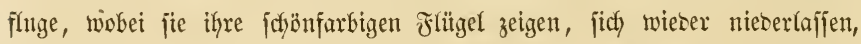

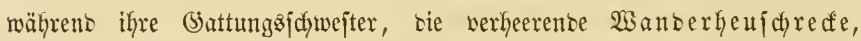

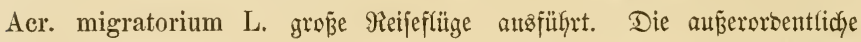
Muáfelfraft biejer Springer fann man am bejten ermefien, wenn man jie auts ber leidht gefchlofienen Şand Keraugipringen läp̧t, wobei man bas fräftige Begenjtämmen ber Sprungbeine jehr bemerffiç mafyrnimmt. Sie übertreffen Gierin bie saubheufdreden, Socuftinen, bon weldyen sas

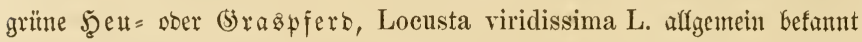

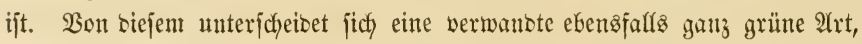
L. cantans L., surch fürzere mehr eirumbe Borterflïgel uno nod längere Fühler. Leberhaupt haben bie Rocuittinen viel längere Fühlex afs bie Acribinen.

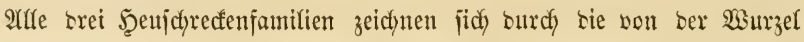
aus fächerartig zufammengefalteten Şinterflïgel auz, weldje von ben geraben Borberflügeln (baher ber Dromungmame) meift blos feitlidy be= becti werben.

All ber 23 urzel ber 2orberflügel liegt bei ben jügenten 2trten, aber wie bei ben Cicaben andy nux bei sen Männchen, ber Stimmapparat, 
bejteheno ans einer feiten Irommelfiant, weldye won einem elajtijachen hor:

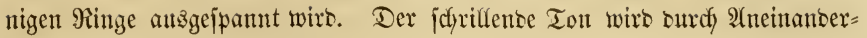
reiben ser bezïglichen Theile ser Borberflügel herborgebracht, wobei aber

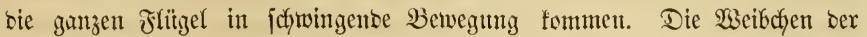
Ranbhenjobredfen haben am Reibesende cine lange jäberförmige segicheibe.

Endich bilset bie Battmtg ber Defrlinge ober Dhrwürmex, Forficula, affein eine Familie uno jugleich bie 3umit ber Dermatopteren (bautfflitgligen). Sie finten jich im Walbe weit verbreitet, Gejonbers unter jich ablöjenben Baumrinben uno zwijhyen trodenen Steinlyaufen. Wir

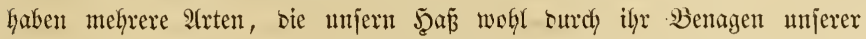
Peffen uno (seorginen unt bes feinen Spalierobjtes, feineswegs aber burch

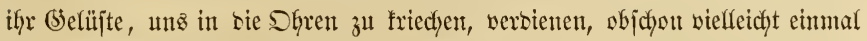
einem jorglos im (3raje Riegenten Dhrtwärmer in's Dhr gefrodyen jein mögen,

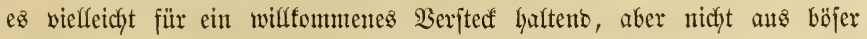

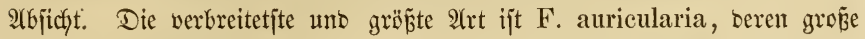
zierlich gefaltete Flägel wir auf S. 49 Fig. 1 fenten lernten. Die Zange, beren 2 Schenfel bei bem Miäundfen ftarf, bei bem $23 e i b c h e n$ nux mentg

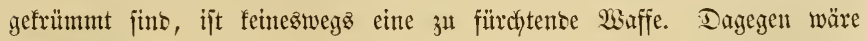

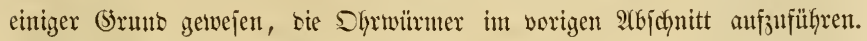
Denn nady De (Seer fütet bas Weibchen feine Eier unb bie Sungen joflen wie bie Sï̈chlein unter bie Miutter joylitwfen. Dafielbe gilt von ber oben

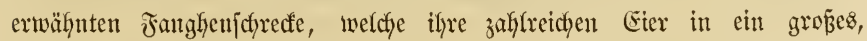

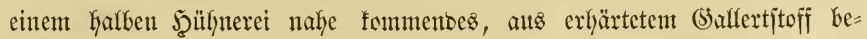
reitetes tno jef̧r regelmäß̄ig in Fädyer gethetltes (sebäuje unterbringt, weldyes fajt einer riejigen Schilb = 2 ffjel gleicht, uno jebenfallz bem Unfun= bigen ein ftumentes was ift bas? entlocft. \&inné ftellte wegen ber

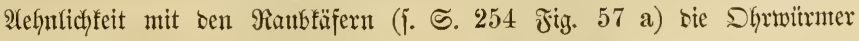

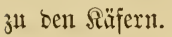

Sndem wir hier bie Drtyopteren berlafjen, betonen wir nochmals, baj

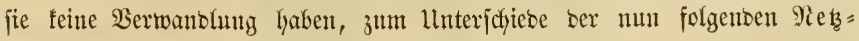
flügler ober Nieuropteren, beren Dronugsfemzeichen uno Eintheifung in brei Zünfte wir bereits auf $\$$. 256 angegeben haben.

alle brei Bünfte finto nidyt nur zahlreidy im 2 albe vertretent, fontoen verbienen mehr nody unjere Beobactutung beshalb, weil jebe berjelben Fälle won merfwïrbigen Refenserjdyeinungen barbietet, jo baj wir leicft $\mathfrak{B} e r a n=$ 


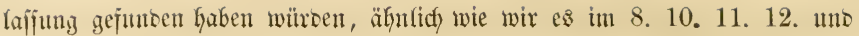

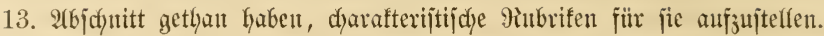

Jn ber Bunft der Blattflïgler, Blanipennien, - jo genannt meil ihre llnterfilïgel nicht fäd)erartig gefaltet jino wie in ber 2. 3mnft finbet jid it ber Fantilie oer (5roffifligler, Meigalopteren oer weltberïhmte Ameifenlöwe, Myrmeleon formicarius L., mit nod) eitrigen (5)attungen

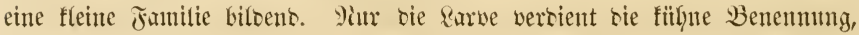
währento Das libellenähnlidje vollfommente 3njeft zientidy harmlos in ber

Fig. 75.
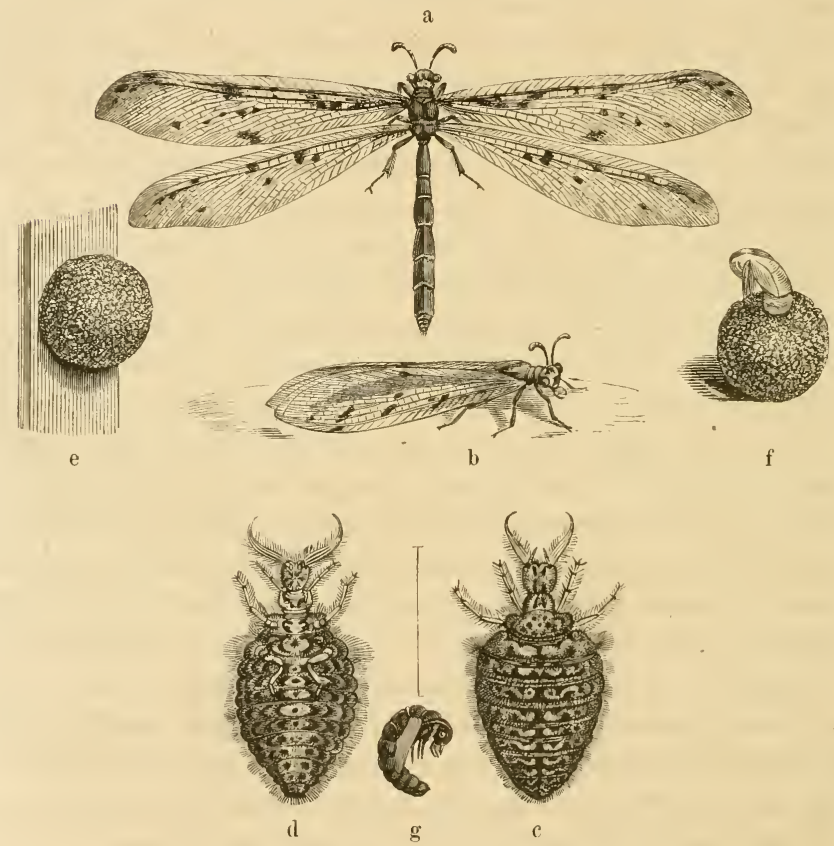

Der Ameijenlöwe, Myrmeleon formicarius L.

a nub b Das volftänbige Injeft. c Rarbe von oken. d biefefbe von unten. e ein

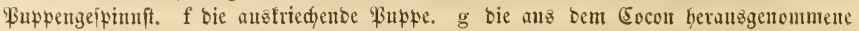
Frape. (c unto d etwaz vergröß̌ert.) 
Buft flattert. Daju hat oer langleibige fertige 2(meijentöwe 4 einanter fajt

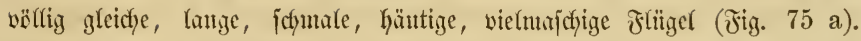
Wir haben in Dentjalanto 2 alfgemcin werbreitete 9 (rten, bie genannte

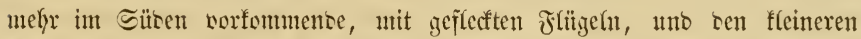
M. formicalynx Fabr., wörtlich ser ?tmeijenfuchs, mit itmmpferen,

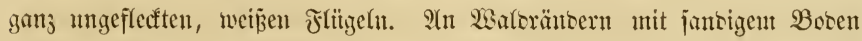
fintot man unter bem Sdyuz ser überbängenten Bweige fefr oft fleine trichterförntige, etwa 1 Zoll tiefe uno biz 3 3 oll Durdymefier haltente

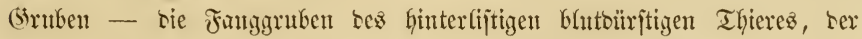
Earwe tes Minrmeleon. Sie hat bie Jig. 75 e d oargeiteflte Sejtalt. Der auf

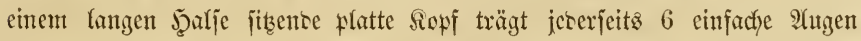

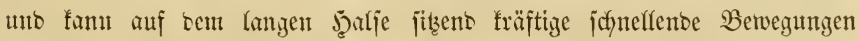

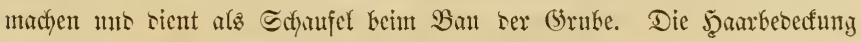
vermittelt ohne 3weifel sas feine (Sehör für bie Benregung ber Santförndfen

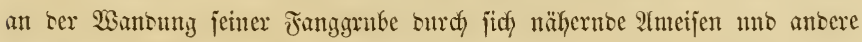
Injeften. Die beisen fintern Beine fint cinwärts geridfet (d) unt unter=

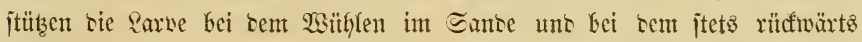

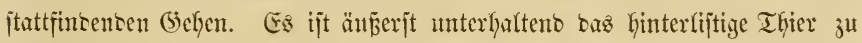

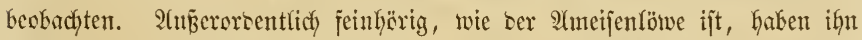
unjere nahenten Tritte zuridfgejhendit, mo mir milifien berwegunglos eine lange weife warten, fiz ber unter sem Sano auf ocr Rauer liegente

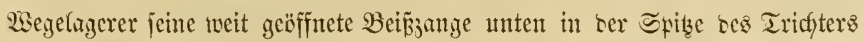
wieber herworitreḉt - weiter läß̈t er won jeiner bejtalt nie etwas jehen.

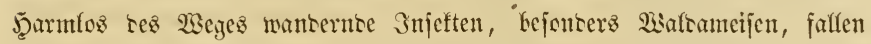

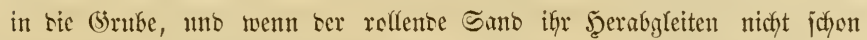
allein kemerfiftelfigt, fo rifft ser lanernbe Mërser mit einem nady ifm ge=

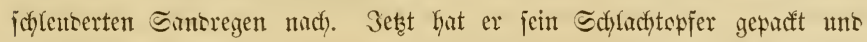

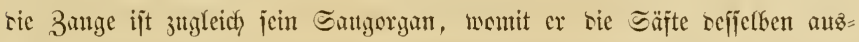
fautgt, tenn bie beiten feinen Styizen entigen in ein Roch unt bie Zangen=

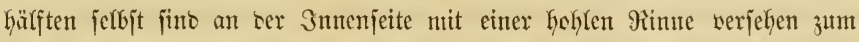
Einjaugen tes Suftes. Mit eincm fräftig fdyeffenten Mucf wirs ter leere Barg weit ïber ben Bore ber (5rube hinatigefchleutert. Bon ben ge= noljenen Säften läp̈t er nichtz mnverhaut uno beshalb brautcht tno hat ex

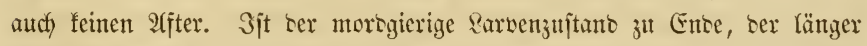

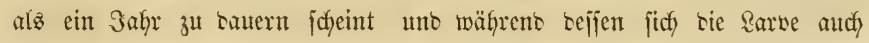


nicht Käutet, fpinnt fie fich mit feiner glänzenter Seibe uno taran haftenten

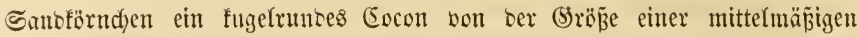
Sirjobe. Das Spinnorgan liegt aber nidyt wie bei ben übrigen ifinnenten 3njeftenlarven im Maule - beffen Stelle ja bie Zange allein vertritt jonbern wie bei ben Spinnen am Ense tes Shinterleibes, unb bejtelyt

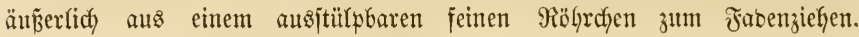

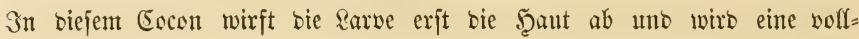

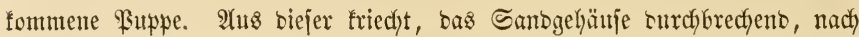

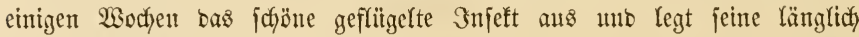
Girnförnigen Fier in ben Sano. Unjere Figuren 75 a-g zeigen uns Den Berwandungagang Des intereffanten Thieres. Der alte $\Re$ öjel, welcher

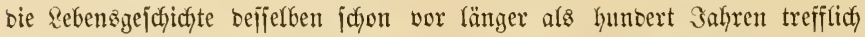
geidjilbert uno mit untabelkajten abbilbungen veranjdyaulicht hat, icheint zufälfig von ber Rarve nidft gefnippen worben zu fein unb traut es if̧r beshalb nicht zu. Wix haben aber mehrmals erfahren, Daj fie recht

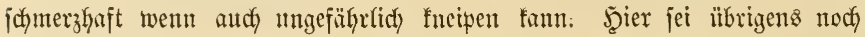

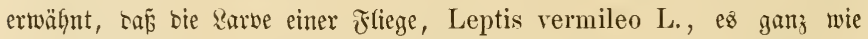
ber 2 (meifenlöwe madht, um fleine Injetten zu fangen.

In heip̄en Eroptridfen fonmen berwantte (battungen bor, welche

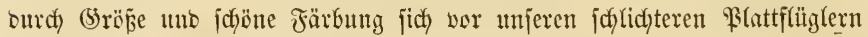

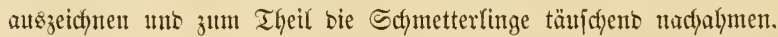

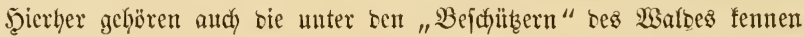
gelernten Florfliegen (i. \$. 256) und bie auffallent langhalijgen meijt jdyarzen Schmalhafte ober Sameelhalsfliegen, Rhaphidia, meldye wie jene uady Injetten jagen. - 2 Inf ren Büfdyen fimsen wir ben ganzen Sommer linburd fefr häufig nody ein anderes in biefe 3unft geförentes Injeft, sie Sforpionfliege, Panorpa communis L., teren vier jiemtich gleidh gejtaltete Gelfe Flügel mit idwwarzen Fledfenbinten gejiert fino, uno seren Meäunden cine rojenrothe immer aufwärt gerichtete biffe Arebsafheere tragen. Der fleme Ropf ijt in eimen langen Rïifjel verlängert, mit bem

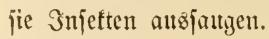

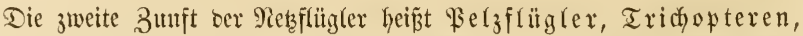
weil ihre Flügel meijt behaart ober bejdyupt jind; bie Ginteren meijt viel fleimeren fönnen ber eänge nadh meijt gefaltet werben. Mandje jint in 


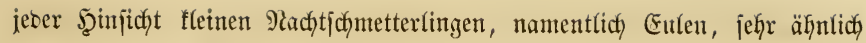
unt haben meijt fehr lange jabenförmige Fühler. (Fig. 76.)

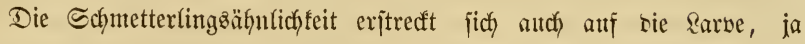
einigermaaß̃en jelbjt auf bie Puppe uno namentlich auf bas Spinnvermögen ber eriteren, wofïr jie wie bie Raupen

Die Zumft ber Bel$_{3} f$ lügler wirb ganj allein von ber jefyr artenteichen Familie ber Frïhlingsfliegen, Maifliegen ober R̈̈beriungfern,

Fig. 76.

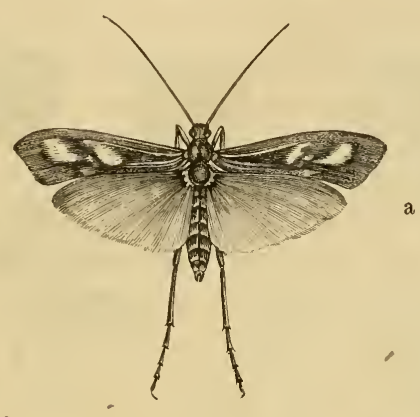

c

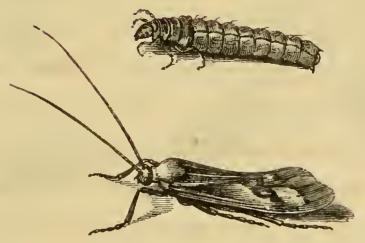

b

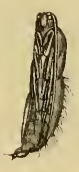

e

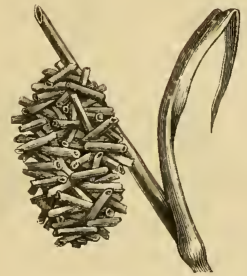

d

Die rautenffeđige $\Omega$ s̈deriungfer, Phryganea rhombica L.

a b Fliege. c freie Rarbe. d Șehäuje aus Şalmftïddjen bereitet. e Puppe.

Bhryganiben, gebilbet, welche outrdy ihren Sunjttrieb fohon jeit langer

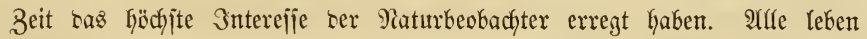
als Rarven wie bie Ribellen im Wajfer, theils von thierifdyer theils von

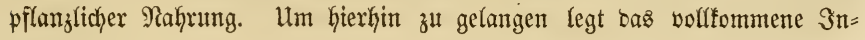


- jeft bie Gier flumpenweije tidyt an tas Mfer tes (Semäfjers. Der Tame

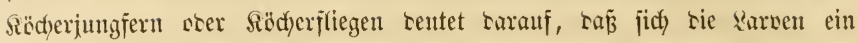
oft füd)erförmiges (Jig. 77 a) Lisongehäuje bereiten. 23 aв nur einize Fulterraupen audy thun, Laß̄ fie auner ber Seise nody frembe Stoffe ju ifrem Cocon verwenten, bas thun bie \$syruganitenlarven ftets uno jinto

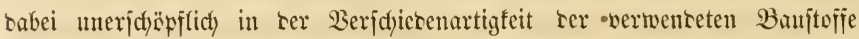
uno felbjit in ber Form bes (5ehäujes, wie sicjes aแı sen fig. 77 abgebil=

Fig. 77.

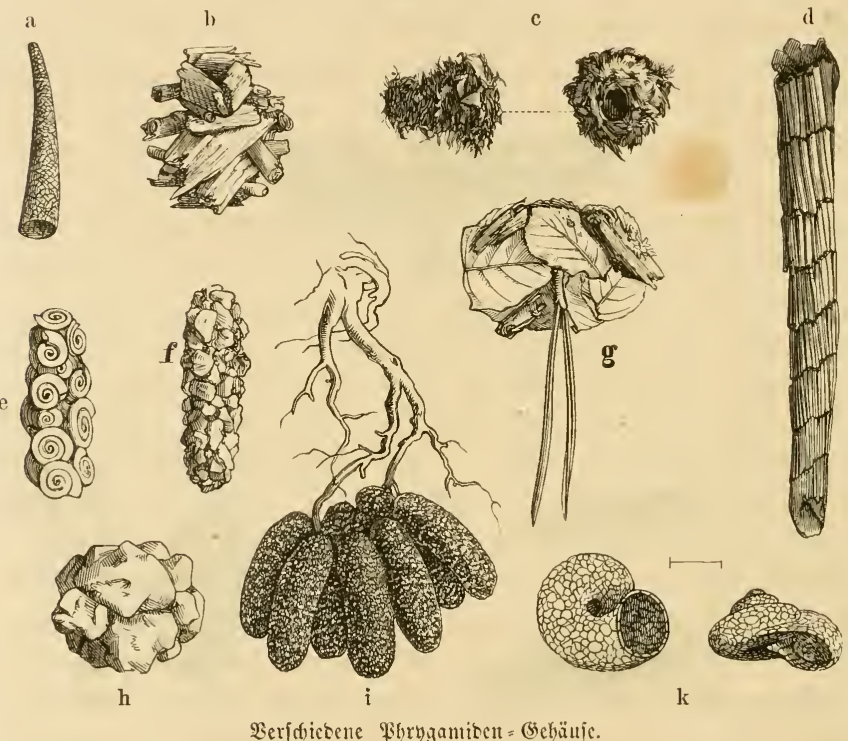

beten Beipielen hervorgeht. Maan fönnte beinuhe jagen, es jei ifnen ?trfes

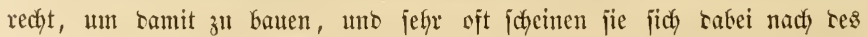
Drtes belegenheit ju jojiden, je nad)oem riejes ocer jenes banmaterial

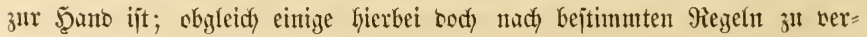
fahren jheinen. Die am bäufigiten werwenteten Baujtofie jino fleine juredft gejduttene Stüfdden von Sdyilf = ober Srazblättern, Zweig = mo Rimben= 


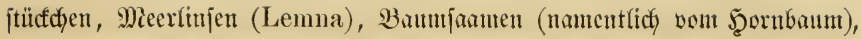

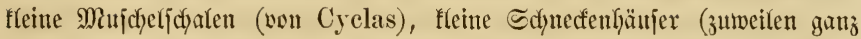
alfein verwenbet), bie ferbjt nod) won ber lebenben Saffnede bewohnt fein

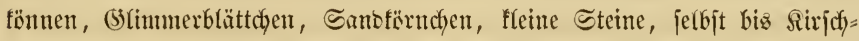

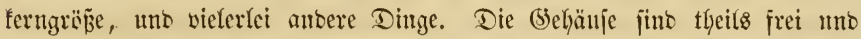
werten bann won ber Sarve twie bie Sdfuctenengeffäuje mit fortgetragen,

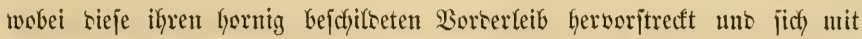

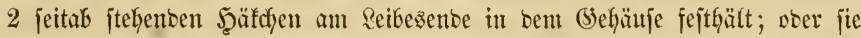
find auf Steinen, bie im $23 a j$ jer liegen, uno zmar meiit auf beren Unter=

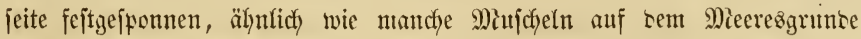

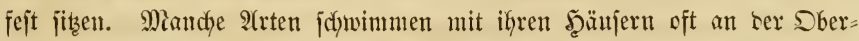

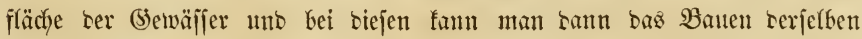
beobactyten unt jefen, wie jie ein Stüfdchen nact) bem antern an ber Münoung bez (Sef̧üufez mit Seibenfäzen anheften.

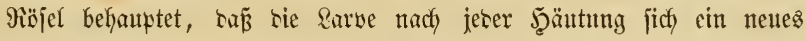

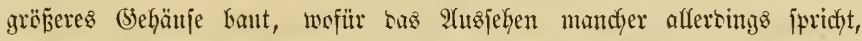
(3. B. e unt f), währent ancere (3. B. a) offenbar mit ben zunefymen=

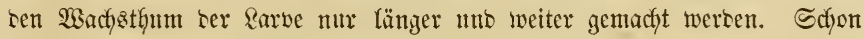

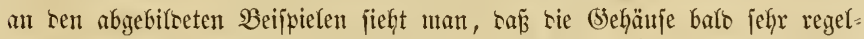

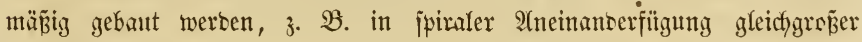

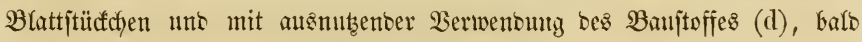

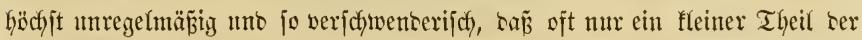

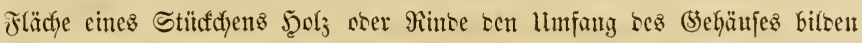
Gifft (b). Meijt fielyt man zu einem (jeghüufe nur einerlei Baujtoff berwenbet

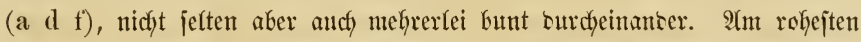
jimb bie jefyr häufig an Kolfen Steflen ber Unterfeete von im $\mathfrak{B a}$ afjer liegen=

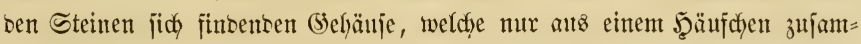
mengejponnerer verfdjieben groß̈er Eteindfen bejtehen (h). Die 3ntenjeite ber (Befäulfe ift jtetz mit Seibe auzgefeteibet uno an beiren Enoen offen. Zur

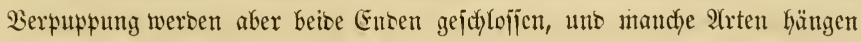

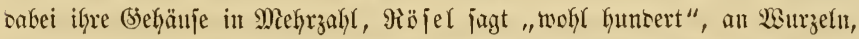

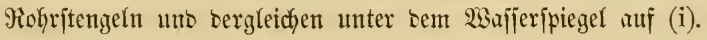

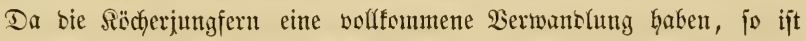

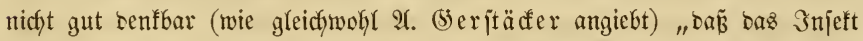

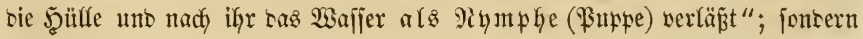




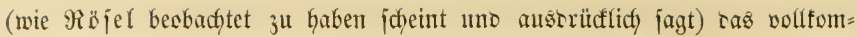
mene Snjeft mirft innerfalb bes (behäujes bie \$uppengaut ab uno friedjt

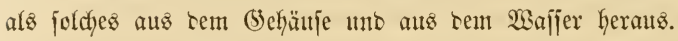

Dies jüb einige Charafterjüge aus bem teben siejer hödjit interejanten Thiere. Doch müjīen wir nodh bejonters anf bas (bef̧üuje g aufmerfiam madjen, welches wir jef̧r Gäıfig um Tharano bei Dresten gefunben haben. Seine Berfertigerin fann bie Exfinberin ses Stenteruters genannt werben, benn als joldjes joll biefleidjt bas Siefermadelpaar sienen, weldyes immer am Şinterende tes jefr platten Bef̧äujes angehejtet ijt.

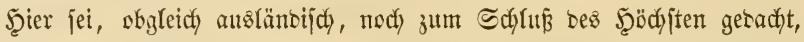

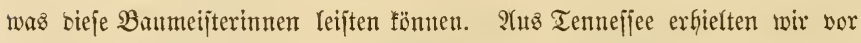
etwa 12 3afren gegen Gunbert fleine itberats regetmäß̈tg uno in volt=

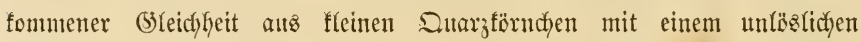

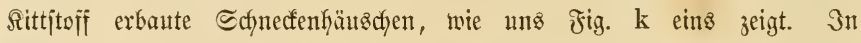
mehreren berjelfen jtectte nody bie Rarve brin. Der norbamerifanijhe

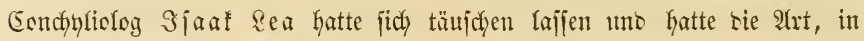
ber er ein Sdynecfenthaus jehen z̆ mitijen glaubte, Valvata arenifera getauft. Epäter erfannte ber Edfweizer Błremi bie afferbings itaun=

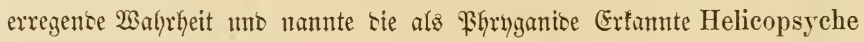

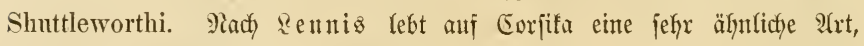
beren häher gemumbenes (sehäule lange fïr eine Sdyneffe gegolten uno ben Namen Valvata granifera erfalten hatte.

3icht minter intereifant, wenn aud in ganj anberer Waeije ijt bas Reben ber fleinen Fädyerflügler, Strepfipteren (ober Rhipipteren),

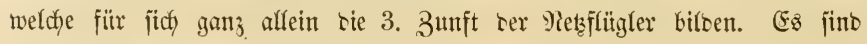

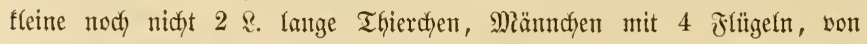
weldyen bas bortere ßaar mux, an ber Spize gefrümmte, Stummel fitro,

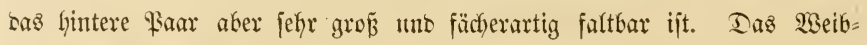
dyen ijt ganj flïgellos unt wumartig. Munotheife berfïmmert. Die

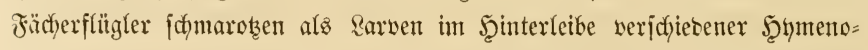

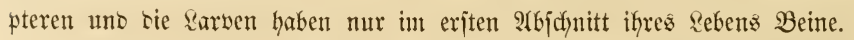

Wir lehen Fig. 78 a won Xenos Peckii Kirby ein wergröß̄ertes Männdfen mit atsgefreiteten Unterflügeln, über benen sben bei a-a bie fleinen hafenförmigen Stummel ter Borberfïligel fidftbar jint. Fig. b ijt bas $\mathfrak{W e i b c t y e n ~ v o n ~ X . ~ R o s s i i ~ K . ~}$ 
SBenn man viele J̧ymnopteren (namentfich) aนs ten Battungen Andrena, Halictus, Vespa, Odynerus, Polystes, Sphex, Pelopoeus) jängt, fo finbet man nidyt felten ben Sapf won Strepfipterenpuppen zwifdjen ben

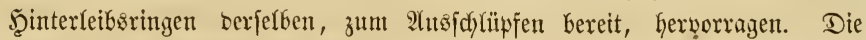

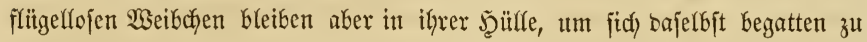
lajīen. Die bon jolchen siseibchen geborenen jungen sarbén merben von

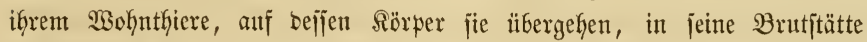

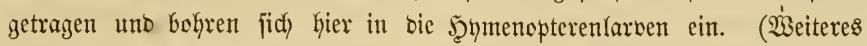

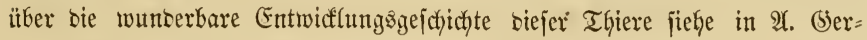

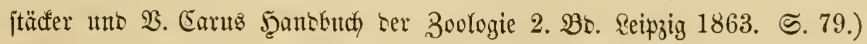
Allz vierte Dronung laffen wir mun bie 3weiflügler, Fliegen, Dipteren, folgen. Wir haben ïber bieje, burdfaus am wenigiten in

Fig. 7s.

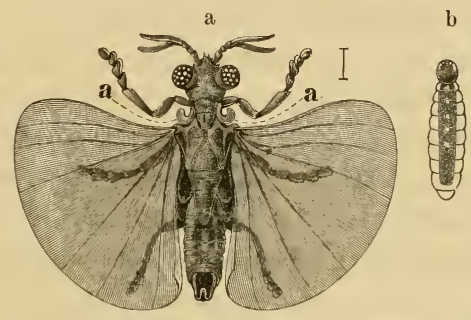

a Xenos Peckii Kirby. b Xenos Rossii Kirby.

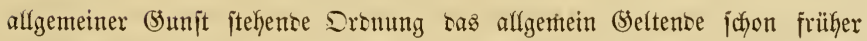
(ङ. 240) fennen gelernt, als es uns sarauf anfam, unter ben Fliegen

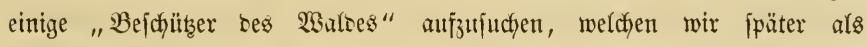
Beifpiel "müttertiçer Füriorge" sie Dafjelffiegen folgen ließ̂en. Zut ben=

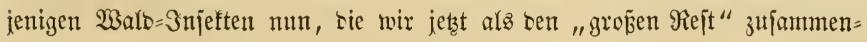
faffen, jtelfen bie Fliegen ein jehr bebentenbes sontigent.

IIm auch hier nit ben unvolffommenen zu beginmen, jo haben wir zunädhit ber jefr fleinen Bunft ber Fehlflügler, Aphanipteren, zu gebenfen, welche in ber Familie ber Flöke, Fuliciben, aufgeht, beren befannte Gejtalt uno sebensweije uns einer ausführlichen Bejajreibung überkebt. 


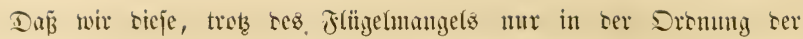

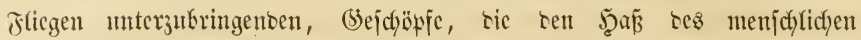

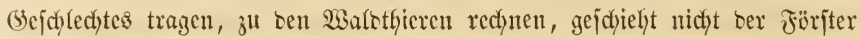

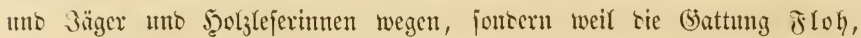

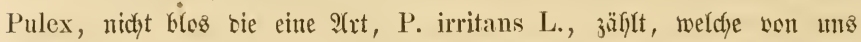

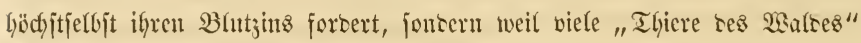
aแz ujercu erjten Bante iłre bejonteren Jloharten beherbergen, 3. B. bas Eichbörndyen, Marter, Sgel, oer Mantwurf, bie Mäuje, Jlectmäuje,

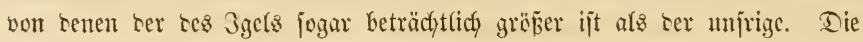

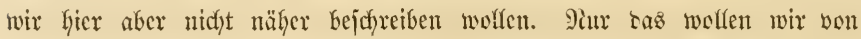

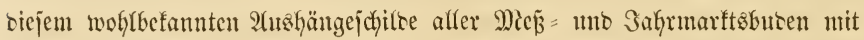

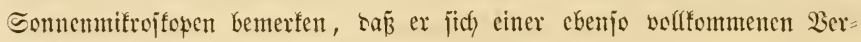
wandlung erfieut als ber joünjte Sdymetterling.

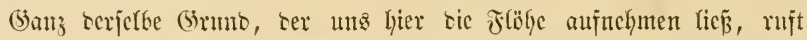

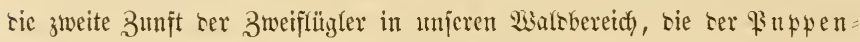
gebäreriunen, Fupiparen, jo genant, weil jie ifye Jungen als Sarben

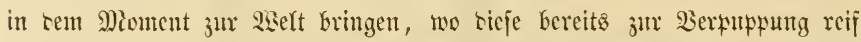
jint, bie and glcidy nady ber (Scburt cintritt. . Dicje jefyr wenig jaflreidjen ifren Rarwenzultano bemnady im Miutterleibe surdymadyenten Fliegenarten zerfalfen in trei Familien, won senen bie ter sattzfliegen, Eoriaceen

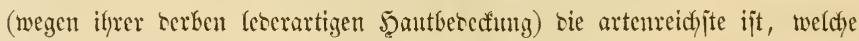
allein, umo audy nidgt eimmal afle (5attungen, geflügelt fint, wägrento sie

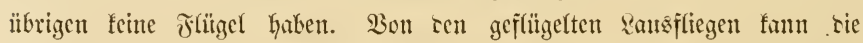
(Gattung Lipoptena, tie Flügel abwerfen แmo lebt tam als ltugejicjer

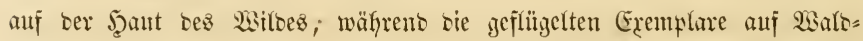
bëgeln jommarotzen. Die befamntejte atrt ijt sie Bjertoclausflicge, Hippobosea equina Latr., weldse auf ben jarteren jaantiteflen nautentlidf

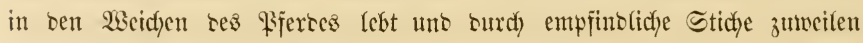

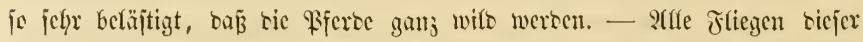
f́einen 3unft haben cinen plattgebrücften ?eib uno meift groß̈en querge=

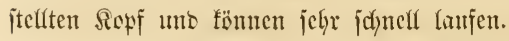

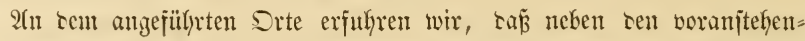
เen 2 jef̧r geringjälyligen Zünften alle übrigen Zweiflïgler in bie cine

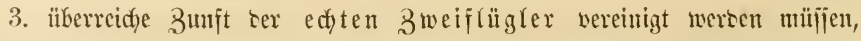

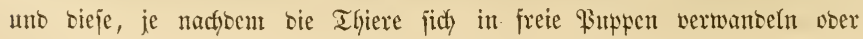


sicje in ber verbleibenton uno ju einem pergamentartigen Tönnchen werbenten leżten Sarbenthant eingejdyloffen fint, in 2 Jुorben getheilt nirt.

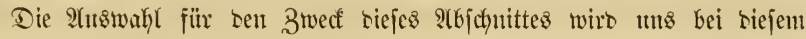

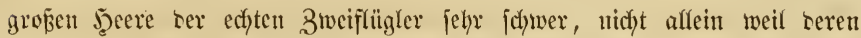
eben jo viele fint, jontern weil jie metyr als antere Injeften mit einanter

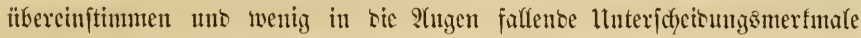

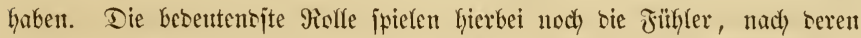
Bejuaffenheit man frïher sie ficgen flaffificirte. Biele echte Dipteren

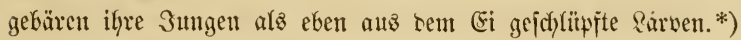

Die uns jifyon befaunte llnbegrenjtheit ses গahrungaggebietes, in weldyem

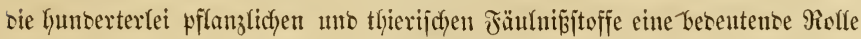

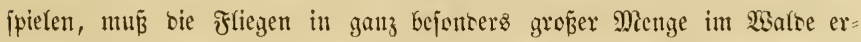
fujeinen lafjen, ber ja an foldyen Stoffen überreich ijt. Diez girt ganj

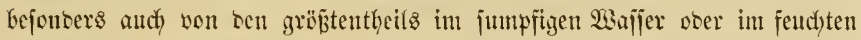
moberreichen Eroboocn Kebentsen itedyenten Fliegen, bie uns bie WGalojpajier

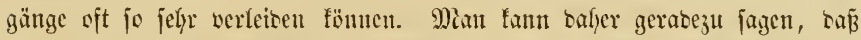
für uns perjünlich im 2 arbe jich feine anbern 3njeften fo läjtig gelteno

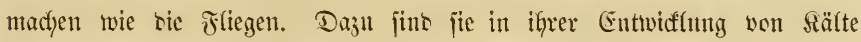

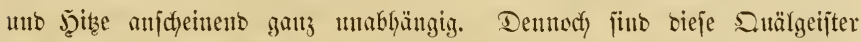

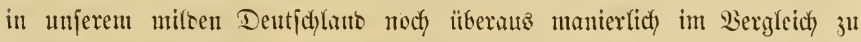
antern Rä̈bern, wo fie sen Mienichen uns fein Sich gerabeju tort quälen, uns, wenigitens zeitweilig, ganje santjtricje unbewolynbar machen.

Wir begegnen biejen feindjeligen Fliegen in betren ફ̧orben, in weldyer namentlich) bie beisen erjten Fantien, bie Schnafen soer Mï̈fen, Tipularim, mo bie bremien, Tabaninen, zum gropen Theil aus

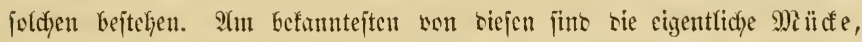

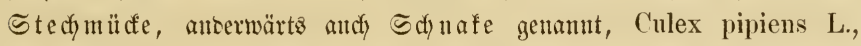
bie Regenbremje, Haematopota pluvialis L. uno bie Duize ober

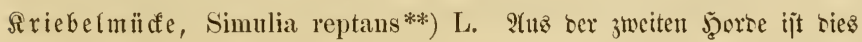

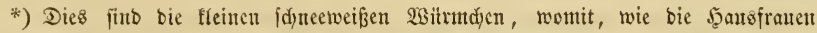

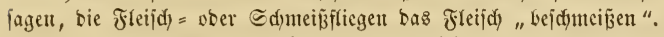

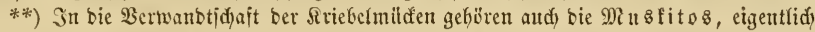
Mostitos, vieler tropifdyer \&änber. Sebod, bezeidunet bieje Benenunth wentiger eine ge= wiffe 2 rt, als mebrere burdh ifren Stid) läftig merbentbe lleine Fliegenarten, benn mosquito heiß̄t im Spanifden überhaupt bie fleine Fliege, Derfleinerungsform bon mosca, Fliege. 
bie unjerer Stubenfliege jebr äfnlidje, nur etwaz fleinere Stedyfliege, Stomoxys calcitrans L. Ebenjo unb mehr nedy als bie Menichen wirb Las Dieh von ber Rinberbremje, Tabanus bovinus L. angefalfen uno bie Eolumbaczer = Mitufe, Simulia columbaczensis Fabr. richtet be=

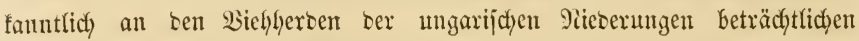
Schaben an. Sene ijt es, gegen beren Beläjtigung wir ben Pjerben Fliegennebe anflegen, nidft bie früher bejdyriebenen Dafjelfliegen (Gastrus und Oestrus).

Sntem unz hier bie unjere Speijevorrätge ober bie unjere 9uts= pflanzen angreifenben Fliegen, joweit biejelben ifyen wejentlidjen 2Uffenthalt ober Uriprung nicht im Waalbe haben, nichts angehen, fo fönnen wir auf ber anberen Seite vielen 2(rten, ja ganjen Familien berfelben nadjü̈fymen,

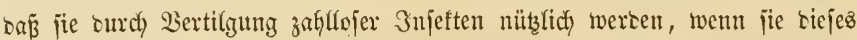

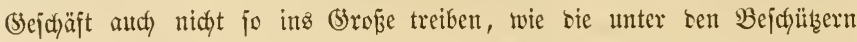
anjgefüfrten Beifpiele. Dies gilt bejonbers von ben Familien ber Empiben unb Ajilinen, weldye beshalb zit Dentidy $\Re$ anbfliegen genant werben.

Diejenigen Fliegen, weldhe als Zarben, unb bann aud meijt als Buppen, im Wajjer leben, haben ganz bejonbers zแr Wajjerathmung ein= gerichtete an entweber am Unterfopfe ober am \&eibesente anfängente 2thenröhren ober zierliche blättchen = ober jternförmige Siemen. Wir jehen 2 Beijpiele bavon an Fig. 79 b uno d, ben jouberbar gebauten Wajfer=farven ber gemeinen Stedyüde uno ber gemeinen Waffenfliege, Stratiomys chamaeleon L., welche letztere mit ifrem Sitemenjtern jidy fopjunter an ben Wajperpiegel jum 2tthmen hängt, twie es bie Mädfentarbe ebenjalls mit ifrem anbers gebilbeten Athemapparat thut. Bon ser 2 affenfiflege

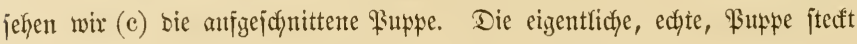
in ber jtehen gebliebenen leizten Rarvenlyant, an weldjer wir bie etwas ver: änterten Siemen ebenfalls wahnel)men. Eime unjer bäufigiten Fliegen= gattungen, die $\sigma_{d y}$ lammfliegen, Eristalis, weldhe ben Bienenbrolnen

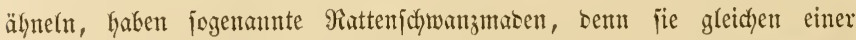

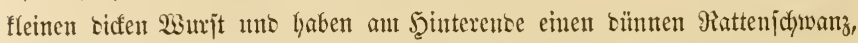
bie Ŷthentröhre. Die Rarven, namentlidy sie - won E., tenax L. leben in

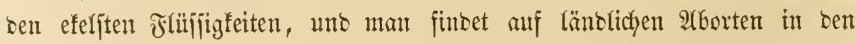
Spinngeweben jelyr oft bie łuppen serjelben am Sdywanze aufgebängt, 
bis wohin fich bie Maben aus iffrem suftrevier, in welchem fie oft zu Şunberttaujenten jafwelgen, emporgearbeitet hatten.

Wenn man mit ciner guten \&upe bewaffinet im 2 altre auf bie Fliegenjago geht, jo wiro man balo eine anjehnliche, wenn autdy nicht jehr formenreidje Beute zujammenbringen. Man wiro namentfich babei eine Menge unjalurbige Tfieve, bie man bisher für jtect)ente Şautflügler ge=

ซig. 79.
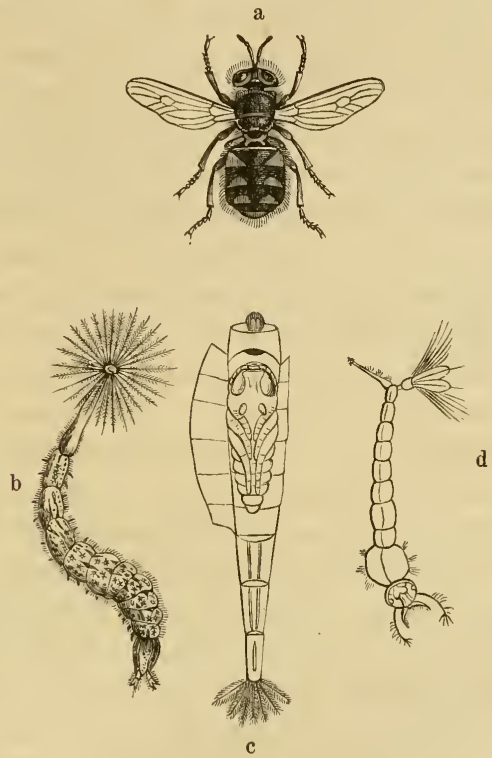

Die gemeine $\mathfrak{B a f f e n f r i e g e , ~ S t r a t i o m y s ~ c h a m a e l e o n ~ L . ~}$

b unb c Earve uno (geöffucte) Puppe. d Rarbe ber gemeinen Mürfe.

Galten Gatte, als Fliegen exfennen, wobei gefagt werben mag, baß jelbjt bie itechenton Fliegen nicht zur Bertheirigung ftechen rwie bie $23 e s p e n$ uno viele anbere Şautflïgler.*)

*) Eine eingehenbe $\mathfrak{B}$ ejdäftigung mit ben Dipteren fann namentfidy in einer wald=

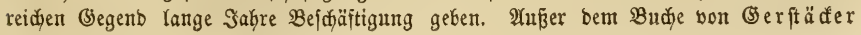


Wenn auch aus feinem anteru haltbaren (5runce, fo lajjen wir hier bie Şaut = ober Aberilügler, Şџnenopteren, beshalb als fünfte 3nfeften= Drounng folgen, weil fie jidy in ben allgemeinen (Septaltwer= hältnifjen an bejten an bie Ffliegen anjodließ̌en, ja vielfach mit biejen ver= wectjelt werben.

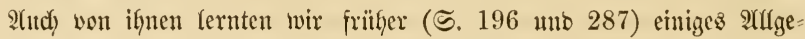

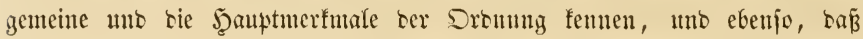
man fie in nenerer zeit in brei greß̃e Gruppen: Stadjeltragende, aculeata, Snfeftenfreffer, entomophaga, uno Bflanzenfeffer, phytophaga, eintbeilt. 2Atz allen brei (5ruppen lernten wir unter ben

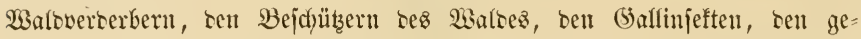
jefligen Infetten ober ben Beifpielen mïtter(idyer Fürjorge cinzelne \$̧ymeno:

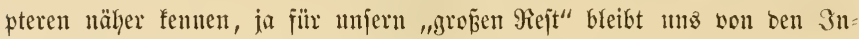

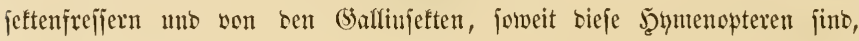
gar nidytz ïbrig.

Demnoch blicbe uns neben ben bereits abgehanbelten fïr biejen 2(bjdynitt eigentlid) nod) jef̧r viel übrig, ba wir a. a. D. erfubren, baja von biejer Эnjeftenoromm bereits gegen 15,000 Arten befannt jür.

Die alfgemeine, afferbings jehr mandfady modificirte (Bejtalt ber

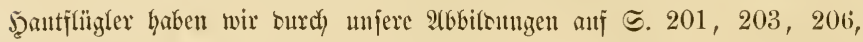
$234,236,238,239,267,273,290,309,320$ un 352 fennen ge= lernt, fo saj Gierïber faum nod, Etmas zu fagen nöthig ijt.

Bon ben Stadyelimmen, weldye mit gegen 10,000 Arten wohl zwei Drittel ber ganzen Dromung Gilten, lyaben wir bie gejellig lebenten mb bie

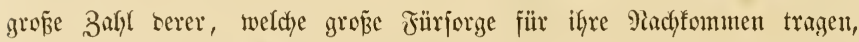
surdf herworragente Beifpiele fenten gelernt. (Es jei von ifnen hier un

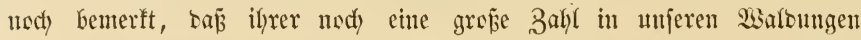
wohnt, ba allein bie Familie ber Bienenartigen, 2(piarien, in etwa

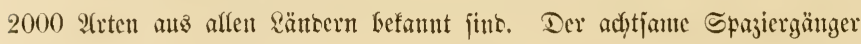

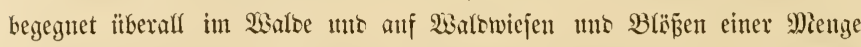

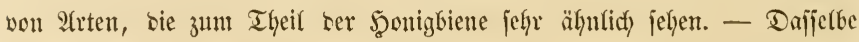

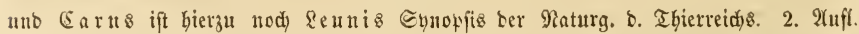

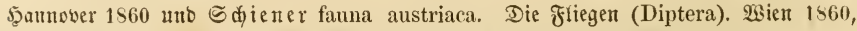
3u empfeblen. Mian mirb atts biefen wenigftens fajt affe beutfden (5attungen fenten rernen fönnen. 
ijt eв unit ber Familie ser $\mathfrak{B e s p e n , ~ 2 e s p a r i e n ~ ( g e z e n ~} 900$ Arten) uno nit ser ser (5rabwespen, Erabroninen (1200 2rten), weldye meijt unter ber Eroe am Enoce cines sft ticfen (banges, ober in Şolzpfählen,

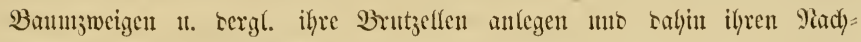
foumen antere Snjeften zur Palywng. Gerbeitragen. Die Gierber gelyörige bunte Bicueuranbwespe, l'hilanthus pietus Fabr., gelyt ober fliegt vielmeby ben Bienen nach menn jie J̧onig fammeln, un fie zu töbten unt ilye sarven mit ben houtigitrozentoen Bienenleibe ju füttern. - Dis gleidfe Zebensweife hat sie etwa 700 9trten zälylenre Familie sex Erowespen,

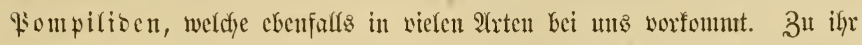
gehört tie Töpferwespe, Trypoxylon figulus Latr., weldye ilyr 9iejt in Bulfen uno Ihïrpfoiten anfegt uno inwentig mit Selym beffeibet. Die

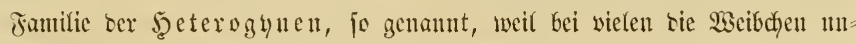
gefflïgelt unt and) jonjt ben Miänndyen jebr unähnlidy jint. - Eine bejon=

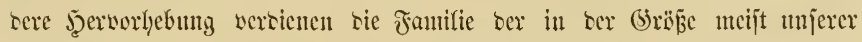
Stubenfliege ctwa gleidhen ocer wenig grëperen (5olowespen, Ehryjisi= Den, seren Europa 40 Arten zähyt. Sie fino bie Colibris ser Dromng, senn sie meijten glänzen in sen prächtigiten Farben mit Mictalfidjummex. Mian jielyt bie wie Smwelen glänjenten Tfiere in sen warmen Stunben

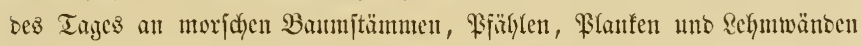

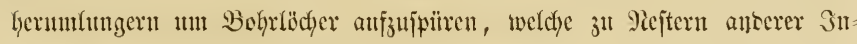

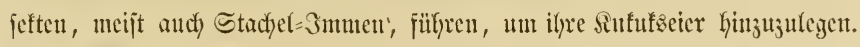

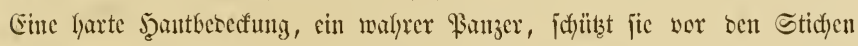

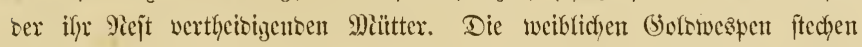
je(bjt jefyr empfindidy, wenn man jie angreift. - Die nvef) übrig bleibente

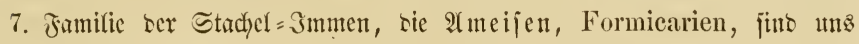
f̧inlängliç) bcfannt.

Die (5ruppe ber $\Im$ njeftenfreffer wurbe uns theilz als Bejdjitizer

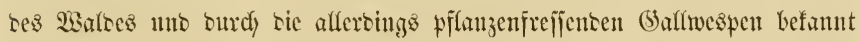
(j. ธ. 273). Dic 1nเs in Walte überall begegnenten Schlupfwespen werten wir leidyt als joldje fenuen, wenn wir uns unfere siguren etwas einprägen. Sie jino surdyaus bie julanfiten Sejtalten ber ganzen Drommy. Dagegen ift bie Begegnung einer Ballwespe cine Seltenheit.

Die britte uno lezzte (5ruppe endich, sie \$iflanzenfrefjer, mure uns unter ben פarbverberbern in ben $\mathfrak{B l a t t w e s p e n , ~ T e n t l y e b i n t o n , ~}$ 


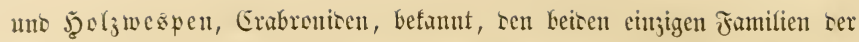

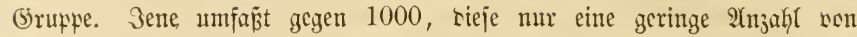
Arten. Die Blattwespen jowoht wie igre Afterraupen genamten Rarben fintet man in groperer 3 ahl in sen Wartungen uno beire merten leidyt erfannt, wenn man jïh ser auf 5.200 f. gezebenen Eharafterijtif uno 2(bGilsunzen erinnert. Mian mirt vicle, ja sie meipten Blattwespen Keidyt

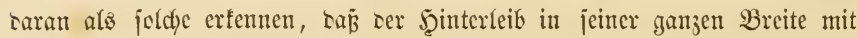
ser B̉rujt verbunten ijt, wäfreno jie sie Jlïgel uno sic Miunotheile ent=

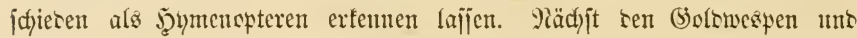
einigen $\mathfrak{B e s p e n ~ j e i g e n ~ s i e ~ I e n t h r e b i n i s e n ~ s i e ~ l e b h a f t e j t e n ~ J a r b e n , ~ n a m e n t = ~}$

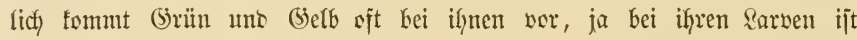
(5rün geratefin bie herridgente Jarbe.

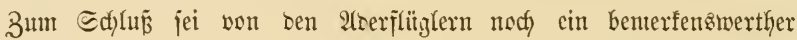

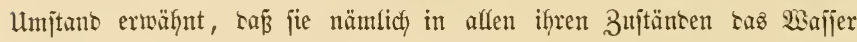

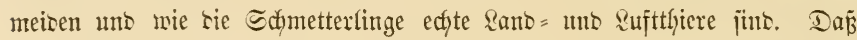
jie in geijtiger Şinjidyt an sie Spize ber ganjen Injeftenflajie ju jtellen jint, ijt oben bereits gelegentlid, gejagt worten. Sie jtehen sariu hod, über alfen antern Injeften, siejenigen nidft ausgenommen, bon tenen wir in

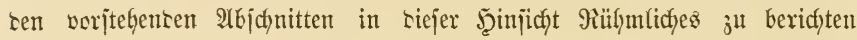
hatten. ’ur aflein sie, in Dentichlano nidyt vertretenen, Termiten (aus

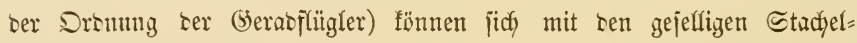
Smmen mejien.

Es bleiben unz noch zwei Drommgen übrig: sie Falter uno bie §äfer, uno bie Entjojeisung wiro uns ichtwer, mit weldjen, alz ben höheren, wir ser breitgrumsigen ßyramise ber Injeftenwelt ben Sitpfel auf́ =

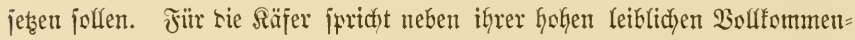
Keit Das Zaflübergewidft, incem man sie Zuahl ser befannten Säjer auf $60-80,000$ idjätst. Die Falter haben sie Sdjönleit uno surdy jie unjere 3uneigung jür jich. Alber aud ifyre 3ahl ijt nidjt ju veradjten, senn bie 3afl ber befanter Sdymetterlinge mag 12-15,000 betragen uno Speyer

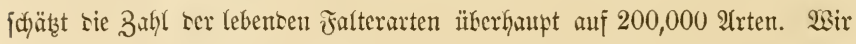
begegneten beisen Dronungen jijon einmal im 2 settitreite, freilid in einem

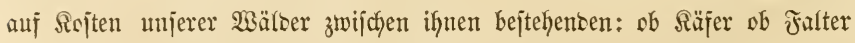

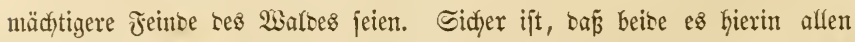
übrigen Snjeften jutworthum. - Folgen mir sem 3ૈuge unjeres Bejdmades. 


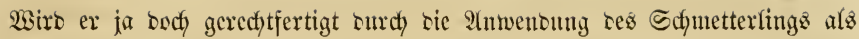
glüubiges Symbor ber fid) sem leiblichen Iobe entringenten Pilyche.

Urfo bie $\Omega$ äfer jteflen jidh uns nod) vor ben Faltern, un zu jehen,

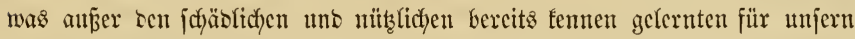
"gropen Giejt" an Säfern nod) ïbrig blcibt. Dejien ijt nun freilidy unge= heuter viel.

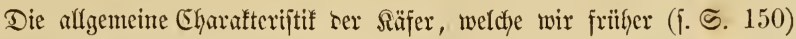

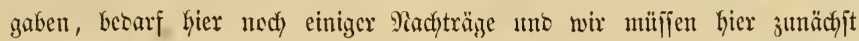

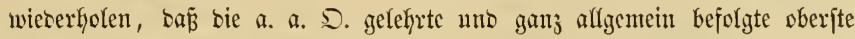
Eintheilung leiber mur eine fünjtliche ijt uno jehr oft anocren verwanbt=

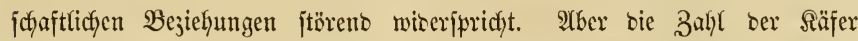
ift eine jo grope uto ber affgemeine Stejtaltcharafter in affen orei $\mathfrak{B e r}=$ wandungsitufen in ber Şauptjache von ber ganzen Sromung jo gut fejtge=

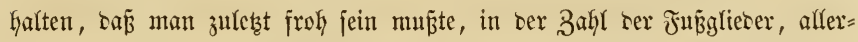
bings ein febr geringfügiges Mierfmal, wenigjtens einigen 2(nhalt bei ber

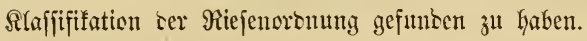

23em es einiger Ernjt mit jeinen Injeftenjtubien ijt, sem bieten wor allen antern Snjeften bie Säfer ben Bortheil bar, bá er an ifnen am

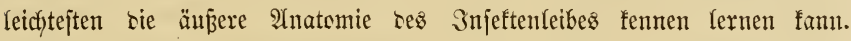
23ährend bei vielen, ja bcn meijten antern Injeften sie (5)lieberung bcs

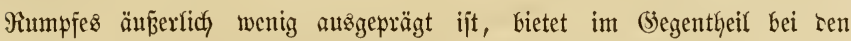
Säfern bie harte Beoccfung, weldje an bie einzetnen Batten uno Schicnen

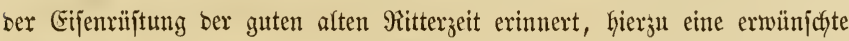
(5elegenheit bar; uno in jehr vortheilf̧after 2 Seije eignen jich Gierz̆ gerabe

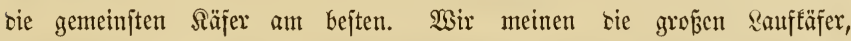
Deren wix 3 arten auf 5 . 251 abgebilbet haben. Atn siejen unb an ben grof̧en, in ifyren Sïrperabjefnitten niçt burch Behaarung verbunfelten, Säfern überkaupt fann man jelbjt bie neueren jefjr betailfirten Sunjtaus=

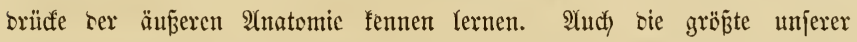
beutichen $\mathfrak{2}$ rten, ber ફ̧irichfäfer, Lucanus cervus L., cignet fich natürlidy fiergu vortrefflich. Man wirb jich leicft einen ober ten antern ver=

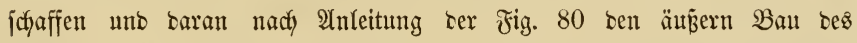

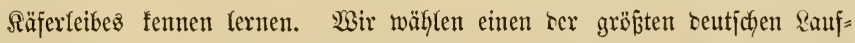
fäjer, Carabus intricatus L., ber in unjern Bebirgg̨twaloungen nicht gerase jelten ift. 


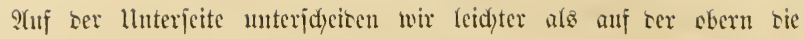
3 J̧aupttheile tes 3njeftenteibes: Sopf, Mitterleib uno ben Şinter= leib (oser Bandy).

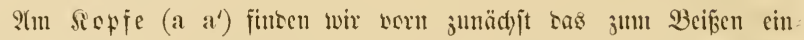

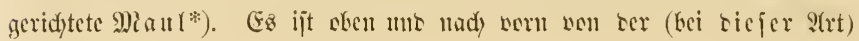

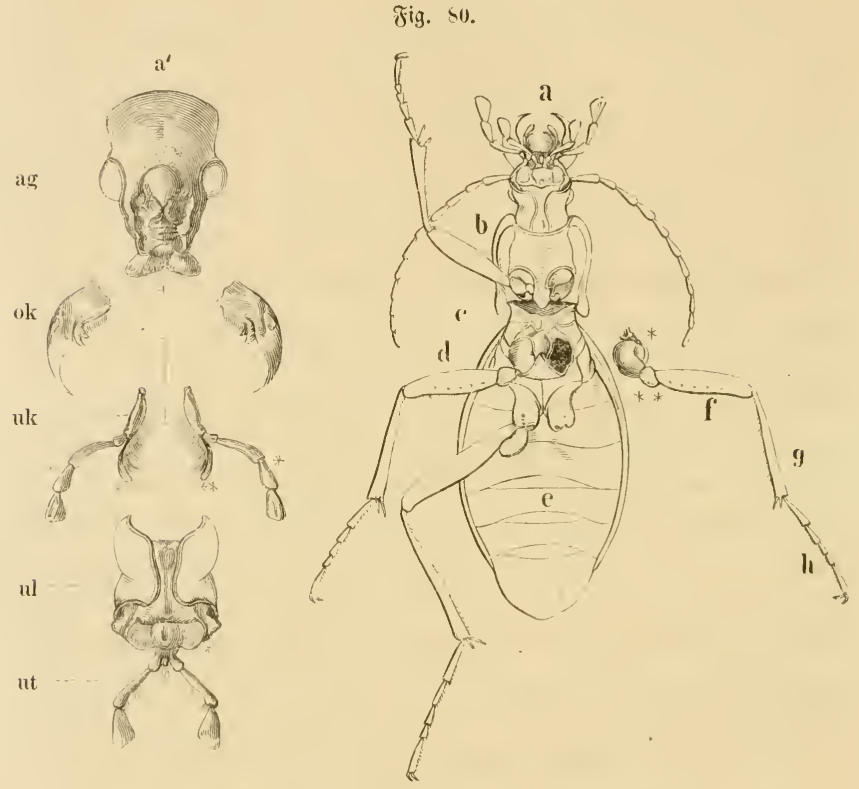

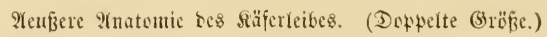

*) 21u beftell ift c8, bав Maut zu zerlegen, woju feine anatontifde Fingerfertig=

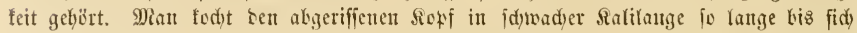

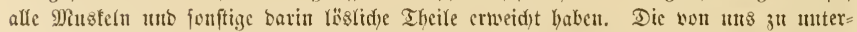
jud)enden Mitubtbeile werben baburd) nid)t in minbeften angegriffen, benn fie befteben

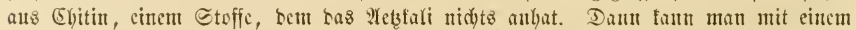

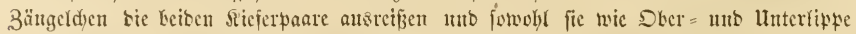

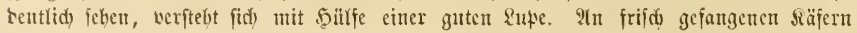
verarf es biejer firneebur gar nidit. 
3meibuditigen Dberlippe $\left(a^{\prime}+\right)$ besectt. Darunter fino sie julahmen

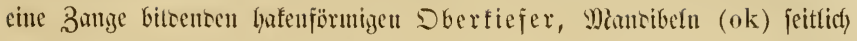

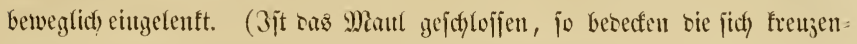
Den Dberfiefer bie tiefer am Miante liegenoen Theile.) Iluter ben Doerfiefern liegen sie lluterficfer, Maxillen (nk), ebenfalls eine fpitze Zunge

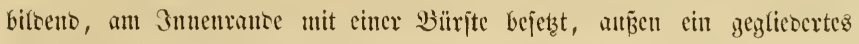
taj̣terartiges (Sebilo**) trageno (**). 21n sen Unterfiefern jtegen 2 lluter=

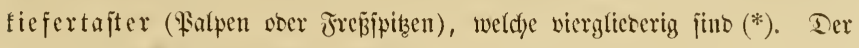

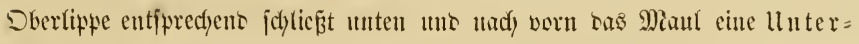
lippe (ul), weldye 2 oreigliecerige llnterlippentajter trägt (ut).

Ferner futren wir au fopfe tie 2 ugen (ag) uno tie (bei allen sauf-

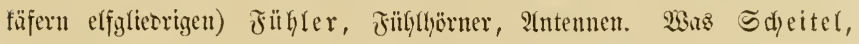
Stirn, sinn, 23anzen fino, fann man leidft ermeffen.

Es folgt ser Mittelfeib, ser bei allen Injeften in 3 lyinter cinander

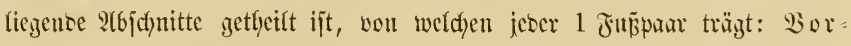
serbrujt, Frothorax (b); Mittelbrujt, Mejotyorax (bie auber rem mitteln Fuß̌paar oben aud, bie Flügel trägt) (c), J̧interbrujt, Mieta thoraç (d). Eei ten Räfern ijt bie Borterbrujt jtets bejonocrs sentlich) vou ser Mittelfrujt surd) eine Einjolyürung abgejetzt, bei vielen antern

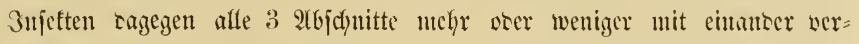

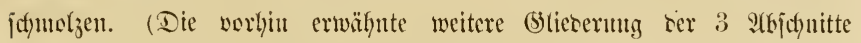
ïberzelyen wir hier.) Der Ilnterjeite ser Siorterbrujt entipricht auf ser

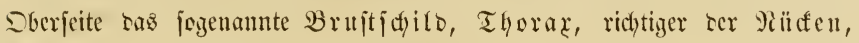
9iotum.

Der J̧inteṛteib giebt jid) bei aflen Snjeften surd) Duerringe funs,

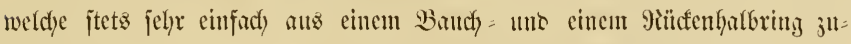
fammengefügt fimo (e). Er trägt niemals bie beine und Flügel.

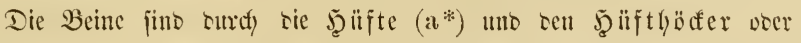
Sdyenferring, Trod)anter (**), angehejtet uno jerfallen in ben

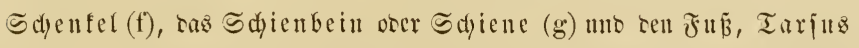
(h), ter bei ten \&auffäfern 5 (b)tiecer (Tarjen- coer Fufigliecer) hat, bereu Enoglieo 2 slauen trägt.

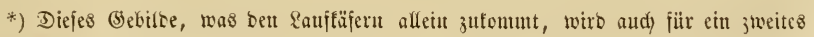
Unterfiefertajter $=$ Faar gehalten. 
Die zu Flügeloedfen*) umtyelwantelten Dber= ober $\mathfrak{B}$ orberflüger jammt ben zujammengefartet sarunter liegenben (ten \&auffäfern aber fehlen=

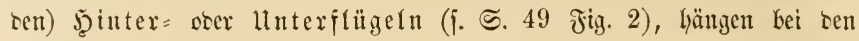

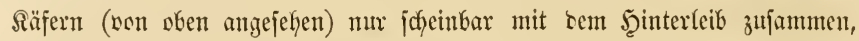

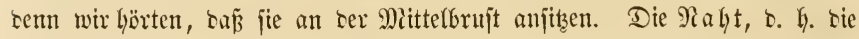
Sängstinie, in weldhe bie beiben Flïgetrecten aneinanberjtoß̄en, füngt oben bei ben Sdyilbdjen an, einem fleinen oft breiectigen \$rättden (i. S. 347 Fig. 71 a).

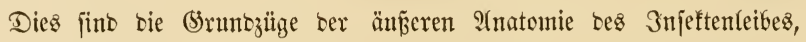
mit benen man bei ber Beftimmung in ben meiften Fällen ausfommen wirt. Sie beziehen fich zunädjit auf bie vollfommenen Snjeften, inben in

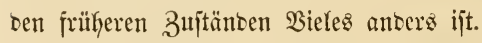

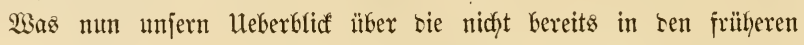

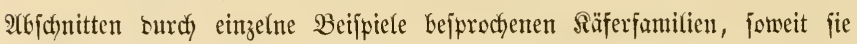
im Salbe vertreten fint, betrifft, fo gehen wir audf hier som Nicsern zum ら̋̈̈heren vor.

Da has "Siäferjanmetn" fo gut wie bas "Sdjmetterlingsjammetn " jeit alter Zeit feine eifrizen Befenner gefhabt hat, viel mehr als bas Sam= meln irgent einer anbern Snjeftenorsmung, fo fint aud sieje beiben Dro nungen am eifrigiten bearbeitet unb mit einer riefigen siteratur beradjt worben. Dafer ift audy in biefen beiben Dronungen bie Syjtematif am auşgebilsetften uno, was fạt unvermeislidy bamit zujammenlängt, bie

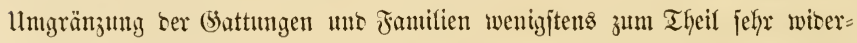

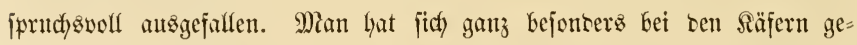

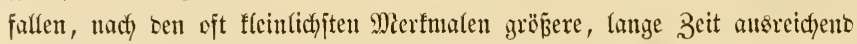
gewejenen (Sattungen in eine Menge fleime Saatnmgen ju zerifalten, wie

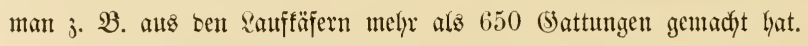

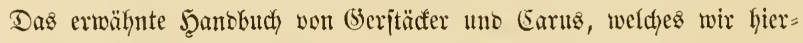
bei verfolgen, oronet bie Räfer in 47 Familien, von weldyen sie größ̈te

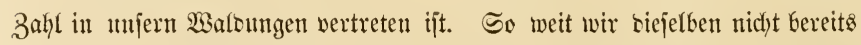
fennen geternt haben unt jie uns bejonters interefjante Seiten sarbieten, wollen wir iun Maxdfolgenten giepräfentanten aus ignen vorfülyen.

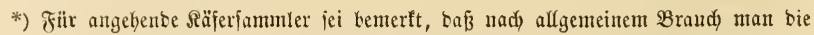

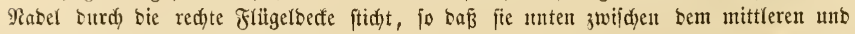
hinterften Beimpaar heraustommt. 


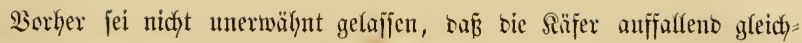

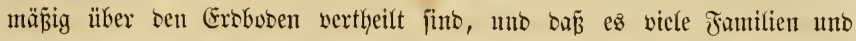

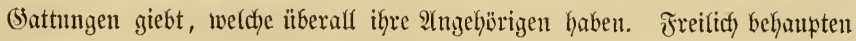

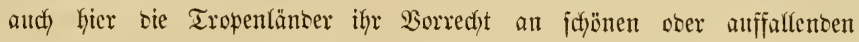
Formen unt Farken, io wie an ungewäbrntictyen Maaß̌en, in weldyen leţteren überhaupt bei sen Säfern bie grelliten Sontrajte vorfonumen. Ptilium minutissimum Gyll. ift nux 1/4 \&inte lang, ber ફ̧erfuległtäfer, Dynastes Hercules L. mişt mefyr als 6 3odl.

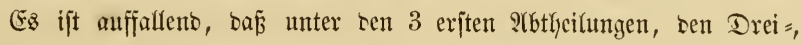

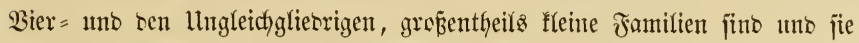
afle zufammen fowofgl in ber Zahl ter Fannilien, nämlidy nur 17 , alz in

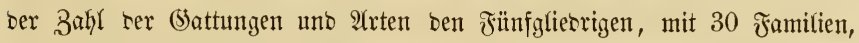
weit nadjitehen. Sogar innerhalb jener 3 abtheilungen ijt ein Steizen wafrnefgmbar: Drcigliebrige mit 2, Siicrgliebrige mit 6 uno Ungleidf= gliebrige mit 9 ₹ramilien.

Son ben 2 Familien ber Dreigliebrigen, weldye eigentlidy Unteut= lidyviergliebrige, Srmptotetrameren, Geisen follten, ijt bie eine, bie ber Marienfäfer, Eoccinelfinen, ini $\mathfrak{B a f h e}_{\text {nidft }}$ nur fehr jtarf bertreten,

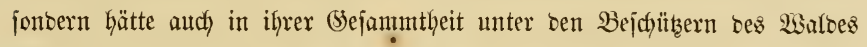
eine rüfmlicfle Erwähnung werbient, Da jie, bejonbers ihre sarven, bie benen ber $\mathfrak{B}$ lattfäfer (i. S. 182 Jig. $39 \mathrm{co}$ g) felyr ähnlidy fint, fid fajt

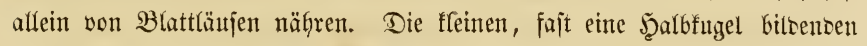

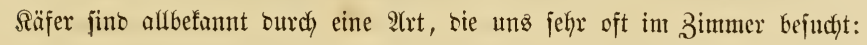
Coccinella bipunctata L., mit idjwarzem, an ben Sorterecten einen geffb=

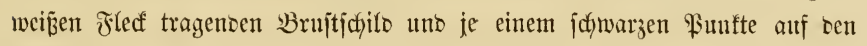
jiegelladtrothen Flügetreden. Die Miamen ந̧errgottidäfdyen, (5ottes: fühd)en, lady-bird, vache à Dieu benten auf ifre Fiopularität. Man fennt bercitz gegen 1000 über bie ganze Erbe vertheilte 2 rtten.

Unter ben Biergliebrigen (aud) eigentlid) Sirnptopentanteren $z^{4}$ nemten) begegnen wir allerbings grośentheils artenreichen Familien, aus weldyen wir bereits viele Sertreter unter ben $23 a$ altoerberbern femnen lernten,

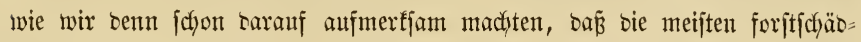

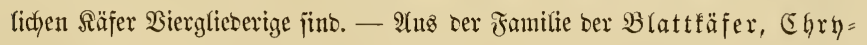
fomelinen, Lernten wir a. a. D. 4 arten temen, von benen bie 2 erjten bic

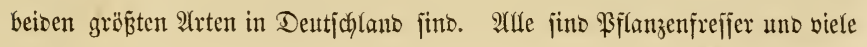


tragen ifgen 2(rtmamen mad) scm Siamen ifrer Futterpflanje. Es mögen $8000-10000$ 2trten betamt jeil, won Iencn eine (Struppe Surd) itjen

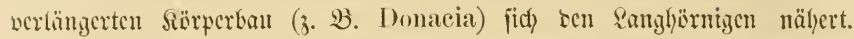
Don Ien ctwa 150 atrten ser (5attumg Clirysomela fino sie meipten

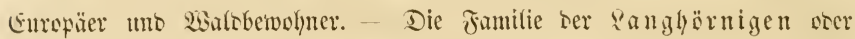
Boffäfer, Pongicornien, Ecrambicinen, ift auper ten bercits be= jdyricbenen (i. S. $175-186$ Jig. 38) nod surdy zafflrcidye arten im

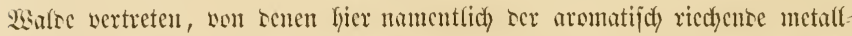

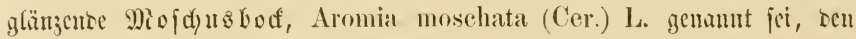

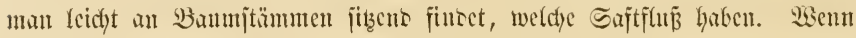

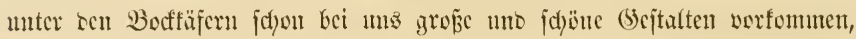
fo ift bies in nod) vief häherem (5ratse in ter Tropentzone ter Fill. -

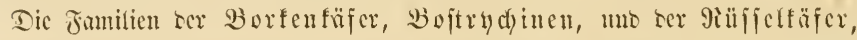
Eurculioninen berïrfen neben sen im 8 . S(bjd)nitt bejchricbencn me abge=

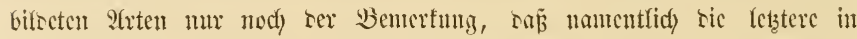

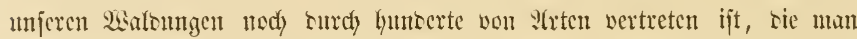
fajt immer leicht erfemen wirt.

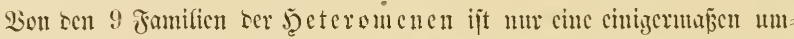
fünglidy. Eine anbere haben wir burd). Den Bflajterfäfer (f. S. 194

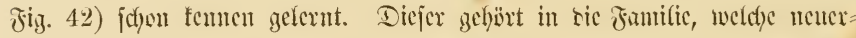

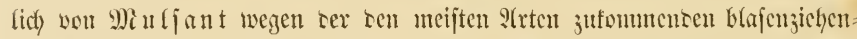
Ien Eigenjafat sen Simen Brajenjichente, Beficanticn, erfalten hat.

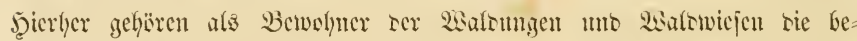
funnten, meijt jtaff(blanch Miain ïr mer, Arten ber (battung Meloe, weldye

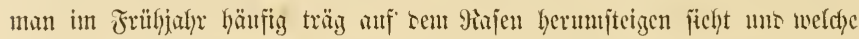

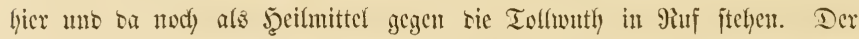
getbe Saft, weldyer ifnen bei ser leijejten Berit/yrumy ans sen Beingelenfen

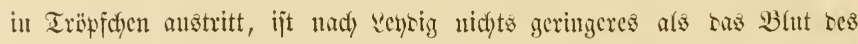
Thicres. Eine ansere Berüfyntheit haben bie Mianürmer in nenerer 3cit Inta) sen Franzojen Fabre crlangt, weldyer bei ifyen cine fo alffallente

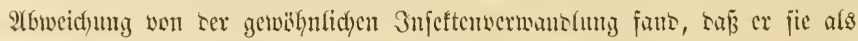

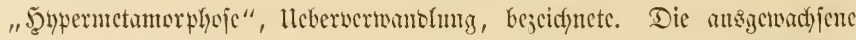

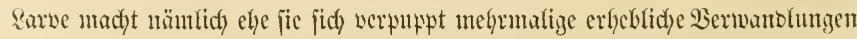

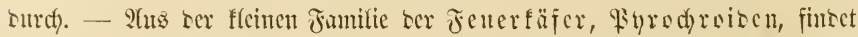

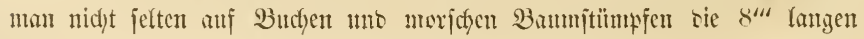


jobarzen Fenerfäfer, Pyrochroa coccinea F., mit lebhaft bhut=

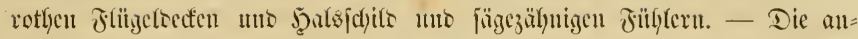

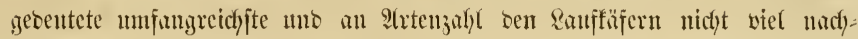
gebente Familic ser Dilfterfäfer, Michajomen, zeidfnet jich, wie jedon

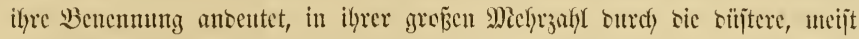

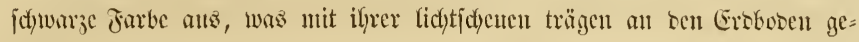

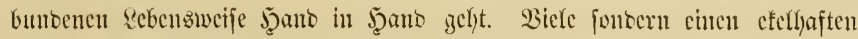

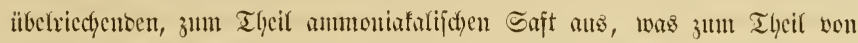

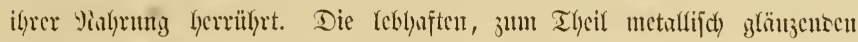

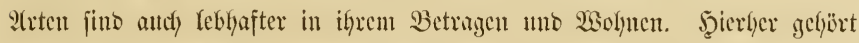

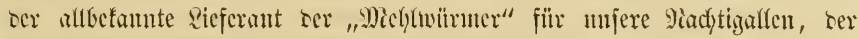
Mieflfäfer, Tenebrio molitor L., seffen Sarven jene Mechtwïmer fint.

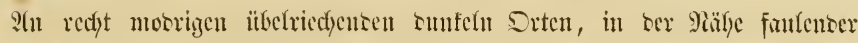

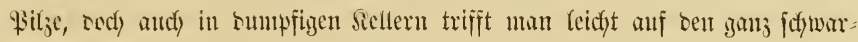
jen glanjlojen Iobtenfäfer, Blaps mortisaga L., ber wie vicle feincr

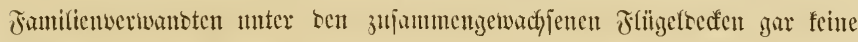
Jlïget hat. Ex, fommt Dem Miaifïfer an Gröze nahe. Ob er ten Too vorlyer fagen fann (mortisaga) mur er am bejten wifjen. - Die Fantilie

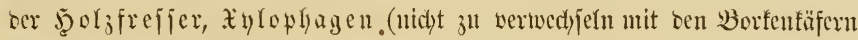

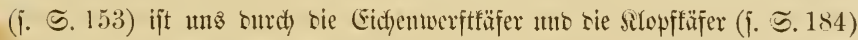
befannt. Serwante unjcheinbure, meift fleine ?trten treiben ifyr sbejen in

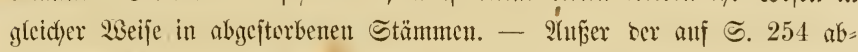

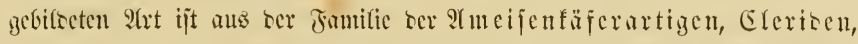

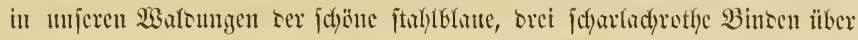

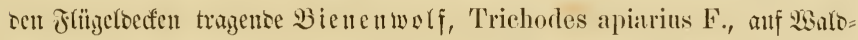
blunen feine Seltenlyeit. Ex jtelft sen wilben Bienen nad). .. Souvoly

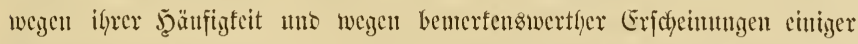

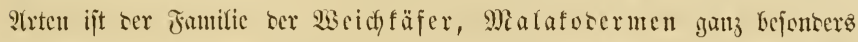

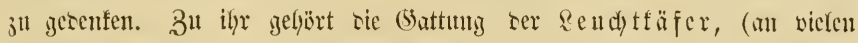

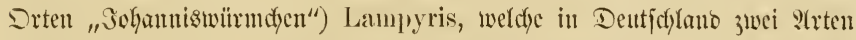
hat, L. noctiluea L. tuto splendidula L., seren flïgclloje fajt wic surven

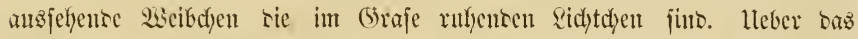

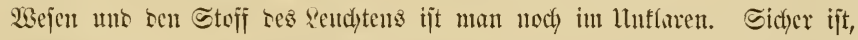

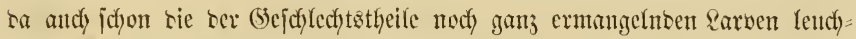

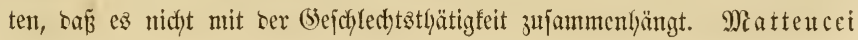




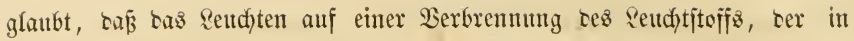

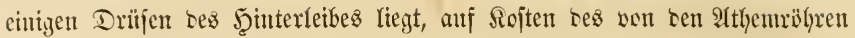

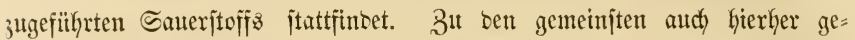

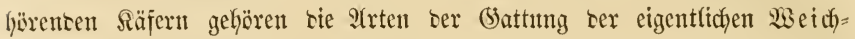

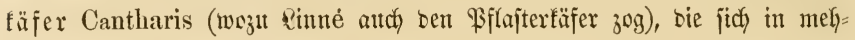
reven $\mathfrak{A}$ rten auf alfen Pflanzen träge nmberfriectjent finten; jie jino gegen

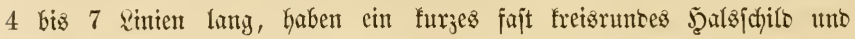
meijt braune Farben. Der j̧böne fupfergrïne Warzenfäfer, Malachius aeneus F., treibt bei ber Berüfrung atts ben Seiten bes Reibez fon= berbare rotbe Warzen herwor, bie er aber balo wieber einzieht. - 2 tube= fannt find bie Sdyellfäfer, Eleteriben, unter bem Namen ber

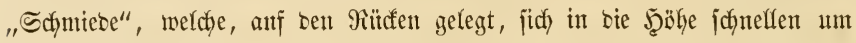

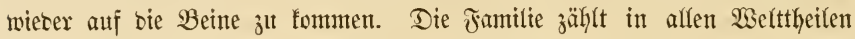
gegen breitaujend $\mathfrak{2}$ rten. Eine ber häuftigiten $\mathfrak{A}$ rten ijt ber mäufefarbige (đ) nelffäfer Lacon murinus (Elater) L. $Z^{\mathfrak{u}}$ biejer in ifyen (Beftaften jehy übereinjtimmenten Familien gehören bie aus Reijebejdyreibungen be=

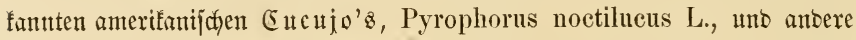

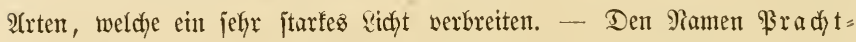
fäfer, Bupejtribeu, redjtfertigen namentlidy in heiß̄en Ränbern, wo eidft uno $\mathfrak{B a ̈ r m e ~ i f y r e ~ F a r b e n p r a d y t ~ b e g u ̈ n j t i g e n , ~ b i e ~ m e i f t e n ~} \mathfrak{A}$ rten ber weit über eintaujeno zählenben Fanilie, weldye in Deutifdlano zwar butrdy ziemlich viele

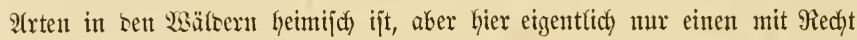
fo zu nennenten, Fradjtfäfer, bie jmaragbgrüne am Ranbe roth glänzente 6 vinien lange Poecilonota rutilans Fabr. uno alfenfallz bie gröpere erz= farbene Chalcophora mariana (Bupr.) L. hat, weldye hünfig in Siefern= waldungen vorfonmt. - Wir fommen zit ter gitejenfantlie ber Blatt= görnigen, sameflicornen, benn jie ijt riejig an lufang mo enthält bie Mitejen oer Säferwert, mit benen jith, wie bereits gejagt, nur einize Bodfäfer mejןen fönten. Der fajt bei aflen jechstaujeno bereits befaunten Arten bentfich ant\&gejprodjene Famifiendjarafter liegt in ter blätrigen Fühler= folbe, wie wir fie in hoher bolffonmenheit bei ben bierber gebörenten Mraifäfern (j. ธ. 191) gejehen haben.। Ittch unjer Räferrieje, ber all= befannte J̨irjafäfex, Lncanus cervus L., gebört in bieje Familie. Die

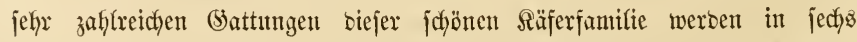
Srutppen georonet, weldhe fänutlich) in unjeren 2 aldungen vertreten jint. 


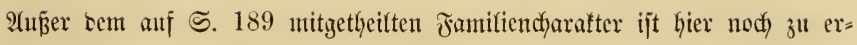

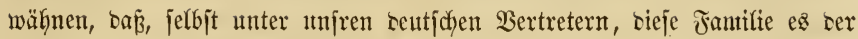
Dromung ber gleidfflügeligen 2 Sanjen (f. S. 364) gleichtfyut an bizarren

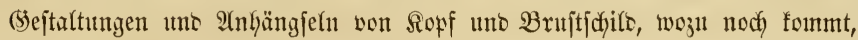

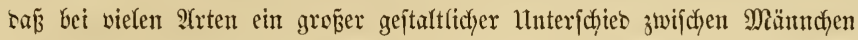

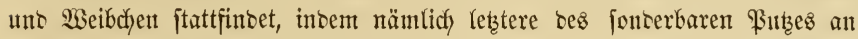

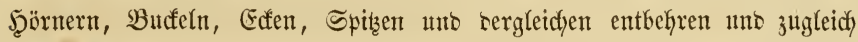
meijt "viel Eleiner fint, was fonjt bei ben Injeften gewöhnlid) ungefehrt ift.

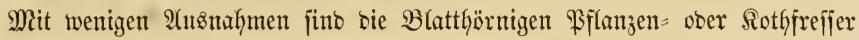
(Maifüfer uno Dungfäfer $\subseteq$. 337). Wenn fđdon in ber gemäpaigten Zonte bie (5)(icter siejer Familie ziemlid) reidy vertreten finb, fo ift fie zwijdyen ben SBentefreijen gerabehin. sie herridyenbe Räferfamilie zu nemnen. Die erjte

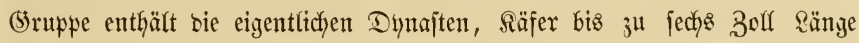

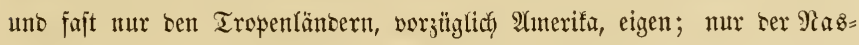
Gornfäfer, Oryetes nasicornis L., ijt bentidy und entwidelt fidy nidyt felten in oem Miulm fernfauler Gichenjtämme, Gäufiger nodh in alter (5)erberloke.

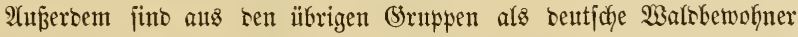
bejonbers folgente 2rten zu nennen. Die Metallfäfer, Cetonia, groß̉e wenig gewölbte Säfer, meift mit gologrünen ober bronzenen metallifid) glänzenten Farben, bie auf Warlboolbenblüthen träg herumjteigeno leidgt inz $\mathscr{U}$ uge fallen (C. fastuosa F. ber fajönjte uno größjte bejonber: an Eichen; ter (5olofäfer ober armeijenfönig, C. aurata L. ber ge= meinjte, †. S. 301 unten); ber Exemit, Osmoderma eremita Scop.

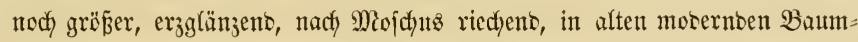

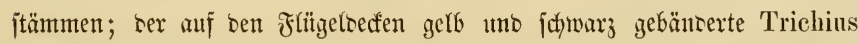
fasciatus uto ber gologrïne Gnorimus nobilis F., alfe brei jonjt in ber Battung Trichius vereinigt. Die frïher befdyriebenen \&aubfäfer, benen wir ben Bolfżnamen Maifäfer gaben, bereinigen um fich in ifrer (Sruppe

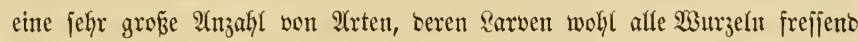
im Booen leben. Mefyrere fleinere Arten fommen bet uns im 2 aldo vor. Atus ber Sruppe ser Sothfreffer, Eoprophagen, haben wir fdon eitnige Arten im 13. 2(bfdynitt genannt, neben benen am gleidjen Drte noch ziemlich viefe $\mathfrak{A}$ rten atı anbren Sattungen leben, won welchen wir nur ben auf bem Brujtichilbe brei gerabe bortwärţ geridjtete ફ̧örner tragenden 
fa)warzen, 1 3. โ. Geotrupes Typhoeus L. *) nennen. S(ın groß̃artigiten,

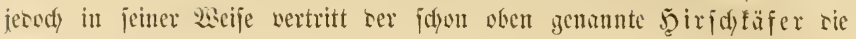

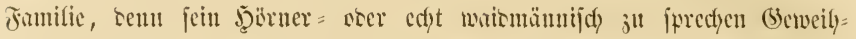

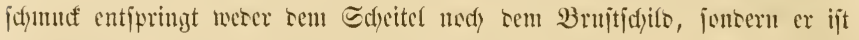

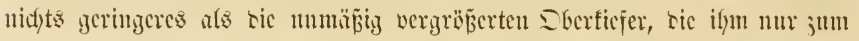

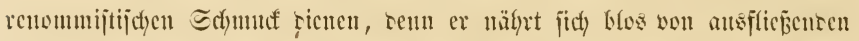
Bammjäfen, sic er mit ocm gegentheiliy zungenartig verfïmmerten n̈brigen

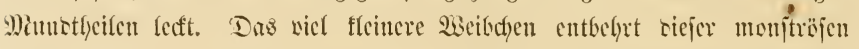

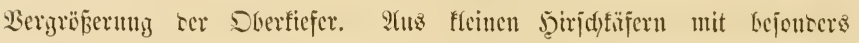

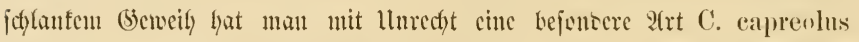

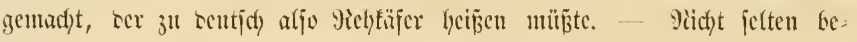
gegnen wir in ber Boochocffe cinem Räfer ans ciner flemen nad) ifm be:

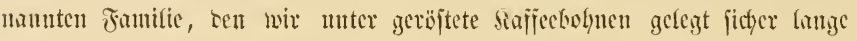

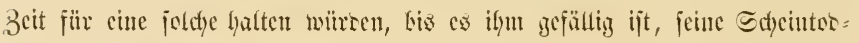

Fig. 51.

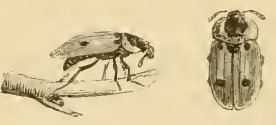

Der vierfutftige $\mathfrak{A}$ a füfer, Silpha quadripunctata L.

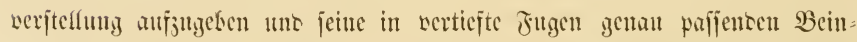

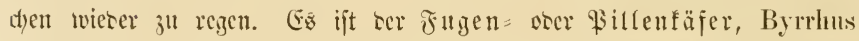
pilula L. - 9(ns ciner Sicilye num folgenter artenarmer Fumifien heben

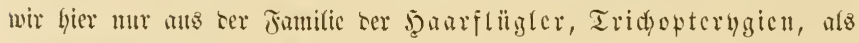

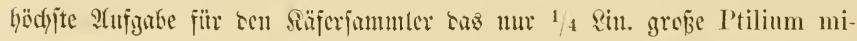
nutissimum hervor. - Dagezen übergefyen wir bie ansvertilgente familie

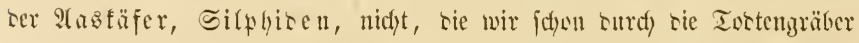

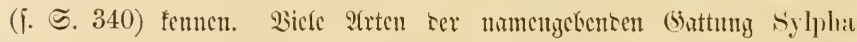

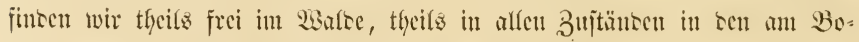

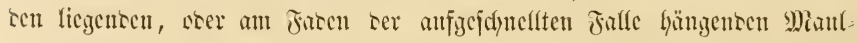
wïnfen nuo in antern fleinen Ifierteidfen. Der Fig. 81 abgebitrete vier $=$

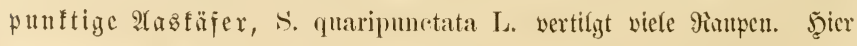

*) Spridy Tiphó-eus, nidyt Typhoe- us. 


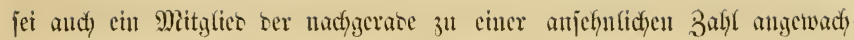

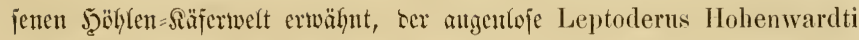
Sturm, ser in ber cwigen Macht ser beritfunten Alselsberger (5rotte lebt,

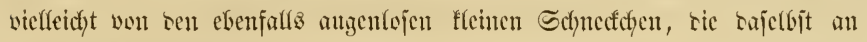

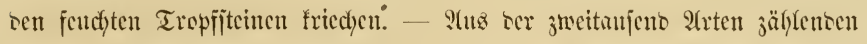
Fantlie ber Inr子flügler, Staplylinioen lernten wir als volfgültigen

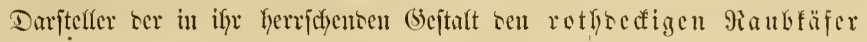

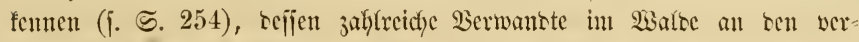
jeficheniten Srten worfommen. - Snbem wir hier brei einanter geftaltfich fefre nalye ftehente Familien werbinten, bie Taumelfäfer, (5y)rinion,

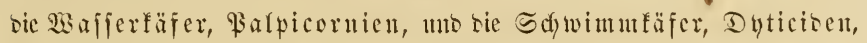

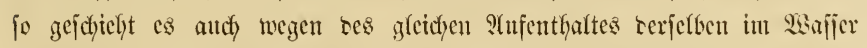

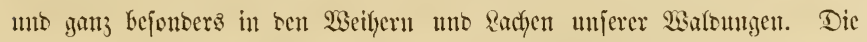
3weitgenante ift uns burch sen nejtbanenon Hydrophilus picens L. jayon

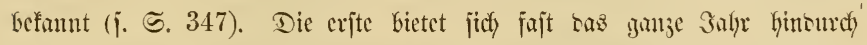

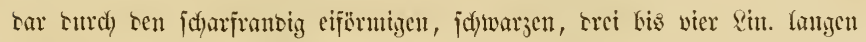
gemeinen Iamelfäfer, Gyrinus natator Fabr., oer in tammefmoen

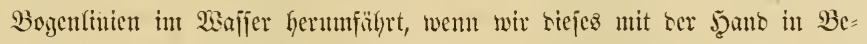

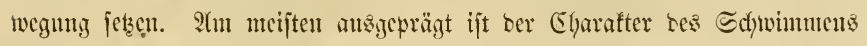

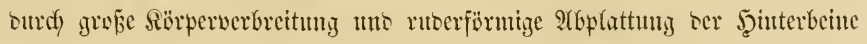
bei sen etwa vier in Dentidylano verbreiteten 2rten ser Schwimmfafer, Dyticus, won benen D. marginalis, grünffywarz mit braungetber ltm=

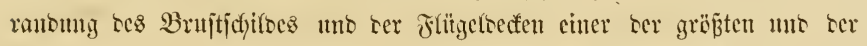

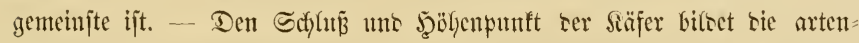
reichjte Familie ber Eauffäfer, Carabioen, beren eleganten Ban wir be=

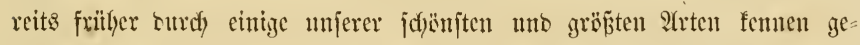
lernt haben (i. S. 251 uno 248). Mit wenigen 9usunafyen ift fecine

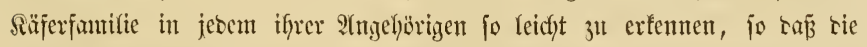
"Sarabibenform" fïr manche Säfer ancerer Famitien als Beranjountichungz=

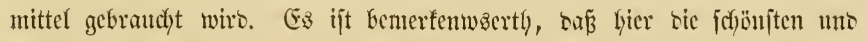
größ̈ten Formen nidyt ben Tropen fonbern unjerem gemän̈igten Slima ange=

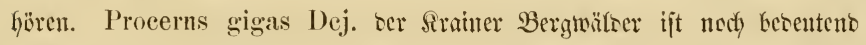

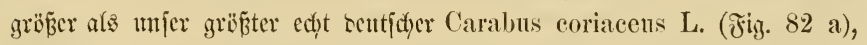
aber ifm jonljt jef̧r äfnlich. Die \&auffäfer juno sie cinjigen Säfer, bei

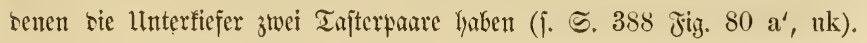


Dẩ bie Sfulptur ber Flïgeldeden bei ocn Qauffäfern eine Şauptrolle bei

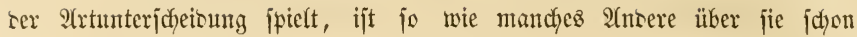

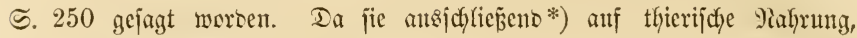
uno jwar meijt 3 njeften, angewiejen jino, fo hat man sie \&auffäfer in ser Miefrefeit am Boben ju juchen, wo nan jelten in Walbe einen Stein

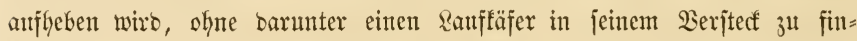

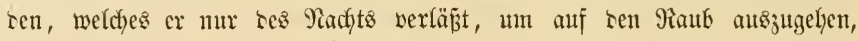
währeno gerabe unjere fajënjten uno größ̈ten 2 (rten befanntlich Tagthjere fins. Die jwei (5ruppen, in weldye man bie Familie fideibet, jino uns

Fig. 52.

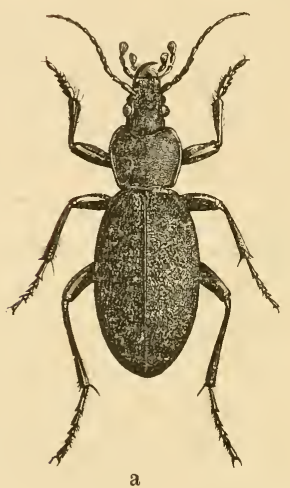

a Carabus coriaceus L. b Carabus intricatus L.

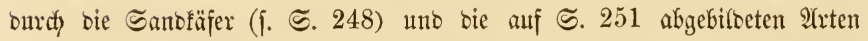

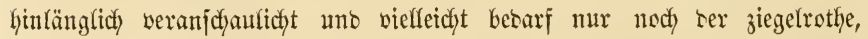
sunfelblaue Slügeldecfen tragente $3 \frac{1}{2} 2$ Rin. lange Bombarbierfäfer, Brachinus crepitans L., einer J̨ervorfyebung, ber fich feinte Berfolger ourch eine überriechenre Dunjtfugel, bie cr aus sen 2 ffter entlaret, nom Reibe zu halten fuddt; eine Munition, weldye freilidy balo veridyoffen ijt.

*) Die cinzige befannte 2 (n) Whurzeln nagen joll, ift eben beshalb als auf ungenauer Beobadjung berubent, vielleidht 3u ftreiden. 
So bleibt uts mur nody bie Drmmng ber Falter ober Schmetter linge, Repibopteren, ïbrig, burch beren Pamen all unjer Wohlgefalfen

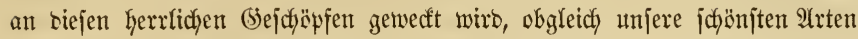
body immer mu Serjuche bleiben, ben unerreichten Borbilbern tropifdyer Sdymetterlinge nahe jt foumen. Seţt am Enbe unjeres Schluíganges

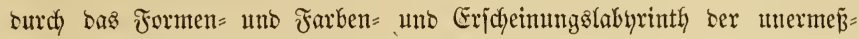
lichen Injeftenwelt verweijen wir mit volfem Drange ber Bejtätigumg auf

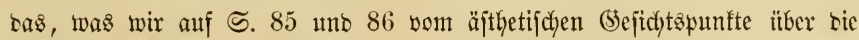
Scymetterlinge gejagt haben. Sa, "berjenige milp̈te bebauternswerth ver=

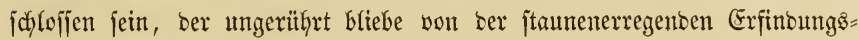
gabe ber Sïnjtlerin Ratur, welche einem joblidyten Motio treu bleibeno mit geringen Mitteln eine Füfle von Stubien zu bidyten weif. Da erfennen

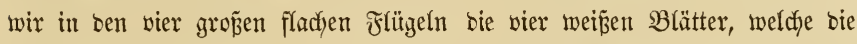

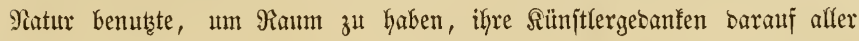

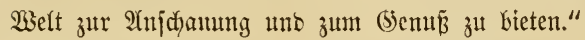

Dabei jutto sieje (Saufler ber süfte, bie, jo weit wir jie ungejucht watyr= nahmen, Wärme uno Sonnentidyt nidjt entbebren zu fönnen fidseinen, fei=

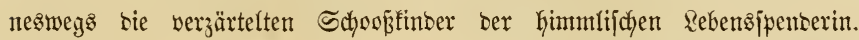
Pridft alfein ber Froftipanner (i. S. 129) jonbern hunbert anbere Schmet=

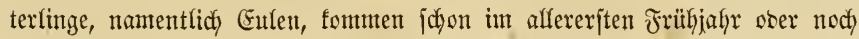
im falten Spätherbjt aus ifyer Buppenruthe hervor. Pur ber funbige Sajmetterlingşammler munbert jïh) nicht barïber, unter sem vom Scerbjt= itum zulammengefegten saube zahlreiche eben ausgefrodjene Eulen zu finten.

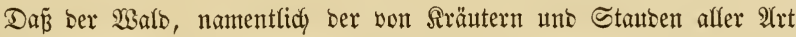
Durchwirfte Piebermalo in Mittelgebirge jehr reidh an Faltern ift, hat wohl an einem marmen Sommertage jojon Seber einmal waljrgenommen; uno ser Sdymetterlinge mit ben Mamen fagi, populi, quercus, tiliae, salicis, alni, rubi, bosulae, pruni, pini, pinastri, ligustri u. f. w. - nach ifgren Wohn = unb Mahrungapplanzen gewählt - ijt gar fein Enbe. - Unb haben unjere Rejer audy jujon an einen 2 orzug gebadjt, ben bie Sdymetterlinge vor alfen anbern Injeften voraus haben? Wir meinen bie oft fo reizente

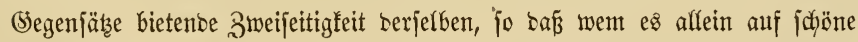
Mandyfaltigfeit anfommt, einen groß̌en, ben jumulfwollyten Theil feiner

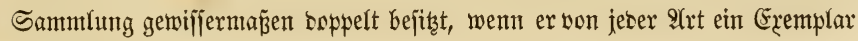


nit ser Sberjeite, ein zweites mit ser Lnterjeite nach oben anfipieß̧t. Uno

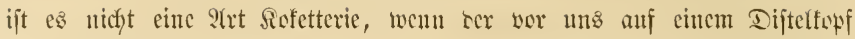

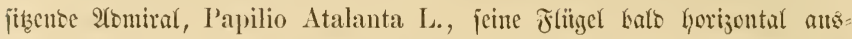
breitet, balo über sem giüden jenfredyt an cinanser flappt, Lamit mis ju won jeiner Schünhcit nid)ts entgeht? Siur sic Sergänglid)feit fann ifyer Sdyänlycit cintigen $2(6)$ rud thum.

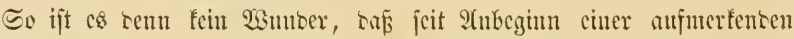
Beadytung ber uns untgebenten 2 sejen sic Edymetterlinge Sieblinge affer

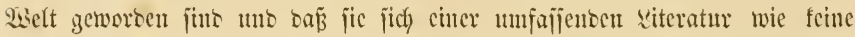

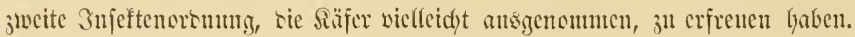

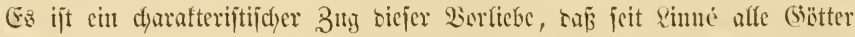

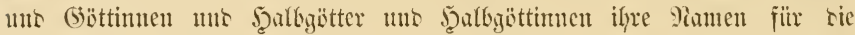

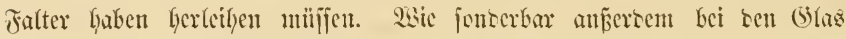
flïgyern unb bet oen Sicinffymettertingen won ben Spumern an abtwärts

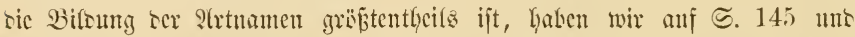

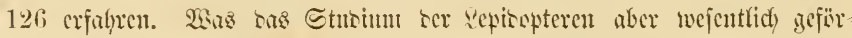
sert hat, ijt sic Eeicftigfeit, nit ser man sie meijten 2(rten ans ser Mampe, ja ans scu Eie crjichen tann, was bei 3njeften anserer Dromungen mu ansmahmsmeije gejdyicht.

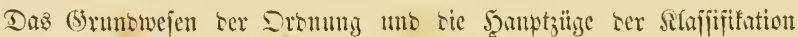

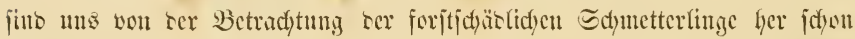

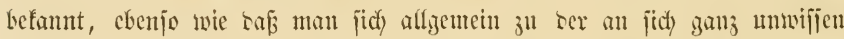

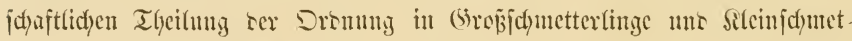
tertinge genöthight gejefen hart.

Die Sleinf(d) metterlinge, nu and) hicr mit rem llnbsffommenen 3n beginnen, zerfalfen in sier Familien, sie zun Theil in methr als eincr

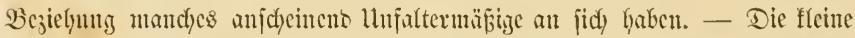
Familie oer fleinen fesermotten, Siterophoriben, hat tief gepaltenc

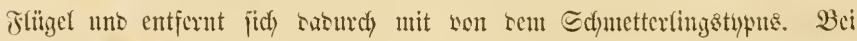
I'terophorus polydactylus L. fins sie Dorberflitizel bis zientich zur Mitte geppalten, bie J̧interflügel weit tiefer gejpalten breizipfelig, am Sianse niber ats fein แnb langgenimpert (Jig. 83). T(m leichtejten bemerft man sen (đ) neeweišen Pt. pentadactylns L. Bei rer fleineren Alncita hexadactyla

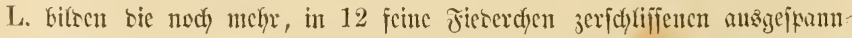

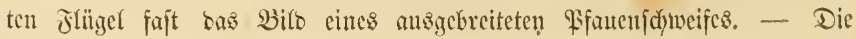


3wergenfamilie ber Miotten ober Sdyaben, Tineinen, wen weldyen man in Europa joyon über cintaujenszweifyutbert zum Iheil jajt mifroffopijach fleine $\mathfrak{A}$ rten fennt, (Lithocollatis Rajella L. hat faum über 2 \&inien Flügel=

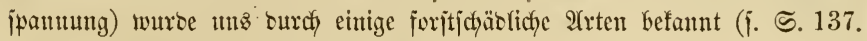
138). Bei einigen 2 rten hat man \$arthenogencjis nactgemicjen, ๖. h. Las Regen cutwidflungää̈biger. Eier ohne vorgängige Begattung. Şierker ge=

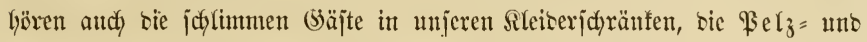
Rleibermotten, Tinea pellionella L. uno T. sarcitella L. Unter bicjen nieblichen ofit präcfitig gefärbten Thierchen finto mebrere "Mintrer", 子. B.

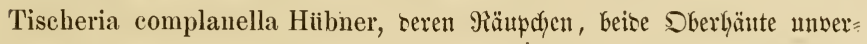

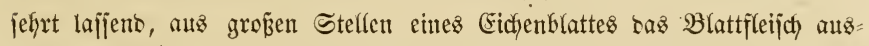

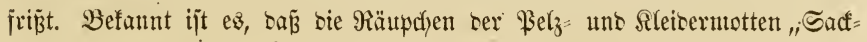

Fig. 83.
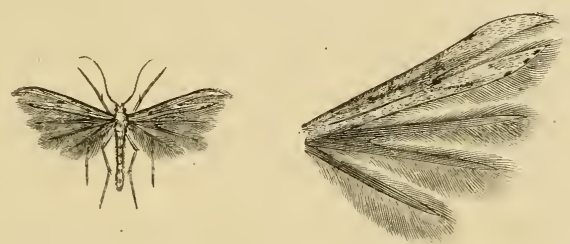

Die vierfrügerige Febermotte, Pterophorus polydactylus L., Daneben bie Früger ber red)ten Seite vergrö̧̈ert.

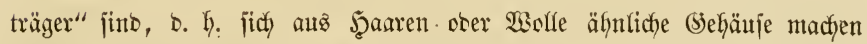
uno jie auth jo mit jich juleppen wie bie sarven ber Rödjerjungfern. -

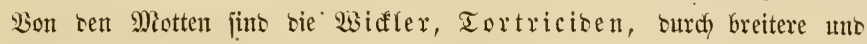

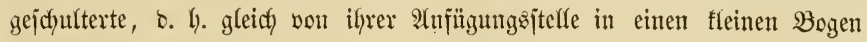
vorgezogene borberflïgel, bie eben io wenig wie bie finteren jefyr breit

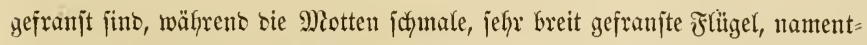
lich bie Ginteren, haben, bie jie im Sizzen tm ben \&eib fol)lagen ober jächer förmig zujammenfalten. Die Zahly ber wiffler ijt nicht minber anjeḅntich uno jie jowohl wie bie Miotten jafeucht man oft in Mienge auf, wenn man ourch Fichtenfdyonungen ober anderes sidjtes. (Sebiijch itreift. - Die Jamilie ber 3 ünsler ober Richtmotten, Pyrafiben, ijt bie vierte unb hödjite Familie ber Miftolepibopteren, ebenfalls fleine Falter, weldye jich 


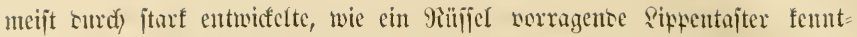

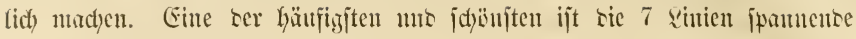
Botys purpuralis, mit purpurothem Scfumer ser mter sicfent getb ge

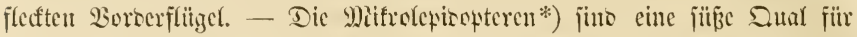

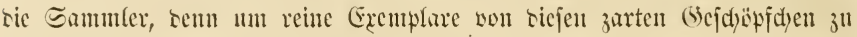

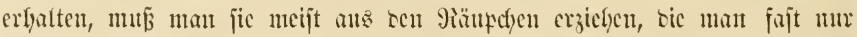
furten fam, wenn man ifje Futterpflanje fennt uns an biefer bie sft win=

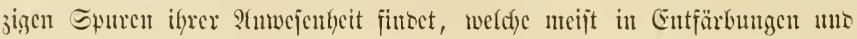

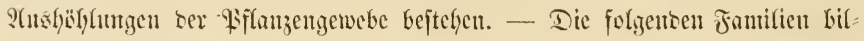

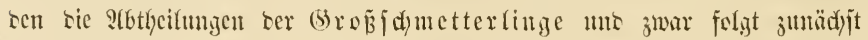
sic ser Spanmer, (Beometrisen, sic uns in ifren wefentficlen Senu=

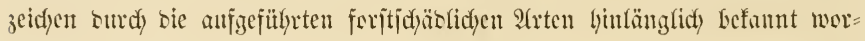

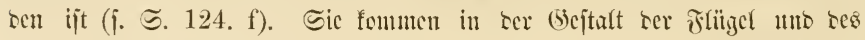

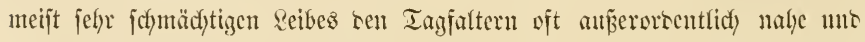

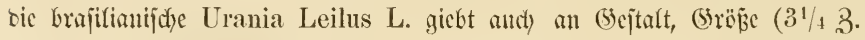

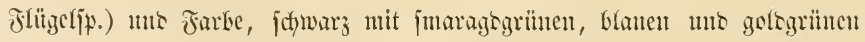

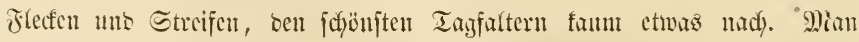

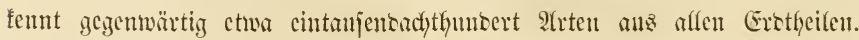

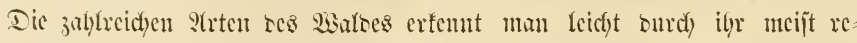

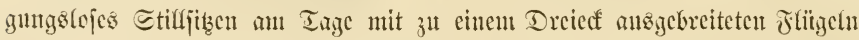
unt meijt siijteren Farben, aber oft ̈̈berans zicrlidyen Beidyungen. Itnjere

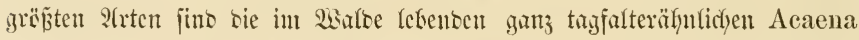
sambucaria L. uno dic ifyen Mamen mit Medyt trajente grïne Geometra

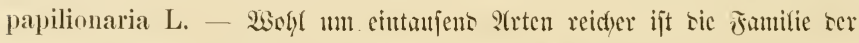

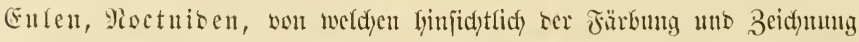
gun bejonters bas oben über bie äfthetijalye Seite ser falter wicberfolt

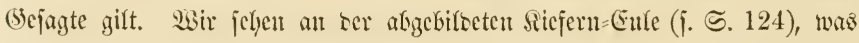

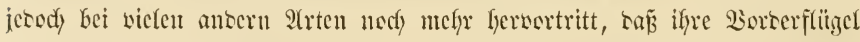

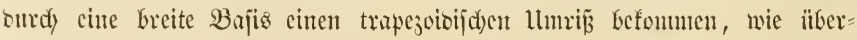

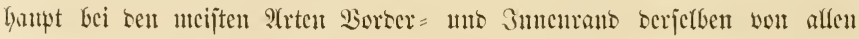

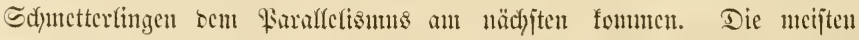

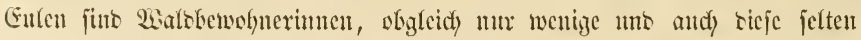

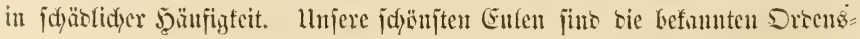

\footnotetext{
*) "Mifre's" mo "Miafro's" beiß̧t c\& futrzmeg in ber Eammlerfpradie.
} 
bänber, Bano Eufen, Catocala, von benen bas blaue Drbenzbano, Catocala fraxini L. urjere größ̄te Eule ijt. Der Grajilianijche Erebus Agrippina Cram. ijt mit 10 3. Ftiigelipanmung jogar ïberfanpt ser gräp̧te Sdymet terfing, sa ber alz jolcher geltente ?ttaz, Attacus Atlas L. nur 7-9 3. jpannt. - Fïr unjer 3nterej̄e bie widytigite Fmuilie ijt bie ber Spinnex; Bombuciocu, benn fie hat miere Maulbeer= Scisenjpinner, Bombyx mori L. geliefert uno hat bann in neuerer Beit atz 2ljien aus ber (5at= tung Saturuia nod) mefyere Epinngehïlfen hinzugefügt, von oenen einige

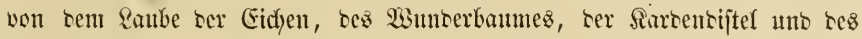
(5ötterbaums (Ailanthus) rebente bereits in Franfreidy uno verjudysmeije and in Dentichlano heimijch gemadyt worben fint. 3n bieje Berwanbt=

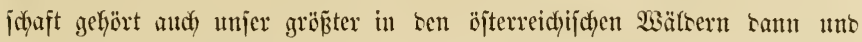

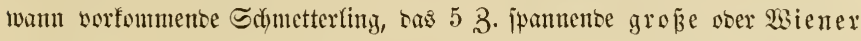
Nachtpfauenauge Saturnia pyri Borkh. Die genannten Sraten gefg̈ren

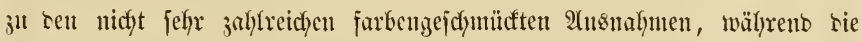
Spinner meijt trïbe Jarben zeigen. Die Spinner dyarafterifiren jidy surch

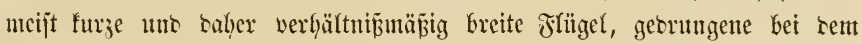

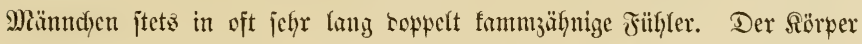
ber 2 seibchen ijt pltump uno sidf uno bafer siejerben wenig zum Fliegen ge=

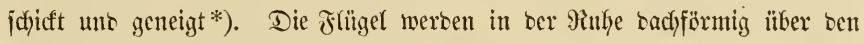

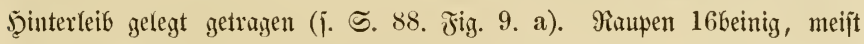

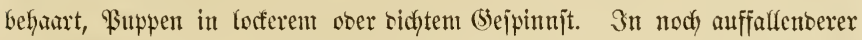

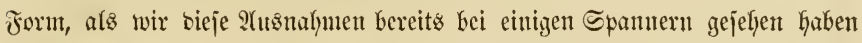

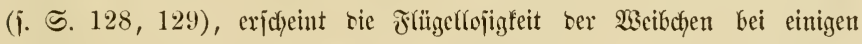

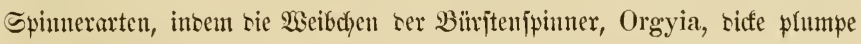

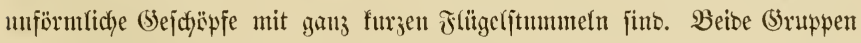

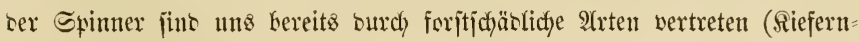

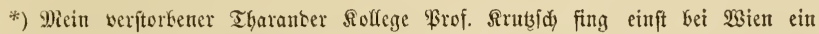

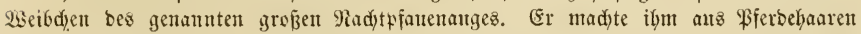
cine Feffer, mit ber er es im Mittelpunte einer Badfidjüfel befeftigte, jebod) fo, Dẩ es in Bereidy berielben frei flattern foute. Er fteffte bie Befangene fo liber Radit in einen Barten uno am anbern Morgen fant er ridjtig ein berzıgeflogentes Männdyen unt beise in ber Beyattung. Mit ten gewontenten Eiern find nadher Sabre lang in Tradjentau in Sadjicn von meinez siollegen Bruber Edjmetterlinge gezogen worben $\mathfrak{b}_{i s}$ zuletzt - aus Mildfidyt auf bie ftarf beraubten Bimbäume Dem Dinge ein Enbe gemadyt werben muß̄te. 


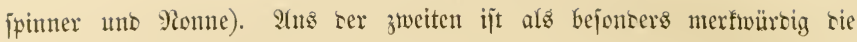
(5attung Psyche zu extwälynen, beren 23 cibchen ganj ungeflügelt uno, ofne Beine umo Fülyler, matenförmig fint. Bon Ps. helix Siebold. jüt blos

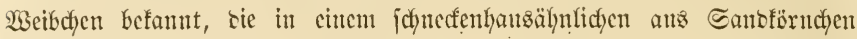

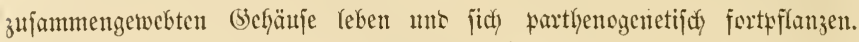

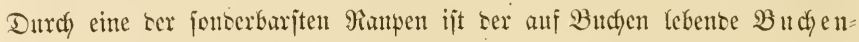
ipinner, Stauropus fagi (Bomb.) L., erwäfnensworth, senn fie hat un=

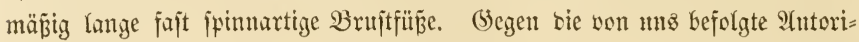
tät ziehen wir bie fajt burdfgehents jän gefärbten $\mathfrak{B}$ ärenipinner hierher,

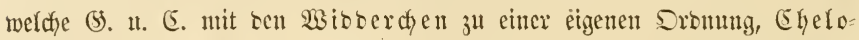
niarier, werbintet. Die fdü̈nen Bären (Euprepia Caja L., villica L., purpurea L., matronula) Gaben iffren beutichen Siamen von ben lang uno

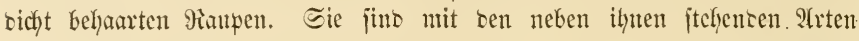
oer (battung Callimorpha (C. dominula L., Hera) unjere fäünfarbigiten Radfffalter. - Die Jumilie ber jel

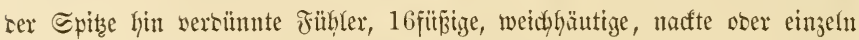

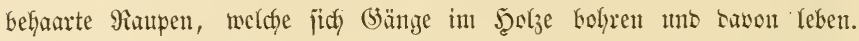

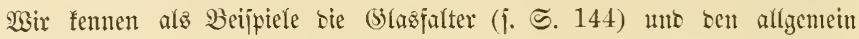
befaunten $\mathfrak{Z e i b e n b o h r e r , ~ C o s s u s ~ l i g n i p e r d a . ~ - ~ D e r ~ a u f ~} 5.143$ ab= gebilbete Siefernichwärmer giebt uns cin treucs Bito ber fantilic ber Sq)wärmer, Sphingiben, teren natte, meijt fd)önfarbige, 16beinige

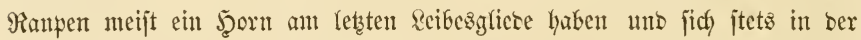

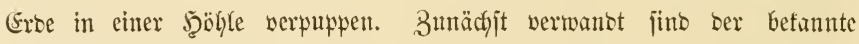
Wintig ober Minbenjdyärmer, Sph. Convolvuli L., mo oer $8 i=$

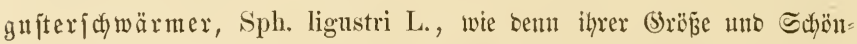
Geit wegen bie Sdywärmer 孔u ben befantejten "Dämmerungefaltern" ge= Gören. Der Tobtenfopf, Acherontia Atropos L., ber gröpte von allen,

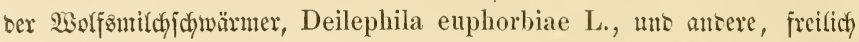

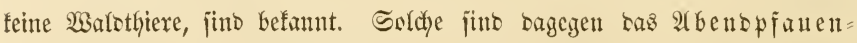
auge, Smerinthus ocellatus L., ter Fapperjedwärmer Sm. populi L.,

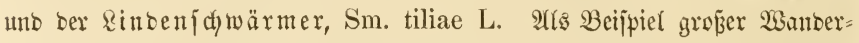

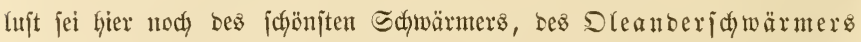
Chaerocampa Nerii L., gebacht, ber in heipen Sommern aus Siltemropa bis zu uns fommt, hier jeine (Eier ablegt, jid) aber nidjt weiter fortpflumbt. Bon ben breifunbert bis vierbuntert betunnten Sphingiben fino übrigens 
bie Meijten 2 merifaner. - $\mathfrak{B a z}$ bie Jarbenpradyt anbelangt, jo hat unfer (5efdymad bolffommen giedyt, bie Tagfalter, Dinrnen, fïr bie bollfom=

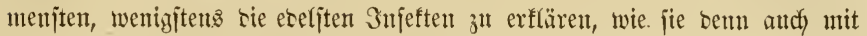

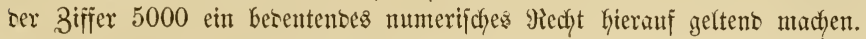
23ïbrento wir unter ben foritjchäblichen Faltern nur einen ber unjheinbar=

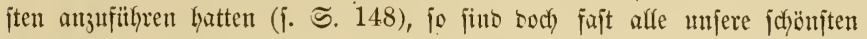
Tagfalter Sinter bes 2 altes, wenn audy ztmu Theil melyr ber niebern, ben W3aloboren bebeffenten Siränter unઠ Stanton. Bei ifnen ijt oer Sörper

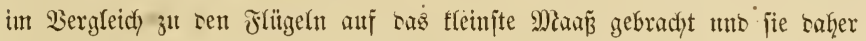

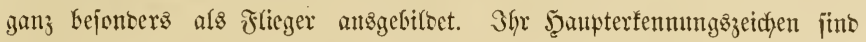
bie an ber Spitze ftets verriften Fühler. Die meift unbehaarten aber oft

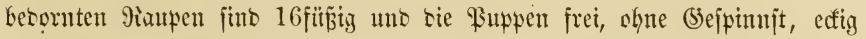
uno oft mit metallfarbigen Flecfen; ïberlyaut mehrfarbiz gefledt soer pun = tirt, was bei sen ïbrigen Faltern faum ber Faff ijt. Wir beuteten fajon

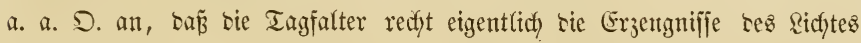

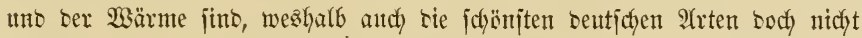

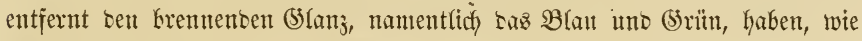

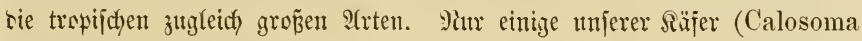
Sycophanta, Cetonia) erreichen 2 ehnulidyes. Pamentlich an bie Tagfalter

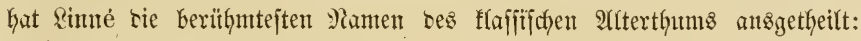
Priamuz, 2tpolfo, Eleopatra, Arethuja, Baphia, Ratonia, Niobe, Aglaja, Daphne, Jris, Sajon, Menelaos uno jefr viele antere. Son ben Tagfaltern gilt ganz Gejombers ber oben herworgehobene Sorzug ber Drfpeltjeitigfeit ber Falter; benn jerbjt einige umferer seutjuen 2 rten zeigen Gierin lleberrajdjentes (ser Ylomiral, Diftelfalter, grope mo fleine Futb, Ferlmutterfalter, Eisfalter, Schillerfalter), wenn auth lange nicft in ser frappanten 23erfochiesenfyeit wie viele. Iropenbewohner, von benten man, wenn man fie umwentet, auf bas ફ̧öchjte ilberrajajt twirb. Die Repioopterologie, um nod) einen B̉ide auf bie gefantmte Dronung zu werjen, hat es wejentlich siefen äjthetifchen Sorzäigen ifyrer Pfleglinge zu barffen,

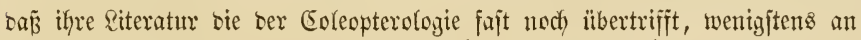

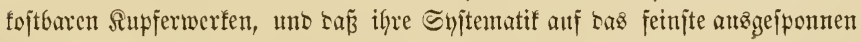

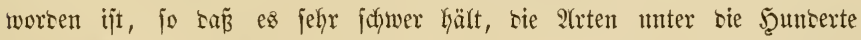
bon Sattungen ridgtig unterzubringen, wobei man meijt auth bie Raupen

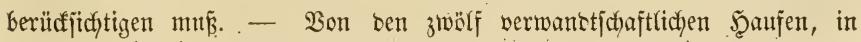




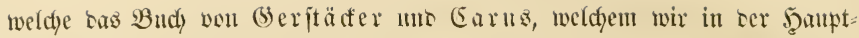
factye folgen, sic Tagfalter cintlyeitt, und weldye, fo weit fie Europäer,

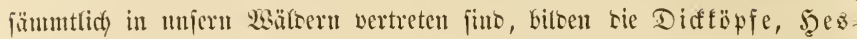

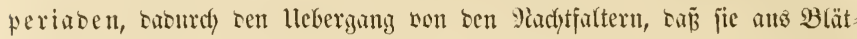

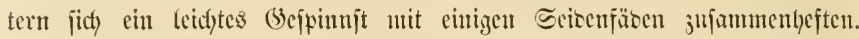
Das befmute Souma, Hesperia comma L., gelgät hierfer. Es folgen

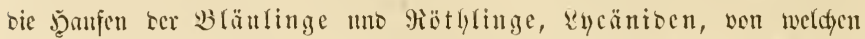

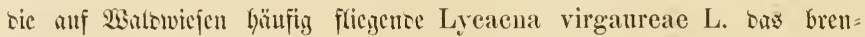
nencjte \&ommeranzemroth unter ben Emopäern hat. Die ifugenfalter,

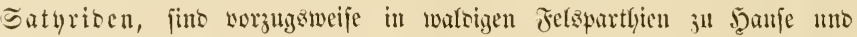

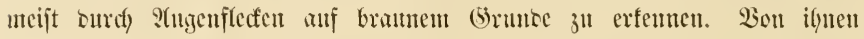

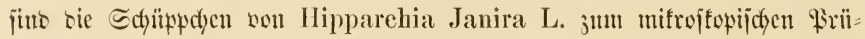
fungsobjett ("Icftobjeft") viel benutzt. Ulıjere jejönjten $23 a$ lovögel fiuren iich unter oen Miymphalioen, bei benen sie Borterbeine z" "Fubpfoten" verfitmuert fint: bie Perluntterfalter, Argynuis, bie Baucjīen, Vanessa, 3. B. Las Iagpfanenauge V. Jo L., der Armiral, V. Atalanta L., ber Diftelfalter, V. eardui L., ter grofe uno fleine Fudys, V. polychloros L. uno urticae L., ber Irauermantel, V. Antiopa, sas 5 , V. C album tho antere. Ferner fino wou ben 9iymphalisen nadffolgenoe

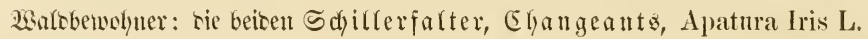
uno llia, ber Bapferfalter ooer Eigvogel, Limenitis populi L., unfer

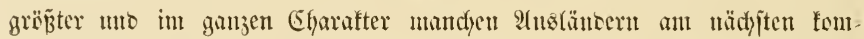

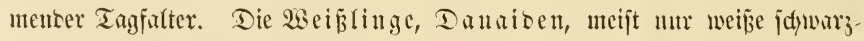

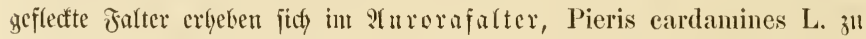
einem glänzenten Miennizrotl. Die hädyften entrich fint bic fatyon von

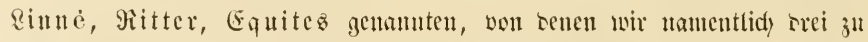
riilymen Yaben, ben Sdywatbenfdyan, Papilio Machaon L., ben Scgel-

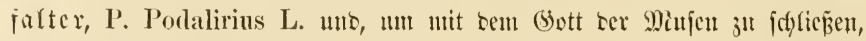

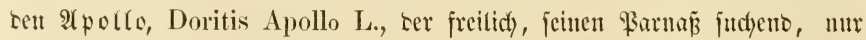
antf lyoben Gebirgen throut. 


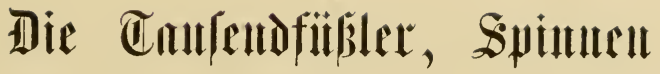

IInD

firelistliete. 



\section{Erfter Ab/dnitt.}

\section{Die Taujentiónler, Myrtopoden.}

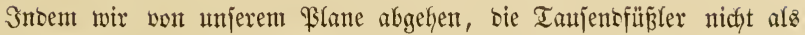
jelbititünsige Thierklajfe zu behanbefn, jonbern bieje viefgehubelte Thier= gruppe mit einer ber anberen (Stiebertfier=Slaffen zu verbinben - eine

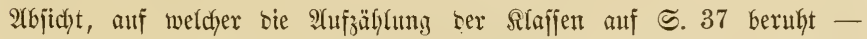
iteffen wix fie nun in (segentheile hier zwifden bie Injeften - zu benen jie Miandye als Dromung ziefyen - uno bie Spinnen.

Bon Rinné wurben befanntlich jie jowohl wie bie Spinnen uno Sirebsthiere (Ermjtaceen) als Flügeffoje zu ber STafje ber Snjeften gejtefft,

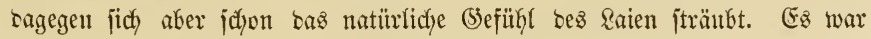

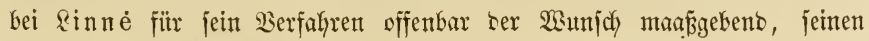

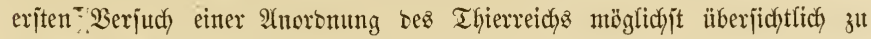
machen. Freilich berfiel ex boburdy bei jeiner jechjten ober wirmerflajfe nod) viel mehr als bei jeiner 3njeftenflajfe sem gropen llebelítande, bie ungleidfartigiten (5ejdÿpfe zujammengepferdjt z" haben. Wer fann ben Flup̧trebs mit bem Sezelfalter, wer sen Bantwum mit einem Seçterne

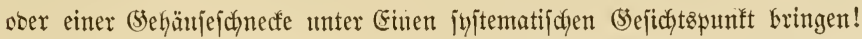

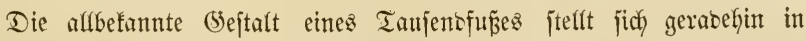
einen greffen (5egenjatz ju jesem edjten $3 n j e f t$, weil man an jenem bie

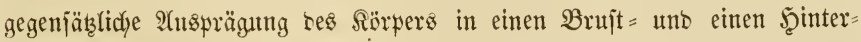
leibstheil vermiß̧st, man vielmehr eine (Sleidjartigfeit ber zahfreidjen Reibes = ringe ganz augenfälfig wahrnimmt, uno eine über 6 weit hinatıgehente Zaht von Beinen.

Mit 3ugrumbelegung siejes augenfälfigiten Merknals jint bie Taujent füßfler, Myriopoden, (s)lieberthiere mit gleidartiger, ben (segen= 


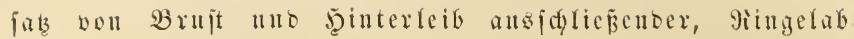

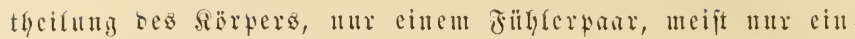
facten ?agen (Oeflen), jefbititänoigem sopfe mo mit žungu= athmung.

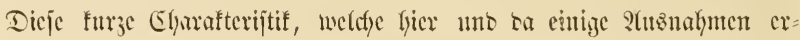

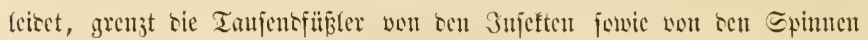

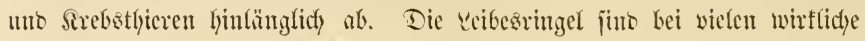

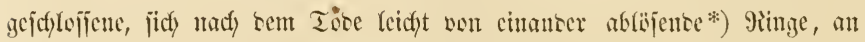

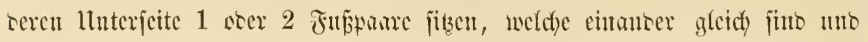

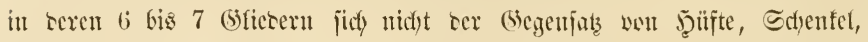

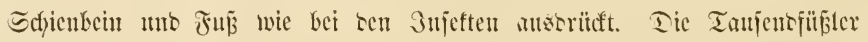

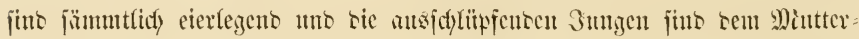
thiere bis auf eine zeringere Bubl ocr reibesringel mo bis anf blos 3 bein-

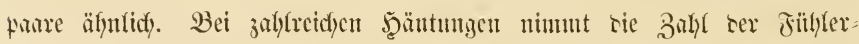

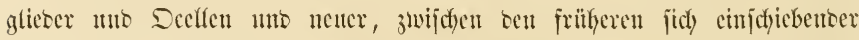

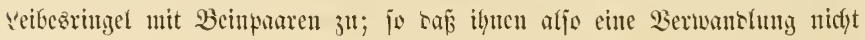
eigen iīt.

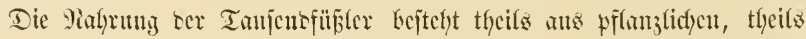
thicrijacten Stofifen. Sie fino meijt fidytfdyene an Ertbwen mter Steinen uno unter fojer Baumrinte febente Thicre. Son ten fictinuten etwa

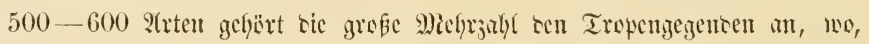
wie andf idyen in Sitocuropa, giftige ?(rten vorfonmmen **).

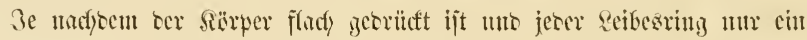

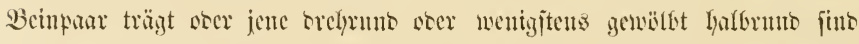

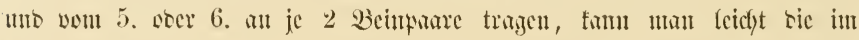

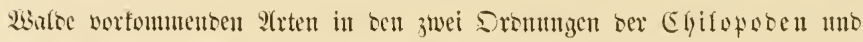

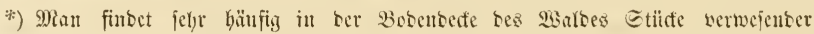

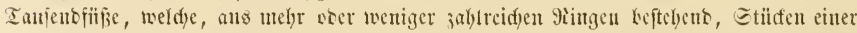
Herlenfidyun gleidyen.

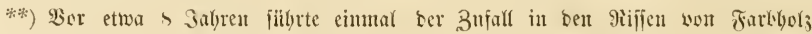

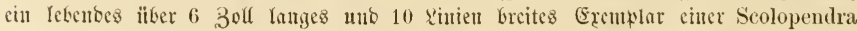

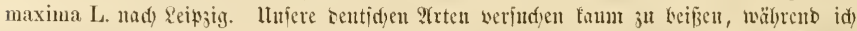

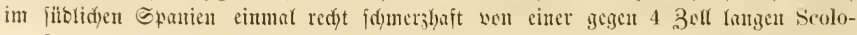

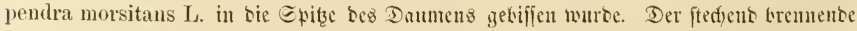

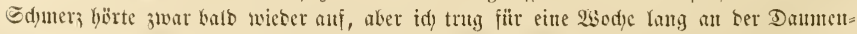
nurzel fleine, Branbblajen älynlidge, näffenbe, bei ber Berïbrung surdy ben 2ermetranto id)uerzende fiufteln bawon. 
ser Ehilognatben unterbringen. Beibe Drommgen weidjen namentlid in

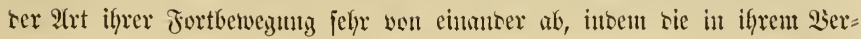

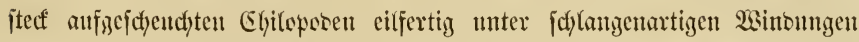

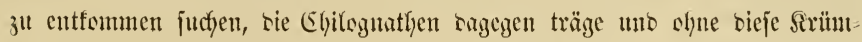

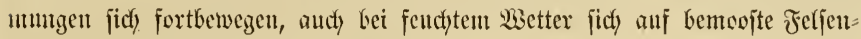

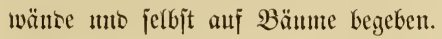

Aus ser eriten Dronung Kegeguten wir unter Steinen un Banmminse

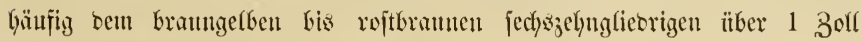
langen Steinfriedfer, Lithobits forficatus (Scolopendra) L. mit 15 Beinfarren, von senen sic binterften bic biefiten uno längften fitto (Fìg. 84 a), tub abmedyjefno breitent utto jchmalen Rücfenplatten, währento oer

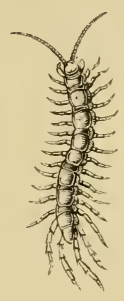

a
Fig. St.

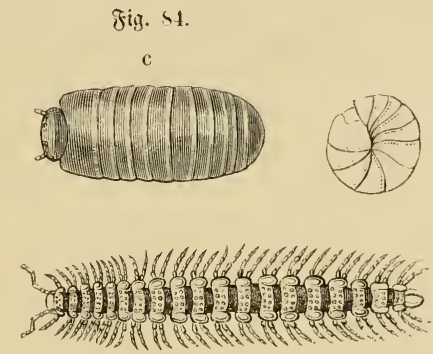

b

a. Der gemeine Steinfrieder, Lithobius forficatus L.

b. Die flatte Mantaffer, Polydesmus complanatus de Geer.

c. Dic gelbgeranbete Rugclaffel, Glomeris marginata Latr., ziemlid) boppelte (5röß̈e, baneben biejelbe jujanmengefugelt.

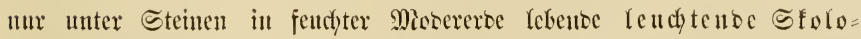
penser, Geophilus electrieụs, geflgetbfict), bis 2 3. Lanty ift uno bis b0 Beinfaare hat. - Don Efjilognnthen, bei senen sie zahlreidyen Beine meift

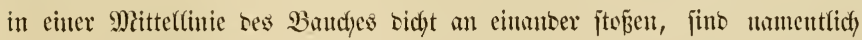

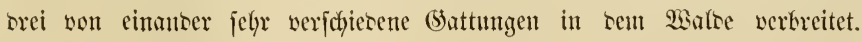
Bunädjit bie eigentlidyen Ianjen

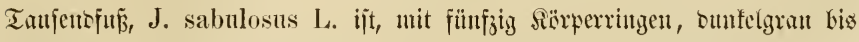

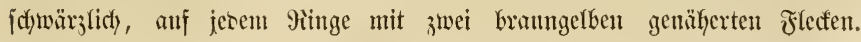


Bem er läuft, fo madjen bie von vorn nady lyinten fortjdyreitens in $\mathfrak{B e}=$ wegung fommenten Beine ben Gintrut ter Wellen eitres vom Sinte bewegten Sornfeltes. Er wiro bis 2 3olf lang. Der fajënjte sentiche Taujenofüźfer ijt tie graue platte Randaffer, Polydesmus complanatus

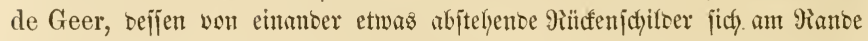
etwas aufbiegen uno jierlid) geförnelt fino (Fig. 84. b). Sie ijt bet $1 \&$. Breite bis ïber 1 3. lantg uno fintret jidf Gäufig unter Baumrinte after anbrïhiger Stämme. Die britte Battuny fino sie $\Re$ «gelafieln, Glome-

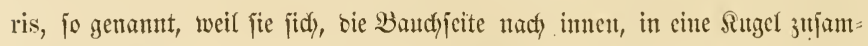
menrollen fönnen, was jie bei ber geringiten Beläjtigung thum. Die ges

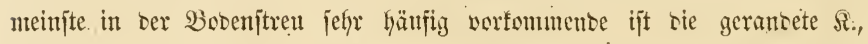

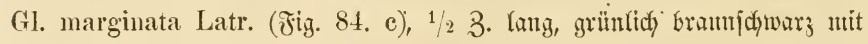

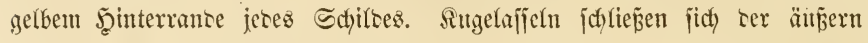
(bejtalt nady an bie eigentfichen arjieln, eine Drommg ber Srebstlyiere, àn. 


\section{Bweiter Auldnitt.}

\section{Die Spinten, $\mathfrak{A}$ iady}

Wenu man jelbjt in ber Sitgelajjel nod) den Typus bes Taujent: füß̈lers erfennen kann, fo fint bagegen bie Spinnentfiere neniger überein= ftimmens gebaut uno twir finten in ber Safije mandye Thiere, weldye feines= wegs bie allbetannte Spinnengejtalt haben, objchon fie ans anteren Srintoen ber Srganijation boch mit biejen in eine Slajpe gejteflt werben müfjen.

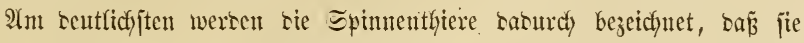
feinen freien Ropf haben, biejer vielnchy nit ber Brujt in Finez verjdymol= zen ijt, fo baj man siejem Theile ben Namen Eephalotharax (Sopfbrujt=

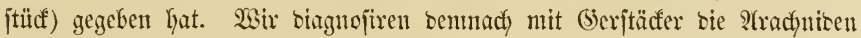
als (5) lieberthiere mit "eingegangenem" Sopfe, fieferförmigen unb am Eephalothorax entipringenden Fühlerm, jtets einfachen

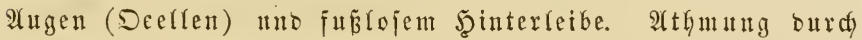
\&ungen, Tradeen orer bie ફ̧aut.

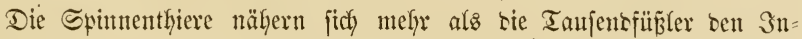
jeften burdh bie Ungleidfartigfeit. Der Sörperabtheilungen, uno lluterbringung ber Beine an einzelne terjelben. Die 3ahl ser 2ungen, welche aber nie= mals Piekangen fint, beträgt zwei bis zwölf uno jtehen oft weit aus einantoer,

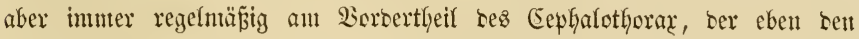
Ropf vertritt, vertheitt. Unter bem freien Rante ses (Sephalothoraz ftehen bie beiben "sieferfügler" zugleidy bie eigentlidjen Fühler uno bie ben Spin=

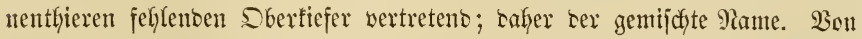
ben vier Beimparen berfelben entipridyt bas vorberjte, obgleich sen übrigen ganz gleid) gebilbet uno angewentet, ben Unterfiefern. Ueberfyapt ppielen

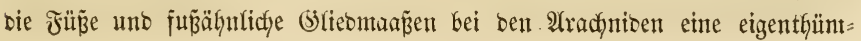


lidye 9ivfle, weldye ber Dentungsfunjt viel Bejefäfigung giebt; iiberlyaupt

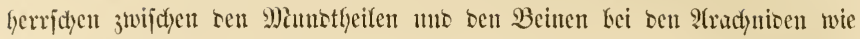

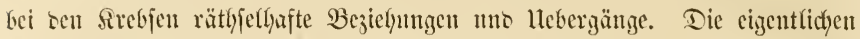

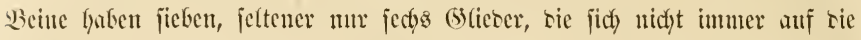

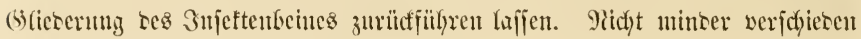

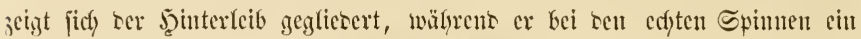

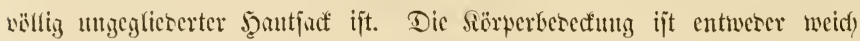

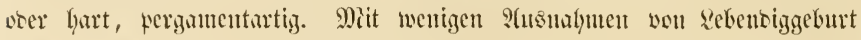

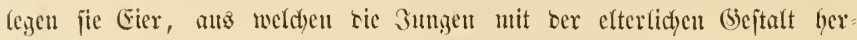
worgelyen.

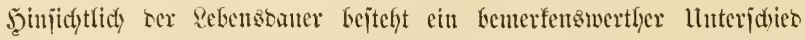

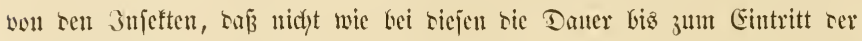

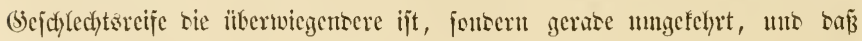
fie uad) ricjem Eintritt nody fortwadyjen, was befanntlidy bei sen 3njeften niemals ser Fafl ijt. Thad) finto jie zu wiecerlyoltemmalen fortfflanzungs:

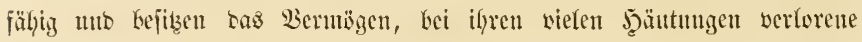

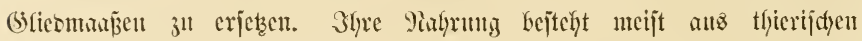
Stoffen, meijt 3njeften, bie jic mu ansjangen. Einige nichere Formen

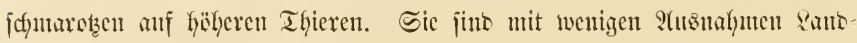
thiere. 2ä̈lyrens twir bei sen 3njeften in Bweifel waren, weldyer Dromung mir sen Gädyjten unb weldyer ben unteriten Jiang eimrätuten follten, fo

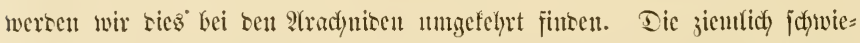

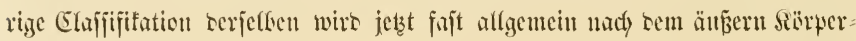
brat vorgenoument.

Die Betradytung oer im 23afre vertretenen Srommigen bon unten be= ginneno uno bie orei unteriten Sronungen meglajiens, beginnen wir mit

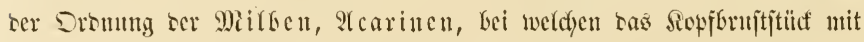

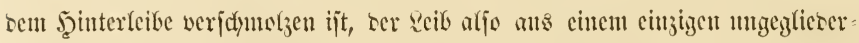

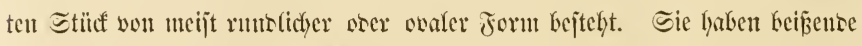

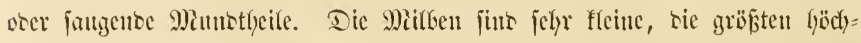
ftens eine Qinie mefienre Thiere. Wair fülyren ans sen jieben Jamilien

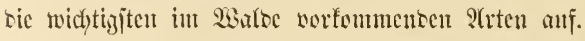

Bon ben eigentlidjen Mirben in engern Eimne jei hier num bemerft,

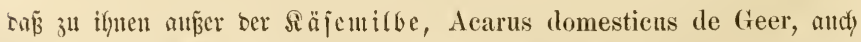

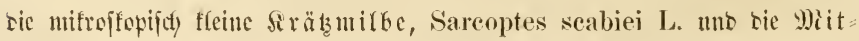


effermilbe, Demodex follieulorum Simon, gefyören, retztere in ben jo-

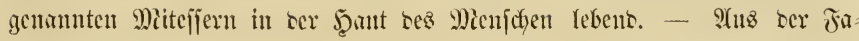

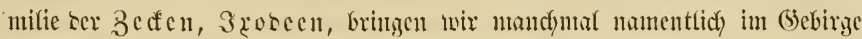

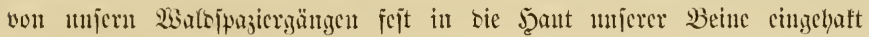

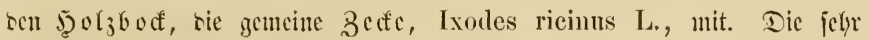

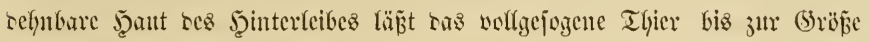
enter Bolfue anjefwellen (Fig. 85 a) - Eme fleme Fantile giebt rie manche Snjeften (†. S. 338) ałв Sct)marober quälense Säfermilbe, Gamasus eoleopterorum L., wäbreno einige verwante Mitbengattungen anf Bäzelı แno Flesermäujen lyanjen. - Dic artenteidye Familie ser

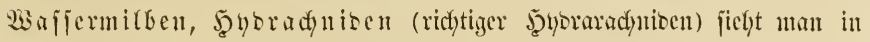

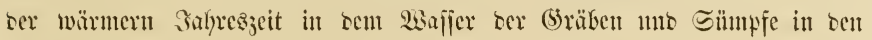

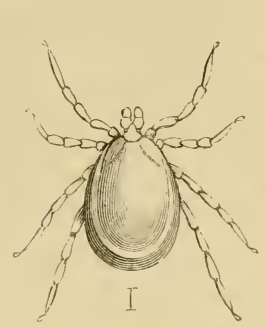

a

รig. 85.

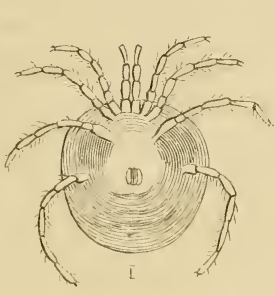

b)

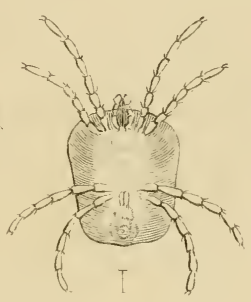

c

a. Dic 5ூutbiacde, Ixodes ricinus $L$.

b. Dic dorufïbige ginifermirbe, Hydrachne spinipes.

c. Die gemeine Sammetmifbe, Trombidim holosericemm L.

(2)le ftarf wergröß̈ert.)

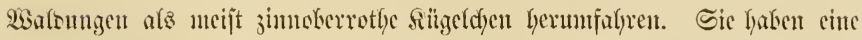

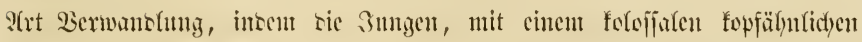

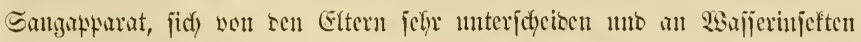

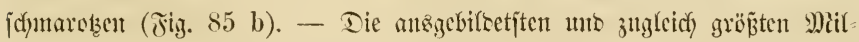
ben jüs bie Fantlie ser Soumermilben, Trombioinen, bie hänfig anf

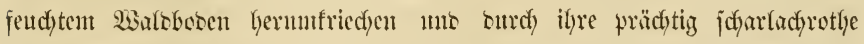

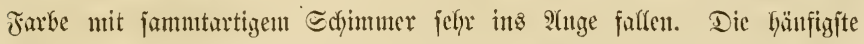
uno gröp̧te ifit sie gemeine V., Tr. holosericenm L., reichfich 1 \&. \&änge 
uno ziemlidy gleidyer Breite. (Jig. $85 \mathrm{c}$ ). Die einem ziegetrothen Sand= förndjen gleidyenton Singen werben als jelbititänoiges Ifier Leptus autumnalis, bie J̧erbjtmilbe, genannt, weldhe zur Erntezeit jidy bejonber oft

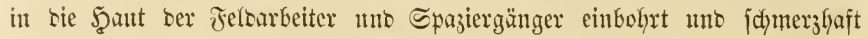
3ndente geröthete \$ufteln Gervorruft. In Ihüringen fanben wir biejelben, bie jïh zuweilen in groß̈er Mienge einjtellen, als "Sommerfriejel" betannt, ofyte baj man bie Urjache faunte.

Die Sronung ber Spinnen (aebipinnen), Araneinen, umaja bereit einige Iaujente befannter 2 (rten mo ift in einigen ifrer 2 Angehörigen

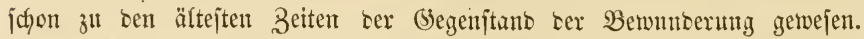

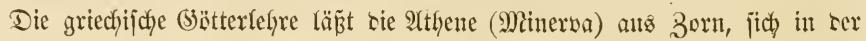

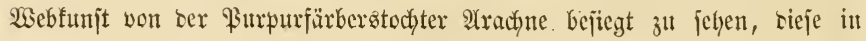
eine Spinne berwanteln, bamit jie, ba jie jich ans (Sram erfyängen wollte,

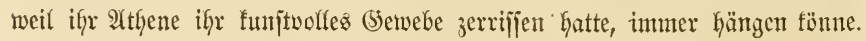
Wenn uns audy leifyt eine jebe Spinne als joldye erfennbar ijt, io umidfreiben wir ifyen Dromungsharafter sody noch ausorücflidy mit sen Worten: je jins $\mathfrak{A}$ rachniben mit beizenten Meunotheilen, furz ge ftieltem ungegliebertem Şinterleibe, beinförmigem ztweiten sie fertafterpar mo vereinigter \&ugen= unb Iradjenathmug.

Die sorfer erwähnten Sieferfüfler jïto bie $23 a f f e n$ ser Spinnen, uno bilben eine zangenartig gegen einanter gejtellte ober gleichlanfento abtwärtz geritdatete fpitzige Doppelflaute, weldye auf je eittem unteren biffen (S)liebe jteht, in welcher bas für Snjeften, von benen fie leben, töbtlidye (Sift befind = lidy ift. Fig. 86 a jtellt von ber Siretzipinne eine joldye Slaute bar mit rer fabenjörmity in bie Sprite berjelben eintretenten (Sijtorüje. Das ge= gfieberte erjte Riteferntajtenpaar - bas zweite Gaben wir als ben eigent licfen fechs Beinen ganz gleich gebilbet tennen gelernt - jtefyt vorn am

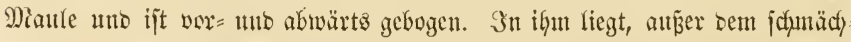

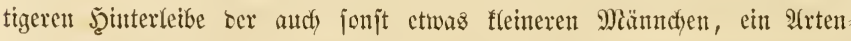

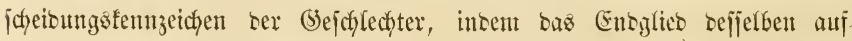
getricben, mit einer Spitze verjehen uno audf fonjt mandhmal jebr auffallento gejtaltet ijt. Sie finten bei ber \$aarung eine cigentyüntidye 2nwentoung.

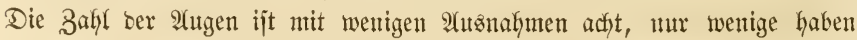
blos jechs. Sie jint am vorberiten Theil tes Sopfbrujtitïdis als fleine

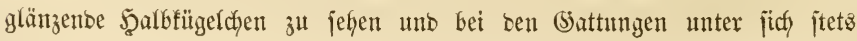




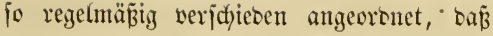
man gropentheit( nad) biejer ?tnorsmung bie (5)attungen untericheiset. Die nekenjtehenoe Sfala zeight bieje 2lugenjtelfung bei sen midy tigiten Sattungen ber Spimmen. AM ben Spitzen ber adyt Fitipe, aljo autdy an ben jogenannten zmeiten Siefertajtern, finten jidy bei sen Spinmen 2 over 3 silauen, weldye bei vielen bie zierfidyjten Siänunchen sarjtelfen (Fig. 86 . b) uno mit weldyen jie jith beim Saufen über ibre Pietze fejthalten uno beren Fäten reinizen. Bum Spinnen riejer Fäben Gaben jie an ber Interjeite ber Bandsjpize 4 ooer 6 Spinnwarzen, weldye auf beut

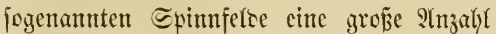
$(100-400$ jese Spinmwarze) feiner horniger 9ührutben haben, seren jehr feine Spitzen ben Spinnitofi austreten lafien, ber an ber Ruft jofort $3^{11}$ cinem numerfbar feinen Fäb= d)en erfärtet. Ė jint aljo die Spinnfäten, jo fein fie uns vorfonment, ordy vielfuntert= bräbtig, was ifye groje Tragleajt erflärt.

Die Marlyung rex Spinnen ift ants= nahmslos thierijace, Snjeften ober aud ihresgleidyen. Sie julagen ifyen Edyladyt= opfern bie J̨afen ibrer Sieferfithlex in ben Yeib unb jaugen jie mit ifyrem als Gaug= organ bienenten Sdjlumbforfe aus. Die

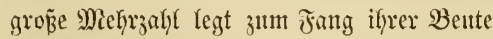
befanntfidy Piebe an, beren werjodiecene $\mathfrak{B}_{e}=$ j(d)affentycit uno Eimridytung ein Mittel zur Eintheilung ber Spinnen abgiebt.

Die Spinnen junt in bis jetzt etwa थugenfterrung bentider Spinuengattungen.

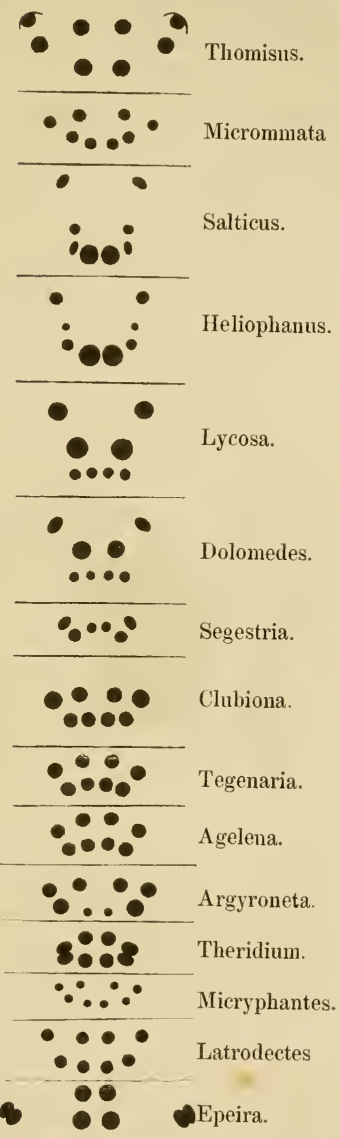

- Tetragnatha. 2000 befannten 2rten über ben ganjen Erbfreis verbreitet. Unjere befann=

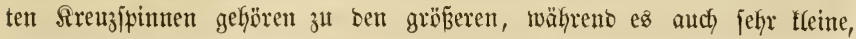


faum 1 \&. Lange giebt. Mad) Ser 2tugenjteflumg, ben 2themorganen, ser Zaht ser Spinmwarzen, ser Mitchtung ber Siefernfülyler werten bie Spinnen weiter in 2 Fautilien uno fleinere Brmpen eingetheilt.

Die F̈ntlie ser Zweilungigen, Dipneumonen, haben 2 sungen= fäfe uno 2 ober 4 suftlëçer (Stigmen), 6 Spinmwarzen, gegen einanber geridytete Slancu ber Siejerfïfler uno 8 jelten nut 6 jtets non einanter

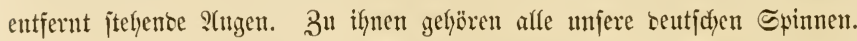

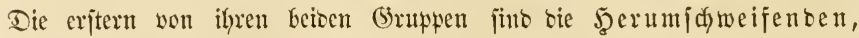
Bagabunoen; iffe Slugen jtelyen meijt in 3 Duerreifen; jie nadyen feine Fanguetze, fontern jagen ifre Bente, unt zwar entweser ifyr nadjennent:

Fig. 86.

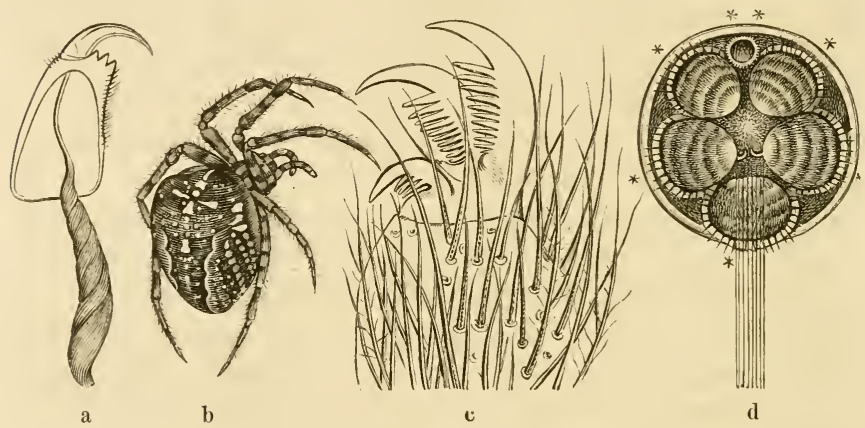

a. Die linte Rlane bes Riefertafterpaares ber Rreuźpinne. Borberfeite aufgefdnitten, un ben Eintritt Des Speidjelorgans zu zeigen.

b. Die gemeine Srentpinne, Epeira diadema L.

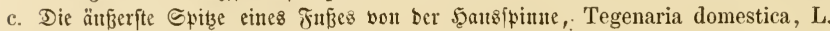

d * Die 5 Spinnwarzen ber §reuzipinne; ** Der 2fiter.

(a. c. d. ftarf vergrößß̈ert.)

Sduerrëufer, Eitigraben, ober jid anf jie jtürzent: Springer, Saltigrasen. Diejen Bagabuncen begegnet man bäufig anf feudytem

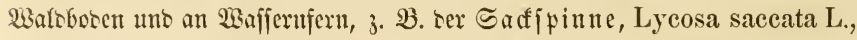

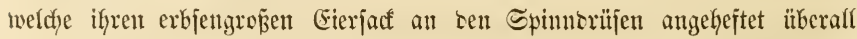

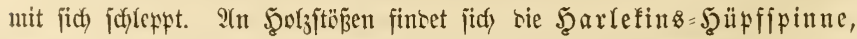

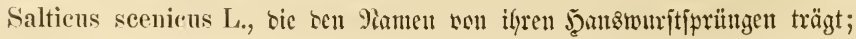




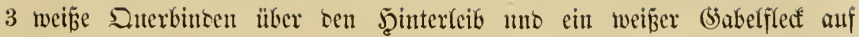
bem Bruftftüff ntadjen jie leidht fenntlich. - Die zweite Bruppe, bie weber, Sežlaften, Sesentaricn, haben ihre 2lugen in 2 Duer= reifyen georonet. Siach ifyren Bctweben theilt man fie weiter ein. Die Seitenläufer, Saterigraben, fpinnen nur einzelne Fäsen, verbergen (iic) in lofer zแjanmengejponnenen Fäten uno laufen gern wou ber Seite. Şierfer gehört eine unjer jhönften Spinnen, bie Smaragb= ipinne, Sparassus smaragdulus Latr., mit grünem (5ephalothorax unt Beinen, bex etroas heffere ફ̧inter(eib beim Männdyen mit purpumrothen unb

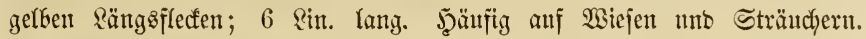
Die Mabipinnen, Drbitelen, fino sie Serfertiger ser affbefanten meijt jenfrecht gejtellten, aus jtrahlenfürmigen uno concentrijd)en Fäben bejtehen

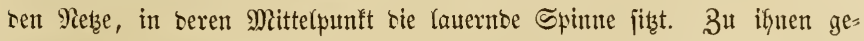
Gören unfere größ̈ten Spinnen, bie ziemlid) zahlreidyen ?trten ber Rretz= ipinnen, Epeira, von benen sie gemeine $\Omega$ r., Ep. diadema L. bie

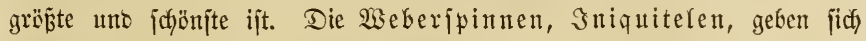
weniger Mäbe, bent ifyre Metze bejtehen aus nad) affen Midytungen aus =

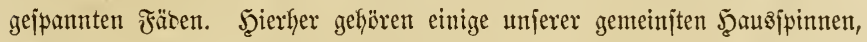
3. $\mathfrak{B}$. Theridium redimitum, 2 \&. lang. Die Beflen= uno $\Re$ öhren= ipinnen, Tubitelen, weben bidjte, fehr verjojieben röhren= ober flajdyen= förmige Betwebe in Mauerjpalten, unter Lojer Baumrinte, muter Steinen,

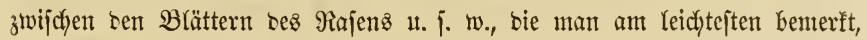
wenn bie ßerldyen bes Morgenthaus an ignen hängen. Die afdygrante atlabharige Sammetipinne, Clubiona holosericea L. finbet man

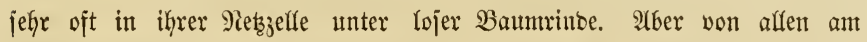
abenteuerfichjten ift bie $\mathfrak{B a j f e r f p i n n e , ~ A r g y r o n e t a ~ a q u a t i c a ~ L . , ~ w e l d i e ~}$

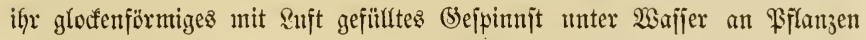

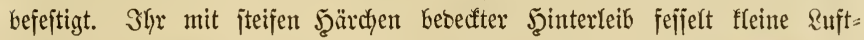
bläschen an biejen, wodurd) ex unter Wajier jüberglänzent ausjieht. Sie ift namentlidy in gropen $\mathfrak{W a l b l a d y e n ~ n i d y t ~ j e l t e n . ~}$

Ebgleich unz bie vierlugigen Spinnen, Ietrapneumonen, als Bemohner marmer sänber hier nidftz angehen, jo jei boch von einer berjelben, ber ats atbrilbungen befannten Bogelipinne, Theraphosa

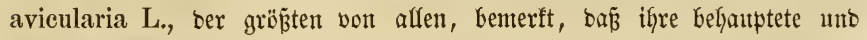

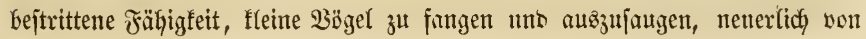


Burmeijter bejtätigt wirt. Die in Sürenropa lebente Miniripinne, Cteniza eaementaria Latr. ijt sie verjd)lagenite mo gejujiftejte son affen, incom fie $1-2$ s. tiefe jenfredyte Eroröbren anlegt uno auf biejen oben eine ausıärtaflappento Jaffthäre mit einem Sharnier wie ein Sannentedfel anbringt, von weldyer ein Spinnfaren biz zu ter untenjizenten Spinne als singelzhtg hinabgelyt.

Miod) haben wir jweier Eridyenumgen $3^{u}$ gesenfen, weldye lange Zeit

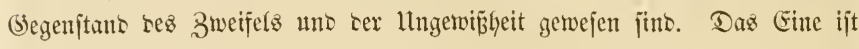

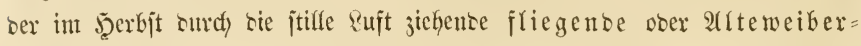
Sommer, Mäbd) ganze fleine Siteratur cxifitit. Sogleich man nod) nicht genau weiß̈, wie ex von ben Spinnen bereitet wirb, fo ift bod) wohl barïber fein 3̂weifel,

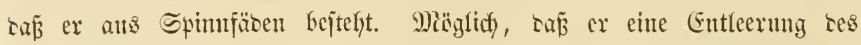

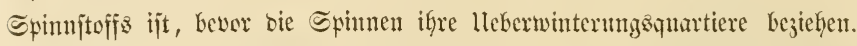
Das Zweite ift bie \&nftidifferei vieler Epinnenarten, welde möglicher:

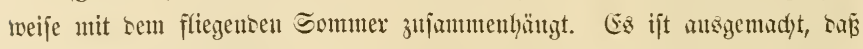

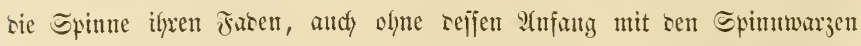
an irgent eimen fejten (Sczenjtano anzubrïfen, ans sen Spinmwarzen frei in bie suft limantstreiben fann. So bereiten fid) viele flemere Spinnenarten, insem fie ben freien Faben mit iffen Beinen 3 n cinem ïberans

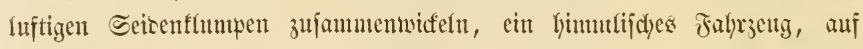
weldyen jofon oft bie Borerfinterimen wan Miontgalfier jegelno gejehen worben futo. Soldfe enftichiffermuen jinto Thomisus viatieus L., bic vorfin genannte Lyeosa saceata L. nto L. paludosa Hahn, melyrere Theridium-2lrten, Mieryphantes elevatus Koch uno andere.

Enolidy jei nod furz ber 2 ettervorberjage oer Eximnen getadyt, worin fie jeood), wenigitens nad) Beobadjtungen oer Wetterfunsigen, nidjt viel mely leijten follen, als bieje jelbjt.

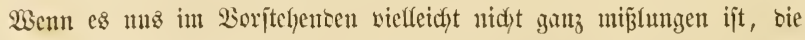

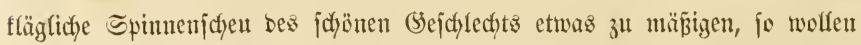
wir es gar nidft werjuden, ifgre Jurdst wor ben Sforpionen, ber widf tigjten Familie ocr höchjten Dromung ber Spimmentfiere: ber (s)lieber= ipinuen, Arthrogajteren, zn wertreiben, benn ocr Stid) jelbjt nujerer flemen jübsentidyen Eforpionen ijt jebenfaffs idumerzhajt, wenn and ganz ungefährłicf. 
Die (5) lieberipinnen find aradyiden mit jizenoem (b. h. un= geftieltem), beutlidy geglieberten seinterleibe, theils ourd sungen, theils ourdh Iradeen athmend.

Die Sieferfïhler (bei ben Sforpionen bie Scherenarme) mit idyeren= fürmigen, juweilen autd) blos flautuförmigen Enogliese. Die âtgen (eben=

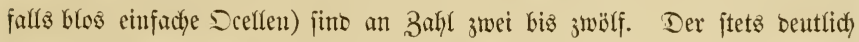

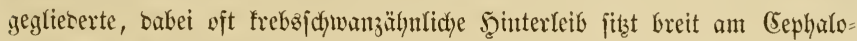
thorax an. Es gebüren zu ignen rie größ̄ten Spinnentriere, namentlidy in sen

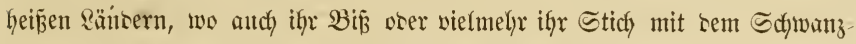

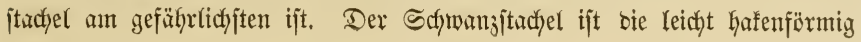

Fig. 57.

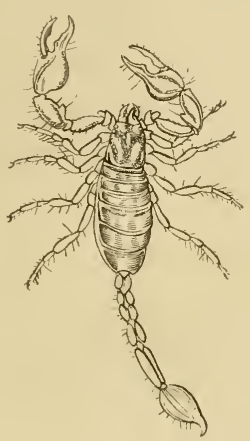

Der beutfue Sforpisn, Scorpio germanus Koch.

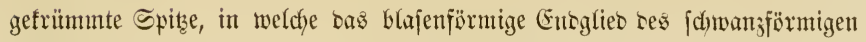

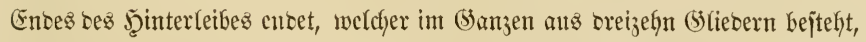
bon welden jerody num sie jedys rebzten auf sen Sdywanjtheil tommen. Sic

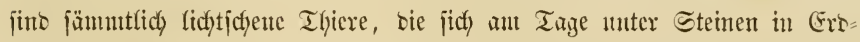

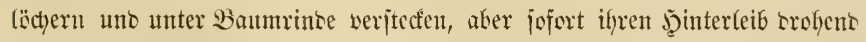
aufridyten, wenn man fie Dajelbjt jtërt. Nidyt affe ju siejer Drmung gehörenten (5attıngen haben bie allbefunte Sforpionengcitalt.

Streng genommen gebout bie ganje Dronung faum in sas Bereich

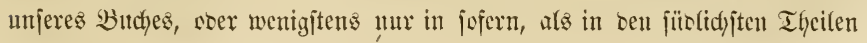


Deutjdylanos von Särntyen uno Sitrtirol an in heis unb trodfen gelegenen feljigen Waloungen unter Steinen ein fleiner edjter, ber europäifdye Sforpion, Scorpio europaeus Schrank vorfommt, wo wir ihn, häufiger aber unter sen Deffiteinen alter Steimmatern, jelbjt gefunben haben. Db biejer ber in Fig. 87 abgebilocte bentjdye Sforpion, Sc. germanus Koch, gewejen ijt, ober, was wir mefr vermuthen, ber triejter Sforpion Se. tergestinus Koch, fönnen wir nidyt mely entiçcisen. Demnach fämen

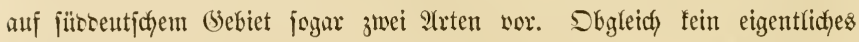
Bartothier, fo fönnen wir bod, nidyt umbin hier bas winjige arbbifo ber

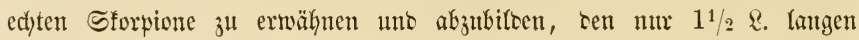
Garmlojen $\mathfrak{B}$ üd)erfforpion, Chelifer cancroides L., ter mit 2 fbredyumg

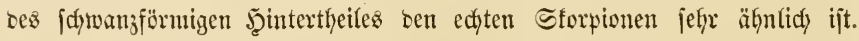

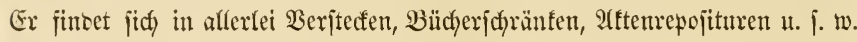

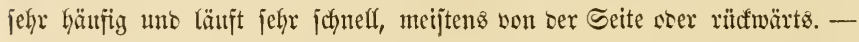

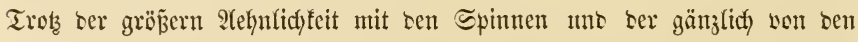
Sforpionen abweidyenten (Sejtalt mur man semtody Gierber jene metandyo= lijaben Thiere jtellen, weldhe ihren fajt fugefrunten Reib auj ummäß̈ig langen fabendïnnen Beinen in zitternoer Balance an alten Baumjtümmen แno

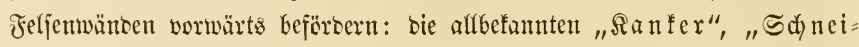
zer," soer am bejten $\mathfrak{B e b e r f n e d y t e , ~ P h a l a n g i n m ~ o p i l i o ~ L . ~ u n o ~ m e f r e r e ~}$ antere 2 trten. Bon ben wahren Spinnen unterjachet jie leidyt ber vom

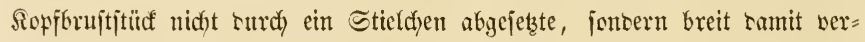
wadffene J̧interleib แno ber Mangel tes Spinnwermögens. 


\section{Dritter Xb[dnuitt.}

Die Srebothiere, Eruftacen.

Wenn wir bei ben Snjeften bie Dreitfeitung bes Rörpers jtreng feft gehalten uno bei ben Tanjentoüïlern ganz aufzegeben fantẹn, fo ift bee sen

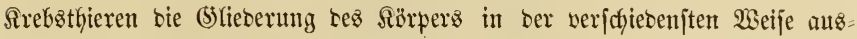
geprägt; ja wir bürfen bei bem 9amen ber Sronung nicht zu fefy an bie unz gelüufige (bejtalt unferer Flußffrebje ober jelbjt ber Seefrabben benfen,

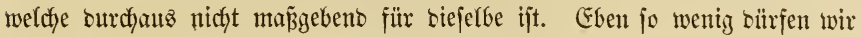

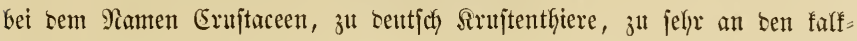

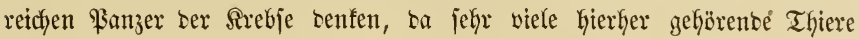
eine weicfe $\Omega$ örperbebectung haben.

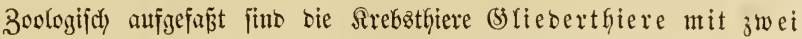
Fithlerparen, meift tajtertragenden Dberfiefern, zuammen= geferten 2 ngen und briebmaa Ben tragendem ફ̧interleibe, an

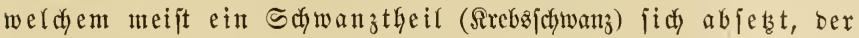
Şinterbaud, Foftabomen; atthmug burd Riemen ober burd) bie Şaut. - Der sopj ijt niemalš ganz frei, jonbern mit bem erjten

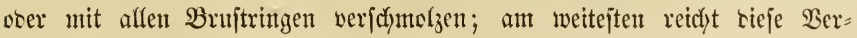

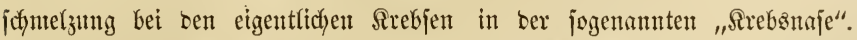

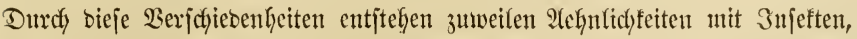

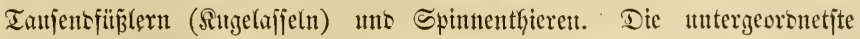
Folle am Eruftaceenteibe ipielt bie Bruft, weldye, nantentlidy bei ren eigent=

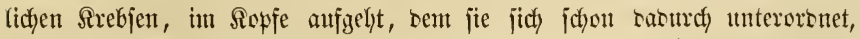

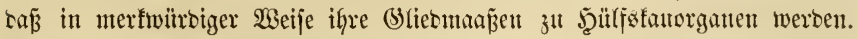

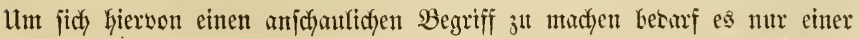

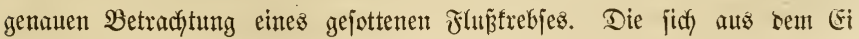


entwidfefnten 3ungen gleidyen meijt ten Eitern, viele surdylaufen aber autd

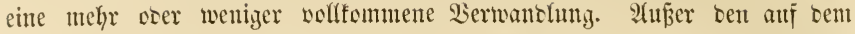
Sanre lebenten 2 (jjęn soer gleid)beinigen Sirebsthieren fint jie fümmtlich 2Bajfer = uno jwar ber Ḧbergropen Miefrzaly nach Seetfiere. Durch Den

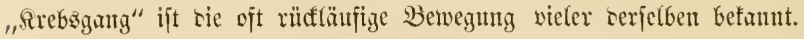

Heberbfict man sie jieben Dromungen ter Sirebsthiere in ihren her-

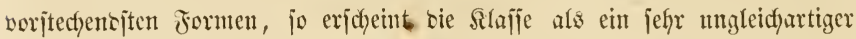

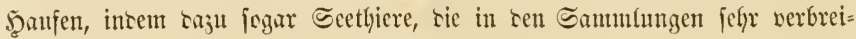

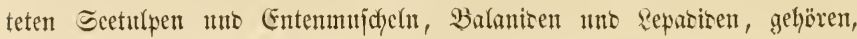

Fig. 85 .

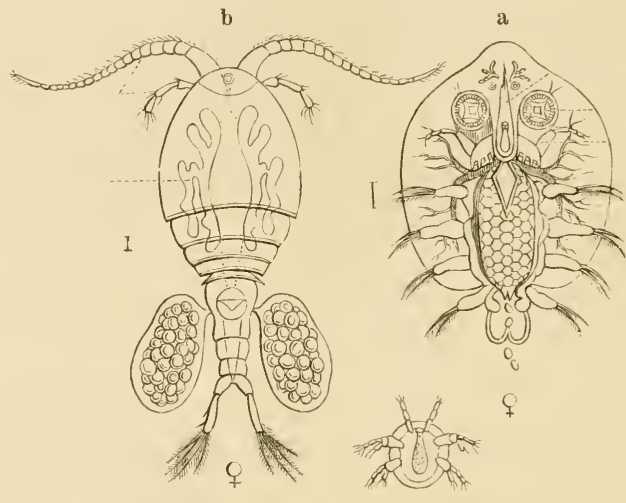

c

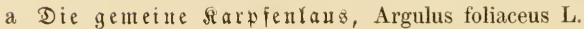

b. c. Der gemeine $\mathfrak{b} \ddot{u} p$ ferling, Cyclops quadricornis F. unt beffen \&arbe (c), (iehr vergröß̨̋ert).

melche ifrer falfigen Schalen wegen jonjt zu ben "Eondfylien" gejteflt wur= ben. Bon ben fieben Dromungen fino fünf im 2 alose vertreten, went auth

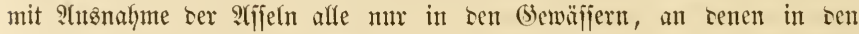

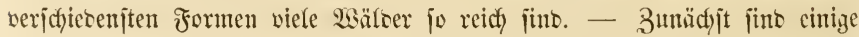
Spaltfübler, Entomojtraceen ju erwägnen, fleme, gemöhntich ju jelyr

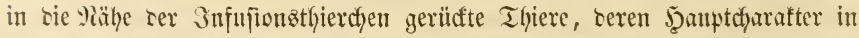

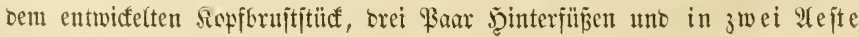


geipaltenen $\mathfrak{B} a u d f$ füßen beruft. Wir füfren bie an Fifden jaugente gemeine Fifd)laub, Argulus foliacens Fabr., an, 2" lang, gritulidy),

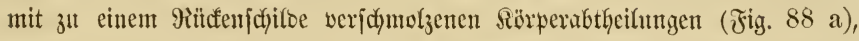
unt Ien gemeiten ந̧̈̈pferling, Cyclops quadricornis L. ${ }^{3 / 4}{ }^{\prime \prime}$ lang, mit jwei ganj bidft beijammen ftelyenden, jueinbar in ein Stirnaube ver:

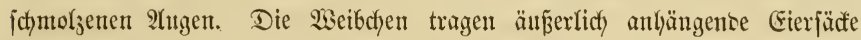

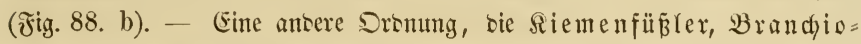
poben, bieten zunächjt bie zuweilen nady langem Fehlen in grofere Mienge

รig. 59.

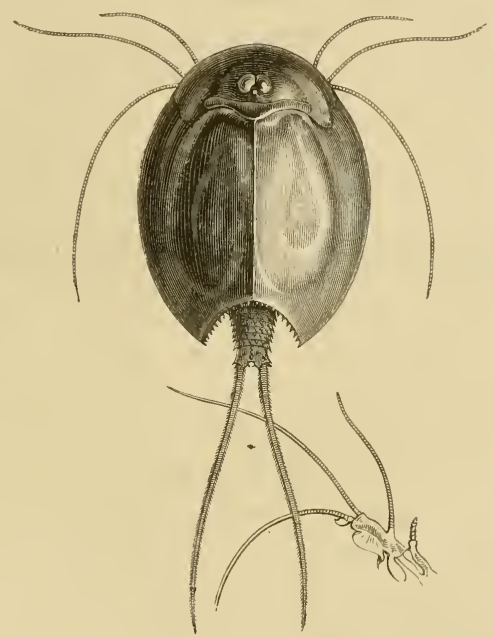

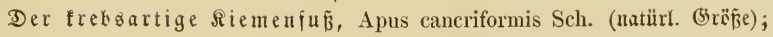
unten eincr ber Sorberfüßje bejonbers.

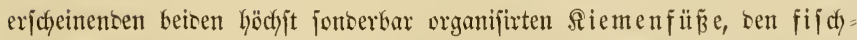
förmigen $\Re$., Bronchipus stagnalis L. (Apus pisciformis Schäff.) ttı

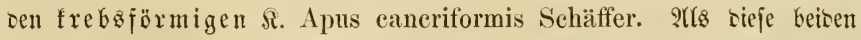
fonberbaren Thiere wox länger als fyutbert Gahren surch bie gitten 2 tbbit=

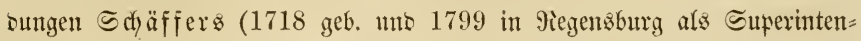
bent geftorben) in Deutichlano wiffenjafyatlich befannt wurben, erregten jie surch ifje abenteuerlichen sörpervergältniffe uno burch igyr räthjelfaftes 


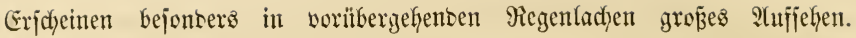

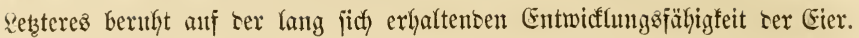
Die taujentomal fopirten Figuren $\subseteq$ d) äffer z mo Möjels haben bie Thiere betannt gemacht uno wir bejdyränfen uns anf einen nach ber Matur gefertig=

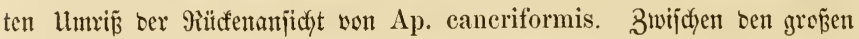

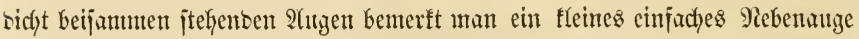

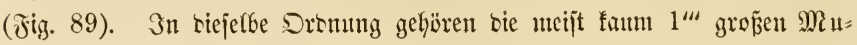
fdelfrebsdyen, Ditracoben, uno 2 ajjerflöhe, Claboceren, beren vielgliebriger Sörper von einer überaus zarten fleinen jweiflappigen an ter

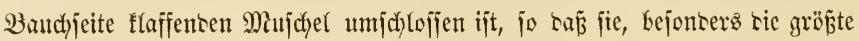

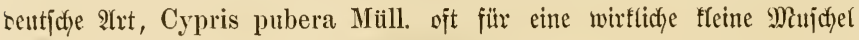
gef̧alten wirt. Bon ignen wimmeln mandynal sie jumffigen Radyen in sen

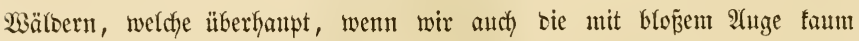

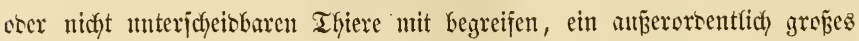

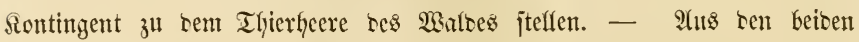

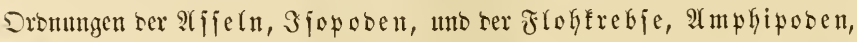
ijt zunädjit bie aud) in $\mathfrak{B a l b e}$ an trodften Feljen uno unter ber abge= jtorbenen Rinbe alter Baumjtänme rebente ajdgraue, allgemein befannte gemeine 2 jןer, Mauerajjel, Oniscus asellus L. zu erwähnen, bie

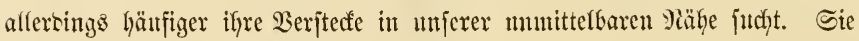

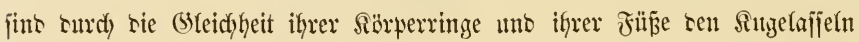

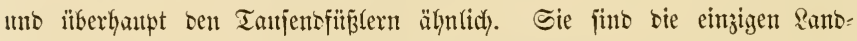

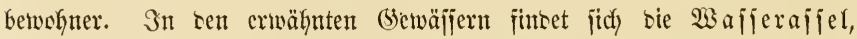
Asellus aquaticus L., obgleich sarin nidyt jdymmmeno, fontern wie bie

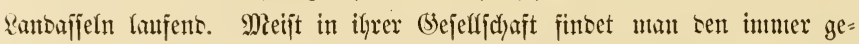

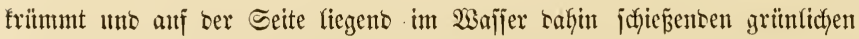

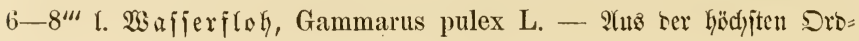

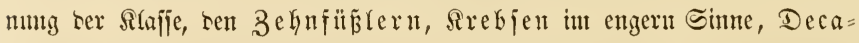
poben, haben wir in gemeinen $\mathfrak{F} \mathfrak{l} \tilde{\beta}=\mathfrak{\Re} r e b j e$, Astacus fluviatilis L.

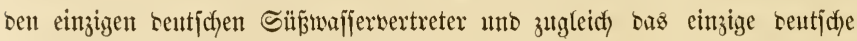

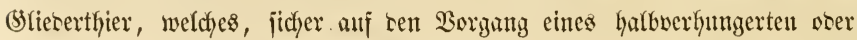
eines ïberjättigten Jeinjdymedfers, einen \$latz auf mierem Speijetijabe gefunben hat. 
Đie Illeidtljiere oner Atlolltsken

$$
\text { Into rie }
$$

Atlurd)elthiere, (Coudhiferen. 



\section{Erfter Ab/dunitt.}

\section{Die פeidythiere ober Molluster.}

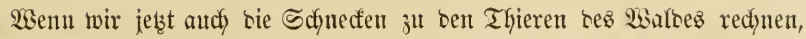

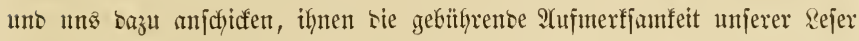

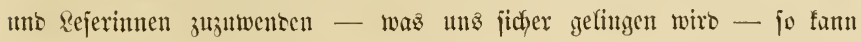

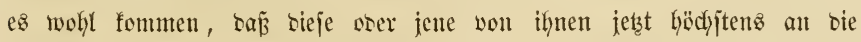

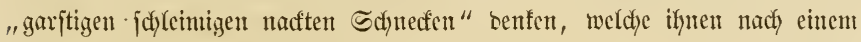
regen zahlreidy über ten 2 eg friecthen. Eben jo möglidy, ja wir tragen

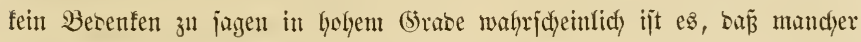

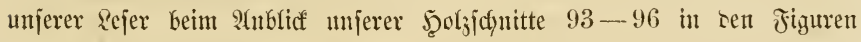
berfelben feine Warthtiere bermuthen wirb, obgleich bieje mur eine geringe Auskeje bavon sarjtellen.

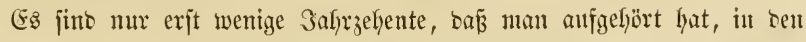

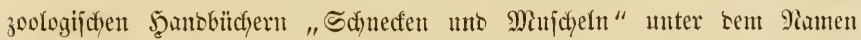
Ler Mantelthiere ober Miantelwürmer, \&alriaten, in Einer Silafje

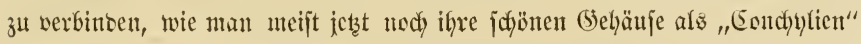
in ben Gammlungen neben cinancer jinzet, als gehörten fie jujtematifa jo bidyt zujammen.

Jedermann fennt bie Schnefen mit igren getwutbenen (sehäufen - Sdynedenhärjern - uno ebcnjo die zmeiflappizen Mujdelthiere, menn aud von lebztern bie Thiere jelbjt viefleidyt mur surdy sie Anjter; unt bennody ift man mit ber Yaturgefdyidyte siejer Thiere uno mit ifjen

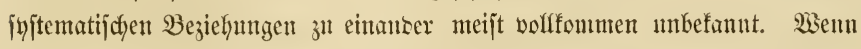
man eine jener präbljtigen porzellanartigen Seejd)edfen einmal nidjt Eondylye, jonbern beutfich amreben will, fo jagt man Miujdyel, was jie burdjaus nidjt ijt, uno went man bagegen verfichert, es jeien bies eben 
jo gut nur Sdynedfenfänjer, wie bie in unjern Gärten uno Wäloern, fo idjütteft man bajı viefleicht unglünbig ben Siopf. Das ijt bie Folge von ber eimjeitigen Sammelei ber "Eondybtien", beren Thiere, weil fie eben

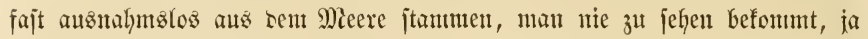
ïber beren jänen Fornen mo Farben man sie Thiere, sie barin Tebten

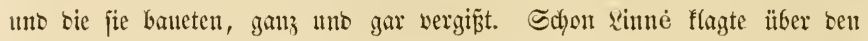
"rohen \&uุus", barbara luxuries jagt er, ber Eondfyltenjammfer, weldye

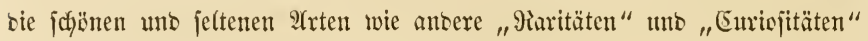
mit ungeheuren Freijen bezahlen. Darin waren namentlid) bie Şollänber

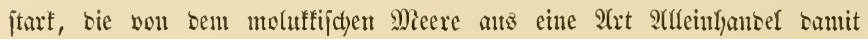

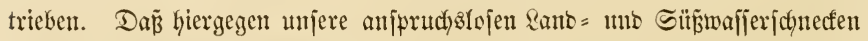
uno Minjajefn nidjt auffommen founten, ja ganj unb gar ubeachtet biteben,

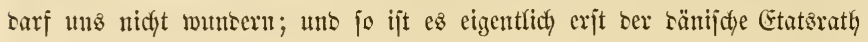
D. F. Müulfer, tweldyer แn 1770, auf Pimté fuzent, ihnen eine allge=

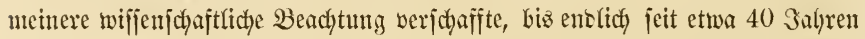

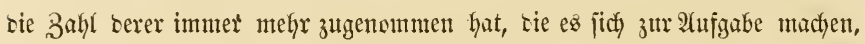

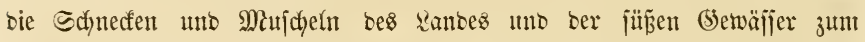
Segenjtanbe ifyres Sammeleifers mto ber eingehenteren Beobadytung zu macfen.

Sntem wir bie oben angebeutete früfere Bermengung ber $23 e i d f t$ there unb ber Manjhelthiere in eine Siajןe nidyt weiter erörtern, wollen wir zแnächjt von ben Midfusfen ober Weichthieren hier auch nur biejenigen Abtheilungen befprectjen, wetde in ben Wälbern unb seren Bewälfern ber=

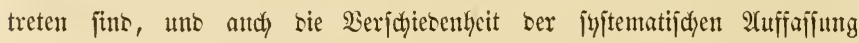
weiter unten mur furz berïlyren, ber jie nod) unterftegen.

In ber iyjtentatijuen Heberjidyt fanben wir anf 5.37 bie 2 seidy $=$ thiere als 9. Thierfajie an ber Spize ber bauththiere, (5ajtrozoa, uno ans ber fuzzen Gharafterijtif biejer exjałen wir, baj biejelben eine ven ben (5) rieberthieren, zu weldyen bie biaher won uns abgehanbelten Thiere

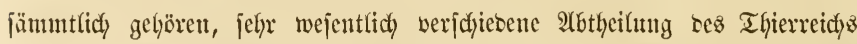

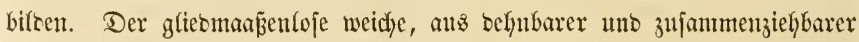

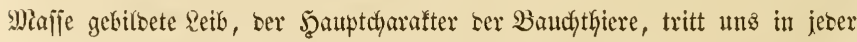
vor uns friechenten Schnede jefr beutlidy vor Âtuen.

Wem wir hier sas Wort Weidythier, Midllaf, atz Rlajןennamen brauchen, fo brautchen es Anbere als Bezeicfunung für eine ganze 9ieige 
von Thierflajjen, ganj gleidj)bconteno mit Banddtficr. Die biefez Re(ztere

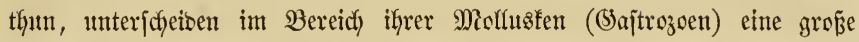
Safife, bie jie Sopfweidythiere, Eephalophoren, nennen, weil jie von

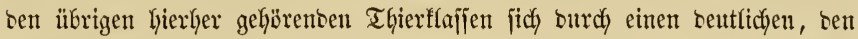
iibrigen melyr soer weniger mantgelnton, Sopf attżeidynen, wic unz ein joldyer mit jeinen 4 ausftreffbaren Füblern an ben Ranbjdynecfen befannt ijt.

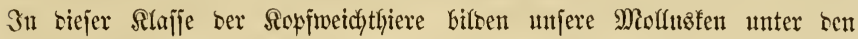
Ramen Baudfitizler, (5ajteropoben ober (5) aftropoben*), nur eine

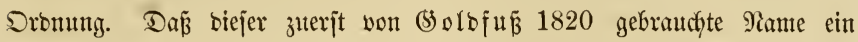

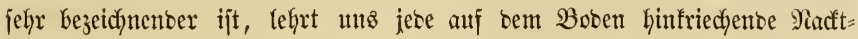

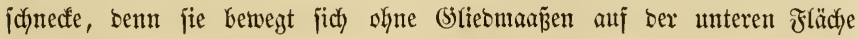
ifyes langgejtrefften Reibes, bie ganz pafjent Baud genannt werben fann.

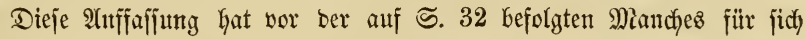
unb wir erwälynen jie hier beshalb ausbrütflich, weil jie wafly jheinlich in

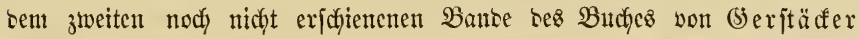

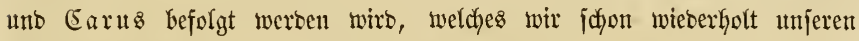
Rejern zu iłrem weitern Stubium empfoflen haben.

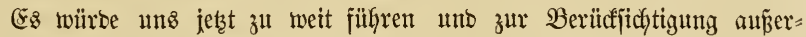

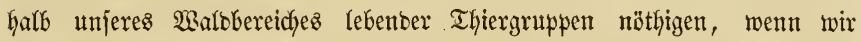
jeşt eine affgemeine, wenn aud nody fo furze Charafterijtil ber ganzen Stajfe geben woflten, mögen wir bieje nun Weidjtbiere (Molftałen) ober Sopfweichthiere (Cephalophoren) nenten. Wir bejdyänfen uns viefmełp auf bie eine Dromung berjelben, welche alfein im Walbe vertreten ijt, uno

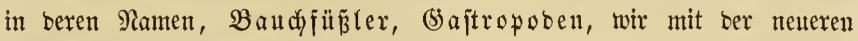
Syjtematif zufmmentreffen.

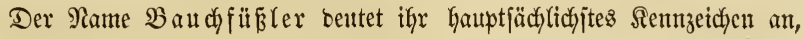
bie platte Baudffläche, in weldyer ein reidjer Małłelapparat bie Betwegung

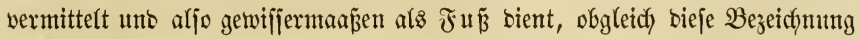
gejtaltlicy jefr umpajient angetwentet ijt. Piidftiger nent man bieje Fläche Sohle, uno Juß bas Gintere Enbe bes aus bem (5iehäuje vorjtrectbaren Theiles bes Thieres. ¿ะs jint nämlich) bei weitem bie meiften (bajtropoben mit einem (behäuje verjeḩen. Bei ben (behäujejduneden - benn ntan fann

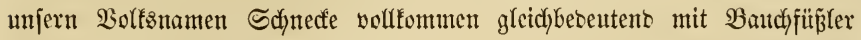

*) Spradylidy lafien fids beibe Sdyreibarten redjtiertigen. 
ocer 2seidythier gebrandyen - ijt bas (sef̧änje inmenbig, wenigitens in

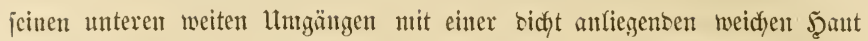
belegt, sie man Miantel nemnt - Saher man sie filajie (mit ben

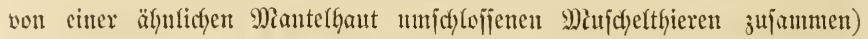
jonit and Mantelthicre, Falliaten, namte. Dicje Saant, bie tiefer

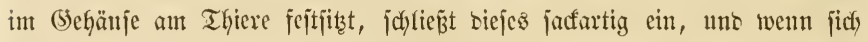

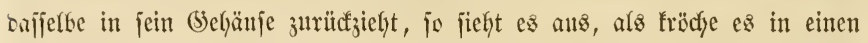
Sacf, inbem ber Mantelrant in ber Münoung zuletżt alfein fidjtbar

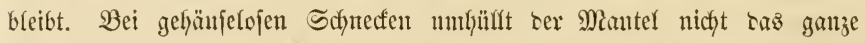

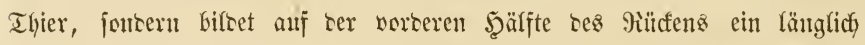
cirunces ङchill, unter welches nautentfich baz Sopfente wie unter eine Sapuze 3urïtfgezogen werten fant. Der Sopf unjerer Weidytgiere sber Schneffen, ın fortfin mur sieje zu berïffichtigen, ijt, wie jese (s)lieserung surch

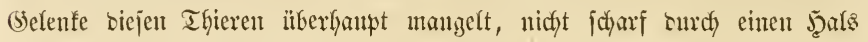
wom ïbrigen seibe abgejęzt uno trägt 4 ober 2 Fïhler, weldye (wenn 4 , Gloz sie 2 oberen längeren) an ifyrer Epitze ober an ifyrem (5runbe 9 tugen tragen. Das Manl ijt mit einer hornigen an Rambe meif́t geferbten Eberfimlabe werjeken ( . weiter unten Jig. 91 a), an melche jidy ein nicht ganz ridftig 3 unge, ridftiger Meibeplatte genanntes, im Edylumbfopfe

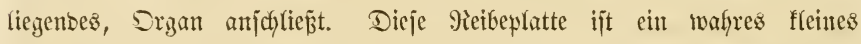
23unterwerf unb hat jeit igrer genaueren Beobadytung wou Seiten ber

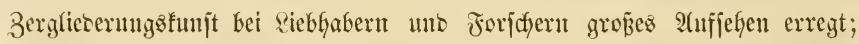
"Sdynedfenzungen" fehlen bafer in feiner ber mancfyerfei verfüıfflichen Sammifungen mifroffopifder Sbjefte. Die Zunge, um ben cimmal angenoumenen älteren Ramen beizubehalten, ift entwerer ein mefy ober weniger

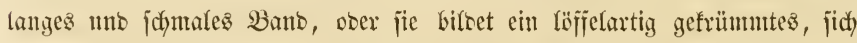
aber für bas Mifroffop flach ansbreiten Lajjentes (Sebiltse. Sic bejtelyt ans

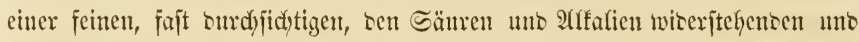

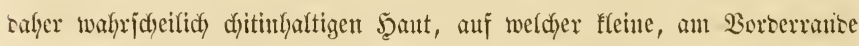

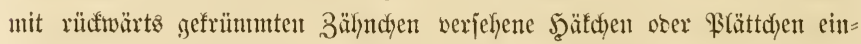

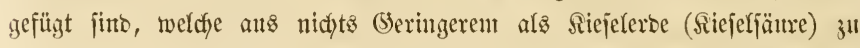

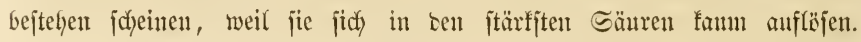
Dicje bitoen, äfnlich wie tie Fapillen anf ber 3nnge vieler Sängetfierc,

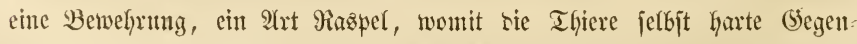

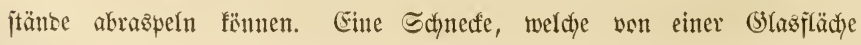


Saran jitzente Stoffe abnagt, fam man von ser (Segenfeite mit einer Smpe

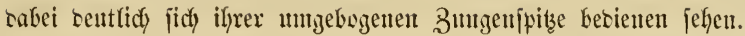

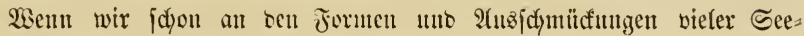

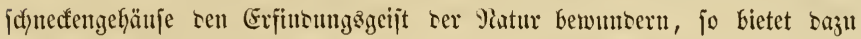

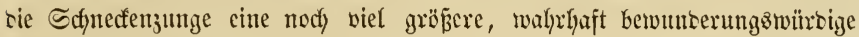

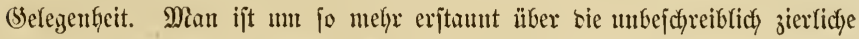

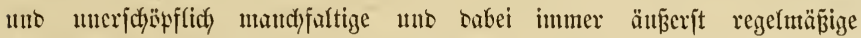

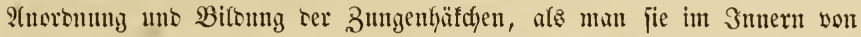
Thieren fütet, seren ganzer Sörper übrigens von alfebent bas Segentheif ijt, eine łeinen 2lugenblicf fejte Formen zeigente, fontern nady allen Seiten

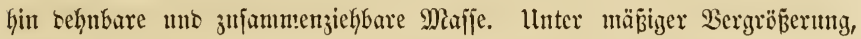

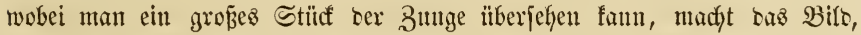

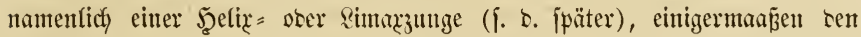
Eincrucf einer fein facettirten Siryjtallglasflädye, weil bie ફ̧äfchen voll=

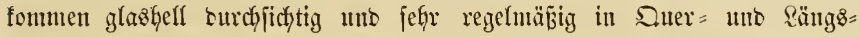

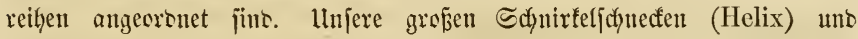

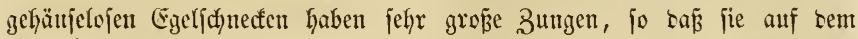
Dbjeftgläschen ausgebreitet biz 3 sinien lang unt $1 \frac{1}{2}$, sinie breit fint.

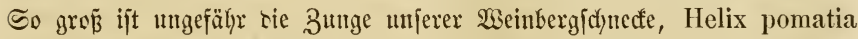

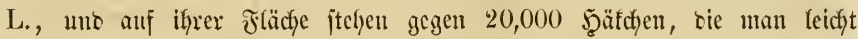
zählen fann, wenn man bie Suerreihen uno in einer berjelben bie einzelnen

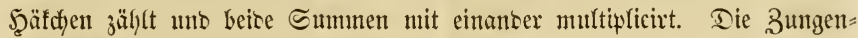

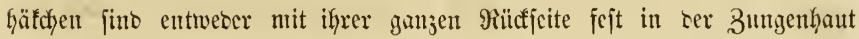
eingewachjen mto auch jeitlich an eimanter bejejtigt, socr, namentfich sie an

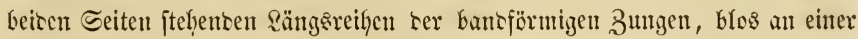

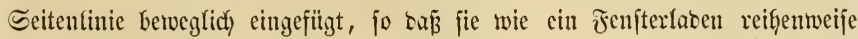

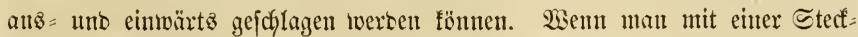
narel von hinten nad) vorwärtz über bie 3umgenflücfe jtreidft, fo fïhlt

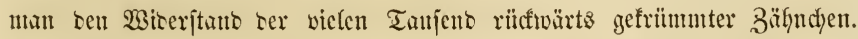
Bejonters hervorzuheben ijt eine bemerfensmerthe (Eigenthümlichfeit ter

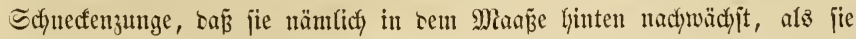
jich) Lurch taz 9eiben an harten Sörpern vorn abnutgt. Wenn man ben Schnedenfoth mifrojfopifdy unterjudyt, fo fintet man barin bejonters bei ben Schnirfeljchnedfen oft ganje f(d)ach)bretartige Feloer von 3 ungenläfchen,

Die Thiere Deß 2Baldeళ. II. 


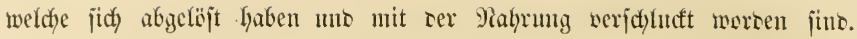
Betradytet man eine Sdjnctfenjunge won born bis linten, fo fintet man

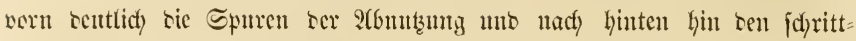
weifen llebergany won jertizen unb harten $z^{\text {ln }}$ ben erjt angelegten ned

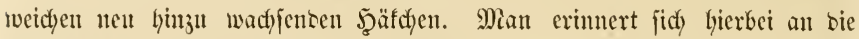

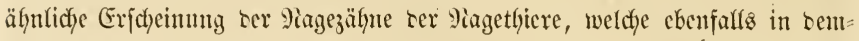
felben Maaje hinten in ber Zahngrube nadtwadyjen, als jie fidy born abuntzen. Sou ganj befonterem Snterefie ift bie Bunge mandjer im

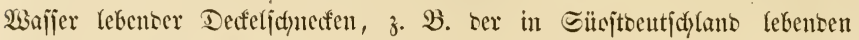
Melarapha glabrata Miihlf., beren 3muge - bremal fo lang afs has ganze Behänfe ijt! Sie ift aber ganz fdymal fabenfürming mo wie cin

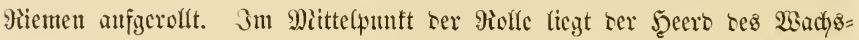
thums, wo bie 3unge immer nad)wächjt, wic jid) sas vortere Ente abrwicfelt unเ abuntzt.

รig. 90.

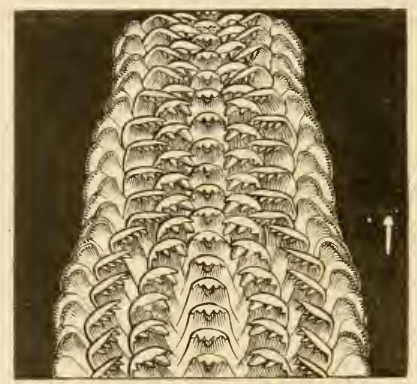

2orberer Theil ber Bunge vou Cyclostoma elegans Lam. (ftarf wergr.)

Bon bicjer bejartebenen Biloung cincr Edyneffenzunge fant mujere Fig. 90 frcilid) nur cine jehr mooll= fommente Boritellung geben, wie $c 8$ ïberbant $3^{\text {nl }}$ ben fofwicrigiten 2 uf = gaben ser naturwififenfdajtlitfen Simpit

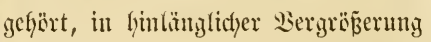
cill in sen Formeinjelkeiten sie Yatur tren wictergebentes Bilo ciner ganjen Sdjnedfenjunge jll jeidjnen, was unferen 2 sij̄ens aud) nod) niemals berjudst worten ift. Ilnjere Figur zeigt

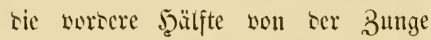
unjerer gräpiten bentictyen Sanc-Decfel= jdjnecte, ser jierlichen sreismunofducfe, Cyclostoma elegans

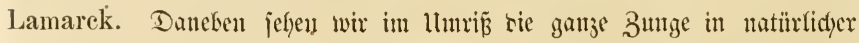

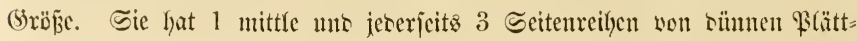

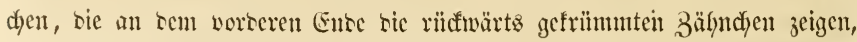

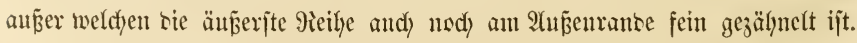
Die 3umge zählt 130 Duerreifen, aljo zujanmmen nux 910 Zungenplättchen. Die bciren Ecitenrcigen jererjeits fönnen wie oben bejdyrieben ansıärtz 
geflappt werben, wo bann bie 3unge viel breiter erjotheint, wie Jig. 90 zeigt.*) Das (5ehäuje biejer Schnedfe jehen wir weiter unten anf Jig. 92 B. q.

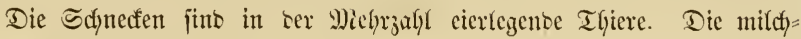

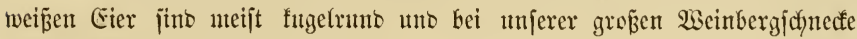
erbjengroß $\left.{ }^{* *}\right)$. Sie haben jelten cine fejte Salfidjale, fontern meift cine

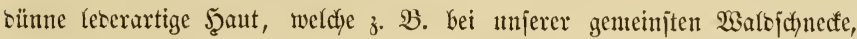

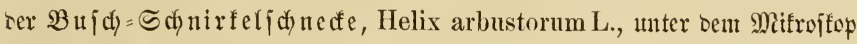
bidyt aber bentlidy unterjacisfar eingeftrente zierfiche fialffrujtalle zeigh.

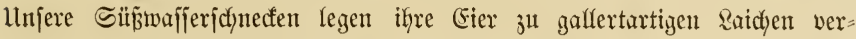
bunben. Mehrere Arten gebären tebentige Sunge. Die meijten Sdjnecfen

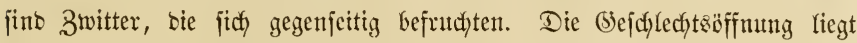

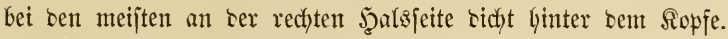

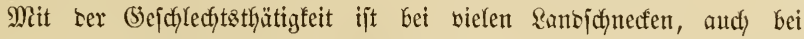
vielen unjerer Walbidyneffen, eine Erjheinming verbunten, welche alle bie in bas hädjite Erjtaumen jetzt, weldye zun erjtenmale bavon hören uno

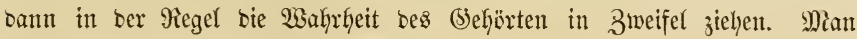

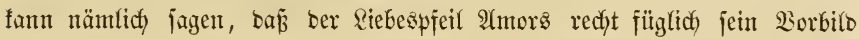
bei sen Schneffen haben fann! - Wir jehen in Jig. 91 a ben (Bejdyedts = apparat unjerer gemeinen ફ̧ain = Sdynirfeljdyneffe, H. nemoralis Müll.

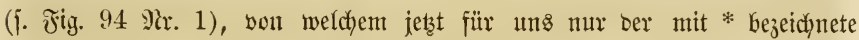
Pfeiljact won Berentung ijt. Es ijt biez ein nahe ber (Bejejledjtäffnumg

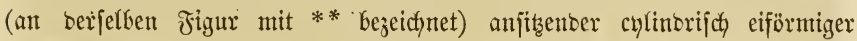

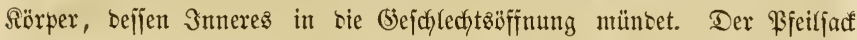

*) Eine Befdreibung ber 3ubereitung von Sdjnedenzungen für bas Mif́rojtop

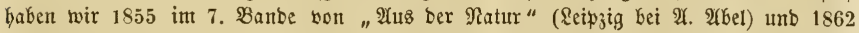

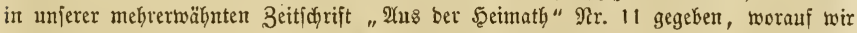
unjere \&efer verweijer. Inatomijde (sejdjidlidfeit fommt babei gar nidyt in Frage. Den Sdylunbfopf, ber bidyt Ginter bem Maule in Ropfe Yiegt, erfennt man in bem abgejdnittenen Ropfe leidjt an feiner futgeligen (Sejtalt; biejen zerfodit man in einem

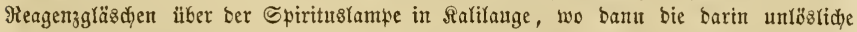

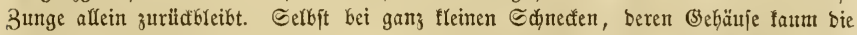

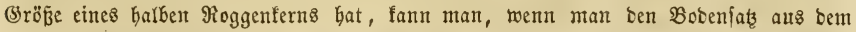

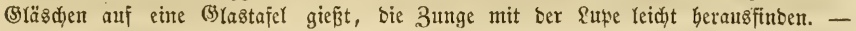
Wer ein Mifroffop befizzt, fantt fidh leidjt eine Sammlung von biejen fleinen zierlidjen Wutberwerfen Gerftellen.

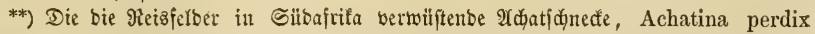
Lam., legt Eier bon ber Fornt uno Bröf̧e ber Taubeneier. Ş̧r (5ebäufe mirb bis 7 3oll lang. Sie ift bie gröfte Eanbjdynecte. 
Fig. 91 .

a
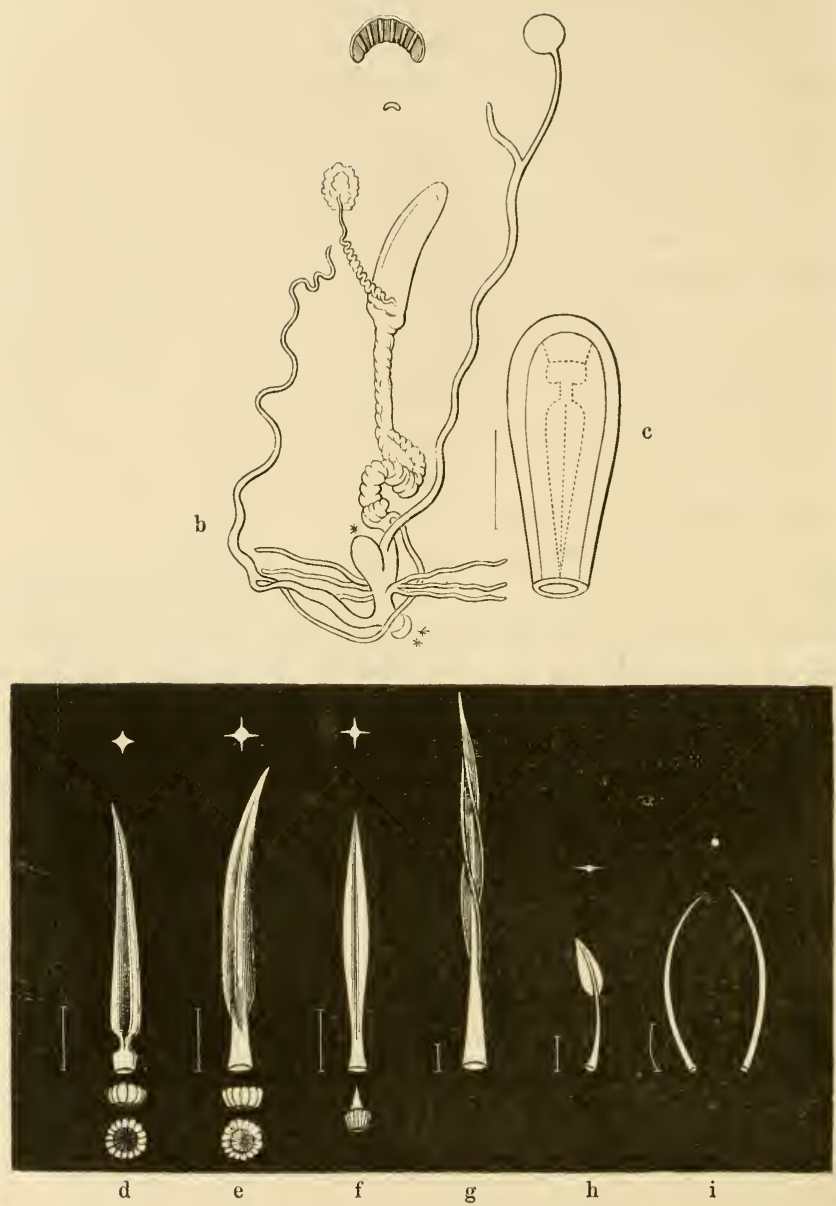

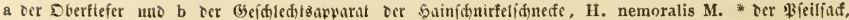

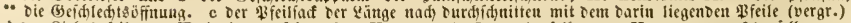

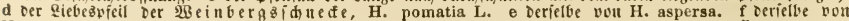

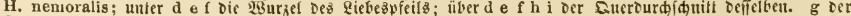
Qiebezpeil vou H. serleea Müll. h Derielbe von H. arbustorum M. i die 2 \&feile von $H$. ericetorum $M$. (शlle vergrïbert.) 


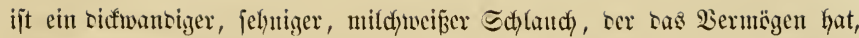

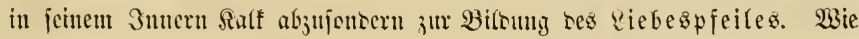

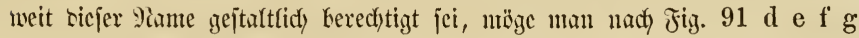

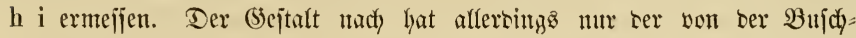

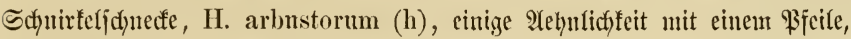
obgreid) ber frumme Gafjaft ocu zuwioer ijt. d e uno f jinto mefyr vier=

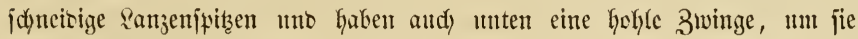

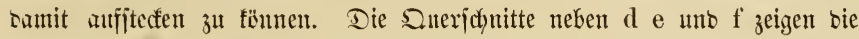
id)arfe Bierjdnneibigfeit. Bei $\mathrm{g}$, ser \&iebespfeil ber nidyt viel über erbjen= groß̈en Hel. sericea Müll., fint dic Schneisen jogar jofraubenförmig

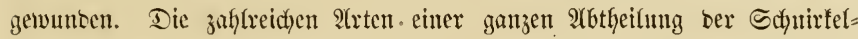
ichnecten, sie jetzt eine eigne (5)attung bitben, haben jogar 2 bidyt an einander liegente Pfeiljäcfe unt in jeben einen frummen idneiserojen Pfeil, von benen rer eine jeroch immer jtärfer gebogen ijt alz ber anbere. Âtjo 2 frunme Säbel! Die unter d e uno f abgebilbeten fronenähnlidjen

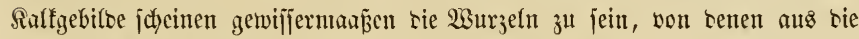

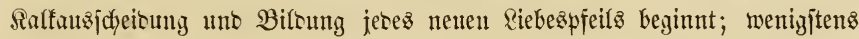
finbet man jie nie an einem von ber Sdjucte abgejdofjenen Bfeile, jonbern nutr an ben aus bem Pfeiljacfe herausgelöiten, weldje aber an biejer 23uzjel inmer nur loje anjizen. Matür(idy fintet jid) biejer Sörper an

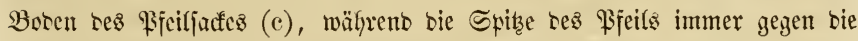
Mlünoung beffelben gericjtet ift. WSenn man recht viele Pfeile aus bem

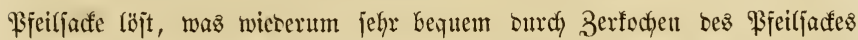

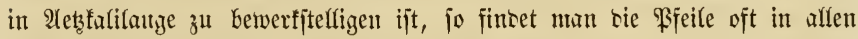
Stufen ser Solfentung, noch weidy uno häutig ober fejt uno auz blentento

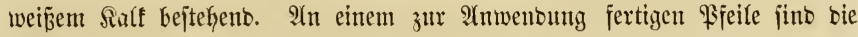
Sdyneisen, wemn er beren hat, uno bie Spize immer haurfdyarf. Weldye ijt aber un sie 2tnwenoung biejer mit jo getwagtem Mamen benannten

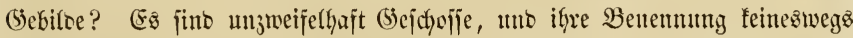
eine gewagte. So viel jtelt fejt, Dẩ vor ser Begattung bie Schnecfe iffrent Bjeil abjchiest, uno jwar faum weniger unjweifelfaft in ber 9tbjicht, bie antere bamit zut treffen. Befanntlich joncern bie meijten Sifnedfen Sdyleim

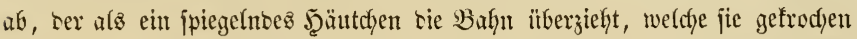
fitte. Dies ift namentlich auf bem Blatse ser Jall, wo cie Wegattung ftatt=

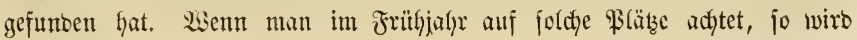


man fajt inmer in tem Schlcimipiezel rie beiben Pfeife flebeno finten. So oft uns bies autch geglitcft ijt, ttno obgleich) wir mefrmals Schnedfen gefmeen haben, tenen ein Pifeil mit ter Spize in ber rectsen J̧arsfeite jectte, ser mur won ciner anbern anf jie abgejchoffen jein fonte, fo haben

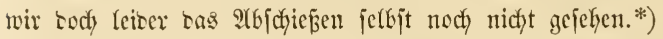

Wir ïberlafjen nach biejer wahrheitsgetrenen Mittheilung unjern \&ejern, über sie Berechtigung oer Benenmung Riebespfeil jelbjt ju enticyeiten, แmo

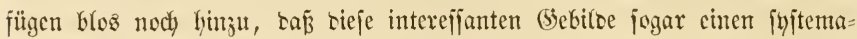

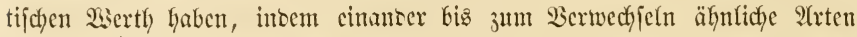
soch ganz verjejiesen gejtaltete siebespfeife haben, z. B. H. ericetorum M. uno H. obvia Ziegl., weldye lange für 2 formen einer uno berjelben 2rit gefarten murben.

Mach) biejer langen Einjdyaltung fafyren wir in ber Bejdyreibung ter Srganifation ber (5)ajtropoden fort uno crmäfnen, baj biejelben theilz surd) Sungen (Emryenjdyedfen), viele im :

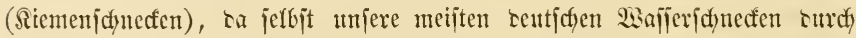
Sungen athmen. Die sungen bejtehen ans einer am Pü̈ffen nach ber Scite

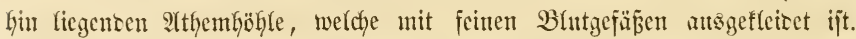
Man jieht fie au beutlichjten bei unjeren gropen gehäujelojen wegjofnedfen,

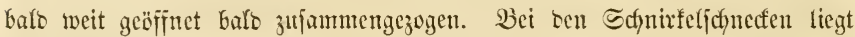
bie Âthemäffnung im Mantefrante (†. Fig. $93 \mathrm{e}^{*}$ ). Die fitemen ber wafjerathmenten jumo meift jierlich vergweigt mo treten $\mathfrak{j}$. $\mathfrak{B}$. bei ber fig.

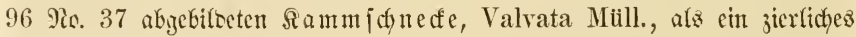
feterdyen hervor.

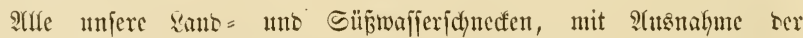
befannten 2 gehüufelojen ober Nactjchneden-(5attungen Arion uno Limax,

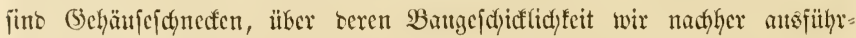
licher iprectyen werben.

*) 23shl aber war ber Berfaffer biejes Banbes einmal bidjt babei. Im 2april 1850 ober 51 war id in Stuttgart mit meinem lieben Frenno Firofeffor $\mathbb{F}$. Rrauń,

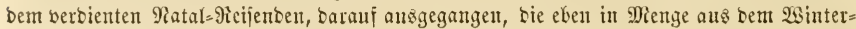

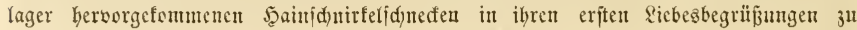

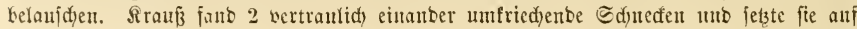

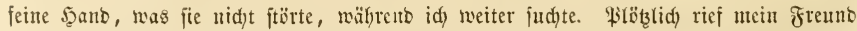
mit fajt erid)redter Stimme ben weltbetannten fräitigen fd)wäbijden Jlud aus. Sd)

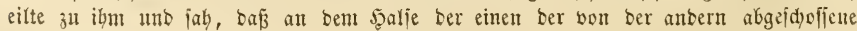
Breil hing.

Rr. 


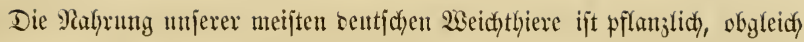

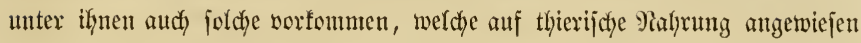
finto, ja mandye frefifen einanber ferbjt fanment bem Befhäuje auf.

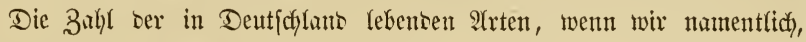

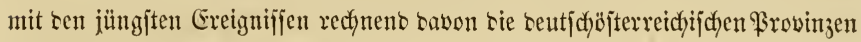

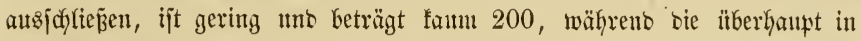

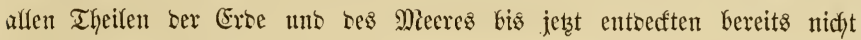
viel unter 20,000 fein werben.

Shren Rebeens = mo Mafhrungsbebürfnififen nach finto fie an cinen

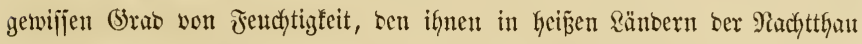

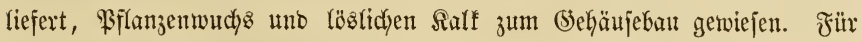

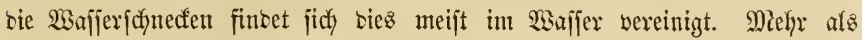
bei irgeno einer anbern niebern Thierflaffe nimmt jelbjt bei bent Bef̧äujen

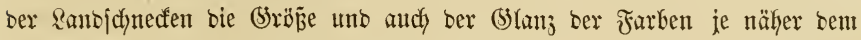

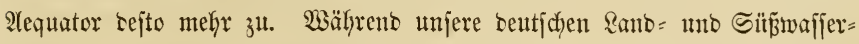
weeidfthjere fajt nur unjdecinbare farben haben, finben jith bort, ganz bejonters auf sen \$riliqpinen, bie brillantejten Jarben, Gejonbers Gelb,

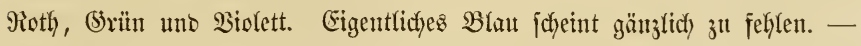
Die Dimenjion ber grösten Ranojdunede haben wir bereitz angegeben

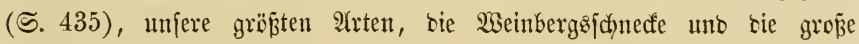

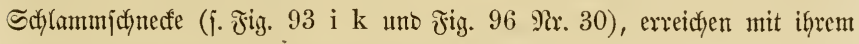

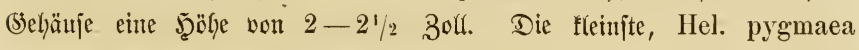
Draparnaud, ift faum $1 / 2$ sinie gro $\tilde{\beta}$.

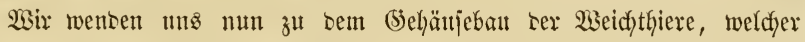
nidft meniger als ifye Bunge uno ber Siebespfeil unfer ganzes Sntereffe in

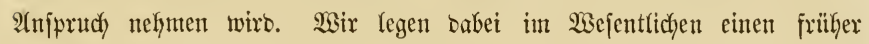

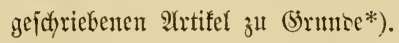

"Omnia mea mecum porto" - all meine Şabe trag" id̆ bei mir iit ser Spruch tes Betters uno tes Meifefertigen. Mit rem wollften

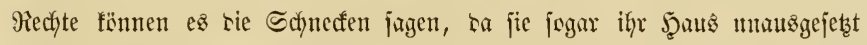

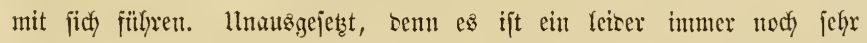

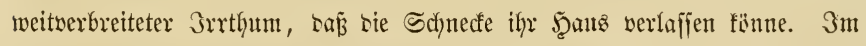

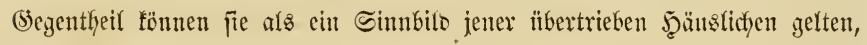

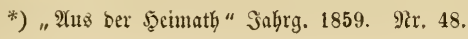


Denen es nirgento wohler als imnerbalb ifjer vier 2 sänbe ijt. "3d) bin ganj mit meinem ફ̧auje verwadjen" - jagt mandye Şansmutter mit ctmas übertriebener Fiflidyttreue, uns sie Schnecfen müß̄ten ez im budjitäb: lichen Sinne jagen, wenn jie reben fönnten, benn fie jinto wirflich, obgleidy mur an ciner cinzigen Stelle von beffen ?(d)je, mit ibrem ફ̧aufe verwadffen.

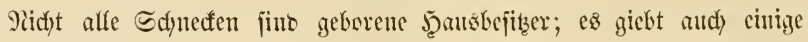
Sbrad)loje, aber feinen einzigen Miethbewobner. Die (şehänjcjdynecfen fino

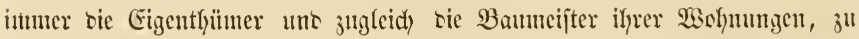
senen jie, wie wir, Salf, un shye weitere Zuthat, werwenten. Den Oroad)=

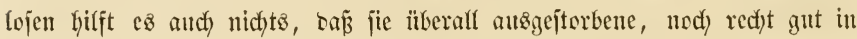

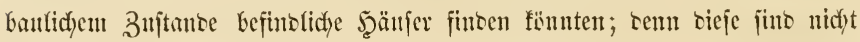

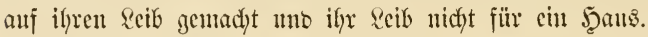

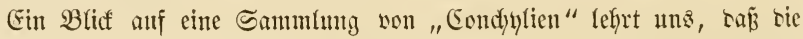

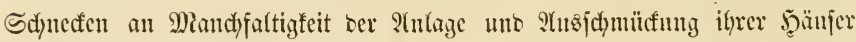
unjeren exfintomgareidyen 2trdjiteften nicht nadjitefyen. Uno boch ift ifye

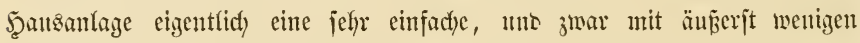

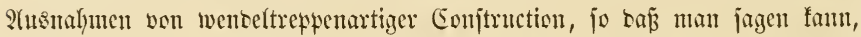
bie Schnedfe betwolynt eigentlid) blos cin Ireppenhans ofne meitere (5emücher, Säle uno Sammern. Das langgệtrectte Tlyier erfüllft immer sen ganzen wenteltreppenförmigen 9aum jeines ફ̧aujes mo liegt mit jeinem Sopfente inmer nahe an ber Thïr, um jecen Stugenblicf barans hervortreten zu fümen.

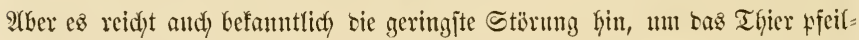

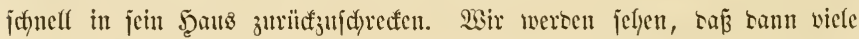
sen nadyoringenten Feino mit ciner hantfeften Thür abzuthalten wiffen.

Wir miiffen junädyjt aber einige Miunten bei sen gebänjelojen, sen fogenannten Madfid) ne ofen verweilen. WBir alfe fennen bie grop̃en, meift

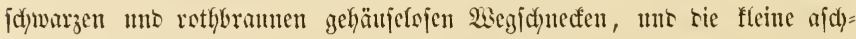

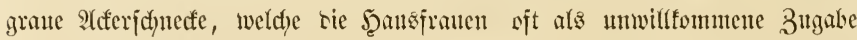

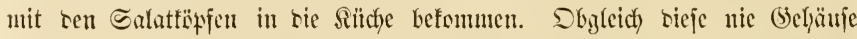

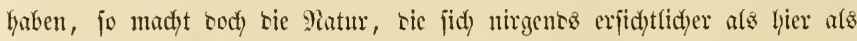
2rrbeiterin in ciner reich geglieterten Stufenfolge ifjer $\mathfrak{W}$ serfe zeigt, fdyon bei ityuen ben ?tufang zแm (bebäujeban.

S(n ber Stelle ses 9iülfens, mit weld)er bic (3ekänjejdynecfen an ter

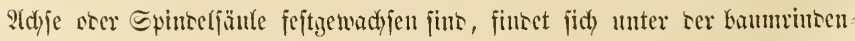

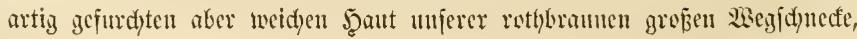




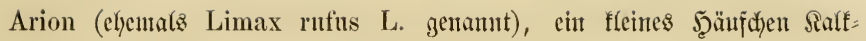

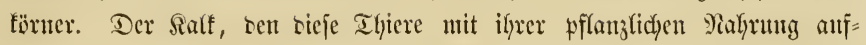

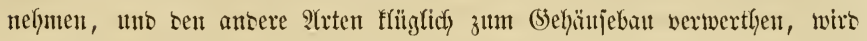

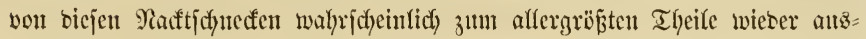
gejujicsen uno nur cin fleiner Theil sawon an ber bezeidyteten Stelle

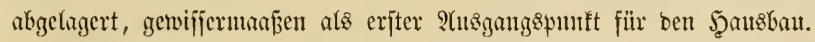

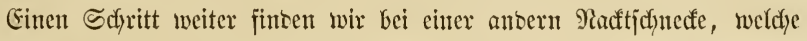

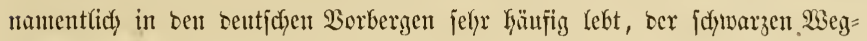
id)neffe, Limax maximus L., unb ber vortyin genannten fleinen granen Ifferid)uctfe, Limax agrestis L. Sie haben an berjefben Stelfe unter ber ફ̧aut verborgen eine fleine \$latte, weldye einem Fingernagel älyntich ift

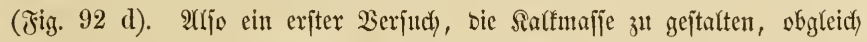

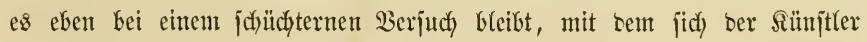
getviffermaaß̧en noch nicht an bas Tagezlidyt wagt. Es fei hier eingejdyaltet,

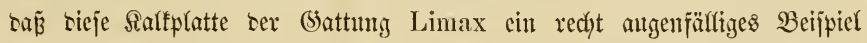

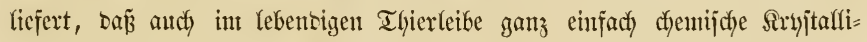
jationsprocefie borfonmen. Wisn man ein nody unatsgewadjpenes Thier affinet uto bie nod) unvollentete Sulfalatte herausnimmt unb unter bem

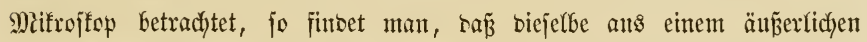

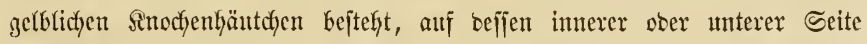

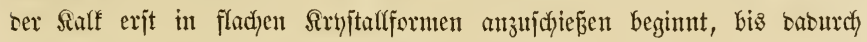

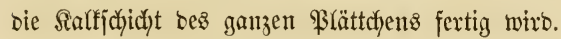

Da wir แnz in biejer ganzen Mittheitung aแf bas bejđyränfen wollen, was unjere beutjcyen sejer uno sejerinnen vor ifyer Thür fefbit beobadyten

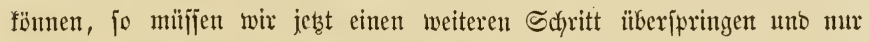

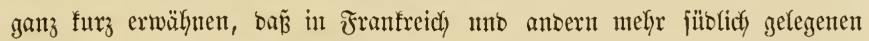
Sänbern, jeoody aud) in Englano, cine Sduncfengattung, Testacella genamut, rebt, bei oer biefe Salfpplatte äuñertich am Thier uno zwar auf Der Schwanzipize liegt, aber nod) nidft entfernt als (Behäuje bient, nod) viel wenizer - als urjere morijtyen Damenfyüte als Sopifbedefłung bienent. Mian faun bci bem Salfiçälchen ber Tejtacelfe ben (5ecanfen nicht unter=

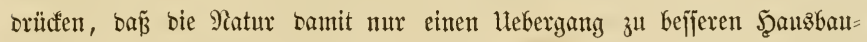
Serjuchen habe einjchalten wollen.

A(z was haben wir aber eigentlich bas Schnedfenfyas jut betractjen?

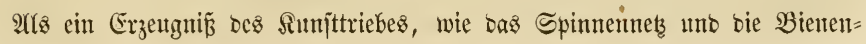




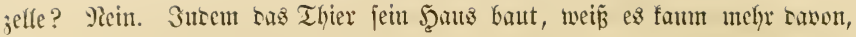

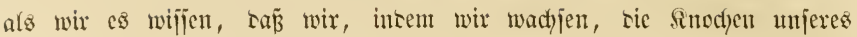

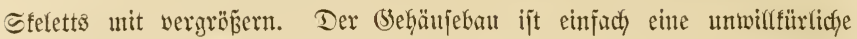

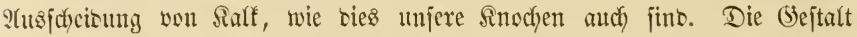

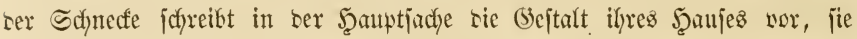
ijt jidy aljo gewifjermanên jelbjt ifyr Bamplan. T(ber nicht jowohl ber ganje seib bes Thieres, als vielntefr blos ein Theil bejielben.

Wenn unjere liebenstwürbigen sejerimen ifye unliebenswitrsige furdjt vor ten Sdhneffen iiberwumben haben, io nehnen jie cinmal cine größ̈ere

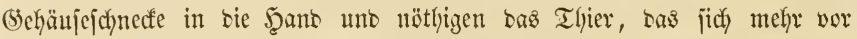

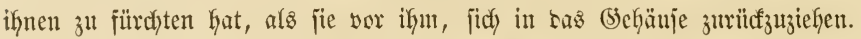

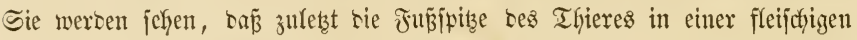
Majie, welche dic Miünoung ganz crfült, gewijijermaaß̌en verjinft. Dieje

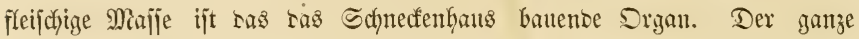

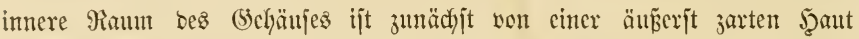
auzgefleiret, in weldfer bas Thier wie in einem Sacfe jteft, mo weldye

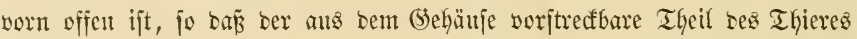
ans ber Mïnoung refielben hervortreten fann. Dieje Definnng sicjer jact= artigen J̧aut Ies Mantels ift jene fleijdyige und bicfe Majie, ber Mantel=

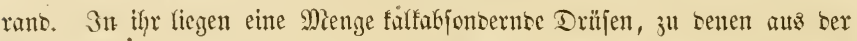

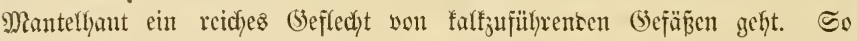
lange Das Thier an feinem (Sef̧üuje baut, liegt ber Mantelranto immer ganz vorn an ter inmeren Seite bes Munbjaumes bes (Befjäujes an, un

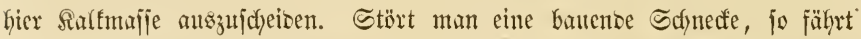

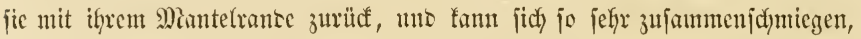

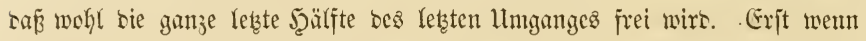
jie wieber trauten zll sürfen glaubt, tritt ser Mantelrano wieber vor uno

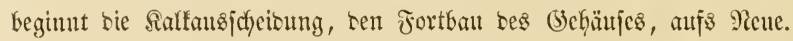

Die Echnecfen bauten aber anbers als wir. Wir mattern erit bie Wänbe auf, unb erjt nadhber werfen wir ben Salfputs auf. Die Sdynecfen

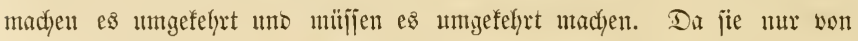

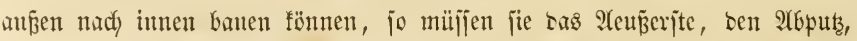
zmerit machen, uno bann erit inmen bie Salfmaner anlegen. Sener ift

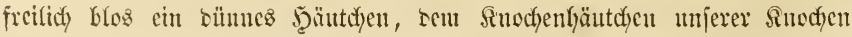
vergleichbar. Diejes ந̧äutçen, Dberl)aut, Espiberm genannt, giebt ben 


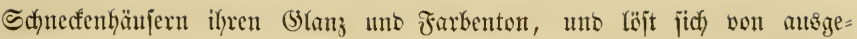

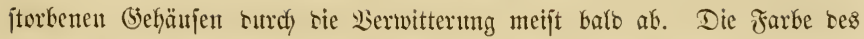

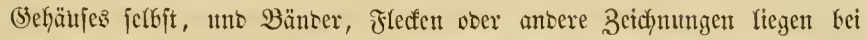
unjeren Sdyedfenbänjern ftets in ser Salfmafie, gehen alfo mit ber Dber= Gaut nidfyt berloren.

Die Sberb̧aut ift bei mieren meijten \&anb = unb bet fajt aflen unjeren

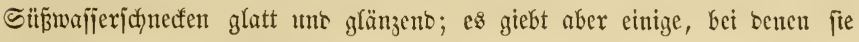

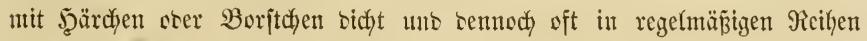
bejetzt ijt.

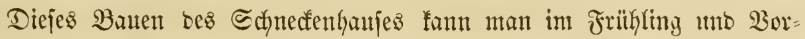

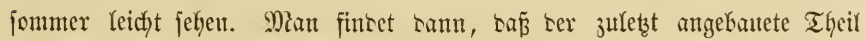

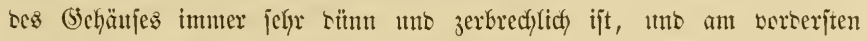
Saume erit mux aus ocr Dberhaut bejtelyt, ber bie Salfunterlagerung nech) fefilt.

Ehe wir ten Bantplan betradten, fragen wir, wie bie Schnedfe ify.

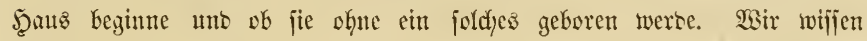

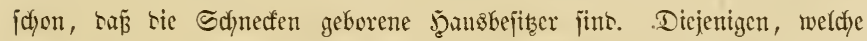

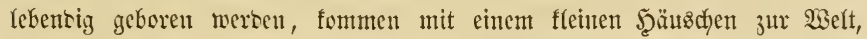

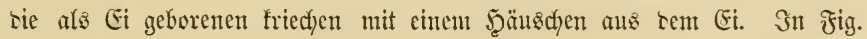

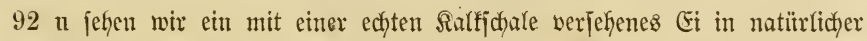

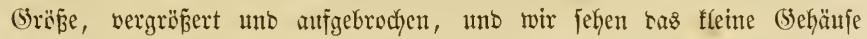
bez vertrodfneten uno sarum nidjt fichtbaren Thierdyens. Neben bem Ei

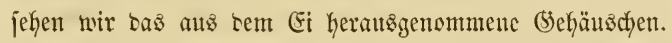

Ehe wir weiter gehen, mödyten wir unjeren Sejern rathen, irgeno eine

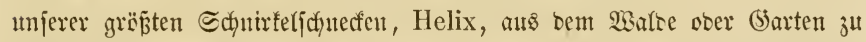
holen uno fie in fietenbent $\mathfrak{3 a j j e r}$ ju tösten. Mach wenty Mimuten hat

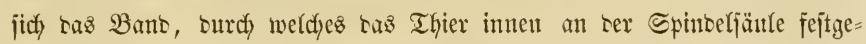
wachjen ijt, gelöit uno man faun mit einer frumm gebogenen Nabel bas Thier leidyt aus bem (sehäuje burch eine Sdyranbenbewegung herausorehen.

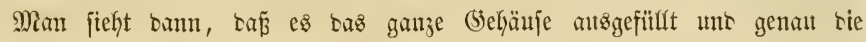
(5citalt hat mie ricfes jelbjt. Man fann nicjt saran benfen, La a burch

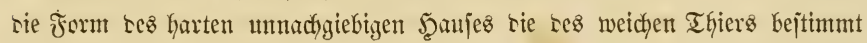
werte; es ijt umgefefprt, bie Umrijie tes Thieres beftimmen bie Gejtaft bes

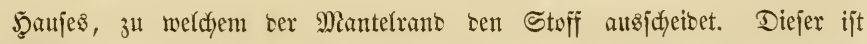

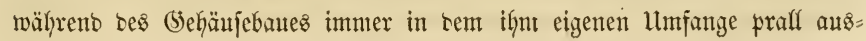




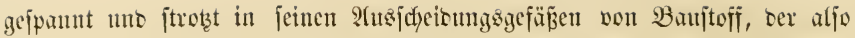

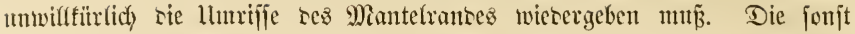

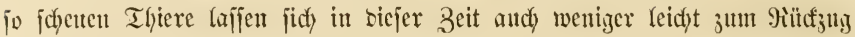

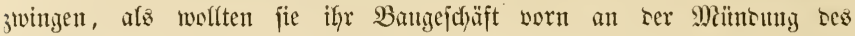

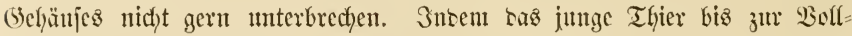

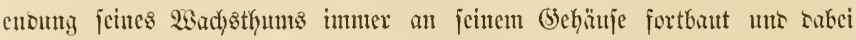

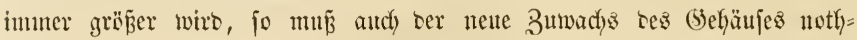
wentig immer weiter merten.

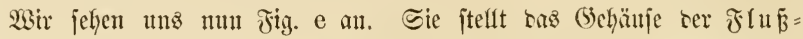

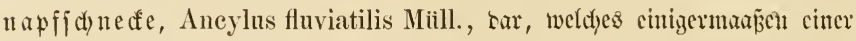

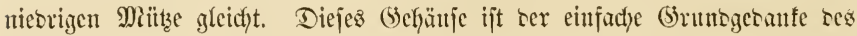
Sdynedfulfaufes: ein Goffler Seger; - ser Mathematif unfuntige Scicr

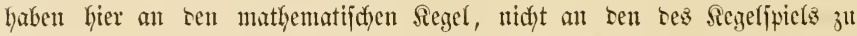

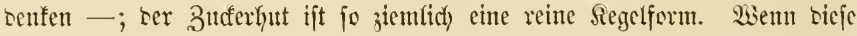

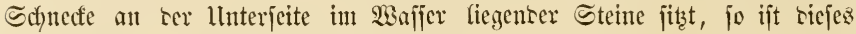

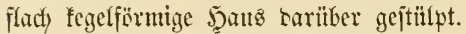

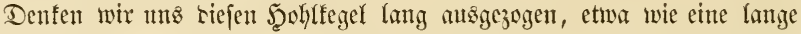
ipitze Frapicroüte, unt fdjraubenförmig getwunben, fo haben wir bie Theorie. ธes gewuntenen Edjnectenljaujes.

Dá biefe Theorie ridytig ift, leffren wie in antern Fällen ser natms=

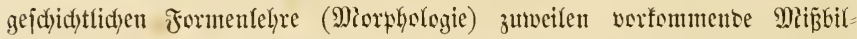

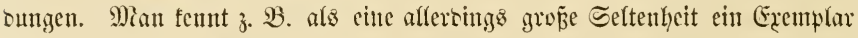
won H. aspersa Mïll. (₹ig. 93 e twirt unz weiter unten bie normale

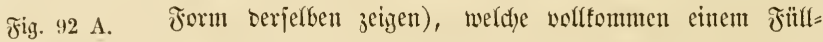

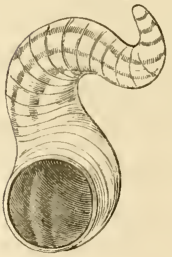

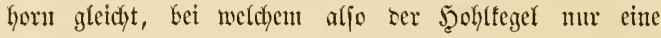
leidyt gefojmungene einem Sufhgorn äfurfidye form ange= noumen hat, nicht idjraubenförmig in an einamter

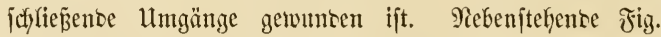
92 A giebt ben llunrī siejer Mişsildung*).

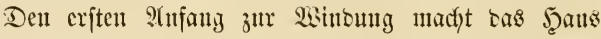
ciner Seejdynede, ber ungarifdyen Mï̈tze, Capulus

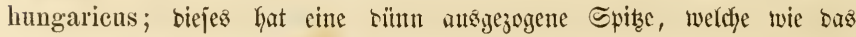

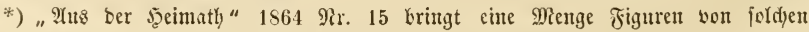

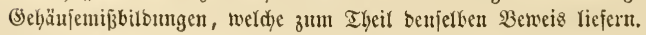




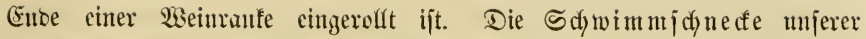
F(iiffe, Neritina fluviatilis (f) jdylię̧t jidy, wenn aud) nidjt unmittelbar, jonbern burdh einige aแţänbijdye Sdfucfenarten vermitttelt, an bie unga=

Fig. 92 B.

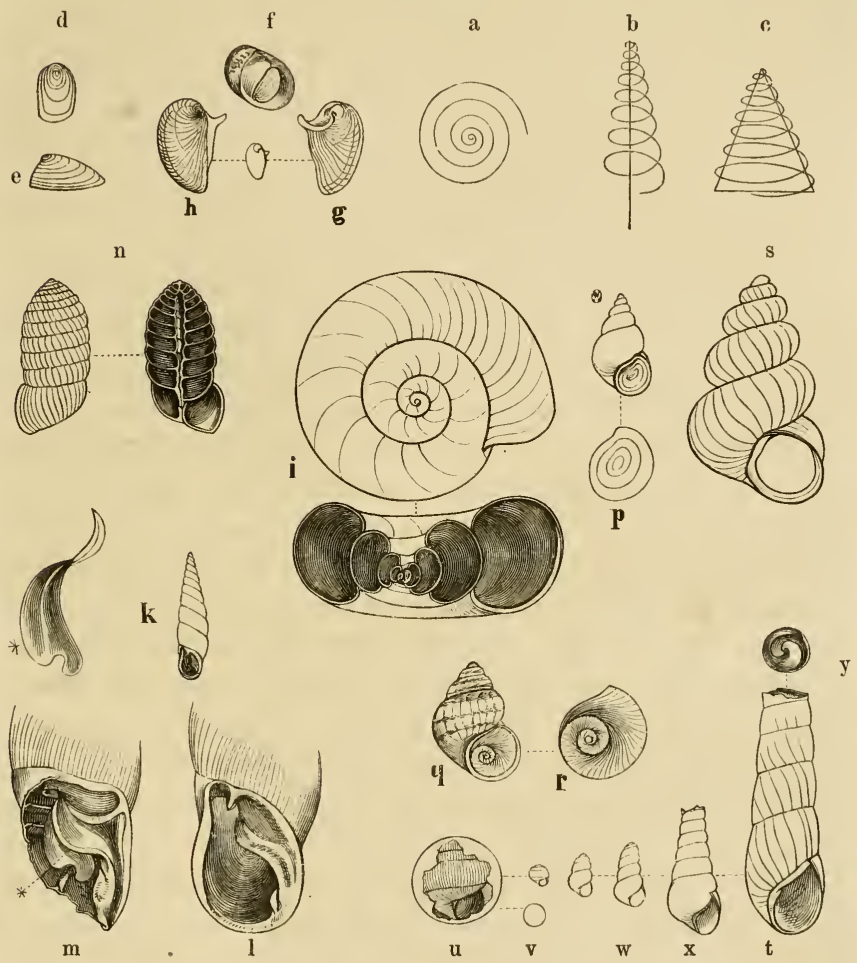

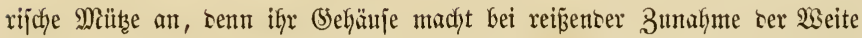
z'wei Umgänge.

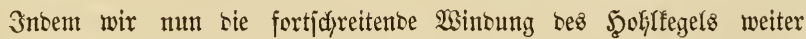
berfolgen, fo haben wix uns zu vergegenwärtigen, um was für eine 2(djje 


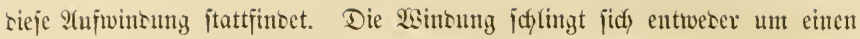
Funf, wie cine Hhrfeber (Jig. a), ober un eine Binie, wie bic Mngänge einex bünnen Sdyratbe (b), ober nu cinen Regel (c). Dicje breifadje Berjojiesenbeit ser wamsmgandje ijt ser eine bejtmmente (5runs für sie

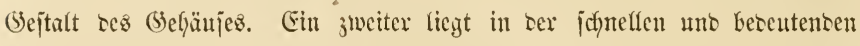

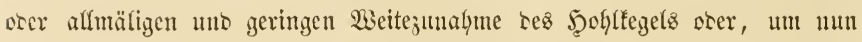
im Sinne ber 2 fmwentung ocs (5ejetzes ju iprethen, ber llmgänge.

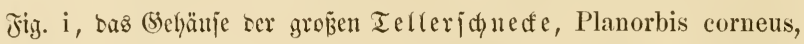

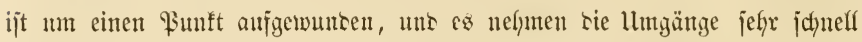

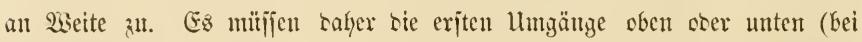

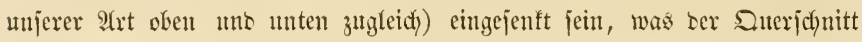
Des (jehäujes unter Fig. i jeigt.

Die Gebäuje ser Areismundichnedfe, Cyclostoma elegans (q),

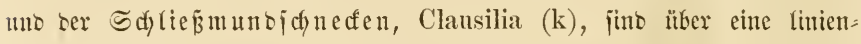
förmize 2 chje von ziemlidy gleidfer eänge aufgewumben uno hätten saher von biejer Scite (5rumb, einanber jelyr älynlidf) jn jein; aber bic llmgänge

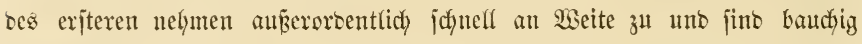

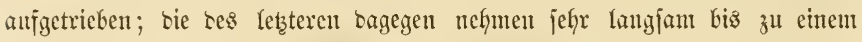

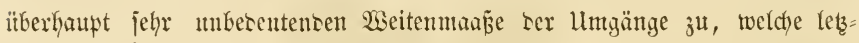

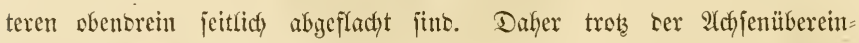

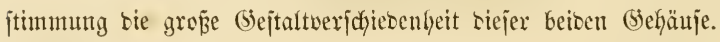

Fin ̈̈ber einen Segel, ober vielmefyr über einen Glos getadyten Segel,

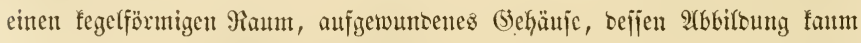
nöthig facjen, muñ, won unten gejeken, won unten bis zux Spizze cine

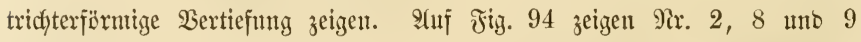
(b)häuje, die über einen jđ)malen, 9ir. 6, chra, weldyes über einen Segel mit fefrr breiter (5rumbfläche getwumben jint.

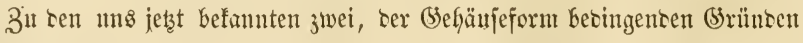

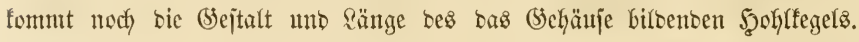
3unächjt ijt bie ani bem Sueridnitt rumbe Bejtalt befjelben Fegel, wie fie

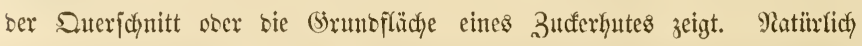
vcrtient bem @ueridnitt halbfreisförmig, halbmonoförmig, breiectig, vierectig, fünj= ectig, was âtles anch vorfonmt, bann ift er fein reiner Siegel melyr; wir

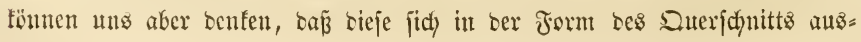




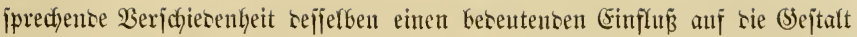
bes Schneffenhanjes ausïben mur. In ben meijten, aber nicht in affen

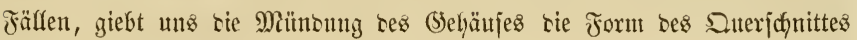
feiner llntgänge wieber.

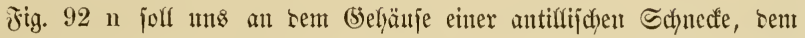
Bienenförbden, Pupa uva, uno an befien Sängasourchjdutte - ber

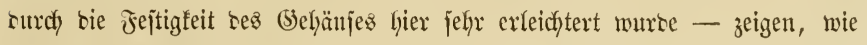

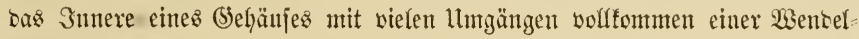
treppe gleicht.

3uweifen werben bie Sdjnedfen burdh ftörenbe Einflüfje genöthigt, von Dem ifyrer 2Trt eigenen Bauplane abzutweichen. Dics zeigt uns s, eine lang

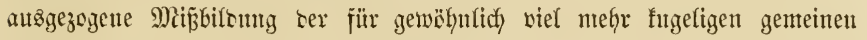

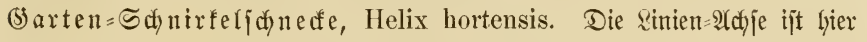
boppelt fo lang als jie bei bicjer 2 art getwöhnlich ijt.

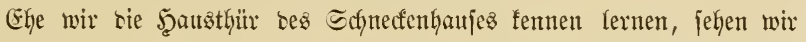
uns in Jig. 92 B. t-x eine burd) ciue unerffärliche Sonterbarfeit in Europa

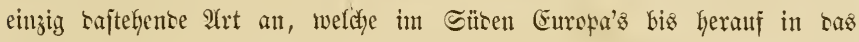

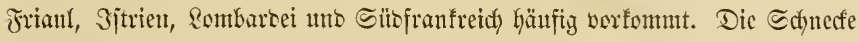

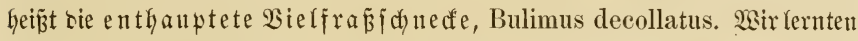

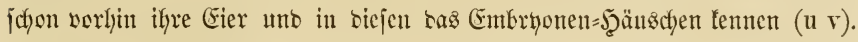
Jig. w zeigt uns ein junges und bie Şauptfigut ein altes aus̊getwachjenes

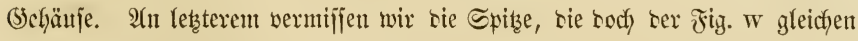
mǖpte. Daz ift eben sie Sonterbarfeit! So twie bas Behäuje bis zum 6. ober 7. Ungange gebaut ift, fo brechen bie oberiten llmgänge inmer ab (x). Weil bies num für sie hier liegenbe zarte Reber bes Thieres nad)= theilig fein witrbe, fo baut bas Ifier an ber Stelle, wo ter Bruch itatt= finten joll, vorker eine Sdyeitemant, jo baß̈, wenn bie Spiz̧e bes Siehänjes

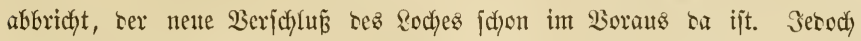
witrbe man ohne 3weifel irren, wenn man es jo anjefen wolfte, wie ebent

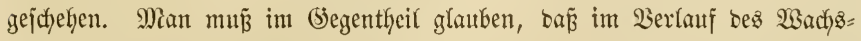
thums bes Thieres sajfelbe in feittem hinteren, bie sberjten Umyänge tes (bef̧äufes erfülfenten, Theile einen anbern Umfang antehne, jo

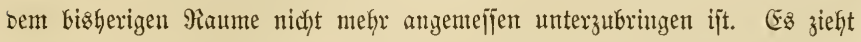
fich baher aus ben oberjten Umgängen zurüaf utto trennt ben verlafjenen 


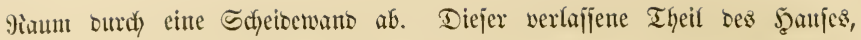

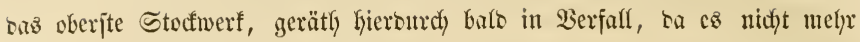
won bem lebendigen Thiere erfitlft ijt, werfüllt ber Berwitterung mto bridjt

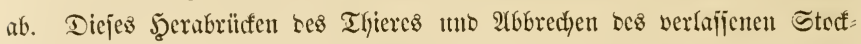
werfs exfolgt 3 bis 4 Mal im Reben tes Thieres. Eigentlidy follte bas

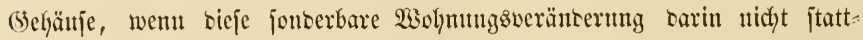
fänte, 14 ltmgänge haben, hat aber fo nie mełhr als 4, wenn ter letze

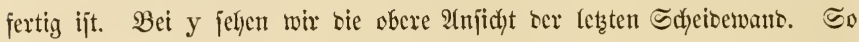

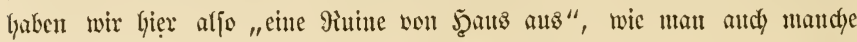
ınjerer leidytfertigen Spefulations = 5̧üufer nennen tönnte.

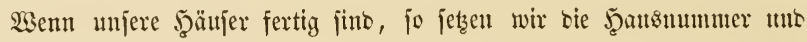

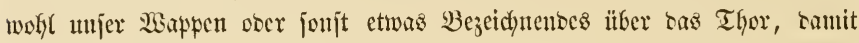
man uns barin finten fönne. Biele Sdynecfen machen ctwas 2(ef)nliches.

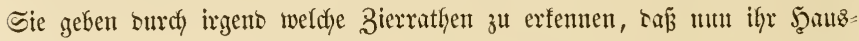
baul wolfentet ijt, uno an riejen bejonteren Bierratben fann man jefh sit

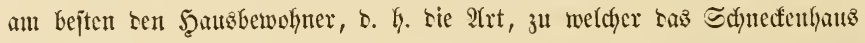
gehärt, exfennen. Diez jint meift porzelfanartige glänzende Fältchen, Seijten,

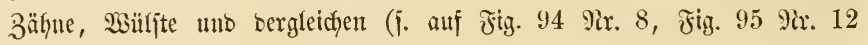

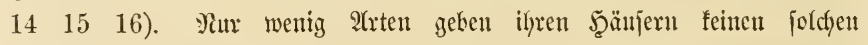

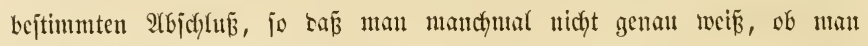

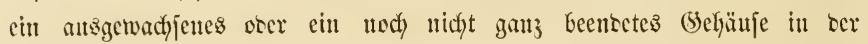
Jantio gabe.

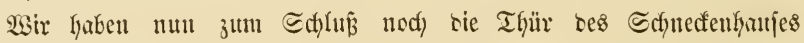

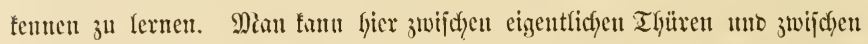

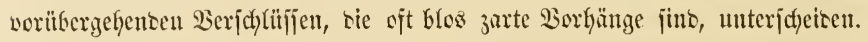

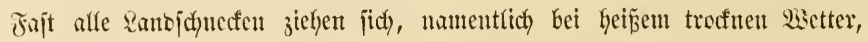

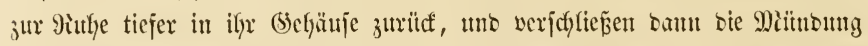

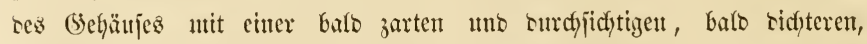
papterartigen uno faffourdybrungenen erhärtenten Schleintlyant, bie jie ent=

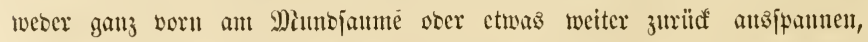

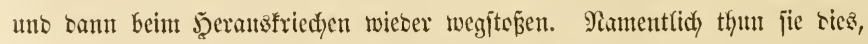

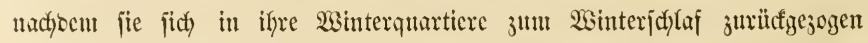
haben. Die groje weinbergajdne ofe, H. pomatia, macht jich einent siffen feiten falfigen winterbedfel. Biele Kegen 3 biz 4 papierartige Decfir

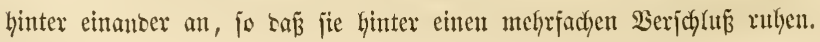


Biel intereffanter fino aber bic eigentidyen Thüren, ober Dedfel wie

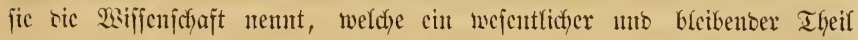

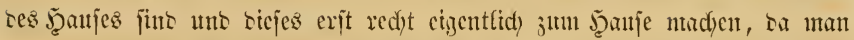

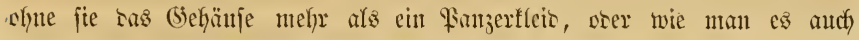

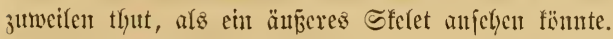

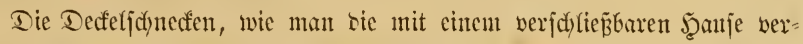
jefenen nennt, bringen gleid) aus $5 \mathrm{~cm}$ Mintterteibe voer ans bem (Fi ben

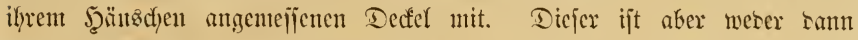
noch autch fpäter surdy cin Banto ober eine Thürangel beweglich nit bem

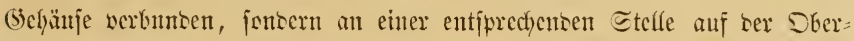

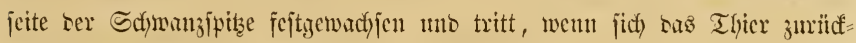

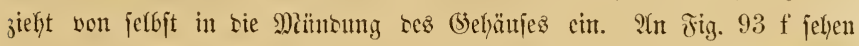

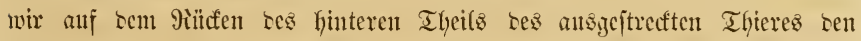

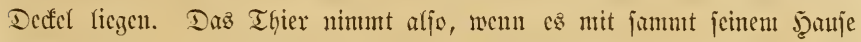
ipazieren gelyen will, fcine J̧ansthÿu anf ben Tü̈cfen.

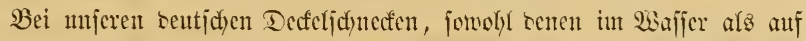

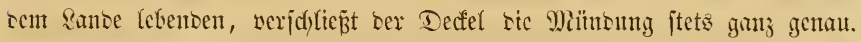

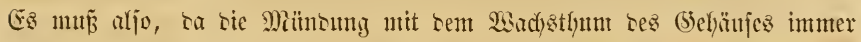

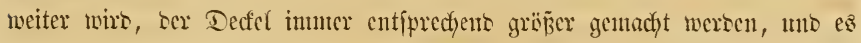

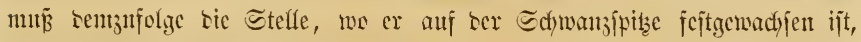
cbenfalls falfansajactoence Drüfen haben.

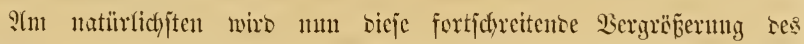
Dectels - wie cz aud) bei cinigen (5iattmingen ser Fall ijt - an befien

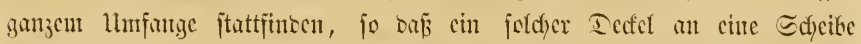
cines Banmitummes mit ifyen cinanter untgefenten Bumachsintingen crinnert. Eituen joldfen Deffel hat sic stg. 92 B o abgebilsete Bithynia tentaculata

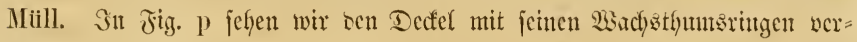
größjert abgebiloct.

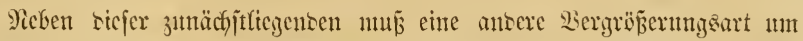

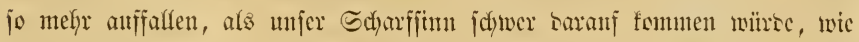

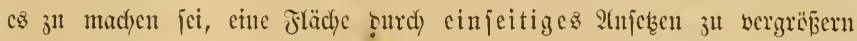

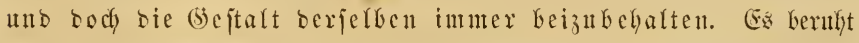

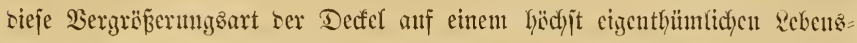
vorgang bes bautenten Thierç. Der 2Anbau fintet näntich) immer nu an

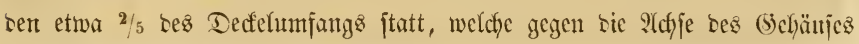


an ter linfen Seite ber Mïnsung liegen, wo inmer ein janjtgetogenes

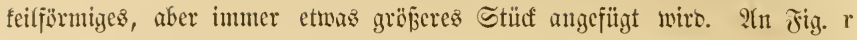

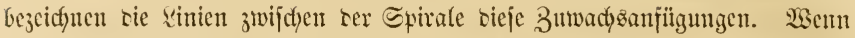
mun aber bieje 2fnfïgung immer an sicjer Etelle ftattfintet, fo mü̈̈te rod)

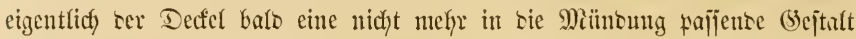
befommen, wenn er jejt auf ber Sdy wanjipize angewadjen ijt. Das ijt er aber eben nicht, jontern er steht jict fortwägrent, aber

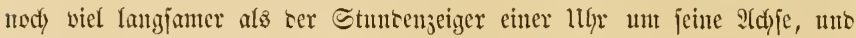
$3_{\text {war }}$ in terjelben Fidftung wie tie Uhyzeiger. Dennod) aber ijt ter Dectel

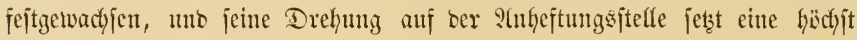
merfwitrbige ununterbrochene orefantse Rebentigfeit tes binsenten Brwebes

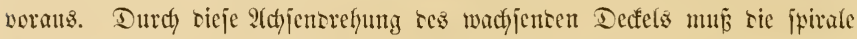

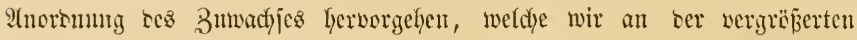

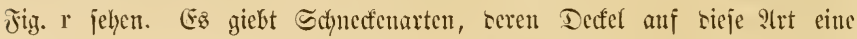
6 bis 7 malige llmorefyng madjen (3. 23. Gei Jiz. 96 9ix. 37). Das Jig. q abgebilsete (Sefänje mit rem Decfel $r$ ijt bas bercitø crwähnte Cyclostoma elegrans.

Der Dedfel $g$ h oer Sdwimmiduedfe (f) madyt mur cine geringe jeitfiche Drefyung, ijt aber mit ciner 2(rt 9iiegel auf ber llnterjeite ver

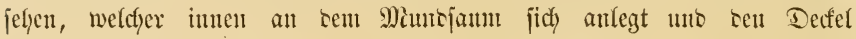
bejejtigen lilift.

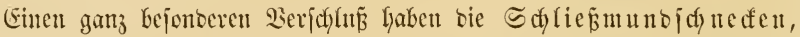

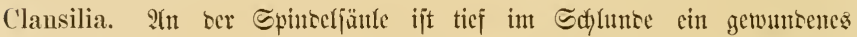

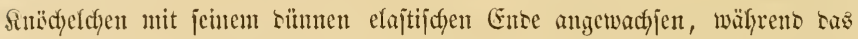
abwärts nidyt ganz bis vor an bie Mï̈nnng reicyente Ence in cinc breite

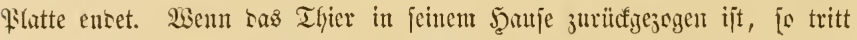

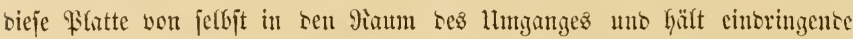

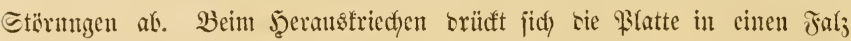
an tie Exinteljäule an. Fig. $\mathrm{k}$ ijt Cl. laminata uno 1 ber vergrö̈perte

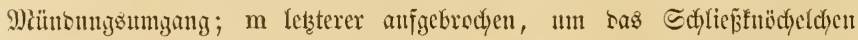
3"l jelyen, auf weldyes కas Stenthen permeijt. Das Keraugenommente

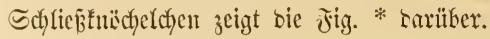

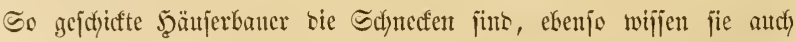

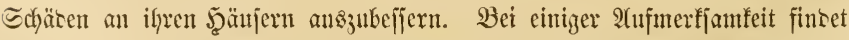

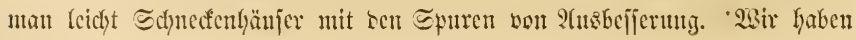


idfon foldfe gefumben, die surdh cinen Drutef ober Stố fajt ganz zer= trïmmert worben waren, aber bie Trünuner waren alf bem Ifjere in jiemlicfer Dromung fleben geblieben uno biejes hatte jie mit Ralffubjtanz

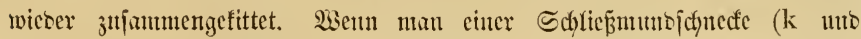
Fig 94 9ix. 16) bie Miüutung verifopft uns bann babinter cin angencifen

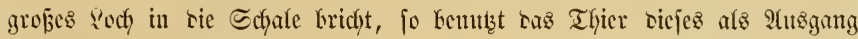

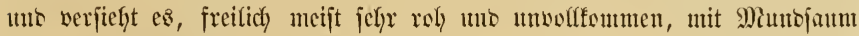
uno jonjtigen ser strt cizenen Bierrathen.

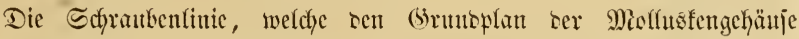
bilbet, ijt fajt inmer rechts gemumben, o. \%. bie Miünumg liegt, wenn

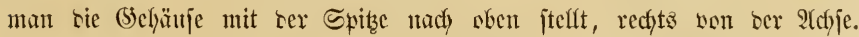

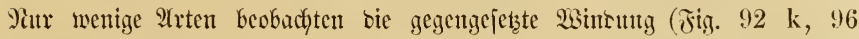

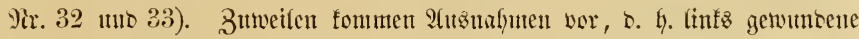

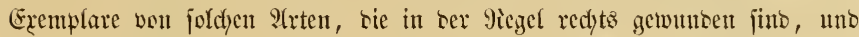
jo ungefehrt.

Da gewí̄ un menize unjerer Sejer turo noch wenigere seferinnen unjeren Schneden cines theilnchmenten bilictes gemïrsigt haben werten, fo

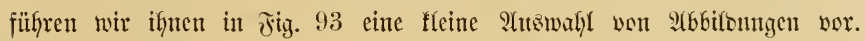

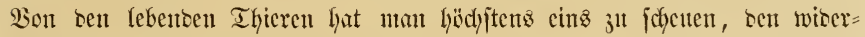
wärtigen zähen Échleim, ten man wou ber ફ̧ant faum wicter los werten

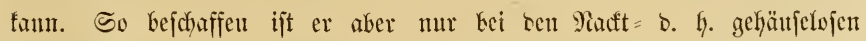
Edhneden. Bei allen ïbrigen bejtelyt ex bloz in einer jelyr geringen $2418=$ jofeibung einer leidft abjuwijdyenben, faum ftebrigen Feudftigfeit.

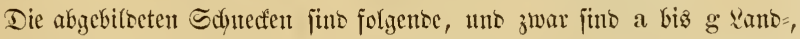

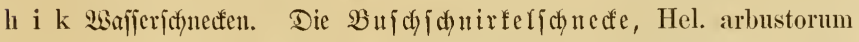

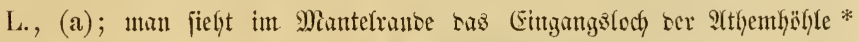

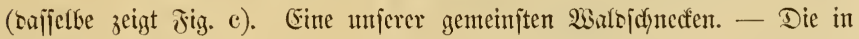
Sübetropa lebenbe H. vermiculata Miill. (b). - Die ebentajelbit bor= fommente H. naticoides Drap. (c), beren Steflung bie firaft unt (5ewantst=

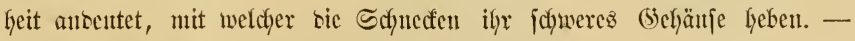

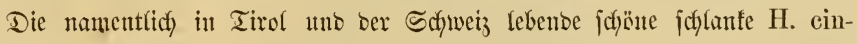
gulata Studer. (d). - Die in Süboentifylano hier und oa anftretenbe aber erft nody füblicher häufig norfommente H. aspersa Miill. (e), eine Berwante unjerer $\mathfrak{B e i n b e r g i c h n e c f e . ~ - ~ D a s ~ i n ~ S i t b m e j t b e n t i c h l a n t ~ i f j e ~ n o ̈ r b = ~}$ licyjte (5renze babenoc, facon mefyrmals genannte Cyclostoma elegans 
รig. 93.

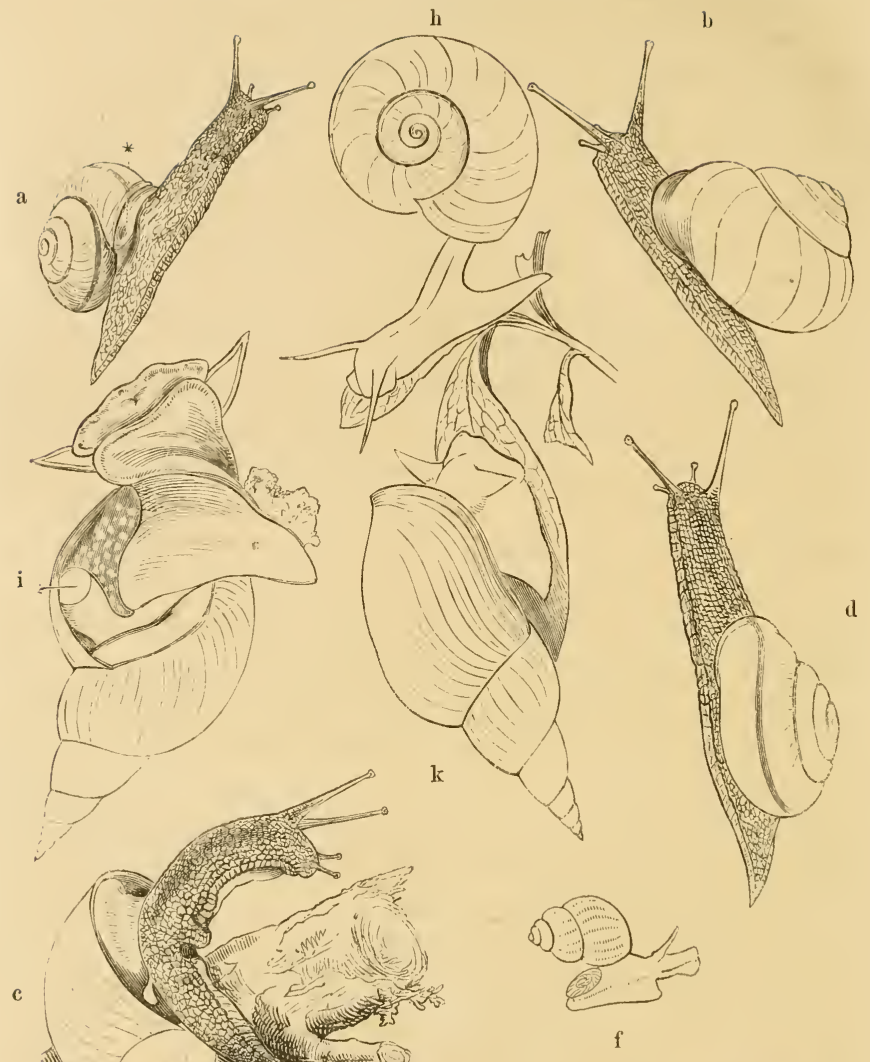


Lam. (f $g$, bei f jieht mtun Ginten ben anf(iegenten Decfee). Der Sepf ijt

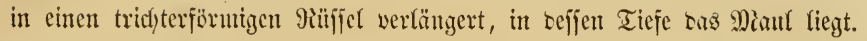

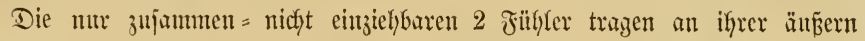

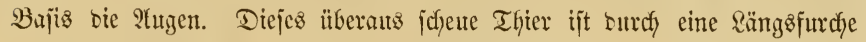

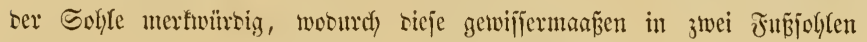
getheilt wiro, bie es abwedjefno anjaugt uno abgebt uns vorichiebt uno fo förmfich) furze Sdyrtte machen fann (g zeigt biez nad) einem an einem (Staje frictjenten Thiere). - Die grofe Iefferfdneffe, Planorbis corneus Drap. (h), mit 2 Gorjtenförmigen jpitzen Füblern, oeren verbreiterte Bajis an ter Interfeite bie 2tugen trägt. Semein in alfen Teidyen mo Sïmtpien. - Die greß̃e Edylammidynedfe, Limnaeus stagnalis Mïll. (i k) mit quer verbreitertem unten burch, cine Furche von ber Solyle gejdjiebenem Sopje, an weld)em 2 platt oreijeitige lappenförnige fälyler

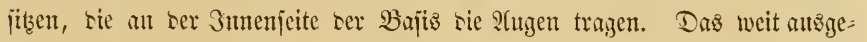
itrecfte Thier (i) hat mit ber jujammengejalteten Sohle ein Etïcfden Broo

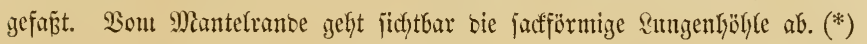

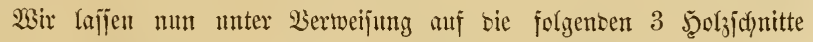
eine fumge Eharafterifitif ber midytigiten bentichen Schnedfengattungen folgen. Die meijten abgebilseten $\mathfrak{A}$ (rten wirb man mit reicjtigfeit im $29 a$ rbe uno ben antern angegebenen Dertliçfeiten fintsen fänmen.

\section{Randidneffert.}

Fig. 94. 1. Helix nemoralis Müll., bie befannte meijt gelbe

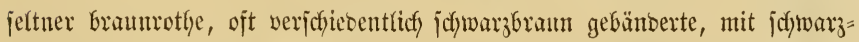

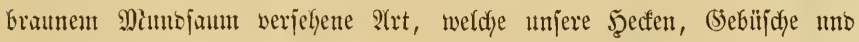
(5ärten - weniger ben $23 a l o$ - bevölfert. Durch gänzliches ober theit=

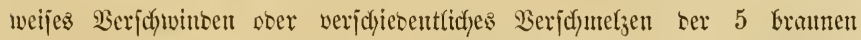
Bänber entïtehen zaflreidye Epielarten siejer jajönen Sdfnecfe. Die ify.

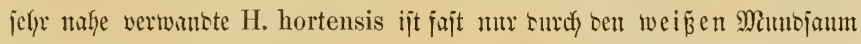
unterjffieben. - 2. Helix ericetorm Müll., etwas jofuntrig freibe=

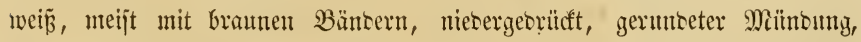
jafmjem tiefer innen etwas gelippten Munbjam uno jefr weitem Nabel*).

*) Mabel nemut man bas Sodj in ber Mitte ber llnterjeite, bie hohle 2(djie, um weldye bie 2 indungen gelegt fint. 
Fig. 91.

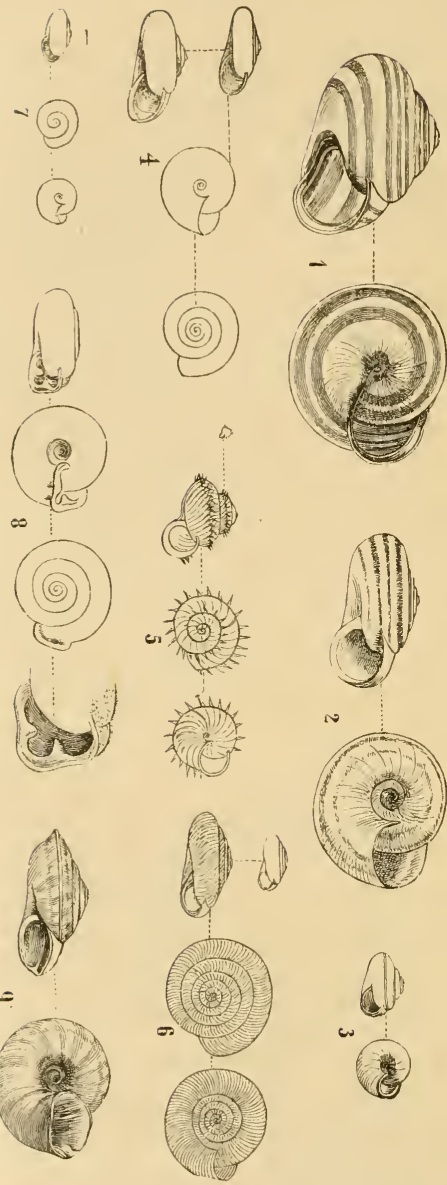

1. Helix nemoralis L. - 2. II. ericetorum Müll. - 3. H. candidıla Studer, - 4. H. cellaria L. - 5. I. aculeata M. (vergr.) 6. H. rotundata M. (vergr.) - 7. H. pygmaea Dr. (vergr.) - 8. H. holoserica Stud. redyts bie vergr. Miün
Miefr in Sïtweiten won Deutich lant zu Şauje, wo fie nake rem Boben auf Sräutern uto Tajen lebt; liebt warme rage, ijt aber nux an felyx früben Diorigen munter uno bängt ant Tage meijt ftill an sen Fiflanzenitengeln jidf mit einer bïnnen Sableimbaut ankeftens. - 3. Helix candidula Studer, frectretveí̄, oft mit einem feinen braunen $\mathfrak{B a n t e}$, Manojam innen mit einer feinen ricfen porzellanartigen Lippe, Rabel=

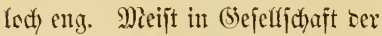
vorigen aud) riejelbe Sebensweije jeizens. - 4. Helix cellaria Mïll., niesergesrïuft, bernjtein= gelblid), surdyjueincns, ftart glänzento, 9iabellod) jicunlich) weit. Sebt an Dunfeln jeuchten Drten, in ser Groc, in Siclleru, yäupity

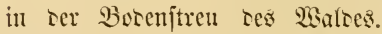
5. Helix aculeata Mill., jeflx flein, jiemlich) funelig, ge= runsete llmgängc, mit Gäutigen Smerripten bezogen, rie anf ser 2 ölbuny rer llnyzänge in ein ipizes Päppdyen auslaufen. Ituter J̨ecfen uno SBüjoen in ser Bosen= itreut. - 6. Helix rotundata Miill., platt, mit sielen ctwas fantigen, fein querigerippten Uu= gängen, grangelblich mit rojt rothen Dueritreifen, Jinkellod) jebr meit, รas ganje (5)minte 


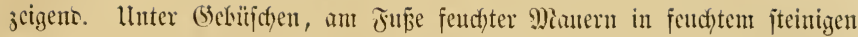
Boren, namentlich gern an ser Itnterjeite auf foldyem Boren liegenter Stcine. - 7. Helix pygma a Draparnaud., bie flemite $\mathfrak{A}$ rt, etwa ${ }_{3 / 4}$ Ditll. hod) uno $1^{1 / 4}$ Mitll. brcit, nut mit $3^{1 / 2}$ Lmbängen, nieberge=

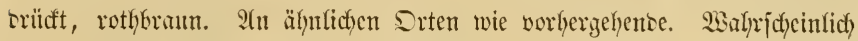
weiter serbreitet als man glautht, weil jic meijt Ḧberfeben wirt. - 8. Helix holoserica Studer, mit flattem (5eminte uno jeitlid) georüaten Um=

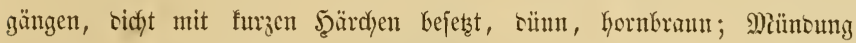
oreibudftig; Mantojaum fdyarf zurüdgebogen, immen mit einer 2 jaflnigen

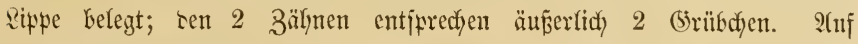

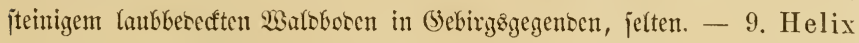
lapicida L., ‘injenfërmig mit jofarf gctictem llmfange; graugetblich mit rotgbraumen Fledfen, Dberfläche von mifioftopijdyen siörndyen ranth un

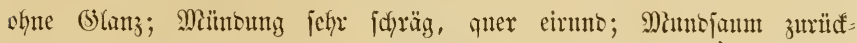

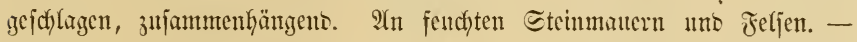
Fig. 95. 10. Bulimus detritus Müll. (B. radiatus Drap.), weldyer

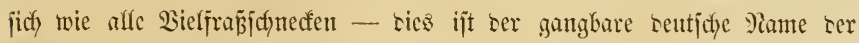

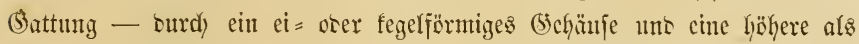
breite Mënoung ven ben übrigens fefyr verwanbten Sd)nirfelfdyedfen unter=

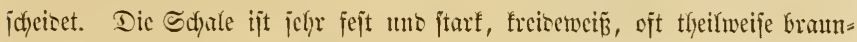

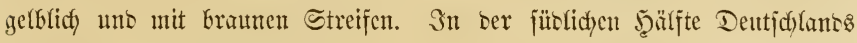
gemein, meijt auf Majen. - 11. Achatina lubrica Bruguière

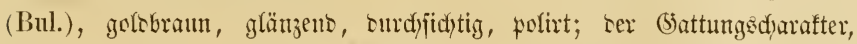
sie unten am Mambjaum abgcjtutz̧te Epintelfäule ijt mur erjt wenig ange= sentet. Leberall verbrcitet im jendyten jteinigen bewad)jenen Boren. 12. Ach. Goodalli Mill., ourdy sic ふెähne in ser Miünoung von voriger, ser jie in Form uns Farbe jefr nahe tommt, fofort zll untericheioen. Sie

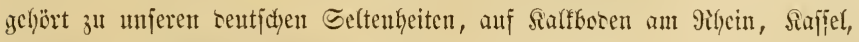
(5öttingen. - 13. Aelı. algira Brug. (Bul.), heflgrïn getblich, geftreift. Selten, in jütlitfen Sirain, bei Triejt zc. - 14. Pupa frumentum

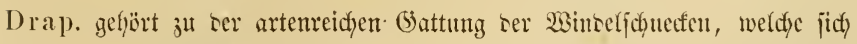
meijt ourd) mefyr ooer weniger zablreidje Zähne uno Jalten in Sdylunte

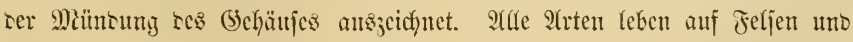

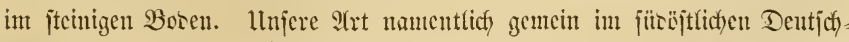
lanc. - 15. Vertigo septemdentata Férussac, bie Sertigo=2lrten 


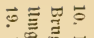

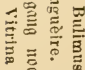

홀

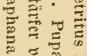

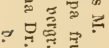

블

言专总家

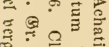

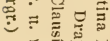

今.

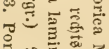

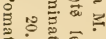

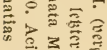

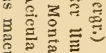

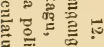

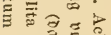

풀류
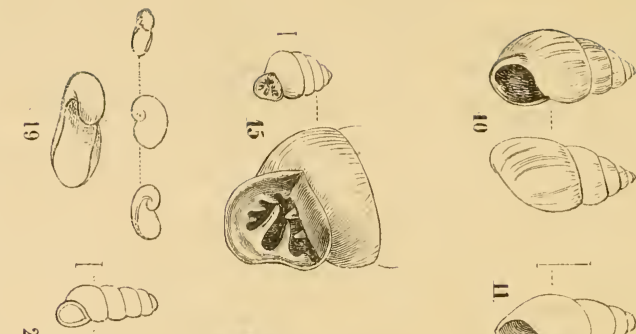

$\triangleq$
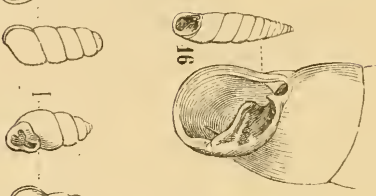

응ㅇㅇ

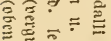

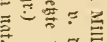

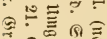

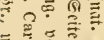

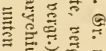

可氖

牙政

范贻

to

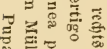

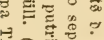

동

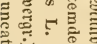

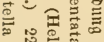

군

है क्षे

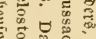

के

के

ศิ

के $\approx$.

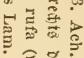
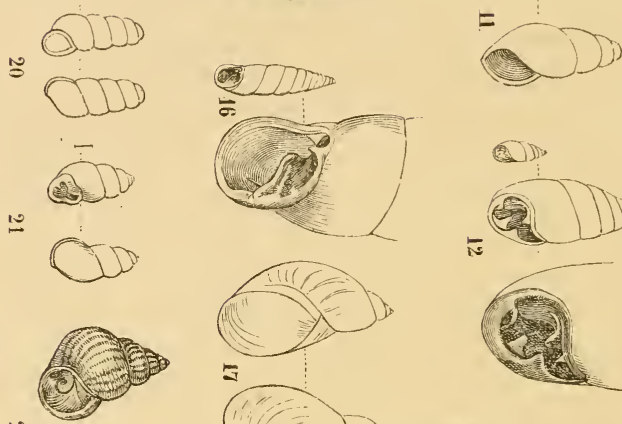

N
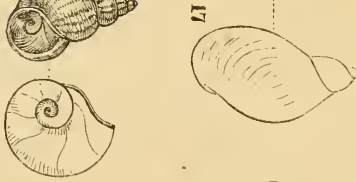

$\Xi$

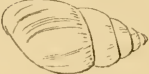

(6) D)
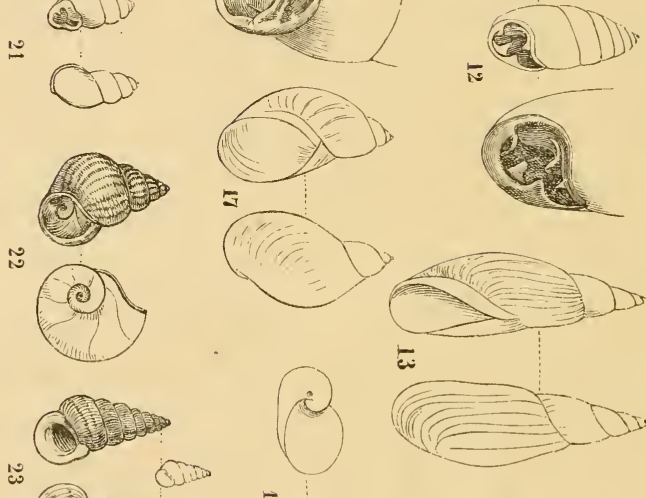

क्षे

이

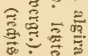
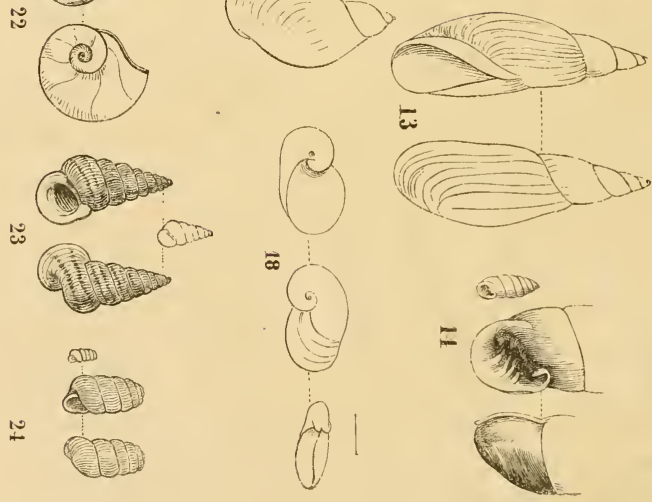


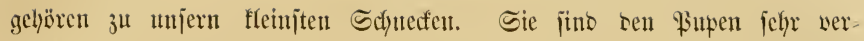

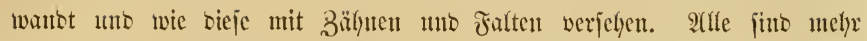
ober wentiger enticfiesen gotofraun unt glä̈zent. Sie leben meijt alf

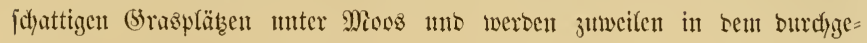
fiebten 9iütfitanto ser J̧enjpeidyer in Menge gefutren. - 16. Clausilia

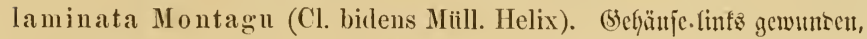

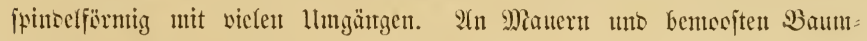

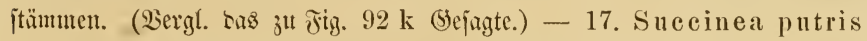

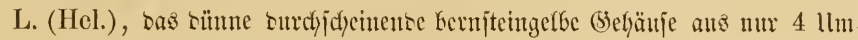

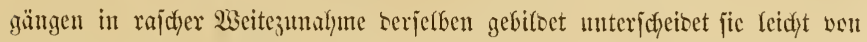

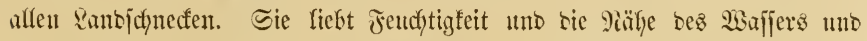
wirb immer an Fiflanjen friedyeno gçunbent. - 18. Da ndebardia rufa Fér., tas fleite auperorbentfich fdynell an weite ser llmgänge zunchmento

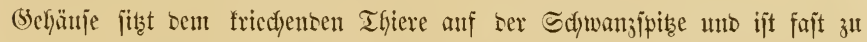

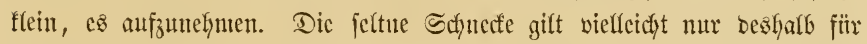

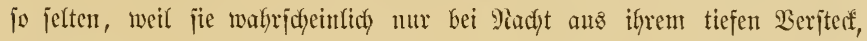
Steinjdyutt uno Feljenjpalten, hervorfommt. - 19. Vitrina diaphana

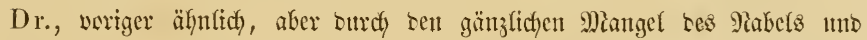
ren Yäutigen Saum tes Snnemantes leidyt zu unterjactoen. Das äuñerit jarte glasartig burdyicheineure, fajt farbloje (schäuje fann bas Thier audy nicht ganz aufuefinten. Es febt auf feutdjtem mit faufenbem \&anb bebeften

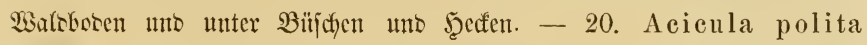

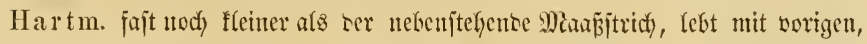
aber fegr jeften, an incujelben Drten. Sie ijt tief braumroth uno ftarf

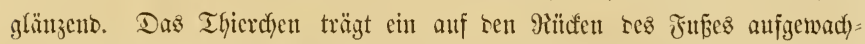

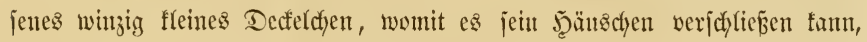
wie bics and in grö̈erem Maajitabe bei 9 x. 22 mo 23 ser Jafl ijt. 21. Carychium minimum Mïll., felyr flein, mit 2 jtumtpfen 3äh)n=

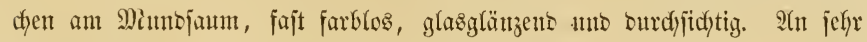
feudyten Srten in bem Borengenifte; fehr verbreitet. -- 22. Cyelostoma elegans Lam., hat ein feîtes, ftarfes (schü̈ıs mit feimen Epirallinieı unb jie fremzenden Duertinien. Der biffe harte pirralgemunbenc Decfel

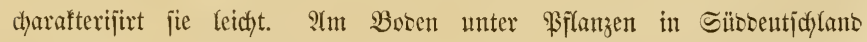
laüufitg, mefyr nörblidy un cinjelt. - 23. Pomatias maculatum (Cyelost.) Drap., won ben edjten Eyflojtomen bejonbers burdy bie nicyt 
getyeilte Solye unterjoficren. Der pergantentartige Decfel ijt ricfter

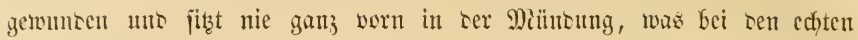
Enflojtomen ftets ber Full ijt. Unter Steinen mo an Feljen im füblidyen Deutidylano. - 24. Pupa Truncatella L. Pf'eiffer, ijt anf Ier Tafel ans Lerjegen fo weit bon Jỉg. 14 entjernt gejtellt worsen. Es ijt

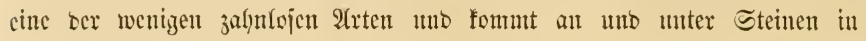
Silbreutidyland vor. -

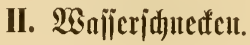

25. Planorbis corneus Draparnaud, von grünticy fornbrauner

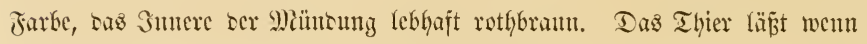
man es reizt cincu fdymutzig firjejrothen Saft austreten uns murbe beshalb

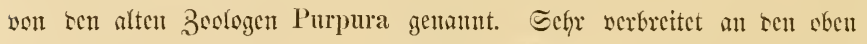
angezebenen Orten. - 26. Pl. earinatus Mïller, vief fleiner uto an

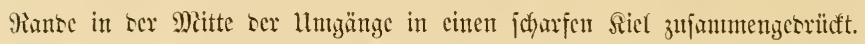
Der äfnticfye Pl. umbilicatus Miill. hat sen mefyr fascnjörmig aujzefebzten Siel nicht in scr Mitte, jontern mefyr unterwärts. Sn ffeincren (5räben uno Teidyen, letzterer häıfiger. - 27. Pl. vortex Muill. ganz platt wic

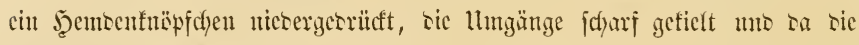
Path anf sem sicl hinlänft, jo ijt sie Unterjeite (f. bie rechte Jigur)

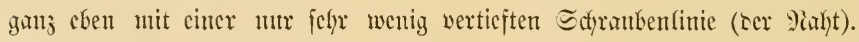
Jarbe gelbgran. Sn (5räben und Sïmpfen. Gs fommen in Deutichlant nody weitere $13-14$ âten wor, dic meift flciner fïto. - 28. Limnaeus ovatus Dr. - 29. L. palustris (Buccinum) Miill. - 30. L. stag-

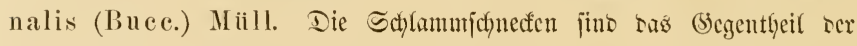

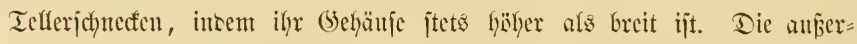

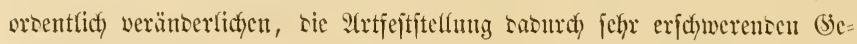

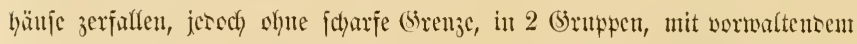

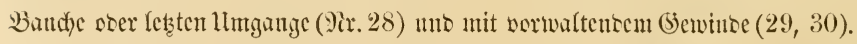

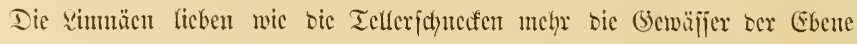

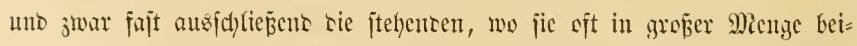

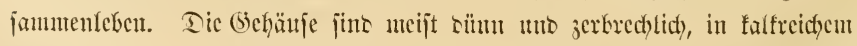
Wajjer body ancty jtärfer uns fejter. Die Sprinbel ijt ftets metyr socr

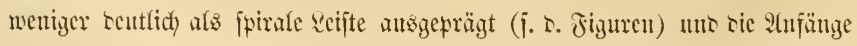


beiber Muntränser fino surd) cine tünne bei tem fortbau mit vor=

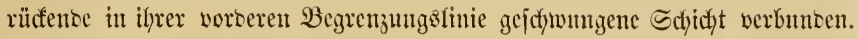

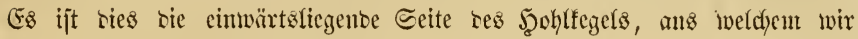
sic gewumbenen (behäuje mfprïnglich angelegt wifjen. Diejer llmichlag

Æig. 96.

25

26

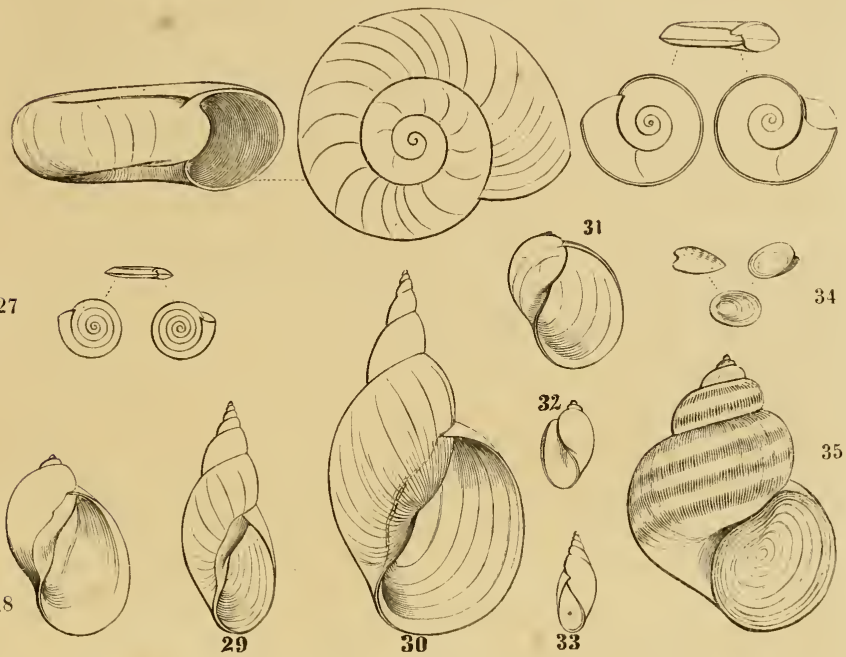

36

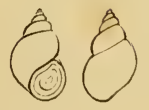

Deutide 2isafieridneden (f. ben Tert S. 45S-461).

37

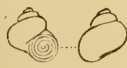

Silret oft einen sentlidyen Mabelritz. Die Farbe ijt surdbgebens eine vieltönige Stutjenleiter jwijdyen 35

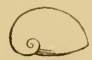
bellem Etrobgelb bei fajt ourtyjebcinenter Sabale แns cinem smufeln Bran (29). Uebrigens erflären

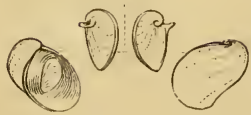
iic) sie Jiguren bon jefbjt. L. stagnalis fommt oft nod) bief größer alz unjere figur vor uno ijt iiberhaupt ein ftattliches Ifler. - 31. Amphipeplea glutinosa

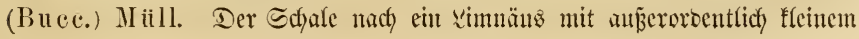




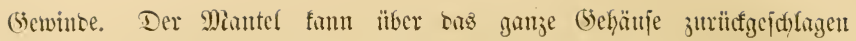

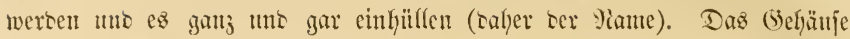

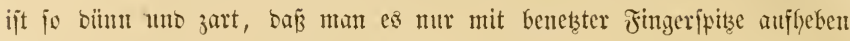
smif. In Tcidfen uno Sadyen; wenig verbreitet. - 32. Physa fontiualis (Bulla) L., uno 33. Ph. Hypnorum (Bulla) L. Dic Báaje

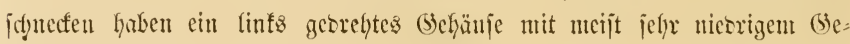

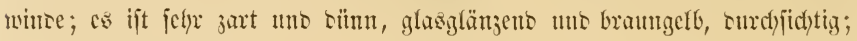
mite aber in ter Sammlung, wie aud sas ber vorigen Atr, balo blino mo

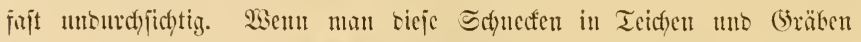

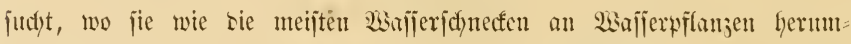
friedyen, is unz man jidy nnd) melyr als bei Amphipeplea füten, fie nicht

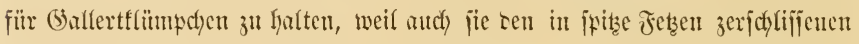

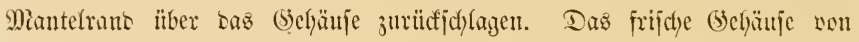
$\mathrm{Pb}$. fontinalis ift heff wadfigefb, aas ocr antern ticf braungelf, uno hat cin fpizzes Getvince. - 34. Ancylus fluviatilis Miill. Då Gefjüıje ijt napff̈̈rmig, aljo ungemumben nub bie Sprize etwas zipfelmilizenartiy nach) finten gefrïnme. Das von sinne ned) ju ben nur in ber See leben= Den Marfichneffen, Patella, gerectynete Thier jitżt immer sidyt an Steinen angebeftet in Bädyen, Queflen uno fleinen Fliifien. Eine nodh flachere

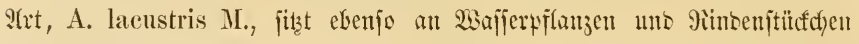
uno ijt leidyt zu ïberjehen, weil man Iarin faum eine Sdynecfe vermuthet. 35. Paludina vivipara (Helix) L. Dic Sumpfichnedfen fint wie alfe folgenten (Sattungen Desfelichnedfen nut jwar ijt ifyr Decfel concentrifict)

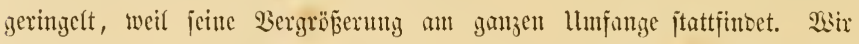

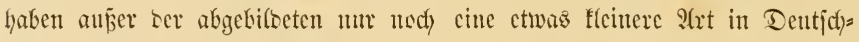
lant mit weniger bandfigen llungängen unto biferer Schale. Sbei beiben finbet man fait immer 3 rothbranne Bänoer auf ber bei unjerer atrt jtahl oter ofivengrïnen, bei ber anteren gefleren Grumbfarbe. Der vom Thiere abgelöjte hornartige bünne rothbramne Decfel pap̈t sam genau in sic

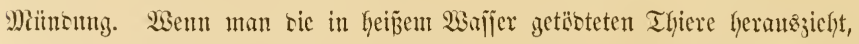

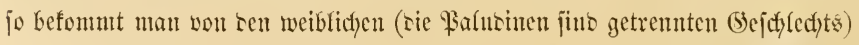
fajt 3u jecer 3afreşzeit eine 3ngabe won 8-12 noch) nicht anżgetragenen 3ungen, bon meldyen ber llterns jtrotzt, unb weldye affe, je nadyom fie

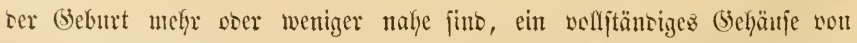
1-4 llmgänzen uno bem Decfel lyaben. Unjre 2irt ijt in Teidyen uno 


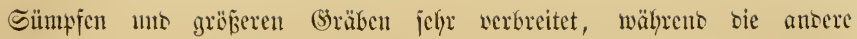
P. achatina Bruguière, melyr in Fliificn lebt. -36 . Bithynia tentaculata (Nerita) Miill. (Paludina impura Drap.) Dieje bon ben wabren Falusinen als cigene (5attung abgetremute fleine Sdyuedfe hat einen nicht lyornartigen, jontern fejten falfichaligen ebenfalf so concentrijach geringelten Dectel. Sie ijt lyorngelb glatt uno gläuzento uno lebt meift in groß̧er 2 (n= 3ahl in (5räben uno Simupfen. - 37. Valrata piscinal is (Nerita)

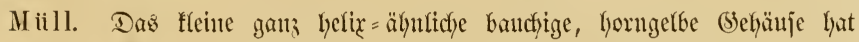

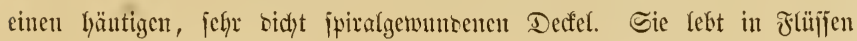

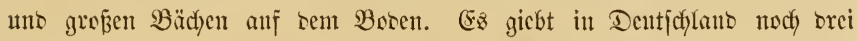
flemere Arten. - 38. Neritina f'luviatilis (Nerita) L. Daz anf

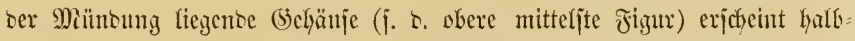

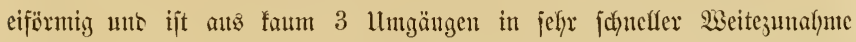
gebifoct. Die Epinel bilset eine platte berticfte, surch eine gerabe sinic

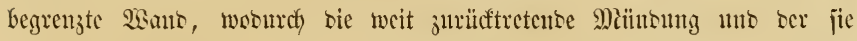

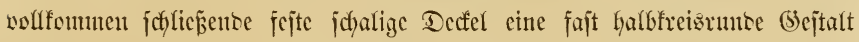
befommen. $\mathfrak{B o r}$ rer unteren Ecfe sez Decfels ijt inwentig ein fleiner

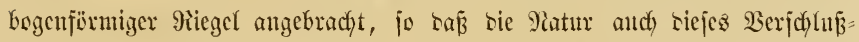

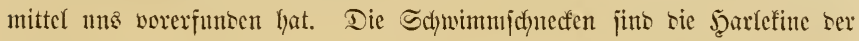

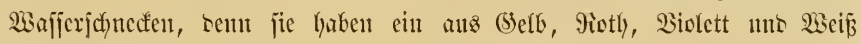

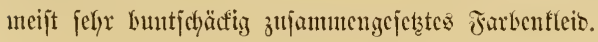




\section{Bweiter Aludunitt.}

\section{Die Mujdeltbierc, Goudiferen.}

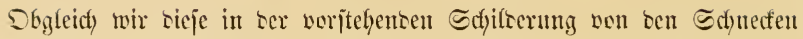

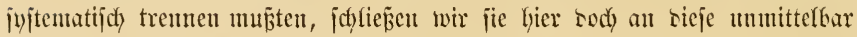

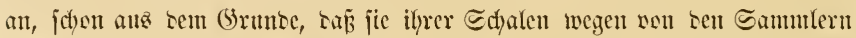

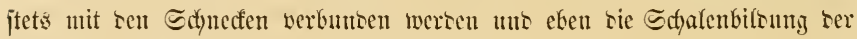
Bifrumg tes Sdyectenthanjes ganz analog ijt.

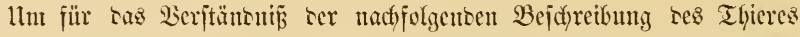

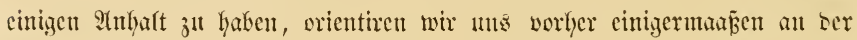

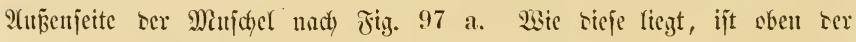
Oberand ober giäfen, ben gezenüber unten ter llnterrant ober bie

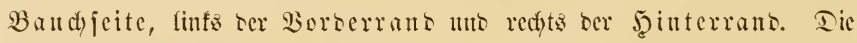
bauchige 2luftretbung aut Sferranbe etwas nad) bem Sorberrante fin,

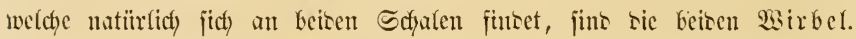

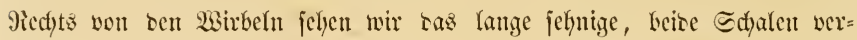

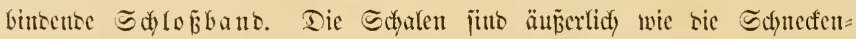

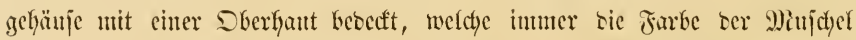

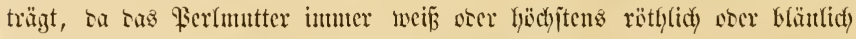

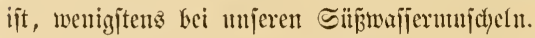

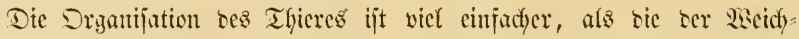

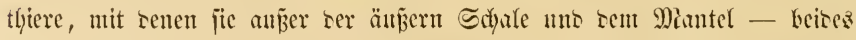

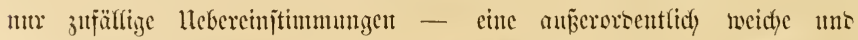

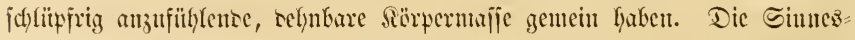

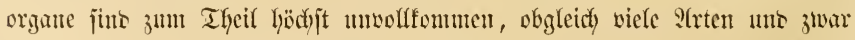

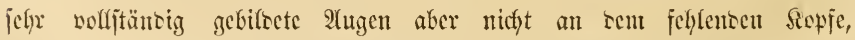
joutertn an bem Miuntelrantoe, haben. Der Miangel eines auzgeprïgten 


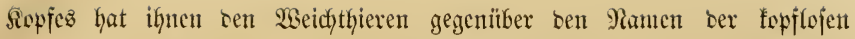
Mianteltyiere, Acephafen, gezcben. Dex äuñere Ban eines Miujchefthierç, Das man jidy. anz jeben Ieidy, Smmpfe ober Fluffe leidft verfdaffen fam, ift, was wenigjtens unjere bentichen (Sattungen betrifft, einfact) folgenter. Die beiben Sdyalen, weldye burd) Das Schlop̈banto łnjammenhängen, fino

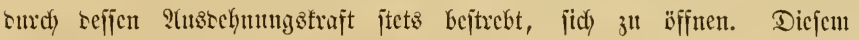

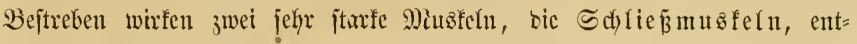
gezen, weldye worn unt Ginten inwentig nake bem 9iüfen an ben Schaten angeheftet fint, uno wenn man jie entfernt, sie beiben verticften $\sigma$ d) $l i e \tilde{\beta}=$ musfeleinbrï de, ben vorbcren unb ren Ginteren, finterlafjen (b 12 ).

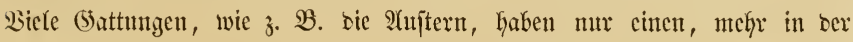
Mitte ber Schalen angebrachten, Schließ̄musfel. (5) (eid)lanfento mit rem Interranto läuft, etwas von biejent entjent, eine vertiefte sinie im Perl= untter ber Schalen vom vortern Mitsfeleinbruft bis zum Ginteren (Jig. b 3 3);

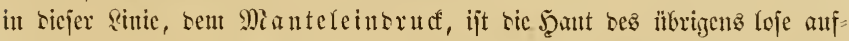
gedrücten Miantels angeheftet. 2Aıf bie beiben Miantellyäute folgen jeber= feits 2 von vorn bis hinten reichente etwa ha्db jo breite meijt heflbräunfich

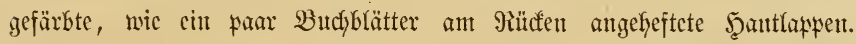
Dies finto bie Stthemorigane, Siemen, weldye wegen iffer blattartigen (Sejtult ber Silaffe atdy ben Namen Blattfiemer, Ramellibrandjien, geben.

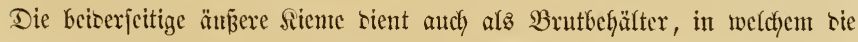

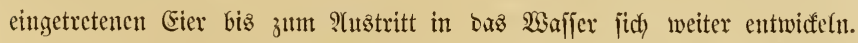

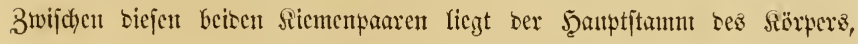
ber $B a n d$, ber jidy nady unten in einen fleijchigen jefr ausbebnbaren

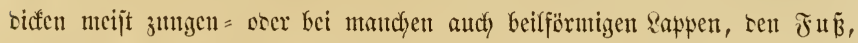

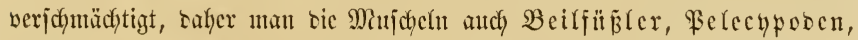
genaunt hat. Diejer Theil, weldyer bei viefen ganz zแngenfürmig ijt, bient

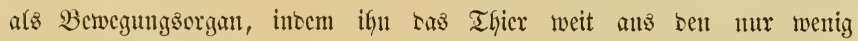

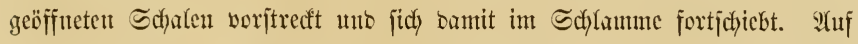
rem mujchelreïd)en Schlaumboben eines Teichez jiegt man oft bie von ben

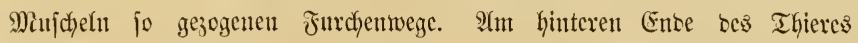
liegen bei mand)en 2 rten in 2 9̈̈̈hren verlängert jüt. T(Ls Iajtorgane bienen am Ginteren Enoe bez Miantefrantos itefyenbe Fithler, jo wie 2 Paare an

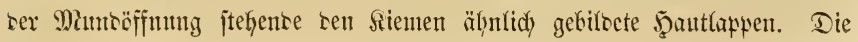




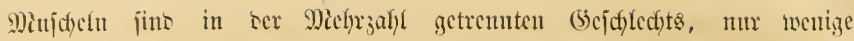
(5attnugen fint edfte fid) felbit bejrudstembe 3witter. Hujere gemeinen

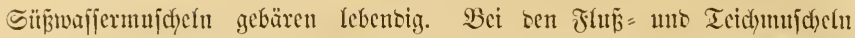

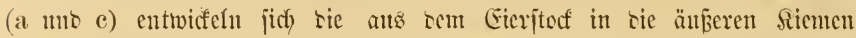

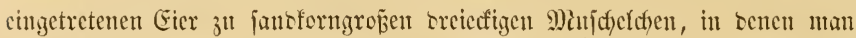
sic fümitige Form gar nidjt erfennt. Soldjer Entbryonen entfält cine

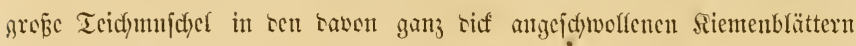

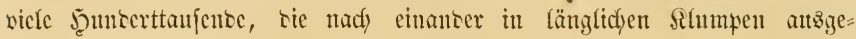
jtếen wertent.

An ber immern Seite fino bie beiben Mufduelfdyalen am Sberranbe

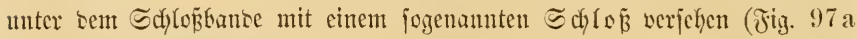

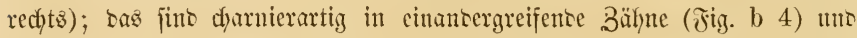

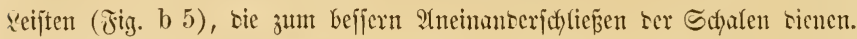

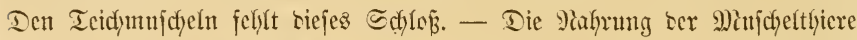
bejtelyt aus ben in 2ajifer aufigelöften organijdyen Stoffen uno hödjtens

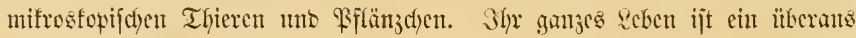

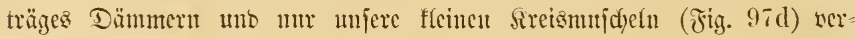
mögen mit ifyem langen zungenfürmigen Juß an 26afjerpflanjen, natünlich) inmer unter bem 2Bafjeripieged, emfor jn friecten, was man in eincu (5) laje leidyt beobadyten fann. Sisen jie nidyt ganz unter bem Edy)(amme

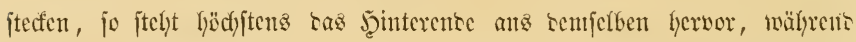

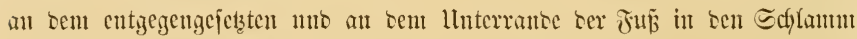

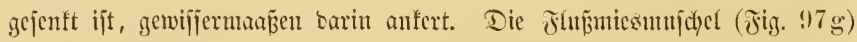

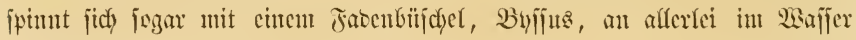
liegenbe (5iegenijtänte feít.

Die sft in anferortentlich) grofer Mienge ben (brunto unferex (Bemäffer

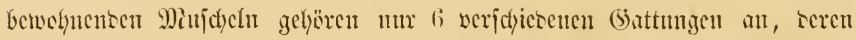
A(rtenzalyl and

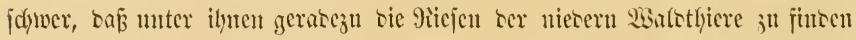

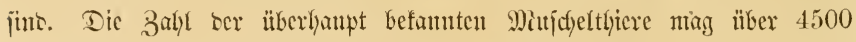
betragen, won welchen sie grefe Mielnzahl Eeetfiere juts.

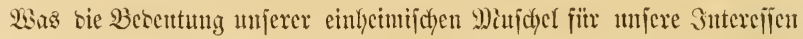

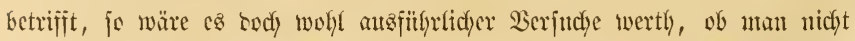

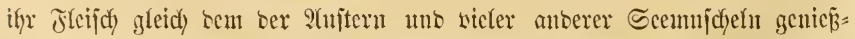
bar madjen fömte, wie man in Glthrien cine im Sjonzo lebente Miujdyel 


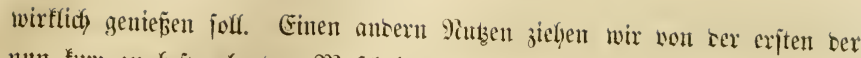
nun furz zu bejpredyenten Maijheln.

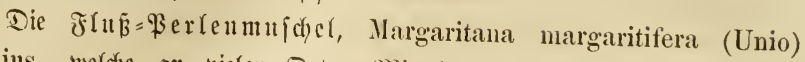
Retzins, weldye au vielen Siten Mittel = uno Mortentropa's mo auth Tortanterifa's in Bächen, namentfid) ber (Sebiriggmaltungen lebt, erzengt

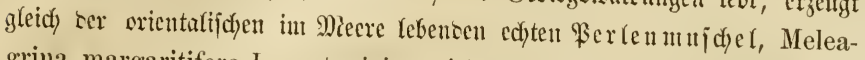
grina margaritifera L., uno cinigen biejer berwanoten STrten, offenbar af: eine abnorme AGjonberumg tes Ferhmutterifteffs, Berlen, welche ten orienta=

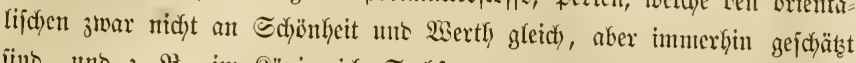

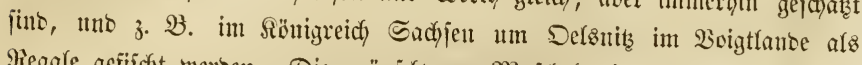

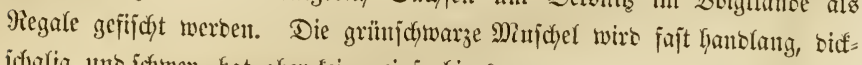
judalig unt jefwer, hat aber fein reinfarbiges, wenn and cinte fobne Folitur

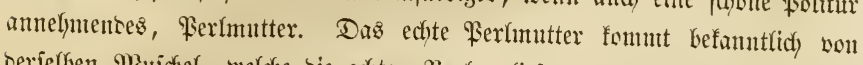

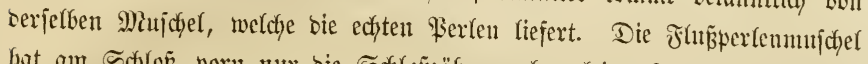

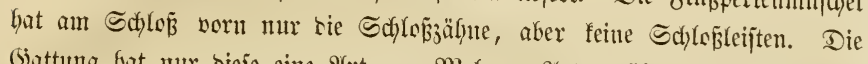

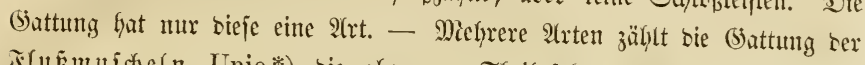

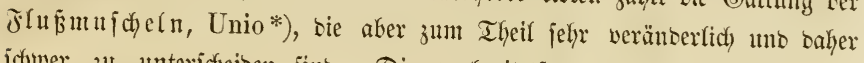
jower $3^{\prime \prime}$ untericheiten fint. Dic verbreitetite uno befanntejte ift bie

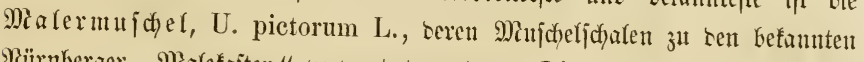

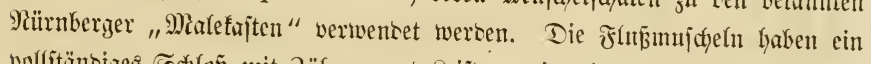

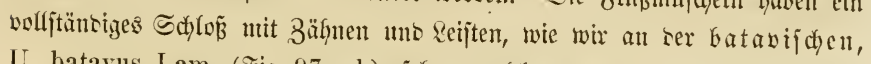
U. batavus Lam. (Jig. $97 \mathrm{a} \mathrm{b}$ ), jefyen, welche namenttich) in (Sebirggftiifijen bäufig ijt. - Mefr in Teichen uno Sïmpfen, sbglcich einige 2(rten aud in Ftinffen, reben bie Teid)mufdern, Anodonta, tie ein zafnhojes afjo

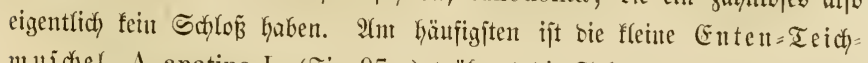

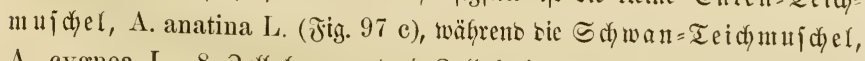
A. cygnea L., 8 3olf lang uno 4 3olf breit uno mit bem Iffere ïber

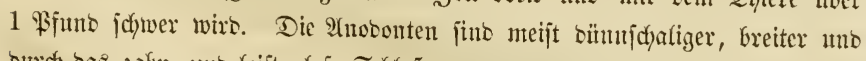

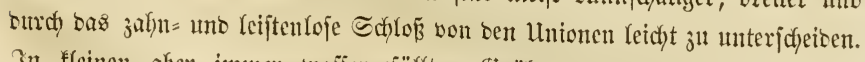
In fleinen aber immer wajjergefïllften Gräben, bejonters in fliç̄enben,

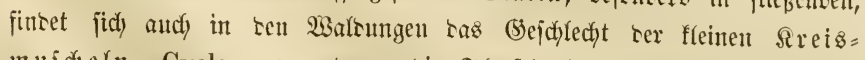

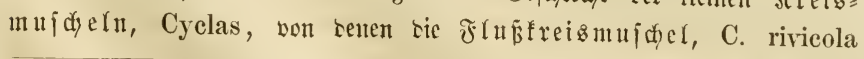

*) Unio bebeutet bier nidjt bie Sereinigung, fonbern bängt mit ber Anwentung

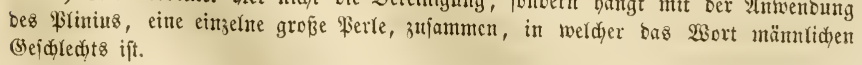

sie sfiere Des æarders. II. 


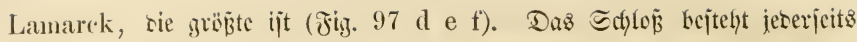

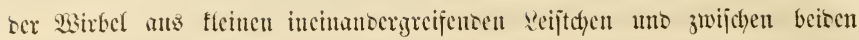

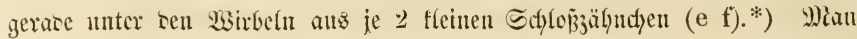
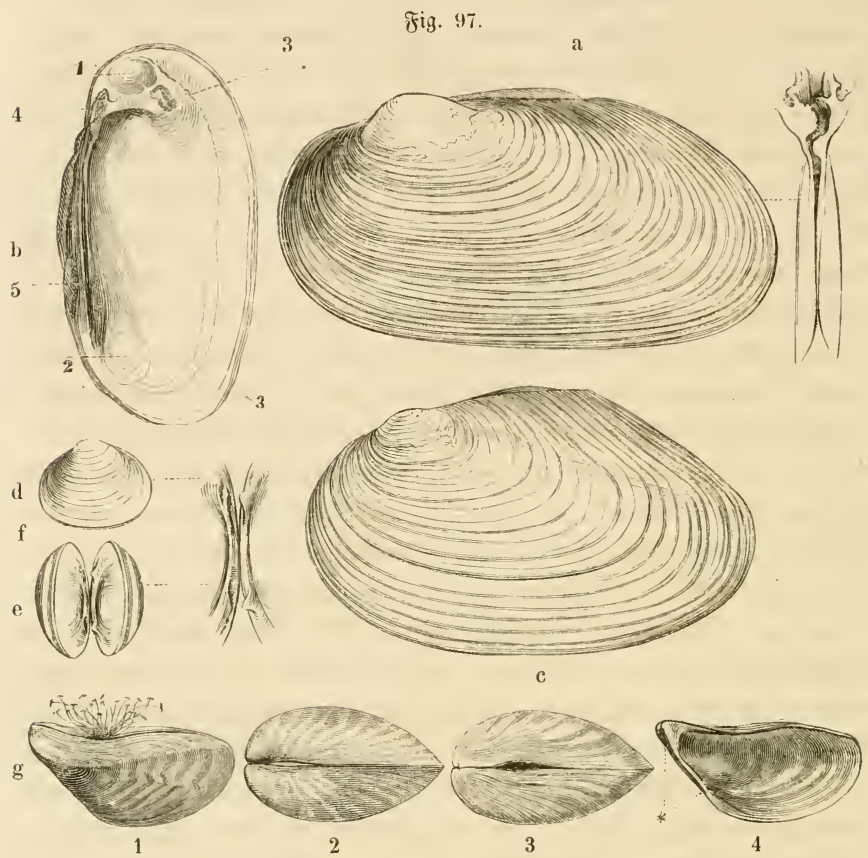

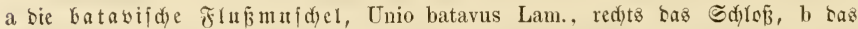
Intere einer Edjale. e sie Enten=Teidfunfdel, Anodonta anatina L. d bie

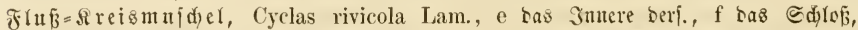

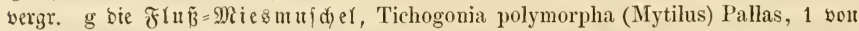
ber Seite, 2 won unten, 3 bon oben, 4 bas Snnere citter Gd)ale. (Streng genommen ift Fig. 2 bie Oberieite, weil ba bas Sdjloß̧band liegt.)

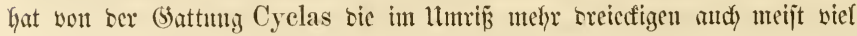
fleineren Arten afร Exbjenmuld elı, Pisidium, abgetrennt. Sie haben

*) Durdy cin Berfelien Dez 3eidnerz fint letztere an Den Figuren weggelaffent.

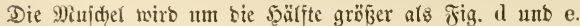




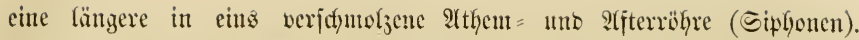

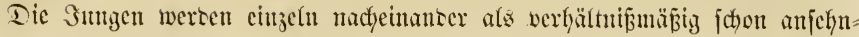

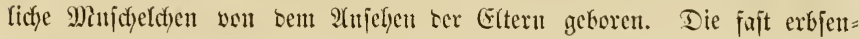
grofje aber plattere C. lacrustis Dr. Gerefft mandfunal ben Schlaum ser

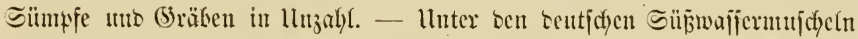
ift bic $\mathfrak{F}(\| \tilde{\beta}=$ Miezmufd)el*), Tichogonia polymorpha (Mytilus) Pallas, won bejonterem Snterefie, weil fie fidf burch cinen bart bon getb=

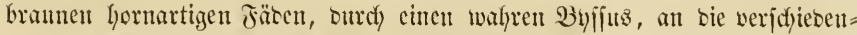
ften Dinge befejtigen fann (Fig. $97 \mathrm{~g}$ ) uno weil fic, vieffechst erjt jeit biejen Saffrhuntert won Diten her in Dentidylano eingewantert, uno in

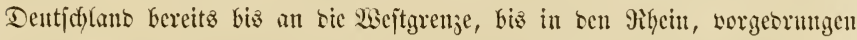
ijt. Sn ser Ecitemanjidyt (1) gleicht bie Minjhel einigermanenen cinem Piachen. Sn ter Epize ift in jeber Schale cine fleine breiectige $23 a n t o$ von Scfjalenjubjtanz angefrad). Bon ber Spitze abuärts an ber gejtrecften

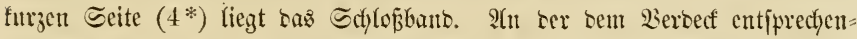
ben fajt ebenen Seite ber Minjchel flaffen bie Sadjuten ans einanber, um

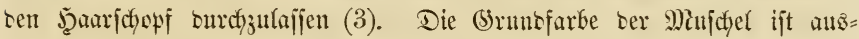

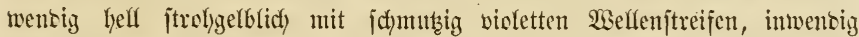
hell graublan. Man finbet jefyr läufig alte Excmplare mit ben Iaran jejt

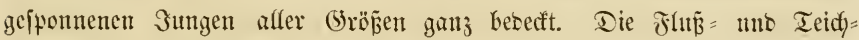

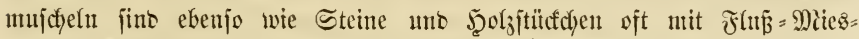
muicheln bejetzt. Sn sem von Riefernwaloungen nugebenen Pichelsberger See bei Gotżoan fanben wir zum 2 alfang in bem $\mathfrak{W a j j e r ~ e i n g e r a m m t e ~}$

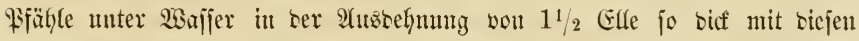

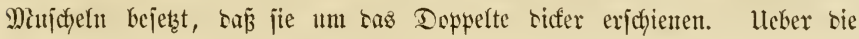
Berbreitungsmittel ber Wanberung in won einanber ganz getrenute Scwäjijer ijt man noch nidgt im Slaren. Lor einizen Sahren fanten wir in scipzig an Spreefrebjen, bejonbers an Schwanze, ganz junge taum

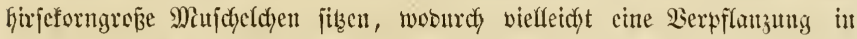
bie Reipziger (Semäfier bewerfferligt worben ift. Meibifdy hat beobactetet,

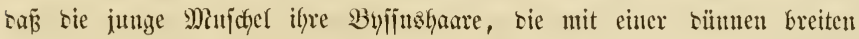

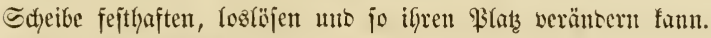

*) Sum Ilnteridjieb won ber im Meere lebenden ihr nabe verwanoten efibarent Mi ie $m$ nj 


\section{Britter Aurdunitt.}

\section{Dic 2 ii $r$ mer.}

"Magente Mätrmer" hat ber Wals, wie wir gejeken baten, fo viele,

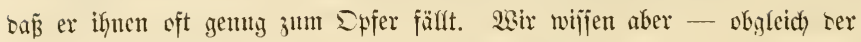

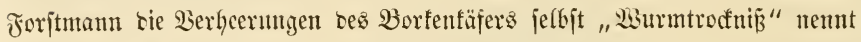

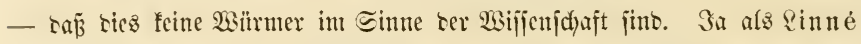
in jeinem Thierityftem jeinen Injeften gegenüber, sie wir in weiterer

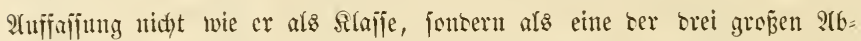

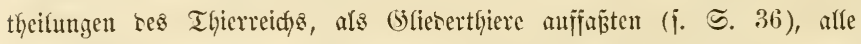

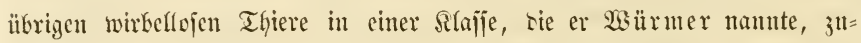
jammenfaj̄te, jo wentete er biejes 23 ort ebenjo unberectitigt uno weitgreifento

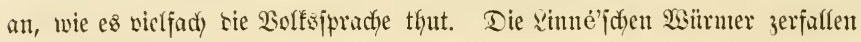

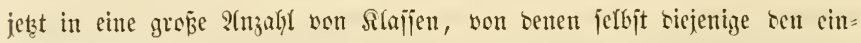

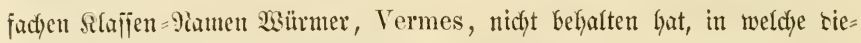

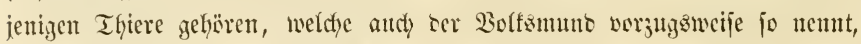
3. 2. Tiegenmürmer, Epuftuïrmer, Bantwitrmer; sbidfon in sem Budbe ven

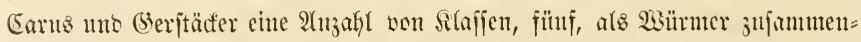

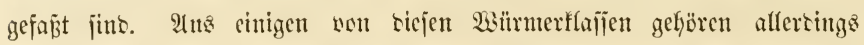

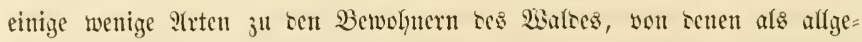
mein befannt jebot) nur bie giegentwïmer nto Eget ju nennen fitt.

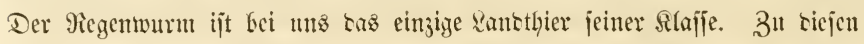

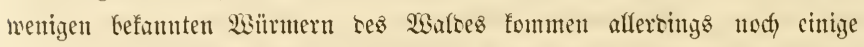
anbere, weldye fich ser Alufmerfiamfeit mefyr entjiehen. Wair fönnen fogar

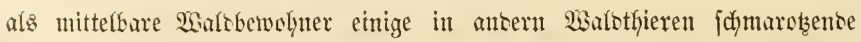

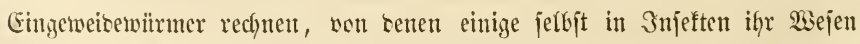
treifen. Ties gilt 3. 23. non jwei volffonmen fabenförmigen $\mathfrak{B}$ Bürmern, 
Mermis albieans v. Siebold uno M. nigrescens Dujardin, von weldyen ธer letztere häıfig in Miaifäfern lebt uno jutweilen gleid)zeitig in jo grofer

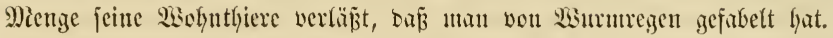

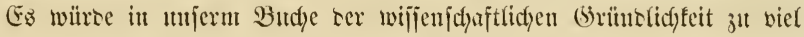

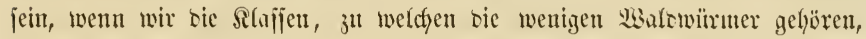

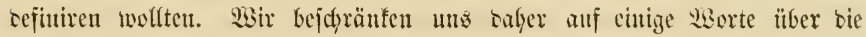

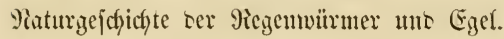

Der biz vor nidjt langer Beit als cinjize ?trt feiuer (5attung aner= fannte giegentwur, Lumbriens terrestris L., ijt jebzt in meffere Arten gejdyicten worben. Bon biejen hat ber gröpte, zuweilen bis weit thber

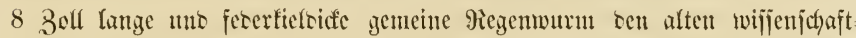

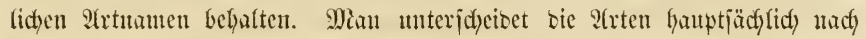

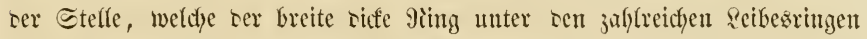

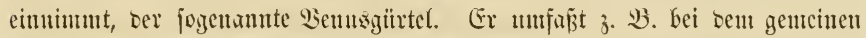
9iegenwurm ben 29. biz 36. 9iing, bei ten 3-10 sinien langen, heflröth= lichen ober blangranten au bäufigiten vorfommenten L. communis Hoff-

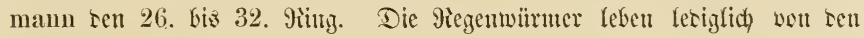
in fendfer fruchtbarer Eroe entfaltenen Moceritofien. Sie vergelyren rieje

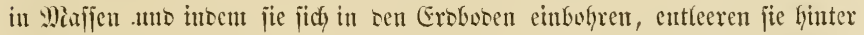

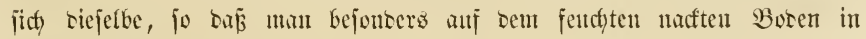

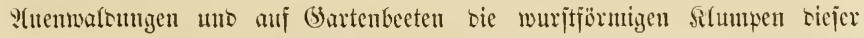

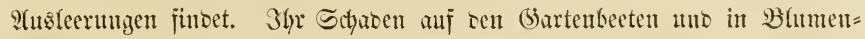

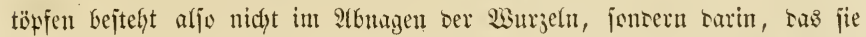

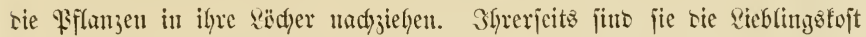

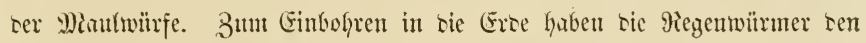
Seib entang in Micifen geortucte winjigfteine ફ̧afenborjtcfen.

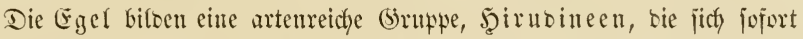
an Den 2 Sangid theiben an ten beicen fïrperencen erfenten läp̈t. Einize jitzen janzeno an anteren Thieren bejtünsig fejt. Es fonmen im Dieere fo gut wie iu jünen Wajajer Egelarten vor. Die Egel betwegen jidy im

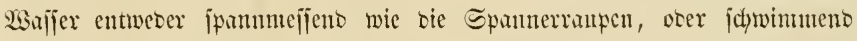

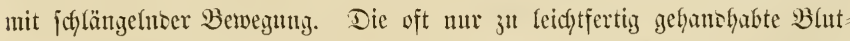

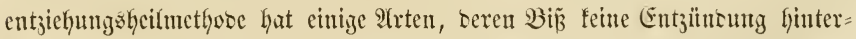

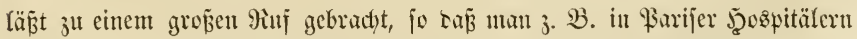

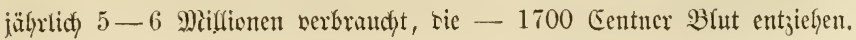




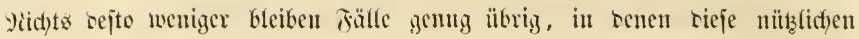

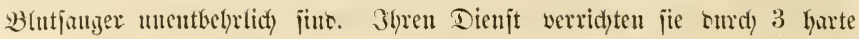

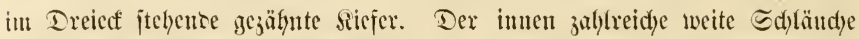

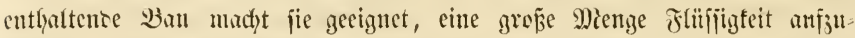

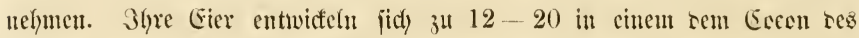
Sciscnipinmers ähncfnten grïnfidybrauten zelligen Eocon, scijen Stofi sem Barcjdywamme gleidyt uno sen tas Thier ans tom Miaule als einen biffen

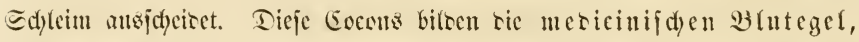

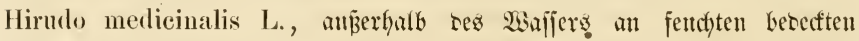
Etellen. TH Siofie haben rie Eiget $2-10$ fleine wenig anżgebifrete Aftgen.

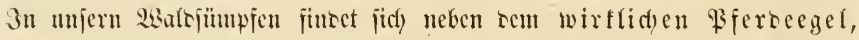

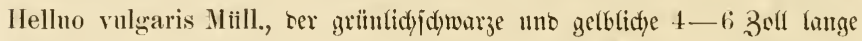
falfde Pifersegel, Aulacostommm nigrescens Moquin-Tandon, tuto

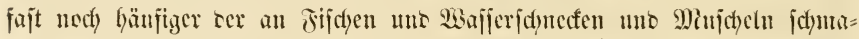
wobente jierlidy buntgeflefte Sanedfenfanger, Clepsine complanata L. 


\section{S d) $1 \mathfrak{1 1}$ 施.}

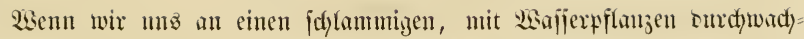

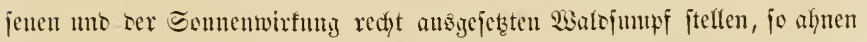

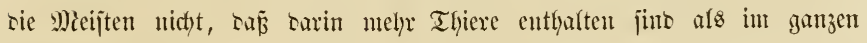

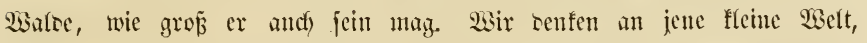

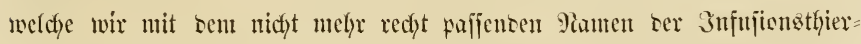
dyen bezeidynen. Wir fünten neben tiejen vieffeidyt jogar in bem

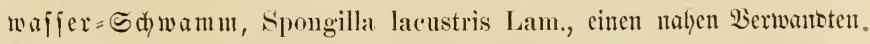
ser ans sen Micere ftummenben Babejcywämme; scer citten, ben Mieer= polypen gleidy Folypenjtëfe (Rorallen) bautenten Syjtemunabar in feber= $\mathfrak{b u f d}=$ Fofypen, Aleyonella stagnorum L.; auct) bie sen fdyönen Meer=

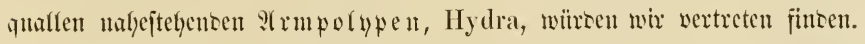

Dicje uno viele anbere Thiere mehy wïrsen wir in bem Smmpfe ent= Decfen, bie uns nod) viel Stoff jux Interfaltung Gieten uno babei wie alfe

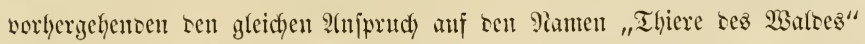

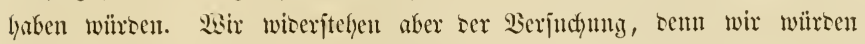

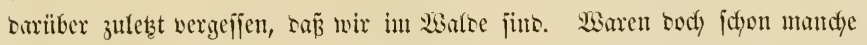

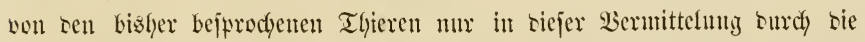

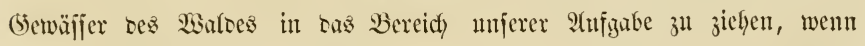

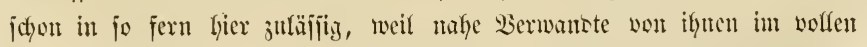
Sinne Wartsthiere waren. Eajjen wir aljo am Salnjije miferes Saltogangeß unz nidyt wie von Irthidftern in sen Sumpf locfen, fontern bejd)ließ̈en wir 


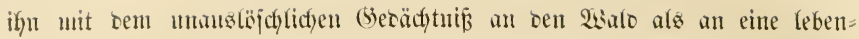

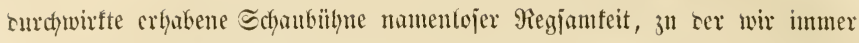

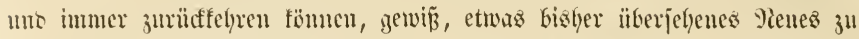
finsen. Llne wie oer Walo für juhlloje hohe mo niesere Thicre tas

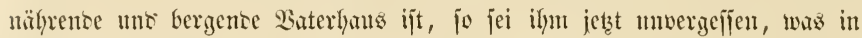

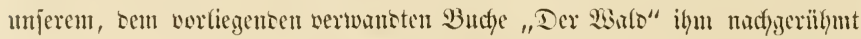

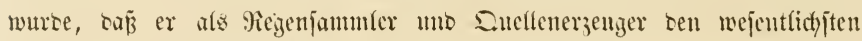
Antheil an ber Frudytbarfeit umjeres (Setreidelanocs hat. 


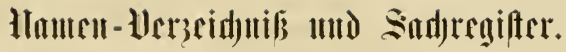

Aasfliegen 241. 397.

26entopfanenange 404.

Acaena sambucaria 402 .

Acanthosoma haemorrhoidale 362.

Acarimen 414.

Acarus domesticus 414 .

Acephala 38.

Achatina algira 455,456 .

- Goodalli 455, 456.

- lubrica $455,456$.

Acherontia Atropos 404 .

Acicula polita 456,457 .

Acidalia brumata 129.

Acribioiben 370.

$\begin{array}{ll}\text { ICcribioiben } 370 . & \text { Anisoplia fruticola } 193 . \\ \text { Acridium coerulescens } 370 . & \text { Anobium carpini } 185 .\end{array}$

- migratorium 370.

- stridulum 370 .

Aculeata 198.

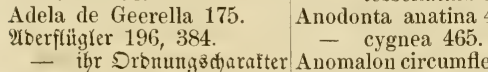

Adela de Geerella $175 . \quad$ Anodonta anatina
\&Derflitgler 196, 384.
$-\quad$ cygnea 465.

Ameiientënig 395

21 meitenlud) 373.

Unteifeniäure 291.

Amphidasis betularia 130.

Amphipeplea glutinosa 459 .

2mptipocen 426.

Ancylus fluviatilis 460 .

- lacustris 460.

Auimalia contractilia 35.

Animalia evertebrata 33.

Animalia oseozoa 33.

Animalia spondylozoa 33.

Animalia vertebrata 33 .

- pertinax $184,185$.

- striatium 185.

- tessellatum 184, 185. 2Ufficlag 183.

Anodonta anatina 465, 466. 2Yngen ber Sujeften 54.

- cygnea 465 . 2lugen ber Sujeftenlarven 55.

(1) 234, 2utgen, einfade 55. 197.

- ifre 3ahl 197.

\&ntennen 53.

- 3weigliebrige, einglieb = rige 198.

Apathus 331.

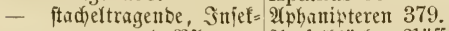

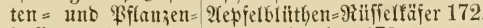
freijende $198,288$.

Inmiral 406.

Aeschna grandis 258.

Afterflïgel 50.

Ifiterfïßze 51.

2fferraupen 63, 200, 386.

Agelastica alni 182, 183.

2grippina 122.

Alcyonella stagnorum 471 . 2riteweiber $=$ Sommer 420 .

Alucita hexadactyla 400 .

2(meife, blutratbe 299.

- rïtblidue 298.

- rothe 290.

2tmeiien 289.

Ameifentäfer 254.

2rbeiter ber Santflügler 288.

2treola 199.

Argulus foliaceus 424.

Argyroneta aquatica 419.

2rme ber Sniften 50.

armooluy 471

Urtliregajteren 420 .

Arthrozoa 34, 36.

2ifiel, gemeine 426.

Asellus aquaticus 426 .

2itipanner 129.

Astynomus aedilis 175, 178, 179.

Ateuchus sacer 339 .

Aufenthaltzorte ber niebern Maldtbiere 5 .

2(119ußstlyierdien 38 .

Utigen, zujammengejetste 55 . 2ugenfalter 406.

. Yugenfteflungen ber Exinnen 417.

Aulacostomum nigrescens

470.

Ưurorajalter 148, 406.

Irpbidinen 278.

Aphis Cerasi 283.

- Mali 283.

- Rosae 278.

- Sorbi 283.

- Tiliae 283.

- Viburni 283.

Aylax Brandtii $273,274$.

Balaninus 165 .

- glandium 173.

- nucum 172.

- venosus 173.

Band $=$ Enlen 403.

A phrophora spumaria 365. Bären (ङd)metterlinge) 404.

A pis mellifica 317,320 .

थpolfo 406.

Apus cancriformis 425 .

Bärenipinner 404 .

$\mathfrak{B}$ aftéfïer 159.

Baı ber Snfettenflüger 43.

9 aud ber Snjeften 56 .

Baudfüïne, gefpalterte 425 .

Arachnidea 37.

Aradiniben 413.

Iraneinen 416.
Baudifitiel 456.

Baudthiere $34,36,37$. 
Bämme, frante merben won Borfentäfer, frummјähuiger Carpocapsa nigricana 132 ben Borfentäfern vorzitgl. $157 . \quad$ pomonana $132,136$. aufigejud)t 156. Bostrychus bidens 97. Carychium minimum 456, Büแmen, Das 215 2ianbit 246,252 .

Banmen 89.

Baumberserber 132 . - chalcographus 97, 154,156 . 457.

Catocala fraxini 122,403 .

- laricis 158, 15\%. - Fagi 284

Saummanze, rotbbeinige 362, - lineatus $97,105,158$, Centrotus cornutus $363,365$. 363.

Baumเeiß̄ling 148, 149.

159.

Eerambucinen 175.

- stenographus 97, 157. Cerambyx $176,177$.

Beseguar 273.

Bieine ber Snjelten 50 .

Beilfiïfler $38,4 \times 3$.

Beidü̈uer bes galises 224

Beftanbwerberber 192.

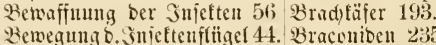

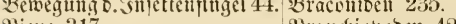

Biene 317.

Bienentörbudsen 447.

Brandjispoben 425.

Bienenranbwespe, bunte 385 Bremen 355.

Sienenjd)wärmer 144.

Bienentwolf 393.

Biesfliegen 355.

Sillo 74 .

- typographus 97.

Botys purpuralis 402 .

Brachelytra 152.

Bradielitren 184, 253.

Brachinuscrepitans $247,398$. Cercopis sanguinolenta 365.
Brad)
Cetonfer 193.

Branchipus stagualis 425

Bremien 355.

Briflantfäfer 152, 166.

Bruft ber Sujeften 55 .

Bruftidils 36.

Birlen = Blattroller 343, 344. Buddoruder 153, 155.

Sirtenblattmespe, groß̧e 203, Budjengaflmïtce 284 . 204.

Birlenipanner $129,130$.

Bithynia tentaculata 419, 461.

Blaps mortisaga 393.

Blajenfiß, Setreioe $=367$.

Blastophaga grossorum 275.

Blatta germanica 369 . - lapponica 369 .

Balatgallen 269.

Blattbörnige $184,189,394$.

Blattlïfer 180,391 .

Bilattfiemer 463.

Błlattlanslöwen 284.

Bifattidyneiber $350,352$.

Blattroespe 198, 199, 385.

Blatifieb 147.

Bräulinge 406.

Blutegel, mebicinifder 470.

Bribthen $=23$ idfer 129 .

Bitutians 278, 283.

Bodfäfer $175,392$.

Bobrer, blaufultirter 147.

Bobrtäfer, đđabtäferäbnlidłer 188.

Bombarbierfäfer 398.

Bombus 314.

- muscorum 330.

- terrestris 327 .

Bombyx mori 403 .

Bortenfäfer $153,392$.

- ibre Brutfolonien 154.

- ibre Sduäblidfeit 153

- ibre Sermebrung 153.

Borfentäferfrã̧ 96.

Budieulauz 187

Bäderifortion 422.

Budjenjpinuer 102, 404

Budfelzirfell 365.

Bulimus decollatus 447 .

- detritus 455,456 . radiatus 455 .

Buntfäfer 255.

Buols = 28 idfler 132 .

Bupreftioen 394.

. Bürfte ber Bienen 322.

Bïrftenpinner 403.

Bujdidnnirfelid)nede 451.

Byrrhus pilula 396.

Callimorpha dominula 404 .

- Hera 404.

Calopteryx virgo 258.

- beros $176,178$.

- cerdo 177.

- indagator 98.

- luridus 98

- fastuosa 395.

Chaerocampa Nerii 404.

Chalcophora mariana 394.

Ebangeasts 406 .

Chartergus sericens 306.

Chelifer cancroides 422 .

(5betoniarier 404.

Chermes Abietis 280, 281.

- coccineus 280.281.

- viridis 280,281 .

Ebiloguathen 411.

Ebilopoden 410.

Ehryjalibe, Ebrvializ, Ehry= iallis $65,147$.

(5)ryjitionen 385.

(Shrt)inelitten 180, 391.

Chrysopa perla 255,256 .

Cicada concinna 364.

- Orni 363, 364 .

Cicindela campestris 246 , 248.

- hybrida 249.

- silvatica $246,248$.

Cimbex variabilis 203, 204.

- amerinae 205.

Eitigraben 418.

Sitiren naturmifienidaratlidyer

Claviger foveolatus 302.

Calosoma inquisitor 253. Clausilia 446, 450 .

- sycophanta 246,252 . Clausilia laminata 456, 157.

Eanthariben 194, 195.

- ibre Elaienistebente Iraft 194.

Cantharis 394. 195.

Capulus hungaricus 414.

Carabus auratus 246, 251.

- coriaceus 387,397 , 398.

- granulatus 250, 251.

- horteusis $250,251$.

- intricatus 247, 398.
Slavicornen 184, 254.

Clepsine complanata 470.

Eleriben $255,393$.

Clerus formicarius 254 .

Clubiona holosericea 419.

Eocinellinent 391.

Coccyx Buoliana 132.

- Clausthaliana 135.

- hercyniana 135.

- nanana 135.

- resinana 134 .

- strobilana 135.

- turioanana 134. 
Coccyx Zebeana 135.

Solumbaczer=2Mitude 382.

Conchifera 38.

Eond)ticu 429.

Eoprophagen 395.

Eoriacell 380.

Cossus ligniperda 144, 146, 404.

Crepuscularia 141.

Crustacea $37,423$.

Cryptorhynchus lapathi 171 , 172.

Cteniza caementaria 420 .

Encuio 394.

Culex pipiens 381 .

Curculio pini 167.

- abietis 167, 170.

Curculionina 165.

Cyclas lacustris 467 .

- - rivicola 465, 466.

Cyclops quadricornis 424,

Cyclostoma elegans 434,446 . $451,456,457$.

Cynips calicis 270.

- disticha 270.

- foecundatrix 267 .

- folii 267.

- gallae tinctoriae 270.

- glandulae 272.

- globuli 272.

- ostria 272.

- ramuli $270,271$.

Cypris pubera 426 .

Dämmeruแg ติalter 141.

Danaiben 406.

Daffelffiegen 355 .

Daffeln 357.

Daudebardia rufa $456,457$.

Dectelid)neden 449.

Deftwanje 362.

Deilephila euphorbiae 404. Entomoftraceen 424

Demodex folliculorum 415.

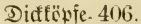

Dipneunonen 418.

Diptera genuina 243.

Dipteren 240.

Dipterologen 242.

Discoibalzelfen 199.

Dispar 107.

Diftelfalter 406.

Ditrocha 198.

Diurna 141.

Diurnen 405.

Donacia 180, 392.

Donnertäfer 192.

Doppellebige 33.

Doritis Apollo 406.

Dornjirte, gebörnte 363, 365. Euprepia Caja 404.

Drobuen 325 .

Drobitenfdyladt 326 .

Dünettfäfer 192.

Dilifterfäfer 393.

Dytieitell 397. $164,165$.

Eget 469.

Ẽid)entolitobrer 188. 267.

Eidjentider 136. 119.

Eintieger 274 . Snleften 218.

Eintagsfliegen 368. 73.

Fiagogel 406.

Elateriben 394.

Engerfing 192

Equites 406.

Erobummel 327.

Erowespen 385.

Eristalis tenax 382 . - fleiner 181.

Eapentoodfäfer 178.

Entle 402.

Eulenfalter 121.
Fuprepia matronula 404.

Dyticus marginalis 397.

Eccoptogaster destructor

- intricatus 164 .

- multistriatus 164 .

- scolytus 161, 165.

Eid)enblatt = (5allmespe 267.

Eid)enbodfiäfer, groß̧er 176.

Eid)entuosten = (5)allmespe

(Eid)ennotle, grïue 136.

(Eid)en='trojefifiongipuner 115

Sidenwerittäfer 185, 188.

Eicrftumpen, fenterdywamm= Fid)tenborfentäfer 153. ähnlidje 107.

Eierring des Fingelfinuter Fid)tennabelmidter, grof̧er

135.

Einfammeln ter simpen forit= idiäblidier Snieften 217.

Eiutagsfliegen, ihre Şüututg Fidonia defoliaria 125, 126,

127.

Eizuftand ber Snieften 59,60. Filitornen 184.

- Dauer beffelten 61.

(Enten= Teid)mujdel 465.

Entimus imperialis 152, 166. Triegentarben 241.

Eutomophagen 198, 231.

Epeira dialema 418, 419.

Evbemeriben $255,368$.

Ephialtes manifestator 234. Florfliege, Eier Derjelben 257.

Erebus Agrippina 122, 403.

Erlenblattfïfer 182, 183 .

Erten= Yï̈ffeltäfer 171.

Eidjenbafttäfer, Gunter 163.

Espenblattläfer, großjer 181.

Fiditentinbentuidter 134.

Fid)ten = Miliffeltäfer, groß̉er 167.

Fiditemrinbenfanger 280.

Fidftenzafiennidfer 135.

- piniaria 124, 125.'

fifid)lans, genteine 424, 425.

Fintterer 143.

F́liege, fpanifje 194.

Fliegen 240.

F́liegenzuftanto Der Snffelten $59,72$.

Flöbe 379, 380.

Flobtrebje 426.

FIorfliege, gemeine 255, 256.

Florfliegetl 374.

Flïger D. Snfeften, ihr $\mathscr{2}$ ถึen=,

Smutn $=$ u. Sointerrand 87 .

Ftügeldeden 48.

Flitigelmal 199.

Fluglod D. Bortentäfer 155.

Flugvermögen D. Infeften 42.

Flughanbertngeu b. Snjelten 42.

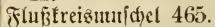

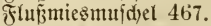

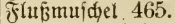

- batavijde 465. 
F⿻ำ

$\hat{F}\lfloor n \tilde{\beta}=$ Yierlemumiduel 465 .

Föbrentpanter $124,125,126$. (5)

Forficnla auricularia 371.

Forf = Eule 123, 124.

Formenmandifaltigfeit b. nie=

bern Galdthiere 4.

Formica cunicularia 299.

- fuliginosa 302 .

- herculanea 290, 304

- rufa $290,302$.

- rufescens 298.

- sanguinea 299.

Tormicatien 289.

Forfitidytis 78,210 .

Treह̂ंpizen 52.

Froitipanuer 129.

Frudtgallen 269.

Fribling fliegen 375

Fritbling $=9$ irittäfer 337 .

(jt)

- grof̧er u. Hleiner 406.

Fugentäfer 396.

Trithibërtter 53.

Fulgora laternaria 365 .

Fungus Rosarum s. Bedeguar 273.

Fitriorge, mütter(id)e, o. Šn= ieftetl 330.

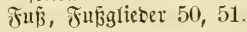

Galeruca alni 183.

(5allen 369.

(5) all $=$ Snjeften 264

(3)allu 8 5ommer 420 .

Gamasus coleopterorum 415.

(5ang, ifannenmefienber 125. 5aarflïgler 396.

(5)arten=ङ Sdnirfelid)nede 447. Haematopota pluvialis 381 .

(5)artenipinner 109.

Gastropacha neustria 118.

- pini 111.

- pinivora 118.

- pityocampa 118.

- processionea 118.

Gastrozoa 35, 37.

Seäber b. Snjeftenflïgef 47.

(sebäníefdnedten 440.

(S)eigen Der Bodtäper 176.

(Seiftd)en 131.

(5)eneratiottzmedjel 279.

Geometra papilionaria 125. 402.

(Seometriben 124, 402.

Geophilus electricus 411.

Geotrupes silvaticus 337.

- Typhoeus 336.

- vernalis 337.

(5) rabfliigler 366.

(5eid)ledtrloie 298.

(Sejdled)tzunterjditebe ber $\mathfrak{S} n=$ Helix aculeata 454 . auges 70.

(3) pinuftutten 138.

Sifthane b. Firoceffiongrante 116.

(अ) โลฮ์ d) wärmer 144.

(5)lieberthiere 34,36 .

Glomeris marginata 411,412.

(5) Dlbafter 109.

(S) olbbente 246 .

(3olbtäfer 301, 395.

(5) blbidntied 246.

(5) olbwe spe 385.

Gonatocera 166.

(3sttesfühd)en 391.

(Grabatme, (Srabjdeite b. Sn= jeften 51.

(strabbeuid)reden 369, 370.

(5) raspferd 370.

Grapholitha 133.

- coniferana 134.

- dorsana 134, 135.

Sreifarme D. Suifeften 51.

(5)rḯze o. Snjeftenflüger 44.

(5)

Gryllotalpa vulgaris 370 .

Gryllus campestris 370 .

Syrintiden 397.

Gyrinus natator 397. (5)aøflïgler 142, 277.

Gnorimus nobilis 395 .

5al6beden 50.

Salbftïgler 276.

- gleidffligelige 364 .

- Ingreidffitigelige 361 .

Halobates 364.

Haltica 181.

Halticus pallicornis 362 .

Hanmaticherus heros 176 .

5arlefins = Ђ̆itpfipinne 418.

5arigallen $=2$ sidfler 134 .

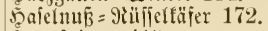

ઝ马ansfpinte 419.

5autflïgler 196, 384. 241.

Secteumeiñling 148.

5eerid)lange 332.

5eerwแก $115,332$. 378 . (3ejpimnt, baflenförmiges Der Helix aspersa $436,444,451$ qrocelfiontaratte 116,117 . candidula 454 .

5ุautlïpwdyen ber 3weiflügler

Helicopsyche Shuttleworthi

Helix aculeata 454.
- cellaria 454 .

- ericetorim 436, 453, 454.

- holoserica 454, 455.

- hortensis 447 .

- lapicida 454, 455 .

- naticoides 451 .

- nemoralis 436,453 , 454.

- pomatia 433,436

- pygmaea 439, 454, 455 .

- rotundata 454 .

- sericea 436

- vermiculata 451 .

Helluo vulgaris 470.

Hemerobius 255.

Hemiptera homoptera 364.

5emipteren 276.

Serbitmilbe 416.

Seerrgottjưädben 391.

Hesperia comma 406.

5esperiaben 406.

Seterogynen 385.

Heteromera 151.

Seterowteren 277.

รูeuterto 370 .

Бetifidede 369.

Sinterleib Der Snieften 55.

Hipparchia Janira 406.

Hippobosca equina 380 .

5ilidutüfer $387,394$.

Sirubinen 470.

Hirudo medicinalis 470 .

5od) zeitsflug Der Bienen 326.

5ösdien Der Bienen 322.

5olijood 415 .

5olabobrer 146, 184.

5olzireifer, equte 153.

- 373 .

5olzgallen 269.

5oliwe soe, grofice 205, 206, 386.

Somopteren 277.

5onigbiene 317,320 .

Sonigtbau 279.

Sornifie $308,309$.

รูïlfisorgane ter (5)id)ledis:oryane Der Snieften 76 .

5ummel $317,327$.

5ूund

süpferling, gemeiner 424,425 .

Hydra 471.

Hydrachna spinipes 415 .

Sybrad)niben 415.

Storrocoribeu 363.

Hydrophilus caraboides 350 .
- cingulata 451 .

- piceus 346,347 .

jeften 76 . 
Hylecoetus dermestoides 188. Răfer, ifr Maul 151.

- proboscideus 189.

Hylesinus ater 162.

- crenatus 164.

- cunicularius 162.

- fraxini 163.

- minor 160, 163.

- micans $159,163$.

- palliatus 97, 163.

- piniperda 97, 160.

- polygraphus $97,163$.

Hylobius Abietis 98, 167, 168.

Hymenoptera aculeata 288. Domenopteren 196.

Hyponomenta coguatella $138,139$.

- evonymella 138,139

- padella 138, 139. Siahneid)enwidter 136.

3d)eumoniben 231.

Imago 74.

Immen 196.

Infusoria 38.

Snfuforien 38.

šniquitelen 419.

Snquilinen 274, 301.

Injeft, volutommentes 74

Insecta 36.

Insecta ametabola 59.

- metabola 59.

Snfeften 34, 36. Siçernblattëäfer 182, 183. Setten, ausgefrodsene, ibr siefern=Bortentäfer 157.

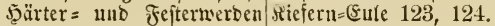

unD Das Erbalten ibrer Fitefernfuospen=23iffler 134. Jarke 74 .

Smeften, fid) vermantelnde 59. - fleiner 160 .

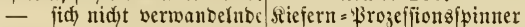
59.

118.

Intefteneier, igre Forn $\operatorname{tnt}$ Riefermraupe, groß̉e 111. Farbe 60.

Intefteneier, igre IInter= bringung 60.

Sniftenflitgel, edjte 48.

snjeftentrejer 231.

Snjeftentarben, ifh iduefles 2Sadistlum 62.

- ibr 5̧autwedjel 62.

Snjeftenleben, feine Dauter 76. Snjeftenverwanblung, woll= ftänoige 59.

- muvolltänoige 59.

Snfeftenwelt 39 .

Siopober 426.

Suliustäper 193.

Julus sabulosus 411.

Jrudeen 415.

Ixodes ricinus 415 .

Räfer $150,387$.

- ibre Ratwest 151.

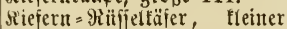
$168,169$.

- weiß̄iduilbiger 169.

Riefernfdywärmer 142, 143. Riefernipanner 124, 126.

Siefernjpinner 111.

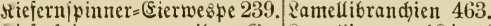

Riejerfpinmerrante, ibre Ge= Zamellicornen 184, 189, 394. fräß̈igfeit, nad ibrer lleber $=$ Lamia textor 177 .

winterung 114.

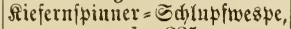
großje, 235.

- Hleine 237.

Sieferntrieb $=$ Widter 132.

Siemenfïß̈ler 425.

รiemenfnß̧, frebsartiger 425. - fifd)förmiger 425.

Riemenidnedten 438.

Rientraupe, groß̉e 113.

§iridffiege 241.

Sitauen 50.

Lacon murinus 294.

¿ärdjenborfentäfer 158,159 .

Eärcben=\$inirmotte 137.

Eärd)enrinden=26iđ̛ler 135 .

Lampyris noctiluca 393.

- splendidula 393.

Zanbwanzen 361.

Earvenfitise 51.

Zarvenjuitand fer Snjeften 59,62 .

Lasiocampa 111.

Qaterigraben 419.

Eaternenträger, furinamijdłer 365.

\&aubbeuidireden 370.

Eauftäfer 247.
Rleibermotte 401.

sileinjdjmettertinge 132.

Лlcinzirpe, geöhrte $363,365$.

Slopitäfer, bunter 184, 185. - gemeiner 184, 185.

Rnodjenthiere 33.

Rnopf $=$ ober 2 aarzentiifder $=$ raupent 87.

Ruspengallen 269.

siönigin ber Bienen $324,325$. sörbden ber Bienen 321,

Solbenmaffertäfer, lauftäfer = artiger 350 .

Romma (Falter) 406.

Siopf Der క̌njeften 51.

Sopilofe 38.

Sorallen 38.

Siotbfrefier 395 .

Sothladt=รieferblat twespe 202. Rrätżntilbe 414.

Sirebsfdjeere o. Storpionfliege 57.

Rrebstbiere 37.

Rreismmojdinecte, jierlide

$434,446$.

アreismujd)eln 465.

Sireuzipinne 418, 419.

Rriebelmitte 381 .

ภriegsmurm 332.

Rrujtentbiere 37.

siryptopentameren 157.

Siubitalzellen 199.

Rugelafiel, gelbgeranbete 411, 412.

Sinfufgbienen 318.

Rulturwerberber 192.

אunftbienen, cinjame 354.

Siurzflitgler $253,396$. 
\&มแส์ไicgen 280.

Rediłunge 52.

Reberbeffen 49.

Ledra aurita 363.

Regbobrer 57.

\{egidjeite 57.

Eegitadjel 57.

¿eid) cnwurm 241.

Lema 180.

Sepibopteren 399

Lepisma saccharina 367 .

Leptis vermileo 374 .

Leptoderus Hohenwardtii 396.

Leptus autumnalis 416 .

Reudtttäfer 393.

Reudt) tirtwell 365.

Sibellen 368.

Libellula depressa 258, 260.

Libellula quadrimaculata 261.

Qibellulioen 255.

Ribelfulinen 258.

Eiditmotte 401.

Qiebespfeil ber Sdnnede 436, 437.

Sigujteridyuärmer 404.

Limax agrestis 441.

- rufus 441.

Limenitis populi 406.

Limnaetis ovatus 458 .

- palustris 458 .

- stagnalis $453,458,45$

Lina populi 181, 182.

- tremulae 181, 182.

Einbenbolirer 147.

Sinbenja)wärmet 404.

sinne'jdier giame 83.

Liparis auriflua 109.

- chrysorrhoea 109.

- dispar 107, 108.

- monacha 86.

- salicis 109.

Lipoptera 380.

Lithobius forficatus 411 .

Lithocollatis Rajella 401.

Sodfen ber Slopftäfer burdy Meleagrina margaritifera - Silovien 186 .

Locusta cantans 370 . - viridissima 370 .

Qoenfitinen 370.

Songicornen 175.

Lophyrus pini 200, 201.

\&otbgänge 155.

Lozotaenia piceana 134.

Lucanus cervus 387, 394.

Lumbricus communis 469 .

- terrestris 469.

Rungenid)neden 438.

\&upe, (Sebraud) berjelben 47. Miciesmuidjel 467.

Luperus pinicola $182,183$. - eह̧̉are 467.

2isalstliete 5 .

Macrolepidoptera 131.

9)iäsd)er = Somuter 420 .

Miaben 63.

Maifliegen 375. $191,192$. fliige 192.

Maimürmer 392.

IIalachius aeneus 394

Dialermutidel 465.

flïgel $42,46$.

Mantelthiere 37, 38, 429.

Nantis religiosa 369 . 465.

Miatroje 188.

Miattbäus = Eommer 420 . 403.

Matretafiel 426.

Diaulwurfiggifle 370.

Meerłäufer 364. 352.

Mieblgallen 269

Miehıı̈fer 393.

465.

Meloe 392.

- fullo $191,192$.

Metallk̈̈fer 395 .

237.

- ordinarius 238.

Microlepidoptera 131.
Miftropteren 253

9)iild)tüle (B̉attläuje) 283.

9)ilben 414.

Minirametie 299.

9) (inirer 137, 401.

Lyda campestris 202, 203. Diniripinne 420 .

Lymexylon dermestoides 98. Mitejiermilte 415.

Lytta vesicatoria98, 194,195. Wolfentick 109.

Mollusea 87.

Diollusten $429,430$.

Maditentfaltung oer nietern Nolorchus 175.

Mionilicomen 184

Monotrocha 198.1

9) tooshummer 330 .

Wiorbfitiege 243.

Morttäfer 252.

Maitäfer, gemeiner 190, 192. Miojdusbod 392.

- grober marmoriter

Miotten 136, 401.

Miüllertïfer 192.

- ifre vierjäbr. Scaupt= Miiitze, ungarijde (Sd)nede)

444.

Minjd) ltretie 426.

Miujdeljd)alen, 2 bau berj. 462.

Miufdeltbiere $38,429$.

Minid)eltbiere, Bau berj. 463.

Diand)faltigfeit ber Jnjeften= Minstito' 8381 .

Mutilla 330.

M)inttergänge 155 .

Mivriopoden 409.

9iv)refophiten 301.

Iyrmeleon formicalynx 373.

Miaftorm = Bremsfliege 358. Mytilus edulis 467 .

Mianlberen = Eeibenipinner

Megachile centuncularis 350 ,

Melolontha vulgaris $176,18 \%$.

Microgaster globatus 112, Necrophorus vespillo 339.

- nemorum 237, 238.

Maber res ๔d)nedtentyaujes 453

Yiadjujieber 65.

Tiadjfialter 141.

Madtyfauenauge, 2 siener, groß̉ez 403.

Niadtidjneden 440.

Taselmartwidfler, fleinfter $13 \%$

Tarefmidler $134,135$.

Malyntg b. Inicftenlarwen 63.

Siamen, bentiche, ber seäfer= arten 170.

Rajenbiesfliege bes Rotbwilbez 358.

- Des ธdıafez 358.

Pashorntäfer 395.

গicbenangen 55.

Nematus 202.

Nematus saliceti 280.

Nepa cinerea 363.

Nerita fluviatilis 445,461 .

. Netzaugen 55 .

Mietzflügler $255,366,371$.

Meurosteren 255. 
Reutra 288.

Noctuiben 402.

Roctuineu, Roctuen 121.

Nocturna 141.

Roune, bie 86, 88.

Nonnentaupe, $23 a b l$

Futteræ 89.

Notonecta glanca 364 .

)intzboljbortentäfer $158,159$.

Sinntphaliben 406.

grymphen 63, 65.

Dberfiefer ber Snjelten 52 .

Dritmaben 132.

Ocypus olens 254.

Debrlinge 371.

Oestrus auribarbis 358 .

- bovis 358 .

- equi 358.

- haemorrhoidalis 358.

- nasalis 358.

- ovis 358

Shrtwurm 371.

Sleanberiduärmex 404.

Oniscus asellus 426.

Drbitelen 419.

Drbenzbatio, blanes 122,403 Orgyia 403.

Ornix laricinella 137.

Orthocera 166.

Oryctes nasicornis 395 .

Osmoderma Eremita 395.

Ditracoden 426.

Otiorhynchus ater 169, 170. - unicolor 170 .

Palfiaten $38,429$.

fialfen 52.

Halpicoruten 397.

Paludina achatina 461.

- vivipara 460 .

Panorpa communis 374 .

Papilio Machaon 400, 406.

- Podalirius 406.

Sáppelbodfäfer, grof̧er 177.

Sappelfalter 406 .

Bappeljdwätmer 404.

Farthenogenejis 279.

Pelecypoda 38.

Ficlifliigler 256, 374.

Fiel $\mathrm{l}_{3}$ motte 401.

Pemphigus bursarins 283. - Fraxini 283.

Pentamera 151.

Pentatoma rufipes 277, 362, 353.

Periplaneta orientalis (Blatta) 369.

Perlenmujidyel, edjte 465.
Fierlhaft 255.

Hijerbeegel, faljder 470.

- wirffidjer 470 .

Hiferbelausfliege 380 .

Pferbemagen= 3 remafliege 358. Ptilium minntissimum 396

\& flanzenlänje 365.

'islajtertüfer 194, 392.

Phalangium opilio 422.

Philanthus pictus 385.

Phryganea rhombica 375.

Phyllopertha horticola 193.

Pliysa fontinalis 460.

- Hypnorum 460.

thyftognomie b. Injeftenflafje 42

Phytophaga 198.

Pieris cardamines 406.

- crataegi 148.

Hillenmälzer 338.

Hilfentäfer, heiliger $339,396$.

Pimpla instigator 234.

Himien = Srozeifionsfpinter 118.

Piophila casei 241.

Pissodes notatus 98, 168, 169. - pini 170 .

Hlanipennien $256,372$.

Planorbis carinatus 458. - corueus $446,453,458$. - vartex 458 .

Plattband)libelle, gemeine 258. $-260$.

Flattflügler 256, 372.

Plusia 122.

Podura villosa 367.

Poecilonota rutilans 394.

Polistes gallica 317.

Polybia catillifex 306 .

- cayennensis 307.

Polydesmus complanatus 411, 412.

Polymeria 34.

Polinen 38.

Holnpenitöde 38.

Polypi 38.

Polyphylla fullo 192.

Polyporus pinicola 105.

Pomatias maculatum 456, 457.

Bompiliten 385.

Pontia cardamines 148.

- crataegi 110, 148, 149.

firad)ttäfer 394.

Wrobebännte 218.

Procerus gigas 397.

Frozcfítonsraupe, ibre ๔djäb= (ide) feit 117.

Psyche helix 404.

Fiteromalinen 235.

Pterophoridae 131.

Pterophoriben 400.
Pterophorus pentadactylus 400.

- polydactylus 400, 401

Ptilinus pectinicornis 187.

Ptinus Fur 187.

Pulex irritans 380.

tinliciben 379.

P'upa frumentum $455,456$.

- truncatella 456,458 .

- uva 447.

'infiparen $243,380$.

Huppen ber Edymetterlinge, siäfer, $\mathfrak{H}_{\text {ber }}$ utto 3 neci= flügler 66,67 .

Fuppengebäterintuen 380 .

Wuppen, ibre Bewegung sivert= zenge 68 .

- ifre geidjledtl. Inter= (d)eisungomerfmale 68.

Fuppen=Futterale 67.

Fuppengehäuje 67.

Fntwengefpinnt 69.

finpenbaut 64.

- Dutrdjoredjen berjelfen 68.

- 2 Ibftreifen berjelben 69.

Sinppenräuber 246.

Fitppenjuptatio ber Sujeften 59,65 .

Fistaliben 131, 401.

Pyrochroa coccinea 393.

Liyrodyroiben 392.

Pyrophorus 394.

Pyrrhocoris apterus 362, 363.

Duitze 381.

Rabialzellen 199.

Radiata 38.

Fabifinner 419.

Rammeltanmer 155.

Ranbafiel, platte 411, 412.

Hanbmal 199.

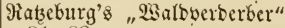
$81,82$.

Maubfliege 382.

Raubläfer, rotbbediger 253.

Hanpen 63.

Maupentejter, großje, fleine 110.

Raupenverbcerung D. Riefer= fpinners, ify Beitraum 114.

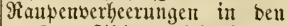
oftpreufijif)en, Yithautifden, majurifjen mo polnijdent Froriten 91.
Dater Defiferben 68. 
Maupenzminger 213.

Regentbremie 381.

Regenwurm 469.

Feid)thum, grïBerer b. nicberen 2Galotbiere 4.

Hevier, fein 2 mblid, nad)rem

ez von ber शonne und forit (d)äblid)en siäfern keimge: ind)t 104.

Rhaphidia 374.

Rbifipteren 378.

Rhizotrogus solstitialis 193 . Rhodites Rosae 272, 273.

Rhynchites Betulae 343, 344 .

Rhynchophora 165.

Rimberbieaniege 358.

Rinterbremje 382.

Hingelfuß̄ 109.

Ringelizinner 118, 119.

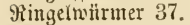

Fitter 406.

9ïbrenjpinmen 419.

アötblinge 406.

Mollrïfïel 52.

Rojenblattlaus 278.

Rojengallmespe 273.

Roß̧ameije 290.

ßoß̉täfer 337.

Roß̉taptanienbobrer 147.

Mioftricormen 184.

Rotbidwanz 120.

Muberbeine 51.

Æï̈đfnjdymimmer 364 .

Mitifiel 52.

Ritilieltäfer $165,392$.

- gerabfiiblerige 166.

- tniefiublerige 166 .

- ibr fefter Wanzer 175

- groker, fowwarjer 168, $169,170$.

Rïjternblafen=2Blattlaus 282. Piiiternblattlaus, weibe 282. アüftergallen = Blattlaus 280, 282.

Riifternbaargallen $=$ Blattlaus 282.

Rïfteriflinttäfer, groß̧er 164.

Sadipinne 418.

ङägebörnige 184.

Бӓ̆ешевреп 198, 199.

Eaftgallen 269.

Salticus scenicus 418.

Saltigraben 418.

Sammetmilbe, gemeine 415 .

Sammetfpinne, atlaghaarige 419.

Sanbtüfer, grüner 246.

- ihre Qarben 249.

Saperda Carcharias 145, 177. Sdwammipinner 107.
Saperda populnea 178, 179. Sdiman 109.

Sarcophaga mortuortum 241.

Sarcoptes scabiei 414 .

Saturnia pyri 403.

Eatyrtsen 406.

Sauger 52.

Sangmaul her Snjeften 52.

Eangröbre 0 . 3meiflïgler 241

Edjabe, Dentide 369.

- Rüdjen $=369$.

- lappländijobe 369.

Sd)aben 131, 136, 369.

Sdianncitabe 365 .

Edjentel 50.

Sdienbein 50.

ङdiffamerfttäfer 188.

Sdilomanze 361.

Edillerfalter 406 .

Schizoneura lanigera 283.

- lanuginosa 282.

- Ulmi 282.

Ed)lajatfel 273.

Sd)laftunzen 273.

ङd)tammfliegen 382.

Sd)lammidncte, großze 439, 453.

Sd)ließ̧munsid)nedfe 446,450 , 451.

Ed)lufmespen 231.

ङdlupfwespenlatven, ibr

2ltbmen $23 \%$.

Sdjmalbafte 374.

Sdmarotscthmmel 331.

ङ) inetterlinge 82, 391.

- iiber ibre giamen= gebung 83.

Ed) nabel rer 2 sanzen 52.

ङdunte 381.

Sd) narrbenfdirecfe 370.

Edinedten 429.

巨d)nedtengebüusbedfel 449.

Sd) 439.

₹d)nedenjauger 470 .

Sd)nedenzunge 433.

Sdineebritde 223.

Sdneiber 422.

Sct)neiberjeele 143.

Sdynelligfeit ber Flïgelbetwe= gung bei ben Injetten 45.

ङđ) nelltäfer, mänjẹarb. 394.

ङd)ellläujer (ङximnen) 418

Sdanirtelidinede 433.

Sdiöpfrüifiel 52.

Sdriten 369.

Emaragolfinte 419

$46 . \quad$ populi 404 .

Sd)närmer $142,404$.

Sd)walkenjidwanj 406.

Sd) wammgallen 269.

- tiliae 404.

Sociales 305.

Solitariae 305.

Sommermilben 415. 
Conneumenbetäfer 191, 193. Sulpbiben 245, 396.

Epaltiilipler 424 .

Spanter 124, 402.

- ibre Rimté'jden গamen 126.

Sparassus smaragdulus 419. Tachina fera 243, 244.

Spbingiben 40.4.

Sphinx 142.

- Convolvuli u. Ligustri 404.

- Nerii 142.

- Pinastri 142, 143.

Spieger, Minupetipiegel 89, 107.

Epiegel ber Tionne 214.

Epiegelzelle 199.

Sritunen 413, 416.

- berumidncijenbe 418

- vierlumgige 419.

- 3meilutugige 418.

Spinnenameife 330.

Spintenaugen 417.

Epinteniüв 417, 418.

Epimenthiere 37.

Spinner 403.

Spintocrmögen D. Snlieften= latbent 63.

Eximmarzen Der Epinnen $417,418$.

Spongia Cynosbati 273.

Spongilla lacustris 471 .

Epringer (Epimue) 418.

Springid)wan3, befaarter 367. Tetraneura alba 282.

Springiđ fwänze 366.

Springmanze 362.

Sprungbeine 51.

Stadjeliumen 384.

Stad)lwanje 362.

Etaphylinidell 253, 396.

Staphylinus erythropterus 254.

Staubfäfer, rotboectiger 396.

Stauropus fagi 404.

Stedien ber Fliegen 241.

Stedffliege 382 .

Stedmitide 381.

Sted)orgatue ber 3weiflitgler 241.

Steinfried)er, gemeiner 411.

Eterngänge 156.

Stigma 199.

Etirujitpe 365.

Stomoxis calcitrans 382 .

Strabltäfer 339.

Strabltbier 38.

Stratiomys chamaeleon 382 , 383.

Strepfipteren 256, 373.

Subuedialzelfen 199.

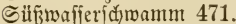

Succinea putris $456,457$.
Syrphus seleniticus 245.

Tabanus bovinus 382.

Tagfalter 141, 147.

Iagialter, Farbentaradyt ber jelben 405

Tagplattenauge 406.

Taututuborfentäfer 158.

Tauteuläfer 192.

Iannenteilidtwanz 143.

Iapezierbicue $350,352$.

Iaratane 369.

Tarien 50.

Tafter 52.

Taumelfäfer, gemeiuer 397.

Taufentoüb̈ler 409.

Iaujentoüßze, eigentlidje 411. Tubitelen 419.

Tegenaria domestica 418.

Teid)mutidichn 465.

Teleas ovulorum 239.

- terebrans 239.

Ielleridunedte, aroß̧e 446, 453.

Tenebrio molitor 393.

Tenthrediniben 198.

Tenthredo 198.

Teras terminalis 272 .

Termes lucifugus 368 .

Testacella 441.

Tetramera 151, 153.

Tortrix viridana 136 .

Trachea piniperda 123, 124.

Trauermautel 406.

Tratterntilde, glasplitgelige 331 .

- Thomas $=331,332$.

Trichius fasciatus 395 .

Trichodes apiarias 393.

Trid)opteren $256,374$.

Tridopterugien 376.

Sriebe, burd) $\mathfrak{B i d f ( e r}$ ge= frïunte 133.

Trimera 151.

Troctes pulsatorius 187 .

Trombidium holosericeum 415.

Troutopf 186.

Trypeta Cerasi 241.

Trypoxylon figulus 385 .

\section{Tetraneura alba 282.}

Tetraputeumonen 419 .

Tetyra nigrolineata 362,363 . Valvata arenifera 378.

Thomas = Tranternitide 331 , - granifera 378 . 332 .

Theerringe 219.

IIngleid)flitgerige 277.

Unio batavus 465,466 .

- pictorum 465.

Unterfiefer ber Strjeften 52.

llnterlispe 52.

Unterlipwentafter 52.

Urania Leilus 402 .

Llrautiben 125 .

Uroceribell 265.

Bagabumben 418 .

Theraphosa avicularia 419. - Atalanta 406.

Theridium redimitum 419. $\quad$ - C album 406 .

Thiere, niebere, böbere 34 - cardui 406.

Thomisus viaticus 420 . $\quad-$ Jo 406 .

Thrips cerealium 367, 368. - polychloros $150,406$.

Tichogonia polymorpha 466, _ urticae 406. 467.

Tiger 192 .

Tinea pellionella 401 .

- laricinella 137.

- sarcitella 461.

Tineina 131.

Tineinten 131.

Tischeria complanella 401 . vulgaris $307,308,316$.

Tobtengräber, gemeiner 339. Sespiten 304.

Todtenfüfer 393.

Sobtentopf 404.

Iobteutulyr 184, 185, 186.

Todfítellen ber fäfer 186.

Töpferweape 385.

Iortriciben 401.

Tortricina 131.
Vermes 37.

Vertigo septemdentata 455 , 456 .

Bertilgung ber idäbl. Şn= ieftenlarven 214.

Serwantung ber Snjeften 58.

Vespa crabro 308,309

447.

Vitrina diaphana 456, 457.

Bogelipinue 419.

2orbaumgemaß̧regelı gegeı

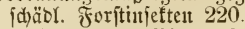

Borjdwarm bet Bienten 325 . 


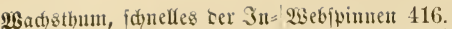
feftenlarven 62.

32affenfliege 382, 383.

W3agegänge 157.

Saloanteile, rothe 290.

9Balbbaummatise 277.

Balbinjeften, gejellige 285.

Balbinjetten, gefellige 285, 26eibenipimer 109.

128

Gaalomifttäfer 337.

M3albiand fäfer 246.

Walberberter unter ben $3 n=$ feften 78 .

Walboerberter, Sampi gegen fie 209.

sarter 192.

28 anderbeuidrede 370 .

2Barzen = B̈̈̈і́d)elranpen 87 .

9arzentäfer, fuғfergrïner 39

B3aiferafiel 426.

Wafierflöbe 426.

Maffertäfer 397.

פaffermilbe, bormï̈ß̄ige 415 .

Wafferifortentwante 363.

खafiferfpinute 419.

26afferwanzen 363.

खecber (Spinnen)-419.

ख̇eberłuted)t 422. $439,448$.

2Scinfäfer 192.

Weifel 325.

2Beiß̄lunge 406.

23erre 370.

o. Srouer 42 .

Gespen 304.

26 idfler 131, 401.

2ittobrüd)e 223.

28 inbig 404. Gäujer 448.

23 irbelloje 33.
26 egidutuede, grop̉e 440.

Qiseidtäfer $393,394$.

23eid)thiere 37, 429, 430.

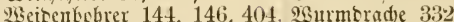

9heibengallen=Blattme

133, 436, Xenos Peckii 378.

Esespe, genteine 316 .

- gefellige 305 .

Miboerdjen 142, 404.

พ3ibser=ฮd) wärmer 142,504 .

Winbenid)märmer 404.

Winterbedel ber Edyueden=

Minteripanner 128, 129. ceffions raitpe 117 .
- Rossii 379 .

ṫulopfagent 184, 393.

Fiblotionben 404.

Zabrus gibbus 246 .

2airbelthiere 17,36 .

23 olfamil djiçnürmer 404.

23ïrmer $34,37,63,468$.

3ange res Shrmurms 57.

Bedten 415.

Bellemipumen 419.

Jerftërungsontittel gegen sie

Eier ber fdäblidjen 引̀n= jeften 212.

Zeuzera Aesculi 146

3immeridröter 177

3irwen 364.

3 uffergajt 367.

3̈̈̈ge, gefdiloffene ber $3 \mathrm{r}=$

3ünsler 131, 401.

3 weiflügler $240,379$.

- eigentlide 243 


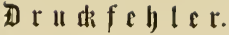

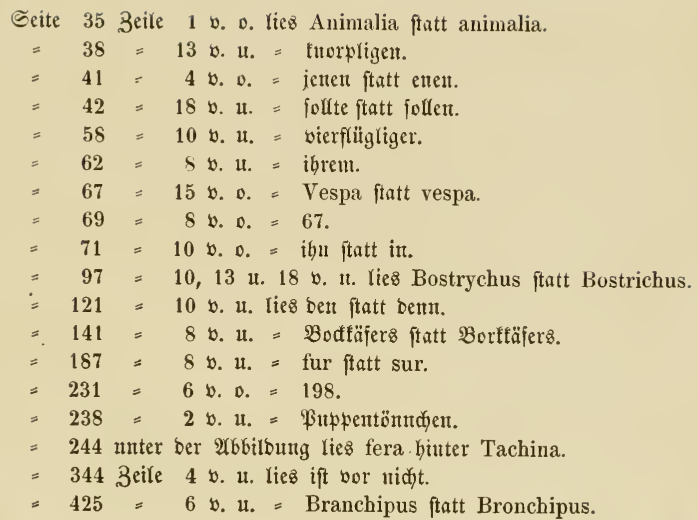



3.
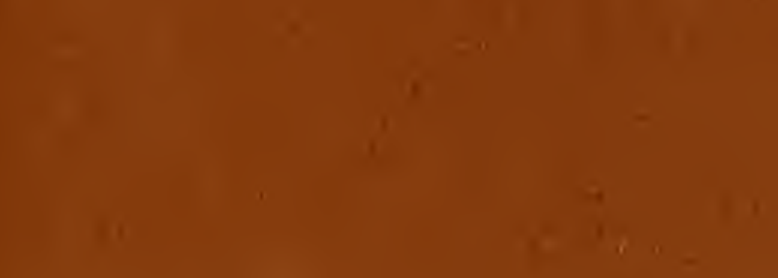

1

,

\section{$-4$}

1

1

t3. 




\section{s.}

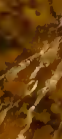

2.

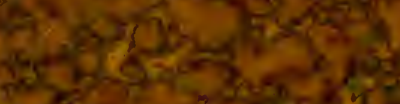

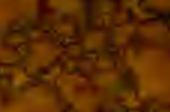

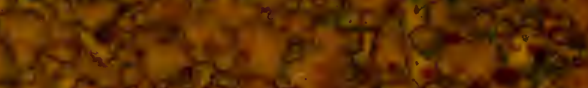

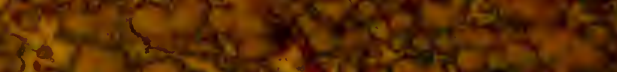

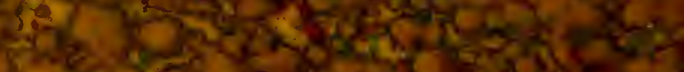

atis

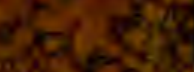

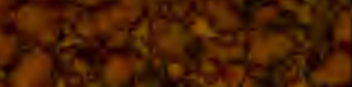

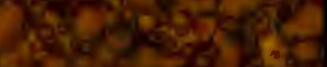
c둥

\section{6.}

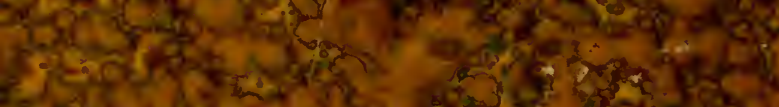

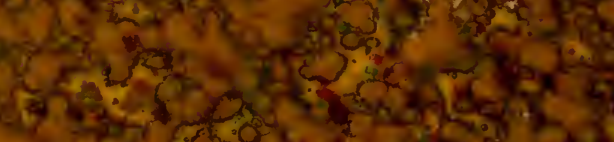

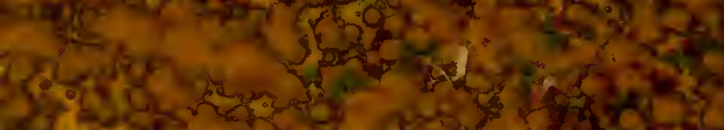

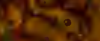

$2+x^{2} x^{2}$

2.5.

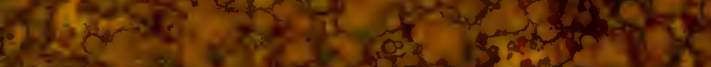

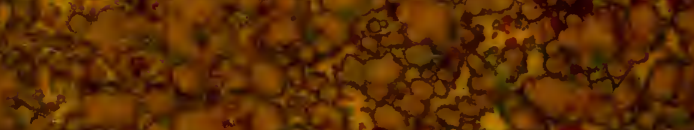
We (F)

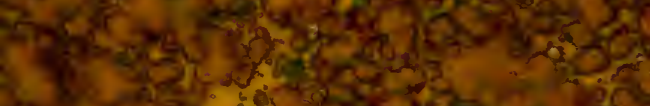

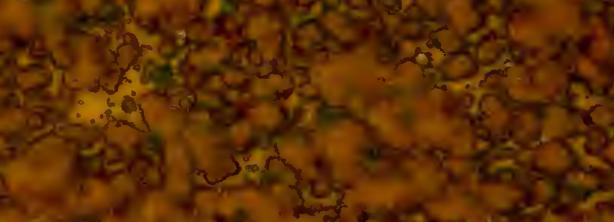

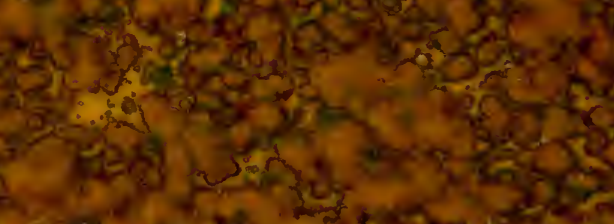

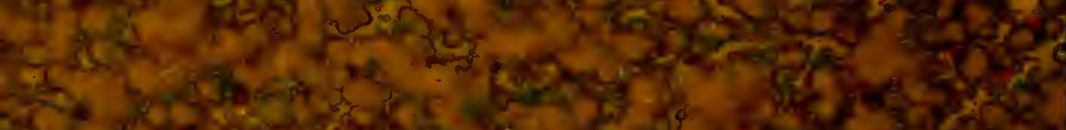

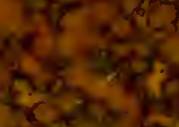

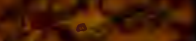
(2) 28.

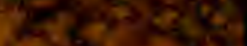

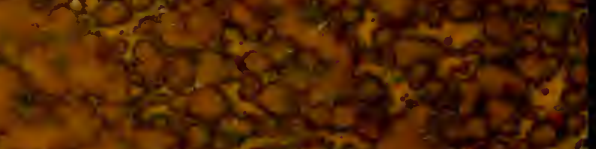

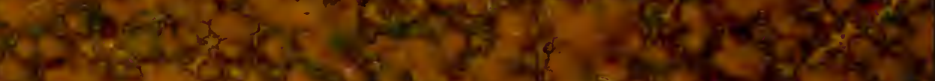

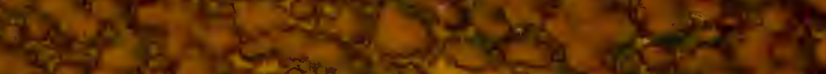

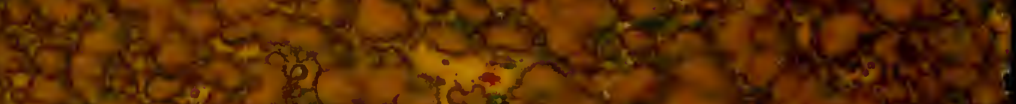

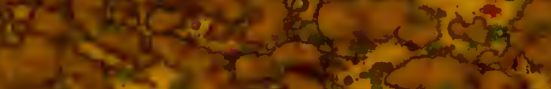

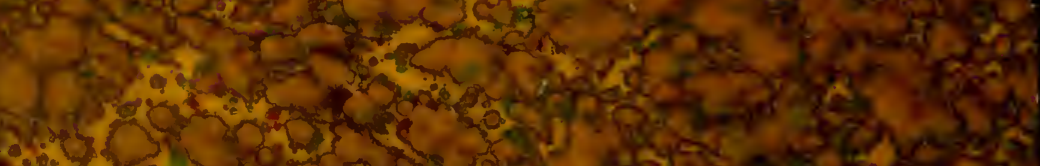

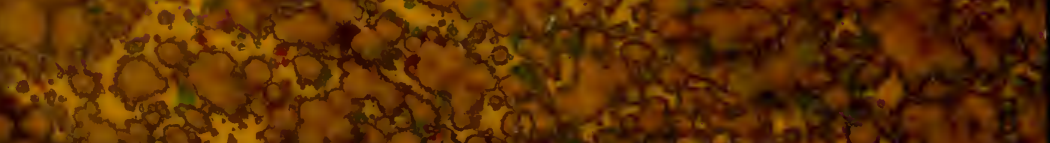

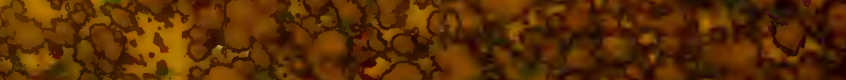

